\title{
Rothen, Marcel
}

\section{Die Elementarschullehrer am Ende des Ancien Régimes. Eine} Kollektivbiografie der Schweizer Lehrerschaft im Spiegel der Stapfer-Enquête von 1799

(Dissertation, Universität Bern, 2018)

Quellenangabe/ Reference:

Rothen, Marcel: Die Elementarschullehrer am Ende des Ancien Régimes. Eine Kollektivbiografie der Schweizer Lehrerschaft im Spiegel der Stapfer-Enquête von 1799. Bad Heilbrunn : Verlag Julius

Bern, 2018) - URN: urn:nbn:de:0111-pedocs-221225 - DOI: 10.25656/01:22122

https://nbn-resolving.org/urn:nbn:de:0111-pedocs-221225

https://doi.org/10.25656/01:22122

in Kooperation mit / in cooperation with:

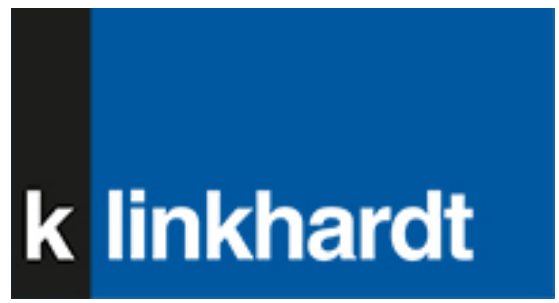

http://www.klinkhardt.de

\section{Nutzungsbedingungen}

Dieses Dokument steht unter folgender Creative Commons-Lizenz: http://creativecommons.org/licenses/by-nc-sa/4.0/deed.de - Sie dürfen das Werk bzw. den Inhalt unter folgenden Bedingungen vervielfältigen, verbreiten und öffentlich zugänglich machen sowie Abwandlungen und Bearbeitungen des Werkes bzw. Inhaltes anfertigen: Sie müssen den Namen des Autors/Rechteinhabers in der von ihm festgelegten Weise nennen. Dieses Werk bzw. der Inhalt darf nicht für kommerzielle Zwecke verwendet werden. Die neu entstandenen Werke bzw. Inhalte dürfen nur unter Verwendung von Lizenzbedingungen weitergegeben werden, die mit denen dieses Lizenzvertrages identisch oder vergleichbar sind.

Mit der Verwendung dieses Dokuments erkennen Sie die Nutzungsbedingungen an.

\section{Terms of use}

This document is published under following Creative Commons-License: http://creativecommons.org/licenses/by-nc-sa/4.0/deed.en - You may copy, distribute and transmit, adapt or exhibit the work in the public and alter, transform or change this work as long as you attribute the work in the manner specified by the author or licensor. You are not allowed to make commercial use of the work. If you alter, transform, or change this work in any way, you may distribute the resulting work only under this or a comparable license.

By using this particular document, you accept the above-stated conditions of use.

\section{Kontakt / Contact:}

\section{peDOCS}

DIPF | Leibniz-Institut für Bildungsforschung und Bildungsinformation Informationszentrum (IZ) Bildung

E-Mail: pedocs@dipf.de

Internet: www.pedocs.de

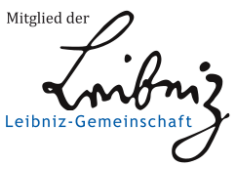




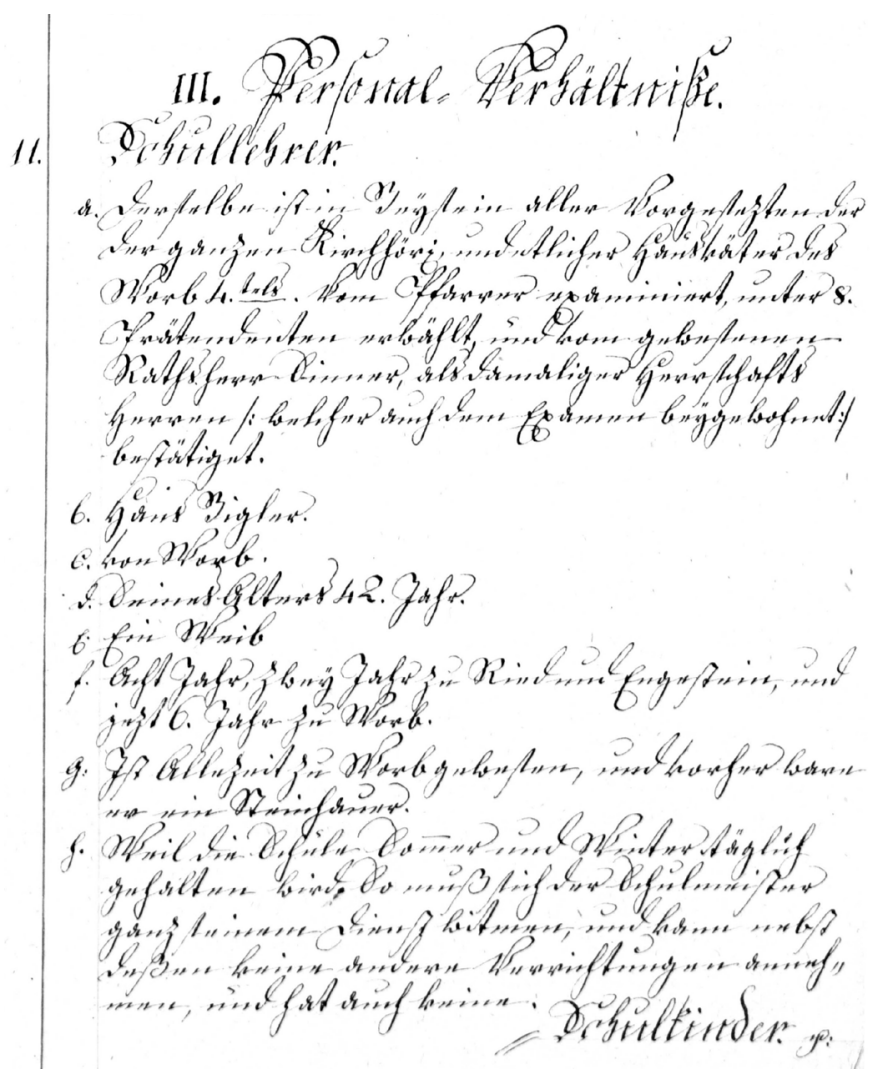

\section{Marcel Rothen}

\section{Die Elementarschullehrer am Ende des Ancien Régimes}

Eine Kollektivbiografie der Schweizer Lehrerschaft im Spiegel der Stapfer-Enquête von 1799 
Rothen

\author{
Die Elementarschullehrer \\ am Ende des Ancien Régimes
}




\section{Studien zur Stapfer-Schulenquête von 1799}

herausgegeben von

Daniel Tröhler, Alfred Messerli, Fritz Osterwalder

und Heinrich Richard Schmidt

\section{In dieser Reibe sind erschienen}

Brühwiler, Ingrid: Finanzierung des Bildungswesens in der Helvetischen Republik. Vielfalt Entwicklungen - Herausforderungen. Bad Heilbrunn 2014.

Tröhler, Daniel (Hrsg.): Volksschule um 1800. Studien im Umfeld der Helvetischen StapferEnquête 1799. Bad Heilbrunn 2014.

Fuchs, Markus: Lehrerinnen- und Lehrerperspektiven in der Helvetischen Republik. Bad Heilbrunn 2015.

Tröhler, Daniel (Hrsg.): Schule, Lehrerschaft und Bildungspolitik um 1800. Neue Studien im Umfeld der Helvetischen Stapfer-Enquête von 1799. Bad Heilbrunn 2016.

Ruloff, Michael Christian: Schule und Gesellschaft um 1800. Der Schulbesuch in der Helvetischen Republik. Bad Heilbrunn 2017. 


\section{Marcel Rothen}

\section{Die Elementarschullehrer am Ende des Ancien Régimes}

Eine Kollektivbiografie der Schweizer Lehrerschaft im Spiegel der Stapfer-Enquête von 1799 
Die Bände und Materialien der Reihe "Studien zur Stapfer-Schulenquête von 1799" erscheinen in Zusammenarbeit mit dem DIPF zugleich im Open Access auf www.pedocs.de. Suchwort: Stapfer-Schulenquête

Publiziert mit Unterstützung des Schweizerischen Nationalfonds zur Förderung der wissenschaftlichen Forschung.

Inauguraldissertation der Philosophisch-historischen Fakultät der Universität Bern zur Erlangung der Doktorwürde, vorgelegt von Marcel Rothen von Guggisberg BE.

Von der Philosophisch-historischen Fakultät auf Antrag von Prof. Dr. Heinrich Richard Schmidt, Historisches Institut der Universität Bern, und Prof. Dr. Danièle Tosato-Rigo, Section d'histoire der Université de Lausanne, angenommen.

Bern, den 19. Oktober 2018, Der Dekan: Prof. Dr. Stefan Rebenich.

Dieser Titel wurde in das Programm des Verlages mittels eines Peer-Review-Verfahrens aufgenommen.

Für weitere Informationen siehe www.klinkhardt.de.

Bibliografische Information der Deutschen Nationalbibliothek Die Deutsche Nationalbibliothek verzeichnet diese Publikation in der Deutschen Nationalbibliografie; detaillierte bibliografische Daten sind im Internet abrufbar über http://dnb.d-nb.de.

2021.k. (C) by Julius Klinkhardt.

Satz: Kay Fretwurst, Spreeau.

Bildnachweis Umschlagseite 1: BAR B0 1000/1483, Nr. 1431, fol. 69 [17.03.1799] - Worb.

Druck und Bindung: Bookstation GmbH, Anzing.

Printed in Germany 2021.

Gedruckt auf chlorfrei gebleichtem alterungsbeständigem Papier.

(c)(1)(2) Die Publikation (mit Ausnahme aller Fotos, Grafiken und Abbildungen) ist veröffentlicht unter der Creative Commons-Lizenz: CC BY-NC-SA 4.0 International

https://creativecommons.org/licenses/by-nc-sa/4.0/

ISBN 978-3-7815-5891-5 Digital

doi.org/10.35468/5891

ISBN 978-3-7815-2449-1 


\section{Zusammenfassung}

Das Zerrbild des vormodernen Elementarschullehrers als armer „Hungerleider“ mit defizitären Bildungskenntnissen ist bis heute in historischen Darstellungen zum Schweizer Elementarschulwesen präsent. Gleichwohl ist bislang wenig über das soziale Profil und über die Lebensverläufe von Elementarschullehrkräften um 1800 bekannt.

Aus der als „Stapfer-Enquête“ bekannten Elementarschulumfrage von 1799 liegen biografische Daten von über 2‘300 Lehrkräften vor, die mit dem methodischen Ansatz der Kollektivbiografie quantitativ vergleichend ausgewertet wurden, um das soziale Profil, die biografischen Werdegänge und den sozialen Status der Elementarschullehrkräfte in der Helvetischen Republik zu erforschen.

In Bezug auf die soziale Herkunft der Lehrkräfte um 1800 zeigt die Studie, dass die Mehrheit der Lehrer - Lehrerinnen waren noch eine grosse Ausnahme - sich entgegen dem proklamierten Armutsparadigma nicht etwa aus den untersten sozialen Schichten rekrutierte, sondern aus kleinbäuerlich-handwerklichen Milieus der lokalen „Mittelschichten“ stammte. Zudem belegen regionale Erhebungen, dass es keineswegs an geeigneten Kandidaten für die Schulen mangelte, das Lehramt gar eine attraktive kommunale Ressource darstellte. Des Weiteren war trotz der enormen lokalen Disparitäten längst nicht jeder Lehrer finanziell arm, denn viele Lehrkräfte konnten bereits allein vom Schuleinkommen ihre Familien ernähren, die im Durchschnitt kinderreicher waren als jene von Vertretern ähnlicher Berufsgruppen.

Dass das Lehramt biografisch keine opportunistische Ausweichtätigkeit war, wird im Vergleich der generationell differenzierten Lebensverläufe ersichtlich. Die Mehrzahl übernahm ungeachtet ihrer Einkommenssituation bereits als Jugendliche oder junge Erwachsene das Lehramt und übte es in langfristiger Perspektive aus. Mit der Übernahme des Lehramtes veränderten viele Lehrkräfte auch ihr Berufsprofil im Sinne einer Destratifizierung ihrer Erwerbstätigkeiten. Diskontinuierliche Berufsprofile wurden häufiger, indem auf frühere Tätigkeiten bewusst verzichtet wurde oder diese durch Kirchenhilfsdienste ersetzt wurden. Der Beginn der Professionalisierung der Lehrerschaft kann somit trotz noch fehlenden einheitlichen Ausbildungsstrukturen bereits in den Lebensverläufen der Lehrkräfte vor 1800 datiert werden.

Das Lehramt selbst, aber auch die vielfach praktizierte Verbindung mit Kirchenhilfsdiensten, verlieh den Lehrkräften nebst Zusatzeinkünften ein hohes immaterielles soziales Kapital. Dieses soziale Kapital schlug sich für die Lehrerschaft etwa in überdurchschnittlich hohen Heiratsquoten nieder.

Aus regionalen Quellenbeständen konnte des Weiteren ein hoher Grad an Zufriedenheit mit den fachlichen Leistungen der Lehrkräfte festgehalten werden, oftmals im schroffen Kontrast zu kritischen Einzelberichten stehend, die gleichzeitig fachliche Unfähigkeit attestierten. So waren die vielfach kritisierten Elementarschullehrer die zentralen Diffusoren der um 1800 bereits weitgehend flächendeckenden Alphabetisierung der Schweiz, was die Leistungen der Lehrerschaft und des frühneuzeitlichen Bildungswesens insgesamt in ein neues Licht rückt. 


\section{Abstract}

The distorted stereotype of the pre-modern elementary school teacher as a poor starving man with deficient educational knowledge is still omnipresent in historical depictions of the Swiss elementary school system. Nevertheless, little is known about the social profile and the lives of elementary school teachers around 1800.

From the Elementary School Survey of 1799 , known as the Stapfer-Enquête, biographical data of over 2,300 teachers is available, which was analyzed quantitatively and comparatively using the methodological approach of collective biographies in order to explore the social profile, biographical careers and social status of elementary school teachers in the Helvetic Republic. With regard to the social background of teachers at the beginning of the $19^{\text {th }}$ century, the study shows that, contrary to the perceived poverty paradigm, the majority of teachers - female teachers were still the exception - were not recruited from the lowest social strata, but came from small-scale farms and craft milieus of the local middle classes. In addition, regional surveys show that there was no lack of suitable candidates for the school classrooms, and that the teaching profession even represented an attractive communal resource. Furthermore, despite the enormous local disparities, not every teacher was destitute, for many teachers were able to support their families from teaching income alone, as teachers, on average, had more children than those of similar occupational groups.

The fact that the teaching profession was not an opportunistic alternative occupation becomes apparent in a comparison of the generationally differentiated career paths. Regardless of their financial situation, the majority of elementary school teachers took up the teaching profession as adolescents or young adults and pursued it in the long term. Upon assumption of the teaching profession, many teachers also changed their professional profile in the sense of a destratification of their gainful activities. Discontinuous professional profiles became more frequent, in that former activities were consciously renounced or replaced by church auxiliary service. The beginning of the professionalization of the teaching profession can thus already be dated in the career paths of teachers before 1800 , despite the still missing uniform training structures.

The teaching profession itself, along with the frequently practiced connection with church auxiliary service, gave teachers a high intangible social capital in addition to income. This social capital is reflected in above-average marriage rates for teachers.

Furthermore, regional sources reveal a high degree of satisfaction with the teachers' professional performance, often in harsh contrast to critical individual reports, which simultaneously attest to professional incompetence. In this way, these often-criticized elementary school teachers were the central diffusers of Swiss literacy, which was already largely comprehensive around 1800 , putting their performance and the early modern educational system in a brand new light. 


\section{Inhaltsverzeichnis}

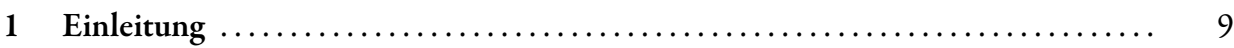

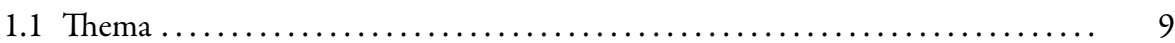

1.2 Schule und Gesellschaft am Ende des Ancien Régimes ................ 11

1.2.1 Der politisch-konfessionelle Kontext im 18. Jahrhundert .......... 13

1.2.2 Der sozio-ökonomische Kontext ........................ 15

1.2.3 Die Helvetische Revolution .............................. 19

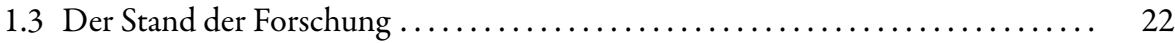

1.3.1 Die Schulgeschichte im deutschen Sprachraum ............... 22

1.3.2 Die Schulgeschichte in der Schweiz .................... 24

1.3.3 Das Bild des Lehrers in der Historiografie $\ldots \ldots \ldots \ldots \ldots \ldots \ldots \ldots . . \ldots \ldots$

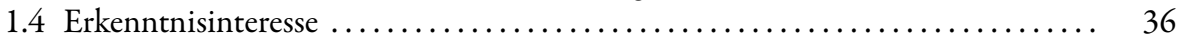

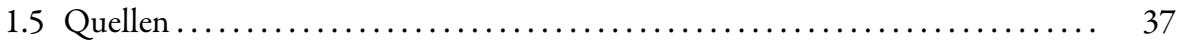

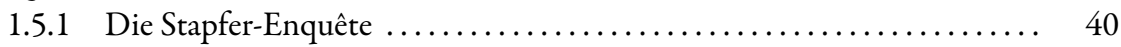

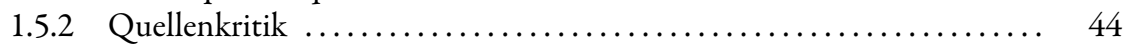

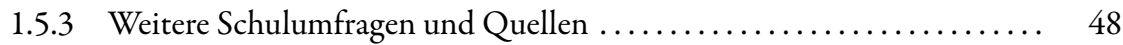

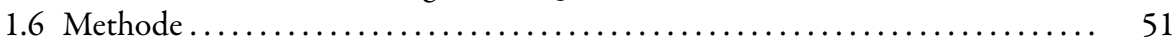

1.6.1 Biografische Indikatoren zur Operationalisierung $\ldots \ldots \ldots \ldots \ldots \ldots \quad 57$

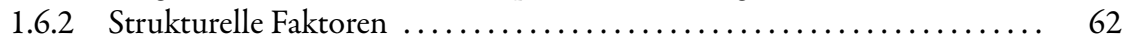

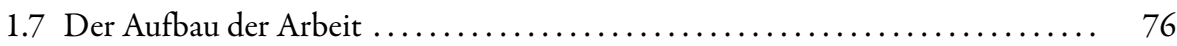

2 Lehrer werden - das soziale Profil der Lehrer und Lehramtsanwärter ......... 79

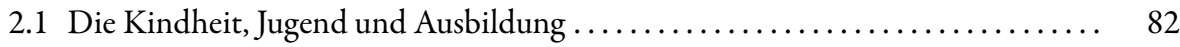

2.1.1 Die Ausbildung zum Lehrer $\ldots \ldots \ldots \ldots \ldots \ldots \ldots \ldots \ldots \ldots \ldots$

2.1.2 Die Normalschule in der Alten Eidgenossenschaft ............... 98

2.2 Die Ersttätigkeiten und das Amtsübernahmealter $\ldots \ldots \ldots \ldots \ldots \ldots \ldots \ldots 1$

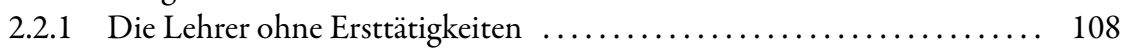

2.2.2 Landwirtschaftliche Tätigkeiten $\ldots \ldots \ldots \ldots \ldots \ldots \ldots \ldots \ldots \ldots \ldots . \ldots \ldots \ldots \ldots$

2.2.3 Handwerkliche Tätigkeiten ........................... 129

2.2.4 Protoindustriell-textilgewerbliche Tätigkeiten ................ 137

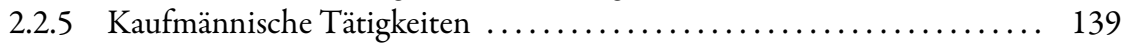

2.2.6 Kommunale Amtstätigkeiten ........................ 141

2.2.7 Kirchliche Amtstätigkeiten ......................... 143

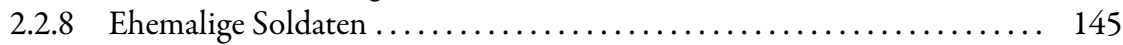

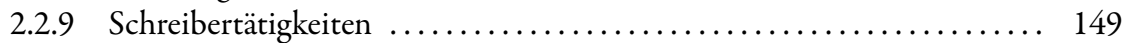

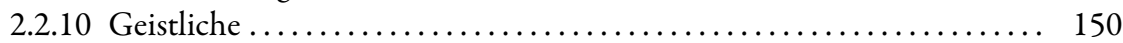

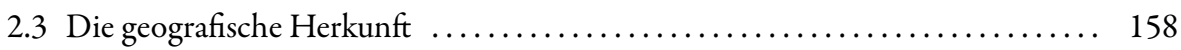

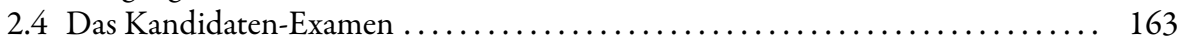

2.4.1 Die normativen Anforderungen an Lehrer-Kandidaten ............. 167

2.4.2 Die Inhalte und der Ablauf der Examina .................... 170

2.4 .3 Das Kandidatenfeld $\ldots \ldots \ldots \ldots \ldots \ldots \ldots \ldots \ldots \ldots \ldots \ldots \ldots \ldots \ldots \ldots \ldots$ 
3 Lehrer sein - Entwicklungen von Lehrer-Biografien ................ 185

3.1 Das Einkommen aus der Schultätigkeit ...................... 186

3.1.1 Die Frage des Mindestlohns im helvetischen Diskurs ............ 190

3.1.2 Regionale Einkommensverhältnisse ..................... 193

3.2 Die Nebentätigkeiten im kollektiven Überblick . . . . . . . . . . . . . . . . . . . 205

3.3 Die Ausgestaltung der Berufsbiografien ....................... 211

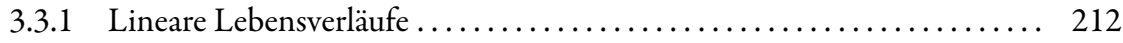

3.3.2 Kontinuierlich-erweiterte Lebensverläufe ................. 216

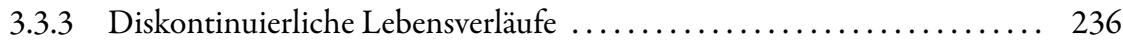

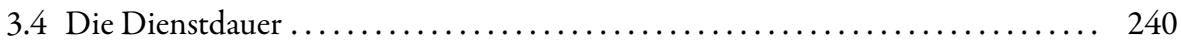

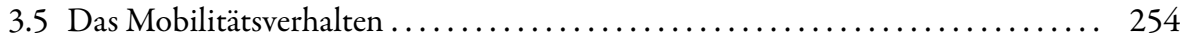

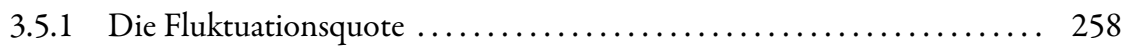

3.5.2 Lehramtliche Mobilität .......................... 261

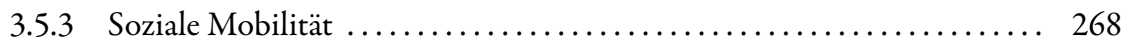

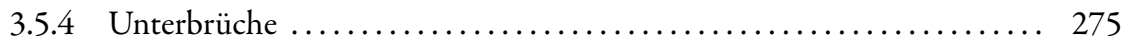

3.6 Freizeit und Mitgliedschaft in Sozietäten ...................... 276

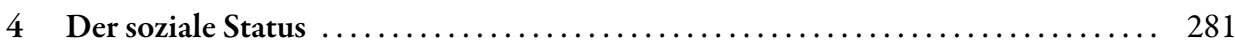

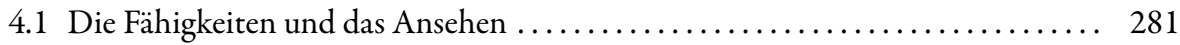

4.1.1 Das Beherrschen der Kulturtechniken und der Amtsfleiss ........... 285

4.1.2 Das Ansehen in den Gemeinden .......................... 298

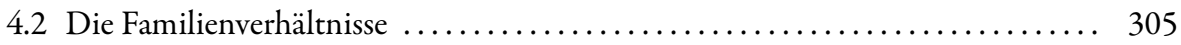

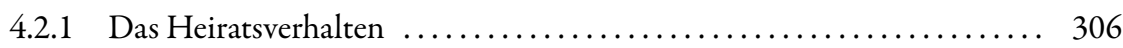

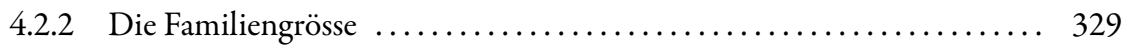

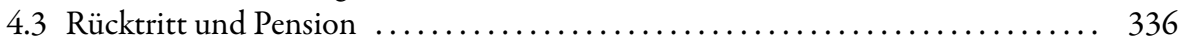

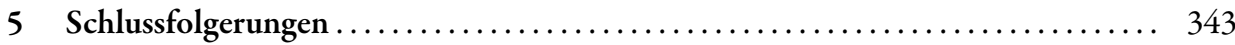

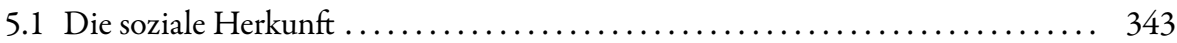

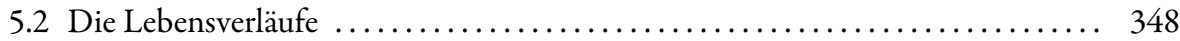

5.3 Der soziale Status . . . . . . . . . . . . 352

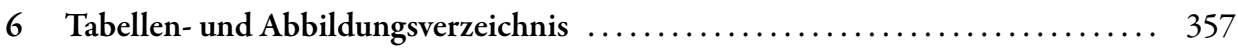

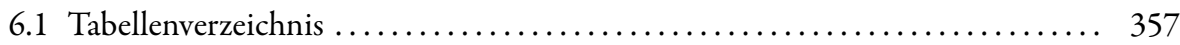

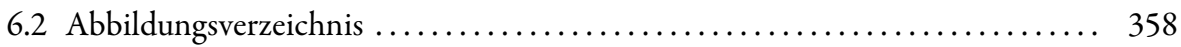

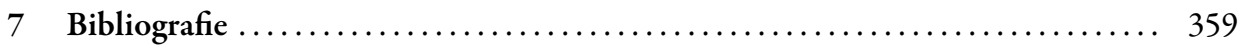

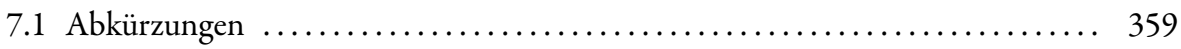

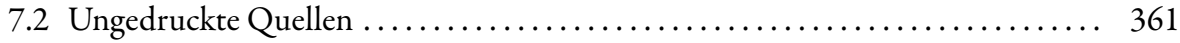

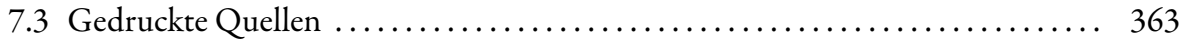

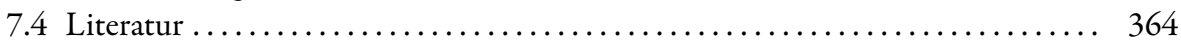

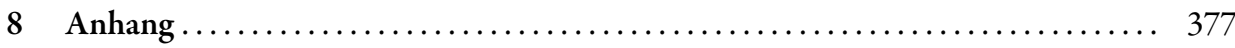

8.1 Anhang I: Stapfer-Enquête Fragebogen ...................... 377

8.2 Anhang II: Altersstruktur der Elementarschullehrer ................ 378 


\section{Einleitung}

\subsection{Thema}

Bildung wird in der heutigen öffentlichen Wahrnehmung und in der Schweizer Politik gerne als der einzige wirkliche Rohstoff des Landes bezeichnet, wie der selbstsprechende Titel eines vor wenigen Jahren veröffentlichten Zeitungsartikels der Neuen Zürcher Zeitung mit den Schlagworten "Schweizer Rohstoff Bildung“ verdeutlicht. ${ }^{1}$ Der bisherige Erfolg des Schweizer Bildungssystems wird als ein Stützpfeiler für den wirtschaftlichen Erfolg des Landes in der jüngeren Vergangenheit angesehen. So ist in einem Positionspapier der „Akademien der Wissenschaften Schweiz“ zur zukünftigen Bildungsentwicklung festgehalten worden: „Die Tatsache, dass sich die kleine Schweiz in Wissenschaft, Technologie und Wirtschaft in den vergangenen Jahrzehnten immer auf Augenhöhe mit den grossen Mitspielern bewegen konnte, hat sie nicht zuletzt ihrem Bildungssystem zu verdanken.“2 Über den hohen Standard unseres heutigen Bildungswesens gibt es denn auch einen breiten politischen und gesellschaftlichen Konsens.

Die reale Bildungsvermittlung funktioniert trotz der fortschreitenden Technisierung und Digitalisierung auch heute - das zeigt die aktuelle Corona-Situation mit dem abrupten Wechsel zu zeitweiligem Fernunterricht deutlich ${ }^{3}$ - noch immer kaum ohne die direkte personale Interaktion zwischen den Lernenden und Lehrenden. Die Lehrperson steht dabei im Zentrum des sozialen Interaktionsraums Schule und bleibt neben den strukturellen Rahmenbedingungen hauptverantwortlich für den letztendlichen Erfolg der Bemühungen um Bildungsvermittlung, wie Studien des Erziehungswissenschaftlers John Hattie aufgezeigt haben. ${ }^{4}$ Eine funktionierende Schule braucht folglich neben bildungsfördernden staatlichen Strukturen und einer zweckdienlichen Infrastruktur vor allem „gute“ Lehrpersonen zur erfolgreichen Umsetzung ihres Bildungsauftrags. Offenbar hat die Schweiz diese „guten Lehrkräfte“ zumindest in der jüngeren Vergangenheit gehabt.

Doch was macht einen „guten Lehrer“ beziehungsweise eine „gute Lehrerin“ aus? Hierüber gehen die Meinungen auseinander und jeder Einzelne hat durch seine individuelle Schulbiografie als Schülerin beziehungsweise Schüler seine eigene Meinung, was eine Lehrperson sein und können soll. Die Person des Lehrers ${ }^{5}$ und insbesondere seine beruflichen Qualifikationen sind jedenfalls bis heute ein Dauerthema von immer wiederkehrender Aktualität im Diskurs um die Qualität der Institution Schule. Besonders in den zyklisch auftretenden Phasen des Lehrkräftemangels auf dem nationalen Arbeitsmarkt wird die Diskussion um das Berufsprofil der Lehrkräfte in Gesellschaft und Politik immer wieder von Neuem aufgegriffen, etwa wenn ver-

1 Haener, Rohstoff: 16.

2 Zimmerli, Zukunft: 9.

3 Dickson, Viruskrise: 12-14.

4 Zur Rolle der Lehrpersonen als zentrale Einflussfaktoren auf den Schulerfolg sei auf die bekannten Studien von John Hattie verwiesen. Exemplarisch: Hattie/Zierer, Visible Learning: 117-132.

5 In der vorliegenden Studie wird der Einfachheit halber ausschliesslich der männliche Terminus für sämtliche Lehrpersonen verwendet, sofern nicht explizit weibliche Lehrkräfte gemeint sind, da Lehrerinnen im frühneuzeitlichen öffentlichen Elementarschulwesen nur eine marginale quellenverbriefte Präsenz aufwiesen (vgl. das Kap. 1.6.2). Als „Lehrer“ werden in dieser Arbeit - wenn nicht durch andere klärende Zusätze hervorgehoben - grundsätzlich Unterrichtende an öffentlichen Schuleinrichtungen verstanden, deren Aufgabe die Initiierung von Lern- und Bildungsprozessen bei Kindern und Jugendlichen ist. Privat- und Hausschullehrer sind hingegen nicht inkludiert. Vgl. zur Definition des Begriffs des Lehrers die Lexikonartikel: Rutz, Lehrer/in; Caspard, Lehrer. 
mehrt unterqualifizierte Pädagogen angestellt werden müssen, wie jüngere Pressetexte aus der nationalen Zeitungslandschaft verdeutlichen. ${ }^{6}$

Die Tätigkeit des Elementarschullehrers ${ }^{7}$ hat in der Schweiz ebenso wie in den übrigen europäischen Staaten in den letzten zweihundert Jahren eine dynamische, wenn auch bei Weitem nicht linear verlaufende Entwicklung der Verberuflichung und Professionalisierung ${ }^{8}$ erlebt. Das Lehramt hat sich hierbei von einer handwerksnahen Tätigkeit zu einem akademischen Beruf gewandelt, wofür heute ein mindestens dreijähriges Studium an einer pädagogischen Hochschule als Voraussetzung zur Berufsausübung notwendig ist. Entsprechend hat sich nicht nur das Qualifikationsprofil in den letzten zweihundert Jahren fundamental verändert, sondern auch das Bild der Lehrperson in der Gesellschaft ist einem steten Wandel unterworfen. „Früher war im Dorf klar: Der Herr Lehrer ist eine respektable Autorität aus gutem Haus, die Wissen vermittelt und beim

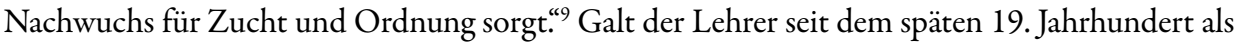
respekteinfordernde Autoritätsperson, hat das Berufsbild des Lehrers spätestens seit der Ablösung der berufspraktisch orientierten Lehrerseminare durch die pädagogischen Hochschulen vor rund zehn Jahren und der damit verbundenen Aufwertung des Lehrerberufs auf die akademisch-tertiäre Bildungsstufe nochmals an zusätzlichem gesellschaftlichen Renommee gewonnen. Gleichwohl beklagen Schweizer Lehrerinnen und Lehrer in internationalen Vergleichen immer noch einen subjektiv eher niedrigen gesellschaftlichen Status ihres Berufsstandes. ${ }^{10}$ Als ebenso ungenügend wird die aktuelle Lohnsituation von zahlreichen Lehrkräften empfunden. ${ }^{11}$

6 Eberhard/Pastega, Wissen: 6; Birrer, Lehrermangel: 4.

7 Der Begriff der „Elementarschule“ umschreibt in dieser Arbeit sämtliche Orte von öffentlicher Grundbildung für Kinder und Jugendliche zur Erlangung der elementaren Kulturtechnikkompetenzen des Lesen, des Schreibens sowie teilweise weiterer Fachelemente wie Rechnen, Geschichte, Vaterlandskunde oder Naturkunde. Auf eine Verwendung der üblichen zeitgenössischen Begrifflichkeiten um 1800, zumeist „deutsche Schule“ oder „,niedere Schule", wird bewusst verzichtet, da sie allesamt einerseits im zeitgenössischen Sprachgebrauch uneinheitlich verwendet wurden, andererseits eine irrtümliche Sprachbezogenheit oder eine ungewollte Hierarchisierung implizieren. Während der Terminus der „deutschen Schule“ die französischsprachigen Elementarschulen nicht einzubinden vermag, schwingt im Begriff der „,niederen Schule“ eine negativ konnotierte, hierarchische Wertung mit, die der zeitgenössischen vertikalen Permeabilität und Komplexität des Schulwesens, besonders im städtischen Umfeld, nicht gerecht wird. Da auch weiterführende höhere Lateinschulen, Realschulen und Gymnasien mitunter in fliessendem Übergang Klassen der Elementarbildung umfassen konnten, scheint eine Abgrenzung nach Bildungsinhalten sinnvoller. Die Begriffe der „Volksschule“ und der „Primarschule“ sind dagegen für das 18. Jahrhundert aus der möglichen Gefahr einer unstatthaften Gleichsetzung der vormodernen Schule mit dem modernen Bildungswesen abzulehnen, da sich beide Begriffe erst im 19. und 20. Jahrhundert herausgebildet haben und zuvor nicht einheitlich verwendet wurden. Vgl. zum Begriffsdiskurs den Lexikonartikel: Bruning, Elementarschule.

8 Bildungsgeschichtlich wird zwischen den beiden Prozessen der „Verberuflichung" und der „Professionalisierung“ unterschieden. „Im ersten Fall handelt es sich um die Durchsetzung und Differenzierung von Spezialkenntnissen für die Ausübung bestimmter Tätigkeiten [...], deren Ensemble ein Beruf beschreibt, im zweiten Fall um die Definition dieser Kenntnisse, des Zugangs zu ihnen und um die Kontrolle ihrer Verwendung speziell in jenen Berufen, deren Modernisierung sich vor allem als Akademisierung vollzog." Herrmann, Experte: 412. Vgl. ferner: Tosch, Professionalisierung: 243ff.

9 Selbst in aktuellsten Artikeln in Lehrerzeitschriften wird regelmässig auf das gewandelte Berufsbild der Lehrerschaft verwiesen: Dickson, Viruskrise: 13.

10 Vgl. die Studie der Varkey GEMS Foundation aus dem Jahr 2013. Der gesellschaftliche Status der Primar- und Sekundarlehrkräfte wurde dabei jeweils verglichen mit Ärzten, Krankenschwestern, Bibliothekaren, Anwälten, Polizisten, Ingenieuren, Webdesignern und Sozialarbeitern: Dolton/Marcenaro-Gutierrez, Status: 15f, 46.

11 Die Löhne der Lehrpersonen seien gegenüber Berufen mit vergleichbaren Anforderungen nicht konkurrenzfähig, vermeldete beispielsweise der Dachverband Lehrerinnen und Lehrer Schweiz (LCH) im Jahr 2014 nach der Präsentation einer Auftragsstudie: Dachverband Lehrerinnen und Lehrer Schweiz, Medienmitteilung. 
Das Bild der Elementarschullehrperson hat sich ferner auch in geschlechtsspezifischer Hinsicht in den letzten zweihundert Jahren fundamental gewandelt. Der Lehrerberuf auf der Primarund Sekundarstufe ist heute wie kaum eine andere tertiäre Profession stark „feminisiert“, was wiederum für stetige Kritik sorgt. ${ }^{12}$ „Der Herr Lehrer ist ein Exot“, titelte etwa die NZZ erst von wenigen Jahren aufgrund des hohen Frauenanteils von über drei Vierteln im Lehrerkorps des Schweizer Primarschulwesens. ${ }^{13}$

Die vorliegende Studie widmet sich jedoch nicht dem Prozess der Verberuflichung und der Professionalisierung der Schweizer Elementarschullehrkräfte an sich. Vielmehr wird auf die Anfänge und auf die Ausgangslage dieses langen und diskontinuierlichen Modernisierungs- und Professionalisierungsprozesses an der Epochenschwelle zur Moderne um das Jahr 1800 zurückgegangen. Ein Blick zurück auf die Anfänge des modernen Schweizer Bildungswesens ist vonnöten, wenn man den heute oft als teleologische Erfolgsgeschichte verstandenen Entwicklungsprozess in ganzer Länge und abseits von ideologisch geprägten Verklärungen verstehen will. Denn das Elementarschulwesen um 1800 ist in der Forschung zur Schweizer Bildungsgeschichte meist in negativer Konnotation als "primitiv“ und „verrottet“, die Lehrer als ungebildet und ungenügend besoldet beschrieben worden. ${ }^{14}$ Nach Holger Böning hat aber bereits um 1800 mit der Helvetischen Revolution und der darauf folgenden kurzen Phase der zentralstaatlich organisierten Helvetischen Republik eine fundamentale Wende im schweizerischen Volksschulwesen eingesetzt. ${ }^{15}$ Die tatsächliche Rolle der Lehrerschaft als Hauptakteure in dieser Wende ist aber in der bisherigen Forschungslandschaft weitgehend diffus geblieben. Die vorliegende Untersuchung widmet sich daher der Elementarschullehrerschaft um 1800 in spezifisch personeller Betrachtung. Denn obwohl sich die schweizerische Öffentlichkeit seit über zweihundert Jahren intensiv mit der Institution „Schule“ und ihrer Ausgestaltung befasst, ist über die Lehrerschaft vor dem Beginn der staatlich organisierten, systematisierten Bildungsreformen der liberalen Ära ab 1830 noch erstaunlich wenig bekannt. ${ }^{16}$ Die Basis für die folgende Untersuchung bildet das Quellenkorpus einer Schulumfrage aus der Helvetischen Republik, die so genannte „Stapfer-Enquête“ von 1799, in der rund 2.400 Lehrkräfte des Elementarschulwesens erfasst und befragt wurden. ${ }^{17}$

\subsection{Schule und Gesellschaft am Ende des Ancien Régimes}

Das frühneuzeitliche elementare Schulwesen des ausgehenden 18. Jahrhunderts unterschied sich in markanter Weise vom heutigen Bildungssystem. Im Gegensatz zum modernen dreistufigen Schulwesen mit Primarschule, sekundärer Mittelschule und den dualen Ausbildungsformen von Gymnasium und Berufsbildung war das frühneuzeitlich-vormoderne Schulwesen vor 1800 als „Standesschule“ bloss zweigliedrig und unterstand faktisch „als Anhängsel“ dem Aufgabenbereich der Landeskirchen. ${ }^{18}$ Es bestand zum einen aus den sogenannten „niederen Schulen“,

12 Zur historischen Entwicklung des Zugangs zum Lehrerberuf für Frauen am Beispiel des Kantons Zürichs vgl. Bloch Pfister, Priester: 511-524. Für den Kanton Bern bis 1989: Scandola, Lehrerschaft: 299ff. Zur modernen Kritik am „feminisierten "Lehrerberuf in der Schweiz vgl. Wolter/Denzler, Erklärungen: 23ff. Zur historischen Kritik an der wachsenden Anzahl an Lehrerinnen in Deutschland vgl. Bölling, Sozialgeschichte: 100. Eine kritische Auseinandersetzung mit der Frage, ob der Lehrerberuf zu einem „Frauenberuf“ geworden sei, leistet: Lundgreen, Feminisierung: 121-136.

13 Daum, Exot: 40.

14 Schlegel, Schulmänner: 44; Hunziker, Volksschule: 21, 27.

15 Böning, Traum: 223.

16 Vgl. Ruloff, Schulbesuch: 10.

17 Zum Quellenbestand siehe das Kap. 1.5.

18 Scandola, Standesschule: 595, 621. 
den muttersprachlich gehaltenen Elementarschulen, deren Hauptaufgaben das Vermitteln der Kirchenlehre und die religiös-moralische Erziehung der Kinder zu gottgefälligen Christenmenschen waren. Praktische Wissensvermittlung durch die elementaren Kulturtechniken des Lesens und des Schreibens dienten vorderhand als Mittel zum Zweck des Erreichens der religiösen Zielsetzungen. So wurde das Lesen und Schreiben in der Regel mithilfe religiöser Texte geübt und die Katechese, das mechanische Auswendiglernen der religiösen Grundsätze, nahm einen dominanten Platz im Unterricht ein. Zudem waren die allermeisten in den Schulstuben zur Verfügung stehenden Lehrmittel von religiöser Natur. ${ }^{19}$

Zum anderen existierten in den Städten und in grösseren Marktflecken ein nicht eindeutig abtrennbares weiterführendes „höheres“ Schulwesen, bestehend aus Realschulen, Lateinschulen und Gymnasien zur Vorbereitung auf das Studium an einer Universität oder Akademie. ${ }^{20}$ Diese grobschematische Zweiteilung des Schulwesens bildete sich ferner in zwei Kategorien an Lehrern von unterschiedlicher sozialer Bedeutung ab: zum ersten in den sozial höher gestellten und besser verdienenden Gymnasial- und Lateinschullehrern, vorwiegend bestehend aus studierten Geistlichen, und zum zweiten in den lokal rekrutierten, aus der einfachen Bevölkerung stammenden Elementarschullehrern. ${ }^{21}$ Die Schullehrertätigkeit war um 1800 denn auch in ganz Europa noch kein eigenständiger Beruf im modernen Sinne, sondern vielmehr ein „Amt“, das von Personen aus verschiedensten Professionen ausgeübt werden konnte und sich erst am Beginn des Wegs der allmählichen Verberuflichung befand. ${ }^{22}$

Das schweizerische Elementarschulwesen des ausgehenden „Ancien Régime“23 war sowohl organisationsstrukturell als auch in der Ausgestaltung der schulischen Realität vor Ort von einer enormen lokalen Heterogenität geprägt, deren Ursachen in der Kleinräumigkeit und Vielfalt des alteidgenössischen politischen Staatswesens, in den konfessionellen Gegensätzen sowie in den unterschiedlichen wirtschaftlichen und gesellschaftlichen Entwicklungen der einzelnen Landesteile zu suchen sind. Um diese immense Vielfalt an Formen von Schule mit ihren Auswirkungen auf das Amt des Lehrers und die schulische Wirklichkeit vor Ort besser verstehen zu können, soll einleitend Grundsätzliches zum historischen Kontext des alteidgenössischen Ancien Régimes geklärt werden. Im Folgenden werden überblickartig die politischen, konfessionellen, wirtschaftlichen sowie sozialen Leitlinien und Prozesse beleuchtet, die das Elementarschulwesen des ausgehenden Ancien Régimes geprägt haben.

19 Böning, Revolution: 149; De Vincenti-Schwab, Landschulen: 20. Zur Dominanz von religiösen Lehrmitteln in der frühneuzeitlichen Schule vgl. die Studie von Nadine Pietzko zur Lehrmitteldistribution am Ende des 18. Jahrhunderts in der Schweiz: Pietzko, Lehrmittellandschaften.

20 Die Universität Basel blieb im Ancien Régime die einzige Universität der Schweiz. Akademien zur Ausbildung von reformierten Geistlichen bildeten sich in Bern, Lausanne, Genf und Zürich. In der katholischen Schweiz übernahmen Jesuitenschulen die mittlere und höhere Schulbildung. Ihre Hauptstandorte lagen in Luzern, Fribourg, Pruntrut, Solothurn, Brig und Sitten. Vgl. Stadler, Schulwesen.

21 Vgl. Scandola, Standesschule: 603; Stefanidou-Kappmann, Geschichte des Volkschullehrers: 131.

22 Sauer, Volksschullehrerbildung: 11; Kesper-Biermann, Kurhessen: 159. Siehe ferner die Ausführungen im Kap. 2.

$23 \mathrm{Als}$ „Ancien Régime“ wird in der schweizerischen Geschichtswissenschaft die zeitliche Phase vor der französischen Militärintervention und der Etablierung der Helvetischen Republik im Frühjahr 1798 verstanden. Über den Beginn der Periode existieren verschiedene Ansatzpunkte. Hans Conrad Peyer folgend, schlägt auch Rudolf Braun das Ende des zweiten Villmergerkriegs von 1712 als „willkürlich“ gewählten Zäsurpunkt vor. Braun, Ancien Régime: 14f.; Peyer, Verfassungsgeschichte: 7. Ulrich Im Hof hat das Ancien Régime dagegen bereits um 1656 mit dem dritten Landfrieden beginnen lassen. Im Hof, Ancien Régime: 675. Für die vorliegende Arbeit umreisst der Begriff die zweite Hälfte des 18. Jahrhunderts, beginnt also erst um ca. 1750 und orientiert sich damit am Konzept der „Sattelzeit“ nach Reinhard Koselleck. Vgl. Koselleck, Einleitung: XV. 


\subsubsection{Der politisch-konfessionelle Kontext im 18. Jahrhundert}

Die politische Landschaft der Alten Eidgenossenschaft ${ }^{24}$ bestand bis ins Jahr 1798 aus einem seit dem zweiten Villmergerkrieg von 1712 zwar territorial weitgehend stabilen, aber höchst komplexen Gebilde von unterschiedlichsten Herrschaftsformen. Darin fanden sich zum einen die dreizehn vollberechtigten Stadt- und Länderorte mit ihren jeweiligen Untertanengebieten. ${ }^{25}$ Zum anderen gehörten eine Reihe von asymmetrisch assoziierten Zugewandten Orten und Schirmorten sowie die von den dreizehn vollberechtigten Orten gemeinsam verwalteten Gemeinen Herrschaften zum „Staatenbündel“ der Alten Eidgenossenschaft. ${ }^{26}$ Alle Glieder waren durch ein Geflecht aus bi- und multilateralen Bündnissen miteinander und zeitgleich mit ausländischen Schutzmächten verbunden, aber sowohl innen- als auch aussenpolitisch weitgehend souverän und autonom. ${ }^{27}$ Entsprechend ungleich gestaltete sich die obrigketitliche Durchdringung in den einzelnen Gliedern der Alten Eidgenossenschaft aus, doch insgesamt verfügten die Gemeinden als unterste Hierarchiestufe gegenüber den Vertretern der Obrigkeit, den Landvögten, über einen hohen Grad an Gestaltungsautonomie. ${ }^{28}$

Das komplexe politische Gebilde der Alten Eidgenossenschaft wurde zusätzlich überlagert von den beiden rivalisierenden Konfessionen des Katholizismus und des Protestantismus, deren Einflussgrenzen seit dem zweiten Villmergerkrieg von 1712 zwar weitgehend gezogen waren, in den gemischtkonfessionellen und grenznahen Gebieten aber weiterhin unterschwellig für Spannungen und Rivalitäten sorgten. Im fortschreitenden Zuge der „Konfessionalisierung ${ }^{\text {“29 }}$ seit der Reforma-

24 Der Begriff der „Alten Eidgenossenschaft“ bezeichnet das seit ca. 1350 beschworene Bündnisnetz im Gebiet der heutigen Schweiz. Es bestand ab 1353 aus acht, von 1513 bis 1798 aus dreizehn vollberechtigten Orten. Vgl. Würgler, Eidgenossenschaft.

$25 \mathrm{Zu}$ den Stadtorten mit patrizischer Verfassung gehörten: Bern, Luzern, Fribourg und Solothurn. Zu den Stadtorten mit Zunftverfassung zählten: Zürich, Basel, Schaffhausen und St. Gallen. Als Länderorte galten Uri, Schwyz, Obund Nidwalden, Glarus, Appenzell und Zug. Diese von Ulrich Im Hof und Hans Conrad Peyer (Im Hof/Staehelin, Handbuch; Peyer, Verfassungsgeschichte: 48-55, 107-116) entwickelte verfassungsrechtliche Dreiteilung der Alten Eidgenossenschaft ist jedoch nur als grobe Schablone zu verstehen und ist aufgrund ihrer Zuspitzung auf die Hauptstädte entsprechend kritisiert worden. Vgl. zur Kritik: Dubler, Patrizische Orte.

26 Braun, Ancien Régime: 15ff. Zugewandte Orte waren: Gersau, Biel, Neuenburg, Wallis, Abtei Engelberg, Fürstabtei St. Gallen, Graubünden, Genf, Fürstbistum Basel, Mülhausen und Rottweil. Zu den Gemeinen Herrschaften zählten: Die Freien Ämter, Grafschaft Baden, Thurgau, Sargans, Rheintal, Lugano, Mendrisio, Locarno, Valle Maggia, Bellinzona, Riviera, Blenio, Schwarzenburg, Echallens-Orbe, Murten, Grandson, Uznach, Gaster Gams. Vgl. Holenstein, Gemeine Herrschaften.

27 Braun, Ancien Régime: 15ff.; Würgler, Eidgenossenschaft.

28 Braun, Ancien Régime: 239f.; Tröhler, Genre: 84. Rudolf Braun betont jedoch regionale Unterschiede hinsichtlich des Grades an Lokalautonomie. Er spricht etwa den bernischen Landvögten eine - im Vergleich zu ihren Zürcher Amtskollegen - weitaus umfangreichere „omnipotente“ Machtfülle in kommunalen Angelegenheiten zu und hält den Status der Berner Landgemeinden für deutlich weniger autonom als die Zürcher Landgemeinden. Vgl. Braun, Ancien Régime: 252ff. Allerdings waren zahlreiche Rechte der bernischen Landvögte, etwa die Aufsichts- oder personellen Bestätigungsrechte in kommunalen Belangen, in der Praxis primär von passiver Natur, dienten eher der Funktion der Legitimitätsstiftung und waren mit wenig aktivem Gestaltungscharakter versehen. Zudem standen die Landvögte bei ihren Entscheidungen stets in engen Abhängigkeitsbeziehungen zu den dörflichen Eliten, was die realen Entscheidungsmöglichkeiten stark begrenzt haben dürfte.

29 Das kontrovers diskutierte Konzept der Konfessionalisierung, massgeblich geprägt durch die Arbeiten von Heinz Schilling und Wolfgang Reinhard, hat sich trotz vielfältiger und berechtigter Kritik - beispielsweise am postulierten Etatismus - zu einem der leitenden Forschungsparadigmen in der (deutschsprachigen) Frühneuzeitforschung entwickelt. Der Konfessionalisierungsprozess umfasste demnach nicht nur die Konfessionsbildung an sich, sondern war eng verknüpft mit der Entstehung der frühmodernen Territorialstaaten, wobei politisches und kirchliches Handeln weitgehend deckungsgleich funktionierten und eine symbiotische Aufgabenteilung zwischen den Staatskirchen und dem Staatswesen entstand. Vgl. Ehrenpreis, Säkularisierung: 28f.; Ehrenpreis/Lotz-Heumann, Reformation: 62-71; von Greyerz/Bischof, Konfessionalismus. 
tion verbanden sich die politisch-staatlichen Zielsetzungen der Obrigkeitsstaaten zur Schaffung eines einheitlichen Untertanenlandes im frühneuzeitlichen Staat mit dem Aufbau von konfessionell abgegrenzten Landeskirchen zu einem gesamtgesellschaftlichen Wandlungsprozess, der ab dem 16. Jahrhundert auf die Leitung, die staatliche Bürokratisierung und die Sozialdisziplinierung der Gesellschaft abzielte. Die Landeskirchen „disziplinierten im Sinne des Staates, ersetzten seine nicht voll nach unten durchgreifende Verwaltung und trugen so zur Schaffung einer formierten Untertanenschaft bei ““ ${ }^{30}$ Oder, um es mit den Worten von Max Weber auszudrücken, gestaltete sich die Herrschaftsausübung im Alltag primär als Akt der Verwaltung. ${ }^{31}$

Aus dem Konkurrenzdruck der beiden Konfessionen entstand eine erhöhte Beachtung des Bildungswesens, um den moralischen Vorsprung gegenüber der jeweils anderen Konfession $\mathrm{zu}$ demonstrieren und um die eigenen Normen verbreiten und durchsetzen zu können. ${ }^{32}$ Der Ausbau des Elementarschulwesens diente hierzu als ein Mittel, wobei die Finanzierung und der Unterhalt der Schulen in der Regel jedoch kommunale Angelegenheiten blieben. In gemischtkonfessionellen Gemeinden entstanden demnach - wo es die lokalen Finanzierungsverhältnisse erlaubten - jeweils konfessionell getrennte Schulen für beide Konfessionen. In zahlreichen gemischtkonfessionellen Gemeinden existierte damit trotz der bescheidenen finanziellen Mittel am Ende des Ancien Régimes eine sich zumindest indirekt konkurrierende parallele Schulinfrastruktur mit doppelten Schulhäusern und Lehrkräften, was besonders in den Gemeinen Herrschaften Baden, Echallens, Thurgau, im Rheintal, im gemischtkonfessionellen Glarus und im Toggenburg weit verbreitet war und mitunter zu kritischen Voten vonseiten der Lehrerschaft führte. ${ }^{33}$ Reichten die Gelder nicht aus, um eine eigene Schule einzurichten oder waren schlicht zu wenig Schulkinder vorhanden, wurden diese aufgrund des freien Schulwahlrechts der Eltern in die nächstgelegene konfessionell passende Schule geschickt. Paritätische Schulen, in denen sowohl katholische als auch reformierte Kinder in derselben Schule unterrichtet wurden, stellten dagegen eine absolute Ausnahmeerscheinung dar. ${ }^{34}$

Die komplexen Strukturmerkmale der übergeordneten politischen und konfessionellen Ebene bildeten den Raum für eine nur schwer überblickbare Formenvielfalt auf der lokalen Ebene. Die finanziellen Limits der frühneuzeitlichen Staaten hatten zur Folge, dass das elementare Schulwesen trotz den staatlichen und religionspolitischen Anstrengungen zur homogenen Konfessionalisierung der Gesellschaft letztendlich eine lokale Angelegenheit blieb und sich weitgehend dem Machtbereich des obrigkeitlichen Verwaltungsstaates entzog. ${ }^{35}$ Obwohl mit der zunehmenden Verwaltungstätigkeit eine Ausdehnung der schriftlichen Staatsbürokratie

30 Schmidt, Dorf und Religion: 367.

31 Weber, Wirtschaft: 126.

32 Ehrenpreis/Lotz-Heumann, Reformation: 66.

33 Die bisweilen von den Lehrkräften bereits als zu hoch empfundene lokale Schuldichte und der daraus entstandene Konkurrenzeffekt unter den Lehrkräften um die Schüler und um die Gunst der Eltern wurde in einzelnen Anmerkungen zur Stapfer-Enquête als Kritik vermerkt. „Jn unsrer ganzen Kirch Gemeinde sind 10 Schulen wenigstens sind 3 überflüßig; Da muste immer eine der andern zur Geißel dienen; Wann die Zeit herbey kam, da die Schulen wieder ihren Anfang nehmen solten, giengen etliche Schullehrer zu den Eltern, hielten um ihre Kinder zum Unterricht an, und musten dabey viel mal versprechen, selbige nach der Eltern Willen zu lehren, damit banden sich die Lehrer die Hände, weil sie die Kinder nicht behandlen durften wie sie es villeicht nothig hatten; Und auch dardurch entstuhnde unter den Schlumeistern selbst vielmal Haß, weil der größere Hang in eine Schule, allemal eine benachbarte in Schaden und Verlegenheit sezte." Schmidt u.a. (Hgg.), Stapfer-Enquête, Nr. 85: Amriswil.

34 Vgl. Brühwiler, Finanzierung: 19.

35 Vgl. die Kritik am etatistischen Verständnis des Konfessionalisierungsparadigmas in Bezug auf Konfessionalisierungsprozesse auf der lokalen Ebene und ohne die Einflussnahme des Staats, wie sie Heinrich Richard Schmidt für die Berner Untertanengebiete nachgewiesen hat: Schmidt, Volksbildung: 21. 
einherging und damit auch auf lokaler Ebene zunehmend lese- und schreibkundige Personen benötigt wurden, bestimmten weiterhin lokalörtliche Eigenheiten, Bräuche, Traditionen und die (Bildungs)-Interessen der lokalen Eliten die konkrete Ausgestaltung der Schulen. Lokale Entscheide bestimmten den Schulbesuch, den Schulhausbau, die Bildungsinhalte, die Lehrerwahl, die jährliche Schuldauer und die Finanzierung und Besoldung der Lehrer. ${ }^{36}$ Von obrigkeitlicher Seite her regelten normative Ordnungen, die sogenannten „Landschulordnungen“, einzig die minimalen Leitplanken der Schulorganisation. Obrigkeitliche Autoritäten griffen bei lokalen Konfliktsituationen in der Regel nicht oder nur sehr niederschwellig in kommunale Belange ein. ${ }^{37}$

\subsubsection{Der sozio-ökonomische Kontext}

Nicht nur in politischer, sondern auch in gesellschaftlicher und wirtschaftlicher Hinsicht präsentierte sich die Alte Eidgenossenschaft am Ende des 18. Jahrhunderts als ein Flickenteppich unterschiedlichster Entwicklungen und Innovationen, die sich indirekt auch auf das kommunale Schulwesen auswirkten. Die frühneuzeitliche Gesellschaft der Alten Eidgenossenschaft lebte mehrheitlich auf dem Land und von einer auf Subsistenz basierenden Landwirtschaft. ${ }^{38}$ Das galt grösstenteils auch für die landhandwerklichen und freien Berufe, die noch kaum ohne gleichzeitige agrarische Teilerwerbstätigkeiten zur Sicherung der Subsistenz auskommen konnten.

Die landwirtschaftlichen Produktionsstrukturen unterschieden sich aufgrund der unterschiedlichen Topografie regional und lokal, woraus sich seit dem Spätmittelalter vier modellartige Agrarzonen ableiten liessen: Im „Kornland“ des flachen Mittellandes dominierte der Acker- und Getreidefeldbau in Dreizelgenwirtschaft mit Flurzwang, an ausgewählten Stellen ergänzt durch Spezialkulturen, Obst- und Rebbau. Entlang der voralpinen Hügelketten und im Jura etablierte sich durch den abgeschwächten oder aufgehobenen Flur- und Zehntzwang die „Feldgraszone“ mit Mischformen der extensiven Feldgraswirtschaft und des Getreideanbaus, während die hochalpinen Regionen als „Hirtenland“ hauptsächlich von hochspezialisierter Milch- und Viehwirtschaft geprägt waren. Dazu durchzog den inneralpinen Raum eine Zone der kleinflächigen „Mehrzweckwirtschaft“ aus Ackerbau, Milch- und Viehwirtschaft. ${ }^{39}$

Agrarische Reformen brachten jedoch im Laufe des 18. Jahrhunderts neue Dynamiken in die ländlichen Regionen, obwohl sich die grundsätzlichen Determinanten der Agrarverfassung noch kaum verändert hatten. ${ }^{40}$ Zum einen tauchte ab 1700 die Kartoffel als neue „Wundernahrung" im Alpenraum auf und verdrängte sukzessive den Getreideanbau, zum anderen verbreiteten sich die Stallhaltung von Vieh und das Düngen der Äcker durch Mist und Futterklee. ${ }^{41}$ Selbst das ackerbaulich geprägte Mittelland wurde so zunehmend zum - später romantisiertverklärten - „Hirtenland“.

Die regional unterschiedlichen Produktionsweisen und die sukzessive initiierten obrigkeitlichen Agrarreformen führten durch eine verstärkte Besitzkonzentration in den Händen der lokalen

36 Vgl. Braun, Ancien Régime: 229f.

37 Ruloff, Schulbesuch: 21.

38 „Rund drei Viertel der Bevölkerung lebten ganz oder teilweise von der Landwirtschaft." Holenstein, Bauern.

39 Vgl. zu den apostrophierten Begrifflichkeiten der Agrarzonen ausführlich: Schluchter, Agrarzonen; Schnyder, Landwirtschaft; Pfister, Strom: 28ff.

40 Unter „Agrarverfassung“ wird die Gesamtheit der grundlegenden rechtlichen Normen und institutionellen Rahmenbedingungen für die Wirtschafts- und Lebensweisen von agrarischen Gesellschaften verstanden, insbesondere Eigentumsverhältnisse, Herrschafts- und Nutzungsrechte an landwirtschaftlich nutzbaren Gütern. Mattmüller, Agrarverfassung.

41 Hauser, Wirtschafts- und Sozialgeschichte: 135-139; Maissen, Geschichte der Schweiz: 141f. 
Eliten, bestehend aus einer schmalen Schicht von Vollbauern, ${ }^{42}$ Müllern, Bäckern, Schmieden und Wirten, zu einer zunehmend ungleichen Wohlstands- und Besitzentwicklung sowie einer intensivierten sozialen Fragmentierung der ländlich-bäuerlichen Gesellschaft. Im Berner Mittelland und im Baselbiet kontrollierten und privatisierten beispielsweise bäuerliche Oberschichten durch Einhegungen, sogenannte „Einschläge“, zunehmend die Allmende zum Nachteil der ärmeren kleinbäuerlichen Mitbürger. ${ }^{43}$ Wo zusätzlich das Erbe in Realteilung gleichmässig auf die Söhne aufgeteilt wurde, zersplitterte der Grundbesitz in unrentable Kleinstparzellen, was den Nutzungsdruck auf die Allmende nochmals vergrösserte. ${ }^{44}$ Die exportorientierte Käseproduktion und das Halten grosser Viehherden brachte beispielsweise vermögenden Bauern im westlichen Berner Oberland und im Emmental grossen Wohlstand, während die mehrzweckwirtschaftliche Betriebsweise im östlichen Berner Oberland zwar für egalitärere soziale Verhältnisse, aber gleichzeitig für einen höheren Armutsgrad sorgte. ${ }^{45}$

Die Abhängigkeit der klein- und nichtbäuerlichen Schichten ohne bedeutenden Landbesitz und ohne Zugtiere von den Vollbauern wuchs unter der teilweise stark anwachsenden Bevölkerung im 18. Jahrhundert zusätzlich und verstärkte den Kampf um die knappen Agrarressourcen. Obwohl die Mittel- und kleinbäuerlichen Schichten je nach Region zwischen fünfzig bis neunzig Prozent aller Haushalte ausmachten und Vollbauern weniger als einen Viertel der ländlichen Bevölkerung stellten, waren Letztere in der frühstaatlichen Lokalverwaltung übervertreten und einflussreiche Ämter wurden über Generationen von Angehörigen weniger Familien aus der Dorfehrbarkeit besetzt. ${ }^{46}$ Diese Dorfnotabeln kontrollierten als Vorgesetzte in der Regel auch die Schulmeister und hatten vielerorts ein Mitspracherecht bei der Lehrerselektion.

Angetrieben durch die Besitzveränderungen in der Landwirtschaft verbreitete sich ferner seit dem 17. Jahrhundert die protoindustrielle Textilproduktion in Heimarbeit in einigen Regionen der Alten Eidgenossenschaft. Besonders in der ackerbaulich weniger nutzbaren voralpinen Feldgraszone etablierte sich die Heimarbeit, denn dort herrschten weniger rigorose Niederlassungs- und Produktionsbestimmungen als im Kornland des Mittellandes. Vorwiegend die landlosen und landarmen Schichten der Bevölkerung sahen in der meist während der Wintermonate im Nebenerwerb ausgeführten Protoindustrie eine willkommene Opportunität, um aus der existenziellen Armut der agrarisch geprägten Wirtschaft auszubrechen, sich durch die Diversifikation ökonomisch abzusichern oder gar sozial aufzusteigen. ${ }^{47}$ Gleichzeitig setzten sich protoindustriell Tätige aber verstärkt den konjunkturell bedingten Preisschwankungen und damit der Gefahr der Verarmung aus. Entsprechend setzte regional ein starkes Wachstum jener Bevölkerungsschichten ein und das ländliche Gesellschaftsgefüge veränderte sich zunehmend. Ausschluss- und Besitzkonzentrationsprozesse waren nicht nur auf dem Land, sondern auch in den Städten und in minderem Masse in den ländlichen Marktflecken auszumachen. Die politische Macht konzentrierte sich seit dem 17. Jahrhundert in einem zunehmenden Oligar-

42 Als „Vollbauern“ wurden Bauern mit Grundbesitz, Kuhbesitz und eigenen Ackergespannen zum Pflügen bezeichnet, deren Betriebsgrösse genug Ertrag abwarf, um die eigene Familie zu ernähren und um Dienstgesinde anzustellen. Kleinbauern, sogenannte „Tauner“, waren dagegen mangels eigener Gespanne in klientelistischer Abhängigkeit auf die Pflughilfe der Vollbauern angewiesen, besassen weniger Land und konnten sich meist nur in guten Jahren in Subsistenz von ihrem Hof ernähren, weshalb sie sich entweder bei den Vollbauern verdingen oder andere Einkommenstätigkeiten ausüben mussten. Mattmüller, Bauern: 380f.; Holenstein, Bauern; Pfister, Strom: 293-301.

43 Huggel, Einschlagsbewegung.

44 Maissen, Geschichte der Schweiz: 142.

45 Hauser, Wirtschafts- und Sozialgeschichte: 142ff.

46 Holenstein, Bauern.

47 Hauser, Wirtschafts- und Sozialgeschichte: 154-157. 
chisierungsprozess auf immer weniger Familien und das städtische Bürgerrecht wurde seltener vergeben. ${ }^{48}$ Hauptverlierer waren die städtischen Mittelschichten, denen ein sozialer Aufstieg in die höchsten politischen Ämter trotz wirtschaftlichem Erfolg zunehmend verwehrt blieb. Gleichzeitig wuchs die Zahl an zugezogenen „Hintersassen“ aus der Landschaft ohne Mitspracherechte in den Städten, was zunehmend für - wenn auch weitgehend erfolglose - Proteste sorgte. Zudem vertieften sich die Abhängigkeitsverhältnisse zwischen ländlicher Bevölkerung und städtischer Obrigkeit durch die zunehmende Agrarverschuldung der Bauern, die obrigkeitliche Verhinderung bäuerlicher Innovationen und durch Handelsverbote von Landbürgern in Städten. ${ }^{49}$

Politische Unzufriedenheit machte sich am Ende des 18. Jahrhunderts nicht nur in den elitären Zirkeln des zunehmend ausgeschlossenen städtischen Bürgertums der Städteorte breit, sondern vermehrt auch unter den ebenso blockierten landstädtischen und ländlichen Oberschichten der Untertanengebiete - meist vermögende Akteure aus dem protoindustriellen Verlagswesen, Händler und wohlhabende Bauern - denen ein sozialer Aufstieg durch die ständischen Schranken weitgehend verwehrt blieb. ${ }^{50}$ Ähnliche sozio-politische Konflikte brachen auch in den Landgemeindeorten aus. ${ }^{51}$ Befeuert von den politisch-gesellschaftlichen Ideen der Aufklärung, wirtschaftlichen Krisen, den Zwängen der ständischen Rechtsordnungen und den revolutionären Ereignissen in Frankreich wuchs die fundamentale Kritik an der Reformund Modernisierungsunfähigkeit des Ancien Régimes auch ausserhalb der sich formierenden politisch-patriotischen Reformgesellschaften. Verstärkt sorgte der kollektive Unmut für mehr Selbstbestimmungsforderungen in den einzelnen Untertanengebieten, worauf die Obrigkeiten zunehmend hilflos reagierten und teils mit militärischer Repression antworteten, teils aber auch politische Zugeständnisse machen mussten. ${ }^{52}$

Die Gesellschaft des ausgehenden 18. Jahrhunderts befand sich somit in einem grundlegenden wirtschaftlichen und sozialen Transformationsprozess, was auch die Bedürfnisse an die Schule laufend veränderte. Ausgehend von vernunft- und nützlichkeitsorientierten Denkströmungen im Kontext der Aufklärung, des reformierten Pietismus, des Reformkatholizismus und des Philanthropismus entstanden ab der Mitte des 18. Jahrhunderts vielfältige pädagogische Reformbestrebungen und Diskurse um die Funktion, die Rolle und die Ausgestaltung des öffentlichen elementaren Bildungswesens. „Die Schule habe, so lauteten die Forderungen, echte Religiosität zu fördern, gute Staatsbürger zu formen, die Unterrichtsmethode der Jugend anzupassen und den Lehrstoff auf das praktische Leben auszurichten." ${ }^{33}$

Das elementare Schulcurriculum bestand am Ende des 18. Jahrhunderts hauptsächlich aus den Lernbereichen des Lesens, Schreibens und Singens. Daneben wurden zumeist fakultativ weitere Inhalte wie Handschriftenlesen oder Kenntnisse in Mathematik angeboten. ${ }^{54}$ Inhaltlich-fachliche Erweiterungen erfuhr das Elementarschulcurriculum meist zuerst in den Städten, grösseren

48 Braun, Ancien Régime: 162f., 218; Peyer, Verfassungsgeschichte: 107ff.; Körner, Stadt.

49 Illi/Zangger, Stadt-Land-Beziehungen.

50 Braun, Ancien Régime: 126, 257, 270f.; Holenstein, Untertanengebiete.

51 Braun, Ancien Régime: 272-276.

52 Beispielhaft sei für die neue Konfliktkultur auf den „Stäfner Handel“ von 1794 verwiesen, in dem sozial blockierte ländlichen Eliten unter dem Eindruck der revolutionären Ereignisse in Frankreich sozio-ökonomische Freiheitsforderungen gegen die Zürcher Obrigkeit vorbrachten. Vgl. Braun, Ancien Régime: 303-307. Auch in der Waadt wurden ab den 1790er-Jahren schrittweise einige Feudalrechte zur Wahrung des inneren Friedens abgeschafft. Vgl. Tosato-Rigo, Waadt.

53 Stadler, Schulwesen.

54 De Vincenti, Wissensordnungen: $67 \mathrm{f}$. 
Marktflecken oder in Orten entlang wichtiger Verkehrsachsen durch eine entsprechende lokale Nachfrage aus der Bevölkerung und dank der dortigen üppigeren Finanzierungsmöglichkeiten. Auf dem Land stachen dagegen erst vereinzelte Schulen als noch isolierte Keimzellen von progressiven curricularen Entwicklungen hervor, oft aber gehemmt durch das Desinteresse der Eltern oder durch fehlende Unterrichtsmedien.

Als Unterrichtsmedien für den Lese- und Schreibunterricht dienten zum einen religiöse Medien wie die Bibel, Katechismen und Psalmenbücher, zum anderen was lokal oder von den Eltern zur Verfügung stand und als „unterrichtstauglich“ und „erwünscht“ betrachtet wurde - Kalender, Briefe, Quittungen, Zeitungen und andere zufällige Druckerzeugnisse. Eigentliche Schul- und Sachbücher zirkulierten dagegen erst in geringer Auflage und räumlich bloss punktuell in den Schulstuben der Alten Eidgenossenschaft. ${ }^{55}$

Zentrale Anliegen der zumeist von elitärer Herkunft gewesenen Reformpädagogen waren eine verbesserte Lehrerausbildung, verbesserte Lehrmethoden, eine verstärkte obligatorische Beschulung der Kinder - insbesondere der Mädchen - und eine ,aufgeklärtere“ Gesellschaft durch eine Ausweitung des Fächerkanons mittels neuer Lehrbücher. ${ }^{56}$ In der Folge diffundierten neue reformpädagogische „kindgerechte“ Schulbücher, pädagogisch-methodische Anleitungen für Schulmeister und Überlegungen zur Verbesserung der Schulorganisation langsam, wenn auch unsystematisch und räumlich punktuell in das alteidgenössische elementare Schulwesen. Andernorts gelangten neue Lehrmethoden oder Schulbücher durch lokale Initiativen „,on unten“ von einzelnen engagierten Bürgern, Pfarrern oder durch die Schulmeister in die Schulstuben. ${ }^{57}$ Obrigkeitliche Versuche zur Einführung neuer Methodenbücher oder kindgerechter pädagogischer Werke „von oben“ waren dagegen oft von Misstrauen und Ablehnung der vielfach konservativ gesinnten Bevölkerung begleitet und scheiterten nicht selten an massiven lokalen Widerständen. ${ }^{58}$

Trotz einem generellen quantitativen Mangel an adäquaten Bildungsmedien war in den Schulstuben um 1800 gleichwohl eine breite Diversität an unterschiedlichsten Materialien und Lehrmethoden festzuhalten und das öffentliche Schulwesen stellte keinen erratischen, sondern einen lebhaften Bildungsmarkt dar. Die meisten Schulmeister an der Basis waren zudem den sich entwickelnden Reformbestrebungen in ihren Inhalten keineswegs abgeneigt, erhofften sie sich doch eine Verbesserung ihrer materiellen und beruflichen Lage. Eine Schlupflicht für alle Kinder oder ganzjähriger Unterricht versprach beispielsweise neben einer lückenloseren Beschulung auch mehr Lohn. ${ }^{59}$ Nicht zuletzt dürfen jedoch die Lehrpersonen selbst als aktive Gestaltungskräfte ihres eigenen Unterrichts nicht vergessen gehen. So versuchten sich zahlreiche Lehrer von sich aus auf niederschwelliger Ebene als experimentelle Initiatoren und Multiplikatoren von Reformideen in ihren eigenen Schulstuben, sei es durch die Abkehr vom mechanischen Auswendig-

55 Vgl. das Dissertationsprojekt von Nadine Pietzko zur Distribution von Lehrmitteln in der Helvetischen Republik: Pietzko, Lehrmittellandschaften.

56 Vgl. Bruning, Elementarschule. Die postulierte Benachteiligung der Mädchen in der elementaren Beschulung ist für die Schweiz um 1800 in jüngsten Studien stark relativiert worden. Vgl. De Vincenti, Wissensordnungen: 249; Rothen, Lesen: 112; Ruloff, Schulbesuch: $207 \mathrm{f}$.

57 Vgl. die Verbreitung der Normalschule in der Ostschweiz im Kap. 2.1.2.

58 Der Lehrer Bendicht Arn von Kappelen BE notierte exemplarisch zur Problematik der Einführung von neuen Schulbüchern in seiner Gemeinde: „Die Schulbücher zu verändern ware wohl nicht rathsam, Theils weil man an die vorhandenen gewohnt ist, und der gemeine Mann dergleichen Enderungen für eine Religions Enderung hält, Theils weil das raffiniren, ausmustern, und einfliken der Realität wirklich zu nahe gehen konnte." Schmidt u.a. (Hgg.), Stapfer-Enquête, Nr. 829: Kappelen. Vgl. auch: Fuchs, Lehrerperspektiven: 255.

59 Vgl. Fuchs, Lehrerperspektiven: 152-155; 200-205. 
lernen, durch das Einführen neuer Lehrmethoden, das Verfassen eigener kinderfreundlicherer Unterrichtsmedien oder durch eigene schulorganisatorische oder disziplinarische Massnahmen zur Verbesserung des Unterrichts. ${ }^{60}$

Die „eine“ elementare Schule gab es folglich nicht. Vielmehr standen sich verschiedenste Schulsysteme in gleichzeitiger Ungleichheit und mit von Ort zu Ort völlig unterschiedlichen Ausprägungen gegenüber. Das elementare Schulwesen des ausgehenden 18. Jahrhunderts war somit nicht nur in regionaler und lokaler, sondern auch in konfessioneller und organisatorischer Hinsicht von markanten lokalen und regionalen Unterschieden geprägt.

\subsubsection{Die Helvetische Revolution}

Unter dem wachsenden militärischen Druck Frankreichs, das die aussenpolitisch isolierte Alte Eidgenossenschaft nach der Beendigung des Ersten Koalitionskriegs im Jahr 1797 als strategisches Aufmarschgebiet für Kriegshandlungen gegen Österreich sah, stieg unter den politisch Unzufriedenen die Hoffnung auf eine baldige Umwälzung durch den Einmarsch französischer Truppen. Nach Verhandlungen zwischen dem Basler Peter Ochs und dem Waadtländer Frédéric-César de La Harpe mit Napoleon Bonaparte über eine neue Verfassung brachen im Januar 1798 in Basel und in der Waadt erste revolutionäre Unruhen aus. Die sogenannte „Helvetische Revolution“ erfasste durch den Einmarsch französischer Truppen und deren Sieg über die bernischen Aufgebote beim Grauholz am 5. März 1798 sowie der Niederschlagung der letzten Widerstände in der Zentralschweiz und im Oberwallis rasch das ganze Land und liessen die Alte Eidgenossenschaft untergehen. Mit der französischen Besetzung wurden sämtliche Untertanengebiete und Gemeinen Herrschaften aufgehoben, die Bürger „befreit“ und rechtlich gleichgestellt, bald danach auch die Feudallasten abgeschafft, die alten Regierungen ihrer Macht enthoben oder zur Abdankung gezwungen und mit der oktroyierten Verfassung vom 12. April 1798 die neue „Helvetische Republik“ als zentralistischer Einheitsstaat und französische Schwesterrepublik proklamiert. ${ }^{61}$

Die Helvetische Revolution im Frühjahr 1798 erwirkte einen massiven politischen und gesellschaftlichen Umbruch. Die bisherigen aristokratisch-patrizischen Eliten mussten mehrheitlich abdanken und wurden durch neue Vertreter aus dem aufgeklärten munizipalstädtischen Bürgertum oder der ländlichen Oberschicht ersetzt, wenngleich in einer längeren zeitlichen Be-

60 Eigene didaktische Methoden entwickelte beispielsweise der Lehrer von Erlenbach BE, David Andrist, der die Kinder in Lektionen nach Alter getrennt unterrichtete: „Alle Morgen sagen alle Kinder die gleiche Lektion im heidelb. Cat. auswendig auf, die ihnen Tags vorher aufgetragen, mit ihnen fleißig gelesen, ihnen erklärt und zu Hause noch mehr zu üben überlaßen worden ist. Darauf wird eine frische Lektion, auf die angezeigte Art, für den künftigen Tag, mit allen zugleich, behandelt. Die übrige ganze Vormitagszeit ist dem Buchstabieren u Lesen mit allen zugleich gewiedmet; dabey wird über Buchstabier- u Leseregeln geredet; die Unterscheidung Zeichen, u alle merkwürdigen Haupt-BeyZeitwörter etc. in Rüksicht auf den Ton der Stimme u Absezen im Lesen, u in Rüksicht auf die deütsche Sprachlehre, Orthographie, etc. erklärt u mit Beyspielen erläutert. Dann folgt eine Ruhestunde. Auf dieselbe wird mit allen zugleich an der Tafel gerechnet, auch die Kleinern werden angefragt, $\mathrm{u}$ antworten nach ihren Fähigkeiten. Von nun an theilen sich die Kinder erst in zwey Klaßen. Die Größern schreiben nach meiner Hand ohne weitere Vorschriften, u nach meiner Methode, die ist: Einen Buchstaben aus dem andern zu folgern, in beständiger Tour den Kindern die Hand zu führen, die Fehler anschaulich zu machen, u zu corrigieren. Die Kleinern lernen innzwischen eine Lektion und sagen sie alle einander nachzeigend, wenn die Schreibstunde zu Ende geht, auf. Zulezt wird wieder an der Tafel vor aller Kinder Augen Unterricht im Singen ertheilt, u selbst daran, so wie auch in Büchern gesungen." Schmidt u.a. (Hgg.), Stapfer-Enquête, Nr. 1389: Erlenbach im Simmental. Vgl. auch: Fuchs, Lehrerperspektiven: 162ff.

61 Fankhauser, Helvetische Revolution. Eine Auflistung der umfangreichen Grundlagenliteratur zur Helvetischen Republik ist beim entsprechenden Eintrag im Lexikonartikel des HLS zu finden: Fankhauser, Helvetische Republik. 
trachtung insgesamt kein radikaler personeller Bruch festzuhalten war. ${ }^{62}$ Aus dem zuvor locker organisierten föderalen, aber hierarchisch komplexen Bündnisnetzwerk der Alten Eidgenossenschaft wurde ein straffer, zentralistisch orientierter Einheitsstaat nach französischem Vorbild geschaffen. Die vormals souveränen Staaten der dreizehn eidgenössischen Orte wurden zu reinen Verwaltungseinheiten degradiert und das vorrevolutionäre territoriale Gefüge durch Verkleinerungen, Zusammenfassungen und Neugründungen von Kantonen bewusst durchbrochen. ${ }^{63}$ Zudem mussten neue Institutionen erschaffen werden, die es vorher noch nicht gegeben hatte: eine zentrale Regierung, ein zentrales Parlament mit zwei Kammern, ein oberstes Gericht und insgesamt sechs Ministerien. ${ }^{64}$

Insbesondere das Erziehungswesen wurde von den reformaufgeklärten neuen Kräften als eine der zentralen Staatsaufgaben begriffen, denn in keinem anderen Gebiet unternahm die neue Regierung so grosse Anstrengungen wie im Bereich des Schulwesens. ${ }^{65}$ Ein modernes rationales Staatswesen bedingte im Ideal aufgeklärte und gebildete Staatsbürger, die als mündige „Citoyens“ am republikanischen Gemeinwohl teilhatten. Entsprechend musste dieses „Staatsvolk“ erst durch Volksbildung und Volksaufklärung zu seiner politischen Mündigkeit gebracht werden. ${ }^{66}$ Die Hauptaufgabe der Elementarschule sollte hierbei die Beförderung einer „ächt religiösen, sittlichen und bürgerlichen Aufklärung sein" ${ }^{67}$ Mit dem neuen rationalen Einheitsstaat sollte die alte Vielfalt im elementaren Schulwesen beseitigt und ein einheitliches Schulsystem mit Schulpflicht und geregelter Schuldauer implementiert werden. ${ }^{68}$ Die Schule sollte säkularisiert werden und von der Kirche in den Aufgabenbereich des nun laizistischen Staates wechseln, staatliche Lehrerbildungsanstalten sollten geschaffen werden und die neugeschaffenen kantonalen Erziehungsbehörden sollten unter der Ägide des neuen helvetischen Ministers für Künste und Wissenschaften - Philipp Albert Stapfer - die Durchsetzung der staatlichen Beschlüsse auf föderaler Ebene überwachen und Fortschritte rapportieren.

Die angestrebten Reformen der jungen Helvetischen Republik, auch jene im Bildungswesen, stiessen in der Bevölkerung jedoch regional und lokal auf sehr ambivalente Resonanz. Sahen die einen in den revolutionären „Patrioten“ und der neuen Regierung die langersehnten politischen Befreier und Reformer, galten sie für andere als Vaterlandsverräter und Handlanger der französischen Besatzer, legitimiert einzig durch die französischen Bajonette. Die radikale territoriale Umgestaltung der Schweiz, die Plünderung der alteidgenössischen Staatsschätze, erzwungene Truppeneinquartierungen und hohe Kriegskontributionen desavouierten die französische Militärpräsenz und damit indirekt auch die neuen Autoritäten in der Folge zusätzlich. Zudem führte die überhastete Abschaffung der Zehnten und Grundzinse ohne Kompensationsmechanismen zu rascher finanzieller Not in den Gemeinden und in den bereits geplünderten Kantonskassen. Gerade im überwiegend

62 Böning, Traum: 183f. Fankhauser, „Staats=Machine“: 78f. Vgl. zur Kontinuität der alten Eliten die Anmerkungen im Kap. 3.3.2.

63 Fuchs, Lehrerperspektiven: 77ff. Es entstanden eine Reihe von neuen Kantonsgebilden, zusammengefügt aus ehemaligen Untertanengebieten, zugewandten Orten oder aus Gemeinen Herrschaften: Aargau, Baden, Bellinzona, Linth, Lugano, Oberland, Säntis, Thurgau, Waldstätten, Waadt. Zudem wurden zahlreiche kleinere territoriale Verschiebungen auf Kantons- und Distriktsebene vorgenommen. Vgl. Höhener, Gebietseinteilung: 21-31.

64 Böning, Traum: 179.

65 Fankhauser, Helvetische Republik.

66 Ruloff, Schulbesuch: 38f. Insofern funktionierte die Helvetische Republik in ihrem „top-down“-Verständnis - wie André Holenstein festgehalten hat - als eine republikanische Variante des aufgeklärten Reformabsolutismus. Holenstein, Republik: 83-104.

67 Böning, Traum: 225.

68 Bütikofer, Staat: 54-59; Ruloff, Schulbesuch: 21. 
lokal-feudalrechtlich finanzierten Schulwesen bewirkte diese Massnahme vielerorts Bezahlungsengpässe und wegfallende Einkommensbestandteile für die Elementarschullehrer, was für Ungewissheit und Unmut bei der Lehrerschaft sorgte. Kündigten an einzelnen Orten Lehrpersonen kurzfristig von sich aus ihre Arbeitsstelle wegen wegfallenden Einkünften, wurden andernorts jedoch missliebige Lehrer aus politischen Gründen oder persönlichen Motiven im entstandenen Machtvakuum der Umwälzung willkürlich abgesetzt oder verjagt. ${ }^{69}$

Während ein Teil der Geistlichen beider Konfessionen aufgrund der Säkularisationsbemühungen der neuen Regierung um ihren Einfluss in der Bevölkerung fürchteten und sich dadurch nur schwach mit der neuen Regierung identifizierten, provozierte der Wegfall von historisch gewachsenen kommunalen und kantonalen Entscheidungskompetenzen durch die Zentralregierung beträchtlichen Widerstand in den Gemeinden und bei föderal gesinnten Personen. In der Zentralschweiz blieb zudem das brutale militärische Vorgehen der Franzosen gegen die Nidwaldner beim Aufstand vom September 1798 in negativer kollektiver Erinnerung, was die Legitimation der helvetischen Behörden massiv untergrub. ${ }^{70}$ Auf der anderen Seite versprach die politische Umwälzung gerade vielen Lehrpersonen neben den neuen persönlichen und politischen Freiheitsrechten auch die Chance auf eine positive Aufwertung ihrer Tätigkeit, mehr Investitionen in das Schulwesen, eine ökonomische Besserstellung und soziale Aufstiegsmöglichkeiten. Deshalb stand das Gros der helvetischen Lehrerschaft der neuen Regierung zumindest in den Anfangsjahren abwartend bis verhalten positiv gegenüber. ${ }^{71}$

Der revolutionäre Bruch vom Ancien Régime zur Helvetischen Republik im Jahr 1798 und deren kurze Existenzphase bis ins Jahr 1803 veränderte freilich an der Grundkonstellation des Elementarschulwesens - trotz der zahlreichen initiierten Bemühungen zur Verbesserung - vorerst in der Praxis für die Lehrkräfte wenig. Obwohl der helvetische Grosse Rat bereits im Mai 1798 festhielt, dass die „Schulmeister [...] in diesen unsern Tagen einer der wichtigsten Männer sein "72 sollten, kamen Stapfers Versuche einer Laisierung des Bildungswesens und einer Verbeamtung der Lehrerschaft nie über den Konzeptcharakter hinaus. ${ }^{73}$ Die notorisch finanzschwachen helvetischen Behörden verfügten weder über die finanziellen Ressourcen zur Besoldung der Lehrerschaft als Staatsbeamte, noch vermochten die zerstrittenen politischen Räte in der kurzen Lebensdauer der Helvetischen Republik ein verbindliches nationales Schulgesetz auf legislativer Ebene zu verabschieden.

Das langfristig einzig wirksame „Erbe“ des zentralistischen Experiments im Bereich des elementaren Schulwesens, das auch in den Folgejahren der Restauration und der Regeneration weiter existierte, waren paradoxerweise die neu geschaffenen föderalen Strukturen der kantonalen Erziehungsräte als neue politische Oberaufsichten über das Bildungswesen. Sie sollten im 19. Jahrhundert zu den neuen Schaltstellen für Reformversuche werden. Aus ihnen erfolgten - als ,administratives Grundgerüst" der kantonalen Regierungen - die wegweisenden Impulse für eine schrittweise Modernisierung des elementaren Schulwesens. ${ }^{74}$ Die bis heute wirkungskräftigen Wurzeln des modernen, föderalen Bildungssystems sind somit ausgerechnet in der zentralistisch organisierten Helvetischen Republik zu suchen.

69 Mancherorts argumentierten die Gemeinden, es gehöre nun in den Bereich der neuerlangten kommunalen „Freiheiten“, ihre Schulmeister nach Belieben einstellen oder entlassen zu können. Vgl. Luginbühl, Stapfer: 137.

70 Schleifer-Stöckli, Nidwalden.

71 Böning, Traum: 225f.

72 Bloch Pfister, Priester: 185.

73 Bütikofer, Staat: 59f.

74 Vgl. Tosato-Rigo/Savoy, Schulumfrageneifer: 123. 
Die schweizerische Gesellschaft war insgesamt in der Epoche der Helvetischen Revolution keineswegs in lähmender Erstarrung und Statik verharrt gewesen, wie es später die liberal geprägte Geschichtsschreibung des späten 19. und frühen 20. Jahrhunderts glauben lassen wollte. Sie war vielmehr in janusköpfiger Weise geprägt von vielfältigen dynamischen Prozessen neben Elementen der Beharrung. Insbesondere die Protoindustrialisierung peripherer Landstriche, das stetige Bevölkerungswachstum, das Aufbrechen der traditionellen Agrarstrukturen, soziale Umschichtungen und die wachsende Mobilität breiter Bevölkerungsschichten waren zwar regional unterschiedlich starke, aber unverkennbare Symptome eines fundamentalen gesellschaftlichen Wandels. ${ }^{75}$ Dieser Wandel involvierte seit der Mitte des 18. Jahrhunderts immer grössere Teile der Bevölkerung. ${ }^{76} \mathrm{Nicht} \mathrm{zu} \mathrm{ver-}$ gessen ist dabei das sich lokal in unterschiedlichster Weise manifestierende Bedürfnis nach Bildung „Von unten“ seitens der Lokalgesellschaft, das sich sowohl innovationsfördernd als auch reformhemmend auf das lokale Schulwesen auswirken konnte und den Lehrkräften an der Basis den Bedingungsrahmen für ihr pädagogisches Handeln vorgab. Gleichzeitig bestanden mannigfache Elemente der Kontinuität weit über die paradigmatische Zäsur der Epochengrenze von 1800 hinweg. ${ }^{77}$ Die Lehrerschaft an Elementarschulen stand somit am Ende des 18. Jahrhunderts zunehmend in einem sich immer stärker akzentuierenden Spannungsverhältnis zwischen dem traditionellen Unterrichtskanon zum einen und neuen pädagogischen Ideen der Volksaufklärung, des Philanthropismus und der Reformpädagogik zum anderen. Inna Beier hat treffend von einer „dichotomisch gekennzeichneten Realität der niederen Schulen“ gesprochen, die einerseits durch die Subsumierung der seit Generationen tradierten Praktiken des Unterrichts und andererseits durch die Durchsetzung und die Weiterentwicklung von neuen pädagogischen Konzeptionen und obrigkeitlicher Normen geprägt war. ${ }^{78}$ Insbesondere die noch fehlende systematische Ausbildung der Lehrpersonen wurde von den Schulreformern als archimedischer Punkt des Wandels im Volksschulwesen identifiziert. ${ }^{79}$ Ohne systematisch gebildete Elementarschullehrer war die Vision einer gesellschaftlichen Transformation unmöglich. Die Lehrerschaft wurde so zwangsläufig zum zentralen Transmissionsriemen zukünftiger gesellschaftlicher Entwicklungen.

\subsection{Der Stand der Forschung}

\subsubsection{Die Schulgeschichte im deutschen Sprachraum}

Im Spannungsfeld zwischen den beiden Disziplinen der Geschichtswissenschaft und der Pädagogik hat die historische Bildungsforschung, insbesondere die Schulgeschichte, in den letzten Jahrzehnten einen markanten thematischen und methodischen Wandel durchlaufen. Die ältere Schulgeschichte des 19. und frühen 20. Jahrhunderts fokussierte sich noch vorwiegend institutionsgeschichtlich auf einzelne städtische Schuleinrichtungen oder auf die Rolle des Staats beim Aufbau der nationalen Schulsysteme. Die historische Pädagogik ihrerseits verstand sich entweder als disziplinorientierte Geschichtsschreiberin der Erziehungswissenschaften oder aber als personenzentrierte Referenzgeberin des pädagogischen Denkens in der Vergangenheit. ${ }^{80}$

75 Zur Frage von Kontinuitäten und Umbrüchen während der Helvetik sei exemplarisch auf die diversen Beiträge im von Daniel Schläppi herausgegebenen Sammelband verwiesen: Schläppi, Umbruch. Darin insbesondere: Holenstein, Republik: 83-104.

76 Scandola, Standesschule: 584.

77 Vgl. Schläppi, Kontinuität: $15 \mathrm{f}$.

78 Beier, Zeller: 10; De Vincenti, Wissensordnungen: 283-288.

79 Neugebauer, Niedere Schulen: 247.

80 Töpfer, Freyheit: $3 f$. 
Heute hat sich die moderne Schulgeschichte im deutschsprachigen Raum aus dieser ideen- und personenzentrierten Tradition der historischen Pädagogik weitgehend gelöst und sich seit ihrer Öffnung zur Sozial- und Alltagsgeschichte in den 1970er-Jahren als interdisziplinär orientierte Subdisziplin methodisch und thematisch ausdifferenziert. Die Schulgeschichte ist damit längst keine „illegitime Disziplin“ ${ }^{\text {"81 }}$ mehr. Seit der Referenzstudie von Wolfgang Neugebauer zur Schulwirklichkeit im absolutistischen Preussen ${ }^{82}$ legen die schulgeschichtlichen Forschungen durch den Einbezug von Quellen niederer Provenienz vermehrt den Fokus auf die „Schulwirklichkeit vor Ort“ im Elementarschulwesen und damit auf „lokale und regionale gesellschaftliche Zustände und Entwicklungen“. ${ }^{83}$ Hierbei wird Schule als ein „sozialer Ort" verstanden, worin neben strukturellen Faktoren, mentalen Haltungen, pädagogischen Konzepten und individuellen Initiativen vor allem die soziale Situation vor Ort die Ausgestaltung der Schulrealität massgeblich beeinflussten. ${ }^{84}$ In diesem Sinne treten die mannigfaltig beteiligten Akteure des „Bildungsmarktes“ - und damit speziell die Elementarschullehrer - zunehmend ins Zentrum der Betrachtung. ${ }^{85}$

An Forschungsarbeiten zur Geschichte des deutschen Bildungswesens mangelt es heute freilich nicht mehr. Es existiert mittlerweile eine stattliche Anzahl an schulhistorischen Publikationen mit lokalem oder regionalem Fokus, ebenso wie thematische Vertiefungen zur Geschichte der Lehrerbildung - etwa Michael Sauers Untersuchung zur institutionalisierten Lehrerausbildung in Preussen ${ }^{86}$ oder Hans Richard Seemanns systematischer Überblick über die Entwicklung der Lehrerbildungsstätten. ${ }^{87}$ Dennoch wird die Person des vormodernen Elementarschullehrers als historischer Akteur teilweise bis in die neueren deutschen Handbücher zur Schulgeschichte bloss stiefmütterlich und holzschnittartig als statischer Strukturfaktor abgehandelt oder gar gänzlich übergangen. ${ }^{88}$ Zudem konzentrieren sich die wenigen konkreten raumübergreifenden Überblickswerke zur Sozialgeschichte des Lehrers in Deutschland bislang mehrheitlich auf die Zeit nach 1800. Diese Darstellungen sind - mit Ausnahme der Dissertation von Sabina Enzelberger $^{89}$ - bereits in die Jahre gekommen und weisen ferner einen starken selbstreferenziellen Charakter auf. ${ }^{90}$ Daneben existieren ferner zahlreiche Laien- und semiwissenschaftliche Publikationen zur Elementarschule und ihrer Lehrerschaft. ${ }^{91}$ Der vormoderne Lehrer der deutschen Elementarschule ist somit zwar bei Weitem kein Unbekannter mehr, dennoch ist er immer noch deutlich zurückhaltender erforscht als seine modernen Berufskollegen ab dem 19. Jahrhundert. Stefan Ehrenpreis hat denn auch gefordert, die Schulmeister als soziale Akteure der frühneu-

81 Vgl. Zymek, Konjunkturen.

82 Neugebauer, Schulwirklichkeit.

83 Vgl. Töpfer, Freyheit: 5f.; Kuhlemann, Modernisierung: 13.

84 Ehrenpreis, Säkularisierung: 31.

85 Töpfer, Freyheit: 9; Tröhler, Genre: 65-93.

86 Sauer, Volksschullehrerbildung.

87 Seemann, Schulpraxis.

88 Nur oberflächlich thematisiert wird die Lehrerschaft bei: Geissler, Schulgeschichte: 48ff., 64, 92-95. Als passiver Strukturfaktor taucht der Lehrer auf bei: Fend, Geschichte des Bildungswesens; Konrad, Geschichte der Schule; Tenorth, Geschichte der Erziehung.

89 Enzelberger, Sozialgeschichte des Lehrerberufs.

90 Bölling, Sozialgeschichte; Lundgreen, Überblick; Keiner/Tenorth, Schulmänner: 198-222; Trinks, Sozialgestalt; Walz, Eselsarbeit. Die genannten Arbeiten beziehen sich allesamt stark auf dieselben fragmentarischen Quellengrundlagen und zitieren sich gegenseitig. Eine Ausnahme stellt die neue Studie von Thomas Töpfer dar, der quellennah auf die diversen städtischen Schulakteure im frühneuzeitlichen Sachsen eingeht. Vgl. Töpfer, Freyheit.

91 Als Anschauungsbeispiel für eine populärwissenschaftliche Darstellung des Schulwesens vgl. die Publikation von Schiffler/Winkeler, Tausend Jahre. 
zeitlichen Erziehungspraxis hinsichtlich ihrer Vorbildung und ihrer familiären Hintergründe vertieft zu untersuchen. ${ }^{92}$

\subsubsection{Die Schulgeschichte in der Schweiz}

Ähnlich disparat zeichnet sich die Situation der Forschungslandschaft für die Schweiz ab. Die Schweizer Schulgeschichte ist erst vor wenigen Jahren von Esther Berner in Bezug auf die Zeit des Ancien Régimes gesamthaft als noch stark „unterbelichtet“ beschrieben worden, wenngleich die Situation heute insgesamt nicht mehr ganz so „desolat“ sei, wie sie noch 1995 von Lucien Criblez und Carlo Jenzer bezeichnet wurde. ${ }^{93}$ Daniel Tröhler ist noch vor wenigen Jahren zum Schluss gekommen, dass die Schulgeschichte in der Schweiz ein noch „vernachlässigtes Genre pädagogischer Historiographie" sei. ${ }^{94}$

Seit ihren Anfängen bis heute ist die Schulgeschichtsschreibung in der Schweiz stark von den Konjunkturen der nationalen Geschichte geprägt, wodurch zwei fundamentale Konjunkturphasen zu differenzieren sind. Eine erste, sehr ergiebige Phase der „älteren“ Schulgeschichtsschreibung begann ab den 1880er-Jahren und dauerte bis nach dem Ersten Weltkrieg. Deren Protagonisten folgten auffallend stark den Deutungen des politischen Liberalismus. ${ }^{95}$ Dabei wurde der Beginn der modernen Schweizer Volksschule auf die 1830er-Jahre datiert, als liberale politische Kräfte in der Regenerationsphase in einzelnen Kantonen die Macht übernahmen und neue kantonale Schulgesetze impementierten. ${ }^{96}$ Hierbei erschien das Ancien Régime als konservativer Negativ-Kontrast zur nun positiv konnotierten, institutionalisierten Moderne seit der liberalen Regeneration. ${ }^{97}$

Diese älteren Schulgeschichtsforschungen des ausgehenden 19. Jahrhunderts standen im Zeichen des Föderalismus und blieben in der Regel räumlich auf die Einzelkantone beschränkt, ohne dass Anknüpfungspunkte oder Vergleiche zu den anderen Kantonen gesucht wurden. ${ }^{98}$ Schulgeschichte wurde somit hauptsächlich kantonal oder lokal geschrieben und verstand sich weitgehend als Institutionengeschichte und Strukturgeschichte. ${ }^{99}$ Nur wenige Arbeiten wagten kantonsübergreifende Darstellungen, wobei die Konfession zur markanten Trennlinie von raumüberspannenden Vergleichen wurde. ${ }^{100}$ Die dreibändige „Geschichte der Schweizerischen Volksschule" von Otto Hunziker blieb denn auch lange Zeit die einzige Publikation mit einer nationalen Perspektive und mit dem Miteinbezug von Lehrer-Biografien - letztere allerdings beschränkt auf bekannte liberale „Schulmänner“ der ersten Reihe. ${ }^{101}$ Der restlichen Lehrer-

92 Ehrenpreis, Perspektive: $93 \mathrm{f}$.

93 Berner, Zeichen: 2; Criblez/Jenzer, Situation: 211.

94 Tröhler, Genre.

95 Berner, Zeichen: $2 \mathrm{f}$.

96 Tröhler, Relevanz: $7 f$.

97 Vgl. Tröhler: Genre: 66. Als Beispiel für die angesprochene liberale ,Brille` kann die Interpretation Hedwig Strehlers dienen, die die „ehrenhaften Bemerkungen über solche, die die Schule über alle Massen wohl versehen“, als eine „Versuchung, das gesamte Schulwesen durch die Brille zu betrachten, welche uns gemütlich und gemütvoll die gute, alte Zeit vorspiegelt, die doch im tiefsten Grunde [...] trostlos und elend ist“ deutete. Strehler, Kulturgeschichte: 96f. Die Studie selbst hat historiografischen Wert, da sie erstmals bildungsgeschichtliche Fragestellungen im Rahmen einer Kulturgeschichte bearbeitete. Vgl. Brändli, Skylla: $292 f$.

98 Zur „älteren“, massgeblich auf den Antworten der Stapfer-Enquête basierenden Kantonsschulgeschichts-Literatur gehören (in chronologischer Reihenfolge) bis zum Zweiten Weltkrieg: Abegg, Beiträge: 40-691; Hess, Landschaft Basel; Dévaud, École primaire; Schneider, bernische Landschule; Klinke, Zürich; Ochsner, Schulberichte: 205310; Mösch, Solothurnische Volksschule; Grosser, Verbesserungen.

99 Berner, Zeichen: 11.

100 Durrer, Urkantonen; Sialm, Waldstätten.

101 Hunziker, Volksschule. 
schaft wurde hingegen bloss als ein passiver Strukturfaktor Beachtung geschenkt, ohne auf die zahlreichen Individualitäten in den Akten einzugehen.

Ein schwaches Intermezzo der Schulgeschichtsschreibung begann nicht zufälligerweise in den 1930er-Jahren und profitierte im Kontext der äusseren Bedrohungen durch den Faschismus und Nationalsozialismus von der Suche nach nationaler Identitätsstiftung durch die vormoderne Geschichte. ${ }^{102}$ Trotz der nationalen Orientierung folgte die Schulgeschichte jedoch weiterhin der Tradition der kantonalen Geschichtsschreibung und konzentrierte sich zeitlich weiterhin vorwiegend auf die Entwicklungen in der Zeit nach der Regeneration ab $1830 .{ }^{103}$

Im Zuge der „empirischen Wende“ zu den Sozialwissenschaften ab den 1960er-Jahren erfolgte eine stetige Zurückdrängung der historischen Komponente in der Bildungsforschung zugunsten einer am Kind orientierten Reformpädagogik und der erziehungswissenschaftlichen Psychologie. Doch auch die Geschichte der Pädagogik im Allgemeinen und die für die Schweiz charakteristische starke Pestalozzi-Forschung im Besonderen hat die pädagogische Kritik am vormodernen Schulwesen als schlechte, unorganisierte und stumpfsinnige Memorierschule mit schlecht ausgebildeten Lehrkräften weitgehend unhinterfragt weitergeführt. ${ }^{104}$ Die kantonalen Schulgeschichten erreichten zunehmend eine Sättigung an Übersichtsdarstellungen ${ }^{105}$, wodurch sich der Fokus vermehrt in die Nische der Jubiläums- oder Fest-Publikationen zu einzelnen Schuleinrichtungen oder über regionale Schulkreise verschob ${ }^{106}$, was zwar auf ein nach wie vor starkes Bedürfnis nach Geschichte schliessen liess, den wissenschaftlichen Bedeutungsverlust der Schulgeschichte jedoch nicht kaschieren konnte. ${ }^{107}$

Erst seit den 1990er-Jahren hat eine neuerliche, wenn auch zaghafte Trendwende eingesetzt, die bis heute anhält. Diese zweite Konjunkturphase ist einerseits geprägt durch eine Ausweitung der Fragestellungen in die Richtung von lokaler Schulwirklichkeit und neuen Themen wie Konfessionalisierung, Säkularisierung und Alphabetisierung. ${ }^{108}$ Andererseits konnten aus neuen räumlichen Vergleichen - hier sei besonders auf die Studie von Pietro Scandola zum Schulwesen von Bern und Zürich verwiesen ${ }^{109}$ - und von interdisziplinären Jubiläumsprojekten zur Geschichte des Volksschulwesens in einzelnen Kantonen oder zur Geschichte von Lehrerbildungsinstitutionen neue Erkenntnisse über die Schulentwicklung und die Schuldiskussionen im 19. Jahrhundert gewonnen werden. ${ }^{110}$ Die Schulgeschichte des 18. Jahrhunderts fiel dieser neuerlichen Konjunktur der historischen Forschung als eigenständiges Thema jedoch weitgehend zum Op-

102 Vgl. Berner, Zeichen: 3; Criblez/Jenzer, Situation: $219 \mathrm{f}$.

103 Mit Ausnahme der Arbeit von Louis Boucard zu den Walliser Schulen entstanden ab 1920 bis nach dem Zweiten Weltkrieg keine umfangreichen kantonalen Schulgeschichten mehr. Boucard, valaisanne.

104 Tröhler, Schulkritik: 104.

105 Zur „neueren“, auf der Stapfer-Enquête basierenden Kantonsschulgeschichts-Literatur gehören in chronologischer Reihenfolge: Panchaud, écoles vaudoises; Haas, Innerschweiz: 508-530; Landolt, Linth; Grosser, Antworten: 48-85; Bossard, Zug.

106 Einige in dieser Arbeit verwendete Beispiele von lokalen Schulgeschichten sind: Flückiger, Murten; Meier, Sturmläuten; Scherwey, Freiburg; Meyer, Langenthal.

107 Brändli, Skylla: 291f.; Criblez/Jenzer: Situation: 221-224.

$108 \mathrm{Zu}$ den bedeutenden regionalen Studien ab 1990 gehören: Salamin, Dans les écoles valaisannes: 45-80; Eigenmann, Brachland: 113-128.

109 Scandola, Standesschule. Eine vertiefte Betrachtung der sozialen Situation der Lehrerschaft leistet Ebengenannter in: Scandola, Lehrerschaft.

110 Zur umfangreichen kantonalen Jubiläumsliteratur zählen: Scandola/Rogger/Gerber, Staat; Lengwiler/Rothenbühler/Ivedi, Schule macht Geschichte; Hofstetter, lumières. Bedeutende Beiträge zur Geschichte der institutionalisierten Lehrerbildung sind: Scandola, Lehrerschaft; Crotti/Oelkers, Ein langer Weg; Jenzer/Jenzer, Lehrerseminar; Noverraz, formation. 
fer und höchstens die Vorgeschichten der erfolgreichen Entwicklungen des 19. Jahrhunderts wurden in der Zeit vor 1800 gesucht. ${ }^{111}$

Im Gegensatz zur deutschen Bildungsforschung mit ihrem Handbuch der deutschen Bildungsgeschichte $^{112}$ existiert für die Schweiz ferner nach wie vor keine kantonsübergreifend vergleichende Strukturgeschichte des elementaren Bildungssystems. Ebenso fehlt eine raumübergreifende Darstellung des Lehrerstandes auf der Basis von Archivstudien für die Zeit vor 1800. Diese eklatante Forschungslücke erstaunt umso mehr, als bereits seit Mitte der 1990er-Jahren verschiedentlich darauf aufmerksam gemacht worden ist und mit der Enquête des helvetischen Bildungsministers Stapfer auch eine hervorragende Quellenbasis von niederer Provenienz für das ausgehende 18. Jahrhundert zur Verfügung stehen würde. ${ }^{113}$ Zwar liegen einige Sammelbände neueren Datums mit einer gesamtschweizerischen Perspektive zum Primarschulwesen vor, allerdings unter schwacher Berücksichtigung der Entwicklungen im 18. Jahrhundert und der vormodernen Lehrerschaft. ${ }^{114}$ Auch die neuere Dissertation von Anna Bütikofer zu den Ursprüngen des modernen Bildungssystems in der Helvetischen Republik geht kaum vertieft auf die Lehrer als Handlungsakteure an der Basis ein. ${ }^{115}$

Wesentlich zu einer „Wiederentdeckung“ der Schulgeschichte des 18. Jahrhunderts in jüngster Zeit beigetragen haben unter anderem auch zwei universitäre Forschungsprojekte: die Edition der Zürcher Landschulumfrage von 1771/1772 und die Edition der Stapfer-Enquête von 1799. ${ }^{116}$ Aus dem Forschungsprojekt zur Edition der Stapfer-Enquête sind bislang vier Dissertationen entstanden, in denen unter anderem auch die Lehrerschaft als Handlungsakteure Eingang fand. Markus Fuchs hat sich in seiner Dissertation den pädagogischen Diskursen in den vielfältigen Zusatzbemerkungen der Lehrkräfte am Ende des stapferschen Fragebogens gewidmet. ${ }^{117}$ Die Dissertation von Ingrid Brühwiler hat dagegen auf der Basis einer Stichprobe von 220 Antwortschreiben die Einkommensverhältnisse der Lehrer um 1799 in Abhängigkeit von ihren sozio-ökonomischen Rahmenparameter untersucht, freilich ohne Miteinbezug des nicht zu beziffernden sozialen Prestiges. ${ }^{118}$ Peter Büttner beleuchtet in seiner Promotionsarbeit die Rolle des Lehrers als Schreibmeister, ${ }^{119}$ während Michael Ruloff die Lehrer als Einflussfaktoren auf die Qualität des Schulbesuchs untersucht hat. ${ }^{120}$ Daneben entstanden aus Forschungstagungen des Editionsprojektes zwei Sammelbände mit einer Vielzahl von aktuellen Forschungsbeiträgen aus dem Umfeld der Stapfer-Enquête. ${ }^{121}$

Explizite vertiefte Auseinandersetzungen mit der vormodernen Schweizer Lehrerschaft, die über die Betrachtungsweise des Lehrers als passiven Strukturfaktor des Systems Schule hin-

111 Tröhler, Genre: 66.

112 Vgl. Hammerstein/Herrmann, Handbuch; v.a.: Neugebauer, Niedere Schulen: 213-261.

$113 \mathrm{Zu}$ den Forschungslücken der Schweizer Schulgeschichte im Allgemeinen vgl. Criblez/Jenzer, Situation: 231; wiederholt bei Brändli, Skylla: 298; Scandola, Standesschule: 595. Zum historischen Wert der stapferschen Schulumfrage vgl. Schmidt, Momentaufnahme: 98-112; Grunder, Bild des Lehrers: 130.

114 Badertscher/Grunder, Geschichte der Erziehung; Criblez, Bildungsraum; Crotti/Gonon/Herzog, Pädagogik und Politik; Hofstetter, Démocratie.

115 Bütikofer, Staat.

$116 \mathrm{Zu}$ den beiden Quellen siehe die Ausführungen im Kap. 1.5. Aus der Edition der Zürcher Landschulumfrage hervorgegangen sind u.a.: Tröhler/Schwab, Volksschule im 18. Jahrhundert; Berner, Zeichen; Bloch Pfister, Priester; Schwab, Schulmeister.

117 Fuchs, Lehrerperspektiven.

118 Brühwiler, Finanzierung.

119 Büttner, Schreiben.

120 Ruloff, Schulbesuch.

121 Tröhler, Bildungspolitik; Tröhler, Volksschule. 
ausgehen, sind insgesamt jedoch noch rar. Die wenigen Studien sind meist kantonal fokussiert und entweder aus pädagogischer, geschlechtergeschichtlicher oder professionalisierungsgeschichtlicher Perspektive entstanden. Eine erste wegweisende, quantitativ orientierte, sozialgeschichtliche Betrachtung der Lehrerschaft hat Georges Panchaud in seiner Schulgeschichte zur Waadt im Ancien Régime von 1952 erarbeitet. ${ }^{122}$ Von Seiten der historischen Pädagogik hat sich ferner Heinrich Tuggener im Jahr 1961 sehr ausführlich dem vormodernen „Lehrerstand“ gewidmet, ohne allerdings quantitative Ansätze als Spiegel für die qualitativen Betrachtungen zu berücksichtigen. ${ }^{123}$ Neuere Forschungen zur Professionalisierungsgeschichte der schweizerischen Lehrerschaft unter dem Einbezug der Vormoderne finden sich bislang am deutlichsten in den beiden Dissertationen von Esther Berner und Alexandra Bloch Pfister zu den Zürcher Volksschullehrern, wenngleich das theoretische Raster der Professionalisierung zu Recht als problematisch im Übertrag auf die vormoderne Lehrerschaft kritisiert worden ist. ${ }^{124}$ Für eine geschlechterfokussierte Geschichte der Lehrerinnen haben Marianne von Wartburg-Adler und Claudia Crotti wesentliche Vorarbeiten geleistet. ${ }^{125}$ Dennoch fehlt bislang ein nationaler Überblick zu den vormodernen Lehrkräften in Form einer vergleichenden Synthese der zahlreichen Regionalforschungen und damit ein konkretes Raster zur Verortung für die teilweisen disparaten Partikularergebnisse. So ist bislang offen geblieben, wie die vormoderne Elementarschullehrerschaft sozialhistorisch und in einer gesamtschweizerischen Perspektive einzuordnen ist. Daher präsentiert sich die schweizerische Schulgeschichte in Bezug auf die Lehrerschaft weiterhin als ein Desiderat. ${ }^{126}$

Die „klassische“ quantitativ orientierte Sozialgeschichte mit ihren makroskalig-strukturalistischen und polit-ideologischen Ansätzen zur Erforschung einzelner sozioökonomischer „Klassen“ oder „Schichten“ der Gesellschaft ist zwar seit den 1980er-Jahren im Zuge des „cultural turns“" von offeneren methodischen Konzepten der Kulturgeschichte abgelöst worden. Dennoch ist die historische Lebenswelt der „kleinen Leute“ noch längst nicht abschliessend erforscht und bleibt von Halb- und Unwissen geprägt. ${ }^{127}$ Gerade Alexandra Bloch Pfister kritisiert bezüglich der Elementarschullehrer „die undifferenzierte und vielfach unhinterfragte Vorstellung eines tiefen sozialen Status der Schulmeister im Ancien Régime "128, die sich bis in die neuere Literatur verfolgen lässt, obwohl die Quellen in Bezug auf Status und Fähigkeiten der Lehrer oftmals eine andere Sprache sprechen. ${ }^{129}$ Die mit überraschenden Befunden zum widersprüchlichen Sozialstand der Zürcher Lehrerschaft argumentierende Arbeit von Bloch Pfister und die Erkenntnisse von Ingrid Brühwiler zu den Lehrerlöhnen ausgewählter Lehrpersonen um 1800 stellen denn auch die Ausgangspunkte für die vorliegende Untersuchung dar. ${ }^{130}$ Sie bieten Anlass, sich vertiefter mit dem sozialen Stand der Elementarschullehrer in schweizweiter

122 Panchaud, écoles vaudoises.

123 Tuggener, Lehrer.

124 Bloch Pfister, Priester; Berner, Zeichen. Berners Forschungen beschränkten sich quellentechnisch allerdings ausschliesslich auf die 1771/1772er-UmFrage in Zürich, während Bloch Pfister auch Vergleiche mit der Stapfer-Enquête zog. Das von Bloch Pfister angewandte Definitionsraster von Professionalisierung ist insofern kritikwürdig, als dass es auf modernen Operatoren aufbaut, so dass die frühneuzeitlichen Lehrkräfte automatisch höchstens als „semi-professionell“ dargestellt werden konnten. Vgl. die Kritik von Tenorth im Kap. 1.3.3.

125 Von Wartburg-Adler, Lehrerinnen; Crotti, Lehrerinnen.

126 Brändli, Skylla: 293.

127 Zur Historiografie der Sozialgeschichte vgl. Merki, Sozialgeschichte.

128 Bloch Pfister, Priester: 98-124, hier: 99.

129 Neueste Forschungen weisen explizit auf die Notwendigkeit eines Überdenkens dieser Stereotype. Vgl. Bloch Pfister, Priester: 102-110; Schmidt, Niedere Schulen: 270; Schwab, Schulmeister: 38.

130 Brühwiler, Finanzierung; Brühwiler, Schwache Schulen: $119 \mathrm{f}$. 
Vergleichbarkeit auseinanderzusetzen, zumal der „Bildungsmarkt“ selbst als ein schichtabhängiges Phänomen gedeutet wird. ${ }^{131}$

Alltagsgeschichtliche Ansätze können dabei dienen, die Lehrkräfte als historische Subjekte mit eigener Mündigkeit und „nicht einfach als Unterworfene übergeordneter Strukturen und Entwicklungen, sondern wieder vermehrt als handelnde Subjekte "132 $\mathrm{zu}$ sehen. Ferner weckt das vielfach proklamierte fehlende Standesbewusstsein der vormodernen Lehrer Zweifel, ob wirklich keine Entwicklungen der identitätsbezogenen Verberuflichung in vorinstitutionalisierter Zeit feststellbar sind. Denn sowohl ältere als auch jüngere Forschungen verweisen durchaus auf Ansätze, zum Beispiel auf das Vorhandensein von Lehrerzünften oder von informellen Ausbildungswegen. ${ }^{133}$ Mögliche Hilfestellungen für die Beantwortung der obigen Fragen zum sozialen Stand und zur Verortung von Alltagshandlungen der Lehrkräfte müssen freilich ausserhalb der traditionellen Schulgeschichte gesucht werden. Hierbei liefern im Rahmen der Sozialgeschichte vor allem die Agrar-, Bevölkerungs- und Familiengeschichte sowie die historische Demografie wichtige subdisziplinäre Anknüpfungspunkte.

Den biografischen Zugängen zur vormodernen Lehrerschaft wurde von der historischen Forschung bislang noch kaum Beachtung geschenkt. Obwohl die Biografieforschung mittlerweile im Wissenschaftsbetrieb als etablierte, schon fast altmodische Herangehensweise taxiert wird, deren Blütezeit bereits wieder verstrichen sei, und die klassischen Annahmen von Autonomie, Handlungsfähigkeit und Identität der untersuchten Subjekte durch die „Subjektkritik“ weitgehend dekonstruiert worden sind, ${ }^{134}$ öffnet sich gerade in der historischen Bildungsforschung noch weitgehend Brachland für die Selbstzeugnis- und Biografie-Forschung. Bereits Otto Hunziker hat 1903 in seinen Vorarbeiten zu einer schweizerischen Schulgeschichte des 19. Jahrhunderts gefordert: „Viel Gewinn wird die Geschichte des Schulwesens auch ziehen aus möglichst intensiver Pflege der Biographien von Schulmännern. Muster solcher Biografien sind in reichlicher Zahl vorhanden. [...] Ausser der Skizzirung ihrer Leistungen für Schule und Erziehung ist dem Gepräge und der Entwicklung ihrer Individualität, ihrer anderweitigen Betätigung als Mensch und Bürger, kurz der Darstellung des ganzen Mannes (und möglichst von innen heraus) in der Schilderung desselben Raum zu gewähren. Nicht genug zu empfehlen ist Genauigkeit und Zuverlässigkeit der Angaben über die wichtigsten Lebensdaten." ${ }^{135}$

Im Fokus der historischen Bildungsforschung der Schweiz standen bislang neben Pestalozzi vor allem die Biografien jener Schulmänner, die in seinem Dunstkreis als unmittelbare Weggefährten und Schüler auftauchten und von denen einige später als Gründer von zumeist höheren Bildungseinrichtungen in Erscheinung traten. ${ }^{136}$ Sie zählen zur sogenannten „zweiten Reihe der an der Reform Beteiligten“. ${ }^{137}$ Verwiesen sei an dieser Stelle einerseits auf die Dissertation von Inna Beier zu Carl August Zeller, einem Schüler und Weggefährten Pestalozzis und Rezipienten der ersten Stunde in Deutschland. ${ }^{138}$ Ein weiterer biografisch sehr gut dokumentierter Lehrer mit Ursprüngen auf dem Land war der Appenzeller Hermann Krüsi, ein Schüler Pestalozzis in Burgdorf und späterer Direktor des appenzellischen Lehrerbildungsseminars Gais AR. Die

131 Die Volksschule als „klassengebundene Schule“ des „common folk“ wurde zur Ausgangslage bei Kuhlemann, Modernisierung: 26. Zum (bürgerlichen Privat-) Bildungsmarkt vgl. Bosche, Reform: $261 \mathrm{f}$.

132 Tanner, Alltagsgeschichte.

133 Trinks, Sozialgestalt: 19; Dantl, Schullehrling; Wenzel, Lehrerbild.

134 Vgl. zur Kritik am frei handelnden Akteur: Duisen, Biographieforschung: 165.

135 Hunziker, Vorarbeiten: 9f.

136 Schlegel, Schulmänner; Hunziker, Volksschule.

137 Nach Jeismann, Beitrag: 11-39.

138 Beier, Zeller. 
aussergewöhnliche Karriere vom einfachen Schulmeister zum persönlichen Mitarbeiter Pestalozzis, später zum Kantonsschullehrer und Direktor des Lehrerseminars in Gais AR, sowie seine umfangreichen autobiografischen Schriften und Lehrmittelpublikationen bildeten die Grundlage für mehrere Biografien. ${ }^{139}$ Zudem trifft man des Öfteren in Biografien von Pfarrern bis weit ins 19. Jahrhundert auf episodische Lebensabschnitte im jungen Erwachsenenalter oder während der Vikariatszeit mit Unterrichtstätigkeiten als Privat- oder Landschullehrer, jedoch ohne dass diese Lebensphasen in einen übergreifenden Vergleich eingebettet worden wären. ${ }^{140}$ Die einfachen Schulmeister hingegen, die „dritte Reihe“ des Bildungswesens, die unmittelbar vor Ort aktiv die Schulwirklichkeit gestalteten, selbst aber weder durch grosse pädagogische Schriften noch aussergewöhnliche Taten in Erscheinung traten, sind biografisch noch kaum erforscht. Zeitgenössische Autobiografien, Biografien und sonstige Ego-Dokumente von ebensolchen Lehrkräften, die um 1800 aktiv im Schuldienst standen, sind Mangelware. Eine der wenigen Ausnahmen stellt die von Reinhard Meyer zusammengefasste Autobiografie des bernischen Lehrers Jakob Eggen (1742-1814) dar, dessen handschriftliches Manuskript noch vorliegt. Der aus ärmlichen Verhältnissen im bernischen Simmental stammende Eggen arbeitete sich vom einfachen Hirtenknaben in Boltigen im Berner Oberland zu einem geachteten Stadtschullehrer hoch, wobei ihn sein beruflicher Werdegang in einer beachtenswerten Mobilität über mehrere Stationen innerhalb des Berner Untertanenlandes von der französischsprachigen Waadt über den Oberaargau bis ins Seeländer Städtchen Aarberg führte. ${ }^{141}$ Eine ähnliche Autobiografie ist von Wilhelm Kradolfer aus der Basler Landschaft über den Lehrer Matthias Buser (1788-1848) überliefert, der als Kind eines armen Bandwebers und Hirten vom einfachen Landschullehrer in Zunzgen BL im Baselbiet zu einem städtischen Schullehrer an der Armenschule in Basel aufstieg. ${ }^{142}$ Beiden Biografien ist im Quervergleich neben der ländlichen Herkunft der Protagonisten das Moment eines aussergewöhnlichen Karriereverlaufs mit dem Wechsel von Landschulen in ein städtisches Lehramt inhärent. Dadurch stellt sich zwangsläufig die Frage nach der Repräsentativität der Aussagen. Entsprachen die genannten Lebensverläufe einer „typischen biografischen Norm“ um 1800 oder stellten sie Ausnahmeerscheinungen dar? Es folgt somit die Frage, wie eine kollektive Biografie der Elementarschullehrer um $1800 \mathrm{zu}$ skizzieren ist.

Den insgesamt vorliegenden Mangel an Autobiografien und weiteren Egodokumenten von frühneuzeitlichen Lehrpersonen über ihr Alltagsleben ${ }^{143}$ hat die bisherige Schulgeschichts-

139 Krüsi, Erinnerungen; Ders., Bestrebungen. Daneben verfasste Krüsi weitere pädagogische Schriften und eigene Lehrmittel. Vgl. das Literaturverzeichnis bei Schiess, Krüsi; Gruntz-Stoll, Appenzeller Schüler. Vgl. auch Schlegel, Schulmänner.

140 Stellvertretend kann auf das schulische Engagement des berühmten Berner Pfarrers und Schriftstellers Albert Bitzius, bekannt unter dem Pseudonym Jeremias Gotthelf, hingewiesen werden. Bitzius half beispielsweise während seiner Vikariatszeit in Utzensdorf BE regelmässig dem Dorfschulmeister in der Schulstube aus. Vgl. Montandon, Utzenstorfer Anfänge: 16-22.

141 Meyer, Langenthal: 24-44; Das ursprüngliche Manuskript der Autobiografie wurde von Jakob Eggen am 1. September 1806 anlässlich seines Rückzugs aus den Schulgeschäften geschrieben. Ein unbekannter Autor (wahrscheinlich aus seiner Nachkommenschaft) erstellte das heute archivierte handschriftliche Dokument im Jahr 1839, das über einen Privatnachlass in den Besitz des Staatsarchivs Bern gelangte. StABE DQ 177.19, S. 1-75: 23.06.1839 - Kurze Lebensbeschreibung. Die Autobiografie Eggens fand ferner über Alfred Messerlis Untersuchung zur Entwicklung der Literarität Eingang in die bisherige Forschungsliteratur. Messerli, Lesen: 246.

142 Kradolfer, Lehrerleben.

143 Erwähnenswert sind hierzu die vielfältigen und einzigartigen Aufzeichnungen des Lehrers Johann Jakob Ambühl aus Wattwil SG über seinen Schulalltag in den Jahren 1739 bis 1745. KaBSG VMs 935: [1739-1745] - Schul-Tagebuch. Weiter erwähenenswert - wenn auch aus dem späten 19. Jahrhundert - ist die handschriftliche siebenbändige Autobiografie des Luzerner Lehrers Xaver Unternährer von Romoos LU: ZHB BB Ms 513.4, Bd. 1-7 - Unternährer. 
forschung stets mit dem Zuzug von Fremdwahrnehmungen auf das Lehramt zu kompensieren versucht. Dabei hat sich für die Zeit vor der zweiten Hälfte des 19. Jahrhunderts das Bild des armen, pädagogisch ungeschickten und sozial deklassierten Lehrers der Vormoderne als eine sehr persistente Meistererzählung in der Historiografie der Schulgeschichte entwickelt, zu deren Verständnis eine kurze Reflexion der zugrunde liegenden Ursachen notwendig ist.

\subsubsection{Das Bild des Lehrers in der Historiografie}

Der hartnäckige Topos des armen und fachlich unfähigen vormodernen Elementarschullehrers ist eng verknüpft mit den zuvor skizzierten Hauptkonjunkturen in der historischen Bildungsforschung. Die Wurzeln des defizitären Lehrerbildes liegen freilich an unterschiedlichen Orten zugleich. Fünf Faktoren haben dabei massgeblich dazu beigetragen, dieses historiografische Bild in den letzten zweihundert Jahren zu verfestigen und als Narrativ zu verselbstständigen.

Erstens wurde die Erzählung des armen, charakterlich schwachen und defizitär gebildeten Lehrers von zeitgenössischen satirischen Überzeichnungen der Lehrerschaft aus dem Volksmund massgeblich beeinflusst. In populären Spottliedern aus dem süddeutschen Raum war das ,arme Dorfschulmeisterlein“ bereits seit dem 17. Jahrhundert die satirische Karikatur einer an ihrem Bildungsdünkel gescheiterten Existenz, gefangen in der doppelten Abhängigkeit vom vorgesetzten Pfarrer und von der finanzierenden Dorfgemeinde. ${ }^{144}$ Der Beginn eines dieser Spottlieder lautet: „In einem Dorf im Schwabenland, da lebt uns allen wohlbekannt, da wohnt in einem Häuslein klein, das arme Dorfschulmeisterlein. Des Sonntags ist er Organist, des Montags fährt er seinen Mist, des Dienstags hütet er die Schwein, das arme Dorfschulmeisterlein. Des Mittwochs fährt er in die Stadt und kauft, was er zu kaufen hat; 'nen halben Hering kauft er ein, das arme Dorfschulmeisterlein. Des Donnerstags geht er in die Schul' und legt die Buben über'n Stuhl. Er haut so lange, bis sie schrei'n, das arme Dorfschulmeisterlein. Und wenn im Dorfe Hochzeit ist, dann könnt ihr sehen, wie er frisst. Was er nicht frisst, das steckt er ein, das arme Dorfschulmeisterlein." ${ }^{145}$

Wirtschaftliche Armut, zwingende Nebenverdienste zur Sicherung des Überlebens, zeitweiliger Hunger, eine wenig ehrenhafte Stellung im Dorf, einen rohen Charakter und kaum pädagogische Kenntnisse umschrieben die leitenden Stereotype dieses populär-ironischen Lehrerbildes, das sich rasch auch in den Köpfen späterer Betrachter festsetzte. Ein weiteres bekanntes Beispiel eines bedauernswerten Dorfschulmeisters ist ferner in Wilhelm Buschs bekannter Bildergeschichte „Max und Moritz“ aus der zweiten Hälfte des 19. Jahrhunderts mit dem Schulmeister Lämpel zu finden, dessen Name nach Rudolf Reiser nicht zufälligerweise einen „einfältigen Tropf " umschreibt. ${ }^{146}$ Sowohl das Spottlied als auch Buschs Kindergeschichte charakterisieren die vielfältigen Merkmale der Zugehörigkeit der Elementarschullehrer zu den Unterschichten, die sich in der Frühen Neuzeit im Wesentlichen durch einen Mangel an Möglichkeiten zur politischen Teilhabe, an Einkommen und Vermögen, an wirtschaftlicher Selbständigkeit und einen Mangel an sozialem Kapital definierten. Als gemeinsame biografische Erfahrungen resultierten daraus eine generelle Unsicherheit der Lebenslage, eine Unmöglichkeit zur langfristigen Lebensplanung und die Erfahrung von sozialer Unterlegenheit. ${ }^{147}$

Eine kritische Betrachtung jener volkstümlich-satirischen Darstellungen - etwa der versteckte Neid der nicht alphabetisierten Mitbürger auf den Bildungsvorsprung des Schulmeisters oder

144 Reiser, Lehrergeschichte(n): 61-67; Vgl. zudem: Grunder, Karikatur: 155-159.

145 Zit. nach Walz, Eselsarbeit: 60.

146 Reiser, Lehrergeschichte(n): 64f.; Enzelberger, Sozialgeschichte des Lehrerberufs: 27ff.

147 Hippel, Unterschichten: 5-15. 
seine Nähe zum lokalen Pfarrer als überdörfliche Autoritätsperson - blieb jedoch in der älteren Schulgeschichtsforschung weitgehend aus. ${ }^{148}$ Zwar wurden ab 1770 auch zunehmend die nicht alphabetisierten Personen in der Gesellschaft zur Zielscheibe von Witzen und populären Überzeichnungen, wodurch sich das Neid- und Spottbild gegenüber der Lehrerschaft stark relativiert hat. ${ }^{149}$ Dennoch blieb primär der Spott gegenüber den Lehrern in populären Tradierungen wirkungsmächtig erhalten.

Zweitens popularisierten überzeichnete fiktive Figuren von naiv-unzulänglichen oder sozialreformerisch (über-)motivierten Schulmeistern aus der Feder von bekannten Literaten des 19. Jahrhunderts die defizitäre Wahrnehmung der Schule vor 1800. Zu nennen sind als Exempel der alte Soldaten-Lehrer Glüphi in Johann Heinrich Pestalozzis Dorfroman „Lienhard und Gertrud“ oder der alte Schulmeister Peter Käser in Jeremias Gotthelfs Roman „Leiden und Freuden eines Schulmeisters“. ${ }^{150}$ Gotthelf, als bildungspolitisch engagierter Pfarrer ein profunder Kenner des elementaren Schulwesens auf dem Land, skizzierte im obgenannten Roman den Schulmeister seines Protagonisten wie folgt: „Ein Kind, das zum ersten Male in die Schule kömmt und es sieht den Schulmeister im Zorn, sieht ihn rauh und auffahrend, wird Jahre lang die Furcht vor ihm festhalten und selten es bis zur Liebe bringen. Ja man wird es mit Schlägen in die Schule treiben müssen, was das Übel nur ärger macht. [...] Er war häßlich und durch Unreinlichkeit fast eckelhaft; er liebte neben dem Schnupf auch den Schnaps, und den trank er manchmal vor, manchmal während der Schule. Sein Lohn war gering, und um sich mehr Geld zu verschaffen, trieb er das Küferhandwerk und hatte im Winter den Zügstuhl in der Schulstube. Er galt für einen bsunderbar e Gschickte, denn er konnte den Bauern das Heu messen und sogar Brieflein und Zeugnisse schreiben für sie. Sein Schulhalten war aber nicht weit her. Des Morgens mußte man zuerst lernen, was man aufsagen wollte, sowohl auswendig, als die Leser ihre paar Zeilen im Fragenbuch, und die Buchstabierer ihre Buchstaben. Dann fing das Aufsagen an, und wenn dieses nicht bis mittags dauerte, so las man noch ein wenig. Des Nachmittags fing man mit Lesen an, später konnten einige manchmal etwas schreiben oder rechnen; die meisten und besonders die Leser und Buchstabierer, kamen nicht von ihren Büchern weg. [...] Ordnung war keine in der Schule, aber Prügel vollauf von dem Alten und von den Jungen." ${ }^{151}$

Dass diese Lehrerfiguren in ihrer starken Verzerrung und mit ihren überzeichneten Schwächen die literarische Funktion der Kritikmanifestation zu erfüllen hatten und nicht unbesehen als Quelle für den realen Zustand des Schulwesens des 18. und 19. Jahrhunderts gelten dürfen, scheint aus heutiger Warte zwar als ein Gemeinplatz. ${ }^{152}$ Dennoch kommen die Schule und ihre Lehrer in der Literatur bis in die Moderne generell eher schlecht weg. „Literatur und Schule scheinen in einer negativ-symbiontischen Beziehung zu einander zu stehen “, folgert Hans Ulrich Grunder zum Verhältnis von Schriftstellern und der Schule, zumal in literarischen Darstellungen weit mehr negativ getönte Bilder von Lehrkräften als positiv gezeichnete zu finden sind, aber paradoxerweise gleichzeitig viele Autoren selbst Lehrer wurden. ${ }^{153}$

$148 \mathrm{Zu}$ einer vertieften kritischen Betrachtung des Lehrerbilds in Karikaturen als Projektion von Stereotypen: vgl. Grunder, Karikatur: 155-159; Grunder, Hungerleider: 160-167.

149 Messerli, Lesen: 40-51.

150 Vgl. Horlacher, Leutnant: 17.

151 Gotthelf, Leiden: 55f. Zur Rezeption des Werkes vgl.: Mahlmann-Bauer, Spiegel: 68ff.

152 Vgl. zur Kritik an Pestalozzis Lehrerbild: Tobler, Gestalt: $20 \mathrm{f}$.

153 Grunder mutmasst, die skeptischen Beurteilungen der Schule seien primär Ausdruck der Selbstentlastung der Autoren. Zudem „bereitet es mehr Spass, in einem Roman einen sadistischen Tyrannen oder einen pedantischen Pauker zu schildern, als ein fachlich und didaktisch kompetente, eine gerechte, eine ,gute Lehrkraft'. Grunder, Lehrkräfte: $7 f$. 
Die zeitgenössische pädagogische Publizistik des ausgehenden 18. und frühen 19. Jahrhunderts hat in ihrer Polemik gegen die Schule jedenfalls eine starke Rolle als Vermittlerin von negativen Bildern in der Historiografie eingenommen und transportieren über ihre „Stars“ wie Pestalozzi bis heute jene Bilder, „die den engagierten pädagogischen Schriftstellern damals auf dem Magen gelegen haben müssen, die aber nicht zwangsläufig die Wahrnehmung aller Beteiligten widerspiegeln." 154

Drittens liegt eine der Hauptursachen für die stark negativ stereotypisierte Darstellung des vormodernen Schweizer Elementarschullehrers in der Provenienz der untersuchten Quellen zum elementaren Schulwesen vor 1800. Die ältere historische Bildungsforschung hat sich hierbei vorwiegend an zwei Quellengattungen orientiert. Zum einen an den politischen Verwaltungsakten der neuen Helvetischen Republik, zum anderen an den Reformvorschlägen und persönlichen Korrespondenzen zwischen den führenden politischen Persönlichkeiten und reformpädagogischen Vordenkern der Helvetischen Republik - allen voran Philipp Albert Stapfer und Johann Heinrich Pestalozzi - und ihren lokalen Gesinnungsfreunden auf den kantonalen oder lokalen Verwaltungsstufen. Bei Letzteren handelte es sich jedoch um einen kleinen Kreis von reformaufklärerisch denkenden Personen aus der neuen Elite des Landes, die im Elementarschullehrer die idealisierte republikanische Person schlechthin des neuen Staatswesens sahen. ${ }^{155}$ Doch gerade jene volksaufklärerisch gesinnten, reformwilligen Pfarrer, Schulinspektoren, Geistlichen, Politiker und Reformpädagogen pflegten in ihrer mannigfaltigen Schreibtätigkeit die Situation im lokalen Elementarschulwesen ihres Einflussbereichs gerne in übertriebener Schwärze darzustellen, um möglichst viel Aufmerksamkeit auf ihre eigenen Bildungsreformideen zu lenken. Der helvetische Bildungsminister Stapfer urteilte etwa im November 1798 in vernichtenden Worten: „Es ist nur zu bekannt, in welchem elenden Zustand sich die Volksschulen fast überall in Helvetien befinden. An vielen Orten sind gar keine Schulhäuser; an andern sind sie nicht hinreichend für die Bedürfnisse des Unterrichts, oder höchst unbequem eingerichtet. Die Schulmeister sind schlecht besoldet. Es fehlt ihnen an den Kenntnissen und Fertigkeiten selbst, welche sie ihren Lehrlingen beibringen sollen; die Lehrgegenstände reichen keineswegs an die Bedürfnisse des Menschen, der seine Würde fühlen, und des Bürgers, der seine Rechte kennen, seine Pflichten erfüllen soll. Die Lehrart ist verkehrt, vernunftwidrig; die Schulzucht ist bald zu streng, bald zu nachlässig und auf alle Fälle unzureichend. ${ }^{156}$ Die geäusserte Pauschalkritik am Schulwesen war als Gesellschaftskritik an den lokalen Ungleichheiten und zugleich als Kritik am alten politischen System gedacht, das diese Ungleichheiten toleriert hatte und nicht gegen Missstände einschritt. Sie zielte aber trotz der vehementen Worte nicht bewusst auf die Bildungsakteure an sich ab. ${ }^{157}$ Dabei sind die Lehrkräfte als kritisierte Betroffene selbst nur selten direkt zu Wort gekommen, denn die zeitgenössischen Beschreibungen blieben in der Regel stets über die Lehrerschaft gefasst, stammten aber selten aus der Lehrerschaft selbst. ${ }^{158}$

Insgesamt bleibt der Platz für die Lehrer in den Reformkonzepten der helvetischen Bildungsvordenker sehr bescheiden, da Lehrer selbst in zeitgenössischen Abhandlungen über das Schulwesen selten als eigenständige Akteure des Wandels oder sogar als zentrale Schaltstellen des

154 Tröhler, Schulkritik: 104.

155 Bütikofer, Staat: $206 f$.

156 Luginbühl, Stapfer: 99f.

157 Vgl. Caspard, Lehrer. Auch Bütikofer betont, dass der apostrophierte schlechte Zustand der alten Schule nicht die bedeutenste Legitimation für Reformen gewesen sei. Bütikofer, Staat: 124.

158 Vgl. Fuchs, Lehrerperspektiven: 15; Bütikofer, Staat: 111. 
schulischen Systems thematisiert wurden. ${ }^{159}$ Quellen von niedriger Provenienz, idealerweise aus der Hand von Landschullehrern, wurden dabei oft nur als Steinbruch zur qualitativen Illustration der defizitären Schulsituation beigezogen. So bestätigten zahlreiche zeitgenössische Klagen aus der Hand von Elementarschullehrern über ihren unzulänglichen Stand, das niedrige Einkommen und die schwierige Lebenssituation das gezeichnete Klischee der Spottlieder. Benedikt Kunz, Schullehrer zu Wiler bei Utzensdorf BE, merkte in seiner Beantwortung der Stapfer-Enquête von 1799 an: „Ein Reicher Man Spricht offt Schul Lehrer Möchte ich nicht Sein, Für Ein So geringes Einkomen meinen Leib möchte ich nicht So Peinigen vertruß und Staub Schlücken Ein armer denkt er Köne diß doch meistes im Winter versehen Es gäbe ihm doch für Eine Zeit Brott für Sich und die Seinigen Ein arbeytr ist Seiner Speise Wärt, Es die Schul arbeit ist Keine Liechte arbeit Einer Schul Rächt vorzustehen, und doch Liecht und Sehr gering die Behlohnung Wenig Eltern der Kinder Suchen Rechte Kinderzucht zu Pflantzen, Beobachten nicht Wie Es ihnen Endlich den untergang mit ihren Kindern Bringen Wie dem Priester Eli und Seinen Söhnen Brachte." ${ }^{60}$

Schule halten war eine Arbeit für Menschen aus armen und minderbenittelten Schichten, so die unmissverständliche Botschaft. ${ }^{161}$ Freilich wurden die verwendeten Quellen aber nie systematisch und vertieft auf die diskursiven Konjunkturen und ihren quellenkritischen Wahrheitsgehalt hin analysiert. Denn der besagte Lehrer Kunz verdiente selbst - entgegen seinen Ausführungen - gar nicht so schlecht wie er klagte, zumal er neben dem Lehrerlohn und weiteren Einkünften als Mesmer eine freie Wohnung und eine kleine Hofstatt zur Selbstversorgung nutzen konnte. ${ }^{162}$ Die bisweilen jammervollen Klagen der Lehrkräfte über ihre Einkünfte sind denn auch in den neuen emanzipierten Diskursprozess zu verorten, bei dem die Lehrpersonen versuchten, sich durch ihre Klagen mehr direktes Gehör bei der neuen Regierung zu verschaffen und ihre Hoffnungen auf einen persönlichen Vorteil zum Ausdruck zu bringen. Erst die neueren Arbeiten von Esther Berner und Alexandra Bloch Pfister beweisen mitunter das Vorhandensein von selbstbewussten, schulstolzen Lehrern als Kontraste zu den obgenannten NegativSelbstbildern. ${ }^{163}$

Viertens erhob die liberale Geschichtsschreibung ab der Mitte des 19. Jahrhunderts bewusst den sozial und ökonomisch prekär positionierten Elementarschullehrer zu einem beliebten paradigmatischen Aushängeschild des bildungsunwilligen, rückwärtsgewandten und reformunfähigen Ancien Régime, um die Zeit vor den 1830er-Jahren und vor dem modernen schweizerischen Bundesstaat in düsteren Schattierungen darzustellen. Die dem Liberalismus zugeschriebenen bildungspolitischen Reformen und Erfolge - etwa die erfolgreiche Durchsetzung der Institutionalisierung der Lehrerbildung und der allgemeinen Schulpflicht - erschienen so in einem weitaus günstigeren Licht. ${ }^{164}$ Die Schulen des Ancien Régimes und mit ihnen ihre Lehrerschaft wurden damit in der Folge zum Opfer der „Siegerperspektive“ der liberalen Geschichtsschrei-

159 Tosato-Rigo, Bild: 62.

160 Schmidt u.a. (Hgg.), Stapfer-Enquête, Nr. 1426: Wiler bei Utzenstorf.

161 Vgl. Bütikofer, Staat: 211.

162 Schmidt u.a. (Hgg.), Stapfer-Enquête, Nr. 1426: Wiler bei Utzenstorf. Der Lehrer verdiente mindestens 600 Berner Bz. pro Jahr, dazu kamen eine freie Wohnung, eine Hofstatt von 1/8 Juchart Land, Waldrechte, unbestimmte Nebeneinkünfte aus der Leinenweberei sowie eine ebenfalls unbestimmte Entschädigung für kirchliche Hilfsdienste als Vorleser, Vorsinger und Leichenbeter. Insgesamt dürfte er wohl um die 100 Fr. jährlich verdient haben, was als ausreichender Lohn für eine Familie angesehen wurde. Vgl. das Kap. 3.1.1.

163 Berner, Zeichen: 97-111; Bloch Pfister, Priester: 65.

164 Vgl. De Vincenti, Wissensordnungen: 20; Horlacher, Leutnant: $17 \mathrm{f}$. 
bung. ${ }^{165}$ Dass sich in den kantonalen und nationalen Archiven mehr als genügend Aktenstücke aus der Hand reformaufgeklärter Zeitgenossen mit Klagen über das vormoderne Schulwesen, die unzulängliche Lehrerschaft und deren ökonomische Armut finden lassen, zementierte das Paradigma zusätzlich. Pietro Scandola resümiert entsprechend: „Wenn die liberalen Kantone nach 1830 gerade das ausgebaute Schulwesen als Aushängeschild eines demokratischeren, fortschrittlicheren Zeitalters lobten und es dabei [...] gerne mit der alten Katechismus-Schule in Kontrast stellten, so vergass man dabei oft etwas Wesentliches. Bei aller Kritik an der alten, religiös ausgerichteten Schule bildete diese doch ein Fundament, auf dem die neue Schule aufbauen konnte. "166

Leise Zweifel am durchwegs negativen Bild des vormodernen Elementarschullehrers sind zwar schon vereinzelt in der schulgeschichtlichen Forschungsliteratur des späten 19. Jahrhunderts und frühen 20. Jahrhunderts auszumachen, jedoch vermochten sie den Diskurs noch nicht entscheidend umzuprägen. In seiner bernischen Schulgeschichte von 1905 bilanziert Ernst Schneider etwa zaghaft: „Vielfach gewinnt man aus der Enquête gar nicht einen so üblen Eindruck von unsern Kollegen von 1799, als man etwa meinen sollte. Die allgemeine intellektuelle Tüchtigkeit stand gewiss recht tief. Doch aus der „Masse“ ragten einige hervor, denen wir nach ihren Berichten unbedingte Achtung entgegenbringen müssen." ${ }^{167}$

Doch selbst Forschungsarbeiten aus der zweiten Hälfte des 20. Jahrhunderts waren nicht davor gefeit, negativ konnotierte Lehrerbilder in einem pauschalisierenden Sinn zu rezipieren. So resümiert Holger Böning noch im Jahr 1998 zum sozialen Stand der helvetischen Lehrkräfte: „Kaum ein Schweinehirt war geringer geachtet als derjenige, der neben dem Pfarrer die grösste Verantwortung für Wissen und Bildung der Jugend trug. Sie [die Lehrer] rekrutierten sich aus den untersten Berufsgruppen und übernahmen ihr Amt, weil sie auf einen Nebenverdienst angewiesen waren. Gern wählte man den Bewerber, der den geringsten Anspruch auf Lohn geltend machte, ein Glück, wenn ein solcher Kandidat dann wenigstens hinreichend lesen und schreiben konnte. ${ }^{168}$ Ungerechtfertigt war der Vergleich mit den Schweinehirten zwar nicht es gibt tatsächlich mindestens eine entsprechende Einzelquelle, die das Zitat bestätigt ${ }^{169}-$ doch stellt sich die quellenkritische Frage nach der Verallgemeinerbarkeit solcher singulären Aussagen im Kontext der bereits zuvor angesprochenen Diskurskonjunkturen.

Ferner ist im historiografischen Diskurs lange grosszügig ausgeblendet worden, dass bereits in fast jedem schweizerischen Dorf und selbst in vielen kleinsten Weilern bis zum Ende des 18. Jahrhunderts eine Schule stand und zahlreiche Regionen der vormodernen Schweiz an der Schwelle zum 19. Jahrhundert über gut funktionierende Schulstrukturen verfügten. ${ }^{170}$ Trotz des mangelnden Schulbesuchs der Kinder während der Schulzeit, oft überfüllten und unzweckmässig eingerichteten Schulstuben, einer meist rein religiös orientierten Grundbildung ohne Fokus auf Sinnverständnis sowie einer verbreiteten Wahrnehmung der Eltern, dass die Schulbildung ihrer Kinder im Angesicht der hohen Kindersterblichkeit als eine unproduktive Lebensperiode

165 Berner, Zeichen: 2f.; Messerli, Normen: 315.

166 Scandola, Standesschule: 621.

167 Schneider, bernische Landschule: 91; Vgl. zur Basler Landschaft ein ähnliches Resümee: Zingg, Basel: 30-65.

168 Böning, Traum: 224; Tuggener, Lehrer: 53ff.

169 „aber wie ist ein Lehrer bey uns in den augen vieler Elteren und kinder bey denselben angesehen, gewiß nicht viel mehr als ein Hirth der Schweinen, aber wie kommt es die Lehrer auf dem Land sind Meistens arme Leüthe, denn ein Bemidtleter und angesehener gehet nicht in die Schul, denn die meisten Einkünffte sind sehr gering, das ein Lehrer nicht Einmahl genugsamen unterhalt für seyn Weib und kinder hat.“ Schmidt u.a. (Hgg.), Stapfer-Enquête, Nr. 1406: Utzenstorf.

170 Bütikofer, Staat: $125 f$. 
mit unsicherer Investition zu betrachten war, wuchs paradoxerweise der Anteil an alphabetisierten Menschen in der Schweiz nach den Ergebnissen jüngerer Alphabetisierungsforschungen in der zweiten Hälfte des 18. Jahrhundert stark an. ${ }^{171}$ Am Ende des 18. Jahrhunderts konnten praktisch alle Schweizer Schulkinder mindestens lesen, wenn sie die Schule verliessen. ${ }^{172}$ Der Durchbruch der Alphabetisierung in der Schweizer Bevölkerung ist denn auch auf die zweite Hälfte des 18. Jahrhunderts vorzudatieren und erfolgte nicht erst auf den Beginn der Regeneration ab 1830. ${ }^{173}$ Dass die lokalen Schulmeister als zentrale Akteure der Bildungsvermittlung für diese enorme Leistung zumindest mitverantwortlich waren und die Schule so schlecht gar nicht sein konnte, wurde historiografisch jedoch noch weitgehend ausser Acht gelassen.

Die Elementarschullehrertätigkeit blieb trotz dieser strukturell belegbaren Erfolge im ausgehenden 18. Jahrhundert grundsätzlich in der historiografischen Betrachtung als eine ökonomische Prekariatstätigkeit eingestuft, die aufgrund der oftmals tiefen monetären Besoldung und der zahlreichen überlieferten Lohnklagen der Lehrer meistens von Angehörigen der gesellschaftlichen „Unterschichten“ mit kausal gefolgertem niedrigem sozialem Ansehen ausgeübt worden sei. ${ }^{174}$ Erst die neuesten Forschungsarbeiten aus dem Umfeld der Zürcher Landschulumfrage und der Stapfer-Enquête haben in Bezug auf die Lehrerschaft das hartnäckige historiografische Paradigma des grundsätzlich defizitären Elementarschullehrers stark in Frage gestellt und fallspezifisch auf grosse Disparitäten und temporale Entwicklungen innerhalb der Lehrerschaft hingewiesen, etwa bei den Einkommensverhältnissen oder beim sozialen Status der Lehrkräfte. ${ }^{175}$

Fünftens folgt die bildungsgeschichtliche Historiografie einer teleologischen Selbstperspektive, die von einem modernen Professionalisierungsverständnis mit einer bestimmten Vorstellung geprägt ist, wie ein Lehrer vor $1800 \mathrm{zu}$ sein hatte. Dadurch wurde der Lehrer zwangsläufig als defizitär beschrieben, da er „Eigenschaften, die im Laufe des 19. Jahrhunderts Teil der ,normalen' Lehrerbiografie werden, noch nicht hatte, gewisse Dinge noch nicht konnte oder noch nicht machte. ${ }^{\text {"176 }}$ Es erstaunt somit nicht, dass besonders die fachlichen Kenntnisse der Lehrer in der Retrospektive sehr häufig als völlig unzureichend erscheinen und entsprechend negativ beschrieben wurden. ${ }^{177}$

171 Scandola, Lehrerschaft: 7f.; Scandola, Standesschule: 586, 621; Messerli, Lesen: 28, 631-636; Von Wartburg-Ambühl, Alphabetisierung: 92; Bütikofer, Staat: 126.

172 Schmidt, Alphabetisierungsforschung: 166. Die pessimistische Einschätzung Rudolf Schendas auf der Basis von Untersuchungen zur Literaturdistribution, dass um 1800 bloss ca. 25\% der deutschen Bevölkerung alphabetisiert gewesen sei (Schenda, Buch), gilt mittlerweile für den gesamten deutschsprachigen Raum als überholt. Vgl. Hinrichs, Schreiben: 389.

173 Messerli, Normen: 314f. In vielen Teilen Deutschlands erfolgte der Ausbau des elementaren Schulwesens erst „weit in das 19. Jahrhundert hineinreichend“, durchzogen von einzelnen „Inseln mit bereits literalisierter Bevölkerung auch in der Weite des Landes“. Geissler, Schulgeschichte: 61. Für einige Regionen der Schweiz wiederum - etwa die Zürcher Landschaft - muss die flächendeckende Alphabetisierung noch früher datiert werden. Siehe dazu: Schmidt/Egger, Lektüre: 104, 126.

174 Siehe dazu etwa die Ausführungen von Landolt zu den Glarner Lehrkräften: „Die Schulmeister stammten fast alle aus dem gemeinen Volke. Sie waren meistens nicht ihrer schulischen Fähigkeiten wegen zum Schulmeister ernannt worden, sondern weil sie den Verdienst am notwendigsten brauchten [...] der Lehrer gehörte zu den Ärmsten der Gemeinde.“ Landolt, Linth: 153f. Vgl. zur postulierten Kausalität von geringem Einkommen und sozialem Stand: Brühwiler, Schwache Schulen: 119; Tuggener: Lehrer: 53-63.

175 Vgl. die Ausführungen im Kap. 1.3.2. Beispielhaft für die Dymanik in Sachen Einkommensverhältnisse sei auf den Aufsatz von Heinrich Richard Schmidt zu den Einkommensveränderungen der Lehrerschaft des Kapitels Bern zwischen 1780-1806 verwiesen: Schmidt, Kapitel Bern: 154.

176 Horlacher, Leutnant: 17.

177 Tosch, Professionalisierung: 245. 
Offen bleibt dabei, wie denn eigentlich eine „normale“ Lehrerbiografie vor 1800 ausgestaltet war, was es aus zeitgenössischer Perspektive hiess, Lehrer zu sein und was man dazu an konkreten Fertigkeiten mitbringen musste. Der Modernisierungs- und Professionalisierungsdiskurs in der jüngeren Forschungslandschaft zur historischen Pädagogik hat somit aktiv dazu beigetragen, dass der Blick auf die Lehrerschaft vor 1800 zunehmend unscharf geworden ist. Denn gemessen an den modernen Kriterien der Professionalisierung der Lehrerschaft, wie sie etwa Heinz-Elmar Tenorth skizziert hat, konnte die vormoderne Lehrerschaft zwangsläufig nur als maximal „semi-professionell“ oder bloss teilweise genügend erscheinen. ${ }^{178}$ Die Lehrpersonen der Frühen Neuzeit sollten daher nach Pierre Caspard nicht als „unfertige Präfigurationen“ der modernen Lehrkräfte und als Vorläufer des modernen Bildungswesens angeschaut werden, sondern vielmehr muss von den Bedürfnissen der vergangenen Epochen nach Elementarbildung ausgegangen und die Frage gestellt werden, an wen sich die Menschen wandten, um diese zu befriedigen. ${ }^{179}$

\subsection{Erkenntnisinteresse}

Der Lehrer des Ancien Régimes und der Helvetik ist trotz mannigfaltiger Erwähnungen in regionalen und lokalen Schulgeschichten für sich betrachtet ein noch wenig bekanntes Subjekt der frühneuzeitlichen Gesellschaft. Ausgehend von der Kritik der neueren Forschungsarbeiten an den mantraartig tradierten negativen Klischees des ungebildeten, armutsgeplagten und sozial verachteten Elementarschullehrers soll die vorliegende Studie durch eine Untersuchung des Berufs- und Sozialprofils mittels einer kollektiven Betrachtung von Lebensverläufen einen Beitrag dazu leisten, die Frage nach der Bedeutung der Lehrerschaft für das elementare Schulwesen um 1800 zu klären.

Besonders drei Themenkomplexe sind in Bezug auf die Stereotypisierung der vormodernen Elementarschullehrerschaft einer kritischen Untersuchung auszusetzen. Zum Ersten gilt es, die soziale Herkunft der Lehrerschaft empirisch genauer zu beleuchten. Hierbei ist zu untersuchen, wer überhaupt am Ende der Frühen Neuzeit Lehrer werden wollte und auch letztendlich zum Lehrer ernannt wurde. Daraus ergeben sich wiederum zwei Subfragestellungen, nämlich zum einen nach der gesellschaftlichen Rekrutierungsbasis der Lehrerschaft und zum anderen nach den intrinsischen und extrinsischen Motiven für das Interesse am Lehramt.

Zum Zweiten sind die eigentlichen berufsbiografischen Entwicklungspfade der Lehrerschaft noch weitgehend im Dunkeln liegend. Die bisherige Schulgeschichtsforschung hat sich aufgrund des Mangels an Biografien und der Statik von Momentaufnahmen aus breitflächigen Enquêten kaum für die vielfältigen Lebensgeschichten von frühneuzeitlichen Lehrpersonen interessiert. Untersucht werden sollen folglich die verschiedenen Formen von Lebensverläufen ${ }^{180}$

178 Tenorth, Professionen: 457f. Die Kritik am Professionalisierungsansatz zielt auf das von vornherein zwangsläufige Ergebnis der frühneuzeitlichen Lehrerschaft als eine "Semi-Profession“, da die vormodernen Lehrer die modernen Elemente einer Profession (Standardisierte Ausbildungsprozesse, eine starke Selbstidentifikation und Berufung, Elemente der Organisation respektive Institutionalisierung, einen ausgeprägten Gender-Habitus sowie der Anspruch auf Autonomie gegenüber der Gesellschaft bezüglich des produzierten „gesellschaftlichen Gutes“) noch gar nicht vollständig erfüllen konnten. Bloch Pfister, Priester: 13-22. Vgl. die Kritik bei Kuhlemann, der sich gegen eine Anwendung ausspricht und lieber von „Verberuflichung“ spricht. Kuhlemann, Modernisierung, S. 29f. Kritik auch bei: Keiner/Tenorth, Schulmänner: 201; Fuchs, Lehrerperspektiven: 187ff.; Crotti, Lehrerinnen: 39-44.

179 Caspard, Lehrer.

180 Unter dem Begriff des „Lebensverlaufs“ wird in dieser Arbeit nach der Definition von Mayer die Abfolge von Ereignissen und Aktivitäten in verschiedenen Lebensbereichen von der Geburt bis zum Tod verstanden. Der Lebensverlauf kennzeichnet damit die sozialstrukturelle Einbettung von Individuen im Verlauf ihrer Lebensgeschichte vornehmlich als Teilhabe an gesellschaftlichen Positionen. Ein wichtiger Aspekt von Lebensverläufen ist ihre zeitliche klar erkenn- 
der Elementarschullehrer in vergleichender Perspektive mit ihren kollektiven Gemeinsamkeiten, aber auch in ihren unterschiedlichen generationellen, geschlechtsspezifischen, regionalen und konfessionellen Ausprägungen. Es stellt sich hierbei die Frage, inwieweit die biografischen Entwicklungen der Lebensverläufe und die Handlungspraktiken der Lehrer als Resultate von einschränkenden Strukturfaktoren und von gesellschaftlichem Wandel oder als individuelle Entscheidungen zu verstehen sind und wie die Lebensverläufe um das gesellschaftliche Erwerbssystem und die Organisation von Schule herum durch die Lehrkräfte als Handlungsakteure ausgestaltet worden sind. Ferner interessiert, ob das Lehramt bloss eine lebenszyklisch bedingte Tätigkeit war, die nur vorübergehend oder in einem bestimmten Altersspektrum ausgeübt wurde. Während die normativen Leitplanken des frühneuzeitlichen elementaren Schulwesens und vor allem die grossen Projekte rund um die Lehrerschaft - insbesondere zur Lehrerbildung - von der bisherigen Schulgeschichtsschreibung gut erforscht sind, ist bislang wenig darüber bekannt, wie sich das Lehramt in biografischer Perspektive auf die Lebensverläufe der Lehrpersonen als individuelle Handlungsakteure auswirkte. Die Rolle des Handelns der Akteure, im angelsächsischen Sprachraum als „human agency“ betitelt, ist zu einem zentralen Thema der neuen Sozialgeschichte geworden, selbst wenn unter Berücksichtigung der Kritik am Ansatz zugleich nicht von völlig frei handelnden Subjekten ausgegangen werden darf, sondern von einem Amalgam aus individueller Aktion und struktureller Reaktion. ${ }^{181}$ Die Elementarschullehrerschaft bietet somit - als ein durch die spezifische Tätigkeitsausübung entstandenes soziales Gebilde - ein ideales „Fenster“ für akteurzentrierte und biografisch-sozialhistorische Fragen an die ansonsten weitgehend stumm gebliebene einfache Bevölkerung um 1800. Bewusst nicht eingegangen wird hingegen auf die pädagogische und didaktische Arbeit der Schulmeister vor Ort in den Schulstuben. Pädagogische und didaktische Einzelheiten, Methoden und deren Umsetzung sind nicht Teil der Untersuchung im engeren Sinne.

Zum Dritten soll die soziale Positionierung der Elementarschullehrer in Bezug auf ihren als prekär beschriebenen sozialen Status im Hierarchiegeflecht der lokalen ständischen Gesellschaft kritisch reflektiert werden. Dabei stehen Fragen nach Bewegungen in vertikaler Statuslinie nach sozialem Auf- und Abstieg - und geografisch-räumlichen Bewegungen durch berufsmobiles Verhalten, durch Einkommensveränderungen oder durch die Ausgestaltung der familiären Situation im Zentrum der Betrachtung. Dazu muss in beschränktem Masse auch nach der Fremdwahrnehmung der Elementarschullehrerschaft als Inhaber von sozialem Kapital gefragt werden, etwa durch die Betrachtung ihres sozialen Ansehens oder mittels Bewertungen der Fähigkeiten der Schulmeister im Umgang mit den elementaren Kulturtechniken des Lesens, Schreibens und Rechnens.

\subsection{Quellen}

Der Untersuchungszeitraum der vorliegenden Arbeit erstreckt sich trotz eines Schwerpunktes auf das Jahr 1799 sowohl auf das letzte Drittel des 18. Jahrhunderts als auch auf die ersten Jahre nach 1800 während der Helvetischen Republik. Dieses Zeitfenster um die Epochenschwelle des Jahres 1800 erweist sich nicht zuletzt aus Gründen der Quellenlage für die Erforschung

bare und sequenzierbare Binnenstruktur, wie z.B. die Verweildauer in bestimmten Zuständen sowie die Altersverteilung bei Übergangsereignissen. Mayer, Lebensverlauf: 446ff. Zur Begriffsabgrenzung von „Lebenslauf“, „Lebensgeschichte" und „Biografie" in den unterschiedlichen Theoriekonzepten der Geistes- und Sozialwissenschaften vgl. ferner die theoretischen Überlegungen bei: Alheit, Biographie-/Lebenslaufforschung: 89-93.

181 Vgl. Hareven, Familiengeschichte: 211. 
der vormodernen schweizerischen Lehrerschaft als besonders fruchtbar. So bietet bereits die vorrevolutionäre Zeit des ausgehenden Ancien Régime für schulgeschichtliche Fragestellungen zu einzelnen Regionen der Alten Eidgenossenschaft eine - wenn auch bloss fragmentarische günstige Quellenlage in Form von protostatistischen Umfragen über das Elementarschulwesen. Umfragen zur gezielten empirischen Informationsbeschaffung entwickelten sich im 18. Jahrhundert gleichermassen zu einem Herrschaftsinstrument des absolutistisch agierenden Obrigkeitsstaats im Sinne der "guten Policey “ ${ }^{182}$ und zur Stillung des Wissensdurstes von volksaufklärerisch gesinnten Eliten. Die Themenbreite reichte dabei von militärischen und wirtschaftlichen bis zu sozialen und naturräumlichen Bestandserhebungen. ${ }^{183}$ Geleitet wurden alle Umfragen vom Motiv der systematischen Problemerkennung und -bewältigung durch das Erheben und Auswerten von flächendeckenden Daten. ${ }^{184}$ Die Absicht zielte also darauf hin, aus einer aktuellen Situation oder Vorbedingung das mögliche zukünftige Verbesserungspotenzial auszuloten. Aufgrund ihres systematisch-empirischen Charakters sind diese Datenerhebungen der „politischen Arithmetik“ beziehungsweise der „Protostatistik“ zuzuordnen. ${ }^{185}$

Besonders in den flächengrössten Stadtrepubliken Zürich und Bern entstanden zahlreiche protostatistische Bestandeserhebungen nicht nur vonseiten der Obrigkeit ausgehend, sondern auch zunehmend aus der Feder von reformorientierten Gesellschaften, was aus obrigkeitlicher Sicht nicht unproblematisch war. ${ }^{186}$ Bereits im Jahr 1715 wurde eine bescheidene Schulumfrage über die Zürcher Landschulen erhoben. ${ }^{187}$ Davon ausgehend entstand im Zuge von volksaufklärerischen Reformversuchen der „Moralischen Gesellschaft“ ${ }^{188}$ die weitaus umfangreichere Zürcher Schulumfrage von 1771/1772, deren Antworten aus fast der gesamten Zürcher Landschaft und aus Teilen der von Zürich kontrollierten reformierten Gemeinden in der Gemeinen Herrschaft Thurgau überliefert sind. ${ }^{189}$ In Bezug auf die Schulmeister beleuchteten zwei Fragekomplexe mit elf detaillierten Einzelfragen zur Anstellung, Besoldung, Nebentätigkeiten und dem Charakter der Schulmeister gezielt die Person des Elementarschullehrers aus der Sicht der vorgesetzten Pfarrer. $^{190}$

Doch auch in Umfragen an die Geistlichen zum Stand der Glaubens- und Sittenzucht oder zum Zustand der Bevölkerung tauchten immer wieder schulpolitische Fragen auf, etwa in der Pfarrumfrage und Volkszählung des deutschsprachigen Berner Untertanengebiets von 1764. ${ }^{191}$

182 Holenstein, Gute Policey: 72-75.

183 Vgl. beispielhaft die Anzahl protostatistischer Erhebungen im Kanton Bern: Pfister, Strom: 44.

184 Pfister, Strom: 44; Holenstein, Gute Policey: 73.

185 Kellerhals-Maeder, Sternlein: 4-7. Für Andreas Kellerhals-Maeder gelten alle Arten von Erhebungen vor der Errichtung des statistischen Büros des Bundes im Jahr 1856 als Protostatistik.

186 Problematisch wurde das private Sammeln und Publizieren von protostatistischen Daten, wenn der Obrigkeitsstaat grundlegende „Staatsgeheimnisse“ verletzt sah. Dies wurde etwa dem reformaufklärerischen Pfarrer JeanLouis Muret zum Verhängnis, dessen Publikation zur schrumpfenden Bevölkerung der Waadt auf der Basis der 1764-Bevölkerungserhebung den Zorn der Berner Obrigkeit auf sich zog. Denn sinkende Bevölkerungszahlen galten als Zeichen von Misswirtschaft und Bevölkerungsstatistiken waren militärische Geheimsache. In Zürich wurde der Pfarrer Johann Heinrich Waser im Jahr 1780 sogar hingerichtet, weil er in statistischen Auswertungen „Staatsgeheimnisse“ verraten haben soll. Vgl. Pfister, Strom: $51 \mathrm{f}$.

187 Schmidt, Momentaufnahme: 99.

188 Zur Moralischen Gesellschaft vgl. Schwab, Wissen: 31-50.

189 Tröhler/Schwab (Hgg.), Volksschule im 18. Jahrhundert; Berner, Zeichen: $41 \mathrm{f}$.

190 Tröhler/Schwab (Hgg.), Volksschule im 18. Jahrhundert: 11-24.

191 StABE B III 204-208: [1764] - Pfarrberichte und Bevölkerungstabellen. Christian Pfister bezeichnet die mit der Umfrage einher gegangene Volkszählung gar als die „bedeutendste Erhebung des Schweizerischen Ancien Régime." Pfister, Strom: 46, 97. 
Aus der näheren Umgebung der Stadt Bern ist ferner aus dem Jahr 1780 eine regionale Umfrage zum Kirchen- und Schulwesen erhalten. Diese erlaubt ebenfalls einen differenzierten Einblick in die schulische Realität vor Ort. ${ }^{192}$ Mit zwei Fragestellungen wurden die Pfarrer des Berner Kapitels aufgefordert, explizit zu den Fähigkeiten, dem Fleiss und Lebenswandel sowie der Besoldung ihrer Lehrerschaft Stellung zu beziehen. Das systematische Erheben von Daten zum Schulwesen hatte somit bereits vor der Helvetischen Revolution und lange vor den heutigen modernen PISA-Studien eine gewisse Tradition. Heinrich Richard Schmidt hat dazu resümiert: „Empirische Bestandsaufnahmen von Schule sind keine Erfindung des späten 20. Jahrhunderts, sondern wurden mit standardisierten Fragebögen bereits im 18. Jahrhundert durchgeführt. ${ }^{193}$ Des Weiteren markierten der Franzoseneinfall und die Etablierung des helvetischen Zentralstaats ab 1798 eine klare politische und historische Zäsur, die das abrupte Ende des Ancien Régimes respektive der alten Eidgenossenschaft besiegelte und eine neue Ära der politischen staatsorganisatorischen Verhältnisse begründete. Die Quellenlage und die Quellenüberlieferung sind durch die neue zentralistische Verwaltungsorganisation und aufgrund der regelrecht explodierenden Verwaltungstätigkeit der helvetischen Behörden ausserordentlich dicht. Das zentralistische Staatsexperiment der Helvetischen Republik produzierte mit seinen zahlreichen neuen Verwaltungsinstanzen auf kantonaler, regionaler und lokaler Stufe nicht nur eine bisher unerreichte Fülle an Schriftlichkeit durch Korrespondenzen, Erhebungen, Befragungen, Berichten und Beschlüssen, sondern schuf erstmals in der gesamtstaatlichen Geschichte der Schweiz auch eine zentral organisierte Archivierung der anfallenden Schriftlichkeit. Dadurch wurde eine Vielzahl an Dokumenten - unter anderem zum elementaren Schulwesen - der Nachwelt überliefert.

Zudem eröffnete die politische Zäsur der Helvetischen Revolution durch das plötzliche und gewaltsame Ende des Ancien Régimes ein gewaltiges Experimentierfeld für neue Ideen der Aufklärung in allen Bereichen der Gesellschaft. Wie aus einem explodierenden Ventil schossen mannigfache Reformvorschläge zu allen Bereichen der Gesellschaft, deren Verwirklichung die beschränkten Strukturen des Ancien Régimes nicht erlaubt hatten, aus dem politischen Boden der Helvetischen Republik. Der Wissensdurst der volksaufklärerisch orientierten, am Aufbau eines „rationalen Staates “ interessierten politischen Führungspersönlichkeiten der Helvetischen Revolution sorgte für die Initiierung von zahlreichen landesweiten protostatistischen Umfragen auf der Basis von standardisierten Fragen. Das sollte den politischen Führern tiefe Einblicke in verschiedenste Bereiche der helvetischen Gesellschaft ermöglichen.

In der kurzen Phase der Helvetischen Republik von 1798 bis 1803 lancierte allein das Ministerium für Künste und Wissenschaften unter dem Minister Philipp Albert Stapfer mindestens sechs nationale Umfragen und gehörte damit zu den häufigsten Initianten von protostatistischen Erhebungen. ${ }^{194}$ Insbesondere in Bezug auf das Schulwesen und das gesellschaftliche Bild des Lehrers versuchte die junge Republik neue Impulse zu setzen, indem die Elementarschullehrer in Stapfers Gesetzesentwurf zum öffentlichen Schulwesen in den Status von öffentlichen Beamten erhoben werden sollten. ${ }^{195}$ Doch auch die subalternen neuen kantonalen Behörden standen den helvetischen Ministerien in ihrem Eifer teilweise in nichts nach und organisierten mitunter eigene protostatistische Umfragen. ${ }^{196}$ Diese zahlreichen, in kürzester Zeit angestosse-

192 StABE B III 209, o. Pag.: [1780] - Kapitel Bern; Siehe dazu die Auswertung bei: Schmidt, Kapitel Bern: 147-164.

193 Schmidt, Momentaufnahme: 98.

194 Holenstein, Reform: 19-23.

195 Tosato-Rigo, Bild: 56-64.

196 Vgl. die Ausführungen im folgenden Kap. 1.5.3. 
nen politischen Reformversuche liessen die kurze Phase der Helvetischen Republik trotz ihres späteren Scheiterns dennoch zu einer fundamentalen, unumkehrbaren Zeitenwende werden. Da der politische Umbruch aber gleichwohl noch jung war, bildeten die erhobenen Umfragen aus der kurzen zentralstaatlichen Verwaltungstätigkeit dennoch zuverlässig den Status des vorrevolutionären Schulwesens ab und erlauben heute primär einen Blick zurück auf das Ancien Régime des ausgehenden 18. Jahrhunderts.

\subsubsection{Die Stapfer-Enquête}

Der zentrale Quellenbestand für die vorliegende Studie stellt die im Februar 1799 lancierte nationale Schulumfrage des helvetischen Ministers für Künste und Wissenschaften, Philipp Albert Stapfer (1766-1840) ${ }^{197}$, die sogenannte „Stapfer-Enquête“ dar. ${ }^{198}$ Stapfer, vor der Revolution als reformierter Theologieprofessor aus dem Aargau an der Akademie von Bern tätig, wurde bereits kurz nach der Initialisierung der Helvetischen Republik am 2. Mai 1798 als erster Bildungsminister der neuen Republik gewählt und unterstand damit direkt der neugeschaffenen helvetischen Exekutive, dem Direktorium. ${ }^{199}$ Als reformierter Theologe gehörte Stapfer zu den progressiven, sich an Kants Moralphilosophie orientierenden, neuhumanistischen Geistlichen, deren Fokus auf der moralischen Erziehung der Bürger zu tugendsamer Sittlichkeit lag. ${ }^{200}$ Der Ort zur Verwirklichung dieser Ideale lag für Stapfer in der Elementarschule, die Aufgabe dazu fiel in seinen Augen jedoch nicht auf das Volk, sondern auf die geistig-moralisch Elite des Landes. ${ }^{201}$ Das Mittel sollte in einer grundlegenden Reform des Schulwesens „top-down“ von oben nach unten liegen, insbesondere in der Etablierung einer staatlich organisierten Lehrerbildung. Politisch stand Stapfer als reformaufgeklärter Vertreter des landstädtischen Bürgertums aus dem Berner Untertanengebiet den zentralistischen Unitariern nahe und suchte folglich die nationale Ebene als Entscheidungsfeld und als idealen Umsetzungsboden für seine Schulreformen. ${ }^{202}$ Die Fundamentalmodernisierung des Landes sollte jedoch nach den Massstäben der Vernunft auf einer modernen, rationalen Grundlage geschehen, wozu erst einmal eine empirische Dokumentation des Ist-Zustandes notwendig war. ${ }^{203}$

Im Bemühen um eine landesweite Reform des Elementarschulwesens und um sein Projekt eines nationalen Schulgesetzes mit empirischen „hard facts“ legitimieren zu können, organisierte Stapfer im Frühjahr 1799 folglich eine flächendeckende protostatistische Bestandsaufnahme des schweizerischen Schulwesens in Form einer Umfrage auf der Basis eines gedruckten Fragebogens. Daneben sollte ein nationales Erziehungsarchiv geschaffen werden, das ein Inventar an verfügbaren Ressourcen im Schulwesen abbilden sollte. ${ }^{204}$ Von dieser empirischen Datenbasis ausgehend, sollten im Anschluss die konkreten Reformen erfolgen, zumal der bereits im Ok-

197 Zur Person von Philipp Albert Stapfer sei auf die beiden umfangreichen Biografien von Rudolf Luginbühl und Adolf Rohr verwiesen: Luginbühl, Stapfer; Rohr, Stapfer. Zur geistesgeschichtlichen Verortung von Stapfers Denken siehe die Arbeit von Martin Bondeli (Bondeli, Kantianismus) sowie das Dissertationsprojekt von Lorenz Theilkäs an der Universität Bern.

198 Die Originaldokumente liegen grösstenteils im Bundesarchiv in Bern (BAR). Einzelne Doubletten liegen ferner in den Kantonsarchiven der Kantone Aargau, Fribourg und Tessin. Sämtliche bekannten Antworten auf die Umfrage sind editiert und online frei abrufbar unter der Website: www.stapferenquete.ch.

199 Ruloff, Schulbesuch: 22.

200 Vgl. Theilkäs, Idee: 232-240.

201 Tröhler, Lehrerbildung: 295.

202 Grunder, Enquête: 104.

203 Holenstein, Reform: 23.

204 Vgl. Tosato-Rigo/Savoy, Schulumfrageneifer: 118. 
tober 1798 vorgelegte Gesetzesentwurf für ein neues Schulgesetz bald in den von Uneinigkeit zerstrittenen politischen Räten der Helvetischen Republik feststeckte. Als inspirative Vorlage dienten Stapfer bei der Ausarbeitung seiner Enquête zum einen die Zürcher Umfrage von 1771/1772, zum anderen die projektierten oder bis zu diesem Zeitpunkt bereits durchgeführten regionalen Umfragen der neu gegründeten kantonalen Erziehungsräte, insbesondere aber die Umfrage des Erziehungsrats aus dem neu geschaffenen Kanton Aargau. ${ }^{205}$

Die Stapfer-Enquête umfasste inhaltlich insgesamt 54 Einzelfragen, unterteilt in vier Teilbereiche zum Schulwesen: die Lokalverhältnisse, den Unterricht, die Personalverhältnisse und die ökonomischen Verhältnisse. ${ }^{206}$ Während die Fragestellungen zum Unterricht mit bloss sechs Einzelfragen erstaunlich knapp gehalten waren, entfielen die meisten und präzisesten Teilfragen auf die ökonomischen Verhältnisse, doch auch die Person des Lehrers wurde mit acht Einzelfragen relativ breit erfasst. Das Ungleichgewicht der Fragestellungen zu den Teilbereichen des Schulwesens war freilich kein Zufall, denn Stapfer war sich sehr wohl der Zusammenhänge zwischen politisch-ökonomischen Zielen und ihrer pädagogischen Realisierung bewusst und war sich im Klaren darüber, dass schulinstitutionelle Reformen weniger von pädagogischen Wünschen als von den finanziellen Vorgaben und Möglichkeiten abhängig waren. ${ }^{207}$

Die Umfrage wurde in gedruckter Form in alle Landesteile der Helvetischen Republik verschickt. ${ }^{208}$ Von den erwarteten etwa 2.900 Antworten sind heute etwas mehr als 2.400 überliefert. ${ }^{209}$ Obwohl sich das helvetische Verwaltungsnetzwerk erst in der Aufbauphase befand, erreichten die meisten Fragebögen ihre Empfänger in einer erstaunlichen Geschwindigkeit. Stapfer selbst drängte seine subalternen Stellen dazu, dass die Fragen binnen 14 Tagen beantwortet wurden. ${ }^{210}$ Auf dem Fragebogen war zudem vermerkt, dass jedermann gebeten war, die Beantwortung und die Einsendung möglichst zu beschleunigen. ${ }^{211}$ Doch auch die neu gegründeten Erziehungsräte in den Kantonen hatten ein grosses Interesse an den Antworten der Schullehrer für ihre eigenen Reformpläne. Ebenso sahen sie die Umfrage bisweilen als einen Test für die Funktionsweise und die Durchsetzung ihrer neuen Autorität an, denn über die Distriktinspektoren sollte ein Doppel der Beantwortung zu den jeweiligen kantonalen Erziehungsbehörden gelangen. Tatsächlich verfehlte der Zeitdruck seine Wirkung nicht und die meisten der Antwortschreiben wurden innerhalb des gewünschten Zeitraums von bloss rund drei Wochen zwischen Februar und März 1799 verfasst. Wo die Implementierung der Helvetischen Republik allerdings auf grundlegenden politischen Widerstand gestossen war, insbesondere in der katholischen Zentralschweiz, blieb auch die Resonanz auf die Stapfer-Enquête bescheiden oder fiel gänzlich aus. Manche Schullehrer antworteten vermutlich als Zeichen des passiven Wider-

205 Büttner, Schreiben: 27f.; Tröhler, Relevanz: 8f. Die Beeinflussung Stapfers durch die Aargauer Umfrage vom Januar 1799 hat Ernst Jörin dokumentiert: Jörin, Aargau: 152.

206 Vgl. Anhang I.

207 Vgl. Grunder, Enquête: 100.

208 Den französischsprachigen Lehrkräften wurde ein normierter vierseitiger gedruckter Fragebogen inklusive Platz für die Antworten zugestellt, während die Deutschschweizer Lehrerschaft bloss die Fragen in gedruckter Form zugesandt bekamen. Der normierte Druck geht auf eine Anregung des Waadtländer Erziehungsrats zurück, der aus den Antworten ein Heft erstellen wollte. Vgl. Tosato-Rigo/Savoy, Schulumfrageneifer: 105. Zwischen den französischsprachigen und deutschen Fragen bestanden allerdings kleine editorische Differenzen. So waren etwa die Fragen III.11.b und III.11.c im französischen Fragebogen vertauscht. Für das italienischsprachige Tessin scheint dagegen kein entsprechender Fragebogen in italienischer Sprache gedruckt worden zu sein, wie die Korrespondenz des Regierungsstatthalters des Kantons Lugano mit Stapfer zeigt. Vgl. Fuchs, Lehrerperspektiven: 10.

209 Tröhler, Meilenstein: 7. Zu den Überlieferungslücken vgl. das folgende Kap. 1.5.2.

210 Die teilweise sehr kurz gehaltenen Fragen sollten zu einer raschen Beantwortung führen. Ruloff, Schulbesuch: $26 f$.

211 Vgl. die III. Anmerkung im Fragebogen im Anhang I. 
stands gegen die unbeliebte, als oktroyiert empfundene Zentralgewalt - wenn überhaupt - erst mehr als ein Jahr später auf die Fragen und das in sehr knapper Form. ${ }^{212}$

$\mathrm{Zu}$ einer gesamthaften Auswertung der Antworten kam es freilich trotz des raschen Rücklaufs nicht, denn das Ministerium von Stapfer verfügte nie über die personellen und ökonomischen Ressourcen, um die eingegangenen Antworten der Umfrage auswerten oder um nicht erhaltenen Antworten systematisch nachgehen zu können. ${ }^{213}$ Ebenso mangelte es den kantonalen Erziehungsbehörden, die ihre Tätigkeit in der Regel ehrenamtlich ausführten, an zeitlichen und personellen Ressourcen. Dennoch erstellten einzelne kantonale Erziehungsräte inhaltlich summarische Zusammenzüge aus den Antworten in Form von Übersichtstabellen, so genannten "Generaltabellen“.214 Der Erziehungsrat des Kantons Säntis ging gar soweit, die stapferschen Fragen ein Jahr später, im Jahr 1800, gleich noch einmal an alle Schullehrer zu versenden und erstellte daraus wiederum Tabellen zu den einzelnen Distrikten. ${ }^{215}$ In anderen Kantonen entstanden auch später in den Jahren 1801-1803 ähnliche gedruckte Generaltabellen auf der Basis von Stapfers Fragen. ${ }^{216}$

Mit der Menge an überlieferten Antworten bildet die Umfrage ein Quellenkorpus von einzigartigem Wert und Umfang für die schweizerische Schulgeschichts- und Bildungsforschung, dessen Bedeutung kaum überschätzt werden kann. Es liefert eine zeitliche Momentaufnahme und einen Querschnitt aller in der damaligen Schweiz vorhandenen Formen von Elementarschule. ${ }^{217}$ Die standardisierten Fragen der Enquête erlauben zudem eine vereinfachte systematische Analyse der erhaltenen Antworten. Die Reichweite und der Umfang der Befragung suchen in zeitgenössischen Vergleichen in der europäischen Dimension ihresgleichen. ${ }^{218}$ Höchstens die freilich über dreissig Jahre später erscheinende Primarschulumfrage des französischen Bildungsministers François Pierre Guillaume Guizot in Frankreich von 1833 war von vergleichbarer räumlicher und quantitativer Dimension. ${ }^{219}$ Bemerkenswert ist an der Stapfer-Enquête im Gegensatz zu ihren Vorläuferumfragen ferner der Umstand, dass sich die Umfrage zum Elementarschulwesen erstmals direkt an die Lehrkräfte wandte und somit einen Zugang zur Sichtweise der Schulmeister auf das Schulwesen ermöglicht. Waren sämtliche vorangegangenen Erhebungen zum elementaren Schulwesen stets an die Geistlichkeit adressiert, von der eine

212 Die Antwort aus Obbürgen NW wurde beispielsweise am „10ten 9vbr 1800“ [10. November 1800], also erst eineinhalb Jahre nach dem Versand der Fragebögen, verfasst. Schmidt u.a. (Hgg.), Stapfer-Enquête, Nr. 1630: Obbürgen. Vgl. auch Fuchs, Lehrerperspektiven: 137.

213 In sämtlichen sechs helvetischen Ministerien arbeiteten insgesamt nicht mehr als 120 Personen. Gegenüber dem Ancien Régime erschien der helvetische Verwaltungsapparat zwar als aufgebläht, in absoluten Zahlen war er jedoch nur sehr bescheiden ausgestattet. Böning, Traum: 182.

214 Die Anregung zum Erstellen der Generaltabellen ging aus Stapfers Instruktionen an die Erziehungsräte hervor, worin die Herstellung von zusammenfassenden Berichten über den Zustand des Schulwesens verlangt wurde. Tosato-Rigo/Savoy, Schulumfrageneifer: 104f.

215 StASG HA R 132, Fasz. 1-8, o. Pag.: [1800] - Antwortbögen. Im Gegensatz zur Stapfer-Enquête liefert die St. Galler Umfrage von 1800 Antworten zu den 1799 fehlenden Distrikten, etwa zu Rorschach und Wil. An einzelnen Orten beschwerten sich jedoch die Lehrkräfte über die erneute identische Befragung, dass sie die Umfrage ja „vor einem Jahre schon beantwortet“ hätten. StASG HA R 132, Fasz. 8, o. Pag.: [1800] - Lütisburg.

216 Für den Kanton Linth existiert eine gedruckte Generaltabelle von 1801: StASG HA R 132, Fasz. 1, o. Pag.: [1801] - Kanton Linth. Für den Kanton Baden existiert eine Tabelle vom Jahr 1802: StASG HA R 132, Fasz. 1, o. Pag.: [1802] - Kanton Baden.

217 Schmidt, Momentaufnahme: 98.

218 Vgl. Fuchs, Lehrerperspektiven: 10.

219 Guizot war ab 1807 Hauslehrer bei Philipp Albert Stapfer, wo er mit der Idee einer SchulumFrage in Berührung gekommen sein dürfte. Luginbühl, Stapfer: 436f. Die Umfrage mit ihren Antworten ist online abrufbar unter: http://www.inrp.fr/she/guizot. 
naturgemäss hohe Sachkompetenz in Bildungs- und Erziehungsfragen erwartet wurde, überschritt die Stapfer-Enquête in ihrer Hinwendung zur Lehrerschaft bewusst erstmals die alten ständischen Grenzen. ${ }^{220}$ Insofern stellte bereits der Verwaltungsakt der Umfragelancierung im Sinne des rational-aufgeklärten neuen Bürgerstaates einen gewollten Bruch mit den ständischen Traditionen dar. Zugleich sandte die neue politische Führung mit der Umfrage ein starkes Zeichen der angestrebten Emanzipation an die Lehrerschaft aus, das unter den Lehrpersonen viele Hoffnungen und zugleich auch neue Begehrlichkeiten weckte.

Die Beantwortung der Umfrage durch die Lehrkräfte an der Stelle der Pfarrer erlaubt des Weiteren, einen Blick aus der Nähe auf das Schulgeschehen vor Ort zu werfen, den summarische und weitaus distanziertere Berichte von Pfarrern oder Schulvisitatoren nicht wiederzugeben vermögen. Selbst wenn dieser Blick auf die scheinbar vorliegende „Schulrealität“ ebenfalls von subjektiven Empfindungen, interessegeleiteten Betrachtungen oder gar taktischen Erwägungen vonseiten der Lehrer geleitet war, wie Andrea De Vincenti jüngst kritisiert hat, verschafft die Stapfer-Enquête dennoch eine neue - wenn auch wiederum gefilterte - Perspektive auf das Schulwesen. ${ }^{221}$

Ein Novum bestand zudem in der explizit am Ende des Fragebogens notierten Aufforderung an die Lehrkräfte, eigene Schlussbemerkungen festzuhalten. ${ }^{222}$ Damit schuf Stapfer ein Gefäss zur freien Äusserung von persönlichen Befindlichkeiten, Problemen und Themen, die den Lehrpersonen besonders erwähnenswert erschienen. Diese persönlichen Kommentare konnten die vorher gemachten Antworten präzisieren oder relativieren, neue Themenfelder ansprechen und die allgemeine Stimmungslage der Lehrerschaft einfangen. Von der Möglichkeit der freien Meinungsäusserung wurde denn auch rege Gebrauch gemacht, rund 18.6\% aller Lehrer liessen ihren Antworten eine freiwillige Anmerkung folgen. ${ }^{223}$ Hier, aber auch andernorts in der Beantwortung, wo die Lehrer nicht befragte Dinge oder weitere freiwillig platzierte Informationen preisgaben, steckt ein besonders grosses Potenzial zur Erkundung der Geistes- und Lebenswelt der Lehrkräfte.

Für die Geschichtswissenschaften und die historische Pädagogik ist die Stapfer-Enquête aus zahlreichen Gründen eine Fundgrube von unschätzbarem Wert geworden. Durch die Standardisierung der Fragebögen wird „ein exakter Vergleich von kulturell, konfessionell, politisch, sprachlich, gesellschafts- und wirtschaftsgeschichtlich unterschiedlichen staatlichen Organisationen von Schule und Unterricht möglich. ${ }^{224}$ Die Antworten lassen sich aufgrund der standardisierten Fragestellungen einfach mit quantitativen Methoden auswerten, was nun durch die abgeschlossene Edition sämtlicher Quellen möglich ist. Das gilt insbesondere in Bezug auf die Fragen zu den Personalverhältnissen der Lehrerschaft. ${ }^{225}$ Die rund 2.400 Antworten erlauben somit Rückschlüsse zur Person jedes Lehrers, zu den Vortätigkeiten, der Vorbildung, zum Familienstand, zu den Nebenbeschäftigungen und liefern Fragmente zur biografischen Entwicklung der einzelnen Personen. Die Antworten der

220 Eine Ausnahme stellt die fast zeitgleich mit der Stapfer-Enquête projektierte Berner Schulumfrage vom Januar 1799 dar, die sich ebenfalls direkt an die Lehrpersonen gewandt hätte. Sie wurde aber angesichts der nationalen Umfrage nicht ausgeführt. Ihre Fragen an die Lehrerschaft waren aber im Vergleich zur Stapfer-Enquête von ungleich persönlicherer Natur, etwa Fragen nach dem Wohlergehen der Lehrer, nach Wünschen an den Erziehungsrat, ob die Ehefrau zur Entlastung mitarbeite und wer die Schule im Krankheitsfall führe. StABE B III 903, o. Pag.: 02.01.1799 - Erziehungs-Rath.

221 De Vincenti, Wissensordnungen: 53f.; Grube, Wissensproduktion: 181f.

222 Vgl. Anhang I.

223 Fuchs, Lehrerperspektiven: 13. Die Dissertation von Markus Fuchs hat sich ebendiesen zusätzlichen Äusserungen in qualitativer Herangehensweise gewidmet.

224 Schmidt, Momentaufnahme: 98.

225 Vgl. Anhang I. 
helvetischen Lehrer auf diese acht Fragen zu den Personalverhältnissen bilden denn auch das zentrale Quellenkorpus und die Ausgangslage für die vorliegende Untersuchung.

Diese ausserordentlich grosse Menge an zeitgleich befragten Personen ist an sich für frühneuzeitliche Erhebungen von einzigartigem Charakter und stellt eine immense Fülle von biografischen Daten über Lehrpersonen zur Verfügung. Die Stapfer-Enquête stellt damit eine „funktionale“ autobiografische Quellensammlung von sehr hoher Homogenität und Selektivität hinsichtlich des erhobenen Personenkreises dar, wenngleich die Erkenntnisabsicht der Quelle nicht primär autobiografisch fokussiert war, die autobiografischen Daten zwar bewusst erhoben, aber nicht unter dem Aspekt einer biografischen Sammlung entstanden sind. ${ }^{226}$ Zentrales Inklusionskriterium für die Kollektivbildung war die eindeutige Identifizierbarkeit der in der Stapfer-Enquête vermerkten Lehrkräfte. Von der Untersuchung ausgeschlossen wurden somit sämtliche Lehrkräfte, deren Namen nicht eindeutig identifizierbar waren, um die Nachvollziehbarkeit durch eine eindeutige Zuordnung zu gewährleisten und um allfällige Missverständnisse durch ähnlich lautende Namensgebungen, insbesondere zwischen Vätern und Söhnen, auszuschliessen. Mit rund einem Dutzend Ausschlussfälle aufgrund von fehlenden Identifikationsmöglichkeiten liegt die Ausschlussquote jedoch bei bloss rund einem halben Prozent, bezogen auf das Gesamtkollektiv. Unter dem Kriterium der eindeutigen personellen Identifizierbarkeit durch den Namen lassen sich insgesamt mindestens 2.305 namentlich bekannte Lehrpersonen des Elementarschulwesens zweifelsfrei identifizieren.

\subsubsection{Quellenkritik}

Trotz ihres beeindruckenden quantitativen Umfangs und ihrer hohen bildungsgeschichtlichen Relevanz begleitet die Stapfer-Enquête eine Reihe von inneren und äusseren Einschränkungen, die es bei der Bearbeitung des Quellenbestands kritisch zu berücksichtigen gilt. Die stapfersche Umfrage selbst ist in ihrem überlieferten Rücklauf nicht vollständig erhalten oder wurde teilweise gar nicht erst flächendeckend vollständig beantwortet. Die gesamthafte Rücklaufquote wird zwar auf rund $83 \%$ geschätzt, was in zeitgenössischen Vergleichen einen ausserordentlich hohen Rücklauf bedeutet, dennoch darf das Quellenkorpus nicht als vollständig angesehen werden. ${ }^{27}$

Die Landesgrenzen der Helvetischen Republik vom Februar 1799 schränkten ferner die Distribution der Umfrage ein, so dass aus einigen Regionen der modernen Schweiz keine Antworten vorliegen. ${ }^{228}$ Grössere territoriale Lücken innerhalb des helvetischen Staatsbereichs kennzeichnen ferner den Rücklauf. Es fehlen etwa die Antworten des gesamten Kantons Luzern aufgrund eines zeitgenössischen „organisatorischen Malheurs“ bis auf eine Ausnahme fast vollständig. ${ }^{229}$ Ebenso sind die Antworten aus den beiden Tessiner Kantonen Bellinzona und Lugano bis auf drei kurzsummarische Berichte fast komplett verschollen, obwohl die Umfrage durchgeführt wurde. ${ }^{230}$ Im Kanton Fribourg verhinderten politische Unruhen im deutschsprachigen Sensebe-

226 Vgl. zur kritischen Quellenreflexion biografischer Quellen: Schröder, Kollektivbiographie: $145 \mathrm{f}$.

227 Tröhler, Meilenstein: 8.

228 Die heutigen Kantone Genf, Graubünden, Neuenburg und Jura sowie die bis 1798 ehemals zugewandten Orte Biel und Mülhausen FR gehörten im Jahr 1799 nicht zur Helvetischen Republik, ebenso wenig wie das damals vorderösterreichische Fricktal. Entsprechend liegen aus diesen Regionen und Orten keine Antworten auf die Stapfer-Enquête vor.

229 Einzig der Antwortbogen der Schule Hochdorf LU ist vom Kanton Luzern überliefert. Schmidt u.a. (Hgg.), Stapfer-Enquête, Nr. 2509: Hochdorf. Alle übrigen Antworten des Kantons gingen vermutlich durch eine archivalische Unachtsamkeit im Jahr 1800 verloren. Vgl. Fuchs, Grenzen: 122-128.

230 Dass die Stapfer-Enquête im Tessin nicht nur angekündigt, sondern wirklich durchgeführt wurde, belegen drei Schriften von Agenten aus dem Tessiner Staatsarchiv: Sant'Antonino, Isone und Preonzo. Schmidt u.a. (Hgg.), Stapfer-Enquête, Nr. 2525: Sant'Antonino; Nr. 2526: Isone; Nr. 2527: Preonzo; vgl. auch: Casagrande, Ticino: 
zirk im April 1799 die Beantwortung, zahlreiche weitere Antworten aus dem französischsprachigen Kantonsteil gingen ferner aufgrund ungeklärter Zuständigkeiten innerhalb der neuen helvetischen Bürokratie verloren. ${ }^{231}$ Ähnliche Gründe - Revolten gegen die neue Verfassung, passiver Widerstand der katholischen Geistlichen, eine unklare Bürokratie oder spätere Archivierungsfehler - sind des Weiteren für das Fehlen der Antworten aus der katholischen Zentralschweiz, dem deutschsprachigen Oberwallis und etlicher französischsprachiger Gemeinden des Unterwallis zu vermuten. ${ }^{232}$ Auch aus den neugeschaffenen Kantonen Baden, Säntis, Waadt sowie aus der Berner Landschaft fehlen etliche Antworten aus ganzen Distrikten aus ungeklärten Gründen, vermutlich ebenfalls aufgrund archivalischer Verluste. ${ }^{233}$

Im Aargauer Distrikt Kulm überlagerte sich die Stapfer-Enquête zeitlich mit einer regionalen Schulumfrage der neu geschaffenen kantonalen Schulbehörde, was für grosse Verwirrung sorgte und die Lehrkräfte abhielt, zusätzlich die Stapfer-Enquête auszufüllen. ${ }^{234}$ Zudem erreichten Stapfers Fragen einige Schulen aus Mangel an vorgedruckten Fragebögen gar nicht erst. So beschwerte sich der Unterstatthalter des Unterwalliser Distrikts Sembrancher am 09. März 1799 in einem Brief an seinen Vorgesetzten über zu wenige erhaltene Fragebögen und über den ungünstigen Zeitpunkt der Umfrage: „J'ai l'honneur de vous accuser la réception des 8 exemplaires imprimés de questions adressés aux Instituteurs pour connoître l'Etat des Ecoles, que vous m'avez envoyés par votre lettre du $2^{\mathrm{e}}$ courant. [...] Ce nombre est absolument insuffisant pour mon District qui n'est à la vérité que de six communes, mais dont trois sont grandes Bagnes, Orsieres et Liddes où il y a au moins 18 Régens entre les trois, et je n'ai pu en remettre qu'un par commune excepté à Bagnes que j’en ai envoyé deux. Pour obtenir des reponses précises et cathégoriques, il en faut un par comune. [...] Je dois encore vous prévenir, que malgré l'activité que j’ai recommandé à mes agens pour ces réponses, je ne les recevrai probablement en partie, que tard, mes agens et leurs aides s'abstenant tous dans ce moment, excepté celui de St. Pierre, pour travailler leurs vignes jusqu’à Pâques, vû que la majeur partie des Régens ne sauroient repondre à ces questions sans être assisté $[s]$ des agens, ou de leurs aides ; absence qui rend encore la publication des Loix inutile et impossible en Entremons jusqu’à Pâques ; je dis inutile, parce que tous les habitans, excepté les vieillards et infirmes, sont aussi au travail de leurs vignes à Martigny et Fully durant cet intervalle. Je crains même que cette absence des agens ne retarde le recensement approximatif des chevaux que vous m’avez demandé. 235

Insbesondere der Hinweis auf den ungünstigen Zeitpunkt der Beantwortung ist in zweierlei Hinsicht wichtig: Erstens fanden zum Zeitpunkt der Verteilung der UmFrage Im Frühjahr 1799 mancherorts wichtige landwirtschaftliche Tätigkeiten statt, etwa das Zurückschneiden der Re-

391. Sie enthalten jedoch keine detaillierten Angaben zu den Lehrpersonen, weshalb sie in der folgenden Untersuchung nicht miteinbezogen wurden. Über den Verbleib der übrigen Stapfer-Antworten ist nichts bekannt. Vermutlich gelangten aber nicht genügend in italienischer Sprache gedruckte Fragebögen in die beiden Kantone, wie Markus Fuchs vermutet hat (siehe Fuchs, Lehrerperspektiven: 10).

231 Tosato-Rigo/Savoy, Schulumfrageneifer: 106f.; Scherwey, Freiburg: 26-30. „Ces feuilles s'égarèrent malheureusement dans les multiples bureaux qu'elles avaient à traverser et beaucoup ne purent être retrouvées." Dévaud, École primaire: 5.

232 Boucard, valaisanne: 167, 195-198; Fuchs, Lehrerperspektiven: 137.

233 Aus dem Kanton Bern fehlen die Antworten der Distrikte Aarberg, Schwarzenburg, Steffisburg und Zollikofen komplett. Vom Kanton Baden sind die Antworten der Distrikte Muri und Sarmensdorf zu grossen Teilen als vermisst zu deklarieren. Ferner sind die Antworten der Distrikte Rorschach und Wil aus dem Kanton Säntis ebenso verschollen wie jene des Distrikts Grandson aus dem Kanton Waadt.

234 Die summarische Antwort liegt ebenfalls im Bundesarchiv: BAR B0 1000/1483, Nr. 1423, fol. 220-226: 30.03.1799 - Kulm. Der gesamte Fragebogen ist abgedruckt bei: Büttner, Schreiben: 30-36.

235 AEVS, H 4.65, o. Pag.: 09.03.1799 - Sous-préfet. Die eingegangenen Antworten des Distrikts Sembrancher wurden schliesslich am 10. November 1799 an Stapfer nach Luzern versandt. Vgl. auch: Boucard, valaisanne: $195 \mathrm{ff}$. 
ben in Weinbaugebieten, was etliche Verzögerungen in der Beantwortung erklärt. Zweitens überschnitt sich die Beantwortungsphase der Enquête im Osten der Helvetischen Republik mit den anbahnenden Militäroperationen im Zuge des Zweiten Koalitionskriegs. Da sich die französischen Armeen direkt aus den von ihnen besetzten Gebieten ernährten, oftmals in den Schulhäusern Quartier bezogen und wertvolle Sachgüter requirierten, litt das elementare Schulwesen als Teil der kommunalen Aufgabenposten in besonderem Masse. Unter diesen Umständen hatte die Beantwortung einer Umfrage eines schwachen, nur halbherzig unterstützten Staatswesens wenig Vorrang, so lange es galt, die unmittelbare materielle Not in den Aufmarsch- und Kriegsgebieten zu lindern und das eigene Überleben zu sichern.

Wiederum an anderen Orten mit scheinbar flächendeckender Erhebung scheint die Enquête einzelne Schuleinrichtungen schlicht nicht erreicht zu haben, während sämtliche Nachbarschulen befragt wurden. ${ }^{236}$ Insbesondere aber Privat- und Hausschulen ohne obrigkeitliche Legitimation wurden kaum von der Umfrage erreicht, was sich im weitgehenden Fehlen von entsprechenden Antworten manifestiert. ${ }^{237}$ Die gravierendste Folge der regional unterschiedlichen Rückläufigkeit der Antworten ist jedoch ein starkes Ungleichgewicht zwischen der konfessionellen Herkunft der Antworten, was konfessionsspezifische Fragestellungen vonseiten der Forschung erschwert, da sich die Lücken vorwiegend auf die katholischen Regionen der Schweiz konzentrieren. Die katholischen Schulen und damit auch die katholische Lehrerschaft sind somit im Direktvergleich in relativer Hinsicht stark unterrepräsentiert. ${ }^{238}$

Eine weitere, vierfach gelagerte Problematik für eine quantitative Erforschung der Enquête liegt im Fragebogen selbst verborgen. Zum Ersten sind einzelne Fragen relativ offen formuliert, wodurch ein erheblicher Interpretationsspielraum bei der Beantwortung entstanden ist, was eine systematische quantitative Auswertung der Antworten erschwert. Beispielhaft sei die Frage III.1 1.f: „Wie lang ist er Schullehrer?" genannt. Nicht wenige Lehrkräfte bezogen die Fragestellung nicht auf die Gesamtdauer ihres Unterrichtens, sondern bloss auf die Dauer der letzten Anstellung. Zum Zweiten provozierten die zahlreichen Doppelfragestellungen, beispielsweise die Frage III.11.g „Wo ist er vorher gewesen? Was hatte er vorher für einen Beruf ?" zahlreiche mehrdeutige, unvollständige oder für quantitative Auswertungen nicht eindeutig interpretierbare Beantwortungen. Die freien Schlussbemerkungen am Ende des Fragebogens verleiteten zum Dritten zahlreiche Lehrkräfte dazu, relevante Informationen zu einzelnen Fragen in die Schlussbemerkungen zu verlagern, wodurch die Antworten bisweilen aus dem Blickfeld der systematischen Datenerhebung fallen. Viertens beantworteten etliche Lehrkräfte vor allem aus der Deutschschweiz die Fragen aus Mangel an einem vorgedruckten Antwortbogen nicht in der vorgegebenen standardisierten Form, sondern in Form von freien Fliesstexten. Dabei wird nicht nur die Zuordnung einzelner Aussagen auf Einzelfragen in der Retrospektive schwierig, sondern

236 Es fehlen etwa die Antworten aus den Stadtschulen von Aarau, obwohl die Antworten aus den umliegenden Dörfern eingegangen sind. Ein Abgleich von benachbarten Schulnennungen aus der Frage I.4.a hat ferner einzelne Schulen identifizieren lassen, deren Überlieferung in der Stapfer-Enquête fehlt. Beispielhaft ist die Schule Sennwald SG im Rheintal genannt, die in den Antworten von Salez SG, Frümsen SG und Lienz SG als benachbarte Schule genannt wurde, wovon aber kein Antwortbogen überliefert ist. Schmidt u.a. (Hgg.), Stapfer-Enquête, Nr. 402: Lienz; Nr. 421: Frümsen; Nr. 422: Salez.

237 Eine der seltenen Beantwortungen eines Privatschullehrers ist aus dem Flecken Herisau AR überliefert. Schmidt u.a. (Hgg.), Stapfer-Enquête, Nr. 1174: Herisau. Privatschulen und Privatunterricht waren jedoch kein ausschliesslich städtisches Phänomen, sondern auch auf dem Land existierten weit verbreitet Privatschulen. So sind beispielsweise gleich zwei Privatschullehrer in Trogen AR vermerkt worden. Schmidt u.a. (Hgg.), Stapfer-Enquête, Nr. 502: Trogen, Bernbrugg.

238 Vgl. das folgende Kap. 1.6.2. 
es ergeben sich zudem zahlreiche nicht beantwortete Fragebereiche durch bewusste oder unbewusste Auslassungen. Entsprechend darf bei Resultaten aus quantitativen Erhebungen nie von einer absoluten Vollständigkeit der Daten ausgegangen werden.

Des Weiteren implizierten viele Fragen eine für die beantwortenden Lehrkräfte durchschaubare deutliche inhaltliche Erwartungshaltung, was denn „korrekt“ geantwortet werden sollte. Bisweilen werden hinter den Fragen im Fragebogen die Grundgedanken von Stapfers reformaufklärerischem Denken mit seinen deutlichen Ressentiments gegenüber dem Elementarschulwesen und seinen selektiven Erkenntnisinteressen offensichtlich. Dass die Schule des Ancien Régimes keine erfreulichen Leistungen erbrachte, schien für Stapfer wohl festzustehen. ${ }^{239} \mathrm{Ne}-$ gativ konnotierte Frageformulierungen, wie die Frage II.6: „Werden die Schulen nur im Winter gehalten? Wie lange? [Hervorhebung M.R.]“, weisen auf den Umstand hin, dass Stapfer durch die Antworten der Enquête wohl im Sinne einer Defizithypothese gezielt nach Missständen suchte, um die Notwendigkeit seiner angestrebten Reformtätigkeiten bestätigt zu sehen. ${ }^{240}$ Die implizierte Erwartungshaltung hinter den Fragen hat so aber vermutlich den Beantwortungshorizont vordeterminiert.

Im Gegensatz zu den wesentlich offener formulierten Personalfragen der zeitgleich lancierten Pfarrer-Enquête erhält man aus der Stapfer-Enquête einen weniger tiefen Einblick in die konkreten Lebensverläufe und Lebensumstände der Lehrer, ungeachtet des individuell unterschiedlich ausgeprägten Mitteilungsbedürfnisses. ${ }^{241}$ An einem umfassenden personellen Portrait der Lehrerschaft zeigte Stapfer insgesamt wenig Interesse, denn andere mögliche Fragefelder - etwa die Ausbildungswege, die Freizeitbeschäftigungen oder der aktuelle Gesundheitszustand - wie sie zeitgleich der Geistlichkeit in der Pfarr-Enquête gestellt wurden, fehlten in der Schulenquête. Zudem formulierten kantonale Erziehungsräte teilweise deutlich präzisere und persönlichere Fragen an die Person des Lehrers in ihren eigenen Schulbefragungsprojekten, von denen Stapfer mit Sicherheit Kenntnis hatte.

Es stellt sich ferner die Frage nach dem Wahrheitsgehalt und der Authentizität der Antworten, zumal die Fragen von einer neuen, noch wenig etablierten zentralstaatlichen Behörde ausgingen, deren Legitimität keineswegs unumstritten war. Wie Ingrid Brühwiler jedoch anhand der Einkommensdaten darlegt, entsprachen zumindest die gemachten Angaben zu den ökonomischen Verhältnissen in der Enquête grundsätzlich der Wahrheit. ${ }^{242}$ Aufgrund der Beantwortungspflicht im Doppel sowie des bekanntgegebenen Durchlaufs der Antwortschriften über die Agenten nach oben in die helvetische Bürokratie stellte sich eine Selbstdisziplinierung für die Beantwortenden durch die Verwaltungshierarchie ein. Den Lehrkräften war bewusst, dass ihre Antworten von vorgesetzten Stellen gegengelesen wurden. In der Tat brachten Pfarrer oder lokale Agenten in den Antwortschriften bisweilen nachträgliche Bemerkungen in ergänzender oder korrektiver Weise an. Es gibt somit keinen Grund, den von den Lehrpersonen festgehaltenen inhaltlichen Angaben zu misstrauen oder diese als potenzielle Lügen in Frage zu stellen. Vielmehr sind aber sowohl unabsichtlich nicht festgehaltene als auch bewusst selektierte Informationen zur persönlichen Biografie mitunter keine Seltenheit. Gerade in Bezug auf die biografischen Angaben muss folglich mit Lücken und bewussten Auslassungen gerechnet werden,

239 Schmidt, Volksbildung: 31.

240 Grunder, Enquête: 108.

241 Nach Leonhard Haas war der Umstand der weitaus ausführlicheren Angaben der Geistlichen zu den Lebensumständen auf deren ,angesehene Stellung“ und ihre ausgeprägte „Gesprächigkeit“ zurückzuführen. Vgl. Haas, Innerschweiz: 513.

242 Vgl. Brühwiler, Finanzierung: 307. 
deren Rekonstruktion beziehungsweise Kontrolle über Drittquellen den Rahmen der vorliegenden Arbeit gesprengt hätte. Zudem beeinflusste der Zeitgeist natürlich auch die Selbstwahrnehmung der Lehrkräfte, was sich wiederum in den biografischen Beschreibungen niederschlug, indem sie versuchten, ihre eigene Perspektive nachvollziehbar, glaubwürdig und gerechtfertigt darzustellen. ${ }^{243}$ Die Stapfer-Enquête darf daher nicht in naiver Betrachtung als ein direktes Abbild der historischen Realität gelesen und verstanden werden, wie kritische Stimmen aus der Autobiografieforschung zu Recht vor der unüberlegten Verwendung von Autobiografiedaten warnen. $^{244}$

Ferner findet sich zwar in der Stapfer-Enquête in den meisten Fällen die Perspektive der Lehrkräfte selbst, doch taugt die Umfrage beispielsweise kaum, um empirisch auf das politische Denken der Lehrer rückzuschliessen oder gar um handfeste Kritik am politischen System der Helvetischen Republik festzumachen. Den Lehrkräften war sowohl der Urheber der Enquête als auch der Dienstweg der Antwortschreiben durch die Verwaltungsebenen trotz der zahlreichen organisatorischen Neuerungen bekannt. Bei kritischen Äusserungen hätten die Betroffenen mit eher nachteiligen Auswirkungen rechnen müssen. ${ }^{245}$ Kaum verwunderlich dominiert in zahlreichen Antworten eine positiv-bestätigende Rhetorik gegenüber der neuen Regierung und ist eine unterwürfig anmutende Beflissenheit, sich den neuen politischen Spielregeln zu unterordnen, feststellbar. Rückschlüsse auf die tatsächliche politische Einstellung der Lehrerschaft gegenüber der revolutionären Regierung sind auf der Basis der Textanalyse daher nur sehr bedingt möglich. ${ }^{246}$ Zudem ist die Urheberschaft der Antwortschreiben nicht in jedem Fall auf die unterzeichnende Person zurückzuführen, die UmFrage Ist demnach keine reine Ego-Quelle der Lehrerschaft. In einzelnen Fällen hatten die Dorfpfarrer oder die lokalen Agenten von sich aus oder im Auftrag ihrer Lehrer die Umfrage ausgefüllt. In etlichen grösseren Kirchspielen fanden sich ferner inhaltlich weitgehend identisch formulierte Antwortschreiben, die ein zuvor abgesprochenes gemeinsames Formulieren der Schriften vermuten lassen. ${ }^{247}$ Es bleibt dabei unklar, ob der lokale Pfarrer, der Agent oder die Lehrer gemeinsam die Texte vorentworfen hatten. Diese direkte oder indirekte Fremddiktion muss aber nicht per se als ein Problem aufgefasst werden, denn die subjektive Sichtweise geht zum einen auch durch die Fremddiktion nicht verloren, zum anderen erzeugte die formale Standardisierung eben gar keine freie Redebasis, die dadurch hätte verloren gehen können. ${ }^{248}$

\subsubsection{Weitere Schulumfragen und Quellen}

Stapfers Enquête stellte während der kurzen Existenzdauer der Helvetischen Republik von 1798 bis 1803 zwar die umfangreichste, nicht aber die einzige flächendeckende und serielle Erhebung von Daten zum helvetischen Schulwesen dar. Im Schatten von Stapfers nationalem Erziehungsministerium planten, projektierten und führten auch einzelne kantonale Erziehungsräte vor- und nach der Stapfer-Enquête ihre eigenen Schulumfragen durch, die freilich von der bisherigen Forschung noch wenig beachtet wurden. ${ }^{249}$ Entsprechend dicht präsentiert sich die

\section{Büttner, Schreiben: 38f.}

244 Vgl. Depkat, Autobiographieforschung: $174 f$.

245 Brühwiler, Finanzierung: 36.

246 Fuchs, Lehrerperspektiven: 209-214; 225.

247 Vgl. Bloch Pfister, Priester: 161; Klinke, Zürich: 4.

248 Vgl. Fuchs, Lehrerperspektiven: $137 \mathrm{f}$.

249 Mattmüller, Umfragen: 244; Vgl. zu den „vergessenen“ Schulumfragen der Helvetik: Rothen/Ruloff, Schulumfragen: 33-54; Zu den fragmentarisch überlieferten Umfragen in der Waadt und in Fribourg vgl. Tosato-Rigo/Savoy, Schulumfrageneifer: 103-126. Die hier aufgeführte Liste an Umfragen erhebt keinen Anspruch auf Vollständigkeit. 
Quellenlage für das Schulwesen um 1800 für einzelne Regionen der Helvetischen Republik auch abseits der Stapfer-Enquête. Weil Letzterer als mehrheitliche Ego-Quelle aber insbesondere die Aussensicht auf die Lehrkräfte fehlt, bieten sich hierfür ergänzend diese verschiedenen zeitnahen regionalen Schulumfragen an, da deren Adressaten in der Regel die lokalen Pfarrer waren. Dabei sind insbesondere Fragen nach den Fähigkeiten der Schulmeister und ihrer sozialen Position von grosser Bedeutung. In der Folge werden jene Umfragen, die für die vorliegende Studie mitberücksichtigt wurden, in chronologischer Reihenfolge und in kurzer summarischer Form bezüglich ihrer Entstehungsgeschichte und ihrem Erkenntnisgewinn gegenüber der Stapfer-Enquête charakterisiert.

Die erste kantonale SchulumFrage in der neuen politischen Ära der Helvetischen Republik entstand im Kanton Basel, wo auch die Helvetische Revolution ihren Ursprung genommen hatte. Bereits wenige Tage nach dem revolutionären Umsturz in Basel und noch bevor die alte Ordnung in der restlichen Eidgenossenschaft zusammengebrochen war, versandte der neu konstituierte Erziehungsrat des Kantons Basel Ende Februar 1798 als erste offizielle Amtshandlung eine Schulumfrage an alle Pfarreien der Landschaft. ${ }^{250}$ Bis zu Beginn des Monats April waren sämtliche verschickten Fragebögen beantwortet und aus insgesamt 44 Schulgemeinden lagen die detaillierten Antworten der Pfarrer vor. ${ }^{251}$ Die Umfrage umfasste insgesamt 31 Fragen zum Schulwesen und forderte die Pfarrer zudem auf, ein Schulexamen durchzuführen und dessen Ergebnisse auf vorgefertigten Tabellen festzuhalten. ${ }^{252} \mathrm{Im}$ Gegensatz zur späteren Stapfer-Enquête stellten die Basler Erziehungsräte weitaus präzisiere Fragen hinsichtlich des Unterrichts, der angebotenen Fächer und insbesondere auch bezüglich der Schulmeister. ${ }^{253}$ Neben der Art der Erwählung, der sozialen Herkunft und dem Alter interessierten sich die Basler Erziehungsräte ferner für die Amtstüchtigkeit und den Lebenswandel der Lehrer, für ihre Fähigkeiten im Schreiben, Lesen und Rechnen, ob die Lehrer das Vertrauen ihrer Gemeinde genossen, ob sie eine freie Wohnung zur Verfügung hätten und ob sie kirchliche Nebenbeschäftigungen ausführten. ${ }^{254}$ Für die vorliegende Studie sind hierbei besonders die Bewertungen der fachlichen und persönlichen Qualitäten der Lehrpersonen als Aussensicht auf die Lehrer von hoher Relevanz, da genau diese Informationen in der Stapfer-Enquête fehlen. Daneben sind aus der Basler Landschaft zahlreiche Einzelakten zum elementaren Schulwesen während der Helvetischen Republik vorhanden, zumal die Basler Erziehungsbehörden sehr gewissenhaft über ihre Aktivitäten in schriftlicher Form Rechenschaft abgelegt hatten, wobei besonders die Kandidatenprüfungen bei vakanten Schulstellen sehr dicht dokumentiert sind. ${ }^{255}$

Ebenfalls eine weitaus umfangreichere Befragung zum elementaren Schulwesen hatte der Aargauer Erziehungsrat am 9. Januar 1799 gestartet, wie zuvor erwähnt wurde. ${ }^{256}$ Der gedruckte Fragebogen, adressiert an die Distriktinspektoren, umfasste insgesamt 74 Einzelfragen, aufgeteilt in neun thematische Kapitel. Darunter sollten die Person und die Fertigkeiten der Lehrer genauer untersucht werden als bei der Stapfer-Enquête: Neben Namen, Alter, Dienstzeit und den Ersttätigkeiten war anzugeben, wie die Lehrer in ihren „Fähigkeiten als Schullehrer“

250 Zingg, Basel: 6f.

251 Rothen/Ruloff, Schulumfragen: 37.

252 Die Fragen sowie die Beantwortungen liegen heute im Staatsarchiv Basel-Landschaft: StABL AA 1012, Lade 200, 07.01.01, fol. 1-314: [1798] - Bericht. Die Examenstabellen sind archiviert unter: StABL AA 1013, Lade 201, 24 (B I), fol. 1-241: [1798] - Tabellen.

253 Rothen/Ruloff, Schulumfragen: $37 \mathrm{f}$.

254 StABL AA 1012, Lade 200, 07.01.01, fol. 2: [1798] - Bericht.

255 Vgl. das Kap. 2.4.

256 Eine gedruckte Version des Fragebogens ist zu finden in: LaGL HA Kiste 27, Mappe C, o. Pag: 09.01.1799 - Aargau. 
hinsichtlich der Handschrift, dem Leseverständnis sowie dem Gesang abschnitten und ob sie auch das „Nöthige von der Rechenkunst“ verstünden. ${ }^{257}$ Aufgrund der zeitgleichen Distribution der Stapfer-Enquête wurde die Aargauer Umfrage jedoch einzig im Distrikt Kulm durch den Pfarrer Daniel Rytz beantwortet, dessen Abschrift aber dennoch an Stapfers Ministerium weitergeleitet. ${ }^{258}$ In der Beantwortung sind insbesondere die angehängten tabellarischen Fähigkeitsbeurteilungen zu den einzelnen Lehrpersonen für die vorliegende Arbeit von grosser Bedeutung, da sie allesamt aus einer Hand stammten und damit quellenkritisch einen hohen Standardisierungsgrad aufwiesen.

Nach der Erhebung der Stapfer-Enquête im Frühjahr 1799 war der Wissensdurst über den Zustand des Bildungswesens zumindest von einzelnen kantonalen Erziehungsräten freilich noch längst nicht gestillt gewesen. Ungeachtet der sich etablierenden regen Kommunikation auf der Ebene der kantonalen Erziehungsräte einzelner Kantone, der sich unter anderem im regen Austausch von Materialien und den empirisch erhobenen Generaltabellen manifestiert hat, initiierten noch während der Helvetik weitere kantonale Erziehungsräte ihre eigenen protostatistischen Datenerhebungen. ${ }^{259}$ Mitunter ein Grund für die erneuten Umfragen war die fehlende personelle Kapazität des helvetischen Erziehungsministeriums um Stapfer gewesen, die erhaltenen Ergebnisse der landesweiten Umfrage auszuwerten und diese Daten an die kantonalen Behörden weiterzuleiten. Zudem machte sich allenthalben unter den kantonalen Erziehungsbehörden das Bedürfnis breit, erste Ansätze von Verbesserungen und konkrete Erfolge seit der stapferschen Erhebung rapportieren zu können. ${ }^{260}$

In diesem Zusammenhang forderte der Erziehungsrat des Kantons Oberland die lokalen Pfarrer am 9. Dezember 1800 auf, neue Rapporte zum Zustand des Schulwesens ihrer Pfarrgemeinde zu verfassen. ${ }^{261}$ Die zeitlich engen Intervalle der Befragung - nach der Enquête von 1799 bedeutete diese erneute Umfrage bereits die zweite Erhebung seit 1799, die über die Arbeitstische der Oberländer Geistlichen ging - stiessen dabei selbst unter den Pfarrern auf kaum mehr verhohlene Kritik. Die sarkastische Einleitung des Pfarrers Niclaus Emanuel Franck von Thun verdeutlicht dies: „Jch werde aufs neüe aufgeforderet, zu einer genauen Kentniss und Verbesserung der Schule abermal Folgende schon mehrmal beantwortete, Fragen wiedermal zu beantworten. ${ }^{262}$ Unter den sieben summarischen Fragen zum Schulwesen ist vor allem die letzte Frage nach den Kenntnissen der Lehrerschaft im Lesen und Schreiben von Interesse für die vorliegende Arbeit, da hiervon wiederum auf den Ausbildungsgrad der Lehrkräfte und auf die Bildungsbedürfnisse der Lokalbevölkerung geschlossen werden kann.

257 Rothen/Ruloff, Schulumfragen: 39.

258 BAR B0 1000/1483, Nr. 1423, fol. 220-226: 30.03.1799 - Kulm.

259 Vgl. zur interkantonalen Kommunikation der Erziehungsräte: Ruloff, Schulbesuch: 32. Insbesondere die gedruckten Generaltabellen zirkulierten offensichtlich unter einzelnen kantonalen Erziehungsräten zum gegenseitigen Informationsaustausch, wie die Archivierungslage aufzeigt, zumal einige der Tabellen auch in anderen Kantonsarchiven abgelegt sind. Die Generaltabelle des Kantons Linth von 1801 ist beispielsweise auch in die Kantone Säntis, Thurgau und Aargau versandt worden. Eine systematische Auswertung der Kommunikationspfade und der Kommunikationsintensität zwischen den helvetischen Erziehungsräten der einzelnen Kantone existiert bis heute jedoch noch nicht.

260 Beispielhaft sei auf die gedruckten Rapportformulare aus dem Kanton Aargau verwiesen, wo explizit nach Erfolgen und Veränderungen seit der Revolution gefragt wurde. So lautete etwa eine Frage: „Hat der Schul-Lehrer zufolge der Aufforderung des Erzieh. Rathes sich in Schön- und Richtigschreiben, so wie im Rechnen fleissig geübt und Fortschritte gemacht?"StAAG HA 9131, o. Pag.: [1802] - Rapport.

261 StABE Helv OL 41, o. Pag.: [1800-1801] - Berichte über die Schulen.

262 StABE Helv OL 41, Nr. 456: 26.12.1800 - Berichte über die Schulen. 
Als die Helvetische Republik, geschüttelt von zahlreichen Staatsstreichen und Unruhen nach dem Rückzug der französischen Besatzungstruppen, bereits politisch kollabiert war, erhob das städtische Deputatenamt von Basel im Herbst 1803 eine Umfrage von insgesamt zwanzig Fragen zum lokalen Schulwesen, diesmal ebenfalls wieder in der traditionellen Kommunikationsbahn des Ancien Régimes an die Dorfpfarrer gerichtet. ${ }^{263}$ Unter anderem wurden in dieser Umfrage wiederum wie schon 1798 die Fähigkeiten, der Fleiss und der Charakter der Lehrerschaft erfragt. Dadurch lassen sich die Antworten gut mit der bereits 1798 durchgeführten Umfrage quervergleichen, zumal unter den bewertenden Pfarrern eine weitgehende personelle Kontinuität bestand, die eine Vergleichbarkeit der Antworten garantiert.

\subsection{Methode}

Ausgehend von der zuvor in der Forschungsübersicht festgestellten Kritik an einer weitgehend fehlenden Überblicksdarstellung zur Schweizer Lehrerschaft um 1800 auf der Basis von seriellen Quellenbeständen von niedriger Provenienz drängen sich quantitativ orientierte Zugangsweisen zur Erforschung des frühneuzeitlichen schweizerischen Lehrerkollektivs in den Vordergrund. Einen besonderen Erkenntniswert verspricht denn auch die gesamtheitliche Betrachtung der Lehrkräfte auf der Makroebene, zumal schon derart umfangreiche Personenkollektive, wie sie die Stapfer-Enquête bereithält, an sich eine quellenbedingte Rarität für die Frühe Neuzeit darstellen und zu einer Untersuchung einladen. Zudem ermöglicht der Umstand, das Personenkollektiv der Lehrerschaft über ein komplettes Landesterritorium hinweg zu betrachten, die bisherigen regionalen und lokalen Forschungsresultate aus der Schulgeschichte in Form einer Synthese zusammenzuführen, zu vergleichen und ihre Ergebnisse kritisch zu bewerten. Ebenso lassen sich Fragen nach dem Einfluss von makrostrukturellen Einflüssen wie der Konfession, der dominanten Wirtschaftsweise, der geografischen Lage oder der ehemaligen Herrschaftsform angehen.

Des Weiteren besteht besonders im Bereich von biografischen Untersuchungen zu den Hauptakteuren des Schulwesens noch ein eklatanter Forschungsbedarf in der Schulgeschichtsforschung zur Frühen Neuzeit, da nur wenige komplette Biografien über Elementarschullehrkräfte oder gar Autobiografien existieren. ${ }^{264}$ Hier bietet insbesondere die Stapfer-Enquête durch die Rekonstruktionsmöglichkeit von Teilbiografien die Chance, die Lücken an vorhandenen Einzelbiografien durch quantifizierende biografische Methoden aus der historischen Sozialforschung zumindest teilweise zu überbrücken und einen Referenzrahmen zu schaffen, in dem einzelne qualitative (auto-)biografische Lebensbeschreibungen verortet werden können.

Die qualitative, individuelle Perspektive des Einzelsubjekts darf jedoch nicht gänzlich aus den Augen geraten. Menschliches Handeln in der Lebensverlaufsperspektive ist - teilt man die gegenseitige Kritik an den modernen empirischen Forschungsansätzen wie an den methodischen Vorgehensweisen der qualitativ orientierten Sozialforschung - ebenso wenig das alleinige reaktive Ergebnis von Makrostrukturen und gesellschaftlichen Präfigurationen, als einzig durch Entscheidungen des aktiv agierenden Subjekts gesteuert. Handlungen entstehen stets in komplexen und empirisch nicht immer nachvollziehbaren Wechselwirkungen zwischen strukturellen Faktoren und individuellen Entscheidungen, die selbst ein Individualbiograf für den einzelnen

263 StABL AA 1012, Lade 200, 07.03.01, o. Pag.: [1803] - Berichte. Einzig die beiden Berichte aus den Gemeinden Wintersingen und Sissach sind davon abweichend wohl versehentlich in der Mappe 07.01.01 archiviert worden.

264 Vgl. die Ausführungen im Forschungsstand im Kap. 1.3.2. 
Protagonisten nicht immer sauber entwirren kann. ${ }^{265}$ Zudem erschafft oder reproduziert jede individuelle Handlung ihrerseits wiederum neue oder bisher existente Strukturen. Erst recht sind solche Interdependenzen bei umfangreichen Personenkollektiven schwierig zu erkennen. Die Untersuchung umfasst somit zwangsläufig zwei Ebenen der historischen Analyse: Sie beschäftigt sich einerseits auf einer Makroebene mit den äusseren makrostrukturellen Prägefaktoren, die das elementare Schulwesen und seine involvierten Akteure beeinflussten und stellt die Frage, ob und inwiefern strukturelle Faktoren in kollektiv prägender Weise auf die Lebensverläufe der Elementarschullehrer einwirkten. Andererseits muss auf einer Mikroebene das einzelne Individuum zu Wort kommen können. Es muss nach individuellen Motiven und Handlungsstrategien der Lehrkräfte gefragt werden, wobei die Vielfalt an Ursachen für das individuelle Handeln oft keine kollektive Beantwortung zulässt und die Untersuchung somit keinen Anspruch haben kann, jeden biografischen Einzelfall erklären zu können.

Die aufgeworfenen Fragestellungen lassen sich in der Konsequenz nur über eine notwendige symbiotische Verbindung von quantitativen und qualitativen methodischen Zugangsweisen erfassen. Quantitativ in der Hinsicht, dass bewusst nicht nur wenige Einzelschicksale und einzelne Lebensverläufe von Lehrkräften untersucht werden sollen, weil dann die Frage nach der Repräsentativität der gewonnenen Erkenntnisse ungeklärt bleibt. Erst in der Vielzahl an untersuchten Lebensverläufen können makrostrukturelle Einflüsse erkannt werden, wenn unter den gleichen strukturellen Voraussetzungen ähnliche Handlungen resultieren.

Reine Zahlen über Häufigkeiten reichen jedoch nicht aus, um Ursachen von biografischen Entscheidungen historisch korrekt zu verorten, weil damit nur wenig über die individuellen Hintergründe und persönlichen Handlungsentscheidungen in Erfahrung gebracht werden kann. Einzelne Handlungsmotive oder Beweggründe sind denn auch mitunter ebenso wertvoll für das Gesamtverständnis wie die Rekonstruktion der kollektiven „grossen Bögen“ durch quantitative Analysen. Gerade das Verständnis für Abweichungen von „normalem“ kollektivem Verhalten erwächst oft nur durch das individuelle Betrachten der historischen Subjekte in ihrem persönlichen Kontext. Entsprechend muss den originalen Aussagen der Individuen sowohl auf sprachlicher wie inhaltlicher Ebene ein hoher Erkenntniswert zugesprochen werden, der in dieser Arbeit nach Möglichkeit stets durch die Wiedergabe von Originalaussagen berücksichtigt werden soll. Um den geforderten quantitativ orientierten makro- und den ebenso notwendigen individualbiografisch-mikrohistorischen Zugang gleichsam gewähren zu können, erweist sich der kollektivbiografische Ansatz als ein die beiden Zugänge auf ideale Weise verbindendes Methodensetting.

Die Ursprünge des interdisziplinären methodischen Ansatzes der Kollektivbiografie liegen im Kontext der Zuwendung der historischen Sozialforschung zu empirischen Untersuchungen in den 1970er-Jahren und sind massgeblich durch die Arbeiten von Lawrence Stone und Wilhelm Heinz Schröder geprägt worden. ${ }^{266}$ Der heute in den Geschichts- und Sozialwissenschaften vielfach angewandte und etablierte Ansatz entstand als Versuch einer Antwortfindung auf den ausgebrochenen Methodenstreit zwischen den Vertretern der neueren empirischen - auch marxistischen - Strukturgeschichte und den qualitativ arbeitenden Einzelbiografen, denen besonders

265 Zur Kritik an quantitativen und qualitativen Methodenzugängen in den biografisch fokussierten Sozialwissenschaften vgl. Gallus, Biographik: 40-46; Wicki, Grosse Rat: 47.

266 Stone, Prosopography: 46-79. Schröder, Kollektive Biographien: 7-17. Stone und auch andere Forschende verwendeten den Begriff der „Prosopografie“ wiederholt teilweise willkürlich als Synonym für eine kollektive Biografik, was mitunter für eine begriffliche Verwirrung sorgt, zumal der Begriff der Prosopografie bereits von der Altertumsforschung und Mediävistik einschlägig belegt ist. Vgl. zur Kritik am Begriff der Prosopografie: Schröder, Kollektivbiographie: 100-103; 127ff.; Harders/Lipphardt, Wissenschaftsgeschichte: 82. 
in der deutschsprachigen Wissenschaftsgemeinde zunehmend eine theoriearme, konservative, ja bisweilen „naive“ Geschichtsverlaufsbetrachtung vorgeworfen wurde. ${ }^{267}$

Im Gegensatz zu Einzelbiografien oder zur klassischen Prosopografie der Altertumsgeschichte als ein Beschrieb von Personenbeziehungen fokussiert die kollektive Biografik oder die Kollektivbiografie nach der Definition von Stone auf das Moment des Vergleichs durch eine Untersuchung der allgemeinen Merkmale einer Gruppe von handelnden Personen der Geschichte durch ein zusammenfassendes Studium ihrer Lebensläufe. ${ }^{268}$ Diese Merkmale werden etwa durch Fragen nach Geburt und Tod, Heirat und Familie, sozialer Herkunft, wirtschaftlicher Stellung, Wohnsitz, Ausbildung, Berufserfahrung oder Religion näher bestimmt und erörtert. ${ }^{269}$ Man versteht unter einer Kollektivbiografie nach der erweiterten Definition von Schröder „die theoretisch und methodisch reflektierte, empirische, besonders auch quantitativ gestützte Erforschung eines historischen Personenkollektivs in seinem jeweiligen gesellschaftlichen Kontext anhand einer vergleichenden Analyse der individuellen Lebensläufe der Kollektivmitglieder ${ }^{\text {“270 }}$. Dabei umschreibt der doppelte Erkenntnisgewinn - Rückschlüsse auf das Typische, das Allgemeine und den Rekurs auf das Untypische, Individuelle - den Vorteil des methodischen Ansatzes. ${ }^{271}$

Von einer prosopografischen Biografiesammlung, die bloss Individualbiografien nebeneinander stellt, unterscheidet sich die Kollektivbiografie ferner durch ihre problemorientierte Fragestellung sowie durch die bewusste Untersuchung von Vernetzungen und Einflüssen, Parallelen wie Differenzen zwischen den einzelnen Personen. ${ }^{272}$ Zudem wird verhindert, dass durch objektivierte Quantifizierungen die alltagsgeschichtlich relevanten subjektiven „Erzählungen“ untergehen, was bekanntlich eine wesentliche Kritik an der rein statistisch-strukturorientierten älteren Sozialgeschichte ist. ${ }^{273}$ Vielmehr erlaubt der Ansatz durch punktuelle qualitative Skizzierungen oder Gegenüberstellungen von Individualerkenntnissen die grossen kollektiven Linien schärfer zu zeichnen. Damit kann zum einen vermieden werden, dass „statistische Gespenster“ erzeugt werden, die mit der historischen Realität wenig zu tun haben, zum anderen kann der Gefahr begegnet werden, dass das subjektiv Spezielle oder Atypische unter der Masse an Kollektivdaten unterbewertet wird. ${ }^{274} \mathrm{Im}$ Umkehrschluss besteht bei der Darstellung der individuellen Positionen jedoch das Risiko, dass sich die markantesten Abweichungen vom hauptsächlichen Verhalten leicht zu einem ungewollten Absurditätenkabinett verdichten. Keinesfalls soll jedoch weder eine künstliche statistische Durchschnittsbiografie oder eine Idealtypologie von Normentwicklungen erstellt werden, noch Einzelschicksale aneinander gereiht werden. Vielmehr ist den biografischen Entwicklungen in ihren eigenen lokalen oder regionalen Kontexten durch quellennahe Einzelbeispiele ein konkretes Gesicht zu geben. Des Weiteren dürfen (auto)biografische Texte aufgrund ihrer Subjektivität nie in naiver Weise als historische Faktenlieferanten gelesen werden, sondern unterliegen ebenso der hermeneutischen Quellenkritik wie alle übrigen historischen Texte, denn auch biografische Fragmente sind mitunter bewusst oder unbewusst manipuliert, weisen Ungenauigkeiten oder Auslassungen auf. ${ }^{275}$

267 Vgl. zum Streit innerhalb der Geschichtswissenschaften sowie zur Kritik an der Methode der Kollektivbiografie den lesenswerten Aufsatz von Alexander Gallus: Gallus, Biographik: 40-46.

268 Stone, Prosopography: 64; Schröder, Kollektive Biographien: 8.

269 Gallus, Biographik: 43.

270 Schröder, Kollektivbiographie: 131.

271 Schröder, Kollektivbiographie: 131.

272 Harders/Lipphardt: Wissenschaftsgeschichte: 82.

273 Kocka, Strukturgeschichte: 69.

274 Gallus, Biographik: 46.

275 Depkat, Autobiografieforschung: 175. 
Für die Schweiz lassen sich insgesamt erst wenige kollektivbiografische Arbeiten festmachen. Die bislang entstandenen Forschungsarbeiten stammen zumeist aus der Zeitgeschichte, widmen sich kleinen Kollektiven aus dem Militär oder der Politik und sind - wie beispielsweise Dieter Wickis Kollektivbiografie über den aargauischen Grossen Rat, die der vorliegenden Arbeit als methodischer Orientierungspunkt dient - fast allesamt der Elitenforschung zuzuordnen. ${ }^{276} \mathrm{Zu}$ nicht-elitären Personengruppen der Frühen Neuzeit liegen dagegen für die Schweiz bis jetzt noch keine Forschungsarbeiten mit kollektivbiografischem Ansatz vor.

Das Quellenkorpus der Stapfer-Enquête bietet sich aus drei Gründen an, mit dem methodischen Ansatz der Kollektivbiografie untersucht zu werden. Zum Ersten präsentiert sich die Quellenlage für eine Anwendung des Ansatzes äusserst günstig, da die Umfrage als weitgehend vollständig angesehen werden kann und in digitaler Form editiert ist. ${ }^{277}$ Zum Zweiten umfasst die Umfrage mit der Elementarschullehrerschaft eine an sich klar umrissene Berufsgruppe als Untersuchungskollektiv, die sich zudem als nichtelitäre Gesellschaftsgruppe von traditionell üblichen Untersuchungskollektiven unterscheidet. ${ }^{278}$ Die Zugehörigkeit zum Kollektiv bildet durch die namentliche Aufführung der Lehrer in der Stapfer-Enquête das spezifische Konstitutionskriterium. Das Kollektiv ist damit primär ein Produkt aus der Quellenüberlieferung sowie aus dem Eigenverständnis der Gruppe als Teil der öffentlich finanzierten und konstituierten Elementarschule. Die Umfrage determiniert somit den quantitativen Adressaten-Umfang des Kollektivs gleich selbst und nimmt diese Bürde dem Forschenden ab. Weitere, nicht in der Stapfer-Enquête aufgeführte Lehrpersonen sind hingegen nicht in das Untersuchungskollektiv mitintegriert worden, obwohl das so konstruierte Kollektiv aus der Enquête natürlich nicht vollständig ist. Auf die grundsätzliche Problematik der Abgrenzung beziehungsweise der $\mathrm{Zu}$ teilung von Individuen zu vordefinierten Kategorien bei der Kollektiverschaffung durch den Historiker haben jüngst Levke Harders und Veronika Lipphardt hingewiesen: „Der Prozess der Gruppenzusammenstellung ist stets problematisch, da er kaum ohne willkürliche oder unscharfe Grenzziehungen von statten geht. [...] Die Einordnung eines Individuums in eine Gruppe kann der komplexen Wirklichkeit selten gerecht werden.“279

Die Abgrenzung des vorliegenden Kollektivs der helvetischen Elementarschullehrer gegenüber den teilweise in der Stapfer-Enquête miterfassten „höheren“ Latein- und Gymnasiallehrkräften basiert in der vorliegenden Studie auf dem bildungsinhaltlichen und funktionalen Kriterium der Vermittlung von Elementarbildung. Zum fachinhaltlichen Kanon der Elementarbildung für das ausgehende 18. Jahrhundert sind folglich die elementaren Kulturtechniken Lesen, Schreiben, die Anfänge des Rechnens bis zu den fünf „Species“280 sowie das Singen religiöser Lieder und die Katechese religiöser Texte zu zählen. In städtischen „vermengten Schulen“ ohne klare Profiltrennung von elementarer und höherer Schulbildung sind die Lehrkräfte entsprechend ihrer unterrichteten Fachgebiete getrennt worden.

276 Eine Übersichtsdarstellung mit einer Auswahl an bisherigen kollektivbiografischen Arbeiten aus der Schweiz findet sich bei: Wicki, Grosse Rat: 33. Zu nennen ist des Weiteren die jüngst erschienene Forschungsarbeit von Daniel Kriemler zur Basler Lesegesellschaft im 19. Jahrhundert: Kriemler, Lesegesellschaft. Eine Ausnahme bezüglich der Wahl von Elitenkollektiven als Ausgangslage bildet ferner die kürzlich veröffentlichte zeitgeschichtliche Studie von Peter Huber zu Schweizern in der französischen Fremdenlegion im 20. Jahrhundert: Huber, Fremdenlegion: 21 .

277 Vgl. zu den allgemeinen Problematiken von Kollektivbiografien: Schröder, Kollektivbiographie: 123-127; 145-148.

278 Schröder, Kollektivbiographie: 147.

279 Harders/Lipphardt, Wissenschaftsgeschichte: 84.

$280 \mathrm{Zu}$ den fünf „Species“ oder Grundrechenoperationen der elementaren Mathematik gehörten die 1. die Numeration, 2. die Addition, 3. die Subtraktion, 4. die Multiplikation, und 5. das Dividieren. 
Zu den exkludierten höheren Bildungsinhalten gehörte einerseits der Fachunterricht in den Septem artes liberales des Triviums respektive Quadriviums: Lateinische Grammatik, Rhetorik, Logik und Philosophie, Arithmetik, Geometrie, Musik und Astronomie. Fremdsprachen wie Griechisch und Französisch, sowie teilweise Realien wie Geschichte oder Geografie ergänzten und erweiterten teilweise das Fachangebot. In seltenen Fällen wurden einzelne der genannten Fachbereiche jedoch auch an elementaren und vermengten Schulen gelehrt, weshalb zusätzlich zum Fächerangebot auch die Ausrichtung der Bildungsinstitution als Gymnasium oder Lateinschule sowie das fortgeschrittene Alter der Zöglinge als Distinktionsmerkmal hinzugezogen werden musste.

Eine Trennung von Lehrkräften elementarer und höherer Schulen ist notwendig, da sich ihre Ausbildungsvoraussetzungen grundsätzlich unterschieden. Von Lehrern an höheren Schulen wurde eine formale Ausbildung an einer Universität oder Akademie mit dem Abschluss eines Gradum magistri vorausgesetzt, während für Elementarschullehrer aufgrund der fehlenden Lehrerausbildung keinerlei formale Ausbildungsvorgaben existierten. Die Grenze zwischen dem Elementarschulwesen und den „höheren“ weiterführenden Schulinstitutionen verlief allerdings keineswegs so trennscharf, wie es der duale Aufbau des frühneuzeitlichen öffentlichen Schulwesens suggeriert. ${ }^{281}$

Aufgrund der vielfach komplexen, weder begrifflich noch inhaltlich trennscharfen Struktur von städtischen Schulen, die oftmals als sogenannte „vermengte Schulen “282 Inhalte elementarer und höherer Bildung vermischten, wurden teilweise auch Lehrpersonen von städtischen „oberen Schulen“, Gymnasien oder Lateinschulen in die Untersuchung miteinbezogen, sofern ihnen die Vermittlung der elementaren Kulturtechniken Buchstabieren, Lesen, Schreiben und die Anfänge des Rechnens oblagen. ${ }^{283}$ Gerade die fliessenden Übergänge zwischen den elementaren und höheren Bildungsangeboten innerhalb derselben Schule verunmöglichten einen Ausschluss der Lehrkräfte allein nach dem Kriterium der Schuleinrichtung. Nicht berücksichtigt wurden folglich einzig Lehrpersonen von städtischen Gymnasien, von höheren Lateinschulen oder von „oberen Schulen“ an zentralörtlichen Schulen, sofern sich deren Unterrichtsgegenstände ausschliesslich auf höhere Bildungsinhalte konzentriert hatten. ${ }^{284}$

Zum Dritten bietet sich der kollektivbiografische Ansatz zur Untersuchung der Stapfer-Enquête an, da sich aus deren Personalangaben sämtliche oben genannten wesentlichen allgemeinen Merkmale einer Personengruppe - Geburt und Tod, Heirat und Familie, soziale Herkunft, wirtschaftliche Stellung, Wohnsitz, Ausbildung, Berufserfahrung und Religion - entnehmen lassen. Obwohl aufgrund des einmaligen Aufnahmezeitpunkts zwar bloss querschnittartige biografische Fragmente zu Teilbiografien „mit retrospektivem Charakter “285 rekonstruierbar sind, deren Dichte an biografischen Angaben teilweise sehr unterschiedlich und lückenhaft ist, lassen sich die daraus rekonstruierbaren Teilbiografien miteinander vergleichen und geben Auskunft über den grundsätzlichen Lebensverlauf der Individuen unter ihren bestimmten umfeld- und altersspezifischen Bedingungen.

Trotz einer gewissen zwingenden Chronologie in den Lebensverläufen darf jedoch nicht a priori von einer linearen Biografik ausgegangen werden. Levke Harders und Veronika Lipphardt betonen

281 Vgl. die Differenzierung des öffentlichen Schulwesens im Kap. 1.2.

282 Begriff nach: Töpfer, Freyheit: 410.

283 Für die Schwierigkeit der Differenzierung zwischen Elementarschulen und Lateinschulen vgl. Brühwiler, Finanzierung: 25 .

284 Insgesamt 70 in der Stapfer-Enquête vermerkte Lehrkräfte von höheren Bildungseinrichtungen wurden von der Untersuchung ausgeschlossen.

285 Brückner, Lebensverläufen: 378f. 
aufgrund des konstruktiven Charakters von biografischer Identität in der Retrospektive die poststrukturalistische Infragestellung von „einheitlichen“ kohärenten Lebensverläufen als eine „biographische Illusion“, wie es Pierre Bourdieu einst kritisiert hat. ${ }^{286}$ Die Problematik, dass eine autobiografische Erzählung immer - bewusst oder unbewusst - dazu neigt, in der Retrospektive einen Sinn hinter den biografischen Stationen zu konstruieren, um die einzelnen Etappen des Lebens als eine logische Abfolge erscheinen zu lassen, führt zu einer Selektion und Kohärenzstiftung durch das erzählende Subjekt. Lebensverläufe erscheinen diesbezüglich oft als "geglättet“ und harmonisiert. Hierbei muss der Biograf aufpassen, nicht als „Komplize“ des Erzählenden in Erscheinung zu treten, der diese künstliche Kreation von Sinn und Harmonisierung vorbehaltlos akzeptiert. ${ }^{287}$ Daher sollen in der vorliegenden Studie die Teilbiografien bewusst auch auf Unterbrüche und diskontinuierliche Lebensverläufe hin untersucht und verglichen werden. Gerade in Lücken der biografischen Erzählung und in biografischen Brüchen liegt denn auch viel Informationsgehalt.

Da die Stapfer-Enquête als Momentaufnahme jedoch verschiedenste Altersgruppen gleichsam vereint, die auf völlig unterschiedlichen Stufen der biografischen Entwicklung stehen, drängt sich der generationstheoretische Ansatz als primärer theoretischer Grundrahmen auf. Der Ansatz besagt, dass verwandte Geburtenjahrgänge durch eine ähnliche Generationslage geprägt sind, „was wiederum bedeutet, dass tendenziell bei einer Generation bestimmte Arten und Weisen des Erlebens, Denkens, Fühlens und Handelns ausgeschlossen, andere dagegen dominant sind." ${ }^{\text {(288 }}$ Generationenbedingte Unterschiede zwischen Angehörigen unterschiedlicher Altersgruppen werden somit als Axiom angenommen. Problematisch ist jedoch die unklare Selbstdeutung der Generationen innerhalb eines historischen Kollektivs, worauf Stefan Brakensieck hingewiesen hat: „Kollektivbiographien nötigen dazu, zeitliche Sequenzierungen zu schaffen, um Wandel im Handeln des untersuchten Personenkreises erkennen und beschreiben zu können. Bei der Konstruktion von Kohorten-Modellen können wir uns auf Veränderungen objektivierbarer Daten des Lebenslaufes stützen, die sich zu typischen Mustern verdichten lassen. Die solcherart gewonnenen Ergebnisse sagen jedoch noch nicht viel über die Selbstdeutung der Zeitgenossen. Sie geben keine Antwort auf die Frage, ob es innerhalb einer bestimmten Altersgruppe ein verbreitetes Bewußtsein davon gab, einer bestimmten Generation anzugehören, die sich klar von vorhergehenden und nachfolgenden Altersgruppen abhob. ${ }^{“ 289}$ Festgehaltene generationenspezifische Unterschiede dürfen jedoch nicht in eine direkte Kausalität zueinander gebracht werden. So sind beispielsweise die jungen Lehrer um 1799 nicht gleichzusetzen mit dem Abbild der Jugend der älteren Lehrkräfte, da deren Jugendzeit unter divergenten Prämissen stand.

Aus den Hauptfragestellungen nach der sozialen Herkunft und nach der sozialen Position der Elementarschullehrkräfte geht ferner eine stratifikationstheoretische Grundannahme hervor. Im Kontext der vormodernen Ständegesellschaft wird in dieser Arbeit von einer grundsätzlich hierarchisch gegliederten Gesellschaft ausgegangen, in der sich die Individuen durch ihre Tätigkeiten, ihren materiellen Wohlstand, aber auch durch ihr individuelles immaterielles soziales Kapital in einer Rangfolge einordneten, deren Grenzen zwar fliessend und aushandlungsfähig, von den Zeitgenossen jedoch erkennbar gewesen waren. Die Positionierung der Elementarschullehrerschaft in dieser Rangfolge ist hierbei als offene Forschungsfrage gegenüber den stereotypischen Zuschreibungen zu den ökonomischen Unterschichten anzugehen.

286 Harders/Lipphardt: Wissenschaftsgeschichte: 82; Bourdieu, Illusion: 75-81.

287 Bourdieu, Illusion: 75f. Zur Kritik an Bourdieus „,biographischer Illusion“ vgl. den Forschungsbericht zum biografischen Ansatz in Frankreich: Pape, Frankreich: $284 \mathrm{f}$.

288 Schröder, Kollektive Biographien: 10f.

289 Brakensieck, Erfahrungen: 44. 
Der gewählte methodische Ansatz der Kollektivbiografie weist in Bezug auf die Stapfer-Enquête als Hauptquelle jedoch auch eine Reihe von Grenzen hinsichtlich des Erkenntnisinteresses auf. So lassen sich wichtige sozialwissenschaftlich relevante Fragen mit dem Ansatz und der Quellenauswahl nicht beantworten. Eine Rekonstruktion der Dynamik von Lebenserfahrungen während der Lebensphasen ist aufgrund der Statik der Momentaufnahme nicht möglich. Ebenso können die individuelle Sozialisation und die Entstehung der mentalen biografischen Identität mangels genügender Informationen nicht in kollektiver Weise nachgezeichnet werden. Auch langfristige gesellschaftliche Veränderungen können mit dem kurzen zeitlichen Betrachtungshorizont nicht erfasst werden.

Der einleitend hervorgehobene doppelte methodische Zugang von makro-kollektiver und mikro-individueller Betrachtung bei der Anwendung des kollektivbiografischen Ansatzes erfordert bei der Umsetzung auf der Analyseebene eine doppelte kategoriale Herangehensweise. Zum einen sind biografische Indikatoren zu bestimmen, nach welchen die Quellenbestände untersucht werden sollen, um überhaupt Teilbiografien und biografische Daten rekonstruieren zu können. Zum anderen müssen die so erhobenen biografischen Daten in ihren historischen Kontext gesetzt werden. Dies bedingt eine Analyse der biografischen Daten nach den bedeutsamsten strukturellen Einflussfaktoren, die auf die Lebenswelt der Elementarschullehrkräfte eingewirkt hatten oder durch die biografischen Handlungen der Lehrkräfte reproduziert beziehungsweise gar erst konstituiert wurden.

\subsubsection{Biografische Indikatoren zur Operationalisierung}

Wilhelm Heinz Schröder schlägt zur Analyse der biografischen Daten im Sinne des Erkenntnisinteresses die Festlegung von zentralen Indikatoren zur Operationalisierung vor. Danach erfolgt pro Indikator die Festsetzung von konkreten Merkmalsklassen. ${ }^{290}$ Die vorliegende Studie verfolgt gemäss den Fragestellungen insgesamt drei fundamentale Erkenntnisinteressen: Neben der sozialen Herkunft sind die Ausgestaltung der Tätigkeiten in den Lebensverläufen und der soziale Status der Elementarschullehrkräfte zu untersuchen. ${ }^{291} \mathrm{Zu}$ jedem der drei Erkenntnisinteressen dienen mehrere konkrete Indikatoren als Grundlage der biografischen Rekonstruktion, die sich entweder aus der Stapfer-Enquête oder aus anderen seriellen Quellenbeständen quantitativ erheben und vergleichen lassen.

Tab. 1: Indikatoren der Kollektivuntersuchung

\begin{tabular}{ll}
\hline Erkenntnisinteresse: & Indikatoren: \\
\hline Soziale Herkunft & Alter bei der Lehramtsübernahme \\
& Ersttätigkeiten \\
& Geografische Herkunft \\
\hline Tätigkeitsausgestaltung & Nebentätigkeiten \\
& Dienstdauer und Anzahl an Stellenwechseln \\
\hline Sozialer Status & Fachliche Fähigkeiten und soziales Ansehen \\
& Zivilstand und Familiengrösse \\
\hline
\end{tabular}

Im Folgenden wird jeder Indikator mit seinen konkreten Merkmalsklassen vorgestellt.

290 Schröder, Kollektivbiographie: 141-149.

291 Vgl. die Fragestellungen im Kap. 1.4. 


\section{Das Amtsübernahmealter}

Anschliessend an die Kindheits- und Jugendzeit erfolgte die biografische Phase des Übergangs ins Erwerbsleben. Das Alter der Lehrkräfte bei der Amtsübernahme ermöglicht die zeitliche Unterteilung der Lebensverläufe in vergleichbare biografische Sequenzen. Das Amtsübernahmealter für das gesamte Kollektiv aus der Stapfer-Enquête ist durch die Subtraktion der Dauer der Unterrichtstätigkeit vom Alter der Lehrkräfte berechenbar. ${ }^{292}$ Zudem erlaubt das Amtsübernahmealter eine Einschätzung der von den Lehrkräften selbst implizit zugesprochenen berufsbiografischen Bedeutung, die das Lehramt für sie hatte. Es wird davon ausgegangen, dass eine Amtsübernahme in jungen Jahren eine berufsbiografisch ungleich stärkere prägende Wirkung auf die Lehrkräfte hatte und folglich unter anderen - idealistischen oder ständischdynastischen - Motiven stattfand als eine Amtsübernahme in fortgeschrittenem Alter, wo eher ökonomisch-opportunistische Motive vermutet werden. Die Einteilung in Merkmalsklassen erfolgt durch eine Zusammenfassung in Mehrjahreskohorten.

\section{Die Ersttätigkeiten}

Weil die Tätigkeiten der Väter als üblicherweise verwendeter Indikator für die soziale Herkunft von Individuen in der Stapfer-Enquête weitgehend fehlen, muss auf die von den Lehrkräften selbst vermerkten Ersttätigkeiten für eine grobe soziale Kategorisierung der Lehrkräfte zurückgegriffen werden. Es ist anzunehmen, dass eine Erhebung ebendieser sozialen Herkunft ein zentrales Ziel von Philipp Albert Stapfer gewesen war, weshalb die doppelte Frage III.11.g „Wo ist er vorher gewesen? Was hatte er vorher für einen Beruf ?" in den Fragebogen aufgenommen wurde.

Operationalisiert werden die Ersttätigkeiten in einem zweifachen Verfahren: Zuerst sind sämtliche Angaben einer expliziten Verneinung von ausserschulischen Ersttätigkeiten von den eigentlichen Ersttätigkeiten zu trennen. Das explizite Verneinen von Ersttätigkeiten abseits des Lehramts stellt für sich bereits eine eigene Merkmalsklasse der biografischen Entwicklung des Lebensverlaufs dar. Erst danach sind in einem zweiten Teilschritt die übrigen Ersttätigkeiten zu klassieren.

Eine quantitative Auswertung der vorhandenen Ersttätigkeitsangaben aus der Stapfer-Enquête für eine soziale Kategorisierung ist allerdings durch zwei methodische Hürden gekennzeichnet. Zum Ersten bewirkt die doppelte Fragestellung eine beträchtliche Anzahl an nicht verwertbaren und unpräzisen Angaben. Zum Zweiten verlangt die Breite an Ersttätigkeiten eine Ordnung und Zusammenfassung der Einzelangaben in zu definierende Sammelkategorien. Hierbei stellt nicht nur die zeitgenössische Semantik der Berufsbezeichnungen eine grundlegende Schwierigkeit dar, die eine präzise Klassifikation der Einzeltätigkeiten erschwert. Alleine für das Ausüben von landwirtschaftlichen Tätigkeiten existiert eine Vielzahl von zeitgenössischen Bezeichnungen, die weder trennscharf voneinander zu unterscheiden, noch eindeutig hierarchisch sortierbar sind. ${ }^{293}$

292 Vgl. die Fragen III.11.d „Wie alt?" und III.11.f, „Wie lang ist er Schullehrer?“ des Fragebogens im Anhang I. Die Erhebung des Amtsübernahmealters ist als angenäherter Höchstwert zu verstehen, da sich mehrere Ungenauigkeiten bei der Beantwortung auf die Qualität der Datensätze auswirken. So notierten etliche Lehrkräfte nur die Dauer ihrer letzten Anstellung, oder - bei Unterbrüchen in der Ausübung des Schuldienstes - nur der letzte Wiedereinstiegszeitpunkt. Zudem liessen etliche Lehrkräfte die Dauer ihrer Vikariatszeit als Schulgehilfe aussen vor und nannten einzig den Zeitpunkt der Erwählung zum Hauptschulmeister als Antwort. Solcherlei ungenaue oder fehlende Angaben zum Amtsübernahmealter betrafen insgesamt 4.3\% der Lehrkräfte.

293 Die Bezeichnungen für landwirtschaftliche Tätigkeiten umfassten ein breites begriffliches Spektrum von über einem Dutzend Variationen, von „Feldbau“, „ländliche Geschäfte“, „meine Güter besorgen“, „Gütergewerb“, „Laboureur“, „Agriculteur“, bis zu „Baurenarbeit“ oder „Tauner“. Vgl. Brühwiler, Finanzierung: 222. Die Begrifflichkeiten konnten sowohl bewusst in hierarchischer Abgrenzung verwendet worden sein - z.B. die zeitgenössische Unterscheidung zwischen Bauern und Taunern - als auch zufälligerweise in synonymer Absicht. 
Die Schaffung von Kategorien zur Sammlung der zahlreichen Tätigkeits- und Berufsangaben ist daher unumgänglich, um überhaupt Aussagen zur sozialen Herkunft anstellen zu können, doch wirft die Zusammenfassung der Merkmalsklasse „Tätigkeit“ in klassifizierbare Gruppen die Frage nach der Verfahrensweise der Gruppierung auf. Dazu kann man entweder auf zeitgenössische Berufsklassifikationen zurückgreifen, sofern solche vorhanden sind, oder aber eigene Kategorien bilden und ähnliche, nur leicht variierende Berufsausprägungen zusammenfassen. ${ }^{294}$ Als Folgeproblem der zweiten Vorgehensweise resultiert die Frage, wie viele Berufsgruppen notwendig sind, um das historische Personenkollektiv prägnant analysieren zu können. ${ }^{295} \mathrm{Die} \mathrm{Zu}-$ sammenfassung der Tätigkeitsgruppen basiert aus forschungspragmatischen Gründen auf dem kleinsten gemeinsamen wirtschaftlichen Nenner der einzelnen Berufstätigkeiten und orientiert sich an der Vorgehensweise der jüngsten Vorläuferstudien zur Gewährung einer rudimentären Vergleichbarkeit. ${ }^{296}$ Auf eine Verwendung von zeitgenössischen Berufskategorien wurde aufgrund der oben skizzierten begrifflichen Unschärfen verzichtet.

Die mannigfaltigen zeitgenössischen Tätigkeitsbezeichnungen aus der Stapfer-Enquête werden zu insgesamt elf Tätigkeitsklassen zugeordnet, deren Grundlage eine wirtschaftssektorale Betrachtung nach Produktionssektoren ist:

1 Landwirtschaftliche Tätigkeiten,

2 Protoindustriell-textilgewerbliche Tätigkeiten,

3 Handwerkliche Tätigkeiten,

4 Kaufmännische Tätigkeiten, ${ }^{297}$

5 Kommunale Amtstätigkeiten,

6 Kirchliche Amtstätigkeiten, ${ }^{298}$

7 Militärische Tätigkeiten,

8 Schreibertätigkeiten,

9 Theologisches Studium,

10 Keine Angabe,

11 Keine Ersttätigkeit.

Auf eine schichtorientierte Hierarchisierung der Berufsgruppen ist dagegen - mit Ausnahme der Kategorie der studierten Theologen - aus mehreren Gründen bewusst verzichtet worden.

294 Problematisch am ersten Verfahren ist, dass erstens die Kriterien für die jeweilige Klassifikation undifferenziert sind und zweitens die Zuordnung der konkreten Berufe zu den gebildeten Berufsgruppen nicht mehr nachvollziehbar wird. Schröder, Kollektivbiographie: $148 f$.

295 Nach Schröder haben differenzierte Gruppierungen für historische Personenkollektive bis zu 45 Berufsgruppen ergeben. Schröder, Kollektivbiographie: 149.

296 Ingrid Brühwiler operiert in ihrer Untersuchung mit neun Vorberufskategorien: Agrarische Tätigkeiten, kirchliche Tätigkeiten, Handwerk, Soldat, Studium, kein Beruf, immer Lehrer, weiterer Unterricht und Anderes. Brühwiler, Finanzierung: 229. Jens Montandon verwendet dagegen bloss fünf Berufsbereiche: Landwirtschaft, Handwerk und Gewerbe, Dienstleistungen und Verwaltung, Kirche, Höhere Ausbildung und Lehrbildungskurse. Montandon, Organisation: 96. Alexandra Bloch Pfister gliedert ihrerseits die Ersttätigkeiten der Zürcher Lehrerschaft um 1799 in 13 Gruppen: Bauer, Professionist, Protoindustrie, Hauslehrer, Schule, Handel/Verwaltung, Pfarrer, Fabrikarbeit, Taglöhner, Knecht, Soldat, Keine Tätigkeit, Keine Angabe. Bloch Pfister, Priester: 170. Vgl. auch: Ruloff, Schulbesuch: 110. Zur Schwierigkeit der Berufsgruppenbildung vgl. die allgemeinen Überlegungen von Schröder, der Zusammenfassungen von 10 bis 15 Berufsgruppen als „kleinster gemeinsamer Nenner“ für legitim hält. Schröder, Kollektivbiographie: 149.

297 Unter die kaufmännischen Tätigkeiten entfielen Ersttätigkeiten wie Kaufmann, Händler/Marchand, Handelsschreiber, Krämer oder Verkäufer.

298 Hierbei sind sämtliche sakralen Hilfsdienste subsumiert, die von weltlichen Personen ausgeübt und in der Regel bezahlt wurden, d.h. Mesmer/Sigrist-Tätigkeiten, Vorsänger- und Vorbeterdienste, Totengräber oder Verantwortliche für das kirchliche Uhrwerk. 
Erstens sind die originalen Tätigkeitsbegriffe aus den Quellen oft zu unscharf, um daraus direkt auf den sozialen Stand der Personen zu schliessen. Zweitens ermöglichen die Berufsbezeichnungen allein und ohne Einbezug von sozialem Kapital nur eine ungenügende Positionierung. Eine ebensolche eindeutige Positionierung ist nur bei den Geistlichen als Angehörige der lokalen Oberschichten überhaupt möglich. Drittens ist die Frage der Schichtzuteilung der Lehrkräfte selbst eine der wesentlichen Forschungsfragen und soll daher möglichst offen angegangen werden. Es muss aber betont werden, dass jede Kategorienbildung der Vielfalt der Lehrerantworten nie vollständig gerecht werden kann, zumal etliche der Tätigkeitsangaben keine eindeutigen, oder aber gleich mehrfache Zuordnungsmöglichkeiten aufwiesen. ${ }^{299}$

Die Auflistung selbst inkludiert ferner nur in der Stapfer-Enquête erwähnte Tätigkeitsgruppen, wodurch gleichzeitig ein Kontrast entsteht, der aufzeigt, aus welchen Tätigkeitsgruppen niemand Schulmeister wurde oder werden wollte. Die Untersuchung des Kandidatenfelds bei Lehramtsanwärtern mittels einzelner qualitativer Fallbeispiele trägt zudem bei, auch den erweiterten Kreis an Personen festzuhalten, für die das Lehramt zumindest eine berufsbiografische Option dargestellt hat, wodurch sich die soziale Herkunft der Lehrkräfte noch enger umreissen lässt.

\section{Die geografische Herkunft}

Die Frage nach der sozialen Herkunft der Lehrerschaft wird ferner mit der in der Stapfer-Enquête festgehaltenen geografischen Herkunft zu eruieren versucht, indem der Herkunftsort der Lehrkräfte mit dem Schulort zum Zeitpunkt der Umfrage verglichen wird. ${ }^{300}$ Die geografische Herkunft lässt als Analyseindikator die Frage zu, ob sich die Lehrkräfte aus dem lokalen Angebot an Arbeitskräften rekrutierten oder ob auf auswärtige Kandidaten zurückgegriffen werden musste, was Rückschlüsse auf das Rekrutierungsverhalten der Gemeinden und dessen Ursachen ermöglicht. Mit dem Ort der Herkunft verbunden sind ferner singuläre Erkenntnisse zur Ausprägung der biografischen Phase der Kindheit und Jugendzeit der Lehrkräfte in Form von freiwilligen Zusatzausführungen. Keine Aussagen sind jedoch aufgrund der Fragestellung zur juristischen Position der Lehrkräfte möglich. Es bleibt somit offen, ob Einheimische die Burgerrechte vor Ort genossen oder aber als rechtlich schlechter gestellte „Hintersassen“ potenziellen sozialen und ökonomischen Benachteiligungen ausgesetzt waren. ${ }^{301}$

\section{Die Nebentätigkeiten}

Die Ausgestaltung der Berufsbiografien als Lehrkraft hing von mehreren miteinander in gegenseitiger Abhängigkeit stehenden Faktoren ab. Das jährliche Einkommen aus der Schularbeit bestimmte in Abhängigkeit von der jährlichen Schuldauer die Notwendigkeit zur Ausübung von Nebentätigkeiten. Mit einzubeziehen ist demnach die jährliche Schuldauer als Ausdruck der ökonomischen Möglichkeit, überhaupt einer Nebentätigkeit nachgehen zu können. Es stellt sich somit die vierfache Frage nach der empirischen Häufigkeit von Nebentätigkeiten zum Lehramt, nach der Art der Nebentätigkeiten, nach den Motiven für oder gegen eine Nebentätigkeitsausübung und nach den biografischen Konsequenzen von Nebentätigkeiten im Sinne einer holistischen Erwerbslaufbahnbetrachtung.

299 Die Antwort des Lehrers von Lussery VD - „Precepteur Commun chés un Particulier dans le Diocèse de Nismes \{Patron\}, pendant environ trois ans \& demi; Régent à Savuit Paroisse de Lutry, pendant le sus dit terme une année écrivain par Lausanne; une année surveillant dans un Domaine aux environs de Genève; Landesy; deux ans Chasseur à Berne, Gerzencée; et deux ans malalade chés moi à Lausanne“ - verdeutlicht die Problematik von Mehrfachantworten. Schmidt u.a. (Hgg.), Stapfer-Enquête, Nr. Nr. 1834: Lussery.

300 Vgl. die Fragen III.11.c „Wo ist er her“ und III.11.g „Wo ist er vorher gewesen? Was hatte er vorher für einen Beruf ?" des Fragebogens im Anhang I.

301 Zum Status von Hintersassen vgl. die Ausführungen im Kap. 2.3. 
Die Nebentätigkeiten werden nach den gleichen wirtschaftssektoralen Merkmalsklassen operationalisiert wie die Ersttätigkeiten. Zusätzlich ist der Operationalisierung eine Kategorie für freiwillige, unentgeltlich ausgeübte Tätigkeiten oder reine Beschäftigungen zur persönlichen Musse hinzugefügt worden, die im weitesten Sinne modernen Freizeittätigkeiten entsprachen.

\section{Die Dienstdauer und lehramtliche Mobilität}

Die Dauer der ausgeübten Dienstjahre sowie die räumlichen Mobilitätsentwicklungen in Form von Stellenwechseln dienen als zentrale Indikatoren für die Rekonstruktion der Ausgestaltung der Erwerbstätigkeiten in der gesamtbiografischen Perspektive. Dabei wird von der Grundannahme ausgegangen, dass eine lange Ausübungszeit des Lehramtes für eine hohe intrinsische Motivation der Lehrkräfte, für einen hohen Grad an Zufriedenheit mit den Rahmenbedingungen und gleichzeitig für ein hohes soziales Kapital vonseiten der Gemeinden spricht. Hinter kurzen Ausübungsdauern und einem gesteigerten Fluktuationsverhalten kann dagegen entweder wirtschaftliche Opportunität oder persönliche Entscheide gegen eine Weiterausübung als prägende Leitmotive vermutet werden. Die Dienstdauer wird wiederum durch eine Gruppierung in Zeitdauer-Kohorten operationalisiert.

Von den beiden Merkmalsklassen der Lebensverläufe mit und ohne Stellenwechsel wird die letztere Kategorie genauer unter die Lupe genommen. Stellenwechsel zwischen einzelnen Lehrerstellen sind aus zweierlei Gründen von Relevanz für die Frage nach der Ausgestaltung der Tätigkeitsbiografien. Zum Ersten liefert die Häufigkeit von Stellenwechseln Anhaltspunkte für die Fluktuationsmöglichkeiten und den -druck innerhalb des öffentlichen Bildungsmarktes. Zum Zweiten muss neben der Quantität besonders auf die Orte des Wechsels fokussiert werden, wodurch Rückschlüsse auf eventuelle soziale Auf- und Abstiegsbewegungen möglich werden. Bewusste Stellenwechsel konnten eine Lehrerkarriere forcieren oder konnten zumindest mithelfen, die ökonomische Situation des Lehrers zu verbessern.

\section{Die fachlichen Fähigkeiten und das soziale Ansehen}

Abseits vom reinen materiellen Wohlstand durch Einkommen oder Vermögen ist das immaterielle „symbolische“ oder „soziale“ Kapital der Lehrkräfte von eminenter Wichtigkeit für die soziale Einordnung in der frühneuzeitlichen Gesellschaftsrangfolge, zumal ein ebensolches hohes Sozialkapital durchaus in der Lage war, materielle Einbussen auszugleichen. ${ }^{302}$ Geht man von einer zunehmend meritokratisch orientierten Lebenswelt am Ende des 18. Jahrhundert aus, in der fachlich "gute" Lehrkräfte vermehrt bewusst an besser bezahle Schulstellen rekrutiert wurden, stellt sich zwangsläufig die Frage nach den Fähigkeiten der Lehrer und nach eventuellen Zusammenhängen von Fähigkeiten und monetären Anreizen.

Die Erhebung und Operationalisierung der Fähigkeiten der Lehrerschaft in der Beherrschung der von ihnen unterrichteten elementaren Kulturtechniken wird durch einzelne regionale Schulumfragen ermöglicht und orientiert sich am jeweilig verwendeten zeitgenössischen Vokabular der prüfenden Geistlichen, unterteilt nach den vier Merkmalsklassen „sehr gut“, „gut“, „mittelmässig“ und „schlecht“.

Für die Einschätzung des sozialen Ansehens der Lehrkräfte dient dagegen der indirekte Indikator des „Vertrauens“ der Dorfbürger zu den Schulmeistern. Aufgrund der noch fehlenden Schulpflicht und der Abhängigkeit der Schulmeister von Schulgeldern konnte sich ein schwach ausgeprägtes soziales Ansehen in der Gemeinde rasch in schwindenden Schulbesuchszahlen und damit in ökonomischen Einbussen für die Lehrer manifestieren, wenn weniger Kinder 
das notwendige Schulgeld bezahlten. Ebenso konnten unbeliebte Schullehrer ihr Amt in Gemeinden mit Eigenwahlrecht rasch wieder verlieren. Das Vertrauen der Gemeinde als „soziales Kapital“ war daher eine soziale Schlüsselressource, die sich die Lehrkräfte erst sichern mussten, wollten sie langfristig erfolgreich arbeiten. Auch hier interessiert, ob das Vertrauen der Gemeinde in die Lehrkräfte mit der Besoldungssituation oder mit den Fähigkeiten der Schulmeister direkt korrelierte. Die Operationalisierung erfolgt durch eine duale Einteilung in die beiden Merkmalsklassen des fehlenden beziehungsweise des vorhandenen Vertrauens in die Lehrkräfte.

\section{Der Zivilstand und die Familiengrösse}

Zum erweiterten Betrachtungsbereich des materiellen Wohlstands und des Sozialkapitals gehören ferner der Zivilstand und die Familiengrösse. Sowohl der Zivilstand als auch die Familiengrössen sind für das gesamte Kollektiv aus der Stapfer-Enquête ableitbar. ${ }^{303}$ Das Eingehen einer Ehe bedingte ein gewisses Quantum an Geld, Sachkapital oder zumindest sozialem Kapital, um die ökonomischen und sozialen Heiratsschranken zu überwinden, die im 18. Jahrhundert vorherrschten. ${ }^{304}$ Es gilt demnach die Annahme, dass eine Heirat stets ein Ausdruck von ökonomischem Wohlstand beziehungsweise von einem hohen Grad an Sozialkapital und damit kein ausschliessliches Produkt von individuellen Entscheidungen war. Entsprechend rückt der Zivilstand der Lehrkräfte als Analyseindikator für den sozialen Status in den Vordergrund, sowohl was Heiratshäufigkeiten als auch die Motive für eine Heirat angehen. Der Zivilstand der Lehrer - entweder ledig, verheiratet, verwitwet oder als katholischer Geistlicher dem Zölibat wird damit zur konkreten Merkmalsklasse.

Ebenso wird die Grösse der Lehrerfamilien zum weiteren indirekten Indikator für den sozialen Status. Viele Kinder zu zeugen und zu ernähren, bedingte eine stabile wirtschaftliche Grundlage, denn nur allzu schnell konnte eine grosse Kinderschar in wirtschaftlichen Krisenzeiten zum Armutsfaktor werden. Unter der Annahme, dass die frühneuzeitlichen Lehrkräfte ihre Familienplanung bewusst den ökonomischen Ressourcen anzupassen versuchten, dient die Familiengrösse der Kernfamilie durch die Zählung der gezeugten Kinder, insbesondere bei den über fünfzigjährigen Lehrkräften als aussagekräftiger Indikator für ein kollektives Handeln innerhalb von wirtschaftsstrukturellen Grenzen. Die Anzahl der gezeugten Kinder bildet die Merkmalsklasse. $^{305}$

\subsubsection{Strukturelle Faktoren}

Aufgrund der immensen politischen und wirtschaftlichen Heterogenität der einzelnen Regionen innerhalb der Helvetischen Republik beziehungsweise der Alten Eidgenossenschaft unterlag das elementare Schulwesen sowohl lokal als auch regional völlig unterschiedlichen strukturellen Vorbedingungen. Den reziproken Einfluss von strukturellen Prägefaktoren auf das vormoderne Schulwesen und deren Akteure hat Heinrich Richard Schmidt hervorgehoben: „Es waren die lokalen strukturellen Faktoren, welche die Schweizer Elementarschule im 18. und auch noch im 19. Jahrhundert geprägt haben. [...] Strukturen steuerten, d.h. ermöglichten und beschränkten, menschliche Handlungen. Und diese Handlungen reproduzieren Strukturen - z.B. die Armut oder die ,zentralörtliche Funktion““306

303 Vgl. die Frage III.11.e „Hat er Familie? Wie viele Kinder?“ im Anhang I.

304 Vgl. zu den Heiratschranken das Kap. 4.2.1.

305 Später verstorbene Kinder sind mitgezählt worden. Es wird von der Annahme ausgegangen, dass den Schullehrern eine gewisse Kindersterblichkeit bewusst war und bei der Familienplanung mit eingerechnet wurde.

306 Schmidt, Elementarschulen: 49. 
Folglich sind auch die Lebensverläufe und biografischen Handlungen der Lehrkräfte beziehungsweise deren Handlungsstrategien stets gleichsam Ursachen als auch Folgen von strukturellen Voraussetzungen. Es ist also davon auszugehen, dass neben den persönlich-individuellen Entscheidungen der Lehrkräfte verschiedene äussere strukturelle Faktoren die individuelle biografische Entwicklung der Lehrpersonen massgeblich mitbeeinflusst und mitgeprägt, allerdings nicht auf jeden biografischen Indikator gleichermassen eingewirkt haben, weshalb sie in der Folge als Variablen betrachtet werden.

Die Strukturfaktoren lassen sich unterteilen in räumliche, organisatorische und persönlichindividuelle Merkmale. Zu den makroskaligen räumlichen Einflussfaktoren, die primär den Schulort geprägt haben, zählen zum einen die geografisch-wirtschaftliche Lage der Schule, zum anderen die vorherrschende Konfession sowie die Ausgestaltung der politischen Machtverhältnisse im Ancien Régime am jeweiligen Ort des Wirkens. Auf der stark kommunal geprägten schulorganisatorischen Ebene wirkten sich vor allem die Verfügbarkeit von Schulhäusern als Wohnraum für die Lehrer und die jährliche Schuldauer in markanter Weise auf die Lebensentscheidungen aus. Auf der personellen Ebene nahmen persönlich-individuelle Merkmale eine strukturell bestimmende Rolle ein, so etwa das Geschlecht oder das Alter der Lehrpersonen im Sinne einer Generationenzugehörigkeit.

Tab. 2: Strukturelle Faktoren und Variablen der Untersuchung

\begin{tabular}{|c|c|c|}
\hline Strukturelle Faktoren: & & Variablen: \\
\hline \multirow[t]{3}{*}{ Räumliche: } & Geografische Lage der Schule & Zentralort, Land \\
\hline & Konfession & Reformiert, katholisch \\
\hline & Ehemalige Herrschaft & $\begin{array}{l}\text { Untertanengebiet, Landort, zugewandter } \\
\text { Ort, gemeine Herrschaft }\end{array}$ \\
\hline \multirow[t]{3}{*}{ Schulorganisatorische: } & $\begin{array}{l}\text { Schulhaus und Wohnung } \\
\text { für die Lehrer }\end{array}$ & $\begin{array}{l}\text { Freie Schulwohnung (gemeindefinanziert), } \\
\text { eigenes Haus des Lehrers, getrennter } \\
\text { Wohn- und Schulort }\end{array}$ \\
\hline & Jährliche Schuldauer & $\begin{array}{l}\text { Ganzjahresschule, Winter- und } \\
\text { Sommerschule, Winterschule }\end{array}$ \\
\hline & Einkommen & $\begin{array}{l}\text { Über dem Mindestlohn, unter dem } \\
\text { Mindestlohn }\end{array}$ \\
\hline \multirow[t]{2}{*}{ Persönlich-individuelle: } & Generation & Junge, Erwachsene, Alte \\
\hline & Geschlecht & Mann, Frau \\
\hline
\end{tabular}

Diese insgesamt sieben strukturellen Untersuchungsfaktoren widerspiegeln gleichzeitig die von der bisherigen Forschung hervorgehobenen zentralen Bruchlinien und Deutungsmuster in Bezug auf die Ausgestaltung des elementaren Schulwesens. So hat etwa die Untersuchung der Einkommens- und Finanzierungsverhältnisse der Elementarschule durch Ingrid Brühwiler den markanten wirtschaftsräumlichen Gegensatz zwischen Stadt und Land untermauert. ${ }^{307}$ Ebenso hat jüngst Michael Ruloff den Schulbesuch der helvetischen Schulkinder mit ähnlichen Variablen untersucht. ${ }^{308}$ 
Die Wirkungskraft eines jeden strukturellen Einflussfaktors beziehungsweise seiner daraus abgeleiteten Variablen ist jedoch eine insgesamt offene Forschungsfrage, die erst empirisch zu klären ist. Allerdings sind sie nicht als starres Korsett zu verstehen, das der gesamten Untersuchung überstülpt wird, sondern die strukturellen Faktoren werden je nach Einzelfragestellung als Untersuchungsgrössen hinzugezogen. Jeder strukturelle Einflussfaktor soll im Folgenden mit seinen resultierenden Variablen kurz vorgestellt werden, zumal aus jeder räumlichen und personell-individuellen Variable wiederum ein eigenes Teilkollektiv an Lehrpersonen entsteht, das in sich eine Untersuchungsgrösse darstellt.

Neben den zuvor genannten Strukturfaktoren waren aber auch indirekte Einflussfaktoren wie die Schulorganisation vor Ort, die lokale Nachfrage nach Bildungsdienstleistungen oder personale Präferenzen der Lokalgemeinschaft von bedeutender Prägekraft auf die Ausgestaltung der individuellen Berufsbiografien der Elementarschullehrkräfte. Lokale kulturelle Traditionen und lokalökonomische Besonderheiten waren vermutlich ebenso entscheidend für die Art und Weise, wie, weshalb, und unter welchen Bedingungen jemand Lehrer wurde und als Lehrer arbeitete. ${ }^{309}$ Insbesondere die Ausgestaltung des Schulraums und die Festlegung der jährlichen Schuldauer waren lokalstrukturelle Einflussgrössen, die in der Analyse von Biografien mitberücksichtigt werden müssen.

Nicht als Strukturfaktor für die gesamte Untersuchung verwendet wird hingegen der Sprachraum. Sprache ist als Strukturdeterminante in der folgenden Untersuchung insofern irrelevant, da sowohl die Unterrichtssprache als auch die Sprache der verwendeten Materialien im Elementarschulwesen in allen Sprachräumen der Helvetischen Republik grundsätzlich der jeweiligen Muttersprache der Kinder entsprach. Ein ortsfremder Sprachunterricht konnte als schulisches Zusatzangebot zwar von der Lehrkraft angeboten werden, blieb aber auf individuelle Lektionen beschränkt oder richtete sich ausschliesslich an Kinder mit ortsfremder Muttersprache. So verfügten etwa zahlreiche Landstädte an ihren Schulen über eigene Lehrkräfte für ihre sprachlichen Minoritäten, insbesondere in der ehemals bernischen Waadt, wo deutschsprachige Lehrer speziell für die deutschsprachigen Kinder des Orts angestellt waren. Insgesamt unterrichteten die Lehrkräfte jedoch in der jeweils am Schulort vorherrschenden Sprache.

\section{Die geografische Lage der Schule}

In räumlich-geografischer Hinsicht wies das helvetische Schulwesen um 1800 enorme regionale und lokale Disparitäten auf. Folgt man dem Axiom der ökonomischen Logik, dass wirtschaftlicher Wohlstand als Treiber für eine hohe Schuldichte und für eine potenziell "gute“ Schule gewirkt hat, müssten die unterschiedlichen wirtschaftlichen Gegebenheiten im Ancien Régime als räumliche Grundlage für eine ökonomische Kategorisierung dienen. ${ }^{310}$ Denn durch den Rebbau und den Seehandel wohlhabend gewordene Gemeinden entlang des Genfersees oder des Zürichsees konnten sich eine ganzjährig dauernde und geschlechtergetrennte Schule in einem zweckmässig eingerichteten Schulhaus mit einem gut ausgebildeten Lehrer eher leisten als eine von Armut geplagte Berggemeinde der inneralpinen Feldgraszone, die keine ähnlichen Ausgaben stemmen konnte und den Schuldienst auf das Minimum reduziert halten musste. Der wirtschaftliche Wohlstand einer Gemeinde oder einer gesamten Region konnte einen Einfluss auf die Qualität und die Ausgestaltung des Schulwesens vor Ort haben. Die historischen Agrar- und Gewerbelandschaften des Ancien Régimes sind indes nur in ihren Kerngebieten klar voneinander zu unterscheiden, denn sie gingen an ihren Randgebieten fliessend ineinander

309 Horlacher, Leutnant: 25.

310 Vgl. zu den Agrar- und Gewerbezonen des Ancien Régimes die Ausführungen im einleitenden Kap. 1.2.2. 
über oder überlagerten sich gegenseitig, was eine passgenaue Zuordnung jeder Schulgemeinde zu einer Agrar- oder Gewerbezone problematisch macht. Deshalb wird im weiteren Verlauf der Untersuchung auf eine systematische Operationalisierung der Agrar- und Gewerbezonen verzichtet. $^{311}$

Demgegenüber ist die Abgrenzung zwischen Städten, Marktorten und ländlichen Orten durch das eindeutige Kriterium des obrigkeitlich verliehenen Stadtrechts beziehungsweise des Marktrechts deutlich einfacher und methodisch sauberer zu gewährleisten. ${ }^{312}$ In Städten und an Marktorten mit konzentrierten zentralörtlichen Funktionen kann von einer generell erhöhten wirtschaftlichen Aktivität und Wertschöpfung als Motoren von schulischen Investitionen ausgegangen werden. Entsprechend lassen sich sämtliche Schulen entweder in die Variablen „zentralörtliche Schule“ oder „Landschule“ einteilen. ${ }^{313}$ Rund $13.7 \%$ oder mindestens 315 Lehrkräfte arbeiteten zum Zeitpunkt der Umfrage an einer zentralörtlichen Schule. Hiervon entfielen 252 Lehrkräfte auf städtische Orte und weitere 63 Lehrkräfte auf Marktorte. Etwas mehr als jede zehnte Elementarschullehrkraft der Helvetischen Republik hatte demnach ihren Schulort in einem zentralörtlichen Umfeld, das zumindest von der ökonomischen Seite her am ehesten eine Bereitschaft zu Optimierungen der Schul- und Unterrichtsqualität bieten konnte. Es bleibt jedoch zu erforschen, ob sich an zentralörtlichen Schulen auch tatsächlich die fachlich besten Lehrkräfte einfanden beziehungsweise wer dort zum Schullehrer ernannt wurde.

Eine städtische Herkunft oder ein städtischer Arbeitsplatz bedeutete freilich nicht per se eine privilegierte soziale Position für die dort arbeitenden Lehrkräfte, zumal längst nicht alle Munizipalstädte oder Marktorte zu dynamischen Zentren des Wohlstands aufgestiegen waren. Zeitgleich existierten mitunter zahlreiche ländliche Orte ohne Stadtrecht mit durchaus deutlich grösserer Wohlstandsakkumulation - etwa durch Protoindustrie, landwirtschaftliche Spezialisierung oder durch spezialisiertes Gewerbe. Dennoch ist der ständischen Rechtsprivilegierung von Städten und von Marktorten gegenüber ländlichen Gemeinden eine grosse kategoriale Deutungskraft zuzusprechen, was auch die Zeitgenossen um 1800 noch taten, wie die Frage I.1.a „Ist es ein Stadt, Flecken, Dorf, Weiler, Hof ?“ des stapferschen Fragebogens bezeugt. Allerdings sind auch einzelne Orte ohne explizites Stadtrecht, aber mit deutlich ausgeprägten zentralörtlichen Funktionen und stadtähnlichem Charakter zu den „zentralen Orten“ zu zählen, etwa die Hauptorte Schwyz SZ, Stans NW, Sarnen OW und Glarus GL der zentralschweizerischen Länderorte. ${ }^{314}$

Neben der rechtlichen Differenzierung zwischen Städten, Marktorten und Landgemeinden konnte sich auf der lokalen Betrachtungsstufe ferner eine günstige Verkehrslage, etwa entlang von überregionalen Transithandelsrouten, positiv stimulierend auf die lokale Schule auswirken. ${ }^{315}$ Das galt aber in gewissem Masse auch für das nähere Umland von Städten und Markt-

311 Zur Problematik der Grenzen der Agrar- und Gewerbezonen vgl. Mattmüller/Schluchter, Vorwort: 6.

312 Vgl. Brühwiler, Finanzierung: 20.

313 Als ,zentralörtliche Schule“ gelten sämtliche Schuleinrichtungen, die in Orten mit obrigkeitlich verbrieften und bis zum Ende des Ancien Régimes gültigen Markt- oder Stadtrechten lagen, unabhängig von der tatsächlichen Grösse oder der Einwohnerzahl des Ortes. Hinzu kommen die Hauptorte der alten Landgemeindeorte, denen aufgrund ihrer konzentrierten Verwaltungs- und Herrschaftsfunktionen trotz fehlenden Stadtrechts eine stadtähnliche Funktion zukam. Auf eine weitere Differenzierung zwischen Munizipalstädten und Hauptstädten wurde verzichtet, da hierin kein spezieller Erkenntnisgewinn geortet werden konnte. Das Konzept des Zentralorts verwendet auch Andrea de Vincenti als Analyseraster in ihrer Untersuchung zu curricularen Räumen. De Vincenti, Wissensordnungen: 121-124.

314 Vgl. zur Kritik an der Abgrenzung von Städten und Flecken: Häusler, Flecken; Körner, Stadt.

315 Vgl. Ruloff, Schulbesuch: 100. 
flecken, wo eine verstärkte Orientierung auf die Versorgung der Städte mit Agrarprodukten einsetzte. Die saubere Abgrenzung solcher „verkehrsgünstiger“, „marktnaher“ oder „stadtnaher“ Gebiete ist jedoch aufgrund der nicht rekonstruierbaren Güterflüsse nur schwer möglich und wäre ein rein willkürlicher Akt, weshalb auf diese Variablen verzichtet wird. ${ }^{316}$

\section{Die Konfession}

Ausgehend vom Paradigma der Konfessionalisierung ist die Religion als bedeutsamer struktureller Einflussfaktor auf das elementare Schulwesen und auf die Lehrkräfte zu berücksichtigen. ${ }^{317}$ Die unterschiedliche Bedeutung der Konfession auf die Ausgestaltung der Schulwirklichkeit ist denn auch verschiedentlich betont worden, insbesondere in Forschungen zu gemischtkonfessionellen Gebieten. ${ }^{318}$ Noch immer ist die von der älteren Bildungsforschung geprägte Lehrmeinung eines Bildungsvorsprungs der reformierten Gegenden gegenüber den katholischen Regionen in der Historiografie der Bildungsgeschichte sehr persistent. ${ }^{319}$ Die seit den 1770 erJahren laufenden Reformtätigkeiten im aufgeklärten Katholizismus um die Einführung der Normalschulmethode nähren jedoch den Widerspruch an der angeblichen Rückständigkeit des katholischen Elementarschulwesens gegenüber den reformierten Schulen. Es ist demnach eine offene Frage, ob und inwiefern sich konfessionelle Differenzen durch die Organisation von Ausbildung, Schulgestaltung und schulischen Inhalten stimulierend auf die Lehrkräfte und ihre Berufsbiografien auswirkten.

Die tatsächliche Konfessionszugehörigkeit der Lehrkräfte ist zwar in den Antworten auf die Stapfer-Enquête nicht explizit festgehalten worden. Sie bleibt damit nur indirekt über die Lage des Schulortes oder über die verwendeten Schulbücher bestimmbar, doch sind von Seiten der Lehrkräfte in der gesamten Enquête keinerlei Vermerke bekannt, dass katholische Lehrer an reformierten Schulen oder vice versa reformierte Lehrkräfte an katholischen Schulen unterrichtet hätten. Darin wird die noch bestehende Hoheit der Landeskirchen über das elementare Schulwesen ebenso manifest wie die latente Furcht vor Häresien und „Irrlehren“ durch fremde Konfessionsangehörige - eine Furcht, die freilich sowohl in der einfachen Bevölkerung genauso geteilt wurde wie von der Obrigkeit.

Für die Untersuchung des Einflusses der Konfession werden demnach die beiden Variablen „reformiert" und „katholisch“ zur Operationalisierung verwendet. Auf eine gesonderte Untersuchung der wenigen paritätischen Schulorte wird dagegen verzichtet, da in der Regel jeweils die Mehrheitskonfession in den paritätischen Orten den Lehrer stellte und die Lehrkraft selbst als Angehöriger einer der beiden Konfessionsgruppen identifiziert werden konnte. In gemischtkonfessionellen Gemeinden entstanden in der Regel zwei separate Schulen mit jeweils eigenen konfessionszugehörigen Lehrkräften, tatsächlich gemischtkonfessionell-paritätische Schulen traten nur in einer Handvoll Fälle auf. ${ }^{320}$

316 Eine Regionalstudie aus dem Kanton Bern, die den Einfluss von verkehrsgünstigen Lagen gezielt untersuchte, ist die Lizentiatsarbeit von Jens Montandon: Montandon, Determinanten.

317 Vgl. zum Konfessionalisierungsparadigma die Ausführungen im Kap. 1.2.1.

318 Beispielhaft: Müller, Bestandesaufnahme: 247; Montandon, Organisation: $98 \mathrm{ff}$.

319 Böning, Revolution: 146ff; Schmidt, Bildungsvorsprung: 92, 103; Schraut, Mädchenbildung: 14ff.

320 Eine der seltenen gemischtkonfessionellen Schulen war beispielsweise im Weiler Rütihof bei Dättwil AG: „die Kinder auf dem Rüthihoof betreffend, wagte ich den Versuch, an diesem Ort selbst einen provisorischen Schullehrer aufzustellen, indem ich eine eigene Schulstuben einnemen konnte, und da die Zahlreichern Kinder der catolischen Bewohner nirgend hin in die Schule geschickt wurden, so ladete ich die Eltern ein, von dieser neüen Schule Gebrauch zu machen zum Besten ihrer Kinder; jezt sizen die Kinder beyder Religionen durch einander in Eintracht und Liebe, und fangen an, zu lernen." Schmidt u.a. (Hgg.), Stapfer-Enquête, Nr. 2288: Dättwil. Vgl. auch Müller, Bestandesaufnahme: 248 . 
Die in der Stapfer-Enquête namentlich erhobenen Lehrkräfte verteilten sich in konfessioneller Hinsicht höchst ungleich. Bloss 464 der total 2.305 Lehrkräfte oder 20.1\% sind aufgrund ihres Schulortes dem römisch-katholischen Glaubensbekenntnis zuzuordnen, was ein konfessionelles Verhältnis von 1:4 zwischen katholischen und evangelisch-reformierten Lehrern im untersuchten Kollektiv ergibt. Die massive konfessionelle Diskrepanz innerhalb des helvetischen Elementarschullehrerkorps war jedoch kein Ausdruck einer unterschiedlich dichten Beschulung in den beiden Konfessionsräumen, sondern erklärt sich primär durch die grossen quellentechnischen Überlieferungslücken aus dem katholischen Konfessionsraum.

Schuleinrichtungen anderer Konfessionsbekenntnisse fanden keinen Eingang in den Quellenbestand der Stapfer-Enquête. Von jüdischen Schulen gingen etwa auf die Fragen des helvetischen Bildungsministers keine Antworten ein. Zumindest in den beiden Gemeinden Endingen AG und Lengnau AG in der ehemaligen Grafschaft Baden hatte jedoch zweifellos vor 1800 mindestens eine jüdische Elementarschule existiert. Die beiden Gemeinden waren innerhalb der Alten Eidgenossenschaft die einzigen Orte, wo sich Juden offiziell niederlassen durften. Da das Judentum aber nicht als offizielle Religionsgemeinschaft anerkannt war und die Juden nur dem Landvogt und nicht den christlichen Gemeindebehörden unterstanden, erreichte die helvetische Verwaltungstätigkeit diese Schuleinrichtungen und ihre Schulmeister offensichtlich nicht, obgleich ein zeitgenössischer Bericht einen „relativ hohen Stand der Jugendbildung“ in den beiden jüdischen Gemeinden festhielt. ${ }^{321}$

\section{Die ehemalige Herrschaftsform}

Die Helvetische Republik brachte zwar allen Gemeinden die juristische Gleichheit und hob die komplexen rechtlichen Standesunterschiede des Ancien Régimes schlagartig auf, wofür insbesondere die Gemeinden der ehemaligen Gemeinen Herrschaften zuvor lange gekämpft hatten. Doch durch die Neufestlegung der kantonalen Grenzen nach der Helvetischen Revolution verschoben sich die herrschaftsrechtlichen Grenzen grundlegend und es entstand eine Reihe von teilweise neuen Kantonsgebilden fernab der historischen Grenzen, in denen die verschiedenen ehemaligen Herrschaftsformen gleichsam innerhalb desselben Territoriums inkludiert waren. Fast alle neuen helvetischen Kantone - besonders aber die gänzlich neuerschaffenen Kantone - bestanden nun aus einem Potpourri aus ehemaligen Untertanengebieten, Landorten, ehemaligen Gemeinen Herrschaften und zugewandten Orten. ${ }^{322}$ Entsprechend dieser vielfältigen Vergangenheit standen die kantonalen Erziehungsbehörden der Helvetischen Republik von Anfang an vor dem Problem eines lokal und regional fragmentierten Schulwesens innerhalb der neuen kantonalen Grenzen.

Die ehemaligen Stadtrepubliken verfügten im Ancien Régime über die grösste territoriale Ausdehnung. Landorte, zugewandte Orte und Gemeine Herrschaften machten dagegen nur einen verhältnismässig geringen Anteil des alteidgenössischen Territoriums aus. Dieses Ungleichgewicht schlug sich auch im elementaren Schulwesen nieder. So unterrichteten insgesamt 1.657 Lehrkräfte oder 71.9\% an einer Schule in einem ehemaligen Untertanengebiet. Weitere 397 Lehrpersonen oder

321 Guggenheim, Juden: 24ff. Ein Reisebericht des reformierten Pfarrers Hans Rudolf Maurers aus Affoltern am Albis $\mathrm{ZH}$ von 1794 beschreibt, dass in Endingen AG gleich vier Schulmeister für die Elementarbildung der jüdischen Kinder angestellt waren. Vgl. Kupfer/Weingarten, Ausgrenzung: 35, $40 \mathrm{f}$.

322 Territorial weitgehend unverändert blieben im Übergang vom Ancien Régime zur Helvetik einzig die Kantone Basel und Solothurn. Die neuen Kantone Aargau, Léman und Oberland entstanden aus ehemaligen Untertanengebieten und Gemeinen Herrschaften der Stadtrepublik Bern, der neue Kanton Thurgau entstand dagegen aus der ehemaligen Gemeinen Herrschaft Thurgau. Nur geringfügige territoriale Veränderungen erfuhren die Kantone Fribourg, Luzern, Schaffhausen, Zürich und Wallis. 
17.2\% standen einer Schule in einer ehemaligen Gemeinen Herrschaft oder an einem ehemaligen Schirm-ort vor. An ehemaligen Landorten unterrichteten dagegen bloss 157 Lehrkräfte (6.8\%), 94 weitere Lehrpersonen standen Schulen in ehemaligen zugewandten Orten vor (4.1\%).

Es ist davon auszugehen, dass sich die ungleichen ehemaligen Herrschaftsstrukturen auch nach dem Ende des Ancien Régimes auf die regionale organisationsstrukturelle Ausgestaltung des elementaren Schulwesens und damit auf die Lebensverläufe der Lehrkräfte fortwirkten. Gerade im Bereich der Lehrerwahl, aber auch hinsichtlich der jährlichen Schuldauer und der zu unterrichtenden Lehrinhalte nahmen die grossen reformierten Stadtrepubliken Bern, Zürich und Basel durch die Verabschiedung von Landschulordnungen einen markanten normativen Einfluss auf ihre Untertanengebiete. Es gilt folglich zu untersuchen, ob und inwiefern sich Unterschiede zwischen den vier grundsätzlichen ehemaligen herrschaftsrechtlichen Ausprägungen der Alten Eidgenossenschaft städtischen Untertanengebieten, Landorten, zugewandten Orten und Gemeinen Herrschaften in der Lebenswelt der Lehrkräfte durch die Prägung von Lokalstrukturen manifestiert haben. ${ }^{323}$

\section{Die Schulraumsituation}

Die Finanzierung und der Bau von Schulhäusern war Sache der Gemeinden. Ebenso vielgestaltig präsentierte sich folglich die Situation bezüglich des Orts der Schule. In zahlreichen Gemeinden bestanden um 1800 bereits eigens für die Schule gebaute Gebäude von freilich sehr unterschiedlicher Bauqualität. Manchmal bestand im Schulhaus zudem eine Wohnung, die der Lehrer gratis oder gegen ein Entgelt nutzen durfte, was ihm mitunter einen grossen sozio-ökonomischen Vorteil verschaffte. Denn mit der garantierten Wohnung konnte er einen eigenen Hausstand gründen und somit rascher heiraten. Häufig mussten die Lehrer jedoch entweder in ihren eigenen Häusern Platz für eine Schulstube schaffen oder auf eigene Kosten eine Stube in einem anderen Haus anmieten.

Ob eine Schule über ein eigenes Schulhaus verfügte oder ob die Lehrkraft selbst für die Bereitstellung des Schulraums sorgen musste, war ein Faktor, der sich mitunter stark auf die Entscheidung auswirken konnte, Lehrer zu werden oder blieben zu wollen. Bestand ein Schulhaus mit einer freien Schulwohnung oder bezahlte die Gemeinde zumindest einen Hauszins an die Lehrkräfte, konnten sich Personen um die Stelle bewerben, die keinen eigenen Wohnraum besassen. Verlangte die Gemeinde jedoch vom Schulmeister, dass dieser eine Schulstube stellt oder in eigenen Kosten mietet, schränkte sich der Kreis an Bewerbern automatisch auf Personen mit genügend eigenen Wohnraum oder auf vermögensstärkere Personen ein. Der Bau eines Schulhauses war denn auch eine äusserst kostspielige Angelegenheit - sei es für die Kommunen oder für die Schulmeister selbst. ${ }^{324}$ Bot dagegen eine Gemeinde sowohl eine Schulstube als auch freien Wohnraum an, konnte dies potentielle Lehrpersonen zum Zuzug von weit her animieren. Die Verfügbarkeit eines Schulhauses und einer freien Schulwohnung war demnach von grosser finanzieller und fluktuationstechnischer Bedeutung für die Lehrer und muss folglich als lokal

$323 \mathrm{Zu}$ den vier Formen von Herrschaft innerhalb der Alten Eidgenossenschaft vgl. die Ausführungen im Kap. 1.2.1 Schulen aus Gemeinen Herrschaften und Schirmorten wurden als Variable addiert, obwohl Schirmherrschaften zwar eine grössere Selbstverwaltung ausübten als Gemeine Herrschaften, aber in der politischen Realität dem Status einer Gemeinen Herrschaft näher standen als dem Status eines zugewandten Ortes. Vgl. Würgler, Schirmherrschaften.

324 In Eisenmoos BE wurde beispielhaft im Jahr 1798 ein neues Schulhaus erbaut. Die Kosten dazu beliefen sich für eine halbe Juchart Land auf 60 Berner Kronen und für den Hausbau 450 Kronen, ohne die Kosten für das Holz und die Steine. Als Referenzgrössen dienen ferner die käufliche Übernahme des Rechts an einer Schulstube in einem Privathaus in Brienz für 100 Kronen sowie der Kaufpreis eines Schulhauses in der Gemeinde Kandergrund BE, der sich auf 129 Kronen belief. Schmidt u.a. (Hgg.), Stapfer-Enquête, Nr. 878: Eisenmoos; Nr. 1595: Brienz; Nr. 1355: Kandergrund. 
wirksame Einflussvariable mitberücksichtigt werden. Die Stapfer-Enquête erhob die Schulraumsituation mit den Fragen IV.15a-d.

\section{Die jährliche Schuldauer}

Die äussere Organisation von Schule unterlag im Ancien Régime zum einen den Satzungen in den Landschulordnungen, zum anderen dem landwirtschaftlichen Arbeitszyklus und dem Willen der schulfinanzierenden Eltern. Letztere bestimmten de facto, wann und wie lange die Kinder in ihrem Ort zur Schule gingen, denn eine allgemeine Schulpflicht bestand noch in keinem Territorium der Alten Eidgenossenschaft. Entsprechend unregelmässig gestaltete sich der Schulbesuch der Kinder im Tages- und Jahresgang von Ort zu Ort. In der Regel wurde die Schule minimal während der Wintermonate vom Martinstag, dem 11. November, bis Ostern gehalten. In dieser Zeit war der Bedarf an Arbeitskräften im Zyklus der landwirtschaftlichen Tätigkeiten am geringsten. Eine verlängerte Schulzeit bis in den Sommer hinein durch verkürzte Sommer- oder Repetierschulen für die älteren Kinder, damit sie das Gelernte des Winters nicht verlernten, hatte sich in der zweiten Hälfte des 18. Jahrhunderts zum einen durch obrigkeitliche Mandate und zum anderen durch ein wachsendes Bedürfnis nach Bildung in weiten Teilen der Alten Eidgenossenschaft auszubreiten begonnen. Bis zum Ende des 18. Jahrhunderts konnte sich die Sommerschule oder gar die Ganzjahresschule jedoch noch nirgendwo in der Alten Eidgenossenschaft vollends durchsetzen. ${ }^{325} \mathrm{Zu}$ gross war der Bedarf an Arbeitskräften während der landwirtschaftlich intensiven Phasen der Erntezeit. In der schulischen Realität schwankte der Schulbesuch jedoch sowohl im Tagesgang, unter der Woche, als auch im Jahresgang von Ort zu Ort teilweise erheblich. Insbesondere im Winter war der Besuch der Schule oft witterungsbedingt sehr unterschiedlich stark, besonders in den voralpinen und alpinen Gegenden mit verstreuten Einzelsiedlungen, weiten Schulwegen, schlechten Pfaden oder schlechter Kleidung der Kinder aufgrund der elterlichen Armut. ${ }^{326}$ Ein regionaler Ausnahmefall war in der Ostschweiz im voralpinen, stark protoindustrialisierten Appenzell und in Teilen des Zürcher Oberlandes zu finden, wo die Kinder vorwiegend im Sommer die Schule besuchten, während sie im Winter kaum besucht oder ganz eingestellt war und die Kinder in der Heimindustrie mithelfen mussten. ${ }^{327}$ Doch auch an Orten mit Sommerschulen oder ganzjährigem Unterricht schwankten die Besuchszahlen im Tages- und Jahresgang je nach Bedarf der Kinder als Arbeitskräfte, nach Witterung oder nach der Willkür der Eltern mitunter enorm.

Die jährliche Schuldauer wurde annäherungsweise mit der Frage II.6 in der Stapfer-Enquête miterhoben. Aus den Antworten kann differenziert werden, ob die jährliche Schuldauer über die traditionelle Schulperiode von rund 18-20 Wochen vom St. Martinstag am 11. November bis Ostern hinaus weiterlief, ob Sommerschulunterricht angeboten wurde oder ob die Schule gleich das ganze Jahr über fortdauerte. ${ }^{328}$

325 Schmidt, Elementarschulen: 34.

326 Ruloff, Schulbesuch: 61-65.

327 Schmidt, Elementarschulen: 34ff. Die Entkoppelung vom ackerbaulichen Rhythmus entstand durch den ausserordentlich hohen Protoindustrialisierungsgrad, denn nur noch rund 1/5 der Bevölkerung Appenzell Ausserrhodens lebte um 1800 ausschliesslich von der Landwirtschaft. Ein ähnliches Phänomen ist auch für das deutsche Obererzgebirge festgestellt worden. Vgl. Neugebauer, Niedere Schulen: 226. Auch in einzelnen Schulen des Toggenburgs und des Zürcher Oberlandes konnten reine Sommerschulen nachgewiesen werden. Vgl. Schmidt u.a. (Hgg.), Stapfer-Enquête, Nr. 381: Büel. In den übrigen stark protoindustrialisierten Regionen der Helvetischen Republik, insbesondere der Basler Landschaft und dem Berner Oberaargau, konnten jedoch keine ähnlichen Verschiebungen der Schulzeit festgestellt werden. Eine lineare Kausalität zwischen einem hohen Grad an Protoindustrialisierung und dem Zeitpunkt der Beschulung ist daher nicht statthaft.

328 Als ganzjährige Schule wurden sowohl entsprechende Quellenaussagen als auch eine Schuldauer von mindestens 40 Wochen pro Jahr gezählt. 
Tab. 3: Jährliche Schuldauer aller Lehrer

\begin{tabular}{lc}
\hline Jährliche Schuldauer: & Anzahl Lehrer: \\
\hline Ganzjährige Schule & $1.058(45.9 \%)$ \\
Winter- und Sommerschule $^{329}$ & $599(25.9 \%)$ \\
Nur Winterschule & $626(27.2 \%)$ \\
Keine Angabe & $22(1.2 \%)$ \\
Total & $2.305(100 \%)$ \\
\hline
\end{tabular}

Insgesamt hielten bereits mindestens sieben von zehn Lehrkräften ihre Schule länger als die traditionelle Schulperiode - von wenigen Tagen bis hin zu mehrwöchigem Sommerschulunterricht. Obwohl sich die Ganzjahresschule noch nirgendwo flächendeckend institutionalisieren konnte, zeigen die Ergebnisse aus der Stapfer-Enquête, dass das minimale Modell der reinen Winterschule im späten 18. Jahrhundert bereits weitgehend am Verschwinden war und man sich um 1800 schon nahe an einer flächendeckenden Etablierung von Sommerschulen befand. Dies ist einerseits als eine der zentralen Leistungen der insgesamt durchsetzungsschwachen $\mathrm{Ob}$ rigkeiten zu würdigen, wenngleich die jährliche Schuldauer zumeist von den Kommunen in Eigenregie festgelegt wurde und letztlich vom finanziellen Spielraum sowie von der Bildungssensitivität der Gemeinden abhing. ${ }^{331}$

In der schulischen Realität des ausgehenden 18. Jahrhunderts waren die Sommerschulangebote jedoch sehr heterogen strukturiert, unterschiedlich organisiert und von zeitlich stark variabler Dauer. In der Regel dauerten Sommerschulen bloss ein oder zwei Tage pro Woche, da die restliche Zeit für agrarische Tätigkeiten genutzt wurde und die Kinder als Arbeitskräfte unentbehrlich waren. Doch auch blockweiser, mehrwöchiger Sommerschulunterricht zwischen den Ernteperioden kam als Variation vor. Auch die tägliche Schuldauer war im Sommer meistens verkürzt und Sommerschulen waren im Vergleich zu Winterschulen meist deutlich schwächer besucht, worüber sich zahlreiche Lehrer beklagten. ${ }^{332}$

Als einkommensrelevanter Faktor hatte die jährliche Schuldauer eine immens wichtige Bedeutung für die Lehrkräfte, weshalb sie als Variable in Verbindung mit lohnrelevanten Betrachtungen stets beizuziehen ist. Doch auch die Möglichkeit zur Ausübung von Nebentätigkeiten wurde durch die jährliche Schuldauer mitbestimmt, weshalb sie ferner in Bezug auf die Ausgestaltung der Erwerbsbiografien insgesamt von grosser Wichtigkeit ist.

329 Die Zählung beinhaltet sämtliche Formen von Schulunterricht nach der traditionellen Schulzeit von einem oder mehreren Tagen im Sommer, der aber nicht durchgehend stattgefunden hat. Eine feinere Ausdifferenzierung der Schulperioden erscheint angesichts der Vielfalt an zeitlichen Modellen von Sommerschulen methodisch nicht sinnvoll.

330 Inklusive der wenigen ausschliesslichen Sommerschulen im Appenzell, im Toggenburg und in Teilen der Zürcher Oberlandes. Als reine Winterschulen wurden Schulen mit einer jährlichen Schuldauer von weniger als 20 Wochen pro Jahr und keinerlei Hinweisen auf Sommerschulunterricht gezählt. Als Referenzdatum für das Schulende wurde nicht der damalige Ostertermin vom 24. März 1799, sondern der mittlere Ostertermin vom 8. April gewählt. Daraus ergibt sich eine Schuldauer von rund 21 Wochen, von der jedoch die schulfreien Weihnachtstage abgezählt werden müssen. Vgl. zur Berechnung der Schuldauer die Referenz bei: Brühwiler, Finanzierung: 200.

331 Vgl. die Ausführungen im Kap. 1.2.2.

332 Beispielhaft die Klage des Lehrers von Fehraltorf zur Zahl der Sommerschüler: „Somer, sehr verschiden, Anfangs gegen 100. und darüber, dann noch u. nach weniger, wie die Feld Geschäfte zunehmen, u. sich ver mehren, so vermindern sich die Schüler, oft auf 3. und 2. herab. bald sind mehr oder weniger Knaben, bald Mädchen doch Meistens der Letsten mehr." Schmidt u.a. (Hgg.), Stapfer-Enquête, Nr. 315: Fehraltorf. 


\section{Das Einkommen und Einkommensveränderungen}

Konkrete Anhaltspunkte zum sozialen Status der Lehrpersonen liefern neben den bereits angesprochenen Nebentätigkeiten und der sozialen Mobilität insbesondere die Einkommensverhältnisse. Ein hohes Einkommen aus der Schultätigkeit und ökonomisch bedeutsame Naturalleistungen wie das kostenlose Bewohnen eines Schulhauses oder Holzlieferungen zum Heizen der Stube im Winter sind direkte Indikatoren für einen gehobenen sozialen Status. Auf der anderen Seite musste ein kleines absolutes Einkommen aus der Schularbeit oder Klagen über die prekäre Besoldung nicht gleichbedeutend mit Armut sein, wenn zugleich ökonomisch lukrativere Nebentätigkeiten ausgeübt werden konnten, andere Ressourcen zur Verfügung standen oder das geringe Einkommen mit „sozialem Kapital“, einem hohen Ansehen, kompensiert werden konnte. Ferner konnte gerade das kleine Zusatzeinkommen aus dem Schuldienst als Mehreinnahmequelle den Unterschied zum Prekariat ausmachen.

Die Ausgestaltung und die Höhe der Lehrerlöhne sind massgeblich durch lokale schulorganisatorische Faktoren geprägt gewesen. Mit der jährlichen Schuldauer setzten die Gemeinden auch die Besoldung ihrer Lehrer weitgehend in Eigenregie fest. Diese bestand üblicherweise aus einem Mix aus Geldbeträgen und Naturalwerten. Die Lehrerlöhne flossen zwar in der Regel aus einer Vielzahl von unterschiedlichen Kapitalquellen, doch das Schulgeld der Eltern sowie Zuschüsse von den Gemeinden oder gemeindefinanzierte Schulfonds gehörten neben kirchlichen Zuschüssen - mit regionalen Unterschieden - zu den wichtigsten Finanzierungsquellen des elementaren Schulwesens. Zuschüsse aus den Zehnten, obrigkeitlichen Fonds und von fremden Kapitalgebern waren dagegen meist nur von untergeordneter beziehungsweise lokaler Bedeutung. ${ }^{333}$ Dadurch, dass die lokalen Instanzen, insbesondere die lokalen Eliten und die Hausväter, die Hauptlast der Schulfinanzierung trugen, sicherten sie sich das Mitspracherecht und die Kontrolle über das elementare Schulwesen. Die lokalen Finanzierungsverhältnisse hingen somit vorwiegend vom Willen der lokalen Eliten, den wirtschaftlichen Möglichkeiten und von der sozialen Situation vor Ort ab. Diese waren wiederum von zahlreichen strukturellen Faktoren, aber auch gesellschaftlichen Vorstellungen, mentalen Haltungen und individuellen Initiativen geprägt. ${ }^{334}$

Die daraus entstandenen immensen regionalen und lokalen Disparitäten zwischen den Lehrerlöhnen sind denn auch in verschiedenen neueren Studien hinlänglich dargestellt worden. ${ }^{335}$ In der vorliegenden Arbeit sind demnach nicht die absoluten Einkommen in einem quantitativen Direktvergleich von Interesse, sondern es soll vielmehr der Frage nach Interdependenzen zwischen der Einkommenshöhe beziehungsweise der Einkommensentwicklung und den biografischen Entwicklungen nachgegangen werden. So stehen Einflüsse von biografischen Voraussetzungen - etwa der individuellen Ausbildungswege, des Geschlechts, des Alters oder der erlernten Ersttätigkeiten - ebenso wie biografische Veränderungen durch die Konstellation der Nebentätigkeiten, Stellenwechsel, durch eine lange Berufstreue oder durch die fachlichen Fähigkeiten auf die Einkommensausgestaltung im Fokus.

Die Einschätzung des materiellen Wohlstands der Lehrkräfte bleibt aber insgesamt von grossen Unsicherheiten begleitet. Zum einen können zahlreiche ökonomische Einkünfte in Naturalform schlicht nicht als Geldwerte quantifiziert werden, da adäquate Bezugspunkte zur Umrechnung fehlen. Ebenso komplex und oftmals unmöglich sind Schulgelderträge aufgrund des stark schwankenden Schulbesuchs im Jahres- und Wochenverlauf zu bestimmen. Zum anderen fehlen

333 Brühwiler, Finanzierung: 32, 126-160. Der Befund erstaunt angesichts der Tatsache, dass die Abschaffung der Zehnten und übrigen Feudallasten durch die Helvetische Republik zu einem zentralen Narrativ für das finanzielle Unvermögen des helvetischen Staates zur Besoldung ihrer Lehrerschaft geworden ist.

334 Ehrenpreis, Säkularisierung: 31.

335 Brühwiler, Finanzierung; Brühwiler, salaries; Berner, Zeichen. 
breitflächige serielle Quellen zum Vermögen an Grund- oder Sachbesitz von Lehrkräften, um Aussagen von kollektiver Bedeutung treffen zu können. Einkommensvergleiche und Einkommensentwicklungen können daher nur fragmentarisch, und anhand von Einzelbeispielen aussagekräftig dargestellt werden.

\section{Die Generationen}

Anhand der Frage III.11.d „Wie alt?“ des stapferschen Fragebogens ist das genaue Alter von fast allen Lehrkräften der Helvetischen Republik zum Zeitpunkt der Umfrage bekannt. ${ }^{336}$ Die Momentaufnahme der Stapfer-Enquête umfasste Lehrkräfte eines enormen Altersspektrums, von damals erst Jugendlichen bis hin zu Greisen. War beim jüngsten in der Umfrage vermerkten Lehrer, Hans Jacob Foster von Happerswil TG, vermerkt: „Jst. 14. 1/2. Jahr Alt", 337 so war der mutmasslich älteste Lehrer zu diesem Zeitpunkt, Nicolas Burdin von Euseigne VS, bereits „environs 80 ans. “ ${ }^{338}$ Der durch die Umfrage erhaltene Querschnitt durch das helvetische Lehrerkorps inkludierte somit Personen aus allen Altersgenerationen.

Daraus erwächst das fundamentale methodische Problem, dass Direktvergleiche bestimmter biografischer Merkmale von Personen unterschiedlichen Alters, beispielsweise die ausgeübte Dienstdauer als Lehrkraft, gezwungenermassen zu generationellen Verzerrungen der Resultate führen. Eine Junglehrkraft konnte - folgt man exemplarisch dem Merkmal der Diensttreue aufgrund ihres geringeren Lebensalters theoretisch noch gar nicht so lange im Amt stehen wie das eine ungleich ältere Lehrkraft zum gleichen Zeitpunkt potenziell tun konnte. Entsprechend verzerrt erscheinen nicht nur quantitative Berechnungen, sondern auch qualitative Betrachtungen, zumal sich gesellschaftliche und politische Veränderungen mitunter auf die einzelnen Generationen auswirken konnten. Gerade die ältere kantonalgeschichtliche Schulgeschichtsforschung ist denn auch mit dem Vorwurf einer ungenügenden Differenzierung der Altersstrukturen bei der Betrachtung ihrer Lehrerkorps zu kritisieren. ${ }^{339}$

Es stellt sich jedoch die grundsätzliche Frage, nach welchen Kriterien die Lehrkräfte überhaupt in Generationen eingeteilt, als ,jung“, „,erwachsen“ oder „alt“ bezeichnet werden und wie Grenzen zwischen den Generationen gezogen werden können. Modelle zur Sequenzierung der Altersstufen innerhalb eines Lebensverlaufs gehen bereits auf die Antike beziehungsweise deren Rezeption im Mittelalter zurück und umfassten mehrere Lebensphasen von Kindheit, Wachstum, Erwachsensein, Alter und Greisentum. ${ }^{340}$ Dennoch fehlt für die Menschen der Frühen Neuzeit eine passgenaue zeitgenössische Terminologie zur Bezeichnung und Abgrenzung von einzelnen Phasen des Lebensverlaufs, da jede Bezeichnung von Generationen stets vom historischen und soziokulturellen Kontext abhängig ist. ${ }^{341}$

Da die Menschen in der Regel bis ins hohe Alter arbeiteten und damit berufsbiografisch aktiv blieben, fehlt - im Gegensatz zur modernen Lebensverläufen mit dem klaren jahrgangsspezifischen Übertritt in die Rente - eine vergleichbare markante Zäsur von der aktiven Lebenspha-

336 Das exakte Alter ist von 2.275 der 2.305 erfassten Lehrkräfte bekannt. Ohne genaue Angabe des Alters blieben folglich die Antworten zu 30 Lehrkräften.

337 Schmidt u.a. (Hgg.), Stapfer-Enquête, Nr. 812: Happerswil.

338 Schmidt u.a. (Hgg.), Stapfer-Enquête, Nr. 2159: Ayer, Euseigne, Mâche.

339 Die Kritik richtet sich an sämtliche kantonalen Schulgeschichtsforschungen bis zur Studie von Georges Panchaud von 1952 zur Waadt, der erstmalig eine altersdifferenzierte Betrachtung einzelner Faktoren etabliert hat: Panchaud, écoles vaudoises: 243-300.

340 Ariès, Kindheit: 76f.; Perrenoud, Lebenszyklus.

341 Vgl. zu den theoretischen Überlegungen des Alters- und des Generationenbegriffs in den Erziehungswissenschaften: Reinhardt, Erwachsenenalter: 116-204, insbes. 116f.; Wulf/Zirfas, Generation/Generationsverhältnisse: 215-221. 
se hin zum Alt-Sein in der zeitgenössischen Wahrnehmung. Nach François Höpflinger galten aber jene Personen als alt, „deren körperliche und geistige Kräfte schwanden; dabei handelte es sich nicht zwangsläufig um Personen, die ein bestimmtes kalendarisches Alter überschritten hatten. “342 Das konnte mitunter bereits für fünfzigjährige Männer und Frauen gelten. ${ }^{343}$ Literarische Werke aus dem 17. und 18. Jahrhundert stellten denn auch bereits Fünfzigjährige als alte Greise dar. ${ }^{344}$ In der Berner Volkszählung von 1764 wurde die Grenze zum Alt-Sein bei Männern dagegen mit sechzig Jahren und bei den Frauen mit fünfzig Jahren angegeben, wobei bei den Männern das Kriterium der Wehrfähigkeit, bei den Frauen die Grenze der biologischen Gebärfähigkeit als Richtschnur zur Abgrenzung verwendet wurde. ${ }^{345}$

Ebenso wenig wie das Alt-Sein war auch der Übertritt vom Kindes- zum Erwachsenenalter in der Frühen Neuzeit nicht an ein eindeutiges kalendarisches Altersmoment gebunden. Kindheit und Adoleszenz waren oft noch vermischte Begrifflichkeiten, deren Differenzierung als eigene Konzepte zur Einteilung des menschlichen Lebenszyklus erst im 18. Jahrhundert allmählich begann. ${ }^{346}$ Vielmehr war der soziale Zustand des Erwachsenseins neben dem Erreichen der biologischen Geschlechtsreife verknüpft mit der sozialen „Mündigkeit“. Diese war wiederum in einem fliessenden individuellen Prozess zwischen dem 25. und 30. Lebensjahr erreicht, sobald man verheiratet war und in einem eigenen Haushalt lebte. ${ }^{347}$ Heirat, Berufsfindung und die Schaffung einer eigenen ökonomischen Basis für die Familiengründung markierten somit das Ende der (männlichen) Jugendphase, die aufgrund des relativ hohen Erstheiratsalters von 27 bis 29 Jahren mitunter sehr lange dauern konnte. ${ }^{348}$

Auch die historische Demografie vermag keine eindeutigen Grenzen zwischen den einzelnen Lebensphasen festzumachen. Angesichts einer mittleren Lebenserwartung von bloss 30-47 Jahren waren die meisten Lehrkräfte am Ende des 18. Jahrhunderts als bereits relativ alt einzuschätzen. ${ }^{349}$ Neuere Forschungen einer umfangreichen Regionalstudie aus der deutschen Kleinstadt Schmalkalden legen jedoch den Schluss nahe, dass die Menschen schon in der ersten Hälfte des 18. Jahrhunderts - sofern sie einmal der Jugendzeit entwachsen waren und somit der verzerrende Effekt der hohen Kindersterblichkeit wegfällt - zum Zeitpunkt ihres Todes deutlich älter, im Mittel zwischen 55 und 60 Jahre alt wurden. ${ }^{350}$ Der Autor der Studie, Kai Lehmann, folgert, dass: „rund zwei Drittel der 18-jährigen Frauen und Männer 50 Jahre und älter wurden. Die Hälfte erreichte mindestens das 60. Lebensjahr und ein Viertel bis ein Drittel der Bevölkerung konnte mindestens seinen 70. Geburts-

342 Höpflinger, Alter.

343 Van Dülmen, Kultur und Alltag: 209f.

344 Ariès, Kindheit: $88 \mathrm{f}$.

345 Pfister, Strom: 70.

346 Ariès, Kindheit: 82f., 86-91; Van Dülmen, Kultur und Alltag: 80.

347 Perrenoud, Lebenszyklus; Dubler, Mündigkeit.

348 Die Definition einer Abgrenzung der Adoleszenz zur Erwachsenenphase anhand der drei Kriterien Heirat, Berufsfindung und Sicherung einer ökonomischen Basis ist nicht unumstritten, zumal sie einer einseitigen Orientierung an männlichen Lebensverläufen entspricht. Vgl. Mitterauer, Sozialgeschichte der Jugend: 27-31. Zum empirisch erhobenen Erstheiratsalter der Lehrer vgl. das Kap. 4.2.1.

349 Die tiefe durchschnittliche Lebenserwartung basiert auf der relativ hohen Säuglings- und Kindersterblichkeitsrate, die im 18. Jahrhundert zwar „allmählich zu sinken begann“, aber erst bis in 20. Jahrhundert auf weniger als 10\% sank. Höpflinger, Bevölkerungswandel: 131ff.; 147. Auch Richard van Dülmen hat zur Lebenserwartung der Menschen in der Frühen Neuzeit resümiert, dass „kaum ein Bauer sein 50. Lebensjahr“ erreichte. Van Dülmen, Kultur und Alltag: 204.

350 Vgl. die wegweisende Studie „1719“von Kai Lehmann, der anhand von Kirchenbüchern die Todesdaten erwachsener Personen über einen Zeitraum von fast 150 Jahren erhob. Untersucht wurden dabei die Sterbedaten von 3.613 Personen von mehr als 18 Jahren. Lehmann, Lebenserwartung: $160 \mathrm{f}$. 
tag feiern. [...] Im Umkehrschluss bedeutet dies aber auch und vor allem, dass ein Bauer, der 65 Jahre alt wurde, dass die Frau eines Leinenwebers, welche im Alter von 70 Jahren für immer die Augen schloss oder dass ein Taglöhner, der mit 75 Jahren seine letzte Ruhestätte fand [...], kein armseliges Leben führte, nicht Not und Elend litt und auch nicht in Mittellosigkeit lebte." 351

Weitere lokale Datenerhebungen zum Alter von Verstorbenen aus den deutschen Städten Trier und Oppenheim verweisen auf ähnliche Entwicklungen und markieren eine Kulmination der Todesfälle jenseits des fünfzigsten Lebensjahres. ${ }^{352}$ Die Lebenserwartung verteilte sich jedoch je nach Berufsgruppe sehr ungleich. Eine relativ hohe Lebenserwartung erreichten tendenziell wohlhabendere Personen wie Geistliche, städtische Beamte, Kaufleute, Ärzte und Wirte. Eine eher tiefe Lebenserwartung wiesen dagegen Handwerker, Taglöhner und Bedienstete auf. ${ }^{353}$ Aufgrund der fehlenden eindeutigen, an kalendarischen Alterskategorien festsetzbaren Grenzen zwischen den Generationen müssen die Generationenabgrenzungen künstlich gezogen werden. Angesichts des mittleren Erstheiratsalters, dem Kriterium der Ehemündigkeit ${ }^{354}$ und des mittleren Amtsübernahmealters ${ }^{355}$ wird die Grenzziehung zwischen der erweiterten „PostAdoleszenz" und dem eigentlichen Erwachsenenalter beim dreissigsten Altersjahr der Lehrkräfte gesetzt. Insgesamt $18.3 \%$ der helvetischen Lehrerschaft oder 422 Lehrer entfielen auf diese Altersspanne einer erweiterten Adoleszenz. Die Grenze zum „Alt-Sein“ ab dem fünfzigsten Lebensjahr ist dagegen begründbar mit der Zunahme des mittleren Sterbealters ab fünfzig Altersjahren und zeitgenössischen Wahrnehmungsbildern, die den Höhepunkt des Lebens und den Beginn des Alterungsprozesses auf nach dem fünfzigsten Altersjahr festsetzten. ${ }^{356}$

Entsprechend entstehen für die konkrete Operationalisierung der Generationen die drei Variablen der „jungen Erwachsenen“ bis zum 29. Lebensjahr, der „Mittleren Erwachsenen“ vom dreissigsten bis zum 49. Lebensjahr und der „Älteren“ jenseits des fünfzigsten Lebensjahres. Der überwiegende Teil der helvetischen Lehrerschaft gehörte mit rund $47.5 \%$ zu den „,mittleren Erwachsenen“, während 32.9\% der Lehrer zur Generation der „Älteren“ von über fünfzig Altersjahren zuzuteilen ist. Für die vorliegende kollektivbiografische Untersuchung ist die Generation der „älteren“ Lehrkräfte von mehr als fünfzig Altersjahren jedoch von besonderem Interesse, da jene Generation mit der längsten Lebensdauer auch gleichzeitig die längsten und damit aussagekräftigsten Erwerbsbiografien aufwies. Ihr soll ein besonderes Augenmerk geschenkt werden.

\section{Das Geschlecht}

Das Geschlechterverhältnis von Mann und Frau in der Elementarschule am Ende des Ancien Régimes stand in klarem Kontrast zur späteren geschlechterspezifischen Entwicklung des Lehrerkorps im 19. und 20. Jahrhundert. Während heute das Primarschulwesen fest in Frauenhand und der moderne Volksschullehrer vorwiegend eine Lehrerin ist, ${ }^{357}$ war die überwiegende Mehrheit der überlieferten helvetischen Lehrpersonen am Ende des 18. Jahrhunderts männlich, obwohl Frauen seit dem Mittelalter im privaten und öffentlichen Bildungsmarkt als Lehrende stets ebenfalls mitwirkten. ${ }^{358}$

351 Lehmann, Lebenserwartung: 161f.

352 Van Dülmen, Kultur und Alltag: 208f.; Zschunke, Oppenheim: 184f.

353 Zschunke, Oppenheim: $184 \mathrm{f}$.

354 Vgl. das Kap. 4.2.1

355 Vgl. das Kap. 2.2.

356 Vgl. Perrenoud, Lebenszyklus.

357 Beispielsweise belief sich der Männeranteil unter den Studierenden für das Primallehramt an der pädagogischen Hochschule Bern im Jahr 2015 auf bloss 10\%. Rutschi, Primarlehrer. Vgl. auch die Anmerkungen in der Einleitung.

358 Zur Rolle der Lehrerinnen seit dem Mittelalter vgl. die Darstellungen von Crotti, Lehrerinnen; Von WartburgAdler, Weg: $442 \mathrm{f}$. 
Durch die wachsende Bevölkerung und die damit verbundenen zunehmenden Klassengrössen, aber auch durch die reformpädagogische Kritik, gewann die Mädchenbildung im 18. Jahrhundert zunehmend an Wichtigkeit. So begannen wohlhabende Orte, zumeist Städte, geschlechtergetrennten Unterricht für die Mädchen an eigens eingerichteten Mädchenschulen einzurichten. ${ }^{359}$ Die Leitung jener neugeschaffenen geschlechtergetrennten Mädchenschulen wurde zwar zunehmend an Frauen übertragen, war jedoch kein automatisches Privileg für Frauen, denn etliche dieser Mädchenschulen wurden nach wie vor wie die übrigen Elementarschulen auch von Männern unterrichtet und geleitet.

Die weltlichen Lehrerinnen beider Konfessionsangehörigkeit sind ihrerseits in zwei funktionsspezifische Untergruppen zu teilen, nämlich zum einen in selbständige Lehrerinnen mit eigenständigem Lehrauftrag, zum anderen in informelle Hilfskräfte. Unter Letzteren sind Ehefrauen oder Töchter von Schulmeistern subsumiert, die im Rahmen der Familienwirtschaft vielfach einen Teil der Aufgaben des Ehemanns übernahmen. Mitarbeitende Ehefrauen oder Töchter werden aber nur selten explizit - und wenn, dann eher zufällig - in den Quellen erwähnt, so dass eine zuverlässige Einschätzung der Häufigkeit dieses Phänomens quantitativ unmöglich ist. Beispielhaft bezeugt ist etwa die Mitarbeit der Ehefrau im Schuldienst in den Anmerkungen eines Stadtzürcher Lehrers in der Stapfer-Enquête: „Obiger Schullehrer fleht animitus, daß man seine l. Frau, die ihm schon 15. Jahre in allen Treüen, und mit unnachläßlichem Fleiß, oft kränkelnd, in der Schule merkbar geholfen, auch wenn er nicht mehr leben sollte, lebenslänglich bedenken, und ein Gehalt machen wolle, weile Sie sich in diesen Jahren nur mit der Schule abgegeben, und die andern weiblichen Geschäfte hintansetzen müßen. - Doch getrost! Wahre Verdienste werden, wie er weiß, belohnt." ${ }^{\text {“360 }}$

Die Lehrerinnen stellen aber in der Quellenüberlieferung die grossen Abwesenden im Quellenkorpus der Stapfer-Enquête dar. Der Anteil an weiblichen Lehrpersonen blieb im relativen Verhältnis zu den männlichen Lehrenden insgesamt marginal, was sich massiv auf die Aussagekraft bei Geschlechtervergleichen anhand von aggregierten Daten aus der Stapfer-Enquête auswirkt. Ihre überlieferte Anzahl beläuft sich für die gesamte Helvetische Republik des Jahres 1799 auf lediglich 2.8\% aller namentlich erfassten Elementarschullehrkräfte, wobei allerdings eine unbekannte Anzahl an nicht identifizierbaren oder nicht erwähnten schulisch tätigen Ehefrauen, Töchtern oder sonstigen Helferinnen hinzugedacht werden muss. ${ }^{361}$ Aus Sekundärquellen sind etwa zahlreiche nicht erfasste Schulinstitutionen mit ihren Lehrerinnen bekannt, beispielsweise aus dem städtischen Umfeld von Aarau, ${ }^{362}$ Basel, ${ }^{363}$ Bremgarten, ${ }^{364}$ Fribourg, ${ }^{365}$ Liestal und Bettingen, ${ }^{366}$ Murten, ${ }^{367}$ Rapperswil, ${ }^{368}$ Sion und Sembrancher, ${ }^{369}$ St. Maurice ${ }^{370}$ sowie von St. Gallen. ${ }^{371}$ Bei Landschulen gestaltet sich die Rekonstruktion von nicht erwähnten

359 Vgl. zur Entwicklung der Mädchenbildung um 1800 in Deutschland: Mayer, Mädchenerziehung: 373-392. Als neuere Überblicksdarstellung zur Mädchenbildung im europäischen Kontext sei verwiesen auf: Jacobi, Frauenbildung.

360 Schmidt et al. (Hgg.), Stapfer-Enquête, Nr. 257: Zürich.

361 Die Stapfer-Enquête umfasst 66 namentlich bekannte Lehrerinnen sowie mindestens ein Dutzend namentlich nicht näher aufgeführte „Gehülfinnen“ oder Töchter von Lehrerinnen als Helferinnen.

362 StAAG HA 9131, o. Pag.: [1802] - Töchterschule Aarau; Vgl. auch Reimann, Stadtschulen: $218 f$.

363 Flueler, Mädchenbildung: 11-16.

364 StAAG HA 9405, o. Pag.: 14.08.1801 - Baden.

365 Crotti, Lehrerinnen: 72.

366 Zingg, Basel: $51 \mathrm{f}$.

367 Flückiger, Murten: 50-55.

368 LaGL HA, Protokollband 84, fol. 160-164: [1798] - Rapperswil.

369 Schmidt et al. (Hgg.), Stapfer-Enquête, Nr. 2235: Sembrancher.

370 Boucard, valaisanne: $57 \mathrm{f}$.

371 StASG HA R 132, Fasz. 1, o. Pag.: [1800] - General-Tabelle. 
Lehrerinnen noch schwieriger, doch existierten auch auf dem Land vereinzelt weitere Schulen mit Lehrerinnen. Aus der Basler Schulumfrage von 1798 hat man beispielsweise Kenntnis von zwei Landschullehrerinnen, die in der Stapfer-Enquête keine Erwähnung fanden, nämlich einer "Schulmeisterin“ in Muttenz sowie einer temporären Lehrerin im Baselbieter Dörfchen Tecknau. ${ }^{372}$ Im Fribourger Dorf Brünisried habe nach den Angaben von Johann Scherwey eine Barbara Fontana unterrichtet, von weiteren Mädchenschulen an anderen Orten des Standes Fribourg kann aufgrund von Nennungen in früheren Quellen ebenfalls ausgegangen werden. ${ }^{373}$ Ferner berichten Esther Berner und Alexandra Bloch Pfister von mindestens einer Nebenschullehrerin in Küsnacht ZH um 1770 sowie von der informellen sporadischen Beteiligung von Ehefrauen und Töchtern an der Schularbeit im Rahmen der Familienwirtschaft in rund einem Dutzend weiteren Schulen der Zürcher Landschaft. ${ }^{374}$ Aufgrund der insgesamt geringen Anzahl an Frauen im Elementarschulamt kann jedoch der männliche Terminus des Schulmeisters oder des Lehrers als massgebend für das Kollektiv der helvetischen Lehrerschaft verwendet werden. ${ }^{375}$ Entsprechende Vorsicht ist aufgrund der dünnen seriellen Datenlage bei der Interpretation von geschlechtsspezifischen Erkenntnissen auf der Basis der Stapfer-Enquête geboten. Insbesondere statistische Aussagen sind aufgrund der geringen überlieferten Fallzahlen nur von sehr bescheidener Aussagekraft. Dennoch lohnt sich ein Blick auf die geschlechtsspezifischen Differenzen, die sich aus den spärlichen Quellen der Stapfer-Enquête aggregieren lassen in mehrerlei Hinsicht: Zum Ersten sind Quellen aus der Ego-Perspektive über die vormodernen Lehrerinnen insgesamt sehr dünn gesät, was erst recht für seriell vergleichbare Quellen gilt. Zum Zweiten sind Geschlechterdifferenzen innerhalb einer homogenen Erwerbsgruppe von grossem sozialgeschichtlichem Interesse für das Verständnis von geschlechtsspezifischen Entwicklungen, zumal Aspekte von Gender zum Standardfragerepertoire der modernen Sozialgeschichte geworden sind. Zum Dritten ermöglicht eine Betrachtung der Lehrerinnen innerhalb des helvetischen Lehrerkorps ferner eine kritische Reflexion von zeitgenössisch oder später zugeschriebenen Geschlechterrollen und Geschlechterbildern.

\subsection{Der Aufbau der Arbeit}

Die vorliegende Studie gliedert sich gemäss den drei Hauptfragestellungen in drei Teile und folgt dabei gleichzeitig der chronologischen Entwicklung einer idealisierten Erwerbsbiografie von der Geburt bis zum Moment der Beantwortung der Stapfer-Enquête.

Der erste Teil entwirft das soziale Profil des zukünftigen Elementarschullehrers am Ende des 18. Jahrhunderts. Ausgehend von der Kindheit und Jugendzeit folgt die Skizzierung einer biografischen Chronologie bis zum Einstieg in die Lehrtätigkeit. Die geografischen Herkunft, das

372 StABL AA 1012 Lade 200, 07.01.01, fol. 185: 070.03.1798 - Bericht; StABL AA 1012 Lade 200, 07.01.01, fol. 217: 17.03.1798 - Bericht; Rothen, Lesen: 57.

373 Scherwey, Freiburg: 37; Tosato-Rigo/Savoy, Schulumfrageneifer: 111.

374 Bloch Pfister, Priester: 90; Berner, Zeichen: 94.

375 Begriffsgeschichtlich interessant ist der empirisch festgestellte Umstand, dass sich weibliche Lehrpersonen im Gegensatz zu den Männern fast ausnahmslos als „Lehrerin“ oder „Institutrice“ bezeichnet hatten. Der Begriff der „Schulmeisterin“ wurde dagegen im deutschsprachigen Raum der Schweiz als Selbstbezeichnung überhaupt nicht verwendet. In der französischsprachigen Schweiz existierten zwar die Begrifflichkeiten der „maîtresse d'école“ und der „régente“ als weibliche Termini, wurden aber nur in knapp einem Dutzend Fällen verwendet und wahrscheinlich - ebenso wie bei den Männern - synonym verstanden, wie das Beispiel der Gabrielle Crochat von Nyon VD zeigt, die ihre Vortätigkeit als "Jnstitutrice, ou maitresse d'Ecole“ beschrieben hatte. Vgl. Schmidt u.a. (Hgg.), Stapfer-Enquête, Nr. 1682: Nyon. 
Amtsübernahmealter, die ausgeübten Ersttätigkeiten der Elementarschullehrkräfte, die Zugänge zum Elementarschullehramt sowie die Kandidatenexamen markieren hierbei konkrete Anhaltspunkte für die Frage, wer am Ende des 18. Jahrhunderts zum Lehrer ernannt wurde und aus welchen Gründen oder Motiven jemand Lehrer werden wollte.

Der zweite Teil befasst sich mit der Ausgestaltung der Berufsbiografien ab dem Moment der Amtsübernahme. Thematisiert werden die ausgeübten Nebentätigkeiten, die Ausübungsdauer der Lehramtstätigkeit und die lehramtlich bedingte Mobilität im Spiegel der schulorganisatorischen Variablen und dem Einkommen.

Der dritte Teil sucht abschliessend nach einer Einordnung des sozialen Status der Elementarschullehrkräfte. Sowohl die Einkommensverhältnisse, die Einkommensveränderungen durch berufliche Mobilität, als auch die Fremdwahrnehmung der Lehrkräfte in Bezug auf ihre Fähigkeiten und ihre Familienverhältnisse dienen als Indikatoren für die tatsächliche Position der Lehrkräfte innerhalb der Gesellschaft. 



\section{Lehrer werden - das soziale Profil der Lehrer und Lehramtsanwärter}

Eine einheitliche Definition, wer überhaupt das Amt des Elementarschullehrers ausüben durfte, was ein Elementarschullehrer an Fertigkeiten mitbringen musste, um die Lehrertätigkeit ${ }^{376}$ ausführen zu können und ab wann man Lehrer werden konnte, existierte im Ancien Régime noch nicht. Entsprechend gross war die Diversität an Personen, die im öffentlichen Elementarschulwesen mitwirkten. Fast allesamt sind die Lehrkräfte in der bisherigen Forschungslandschaft zum Elementarschulwesen den gesellschaftlichen „Unterschichten“ zugeordnet worden. ${ }^{377}$ Doch welche Berufsgruppen der Frühen Neuzeit sind überhaupt jenen „Unterschichten“ zuzuordnen und rekrutierten sich die Elementarschullehrer tatsächlich aus den gesellschaftlichen Unterschichten?

Der Begriff der gesellschaftlichen „Schichtung“ entspringt dem modernen Sprachgebrauch des 19. und 20. Jahrhunderts und impliziert eine klare horizontale Trennung der Gesellschaft nach sozio-ökonomischen Kriterien unter der Annahme, dass innerhalb der Gesellschaft deutlich fassbare Rangunterschiede im Sinne einer Über- und Unterordnung bestehen. Es fehlen jedoch adäquate zeitgenössische Begrifflichkeiten zur Erfassung der gesellschaftlichen Verhältnisse in der Frühen Neuzeit, da insbesondere die Begrifflichkeit des „Standes“ von den Zeitgenossen nicht primär sozial, sondern vielmehr normativ-ethisch differenzierend begriffen wurde und daher durch seine Unschärfe nicht geeignet ist, um die individuelle Stellung in der damaligen Gesellschaft zu umreissen. ${ }^{378}$

Hinsichtlich der lokal, sozial, mental und rechtlich vielfach segmentierten und hierarchisch stark fragmentierten frühneuzeitlichen Gesellschaft sind eindeutige soziale Zuordnungen schwierig und die Übergänge zwischen Unter-, Mittel- und Oberschichten waren stets von fliessendem und dynamischem Charakter. Nach Hans-Ulrich Wehler sind der ökonomisch validierbare Besitz, politische Macht und das Sozialprestige als die drei ausschlaggebenden Dimensionen von sozialer Ungleichheit in der Frühen Neuzeit zu verstehen. ${ }^{379}$ Die Trennlinien zwischen Ober-, Mittel- und Unterschichten verliefen denn auch in mehrfacher Weise entlang des Grundbesitzes, von ökonomischem Vermögen und monetärem Einkommen, aber auch entlang immateri-

376 In der vorliegenden Studie wird der neutralere Begriff der „Tätigkeit“ gegenüber dem Begriff des „Berufs“ für die Lehramtsausübung bevorzugt. Der Terminus des „Berufs“ impliziert im modernen Verständnis eine langfristig ausgeübte Tätigkeit, die ein Mensch aufgrund einer Ausbildung oder besonderer Kenntnisse, Fertigkeiten und Erfahrungen als seine Aufgabe im Rahmen der Volkswirtschaft erfüllt und die ihm die Grundlage zu seiner Existenz schafft. Aufgrund der noch unsystematischen Ausbildungssituation ist der Begriff in der Anwendung auf die Lehrpersonen des frühneuzeitlichen Elementarschulwesens jedoch umstritten. Trotz spezifischen Kenntnissen in Bezug auf die Kulturtechniken und der verstärkten Betonung der inneren „Berufung“ im mittelalterlichen Sinne des Begriffs ist es eine offene Frage, ob die Tätigkeiten der Lehrkräfte als eine Lebenstätigkeit, die von einer Ausbildung und Qualifikation abhing, angesehen werden kann. Vgl. Dubler, Beruf. Zudem ist festzuhalten, dass sich im 18. Jahrhundert die Bedeutung der Begrifflichkeiten von Beruf, „Profession“ und „Amt“ im deutschen Sprachgebrauch zunehmend zu überschneiden begannen, wobei der Terminus des Berufs zwar allmählich aus der theologischen Deutung heraustrat und den säkularen Begriff der „Profession“ in den handwerklichen Bereich zurückdrängte, aber dennoch teilweise als ständisches Vokabular in uneinheitlicher Deutungszuschreibung verwendet wurde. Vgl. Conze, Beruf: 496-503.

377 Vgl. die Ausführungen im Kap. 1.3.3.

378 Hippel, Unterschichten: $4 f$.

379 Wehler, Deutsche Gesellschaftsgeschichte: $125 f$. 
eller Grenzen von sozialer und politischer Teilhabe am Dorfalltag sowie entlang des Kapitals an sozialer „Ehre“ beziehungsweise dem sozialen Prestige. Albert Schnyder hat denn auch die Notwendigkeit einer gleichrangigen Betrachtung von ökonomischen und immateriellen Elementen bei der Wertung der Sozialstruktur hingewiesen: „Welchen Platz Männer und Frauen bzw. ihre Haushalte innerhalb des sozialen Gefüges des Dorfes einnahmen, hing zwar sicher und in nicht geringem Mass von ihren ökonomischen Ressourcen ab. Ihr sozialer Status, und daraus abgeleitet die Grundlage ihrer sozialen Existenz, d.h. das Recht, im Dorf jemand zu sein, hing jedoch auch mit ihrem sozialen Verhalten innerhalb der dörflichen Öffentlichkeit zusammen, so z.B. mit ihrer Ehre. Dabei spielten familiäre Traditionen nicht selten eine wichtige Rolle; sie bildeten ein symbolisches Kapital, das vererbbar war und das nicht in direkt proportionalem Verhältnis zum ökonomischen Kapital stehen musste."380

$\mathrm{Zu}$ den lokalen Oberschichten der ländlichen Gesellschaft gehörten neben den Pfarrern von auswärtiger, meist städtischer Herkunft, die grundbesitzvermögenden Vollbauern mit eigenem Ackerzug $^{381}$ sowie die Inhaber von „ehaften Handwerken“ mit wertvollem infrastrukturellem Sachinventar. Dazu zählten Schmiede, Müller, Metzger, Bäcker und Wirte. ${ }^{382}$ Die Zugehörigkeit zu den lokalen Oberschichten manifestierte sich neben dem Grund- und Sachbesitz insbesondere durch die Teilhabe an der politischen Bestimmungsmacht oder in der Ausübung klientelistischer Patronage. ${ }^{383}$

Weniger trennscharf sind die soziohierarchischen Unterscheidungen zu den darunter folgenden Mittel- und Unterschichten. Nach Wolfgang von Hippel waren in der sozialen Übergangszone der dörflichen Hierarchie zwischen Ober- und Unterschichten als „Mittelschicht“ die Kleinhandwerker und Handwerkgesellen des Bau-, Versorgungs- und Textilgewerbes wie Küfer, Wagner, Schreiner, Schuhmacher und Schneider platziert. Darunter folgten die Kleinbauern respektive Tauner, deren schmale Existenzgrundlage auf der Basis des Grundbesitzes nur in „Normaljahren“ ausreichend für die Versorgung einer Familie war, die aber in Krisenzeiten sehr rasch in die temporäre Bedürftigkeit abrutschen konnten und daher gezwungen waren, Ergänzungstätigkeiten auszuüben. ${ }^{384}$

Die Frage nach der Armutsgefährdung ist somit ein entscheidendes Distinktionsindiz zwischen Mittel- und Unterschichten. Doch da im Ancien Régime deutlich zwischen unverschuldeter Armut aus Arbeitsunfähigkeit, der „würdigen Armut“, und selbst verschuldeter Arbeitsunwilligkeit, der „unwürdigen Armut“, unterschieden wurde, waren nur die „würdigen“ dörflichen Armen überhaupt berechtigt, Armenleistungen zu beziehen, während dem die unwürdigen Armen disziplinarisch verfolgt wurden. Zu den in würdiger Armut lebenden Unterschichten ohne ausreichenden Grundbesitz gehörten in der Regel das Dienstgesinde, landlose Hilfsarbeiter auf Tagelohnbasis, Hirten, textilverarbeitende Heimarbeiter, gemeine Soldaten, Alleinerziehende, Witwen und körperlich Invalide. Als in unwürdiger Armut lebende Unterschichten wurden dagegen Bettler, Prostituierte, als Kriminelle gebrandmarkte Personen, Juden, Umherziehende und Zigeuner angesehen, die keinen Anspruch auf lokale Armenfürsorge geltend machen konnten. ${ }^{385}$

Polyprofessionalität, besonders die saisonal getrennte Kombination von agrarischen und handwerklichen oder protoindustriell-textilproduzierenden Tätigkeiten, eröffnete der landarmen oder

380 Schnyder, Unterschiede: 160.

381 Mattmüller, Bauern: 382ff.

382 Meier, Handwerk: 221-267; Berner, Zeichen: 99.

383 Vgl. Pfister, Klientelismus: 152.

384 Hippel, Unterschichten: 5ff.

385 Vgl. Flückiger Strebel, Wohlfahrt: 74f.; Brühwiler, Finanzierung: 64. 
landlosen Bevölkerung jedoch zunehmend neue Möglichkeiten zur sozialen und ökonomischen Absicherung. Das erklärt das teilweise überproportional starke Wachstum der Unterschichten im 18. Jahrhundert trotz den immer knapper werdenden Ressourcen an Grundbesitz und Grundertrag. ${ }^{386}$ Diese Formen der polyprofessionellen Ökonomie der ländlichen Unterschichten, von David Sabean unter dem Begriff der „Ökonomie des Notbehelfs“ ${ }^{\text {“387 }}$ subsumiert, umfasste drei Bereiche: landwirtschaftliche Aktivitäten zur Ernährung der Familie, Lohnarbeit zur Generierung von Geldeinkommen sowie eigenständige Marktaktivitäten zur Veräusserung der produzierten Produkte. ${ }^{388}$ Die ökonomische Vulnerabilität der Unterschichten verringerte sich mit der polyprofessionellen Subsistenzstrategie der Notbehelfsökonomie in Krisensituationen jedoch trotz des Zugewinns an Flexibilität insgesamt nicht wesentlich. Im Gegenteil, der Anteil an unterstützungsbedürftigen Personen wuchs besonders in textilgewerblich-protoindustriell und handwerklich orientierten Dörfern zum Teil massiv an, sofern der Zugang zu agrarischen Ressourcen durch das Erbrecht oder durch Besitzkonzentration eingeschränkt war. ${ }^{389}$

Da das Elementarschullehramt in der Regel nur saisonal beschränkt während der Wintermonate und während einiger Tage im Sommer ausgeübt wurde, die Besoldung mehrheitlich in Geld und Naturalwerten bestand, stellte es hinsichtlich seiner Flexibilität und seines hohen Spezialisierungsgrades eine geradezu ideale Ergänzungstätigkeit im Kontext der polyprofessionellen Sammelwirtschaft dar. Es stellt sich somit die fundamentale Frage, ob - und inwieweit - Lehrkräfte des Elementarschulwesens das Lehramt als ökonomischen Notbehelf zur Armutsvermeidung im Geiste einer polyprofessionellen Ausrichtung ausübten. Ebenso muss erforscht werden, ob das Lehramt als Katalysator für die sozio-ökonomische Sicherung oder gar zum Aufstieg in die dörflichen Mittel- und Oberschichten genutzt wurde. Denn dass nicht alle Schulmeister des Ancien Régimes nur arme Schlucker waren, hat beispielhaft Thomas Meier in seiner Studie zur sozialen Situation von Professionisten für das Zürcher Unterland festgehalten: „Eine krasse Ausnahme bilden allerdings die Schulmeister, welche nicht nur rangmässig, sondern auch vom durchschnittlichen Landbesitz her selbst mit Ehaftenbesitzern mithalten können. “390

Auf die Grenzen einer allzu starren Schichtzuteilung einzelner Berufe der frühneuzeitlichen Gesellschaft in die klassische Trias von Ober-, Mittel- und Unterschichten hat ferner Albert Schnyder hingewiesen. Nicht nur ist das Kriterium des Grundbesitzes zur Einordnung von mischökonomischen Professionisten problematisch, sondern auch die dörflichen Oberschichten des Ancien Régimes stellten keineswegs eine homogen abgeschlossene Gruppe dar. Des Weiteren waren Angehörige der Oberschichten ebenso von sozialem Abstieg bedroht wie die Mittel- und Unterschichten. ${ }^{391}$

In einem ersten Untersuchungsschritt stehen demnach Fragen zur Eingrenzung der sozialen Herkunft der helvetischen Lehrkräfte im Zentrum der Untersuchung: Wer wurde überhaupt Lehrer beziehungsweise wollte um 1800 Lehrer werden? Aus welchen Tätigkeitsgruppen rekrutierte sich die Elementarschullehrerschaft und in welche sozialen Zugehörigkeitsmuster sind diese Lehrer einzuordnen? Für wen stellte das Lehramt eine berufliche Chance oder zumindest eine Alternative zum Erstberuf dar?

386 Hippel, Unterschichten: 16f.; Trossbach, Agrargesellschaft: 116.

387 Zit. in: Trossbach, Agrargesellschaft: 116.

388 Prass, Agrargeschichte: 109.

389 Vgl. die Einflüsse von Erbrecht, Grundbesitzverteilung und der Wirtschaftsstruktur auf die Sozialtopografie am Beispiel des Kantons Bern: Pfister, Strom; 293-310; Schmidt, Handlungsstrategien: 240.

390 Meier, Handwerk: 237.

391 Hauser, Wirtschafts- und Sozialgeschichte: 162; Schnyder: Unterschiede: 163. 
Lineare Schlüsse von der sozialen Herkunft auf das soziale Verhalten sind jedoch kritisch zu paraphrasieren. Nach Keiner und Tenorth sind die Herkunftsbedingungen allein noch kein brauchbarer Schlüssel zur Erklärung des sozialen Verhaltens. Es sei vielmehr notwendig, die Sozialisation in den Beruf und die berufliche Lage selbst als weitere Faktoren mit zu berücksichtigen. ${ }^{392}$ Hierzu müssen insbesondere die Wege zum Lehramt und die Dienstdauer der Lehrkräfte als Indikatoren für die Sozialisation in den Beruf miteinbezogen werden. ${ }^{393}$ Entsprechend beginnt die Untersuchung bei der Frage, ab wann und wie man überhaupt am Ende des 18. Jahrhunderts Lehrer werden konnte.

\subsection{Die Kindheit, Jugend und Ausbildung}

Jeder Lebensverlauf beginnt mit der Geburt und der darauf folgenden ersten Lebensphase der Kindheit und Jugend des Protagonisten. Über die Kindheits- und Jugendzeit der helvetischen Elementarschullehrer ist insgesamt aus der bisherigen Forschungslandschaft nur wenig bekannt, da hierzu kaum seriell verwertbares Quellenmaterial vorliegt. Auch die Stapfer-Enquête erhob keine expliziten Daten zu dieser ersten biografischen Lebensphase, die eng verknüpft ist mit der Frage nach der sozialen Herkunft der Lehrkräfte. Einzig vereinzelte Antworten auf die beiden Fragen III.11.c und III.1 1.g zur geografischen Herkunft und zu den Ersttätigkeiten ermöglichen in sehr bescheidenem Umfang fragmentarische qualitative Einblicke in die Kindheit der Lehrkräfte als erste Lebensphase.

Allerdings ist bereits das Postulat einer eigenständigen Kindheits- und Jugendzeit als erste biografische Entwicklungs- und Lebensphase ein modernes Betrachtungskonstrukt und nicht deckungsgleich mit den frühneuzeitlichen Vorstellungen von Lebensphasen. Nach Philippe Ariès war das Konzept der Kindheit bis zum Ende des 18. Jahrhunderts von zwei fundamental unterschiedlichen Vorstellungen geprägt: Im volkstümlichen Verständnis dominierte die Wahrnehmung einer „kurzen“ Kindheit mit einer Dauer bis ungefähr zum siebten Altersjahr, in der das Kind ein unbeholfenes Wesen war, das sich im Anschluss übergangslos unter die Erwachsenen mischte und bis nach der Pubertät als kleiner Erwachsener angesehen wurde. Die Vorstellung einer „langen“ Kindheit, in der die Kindheit und Jugend überhaupt eine eigene Lebensphase bilden, worin das Kind durch seine Schwäche und Unschuld einer besonderen Zuwendung von den Erwachsenen bedarf, existierte am Ende des 18. Jahrhunderts zwar bereits, setzte sich aber erst langsam von den gesellschaftlichen Eliten nach unten durch. ${ }^{394}$

Gerade die Institution Schule unterstützte jedoch durch die - wenn auch noch zeitlich flexible - Schulzeit eine allmähliche Verlängerung der kindlichen Lebensphase im Sinne des Konzepts einer „langen“ Kindheit für alle Menschen der damaligen Schweiz, allerdings ohne eine verbindliche fixe Altersobergrenze zu definieren. Überhaupt bildete der Besuch der Schule um 1800 trotz des noch fehlenden Obligatoriums zwar eine eigenständige biografische Phase innerhalb der Kindheit, doch existierte weder eine Altersuntergrenze beim Eintritt in die Schule noch eine Altersobergrenze für den Schulaustritt. Der Schuleintritt in die Elementarschule erfolgte mit regionalen und lokalen Unterschieden mehrheitlich zwischen dem fünften und siebten Lebensjahr, was zeitgenössische Reformpädagogen mit der „natürlichen Entwicklung“ des Kindes zu diesem Alterszeitpunkt befürworteten. ${ }^{395}$ Nichtsdestotrotz besuchten mitunter deutlich

392 Keiner/Tenorth, Schulmänner: 208.

393 Zur Dienstdauer vgl. das Kap. 3.4.

394 Ariès, Kindheit: 457-466.

395 Bütikofer, Staat: 173; Ruloff, Schulbesuch: $52 \mathrm{f}$. 
jüngere Kinder von vier oder weniger Altersjahren bereits sporadisch die Schulen. Sie folgten meist den älteren Geschwistern zur Obhut in die Schule, damit die Eltern zu Hause ungestört arbeiten konnten. ${ }^{396}$ Diese Bewahrungsfunktion geriet um 1800 jedoch allenthalben in Kritik und führte in den frühen Jahrzehnten des 19. Jahrhunderts zum langwierigen Diskurs über die Einrichtung von Kleinkinderschulen oder Kindergärten in der restaurierten Schweiz. ${ }^{397}$

Der biografische Übergang von der Kindheit ins Erwerbsleben der Erwachsenen wurde am Ende des 18. Jahrhunderts einerseits durch den Schulaustritt, andererseits durch die zeremonielle Aufnahme in die christliche Gemeinschaft in Form der reformierten Abendmahlszulassung respektive der katholischen Kommunion markiert. Beide Momente gingen in der Praxis meist zeitnah einher, indem die sakrale Zeremonie unmittelbar auf die Prüfungen der Kinder durch die Pfarrer zum Ende der Winterschule erfolgte. Somit ist eine deutliche lebensverlaufsspezifische Sequenzierung möglich. Der konkrete altersbezogene Zeitpunkt war allerdings aufgrund der nicht an ein fixes Alter gebundenen Abendmahls- beziehungsweise Kommunionsreife als Voraussetzung für das Verlassen der Schule flexibel und primär abhängig von der individuellen Reife des Kindes sowie vom Willen seiner Eltern, das Kind in die Schule zu schicken. Ferner oblag es den Ansprüchen der lokalen Pfarrer als Examinatoren, wann sie den Bildungsgrad und die religiös-katechetischen Fähigkeiten der ihnen anvertrauten Kinder als genügend für den Empfang der sakralen christlichen Weihe taxierten. Entsprechend individuell und different gestaltete sich der biografische Übergang von der Kindheit zum Erwachsenenleben für jede einzelne Person.

In der Regel erfolgten der Austritt aus der Elementarschule und die Erlangung der Abendmahlsbeziehungsweise Erstkommunionsreife in einer breiten Spanne zwischen dem 12. und 16. Lebensjahr, in seltenen Fällen früher oder später. ${ }^{398}$ Kinder, welche bereits früher aus der Schule entlassen, von ihren Eltern vorzeitig aus der Schule genommen wurden oder unter kognitiv-geistigen Beeinträchtigungen litten, mussten oftmals vor der Abendmahlsreife sogenannte Repetierschulen während der Sommermonate oder an tageszeitlichen Randzeiten besuchen, um ihre katechetischen Kenntnisse sowie die elementaren Kulturtechnikkompetenzen aufzufrischen. ${ }^{399}$ Der Besuch der Schule war jedoch nicht nur durch das schulische Angebot durch den Lehrer vor Ort, sondern mehrheitlich von ökonomischen Überlegungen vonseiten der Elternschaft gesteuert. Kinder und Jugendliche waren in den Augen der meisten nichtelitären Zeitgenossen um 1800 nicht nur unbeholfene Wesen, die erzogen, zu zukünftigen Christenmenschen und in volksaufklärerischer Sichtweise - zunehmend zu rationalen Staatsbürgern gebildet werden mussten, sondern auch nicht zu unterschätzende Arbeitskräfte für die kleinste ökonomische Einheit, die Familienwirtschaft. „Die zentrale Wirtschaftseinheit bildete [...] in erster Linie die Familie, wobei die Glieder je nach Beschäftigungsmöglichkeiten und Arbeitskapazität saisonal oder teilweise auch über die Lebenszeit auf verschiedene Weise zur Familienökonomie beitrugen. “ 400

396 Ariès, Kindheit: 330f.; Messerli, Lesen: 245f. Regionale Schülerlisten mit Altersangaben zeugen mitunter von erst vierjährigen Kindern in der Schule. Vgl. Jenzer, Schulklasse: 30; Rothen, Lesen: 41; Ruloff, Schulbesuch: $55 f$.

397 Messerli, Lesen: 246; Gruner, Bemerkungen: 141.

398 Bütikofer, Staat: 174; Rothen, Lesen: 41; Ruloff, Schulbesuch: 53f.

399 Dass geistig zurückgebliebene Kinder und Jugendliche teilweise bis über das 16. Altersjahr in die Schule gehen mussten, bezeugen Schulbesuchstabellen mit Altersangaben der Kinder, so beispielsweise aus der Basler Landschaft. In Hölstein BL wurde etwa die 17-jährige Schülerin Verena Tschopp mit den Worten „Jst ein halber Tohr und buchstabiert noch" geprüft. StABL AA 1013, Lade 201, Bd. 24 (B I), fol. 83: [1798] - Tabellen.

400 Berner, Zeichen: 93. 
Die Verpflichtung sämtlicher Familienmitglieder zum Erhalt der Familienökonomie betraf somit auch die Kinder. Kinderarbeit gehörte zum Alltag bei beinahe sämtlichen ruralen Bevölkerungsschichten, war aber auch in städtischen Haushalten der Unter- und Mittelschichten fast durchwegs üblich. Bereits kleinste Kinder führten simple Stall- und Feldarbeiten aus, mit zunehmendem Alter kamen neue Aufgabenbereiche in der Hauswirtschaft, in der Werkstatt oder auf dem Feld hinzu. Besonders der unterschiedliche saisonale Bedarf an Arbeitskräften im jährlichen Agrarzyklus wirkte sich prägend auf die Kindheits- und Jugendjahre der ländlichen Bevölkerung aus. Während der arbeitsintensiven Sommermonate war die Arbeitskraft der Kinder und Jugendlichen zur Unterstützung der elterlichen Subsistenz oftmals unentbehrlich. ${ }^{401}$ In zahlreichen Antworten aus der Hand von ländlichen Lehrkräften sind diese Lebenserfahrungen aus der Kindheit nachvollziehbar, wie exemplarisch der nachfolgende Bericht des Lehrers Hans Jacob Zimmermann aus Starkenbach SG verdeutlicht: „Er brachte die Meiste Zeit in der Jugend mit Lehren zu Bey Hauß dan zu winters Zeit wurde die schull auch in seiner wohung gehalten nach Ende deßen mußte ych mein Zeit Sommers Zeit mit ein samlung Futter, vor das Vieh und mit Holtz vor die behausung verrichten, und nach vielle Nebend Stunden an wenden zum Lehren. “402

Der frühe Miteinbezug der Kinder in die elterliche Hauswirtschaft ist denn auch in den wenigen ausführlichen Lehrerbiografien ein wiederkehrendes biografisches Element. Der spätere Stadtschullehrer Jakob Eggen verdiente bereits mit 14 Jahren sein erstes Einkommen als Schafhirte im Berner Oberland, ebenso wie der Armenschullehrer Buser in der Basler Landschaft, der schon ab dem elften Lebensjahr als Hirtenknabe und Posamenter arbeiten musste. ${ }^{403}$ In den protoindustriell dominierten Regionen der Alten Eidgenossenschaft, wo die textile Heimindustrie weit verbreitet war, wurden die Kinder und Jugendlichen, sobald sie eine gewisse manuelle Fertigkeit erlangt hatten, zudem nicht selten für Arbeiten an Webstühlen zur Verarbeitung von Flachs, Baumwolle oder Seide hinzugezogen. So lautete der Bericht des sechzigjährigen Lehrers von Hühnerbach BE, Hans Lehmann zu seiner Jugendzeit: „Jch wahr von Jugent auf zur Schul geneigt, und habe oft meinen Bruder in seyner Abwesenheit seiner Schull Dienste gethan. [...] jm. 12.ten Jahr meins alters wahre ich zu Herbst-Zeit Zum Hächler Handwärk gethan, im sommer hab ich so bald ich die fähigkeit hab gehabet, hab ich das Leinweben Lehren müßen. “ ${ }^{404}$

Die Mitarbeit der Kinder im Haushalt und im Gewerbe war dabei aber von eminenter Bedeutung, um die ökonomische Situation zusätzlich zu verbessern. ${ }^{405}$ Der Bedarf an der kindlichen Arbeitskraft hatte jedoch für die Schule den nachteiligen Effekt, dass viele Eltern ihre Kinder vorzeitig aus der Schule nahmen oder unregelmässig zur Schule schickten, was sich wiederum negativ auf das Schulgeld und damit auf das Schuleinkommen des Lehrers auswirkte. Dutzendfach überlieferte Klagen vonseiten der Lehrerschaft über zu kurze oder unregelmässige Beschulungsperioden bestätigen einen mangelhaften Schulbesuch. Kompensiert wurden solche Ausfälle oft mit den bereits genannten Repetierstunden zu Randzeiten. Insbesondere in protoindustriellen Regionen zeichnete sich der Schulabsentismus als ein ganzjähriges Übel aus, da die protoindustrielle Heimarbeit im Gegensatz zu den saisonal unterschiedlich intensiven Tätigkeiten der Landwirtschaft ganzjährig ausgeübt werden konnte, die Kinder somit sowohl

401 Herrmann, Familie, Kindheit, Jugend: 85; Scandola, Lehrerschaft: $5 f$.

402 Schmidt u.a. (Hgg.), Stapfer-Enquête, Nr. 513: Starkenbach.

403 Meyer, Langenthal: 27; Kradolfer, Lehrerleben: 12f.

404 Als „Hächlen“ wird das Kämmen von Flachs und Hanf bezeichnet. Vgl. Schweizerisches Idiotikon: 970f. Schmidt u.a. (Hgg.), Stapfer-Enquête, Nr. 666: Hühnerbach.

405 Herrmann, Familie, Kindheit, Jugend: 79. 
im Sommer als auch im Winter der Schule fernblieben. ${ }^{406}$ Die tieferliegende Ursache hinter dem stark schwankenden Schulbesuch lag jedoch letztendlich in der noch nicht durchgesetzten Schulpflicht gegenüber der elterlichen Freiheit zur Selbstbestimmung der Schulbesuchsdauer ihrer Kinder.

Zum unbeschwerten kindlichen Spielen blieb neben den Hilfsarbeiten für den elterlichen Haushalt und der Schulzeit fast keine Zeit mehr übrig. Eine Erwähnung von freier Kindheitszeit war denn auch in keiner Beantwortung explizit überliefert. Die Überprägung der Lebensverläufe durch die Mitarbeit im elterlichen Haushalt erscheint demnach als „typisch“ für fast alle Menschen der Frühen Neuzeit gewesen zu sein.

Einzig wenige sozio-ökonomisch privilegierte Kinder hatten auf dem Land - sofern überhaupt ein lokales Angebot bestand - die Möglichkeit, sich mittels Privatunterricht bei einem Privatlehrer, einem gebildeten Ortsbürger oder beim lokalen Pfarrer individuell über den Schulstoff der lokalen Elementarschule hinaus weiterzubilden, um später ein Studium an einer Universität absolvieren zu können. Aus dem Nekrolog des reformierten Appenzeller Pfarrers Leonhard Hohl von Wolfhalden AR, zur Zeit der stapferschen Umfrage gerade selbst ein eben der Elementarschule entlassener Jugendlicher, kann ein solches schulisches Zusatzangebot sinnbildhaft entnommen werden: „Leonhard Hohl, der Sohn des Ratsherrn Hohl [...] wurde in Wolfhalden geboren den 2. Februar 1784. Jn dortiger Primarschule eignete er sich an, was damals möglich war: eine schöne, leserliche Handschrift und durch vieles Auswendiglernen die Entwickelung seines vorzüglichen Gedächtnisses. Jn der Jugendzeit des Hohl war das Pfarrhaus in Wolfhalden, [...] ein Lieblingsaufenthalt fähiger Knaben und strebsamer Jünglinge, indem der verdienstvolle Ortspfarrer Walser neben drei seiner eigenen Söhne noch mehrere andere in seine Privatschule aufnahm, um selbige für das Studium der Theologie auf die Hochschule vorzubereiten. “407

Die Notwendigkeit zu privater Fortbildung nach dem Besuch der elementaren Schulen ergab sich aus dem Fehlen von höheren Schulinstitutionen auf dem Land, welche die Lücke zwischen Elementarbildung und Universität überbrückten. Weiterführende Real- oder Lateinschulen zur gezielten Vorbereitung auf das Universitätsstudium existierten nur in den Städten und grossen Marktflecken, zudem waren diese Schulen von unterschiedlicher curricularer Qualität und Ausrichtung geprägt. Für die zunehmend bildungssensitiven ländlichen und kleinstädtischen Eliten blieb daher der Rückgriff auf Privat- und Hauslehrer zur Förderung ihres Nachwuchses oftmals unumgänglich. Gleichzeitig schuf diese Lücke im ländlichen Schulsystem einen sozialen Zensus, der es ökonomisch schlechter gestellten Eltern in der Regel nicht gestattete, ihren Kindern eine weiterführende Bildung zu ermöglichen, selbst wenn es die intellektuellen Anlagen der Kinder erlaubt hätten. Der private Bildungsmarkt am Ende der Frühen Neuzeit ist in der historischen Bildungsforschung jedoch noch weitgehend unerforscht, obwohl er nicht nur im städtischen Milieu, sondern auch auf dem Land breitflächig parallel, ergänzend, aber auch subsituierend zum Elementarschulwesen in Erscheinung trat. ${ }^{408}$ Die Stapfer-Enquête erreichte Privatlehrer bedauerlicherweise nur zufällig, weshalb sich die Umfrage als Quellengrundlage zur Erforschung des privaten Bildungsmarkts nicht eignet. In den sporadischen Erwähnungen von Privatschulen

406 Ruloff, Schulbesuch: 62. „Die meisten Kinder werden hier überhaupt schon vor dem 5 Jahr in die Schule geschikt; und wenn sie die besten Anlagen - das schiklichste Alter - einen wirklichen Anfang im lesen und schreiben hatten wurden sie schon durch die Eltern der Schule enzogen - Dieses ist bey uns ein Haubtfehler vor die Jugend!“ Schmidt u.a. (Hgg.), Stapfer-Enquête, Nr. 296: Männedorf.

407 S. n., Hohl: 39 f.

408 Eine der wenigen Ausnahmen stellt die detaillierte Untersuchung von städtischen Privatschulen im Kurfürstentum Sachsen durch Thomas Töpfer dar: Töpfer, Freyheit. 
als Randnotiz der öffentlichen Elementarschulantworten sowie den wenigen einzelnen Antworten von Privatlehrern lässt sich jedoch erahnen, dass der private Bildungsmarkt nicht nur in den Städten, sondern auch auf dem Land eine zunehmend bedeutendere Rolle einnahm.

Nach dem Verlassen der lokalen Elementarschule und dem Erlangen der Abendmahlsreife erfolgte für die Jugendlichen in der Regel der direkte Einstieg ins Erwerbsleben. Hierbei öffneten sich zwei grundsätzliche biografische Pfade: Die meisten Jugendlichen wählten entweder die Berufstätigkeit der Eltern beziehungsweise des Vaters in der traditionellen ständisch-dynastischen Berufsweitergabe, oder aber sie absolvierten eine familienexterne Ausbildung in Form einer praktischen Anlehre bei einer Drittperson, wie es besonders bei Handwerkstätigkeiten üblich war. Danach folgte die Mitarbeit im elterlichen Haushalt, der typische Gesellenstatus eines jungen Handwerksgesellen mit der obligatorischen Wanderzeit nach dem Abschluss der Lehre, der sogenannten „Walz“ ${ }^{409}$, oder die Fortführung der erlernten Tätigkeiten bis zum Ableben der Eltern in der elterlichen Hauswirtschaft.

In Bezug auf die Lehramtstätigkeit zeigen sich - wie anhand der zuvor zitierten Aussagen sichtbar wird - ebenfalls zwei grundsätzlich verschiedene Pfade der berufsbiografischen Entwicklung ab dem Verlassen der Elementarschule: Zum Ersten der Weg einer linearen, kontinuierlichen Berufsbiografie mit dem sofortigen nahtlosen Übergang von der Jugendzeit in die eigentliche Ausbildungsphase zum Lehrer und der anschliessenden Ausübung der erlernten Berufstätigkeit als Vollzeit- oder Nebentätigkeit bis zum Zeitpunkt der Umfrageerhebung.

Zum Zweiten stand der berufsbiografische Pfad über das Erlernen und Ausüben einer ausserschulischen Ersttätigkeit dem direkten Berufseinstieg gegenüber, wobei der erst zu einem späteren Zeitpunkt stattgefundene Wechsel in das Lehramt als berufsbiografischer Wandel zu einer grundsätzlich nichtlinearen Berufsbiografie führte. Entsprechend der Verzögerung durch das Erlernen beziehungsweise Ausüben einer Ersttätigkeit erfolgte ferner der Einstieg in die Lehrtätigkeit mutmasslich später. Es stellt sich somit die doppelte Frage, ab welchem Alter die späteren Lehrkräfte in der kollektiven Betrachtung ihr Lehramt übernommen und womit sie sich zuvor beschäftigt hatten.

Bevor allerdings die beiden Einstiegspfade ins Lehramt reflektiert werden, sind die grundsätzlich existierenden Formen der Ausbildung zum Lehrer vor 1800 für die Alte Eidgenossenschaft und die Helvetische Republik zu skizzieren.

\subsubsection{Die Ausbildung zum Lehrer}

Die Berufsgeschichte der Elementarschullehrer erlebte während des „pädagogischen 18. Jahrhunderts ${ }^{\text {}} 410$ im Bereich der Lehrerausbildung ihre ersten grundlegenden Reformimpulse auf dem „Weg von anarchischen Formen der Lehrerausbildung zu privat oder staatlich organisierten berufspraktischen seminaristischen Ausbildungsformen." ${ }^{111}$ Im Spannungsfeld einer immer dichteren Beschulung der Landbevölkerung durch obrigkeitlich veranlasste Schulgründungen und durch einzelne praktische Reformprojekte von Volksaufklärern aus den gesell-

409 Reininghaus, Handwerkern: 195-212; Simon-Muscheid, Gesellen.

410 So der leicht veränderte Titel eines Sammelbandes von Ulrich Herrmann zum Thema der Volksaufklärung und Erziehung in Deutschland, der zu einem Schlagwort für die bildungstheoretischen Impulse im 18. Jahrhundert geworden ist. Herrmann, Jahrhundert.

411 Ebert, Schul-,Meister“: 37. Der Begriff „Ausbildung“ ist jedoch nicht in einem modernen Verständnis zu deuten, denn er suggeriert so eine klar umrissene zeitliche Phase mit einem eindeutigen Lern-Curriculum, das eine innere Vergleichbarkeit und gleichzeitige äussere Abgrenzung von Lerninhalten, Methoden und Lehrmitteln postuliert. Ausbildung im frühneuzeitlichen Sinn meint dagegen einen noch nicht standardisierten „Erwerb von spezifischen Qualifikationen oder Fertigkeiten“ durch Nachahmung oder Autodidaktentum. 
schaftlichen Eliten, aber auch aus der steigenden Nachfrage nach Elementarbildung aus der Bevölkerung, rückte das wachsende Bedürfnis nach einer verbesserten Schulbildung zunehmend ins breite gesellschaftliche Bewusstsein.

Der aus reformaufklärerischer Perspektive zunehmend als prekär deklarierte Sozial- und Bildungsstand der Elementarschullehrer wurde hierbei im Diskurs um eine erfolgreiche Reform des elementaren Schulwesens rasch als einer der Schlüsselfaktoren erkannt, womit auch die Diskussionen um geeignete Formen der Ausbildung für Elementarschullehrer lanciert waren. Es formierten sich gegen Ende des 18. Jahrhunderts gleich zwei Stossrichtungen mit gleichsam ähnlichen Zielsetzungen, einerseits „bottom-up“ von unten aus der Bevölkerung, andererseits „top-down“ von oben aus der Obrigkeit. Diverse Ideen und Modellvarianten zur Verbesserung der Lehrerbildung standen am Ende des Jahrhunderts zeitgleich miteinander im Wettstreit, entstanden neben- oder nacheinander und konkurrierten um die Gunst der Obrigkeiten ebenso wie um die Akzeptanz in der Bevölkerung. Doch wohin der Weg der Reformen allerdings führen sollte und welche konkreten Modelle zur Umsetzung am geeignetsten erschienen, darüber schieden sich allenthalben die Geister.

In der zweiten Hälfte des 18. Jahrhunderts setzten an unterschiedlichen Orten in Mitteleuropa in einer zeitnahen Entwicklung verschiedene Versuche ein, das Elementarschulwesen über Veränderungen in der Lehrerbildung zu reformieren oder zumindest die bereits existierenden Ausbildungsformen zu verbessern. Das galt insbesondere für die Frühphase der Helvetischen Republik, wo nicht nur Pestalozzis international bekannte Lehrerbildungsprojekte trotz ihres bescheidenen Erfolgs in der Breite auf grosse Resonanz in aufgeklärten Kreisen und das besondere Wohlwollen des Bildungsministers Stapfer stiessen, sondern mitunter auch andere Konzepte für die Verbesserung der Lehrerbildung unter den reformaufgeklärten helvetischen Eliten zirkulierten. ${ }^{412}$ Das Volksbildungswesen wurde gerade durch die revolutionäre politische Zäsur zu einem veritablen Laboratorium für reformaufklärerische Ansätze aller Art. Diesen Ausbildungsformen für die Elementarschullehrerschaft und den konkreten Ideen zur Verbesserung der Lehrerbildung soll ein erster Betrachtungsschwerpunkt gewidmet werden.

Der Zugang zum elementaren Schuldienst unterlag in der Alten Eidgenossenschaft bis am Ende des 18. Jahrhunderts noch keinen einheitlichen Regelungen und war zumindest formal für Jedermann und zu jedem Zeitpunkt zugänglich, der das Amt des Schulmeisters auszuüben begehrte. Gleichwohl standen verschiedenste Zugangspfade zum Lehramt und Ausbildungsformen in einem zeitgleichen parallelen Nebeneinander. In dieser Situation der offenen Zugänge unterschied sich die Ausgangslage im elementaren Schulwesen in der Alten Eidgenossenschaft jedoch nur wenig vom restlichen Mitteleuropa.

Die deutsche Schulgeschichtsforschung unterscheidet grundsätzlich drei verschiedene Pfade der frühneuzeitlichen Lehrerausbildung, die sich in Mitteleuropa seit dem 17. Jahrhundert nebeneinander gebildet und schematisch auch für die Alte Eidgenossenschaft ihre Gültigkeit hatten. Zum Ersten umschrieben das von der Handwerkerlehre übernommene Modell der praktischen Schulmeister-Anlehre bei einem etablierten Schulmeister, individueller Unterricht bei einem Pfarrer oder das Autodidaktentum die typischen individuellen, fachinhaltlich unsystematischen Varianten der Lehrerausbildung. ${ }^{413}$ Zum Zweiten bildeten einzelne lokale Institutionen in städtischen Waisenhäusern mit einem mehr oder minder formalisierten Curriculum an

412 Hier sei vor allem in der Schweiz auf die konkurrierenden Vorschläge von Johann Rudolf Steinmüller verwiesen, denen vonseiten der helvetischen Behörden jedoch deutlich weniger Anerkennung zukamen als Pestalozzis Projekte. Vgl. Tröhler, Lehrerbildung: 297-302.

413 Tuggener, Lehrer: 60. 
Unterrichtsfächern und Fachinhalten teilweise gezielt, mehrheitlich aber unsystematisch Landschulmeister für ihre lokale Umgebung aus. Zum Dritten führte die josephinisch-theresianische Schulreform von Johann Ignaz Felbiger, ausgehend von Schlesien, ab 1763 in den katholischen Landen zur Gründung von sogenannten „Normalschulen“ mit mehrwöchigen Ausbildungskursen für etablierte Landschullehrer und Lehramtskandidaten, in denen eine gänzlich neue Lehrmethode, die „Normallehrart“, systematisch vermittelt wurde. Keimzellen für die neuartigen Normalschulen waren einerseits höhere städtische Bürgerschulen, andererseits geistliche Einrichtungen, zumal zahlreiche gebildete Geistliche zu den Ausbildnern der ersten Stunde zählten. Daneben entstanden ab 1726 im Umfeld von höheren städtischen Bildungseinrichtungen - Gymnasien und Lateinschulen - vereinzelte Lehrerseminare mit szientifischem oder praktisch-technischem Gepräge. ${ }^{414}$

Während der letztgenannte Pfad in der Alten Eidgenossenschaft nicht existierte, fanden aber sowohl die Normalmethode in den katholischen Landesteilen partiell Eingang als auch weitere proto-institutionalisierte Ausbildungsformen. Eine zumindest in Ansätzen formalisierte Ausbildung für Lehrpersonen entstand unabhängig voneinander in den beiden reformierten städtischen Waisenhäusern von Zürich und Lausanne. So bildete zum einen die private École de Charité in Lausanne bewusst, wenn auch in bloss beschränktem Ausmass und in unsystematischer Art und Weise, Landschullehrer für die französischsprachige Waadt aus. ${ }^{415}$ Zum anderen wurden im Waisenhaus der Stadt Zürich einzelne Schulmeister für die Zürcher Landschaft ausgebildet. ${ }^{416}$ Ferner bezogen einige der weltlichen katholischen Landschulmeister ihre Ausbildung in den Kulturtechniken aus Aufenthalten in Klosterschulen. ${ }^{417}$

Eine flächendeckend formalisierte Ausbildung für Landschullehrer existierte allerdings in der Alten Eidgenossenschaft im Gegensatz zu einigen deutschen Territorien - abgesehen vom Stand Solothurn - noch nicht. ${ }^{418}$ Die Alte Eidgenossenschaft blieb punkto Lehrerausbildung gegenüber anderen europäischen Ländern, etwa Deutschland, Dänemark, Schweden, Holland und Österreich, noch „in argem Rückstand“ ${ }^{419}$. Es gab insgesamt weder einheitliche Mindestnormen an fachlichen, didaktischen und methodischen Fertigkeiten für Kandidaten, noch einen Konsens über die Formen der Ausbildung, von wem und wie Lehrer ausgebildet werden sollten, durch wen die Selektion erfolgen und wer die Entscheidungsgewalt über die Anstellung von Schulmeistern inne haben sollte. Auf die beiden in der Alten Eidgenossenschaft existierenden Ausbildungspfade für Elementarschullehrer soll im Folgenden genauer eingegangen werden.

Grossmehrheitlich erfolgte die Ausbildung zum Schulmeister nach wie vor über die traditionelle berufspraktische Anlehre bei einem etablierten Schulmeister oder durch autodidaktisch angeeignete Kenntnisse, selbst wenn genaue Quantifizierungen nicht möglich sind. Während in etlichen grösseren Städten Süd- und Norddeutschlands im 16. und 17. Jahrhundert in An-

414 Eine detaillierte Betrachtung der frühneuzeitlichen Ausbildungspfade hat Richard Seemann erarbeitet: Seemann, Schulpraxis: 7-46. Sabina Enzelberger umschreibt für die deutsche Bildungslandschaft am Ende des 18. Jahrhunderts ebenfalls drei grundsätzliche Formen der Lehrerausbildung: 1. Die Schulmeisterlehre, 2. Die Normalkurse, 3. Das zweijährige Landschulseminar, in Verbindung mit städtischen Waisenhäusern, Realschulen oder Gymnasien. Enzelberger, Sozialgeschichte des Lehrerberufs: 39.

415 Dévaud, École primaire: 82; Tosato-Rigo, Paroles.

416 Crespo, Waisenhaus. Vgl. das Kap. 2.2.1.

417 Beispielhaft besuchten die beiden Lehrer von St. Margarethen TG und Egerkingen SO die Klosterschule des Benediktinerklosters Fischingen TG. Ebenso erhielten die Lehrkräfte von Bad Ragaz SG, Reichenburg SZ und Sargans SG ihre Ausbildung im Kloster Pfäfers SG, ebenfalls eine Benediktinerabtei.

418 Helfenberger, Aspekte: 41.

419 Jenzer, Lehrerseminar: 19. 
lehnung an die städtischen Handwerke regelrechte Schulmeisterzünfte mit eigenen Zunftordnungen entstanden waren, ${ }^{420}$ blieb eine zunftmässige Organisation der Schulmeister auf dem Gebiet der Alten Eidgenossenschaft aus. Entsprechend existierten weder eine durch Zünfte reglementierte, systematisierte Ausbildung der neuen Schulmeister, noch Schutzfunktionen für etablierte Schulmeister gegenüber ortsauswärtigen Privatschulmeistern in eidgenössischen Städten. Ebenso wenig verfestigte sich ein eigenständiger, tradierbarer Kanon an Methoden und Fähigkeiten oder ein gemeinsames Standesbewusstsein auf der Basis geteilter Identifikationsmerkmale. ${ }^{421}$ Das elementare Lehramt war folglich eine unsystematische „zunftfreie“ Berufstätigkeit ohne jegliche formalisierte Exklusionsmechanismen gegenüber Aussenstehenden und stand damit im Prinzip für jedermann offen, der es auszuüben begehrte.

Dennoch ähnelte die „zunftfreie“ Schulmeisterausbildung als „Typus ständischer Personalrekrutierung “422 stark dem traditionell-ständischen Wissenstransfer der Handwerkerzünfte, da sie auf einer individuellen, praxisorientierten Weitergabe von spezifischem Wissen und methodischen Praktiken zwischen dem erfahrenen Schul-,Meister“ und seinem „Gesellen“, dem Schulgehilfen oder „Adjunkten“, basierte. ${ }^{423}$ Die Tätigkeit des Schulhaltens wurde mitunter als ein eigenes „Handwerk“ verstanden, was sich anschaulich in der Semantik des Begriffs des „Schulmeisters“ widerspiegelt. Als „Meister“ seines spezifischen Tätigkeitsfeldes orientierte sich der Schulmeister am praktischen Expertenkönnen und -wissen des Handwerksmeisters. Erst allmählich begann sich um 1800 der synonyme Ausdruck des „Schullehrers“ auf der Ebene der elementaren Schulen durchzusetzen, was vielfach in der älteren Forschungslandschaft als Angleichung an die Gelehrten der höheren städtischen Schulen und als erwachtes Standesbewusstsein interpretiert worden ist. ${ }^{424}$ Ob die befragten Lehrer der Stapfer-Enquête mit der gewählten Begrifflichkeit des „Lehrers“ an Stelle des „Schulmeisters“ aber tatsächlich eine bewusste semantische Differenzierung nach sozialem Status anstrebten, die auf ein gesteigertes Standesbewusstsein hinweisen sollte, ist nach umfangreichem Quellenstudium in Frage zu stellen. Beide Begriffe sind in der stapferschen Umfrage stark synonym verwendet worden, was sich in der etwa gleichen Häufigkeit der Verwendung manifestiert. ${ }^{425}$

Unter das Modell der individuellen, praxisorientierten Anlehre bei einem etablierten Schulmeister fiel zum einen die dynastische Weitergabe der Berufskenntnisse im innerfamiliären Kreis vom Vater auf den Sohn oder auf einen anderen nahen Verwandten. ${ }^{426}$ Doch die Weitergabe des Professionswissens erfolgte zum anderen auch auf nicht verwandte Drittpersonen, da

420 Seemann, Schulpraxis: 8-10. Vgl. auch Trinks, Sozialgestalt: 19; Walz, Eselsarbeit: 46; Sauer, Volksschullehrerbildung: 11; Rutz, Lehrer/in.

$421 \mathrm{Zu}$ den Ursachen des fehlenden Standesbewusstseins der Schulmeister resümiert Heinrich Tuggener: „Die soziale Isolierung, verschiedenartiges Herkommen der einzelnen Berufsträger, eine uneinheitliche, aufs Ganze planlose Ausbildung und die Bevormundung durch die Kirche lassen keine einheitliche Berufsgesinnung aufkommen." Tuggener, Lehrer: $62 \mathrm{f}$.

422 Neugebauer, Niedere Schulen: 227.

423 Tuggener, Lehrer: 60; Seemann, Schulpraxis: 11; Enzelberger, Sozialgeschichte des Lehrerberufs: 19.

424 Tuggener, Lehrer: 61f. Hinter der Berufsbezeichnung des Lehrers steht eine lange begriffsgeschichtliche Entwicklung, die im Mittelalter mit der Trennung von niederem und höherem Schuldienst begann und sich bis in die Moderne fortgesetzt hat. Während sich im 17. Jahrhundert die Termini „Schulhalter" und „Schulmeister" gleichsam verbreiteten, setzte sich im 18. Jahrhundert der Begriff des „Schulmeisters" durch, der seinerseits gegen Ende des 18. Jahrhunderts allmählich vom Begriff des "Schullehrers“ abgelöst wurde. Der Terminus des „Volksschullehrers“ ist dagegen ein weitgehendes Produkt des 19. und 20. Jahrhunderts. Vgl. Walz, Eselsarbeit: 49f. Für das ausgehende 18. Jahrhundert kann daher von einer weitgehenden Synonymie der Begrifflichkeiten ausgegangen werden.

425 Fuchs, Lehrerperspektiven: $189 \mathrm{f}$.

426 Vgl. dazu das folgende Kap. 2.2.1. 
insbesondere in der zweiten Hälfte des 18. Jahrhunderts deutlich mehr Schulen gegründet wurden und mehr Lehrkräfte benötigt wurden als über dynastisch-familiäre Netze bereit gestellt werden konnten. Der Wissenstransfer erfolgte dabei aber in einem weitgehend geschlossenen Kreislauf der direkten personalen Weitergabe durch das praktische Einüben als „learning by doing“, wobei die Bildungsinhalte und die Qualität der vermittelten Fertigkeiten stark durch die individuellen Kenntnisse des Ausbildners determiniert waren. Im liberalen Narrativ der Geschichtsschreibung des 19. und 20. Jahrhunderts wirkte diese frühneuzeitliche Schulmeisterlehre in der Retrospektive „planlos“ und „uneinheitlich“: „Es blieb durchaus den Bewerbern um Schulstellen überlassen, sich auf irgend eine Weise auf das Schulamt vorzubereiten. Gewöhnlich traten diese bei einem ,Schulmeister' als Adjunkt ,in die Lehre' oder suchten sich die nötigen Kenntnisse und Fertigkeiten durch Privatunterricht beim Ortspfarrer zu erwerben. “ ${ }^{27}$

Als äussere Korrektive auf die Inhalte und Methoden des Unterrichtens fungierten zum einen die lokalen Pfarrer, denen als unmittelbare Vorgesetzte der Lehrer die Aufsicht über die Schulmeister oblag. Daneben steuerten zum anderen die Bildungsnachfrage und Bildungssensitivität der Lokalbevölkerung massgeblich den Kanon an Unterrichtsinhalten. Natürlich konnten auch aus Eigeninitiativen von einzelnen Lehrkräften neue Impulse ausgehen, ${ }^{428}$ doch beschränkten die kommunalen und pfärrerlichen Ansichten zum Schulwesen dessen innere Ausgestaltung ungleich stärker.

Die Ausbildungstätigkeit an sich schien bei zahlreichen Elementarschullehrern nicht unbeliebt gewesen zu sein, zumal etliche Lehrkräfte aus der gesamten Helvetischen Republik eine ebensolche Tätigkeit in der Stapfer-Enquête ungefragt deklariert hatten. Einzelne Lehrer waren bisweilen sogar an weiter entfernte Orte gereist, um junge Lehrer auszubilden, wie der reformierte Lehrer von Starkenbach SG exemplarisch berichtet hatte: „ein Spatt Jahr mußte ich den Neü er wehlten Jungen Schull lehrer Jacob Eggly im Hag unter richten und auch Darbey sein schull von 31 kindr halten auf gut achten und Damahliger Landtvogts anrathen mit genehmigung des Pfarrers und Daßigem Stildstand. “ 429

Andernorts erarbeiteten sich erfahrene Schulmeister, meist in zentralen Orten situiert, aufgrund der ihnen attestierten pädagogischen Fähigkeiten einen entsprechenden positiven Ruf, worauf andere Landschullehrer aus der näheren Umgebung zu ihnen in die Lehre kamen oder auf Empfehlung der lokalen Pfarrer für ein paar Wochen zu individuellen Weiterbildungszwecken hinreisten. Solche bekannten Lehrer-Persönlichkeiten etablierten sich gewissermassen zu lokalen Zentren des unsystematischen individuell-persönlichen Wissenstransfers, indem sie als allgemein anerkannte Spezialisten des Unterrichtens andere Landschulmeister aus- oder weiterbildeten.

Am Beispiel der beiden reformierten Schulmeister der Schule von Weinfelden TG, Josef und Paulus Dünner, kann ein erstaunliches prosopografisches Netzwerk an regionalen Ausbildungsbeziehungen exemplarisch sichtbar gemacht werden. Josef Dünner hatte im Verlauf der Jahre in Zusammenarbeit mit seinem Sohn Paulus Dünner etliche Landschullehrer des Thurgaus ausgebildet. Beide galten als berühmte Persönlichkeiten unter den Thurgauer Landschullehrern und hatten in der Frühphase der Helvetischen Republik aktiv mit Stapfer zu Elementarbildungsfragen korrespondiert. ${ }^{430}$ So sind mindestens fünf Lehrkräfte aus dem Thurgau in der

427 Klinke, Zürich: 114f.; Tuggener, Lehrer: 63.

428 Vgl. Fuchs, Lehrerperspektiven: 162-165.

429 Schmidt u.a. (Hgg.), Stapfer-Enquête, Nr. 513: Starkenbach.

430 Vgl. Tosato-Rigo, Bild: 62; Josef Dünner hatte seine Ausbildungstätigkeit in der Stapfer-Enquête notiert: „Auch einiche welche zu Schullehreren habe Bilden müßen, die von Jhrern Pfarrern und Vorstehern, mir ubergeben worden." Schmidt u.a. (Hgg.), Stapfer-Enquête, Nr. 375: Weinfelden. 
Stapfer-Enquête überliefert, die von Josef Dünner oder seinem Sohn Paulus persönlich ausgebildet worden waren: die Lehrer Hans Geörg Huldi in Holzenstein TG, Johannes Kellenberg in Häuslen TG, Johannes Schalk in Mauren TG, Daniel Keller in Kümmertshausen TG und vermutlich auch Martin Kern von Berlingen TG. ${ }^{431}$ Einzelne dieser ausgebildeten Lehrkräfte wurden anschliessend wiederum selbst zu Distributoren ihres empfangenen Wissens. Daniel Keller in Kümmertshausen TG hatte etwa den Junglehrer Hans Jacob Foster aus Happerswil TG während eines Sommers zum Schullehrer ausgebildet. ${ }^{432}$

Die Anstellung eines auszubildenden Schulgehilfen brachte für den etablierten ausbildenden Schulmeister eine Reihe von Vorteilen mit sich, die das Ausbilden zusätzlich attraktiv machte: Erstens erleichterten die jungen Gehilfen dem Hauptlehrer die Arbeit markant, indem sie sich um einen Teil der Schülerschaft kümmerten, während sich die Gehilfen in der Praxis durch Abschauen und Imitation des Hauptschullehrers üben konnten. Gerade in Gemeinden mit hohen Schülerzahlen wünschten sich viele Lehrkräfte nicht selten einen „Adjunkten“ zur Entlastung anstellen zu können. Da der Unterricht in der Regel methodisch aus kollektivem Individualunterricht bestand, in dem die Schulkinder nicht in nach inhaltlichen Pensen in Klassen eingeteilt waren, sondern jeder Schüler gleichzeitig sein individuelles Pensum erarbeitete, musste der Lehrer bei jedem Kind einzeln den Lernfortschritt prüfen, was umso zeitintensiver war, je mehr Kinder in der Schule zugegen waren. ${ }^{433}$ Ein Gehilfe oder ein älterer Schüler konnte hierbei den Schulmeister entlasten, indem er die Abhör-, Abfrage- und Kontrollfunktion gegenüber den jüngeren Schulkindern übernahm. In Abwesenheitsfällen des Schulmeisters sorgten die Gehilfen überdies für eine unterbruchfreie Fortführung des Unterrichts, sofern kein Familienmitglied des Lehrers ersatzweise einspringen konnte.

Das Ausbilden junger Lehramts-„,Adjunkten“ war zweitens für erfahrene und gesellschaftlich angesehene Lehrkräfte eine relativ bequeme Möglichkeit, um sich einen lukrativen finanziellen Zusatzverdienst zu sichern. Als „Pensionaires“ schuldeten die Ausbildungswilligen dem Meister in der Regel ein Lehr- und Kostgeld, wie es in den Handwerksberufen gemeinhin Usus war. ${ }^{434}$ Der Baselbieter Lehrer Matthias Buser berichtete in seiner Autobiografie über einen eigentlichen Lehrvertrag, einen „Accord“, der seine Ausbildung gegen ein relativ bedeutsames Entgelt regelte: „Nun wurde mit Schullehrer [Erhard] Schneider ein Accord getroffen, dass ich in seiner Schule gegen eine Entschädigung von zwei Louisdors 12 Wochen arbeiten und Mittags an seinem Tisch essen dürfte. “ 435

Ebenso hatte auch der Berner Stadtschullehrer Johannes Knöri junge Lernwillige bei sich aufgenommen, wie er in seinem Bericht an Stapfer festhielt. ${ }^{436}$ Einige Lehrer in der französischsprachigen Waadt boten gegen ein entsprechendes Entgelt sogar spezielle Ausbildungsplätze für deutschsprachige Personen an, welche die französische Sprache erlernen wollten. ${ }^{437}$

Die Aufnahme von Ausbildungswilligen war damit eine finanziell attraktive Handlungsstrategie von Lehrkräften mit einem besonders guten Ruf zur Erweiterung des Schuleinkommens.

431 Schmidt u.a. (Hgg.), Stapfer-Enquête, Nr. 883: Affeltrangen; Nr. 1059: Häuslen; Nr. 84: Holzenstein; Nr. 366: Mauren; Nr. 94: Kümmertshausen; Nr. 229: Berlingen.

432 Schmidt u.a. (Hgg.), Stapfer-Enquête, Nr. 812: Happerswil.

433 Bloch Pfister, Priester: 138.

434 Enzelberger, Sozialgeschichte des Lehrerberufs: 19; Meier, Handwerk: 210.

435 Kradolfer, Lehrerleben: 24. Die Ausbildung Busers fand in Sissach statt. Der Wert von 2 Louis d'or entsprach rund 320 Basler Bz. (Umrechnung: 1 Louis d'or $=160$ Bz. Vgl. Notz, Kaufkraft: 52f.).

436 Schmidt u.a. (Hgg.), Stapfer-Enquête, Nr. 1082: Bern.

437 „Jl tient des pensionnaires Allemands à qui il enseigne l'Ecriture et la Langue française." Schmidt u.a. (Hgg.), Stapfer-Enquête, Nr. 1995: Rougemont. 
Der dritte Vorteil der praktischen Schulmeisterlehre lag in der Möglichkeit einer frühzeitigen Nachfolgeregelung. So konnte entweder ein eigener Sohn in ständisch-dynastischer Sicherungsabsicht oder ein guter Schüler frühzeitig als Ersatz für sich selbst und für das eigene Schuleinkommen aufgebaut werden. Damit liess sich eine personelle Kontinuität schaffen, die in der Regel ganz im Sinne der Gemeinde und auch des vorgesetzten Pfarrers war. Ferner darf die gesellschaftlich-soziale Bedeutung des sozialen Rufs nicht ausser Acht gelassen werden. Es ist anzunehmen, dass solche etablierten Ausbildner-Persönlichkeiten wie die zuvor erwähnten Vater und Sohn Dünner aus Weinfelden TG von ihrem positiven Ruf und dem Prestige auf lokalgesellschaftlicher Ebene profitierten. Dadurch dass sowohl ihr Name als auch ihre Fähigkeiten in einem weiteren Umkreis bei den Pfarrern und der Dorfbevölkerung bekannt waren, dürfte einerseits das nichtmonetäre soziale Ansehen gestiegen sein, andererseits die Position des Lehrers bei Lohnverhandlungen mit der Gemeinde ungleich stärker geworden sein.

Andererseits brachte das Ausbilden von Gehilfen mitunter auch gewichtige Nachteile für den Ausbildner mit sich. So mussten manche Lehrer ihr Schuleinkommen mit dem neuen Gehilfen teilen, wodurch die Anstellung eines Adjunkten für den etablierten Schulmeister ein finanzielles Risiko darstellen konnte. Einige Beispiele zeigen die Summen auf, welche die Lehrkräfte an ihre Gehilfen abgeben mussten. Die Lehrerin der Berner Stadtschule an der Aarbergergasse, Elisabetha Fetscherin, musste etwa ihre beiden unbekannten Helferinnen aus ihrem eigenen Schuleinkommen finanzieren. Sie notierte bei ihren Einkommensverhältnissen: „A: An Geld per Fronfasten dreyßig Cronen sechs bazen ein keüzer. B: Getreide alle Fronfasten fünf ein viertel Mutt. C: Wein alle Fronfasten einen Saum welschen Wein. D: Holz zehen Klafter für den ganzen Jahrgang. Anmerkung: Aus diesem Einkomen werden nun die zwey Gehülfinnen besöldert, jeder Person im Jahr fünf und zwanzig Cronen; Also Abzug deß Einkomens der Ober Lehrerin, sind fünfzig Cronen jährlich“ “438

Die beiden Helferinnen kosteten die - im Vergleich zu einem Landschullehrer zwar sehr wohlhabende - Lehrerin immerhin rund einen Viertel ihres jährlichen Gesamteinkommens. ${ }^{439}$ In einem anderen Fall musste der Landschullehrer von Ossingen ZH seinem Gehilfen ein Gehalt von knapp $20 \%$ des Gesamteinkommens abtreten. ${ }^{440}$ In finanziell schwierigen Situationen mussten manche Lehrer selbst bei hohen Schülerzahlen bisweilen auf Gehilfen oder Zweitlehrer verzichten, wenn die Gemeinde die Finanzierung nicht mehr sicherstellen konnte. So setzte der Lehrer Johannes Leuenberger von Ursenbach BE seinen Sohn als unbesoldeten Helfer ein, da ein zweiter Lehrer von der Gemeinde nicht mehr getragen werden konnte, die Schule im Winter jedoch von bis zu 100 Kindern besucht wurde: „Vor der Revolution, war noch ein Bey Schulmeister, welcher jährlich aus dem armen gute bezahlt worden, jetzt aber wegen Ersparung aufgehoben, dabey aber dem Schulmeister vergönnt ward, an Repetiertagen, oder wann bey schönem Wetter, sehr viele Schuler eintreffen seinen Sohn als Gehülfen nemmen zu können.“441

Da das Modell der praktischen Schulmeisterlehre auf dem Prinzip der Nachahmung basierte, indem der Schullehrling sowohl die guten als auch die schlechten Eigenschaften und Methoden des Meisters übernahm, tradierten sich ferner eine Reihe von Unzulänglichkeiten: So fand

438 Schmidt u.a. (Hgg.), Stapfer-Enquête, Nr. 1077: Bern.

439 Berechnung der Einkommensbestandteile: A: $4^{*}(30$ Kr. +6 Bz. +1 xr. $)=3.024$ Bz., 4 xr. B: $4^{*}(5$ 11/4 Mütt à 22 Bz. (Preis für 1 Mütt Kernen: StABE B VI 213, o. Pag.: [1783-1823] - Berechnung.)) = 462 Bz. C: $4^{*}(1$ Saum Wein à $190 \mathrm{Bz}$. (nach Brühwiler, Finanzierung: 346ff.)) =760 Bz. D: 10 Klafter Holz à 60 Bz./Klafter (Brühwiler, Finanzierung: 346$)=600 \mathrm{Bz} .=$ Total: $4.846 \mathrm{Bz} .4 \mathrm{xr}$. Die davon subtrahierten 50 Kronen $(1250 \mathrm{Bz}$. $)$ ergeben ein Jahressalär von 3.596 Berner Bz.

440 Der Hauptschulmeister verdiente an Geld rund 144.5 Gulden, der Gehilfe erhielt davon 27.5 Gulden. Schmidt u.a. (Hgg.), Stapfer-Enquête, Nr. 20: Ossingen.

441 Schmidt u.a. (Hgg.), Stapfer-Enquête, Nr. 659: Ursenbach. 
kaum eine Reflexion über die Unterrichtsvermittlung, die Methode oder über inhaltliche Themen statt. Der Verbleib bei den einmal erlernten Exempeln ohne Ausdehnung des Wissenshorizontes, mangelnde Selbstkritik über fehlerhafte Angewohnheiten und Marotten, sowie eine nicht kindgerechte Pädagogik waren als weitere Kritikpunkte an der praktischen Schulmeisterlehre der Frühen Neuzeit angebracht worden. ${ }^{442}$

Neben der eigentlichen, praktischen Ausbildung, die primär auf der Nachahmung der Unterrichtsmethoden des Schulmeisters durch seinen Lehrling basierte, markierte die individuelle Weiterbildung nach der Amtsübernahme den wichtigsten zweiten Pfeiler im Grundgerüst der unsystematischen frühneuzeitlichen Landschullehrerbildung. Im Gegensatz zum heutigen modernen Bildungswesen wurden von einem frühneuzeitlichen Lehramtskandidaten weder einschlägige Unterrichtserfahrung noch ein vollkommenes Repertoire an methodischen oder didaktischen Fertigkeiten zur Unterrichtsgestaltung erwartet. Vielmehr sollte sich ein tüchtiger Schulmeister durch seine praktische Tätigkeit, durch den Rat seines Pfarrers, durch sporadische Weiterbildung bei einem anderen Schulmeister oder durch individuelle Lektüre kontinuierlich in seinen Fertigkeiten verbessern. Man konnte also Lehrer werden, ohne jemals eine entsprechende Ausbildung absolviert zu haben. Es ist daher naheliegend, dass die ersten Reformmassnahmen im Elementarbildungswesen im späten 18. Jahrhundert, namentlich die Normalschulkurse nach Felbiger, aber auch die zahlreichen gedruckten Broschüren zur Verbesserung des Schulwesens an die Adresse der Landschullehrer ${ }^{443}$ sowie die zahlreichen Pläne aus Stapfers Ministerium während der Helvetischen Republik zur Hebung der Lehrerbildung primär die Weiterbildung des bereits bestehenden Lehrerkorps ins Auge fassten. ${ }^{444}$

Die lokalen Pfarrer waren hierzu die Schlüsselpersonen zur Förderung des Bildungsstandes der Landschulmeister. Sie übernahmen in Einzelfällen auch die Ausbildungsfunktion für junge Schulmeister, obwohl „die Ausbildung künftiger Landschulmeister durch Pfarrer [...] nicht die Regel [war].“445 Die beständige Weiterbildung ihrer untergebenen Schulmeister gehörte zwar zum Aufgabenkatalog der Pfarrer, nicht aber deren Primärausbildung. ${ }^{446}$ Dennoch übten einige Pfarrer diese Funktion auf freiwilliger Basis aus und entwickelten sich zu ebensolchen individuell-persönlichen Zentren lokaler Wissenstransfers wie die voran genannten Schulmeister. Im Berner Oberland übte beispielsweise der Pfarrer Altmann im Kirchspiel Meiringen BE die lokale Ausbildungsfunktion aus, nach eigenen Angaben aber freilich ohne nachhaltigen Erfolg.

442 „Es war der Weg der schablonenhaften Routineaneignung und des mechanischen Abrichtens, bei dem der jahrhundertealte Schlendrian in lückenloser Erbfolge die Zeiten überdauerte." Vgl. Seemann, Schulpraxis: 12-16, hier S. 13.

443 Beispielhaft sei auf die „Bemerkungen für Landschullehrer und Freunde derselben“ von Johannes Büel verwiesen. Noll, Hofrat: 54-58.

444 Es existierten unter anderem Pläne von Stapfer für die Etablierung von Lehrerbildungsanstalten in den Klöstern Einsiedeln, St. Urban, Beromünster und Brig. Sein Bürochef, Johann Rudolf Fischer plante überdies die Einrichtung von sechs bis sieben Seminarien nach dem Modell der Normalschule, wovon ein Testseminar im Schloss Burgdorf unter der Leitung von Johann Heinrich Pestalozzi kurzzeitig in Betrieb genommen wurde. Rohr, Stapfer: 81f. Aus dem Schriftverkehr zwischen Stapfer und seinem Netzwerk an Bildungsinteressierten ist zudem bekannt, dass die Ausbildung der Landschullehrer durch Geistliche in Seminarien oder an Normalschulen in Stapfers Korrespondenzumfeld stark angeregt wurde. Vgl. Tosato-Rigo, Bild: 62.

445 Neugebauer, Niedere Schulen: 227.

446 Viele Schulmeister - besonders jüngere - liessen sich durch die Dorfpfarrer gezielt in einzelnen Fertigkeiten zusätzlich aus- oder weiterbilden. Der dreissigjährige Lehrer Caspar Schärer von Schönenberg ZH hielt exemplarisch in der Stapfer-Enquête als Nebenbeschäftigung fest: „Jch lerne bey dem B. Pfarrer Orthographie und Rechnen." Schmidt u.a. (Hgg.), Stapfer-Enquête, Nr. 36: Schönenberg. Ebenso besuchte der 24-jährige Lehrer Rudolf Hoffmann von der benachbarten Schule Mittelberg bei Pfarrer Finsler in Schönenberg zusätzlichen OrthografieUnterricht. Schmidt u.a. (Hgg.), Stapfer-Enquête, Nr. 39: Mittelberg. Auch zitiert bei: Klinke, Zürich: 115. 
In der Oberländer Schulumfrage von 1800 schrieb er entmutigt und symptomatisch für die problematische Lehrerrekrutierung im Berner Oberland: „Jch habe ehedessen einige junge Leüthe, so gut möglich, selber zu Schul-Meisteren zu bilden gesucht; Aber die meisten haben wegen den geringen Löhnen die Schulen wider verlassen. “447

Dass die Geistlichkeit im Sinne ihrer erzieherischen Verantwortung im öffentlichen Schulwesen weiterhin eine sehr wichtige Rolle spielen sollte, war für die Repräsentanten der neuen helvetischen Ordnung eine klare Sache. Die gleichzeitigen antiklerikalen Intentionen der neuen Behörden verunsicherten jedoch zahlreiche Geistliche zutiefst ob ihrer zukünftigen Rolle im neuen Staatswesen. Zahlreiche Projektideen der helvetischen Vordenker widmeten sich der konkreten Ausgestaltung des Verhältnisses zwischen der Geistlichkeit und dem Schulwesen, dahingehend bis zur Forderung nach einer Unterrichtspflicht für Pfarrer im Elementarschulwesen, wie es etwa der Schaffhauser Professor Johann Georg Müller vertrat. ${ }^{448}$ Stapfer seinerseits regte neben seinem Wunsch nach der Etablierung von Normalschulkursen in allen Kantonen die individuelle Fortbildung der Lehrerschaft durch belehrende „Instruktionsgespräche“ an, wobei die Schulmeister analog zu den „Bauerngesprächen“ der ökonomischen Gesellschaften in Zusammenkünften vom lokalen Schulinspektor mittels Vorlesungen oder Abhandlungen belehrt werden sollten. ${ }^{449}$

Auf der lokalen Ebene befanden sich die Dorfpfarrer und die neu installierten Schulinspektoren der helvetischen Kantonalbehörden bei ihren Verbesserungsabsichten in den ihnen anvertrauten Elementarschulen jedoch oft in einem doppelten Dilemma gegenüber den bisherigen Schulmeistern und gegenüber den jeweiligen Gemeinden. Zur nachhaltigen Verbesserung des Schulwesens hätten die altgedienten, ehrenhaften, aber reformunwilligen Schulmeister zugunsten von jungen, reformwilligen Kandidaten ersetzt werden müssen, so der Tenor vieler Pfarrer. ${ }^{450}$

447 StABE Helv OL 41, Nr. 459, 22.12.1800 - Berichte über die Schulen. Von ähnlichen persönlichen Problemen bei der Rekrutierung von jungen Lehrkräften berichtete auch der Pfarrer Gottlieb Samuel Lauterburg. Vgl. TosatoRigo, Bild: 62.

448 Vgl. Tosato-Rigo, Bild: 68ff.

449 Oberstes Ziel dieser Idee war neben der individuellen Bildung die Förderung des professionellen Bewusstseins der Lehrerschaft. Tosato-Rigo, Bild: $60 \mathrm{f}$.

450 Beispielhaft zeigen die Anmerkungen des Basler Pfarrers Merian die Problematik: „Man könnte villeicht bey der Übersicht des äusserst eingeschränkten Unterrichtes, den die Jugend zu Lauwyl in der Schule empfängt, dem Pfarrer den Vorwurf machen: Warum er denn nicht das Seinige zu einer bessern Vervollkommnung derselben beytrage? Allein er bittet zu bedenken: Wie sehr schwer es halte, einen 72 jährigen, mit Vorurteilen für das Alte eingenommnen, und im angewähnten Schulschlendrian ergrauten Manne andre Grundsätze beyzubringen. Zwar giebt der arme, ehrliche Greis seinen Schülern getreulich wieder, was er ehmals von seinem Lehrer empfangen hat, welches freylich wenig genug ist; er versieht sein schweres und mühseliges Amt mit einer Treue und Gewissenhaftigkeit, die ihm Ehre macht; und doch fehlt es ihm, bey aller angewandten Mühe und Anstrengung an einer guten Lehr-Methode. Z: E: Die Auswahl der Schulbücher verursacht ihm wenig Kopfzerbrechens. Calender, Bänkelsängerlieder, Obligationen, Handschriften, uralte Gebetbücher - alles ist ihm willkommen, wenn's nur schwarz auf weiss gekleckset ist. Die Kinder selbst lesen ihre Lektionen frohnsmässig, in einem ganz eignen und unerträglichen Schultone her; sie beten die Schwänke des lustigen Schweizers und Bernerkalenders mit der gleichen Andacht und mit gefaltnen Händen her, wie die Biebel und andre Erbauungsbücher. Wer seinen Namen, (freylich oft elend und erbärmlich genug) hinkratzen kann, der gehört schon in die Classe der Literaten [...]; einige können auch singen, daß einem die Ohren gellen, und man braucht eben kein Gluck oder Händel zu seyn, um bey dieser Musik entweder vor Lachen beynahe zu bersten, oder vor Ärgerniss zu zerplatzen. [...] Soll nun das wolthätige Licht der Aufklärung die Finsternisse der Barbarey und Unwissenheit in diesem Dörfchen zerstreuen, so müsste nach meiner unmaasgeblichen Mejnung, der bisherige schwache und abgelebte Schullehrer, gegen eine, seinen langen und mühsamen Arbeiten angemessene Entschädigung seines Dienstes entledigt, und an dessen Stelle ein junger, geschickter thätiger und unterrichts-begieriger Mann gesetzt werden; dann hoffe ich, in Vereinigung mit demselben die Einwohner Lauwyls, oder wenigstens die Jugend desselben, mit der Hülfe Gottes nach und nach geschickter, tugendhafter, und folglich besser und glücklicher zu machen; ich verspreche meinerseits, alles, was in meinen geringen Kräften stehet, zur Bildung des künftigen Lehrers bey zutragen!“ Schmidt u.a. (Hgg.), Stapfer-Enquête, Nr. 2224: Lauwil. 
Doch die Einflussnahme der Pfarrer wurde meist durch die limitierten kommunalen finanziellen Möglichkeiten, durch den fehlenden Willen der Gemeinde oder durch das aktive Mitspracherecht der Gemeinden bei der Schulmeisterwahl begrenzt. Andernorts verliefen die Verbesserungsbemühungen der Ortspfarrer hingegen erfolgreicher und ohne Opposition vonseiten der Gemeinden, wie die Antwort aus Oberbipp BE berichtet, wo neue Lehrgegenstände vom Lehrer erlernt und übernommen wurden: „Ob schon $\{\mathrm{an}\}$ der Schule in Oberbipp noch sehr viel Fehlerhaftes auszusezen war, und daher durch gute Veranstaltungen (so wirklich von \{unsern\} Gesätzgeberen getroffen worden) in einen weit beßeren Zustand kann gebracht werden: So muß ich doch in Wahrheit sagen, $\{$ daß\} dieselbe in Zeit von 8. Jahren, durch unsern Lieben und getreüen Seelsorger Namens Bürger Wenger, gar viel ist verbeßert worden. Denn derselbe hatte nicht nur das Lesen - nach der Punktation, sondern auch das Construiren, die Ortographie Jtem das Rechnen, und die Musik in dem Schmidlin eingeführt, wormit Er sich bey Einer Gemeinde nicht nur verdient gemacht, sonderen er auch zu seinem Lob gereichen soll.“ ${ }^{451}$

Die zeitliche Dauer der praktischen Schulmeisteranlehre war für die Lehrlinge enorm unterschiedlich und hing von mehreren Faktoren ab. Erstens war entscheidend, ob das Lehramt innerhalb der Familie weitergegeben wurde oder ob der Gehilfe ausschliesslich zur Anlehre zu einem nicht verwandten Schulmeister geschickt wurde. Die Ausbildungsdauer innerhalb des familiären Wissenstransfers kann nicht umrissen werden, da Lehrersöhne in der Regel bereits unmittelbar nach dem Ende der eigenen Schulzeit zwischen dem 11. und 14. Lebensjahr zum Gehilfen des Vaters oder des Verwandten ernannt wurden und oft erst mit deren Ableben oder Abtreten die Stelle übernehmen konnten. ${ }^{452}$ Diese Gehilfenphase konnte sich mitunter über mehrere Jahre bis Jahrzehnte hinziehen. Der 26-jährige Lehrer Adam Hörler aus Teufen AR beschrieb 1799 seine Ausbildungsdauer als Beispiel für einen Lehrersohn folgendermassen: „die Schul halte schon 12. Jahr; und zwaren, nachdem der Vater mit Tod abgegangen, ich angestanden. Bin vorher immer bei dem Vater gewesen, so lang er gelebt; weil der Vatter 33 Jahre lang die Schule gehalten, so erhellet daraus, daß ich von Jugend auf zu dem Beruf bin angehalten worden. “453

Fand die Lehrzeit jedoch ausserhalb der Familie bei einem nicht verwandten Schulmeister statt, entschied entweder die Höhe des auszurichtenden Lehrgeldes oder der individuelle Lernfortschritt über die Dauer der Lehrzeit. Die Lehrzeit variierte somit zwischen wenigen Wochen und mehreren Jahren Dienstdauer, zumal der Übergang vom Schullehrling zum fertig ausgebildeten Schulmeister meist fliessend war. Reine kostenpflichtige Weiterbildungsaufenthalte bei einem anderen Schulmeister dauerten dagegen wesentlich kürzer und beschränkten sich auf wenige Wochen, meist während der weitgehend schulfreien Sommerzeit.

Das Modell der praktischen Schulmeisterlehre bewies trotz seiner Schwächen eine enorme zeitliche Persistenz und bestand sowohl in der Schweiz als auch in zahlreichen deutschen Territorien bis weit ins 19. Jahrhundert hinein fort, selbst als die ersten seminaristischen Lehrerbildungsanstalten bereits entstanden waren. Gerade die erste Hälfte des 19. Jahrhunderts war vom zeitgleichen Nebeneinander der Lehrerbildungsformen geprägt, was die Zusammensetzung der Volksschullehrerschaft bis zum 20. Jahrhundert beeinflusste. Erst in der zweiten Hälfte des 19. Jahrhunderts wurde die seminaristische Ausbildung zum flächendeckenden Regelfall, auf nicht-seminaristisch gebildete Lehrkräfte wurde zunehmend nur noch bei Lehrermangel

451 Schmidt u.a. (Hgg.), Stapfer-Enquête, Nr. 948: Oberbipp.

452 Für städtische Lehramtsadjunkten betrug die reine Lehrzeit fünf bis sechs Jahre und begann in der Regel ab dem 15. Lebensjahr. Für Lehrersöhne dauerte sie bloss vier Jahre. Vgl. Enzelberger, Sozialgeschichte des Lehrerberufs: 19.

453 Schmidt u.a. (Hgg.), Stapfer-Enquête, Nr. 506: Teufen. 
zurückgegriffen. ${ }^{454}$ Dennoch dauerte es bis zum Beginn des 20. Jahrhunderts, bis nur noch seminaristisch ausgebildete Lehrkräfte in der Schweiz unterrichteten.

Obwohl des Absolvieren einer praktischen Anlehre bei einem etablierten Schulmeister der Normalfall war, konnte man auch autodidaktisch, also gänzlich ohne irgendeine Form von vorgängiger Ausbildung zur Lehrkraft werden, sofern man über die notwendigen Kenntnisse und charakterlich-moralischen Fertigkeiten verfügte. ${ }^{455}$ Der Lehrer und spätere Seminardirektor des ersten Appenzeller Lehrerseminars, Hermann Krüsi aus Gais AR, berichtete in seiner Beantwortung der Stapfer-Enquête über die Erlangung des Schuldienstes sinnbildlich für die autodidaktische Aneignung: „Jn meinem 18ten Jahre nun wurde mir der Schuldienst anvertraut. Ohne alle Vorbereitung erhielt ich da einen Beruf, wo Einsicht, Erfahrung und Menschenkenntniß so unentbehrlich nothwendig sind, und wo beim Mangel dieser Eigenschaften unzählige Hinderniße und Schwierigkeiten den neüangehenden Lehrer bestürmen. Dieß erfuhr ich auch. Nur meine natürliche Neigung zu diesem Geschäffte, war vermögend, jene zu besiegen. “456

Gemäss seinen eigenen Aussagen hatte sich Krüsi einzig mit einer Vorschrift eines als Schönschreiber bekannten Stadtschullehrers aus dem nahe gelegenen Rheintaler Städtchen Altstät$\operatorname{ten}^{457}$ auf die Kandidatenprüfung vorbereitet, in dem er damit seine Handschrift übte: „diese einzige Vorlage schrieb ich wohl hundertmal ab, um mir eine bessere Handschrift anzueignen. "458 Auch der Lehrer Johann Lorenz Kälin aus dem Talviertel Gross bei Einsiedeln SZ hatte sich seine Kenntnisse autodidaktisch angeeignet, da er nicht aus einer Lehrerfamilie stammte, sondern als Bauer aufwuchs. Er rapportierte in der Stapfer-Enquête zu seinen Ersttätigkeiten: „Jch hab schon 20. Jahr lang Schul gehalten: vorher habe ich Unter meinen Eltern gelebt, und von mir selbsten gelehrt Schreiben und lessen, unter beständiger Bauren Arbeit. ${ }^{4599}$ Ferner berichtete Eduard Zingg aus der Basler Landschaft vom Lehrer Martin Jöry in Arisdorf BL, dass dieser „das Schulwesen von sich selbst erlernt ${ }^{\text {“460 }}$ hatte.

Das Modell einer reinen autodidaktischen Ausbildung zum Lehrer muss entgegen der immer wiederkehrenden Beschreibungen zur frühneuzeitlichen Schulgeschichte gesamthaft betrachtet jedoch als ein sehr seltenes Phänomen eingeschätzt werden, das nur auf eine geschätzte Handvoll an Individuen zutraf und kaum eine kollektivbiografische Relevanz hatte, sondern vielmehr eine Randerscheinung darstellte. Die autodidaktische Form der Ausbildung dient allerdings als ein starkes Indiz für einen bewussten und freiwillig angestrebten Erwerb des Lehramtes, zumal gerade das Beispiel des Einsiedler Lehrers Kälin zeigt, dass mit dem elterlichen Bauernbetrieb durchaus ökonomische Alternativen bestanden hätten.

Weitaus verbreiteter als die autodidaktische Grundausbildung war dagegen das autodidaktische Weiterbilden der Lehrkräfte in freien Nebenstunden. Besonders jüngere Lehrer berichteten bei der Frage III.11.h zu ihren Nebentätigkeiten, dass sie sich fortbildeten. Stellvertretend kann die Antwort des 24-jährigen Lehrers Hans Ulrich Weser von Unterrechstein AR dazu zitiert werden:

454 Vgl. das Beispiel des Oberpfälzer Lehrers Josef Zintl, der noch im Jahr 1857 als Schullehrling in den Schuldienst eintrat, da die Oberpfalz erst ab 1866 über eine eigene Lehrerbildungsanstalt verfügte. Dantl, Schullehrling: $92-$ 104; Stratmann, Lehrer werden: 32; Bölling, Sozialgeschichte: 56; Sauer, Volksschullehrerbildung: $94 f$.

455 Enzelberger, Sozialgeschichte des Lehrerberufs: 39.

456 Schmidt u.a. (Hgg.), Stapfer-Enquête, Nr. 1591: Gais.

457 Die Vorschrift stammt vermutlich vom damaligen oberen Stadtschullehrer, Jacob Schläpfer, der ebenfalls aus dem appenzellischen Schwellbrunn gebürtig war. Die überlieferte Antwort zeichnet sich durch eine saubere, orthografisch relativ korrekte Handschrift in Kurrent und Fraktur aus, welcher man durchaus Vorbildcharakter zuschreiben konnte. Schmidt u.a. (Hgg.), Stapfer-Enquête, Nr. 1204: Altstätten.

458 Gruntz-Stoll, Appenzeller Schüler: $17 f$.

459 Schmidt u.a. (Hgg.), Stapfer-Enquête, Nr. 2051: Gross. Auch erwähnt bei Durrer, Urkantonen: 24.

460 Zingg, Basel: 58. 
„Nebst Den Schulstunden übe ich Mich in Den nötigen Kentnisen Die zur Schule gehören, um Dereinst ein Tüchtiger Schullehrer zu werden. Wiederum andere Zeit wende ich an zu meinen geschäften, wil ich wie natürlich unmöglich aus Den Einkünften Der Schule leben konte. ${ }^{\text {"461 }}$

Etliche weitere Lehrer äusserten in der Stapfer-Enquête zumindest den Willen, sich individuell weiterzubilden, sofern die ökonomischen und schulpolitischen Rahmenbedingungen dazu gegeben wären. Der Lehrer Joseph Hüsler von Steinhausen ZG merkte in seiner Antwort an: „Würde mir ein anständiger gehalt angewiesen; so würde ich das ganze Jahr die schule halten, u mich befleissen die mir noch manglenden Kentnise Zu erwerben, um den Pflichten eines schullehres genug zu thun. - doch wünschte ich zu erst zu wissen, was für Kenntnise die helvetische Regierung von einem Schullehrer für diese gemeinde fodere, um einsehen $\mathrm{Zu}$ können, ob ich noch das mir mangelnde Zu lernen im Stande sey. ${ }^{\text {“462 }}$

Wie viele der Beteuerungen um den Willen zur Weiterbildung jedoch eher dem Motiv der versuchten Schmeichelei gegenüber den neuen Behörden zu verorten sind, muss offen bleiben. Insgesamt kann die Ausbildungssituation der meisten helvetischen Lehrer gleichsam wie die der deutschen Lehrerschaft mit den Worten Neugebauers als „ungeordnet-anarchisch“ ${ }^{663}$ beschrieben werden. Neue zeitgenössische Konzepte für eine breite Formalisierung und Standardisierung der Lehrerbildung auf territorialer Ebene wurden jedoch bereits seit längerem nicht nur in reformpädagogischen Kreisen intensiv diskutiert, sondern waren selbst der Lehrerschaft an der Basis bekannt, was einzelne Äusserungen von Lehrern zu einer Verbesserung der Lehrerbildung in der Stapfer-Enquête belegen: „Noch dringender, das Bedürftniß, Anstalten zu treffen, und zu verfügen daß geschikte, tüchtige und würdige Schullehrer gebildet werden, die cabable seyen, die Jugend in allen Theilen der Wüßenschaften zu unterrichten, und zu guten nüzlichen Republikanern zu bilden. “ ${ }^{464}$

Über die Notwendigkeit der Schaffung einer breitflächigen formalisierten Lehrerbildung herrschte sowohl bei Stapfer und seinem persönlichen Umfeld, als auch bei den Schulinspektoren, Pfarrern und Lehrern an der Basis zwar weitgehender Konsens, doch über die konkrete Umsetzung gingen die Meinungen stark auseinander, wobei jedoch zwei unterschiedliche Konzepte den Diskurs dominierten. Einerseits stand die Idee von neuen kantonalen Schulmeisterseminaren als zentrale Ausbildungsstätten unter kantonaler Hoheit, andererseits die Verbreitung der schon existierenden, zeitlich begrenzten Normalschulkurse für bereits etablierte Schulmeister nach österreichisch-josephinischem Vorbild und St. Urbaner Prägung. ${ }^{465}$ Es erstaunt daher kaum, dass während der Helvetischen Republik und in der darauf folgenden Mediationszeit im ersten Jahrzehnt des 19. Jahrhunderts in mehreren Kantonen neue Lehrerausbildungsstätten gegründet wurden. So entstanden neben den bekannten Lehrerbildungsstätten Johann Jakob Pestalozzis in Burgdorf ab 1799-1800 und Yverdon-les-Bains ab dem Jahr 1805 auch in anderen Regionen der Schweiz erste Ausbildungsstätten für Lehrkräfte. Etwa entstand in Gais AR im Jahr 1801 durch Pfarrer Johann Rudolf Steinmüller ein Institut, in Zürich entstand eine erste Lehrerweiterbildungsstätte im Jahr 1806, in Bern ab 1807 und in Sissach ab 1808 für die Basler Landschullehrer nach Pestalozzis Lehrart. ${ }^{466}$

Diese von der historischen Pädagogik gut erforschten neuen kantonalen und privaten Initiativen stellten aber nur eine weitere von mehreren zeitgleich koexistierenden Formen der Land-

461 Schmidt u.a. (Hgg.), Stapfer-Enquête, Nr. 1283: Unterrechstein.

462 Schmidt u.a. (Hgg.), Stapfer-Enquête, Nr. 2040: Steinhausen.

463 Neugebauer, Niedere Schulen: 226.

464 Schmidt u.a. (Hgg.), Stapfer-Enquête, Nr. 315: Fehraltorf.

465 Vgl. zu den Ausbildungs-Ideen aus dem Umfeld Stapfers: Tosato-Rigo, Bild: 62. Zu St. Urban vgl. das nachfolgende Kapitel 2.1.2.

466 Godenzi, Anfänge: 33; Scandola, Standesschule 604f.; Helfenberger, Aspekte: 52-56; S. n.: Beitrag: 79-87; Martin, Pestalozzi: 154-196. 
schullehreraus- und Weiterbildung dar und vermochten weder eine exklusive Monopolstellung einzunehmen, noch eine Ablösung der traditionellen Ausbildungspfade zu bewirken. Vielmehr bildeten sie die Eckpfeiler für die späteren, föderal organisierten Lehrerbildungsinstitutionen im Übergang zum modernen Bundesstaat in der Mitte des 19. Jahrhunderts. Ob die zentralstaatliche Funktionsweise der Helvetischen Republik dabei den entscheidenden Anstoss zur Realisierung einer modernen formalisierten Lehrerbildung gegeben hat oder bloss als „Katalysator" einer ohnehin sich abzeichnenden Entwicklung wirkte, bleibt offen.

Die Zäsur durch die Helvetische Revolution und die neue zentralstaatliche Organisation des Bildungswesens eröffnete ein Laboratorium für verschiedenste Ausbildungsprojekte im Bereich der Lehrerbildung, von denen allerdings nur die wenigsten eine unmittelbare Breitenwirkung entfalten konnten. Ferner waren in den Elementarschulen der Alten Eidgenossenschaft bei beiden Konfessionen stets auch Geistliche mit einer theologischen Ausbildung als „Zufallsprodukt “ in der Elementarschullehrerfunktion vorzufinden - im Gegensatz zum deutschen Reich aber mitunter auch an ländlichen Orten ohne Zentrumsfunktion. ${ }^{467}$ Bedauerlicherweise hatte Philipp Albert Stapfer in seiner Umfrage keine Frage zu den Formen der Ausbildung der Lehrkräfte integriert. Es ist zu vermuten, dass die Auslassung dieser - aus heutiger Perspektive wichtigen - Frage kein zufälliges Produkt in der Entstehung des Fragebogens war, sondern primär auf den negativen Vorurteilen des Bildungsministers gegenüber den vorhandenen Lehrerausbildungsformen beruhte. Die Frage nach einer einheitlichen Lehrerausbildung für Elementarschullehrer beschäftigte Stapfer gleichwohl seit dem Beginn seiner Amtszeit an sehr intensiv, denn bereits am 24. Juli 1798 erliess Stapfer ein provisorisches Schulgesetz, das in allen Kantonen die Einrichtung von Normalschulen im Kantonshauptort zur Aus- und Weiterbildung der helvetischen Lehrerschaft forderte. ${ }^{468}$ Zudem fragte er in der zeitgleich gestarteten Pfarr-Enquête die Geistlichen - im Gegensatz zur Lehrerschaft - in der Rubrik „Verdienste“ auch offen nach ihren Studien, den literarischen Beschäftigungen und nach ihrer Mitgliedschaft in Sozietäten. ${ }^{469}$ Umso unverständlicher wirkt es daher in der heutigen ex-post-Betrachtung, dass gerade diese zentrale Frage nach der Ausbildung und des Bildungsstandes nicht in der Lehrer-Umfrage flächendeckend miterhoben wurde. Vermutlich schätzte Stapfer aber die Bildungssituation des Elementarschullehrerkorps in seiner Reformabsicht vorauseilend als dergestalt ungenügend ein, dass die Erhebung des tatsächlichen Bildungsstandes für ihn obsolet wurde.

Nicht zu vergessen ist in diesem Zusammenhang, dass unter anderem diese Auslassung einen Grundstein für die spätere liberale Kritik am vorrevolutionären Bildungswesen gelegt und das hartnäckige Bild des ungebildeten Schulmeisters in der Historiografie zementiert hat. Gerade die tradierte Erkenntnis über den Stand der Lehrerbildung vor den liberalen Reformen beruht nach den Erkenntnissen von Marianne Helfenberger unter anderem auf dieser nicht gestellten Frage. ${ }^{470}$

\subsubsection{Die Normalschule in der Alten Eidgenossenschaft}

Eine curricular und inhaltlich formalisierte Form der Lehrerausbildung und -weiterbidlung erreichte die Alte Eidgenossenschaft von katholischer Seite her in der Gestalt der Normalschulmethode bereits im letzten Drittel des 18. Jahrhunderts. Ausgangspunkt war das Kaiserreich Österreich unter der Kaiserin Maria Theresia. In der theresianischen Schulreform von 1774 wurde die vorgängige Ausbildung an einer Normalschule zur neuen Pflicht für alle angestellten Schullehrer

467 Vgl. Neugebauer, Niedere Schulen: 230.

468 Strickler/Rufer, ASHR: 607-613; Fuchs, Grundlagen: 80ff.; Dévaud, École primaire: 82.

469 Tosato-Rigo, Bild: 71.

470 Helfenberger, (Normal-)Lehrer: 130. 
in den österreichischen Untertanenländern erhoben. Die schon tätigen Lehrkräfte wurden zudem angewiesen, die neue Lehrart und Lehrgegenstände zu beachten. Neu anzustellende Lehrer mussten gar zwingend an einer Normalschule in der Normalmethode ausgebildet sein. ${ }^{41}$ Trotz teilweise heftigem Widerstand aus der Bevölkerung - etwa im grenznahen Vorarlberg - führte die „top-down“ verordnete Einführung von Felbigers Normalmethode und die Eröffnung zusätzlicher Schulstandorte in allen Ländern der österreichischen Monarchie zu einer raschen Zunahme der Schulbesuchszahlen. ${ }^{472}$ Über das österreichische Fricktal und Oberschwaben diffundierte die Normalmethode anschliessend rasch an die Grenze zur Alten Eidgenossenschaft. ${ }^{473}$

Die Zisterzienserabtei St. Urban im heutigen Kanton Luzern führte unter dem Abt Benedikt Pfyffer von Altishofen (1768-1781) im Jahr 1780 erste Normalschulbücher des österreichischen Bildungsreformers Felbiger ein und errichtete ein Jahr später unter der Leitung des Paters Nivard Krauer eine Musterschule am Kloster. Krauer begann sogleich, die Lehrmethoden Felbigers an die eidgenössischen Verhältnisse anzupassen und Felbigers Normalschulbücher umzuschreiben, woraus das bekannte St. Urbaner „ABC- oder Namenbüchlein“ entstand. Die Musterschule, obwohl zuerst nur für lokale Zöglinge gedacht, entwickelte rasch eine starke Anziehungskraft auf die benachbarten Regionen, wodurch diese zum ersten eigentlichen Landschullehrerseminar der Alten Eidgenossenschaft wurde. ${ }^{474}$

Der St. Urbaner Normalschullehrgang war denn auch ganz nach dem schlesischen Vorbild konzipiert und richtete sich als zeitlich kurz gedachte „Weiterbildungsveranstaltung“ primär an bereits etablierte Landschullehrer, wobei die Besucher zuerst mehrere Wochen lang selbst in den Unterricht der Normalschule gingen und nebenher in der Methode unterwiesen wurden. Danach kehrten die Schulmeister in ihre Heimatorte zurück, um die neue Lehrart an ihrer Schule einzuführen. ${ }^{475}$ Die Normalschulkurse, abgehalten in zwei Zeiträumen zwischen 1781 bis 1785 und von 1801 bis 1805 verbreiteten die neue Normalmethode von St. Urban her unsystematisch in Teilen der deutschsprachigen katholischen Schweiz. ${ }^{476}$ Einzig dem katholischen Stand Solothurn gelang es jedoch in der Folge, seine gesamte katholische Elementarschullehrerschaft in corpore verpflichtend an eigenen, von St. Urban inspirierten Normalschulkursen im Solothurner Waisenhaus teilnehmen zu lassen und die Normalmethode als Volksbildungsstandard im katholischen Landesteil flächendeckend zu etablieren. ${ }^{477}$ Die Ausstellung eines schriftlichen „Lehrpatents“ als Bescheinigung des erfolgreichen Besuchs des Normalkurses beschleunigte die flächendeckende Durchsetzung, indem das Patent den patentierten Lehrkräften „festen Halt gegenüber der Willkür von Gemeindemitgliedern und der Konkurrenz von Privat- und Winkelschulmeistern “ ${ }^{\text {“ } 78}$ gab und nur noch patentierte Schulmeister die obrigkeitliche Bestätigung zur Ausübung des Lehramts erhielten. In den übrigen katholischen Orten, selbst im Standortkanton des Klosters St. Urban, dem

471 Seel, Schulgeschichte Österreichs: 33; Vgl. auch Scheipl/Seel, Entwicklung: 15f. Zur Entwicklung der Normalmethode in Solothurn vgl. Jenzer/Jenzer, Lehrerseminar; Mösch, Solothurnische Volksschule; Schmidt, Elementarschulen: 44ff.

472 Boyer, Fibeln: 236.

473 Vgl. Pfammatter, Lebenswelt.

474 Hug, Schulreform: 60-63; 69f.

475 Seemann, Schulpraxis: 30.

476 Zur Diffusion der Normalmethode in der Schullandschaft der katholischen Schweiz vgl. Hug, Schulreform: 195273; Egli, Schulreform in der Praxis: 20; Durrer, Urkantonen: 22; Schmidt, Elementarschulen: 45.

477 Der reformierte Teil des Standes Solothurn, der Bezirk Bucheggberg, unterstand nicht der solothurnischen, sondern der Berner Kirchengewalt. Die reformierten Schulen dieses Bezirks blieben daher von der Normalschulmethode unberührt. Tatsächlich fanden sich in den Antworten der Lehrerschaft aus dem Bucheggberg keinerlei Hinweise auf eine Einführung der Normalschulmethode.

478 Mösch, Solothurnische Volksschule: 93. 
Stand Luzern, vermochte die Normalmethode nur schwer durch einzelne am Kloster ausgebildete Lehrer oder durch die verbreitete Distribution von Felbigers Schulbuch, dem „Normalbüchlein“, Fuss zu fassen, freilich ohne dass daraus bis zum Ende des 18. Jahrhunderts eine weitere Normalschule als Ausbildungsstätte für Lehrer entstanden wäre. Die Einführung der Normalmethode an Landschulen erfolgte daher weitgehend unsystematisch auf der Basis individueller Initiativen von reformaufgeklärten Geistlichen oder einzelner Normalschullehrer.

Das Kloster St. Urban war jedoch nicht der einzige Weg, über den Felbigers Normalmethode in die katholischen Orte der Alten Eidgenossenschaft diffundierte. Zeitnah führten in der Ostschweiz einzelne bildungsaffine Bürger des Städtchens Rorschach in der Fürstabtei St. Gallen aus dem angrenzenden Oberschwaben die neue Lehre „bottom-up“ von unten her ein. ${ }^{479}$ Daraufhin versuchte auch der Fürstabt Beda Angehrn, die Normalmethode in seinen übrigen Landschulen freilich mit mässigem Erfolg - zu verbreiten. Die St. Galler Normal ist jedoch nur bedingt als reformorientiert zu bezeichnen. Sowohl ihre Bezugsquelle, das Kloster Neresheim in Oberschwaben, als auch ihr Diffusor, Fürstabt Beda Angehrn, waren grundsätzlich eher barock-konservativ geprägt. Fürstabt Angehrn war denn auch wenig durch aufklärerischen Reformeifer aufgefallen und zählte eher zur abwartend konservativen Seite des europäischen Katholizismus. ${ }^{480}$

Ausgeprägte Widerstände auf lokaler Basis vonseiten der Elternschaft verhinderten nicht zuletzt eine flächendeckende Einführung der Methode in der übrigen katholischen Schweiz, denn längst nicht überall wurde die neue Methode, deren Neuerungen aus pädagogischer Sicht unbestritten waren, von der Landbevölkerung begrüsst. So notierte der katholische Lehrer von Niederbüren SG aus der ehemaligen Fürstabtei St. Gallen zur Frage II.10 in der Stapfer-Enquête: „Das Wort Klassen, wie das Wort Normal [Hervorhebung in der Quelle], würde die Einwohner betäuben. ${ }^{481}$ Vielerorts sahen konservative Kleriker und Dorfleute im Reformversuch der Normalschule eine Störung der althergebrachten Orthodoxie im schulischen Fächerkanon und befürchteten die Einführung von glaubensfeindlichen häretischen Irrlehren. ${ }^{482}$

Die Dorfbevölkerung musste mancherorts erst in mühsamer langwieriger Überzeugungsarbeit von der neuen Lehrmethode überzeugt werden, wie die Aussage des Kaplans Joseph Bumbacher von Bauen UR eindrücklich verdeutlicht: „denn man hate Anfanglich so eine Abneigung gegen meine Lehr Art daß es auf der Spitzstund kein Schuhlkind zu bekomen, ich hielt an man solt es einen Winter probiren, es hat mir gegluckt; alles ist so zufrieden daß sie sich einer Anderen Methode wiedersetzen werden “483.

Trotz der Widerstände markierte die Einführung der progressiven Normalmethode in etlichen Teilen der katholischen Schweiz einen wichtigen Meilenstein auf dem Weg zur Modernisierung des Elementarschulwesens, zumal die methodischen Neuerungen auch in den reformierten Landesteilen mit viel Respekt und wachsendem Interesse beobachtet wurden. ${ }^{484}$ Gerade in konfessionell rivalisierenden Gegenden wie dem gemischtkonfessionellen Toggenburg entwickelte sich die Normalmethode - zumindest in den Augen der reformorientierten Vorgesetzten - zu einer

479 Di Cioccio, Klerus.

480 Der Fürstabt sah sich zwar in der Rolle des Volkserziehers, war jedoch kein Freund der Aufklärung. Vgl. Marti, Klosterkultur: 14-17.

481 Schmidt u.a. (Hgg.), Stapfer-Enquête, Nr. 1240: Niederbüren.

482 Vgl. exemplarisch zum Widerstand gegen die Schulreform in der Fürstabtei St. Gallen: Baumann, Alltag: 74f. Zur Ablehnung der St. Urbaner Lehrmethode im Kanton Luzern: Pfenniger, Luzerner Volksschule: 44. Vgl. ferner Mösch, Solothurnische Volksschule: 105-111.

483 Schmidt u.a. (Hgg.), Stapfer-Enquête, Nr. 1938: Bauen.

484 Beispielsweise wurden die Normalschullehrgänge in St. Urban auch von einzelnen reformierten Lehrkräften aus dem Kanton Bern besucht. Vgl. Mösch, Solothurnische Volksschule: 4. 
raschen Erfolgsgeschichte. Ein Inspektionsbericht über die katholischen Schulen des Distrikts Lichtensteig aus dem Jahr 1800 hielt denn auch fest: „Die Schulen dieses Distrikts zeichnen sich so wohl in Ansehung der Lehrer, als auch der bereits in einigen Gemeinden eingeführten bessern Schulanstalten vor den übrigen katholischen Schulen andrer Distrikte merklich aus. Schon die Handschrift und der Aufsaz der meisten Schulmeister beweiset: dass in diesem Distrikte Männer als Lehrer angestellt sind, von denen man sich für die Zukunft recht viel gutes versprechen kann. Jn Liechtensteig, Oberhelfenschwyl, Hemberg und St. Peterzell ist bereits die Normalschule eingeführt. Alle diese Gemeinden wünschen dieselbe beibehalten zu können.“485

War die lokale Bevölkerung erst einmal von den Neuerungen überzeugt und eine Normalschule eingerichtet worden, entwickelte sich auch gegenüber den Nachbarschulen der eigenen Konfession ein stimulierender Konkurrenzdruck und die übrigen Lehrer mussten wohl oder übel mitziehen, wenn sie eine Abwanderung der Schulkinder zu „besseren“ Schulen verhindern wollten. ${ }^{486}$ Die Normalschulmethode stellte aber auch konfessionsübergreifend auf die reformierten Schulen einen wichtigen Impuls für Bildungsreformen im Elementarschulbereich dar. Entgegen dem hartnäckigen Paradigma des auf Max Weber zurückgehenden angeblichen Bildungsvorsprungs protestantischer Gesellschaften bis zum frühen 20. Jahrhunderts erfolgte somit der wohl wichtigste Stimulus für Reformen im Schweizer Elementarschulwesen im ausgehenden 18. Jahrhundert nicht von der protestantischen Seite her, sondern paradoxerweise über den Reformkatholizismus. ${ }^{487}$

\subsection{Die Ersttätigkeiten und das Amtsübernahmealter}

Die vor dem Lehramt ausgeführten Tätigkeiten dienen in zweifacher Hinsicht als ein Indikator für die soziale Herkunft der Lehrkräfte. Zum Ersten lassen sich aus den Angaben zu den Ersttätigkeiten kategorisierbare Rückschlüsse ziehen, aus welchen sozialen Schichten sich die Lehrerschaft abseits der Selbstrekrutierung über die dynastische Berufsweitergabe zusammengesetzt hatte. Zum Zweiten kann untersucht werden, ob bestimmte konkrete Tätigkeitsgruppen insgesamt eine Präferenz zur Übernahme des Lehramts aufgewiesen haben und aus welchen Motiven das Lehramt übernommen wurde.

Über die soziale Herkunft der Elementarschullehrer gehen die bisherigen Ergebnisse der Schulgeschichtsforschung weit auseinander. Forschungen aus den deutschen Territorien halten in Bezug auf die soziale Herkunft der Lehrer allesamt einerseits einen hohen Grad an Heterogenität an beteiligten Berufsgruppen fest. Andererseits betonen sie gleichzeitig die Präferenz einiger weniger konkreter Berufsgattungen für das Elementarschullehramt: „Schule halten Personen unterschiedlichster Profession. Am häufigsten sind dabei Handwerker, insbesondere jene, die eine "professio sedentaria“ ausüben - Schneider oder Schuhmacher erledigen das Schulamt neben und zugleich mit ihrer eigentlichen Arbeit. Auf dem Lande rekrutieren sich Schulmeister ausserdem aus Hirten, ehemaligen Bedienten, ausgedienten Soldaten und Invaliden. “488

Obwohl die deutschen Schulmeister im 17. und 18. Jahrhundert zwischen 100 und 150 verschiedenen Einzelberufen ausübten, sich also aus einer äusserst breiten, heterogenen Schicht rekrutierten, tauchen doch vornehmlich die landhandwerklichen Tätigkeiten der Schneider, Schuster, Weber, Zimmerleute sowie aus dem agrarischen Bereich die Viehhirten wiederkehrend in den Aufzählungen der jüngeren Forschungsresultate auf. Gleichwohl werden gewisse

485 StASG HA R 132, Fasz. 7, s. Pag.: [1800] - Bemerkungen.

486 Vgl. das Fazit zur Linther Schulumfrage von 1798: Rothen/Ruloff, Schulumfragen: 49.

487 Vgl. dazu auch Schmidt, Volksbildung: 37ff.; Schmidt, Bildungsvorsprung: 91, 99-105.

488 Sauer, Volksschullehrerbildung: 11. 
Differenzen zwischen den regionalen Forschungsgebieten betont. ${ }^{489}$ Daneben gesellten sich evangelische Pfarrer, katholische Priester und „gescheiterte Theologiestudenten“ sowie in den katholischen Gebieten zunehmend Ordensgeistliche als Elementarschullehrkräfte für die Elementarbildung beider Geschlechter hinzu. ${ }^{490}$

Lehrkräfte mit geistlich-theologischer Vorbildung stellen denn auch einen dritten, berufsbiografisch autochthonen Weg zum Lehramt dar. Als katholische Kapläne, Ordensgeistliche, Pfarrvikare oder ehemalige Theologiestudenten hatten diese geistlichen Lehrer zuerst ein Studium der Theologie an einer Universität oder an einer geistlichen Bildungseinrichtung absolviert. Sie gelangten anschliessend im Zuge von Vikariatstätigkeiten oder als Ersatz für vakante Lehrer entweder eher zufällig ins Lehramt oder übernahmen das Elementarschullehramt auf freiwilliger Basis in Kombination mit der geistlich-seelsorgerischen Tätigkeit, wenn das Lehr- und Seelsorgeamt miteinander verbunden waren. Aufgrund ihres divergenten Ausbildungsweges müssen die im Elementarschulwesen tätigen Geistlichen gesondert betrachtet werden.

Für die Territorien der Alten Eidgenossenschaft beziehungsweise der Helvetischen Republik skizzierten die älteren Forschungen eine ähnliche Präferenz von einzelnen Berufsgruppen für das Lehramt. Rudolf Luginbühl beschrieb die berufliche Herkunft der helvetischen Lehrkräfte im Allgemeinen als „ausgediente, öfters invalide Soldaten, Landarbeiter, Handwerker [...]. An manchen Orten, namentlich katholischen, übernahm der Pfarrer den Unterricht. ${ }^{\text {“491 }}$ Regionale Differenzen wurden jedoch nicht nur auf konfessionelle Unterschiede, sondern primär auf sozio-ökonomische Eigenheiten der Regionen zurückgeführt, wie Ernst Schneider für die Berner Lehrerschaft resümierte: „Ungefähr die Hälfte der Schulmeister mag sich mit Landwirtschaft in irgend einer Form beschäftigt haben, und die andere Hälfte setzte sich zusammen aus Handwerkern. Die Erstern treffen wir vorwiegend im Oberland und die andern im Unterland, wo der landwirtschaftliche Betrieb eine grössere Arbeitsteilung verlangte. Die Vertreterzahl der einzelnen Handwerker wechselte mit der Verbreitung der betreffenden Berufsart und mit der Gelegenheit, die sie boten, sie ausser der Schule zu betreiben. So stehen Weber, Schneider, Schuster obenenan. " 492

Landwirtschaftliche Tätigkeiten und Landhandwerke, vor allem Schuster, dominierten nach den bisherigen Forschungserkenntnissen neben dem Berner Mittelland auch in der Waadt, in Zürich und in der Ostschweiz. ${ }^{493}$ In der Basler Landschaft übten dagegen heimindustriell tätige Seidenbandweber, Posamenter genannt, vor Handwerkern und landwirtschaftlich Tätigen das Lehramt aus. ${ }^{494}$ In den katholischen Landesteilen der Zentralschweiz waren dagegen Ordens- und Weltgeistliche im elementaren Schuldienst dominant. ${ }^{495}$ Bislang am differenziertesten mit der Frage nach der sozialen Herkunft der Elementarschullehrkräfte setzte sich Georges Panchaud auseinander. Er

489 Die Präferenz der Schneider für das Lehramt erklärt Rudolf Reiser hypothetisch mit ihren Mathematikkenntnissen: „Vielleicht befähigt sie [die Schneider] schon der Umgang mit den Zahlen am Ellstock zum Schulmeisterdienst." Reiser, Lehrergeschichte(n): 86ff. Vgl. auch Enzelberger, Sozialgeschichte des Lehrerberufs: 25, 39f.; Walz, Eselsarbeit: 32, 40f., 74. Olga Stefanidou-Kappmann wiederum betont die Mehrzahl an Handwerkern im Lehramt: Stefanidou-Kappmann, Geschichte des Volkschullehrers: 132f. Im Gegensatz zu den Darstellungen von Walz und Enzelberger hebt dagegen Wolfgang Neugebauer in seinem Handbuchartikel zur deutschen Bildungsgeschichte die Seltenheit von landwirtschaftlichen Tätigkeiten in Kombination mit dem Lehramt hervor: „Weit verbreitet war deshalb das Phänomen, dass (Land-) Handwerker Schulstellen innehatten, wobei Berufe des Textilgewerbes im weiteren Sinne, zumeist Landschneider, schon seltener Weber, entschieden dominierten. Landwirtschaftliche Tätigkeit, wesentlich schwerer vereinbar mit der Unterrichtspraxis, kam, wie im Thüringischen, weniger häufig vor." Neugebauer, Niedere Schulen: 230.

490 Enzelberger, Sozialgeschichte des Lehrerberufs: 25, 30f.

491 Luginbühl, Stapfer: 69.

492 Schneider, bernische Landschule: 86f.

493 Panchaud, écoles vaudoises: 253f.; Klinke, Zürich: 116; Bloch Pfister, Priester: 170; Landolt, Linth: $153 f f$.

494 Zingg, Basel: 50; Rothen, Lesen: 53f.

495 Durrer: Urkantonen. 
unterschied grundsätzlich zwei Kategorien von Lehrkräften: „D’un côté, ceux qui ont toujours été régents, en quelque sorte les pédagogues de profession et, de l'autre, ceux qui ne le sont devenus quau hasard des circonstances, les pédagogues d'occasion [Hervorhebung im Zitat] “ ${ }^{496}$ Erstere, quantitativ kleinere Gruppe bestand nach Panchaud vorwiegend aus Lehrersöhnen, guten Schülern, Waisen und unehelichen Kindern von lokalen Honoratioren. Die letztere, etwa zwei Drittel der Lehrer ausmachende Gruppe, rekrutierte sich dagegen mehrheitlich aus Kranken, Verletzten und Alten, Arbeitslosen, Flüchtlingen, Proselyten ${ }^{497}$ sowie ehemaligen Soldaten und Auslandsrückkehrern. ${ }^{498}$ Die soziale Position dieser zumeist aus der Landwirtschaft und dem Landhandwerk stammenden Lehrkräfte ist bis in die jüngere Forschungslandschaft aufgrund der vermuteten Landlosigkeit, der prekären Besoldung und der vielfältigen Nebenbeschäftigungen insgesamt als gering eingeschätzt worden, insbesondere dort, wo die Lehrkräfte zu ihrem Amt nicht auf längere Dauer gewählt waren. Der Elementarschullehrer gehörte somit unhinterfragt zu den sozio-ökonomischen Unterschichten der frühneuzeitlichen Gesellschaft, zumal Schulmeister im 18. Jahrhundert überdies nicht selten in Armenlisten als Bezüger von Armenleistungen auftauchten. ${ }^{499}$ Einzig in Gegenden, wo der Schulmeisterdienst mit dem Mesmeramt oder mit Schreiberdiensten verbunden war, erschien ihre soziale Position weitaus günstiger. ${ }^{500}$

Aus der empirischen Erhebung der Ersttätigkeitsangaben in der Stapfer-Enquête öffnet sich ein Panoptikum von weit über hundert Einzeltätigkeitsnennungen aus zahlreichen Tätigkeitsfeldern der Frühen Neuzeit. ${ }^{501}$ Dennoch sind nach der Zuteilung in die elf Untersuchungskategorien klare Trends ersichtlich, aus welchen Tätigkeitsfeldern sich die Elementarschullehrerschaft hauptsächlich rekrutierte. ${ }^{502}$

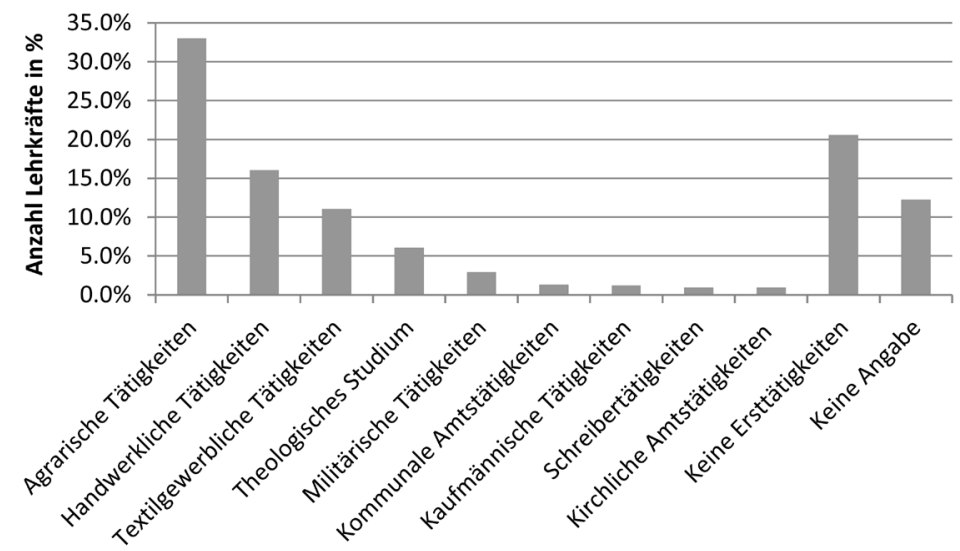

Abb. 1: Ersttätigkeiten der Lehrkräfte 1799

496 Panchaud, écoles vaudoises: 254.

497 Gemeint waren protestantisch-hugenottische Glaubensflüchtlinge aus Frankreich, die sich seit dem 17. Jahrhundert in der Waadt niederliessen.

498 Panchaud, écoles vaudoises: 254-258.

499 Beispielhaft für den Kanton Bern dokumentiert bei: Flückiger Strebel, Wohlfahrt: 75. Für die Zürcher Landschaft erwähnt bei: Braun, Volksleben: 27.

500 Neugebauer, Niedere Schulen: 230.

501 Vgl. Montandon, Organisation: 96.

$502 \mathrm{Zu}$ den Kategorien vgl. die Ausführungen im Kap. 1.6.1. 
Mit insgesamt 79.4\% übte die deutliche Mehrheit der helvetischen Elementarschullehrkräfte mindestens eine Ersttätigkeit vor der Lehramtsübernahme aus. Das Ausüben einer ausserschulischen Ersttätigkeit vor dem Lehramt stellte also den biografischen Normalfall im Lebensverlauf eines Elementarschullehrers dar. Dadurch qualifiziert sich das Lehramt in den meisten Fällen gleichzeitig als eine Tätigkeit, die vorwiegend als ökonomische Zusatz- oder Ausweichtätigkeit ausgeübt wurde.

Unter den ausgeübten Ersttätigkeiten ist die Dominanz von agrarischen Tätigkeiten mit mehr als 30\% augenfällig. Damit bestätigen sich die Befunde der zuvor zitierten regionalen Forschungsliteratur grundsätzlich, dass ein bedeutender Teil der helvetischen Lehrkräfte einen landwirtschaftlichen Hintergrund hatte. Diese Erkenntnis setzt aber die postulierte verbreitete Landlosigkeit und damit die Zugehörigkeit der Lehrkräfte zu den sozialen Unterschichten infrage. Auf die agrarischen Tätigkeiten folgten - kongruent zu den bisherigen Forschungsergebnissen - handwerkliche und textilgewerbliche Ersttätigkeiten mit jeweils über $10 \%$ Gesamtanteilen. Deutlich weniger dominant waren in kollektiver Betrachtung jedoch ehemalige Soldaten und Geistliche, verglichen mit ihrer starken Betonung in der Forschungsliteratur. Eine bedeutende Minderheit von rund 20\% der Lehrpersonen strebte allerdings auf direktem Weg über die skizzierten Ausbildungspfade ins Lehramt, ohne zuvor eine Ersttätigkeit ausgeübt zu haben. Diese bedeutende kollektive Gruppe ist bislang aber bloss bei Panchaud in der Schweizer Forschungsliteratur detaillierter betrachtet worden.

Aus der Tatsache, dass das Lehramt zumeist als Zweittätigkeit ausgeübt wurde, haben ältere Forschungsergebnisse ferner ein grundsätzlich hohes Einstiegsalter in die Lehrtätigkeit postuliert, allerdings nur mit einer schwach differenzierten Berücksichtigung der Frage des Vorhandenseins einer biografischen Ersttätigkeitsphase. Aus dem relativ hohen Durchschnittsalter der Zürcher Lehrkräfte leitete Wilibald Klinke zudem eine generell geringe Attraktivität des Lehramts für junge Kandidaten und folgerte ein relativ hohes Alter beim Wechsel in das Lehramt: „Vorwiegend waren es Ältere und Verheiratete, die sich für Schulstellen meldeten. Das geringe Ansehen und die unzulängliche Besoldung der Lehrer waren nicht dazu angetan, junge Leute zu ermutigen, sich dem mühevollen Schulamte zu widmen. [...] Wo wir jüngere Lehrer finden, sind es gewöhnlich Lehrerssöhne, die sich zu Hause frühzeitig für den Lehrerberuf vorbereitet hatten, indem sie ihrem Vater einige Jahre als ,Adjunkt' dienten." ${ }^{503}$

Konkreter ist Alexandra Bloch Pfister in Bezug auf dieselben Zürcher Lehrkräfte geworden. Sie errechnete zum Vergleich für die Zürcher Landschullehrer ein mittleres Amtsübernahmealter von 29.2 Jahren für Filialschulmeister und von 30.5 Jahren für Hauptschulmeister. ${ }^{54}$ Auch Ernst Schneider gelangte für die Berner Lehrkräfte zur ähnlichen Schlussfolgerung, dass das Lehramt eher von älteren Männern übernommen wurde. ${ }^{505}$ Die bisherigen Forschungsresultate sind sich ob der Frage des Diensteinstiegs aber in regionaler Hinsicht uneinig, denn entgegen den Befunden von Klinke und Schneider berechnete Georges Panchaud für die Waadt ein deutlich tieferes durchschnittliches Amtsübernahmealter von bloss 24 Jahren, die meisten

503 Klinke, Zürich: 116f. Klinkes Annahme liegt die Errechnung des Durchschnittsalters der Lehrkräfte zum Zeitpunkt der Umfrage zugrunde. Dieselbe Klage der fehlenden Attraktivität des Lehramts für junge Menschen scheint weit verbreitet und sehr persistent gewesen zu sein, taucht sie noch in den 1840er-Jahren in Kurhessen auf, freilich entgegen der tatsächlichen Realität. Kesper-Biermann, Kurhessen: 161f.

504 Bloch Pfister, Priester: 162.

505 „Der ,Schwerpunkt' liegt zu beiden Seiten des dreissigsten Lebensjahres, jenseits des gewöhnlichen Heiratsalters. Diese Tatsache sagt uns, dass entweder ältere oder verheiratete sich zur Stelle meldeten oder bei der Wahl auf solche meistens Rücksicht genommen wurde.“ Schneider, bernische Landschule: 89. 
Waadtländer Lehrkräfte hätten zwischen dem 15. und 25. Lebensjahr mit der Lehrertätigkeit begonnen. ${ }^{506}$

Das empirisch erhobene mittlere Amtsübernahmealter aller 1.830 Lehrkräfte mit einer zuvor ausgeübten Ersttätigkeit lag bei 30.2 Jahren. Der Wechsel ins Lehramt erfolgte somit in der biografischen Perspektive im Durchschnitt am Ende der erweiterten Adoleszenz, aber gleichwohl nicht erst im gesetzten Alter. Es waren also keineswegs nur „Alte und Verheiratete“, die zum Lehrer gewählt wurden, sondern zumeist deutlich jüngere Personen nach dem Erreichen des frühneuzeitlichen Erwachsenseins. ${ }^{507}$

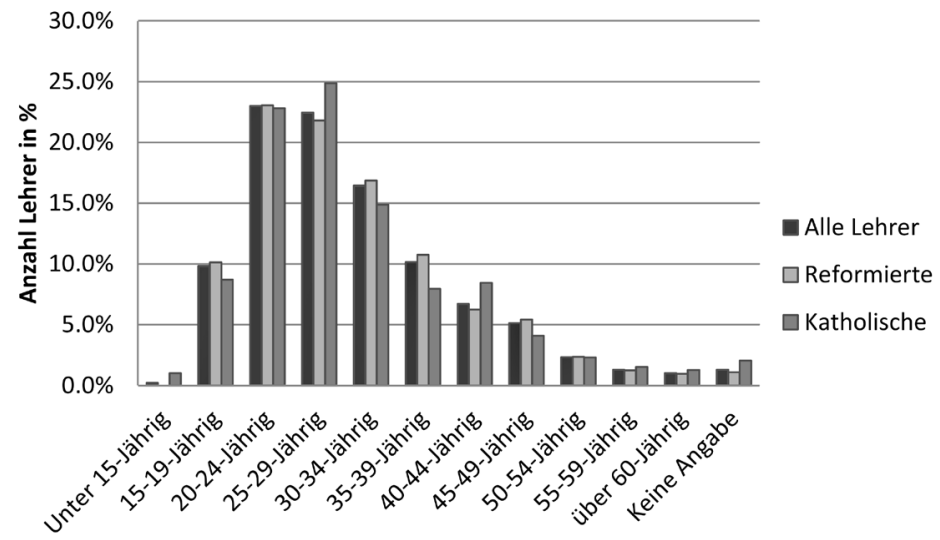

Abb. 2: Amtsübernahmealter der Lehrer mit Ersttätigkeiten

Der Diensteintritt erfolgte beim grössten Teil der helvetischen Lehrkräfte mit einer zuvor ausgeübten Ersttätigkeit jedoch schon deutlich früher als es der Mittelwert anzeigt. Die relative Mehrheit übernahm ihr Amt in einer grossen Bandbreite zwischen dem 20. und 30. Lebensjahr, mit einem Hauptakzent auf dem 24. Lebensjahr. Amtsübernahmen vor dem 20. Lebensjahr, insbesondere aber noch vor dem 15. Lebensjahr, stellten eine klare Ausnahme dar. Auf der anderen Seite des Altersspektrums nahm die relative Anzahl an Einsteigenden nach dem 30. Lebensjahr ebenso rapide ab. Weniger als $17 \%$ aller Lehrkräfte hatte das Lehramt mutmasslich erst nach dem 40. Lebensjahr angenommen. Die Tatsache, dass weniger als $5 \%$ aller Lehrkräfte mit Ersttätigkeiten das Amt erst nach ihrem 50. Lebensjahr übernahmen, zeigt ferner, dass alte Quereinsteiger ebenso wie auch ganz junge, eben erst selbst der Schule entlassene Schulmeister im Jugendalter kollektivbiografisch als Ausnahmefälle anzusehen sind.

Signifikante konfessionelle Differenzen konnten hinsichtlich der Amtsübernahme nicht festgestellt werden. Sowohl die reformierten als auch die katholischen Lehrkräfte gruppierten sich in Einmütigkeit weitgehend identisch. Einzig die schwache Präferenz der Amtsübernahme von katholischen Lehrern zwischen dem 25. und 29. Lebensjahr fällt als Ausreisser auf, was den zahlreichen als Lehrer aktiven Kaplänen im katholischen Schulwesen geschuldet war, deren Ausbildung in der Regel bis etwa zum 25. Lebensjahr dauerte. ${ }^{508}$ Das Lehramt war somit eine

506 Panchaud, écoles vaudoises: $252 \mathrm{f}$.

507 Zum Heiratsalter vgl. die Ausführungen im Kap. 4.2.1.

$508 \mathrm{Zu}$ den Kaplan-Lehrern vgl. das folgende Kap. 2.2.10. 
Tätigkeit, die bei beiden Konfessionsgruppen überwiegend von jüngeren erwachsenen Personen übernommen wurde.

Nach Generationskohorten aufgeschlüsselt belief sich das mittlere Amtsübernahmealter der total 1.830 untersuchten Lehrkräfte auf 21.9 Jahre für die 319 Lehrkräfte unter 30 Altersjahren, 29.4 Jahre für die 883 Lehrkräfte zwischen 30-49 Altersjahren und 35.7 Jahre für die 604 Lehrkräfte von über 50 Altersjahren. ${ }^{509}$ Die Generation der älteren Lehrkräfte von über 50 Altersjahren hatte das Lehramt somit zwar später als die nachfolgenden Generationen, aber gleichwohl zu einem ähnlichen Alterszeitpunkt übernommen wie die jüngeren Lehrer um 1799. Besonders aussagekräftig ist hierzu das Amtsübernahmealter der mittleren Generationenkohorte der 30-49-jährigen Lehrkräfte mit Ersttätigkeiten, das im Mittel vor dem 30. Altersjahr lag. Zudem zeigt sich die Tendenz, dass die jüngeren Generationen um 1799 das Lehramt insgesamt immer früher übernommen hatten als ihre älteren Berufskollegen. Generationelle Differenzen hinsichtlich des Amtsübernahmealters sind jedoch mitunter unvollständigen Angaben geschuldet, da die Dienstdauerangaben bei älteren Lehrkräften manchmal nur die Dauer der letzten laufenden Anstellung umfassten. Es kann daher vermutet werden, dass etliche der älteren Amtseinsteigenden tatsächlich bereits deutlich früher mit der Lehrtätigkeit begonnen hatten als sie in der Umfrage vermerkt hatten. Die Behauptung einer gesamthaft mangelnden Attraktivität des Lehramts für jüngere Erwachsene kann angesichts des Amtsübernahmealters insgesamt als widerlegt betrachtet werden.

Ebenso wenig konnten markante Unterschiede zwischen Lehrkräften an zentralörtlichen Schulen und Landschullehrern bezüglich des Amtsübernahmealters der Lehrkräfte festgemacht werden. Das mittlere Einstiegsalter der 315 zentralörtlichen Lehrer lag bei rund 29.1 Jahren. ${ }^{510}$ Rund 40\% der Lehrkräfte an zentralörtlich gelegenen Schulen hatten das Lehramt vor ihrem 25. Lebensjahr ergriffen, das relative Maximum lag ebenso wie in der Gesamtschau bei der Altersspanne vom 20. bis zum 24. Lebensjahr. ${ }^{511}$ Ebenso wurde vor dem zwanzigsten und nach dem vierzigsten Lebensjahr auch an zentralörtlich gelegenen Schulen nur noch in Ausnahmefällen eine Person zur Lehrkraft ernannt. ${ }^{512}$ Der Befund ist insofern erstaunlich, als bis zum Ende des Ancien Régimes an den in der Regel besser besoldeten Schulen von zentralörtlichen Orten offensichtlich nicht überdurchschnittlich stark auf ältere, erfahrene Personen gesetzt wurde, wie ein nach modernem Verständnis meritokratisch orientiertes Wahlverhalten mit den Kriterien der zunehmenden Berufserfahrung und Fähigkeitskenntnissen hätte erwarten lassen.

Unterschiede hinsichtlich des Amtsübernahmealters bestanden - unter dem Vorbehalt der dünnen quantitativen Quellenlage - einzig zwischen den Geschlechtern. Zwar hatte auch bei den Lehrerinnen die relative Mehrheit von rund 20\% ihr Lehramt zwischen dem 20. und 24. Lebensjahr übernommen und mindestens ein Drittel aller Lehrerinnen war zum Zeitpunkt ihrer Amtsübernahme noch jünger als 25 Jahre alt. ${ }^{513}$

509 Dazu kommen 24 Lehrer ohne Altersangabe und folglich ohne errechenbares Amtsübernahmealter.

510 Bei 9 der 315 zentralörtlichen Lehrkräften wurde aufgrund von fehlenden Dienstdauerangaben eine minimale Amtsausübungsdauer von 0.5 Jahren angenommen, weitere 8 Lehrkräfte blieben ohne Altersangabe.

511 Mindestens 79 der 315 zentralörtlichen Lehrkräfte war bei der Amtsübernahme zwischen 20 und 24 Jahre alt gewesen (25\%).

512 Vor dem 20. Lebensjahr hatten 48 (15\%), nach dem 40. Lebensjahr 53 (17\%) zentralörtliche Lehrkräfte das Lehramt übernommen.

513 Die einzige Lehrerin, deren Amtseinstieg bereits vor dem 15. Lebensjahr begonnen habe, war die 50-jährige Ordensschwester der Ursulinen, Françoise Giroult, von Estavayer-le-Lac FR. Sie sei „de puis pres de 40 ans“ Lehrerin, womit allerdings der Eintrittszeitpunkt in den Orden gemeint war. Schmidt u.a. (Hgg.), Stapfer-Enquête, Nr. 226: Estavayer-le-Lac. 


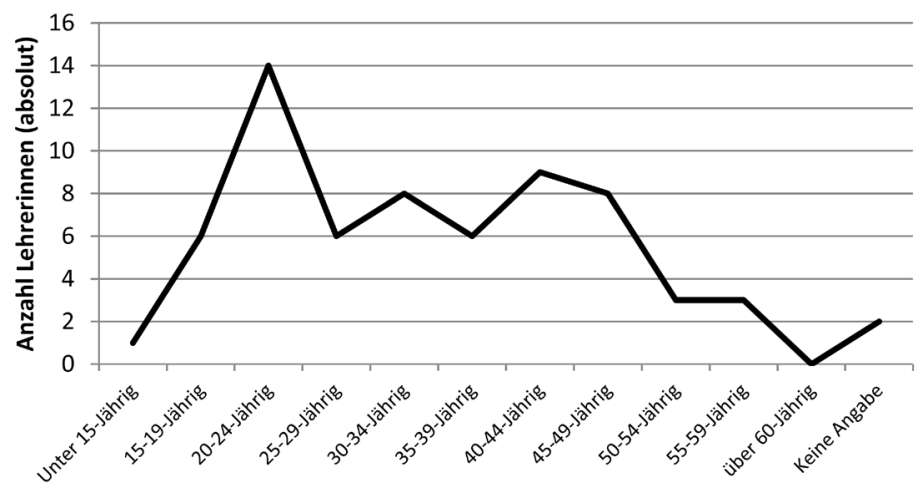

Abb. 3: Amtsübernahmealter der Lehrerinnen

Allerdings bestand ein zweiter Peak in der breiten Altersspanne zwischen dem 30. und dem 49. Lebensjahr, worauf rund $43 \%$ aller Lehrerinnen entfielen, was sich in einem deutlich späteren mittleren maximalen Amtsübernahmealter von 33.5 Jahren zeigt. Das deutlich retardierte Einsteigen der Frauen in die Lehrtätigkeit ist auf zwei mögliche Faktoren zurückzuführen: Zum einen waren zahlreiche Lehrerinnen im Rahmen der Familienwirtschaft mutmasslich deutlich länger an ihrer Schule tätig als tatsächlich in den Quellen vermerkt worden ist. Vielfach wurde nur die Amtsdauer ab der offiziellen Bestellung als Schulmeisterin vermerkt, ohne die Jahre als informelle Helferin mitzuzählen. Da sich zudem die meisten der vermerkten Elementarschullehrerinnen in der frankophonen Schweiz aufhielten, wo die Lehrkräfte häufig nur die Dauer ihrer letzten Anstellung angaben, dürften zahlreiche Amtsausübungsangaben zu kurz ausgefallen sein. Zum anderen war das höhere Amtsübernahmealter zumindest in Einzelfällen auf den Umstand zurückzuführen, dass in kinderreichen Gemeinden aus Gründen der sozialen Versorgung bewusst ältere Lehrerinnen ins Lehramt berufen wurden, wenn separate Schulen für Schulanfänger zur Entlastung des Hauptschullehrers gegründet wurden. Mindestens ein Beispiel aus Begnins VD beweist, dass gezielt eine arme ältere Witwe als Lehrerin für die Schulanfänger angestellt worden ist: „la veuve Lacombe agée de 47 ans Bourgeoise du lieu, pauvre, chargée de deux enfants, et qui quoi quinfirme, est tres propre a la place quon lui a confiée. ${ }^{\text {"5 } 14} \mathrm{~W}$ ie oft das Motiv der sozialen Versorgung von älteren Witwen oder von armen Frauen tatsächlich für die Anstellung von älteren Lehrerinnen ausschlaggebend war, muss anhand der dünnen Quellenbasis freilich offen bleiben.

Zur Frage der kollektiv am häufigsten genannten Ersttätigkeiten hat die Abb. 1 vier deutliche Präferenzen dargestellt, die im Folgenden eingehender betrachtet werden: Landwirtschaftliche, handwerkliche und textilgewerbliche Tätigkeiten sowie keine Ersttätigkeiten. Zunächst soll dem linearen Berufsprofil jener Lehrkräfte gefolgt werden, die unmittelbar nach dem Ende ihrer eigenen Schulzeit zum Lehrer wurden und keine Ersttätigkeiten ausgeübt hatten. Danach richten wir den Blick auf die Lebensverläufe derjenigen Lehrkräfte, die mindestens eine der obgenannten Ersttätigkeiten ausgeübt und folglich erst später ins Lehramt gewechselt hatten. Zum einen soll hierbei das räumliche Auftreten von jeder Ersttätigkeitskategorie beschrieben werden, zum anderen soll anhand von einigen typischen Einzelbeispielen die fundamentale Frage nach 
den Ursachen beziehungsweise den Motiven für den Tätigkeitswechsel eruiert werden, um so die unterschiedlichen Milieus, aus denen die Lehrkräfte heranwuchsen, zu skizzieren.

\subsubsection{Die Lehrer ohne Ersttätigkeiten}

Zahlreiche Lehrkräfte notierten bei der Frage III. 11.g zu ihrem Vorberuf, dass sie entweder „vor hero keinen anderen Beruf gehabt “515 oder „sich von Jugend auf der Schule gewidmet “516 hätten. Die empirische Auszählung der Angaben zu den Ersttätigkeiten ergab, dass mindestens 20.6\% aller Lehrkräfte in der Helvetischen Republik im Frühjahr 1799 in ihren Antworten keine explizite ausserschulische Ersttätigkeiten als das Lehramt oder private Unterrichtstätigkeiten auswiesen. ${ }^{517}$ Mindestens jede fünfte helvetische Lehrperson hatte somit keine eigentliche berufsbiografische „Erstphase“ vorzuweisen und war in linearer Lebensverlaufsentwicklung entweder vom Jugendalter an zum Lehrer geschult worden oder schlug sich vor der Übernahme des Lehramts als ein undefinierter Polyprofessionist ohne spezifische Berufsausbildung durchs Leben. Es muss allerdings berücksichtigt werden, dass aufgrund der doppelten Fragestellung der Frage III.11.g des Fragebogens sich die Antworten teilweise nur auf eine der beiden Teilfragen beschränkten. So fehlt von zahlreichen Lehrkräften eine aussagekräftige Beantwortung der Fragestellung. ${ }^{518}$ Des Weiteren bedeutete eine verneinende Antwort auf die Frage nach den Ersttätigkeiten nicht zwingend, dass die Lehrer tatsächlich keine Ersttätigkeiten ausgeübt hatten. Eine Nichterwähnung konnte aus Gründen der hohen Selbstidentifikation mit dem Lehramt geschehen oder die Vortätigkeit wurde von der Lehrperson im Zusammenhang mit der Umfrage als nicht bedeutend und damit als nicht erwähnenswert taxiert. ${ }^{519}$ So ist anzunehmen, dass etliche der Lehrer ohne Ersttätigkeit zur Sicherung ihrer Subsistenz dennoch im kleinen Rahmen diversen agrarischen oder handwerklichen Tätigkeiten nachgingen, diese Arbeiten aber als Alltagshandlungen ansahen und für nicht erwähnenswert hielten.

Weitere Gründe für eine unvollständige oder gänzlich fehlende Beantwortung der Frage nach den Ersttätigkeiten dürften im unachtsamen Verfassen der Antworten, in Unsicherheiten bezüglich der Fragestellung, in mangelndem Selbstvertrauen der Lehrerschaft im Umgang mit der neuen Autorität der helvetischen Behörden oder aber in der Unwilligkeit zur ausführlichen Beantwortung durch die grundsätzliche Ablehnung der Behörden gelegen haben. Ferner dürfte auch eine gewisse Furcht einzelner Lehrer vor der Konstruktion eines subjektiv minderwertigen Lebensverlaufes dazu beigetragen haben, dass so viele Antworten zum vorherigen Werdegang unvollständig oder leer ausfielen. Es kann ferner vermutet werden, dass viele Lehrer die beabsichtigten Intentionen hinter den Fragestellungen gespürt hatten, was sie veranlasste, ihre Antworten entsprechend an den vermuteten Erwartungshorizont anzupassen. Man muss deshalb davon ausgehen, dass etliche der leeren oder unvollständigen Antworten aus den oben genannten Gründen kein Zufallsprodukt, sondern eine bewusste subjektive Handlung der Lehrer darstellten.

Die Folgerung, keine Ersttätigkeiten hätten bloss die jüngsten Lehrkräfte des gesamten Lehrerkollektivs aufgewiesen, ist falsch. Die Aufschlüsselung der Lehrkräfte ohne Ersttätigkeiten nach

515 Schmidt u.a. (Hgg.), Stapfer-Enquête, Nr. 642: Vordemwald.

516 Schmidt u.a. (Hgg.), Stapfer-Enquête, Nr. 1079: Bern.

517 Mindestens 475 der 2.305 Lehrkräfte nannten explizit keine andere berufliche Vortätigkeit vor dem Lehramt. Vgl. Rothen, Erkenntnisgewinn: 32.

518283 Lehrkräfte hatten keine oder bloss unpräzise Angaben zu ihren Ersttätigkeiten gemacht.

519 „Er hat Keinen Beruff dann nur seine tägliche handarbeit“. Schmidt u.a. (Hgg.), Stapfer-Enquête, Nr. 697: Gerlikon. Es bleibt unklar, aus was die genannte „Handarbeit“ bestand. 
Alterskohorten lässt erkennen, dass nicht etwa nur die jüngsten Lehrkräfte von unter zwanzig Altersjahren, welche altersbedingt gar keine andere Tätigkeit als das Lehramt erlernen konnten, das Gesamtsample dominieren. Vielmehr deklarierten die erwachsenen Lehrkräfte der mittleren Altersgruppen zwischen dem 30. und 50. Altersjahr in absoluter Hinsicht deutlich öfter keine Ersttätigkeit in der Umfrage.

Tab. 4: Lehrkräfte ohne Ersttätigkeiten nach Alterskohorten

\begin{tabular}{lccc}
\hline Alter der Lehrer: & Absoluter Anteil: & In Prozent: & Anteil an Alterskohorte: \\
\hline Unter 20 Jahre & 16 & $3.4 \%$ & $39.0 \%$ \\
20-29 Jahre & 87 & $18.1 \%$ & $22.3 \%$ \\
30-39 Jahre & 118 & $24.8 \%$ & $20.8 \%$ \\
40-49 Jahre & 94 & $20.2 \%$ & $17.9 \%$ \\
50-59 Jahre & 89 & $18.7 \%$ & $19.9 \%$ \\
60-69 Jahre & 54 & $11.3 \%$ & $21.0 \%$ \\
über 70 Jahre & 11 & $2.3 \%$ & $16.9 \%$ \\
Keine Angabe & 6 & $1.3 \%$ & $20.0 \%$ \\
\hline Total & 475 & $100.0 \%$ & $20.6 \%$ \\
\hline
\end{tabular}

Da die Altersgruppen jedoch nicht in gleichmässigen Proportionen im Gesamtkollektiv vertreten sind, ist ein Vergleich der Anteile an Lehrkräften ohne Ersttätigkeit pro 10-Jahres-Alterskohorte aussagekräftiger. Hierbei offenbaren sich markante empirische Erkenntnisse. Zum einen lag der relative Anteil an Lehrern ohne Ersttätigkeiten bei den unter 20-Jährigen zwar erwartungsgemäss mit 39\% Gesamtanteil an ihrer Alterskohorte am höchsten. Doch selbst bei den jüngsten Lehrern mit einer temporal sehr bescheidenen Berufsbiografie war demnach das Ausüben des Lehramts bereits mehrheitlich die zweite Erwerbstätigkeit.

Zum anderen zeigen die Befunde bei den übrigen Alterskohorten dagegen nur schwache Unterschiede. Die Anteilswerte innerhalb der einzelnen Kohorten oszillieren um den Gesamtmittelwert von rund 20\%. Selbst bei der abstrahierten Betrachtung nach den fundamentalen drei Altersgenerationen verändern sich die Anteile an Lehrkräften ohne Ersttätigkeiten bei allen drei Generationen kaum. Bei den unter Dreissigjährigen waren 23.9\% ohne Ersttätigkeiten, bei den 30-49-jährigen Lehrern betrug der Anteil 19.4\%, bei den über Fünfzigjährigen 20.0\%. Es kann daraus gesamthaft gefolgert werden, dass generationenunabhängig rund jede fünfte Lehrkraft das Lehramt ergriffen hatte ohne vorher eine andere Tätigkeit ausgeübt oder diese Ausübung für erwähnenswert gehalten zu haben. Damit wird aber gleichzeitig deutlich, dass zumindest bis zu den Lehrkräften mittleren Alters um 1800 noch kein breitflächiger Spezialisierungsprozess mit einer verstärkten exklusiven Zuwendung zum Lehramt eingestellt hatte. Ab dem 25 . Altersjahr blieb der Anteil an Lehrkräften ohne Ersttätigkeiten im Vergleich zur Gesamtkohorte stabil bei rund $20 \%$.

Das empirisch ermittelte maximale mittlere Amtsübernahmealter der Lehrer ohne vorgängige Berufstätigkeiten, unabhängig vom tatsächlichen Alter, liegt bei 24.2 Jahren. Der grösste Anteil an Lehrkräften ohne Ersttätigkeiten, rund 33.5\%, war aber bereits zwischen dem 15. und 20. Lebensjahr in den Schuldienst eingetreten. 


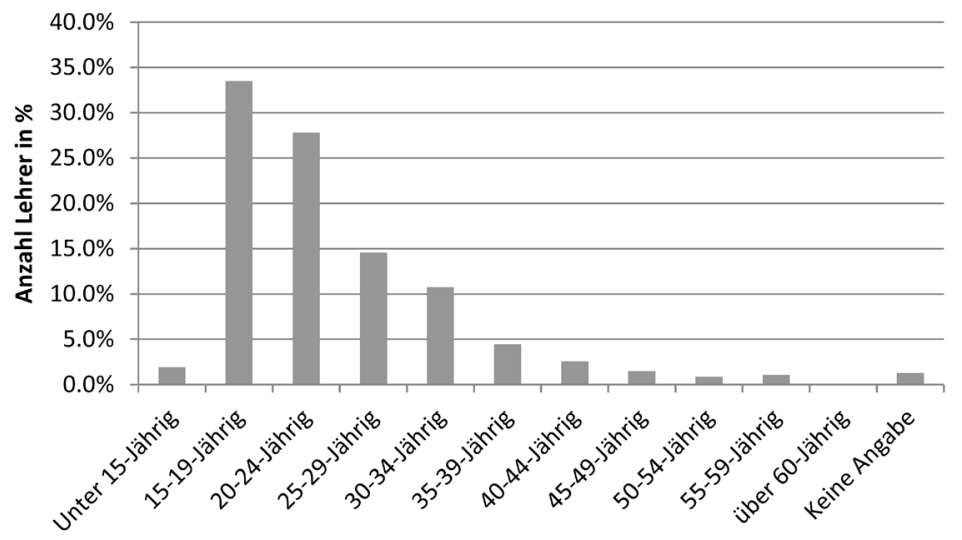

Abb. 4: Amtsübernahmealter der Lehrer ohne Ersttätigkeiten

Der mehrheitliche Eintritt erfolgte somit unmittelbar nach der Beendigung der eigenen Schulzeit respektive nach einer kurzen Periode der individuellen Ausbildung während der Adoleszenz. Eine Amtsübernahme vor dem fünfzehnten Lebensjahr war in kollektiver Betrachtung sehr selten. Der jugendliche, im Jahr 1799 erst 15-jährige Schullehrer Joseph Leonzi Fuchs in Willerzell SZ hatte das Lehramt als Extrembeispiel bereits mit 13 Jahren übernommen und war damit einer der jüngsten Lehrkräfte in der Helvetischen Republik überhaupt: „Jch als wirklicher Schulmeister, heisse Joseph Leonzi Fuchs von Willerzell 15. Jahre Alt unverheirathet, Schulmeister bin ich 2. Winter. ${ }^{\text {"5 } 20}$

Weshalb einige Gemeinden so junge, kaum selbst der Schule entlassene Jugendliche bereits als Lehrkräfte einstellten, ist aus der Antwort des fast ebenso jungen, zum Zeitpunkt der Umfrage erst vierzehnjährigen Lehrers Hans Jacob Foster aus Happerswil TG zu erfahren. Der schrieb: „Die Gemeinde Hate vordem, Bey mans Dencken allezeit einen eignen Bürger zu einem Schullmeister gehabt, aus dem Dorff Happerschweill, Seit Seinem Absterben, haben wir 10. Jahr lang Fremde Schullmeister gehabt, Fast alle Jahr einen Anderen - Seit Martinitag. Anno 1798, Die Gemeinde Forderte meinen vater auf, den Johannes Foster, daß er mich beßer lerrnen laße Dießen Winter, wollen, Sie Gedult Haben mit mir - Sie haben dermahlen nur kleine Kinder, [...] Ends unterschreibene [Schulpfleger] Bezeügen bey dießem Anlaas - Für Sich und im Nammen der Gemeind Happerschweill, daß der Schullohn bey ihnen, Abenderlich, und nicht alle Jahr Gleich geweßen, und daß die Gemeind, manchmahl verlegen war einen Schullmeister zuerhalten, Meistens Sich nur einer Gemeldet Den Man Nemmen müßte, Darum habe die Gemeind, Darauf gedacht, einen jungen B[ürger]: aus ihrem Dorff nachzuziehen, damit sie nach und nach einen Thüchtigen Schullmeister erhalten, der dan bey Gutem verhalten lebenslang, Schullmeister bleibe, Und sie nicht alle Jahre einen Anderen haben müßen - Die Ganze Gemeind wünschte solche Gnad zuerhalten." ${ }^{21}$

Die Wahl eines Minderjährigen zum Landschullehrer brachte den Gemeinden mehrere konkrete Vorteile, wie das eben zitierte Beispiel verdeutlicht. Erstens versprach man sich von einem einheimischen Lehrer aus der Dorfbürgerschaft durch eine frühe Einsetzung eine erhöhte Loyalität und 
eine langandauernde personelle Kontinuität auf dem Schulmeisterposten. Zweitens erhielt die Gemeinde die Möglichkeit, die Kosten für das Schulamt für eine längere Zeit tief zu halten, da das Salär dieses sehr jungen Lehrers geringer ausfallen durfte als für eine Person mit familiären Versorgungspflichten. In der zuvor zitierten Schule Happerswil war das Gehalt des jugendlichen Lehrers denn auch rund ein Drittel geringer als die Löhne in den umliegenden Gemeinden. Der Happerswiler Lehrer verdiente für die zwanzig Wochen Schuldienst total 34 Gulden mit der expliziten Begründung: „will der Schullmeister noch jung war“. Die etwas älteren Lehrkräfte der unmittelbar benachbarten Schulorte Grüt TG (35 Jahre alt, verheiratet und 2 Kinder, seit 11 Jahren Lehrer, 50 Gulden), Kümmertshausen TG (22 Jahre alt, ledig, seit 4 Jahren Lehrer, 60 Gulden) und Andwil TG (20 Jahre alt, ledig, seit 3 Jahren Lehrer, 55 Gulden) verdienten dagegen für dieselbe jährliche Schuldauer fast doppelt so viel. ${ }^{522}$ Da der junge Schulmeister aber noch zu Hause bei seinen Eltern lebte und keinen eigenen Hausstand zu versorgen hatte, genügte die niedrigere Entschädigung als Beitrag an die elterliche Hausökonomie. Drittens reichten die Fertigkeiten des eben selbst erst der Schule entlassenen Knaben aus der Sicht der Gemeindeverantwortlichen offensichtlich aus, um den vorhandenen Schulanfängern - „dermahlen nur kleine Kinder“ - die Anfänge der Kulturtechniken zu vermitteln, zumal der jugendliche Lehrer zeitgleich beim Ortspfarrer und dem erfahreneren, gleichwohl noch jungen Lehrer Daniel Keller in Kümmertshausen TG Weiterbildungsunterricht nahm. ${ }^{523}$

Der Hauptakzent der Amtsübernahme von Lehrkräften ohne Ersttätigkeitsangabe lag unabhängig vom tatsächlichen Alter der Lehrer zum Zeitpunkt der Umfrage auf der Altersspanne zwischen dem 15. bis zum 24. Lebensjahr. Demgegenüber traten weniger als 20\% aller Lehrer ohne Ersttätigkeitsangabe spätestens nach dem 30. Lebensjahr in den Schuldienst ein. Ältere Quereinsteiger ohne Ersttätigkeitsangabe sind in der kollektiven Betrachtung den ungenauen Dienstdauerangaben in der Beantwortung der Umfrage geschuldet. Dies war insbesondere dann der Fall, wenn Lehrpersonen von einem schulischen Engagement „,on Jugend auf “ oder „seit ihrer Entlassung aus der Schule“ sprachen, ihre Dienstdauerangaben im Vergleich zu ihrem Alter jedoch wesentlich kürzer ausfielen. Unter der Berücksichtigung einer Korrektur der Dienstdauerangaben bei all jenen Lehrkräften mit expliziten Aussagen zu einer Arbeitserfahrung seit der Jugend auf das standardisierte 16. Altersjahr fiel das mittlere maximale Amtsübernahmealter nochmals leicht auf 23.1 Jahre. ${ }^{524}$

In konfessioneller Hinsicht sind nur marginale Differenzen feststellbar. Etwa 16\% der katholischen Lehrkräfte, aber rund 22\% der reformierten Lehrer führten die Lehrtätigkeit als einzige Tätigkeit in ihrer Berufsbiografie auf. Die Ursache liegt indes in zwei regionalen Anomalien in den Kantonen Léman und Thurgau verborgen. Beide Kantone wiesen einen besonders hohen Anteil an reformierten Lehrern ohne Ersttätigkeiten mit Anteilen von 38\% respektive 28\% in ihrem kantonalen Lehrerkorps aus, was sich aufgrund der personellen Grösse der beiden kantonalen Lehrerkorps signifikant auf die Gesamtbilanz auswirkte. ${ }^{525}$

522 Schmidt u.a. (Hgg.), Stapfer-Enquête, Nr. 812: Happerswil; Nr. 348: Andwil; Nr. 802: Grüt; Nr. 94: Kümmertshausen.

523 Der erst 22-jährige Kümmertshauser Lehrer Daniel Keller wurde entweder vom bekannten Weinfelder Schulmeister Joseph Dünner oder seinem Sohn Paulus Dünner ausgebildet, denn er stammte selbst aus Weinfelden TG und antwortete auf die Frage nach seinem Vorberuf: „Vorher war ich bey meinem Vatter, er schikte mich fleißig in die Schule." Schmidt u.a. (Hgg.), Stapfer-Enquête, Nr. 94: Kümmertshausen. Zu den Lehrern Dünner vgl. die Ausführungen im Kap. 2.1.1.

524 Die Korrektur umfasst 45 Eingriffe in die gemachten Dienstdauerangaben, was einer Dimension von knapp 10\% an veränderten Daten bedeutet. Das 16. Altersjahr ist empirisch als durchschnittliches Alter für die Zulassung zum Abendmahl gewählt worden.

525 Die hohe Anzahl an Lehrer ohne Ersttätigkeiten in der Waadt ist auf die Verbreitung von ganzjährigem Schulunterricht und den damit verbundenen hohen Lehrerlöhnen zurückzuführen. Vgl. das Kap. 3.1.2. Für das Verhalten der thurgauischen Lehrkräfte fehlt hingegen eine schlüssige Erklärung. 
Eine leichte Signifikanz bestand ferner beim Geschlecht der Lehrkräfte ohne Ersttätigkeiten. Unter den Lehrkräften ohne ausserschulische Ersttätigkeiten waren insgesamt 21 Frauen vertreten, was einem Gesamtanteil von knapp einem Drittel aller weiblichen Lehrkräfte entsprach. Diese stammten - mit zwei Ausnahmen, der Lehrerin von Bière VD und einer Lehrerin an der Lausanner École de Charité - allesamt aus einem zentralörtlichen Umfeld und hatten als biografische Gemeinsamkeit zuvor mehrheitlich als Hauslehrerinnen oder im Familienverband als Lehrhelferinnen gearbeitet. Die verwitwete Lehrerin Maria Magdalena Wyss-Lehmann aus Bern notierte zu ihrem beruflichen Werdegang in der Stapfer-Enquête, sie sei „vorher ein zeit lang Hauslehrerin, hernach 7. Jahr Gehülfin in der offentlichen Lehr an der Brungaß“526 gewesen. Die Lehrerin Jeanne Baud-Crochat von Nyon VD war ihrerseits zuvor „chez sa soeur Gabrielle Crochat a qui elle aidoit à montrer à ses écolières."527

An den beiden exemplarisch genannten Lehrerinnen werden ferner kollektive Merkmale sichtbar, die für zahlreiche der männlichen und weiblichen Lehrkräfte ohne ausserschulische Ersttätigkeiten gleichermassen verallgemeinerbar sind. Zum Ersten wiesen viele der Lehrer direkte familiäre Bezüge zur Lehrertätigkeit auf. Zum Zweiten tauchten Lehrkräfte ohne weitere Ersttätigkeitsangaben besonders häufig an zentralörtlichen Schulen auf, denn jede fünfte Lehrkraft ohne ausserschulische Ersttätigkeiten war an einer zentralörtlichen Schule tätig. ${ }^{528}$ Eine ökonomische Kausalität drängt sich hierbei auf, zumal die Mehrheit der Lehrer ohne Ersttätigkeiten an einer Schule mit ganzjähriger Unterrichtsdauer arbeitete. ${ }^{529}$ Zum Dritten hatten sich zahlreiche Lehrkräfte ohne ausserschulische Tätigkeiten vor der Lehramtsübernahme an einer öffentlichen Schule an einer Privatschule oder als Hauslehrkraft geübt.

Doch wer waren diese Lehrer ohne Ersttätigkeiten und lassen sie sich trotz der fehlenden Berufsangaben dennoch sozial verorten? Nach der Klassifikation von Georges Panchaud zählten Lehrkräfte ohne ausserschulische Ersttätigkeiten zu insgesamt fünf Personengruppen: erstens Lehrersöhne, zweitens gute Schüler, drittens Waisen, viertens Bastarde und fünftens körperlich Invalide. ${ }^{530}$ Anhand dieser Klassifikation sollen die Lehrkräfte ohne Ersttätigkeiten im Weiteren untersucht werden.

\section{Lehrersöhne und -töchter}

Die Weitergabe des spezifischen Professionswissens des Schulmeisters innerhalb des Familienverbundes durch die Mitarbeit von Familienangehörigen, vom Vater oder einem nahen Verwandten zum Sohn oder - seltener - von der Mutter zur Tochter geschah im Kontext der unsystematischpraxisorientierten Schulmeisteranlehre häufig. ${ }^{531}$ Entsprechend sind Lehrersöhne oder Lehrerinnen-Töchter als quantitativ dominante Gruppe unter den Lehrkräften ohne Ersttätigkeiten zu vermuten. Mindestens jede fünfte Lehrkraft ohne Ersttätigkeiten deutete in der Stapfer-Enquête einen verwandtschaftlichen Bezug zum Ausbildungserwerb an, die Dunkelziffer dürfte aufgrund der Freiwilligkeit der Angaben weitaus höher gewesen sein. ${ }^{532}$ So berichtete der Lehrer Franz Justi-

526 Schmidt u.a. (Hgg.), Stapfer-Enquête, Nr. 1083: Bern. Mindestens 7 der 21 Lehrerinnen ohne ausserschulische Ersttätigkeiten hatten vorgängig Privat- oder Hauslehrerdienste ausgeübt.

527 Schmidt u.a. (Hgg.), Stapfer-Enquête, Nr. 1683: Nyon.

528 Insgesamt mindestens 97 der 475 Lehrkräfte standen zentralörtlichen Schulen vor (20.4\%). Davon waren 69 von zentralörtlicher Herkunft.

529292 der 475 Lehrkräfte ohne Ersttätigkeiten hielten ihre Schule ganzjährig. Vgl. ferner die Ausführungen im Kap. 3.3.1.

530 Panchaud, écoles vaudoises: $254 \mathrm{ff}$.

531 Vgl. das Kap. 2.1.1.

532 Mindestens 94 der 475 Lehrkräfte ohne Ersttätigkeitsangaben erwähnten einen direkten familiären Bezug zum Lehramt in ihren Angaben. 
nus Gerschwiller von Andwil SG in der Stapfer-Enquête exemplarisch: „Von der Gemeind Andwil als angenommen Schul-Meister, bin ich 7 Jahre. Vorhero habe ich 6. Jahre an statt meinem Vatter denselben versehen. Mein Bruf, hat mein Vatter durch seine Vätterliche Pflicht, mir den Nöthigen Unterricht gezeigt; Damit ich eines Rechtens Schul-Dienstes Fähig werde. ${ }^{\text {" } 33}$

Da Lehrersöhne aber oftmals bis zum Rücktritt oder gar bis zum Tod des Vaters warten mussten, bis sie die Stelle übernehmen konnten, wiesen sie ein höheres mittleres Amtsübernahmealter auf als zuvor das Mittel der Lehrer ohne Ersttätigkeiten angezeigt hat. Ihre Amtsübernahme erfolgte durchschnittlich erst mit 25.7 Jahren, was der verlängerten Karenzzeit auf den väterlichen Rücktritt geschuldet war. Die jüngsten Schulmeister in der Stapfer-Enquête - wie die beiden zuvor zitierten aus Willerzell und Happerswil - waren somit meist eher gute Schüler oder Waisen denn Lehrersöhne.

Mit dem Wissensvorsprung, den die Schulmeistersöhne von ihren Vätern erhielten, wurde der langfristige Erhalt des Schuleinkommens als Teil der Familienwirtschaft angestrebt. Mancherorts entstanden so regelrechte Schulmeisterdynastien, wo das Schulamt über mehrere Generationen hinweg als gewohnheitsrechtliche Pfründe im Familienbesitz blieb. ${ }^{534}$ In Fluntern ZH lag das Lehramt um 1799 beispielsweise bereits seit drei Generationen in derselben Familie: „bin 11 Jahr Schullehrer, dabey ich auch erzogen worden, dann mein Vater und Großvater waren Schullehrer in dieser Gemeinde. ${ }^{\text {"535 }}$

Das Phänomen der Schulmeisterdynastien mit bis zu mehr als 200 Jahren Persistenz beschränkte sich nicht nur auf den helvetischen Raum, sondern war auch an Land- und Stadtschulen des süddeutschen Raums weit verbreitet. ${ }^{536}$ Einige Schulmeister-Familien liessen sich das Schulamt gar gewohnheitsrechtlich als exklusives Familienprivileg absichern. Aus der Gemeinde Reiden LU ist beispielhaft zu erfahren: „die schmiedische familie ist im Besitz des schulrechts: jeder andere würde vergeben zu diesem amte sich tauglich zu machen suchen." 537

Ein entscheidender Punkt für die fixe Vergabe des Lehramts an eine einzelne Familie war unter anderem der erbliche Besitz des Schulhauses, womit sich die Gemeinde im Gegenzug wesentliche Kosten ersparte. Die Verknüpfung von erblichem Besitz zuhanden der Schule mit der Weitergabe der Lehrfunktion an die erbberechtigten Familienangehörige versprach den Gemeinden so eine attraktive Sozialstabilität und Kostenersparnis. Gleiches resümiert Wolfgang Neugebauer für die deutschen Elementarschulen: „Die Gemeinden haben an der bisherigen Tradition [der erblichen Weitergabe des Lehramts] ein grosses Interesse gezeigt, eine Tradition, die über die

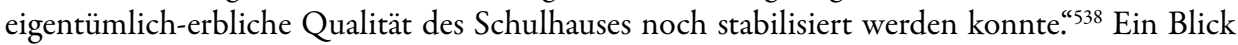
auf die lokale Ebene zeigt, dass diese Praxis bereits im 17. Jahrhundert in einigen Gemeinden Eingang fand, indem Personen durch den eigenen Ausbau ihrer Häuser versuchten, das Lehramt dynastisch zu sichern. Ein Bericht aus der Gemeinde Gachnang TG zeigt etwa, dass der Lehrer Hans Schrämli im Jahr 1686 sein Haus gegen das Versprechen ausbaute, dass die Schule fortan seiner Familie vorbehalten bliebe. ${ }^{539}$

533 Schmidt u.a. (Hgg.), Stapfer-Enquête, Nr. 1158: Andwil.

534 Zahlreiche Beispiele von Schulmeisterdynastien aus der Zürcher Landschaft finden sich bei: Bloch Pfister, Priester: 91; Berner, Zeichen: 94.

535 Schmidt u.a. (Hgg.), Stapfer-Enquête, Nr. 255: Fluntern.

536 Neugebauer, Niedere Schulen: 227.

537 Tatsächlich unterrichtete um 1800 ein Lehrer mit dem Namen Zacharias Schmid in der benannten Gemeinde Reiden LU. Vgl. zum Zitat: BAR B0 1000/1483, Nr. 1454, fol. 13-14, 23-23v: [1799] - Schultabellen Luzern.

538 Neugebauer, Niedere Schulen: 227.

539 Scheurer, Gachnang: 103. 
Der empirischen Tatsachenprüfung anhand der Stapfer-Enquête hält diese Folgerung in Ansätzen stand. Von den insgesamt 94 Lehrkräften mit vermerkter familiär-dynastischer Amtsübernahme von einem Familienmitglied hatten 31 Lehrer den Schulunterricht in ihrem eigenen Haus aus Mangel an einem Schulhaus durchgeführt. Zumindest bei diesem Drittel an Lehrkräften kann die Verbindung der Lehramtsweitergabe mit der Verfügbarkeit von privat bereit gestelltem Schulraum vermutet werden. Allerdings bewohnten mindestens ebenso viele Lehrkräfte mit familiärer Bindung eine von der Gemeinde zur Verfügung gestellte Schulwohnung im Schulhaus. ${ }^{540}$ Der Besitz des Schulhauses und die dynastische Weitergabe des Lehramts konnten, mussten aber nicht miteinander verbunden sein.

Die erbliche Weitergabe von Lehrfunktionen an Familienangehörige wurde in allen Regionen der Helvetischen Republik praktiziert. Dass Lehrersöhne ebenfalls Lehrer wurden, war oft eine Folge der Pfadabhängigkeit durch den Vorteil des Spezialwissens. Die so entstandene Selbstrekrutierungsquote der Lehrer blieb im Verlauf des 19. Jahrhunderts in den deutschen Territorien recht hoch, sie betrug beispielsweise in Kurhessen 30\%, in Bayern 30\% oder Württemberg 25\% des gesamten Lehrerkorps. ${ }^{541}$ Zwar sank die Bedeutung von Lehrerdynastien mit der fortschreitenden Institutionalisierung der Lehrerbildung im frühen 19. Jahrhundert langsam, wurde aber erst mit der zunehmenden inneren Berufung als Voraussetzung für den Lehrerberuf und der Durchsetzung des Ausbildungsprimats durch kantonale Ausbildungseinrichtungen ab Mitte des 19. Jahrhunderts endgültig überwunden. ${ }^{542}$

Nicht in jedem Fall von innerfamiliärem Wissenstransfer wurde das Lehramt allerdings linear vom Vater auf den Sohn übertragen, auch andere Mitglieder des Familienverbunds konnten die Transferfunktion übernehmen, wie einzelne Beispiele belegen. Der Lehrer Rudolf Rinderknecht in Oberstrass ZH hatte seine Lehramtsqualifikation von seinem Schwager erlernt ${ }^{543}$, der Lehrer in Buchthalen SH wurde dagegen vom Grossvater unterrichtet und ausgebildet. ${ }^{544}$ Geschwister beiderlei Geschlechts konnten ebenso in die Rolle des Ausbildners schlüpfen, wie das Beispiel der Lehrerin Jeanne Baud-Crochat weiter oben gezeigt hat. ${ }^{545}$ Der Lehrer Alexander Kessler von Unterhallau SH erlernte als Waisenkind die Lehramts-Fähigkeiten gar von seinem Vetter: „Von Ehrlichen Ältern bin ich gebohren, bis in daß 11 Jahr meines Alters, \{da\} dann beede in einer Hizigen Krankheit in zeit 8 Tagen gestorben, aldann hat mich mein Vetter Christian Schweizer Schulmeister sel. als ein armes Wäislein angenommen u: mich an älternstatt aufferzogen, $\mathrm{u}: \mathrm{zu}$ aller guther Lehr angehalten hat so daß ich mich erkühnen dörffen umm ein Schuldienst zu bewerben: den ich schon, wie vorgemeldt, über 52 Jahr nach möglichen kräfften versehen hab. ${ }^{\text {"5 } 46}$ Die innerfamiliäre Weitergabe des Lehramts funktionierte bisweilen auch matrilinear von der Mutter auf die Tochter, wenn die Mutter selbst Lehrerin war. ${ }^{547}$ In einigen Fällen lief die dynas-

540 Von den 94 Lehrkräften mit familiärer Berufsweitergabe bewohnten 34 eine Schulwohnung, 31 hielten in ihrem eigenen Haus die Schule, acht Lehrer wohnten explizit an Drittorten und 21 machten keine weiteren Angaben zu ihrer Wohnsituation.

541 Kesper-Biermann, Kurhessen: 140.

542 Vgl. Bloch Pfister, Priester: 91. Inwieweit eine kontinuierliche Abnahme der Selbstrekrutierung im 19. Jahrhundert der Realität entspricht, ist - zumindest für Deutschland - umstritten. Vgl. Kesper-Biermann, Kurhessen: 140.

543 „13. Jahr Adjunktus neben meinem Lieben Schwäher Selig.“ Schmidt u.a. (Hgg.), Stapfer-Enquête, Nr. 263: Oberstrass.

544 „wohnte vorher im Dorf bei seinem Gros Vater der auch Schuhlmeister gewesen“. Schmidt u.a. (Hgg.), StapferEnquête, Nr. 1021: Buchthalen.

545 Für die Übergabe des Lehramts unter Brüdern: „Jch wahr von Jugent auf zur Schul geneigt, und habe oft meinen Bruder in seyner Abwesenheit seiner Schull Dienste gethan." Schmidt u.a. (Hgg.), Stapfer-Enquête, Nr. 666: Hühnerbach.

546 Schmidt u.a. (Hgg.), Stapfer-Enquête, Nr. 994: Hallau.

547 „Toujours à l'Ecole avec sa Mère à qui elle à succedés.“ Schmidt u.a. (Hgg.), Stapfer-Enquête, Nr. 1849: Lausanne. 
tische Sicherung des Lehramts somit über die Ehefrau. So führten Schulmeister-Witwen nach dem Ableben ihres Ehemanns dessen Schulgeschäfte allein oder mit weiteren Familienmitgliedern weiter, um das Einkommen des Schulamts dynastisch zu sichern. Mitunter konnte das Schulmeisteramt auch durch das gezielte Einheiraten in eine Schulmeisterfamilie erworben werden. ${ }^{548}$ Mit der gezielten Heirat einer Schulmeisterwitwe konnte indes auch das Lehramt quasi „ererbt“ werden. ${ }^{549}$ Die Schulmeisterwitwen wurden so einerseits zu umworbenen Trägerinnen einer Ressource, sofern es sich um eine ökonomisch lohnenswerte zentralörtliche Schulstelle handelte. Andererseits verblieb das Schulwesen in der ständisch-dynastischen Tradition und die Kommunen mussten sich nicht mit der Versorgung der Schulmeisterwitwen herumschlagen. Es bleibt jedoch aufgrund fehlender expliziter Bemerkungen offen, wie oft solche „Geschäftsheiraten" in der Alten Eidgenossenschaft beziehungsweise der Helvetischen Republik tatsächlich praktiziert wurden. ${ }^{550}$ In der Gemeinde Worb BE übernahm die Ehefrau des Lehrers ferner aus Kostengründen die Stelle des Schulhelfers, damit das Einkommen des gesamten Schuldienstes in der Familie blieb und nicht durch eine familienfremde Person geschmälert wurde. ${ }^{551}$ Keine Fälle sind jedoch bekannt, bei der das Lehramt vom Vater direkt auf eine Tochter weitergegeben wurde.

Allerdings gab diese traditionelle Form der vormodernen Qualifikation zunehmend Anlass für Kritik an der Qualität des Bildungsstands der Lehrkräfte. Sie stand jedem Versuch einer reformorientierten Formalisierung von Anforderungskriterien für eine Institutionalisierung der Lehrtätigkeit entgegen, da weder die Gemeinden noch die betroffenen Lehrkräfte ein besonderes Interesse an äusseren Einflussnahmen zeigten und neuen normativen Reglementierungen skeptisch bis ablehnend gegenüberstanden. ${ }^{552}$ Insbesondere die Versuche einzelner kantonaler Erziehungsräte, freie Lehrerstellen nur noch an patentierte Lehrkräfte mit zuvor absolvierten Fortbildungskursen und mit bestandener Prüfung zu vergeben, stiessen auf teilweise heftigen Widerstand bei ständisch-dynastisch gebildeten Lehrern, die einen Verlust ihrer Stellen und ihres Wissensvorsprungs fürchteten. Aber auch bei der Landbevölkerung, welche zum einen ihr Wahlrecht durch die willkürliche Einstellung von ausschliesslich patentierten fremden Lehrkräften in Gefahr sah, regte sich Widerstand. Zudem wurden Versuche zur Institutionalisierung der Lehrerausbildung in der Bevölkerung mit Argwohn beobachtet, da man um die Orthodoxie der althergebrachten Bildungsinhalte und Bildungsmethoden fürchtete. ${ }^{553}$ Ferner drohte ein zunehmender Autoritätskonflikt zwischen formal geprüften, in institutionalisierten Bildungseinrichtungen ausgebildeten Lehrern und den traditionell-dynastisch rekrutierten, unsystematisch ausgebildeten Lehrkräften.

Die unsystematisch-personale Wissensweitergabe war angesichts der artikulierten Kritik jedoch keineswegs von erratischer Natur. Auch Söhne von etablierten Lehrkräften, welche bereits einen

548 „der jezige Schulmeister heist Hs Jakob Pfister [...] Jm May. 1796. ward er vom Examinator Collegium an stat seinens verstorbenen Schwehrvaters zum Schulmeister erwählt." Schmidt u.a. (Hgg.), Stapfer-Enquête, Nr. 116: Gfenn.

549 Vgl. das Beispiel des Mädchenschullehrers Carl Daniel Gaiser aus der deutschen Stadt Tübingen, der als Vorbedingung zur Erlangung einer städtischen Schulstelle die Witwe des Amtsvorgängers ehelichen musste. Hauer, Schulentwicklung: $270 \mathrm{f}$.

550 Neugebauer, Niedere Schulen: 229.

551 Schmidt u.a. (Hgg.), Stapfer-Enquête, Nr. 967: Worb.

552 Neugebauer, Niedere Schulen: 227.

553 Die Solothurner Obrigkeit sah sich beispielsweise veranlasst, die Einführung der Normalmethode an den Landschulen mit gedruckten „Bauerngesprächen“ zu begleiten, um die Landbevölkerung von den Neuerungen zu überzeugen. Mösch, Solothurnische Volksschule: 92f., 105-111. 
Wissensvorsprung aus dem familiären Wissenstransfer aufwiesen, wurden bisweilen von ihren Vätern zur weiteren Ausbildung bewusst zu anderen Lehrkräften geschickt, um ihre Chancen auf eine zukünftige freie Schulmeisterstelle zu verbessern. Der angesehene Lehrer Josef Dünner von Weinfelden TG hatte beispielsweise seinen Sohn Paulus nach Bischofszell TG zu einem anderen Lehrer in die Weiterbildung geschickt, um dessen Kenntnisse zu erweitern, wie dieser in der Stapfer-Enquête festhielt: „Hat sich von Jugend auf diesem Beruf gewidmet, und eine Zeit lang zu Bischofzell den Unterricht des Bürger Germann, gewesenen Provisors, und nunmehrigen Lehrer an der Kunst Schule in Zürich, genoßen. ${ }^{\text {"554 }}$ Dass der Weinfelder Lehrer Dünner mit diesem bewussten Akt der Fremdausbildung keine Ausnahme war, zeigt ferner die Antwort des Lehrers Johannes Trittenbach aus der benachbarten Gemeinde Oberneuwilen TG: „Der Schul Meister heist Johannes Triten Bach Zu Ober Neüweilen, Mein Alter ist 59 Jahr, hat 4 Kinder, Von welchen Jch ein Sohn Zur Bey Heulff habe, den Jch weret Mein Ammpt nach 2 Jahr in Ein Fremde Schul geschickt, dar mit er im Schreiben Rechnen und Leßen Beßer als ich gelehret werde; Auf welchem Jch Mein Ammpt auf das früh Jahr wegen Alter Schwachheit mit Ausgang Der dis Jährigen Schul Einem anderen über Laßen werde." 555

Es war also selbst in etablierten Lehrerfamilien mit einem informellen Wissensvorsprung durchaus üblich, die eigenen Söhne an fremder Stätte durch andere angesehene Lehrkräfte weiterzubilden, wo sie unter Umständen mit neuen Lehrmedien, neuen didaktischen Methoden oder neuen Lehrinhalten in Berührung kommen konnten. Damit wurde der Wissenskanon trotz der traditionellen Weitergabe mit ständischer Ausprägung partiell durchlässig, wenn auch mit einer deutlich beschränkten räumlich-zeitlichen Diffusionswirkung. Insgesamt unterschied sich die Berufsweitergabe der Lehrer innerhalb der Familie nicht von anderen spezialisierten Wissens- und Handwerkstätigkeiten, denn gerade in zahlreichen Handwerksberufen entsprach die innerfamiliäre Wissensweitergabe dem pragmatischsten Pfad einer Sicherung von ökonomischen Vorteilen.

\section{Gute Schüler}

Trotz der mutmasslich hohen Selbstrekrutierungsquote der helvetischen Schulmeister blieb das Lehramt weiterhin offen für Kandidaten ohne direkten familiären Bezug zum Lehramt. Die überaus hohe Schuldichte auf dem Gebiet der Alten Eidgenossenschaft sowie die natürliche Fluktuation schufen denn auch einen kontinuierlichen Bedarf an neuen Schulmeistern, was sich durch eine rein dynastische Berufsweitergabe alleine längst nicht mehr abdecken liess. ${ }^{556}$ Zahlreiche spätere Lehrer qualifizierten sich durch herausragende Schulleistungen entweder zum Schulgehilfen des bestehenden Lehrers oder gleich direkt als potenzieller Lehramtskandidat, wenn eine Schulmeisterstelle vakant wurde. Wie sich Jeremias Gotthelfs literarischer Protagonist Peter Käser in „Leiden und Freuden eines Schulmeisters“ als ein nicht standesgemässer, aber williger und talentierter Schüler zum Gehilfen des Schulmeisters aufdrängte, kamen über den Pfad der schulischen Leistung zahlreiche gute Schüler zu ihrer späteren Berufstätigkeit. ${ }^{557}$ Quellentechnisch sind gute Schüler jedoch nur schwierig fassbar. Jean Jsaac Béboux von Epalinges VD muss ein ebensolcher entsprechend talentierter Schüler gewesen sein, denn obwohl er aus einer landwirtschaftlich orientierten Tauner-Familie stammte, wurde er noch im Schulbesuchsalter zum Gehilfen des ehemaligen Lehrers seines Geburtsortes: „A l'âge de 12 ans il était

554 Schmidt u.a. (Hgg.), Stapfer-Enquête, Nr. 374: Weinfelden.

555 Schmidt u.a. (Hgg.), Stapfer-Enquête, Nr. 1062: Oberneuwilen.

556 Zur Fluktuation im Lehramt vgl. das Kap. 3.5.1.

557 Vgl. Gotthelf, Leiden. 
subside du Régent a Montpreveyres \& a refusé la place apres la mort du Régent, sa vocation etait Laboureur. ${ }^{\text {“558 }}$ Auch der Autobiografie des Basler Armenschullehrers Matthias Buser kann man entnehmen, dass er - als Kind eines armen, nicht alphabetisierten Posamenters der Basler Landschaft - bereits mit sieben Jahren genügend gut lesen und schreiben konnte, um aus der Dorfschule entlassen zu werden und später durch fleissigen Nachtschulbesuch die notwendigen Kenntnisse erwarb, um als Landschulmeister arbeiten zu können. ${ }^{559}$

Gute Schüler wurden wie Lehrersöhne bereits sehr früh, meistens unmittelbar nach dem Verlassen der regulären Schule mit 12 bis 16 Jahren, spätestens nach erfolgter Admission zum Abendmahl, zum Schulgehilfen ernannt. So erklärt sich das zuvor festgehaltene, teilweise sehr jugendlich-tiefe Amtsübernahmealter gewisser Lehrer, selbst wenn keine familiären Bezüge zum Lehramt sichtbar sind. Der erst 17-jährige Lehrer von Chexbres VD, Jean Pierre Rattaly, übernahm beispielsweise das Lehramt bereits mit 14 1 지 Jahren: „En sortant de la grande Ecole il à été fait second Régent." ${ }^{\text {"560 }}$

Längst nicht jede Lehrperson wurde aus familiären Pfadabhängigkeiten oder aus ökonomischen Überlegungen zum Lehrer. Insbesondere intrinsische Beweggründe abseits von ökonomischstrukturellen Überlegungen sind als weitere Erklärungsansätze mit zu berücksichtigen. Das Lehramt wurde - wie schon das im Kap. 2.2.1 stehende Beispiel aus Engishofen TG verdeutlicht hat - mitunter aktiv als bewusste Berufswahl vom Jugendalter an angestrebt, was in diametralem Gegensatz zur postulierten grundsätzlichen „Not- und Hilfstätigkeit“ des Lehramtes stand. Der Einstieg ins Lehramt erfolgte unter mutmasslich guten Schülern ohne familiäre Bindung ans Lehramt denn auch deutlich früher als bei Lehrersöhnen. Bereits mit durchschnittlich 23.9 Jahren standen sie ihren ersten Schulen vor.

Wer über die intellektuellen Anlagen und über den Willen zur Ausübung der Lehrtätigkeit verfügte, konnte schon vom Jugendalter an zum Lehrer werden. Beide Voraussetzungen - Intelligenz und Wille - galten jedoch auch für Personen mit erlernten ausserschulischen Ersttätigkeiten als Leitursachen für einen späteren Wechsel ins Lehramt.

\section{Waisen}

Das Waisenkind, aus utilitaristischen Gründen von aufgeklärt-absolutistischen Obrigkeiten zum Schulmeister ausgebildet, hat sich als wirkungsstarkes Stereotyp in der historischen Bildungsforschung gehalten. Den Ursprung des Waisen-Topos muss man im städtischen Umfeld suchen. Städtische Waisenhäuser wurden bereits ab dem späten 17. Jahrhundert zu vereinzelten Keimzellen einer institutionalisierten Lehrerausbildung, wo begabte Waisen unter obrigkeitlicher Aufsicht zu Schulmeistern ausgebildet werden sollten. Im Fürstentum Gotha hatte Fürst Ernst der Fromme bereits im Jahr 1696 im städtischen Waisenhaus ein erstes Lehrerbildungsseminar eingerichtet und auch in Potsdam entstand 1748 unter Friedrich dem Grossen ebenfalls ein erstes Lehrerbildungsseminar in einem städtischen Waisenhaus. ${ }^{561} \mathrm{Im}$ Unterschied zu den gymnasialen Lehrerseminaren, wo sich die Seminaristen aus der Gymnasialschülerschaft auto-

558 Schmidt u.a. (Hgg.), Stapfer-Enquête, Nr. 1888: Epalinges.

559 Kradolfer, Lehrerleben: 19-24.

560 Schmidt u.a. (Hgg.), Stapfer-Enquête, Nr. 2128: Chexbres.

561 Enzelberger, Sozialgeschichte des Lehrerberufs: 37; Sauer, Volksschullehrerbildung: 13ff. Für Hans Richard Seemann war das Seminar in Gotha jedoch nicht als erstes „echtes“ Lehrerseminar anzusehen, da die Prätendenten den Beruf des Geistlichen und nicht des Elementarschullehrers angestrebt hätten. Er sieht demgegenüber das 1726 eingerichtete Weimarer Lehrerseminar am städtischen Gymnasium als „erstes Lehrerseminar Deutschlands“ mit szientifistischem Gepräge. Seemann, Schulpraxis: 17ff. 
gen rekrutierten, wurden Lehrerseminare mit praktisch-technischem Gepräge gezielt für die Ausbildung von Schulmeistern gegründet. ${ }^{562}$

Die Ansiedlung von Seminaren in Waisenhäusern oder Armenanstalten entsprang einerseits dem utilitaristischen Gedanken des Eigenbedarfs an Schullehrern für diese Armen- oder Waisenhausschulen, andererseits der Verwendung von begabten Waisen als künftige Landschullehrer in einem gesellschaftlich nützlichen Sinne. Der württembergische Schulreformer und Schulbuchautor Carl August Zeller erkannte im Waisenhaus als Lehrerbildungsort zudem weitere Vorteile: „Das Ideal [...] ist die Erziehungsanstalt für künftige Lehrer und Lehrerinnen des Volks. Das einzige Medium, hiefür ist in politisch-ökonomischer Rücksicht, das Waisenhaus, als fundirte, für Kinder der Armen bestimmte, von der Willkühr verdorbener Eltern unabhängige, für den höhern Zweck des Staats hingegen leicht zu organisierende Erziehungsanstalt." ${ }^{\text {"563 }}$ Da sich Waisenhäuser in obrigkeitlich-staatlichem Besitz befanden, verfügten reformwillige Obrigkeiten über einen Ort zur Einrichtung von Lehrerbildungsanstalten, wo sich die Seminaristen zeitgleich in schulpraktischen Übungen für die Allgemeinheit nützlich machen konnten. Zudem unterstanden diese Orte keinerlei Einflussnahme durch die Eltern, was es erlaubte, bildungsinhaltliche Reformen umzusetzen, ohne mit harschen konservativen Reaktionen von Seiten der Elternschaft rechnen zu müssen.

Die Idee der Ansiedlung von Lehrerbildungsseminaren in städtischen Waisenhäusern etablierte sich alsbald im gesamten deutschsprachigen Raum. Auch in drei Städten der Alten Eidgenossenschaft rückten die Armen- beziehungsweise Waisenhäuser ins Zentrum von Bemühungen um eine institutionalisierte Lehrerbildung. So entwickelten sich zum einen in der bernischen Waadt die private École de Charité in Lausanne und zum anderen das Waisenhaus der Stadt Zürich zu lokalen Ausbildungsstätten für Schulmeister, während die katholische Solothurner Elementarschullehrerschaft nicht zufälligerweise im Waisenhaus der Stadt Solothurn die Normalschulmethode nach St. Urbaner Vorbild erlernte.

Die École de Charité entstand 1726 aus privater Initiative in Lausanne als eine Armenschule nach dem Vorbild der englischen „charity schools“. Sie richtete sich ursprünglich an arme Kinder beiderlei Geschlechts aus der Stadt Lausanne und ihrem Umland, insbesondere an Hintersassenkinder, und sollte eine kostenlose öffentliche Grundbeschulung gewährleisten. Integral mit der Armenschule verbunden war eine Arbeitsschule, wodurch die Kinder nach dem Absolvieren der Elementarschule und dem Erhalt des heiligen Abendmahls in eine berufspraktische Lehre überführt wurden. ${ }^{564}$ Seit den 1760 er-Jahren nahm die École de Charité aber zunehmend auch Waisenkinder in ihre Anstalten auf, wenngleich die Funktion der Schule keine reine Waisenverwahrung sein sollte.

Seit 1757 wurde in der École de Charité erstmalig ein „Seminaire d'élève régents“ zur gezielten Landschullehrerausbildung gegründet. Fortan wurden hier begabte Waisen sowie Schüler aus der Armenschule und aus den Landschulen der Waadt zu Landschullehrern ausgebildet. Den Erfolg der Ausbildungsbemühungen der École de Charité hat Danièle Tosato-Rigo folgendermassen beurteilt: „Une enquête réalisée en 1799 auprès des instituteurs de Suisse par le ministre de l'éducation Philipp Albert Stapfer, sous la République helvétique, confirme la présence des élèves-régents des Ecoles de charité dans l'ensemble du canton. Georges Panchaud (1952) en avait retrouvé une quinzaine [...]. Grâce aux transcriptions désormais en ligne de cette enquête, et en comparant la liste de noms d'élèves-régents figurant dans le registre des Ecoles avec celle

562 Seemann, Schulpraxis: $25 \mathrm{f}$.

563 Zit. aus: Beier, Zeller: 220.

564 Modoux, Charité: 269; Noverraz, formation: $11 \mathrm{f}$. 
des instituteurs qui ont répondu à l'enquête, c'est une quarantaine d'anciens élèves qui émerge. Sur approximativement 400 postes de maîtres d'écoles élémentaires actives à la fin du siècle ils en occupaient donc grosso modo le 10\%. [...] Les réponses de ces anciens élèves [...] font apparaître qu'ils écrivaient mieux et avec moins d'erreurs que la moyenne des enseignants vaudois. Et que certains d'entre eux présentent un profil de pédagogue, du moins si l'on neutralise cette catégorie (en lui enlevant nos présupposés) pour l'ouvrir aux représentations des acteurs." ${ }^{\text {"565 }}$

Mit rund 10\% Gesamtanteil an der regionalen Lehrerschaft hatte die École de Charité einen mitbestimmenden Wirkungseffekt auf das lokale Schulwesen der Waadt und bewirkte durch ihre besser gebildeten Abgänger eine Intensivierung der lokalen Konkurrenzsituation auf dem Bildungsmarkt und damit einhergehend eine breitere Sensibilisierung für die Hebung der Bildungsansprüche vor Ort. Konkreter Ausdruck dieser neuen Konkurrenzsituation war unter anderem eine erhöhte berufliche Mobilität der Waadtländer Lehrerschaft. Allerdings blieb die École de Charité weit entfernt von einer flächendeckenden Durchdringung und einer Standardisierung der Bildungsanforderungen an die Landschulmeister, wie es im Stand Solothurn mit der Durchsetzung der Normalmethode gelang. Ferner gelang es nie, sich als einzige kantonale Lehrerbildungsanstalt mit absolutem Hoheitsanspruch durchzusetzen. Daneben blieb die Lehrerausbildung stets eine "tâche accessoire" Ausbildungsangeboten der École de Charité, was sich in einigen der Biografien von École de Charité-Absolventen und späteren Lehrpersonen widerspiegelt. So hatte der 19-jährige Lehrer von Jouxtens-Mézery VD in der École de Charité nicht nur die Lehrertätigkeit, sondern auch das Schneiderhandwerk erlernt: „Jl avoit été formé à cette vocation dans les Ecoles de Charité de Lausanne ou il y à un institut particulier pour c'est objet et ou il avoit apprit encore la profession de Cordonnier." ${ }^{\text {567 }}$

Das Waisenhaus Zürich begann etwas später als die École de Charité in Lausanne ab dem Jahr 1771 ebenfalls unsystematisch mit der Ausbildung von Landschullehrern, wenngleich diese Form der Ausbildung nicht im Zentrum des utilitaristisch motivierten Konzepts des Waisenhauses stand. Mindestens zwei Waisen aus dem Waisenhaus Zürich sind in der Stapfer-Enquête als Lehrer überliefert. Ihre biografischen Angaben zeugen wiederum von der angestrebten Polyprofessionalität, um einen Fall in die Armengenössigkeit zu verhindern. Der Lehrer von Dällikon $\mathrm{ZH}$,wurde im wäisenhaus in Zürich erzogen. und hernach erlernte er das Leinweber handwerk“ ${ }^{568}$ ebenso wie der Lehrer von Flurlingen $\mathrm{ZH}$ berichtete: „Vorher bin ich in Zürich in dem Weisenhaus Auferzogen worden, hernach hab ich daß Schneider Handwerck gelernt, darnach bin ich zwölf Jahr in der frömde gewesen. "569

Nach dem Umzug des Waisenhauses aus dem Dominikanerinnenkloster Oetenbach in den städtischen Neubau wurden neben verwaisten städtischen Kindern zunehmend auch Knaben von „ehrlichen Eltern“ aus der Landschaft zur gezielten Ausbildung zu Landschulmeistern aufgenommen. Diese blieben in der Regel für die Dauer von einem bis zwei Wintern vor Ort, wobei sie vom Schulmeister des Waisenhauses im praktischen Anlehre-Verfahren ausgebildet wurden. Ihr Aufenthalt erfolgte gegen ein Tischgeld, im Ausnahmefall aber auch gratis. ${ }^{570}$ Aus den Angaben der Stapfer-Enquête konnten denn auch drei weitere Absolventen dieses Waisenhaus-Lehrganges

565 Tosato-Rigo, Paroles: $151 \mathrm{f}$.

566 Dévaud, École primaire: 82.

567 Schmidt u.a. (Hgg.), Stapfer-Enquête, Nr. 1852: Jouxtens.

568 Schmidt u.a. (Hgg.), Stapfer-Enquête, Nr. 1104: Dällikon.

569 Schmidt u.a. (Hgg.), Stapfer-Enquête, Nr. 465: Flurlingen.

570 Crespo, Waisenhaus: 85. 
identifiziert werden, die selbst keine Waisen gewesen waren. Der Lehrer Hans Heinrich Meyer von Kirchuster ZH besuchte das Waisenhaus Zürich beispielsweise während drei Wintern, um sich die notwendigen Kenntnisse eines Landschullehrers anzueignen: „Diese [Schule] Exestiert seid 1780, da wurde es von E.E. Stillstand gut befunden bey Anlas eines neü zu erwählenden Sigristen die Beschwerde dieser Schule bey zubringen, wurde also $3 \mathrm{Jahr}$ in das Waysen haus auf Zürich geordnet, um da die nöthigen Kenntniße zu deßen Zwek diese Schule bestimmt zu erlernen. Noch Verfluß dieser 3 Jahren wurde ich von den Examinatoren zu diesem Beruf erwählt und bestättet."571

Ähnlich wie bei der École de Charité in Lausanne dürften weitere Schulmeister in der Zürcher Landschaft oder in den von Zürich dominierten Gemeinen Herrschaften ihre Ausbildung im Waisenhaus von Zürich absolviert haben, auch wenn keine weiteren unmittelbaren Hinweise in den Quellen vorliegen. Eine allmähliche Emanzipation oder Abnabelung der Lehrerausbildung vom Waisenhaus fand jedoch nicht statt, da der Zweck des Waisenhauses stets utilitaristisch und polyprofessionell orientiert blieb und nicht ausschliesslich auf das Bedürfnis der Rekrutierung von Landschulmeistern fokussierte - dies im Unterschied zu vielen Waisenhausseminaren im deutschen Raum. ${ }^{572}$ Die Ausbildung von Landschulmeistern blieb bestenfalls ein Nischenprodukt ihres Auftrags, für die Gesellschaft ökonomisch nützliche und produktive Menschen heranzuziehen. Nicht zuletzt die Polyprofessionalität der beiden zitierten Lehrer von Dällikon $\mathrm{ZH}$ und Flurlingen $\mathrm{ZH}$ zeugt von dieser utilitaristischen Ausrichtung der Institution. Im Gegensatz zur École de Charité in Lausanne erreichte das Waisenhaus Zürich jedoch weder eine annähernd ähnliche flächendeckende Durchdringungswirkung noch konnten sich die am Waisenhaus ausgebildeten Schulmeister über spezielle Vorteile bei der Stellensuche freuen, zumal eine schriftliche Patentierung als vereinheitlichtes Instrument der Qualitätssicherung ausblieb. Wie viele der zum Landschulmeister am Waisenhaus von Zürich oder an der École de Charité ausgebildeten Personen tatsächlich Waisenkinder waren, lässt sich nicht rekonstruieren. Mit Sicherheit kann jedoch gesagt werden, dass die Mehrzahl der dort ausgebildeten Landschulmeister keine Waisen waren, sondern bewusst zur Ausbildung in die beiden Institutionen geschickt worden waren und diese Orte nach abgeschlossener Ausbildung wieder verliessen. Das zum Landschulmeister ausgebildete Waisenkind als Verkörperung des utilitaristischen Grundgedankens war zumindest in der Schweiz um 1800 nicht in signifikanter Anzahl anzutreffen. Gänzlich falsch ist es indes nicht, denn es wird durchaus vereinzelt von lokalen Quellen bezeugt. Im Marktflecken Ermatingen TG war beispielsweise um 1780 ganz bewusst ein Waisenkind, (Hans) Jakob Geiger, als Hilfskraft für den damaligen alten Schulmeister angestellt worden. ${ }^{573}$ Allerdings traten in der empirischen Überprüfung anhand der Stapfer-Enquête nur wenige explizite Waisen als Lehrer in Erscheinung. Waisen spielten damit in der sozialen Herkunft der Schweizer Landschullehrer im kollektivbiografischen Sinn keine bedeutsame Rolle. Das Waisenhaus hatte sich jedoch als ein idealer Testraum für reformpädagogische Ideen herauskristallisiert, da es einerseits auf obrigkeitliche Wohltätigkeit zurückgreifen, andererseits im geschützten Raum private Initiativen fördern konnte. Dass Johann Heinrich Pestalozzi bei seinem Musterschul-Projekt in Burgdorf ab 1803 eine Kombination von Schule, Lehrerausbildungsanstalt und Waisenhaus wählte, ist in diesem Kontext zu verorten.

Hinweise auf die Anstellung von unehelichen Kindern von lokalen Honoratioren zum Schulmeister, wie es Georges Panchaud für die Waadt aufgrund eines einzelnen Schriftdokuments

571 Schmidt u.a. (Hgg.), Stapfer-Enquête, Nr. 283: Kirchuster. Ebenso hatten sich die Lehrer der Schulen Grüt ZH und Obersteinmaur ZH nachweislich im Waisenhaus Zürich zu Ausbildungszwecken aufgehalten.

572 Vgl. Seemann, Schulpraxis: $25 \mathrm{f}$.

573 Der Lehrer nannte sich selbst nur Jakob Geiger. Vgl. Mayer, Ermatingen: 5-71. 
hypothetisch vermutet hat, liessen sich auf der gesamthelvetischen Betrachtungsebene nicht weiter bestätigen. ${ }^{574}$ Ihre mutmassliche Existenz bleibt damit ungeklärt.

\section{Invalide}

Menschen mit körperlicher Invalidität seit der Geburt oder durch schwere Unfälle in der Jugendzeit zählten in der Frühen Neuzeit aufgrund ihrer Unfähigkeit zur Ausübung von körperlicher Berufsarbeit im agrarischen oder handwerklichen Tätigkeitsfeld zu den sozialen Unterschichten. Da körperliche Beeinträchtigungen jedoch als unverschuldete Arbeitsunfähigkeit und somit nicht als disziplinarisch zu bestrafende Arbeitsunwilligkeit angesehen wurde, galten Invalide zusammen mit Waisen, Witwen, alleinstehenden Frauen und den geistig Behinderten als unterstützungswürdig, wodurch sie mit sozialer und finanzieller Hilfe durch die Gemeinschaft rechnen konnten. ${ }^{575}$ Die Armenbezüger wurden in der Regel mit Naturalleistungen versorgt, Geldleistungen waren dagegen eher selten. ${ }^{576}$ Das Lehramt schien sich aufgrund der mehrheitlich kommunal organisierten Finanzierung und der ausschliesslich intellektuellen Arbeitsbelastung geradezu ideal für die soziale Versorgung von körperlich Beeinträchtigten anzubieten.

Es stellt sich somit die Frage, ob das Lehramt als mehrheitlich kommunal finanziertes Amt tatsächlich verbreitet bevorzugt an körperlich invalide Mitbürger abgegeben wurde? Diese Schlussfolgerung ist insofern naheliegend, als dass zumindest an manchen Orten die Besoldung des Lehrers unter anderem aus dem Armensäckel der Gemeinde bezahlt wurde und in der Stapfer-Enquête selbst nach der eventuellen Verknüpfung von Armengut und Kirchengut gefragt wurde. ${ }^{577}$ Mit der Vergabe des Lehramts an Invalide hätten sich so für die Gemeinden eine finanziell attraktive Optimierung der Kommunalausgaben und eine gleichzeitige soziale Versorgung von Armengenössigen ergeben. Wie in der Einleitung zum Kapitel 2 angesprochen, galten körperlich invalide Personen in der bisherigen Schulgeschichtsforschung als „typische“ Präferenzpersonen für das Lehramt.

Tatsächlich finden sich in den Antworten der Stapfer-Enquête Lehrkräfte mit körperlichen Beeinträchtigungen, denen das Lehramt als eine der wenigen beruflichen Optionen ohne besondere körperliche Kraftarbeit übrig geblieben war. Der Lehrer Ambrosi Weibel von Itingen BL schilderte seinen Werdegang als Lehrer wie folgt: „Er ist schon 50. Jahr Schul Lehrer. er hat sonst kein Beruff weil er schon jn der Jugend mit einem Schlagfluß ist berührt worden auff der Linken seitten kan er sonsten nicht anders Gewerben. ${ }^{\text {"578 }}$ Auch der Lehrer Jacques Abraham Ozelley aus Oppens VD wurde vermutlich aufgrund seiner wahrscheinlich geburtsbedingten körperlichen Behinderung zum Lehrer: „comme il est estropié il faisoit ce qui pouvoit pour gagner sa vie.“579

Offen bleibt in der kritischen Retrospektive, ob das Lehramt für diese von Geburt oder dem Jugendalter invaliden Personen tatsächlich die einzige Option gewesen war, um sich ihren Lebensunterhalt zu sichern. Weitere kommunal bezahlte „leichte Arbeiten“ ausserhalb der körperlich intensiven Landwirtschaft waren im Spektrum des dörflichen Beschäftigungsangebots durchaus vorhanden gewesen, etwa in der protoindustriellen Heimarbeit, als Mesmer oder in Wächterfunktionen.

Wesentlich häufiger als geburtsbedingte Beeinträchtigungen tauchten in den Quellen verletzungsbedingte Invaliditätsvermerke auf, bei der sich spätere Lehrer in ihren Erstberufen körperlich so schwer verletzt hatten, dass sie keine andere Arbeit mehr verrichten konnten. Beispielhaft spricht

574 Vgl. Panchaud, écoles vaudoises: 256.

575 Vgl. Hippel, Unterschichten: 6.

576 Schmidt, Handlungsstrategien: 241f.

577 Vgl. Brühwiler Finanzierung: 64ff, 130f.

578 Schmidt u.a. (Hgg.), Stapfer-Enquête, Nr. 1600: Itingen.

579 Schmidt u.a. (Hgg.), Stapfer-Enquête, Nr. 1472: Oppens. 
das Schicksal des Lehrers von St. Ulrich SG für die Einsetzung eines schwer verletzten Mannes als Lehrer: „Vorher in Holand im Haag, hernach zu Haus Bauren Arbeit, Bis 19 ten Christmo. 1790. da hat mich im Wald ein Trauriges Schicksal getroffen, wie solches dem B. Representanten Markus Vetsch Bekant ist. \{ein Mann, der theils wegen dem Verlust eines Beins, theils wegen seinem Charakter Attention verdient. ${ }^{\text {“ } 580}$ Die Aussage zeigt aber, dass neben der schweren Verletzung auch die charakterlichen Eigenschaften bei der Wahl eine Rolle gespielt haben musste. Die Vergabe des Lehramts an körperlich beeinträchtigte Gemeindebürger scheint in einzelnen Fällen sicherlich ein bewusster, utilitaristisch motivierter Akt der Kommunen zur sozialen Versorgung des Invaliden gewesen zu sein, sofern die Gemeinden über das alleinige Wahlrecht des Schulmeisters verfügten. Georges Panchaud bezeichnete die Vergabe des Lehramts an Invalide, Kranke und Verletzte als Akt der kommunalen Mildtätigkeit: „Le metier de régent était une planche de salut pour les infirmes de naissance, pour ceux qu'un accident avait mutilés." ${ }^{581}$

Empirisch konnte die soziale Versorgung aus Mildtätigkeit jedoch nicht als systematisch angewandtes Phänomen beobachtet werden. Physische Invalidität konnte zwar im Einzelfall tatsächlich zum ausschlaggebenden Grund für die Übernahme des Lehramts gewesen sein, invalide Schulmeister blieben jedoch gesamthaft betrachtet eine absolute Marginalerscheinung, insbesondere körperlich Invalide von Geburt an. Unter den 2‘305 Lehrkräften der Helvetischen Republik hatte weniger als ein Dutzend Lehrer eine körperliche Invalidität als expliziten Grund für ihre Amtsausübung angegeben. Nur ein einziger Lehrer, Hans Wenger von Pohlern $\mathrm{BE}$, brachte zudem seine körperliche Invalidität mit dem Faktor Armut in direkte Verbindung: „[III.11.g]: Allezeit hier, Feldarbeyt, Jst aber in seiner jugend an einem Bein erlahmet, das es sonst wenig Arbeyt verrichten können. [III.11.h]: Ja. Jst Allmoßner. ${ }^{\text {“582 }}$

Von einer kollektivbiografisch relevanten, systematischen Versorgung von invaliden Personen im Lehramt kann daher nicht gesprochen werden. Des Weiteren spielte die Armenfinanzierung im Schulwesen nur eine untergeordnete Rolle, so dass in der Realität kaum Synergieeffekte durch die systematische Anstellung von Invaliden entstanden wären. ${ }^{583}$ Entgegen der persistenten Erwähnung in der älteren Forschungsliteratur als prädestinierte Gruppe für das Lehramt, entpuppt sich der invalide Schulmeister als ein empirisch widerlegbarer Mythos der älteren Schulgeschichtsforschung.

\subsubsection{Landwirtschaftliche Tätigkeiten}

Die überwiegende Mehrheit der zukünftigen helvetischen Lehrer wuchs in einem landwirtschaftlichen Tätigkeitsumfeld auf. Mindestens rund ein Drittel aller Lehrkräfte, 32.8\%, hatte zuvor eine landwirtschaftliche Tätigkeit ausgeführt. ${ }^{584}$ Die Landwirtschaft machte in der regionalen Betrachtung in den meisten Regionen der Helvetischen Republik - mit Ausnahme des Kantons Basel mit seiner starken Seidenband-Protoindustrie, dem Kanton Solothurn sowie der katholischen Zentralschweiz, wo Geistliche dominierten - mit einem Viertel bis zur Hälfte der ehemaligen Lehrer das Hauptrekrutierungsfeld der Elementarschullehrkräfte aus. ${ }^{55}$ Verglichen

580 Schmidt u.a. (Hgg.), Stapfer-Enquête, Nr. 476: St. Ulrich.

581 Panchaud, écoles vaudoises: 256.

582 Schmidt u.a. (Hgg.), Stapfer-Enquête, Nr. 715: Pohlern.

583 Ingrid Brühwilers Analyse der Haupteinkommensquellen der Lehrereinkommen hat aufgezeigt, dass Armenfonds im Vergleich zu anderen Einkommensquellen bloss eine marginale Rolle gespielt haben. Brühwiler, Finanzierung: 128-132.

584 Mindestens 756 Lehrkräfte hatten eine landwirtschaftliche Ersttätigkeit in der Stapfer-Enquête vermerkt.

585 Anteile an agrarisch Ersttätigen pro Kanton: Aargau: 45\%, Baden: 31\%, Basel: 27\%, Bern: 27\%, Fribourg: 26\%, Léman: 32\%, Linth: 27\%, Oberland: 48\%, Säntis: 29\%, Schaffhausen: 34\%, Solothurn: 22\%, Thurgau: $27 \%$, Wallis: $56 \%$, Waldstätten: $7 \%$, Zürich: $43 \%$. In konfessioneller Betrachtung hatten nur unwesentlich mehr reformierte 
mit der Sozialstruktur der Alten Eidgenossenschaft ist dieser Befund an sich wenig überraschend. ${ }^{586}$ Im Unterschied zu den deutschen Territorien nahmen landwirtschaftliche Tätigkeiten auf dem Gebiet der Alten Eidgenossenschaft eine eindeutig dominante Rolle als Erstbeschäftigungen von Lehrkräften ein, und das unabhängig von der ehemaligen Herrschaftsform. ${ }^{587}$ Lehrer mit agrarischem Tätigkeitshintergrund waren an zentralörtlichen Schulen deutlich unterrepräsentiert. Nur gerade 10\% aller Lehrkräfte an zentralörtlichen Schulen hatten einen agrarischen Ersttätigkeitshintergrund, wobei zudem eine starke räumliche Konzentration der wenigen Personen auf Landstädte in der ehemals bernischen Waadt festzustellen war. ${ }^{588}$ Gleichwohl verweisen diese Einzelfälle exemplarisch auf die gut erforschte Tatsache, dass auch die Bevölkerung in zentralörtlichen Landstädten und an Marktorten noch eng mit landwirtschaftlichen Erwerbstätigkeiten verbunden war. ${ }^{59}$

Das Spektrum an in der Stapfer-Enquête aufgeführten landwirtschaftlichen Tätigkeiten umfasste Bauern, Tauner, Taglöhner, Dienstknechte, Winzer, Holzfäller, Hirten, Viehzüchter und Fischer. Die diversen Tätigkeiten in der Landwirtschaft unterlagen in ihren Begrifflichkeiten einer sozialen Rangfolge nach dem Kriterium des Grundbesitzes und nach dem Besitz von Zugtieren für den Ackerzug. In der Regel wurde die bäuerliche Gesellschaft bereits von den Zeitgenossen in vier ständischen Kategorien begrifflich zwischen Vollbauern, Halbbauern, Taunern und Taglöhnern unterschieden. ${ }^{590}$ Als „Tauner“ wurden Kleinbauern bezeichnet, die über keinen Ackerzug verfügten und deren Landbesitz im Gegensatz zu den Vollbauern bzw. „Laboureurs“ zu klein war, um ausschliesslich von der Landwirtschaft zu leben, weshalb sie zusätzlich einem Nebenerwerb nachgehen mussten, um einen Taglohn zu erwirtschaften. ${ }^{591}$ Dazu kamen diverse agrarische Hilfstätigkeiten ohne eigenen Landbesitz mit einem niedrigen sozialen Rang, namentlich Holzfäller, Fischer, Mäusefänger, Sennen und Hirten. ${ }^{592}$ Grossgrundbesitz beziehungsweise der Status als Vollbauer war aber in der zweiten Hälfte des 18. Jahrhunderts insgesamt seltener geworden, in der Regel dominierten Mittel- und kleinbäuerliche Betriebsstrukturen die Agrarlandschaft. ${ }^{593}$ Die Grenzen zwischen den sozialen Schichten waren jedoch innerhalb der dörflichen Sozialstrukturen fliessend geworden, regional unterschiedlich ausgeprägt und am Ende des 18. Jahrhunderts immer stärker werdenden Veränderungen ausgesetzt. Ein ökonomisch geschickter Handwerker oder ein erfolgreicher Heimarbeiter konnte

als katholische Lehrkräfte einen agrarischen Tätigkeitshintergrund: 636 reformierte (84\%) gegenüber 120 katholischen Lehrkräften (16\%). Das leichte Ungleichgewicht wird auf die Präsenz der geistlichen Lehrkräfte im Kollektiv der katholischen Lehrer zurückgeführt.

586 Vgl. die Ausführungen im Kap. 1.2.2.

587588 der 756 Lehrkräfte stammten aus einem ehemaligen Untertanengebiet (78\%), 17 aus einem zugewandten Ort (2\%), 22 aus einem Landort (3\%) und 129 aus einer Gemeinen Herrschaft bzw. Schirmort (17\%). Einzig aus ehemaligen zugewandten Orten und Landorten waren im Verhältnis weniger Lehrkräfte mit agrarischem Hintergrund verzeichnet.

588 Insgesamt 32 der 756 Lehrer mit landwirtschaftlichen Ersttätigkeiten standen einer zentralörtlichen Schule vor, was gemessen am Total von 315 zentralörtlichen Lehrkräften einen Anteil von 10\% entsprach. Davon hatten 12 an einer zentralörtlichen Schule in der Waadt gearbeitet, allerdings wiesen acht eine ländliche Herkunft innerhalb der Waadt aus, waren somit zugezogene Hintersassen.

589 Zur Ausübung von agrarischen Tätigkeiten bei städtischen Handwerkern: Dubler, Handwerk.

590 Vgl. Simon, bäuerliche Revolution: 170f. Die französischen Begriffe „Agriculteur“ und „Cultivateur“ wurden synonym verwendet und den kleinbäuerlichen Taunern gleichgesetzt, der Begriff „Laboureur“ als „Vollbauer“ gezählt. Zur französischen Begrifflichkeit vgl. die französischen Übersetzungen der Artikel: Holenstein, Bauern; Landolt, Tauner.

591 Vgl. Mattmüller, Tauner: 380f.; Landolt, Tauner.

592 Gschwind, Bevölkerungsentwicklung: 343-381; Mattmüller, Tauner: 381ff.

593 Hippel, Unterschichten: 67f.; Trossbach/Zimmermann, Dorfes: 109-120; Holenstein, Bauern. 
trotz fehlendem Landbesitz durchaus zu grösserem materiellem Reichtum und sozialem Ansehen gelangen als ein Vollbauer.

Umgekehrt finden sich aber ebenso vereinzelte Attribute von sozialem Abstieg und Armut in Kombination mit dem Bauernstand. So berichtete der katholische Pfarrer in Oberhelfenswil SG über seinen Lehrer, dieser sei „,orhin - und izt noch ein armes Baurchen“594 gewesen. Zudem sorgten agrarische Reformen und Modernisierungsbemühungen wie die Aufhebung des Flurzwangs, Allmendteilungen oder neue Anbauprodukte für zusätzliche Dynamiken innerhalb der bäuerlichen Gesellschaftsschichten. ${ }^{595}$ Die Mikrostudie von Peter Stöcklin zur baselländischen Gemeinde Diegten zeigt exemplarisch die Vielschichtigkeit der sozialen Rangfolge bei einer Rangierung anhand des Grundbesitzes, zumal einige Vollbauern mit verhältnismässig wenig Landbesitz auffielen, während es unter den Handwerkern, Taunern und Posamentern durchaus Begüterte mit grossem Grundbesitz gab. Der Schulmeister rangierte hierbei mit seinem Besitz als 62. von 114 Hausvätern mit Grundbesitz im breiten Mittelfeld der Kleinparzellenbesitzer. Zudem hatte der Schulmeister trotz seiner Klassierung als Posamenter eine beachtliche Position inne, war er nicht nur der letzte Untervogt gewesen, sondern später Gemeinderat und Präsident des Zivilgerichts des Orts. ${ }^{596}$

Semantisch sind die zeitgenössischen Begrifflichkeiten kaum voneinander zu unterscheiden, was eine Kategorisierung der landwirtschaftlichen Tätigkeiten für eine soziale Hierarchisierung nahezu verunmöglicht. ${ }^{597}$ Textanalytische Indizien sprechen ferner für eine nicht konsequente Begriffsverwendung durch die Zeitgenossen respektive für eine sozialrangunabhängige, synonyme Verwendung der Termini „Bauer“ und „Landarbeiter“598 als Landbewohner in der ständischen Logik der Abgrenzung zur städtischen Bevölkerung, so dass aus den Begrifflichkeiten selbst nur bedingt abschliessenden Rückschlüsse auf die hierarchisch-soziale Position der Person gezogen werden können. ${ }^{599}$

Eine textanalytische Untersuchung der in der Stapfer-Enquête vermerkten landwirtschaftlichen Ersttätigkeitsbezeichnungen illustriert das Problem der Begriffszuordnung nach soziohierarchischen Gesichtspunkten.

Tab. 5: Agrarische Ersttätigkeiten nach Bezeichnungen

\begin{tabular}{lcc}
\hline Berufsbezeichnung: & Anzahl Lehrer: & In Prozent: \\
\hline "Bauer“/„Laboureur“ & 142 & $18.8 \%$ \\
„Agriculture“/,Feldarbeit“/„Güter“ & 538 & $71.2 \%$ \\
Bedienstete/Knechte & 27 & $3.6 \%$ \\
Taglöhner & 21 & $2.8 \%$ \\
Tauner & 9 & $1.2 \%$ \\
Hirten/Sennen & 9 & $1.2 \%$ \\
Rebbauer/Winzer/Vigneron & 8 & $1.1 \%$ \\
Fischer & 1 & $0.1 \%$ \\
Holzfäller & 1 & $0.1 \%$ \\
\hline
\end{tabular}

594 Schmidt u.a. (Hgg.), Stapfer-Enquête, Nr. 1190: Oberhelfenschwil.

595 Huggel, Einschlagsbewegung; Prass, Agrargeschichte: 75-106.

596 Stöcklin, Diegten: 30-39.

597 Vgl. Brühwiler, Finanzierung: 222.

598 „Baur. Landarbeiter." Schmidt u.a. (Hgg.), Stapfer-Enquête, Vgl. Nr. 2198: Holderbank; Schmidt u.a. (Hgg.), „Fermier Làboureur." Stapfer-Enquête, Nr. 205: Vauderens.

599 Simon, bäuerliche Revolution: 170; Trossbach, Bauern: 36. 
Unter den insgesamt 756 Lehrpersonen mit agrarischen Ersttätigkeiten konnten 142 vormalige „Bauern“ oder „Laboureurs“ gezählt werden. Somit gehörte - unter der Annahme einer bewussten Begriffsverwendung zur sozialen Distinktion - maximal ein knappes Fünftel der vormals agrarisch tätigen Lehrerschaft hypothetisch zur Oberschicht der Bauern. ${ }^{600}$ Die überwiegende Mehrzahl der genannten landwirtschaftlichen Ersttätigkeiten entfiel jedoch auf soziohierarchisch nicht näher bestimmbare Begriffe wie „Agriculture“, „Feldarbeit“ oder „Gütergewerb“, die jedoch einen gewissen Grundbesitz suggerieren. Explizit als landarme Tauner bezeichnet hatten sich dagegen bloss wenige Einzelpersonen. Ebenso selten sind landlose ehemalige Bedienstete, Taglöhner, Holzfäller, Fischer, Viehhirten oder Sennen als Angehörige der bäuerlichen Unterschichten zum Lehrer geworden, obwohl der Viehhirte bekanntlich in der älteren Literatur als „typischer“ Vorberuf für Lehrer galt. ${ }^{601}$ Insgesamt sind eindeutige Tätigkeitsbezeichnungen aus den untersten sozialen Schichten des agrarischen Tätigkeitsspektrums mit weniger als 10\% der Nennungen ebenfalls als Ausnahmeerscheinungen im Kollektiv der erstberuflich agrarisch tätigen Lehrkräfte zu werten. Die weitgehende quantitative Abwesenheit von eindeutigen Unter- und Oberschichtsbezeichnungen indiziert, dass das Lehramt entweder besonders bei der agrarischen „Mittelschicht“ der Kleinbauern als ergänzende Erwerbstätigkeit beliebt war, oder aber durch die Lokalnotabeln vorzugsweise an Personen aus der landwirtschaftlichen Mittelschicht vergeben wurde.

Dass es sich bei den meisten in der Landwirtschaft tätigen, zukünftigen Lehrern mit grosser Wahrscheinlichkeit um Angehörige der kleinbäuerlichen Mittelschichten gehandelt haben dürfte, zeigt neben der Auswertung der Tätigkeitsbezeichnungen zudem eine Auswertung der subjektiv formulierten Besitzgrössenangaben aus der Stapfer-Enquête. Gelegentlich hatten die Lehrer in ihren Antworten die Besitzgrösse der zu bearbeitenden Güter beschrieben, wobei fast durchwegs die Attribute „klein“ oder „armselig“ verwendet wurden, oft sprachlich mit zusätzlichen Minuskeln verstärkt. Der Lehrer Hans Jacob Rysler von Arn ZH notierte beispielhaft, er besitze: „Ein klein beschwertes Güetlein, das ich über den Sommer zur erhaltung etwas Speis pflanzen kann. ${ }^{602}$ Zur Frage, ob es sich bei den angegebenen Besitzgütern tatsächlich um das Eigentum der Lehrkräfte oder um Lehenspachtbesitz handelte, gibt eine weitere Textanalyse Aufschluss: Mindestens 188 der 756 Lehrkräfte mit einem agrarischen Tätigkeitshintergrund hatten in der Stapfer-Enquête einen eigenen Grundbesitz beiläufig miterwähnt. ${ }^{603} \mathrm{Da}$ es sich hierbei um eine freiwillig hinzugefügte Angabe handelte, kann eine entsprechend mindestens ebenso hohe zusätzliche Dunkelziffer vermutet werden.

Tab. 6: Einschätzung des Grundbesitzes der Lehrer

\begin{tabular}{lr}
\hline Eigener Grundbesitz erwähnt: & 188 \\
Davon als „klein“ beschrieben: & 85 \\
Davon als „wohlhabend“ beschrieben: & 1 \\
\hline
\end{tabular}

600 Bei Mehrfachnennungen von agrarischen Tätigkeiten wurde die jeweils erste Tätigkeitsbezeichnung übernommen, in der Annahme, dass die Tätigkeitsreihenfolge einer subjektiven Gewichtung durch die Lehrpersonen entsprach.

601 Vgl. Kap. 2.2 und die beiden biografischen Beschriebe der Lehrer Eggen und Buser, in denen Hirtentätigkeiten als Ersttätigkeiten erwähnt wurden.

602 Schmidt u.a. (Hgg.), Stapfer-Enquête, Nr. 26: Arn.

603 Gezählt wurden sämtliche eindeutigen Angaben zu Besitzverhältnissen, etwa „Er bearbeitet sein kleines gütli“” [Hervorhebung M.R.] Schmidt u.a. (Hgg.), Stapfer-Enquête, Nr. 1134: Wiesendangen. 
Die kollektiv zwar unbewusst entstandene, aber auffällig häufige Betonung des Eigenbesitzes ist ein Indiz, dass ein grosser Teil der zuvor landwirtschaftlich tätigen Schulmeister nicht als landlose Agrarhilfskräfte einzuschätzen ist, sondern als Angehörige der kleinbäuerlichen Mittelschichten mit beschränktem Grundbesitz. Gleichwohl bezeichnete sich kein ehemals agrarisch tätiger Schullehrer selbst als zuvor wohlhabend und bloss ein einziger Lehrer wurde als Sohn eines wohlhabenden Bauern beschrieben. ${ }^{604}$

Ob dieser Land- und Güterbesitz freilich tatsächlich so armselig und klein gewesen ist, wie ihn die Lehrer beschrieben haben, muss kritisch apostrophiert werden. Dagegen spricht zum einen die Tatsache, dass viele gut verdienende Lehrkräfte sich larmoyant über ihre mangelhafte Besoldungslage beklagt hatten, was mitunter auch durch ein simultanes Kleinreden des eigenen Besitzes geschehen konnte. Zum anderen sind innerhalb der bäuerlichen Herkunft der Lehrkräfte starke regionale Disparitäten festzustellen. In einigen Regionen des traditionellen mittelländischen „Kornlandes“ rekrutierte sich die Lehrerschaft aus dem Vollbauernstand mit teilweise beachtlichem Landbesitz, selbst wenn sie diesen nicht explizit erwähnten. ${ }^{605}$ Es bleibt zudem offen, was in den Augen der Lehrer ein „kleiner“ oder „grosser“ Grundbesitz bedeutete, zumal die Lehrkräfte keine konkreten Flächenmassangaben ihres Eigenbesitzes als Referenz für ihre subjektiven Äusserungen genannt hatten.

Hinsichtlich der weitgehenden Abwesenheit von typischen landlosen Unterschichtsberufen in den Ersttätigkeiten der Lehrkräfte kann ferner das Motiv der Versorgung von Armen durch die Vergabe des Lehramts als historiografischer Mythos entlarvt werden. Wäre für die Gemeinden respektive für die Lokalnotabeln tatsächlich die karitative Versorgung von Armen im Zentrum der Lehrerwahl gestanden, hätte der Anteil an sozial geringer geachteten Tätigkeiten wie Hirten, Bediensteten oder Taglöhnern wesentlich markanter ausfallen müssen. ${ }^{606}$ Die historiografische Betonung der Armenversorgung erscheint vielmehr als das Produkt einer Fehlinterpretation der Bevorzugung von Einheimischen bei der Lehrerwahl und einer zu grossen Bedeutungszuschreibung der Armutserwähnungen aus den Selbstdeklarationen der Lehrer.

Die Ursachen und Motive, weshalb sich letztlich jemand aus dem kleinbäuerlichen Umfeld zum Schulmeister wählen liess, sind überaus vielfältig und können nur anhand von Einzelfällen dokumentiert werden. Zum einen war bereits der Vater sowohl Lehrer als auch in der Landwirtschaft tätig, woraufhin der Sohn diese polyprofessionelle Tätigkeitskombination von Lehramt und Landwirtschaft nach dem Tod des Vaters weiterführte. ${ }^{607}$ Bei anderen Lehrkräften mit einem agrarischen Ersttätigkeitshintergrund dürfte das Vorhandensein einer genügend grossen Stube im Wohnhaus zum Schulunterricht ausschlaggebend für den Erhalt des Lehramts gewesen sein. So merkte der Lehrer Heinrich Gass von Rothenfluh BL in seiner Beantwortung der Stapfer-Enquête an, dass er die Stube in seinem Haus gewinnbringender an einen Posamenter

604 „der ledige Schulmeister hielte die Schule bis her in seines Vaters Hause, der von der Gemeine keinen Stuben zins dafür empfangt. da er ein wohlhabender baur, und eine starke Haushaltung." Schmidt u.a. (Hgg.), Stapfer-Enquête, Nr. 2101: Tennwil.

605 Beispielhaft sei auf das Zürcher Unterland verwiesen, wo Schulmeister im Durchschnitt über 20 Juchart Land als Eigenbesitz verfügten. Meier, Handwerk: 238.

606 „Eine Gemeinde, die einen weniger gut bemittelten Kandidaten aus ihren Reihen einem auswärtigen vorzog, hatten einen Armen weniger zu verpflegen und schnitt finanziell besser ab - ein Argument, das fast immer zählte." Schibler, Schulalltag: 17. Vgl. Ruloff, Schulbesuch: 67.

607 „Hat sich vor seiner erwehlung meistens in Binningen aufgehalten, und war seinem Vatter in der Schule, wie auch in der Feld Arbeit behülflich." Schmidt u.a. (Hgg.), Stapfer-Enquête, Nr. 2280: Binningen. Bei mindestens 23 weiteren Lehrkräften ist eine Erwähnung des Vaters als Lehrer und agrarisch Tätiger nachvollziehbar. 
mit Webstuhl hätte vermieten können, als die Stube der Gemeinde als Schulraum zur Verfügung zu stellen. ${ }^{608}$

Für den Lehrer Jean Pernet aus dem Städtchen Villeneuve VD war dagegen berufsbiografische Mobilität durch einen längeren Aufenthalt in der Stadt Genf verantwortlich für den späteren Tätigkeitswechsel, wie er in seiner Beantwortung der Stapfer-Enquête prosaisch festhielt: „Celle de paysan Cultivateur! Ô heureux état pourquoi táa-je quitté pour la pénible $\&$ ingrate vocation d'Jnstituteur? Quand jeus communié, mon pére me plaça chez le Citoyen Joneli, à présent Préfect National du Canton de l'Oberland pour apprendre la Langue Allemande, - delà jai été à Genève, cinq ans et demi, Commis dans le Commerce Au mot de Genève. mon coeur s'épanouit - Jmmortel Rousseau! C'est là, c'est dans la ville qui t'a vû naitre, qu jai commencé à connaitre tes sublimes écrits - mon patriotisme datte depuis cette époque, \& il y a près de vingt ans - Doux et vertueux Fénélon! modèle de l'honnête \{homme\} \& du Chrêtien, c'est aussi à Genève que jai apris à t'aimer -“609

Persönliche Schicksalsschläge mit ökonomischen Folgen standen bei anderen Lehrern am Ursprung ihres späteren beruflichen Tätigkeitswechsels. Starb ein Elternteil einer kinderreichen Familie, mussten die älteren Kinder für ein Zusatzeinkommen besorgt sein. ${ }^{610}$ Schwere Unfälle oder schwerwiegende Krankheiten mit der Folge von körperlichen Einschränkungen zwangen vereinzelt andere Lehrer zu einem fundamentalen Tätigkeitswechsel, waren insgesamt aber Randphänomene. ${ }^{611}$

Ökonomische Armut wurde dagegen als ein Motiv für eine Amtsübernahme von ehemals agrarisch tätigen Lehrkräften praktisch nie explizit erwähnt. Diese auffällige Nichterwähnung von zuvor bestandener Armut lässt wiederum den doppelten Schluss zu, dass erstens oftmals nicht die ärmsten Personen das Lehramt übernahmen, zweitens gerade die Kombination von agrarischen Tätigkeiten mit dem Lehramt für eine Verbesserung der ökonomischen Situation sorgen konnte. Bislang kaum von der Forschung beachtet worden sind Argumente der freiwilligen und bewussten Zuwendung zum Lehramt. Den Wunsch, das Lehramt aus innerer Berufung zu ergreifen, stellt aus handlungszentrierter Perspektive ein mindestens ebenso starkes Motiv für einen Tätigkeitswechsel dar, wie aus äusseren (ökonomischen) Gründen. Die ältere, vorwiegend strukturorientierte Schulgeschichtsforschung hat den individuellen Handlungsspielraum der Lehrer als aktive Gestalter ihrer eignen Biografie bislang stark vernachlässigt und die Handlungsstrategien vor allem als Reaktionshandlung auf äussere Impulse gedeutet. So fehlt etwa das Motiv eines freiwilligen Berufswechsels in der Herkunftstypologie von Georges Panchaud ebenso, wie in den bedeutsamen älteren kantonalgeschichtlichen Betrachtungen von Klinke, Schneider und Zingg. ${ }^{612}$ Selbst neuere Studien gestehen dem Motiv der freiwilligen Amtsübernahme aus innerer Berufung bislang nur eine bescheidene Bedeutung zu, obwohl die „innere Disposition“ bereits für die Zeitgenossen als wichtiges Kriterium für das Berufsprofil eines guten Lehrers galt und etwa in der Zürcher „Anleitung an die Landschulmeister" von 1771 schriftlich festgehalten wurde. ${ }^{613}$

608 „da das Schulhaus mein Eigenthum ist, so könte ich von der Schulstuben, wan ich sie einem Pasamenter Verliehen würde, Jährlich 30 lb. hauss zins haben, nun zalt mir die gemeind nur $4 \mathrm{lb}$. da auch der boden in der selben Gantz zerttreten ist, und das dieses Ohnstreitig, Von dem Vielen \{laufen\} der Schulkinder herkomt, so Glaubte ich, derselbe solte nicht Auf meine eigenen Umkösten gemacht werden. Schmidt u.a. (Hgg.), Stapfer-Enquête, Nr. 1554: Rothenfluh.

609 Schmidt u.a. (Hgg.), Stapfer-Enquête, Nr. 1973: Villeneuve.

610 „vorher die meiste Zeit in Sanen im Turbach bey meiner Muter und Geschwisterden, hate keinen anderen beruf als meiner Muter (die durch früh zeitige Absterben Jhres Ehemans Unsers Lieben Vatters in Wittwenstand gesetzt wurde) beizustehen, nach alhiesigem Hirten Landesart mit arbeit damit sie \{mit $\}$ ihren 8 . Kindern der Gemeinde nicht beschwärlich werden Müße“. Schmidt u.a. (Hgg.), Stapfer-Enquête, Nr. 1442: Bissen.

611 Weitere Ausführungen zu Lehrkräften mit körperlichen Behinderungen sind im Kap. 2.2.1 zu finden.

612 Panchaud, écoles vaudoises: 254-258; Klinke, Zürich; Schneider, bernische Landschule; Zingg, Basel.

613 Bloch Pfister, Priester: 66ff; Berner, Zeichen: 245-252. 
Wenngleich sich entsprechende Äusserungen nur sporadisch in den Quellen finden lassen, ist doch davon auszugehen, dass zahlreiche Lehrkräfte den späteren beruflichen Wechsel ins Lehramt aus eigenem Willen angestrebt hatten. Der Lehrer von Engishofen TG hatte beispielhaft notiert, er sei: „Vorher bey hauß gewesen; jn einen Baursamen beruf auf erzogen zu diensten, Vieler Privat Leüten gearbeitet, auch in meinen Jungen Jahren, schon Lust u: eine begierde gehabt zu solchen Schulgeschäfften; da ich in meinem 17 den Jahr schon in Zürich. als ein predtendent selb 4te vor Examen gestanden. um solche stell zu betreten, Auch innert denen 14 Jahren bey langen Sommertagen nebst den gewohnten Schulstunden, auch wieder die gleichen Baursamen Geschäffte. Besonders im Heüet und jn der Ernde: da ich einem Jeweiligen Bürger, wo ich einge quartiert bin, zur Hilf dienen, wann er es von nöthen hat. ${ }^{\text {“614 }}$

Der Wechsel ins Lehramt erfolgte bei ehemals landwirtschaftlich Tätigen nicht später als im Gesamtdurchschnitt aller Lehrer mit Ersttätigkeiten, denn das maximale Amtsübernahmealter von agrarisch Ersttätigen lag bei durchschnittlich 29.3 Jahren, die relative Mehrheit trat zwischen dem 20. und dem 30. Lebensjahr ins Lehramt ein.

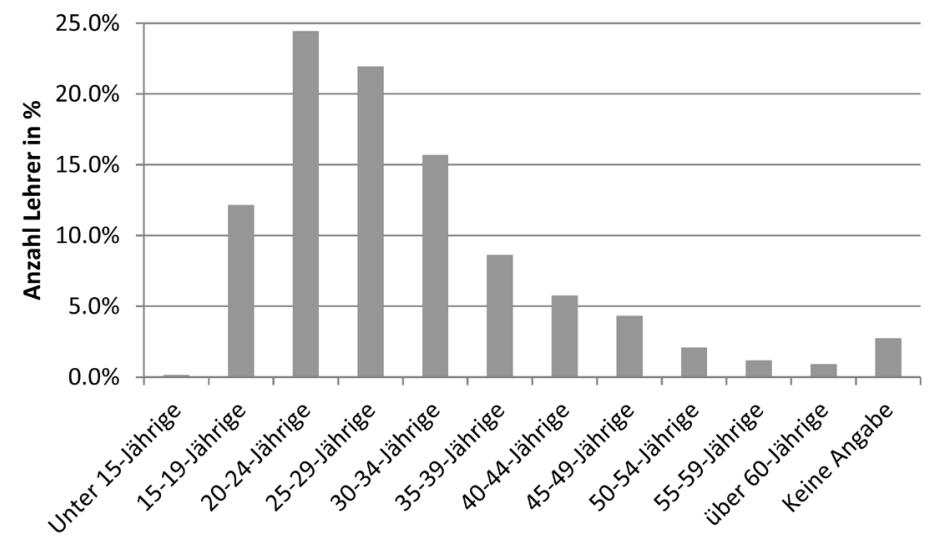

Abb. 5: Amtsübernahmealter der agrarisch tätigen Lehrer

Eine generationenbedingte Veränderung der Häufigkeit an ehemals agrarisch Tätigen im Lehramt ist nicht festzustellen. ${ }^{615}$ Analog der Gesamtbetrachtung in Abb. 1 bildet sich auch bei den agarisch Ersttätigen ein kollektives Muster der Annahme des Lehramts im jungen Erwachsenenalter $\mathrm{ab}$, was indizienhaft gegen die Kategorisierung des Lehramts als verbreiteter Not- und Hilfserwerb für landwirtschaftlich Tätige spricht.

Agrarische Ersttätigkeiten waren ferner unter den wenigen Lehrerinnen in der Stapfer-Enquête kaum vermerkt. Bloss zwei Lehrerinnen - beide an einer Stadtschule in Nyon beziehungsweise Lausanne tätig - hatten eine entsprechende Bemerkung notiert. ${ }^{616}$ Paradoxerweise wurden aber agrarische Tätigkeiten als Erst- oder als Nebentätigkeiten bei den wenigen Landschullehrerinnen nicht erwähnt. Aufgrund der geringen Anzahl an Lehrerinnen kann über die Gründe dieser

614 Schmidt u.a. (Hgg.), Stapfer-Enquête, Nr. 88: Engishofen.

615 21\% aller agrarisch Ersttätigen (155 Lehrer) waren unter 30 Jahre alt, 46\% zwischen 30 und 49 Jahre alt (350 Lehrer) und 32\% über 50 Jahre alt (246 Lehrer), bei zwei Personen ohne Altersangabe. Die generationelle Verteilung entspricht damit praktisch passgenau den relativen Verhältnissen der Gesamtgenerationskohorten (vgl. den Anhang II). 616 Schmidt u.a. (Hgg.), Stapfer-Enquête, Nr. 1684: Nyon; Nr. 1882: Lausanne. 
Nichterwähnung nur spekuliert werden; vermutet wird eine gleichwohl informelle Ausübung agrarischer Tätigkeiten im Familienverband.

\subsubsection{Handwerkliche Tätigkeiten}

Handwerksarbeit bot während des 18. Jahrhunderts in zahlreichen Gegenden Mitteleuropas ein willkommenes Ventil für den zunehmenden Bevölkerungsdruck der ländlichen Unterschichten, was zu einer allmählichen „Territorialisierung der Gewerbe“ von der Stadt in die Landschaft führte. ${ }^{617}$ In Regionen mit einer Realteilung der Erbmasse, schwachem Zunftzwang und einer lockeren obrigkeitlichen Gewerbeniederlassungspolitik resultierte rasch eine arbeitsteilige Ausdifferenzierung der Lokalgesellschaft, wobei sich besonders die landarme und landlose Bevölkerung zunehmend auf die nichtagrarische Güterproduktion zu konzentrieren begann, was wiederum die lokale Nachfrage nach Nahrungsmitteln stimulierte und lokale Märkte des Nahrungsmittel- und Güterhandels entstehen liess. ${ }^{618} \mathrm{Im}$ Zentrum der nichtagrarischen Produktion stand primär der lokale Konsumbedarf in den Bereichen der landwirtschaftlichen Betriebsmittel, des Häuserbaus, der Textilproduktion und der Alltagsgegenstände. Dieses meist zunftfreie, dörfliche Landhandwerk war nur selten auf überregionale Märkte fokussiert, sondern beruhte massgeblich auf der lokalen Nachfrage und innerdörflichen Austauschprozessen. ${ }^{619}$

Entsprechend volatil gestaltete sich der ökonomische Erfolg von Landhandwerkern im Angesicht von schwankender lokaler Nachfrage, dem durch naturbedingte Krisen ungleichen Angebot an Lebensmitteln und möglicher Konkurrenz durch andere Handwerker, was sich wiederum auf die Strategien zur ökonomischen Absicherung auswirkte. Landhandwerker neigten daher stark zu Strategien der polyprofessionellen Erwerbsarbeit, deren Kern zwar die landwirtschaftliche Subsistenz blieb, wobei das Lehramt oder andere Dorfämter aber eine mögliche Ergänzungsalternative des lokalen Arbeitsangebots darstellen konnte. ${ }^{620}$ Zudem traten einzelne spezialisierte Handwerke - beispielsweise die Uhrenmanufaktur im Waadtländer Jura - regional in stark unterschiedlicher Dichte auf, was den Konkurrenzeffekt in konjunkturell schwierigen Zeiten zusätzlich verstärken konnte und die Betroffenen zwang, rasch neue Ressourcen der ökonomischen Sicherung zu erschliessen. Polyprofessionalität und die Fortführung von agrarischen Subsistenztätigkeiten prägten den Lebensverlauf der meisten Landhandwerker und nur eine verschwindend kleine Minderheit vermochte ohne landwirtschaftlichen Rückhalt zu wirtschaften, selbst wenn die Quellen kaum darüber berichten. ${ }^{621}$

Rund 16\% aller helvetischen Elementarschullehrkräfte vermerkten in der Stapfer-Enquête einen handwerklichen Ersttätigkeitshintergrund, sondert man die protoindustriell-textilgewerblichen Weber als eigene Tätigkeitsgruppe vom traditionellen Handwerk ab. ${ }^{622}$ Handwerker stellten damit die insgesamt zweitgrösste Tätigkeitsgruppe dar, die später das Lehramt ausübte. Darin subsumieren sich insgesamt mehr als 30 Einzelberufe, unter anderem Bäcker, Blattmacher, Buchbinder, Büchsenmacher, Chirurgen, Dachdecker, Drechsler, Eisenschmiede, Gärtner, Gerber, Glaser, Graveure, Handschuhmacher, Hutmacher, Knopfmacher, Köhler, Korbmacher,

617 Hippel, Unterschichten: 16.

618 Hippel, Unterschichten: 82; Trossbach/Zimmermann, Dorfes: 127f.; Trossbach, Bauern: 55f.; Prass, Agrargeschichte: $38 \mathrm{f}$.

619 Trossbach/Zimmermann, Dorfes: 127.

620 Trossbach/Zimmermann, Dorfes: 129; Meier, Handwerk: $174 \mathrm{f}$.

621 Meier, Handwerk: 174-184.

622 Es konnten mindestens 368 Lehrkräfte mit handwerklichen Ersttätigkeiten gezählt werden. 
Maler, Maurer, Nagelschmiede, Sattler, Schiffbauer, Schlosser, Seiler, Sesselmacher, Steinhauer, Steinschleifer, Tischler, Töpfer, Uhrmacher und Ziegler.

Die Handwerke lassen sich ihrerseits in vier Kategorien der traditionellen ländlichen Gewerbestruktur einteilen: Zum Ersten in die landwirtschaftlichen Bedarfsgewerbe, zu denen Schmiede, Müller, Wagner, Küfer, Drechsler, Schreiner, Sattler, Seiler und Mühlebauer zu zählen sind. Die zweite Gruppe umfasste die Gewerbe mit Massennachfrage und beinhaltete die textile Produktion der Schuhmacher, Schneider, Hutmacher, Handschuhmacher und Weber. Zur dritten Kategorie, dem traditionellen Baugewerbe, zählten Maurer, Maler, Dachdecker und Zimmerleute. Dazu gesellten sich die Gewerbe der Wirte, Krämer, Barbiere, Chirurgen und weiterer Spezialgewerbe. ${ }^{63}$ Wie die agrarischen Tätigkeiten waren auch die landhandwerklichen Berufe im Ancien Régime von einer gewissen soziohierarchischen Schichtung geprägt. Zu den Handwerkstätigkeiten mit dem höchsten sozialen Status analog den Vollbauern gehörten gewöhnlich die Wirte, Müller, Öler, Metzger und Schmiede. Diesen Berufen war die sogenannte „Ehaftigkeit“ gemein, ein monopolartiges Rechtsprivileg auf den Betrieb von konzessionspflichtigen Liegenschaften. Auch Chirurgen, Viehärzte oder Bäcker konnten neben den Vollbauern zur dörflichen Aristokratie gezählt werden. ${ }^{624}$ Die Tätigkeiten des Baugewerbes und der landwirtschaftlichen Grundbedarfsproduktion folgten darunter, vergleichbar mit dem Sozialstatus der kleinbäuerlichen Tauner. Einen eher prekäreren Sozialstatus nahmen dagegen die Handwerke der Bekleidungsproduktion ein. Keinesfalls waren Landhandwerker jedoch wegen ihres Berufes oder wegen ihres geringen beziehungsweise fehlenden Landbesitzes geringer geschätzt als Bauern oder Tauner, erst recht nicht sind sie als sozial Deklassierte zu bezeichnen. ${ }^{625}$

Dass der Prozess der Verbreitung der Handwerke regional unterschiedlich stark erfolgte, wurde vorgängig bereits angesprochen. Ähnliches kann für die Alte Eidgenossenschaft postuliert werden. Die auch im Lehramt häufig aufgetretenen textilen und holzverarbeitenden Handwerke Schuhmacher, Schneider, Küfer, Schreiner - verbreiteten sich vor allem in den Zonen der mittelländischen Ackerbaugebiete und entlang von Verkehrsachsen sowie bei Marktplätzen. ${ }^{626}$ Ebenso konzentrierten sich eisenverarbeitende Handwerker stark auf das städtische Umfeld ${ }^{627}$ Besonders zahlreich waren Lehrkräfte mit einer handwerklichen Vergangenheit in der empirischen Überprüfung denn auch in den mittelländischen helvetischen Kantonen Bern mit 30\% Anteil am kantonalen Lehrerkorps, Aargau (25\%), Schaffhausen (24\%), Léman (19\%) und Solothurn (18\%) vertreten. ${ }^{628}$ Immerhin noch mehr als jeder zehnte Lehrer der Kantone Oberland (16\%), Baden (14\%), Basel (14\%) und Thurgau (14\%) hatte ebenfalls eine handwerkliche Vergangenheit vermerkt. Wo Handwerker folglich in der ländlichen Gesamtgesellschaft häufig vorkamen, tauchten sie simultan auch im elementaren Schulwesen in besonderer Häufigkeit auf. An zentralörtlichen Schulen traten ehemalige Handwerker dagegen kaum in überproportionaler Weise auf. ${ }^{629}$

623 Meier, Handwerk: $106 f$.

624 Meier, Handwerk: 238-247; Berner, Zeichen: 99; Trossbach/Zimmermann, Dorfes: 127.

625 Meier, Handwerk: 247.

626 Vgl. Meier, Handwerk: 40-47.

627 Thomas Meier bestätigt die Konzentration von eisenverarbeitenden Handwerkern in Landstädten exemplarisch in seiner Studie zum Zürcher Unterland. „obschon man auf dem Lande viele ausgesprochene Spezialisten antrifft, sind die eigentlichen Zentren differenzierter Metallberufe ganz eindeutig die Landstädte [...]. Diese Tatsache lässt sich mit der dort herrschenden, gegenüber der Landschaft unterschiedlichen Bedürfnisstruktur sowie der rechtlichen Monopolstellung der Städte bezüglich bestimmter Gewerbe erklären.“ Meier, Handwerk: $46 f$.

628 Für das Bernbiet ist gesamtgesellschaftlich insgesamt eine hohe Dichte an nichtagrarischen Professionisten belegt. Vgl. Dubler, Handwerk.

629 Nur 46 der insgesamt 368 ehemaligen Handwerker-Lehrer (13\%) arbeiteten an einer zentralörtlichen Schule. Gemessen am Gesamtanteil von 315 zentralörtlich tätigen Lehrkräften waren somit bloss 14.6\% als Handwerker tätig gewesen. 
Nicht überall im schweizerischen Mittelland waren Handwerker freilich gerne im Lehramt gesehen. Im Zürcher Untertanenland wurde das Engagement von Handwerkern im Schuldienst bisweilen harsch kritisiert. So hielt der Pfarrer von Uster ZH in der Zürcher Schulumfrage von 1771 in markigen Worten fest: „Gott Lob! in meiner Gemeind hab ich keinen schulm[ei]ster der zugleich ein handwerksmann ist und wünsche auch keinen zubekommen. Ein Schulmeister der zugleich ein handwerksmann ist, nüzet einer Gemeind so vill, als ein vogt oder Weibel, der zugleich ein Wirth ist.“630 Die Kritik zielte auf den Vorwurf, dass Handwerker-Lehrer ihr Handwerk während der Schulzeit weitertreiben und dadurch den Unterricht vernachlässigen würden. Entsprechend fiel der Anteil an ehemaligen Handwerkern im Kanton Zürich mit 9\% relativ gering aus.

Insgesamt seltener waren Landhandwerksberufe bei der Lehrerschaft in der subalpinen Hügelzone und den inneralpinen Viehwirtschaftsgebieten verbreitet, wo einerseits die textile Protoindustrie, andererseits die extensive Vieh- und Milchwirtschaft als Alternativen zur kleinbäuerlichen Subsistenzwirtschaft fungierten. ${ }^{631}$ Die Erklärung für diese räumliche Diskrepanz liegt indessen weder in konfessionellen noch marktgeografischen Gründen, sondern vielmehr in der überregionalen Marktorientierung der sub- und inneralpinen Produzenten. Anders als in den Ackerbaugebieten des Mittellandes war sowohl die protoindustrielle Textilheimarbeit als auch die alpine Milch- und Viehwirtschaft primär auf überregionale, ausländische Märkte orientiert, wodurch kaum Stimuli für Austauschprozesse im lokalen Nahbereich entstanden und folglich nur eine schwache Nachfrage nach Handwerks-produkten bestand, was seinerseits eine breite Ausdifferenzierung und die Territorialisierung der Gewerbe beschränkte. ${ }^{632}$ Die wachsende ländliche Bevölkerung reagierte in Regionen mit knappen ökonomischen Ressourcen und einer beschränkten Ernährungsbasis auf die drohende Armut durch Unterbeschäftigung eher mit geografischer Mobilität - mit der zeitweiligen oder dauerhaften Abwanderung oder dem Gang in die militärischen Solddienste - als mit beruflicher Spezialisierung und Diversifizierung. ${ }^{633}$

Unter der Abgrenzung der protoindustriell arbeitenden Weber vom traditionellen Handwerk ergibt sich unter den später zum Lehrer gewordenen ehemaligen Handwerkern eine Gewerbestruktur, die deutlich von Repräsentanten aus dem Bekleidungsgewerbe dominiert wurde. ${ }^{634}$

Tab. 7: Gewerbestruktur der handwerklichen Tätigkeiten

\begin{tabular}{lll}
\hline Branche: & Anzahl Lehrer: & In Prozent: \\
\hline Traditionelles Baugewerbe & 69 & $19 \%$ \\
Bekleidungsgewerbe & 148 & $40 \%$ \\
Landwirtschaftliche Bedarfsgewerbe & 82 & $22 \%$ \\
Spezialgewerbe & 69 & $19 \%$ \\
\hline Total & 368 & $100 \%$ \\
\hline
\end{tabular}

630 StAZH E I, 21.8 - Uster.

631 Die Werte an ehemaligen Handwerkern im Lehrerkorps lag in den voralpinen und inneralpinen Kantonen Fribourg (5\% des Lehrerkorps), Linth (8\%), Säntis (10\%), Waldstätten (3\%) und Wallis (9\%) deutlich unter dem gesamthelvetischen Durchschnitt.

632 Vgl. zu den Absatzmärkten von schweizerischen Agrarprodukten: Hauser, Wirtschafts- und Sozialgeschichte: 135-144.

633 Trossbach, Bauern: 56f.; Head-König, Auswanderung.

634 Die Abgrenzung der protoindustriell produzierenden Weber vom Handwerk orientiert sich an der Definition von Handwerk als „Professionismus“ nach Meier, Handwerk: 23f. 
Personen mit textilgewerblichem Handwerkshintergrund zeigten mit rund 40\% Gesamtanteil die stärksten Präferenzen zur späteren Übernahme des Lehramts, während Handwerker aus dem traditionellen Baugewerbe, dem landwirtschaftlichen Grundbedarfsgewerbe sowie aus den übrigen Spezialgewerben mit je einem Fünftel relativ gleichmässig repräsentiert waren. Noch deutlicher wird der Eindruck bei einer spezifischen Betrachtung der Einzelberufe, denn zwei Drittel aller vorherigen Handwerkstätigkeiten entfielen auf nur sechs Einzelhandwerke, wobei Schuhmacher und Schneider aus dem Bekleidungsgewerbe mit Abstand am häufigsten später ins elementare Lehramt wechselten.

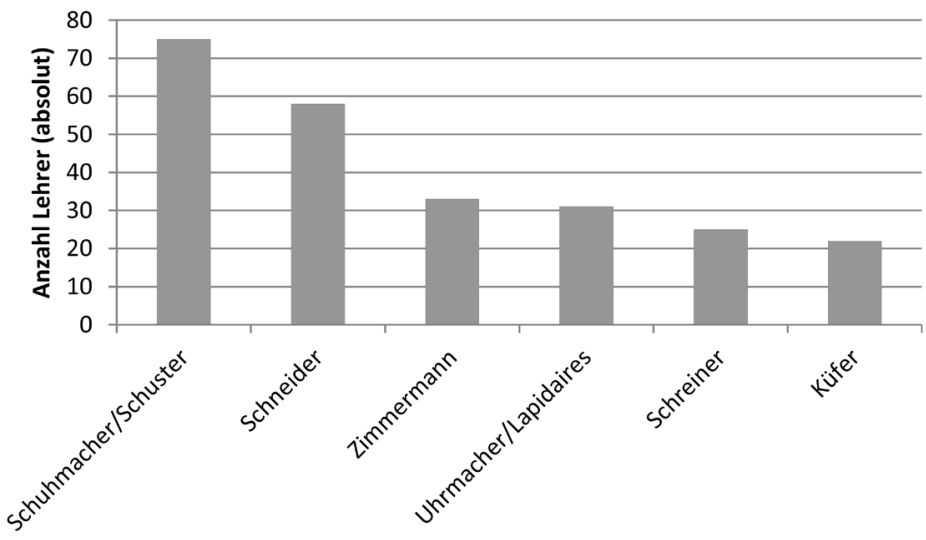

Abb. 6: Häufigste Handwerkstätigkeiten als Ersttätigkeiten

Alleine auf die Tätigkeit des Schuhmachers respektive des Schusters entfielen rund 20\% der zuvor handwerklich tätig gewesenen Lehrer. Darauf folgen mit 16\% Anteil die ehemaligen Schneider. Damit bestätigen sich die einleitend im Kapitel 2.2 skizzierten Berufspräferenzen der „Professio sedentaria“ aus der deutschen Schulgeschichtsforschung weitgehend für das Lehrerkorps der Helvetischen Republik. Weitere relativ häufig vermerkte Handwerke bei Lehrpersonen waren mit rund 9\% die Zimmerleute, mit 8\% die Uhrmacher/Lapidaires, mit 7\% die Schreiner und mit 6\% die Küfer. Alle diese sechs Tätigkeitsfelder wurden als ständisch ungeschützte „Allerweltsberufe“ auf dem Land häufig ausgeübt und unterstanden dadurch einer harten lokalen Konkurrenz, die nicht nur in Krisenzeiten zur Ausübung von ökonomischen Alternativtätigkeiten animierte. ${ }^{635}$ Allerdings war eine polyprofessionelle Ausrichtung vor der Lehramtsübernahme für die meisten späteren Handwerker-Lehrer kein Thema, nur gerade 13\% hatten zuvor neben dem Handwerk eine weitere Tätigkeit ausgeübt. ${ }^{636}$

Aus dem Feld der „typischen“ handwerklichen Berufe waren demgegenüber zumindest vier Berufe in auffälliger Weise abwesend respektive unterrepräsentiert: die ehaften Bäcker, Müller, Metzger und Wirte. ${ }^{637}$ Einzig eine Handvoll ehemaliger Bäcker und bloss drei ehemalige Müller

635 Dubler, Handwerk.

636 Insgesamt 48 der 368 ehemaligen Handwerker hatten eine Zweittätigkeit neben dem Handwerk aufgeführt, die allermeisten davon - bei 36 Personen - entfielen auf agrarische Zusatztätigkeiten. Nach den Feststellungen von Meier zur Zürcher Handwerkerschaft dürften indes sowohl die Polyprofessionalität als auch landwirtschaftliche Nebentätigkeiten unter Handwerkern weit verbreitet gewesen sein. Vgl. Meier, Handwerk: 182f.

637 Trossbach/Zimmermann, Dorfes: 127. 
konnten aus der Stapfer-Enquête zweifelsfrei extrahiert werden. Der Lehrer von Käpfnach ZH, Jacob Stapfer von Horgen, wies dabei einen imposanten erstberuflichen Lebensverlauf als ein ehemaliger Pasteten- und Zuckerbäcker in Venedig und Paris auf - ein Beruf, mit dem zahlreiche Schweizer Bäcker in europäischen Städten zu grossem Wohlstand gelangten. ${ }^{638}$ Ehemalige Metzger und Wirte fehlen in der Umfrage jedoch komplett. Letzteren könnte wahrscheinlich ihren oftmals zweifelhaften moralischen Ruf zum Hindernis für eine Wahl in das Lehramt geworden sein, sofern sie das Lehramt begehrt hätten, zumal ein einwandfreier sittlich-moralischer Lebenswandel zu den zentralen Anstellungskriterien in das Lehramt gehörte. An wenigen Orten lag die Schule zwar aus Platznot im selben Gebäude wie das Wirtshaus, was mitunter für Kritik vonseiten der Lehrer sorgte, sich aktiv als Wirt betätigte sich jedoch bloss ein einziger Lehrer in der gesamten Helvetischen Republik. ${ }^{639}$

Ferner konnten aus der ehaften Berufsgruppe der Schmiede für die gesamte Helvetische Republik nicht mehr als drei Personen im Lehramt gezählt werden. ${ }^{640}$ Vertreter der handwerklichen „Oberschichtsberufe“, insbesondere der ehaften Handwerke, interessierten sich somit insgesamt kaum bis überhaupt nicht für die Ausübung des Schulamtes. Dieses klare kollektive Desinteresse der handwerklichen Oberschichten am Lehramt begrenzt das Rekrutierungsfeld für Schulmeister in der sozialen Stufung nach oben hin deutlich ab. Söhne von ehaften Müllern, Metzgern, Wirten, Ölern und Bäckern sahen im Lehramt in kollektiver Einmütigkeit keine vergleichbar günstige Berufsoption, weder als Ergänzungstätigkeit noch als Spezialisierung. Bei jenen wenigen Lehrern, die dennoch aus den genannten Tätigkeitsfeldern stammten, ist dagegen eine individuelle ökonomische Abstiegs- respektive Verarmungssituation anzunehmen. Wie zuvor bereits bei den ehemals agrarisch Tätigen festgestellt worden ist, interessierten sich vorwiegend Vertreter der mittleren und unteren Handwerkerschichten für das Lehramt, während die Handwerker mit Zugang zur lokalen Elite fernblieben.

Lehrerinnen mit Handwerkserfahrung traten einzig marginal aus dem Umfeld des Bekleidungsgewerbes auf. Vier Schneiderinnen und drei Näherinnen sind uns überliefert, sie alle stammten aus der frankophonen Schweiz, hauptsächlich aus dem Waadtländer Landstädtchen Nyon VD. ${ }^{641}$ Generell waren jedoch Frauen im traditionellen ländlichen Handwerk nach den Erkenntnissen von Meier eine sehr seltene, auf Näherinnen, Krämerinnen und das Gastgewerbepersonal beschränkte Erscheinung. ${ }^{642}$ Insofern ist die weitgehende Abwesenheit von Frauen mit Handwerkserfahrung im späteren Lehramt bloss ein Abbild der geringen gesellschaftlichen Vertretung.

Das mittlere maximale Amtsübernahmealter aller vormals handwerklich tätigen Lehrkräfte lag mit 30.3 Jahren rund ein Jahr über dem Einstiegsalter von vormals agrarisch tätigen Lehrern. Der leicht später erfolgte Tätigkeitswechsel der Landhandwerker war zum einen die Folge der

638 „10. Jahr in Venedig, als Basteten Bek 3, 1/2 Jahr in Paris - als Zuker Bek“. Schmidt u.a. (Hgg.), Stapfer-Enquête, Nr. 25: Käpfnach; Zur Emigration von Zuckerbäckern vgl. Head-König, Auswanderung.

639 Der Lehrer von Hottingen ZH führte nebenbei eine Weinschenke als Einkommensprivileg. Schmidt u.a. (Hgg.), Stapfer-Enquête, Nr. 260: Hottingen. Den negativen Einfluss eines Wirtshauses als unmittelbare Umgebung einer Schule beklagte ferner der Lehrer von Tanay VD in deutlichen Worten über die Lokalität des Schulhauses: „A Tanay il à besoin de reparer et il se trouve \{placé\} sur un Cabaret d'où les Enfans entendent quelquefois ce qui ils ne devroient jamais entendre." Schmidt u.a. (Hgg.), Stapfer-Enquête, Nr. 1707: Mies, Tannay.

640 Nagelschmiede galten nicht als ehaft, weswegen die drei ehemaligen Nagelschmiede und ebenso die zwei Kupferschmiede nicht mitgezählt wurden. Vgl. Dubler, Ehaften.

641 Schmidt u.a. (Hgg.), Stapfer-Enquête, Nr. 1680: Nyon; Nr. 1686: Nyon; Nr. 1687: Nyon; Nr. 1996: Ciernes Picat; Nr. 2167: Vex, La Vernaz.

642 Vgl. Meier, Handwerk: 183. 
teilweise längeren Ausbildungszeit bei einzelnen Handwerken, deren Gesellenstatus sich etwa bei Zimmerleuten, Schreinern oder Steinhauern durch die Wanderpflicht mitunter auf mehrere Jahre belaufen konnte.

Tab. 8: Amtsübernahmealter der ehemaligen Handwerker

\begin{tabular}{lcc}
\hline Tätigkeit: & Anzahl Lehrer: & Amtsübernahmealter: \\
\hline Schuhmacher/Schuster & 75 & 27.6 \\
Schneider & 58 & 31.6 \\
Zimmermann & 33 & 35.1 \\
Steinhauer/Maurer & 19 & 31.2 \\
übriges Baugewerbe & 17 & 27.5 \\
Küfer & 22 & 31.9 \\
Schreiner & 25 & 30.4 \\
Uhrmacher/Lapidaires & 31 & 28.7 \\
Alle Handwerker & 368 & 30.3 \\
\hline
\end{tabular}

In Handwerken ohne Gesellenwanderungspflicht und in den neu entstandenen Gewerben wie der Uhrmacherei herrschte dagegen eine grössere berufsbiografische Flexibilität, wie die Lebensverläufe von ehemaligen Schuhmachern, einzelnen Spezialisten des Baugewerbes - Dachdecker, Glaser, Maler - und Uhrmachern demonstrieren. Diese hatten das Lehramt im Durchschnitt bereits nach dem 27. Altersjahr übernommen, also rund drei Jahre früher als im Gesamtdurchschnitt aller ehemaligen Handwerker. Diese Tendenzen der frühen Amtsübernahme vor dem dreissigsten Lebensjahr weisen auf eine bewusste berufliche Neuorientierung hin. Demgegenüber hatten Handwerker mit Gesellenpflicht wie Wagner, Küfer und Zimmerleute das Lehramt im Durchschnitt zwei bis fünf Jahre später übernommen als die übrigen Handwerksgenossen. Bei diesen drei Berufsgruppen ist aufgrund des späteren Amtsübernahmealters schon eher von einer Strategie der ökonomischen Notbehelfsabsicherung als Motiv für die Lehramtsübernahme auszugehen.

Die Gründe, um von einem Handwerker zum Lehrer zu werden, waren vielfältig. Wie schon bei den ehemals agrarisch Tätigen erwähnt, nannten auch einzelne Lehrkräfte mit handwerklichem Hintergrund gesundheitliche Probleme als Ursache für den Tätigkeitswechsel ins Lehramt. So hielt der Lehrer von Cuarny VD zu seinen Ersttätigkeiten fest: „Nulle part; il étoit avant cela Menuisier vocation à la quelle il à été obligé de renoncer parce qu'il est atteint d'un Cruël rhumatisme. " ${ }^{643}$ Allerdings waren explizite Hervorhebungen des Gesundheitszustandes als Motiv für den Tätigkeitswechsel aber auch unter den ehemaligen Handwerkern selten. Krankheitsoder verletzungsbedingt zum Lehrer gewordene Handwerker blieben ein Randphänomen des elementaren Schulwesens.

Die Hervorhebung von inneren Beweggründen zur Ergreifung des Lehramts ist ebenso wie bei einzelnen ehemals agrarisch Tätigen in wenigen Quellen fragmentarisch greifbar, wenn auch aufgrund fehlender konkreter Fragestellungen nicht quantifizierbar. Der Lehrer von Häuslen TG berichtete etwa zu seinem Werdegang: ,ich lernte von meinem Vatter das Schuhmacher 
Handwerk, Arbeitete 1 1/2. Jahr darauf in St: Gallen allein die Begirde, mich dem Schuldienst zuwidmen ward immer reger in mir, ich eröffnete solches dem Bürger Pfarrer, u: den Vorsteheren der Gemeinde die meinem sehnlichen Verlangen entsprachen, u: dazu verhilflich waren, daß für 1. Jahr die beste gelegenheit genoß in - Weinfelden von einem erfahrnen Schullehrer, mich zu einem Dorf-Schulmstr: bilden zu laßen“"644

Ebenso sind in einem Brief des Lehrers Daniel Rimmensperger an den Erziehungsrat des Kantons Säntis ebensolche inneren Beweggründe als Leitmotiv für die Ausbildung zum Schulmeister zu entnehmen: „Es sind [...] schon bereits 12 Jahre verfloßen als in mir der Wunsch reg wurde, Schullehrer zu werden, da bereitete ich mich theils aus mir selbst, theils unter der getreüen Anführung deß würdigen Schullehrers Joh. Heinrich Edelmann von Degerschen darauf vor, so viel das geringe Vermögen meiner Elteren und die Zeitumstände mir erlaubten.“645

In anderen Fällen formten lokale Konstellationen die Bildungsmöglichkeiten. So wirkten glückliche äussere Umstände in Einzelfällen fördernd auf die innere Berufung, etwa wenn von einem speziellen Bildungsangebot profitiert werden konnte. Der damals 26-jährige Lehrer von Horgenbühl SG berichtete: „ware bis ins 13. Jahr in St Gallen, hernach kam ich zum Stein das Schneiderhandwerk zu erlernen und hab es getrieben bis mir vor 3 Jahren die Schule übergeben worden. [...] Anbey möchte ich noch einige Gründe anführen, die mich zum Schulhalten bewogen haben, nebst Lust vieles zuerlernen hate ich in der Jugend noch daß Glük gehabt durch die Güte eines vortreflichen Bürgers von St: Gallen, der seine Großmuth sonderheitlich an mir erwiesen hat, und mich in Deutscher und Französischer Sprach unterrichten lassen und ein mit den nöthigen büchern darzu versehen, 6 Jahre lang hate ich allda die Schule besucht, und weil ohne das wohleingerichtte Schulen in St. Gallen sich befinden, wo Rechnen, Singen Moral und Sitten, und alles nöthige und nüzliche allda gelehrt wird, so ward ich theils darzu angetrieben, und aber meistens durch mein eigen Lust und Begierde selber zum Schulhalten geneigt gewesen." ${ }^{\text {646 }}$

Äusserungen von Schulmeistern zu ihrer inneren Berufung zum Lehramt müssen allerdings im Kontext der Umfrage von 1799 einer quellenkritischen Betrachtung ausgesetzt werden, denn es drängt sich automatisch der Verdacht der Anbiederung bei der neuen Regierung auf. Zweifellos verstanden viele Lehrpersonen die Enquête nicht nur als Medium zur Informationsvermittlung an die neuen vorgesetzten Behörden, sondern sahen darin in der Hoffnung auf eine monetäre oder soziale Besserstellung gleichzeitig ein Mittel zur positiven Selbstdarstellung. Das breitwillige Hervorstreichen von Loyalitätsbekundungen, aber auch die Möglichkeit, sich berechnend in ein möglichst positives Licht zu rücken, muss deshalb im Sinnzusammenhang der Umfrage als eine mögliche Kommunikationsstrategie der Lehrer verstanden werden. Demgegenüber kann als entschärfende Argumente für die Vertrauenswürdigkeit der inneren Berufungsbekundungen das mindestens ebenso oft in den Texten erkennbare Selbstbewusstsein der Lehrer, eine positiv konnotierte Naivität im schriftlichen Ausdruck und die grundsätzliche Richtigkeit der in der Enquête festgehaltenen Angaben ins Feld geführt werden, was sich unter anderem bei den finanziellen Angaben bestätigen liess. ${ }^{647}$

Makroökonomische Folgen eines tiefergreifenden Strukturwandels waren in der Waadt verantwortlich für das regionale Phänomen der ehemaligen Uhrmacher beziehungsweise der als „Lapidaires“ bezeichneten Uhrmachereizulieferer im Lehramt. Ausgehend von der Stadt Genf

644 Schmidt u.a. (Hgg.), Stapfer-Enquête, Nr. 1059: Häuslen.

645 StASG HA R 130, Fasz. 3, o. Pag.: 11.11.1800 - Daniel Rimmensperger.

646 Schmidt u.a. (Hgg.), Stapfer-Enquête,Nr. 1234: Horgenbühl.

647 Vgl. die Ausführungen im Kap. 1.5.2, insbes. Brühwiler, Finanzierung: 307. 
hatte sich im Waadtländer Jurabogen im 17. Jahrhundert punktuell die hochspezialisierte Uhrenindustrie angesiedelt. Hierbei wurden analog zum Prinzip des textilen Verlagswesens die rohen Werke für Uhren sowie die Uhrensteine von Fachhandwerkern auf der Landschaft hergestellt, einzig die Endfertigung fand dagegen in den Städten statt. Das Uhrmachergewerbe geriet jedoch am Ende des 18. Jahrhunderts unter starke ausländische Konkurrenz aus Frankreich und Grossbritannien, des Weiteren stürzte die französische Annexion Genfs 1798 die Branche in eine grosse Krise mit hoher Arbeitslosigkeit. ${ }^{648}$

Die Krisenhaftigkeit des Uhrmachergewerbes um 1800 widerspiegelt sich denn auch in zahlreichen Lehrerbiografien aus der Stapfer-Enquête in symptomatischer Art und Weise. In der Aussage des ehemaligen Uhrmachers Jean-Etienne Genand aus Crans-près-Celigny VD ist jener Strukturwandel exemplarisch festgehalten: „J'étois à Vevey, et ayant quitté l'horlogerie en 1770, lors qu'elle n'alloit que très mal, pour me voüer à l'instruction de la Jeunesse que je n'ai pas discontinué jusquà présent, ayant reçu mon Brevet à Lausanne au mois de Xbre. ditte année pour le Village de Publoz. ma première place. “649

In der Tat tauchten in den Lehrerantworten der Waadt als regionales Spezifikum „une trentaine de lapidaires et d'horlogers abandonner leur métier pour se faire régents" ${ }^{650}$ auf. Zwei Drittel dieser ehemaligen Steingraveure und Uhrmacher entstammten aus dem Vallée de Joux, dem damaligen Epizentrum der Waadtländer Uhrenindustrie am Ende des 18. Jahrhunderts. ${ }^{651}$ Die bereits länger andauernde Krise in der Uhrenindustrie liess selbst weitergebildete und hochspezialisierte Professionisten des Uhrmachergewerbes auf das Lehramt ausweichen, wie das Beispiel des Lehrers Gabriel Marmillod aus La Tour-de-Peilz verdeutlicht, der trotz eines für diese Zeit aussergewöhnlichen Fortbildungsaufenthalts in England zur Verbesserung seiner beruflichen Fähigkeiten das Lehramt der bisherigen Berufstätigkeit vorzog: „Né à la Tour aprentif Horloger à Vevey, dès la à passé en Angleterre pour dy Perfectionner en son Profession les Sept derniéres anneés avant son Jnstalation [im Jahr 1788].“652

Dass sich die Uhrenindustrie in der Waadt schon seit längerem im Umbruch befand und die etlichen ehemaligen Uhrmacher und Feingraveure kein Produkt der politischen Krisenjahre seit 1798 waren, zeigt ein Blick auf die Schuldienstdauer jener Lehrer: Im Durchschnitt waren diese bereits seit 17 Jahren als Lehrer tätig, bloss sechs der 30 Lehrer standen dem Schuldienst seit weniger als fünf Jahren vor, sieben ehemalige Uhrmacher übten das Lehramt hingegen schon seit rund dreissig Jahren aus. Das mittlere Amtsübernahmealter lag mit 28.5 Jahren zudem nahe des gesamthelvetischen Übernahmealters, wobei bloss sieben jener Lehrkräfte beim Berufswechsel mutmasslich über 30 Jahre alt waren. Der berufliche Wechsel erfolgte somit bei den meisten ehemaligen Beschäftigten der Uhrenindustrie nicht schlagartig als ein Reflex auf eine unmittelbare Krisensituation, sondern als Folge gesunkener ökonomischer Zukunftschancen in einem langfristigen Abwägungsprozess seit den 1770er-Jahren und vornehmlich zwischen dem 20. und 30. Lebensjahr, in der Phase der beruflichen Absicherung und Familiengründung.

648 Fallet/Veyrassat, Uhrenindustrie.

649 Schmidt u.a. (Hgg.), Stapfer-Enquête, Nr. 1729: Crans-près-Céligny. Zitiert auch bei Panchaud, écoles vaudoises: 257.

650 Panchaud, écoles vaudoises: 257. Als „Lapidaires“ wurden Feingraveure für die Uhrensteine der Zifferblätter bezeichnet.

651 Mindestens 20 der rund 30 ehemaligen Beschäftigten in der Uhrenindustrie gaben einen Herkunftsort im Distrikt des Vallée de la Joux an. Die Übrigen kamen aus den weiteren Verbreitungsgebieten der Uhrenindustrie, aus der Umgebung von Vevey, Rolle, Orbe, Genf und Neuchâtel. Zur Verbreitung der Uhrenindustrie im Jurabogen und der Waadt vgl. Fallet/Veyrassat, Uhrenindustrie.

652 Schmidt u.a. (Hgg.), Stapfer-Enquête, Nr. 1770: La Tour-de-Peilz. 


\subsubsection{Protoindustriell-textilgewerbliche Tätigkeiten}

Mit einem Gesamtanteil von rund $\mathbf{1 1 . 1 \%}$ hatte etwas mehr als jeder zehnte helvetische Lehrer vorgängig als Weber, Indiennedrucker, Strumpfhersteller oder Posamenter in der heimindustriellen Textilproduktion gearbeitet. ${ }^{653}$ Die Protoindustrie stellte damit das drittgrösste Rekrutierungsfeld für Elementarschullehrer in der Alten Eidgenossenschaft dar. Aufgrund der unterschiedlichen räumlichen Ansiedlung und Verbreitung der textilen Protoindustrie in der Alten Eidgenossenschaft mit Leinen-, Baumwoll- und Seidenproduktion traten ehemalige Textilarbeiter jedoch nur insular in einzelnen Regionen und nicht flächendeckend in besonderer Häufung als Schulmeister in Erscheinung. Die Ostschweiz war schon seit dem 16. Jahrhundert das Zentrum der Schweizer Leinwandherstellung gewesen, aber auch in einzelnen höher gelegenen Regionen der Kantone Bern, Luzern, Aargau sowie in Solothurn erlebte die Leinenweberei und später die Baumwollweberei im 18. Jahrhundert einen markanten Aufschwung. ${ }^{654}$ Die Basler Landschaft entwickelte sich simultan zum Zentrum der Seidenbandherstellung. Im Zürcher Oberland, im Glarnerland, im Rheintal und in Teilen der Zentralschweiz etablierte sich die Seiden- und Baumwollstoffproduktion im Heimverlagswesen. ${ }^{655}$ Westlich der Aare blieb die Textilproduktion dagegen marginal. Vorwiegend in den Kantonen Aargau (34\% der Lehrer), Basel (27\%), Thurgau (20\%), Bern (16\%), Säntis (15\%) und Zürich (13\%) entschieden sich Heimarbeitende denn auch besonders oft für das Lehramt als berufliche Alternative.

Für die lokalen Schulen bedeutete die Protoindustrialisierung eine ambivalente Anpassung an die Bedürfnisse der Bevölkerung. Zwar hielt die Heimarbeit einerseits manche Kinder vom Besuch der Schule ab, andererseits bedeutete das Bevölkerungswachstum mehr Kinder und damit mehr Schulen, die nötig wurden. ${ }^{656}$ Zudem musste mancherorts die Hauptschulzeit vom Winter in den Sommer verlegt werden, um dem Absentismus der Schulkinder pragmatisch zu begegnen. ${ }^{657}$

Viele der protoindustriell tätigen Heimarbeiter übten zudem agrarische Nebentätigkeiten zur weiteren Sicherung ihrer Subsistenz aus, denn mindestens 24\% aller vormals heimindustriell tätigen Lehrkräfte vermerkten in ihren Antworten gleichzeitig landwirtschaftliche Tätigkeiten als weitere Ersttätigkeiten. ${ }^{658}$ Es ist anzunehmen, dass etliche weitere Lehrkräfte ebenfalls ohne explizite Erwähnung agrarischen Subsistenztätigkeiten nachgingen. Die protoindustrielle Textilproduktion reichte als alleinige Tätigkeit offensichtlich kaum für den Erhalt einer Familienwirtschaft aus, so dass weitere einkommensgenerierende Tätigkeiten gesucht werden mussten, wobei das Lehramt eine Alternative bot.

Die Kombination von Textilproduktion und Schulamt bot jedoch sowohl für die Gemeinden als auch für die einzelnen Lehrer durchaus Vorteile: Zum Ersten bot das Schuleinkommen alleinig betrachtet oftmals zu gering zum Leben - eine konstante finanzielle Absicherung zum konjunkturell unsicheren und stark schwankenden Einkommen aus der Textilproduktion. Nimmt man die Angaben des Lehrers Kaspar Leutzinger von Netstal GL als Referenz, der als „sehr schlächte und geringe verdienst“ rund 8 Kreuzer pro Tag mit der Produktion von Woll-

653 Mindestens 255 Lehrer wiesen eine protoindustriell-textilgewerbliche Vorbeschäftigung als Weber oder Posamenter aus.

654 Mayer, Leinwand; Tanner, Baumwolle.

655 Suter, Zürich; Braun, Volksleben: $54 f f$.

656 Brühwiler, Finanzierung: 47; Rosenmund, Verzichtsleistung: 59.

657 Vgl. das Kap. 1.6.2.

658 Mindestens 61 der 255 Lehrkräfte mit protoindustriell-textilgewerblicher Vergangenheit hatten gleichzeitig landwirtschaftliche Ersttätigkeiten in ihren Antworten notiert. 
strümpfen verdiente, ergab sein Jahreslohn von 55 Gulden für eine Ganzjahresschule bei sechs Arbeitstagen mit rund 10 Kreuzern pro Tag immer noch einen höheren Ertrag, als wenn er in der gleichen Zeit bloss Strümpfe produziert hätte. ${ }^{659}$ Die Attraktivität des Schuleinkommens lag gerade in dessen Verlässlichkeit, während die Einkommen aus der Textilproduktion analog der Uhrenindustrie starken konjunkturellen Schwankungen unterworfen waren. Ermöglichte die Protoindustrie besonders landlosen oder landarmen Bevölkerungsschichten in guten Konjunkturlagen eine soziale und ökonomische Emanzipation gegenüber den landbesitzenden Halbund Vollbauern, drohte vielen dieser Heimindustriellen mit den wegbrechenden Einnahmen ein erneuter Sturz ins dörfliche Prekariat, folglich stieg der Druck zur erfolgreichen Spezialisierung oder zum Berufswechsel. Exemplarisch zeigt der Bericht des Lehrers von Rheineck SG die Folgen der Konjunkturschwankungen auf seine Individualbiografie: ,ich hate vorher die Gürtler Profession geführt, aber daß ohrt ist zu klein, aus-werthige Fabriken haben mit ihren Waaren daß ganze Land angefült. Also mir großen Schaden gethan, das ich meine Haushaltung mit diesem allein nicht kann durch bringen, mußte mich also zu einer Schule vorbereiten. " ${ }^{\text {660 }}$ Einzelne ehemalige Textilproduzenten hatten ferner das Lehramt aus gesundheitlichen Gründen gegen die Heimarbeit eingetauscht. ${ }^{661}$ Dennoch sind Berichte über Berufswechsel aus wirtschaftlicher oder persönlicher Not auch unter den ehemaligen Heimarbeitern insgesamt rar und kaum von kollektiver Bedeutung.

Zum Zweiten liess sich die Textilproduktion im Familienverbund - durch die Ehefrau oder Kinder - auch während der Schulzeit im Winter zeitgleich weiterführen, wenn keine Arbeitskräfte für agrarische Tätigkeiten benötigt wurden, womit sich die landwirtschaftlich unproduktive Winterphase gleich doppelt in Wert setzen liess und ein Mehrfaches verdient werden konnte. Drittens benötigten Heimarbeiter zur Textilproduktion grosse Häuser mit genügend Platz für die Webstühle, wobei oftmals ein Teil des Platzes für eine Schulstube umgenutzt werden konnte. Gewisse Gemeinden bevorzugten bei der Lehrerwahl folglich Personen mit einem eigenen geräumigen Haus, um kein Schulhaus zur Verfügung stellen zu müssen. Aus der Basler Landschaft, durch die Seidenbandherstellung zu einer der am stärksten heimindustrialisierten Regionen der Alten Eidgenossenschaft geworden, berichtete Eduard Zingg über die Kriterien bei der Lehrerwahl: „Überhaupt gab bei der Wahl des Lehrers vielfach das Umstand den Ausschlag, dass er eine einigermassen brauchbare Stube zur Verfügung zu stellen vermochte. “662 Um genügend Platz für die relativ grossen mechanischen Webstühle zur Seidenbandweberei zu haben, mussten tatsächlich grosse Häuser gebaut werden.

Die empirische Auswertung der Schulraumsituation unter der Gruppe der vormalig protoindustriellen Lehrer ergab jedoch, dass von den 255 ehemals protoindustriell tätigen Lehrern nur $32 \%$ in ihrem eigenen Haus unterrichtet hatten. $56 \%$ hielten die Schule in einem eigens dafür eingerichteten Schulhaus der Gemeinde, weitere 12\% arbeiteten in eigens zum Schulgebrauch dazu gemieteten Stuben. Regional verbreitet war die Präferenz des eigenen Hauses als Schulraum bei protoindustriell tätigen Lehrern einzig in der Ostschweiz, in den Kantonen Thurgau, Säntis sowie teilweise im Zürcher Oberland. Für die Basler Landschaft bestätigte sich hingegen die von Zingg apostrophierte Präferenz kaum, denn nur knapp die Hälfte der Basler Lehrer mit protoindustriellem Hintergrund unterrichteten in ihrem eigenen Haus, die Mehrheit hielt die

659 Berechnet mit hypothetischen 52 Wochen à 6 Arbeitstagen: Schmidt u.a. (Hgg.), Stapfer-Enquête, Nr. 575: Netstal.

660 Schmidt u.a. (Hgg.), Stapfer-Enquête, Nr. 1264: Rheineck.

661 „Er war Vorher ein Weber, welcher Profession er aber wagen Verletzten Linken Hand nicht mehr treiben kann.“ Schmidt u.a. (Hgg.), Stapfer-Enquête, Nr. 2405: Flumenthal.

662 Zingg, Basel: 48. 
Schule in Schulhäusern der Gemeinden. ${ }^{663}$ In den ebenfalls stark protoindustrialisierten Kantonen Bern und Aargau verfügten die Gemeinden dagegen fast ausnahmslos über eigene Schulhäuser, die - unabhängig von ihrem baulichen Zustand - genutzt wurden und wo praktisch keine Lehrer die Schule in ihrem eigenen Haus halten mussten.

Auch im Berner Oberland sei es eine anstössige Gepflogenheit gewesen, die Schule an Personen zu vergeben, welche über ein genügend grosses Haus zum Schulhalten verfügten, unabhängig von den Talenten der Kandidaten. ${ }^{664}$ Einer quantitativen Überprüfung hält die Aussage allerdings nur bedingt stand, denn bloss 36\% aller Oberländer Lehrer unterrichteten in ihren eigenen vier Wänden, während $46 \%$ in einem Schulhaus arbeiten konnten und weitere $18 \%$ ihren Schulraum von der Gemeinde in einem Privathaus dazu gemietet bekamen.

Der Besitz eines grossen Hauses kann seinerseits aber auch als ein Merkmal von ökonomischem Wohlstand interpretiert werden, der mit dem Paradigma der armen Heimarbeiter- und Taunerfamilien und somit mit dem Bild des armen Schulmeisters in eklatantem Widerspruch steht. ${ }^{665}$ Nicht nur in der Basler Landschaft, sondern auch anderswo verfügten Lehrer gesichert über grosse Privathäuser. Durch die militärische Besetzung der Dörfer in der Ostschweiz während des Zweiten Koalitionskriegs wurden die Schulhäuser vielerorts von französischen Truppen requiriert und die Schulmeister mussten auf ihre Privathäuser ausweichen, sofern diese genügend Raum boten. So entpuppte sich etwa das Haus des Webers und Lehrers Jacob Stäffen als genügend gross, um darin die Schule zu halten: „Vor den Einquartierungen: ware es [das Schulhaus] in zimlich gutem Zustand, allein weil es bey den Einquartirungen zur Hauptwacht dienen mußte, wurde von dem Militair vieles an Rigel-wänden, Fenstern, Ofen, Bänken. ect: ruinirt. [...] dißmahl wird die Schul, (wegen Einquartierung) in des Schulmstrs Haus gehalten, weil er zimlich Plaz dazu hat. ${ }^{\text {“666 }}$ Einzelne Lehrer bauten sich sogar selbst ein Schulhaus oder kauften das Schulhaus später als Eigenbesitz, ohne selbst darin zu wohnen, vermutlich um die Besitzansprüche auf das Lehramt gegenüber anderen Kandidaten langfristig zu festigen und um eine dynastische Weitergabe des Lehramts in der Familie zu sichern, wie ein Beispiel aus dem Thurgau zeigt: „Da doch mein Vater dieses Haus extra zum Gebrauche der Schule erkauft, (denn wir besizen zur Bewohnung ein anderes Haus) und dafür sorgen, und im baulichen Stande erhalten müßen." ${ }^{“ 67}$

Das finanzielle Risiko eines Schulhausbaus oder Kaufs setzte entweder ein entsprechendes Vermögen oder die Inkaufnahme einer hohen Verschuldung voraus, die unvermögenden Personen nicht zur Verfügung gestanden hätten. ${ }^{668}$ Hinweise auf den Eigenbesitz des Schulhauses zeugen demnach von einem Wohlstand, der allein mit Prekariatstätigkeiten nicht erworben werden konnte.

\subsubsection{Kaufmännische Tätigkeiten}

Personen mit kaufmännischen Ersttätigkeiten, deren Ausübung fundierte Schreib- und Zahlenkenntnisse voraussetzte, stellten empirisch betrachtet bloss ein Randphänomen im Kollektiv der helvetischen Elementarschullehrer dar. Nur gerade etwas mehr als 1\% aller Lehrkräfte hatte vor dem Lehramt als Buchhalter, Handelsreisende, Kaufmannsbediente, Krämer oder als Ver-

663 Von 18 protoindustriell tätigen Lehrern der Basler Landschaft unterrichteten bloss acht Lehrer in ihrem eigenen Haus.

664 Schneider, bernische Landschule: 83.

665 Rothen, Lesen: 54.

666 Schmidt u.a. (Hgg.), Stapfer-Enquête, Nr. 110: Brütten.

667 Schmidt u.a. (Hgg.), Stapfer-Enquête, Nr. 84: Holzenstein.

668 Vgl. zu den Kosten eines Schulhauses die Ausführungen zum Schulhausbau durch Lehrerfamilien im Kap. 2.2.1. 
käuferin gearbeitet. ${ }^{69}$ Zwar betätigten sich am Ende des 18. Jahrhunderts gesamtgesellschaftlich erst relativ wenige Menschen überhaupt im Klein- und Fernhandelswesen, dennoch soll die Handelsbranche mit ihren geforderten Kulturtechnikkompetenzen einen wichtigen lokalen Nachfragestimulus gegenüber dem Elementarschulwesen dargestellt haben. Schreib- und zahlenkundige Personen waren die unabdingbare Voraussetzung, um erfolgreich im Handelswesen Geschäfte treiben zu können, insbesondere im immer wichtiger werdenden Fernhandel. Die Voraussetzungen dazu - die elementaren Kulturtechniken - sollte die Elementarschule vor Ort durch eine intensivierte und durch ein fachlich extendiertes Bildungsangebot leisten.

Naheliegend wären ehemalige Kaufleute aufgrund ihrer angewandten Kulturtechnikkompetenzen im Schreiben und Rechnen ideale Elementarschullehrer gewesen. Dennoch suchte kaum ein kaufmännisch Tätiger sein Glück im Schulwesen, wie die empirische Auswertung aufzeigt. Kaufmannstätigkeiten - insbesondere des Fernhandels - konzentrierten sich räumlich in der Regel auf die Städte und auf wichtigen Marktorte, während auf dem Land Krämer und Hausierer für die kleinräumige Feinverteilung der Güter sorgten. ${ }^{670}$ Unter den wenigen Einzelfällen, die dennoch Schulmeister wurden, fanden sich denn auch sowohl eine Handvoll Kleinkrämer von ländlicher Herkunft wie der Lehrer von Gurzelen BE, der vor der Lehramtsübernahme „Ein kleines kramhändeli “671 geführt hatte, als auch Personen von zentralörtlicher Herkunft. ${ }^{672}$ Ebenso verblieben aber einzelne Landbürger als Hintersassen im städtischen Umfeld, nachdem sie im Handelswesen tätig geworden waren. So stammte etwa die einzige überlieferte Lehrerin, die vor der Übernahme des Lehramts im kaufmännischen Bereich gearbeitet hatte, Jeanne Jacquerod, als Ehefrau eines Holzhändlers aus dem ländlichen Pays d'Enhaut und hatte sich zuvor als lokale "Marchande de Fromage" in Nyon betätigt. ${ }^{673}$

Unter den ehemaligen Fernhandelskaufleuten sind trotz der unterschiedlichen Herkunft indes sehr ähnliche Lebensverläufe um zwei räumliche Gravitationszentren festzustellen: die Handelsstädte Augsburg und Genf. Zum einen wiesen gleich drei spätere Lehrkräfte aus dem ehemaligen Glarnerland sowie ein Schaffhauser Lehrer weitgehend identische Berufsbiografien auf. Die Lehrer der Glarner Orte Sool, Mitlödi, Ennenda und Thayngen SH waren alle gleich nach der Beendigung der eigenen Schulzeit als Jugendliche oder junge Erwachsene in die deutsche Stadt Augsburg emigriert, um sich dort zum Handelskaufmann oder Kaufmannsbediensteten ausbilden zu lassen. ${ }^{674}$ Zwischen den Textilverlegern der alten Handelsstadt Augsburg und dem Glarnerland bestanden schon seit dem 17. Jahrhundert durch den Handel mit Baumwollprodukten beziehungsweise der protoindustriellen Produktion von Baumwollstoffen im Glarnerland enge wirtschaftliche Verbindungen. ${ }^{675}$ So erstaunt nicht, dass umtriebige Glarner Kaufleute in ganz Europa tätig waren. Das lässt sich beispielhaft in der Antwort des Lehrers von Ennenda GL nachvollziehen, der vor der Lehramtsübernahme „in Handlungs Geschäften nach Curland. 5. bis 6. Jahre lang ${ }^{\text {“676 }}$ gereist war. Nach wenigen Jahren der Tätigkeit als Fernhandelsreisende kehrten sie aber alle wieder in ihre Heimatdörfer zurück, wo sie später das Elementarschullehramt übernahmen.

669 Nur insgesamt 28 der 2.305 helvetischen Lehrkräfte hatten in der Stapfer-Enquête eine kaufmännische Ersttätigkeit vermerkt. Konfessionelle und herrschaftsrechtliche Differenzen sind aufgrund der geringen Quantität an Lehrkräften irrelevant.

670 Vgl. Radeff, Kleinhandel.

671 Schmidt u.a. (Hgg.), Stapfer-Enquête, Nr. 722: Gurzelen.

672 Sieben der 28 Lehrkräfte mit kaufmännischem Hintergrund waren von zentralörtlicher Herkunft.

673 Schmidt u.a. (Hgg.), Stapfer-Enquête, Nr. 1685: Nyon.

674 Schmidt u.a. (Hgg.), Stapfer-Enquête, Nr. 415: Sool; Nr. 416: Mitlödi; Nr. 569: Ennenda; Nr. 1011: Thayngen.

675 Heer/Blumer, Glarus: 464ff.

676 Schmidt u.a. (Hgg.), Stapfer-Enquête, Nr. 569: Ennenda. 
Zum anderen zogen die in der Stadt Genf angesiedelten Handelsgeschäfte zahlreiche Personen aus der ganzen Alten Eidgenossenschaft an, die sich zum Kaufmann ausbilden lassen wollten. Mindestens fünf spätere Lehrkräfte - aus dem zürcherischen Kyburg, von Murten, aus dem Waadtländer Mittelland und dem Pays d'Enhaut - berichteten von einem längeren Aufenthalt in der Stadt Genf, verbunden mit einer Ausbildung im Handelswesen. Doch auch sie blieben kollektiv nur für eine relativ kurze Zeit von wenigen Jahren im Handelswesen tätig und wechselten bald entweder an eine städtische Schule oder kehrten in ihre Herkunftsgemeinden zurück. ${ }^{677}$ Die Rückkehr an den Herkunftsort ist ein insgesamt häufiges biografisches Verlaufsmotiv, denn insgesamt mindestens 14 der 28 Lehrkräfte mit kaufmännischer Vergangenheit waren wieder in ihre Herkunftsorte zum Schulhalten zurückgekehrt, nur sechs Personen nahmen eine Schulstelle als Hintersassen an einer fremden Schule an, von den acht übrigen späteren Lehrkräften sind die erstberuflichen Mobilitätspfade unbekannt.

Als Leitmotive für die Rückkehr in die Heimat und für die Abkehr vom Fernhandel sind von den Lehrkräften selbst hauptsächlich wirtschaftlicher Misserfolg und die schwierige konjunkturelle Gesamtsituation im Handelswesen am Ende des 18. Jahrhunderts angeführt worden. Der Glarner Schulmeister Johann Heinrich Ruch von Sool schrieb beispielhaft: ,ich war vom 12ten Jahr 5 Sommer in augspurg bei meinen Hrl. wo ich ihnen treü und redlich gedienet habe, her nach wolte ich mein Glück durch Camrad-Schaft im Teütschland und Frankreich Probieren mit einem kleinen Comers, ich musste aber das gegentheil erfahren. ${ }^{\text {"678 }}$

Der Lehrer Salomon Brändli von Kyburg ZH machte dagegen die konjunkturell ungünstige Wirtschaftslage ab 1770 für die Beendigung seiner Karriere im Kaufmannswesen verantwortlich: ,Jst vorher schon im 14ten Jahr seines Alters in Loblicher Stadt Genf gewesen, um die Französische Sprache zu lernen weilen er als Kaufmanns-Bedienter eintretten sollte: und war in dieser Stadt bey einem bekannten Schuhster am Tisch; um zugleich dieses Handwerk zu lernen. Da die Handelschaft sank, und keine neüen Kaufmannsbedienten begehrt wurden, arbeitete er einige Zeit auf dem Handwerk, auch selbst bey Hause. Bald hernach war er als Schullehrer beruffen." ${ }^{\text {(679 }}$

Individuelle ökonomische Not, Misserfolge oder vorgeschobene gesundheitliche Probleme ${ }^{680}$ deuten an, dass hinter zahlreichen Biografien von ehemaligen Handelskaufleuten soziale Abstiegstendenzen standen und das Lehramt primär zur sozialen Absicherung übernommen wurde. Das leicht retardierte Amtsübernahmealter von durchschnittlich 30.3 Jahren unterstützt die Vermutung, dass das Lehramt eher aus Opportunitätsgründen als aus intrinsischem Interesse und innerer Berufung zum Unterrichten übernommen wurde. Ebenso entsprach die verbreitete Rückkehrmentalität in die Heimatgemeinden einem durchaus normalen Verhalten bei wirtschaftlichen Misserfolgen, da zu Hause am ehesten auf sozial-familiäre Netzwerke oder Klientelbeziehungen zurückgegriffen werden konnte.

\subsubsection{Kommunale Amtstätigkeiten}

Unter der Merkmalsklasse der kommunalen Amtstätigkeiten subsumieren sich einerseits die althergebrachten, teilweise in der Helvetischen Republik weiter existierenden dörflichen Re-

677 Im Durchschnitt von sieben Ausübungsdauerangaben hatten die späteren Lehrkräfte rund 6.5 Jahre im kaufmännischen Bereich gearbeitet.

678 Schmidt u.a. (Hgg.), Stapfer-Enquête, Nr. 415: Sool.

679 Salomon Brändli war 1799 bereits 24 Jahre Schulmeister. Schmidt u.a. (Hgg.), Stapfer-Enquête, Nr. 320: Kyburg.

680 „A Genève, Commis chez un marchand. environ quatre ans 1/2 au bout desquels ma Santé mayant obligé de reprendre l'air natal pour me rétablir j'ai ensuite pris de préférence la vocation que j’occupe actuellement." Schmidt u.a. (Hgg.), Stapfer-Enquête, Nr. 1408: Yverdon-les-Bains. 
präsentations- und Ehrenämter der kommunalen Selbstverwaltung aus dem Ancien Régime wie Untervogt, Weibel, Geschworener, Säckelmeister, Zolleintreiber, Ungeltner ${ }^{681}$, Armenschaffner, Sittengerichts- oder Chor-Richter, Ehegaumer oder Mitglied des kirchgemeindlichen Stillstands. Der Stillstand stellte die eigentliche exekutive Behörde der Kirchgemeinde im Ancien Régime dar, dem mitunter auch die Schulmeister von Amtes wegen angehörten. ${ }^{62}$ Das Ausüben eines kommunalen Ehrenamtes war in der Regel ein Privileg der dörflichen Eliten und ein Ausdruck von grossem sozialem Kapital. Die Amtsausübung erfolgte denn auch meist ohne Besoldung, war also keine primär ökonomisch motivierte Tätigkeit.

$\mathrm{Zu}$ den niederen kommunalen Ämtern ohne politische Bedeutung gehörten andererseits die in der Regel besoldeten funktionalen Dienste als Nachtwächter, Quartiermeister, Vieh- oder Weg-Inspektor, Mäusefänger, Bannwart, Feuerbeschauer, Vogtei- oder Gemeindeschreiber und Hirte. Da jene besoldeten kommunalen Dienste mitunter zur karitativen Verwahrung an arme Leute vergeben wurden, war ihnen ein gewisser sozialer Umverteilungseffekt inhärent, gleichzeitig aber entsprang ihnen ein ungleich geringeres soziales Ansehen. ${ }^{63}$

Der revolutionäre Umsturz und die zentralistische Verfassung der Helvetischen Republik brachte mit der Einführung der Einwohnergemeinden - „Munizipalitäten“ genannt - an der Stelle der Kirchgemeinden eine markante Umwälzung der Struktur der Gemeindebeamten mit sich. Die alten dörflichen Vorsteher, Landvögte, Untervögte und Weibel verloren mit der Revolution fast allesamt ihre Ämter als Vertreter der alten Obrigkeit. An ihrer Stelle schuf die helvetische Verfassung nachfolgend zum Distriktstatthalter die beiden neuen politischen Ämter des Agenten $^{684}$ und der Unteragenten als exekutive Vollzugsorgane der helvetischen Ordnung auf kommunaler und munizipaler Ebene. Ein gewählter Munizipalrat mit dem Munizipalräsidenten regelte die kommunalen Belange. Für die Judikative lösten die neu geschaffenen Distriktgerichte mit ihren neu gewählten Distriktrichtern und vollamtlich angestellten Distriktgerichtsschreibern die ehemaligen Landrichter und Landschreiber ab.

Studien zum sozialen Stand der helvetischen Beamten von Matthias Manz zur Basler Landschaft und von Hans Weber zur Zürcher Landschaft zeigen in einhelligen Schlüssen, dass auf personeller Ebene einzig auf der obersten Hierarchiestufe eine fast gänzliche Ablösung der alten Notabeln stattfand, freilich viele Angehörige des kommunalen alten Stillstands in Amtsfunktionen verblieben und im Frühjahr 1799 als neue Munizipalitätsmitglieder die Angelegenheiten der Kommunalverwaltung weiterführten. Während die Revolution somit einzig an der Spitze der kommunalen Hierarchie für einen personellen und generationellen Wechsel sorgte, zeigten sich auf den unteren Chargen der kommunalen Selbstverwaltung starke Tendenzen der Kontinuität, nicht zuletzt aufgrund ihres Erfahrungsschatzes, ihres ökonomischen Wohlstandes und ihrer Klientelbeziehungen nach unten. ${ }^{65}$ Ein eigentlicher Elitenaustausch fand damit auf breiter Basis nicht statt.

681 Das „Ungeld“ oder „Ohmgeld“ bezeichnet eine mittelalterlich-frühneuzeitliche Getränkesteuer auf Wein und anderen alkoholischen Getränken, welche durch den „Ungeltner“ bei den Wirten eingezogen wurde. Vgl. Dubler, Ungeld. In der Stapfer-Enquête sind eine Handvoll „Ohmgeltner“ zu finden, beispielhaft: Schmidt u.a. (Hgg.), Stapfer-Enquête, Nr. 1987: Dintikon.

682 Weber, Landgemeinden: 43.

683 Trossbach/Zimmermann, Dorfes: 92; Trossbach, Bauern: 29.

684 Die Agenten wurden durch den Unterstatthalter bestimmt. Weber, Landgemeinden: 55-88.

685 Vgl. Manz, Landschaft: 143-151; Weber, Landgemeinden: 45f. Beide Autoren heben trotz des festgehaltenen scharfen personellen Bruchs an der Spitze der Gemeinden zu Beginn der Revolution für ihre Untersuchungsräume eine Rückkehrbewegung der alten Notabeln mit dem fortschreitenden Zerfall der Helvetischen Republik im Übergang zur Mediation hervor, wodurch das Element der personellen Kontinuität überwiegt. Christian Simon 
Empirisch spielten kommunale Ämter als Ersttätigkeiten im helvetischen Lehrerkollektiv nur eine marginale Rolle. Bloss 1.3\% aller Schulmeister hatten vor der Helvetischen Revolution nach eigenen Angaben ein von der Gemeinde vergebenes säkulares Kommunalamt inne gehabt. ${ }^{686}$ Davon entfielen die Mehrzahl der Nennungen auf bezahlte niedere Kommunalämter und nur ein geringer Teil auf die unbezahlten kommunalen Ehrenämter. ${ }^{67}$ Das Spektrum an Ehrenämtern reichte freilich von ehemaligen Gemeindepräsidenten zu Mitgliedern des lokalen Stillstands und Richtern. Deutlich häufiger wurden dagegen Gerichts- und Gemeindeschreibertätigkeiten ausgeführt, was die Personen zur späteren Lehramtsübernahme aufgrund ihrer Kulturtechnikfähigkeiten geradezu prädestinierte. Kommunalämter waren ferner - unter dem Vorbehalt des eingeschränkten Blicks aus dem Lehrerkollektiv - eine ausschliessliche Männerdomäne, da keine Lehrerin eine kommunalamtliche Ersttätigkeit überliefert hatte.

Einzelne Lehrkräfte hatten mit der Lehramtsübernahme auf die weitere Ausübung von bezahlten Kommunalämtern freiwillig verzichtet, so wie der Lehrer Christen Leemann von Signau BE festhielt: „Wahre eniche Jahre Siegerist; und Gemeinds-Schreiber; hat aber diese 2. Posten Aufgegeben: um sich der Anwachßenden Schul-Arbeit beßer zu wiedmen“688

Spätestens mit der Helvetischen Revolution gab jedoch eine Mehrheit ihre Kommunalämter freiwillig oder gezwungenermassen $a b$ und nur eine Minderheit der Lehrer mit vormaligen Amtstätigkeiten verblieb in ihren Amtsfunktionen oder wurde zu Repräsentanten der neuen Regierung. ${ }^{689}$ Nur bei wenigen Schulmeistern konnte somit eine durchgehende Ämterkontinuität vom Ancien Régime in die Helvetische Republik beobachtet werden. Insgesamt spricht die weitgehende Abwesenheit von dörflichen Ehrenämtern unter den Ersttätigkeiten der Lehrer für eine weitgehende Nicht-Zugehörigkeit zu den dörflichen Eliten. Die wenigen Lehrkräfte mit höheren kommunalen Ehrenämtern erscheinen als Ausnahmefälle.

\subsubsection{Kirchliche Amtstätigkeiten}

Säkulare Hilfsdienste zur Unterstützung der Pfarrer vor- und während der Gottesdienste sowie zum Unterhalt der kirchlichen Infrastruktur wurden wie das Lehramt und andere niedere Kommunalämter in der Regel von den Gemeinden frei vergeben. Die ausübenden Personen erhielten dafür meist eine finanzielle Entschädigung. Kirchenhilfsdienste stellten damit ebenfalls eine kommunale Ressource dar, deren Vergabe von lokalpolitischen oder klientelistischen Motiven der Lokaleliten gesteuert sein konnte.

Die kirchlichen Hilfsämter umfassten an sich ein breites Spektrum von Einzelaufgaben, die entweder einzeln oder in beliebiger Kombination von einer oder mehreren Personen ausgeführt werden konnten. Sie bestanden einerseits aus dem „niederen“ Mesmerdienst ${ }^{690}$ zum Unterhalt

betont zudem, dass der Machtwechsel oft einen Übergang der wichtigsten Positionen von einem „Clan“ der Dorfaristokratie auf einen anderen bewirkte, ohne die sozialen Verhältnisse grundlegend zu verändern, sondern bloss die relative Stellung der Klientelgruppen zueinander. Simon, bäuerliche Revolution: 175.

686 Insgesamt konnten 30 Lehrkräfte mit einer kommunalen Ersttätigkeit gezählt werden. Auf eine Differenzierung nach der geografischen Lage, der Konfession, nach den ehemaligen Herrschaftsrechten und nach Generationen wird aufgrund der geringen Quantität verzichtet.

68712 der 30 genannten Ämter sind als „Ehrenämter“ einzuordnen, 18 als niedere Kommunalämter.

688 Schmidt u.a. (Hgg.), Stapfer-Enquête, Nr. 723: Signau.

689 Insgesamt 12 der 30 Lehrkräfte mit vorrevolutionären Kommunalämtern behielten ihr Kommunalamt bei oder übernahmen ein neues Amt der helvetischen Verwaltungsorganisation. Vgl. das Kap. 3.3.2.

690 Der Begriff des „Mesmers“ umschreibt das Amt des säkularen Kirchendieners oder „Küsters“ und wird hier als synonym mit dem in der Schweiz gebräuchlichen Begriff des „Sigrists“ verstanden. Die äquivalenten zeitgenössischen französischen Begriffe lauteten „Marguillier“ oder „Clerc d'Eglise“. 
der Kirche. Dieser umfasste die Reinigung des Kircheninnern, die Pflege und Reparatur der Kirchgebäude sowie das Bereitstellen der liturgischen Gegenstände für den Gottesdienst. Ferner gehörten mancherorts die Pflege und der Unterhalt der Kirchenuhren ${ }^{691}$ sowie das Läuten der Kirchenglocken zu weiteren spezifischen optionalen Aufgaben der niederen Mesmer. Die „höheren“ Mesmerdienste betrafen andererseits die unmittelbare Begleitung und Mitgestaltung der Gottesdienste durch Vorsingen, Vorbeten oder Vorlesen religiöser Texte. ${ }^{692}$

Obwohl die Grenzen zwischen den unterstützenden Hilfsdiensten in Kirchensachen gegenüber den traditionellen Aufgabenbereichen der Pfarrer respektive Kapläne und Priester nur schwer $\mathrm{zu}$ ziehen sind und in lokalen Situationen mitunter fliessend ineinander übergingen, lag die Trennlinie zwischen Mesmern und Geistlichen neben der differenten Ausbildung vor allem im Bereich der Seelsorge und der Predigt als exklusive Aufgabe der geistlichen Pfarrer, Kapläne und Priester. Obwohl katholische Weltgeistliche zwar teilweise ebenfalls Mesmerdienste ausübten, war das Amt des Mesmers auch in den katholischen Regionen vielerorts eine eigenständig zu vergebende Tätigkeit des kommunalen Aufgabenbereichs.

Als Ersttätigkeiten von Lehrkräften traten kirchliche Hilfsämter quantitativ jedoch noch seltener in Erscheinung als kommunale Amtstätigkeiten oder kaufmännische Erstberufe. Weniger als $1 \%$ aller helvetischen Lehrkräfte hatte vor der Lehramtsübernahme als weltlicher Kirchendiener gearbeitet. ${ }^{693} \mathrm{Zu}$ den zuvor ausgeübten kirchlichen Hilfstätigkeiten der späteren Lehrer zählte vorwiegend der Mesmerdienst, des Weiteren waren wenige Lehrkräfte vor ihrer Amtsübernahme ferner als Vorsänger, Organist oder als Kirchmeier tätig gewesen. ${ }^{694}$ Am häufigsten rekrutierte sich die Lehrerschaft aus zuvor kirchlichen Hilfsdienern in der katholischen Schweiz, besonders im Kanton Solothurn. ${ }^{695}$

Interessant ist die weitgehende Abwesenheit von Kirchenhilfsdiensten als Ersttätigkeiten insofern, als Schulmeister kirchliche Hilfsdienste favorisiert als Nebentätigkeiten zum Lehramt ausübten ${ }^{696}$ Kirchliche Hilfsdienste stellten somit keine direkte Eintrittspforte in das Lehramt dar, sondern sind fast ausschliesslich als Ergänzungstätigkeiten zum Schulamt zu verstehen.

In einigen Fällen wurden kirchliche Hilfsdienste allerdings innerfamiliär vom Vater auf den Sohn weitergegeben, wie die Aussage des Lehrers von Langrickenbach TG illustriert: „Jch hate vorhar sind 1768. den 9 ten April. Nemmlich vom Hl. Oster Tag an, schon in dem 17 ten Jahr meines Alters Meinem Vatter den Vorsinger dienst geleistet. und ihme Jn der Kirchen Beygestanden. Walches Nächste Ostern thut 31. Jahr und Jetz stad ich vor 14 Jahr allein." 697

Aufgrund der geringen Anzahl an erstberuflich tätigen Kirchendienern im untersuchten Lehrerkollektiv kann die Häufigkeit von familiär-dynastischer Tätigkeitsweitergabe nicht abge-

691 Der Unterhalt der Kirchenuhren wurde - zumindest in den relativ wohlhabenden Weinbaudörfern der Waadt vergleichsweise gut bezahlt, wie Beispiele aus Grandvaux VD und Rivaz VD dokumentieren. So erhielt der Lehrer von Grandvaux VD als Entschädigung „pour le gouvernement de l'horloge“ 33 Gulden, was knapp 10\% seines Gesamteinkommens von 391 Gulden entsprach. Vgl. Panchaud, écoles vaudoises: 294.

692 Vgl. zur Differenzierung von niederem und höherem Mesmer-Dienst: Walz, Eselsarbeit: 58. Zur Differenzierung von Sigrist- und Vorsingerdienst vgl. Bloch Pfister, Priester: 87.

693 Nur gerade 22 konkrete Nennungen von kirchlichen Hilfsdiensten konnten als Ersttätigkeiten unter den 2.305 Lehrkräften gezählt werden. Nicht mitgezählt sind freilich sämtliche Geistlichen, die im Kap. 2.2.10 separat diskutiert werden.

69413 der 22 späteren Lehrer waren zuvor Mesmer, 4 betätigten sich als Organist, 3 als Vorsänger und 2 als Kirchmeier.

69514 der 22 späteren Lehrer entstammten aus einer katholischen Gemeinde, davon 5 aus dem Kanton Solothurn. Auf eine weitere Differenzierung nach Region, ehemaliger Herrschaftsform und Generationen wird aufgrund der geringen Quantität an Fallbeispielen verzichtet.

696 Vgl. das Kap. 3.3.2.

697 Schmidt u.a. (Hgg.), Stapfer-Enquête, Nr. 801: Langrickenbach. 
schätzt werden. ${ }^{698}$ Kirchendienste stellten jedoch - das zeigt das Exempel auf - gleichwohl eine wichtige Einkommens- oder Sozialkapitalressource dar, wenn eine innerfamiliäre Weitergabe angestrebt wurde.

Konkrete Motive für die Übernahme des Lehramts durch ehemalige Kirchendiener sind in den Antworten auf die Stapfer-Enquête rar. Finanzielle Überlegungen spielten zumindest bei einigen Personen sicherlich eine wichtige Rolle, denn die Einkommen der Mesmer waren bisweilen nicht ausreichend ausgestattet. Wie auch für das Schulamt waren die Entschädigungen für kirchliche Hilfsdienste vielerorts nur auf die tatsächlich zu verwendende Zeit bemessen und nicht ausreichend, um allein davon leben zu können. Das machte die Ausübung zusätzlicher Funktionen notwendig, wie das Beispiel des Mesmers, Unteragenten und Lehrers von Steinerberg SZ verdeutlicht: ,ich halfe meinem Vatter in dem sigriste dienste, und anderen verrichtungen. jetz bin ich sigrist und Erster unteragent. [...] weil ich aber vom sigriste dienste eine sehr geringe bezahlung habe. so mus ich verdienen, was ich kann, es ist beser zwey stücklin brod, als nur eines. ich empfehle beyde zur vergrösserung. weil sehr viel mühe walte darbey. ${ }^{\text {(699 }}$

Ferner wiesen die wenigen Lehrkräfte mit einer kirchlichen Hilfstätigkeit eine ausgeprägte Kontinuität ihrer Ersttätigkeiten auf, denn mindestens 12 der 21 ehemaligen Kirchenhilfsdiener setzten ihre Tätigkeit auch nach der Lehramtsübernahme fort. ${ }^{700}$ Insofern dürfte das Lehramt zumindest für einige der ehemaligen Kirchendiener tatsächlich die Funktion einer Ausdehnung der Erwerbsmöglichkeiten angenommen haben, zumal die Zusammenführung von Mesmerund Schuldiensten durchaus im Interesse der Obrigkeiten lag. ${ }^{701}$

\subsubsection{Ehemalige Soldaten}

Das hartnäckige Klischee, dass ausgediente und invalide Soldaten im Ancien Régime favorisiert zu Landschulmeistern umgeschult worden seien, weil sie sich aufgrund ihres erlernten militärischen Drills für Zucht und Ordnung in der Schulstube besonders ideal eignen würden, geht auf ein Edikt des preussischen Königs Friedrich II. aus dem Jahr 1779 zurück, das die Versorgung von invaliden Veteranen in Landschulen verfügte: „wenn unter den Invaliden sich welche fänden, die lesen, rechnen und schreiben können und sich zu Schulmeistern auf dem Lande eigneten und sonsten gut schickten, sie dazu besonders an den Orten, wo der König die Schulmeister salarierte, employiert werden sollten. ${ }^{\text {“702 }}$ Rasch entwickelte sich aus dieser Verfügung ein historiografischer Mythos von enormer Wirkungsmacht auf die Forschungsliteratur zur Schulgeschichte im deutschsprachigen Raum, zumal besonders das preussische Schulwesen für lange Zeit zum Modellgegenstand der deutschen Schulgeschichte wurde. Fortan fehlte der invalide ehemalige Soldat in kaum einer Aufzählung zur sozialen Herkunft der vormodernen Landlehrerschaft mehr. ${ }^{703}$

Neuere quantitative Forschungen haben den ehemaligen Kriegsversehrten im Elementarschulwesen sowohl für Preussen als auch für die übrigen deutschen Territorien als eindeutigen Mythos entlarvt und widerlegt, denn lediglich 79 von über 4.000 preussischen Invaliden des Jahres

698 Mindestens zwei weitere Lehrkräfte hatten das Mesmeramt von ihren Vätern geerbt.

699 Schmidt u.a. (Hgg.), Stapfer-Enquête, Nr. 2018: Steinerberg.

700 Vgl. zu den kirchlichen Hilfsdiensten das Kap. 2.3.7.

701 Vgl. hierzu die Ausführungen im Kap. 3.3.2.

702 Zit. nach: Sauer, Volksschullehrerbildung: 14.

703 Beispielhaft: „war der Lehrerberuf nur ein Notberuf, in den sich alle möglichen Leute flüchteten: Handwerker, Hirten invalide Soldaten und Predigtamtskandidaten.“ Trinks, Sozialgestalt: 20. Vgl. zur Kritik am Militärinvaliden als Schulmeister: Neugebauer, Schulwirklichkeit: 353. 
1779 wurden als tauglich für den Schuldienst eingeschätzt. ${ }^{704}$ Wolfgang Neugebauer hat angesichts dieser eindeutigen Zahlenlage resümiert: „Die Zahl der im Jahre 1779 auf Schulstellen gelangten Invaliden war also absolut und relativ, gemessen an der Gesamtzahl der Invaliden als auch im Vergleich mit der Zahl an Landschulen in Brandenburg-Preussen [...] verschwindend gering. ${ }^{\text {“705 }}$ Auch Michael Sauer hat in seiner detailreichen Abhandlung zur Volksschullehrerbildung in Preussen vor einer Überschätzung des Phänomens der Soldaten und Invaliden im Schuldienst um 1800 gewarnt, da die meisten dieser ehemaligen Soldaten zugleich auch Handwerker waren und somit in mehreren Berufskategorien gezählt werden konnten. ${ }^{706}$

In der älteren schweizerischen Schulgeschichte fand der Soldaten-Lehrer aufgrund der mangelhaften historiografischen Rezeptionskritik ebenfalls Eingang als eine „typische “ Sozialgestalt der vormodernen Schulwirklichkeit. Heinrich Tuggener resümiert für die schweizerischen Lehrer: „Unter diesen Subjekten, deren Leben in diesen Noth- und Elendsstand einmündet, befinden sich nicht selten ehemalige Soldaten und Unteroffiziere, welche, zum Felddienst untauglich und eines bürgerlichen Arbeitslebens ungewohnt, für den Schuldienst gerade gut genug sind. Diese in der friederizianischen Epoche beliebte Lösung bleibt allerdings nicht nur auf Preussen und Deutschland beschränkt, sie findet sich auch bei uns, sogar in Gebirgsgegenden. ${ }^{\text {"707 }}$ Louis Boucard bestätigt ebendiese Neigung zur Anstellung ehemaliger Soldaten bei der Walliser Bevölkerung: „Cette préférence des gens de la montagne pour ceux ,qui ont voyagé de par le monde‘, avantageait, parmi tous les candidats à la régence, les vieux troupiers revenus de leurs campagnes de France, d'Espagne ou de Naples. ${ }^{\text {“708 }}$ In den 66 Walliser Antworten auf die Stapfer-Enquête konnte jedoch kein einziger ehemaliger Soldat gefunden werden und Boucard selbst hat keine weiteren einschlägigen Quellen als Beweise für seine Behauptung geliefert. Demgegenüber apostrophierten auf der anderen Seite mehrere ältere Forschungsarbeiten kritische Anmerkungen zum invaliden Militärveteranen, etwa Ernst Schneider, der den Soldatenlehrer für den Kanton Bern in quantitativer Hinsicht ,ins Reich der Fabel“709 verwies, oder Georges Panchaud, dessen Erkenntnis lautete: „L'enquête Stapfer ne confirme absolument pas ce tableau pour le Pays de Vaud. On n'y recontre que quatre anciens soldats." ${ }^{\text {“710 }}$

Über die gesamte Helvetische Republik betrachtet, konnte bei insgesamt mindestens 67 der total 2.305 bekannten Elementarschullehrern der Stapfer-Enquête eine eindeutige militärische Vergangenheit nachvollzogen werden, was einem Anteil von $2.9 \%$ aller helvetischen Lehrer entspricht. Sicherlich sind einige wenige weitere ehemalige Soldaten zu vermuten, die ihre militärischen Ersttätigkeiten entweder nicht in der Umfrage aufführten oder gar nicht erst von der Enquête erreicht wurden, dennoch dürfte diese Dunkelziffer vernachlässigbar sein. Der Gesamtanteil an Lehrpersonen mit militärischem Hintergrund dürfte kaum über $5 \%$ betragen haben, was annähernd mit der Stichprobe von Ingrid Brühwiler korrespondiert, die bei total 180 untersuchten Lehrern bloss 11 ehemalige Soldaten zählt, was einem relativen Anteil von rund $6 \%$ entspricht. ${ }^{711}$ In fast jedem helvetischen Kanton konnte konfessionsunabhängig zwar mindestens ein ehemaliger Soldat als Landschullehrer gefunden werden, doch einzig in den beiden

704 Bölling, Sozialgeschichte: 54; Sauer, Volksschullehrerbildung: 14.

705 Neugebauer, Schulwirklichkeit: 356.

706 Sauer, Volksschullehrerbildung: 11.

707 Tuggener, Lehrer: 54f. Vgl. auch: Luginbühl, Stapfer: 69.

708 Boucard, valaisanne: 75 .

709 Schneider, bernische Landschule: 87ff. Auf die rund 300 Berner Lehrer zählte Schneider bloss 13 ehemalige Soldaten, was einen Anteil von rund $4 \%$ ausmacht.

710 Panchaud, écoles vaudoises: $257 \mathrm{f}$.

711 Brühwiler, Finanzierung: 225. 
Bergkantonen Linth und Oberland sowie in den Kantonen Zürich, Thurgau und Schaffhausen waren in absoluten Zahlen mehr als eine Handvoll Lehrer vor der Amtsübernahme in militärischen Diensten gestanden. Gemessen an der Gesamtzahl der Lehrer pro Kanton wiesen nur die drei Kantone Linth (6.8\%), Oberland (8.0\%) und Schaffhausen (10.3\%) einen relativen Anteil von mehr als fünf Prozent an ehemaligen Soldaten im Schuldienst aus.

Die ökonomische Bedeutung der Solddienste in fremden Mächten schwächte sich im Verlauf des 18. Jahrhunderts zwar ab, dennoch bildeten die fremden Dienste nach wie vor das Rückgrat der alteidgenössischen Aussenbeziehungen mit den europäischen Mächten. ${ }^{712}$ Weiterhin rekrutierten Militärunternehmer aus allen eidgenössischen Orten entlang der konfessionellen Grenzen Soldaten aus ihrer lokalen Klientel für ihre Soldkompanien in Frankreich, Österreich, Sardinien-Piemont, Spanien oder in den Niederlanden. Der risikobehaftete Gang in fremde Dienste blieb somit bis zum Ende des Ancien Régimes eine Option, insbesondere für landlose oder landarme Angehörige der ländlichen Unterschichten in den von Armut und knapper Nahrungsmittelproduktion betroffenen vor- und inneralpinen Regionen. Die empirische Häufung von ehemaligen Soldaten-Lehrern in den voralpinen Berggebieten bestätigt diese Annahme. Die Attraktivität des Solddienstes nahm im 18. Jahrhundert durch die fortlaufende Geldentwertung, gestiegene Abzüge auf dem Sold und der dadurch entstandenen Verminderung des Einkommens jedoch stetig ab. Die Auflösung der Schweizerregimenter in Frankreich während der Französischen Revolution läutete das langsame Ende der fremden Dienste ein. ${ }^{713}$

Der Militärdienst nahm in berufsbiografischer Hinsicht für die späteren Lehrkräfte allerdings eine bemerkenswert wichtige Funktion als Ausbildungsstation ein. Gleich mehrere der ehemaligen Söldner, die später Schulmeister wurden, schrieben ihre Kulturtechnikkenntnisse direkt dem Militärdienst respektive den während des Militärdienstes ausgeführten militärischen Funktionen zu. Der Lehrer Conrad Meßmer von Dörflingen SH hielt in seiner Antwort an Stapfer beispielhaft fest: „Jn Holländischen diensten Hat Er Gelernt Schreiben Rechnen u Singen."714

Der Militärdienst in der Ferne trug somit dazu bei, dass sich einige der späteren Schulmeister überhaupt erst für das Schulamt qualifizieren konnten. Etwas ausführlicher beschrieb der Lehrer Johann Joseph Mutter aus Erstfeld UR die Vorteile des Soldatenlebens für seine spätere Karriere: „Daß ich eben also bevor ich dieses Lehrammte angetretten mich in Millitärischen Diensten befande, daß kann ich noch mit mein erhaltenen Ehren schriften beweisen. solche Jahre wendete ich neben meinen Dienstpflüchten gänzlich an? für Lesen und Schreiben etc. auch für Musik, und buchbünden. (es kann also jeder Jüngling einsehen, daß das Millitärische Leben nicht zum Nachtheil, sondern. daß jeder vielen Nuzen daraus schöpfen kann, wann er nur will) ich kan mit wahrheit bezeugen, daß ich viele nützliche sachen dabey erlernet habe." ${ }^{\text {"715 }}$ Die vielfältigen Funktionen innerhalb des Militärdienstes erlaubten ferner das Erlernen von Spezialkenntnissen, die im späteren zivilen Leben als ökonomische Grundlage genutzt werden konnten. Der Lehrer Fridolin Ott als dem Städtchen Bischofszell TG erlernte im Militär beispielsweise die Grundzüge der medizinischen Versorgung: „Bin 12 Jahre in Sardinischen Diensten gestanden, bey den Regimenten Fatio und Zirten, unter welcher Zeit ich 4 Jahre als Bataillons-Chyrurgen unter den Regiment Kalbermatten gedient. Neben der Schule hab ich noch eine kleine unbedeütende Chyrurgische Praxie." ${ }^{\text {(716 }}$

712 Holenstein, Beschleunigung: 339.

713 Holenstein, Mitten in Europa: 32-40; Henry, Fremde Dienste.

714 Schmidt u.a. (Hgg.), Stapfer-Enquête, Nr. 1004: Dörflingen.

715 Schmidt u.a. (Hgg.), Stapfer-Enquête, Nr. 1954: Erstfeld; Durrer, Urkantonen: $24 f$.

716 Schmidt u.a. (Hgg.), Stapfer-Enquête, Nr. 105: Bischofszell. 
Insbesondere Feldprediger- und Schreiber-Dienste innerhalb des Militärs stellten eine Basis für eine spätere Lehreranstellung dar. ${ }^{717}$ Dieser durchaus positive Umstand verhalf dem ehemaligen Soldaten neben der preussischen Gesetzesbestimmung zu seiner Prominenz in der Schulgeschichte. Zudem stellte der ehemalige Soldaten-Lehrer eine dankbare Anekdote für die liberale Forschungsperspektive dar, da er wie kaum eine andere Person für die pädagogische Rückständigkeit und Rohheit in den frühneuzeitlichen Schulzimmern stand. Die ausdrückliche Hervorhebung der positiven Aspekte des Militärdienstes auf den späteren Lebensverlauf als Lehrer kann ferner dahingehend interpretiert werden, dass sich die ehemaligen Soldaten-Lehrer unter dem zunehmenden Druck einer von physischer Gewalt befreiten philanthropischen Pädagogik bereits selbst in einem besonderen Rechtfertigungszwang wähnten. Gleichwohl ist das Element der verbreiteten physischen Gewaltausübung zur Züchtigung der Schulkinder selbst ein weitgehender Mythos der modernen Pädagogik, da viele Lehrkräfte schon um 1800 nach eigenen Aussagen physische Gewalt gegen Kinder als nicht zielführend zur Bestrafung von deviantem Verhalten ablehnten und angesichts der Abhängigkeit vom elterlichen Schulgeld als gar ökonomisch schädlich für den eigenen Schulgeldertrag betrachteten. ${ }^{718}$

Die ehemaligen Soldaten wiesen ferner in ihrem räumlichen Bewegungsverhalten wie die ehemaligen Kaufleute eine ausgeprägte Rückkehrmobilität an ihren Herkunftsort auf. ${ }^{719}$ Obwohl sie lange Jahre in der Fremde gedient hatten und damit über einen riesigen Mobilitätsradius verfügten, suchten sich die ehemaligen Söldner kaum vakante Schulstellen an anderen Orten innerhalb der Alten Eidgenossenschaft, sondern kehrten fast ausnahmslos wieder in ihre Herkunftsgemeinden zurück. Hierzu können mit den sozial-familiären Netzwerken und allfälligen Klientelbeziehungen zum Herkunftsort dieselben Treibkräfte angebracht werden, wie schon bei den ehemals kaufmännisch Ersttätigen aufgelistet worden sind, selbst wenn diese Treiber nicht explizit erwähnt wurden.

Dass ein frei gewordenes Lehramt in der Herkunftsgemeinde freilich nicht der primäre Rückkehrgrund gewesen sein dürfte, erschliesst sich ferner aus dem mittleren Amtsübernahmealter der ehemaligen Soldaten. Denn obwohl die meisten ehemaligen Reisläufer im Durchschnitt zwischen dem 28. und 29. Lebensjahr wieder zurückkehrten, lag das mittlere Amtsübernahmealter der späteren Lehrer mit militärischem Hintergrund deutlich höher bei rund 34.8 Jahren. ${ }^{720}$ Die zeitliche Differenz zwischen der üblichen Rückkehr und der Lehramtsübernahme evoziert die Vermutung, dass die zurückgekehrten Soldaten zwischenzeitlich andere Tätigkeiten ausgeführt und erst später das Lehramt übernommen hatten. Sie scheinen daher am ehesten dem Typus des "pédagogue d'occasion“ nach Panchaud entsprochen zu haben.

Eine auf territorialer Ebene verfasste Absicht, in Kriegsdiensten verletzte oder ausgemusterte ehemalige Soldaten systematisch zu ihrer sozialen Versorgung als Schulmeister aufzunehmen, existierte in der Alten Eidgenossenschaft allerdings nirgendwo. Unter jenen 67 namentlich bekannten ehemaligen Soldaten befanden sich zudem - mit einer Ausnahme eines erst bei der Schlacht von Laupen im Frühjahr 1798 verletzten Leutnants der Berner Truppen ${ }^{721}$ - keine expliziten Kriegs-

717 Schmidt u.a. (Hgg.), Stapfer-Enquête, Nr. 1175: Sangen; Nr. 1443: Gsteig.

718 Vgl. zur zeitgenössischen Wahrnehmung von Strafen für deviantes Verhalten im Unterricht: Rothen/Ruloff, Schulumfragen: $44 \mathrm{ff}$.

719 Nur 13 der 67 Lehrkräfte mit militärischem Hintergrund (20\%) arbeiteten 1799 an einer Schule ausserhalb des Herkunftsortes.

720 Vgl. zum mittleren Rückkehralter von Söldnern die Studie zu Bern: Pfister, Strom: 129.

721 „Den 5.ten Merz. 1798. wurde er als Lieutenant zu Laupen, in der Schlacht, in das rechte Bein geschoßen, worauf er kontrakt geblieben ist, so daß das Bein vielmehr, als in das Winckelmäß krum gebogen ist, mit grösester Not an zweyen Krücken, auf einem Bein gehen kan, seine Lehrfunktion, an Werk und Sontagen, auf einem Stuhl sitzend 
invaliden. Mit den Worten Wolfgang Neugebauers ist die Stilisierung des militärischen InvalidenLehrers zu einem „Leitmotiv der Schulwirklichkeit ${ }^{\text {“722 }}$ nicht nur für Preussen, sondern auch für die Alte Eidgenossenschaft und die Helvetische Republik entschieden zurückzuweisen.

\subsubsection{Schreibertätigkeiten}

Ausserkommunale Verwaltungs- und Schreibertätigkeiten aller Art wären aufgrund der dazu erforderlichen Kulturtechnikkenntnisse die eigentlich ideale Voraussetzung gewesen, um Elementarschullehrer zu werden. Dennoch hatten unter den 2.305 helvetischen Lehrkräften des Elementarschulwesens bloss eine verschwindend kleine Minderheit von 1\% vor der Lehramtsübernahme als Schreibverständige gearbeitet. Davon waren ein halbes Dutzend ehemalige Kanzleischreiber, Kopisten, Schreibmeister und Feldvermesser; aber auch „exotische“ Tätigkeiten wie ein ehemaliger Kartograph, eine Spitalverwalterin oder ein Weinkellerverwalter befanden sich darunter. ${ }^{723}$ Die Herkunft dieser Schreiber war ohne räumliche und konfessionelle Schwerpunkte bedeutend zentralörtlich geprägt. ${ }^{724}$

Für Spezialisten der Kulturtechniken war das Lehramt an Elementarschulen offensichtlich kaum eine berufliche Option. Genauso wie ehemalige Handelstätige und Gemeindeschreiber hatten auch professionelle Schriftkundige kaum das Elementarschullehramt als neues oder zusätzliches Betätigungsfeld gesucht und blieben in der kollektivbiografischen Betrachtung der Lehrerschaft deutliche Ausnahmeerscheinungen. Gleichwohl verbergen sich hinter den wenigen zufälligen Personen mit professionellen Schreiberfahrungen bisweilen bewegte individuelle Lebensverläufe. Der Lehrer Jacques Daniel Cuche von Avenches VD hatte beispielsweise zu seinen Ersttätigkeiten mit einer Prise Ironie notiert: „A Vevey, où il a exercé l'arpentage et donné des leçons de calcul, de géométrie, et enseigné la manière de faire les écritures dans le commerce jusqu'à ce qu'il fit la folie de se faire instituteur." ${ }^{\text {“725 }}$

Einen ebenso beeindruckenden wie ungewöhnlichen Lebensverlauf mit gleich mehreren Ersttätigkeiten wies ferner der ehemalige Zeichner, Feldvermesser und Schreiner Emanuel Heinzgen, Lehrer in Muttenz BL, auf, in dessen Vita sich gleich mehrere berufsbiografische Elemente und Entwicklungen von kollektiver Bedeutung kumulierten: „Ehe dessen war er auf einem Güthlein Er hatte in seiner Jugend, nachdem er alle Classen des Gymnasy passiert, 3 Jahr die Zeichnung Schule besucht, dene er hatte eine besondre Lust zum Zeichnen und Kupferstecherey. - Er ward auch von $\mathrm{Br}$ Christian Von Mechel als der erste in seine Lehr genommen, erlernte daselbst noch die Geometrie und Feldmessen, u.e.m. ohngeachtet seiner Kenntnisse u. Beweißthum des Wohlverhaltens, lernte ihn Br. C. Von Mechel das Kupferstechen nicht, sondern wollte ihnen zu seinen Einschlagenden Geschäften widmen. Sein Vater, der mehrere Kinder hatte vermochte nicht, diesen seinen Sohn anderswo in die Lehre zu thun, nahm ihn also zu Hauß, lernte ihn

verrichten mus; Und in zukunft ganz keine Hofnung. zu verrichtunng. einecher Arbeit übrig ist." Schmidt u.a. (Hgg.), Stapfer-Enquête, Nr. 1344: Turbach. Die Invalidität dieses Milizsoldaten ist ferner nicht gleichzusetzen mit der Invalidität aus Solddiensten, da der genannte Lehrer zwar vor der Lehramtsübernahme als Söldner in Holland war, die Verletzung aber aus Gründen der Landesverteidigung und nicht während der Dienstzeit als Söldner geschah. Zudem war die genannte Person bereits vor der Verletzung als Lehrer tätig gewesen.

722 Neugebauer, Schulwirklichkeit: 363.

723 Insgesamt sind 22 Personen mit vormaligen Schreibertätigkeiten in der Stapfer-Enquête vermerkt, darunter 6 ehemalige Schreibmeister, 5 Kanzleischreiber/Kopisten, 4 Feldvermesser, 2 Zeichner, je 1 Buchhalter (Glarus), Weinkellerverwalter („Partisseur“, Sembrancher), Bibliothekar (Goumoens-la-Ville), Kartograph (Noville) und eine ehemalige Spitalverwalterin, die Lehrerin Madgalena Weltner von Solothurn.

7249 der 22 Lehrkräfte mit ehemaligen Schreibertätigkeiten entstammten einer zentralörtlichen Gemeinde bzw. Stadt.

725 Schmidt u.a. (Hgg.), Stapfer-Enquête, Nr. 2528: Avenches. 
wider seinen Willen die Schreiner Profeßion, auf welcher Profeßion er hernach ein baar Jahr gewandert, aber in seiner Rückkehr nur ein Jahr die Profeßion getrieben, er erwehlte das Landleben, welches er dem andren vorzog, und auch ein guter Kenner in der Oekonomie ist. ${ }^{\text {“726 }}$

Das Erlernen von mehreren Berufstätigkeiten nacheinander, wie es Heinzgen geschildert hat, war kollektivbiografisch unter den Lehrkräften keine Seltenheit, gleichwohl aber auch nicht die Regel. Mindestens 6\% aller Lehrkräfte hatten nach ihren eigenen Angaben vor der Lehramtsübernahme mehr als eine ökonomisch relevante Tätigkeit ausgeübt. Am häufigsten wurden dabei landwirtschaftliche und protoindustriell-textilgewerbliche Tätigkeiten sowie landwirtschaftliche und handwerkliche Arbeiten miteinander oder nacheinander ausgeübt. ${ }^{727}$

Die Triebkräfte für einen frühen polyprofessionellen Werdegang dürften freilich - wenn auch in den Quellen unausgesprochen - ähnlich gelagert gewesen sein wie beim beispielhaft zitierten Lehrer Heinzgen: die Armut der Eltern, Armut durch die erlernte Tätigkeit, Versuche der zusätzlichen Subsistenzsicherung oder individuelle Unzufriedenheit mit dem elterlichen Berufsfeld. Am Beispiel des genannten Lehrer Heinzgen wird aber auch die Breite an individuellen Handlungsmöglichkeiten in Bezug auf die Berufswahl sichtbar, die trotz der angeblichen Armut seiner Eltern beträchtlich war. Dies zeigt, dass man die Lebensverlaufsgestaltung von einfachen Menschen am Ende der Frühen Neuzeit als komplex begreifen muss. Zwar prägte die innerfamiliäre Berufsweitergabe nach wie vor die meisten Lebensverläufe, dennoch beschritt bereits eine beachtliche Minorität deutlich flexiblere Lebenswege und fundamentale Brüche in den Berufsbiografien waren auch abseits der temporär mobilen Söldner und des Dienstgesindes keine Seltenheit mehr.

\subsubsection{Geistliche}

Aufgrund der Zugehörigkeit des elementaren Schulwesens zum Aufgabenbereich der Landeskirchen waren seit der Reformation bei beiden Konfessionen bis zum Ende des 18. Jahrhunderts stets auch Geistliche aktiv als Lehrpersonen am Unterricht beteiligt. Für das vormoderne Deutschland hat Ursula Walz die Präsenz von geistlichen Lehrkräften in drei unterschiedlichen biografischen Gruppen festgehalten: „ehemalige Pfarrer, die in ihrem Beruf gescheitert waren, Theologiestudenten, die ihr Studium aus Armut nicht beendet hatten [...]. Oft bewarben sich Pfarramtskandidaten, die lange auf eine Pfarrstelle warten mussten, um das Küsterlehramt in der Hoffnung, später doch noch den viel lukrativeren Posten als Ortspfarrer zu erlangen. ${ }^{\text {"728 }}$ Gemeinsam ist allen drei dargestellten Biografieprofilen, dass sie implizit allesamt gebrochene, in gewisser Hinsicht "gescheiterte“ Lebensverläufe repräsentieren, was Anlass für eine kritische Betrachtung der im Schuldienst stehenden Geistlichen beider Konfessionen gibt und eine Vielzahl von kollektivbiografischen Fragen aufwirft: Wie viele Geistliche waren tatsächlich um 1800 im Lehramt tätig? War das Lehramt an Elementarschulen für diese Geistlichen tatsächlich eine biografische Sackgasse oder das Eingeständnis einer gescheiterten Karriere? Fanden sich im Lehramt demnach eher minderqualifizierte Theologen wieder? Wo und aus welchen Gründen waren überhaupt Geistliche im Schuldienst tätig? Aus welchen sozialen Schichten der Gesellschaft entstammten die als Elementarschullehrer tätigen Geistlichen? Gab es konfessionsübergreifende Gemeinsamkeiten hinsichtlich des biografischen Werdegangs oder der organisationsstrukturellen Voraussetzungen?

726 Schmidt u.a. (Hgg.), Stapfer-Enquête, Nr. 2317: Muttenz.

727 Mindestens 137 der 2.305 Lehrkräfte hatten insgesamt mehr als eine Ersttätigkeit vor der Lehramtsübernahme notiert. Davon entfielen mindestens 59 auf landwirtschaftlich-protoindustrielle Kombinationen, weitere 34 auf landwirtschaftlich-handwerkliche Tätigkeitsverbindungen.

728 Walz, Eselsarbeit: 32. 
In quantitativer Hinsicht spielten Geistliche im Schweizer Elementarschulwesen am Ende des 18. Jahrhunderts nur noch eine Nebenrolle. Insgesamt rund 6\% aller in der Stapfer-Enquête vermerkten Lehrkräfte waren entweder als reformierte Pfarrer oder katholische Kapläne, Priester oder als Ordensgeistliche im Elementarschullehramt tätig. Davon bekannte sich die überwiegende Mehrheit mit 70\% zum katholischen Glaubensbekenntnis, bloss 30\% der als Elementarschullehrer tätigen Geistlichen waren reformierten Glaubens. ${ }^{729}$ In Bezug auf das Kollektiv der Elementarschullehrer war damit jeder fünfte katholische Lehrer ein Geistlicher, während bloss 2\% aller reformierten Lehrer zur Stand der Geistlichkeit zählte. ${ }^{730}$

Das konfessionell extrem ungleiche Verhältnis war das Resultat eines zeitlich ungleich verlaufenden Prozesses der allmählichen Ausdifferenzierung und Ablösung der Elementarschulunterrichtstätigkeit weg von der Geistlichkeit und hin zu den weltlichen Schulmeistern, der in den reformierten Landesteilen weitaus früher einsetzte als in den katholischen Regionen. So ist der Beginn dieses Säkularisierungsprozesses in den reformierten Landesteilen bereits im späten 16. Jahrhundert zu verorten, denn bereits um 1700 hielten beispielsweise nur noch wenige Pfarrer auf der Zürcher Landschaft selber Schule. ${ }^{731}$ Ähnliches gilt für das Berner Untertanengebiet, wo vor 1700 noch zahlreiche Geistliche - mitunter als Wanderlehrer - nach Arbeit in Schulstuben suchten, wohingegen sich am Ende des 18. Jahrhunderts praktisch keine mehr vorfanden. ${ }^{732}$ Für die reformierten Landesteile der Alten Eidgenossenschaft kann dieser Ausdifferenzierungsprozess um 1800 als weitgehend abgeschlossen betrachtet werden, was sich in der geringen Anzahl an schulisch aktiven reformierten Geistlichen manifestiert.

Einigermassen erstaunlich ist diese Entwicklung jedoch im Lichte des zunehmenden Überschusses an Absolventen der Theologie, sogenannten „Exspektanten“, wie er mindestens für das reformierte Zürich im 18. Jahrhundert feststellbar ist, der zu einer verschärften Konkurrenzsituation im Kampf um freiwerdende Pfarrerpfründen führte. ${ }^{733} \mathrm{Im}$ Schulmeisterdasein einen Ersatz zu suchen, kam aber gemäss der empirischen Bestandesaufnahme offensichtlich für die allermeisten dieser reformierten Pfarramtskandidaten aus sozialen, statusbedingten oder ökonomischen Gründen nicht mehr in Frage, obwohl ihre Zukunftsaussichten mit der alleinigen Konzentration auf Pfarrerstellen ungleich schlechter standen. Teilweise vermochte zwar der wachsende Verwaltungsapparat der spätabsolutistischen Stadtrepubliken durch neugeschaffene Stellen die mangelnden Pfarreipfründen zu kompensieren. Zudem hielt wahrscheinlich auch das kommunale Mitspracherecht ortsfremde Theologen von städtischer Herkunft ab, sich als Lehrer in eine ihnen unbekannte Landgemeinde wählen zu lassen, zumal sie dort als „Fremde“ ohne soziales Netzwerk einen ungleich prekäreren sozialen Status gehabt hätten. ${ }^{734}$ Dennoch zogen offensichtlich viele junge Pfarramtskandidaten eine prekäre Lebenssituation als Pfarrhel-

729 Aus der Stapfer-Enquête konnten insgesamt mindestens 140 Elementarschullehrer mit einem mutmasslichen geistlichen Hintergrund eruiert werden. Davon entfielen 98 auf den katholischen, 42 auf den reformierten Glauben. Selbst unter Berücksichtigung der zweifellos vorhandenen Dunkelziffer an nicht erfassten Lehrern durch die stapfersche Umfrage, insbesondere der zahlreichen Ordensgeistlichen in Kloster- oder Konventsschulen der katholischen Schweiz, dürfte der Gesamtanteil an geistlichen Lehrern im Elementarschulwesen für die gesamte Helvetische Republik auf nicht grösser als maximal 10\% geschätzt werden. Der von Brühwiler berücksichtigte relativ hohe Anteil an Geistlichen im elementaren Schulwesen von rund 31\% ist ihrer spezifischen Stichprobenauswahl zur repräsentativen Abbildung aller zehn Schulkombinationstypen geschuldet und kann daher nicht verallgemeinert werden. Vgl. Brühwiler, Finanzierung: 101.

730 Vgl. zu den Konfessionsverhältnissen im Lehrerkollektiv die Zahlen im Kap. 1.6.2.

731 Bloch Pfister, Priester: 81.

732 Fetscherin, Zweite Periode: $29 f$.

733 Berner, Zeichen: 30f.; Braun, Ancien Régime: $292 \mathrm{f}$.

734 Trossbach/Zimmermann, Dorfes: $96 \mathrm{f}$. 
fer oder in einer anderen subsidiären kirchlichen Position vor, als den niedrigeren sozialen Rang eines Schulmeisters einzunehmen, wenngleich die im Schulwesen tätigen Geistlichen im Mittel stets deutlich besser besoldet wurden als ihre weltlichen Berufskollegen. ${ }^{735}$

In den meisten reformierten Landesteilen der Alten Eidgenossenschaft waren Geistliche im Rang eines studierten Theologen oder Pfarrers nur noch aushilfsweise oder auf freiwilliger Basis im Elementarschulwesen tätig. Der Pfarrhelfer Sigmund Stooss von Büren an der Aare BE notierte beispielhaft: „versihet diese Stelle seit dem 26. Nov. 1798. ist Candid: des Predigtamts seit 1783. und Helfer zu Büren seit 1787. da er in der Woche keine Amtsverrichtungen als Helfer hat, so hat er diese Schule gerne über sich genommen."736

Das Betätigungsfeld im Bildungswesen hatte sich in der Regel in die höheren Bildungseinrichtungen des städtischen Umfelds oder in den privaten Bildungssektor verlagert. In ländlichen Regionen betätigten sich reformierte Geistliche einzig an den städtisch finanzierten Deputatenschulen der Basler Landschaft systematisch als aktive Landschullehrer. ${ }^{737}$ Die finanziell lukrativen Deputatenschulen, deren Stellen bis kurz vor der Helvetischen Revolution zwingend Stadtbürgern vorbehalten waren, stellten für städtische Pfarramtskandidaten mit dem Gradum magistri eine attraktive Möglichkeit zur zeitlichen Überbrückung des Wartens auf eine Pfarrpfründe dar. Die Besoldungshöhe der Deputatenschulen lag zwar unter dem Gehalt eines Pfarrers und unter dem Einkommen der städtischen Schullehrer, fiel aber gegenüber den übrigen Landschulen deutlich überdurchschnittlich aus. ${ }^{738}$

In dieser regionalen Besonderheit nahm das Lehramt an einer Deputatenschule die Form eines zeitlich unbegrenzten Karrieremoratoriums für reformierte Geistliche an. Denn bis eine Pfarreipfründe durch das Ableben oder den Rücktritt des Vorgängers frei wurde, konnten viele Jahre vergehen, was besonders junge Geistliche dazu zwang, sich beruflichen Alternativstrategien zuzuwenden. ${ }^{739}$ Gleiches galt aber auch für städtische Lateinschulen in deutschen Territorien, wo studierte Theologen oft nur so lange arbeiteten, bis sie an eine besser bezahlte Pfarrstelle kamen. ${ }^{740}$ Dieses Moratorium ist dennoch keinesfalls als biografische Sackgasse zu verstehen, wenngleich es bei einzelnen Individuen durchaus den Charakter eines „Abstellgeleises“ annahm, indem die Kandidaten bisweilen Jahrzehnte als Lehrer auf eine Pfarrpfründe warteten. ${ }^{741}$ Spätere Berufungen an Pfarrstellen nach der Ausübung eines Lehramts waren aber dennoch möglich, wie das Beispiel des Lehrers Gysendörfer von Sissach BL exemplarisch illustriert, dem im übernächsten Kapitel noch Beachtung geschenkt wird. ${ }^{742}$

735 Brühwiler, Finanzierung: 85-87, 101-105.

736 Schmidt u.a. (Hgg.), Stapfer-Enquête, Nr. 757: Büren an der Aare.

737 Vgl. zu Basel: Vischer, Wandlungen: 44.

738 Brühwiler, Finanzierung: 105-113, 407-411.

739 So berichtete der damals 28-jährige Katechet Caspar Weiss zum Motiv seiner Schultätigkeit: „Er [...] beschäftigt sich daneben noch mit Information der Jugend in der Stadt, da das geringe Einkomen ihm noch einen andern Nahrungszweig nothwendig macht: u: Betrachtet überhaupt diese seine Stelle eher als eine Übung auf mehrere Geschäfte, als daß er dabey etwas mehr, als nur im kleinen nüzlich zu seyn sucht." Schmidt u.a. (Hgg.), StapferEnquête, Nr. 266: Unterstrass.

740 Enzelberger, Sozialgeschichte des Lehrerberufs: 24.

741 „Anno 1760. den 18.ten Decembr; durchs Loos als Schul Lehrer zu Buckten erwählt, folgl. bald 40. Jahre im Amte; War vorhin immer in seiner Vaterstadt, denen Studien gewiedmet, erhielte nach überstandenen genauen Prüfungen in öffentlicher Promotion 1760. im May, als dem dritten Academischen feyerlichen Jubeljahr der Universitaet Basel, den Magister Grad, Studirte Theologie." Schmidt u.a. (Hgg.), Stapfer-Enquête, Nr. 2226: Buckten.

742 StABL AA 1012, Lade 200, 07.02.01, o. Pag.: 18.07.1800 - Holzach. Vgl. zur Person des Lehrers Gysendörfer die Ausführungen im folgenden Kap. 2.4. 
Neben der Basler Landschaft traten reformierte Geistliche einzig noch im reformierten Teil des gemischtkonfessionellen Glarus in auffälliger Dichte als Landschullehrer auf. Hier, im ökonomisch schwachen voralpinen Gebiet der Vieh- und Weidewirtschaft, wo die lokale Armut und die Abgelegenheit einzelner Siedlungen die Errichtung einer flächendeckenden Beschulung verlangsamten, sprangen etliche Geistliche in die Bresche und unterrichteten selbst in den ihnen anvertrauten Landschulen. Zurückzuführen war diese Eigenheit einerseits auf den volksaufklärerisch verstärkten Selbstanspruch der Pfarrer als Tugend- und Volkslehrer, andererseits auf die ökonomische Notwendigkeit des benötigten Zusatzeinkommens, insbesondere für Pfarrhelfer. ${ }^{73}$ Daneben dürfte jedoch auch ein gewisser kleinräumiger Konkurrenzeffekt gegenüber der katholischen Minorität eine Rolle gespielt haben, zumal auch etliche katholische Geistliche im lokalen katholischen Elementarschulwesen tätig waren, was wiederum die reformierte Geistlichkeit zu einem verstärkten persönlichen Engagement bewegt haben dürfte.

Für die katholischen Geistlichen sind dagegen andere Vorzeichen zu setzen: Von einem allgemeinen Rückzug der Welt- und Ordensgeistlichen aus dem Elementarschulbereich kann um 1800 noch nicht die Rede sein. Vielmehr bildeten sie vielerorts nach wie vor das Rückgrat des regionalen Lehrerkorps, was vielfältige Auswirkungen auf die Schulwirklichkeit vor Ort bewirkte. In den katholisch geprägten Landesteilen der Helvetischen Republik hatte die vielerorts praktizierte Verbindung von Schul- und Kaplaneiamt zur Folge, dass sich studierte katholische Geistliche nicht nur in den städtischen Bildungseinrichtungen sammelten oder als private Hauslehrer agierten, sondern sich entgegen dem Habitus der reformierten geistlichen Lehrer breit in der Landschaft verteilten und Stellen des Elementarschulwesens übernahmen.

Der Grund für das verbreitet praktizierte Zusammenführen von Kaplanei- und Schuldienst lag in der Regel in den schwierigen ökonomischen Umständen vor Ort. So wuchs zwar in vielen Gemeinden das Verlangen nach einer eigenen Schule, doch aufgrund der knappen kommunalen finanziellen Ressourcen mussten die Geistlichen als Aufsichtsverantwortliche für das Bildungswesen in die Bresche springen und errichteten Kaplaneistiftungen zu schulischen Zwecken. Es kann daraus gefolgert werden, dass sich Kaplaneischulen vorwiegend in stark von Armut geplagten Gemeinden konstituierten, denn wo „die Mittel fehlten, durften Kapläne oder Mesner in den Riss treten und die Mittel dazu aus den Zehnten oder der Kirchenfabrik genommen werden." ${ }^{\text {744 }}$

Weil die Pflicht des Schulhaltens vielerorts von den Gemeinden vertraglich an den Kaplan als Helfer des lokalen Priesters übertragen wurde, war der Schuldienst für zahlreiche Kapläne keine aus freien Stücken ausgeführte Tätigkeit, sondern eine mehr oder minder als Belastung empfundene zusätzliche Pflicht, zumal das Einkommen der Kapläne manchmal nur mit dem zusätzlichen Schulverdienst eine ausreichende Besoldung ergab. ${ }^{75}$ Der Kaplan-Lehrer aus St. Niklausen OW beschrieb die Vor- und Nachteile der Zusammenlegung von Kaplaneidienst und Schuldienst folgendermassen: „Die Einwohner der Filiale hatten bisher das Recht einen Schulmeister zu bestellen, nach demokratischer Weise. Er heisst Niklaus Huber aus der dasigen Gemeine, 30 Jahr alt: hat keine Familie: ist ein Geistlicher und seit 2 Jahren Kaplan daselbst und Schullehrer zugleich, weil er bey Annahme der Pfründe zugleich auch die Schule der Kaplaney zu übernehmen sich verpflichtet hat. Vorher als lediger Priester hatte er den Beruf sich von den Verpfründeten Geistlichen der Pfarrey zu geistlichen Verrichtungen brauchen zu lassen. Nebst dem Lehramte hat er in seiner Filiale Seelsorger Pflichten, Predigen, Christenlehren. Wer sieht nicht, das tägliche 5 Stundenlange

743 Landolt, Linth: $57 \mathrm{f}$.

744 Sialm, Waldstätten: $17 \mathrm{f}$.

745 Vgl. Landolt, Linth: 58; Scherwey, Freiburg: 12-16, $20 \mathrm{ff}$. 
Schularbeiten mit Seelsorge verbunden zu lastend sey. Doch da lehrt der Seelsorger die Kinder kennen, kann sie in ihrem zarten Alter bilden, erziehen. Sie hingegen gewöhnen sich schon frühe an Jhn, gewinnen Jhn lieb, und werden in reiferen Jahren ein größeres Zutrauen, als gewöhnlich gegen Jhn nähren. Und in solcher Erwägung hab ich mir freywillig diese Last der Schule zur Seelsorge hinzulegen lassen; besonders da nach Verlauf 3 1/2 Monat alljährlich die Schule wegfällt: und für selbe hier keinen nur halb fähigen Mann zu haben wäre.“746

Andernorts sorgte der Mangel an geeigneten oder gewillten weltlichen Lehrern zur Übernahme des lokalen Schulwesens durch Kapläne. ${ }^{747}$ Die Kapläne konnten aber mitunter ihre Lehrpflicht wiederum an weltliche Lehrer delegieren, sofern die Gemeinde den Kandidaten akzeptierte. ${ }^{748}$ Die Gemeindeautonomie bei der Lehrerwahl blieb auch beim Typus der Kaplaneischulen in der Regel gewahrt, zumal auch die Kapläne der Wahl durch die Gemeinden oblagen. Das Engagement der Kapläne hatte somit weder einen obrigkeitlich verordneten Charakter, noch war es eine aus einer kirchenhierarchischen Machtstellung heraus entstandene Situation, sondern eine lokal abgestützte, bewusst gewählte Verbindung, bei der die Gemeinde die Entscheidungsgewalt über die Schule nach wie vor inne halten konnte.

Gänzlich frei von Opposition gestaltete sich das Engagement der Kapläne im katholischen Elementarschulwesen freilich nicht. An manchen Orten sahen sich etablierte weltliche Schulmeister im Gegensatz zu ihren reformierten Kollegen durch die schulischen Aktivitäten von Kaplänen in ihrer Aufgabe konkurriert und in ihrer Existenz bedroht. So merkte der weltliche Schulmeister von Bürglen UR in den Anmerkungen zum stapferschen Fragebogen mit spürbarem Ärger an: „über dies ist die schule verstümpelet $\mathrm{Da}$ Sie doch dem schul Meister alein gebührte, so haben dennoch alle Winter noch die Kapläne schul! also verliert der schullehrer die Edle zeit und gewint weder für Sich noch die Kinder einen Nutzen, weil er auch nur wenigen schule zu halten verbunden ist. ${ }^{\text {“79 }}$ In gewissen Konstellationen übte die Mitwirkung der Kapläne somit einen realen Konkurrenzeffekt auf die weltlichen Schullehrer aus, insbesondere wenn die Eltern aufgrund der freien Schulwahl den Schulbesuch bei einer nahe gelegenen Kaplaneischule bevorzugten und dadurch für den weltlichen Lehrer einen Teil der Einnahmen durch das Schulgeld wegbrach.

Der Konkurrenzdruck durch Geistliche im Lehramt wirkte aber in Bezug auf die Schulinhalte gleichzeitig als Motor und Katalysator von Innovationen. Eindeutig evident ist der positive Impetus von schulisch aktiven Geistlichen auf das lokale Bildungsangebot. In Elementarschulen mit studierten Theologen als Schulmeister wurde insgesamt ein breiteres Spektrum an Lehrmitteln verwendet und zusätzliche Fachgegenstände eingeführt. Im solothurnischen Bättwil lernten die Kinder beispielsweise dank ihres an der Universität von Fulda studierten Lehrers erweiterte Mathematikkenntnisse. ${ }^{750}$ In keiner anderen Landschule des Kantons Solothurn er-

746 Schmidt u.a. (Hgg.), Stapfer-Enquête, Nr. 2155: St. Niklausen.

747 „Schon seit sieben Jahren da ich als Geistlicher Von den Schulen aus Deütschland nach Hause kam, und als Pfarrvikar die Seelsorge hier übernahm. so wurde ich gebethen auch die Schule zu übernehmen weil gerade Niemand da war, dem sie konnte anvertraut werden." Schmidt u.a. (Hgg.), Stapfer-Enquête, Nr. 1641: Hergiswil.

748 „der dortige Kaplan hat schuldigkeit die schul zu halten, oder halten zu lassen. damit er aber als alleinigen Pfrundtherr dort - seiner beschwärlichen Pfrundt mit mehr Muse und Würde vorstehen könne, so bestellt er nach dem beyspiele seiner vorfahrer einen anderen Tauglichen Mann, der hernach von der gemeinde gutgeheissen wird.“ Schmidt u.a. (Hgg.), Stapfer-Enquête, Nr. 2055: Oberwilen, Stalden.

749 Schmidt u.a. (Hgg.), Stapfer-Enquête, Nr. 1939: Bürglen.

750 „Sie machen Rechnungen, sowohl ganzer als gebrochnen Zahlen, Verhältnißregeln Gesellschaftsregeln Progresionen Ausziehung der Quadratwurzel.“ Schmidt u.a. (Hgg.), Stapfer-Enquête, Nr. 2358: Bättwil. Aufgrund der bescheidenen Angaben in der Stapfer-Enquête bleibt unklar, ob der Lehrer Andreas Knittel sein Studium an der Universität von Fulda beendet hatte oder als ein Studienabbrecher anzusehen ist. 
reichte der Mathematikunterricht eine ähnliche inhaltliche Vertiefung wie an besagter Schule, was zweifellos auf die studentische Vergangenheit des Lehrers zurückzuführen ist.

Zu den Motiven für die rege Ausübung von Lehramtstätigkeiten durch die Kapläne abseits von übertragenen Pflichten ist anzunehmen, dass zahlreiche unverpfründete junge Geistliche aus Arbeitslosigkeit in das Lehramt drängten, da weitaus weniger freie Kaplanei- und Pfarreistellen zur Verfügung standen, als es studierte Kandidaten gab. Die Kaplaneistellen erfüllten damit im Sinne der zuvor genannten Klassifikation von Walz ebenso die implizite Funktion eines zeitlichen Biografie-Moratoriums für die katholischen Geistlichen auf dem Weg zur eigenen Priesterpfründe wie die Deputatenschulen in der reformierten Basler Landschaft. Als Hilfsfunktion war die Kaplaneipfründe in der biografischen Perspektive des Klerus denn auch nur eine Zwischenstation zur anvisierten besser besoldeten Priesterpfründe. Viele der Geistlichen übten den Schuldienst jedoch genauso wie ihre reformierten Kollegen aus freien Stücken und aus innerer Überzeugung aus, verstanden sie doch die schulische Tätigkeit als Dienst für die religiöse Unterweisung zum Heil der ihnen anvertrauten Seelen, für die sie sich verantwortlich fühlten. ${ }^{751}$ Katholische Geistliche - insbesondere Weltgeistliche im Rang eines Kaplans oder Priestervikars - nahmen vor allem in der Zentralschweiz eine wichtige Rolle als Landschullehrer ein. Allein im Kanton Waldstätten war rund die Hälfte aller Elementarlehrkräfte im Jahr 1799 von geistlichem Stande, davon die überwiegende Mehrzahl gleichzeitig zum Lehramt als Kapläne tätig. ${ }^{752}$ Für die Landschaft Schwyz resümierte Placidus Sialm allerdings: „Überall begegnet man ursprünglich Schulmeistern geistlichen Standes. Im Laufe der Zeit glitt dann da und dort das Amt in weltliche Hände. ${ }^{\text {“753 }}$ Anders präsentierte sich die Situation im ebenfalls mehrheitlich katholischen Kanton Fribourg. Sowohl im deutsch- als auch im französischsprachigen Kantonsteil des Kantons Fribourg waren im 18. Jahrhundert vielerorts bewusst Kaplaneischulen auf Verlangen der Bevölkerung entstanden, meist als Nebenschulen von bereits bestehenden Pfarreischulen. ${ }^{754}$

In den übrigen mehrheitlich katholischen Regionen der Helvetischen Republik - insbesondere Baden, Säntis, Solothurn und Wallis - traten Kaplan-Lehrer dagegen nur noch vereinzelt als Landschullehrer in Erscheinung. ${ }^{755}$ In den katholischen Schulen der ehemaligen Waadtländer Landvogtei Orbe und Echallens unterrichteten gar ausschliesslich nur noch weltliche Lehrer. Überall dort hatte der Säkularisierungsprozess analog der reformierten Territorien bereits weitgehend stattgefunden. Dadurch kann das System der zentralschweizerischen Kaplaneischulen nicht als ein „typisches“ Modell für die gesamte katholische Schweiz angesehen werden, sondern muss als eine regionsspezifische Ausprägung verstanden werden.

Nicht zu vergessen sind neben den Weltgeistlichen zudem die etlichen Ordensgeistlichen von unbekannter Anzahl, die primär in den verschiedenen Lateinschulen der grösseren Flecken und insbesondere in den noch aktiven Klosterschulen als Lehrkräfte gearbeitet hatten. ${ }^{756}$ In den katholischen Regionen engagierten sich überdies seit dem 17. Jahrhundert auch weibliche Ordensangehörige als Lehrerinnen, die am Ende des 18. Jahrhunderts gegenüber weltlichen Lehrerinnen eigenstän-

\footnotetext{
751 Vgl. Kälin, Aufklärung: $119 \mathrm{f}$.

752 Mindestens 46 von 100 Lehrkräften des Kantons Waldstätten waren Geistliche. Vgl. Durrer, Urkantonen: 19, 24; Kälin, Aufklärung: 118.

753 Sialm, Waldstätten: 19.

754 Dévaud, École primaire: 80; Scherwey, Freiburg: 16, 20-52.

755 Vgl. zu Baden: Müller, Bestandesaufnahme: 246; zum Wallis: Boucard, valaisanne: 41-45; zu Linth: Glaus, Kanton Linth: 123; Landolt, Linth: 57f.; zu Waldstätten: Sialm, Waldstätten: 108-109.

756 Sialm, Waldstätten: 16-20.
} 
dige Traditionslinien aufwiesen. ${ }^{757}$ Vorwiegend engagierten sich die Ordensschwestern der Ursulinen für die elementare Mädchenbildung, wodurch bis zum Ende des 18. Jahrhunderts zahlreiche Mädchenschulen in der katholischen Schweiz entstanden. ${ }^{758}$ Daneben hatten Kapuzinerinnen ein Mädchenpensionat in ihrem Kloster Maria Opferung in Zug gegründet, das später während der Periode der Helvetischen Republik in eine öffentliche Mädchenschule umfunktioniert wurde, in der die Normalmethode nach St. Urbaner Vorbild gelehrt wurde. ${ }^{759}$ Die Mädchenbildung war in den katholischen Regionen allerdings kein exklusives Privileg der Ordensschwestern, denn auch weltliche Lehrerinnen traten daneben vereinzelt in Erscheinung. Besonders im französischsprachigen Unterwallis überliefert die Stapfer-Enquête gleich drei weltliche Lehrerinnen, wovon zwei aus dem weiter entfernten Kanton Fribourg stammten und nebenher als Schneiderinnen gearbeitet hatten. ${ }^{760}$ Die Ordensschwestern waren aber im Gegensatz zu den weltlichen Lehrerinnen von einer Prüfung durch die Ortsgeistlichkeit befreit. Zudem standen ihre Bildungseinrichtungen in keiner Konkurrenz zu den übrigen Schulen, während weltliche Lehrerinnen sowohl in der Stadt als auch in den Dörfern ihr Berufsfeld mit ihren männlichen Kollegen teilen mussten. ${ }^{761}$

In Bezug auf die soziale Herkunft bestanden sowohl zwischen der Geistlichkeit beider Konfessionen als auch zwischen den Geistlichen und der weltlichen Elementarschullehrerschaft markante Unterschiede. Die reformierte Geistlichkeit unterschied sich aufgrund ihrer ständischsozialen Herkunft von der Landbevölkerung, da Landbewohner in der Regel vom Studium in den Städten ausgeschlossen waren und fast nur Stadtbürger überhaupt Zugang zum Studium an einer Hochschule hatten. ${ }^{762}$ Von wenigen Ausnahmen abgesehen, stammten denn auch fast alle der aktiv im Landschulwesen tätigen reformierten Geistlichen um 1799 aus dem städtischen Bürgertum. ${ }^{763}$ Landbürgern war es beispielsweise in der Zürcher Landschaft faktisch verwehrt, eine höhere Schule zu besuchen und sich zum Theologen weiter zu bilden. ${ }^{764}$ Selbst in ehemaligen Untertanengebieten wie Bern, wo das Pfarramt theoretisch zwar auch Landbürgern offenstand, fanden sich in der Praxis - mit Ausnahme der Waadt - ausschliesslich Stadtbürger in der Rolle des unterrichtenden Theologen. ${ }^{765}$

Katholische Geistliche rekrutierten sich dagegen - aufgrund des deutlich grösseren Personalbedarfs, da neben den eigentlichen predigenden Priestern meist auch Kirchenhilfsdienste von Kaplänen ausgeführt wurden - stärker lokal aus der Landbevölkerung. Die soziale Herkunft von katholischen Geistlichen präsentierte sich demnach heterogener und permeabler als bei re-

757 Crotti, Lehrerinnen: 62, 74 .

758 Crotti, Lehrerinnen: 71ff. Die Antwort der Mädchenschule von Estavayer-le-Lac VD ist allerdings das einzige erhaltene Zeugnis einer Ursulinen-Mädchenschule in der Stapfer-Enquête. Schmidt u.a. (Hgg.), Stapfer-Enquête, Nr. 226: Estavayer-le-Lac. Vgl. auch: Mayer, Mädchen: 188ff.

759 Bossard, Zug: 188f.; Schmidt u.a. (Hgg.), Stapfer-Enquête, Nr. 2135: Zug.

760 Schmidt u.a. (Hgg.), Stapfer-Enquête, Nr. 2167: Vex, La Vernaz.

761 Crotti, Lehrerinnen: 74.

762 Am Karolinum in Zürich und an der hohen Schule von Bern durften nur Stadtbürger aus dem Patriziat sowie aus der Bürgerschaft der Landstädte studieren. Gleiches galt für die im späten 18. Jahrhundert neuerrichteten Realund Kunstschulen, die dem „Überangebot“ an Theologen und dem Mangel an „nützlich-praktischem Wissen“ begegnen sollten. Berner, Zeichen: 21-31; Braun-Bucher, Hohen Schulen: 276; Ruloff, Schulbesuch: 19.

763 Nur fünf reformierte Geistliche entstammten nicht aus einer Stadt. Eine Ausnahme stellt beispielsweise der Lehrer Johann Heinrich Schweizer aus Oberhelfenschwil SG dar, der in Basel studiert hatte: Schmidt u.a. (Hgg.), StapferEnquête, Nr. 1189: Oberhelfenschwil, Wasserfluh.

764 Vgl. zu Zürich: Bloch Pfister, Priester: 81; Braun, Ancien Régime: 249.

765 Nach Rudolf Braun mussten die Berner Pfarrer keine Stadtbürger sein, wohingegen eine ebensolche zwingende städtische Herkunft von Peter Schibler bestätigt wird. Einzig in der bernischen Waadt mussten die Pfarrer zumindest nicht stadtbernischer Herkunft sein, wie Gilbert Marion festgehalten hat. Marion, Pfarrer (reformiert). Vgl. ferner: Braun, Ancien Régime: 251; Schibler, Schulalltag: 14. 
formierten Geistlichen, denn auch ärmeren Personen von ländlicher Herkunft stand theoretisch ein Werdegang als katholischer Geistlicher offen und ein sozialer Aufstieg über eine Priesterpfründe war grundsätzlich möglich. ${ }^{766}$ Dennoch rekrutierte sich auch die katholische Geistlichkeit aufgrund der hohen finanziellen Belastungen, die ein geistliches Studium und das Erlangen der höheren Würden nach sich zog, vorwiegend aus den ländlichen Oberschichten. ${ }^{767}$

Im Vergleich der Lebensverläufe ist trotz der unterschiedlichen sozialen Herkunft und Konfession eine Reihe von markanten Parallelen festzustellen. Die als Schulmänner tätigen studierten Theologen beider Konfessionen hatten in der Regel vor ihrem Theologieexamen als gemeinsamer biografischer Nenner eine Universität oder eine höhere Bildungsinstitution besucht, was eine gewisse Formalisierung, Standardisierung und Kanonisierung der Bildungsinhalte und Methoden ermöglichte. ${ }^{768}$ Diese höhere universitäre oder seminaristische Bildung, insbesondere das fortgeschrittene Beherrschen der Kulturtechniken sowie die religiös-katechetischen Inhalte, prädestinierte Universitätsabgehende als eigentliche Bildungsfachpersonen für das Schulhalten auf allen Stufen der frühneuzeitlichen Standesschule.

Innerhalb der kurzen Lebensphase der Ausbildung beziehungsweise des Studiums stach ferner das Arbeiten als Haus- oder Privatschullehrer als konfessionsübergreifende Gemeinsamkeit bei reformierten und katholischen Geistlichen heraus, denn mindestens jeder fünfte spätere geistliche Lehrer hatte bereits während seines Studiums erste Erfahrungen in der praktischen Unterrichtstätigkeit gesammelt, vorzugsweise als Hauslehrer in städtischen Bürgerfamilien oder als Privatschullehrer. ${ }^{79}$ Exemplarisch lässt sich dies bei der Antwort des reformierten Basler Stadtschullehrers Johann Jakob Leucht nachvollziehen: „Vorheriger Aufenthalt u. Beruf. Jch studierte auf der hiesigen Universität erst Humaniora, dann die Rechtsgelehrsamkeit widmete mich alsdann einige Jahre in Oberdießbach, Kant. Bern als Hauslehrer bey dem Bürger Haubtmann Johannes Bürki der Kindererziehung - und erst - nachdem ich nach meiner Rückkehr in meine Vaterstadt meine jetzige Lehrerstelle erhalten u. mich darauf verehlichet hatte - wählte ich noch das Studium der Theologie u. wurde auch im Mai. 1795. nach vorhergegangnen gewöhnlichen Prüfungen ordnungsmässig in das Ministerium der Kirche aufgenommen. Meine jetzige Verrichtungen neben dem Lehramte sind zum Theil die Kirchenverrichtungen der Religionslehrer - theils aber weil ich vom Ertrage des Amtes \{allein\} nicht leben kann, bin ich gezwungen von Morgens 7 Uhr biß Abends 8 Uhr Privatinformation zu geben." ${ }^{\text {“770 }}$

Die Betätigung als Hauslehrer während der kostspieligen Studienjahre war sicherlich vor allem für finanziell schlechter gestellte Studenten eine kollektive episodische Lebenserfahrung, musste aber keinesfalls ausschliesslich ökonomisch begründet sein. So könnte auch das Selbstverständnis als „geistiger Lehrer“ des Volkes die starke Neigung zur Unterrichtstätigkeit erklären. Es bleibt freilich eine offene Forschungsfrage, inwiefern das kollektive episodische Ausüben von Privat- und Hauslehrerdiensten ökonomisch motiviert war. Die Arbeit als privater Hauslehrer dauerte indes bei den meisten Geistlichen nur als kurze Episode während der Studienjahre oder zur Überbrückung von Phasen der Erwerbslosigkeit während des Wartens auf eine Pfrund. Diese Episode ist ferner auch bei vielen pädagogischen Persönlichkeiten und in zahlreichen Pfarrerbiografien nachvollziehbar. ${ }^{771}$

766 vgl. zur sozialen Herkunft von katholischen Geistlichen die Regionalstudie von Mauro Di Cioccio zur Luzerner Geistlichkeit: Di Cioccio, Barockfrömmigkeit: 57-62.

767 Hörsch/Bannwart, Weltklerus: 18; Ries, Klerus.

768 Der Besuch einer höheren Schule war keine zwingende Voraussetzung zum Antritt an das theologische Examen, denn man konnte sich auch privat bei einem Hauslehrer auf das Zulassungsexamen vorbereiten. Vgl. exemplarisch die Biografie des reformierten Pfarrers Johannes Büel: Noll, Hofrat: 11-20.

769 Bei mindestens 29 von 140 geistlichen Lehrern ist eine vorgängige Tätigkeit als Privat- oder Hauslehrer verbürgt.

770 Schmidt u.a. (Hgg.), Stapfer-Enquête, Nr. 2334: Basel.

771 Beispielhaft: Beier, Zeller, 238; Kreis, Erinnerungen: 95-102; Noll, Hofrat: 20-24. 
Gewiss gab es sie auch, die gescheiterten Berufskarrieren angehender Theologen, wie sie Ursula Walz einleitend beschrieben hat. Als Erkennungsmerkmal für gescheiterte Theologiekarrieren wird ein bewusst beschriebener äusserer Stimulus angenommen, der den ursprünglichen Lebensverlauf in den Augen der betroffenen Person entscheidend und zwangsweise verändert hat. Aus der Stadt Zürich sind uns zwei Beispiele in der Stapfer-Enquête überliefert - etwa der Lebensverlauf von Hans Jakob Kesselring, dessen Studienzeit aufgrund von persönlichen Konflikten ein unfreiwilliges Ende nahm. ${ }^{772}$ Sein Berufskollege an der gleichen Schule war hingegen aus gesundheitlichen Gründen vom Studium verwiesen worden. ${ }^{73}$ Studienabbrecher und „gescheiterte" ehemalige Geistliche als Beispiele von diskontinuierlichen Lebensverläufen im Sinne der Typologie von Walz finden sich zwar auf beiden Seiten der konfessionellen Trennlinie, allerdings in quantitativ sehr bescheidenen Ausmassen. ${ }^{774}$ Sie gehörten damit zu den berufsbiografischen Randphänomenen der Geistlichkeit.

Obwohl die geistlichen Lehrkräfte in einem langsamen Ausdifferenzierungs- und Aushandlungsprozess der kommunalen Emanzipation gesamthelvetisch bereits weitgehend durch weltliche Elementarschullehrer abgelöst worden waren, standen bei beiden Konfessionsgruppen am Ende des 18. Jahrhunderts immer noch vereinzelt Geistliche im aktiven Elementarschuldienst. Die enge Verbindung von Kirche und Schule löste sich zwar im 19. Jahrhundert endgültig, wies jedoch allenthalben in einzelnen Gegenden eine beeindruckende Persistenz auf, insbesondere im Wallis. Im Oberwallis standen um 1828 immer noch zahlreiche Priester den Elementarschulen vor, im Lötschental blieb beispielsweise der Elementarschulunterricht noch bis weit über die Mitte des 19. Jahrhunderts vollständig die Aufgabe des Klerus. ${ }^{775}$

\subsection{Die geografische Herkunft}

Kollektivbiografisch zuverlässig erforscht werden kann die Frage nach der räumlichen Herkunft der Lehrkräfte. Die Stapfer-Enquête liefert hierzu umfassende Erkenntnisse, da sie die geografische Herkunft aller Lehrkräfte mit der Frage III.11.c „Wo ist er her“ festhielt. ${ }^{776}$ Daraus kann im Vergleich zum Schulort abgeleitet werden, ob die Lehrkraft grundsätzlich ortsansässig oder ob sie von ortsfremder Herkunft war. In den bisherigen kantonal fokussierten Arbeiten zum frühneuzeitlichen Schulwesen der Schweiz ist auf dieser Basis summarisch mehrheitlich die Ortsansässigkeit der Lehrkräfte als Norm festgehalten worden. Für den Kanton Zürich hat Wilibald Klinke in Bezug auf die geografische Herkunft der Zürcher Lehrerschaft sinnbildlich für die meisten kantonalen Untersuchungen resümiert: „Mit wenigen Ausnahmen waren die Lehrer Ortsbürger. Dies erklärt sich namentlich aus der Abneigung der Gemeindebürger gegen die von jeder politischen Gleichberechtigung ausgeschlossenen ,Hintersässen` oder ,Beisässen’, d.h. der nicht am Orte verbürgerten Niedergelassenen."

772 „Bin sint 1776. schulmstr. Sollte studieren, kam bis in Claßem Philol: da gefiel es einem Schul Oligarchen, meiner Kürze und andern seinen ausreden halben, mich nicht ausstudieren zulaßen. Von da an ware mehr als 20. Jahr Haus Jnformator." Schmidt u.a. (Hgg.), Stapfer-Enquête, Nr. 258: Zürich.

773 „Er war immer in seiner Vaterstadt. - Er war willens, ad Cathedral zu studieren - Krankheiten hinderten ihn an den Studien aufs Merkbarste. Erhielt als Studiosus in Collegio Humanitatis das Consilium abeundi - Bis daß er Schullehrer geworden, gab er sich mit Privatinformationen ab.“ Schmidt u.a. (Hgg.), Stapfer-Enquête, Nr. 257: Zürich.

774 Bei rund 11 der insgesamt 140 Geistlichen aus der Stapfer-Enquête konnte ein Studienabbruch bestätigt oder zumindest vermutet werden.

775 Boucard, valaisanne: 40; Gruntz-Stoll/Steiner, Tafeln: 49.

776 Vgl. Anhang I. Interpretatorisch bot die offene Fragestellung bei der Beantwortung einigen Spielraum, zumal nicht alle Lehrkräfte unter der Frage die Angabe des (vermutlich von Stapfer beabsichtigten) Ortsburgerrechts verstanden. Manche Beantwortungen bezogen sich denn auch auf den aktuellen Wohnort der Lehrkraft und nicht auf den Heimatort.

777 Klinke, Zürich: $109 f$. 
In ähnlicher Weise äusserte sich auch Ernst Schneider für die bernische Lehrerschaft: Die Gemeinden wollten keine eventuell später unterstützungsbedürftigen Fremden ins Dorf holen und ferner konnten ortseigene Kandidaten bereits auf soziale Netzwerke und Klientelsysteme zugreifen, was vielfach in der Besoldungsfrage für den Schulmeister von Vorteil sein konnte. ${ }^{778} \mathrm{Zu}$ dem war vielerorts - sofern noch nicht durch Einschläge privatisiert - der Zugang zur Allmend und zu allfälligen Armenfürsorgeleistungen exklusiv auf die Ortsburger eingeschränkt gewesen, ein Wegzug aus der Burgergemeinde bedeutete somit den Verlust dieser Ressourcenzugänge für sich und seine Nachkommen. ${ }^{779}$ Aus diesen Gründen hätten die Gemeinden ihre Schulmeister wenn immer möglich aus ihrer Bevölkerung rekrutiert und auf Nichtburger, so genannte „Hintersassen “, wenn immer möglich verzichtet. ${ }^{780}$

Allerdings ist eine Trennung von Ortsbürgern mit Burgerrecht und „Hintersassen“ methodisch schwierig und auf der Basis der Stapfer-Enquête gar unmöglich, da die Fragestellung des stapferschen Fragebogens das Burgerrecht nicht explizit hervorhob. Ortsansässigkeit von Geburt an bedeutete somit keineswegs das Innehaben des Burgerrechts des jeweiligen Ortes. Hintersassen sind also nur dort identifizierbar, wo sie eindeutig aus einer anderen Gemeinde stammten. Es dürfte aber eine wesentliche Dunkelziffer von nicht erkennbaren Hintersassen gegeben haben. In der empirischen Gesamtbetrachtung der Antworten auf die Frage III.11.c rekrutierte sich die Mehrheit der helvetischen Lehrkräfte mit rund 73\% zwar durchaus lokal aus ihrer Schulgemeinde, doch entstammte eine grosse Minderheit von mindestens 23\% aus einer anderen Gemeinde innerhalb des gleichen Kantons in den Grenzen von 1799 und war damit ein „Hintersasse“ mit eingeschränkten Rechten. Dass Hintersassen aus dem eigenen obrigkeitlichen Territorium zum Lehrer ernannt wurden, war also durchaus relativ häufig der Fall, zumal Hintersassen je nach Region eine bedeutende Minderheit vor Ort darstellten. ${ }^{781}$

Ausserkantonale Lehrer machten dagegen mit weniger als fünf Prozent insgesamt bloss einen verschwindend kleinen Teil des Kollektivs aus. Ihre Präsenz war in allen Regionen der Helvetischen Republik um 1799 gleichermassen eine deutliche Ausnahmeerscheinung. Das galt erst recht für Ausländer, insbesondere Glaubensflüchtlinge, die auf gesamthelvetischer Ebene im Elementarschulwesen praktisch inexistent waren. Nur gerade 29 Schullehrer von ausländischer Herkunft konnten aus der Stapfer-Enquête zweifelsfrei identifiziert werden, was einen Anteil von bloss $1.3 \%$ am gesamthelvetischen Lehrerkorps ausmachte. ${ }^{782}$ Einzig in der ehemals bernischen Waadt existierte mit der „Corporation Française“ in Lausanne eine grössere Kolonie an ausländischen Bürgern, einschliesslich von neu bekehrten „Proselyten“, wovon einige wenige als Landschullehrer in der Landschaft arbeiteten. ${ }^{783}$ Zudem waren eine Handvoll Waadtländer Lehrer aus dem angrenzenden Val de Travers des Fürstentums Neuchâtel gebürtig. ${ }^{784}$ Trotzdem betrug der Gesamtanteil an ausländischen Lehrkräften auch in der Waadt nicht über 1\%. ${ }^{785}$

778 Schneider, bernische Landschule: 83ff. Schneider bezog sich räumlich auf die Lehrerschaft in den Grenzen des Kantons Bern um 1900, also inklusive des Berner Oberlands.

779 Schmidt, Handlungsstrategien: 243ff.

780 Vgl. zur Begriffsdefinition und den gemeinsamen Merkmalen von Hintersassen die Ausführungen bei: Dubler, Hintersässe: 143 .

781 Vgl. zur räumlichen Verteilung der Hintersassen die Ausführungen im Kap. 3.5.

782 Inklusive einer Herkunft aus dem preussischen Fürstentum Neuchâtel, Genf oder Graubünden.

783 Als „Proselyten“ identifizierte Georges Panchaud den Leiter des Collèges von Moudon mit Namen Lanjuinais. Panchaud, écoles vaudoises: 257; Schmidt u.a. (Hgg.), Stapfer-Enquête, Nr. 1703: Moudon.

784 Schmidt u.a. (Hgg.), Stapfer-Enquête, Nr. 1501: Chamblon; Nr. 1507: Essert-sous-Champvent ; Nr. 1552: Orbe, Nr. 2236: Marchissy.

785 Panchaud, écoles vaudoises: 259. 
Andernorts konnten keine nennenswerten Konzentrationen an Ausländern im helvetischen Schuldienst ausgemacht werden. Zwar wiesen insbesondere die Grenzkantone hin und wieder einzelne Lehrer aus dem ausländischen Umland auf, doch war die internationale Mobilität der Lehrkräfte sehr gering. So arbeiteten etwa im Unterwallis vier Lehrer aus den benachbarten italienischen Tälern, ${ }^{786}$ eine Handvoll Lehrer stammte aus der Markgrafschaft Baden sowie aus dem Herzogtum Württemberg und arbeitete verstreut in den Kantonen Basel, Bern und Baden. Einzelne Lehrkräfte entstammten ferner aus Vorderösterreich, ${ }^{787}$ Konstanz,${ }^{788}$ Graubünden, ${ }^{789}$ der Freigrafschaft Franche-Comte ${ }^{790}$ und aus Genf. ${ }^{791}$ Die pauschale Kategorisierung dieser ausländischen Lehrkräfte als Flüchtlinge, wie es Georges Panchaud vorgenommen hat, entspricht allerdings kaum der historischen Realität. Ihre Anwesenheit in der Helvetischen Republik ist mutmasslich vielmehr auf freiwillige individuelle Wanderungsbewegungen aus ökonomischen Gründen zurückzuführen. Genauso wie einzelne eidgenössische Lehrkräfte ihr Glück zeitweise oder dauerhaft im umliegenden Ausland suchten, fanden sich diese wenigen ausländischen Lehrpersonen auf dem Gebiet der Helvetischen Republik wieder. Sie stammten aus allen Altersschichten und kamen aus den verschiedensten Ersttätigkeiten ohne signifikante gemeinsame Merkmale.

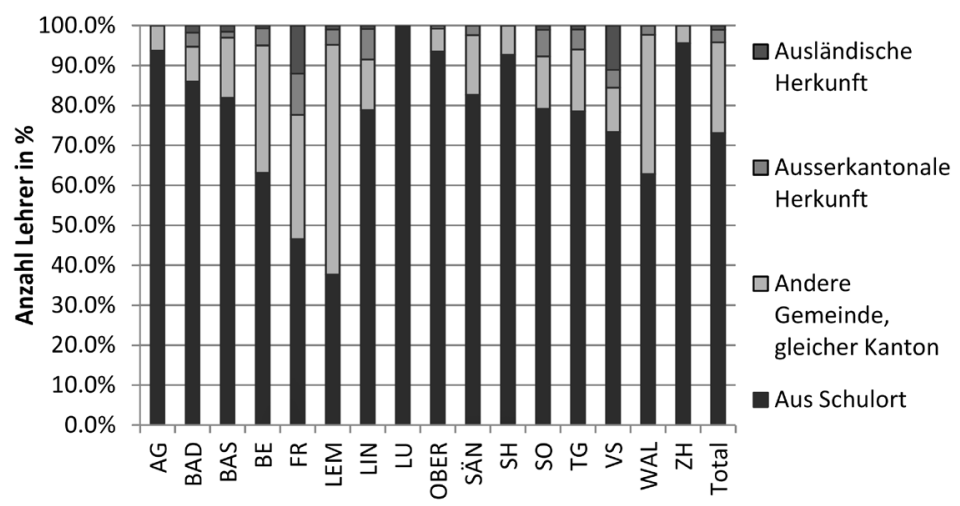

Abb. 7: Geografische Herkunft der Lehrer 1799

Zwischen den einzelnen Regionen - selbst innerhalb der ehemaligen Untertanengebiete bestanden jedoch beträchtliche Unterschiede hinsichtlich der geografischen Herkunft beziehungsweise der Lokalrekrutierung der Lehrerschaft. Am deutlichsten manifestiert sich die Abweichung der geografischen Herkunft vom Schulort in der frankophonen Waadt. Georges Panchaud hat als erster Schweizer Schulhistoriker überhaupt die geografische Herkunft einer gesamten kantonalen Lehrerschaft vor 1800 systematisch quantitativ untersucht und festgestellt, dass - im eklatanten Gegensatz zu den deutschschweizerischen Ergebnissen und trotz der normativen Vorgabe der bernischen Landschulordnung - bloss eine Minderheit der waadtländischen Lehrkräfte „de l'endroit“, also aus dem Schulort selbst stammte. Die Mehrheit kam da-

786 Vgl. Boucard, valaisanne: 75 .

787 Schmidt u.a. (Hgg.), Stapfer-Enquête, Nr. 512: Alt St. Johann.

788 Schmidt u.a. (Hgg.), Stapfer-Enquête, Nr. 677: Frauenfeld.

789 Schmidt u.a. (Hgg.), Stapfer-Enquête, Nr. 606: Grabser Berg.

790 Schmidt u.a. (Hgg.), Stapfer-Enquête, Nr. 2531: Neirivue.

791 Schmidt u.a. (Hgg.), Stapfer-Enquête, Nr. 1950: Rolle. 
gegen aus anderen Teilen des gleichen Distrikts oder sogar aus anderen Distrikten des Kantons, kaum aber aus anderen Teilen der Schweiz. In den Landschulen der bernischen Waadt waren somit um 1800 weit mehr als die Hälfte aller Lehrkräfte, insgesamt mindestens 59\%, ausserhalb ihres Schulorts oder als Hintersassen geboren. ${ }^{792}$

Anteile von mindestens $20 \%$ an ortsfremden Lehrkräften wiesen in der empirischen Prüfung der Herkunftsangaben ferner die Lehrerkorps der helvetischen Kantone Waldstätten (34\%), Thurgau (22\%), Linth und Solothurn (je 21\%) auf. In den übrigen Kantonen lagen die Anteile an ortsfremden Lehrkräften dagegen deutlich unter einem Sechstel des jeweiligen kantonalen Lehrerkollektivs. ${ }^{793}$ Erklärungsansätze für die Heterogenität der Rekrutierungspraxis gestalten sich freilich vielschichtig und müssen regional differenziert werden.

Konfessionelle Prägungen des Schulwesens spielten hierbei eine strukturell bestimmende Rolle: so lässt sich der hohe Anteil an ortsfremden Lehrern in den mehrheitlich katholischen Gegenden der Zentral- und Ostschweiz beziehungsweise der Kantone Waldstätten und Linth weitgehend auf die Präsenz der hochmobilen geistlichen Kaplan-Lehrer rückführen. Zwischen den beiden frankophonen Kantonen Fribourg und Waadt bestanden dagegen trotz der gemeinsamen Sprache aufgrund der konfessionellen Grenzen praktisch keine personellen Austauschbewegungen von Lehrkräften. ${ }^{794}$ Im Kanton Solothurn beschränkten sich die ortsfremden Lehrkräfte räumlich fast ausschliesslich auf die unter bernischem Kirchenrecht stehenden Schulen des reformierten Distrikts Bucheggberg im Südwesten des Kantons, wobei die auswärtigen Lehrkräfte grösstenteils aus dem angrenzenden ehemaligen bernischen Untertanengebiet stammten. ${ }^{795}$ Die Vermutung liegt nahe, dass die ebenfalls aus dem Bernbiet stammenden Ortspfarrer im Distrikt Bucheggberg favorisiert Lehrpersonen aus ihren eigenen konfessionellen Herkunftsgemeinden rekrutierten oder zumindest die Rekrutierung über ihre bernischen Informationsnetzwerke laufen liessen.

Anderswo zeichneten sich jedoch regionale Eigenheiten der Schulorganisation verantwortlich für die Herkunftsdifferenzen. Im südlichen Teil des katholischen Kantons Fribourg und in Teilen der angrenzenden reformierten Waadt waren neben vereinzelten Geistlichen zahlreiche „Wanderlehrer" tätig, die während der Woche reihum in mehreren Gemeinden gleichzeitig unterrichteten. ${ }^{796}$ Die Kommunen nutzten dadurch - ganz im Gegensatz zu den gemischtkonfessionellen Gemeinden der Ostschweiz - bewusst Synergien, etwa bei geringen eigenen Kinderzahlen oder durch das Teilen der Kosten für die Lehrerbesoldung. In der reformierten Basler Landschaft wiederum stammten dagegen fast alle ortsfremden Lehrer aus der Stadt Basel und

792 „Etre de l'endroit peut aujourd'hui encore fait pencher la balance en faveur d'un candidat, mais cet élément ne joue qu'un rôle très secondaire. Peu de régents sont bourgeois de la commune où ils enseignent." Panchaud, écoles vaudoises: 258f. Georges Panchaud hat bei einem etwas kleineren Total von 397 statt 414 Lehrkräften eine Auswärtigen-Anzahl von 59\% berechnet. Die eigenen Berechnungen ergaben eine Anzahl von 62\% an nicht aus dem Schulort stammenden Lehrkräften zum Zeitpunkt der Umfrage.

793 Nicht repräsentativ sind die Werte der helvetischen Kantone Fribourg, Luzern und Wallis, da allesamt bedeutende Teile des Lehrerkollektivs nicht erfasst wurden. Vgl. die Ausführungen im Kap. 1.5.2.

794 Auf Fribourger Territorium waren einzig die beiden reformierten Lehrer der Städtchen Cudrefin VD und Avenches VD - beide Orte waren Teil der ehemaligen bernischen Landvogtei Avenches und erst 1798 mit der Vogtei Payerne zum Kanton Fribourg zugeschlagen worden - um 1799 von waadtländischer Herkunft. In der Waadt unterrichteten zum gleichen Zeitpunkt keine Lehrkräfte aus dem Kanton Fribourg.

795 Sieben der insgesamt siebzehn Lehrkräfte des reformierten Distrikts Bucheggberg stammten ursprünglich aus dem Berner Untertanenland, vier weitere hatten innerhalb des Distrikts an eine andere Schule gewechselt. Vgl. die Herkunftsangaben der Lehrkräfte in der Übersichtstabelle: B0 1000/1483, Nr. 1460, o. Pag.: [20.02.1799] - Bucheggberg.

796 Beispielhaft sei auf die Wanderlehrer der Kirchgemeinden Autigny FR, Farvagny FR und Estavayer-le-Gibloux FR verwiesen, die an mindestens vier unterschiedlichen Orten im Turnus unter der Woche unterrichtet hatten. Vgl. Brühwiler, Schwache Schulen: 120. 
unterrichteten an so genannten Deputatenschulen, da die Besetzung der Deputatenschulen bis kurz vor der Helvetischen Revolution ein exklusives Privileg für Stadtbürger der Stadt Basel war. $^{797}$

Neben der artikulierten grundsätzlichen Abneigung gegen Ortsfremde muss die Hauptursache für die hohe Lokalrekrutierung der helvetischen Lehrkräfte allerdings auch in den normativen Grundsätzen, den Landschulordnungen, gesucht werden. Die erneuerte Ordnung für die Schulen der Landschaft Zürich von 1778 hielt eine grundsätzliche Präferenz von lokalen Kandidaten bei der Rekrutierung fest, indem fähigen lokalen Kandidaten bei der Wahl den Vorzug gegeben werden und erst bei Mangel an geeigneten Kandidaten auf auswärtige Kandidaten zurückgegriffen werden sollte. ${ }^{798}$ Die Praxis der obrigkeitlich verordneten Lokalpräferenz wirkte sich in der Zürcher Landschaft frappant auf die Herkunft der Lehrkräfte aus. Tatsächlich entstammte kein einziger Lehrer einer Zürcher Elementarschule im Jahr 1799 aus einem anderen eidgenössischen Kanton oder aus dem Ausland. Bloss 4.5\% der Zürcher Lehrkräfte hatten in der Stapfer-Enquête einen anderen Herkunftsort als den damaligen Schulort zum Zeitpunkt der Umfrage genannt, alle entstammten sie jedoch aus dem ehemaligen Zürcher Herrschaftsbereich. ${ }^{799}$

In der bernischen Landschulordnung 1759, gültig für die Berner Landschaft, das Oberland, den Aargau und die Waadt bis zum Ende des Ancien Régimes, war die ebenfalls enthaltene Lokalpräferenz dagegen abgeschwächt formuliert. ${ }^{800}$ In der empirischen Überprüfung trat die Präferenz von ortsansässigen Kandidaten für das Schulmeisteramt nur noch in den beiden ehemaligen Untertanengebieten des Aargaus und des Berner Oberlands in markanter Weise in Erscheinung, obwohl sie in einzelnen Antworten auf die Stapfer-Enquête nach wie vor explizit erwähnt wurde. Beispielsweise in der Gemeinde Niederbipp BE, wo der Schulmeister zum Wahlverfahren notierte: „Ein jeweiliger Amtsman, und die Chorrichter in der Gemeine, haben die Schulmeister durch ein Examen auf die prob gesezt, und dann der tüchtigst erfunden erwehlt; jedoch so: daß ein einheimischer vor einem Fremden der vorzug gehabt hate. ${ }^{\text {“801 }}$

So erweist sich die zuvor von Ernst Schneider festgehaltene Feststellung einer vorwiegend lokal rekrutierten Lehrerschaft zumindest für die Berner Lehrerschaft in den Grenzen des Kantons Bern von 1799 in der empirischen Überprüfung als nur bedingt zutreffend. Eine beträchtliche Minderheit von mindestens 37\% der Berner Lehrer entstammte im Jahr 1799 nicht aus dem Schulort, an dem sie 1799 unterrichtet hatte. ${ }^{802}$ Hauptgrund aus der Sicht der Lehrer dürfte das gleichrangige Einkommen gegenüber Ortsansässigen gewesen sein. Auf der Basis der Lohnberechnungen von Ernst Schneider, die im folgenden Kapitel 3.1.1 erläutert werden, schnitten die Lehrerlöhne von Ortsfremden gegenüber bereits Ortsansässigen sogar leicht besser ab. Fast jeder zweite Ortsfremde im helvetischen Kanton Bern stand einer Schule vor, die einen Mindestlohn von rund 100 Franken pro Jahr bezahlte, während diese Tatsache bloss auf 33\% der Einheimi-

797 Vgl. zum Schultyp der Deputatenschulen die Ausführungen im Kap. 2.4.3.

798 Erneuerte Schul- und Lehr-Ordnung für die Schulen der Landschaft Zürich 1778: $6 f$.

799 Ohne die von Zürich verwalteten Gemeinen Herrschaften des Thurgaus und des Rheintals.

800 „Deswegen auch (obwohlen ein Einheimischer, so sehr er die erforderliche Tüchtigkeit hat, billich einem Fremden vorzuziehen) und des Schulmeisters Erwählung nicht bloss und allein auf das Heymath, Herkommen und Freundschafft, sondern vornehmlich und allein auf die Tüchtigkeit zu sehen." Erneuerte Schul-Ordnung für der Stadt Bern Deutsche Landschaft [1759]: 6. Die bernische Schulordnung war ab 1676 auch für die französischsprachigen Landschulen der Waadt gültig. Vgl. Panchaud, écoles vaudoises: 36.

801 Schmidt u.a. (Hgg.), Stapfer-Enquête, Nr. 953: Niederbipp.

802 Mindestens 111 der 301 Berner Lehrer wiesen eine vom Schulort abweichende Herkunft aus. 
schen zutraf. ${ }^{803}$ Ein Ortsfremder zu sein schien um 1799 im Bernbiet an negativer Bedeutung verloren zu haben - sowohl für die betroffenen Lehrer als auch für die rekrutierenden Gemeinden. Die normative Überordnung von Leistung gegenüber der Herkunft sowie eine Gleichbehandlung von Ortsfremden und Ortsansässigen in Besoldungsfragen trugen hierzu bei.

Nicht zu vernachlässigen ist ferner der Umstand, dass mitunter ortsfremde Lehrkräfte auch eingebürgert wurden und so von rechtlich benachteiligten Hintersassen zu vollberechtigten Ortsburgern aufsteigen konnten. Zahlreiche Lehrkräfte aus fremden Orten waren im Verlaufe ihres Lebens nach eigenen Angaben im neuen Arbeitsort „naturalisiert“ beziehungsweise in die Dorfgemeinde eingebürgert worden, so wie der Lehrer von Oberschneit ZH zu seiner Herkunft berichtete, er sei: „von Seützach bei Winterthur, Jez aber bürg[er] daselbst.“ ${ }^{804}$ Die praktizierten Einbürgerungen von Lehrern als Hintersassen erstaunen angesichts der zunehmend restriktiven Einbürgerungspolitik vieler Kommunen gegenüber den ärmeren Hintersassen. Offensichtlich hielten es etliche Gemeinden aber für angebracht, die ortsfremden Schulmeister einzubürgern und sie so rechtlich besser zu stellen. Oder aber es gelang den Schulmeistern selbst, sich in das Bürgerrecht einzukaufen, wie der Lehrer von Robank ZH zu seiner Herkunft festhielt: „Jn seiner Jugend zu Hermatschweil; Einkäufer hier seit 11 Jahren.“ ${ }^{\text {“805 }}$

Diese mehrfach geschilderten Vorgänge von Einbürgerungen sind somit als Indizien für eine angesehene beziehungsweise aufgewertete soziale Position und für einen ausreichenden ökonomischen Wohlstand der betroffenen Lehrkraft zu deuten, zumal armen Hintersassen eine Einbürgerung in den Wohngemeinden in der Regel verwehrt blieb. Selbst ausländische Lehrkräfte wurden bisweilen in Einzelfällen eingebürgert, wie der Fall des Lehrers von Chailly VD zeigt: "Jl est natif de Chernex en la Commune du Chatellard, mais Bourgois de la Commune de Bussigni distric d'Oron Originaire Français \& naturalisé Helvétien“806

Zuletzt schränkten die noch kaum vorhandenen Kommunikationskanäle und Kommunikationsmedien zur Distribution von freien Schulstellen den Kandidatenkreis räumlich ein, weshalb die meisten ortsfremden Lehrkräfte aus der näheren Umgebung stammten. Versteckt hinter der statisch anmutenden geografischen Herkunft der Lehrkräfte stehen aber auch vielfältige Mobilitätsprozesse, denen Beachtung geschenkt werden muss. Eine Übereinstimmung der geografischen Herkunft mit dem Schulort bedeutet keineswegs, dass die Lehrperson in ihrer Berufsbiografie immobil gewesen wäre, wenn sie wieder an ihren ursprünglichen Herkunftsort zurückgekehrt ist. Diese Mobilitätsformen und ihre Motive werden später unter dem Blick der Berufsausgestaltung gesondert betrachtet. ${ }^{807}$

\subsection{Das Kandidaten-Examen}

Frei gewordene oder neu geschaffene Lehrerstellen wurden im Ancien Régime in der Regel öffentlich durch die Pfarrer während der Sonntagsmesse an die Lokalbevölkerung verkündet. So konnte sich jeder, der sich das Amt zutraute und sich für tauglich befand, dafür bewerben.

803 Zum Mindestlohn und zu den Lohnberechnungen von Schneider vgl. das folgende Kap. 3.1.1. Von den 111 ortsfremden Lehrkräften des helvetischen Kantons Bern erreichten mindestens 46 den Mindestlohn von 100 Franken (41\%). Demgegenüber hatten unter den einheimischen 190 Lehrern bloss weitere 62 Personen den Mindestlohn erreicht (33\%).

804 Schmidt u.a. (Hgg.), Stapfer-Enquête, Nr. 279: Oberschneit.

805 Schmidt u.a. (Hgg.), Stapfer-Enquête, Nr. 567: Robank, Heusberg, Sack.

806 Schmidt u.a. (Hgg.), Stapfer-Enquête, Nr. 1774: Chailly. Mindestens ein weiterer Lehrer von ausländischer Herkunft, der Lehrer im Städtchen Kaiserstuhl AG, bestätigte seine Einbürgerung: Schmidt u.a. (Hgg.), Stapfer-Enquête, Nr. 2286: Kaiserstuhl.

807 Vgl. das Kap. 3.5. 
Vor der Wahl wurden die Kandidaten, sofern mehrere die Stelle begehrten, einer Prüfung unterzogen. Auf dem Gebiet der Alten Eidgenossenschaft gehörte das Prüfen von Kandidaten und die Berücksichtigung der individuellen Fähigkeiten bei der Neubestellung von vakanten Schulstellen am Ende des 18. Jahrhunderts zum verbreiteten, wenn auch noch nicht flächendeckenden Standard, zumal die Schulordnungen der meisten grossen Territorialstände eine vorgängige Prüfung der Kandidaten verpflichtend vorschrieben. Besonders in den flächengrossen reformierten Kantonen Zürich, Basel und Bern waren Lehrerexamen durch die obrigkeitlichen Schulordnungen als normative Pflicht festgeschrieben worden. ${ }^{808}$

In der Stapfer-Enquête beschrieben die meisten Lehrkräfte mehr oder weniger detaillierte Selektionsprozesse im Vorfeld ihres Stellenantritts. Selbst die ältesten Lehrkräfte um 1799 mit der längsten Schulausübungsdauer hatten in der Regel bei ihrem Stellenantritt ein Examen durchlaufen, womit eine systematische leistungsbezogene Rekrutierung der Schullehrer auf mindestens die zweite Hälfte des 18. Jahrhunderts rückdatiert werden kann und somit nicht als eine Errungenschaft der Helvetischen Revolution anzusehen ist. Beispielhaft berichtete der siebzigjährige Lehrer Bendicht Hofer von Heimiswil BE in der Stapfer-Enquête über seine Ernennung: „Der Schullehrer werd. nach Vorgegangener Prüffung, auf Empfehlung des Pfarrers und gutheißen der Vorgesetzten, Von dem Amtmann erwählt. ${ }^{\text {“809 }}$

Mindestens ein Drittel aller weltlichen Lehrkräfte absolvierte vor der Wahl zum Schulmeister ein leistungsbezogenes Examen, was unter anderem auch für viele Lehrersöhne galt, die trotz ihres Wissensvorsprungs dennoch ihre Fähigkeiten ebenso unter Beweis stellen mussten wie alle übrigen Kandidaten. ${ }^{810}$ In der ehemals bernischen Waadt erwähnten sogar mindestens $79 \%$ der Lehrer im Jahr 1799 ein Examen als vorgängige Zulassung, in Zürich, Basel und dem ehemals bernischen Aargau waren es des Weiteren mindestens rund 60\% der Lehrer, die eine vorgängige Prüfung notierten. ${ }^{811}$ Zuständig für die Prüfung der Kandidaten waren im Ancien Régime in der Regel die Pfarrer, oftmals unter Beisitz der lokalen Dorfvorsteher oder des lokalen kirchlichen Chorgerichts. Allerdings existierte eine Fülle an lokalen und regionalen Variationen hinsichtlich der Lehrerwahl: Im Stand Zürich mussten die meisten Kandidaten vor dem kirchlich-weltlich paritätischen obrigkeitlichen Examinatorenkonvent eine Prüfung ablegen und von selbigem gewählt werden. ${ }^{812}$ Andernorts, in Solothurn, Bern, Aargau und in der Waadt, beschränkten sich staatliche Amtsträger - Amtmänner und Landvögte - auf die reine Bestätigung der Empfehlungen der prüfenden Pfarrer. In den beiden reformierten Städten Schaffhausen und Basel entschied dagegen das Los über die zur Auswahl vorgeschlagenen Kandidaten nach der Prüfung. ${ }^{813}$ Die Gemeinden hatten dagegen meist nur ein zweitrangiges Mitspracherecht, oft eingeschränkt auf die Lokalnotabeln oder Dorfältesten. Allerdings traten vor Ort in der Praxis bisweilen auch Mischformen auf, so dass geprüfte Lehrer in derselben Gemeinde neben Ungeprüften arbeiteten. Beispielsweise prüfte der

808 Erneuerte Schul- und Lehr-Ordnung für die Schulen der Landschaft Zürich: 6; Erneuerte Schul-Ordnung für der Stadt Bern: 6; Ordnung, welche auf der Landschafft des löbl. Stands Basel: 22.

809 Schmidt u.a. (Hgg.), Stapfer-Enquête, Nr. 1374: Heimiswil.

810 Brühwiler, Finanzierung: 187. Als Beispiel für examinierte Lehrersöhne ist die Aussage des Lehrers Heinrich Alder von Küsnacht ZH angefügt: „Ware Gehülfe seines Vaters, und nach deßelben erfolgtem s: Absterben zu Ende Junii 1798. nach ausgehaltenem Examen, vor dem Schul-convent in Zürich - welches vor dem die Wahl hatte, - von der Verwaltungs-Kammer erwehlt." Schmidt u.a. (Hgg.), Stapfer-Enquête, Nr. 293: Küsnacht.

811 Mindestens 329 der 417 waadtländischen Lehrkräfte, 40 der 66 baslerischen, 67 der 111 aargauischen und 232 der 381 zürcherischen Lehrer hatten explizit ein Examen erwähnt.

812 Erneuerte Schul- und Lehr-Ordnung für die Schulen der Landschaft Zürich: 6. Der Zürcher Examinatorenkonvent berief jedoch in der Praxis auch stillschweigend Personen mit guten Zeugnissen ohne Prüfung ins Lehramt.

813 Lang, Schaffhausen: 7; Zingg, Basel: 33. 
Stadtrat von Payerne VD nur die männlichen Lehrpersonen des örtlichen Collèges, während die drei Lehrerinnen der Elementarschulen „Sans éxamen“ angestellt worden waren. ${ }^{814}$

Das individuelle Prüfen der Kandidaten vor der Lehrerwahl war aufgrund von fundamentalen institutionellen Schwächen der obrigkeitlichen Verwaltungsstrukturen im Ancien Régime zunehmend zum unverzichtbaren Organisationsakt geworden: Zum Ersten fehlten von obrigkeitlicher Seite her überlokale normative Anforderungskriterien an die Lehrertätigkeit und einen gemeinschaftlichen Konsens, was ein Lehrer überhaupt können musste, um sein Amt zufriedenstellend auszuführen. Zum Zweiten brachten die Kandidaten - sofern sie überhaupt eine Form der Ausbildung genossen hatten - durch die weitgehend unsystematische Schulmeisteranlehre völlig unterschiedliche Fachkenntnisse und Fähigkeiten mit sich. Nur eine Prüfung konnte hier eine quasi-objektiv vergleichbare Klarheit zwischen den einzelnen Kandidaten schaffen. Zum Dritten existierten auf verwaltungstechnischer Ebene noch kaum Mittel, um bereits etablierten Schulmeistern oder fähigen Kandidaten ihre Befähigung zum Schulhalten zu bestätigen. Da Landschulmeister im Gegensatz zu städtischen Schulmeistern selten allgemein anerkannte schriftliche Zeugnisse in Form eines „Lehrbriefs“ ${ }^{\text {“ }} 15$ erhielten, welche die Befähigung zum Schulhalten explizit auswiesen, kamen willige Schulmeister-Kandidaten nicht umhin, sich auf jede freie Stelle einzeln zu melden und sich jeweils von Neuem von den vorgesetzten Pfarrern examinieren zu lassen. Schriftliche Zeugnisse lagen höchstens in Form von Empfehlungsschreiben von lokalen Pfarrern als Referenzen vor. Einzig die katholischen Solothurner Lehrer erhielten nach dem Besuch des obligatorischen Normalschulkurses ab 1783 ein schriftliches Patent, das ihnen eine bevorzugte Stellung gegenüber nicht patentierten Privatschulmeistern einräumte. ${ }^{816}$ Ferner etablierte sich in der Waadt ein schriftliches „Brevet“ aus den Händen des Landvogtes, das ein erfolgreiches Bestehen des Lehrerexamens dokumentierte und die nachfolgende Stellensuche für den brevetierten Lehrer vereinfachte. ${ }^{817}$

Auf ein Examen wurde meistens nur verzichtet, wenn sich bloss ein einziger Kandidat für die vakante Stelle meldete ${ }^{818}$, bei kurzfristigen Vakanzen aus purer Not eine Person ungeprüft angestellt werden musste ${ }^{819}$, das Lehramt als gewohnheitsrechtlicher Familienbesitz dynastisch weitervererbt wurde oder wenn die Dorfgemeinde das alleinige Wahlrecht des Schulmeisters inne hatte und keinen Wert auf eine Prüfung der Kandidaten legte. ${ }^{820}$ Doch nur relativ wenige Lehrkräfte am Ende des 18. Jahrhunderts hatten überhaupt kein Examen ablegen müssen, etwa weil ihre Fähigkeiten bereits hinlänglich bekannt waren - wie es etwa beim Sohn des bekannten Aarberger Lehrers Jakob Eggen in Nidau BE der Fall gewesen war - oder weil sie willkürlich zum Lehrer ernannt wurden. ${ }^{821}$

814 Schmidt u.a. (Hgg.), Stapfer-Enquête, Nr. 621: Payerne.

815 Vgl. Seemann, Schulpraxis: 10.

816 Mösch, Solothurnische Volksschule: 90-93.

817 „Jusqu'ici le Régent a été établi par Brevet Signé du Baillif de Rougemont au nom de l'Ancien Gouvernement, après avoir subi un Examen fait par le Pasteur de Châteud'Oex assisté de ses Collégues de Rougemont, Rossinière, et l'Etivaz“. Schmidt u.a. (Hgg.), Stapfer-Enquête, Nr. 1978: Château-d‘Oex.

818 „die Schulmeister wurden vom Kirchenrath bestelt, aber ohne genaue Prüfung, weil mann meistens nur den Einen zu wehlen hatte, der sich etwa meldete." Schmidt u.a. (Hgg.), Stapfer-Enquête, Nr. 492: Krummenau, Sibold, Ämelsberg.

819 „Der Lehrer dieser Schule, wurde im Wintermonath 1798 aus mangel eines anderen, beßeren Subjects. von der verwaltungs-Kammer erwählt." Schmidt u.a. (Hgg.), Stapfer-Enquête, Nr. 2120: Holziken.

820 „Der Schullehrer wurde bis dahin von der Gemeinde bestellt ohne irgend eine vorhergegangene Untersuchung seiner Lehrer-Fähigkeit und Kenntniße. Der gegenwärtige erlangte bey aller Untauglichkeit dazu dieses Amt gleichsam erbsweise von seinem Vater." Schmidt u.a. (Hgg.), Stapfer-Enquête, Nr. 435: Azmoos.

821 „Mit mir ist eine Ausnahme; indeme von der ganzen Bürgerschafft erwählt, und ohne Examen bestellt worden weilen sie meine Aufführung, und Fähigkeiten zu kennen glaubten." Schmidt u.a. (Hgg.), Stapfer-Enquête, Nr. 761: Nidau. 
Ebenso selten trat die Situation ein, dass eine Person zur Ausübung des Lehramts gedrängt oder gar gezwungen werden musste. Das Narrativ des unfreiwillig zum Lehrer gewordenen Dorfbürgers war zwar für die liberale Geschichtsschreibung ein spannender Beweis der Rückständigkeit des Ancien Régimes, in seiner kollektivbiografischen Erscheinungsmenge besitzt es aber höchstens anekdotischen Wert. Kaum eine Handvoll Lehrkräfte gab denn auch in der StapferEnquête freimütig an, der Lehramtsausübung nur unter Druck zugestimmt zu haben. ${ }^{822}$

Entscheidend für das Abhalten eines Examens zur Prüfung der Lehrerkandidaten war die Frage, wer das Wahlrecht für die Lehrer innehatte. Wo die Gemeinden über das alleinige exklusive Wahlrecht für ihre Lehrer verfügten, waren Lehrerexamen deutlich seltener als an Orten, wo obrigkeitliche Herrschaftsträger ein Mitspracherecht besassen. Entsprechend konnten bereits im Ancien Régime die Lehrerkandidaten bei Vakanzen willkürlich und ohne eine vorgängige Prüfung gewählt beziehungsweise bisherige Lehrer abgewählt werden, ohne dass gegenüber der lokalen Geistlichkeit oder den Obrigkeiten eine Rechenschaftspflicht bestanden hätte. Das war vorwiegend in den ehemaligen Gemeinen Herrschaften der Fall. Hier - insbesondere in den gemischtkonfessionellen östlichen ehemaligen Gemeinen Herrschaften des Rheintals, des Gaster, der March und des Sarganserlandes - hatten in der Regel die Gemeinden das exklusive Lehrerwahlrecht inne. ${ }^{823}$ Das führte im Gegensatz zu den meisten übrigen Regionen der Alten Eidgenossenschaft zu einer hohen Fluktuation und einer geringeren durchschnittlichen Dienstausübungsdauer unter den Lehrern, da diese zudem jährlich von neuem um den Schuldienst vor der Gemeinde anhalten mussten und jederzeit abgewählt werden konnten. ${ }^{824}$

An den Lehrerwahlmodi und der Frage nach den Kandidatenexamina wird somit ebenfalls exemplarisch sichtbar, wo und wie obrigkeitliche Herrschaftsnormen auf die lokale Lebenswelt einwirkten. Denn wo das Wahlrecht an obrigkeitlich legitimierte Entscheidungsträger teilweise oder gänzlich delegiert und die Gemeinden in dieser Angelegenheit mehr oder weniger entmachtet waren, entstand im Gegenzug eine Art „Rechenschaftspflicht“ der Obrigkeiten gegenüber ihrer Landbevölkerung, die in Form der Lehrerexamina umgesetzt wurde. Die Obrigkeiten waren hierbei gleichwohl auf das Wohlwollen der Gemeinden angewiesen, was sich in einzelnen Äusserungen zeigt, dass bei Lehrerwahlen bewusst auch auf die Stimmung in den Gemeinden Rücksicht genommen werden musste. ${ }^{825}$ Das galt für die meisten Schulen der ehemaligen städtischen Untertanengebiete. Wo hingegen wie in den Landorten, zugewandten Orten und Gemeinen Herrschaften die Obrigkeiten keine beziehungsweise bloss eine beschränkte Mitsprache in kommunalen Angelegenheiten für sich reklamierten und die Gemeinden in ihrer Entscheidungshoheit nicht tangiert wurden, brauchte es auch schlichtweg keine Instrumente zur Rechtfertigung der Verhältnisse, da die Gemeinden die Verantwortung für ihre Lehrer selbst trugen. Die Lehrerexamen sind daher neben dem Versuch einer minimalen Qualitätskontrolle

822 „der gegenwärtige Schulmeister [...] übernahm die Schule, zu welchen sich niemand gebrauchen laßen wollte, auf Einreden der Pfarrers u der Vorgesezten, glaubt ale bey seinen zu nemmendem Alter diesen \{dienst\} nicht lange mehr mit Nuzen versehen zu könen. u für seinen Theil seine Pflicht an dieser Schule ein Genüge gethan zu haben." Schmidt u.a. (Hgg.), Stapfer-Enquête, Nr. 1619: Schwanden bei Brienz. Ferner hätten auch die Lehrer von Seltisberg BL und Eptingen BL nur unter „Zureden“ ihr Amt übernommen. Zingg, Basel: 47.

823 Von den 118 Lehrkräften des Kantons Linth, der sich grösstenteils aus ehemaligen Gemeinen Herrschaften zusammensetzte, waren 84 alleine durch die Gemeinden gewählt worden.

824 Vgl. zur Dienstdauer der Lehrkräfte in den östlichen Gemeinen Herrschaften die Ausführungen im Kap. 3.4.

825 „Der Schulmeister wurde nach vorhergegangner Publikation u: Examination durch den Pfarrer, von diesem, doch mit einigem Zuthun der Vorgesetzten u: mit Wißen des Oberamtmannes, auch womöglich mit Rücksichtnehmung auf die Stimmung der Hausväter bestellt." Schmidt u.a. (Hgg.), Stapfer-Enquête, Nr. 1388: Aeschiried. 
zum einen als ein bewusst initiiertes Instrument der frühneuzeitlichen Herrschaftsgestaltung der alteidgenössischen Städteorte in ihren Untertanengebieten anzusehen.

Zum anderen bewirkten Examen in professionalisierungstheoretischer Perspektive als Selektionsprozesse und als gemeinsame biografische Erfahrung selbst eine allmähliche Verstärkung des Selbstverständnisses bei den Neulehrkräften als Teil einer spezifischen Professionsgruppe. Das Absolvieren und Bestehen der Lehrerexamen stellte eine erste berufsbiografische Gemeinsamkeit dar, die wahrscheinlich unter den Lehrkräften zur Identifikationsbildung beigetragen hat, selbst wenn entsprechende explizite Aussagen mit Bezug auf die Identitätsstiftung fehlen.

\subsubsection{Die normativen Anforderungen an Lehrer-Kandidaten}

Was wurde von den Lehrerkandidaten beim Examen konkret erwartet? Das Anforderungsprofil an den Landschulmeister wurde zwar durch die obrigkeitlichen Landschulordnungen der einzelnen Stände in groben Zügen umrissen, ohne allerdings einen Detailkatalog an konkreten Fähigkeiten normativ zu verankern. Ein exemplarischer Blick auf drei bis zum Ende des Ancien Régimes geltenden Landschulordnungen der reformierten Stände Bern, Zürich und Basel verdeutlicht die Problematik der unterschiedlichen normativen Vorgaben für die Lehrer vor der Helvetischen Revolution und hilft die Frage zu klären, welche Anforderungen bezüglich Fähigkeiten und personalen Eigenschaften ein zukünftiger Lehrer erfüllen musste, um der normativen Erwartungshaltung gerecht zu werden.

Die erneuerte bernische Landschulordnung von 1759 umschrieb das Berufsprofil und die fachlich-pädagogischen Aufgaben der Schulmeister wie folgt: „Und um zum Schul-Dienst Gottesförchtige und Tugend-liebende Persohnen, die zur Unterweisung der Jugend von Natur geneigt und tüchtig, erwehlt und bestätiget werden, nachdeme sie ihrer Erkanntnuß, Tüchtigkeit und ohnanstößigen Handel und Wandels halber, [...], werden durch ein vorgehendes Examen auf die Prob gesetzt worden seyn. [...] Welche dann [...] die Kinder fleißig, verständlich und deutlich lehren Bätten, Lesen, und zum Wort Gottes anhalten, auch sie die Kinder auswendig lehrnen. [...] Die Grösseren aber soll er zum Schreiben fleißig anhalten, und das Geschriebene lehrnen lesen; Jm Catechismo aber also unterweisen, dass er es bey dem blossen auswendig lehrnen nicht bleiben lasse." 826

Dazu gesellte sich noch das Singen von Psalmen. ${ }^{827}$ Zentrale notwendige Eigenschaften der Kandidaten waren somit die Rechtschaffenheit ihres Lebenswandels, ein kinderliebender Charakter sowie das Beherrschen der Lese-, Schreib- und Gesangskunst. Weitere Fachkenntnisse oder ein spezifisches methodisch-didaktisches Wissen waren nicht erforderlich. Entsprechend niedrig fiel beispielsweise der Anteil an Schulen mit dem Fach Rechnen im Bernbiet aus, da die Prüfung der Kandidaten im Rechnen freiwillig geschah. ${ }^{828}$ Auf der anderen Seite bewirkte die Schulordnung, dass die deutliche Mehrheit der Lehrkräfte der ehemaligen bernischen Untertanengebiete eine ebensolche Prüfung absolviert hatte.

Konkrete Hinweise auf die Anforderungen an die Schulmeister sind in der überarbeiteten Zürcher Schul- und Lehrordnung von 1778 nur in indirekter Weise greifbar. Der Schulmeister sollte hinsichtlich seiner charakterlichen Eigenschaften: „äusserst beflissen seyn, wie es seinem so wichtigen Beruf anständig ist, eine christliche, fromme und unsträfliche Aufführung zu beob-

826 Erneuerte Schul-Ordnung für der Stadt Bern: 6f.; Schneider, bernische Landschule: $79 f$.

827 Erneuerte Schul-Ordnung für der Stadt Bern: 8.

828 Von 407 Schulen der helvetischen Kantone Bern und Oberland zählte Ernst Schneider 254 Schulen ohne das Fach Rechnen. Vgl. Schneider, bernische Landschule: 164. 
achten, und vorzüglich der Laster des Schwörens, Fluchens, Berauschens und Trunkenheit, der Unzucht, des Spielens, des Tröllens, der Zänkereyen und des Jagens sich enthalten." ${ }^{\text {829 }}$

Deutlich detaillierter als die bernische Landschulordnung formulierte die Zürcher Schulordnung den Negativkatalog an charakterlichen Schwächen, die der Eignung für das Lehramt im Wege standen. Die fachlichen Kompetenzen sind dagegen in der auf die konkrete Unterrichtsgestaltung fokussierten Lehr-Ordnung in den zu unterrichtenden Fachgegenständen verklausuliert: Buchstabieren, Syllabieren, das Lesen von Gedrucktem und von Handschriften, das Auswendiglernen von Psalmen, Gebeten und des Katechismus, das Schreiben nach Vorschrift und freies, expressives Schreiben sowie Singen bildeten die Unterrichtsinhalte, die ein Schulmeister beherrschen und lehren sollte. Das Rechnen sollte auf dasjenige beschränkt werden, was den Kindern „nach ihrem Stande nöthig seyn mag. ${ }^{\text {“30 }}$

Im Gegensatz zur Berner Landschaft etablierte die Zürcher Obrigkeit somit die Anfänge des Rechenunterrichts als zusätzliches Unterrichtsfach, wenngleich die Breite und Tiefe dieser Mathematikkenntnisse undefiniert blieben. Trotz der normativen Vorgabe unterrichteten aber am Ende des Ancien Régimes noch längst nicht alle Zürcher Landschulmeister das Rechnen in ihren Schulen. Zum einen gaben etliche Lehrer freimütig zu, selbst über keine genügenden Rechenkenntnisse zu verfügen, andere Lehrer unterrichteten die Anfänge der Mathematik nur auf besondere Nachfrage hin in Neben- oder zusätzlich bezahlten Privatstunden. Zum anderen fehlte mancherorts schlicht die Nachfrage nach Mathematikkenntnissen in der lokalen Bevölkerung oder das Rechnen wurde ausserschulisch im privaten Rahmen vermittelt. ${ }^{831}$

Den ausführlichsten Beschrieb zum Ablauf und Inhalt einer Lehramtskandidatenprüfung ist in der Basler Landschulordnung von 1759 zu finden: „In dieser Prüfung aber soll fürnehmlich dahin gesehen werden, Erstlich dass der anzunehmende Schulmeister in seinem Leben und Wandel unanstössig sey. Zweytens dass er wohl und fertig lese, sauber und deutlich schreibe, nach den Noten vorzusingen wisse, und die ersten Anfänge des Rechnens verstehe; auch die Fähigkeit besitze, dieses alles denen Kindern beyzubringen, und sie darinnen wohl zu unterrichten. Drittens dass er in Ansehung der Lehr richtig und gesund sey, sich auch durch irgend eine Gemeinschafft, oder anhänglichen Umgang mit Sectierern und Irrgeistern dissorts niemalen nur in dem geringsten verdächtig gemachet, oder einigen zu Verachtung des öffentlichen Gottesdienstes gereichenden Versammlungen beygewohnet habe. ${ }^{\text {832 }}$

Ebenso wie in Bern und Zürich bestand auch die Basler Geistlichkeit auf einem einwandfreien Leumund seiner Schulmeisterkandidaten, die zudem keine Diskrepanzen zur religiösen Orthodoxie aufweisen durften. Mit den letztgenannten „Sektierern und Irrgeistern“ waren die pietistischen Strömungen angesprochen, die im 18. Jahrhundert in der Basler Landschaft einigen Zuspruch erlebten. ${ }^{833} \mathrm{~W}$ ie in Zürich etablierte auch die Basler Geistlichkeit das Rechnen als fester Bestandteil des Elementarschulunterrichts, doch auch in der Basler Landschaft blieb der Erfolg der normativen Vorgabe ambivalent: einerseits fehlte die lokale Nachfrage vonseiten der Eltern, zudem bot nicht jeder Schulmeister das Fach Rechnen an und wenn gerechnet wurde, blieb nur wenig Unterrichtszeit dazu reserviert. ${ }^{834}$ Dennoch wurde am Ende des 18. Jahrhunderts bereits in $60 \%$ der baselländischen Schulen gerechnet und jeder dritte schulabgehende Knabe hatte

829 Erneuerte Schul- und Lehr-Ordnung für die Schulen der Landschaft Zürich: 20.

830 Erneuerte Schul- und Lehr-Ordnung für die Schulen der Landschaft Zürich: 5-13; Berner, Zeichen: $242-245$.

831 Vgl. Berner, Zeichen: $242 \mathrm{f}$.

832 Ordnung, welche auf der Landschafft des löbl. Stands Basel: 22.

833 Berner, Basel (Kanton).

834 Zingg, Basel: 83; Hess, Landschaft Basel: 224, $247 \mathrm{f}$. 
zumindest mathematische Kenntnisse im schulischen Umfeld erlangt, was im Vergleich zu anderen helvetischen Regionen ausserordentlich hohe Werte darstellt. ${ }^{835}$ Hinsichtlich der musikalischen Kenntnisse setzte ferner die Basler Landschulordnung den strengsten Massstab, indem das Vorsingen „nach den Noten“ verlangt wurde. ${ }^{836}$

Die Problematik der ungeregelten Lehrerkandidatenexamina sollte nach der Helvetischen Revolution alsbald in der neuen helvetischen Verwaltungsstruktur auf kantonaler Ebene angegangen werden. Die neu installierten Erziehungsräte versuchten die Lücke mittels eigener normativer Erlasse zu schliessen, um eine Standardisierung und Vereinheitlichung der Kandidatenexamina auf ihrem Territorium zu erreichen. Vom Erziehungsrat des neuerschaffenen Kantons Säntis ist ein „Reglement nach welchen die Schulmeister Examina im Kanton Säntis vorgenommen werden sollen “837 vom November 1800 überliefert. Das Reglement umfasste zusammengefasst zehn Punkte zur Regelung der Examina, der Lehrerwahl und den Umgang mit bereits geprüften Lehramtskandidaten. Hierzu sollten freie Schulmeisterstellen zentral beim Erziehungsrat gesammelt und öffentlich ausgeschrieben werden, das verantwortliche Prüfgremium sollte neben dem jeweiligen Ortspfarrer auch den Gemeindepräsidenten und ein Mitglied des Erziehungsrats umfassen, die Prüfung sollte mündliche und schriftliche Teile mit separaten Schriftproben umfassen, aber die Wählbarkeit der Kandidaten sollte durch den Erziehungsrat entschieden werden. Die Gemeinden erhielten einzig das abschliessende Wahlrecht der genehmigten Kandidaten. Ferner sollten die Lehramtskandidaten in zwei Klassen geteilt werden. Die Kandidaten der besseren Klasse sollten ein Testat erhalten, mit dem sie sich auf weitere Stellen hätten bewerben können, ohne erneut geprüft zu werden. Die zweitklassigen Aspiranten sollten dagegen nur für ein Jahr prüfungsfrei bleiben. Zudem sollte ein Verbot des Stimmenfangs durch die wählbaren Kandidaten im Dorf bei der Androhung einer Anzeige und des Verlusts der Wählbarkeit gelten.

Das Reglement ist als ein Ausdruck der von Stapfer in seinem Gesetzesentwurf zum elementaren Schulwesen verlangten Verlagerung von Entscheidungskompetenzen von der Lokalebene hin zum Erziehungsrat und den helvetischen Zentralbehörden zu deuten, wenn auch unter Miteinbezug der basisdemokratischen Entscheidungsfindung auf Gemeindeebene. Damit sollten einerseits die Lehrkräfte durch das doppelte Wahlverfahren doppelt legitimiert und somit in ihrer gesellschaftlichen Stellung gestärkt werden. Andererseits sollten sich die neuen Erziehungsräte mittels der Examenshoheit zusätzliche Autorität gegenüber den Lokalgeistlichen, den Lehrern und der Bevölkerung verschaffen können. Stapfer bevorzugte selbst in seinem Gesetzesvorschlag zum Schulwesen eine noch stärkere Verschiebung der Kompetenzen in Richtung der neuen staatlichen Behörden bei der Wahl der Schulmänner: „Die Lehrer sollen durch den Erziehungsrath ernannt werden, nachdem sie von dem Aufseher des Districts, zu welchem die zu besetzende Stelle gehört, vorgeschlagen sein, und die von der Regierung vorgeschriebenen Prüfungen bestanden haben werden, mit Vorhalt der Genehmigung des Directoriums. ${ }^{\text {“838 }}$ Das Verankern des Öffentlichkeitsprinzips durch die öffentliche Ausschreibung von Schulstellen zeigt ein weiteres Element des angedachten modernen Verwaltungsstaats an. Ferner ist die schriftliche Attestierung von bestandenen Examen als eine Frühform der professionalen Diplomierung zu bewerten, mit dem Ziel, einen überschaubareren Pool an zukünftigen, vorselektio-

835 Vgl. zur Anzahl an rechnenden Schulkindern in der Basler Landschaft und zum Forschungsstand des Rechnens in Elementarschulen ausgewählter Regionen: Rothen, Lesen: 87-108.

836 Ordnung, welche auf der Landschafft des löbl. Stands Basel: 22.

837 StASG HA R 132, Fasz. 2, o. Pag.: 12.11.1800 - Reglement.

838 Nach: Hunziker, Volksschule: 11. Vgl. auch: Bütikofer, Projekt: 38. 
nierten Kandidaten zu erhalten. Auffallend bleibt aber, dass der fachliche Inhalt der Prüfungen bewusst undefiniert blieb und einzig die methodischen Formen des Examens - der mündliche und schriftliche Teil - normiert wurden. Die Achillessehne der neuen Testate für Landschulmeisteraspiranten blieb jedoch die Frage nach deren Akzeptanz in der Bevölkerung.

\subsubsection{Die Inhalte und der Ablauf der Examina}

Über die konkreten Abläufe der meistens öffentlich durchgeführten Lehrerexamina gibt es zahlreiche Berichte, kaum jedoch konkrete Erfahrungsreflexionen aus der Sicht der Lehrkräfte. Der prosaisch beschriebene Ablauf eines Lehrerexamens um 1770 aus der bernischen Landstadt Langenthal BE aus der Autobiografie des Lehrers Jakob Eggen dient als erste Annäherung: „Nach Mittag war nun das Examen in der Kirche. Es waren drey Pfarreherren und die Vorgesetzten nebst vielen Gemeindsbürgern als Zuhörer. Praetendenten waren unser 6. Davon ich weit der jüngste war. Durchs Los war ausgemacht, welche zwey und zwey einer Katechisiseren und der andere antworten sollte, so dass jeder einen fragen und hernach einem andern antworten musste. [...] Ich musste meinem Antworter die Fragen mehr als auf einer Seite zeigen, und ihn so auf die Antwort führen, diss gefiel den Herren sehr wohl, dagegen liess ich menen Catecheten keine Frage unbeantwortet. Auch diss fand Beyfall. Ich hörte die Pfarrherren etliche mal etwas französisch von den anderen reden, wenn sie aber von mir oder meinem genannten Collegen redten, so sprachen sie Latin [...]. Ich machte alles ganz frölich und heiter bis an das Rechnen, da zitterete ich aus Furcht, weil ich meine Schwäche kannte. [...] Am Ende hiess man uns alle abtretten." 839

Auch in der Stapfer-Enquête sind Examensabläufe teilweise beschrieben worden. Ein Bericht aus dem Berner Oberland beschrieb das Prozedere folgendermassen: „Die Schullehrer, sind bißher von Pfarrern erwehlet und gesezt worden, da ist von Kanzell verkündet: wer die verledigte schul bedienen wolle, die können auf bestimmte zeit und ort, zum Examen sich einfinden. Mit mir Jakob Burgener, im reichenstein, gebohren; den 12.ten Nov. 1730, und allda erzogen, ist das Examen folgender massen für sich gangen: Der damalige Pfarrer Sprüngli, in Zweysimmen, versuchte mich, im buchstabieren, im läsen, singen, vom rechten gebrauch der Buchstaben u. unterscheiden. im Catechisieren, und was sonst von einem schuldiener zu fordern etc. Tags darauf, wurde dem Ober Amtmann vorgestellt, welcher Sein Consens und bewilligung darzu geben. ${ }^{\text {"840 }}$ Beim Examen wurden die Lehramtsaspiranten in der Regel auf ihre Fertigkeiten in den Kulturtechniken Buchstabieren, Lesen, Schreiben und - sofern von den Pfarrern erwünscht - in den Anfängen des Rechnens geprüft. Auch eine Singprobe und eine Demonstration in Katechese, das so genannte „Katechisieren“, gehörten dazu. ${ }^{841}$ Beim Lesen differenzierte man zusätzlich in gedrucktes Lesen und handschriftliches Lesen, wie in obiger Tabelle bei der Frage 1d. sichtbar wird. ${ }^{842}$ Manchmal wurden wie im obigen Beispiel weitere Fähigkeiten mitgeprüft, zum Beispiel Schönschreiben (Kalligrafie), die Federhaltung beim Schreiben oder - wie an einzelnen baselländischen Schulen - sogar das Federschneiden für Federkiele. ${ }^{843}$ Auch orthografisch und grammatikalisch korrektes Schreiben sowie schriftlich zu lösende einfache Mathematikaufgaben

839 Meyer, Langenthal: 32.

840 Schmidt u.a. (Hgg.), Stapfer-Enquête, Nr. 1468: Vordere und Hindere Rychestei.

841 Ein genaues Protokoll der Prüfungsfragen eines Schulmeisterexamens liegt aus Andwil SG vor: StASG HA R 133, Fasz. 1, o. Pag.: 12.12.1800 - Andwil.

842 Vgl. Messerli, Handschriften: 244.

843 Vgl. zum Federnschneiden das Examen von Bottmingen BL: StABL AA 1013, Lade 201, Mappe C, o. Pag.: 18.10.1800 - [Examensbericht Bottmingen]. Vgl. Büttner, Schreiben: $34 f$. 
konnten Teil des Examens sein, ebenso wie der allgemeine Lebenswandel, die Tüchtigkeit, die Unterrichtsmethodik oder eventuelle Unterrichtserfahrung als Kriterien miteinflossen. In Lavigny VD wurden etwa neben der Unterrichtsart auch Kenntnisse in der „Aufklärung“ geprüft: „on faisoit un examen détaillé pour connoître l'etendue des lumières, \& la manière dinstruire. ${ }^{\text {"844 }}$ Entsprechend variierten das Niveau und die einzelnen Prüfungsinhalte, da sie im Ermessen des prüfenden Geistlichen lagen, je nach Ort, Schuleinrichtung und Pfarrer enorm. Der junge Lehrer Hermann Krüsi aus Gais AR, späterer Seminardirektor des Lehrerseminars Gais, hatte zu seinem Wahlverfahren in der Stapfer-Enquête denn auch lakonisch notiert: „Bisher wurden die hiesigen Schullehrer von den Gemeindsvorgesezten in Beyseyn des Pfarrers gewählt. Das Examen ist nicht der Rede werth. Ein Kapitel lesen und einige Zeilen schreiben, war alles. ${ }^{\text {"845 }}$

Die geforderten Fähigkeiten als auch die Bewertung der Resultate hingen somit vorwiegend von den Erwartungshaltungen der prüfenden Pfarrer und lokalen Vorgesetzten vor Ort ab. Dabei ist ferner anzunehmen, dass die Pfarrer wiederum ihre Erwartungshaltungen den tatsächlich präsentierten Fähigkeiten der zur Verfügung stehenden Kandidaten anpassten, zumal einmal gewählte Schulmeister im Anschluss durch die Pfarrer individuell weitergebildet werden konnten und noch gar nicht alle notwendigen Fertigkeiten in Perfektion beherrschen mussten.

\subsubsection{Das Kandidatenfeld}

Wenn das Lehramt gemäss den apostrophierten historiografischen Vorurteilen eine Nottätigkeit von geringster sozialer Achtung gewesen sei, in die sich nur die ärmsten Personen geflüchtet hätten, dürften sich folglich nur wenige Personen um freie Lehrerstellen beworben haben. Es stellt sich daher die grundsätzliche Frage, wie viele Personen sich jeweils um eine vakante Schulstelle bemüht hatten, ob ein leistungsorientierter Wettstreit um die Stellen stattfand oder ob die Examen nicht eher als „Alibiübungen“ zur Legitimation von vornherein bestimmten Personen anzusehen sind und wer von den Kandidaten letztlich das Schulamt übernehmen konnte.

Dass überall in der Alten Eidgenossenschaft und später in der Helvetischen Republik leistungsorientierte Examen von Lehramtskandidaten verbreitet waren, ist zuvor bereits festgestellt worden. Ein echter Leistungswettbewerb bedingt jedoch eine Auswahl an potenziellen Kandidaten. Nach den Erkenntnissen von Georges Panchaud hatten die Pfarrer zumindest in der Waadt selten Mühe, genügend Kandidaten für ein leistungsorientiertes Examen zu finden: „les examinateurs avaient presque toujours la possibilité de choisir entre plusieurs postulants. ${ }^{\text {(866 }}$ Die Antworten auf die Stapfer-Enquête aus der Waadt bezeugen denn auch, dass an den meisten Orten tatsächlich jeweils mehrere Kandidaten zur Prüfung erschienen waren, was sicherlich mit den überdurchschnittlich hohen Lehrerlöhnen in der Waadt zusammenhing, die das Lehramt ökonomisch attraktiv machten. ${ }^{847}$ Doch auch im Kanton Zürich waren die meisten freien Lehrerstellen jeweils von mehreren Kandidaten begehrt gewesen, ungeachtet der Höhe der Besoldung. So berichteten zahlreiche Lehrer in der Stapfer-Enquête bei der Frage III.11.a zum Wahlverfahren, dass sie sich gleich gegen mehrere Kandidaten in einem Examen durchsetzen mussten: „Zum Schulmeister Bin ich erwehlt worden, von meinen Hochgeehrten Herren Examinatoren. in Zürich. Nebst. 6. Prettendenten aus unseren Gemeind. weillen ich Examiniert worden $\{$ bin $\}$ “ ${ }^{848}$

844 Schmidt u.a. (Hgg.), Stapfer-Enquête, Nr. 1836: Lavigny.

845 Schmidt u.a. (Hgg.), Stapfer-Enquête, Nr. 1591: Gais.

846 Panchaud, écoles vaudoises: 248.

847 Vgl. zu den Einkommen in der Waadt das Kap. 3.1.2.

848 Schmidt u.a. (Hgg.), Stapfer-Enquête, Nr. 17: Oberhof. 
Fast alle Zürcher Elementarschullehrer wurden denn auch vom Examinatorenkonvent vor ihrer Wahl auf ihre Tauglichkeit hin geprüft. In den meisten Antworten auf die Stapfer-Enquête aus dem Kanton Zürich wurde zudem von den Lehrern explizit betont, dass sie als der „tüchtigste“ Kandidat am Examen die Wahl durch die Examinatoren gewonnen hätten. ${ }^{849}$ Die Konkurrenzsituation und der Leistungsdruck an den Examen des Examinatorenkonvents zeugen somit von einer erfolgreich institutionalisierten und leistungsorientierten Selektionstätigkeit der Obrigkeit im Zürcher Schulwesen, gleichzeitig aber auch von einer grundsätzlichen freiwilligen Bereitschaft der Kandidaten, sich mit anderen Kandidaten im Wettstreit des Examens um eine Lehrerstelle messen zu wollen. Dass es im Kanton Zürich allgemein oft an geeigneten Kandidaten für das Schulamt gefehlt hätte, wie Klinke aufgrund von provisorischen Halbjahresanstellungen aus dem Jahr 1800 resümiert hat, scheint hingegen den schwierigen Umständen des Betrachtungszeitpunkts geschuldet gewesen zu sein und kann nicht für die vorrevolutionäre Zeit bestätigt werden. ${ }^{850}$ Neuere Forschungen zu Bern haben ebenfalls bewiesen, dass für die wachsende Nachfrage an Lehrkräften durchaus ein entsprechendes Angebot an Kandidaten bestand, wobei zunehmend bei der Stellenbesetzung explizit auf jüngere Kandidaten gesetzt wurde. ${ }^{851}$

Regionale Einzelbetrachtungen untermauern die Verfügbarkeit von Kandidaten für das Lehramt in quantitativer Hinsicht. In der Stadt Schaffhausen wurden während des gesamten 18. Jahrhunderts Lehramtsbewerber für vakante städtische Schulstellen geprüft, da man wegen dem zufälligen Loswahlverfahren stets mehr Kandidaten brauchte als es freie Stellen gab. In der Konsequenz wurden die meisten Kandidaten in den Examen für tauglich befunden und zugelassen, und nur wenige abgelehnt. Robert Lang hat zum Losverfahren kritisch angemerkt: „Solange eine strenge Auswahl getroffen wurde, konnte diese Einrichtung wohl nicht viel Schaden anrichten. Es kam aber soweit, dass 30 und mehr Bewerber sich meldeten, von denen oft keiner, oft nur wenige abgewiesen wurden, sodass das Los auch auf sehr mittelmässige Individuen fallen konnte. Wohl nahm man sich wiederholt vor, bei der Zulassung zum Los strenger zu sein; aber jedesmal blieb es bei dem Vermerk im Protokoll, dass man es das nächste Mal ganz gewiss sein werde." ${ }^{\text {852 }}$

In einer studentischen Forschungsarbeit sind auf der Grundlage der Schaffhauser Schulrats- und Schulherrenprotokolle die Lehrerkandidatenprüfungen im 18. Jahrhundert untersucht worden. Hierbei ist festgestellt worden, dass in insgesamt 22 Prüfungen von insgesamt 634 examinierten Personen 423 zugelassen wurden. Zahlreiche Personen nahmen zudem immer wieder an den Prüfungen bzw. Verlosungen teil. ${ }^{853}$ Ganz offensichtlich waren die - in Schaffhausen gut bezahlten - städtischen Schulstellen während des gesamten 18. Jahrhunderts äusserst beliebt gewesen, denn anders lässt sich die hohe Beteiligung an den Examen und das wiederholte Auftauchen derselben Kandidaten trotz der geringen Wahlchance durch das Los nicht erklären.

Einen quantitativen Überblick über das Reservoir an potenziellen Kandidaten für frei werdende Lehramtsstellen für ein gesamtes Standesterritorium ermöglichen ferner die Luzerner Schultabellen von Franz Regis Krauer aus dem Jahr 1798-99. Die zwölfte Frage in dieser von der Stapfer-Enquête unabhängig durchgeführten Umfrage lautete: „Sind zum Schulunterricht taugliche Männer?“854

849 „Der Prediger und Stillstand des Orts erwählten 3. Männer - Es könnten aber Praetendenten gehen so viel Lusthatten - diese wurden sodann in Zürich, bey dem Bürger Antistes von einem Chorherrn u. einem Cantor Examiniert, und sodann von dem Convent der Beste gewählt!“ Schmidt u.a. (Hgg.), Stapfer-Enquête, Nr. 135: Marthalen.

850 Vgl. Klinke, Zürich: 114 .

851 Helfenberger, (Normal-)Lehrer: 133f.

852 Lang, Schulgeschichte: 7.

853 Die Daten stammen aus einer unveröffentlichten Seminararbeit: Ruch, Examinierung: 20f. Die Quellenbasis befindet sich im Staatsarchiv Schaffhausen: StASH Schule 1/1-17 Schulherrenprotokolle.

854 BAR B0 1000/1483, Nr. 1454, fol. 1-23v - Schultabellen Luzern. 
Die Antworten zeigen, dass im Kanton Luzern im Jahr 1799 in mindestens 26 von 78 Landschulorten eine alternative Besetzung des Schulmeisteramts möglich gewesen wäre, unabhängig von der Qualität des bestehenden Schulmeisters. Mindestens bei jeder dritten Schule stand damit mindestens ein möglicher Kandidat für eine hypothetische Neubesetzung bereit oder es hätte sich eine Person gefunden, die man hätte zum Lehrer ausbilden können. Insgesamt sind 25 potenzielle Kandidaten namentlich sowie mehrere diffuse Nennungen - beispielsweise „einige Jünglinge“ - aufgelistet worden.

Aus diesem Kandidatenfeld stach besonders hervor, dass 20 dieser 25 potenziellen Kandidaten jünger als dreissig Jahre alt waren, fünf davon waren gar zum Zeitpunkt der Erhebung noch unter zwanzig Jahre alt. Bei neun dieser zwanzig „Jünglinge“ war zudem explizit vermerkt, dass sie sich willentlich zum Lehrer ausbilden lassen wollten. ${ }^{855}$ Doch nicht nur die jungen Männer selbst, sondern auch die Dorfgemeinden zeigten bisweilen ein Interesse daran, eigenen Lehrernachwuchs zu generieren. ${ }^{856}$ An willigen jugendlichen Nachwuchskräften mangelte es damit an vielen Orten der Luzerner Landschaft nicht und das Bedürfnis, sich zum Lehrer ausbilden zu lassen, bestand besonders bei jungen Personen in bemerkenswertem Masse. Doch auch bereits bekannte, erfahrene ältere Lehrkräfte waren bisweilen notiert worden. So wurde in Horw LU der alte Schulmeister weiter empfohlen. ${ }^{857}$ Andernorts wünschte man sich den Kaplan als Schullehrer, so etwa in Beromünster LU oder Meggen LU, in Werthenstein LU wurde dagegen auf die gebildeten Ordensgeistlichen des nahe gelegenen gleichnamigen Klosters der Franziskaner als mögliche Alternative verwiesen. ${ }^{858}$ Bei einem knappen weiteren Drittel der Schulen, bei 21 Schulen, wurde die Frage hingegen explizit verneint. ${ }^{859}$ Begründet wurde das Fehlen von möglichen Kandidaten mit dem geringen Schullohn oder der gewohnheitsrechtlichen Vergabe des Schulamts an eine bestimmte Familie. Mit Ausnahme des Distrikts Willisau wurden jedoch in allen Regionen der Luzerner Landschaft potenzielle Kandidaten genannt. An einigen Orten wurden gleich bis zu drei potenzielle Kandidaten aufgeführt. Damit zeigt sich, dass insgesamt kein allgemeiner Mangel an potenziell fähigen und willigen Personen bestand und Probleme bei der Besetzung von Schulmeisterstellen in der Regel eine Folge des Lokalrekrutierungsprinzips waren, wenn sich Gemeinden weigerten, einen auswärtigen Kandidaten zu erwählen. Ironischerweise war ausgerechnet bei der Schule St. Urban LU, wo das erste Landschullehrerseminar der Schweiz entstanden war, auf die Frage nach verfügbaren Alternativkandidaten notiert: ,ja, aber nicht Landtbürger. ${ }^{\text {“860 }}$

Dass die Gemeinden mancherorts durchaus in der Lage waren, genügend valable Kandidaten für Schulstellen zu rekrutieren, manifestiert sich ferner in ungewöhnlichen Begleitmassnahmen zu den Examen. Im wohlhabenden Schaffhauser Marktflecken Hallau SH war es gewohnheitsrechtlich üblich, dass die erfolgreich gewählten Kandidaten die Kosten ihres Amtsantritts, namentlich die Kosten des Examens, selber tragen mussten: „Schullehrer seind allhier 3. u: wurden bishero von einem jeweiligen L: Vogt. Pfarrer. Vogt, u: Kirchenpflegern gewählt. die dabey vor-

855 „Ein Jüngling der schreiben und lesen kann, wünscht sich zu vervollkommen“. BAR B0 1000/1483, Nr. 1454, fol. 3-4 - Schultabellen Luzern.

856 „ein jüngling von 23 Jahren wünschte sich tauglich zu machen, und die gemeine verlangt es." BAR B0 1000/1483, Nr. 1454, fol. 9-10 - Schultabellen Luzern.

857 „der br. pfarrer empfielt den alten schulmeister wegen fleiss und thätigkeit." BAR B0 1000/1483, Nr. 1454, fol. 1-2 - Schultabellen Luzern.

858 „taugliche männer werden gehalten. 1. die im Barfüsser kloster. 2. peter Meyer ab staldig. alt 21. Jahr." BAR B0 1000/1483, Nr. 1454, fol. 19-20 - Schultabellen Luzern.

859 „nein. man findet nicht ohne mühe einen, der im stande ist die kinder nur in etwas zu unterrichten.“ BAR B0 1000/1483, Nr. 1454, fol. 11-12 - Schultabellen Luzern.

860 BAR B0 1000/1483, Nr. 1454, fol. 15-16 - Schultabellen Luzern. 
gefallene Kösten, mußte der Neu Erwählte Bezahlen. welche auf 2 douplonen sich erstrekten." ${ }^{\text {"61 }}$ Aus der Bereitschaft der Kandidaten, die relativ hohen zusätzlichen Kosten zu übernehmen, kann gefolgert werden, dass es nicht nur genügend Kandidaten gab, sondern dass die Kostenübernahme gleichzeitig als aktives Selektionskriterium vonseiten der Gemeinde funktionierte. Arme Kandidaten wurden so von vornherein vom Wahlverfahren ausgeschlossen. Ähnliche finanzielle Hürden gab es auch in einzelnen katholischen Gemeinden, wie das Beispiel der Kaplaneibesetzung der Gemeinde Baar ZG zeigt: „Mein beneficium wurde immer von den hiesigen Gemeinds-Representanten, und 5. Aeltesten aus den Familien Reidhaar, Zumbach und Ohnsorg besetzet mit der vom Stifter beygesetzten Bedingniss einer Taxe von einem Kronthaler, den jeder neüerwählte Caplan jedem der Collatoren zu entrichten hat. ${ }^{\text {“862 }}$

Diese Beobachtungen verdeutlichen noch mehr, dass zumindest einzelne Gemeinden eine ganz bewusste soziale und ökonomische Selektion ihrer Kandidaten betrieben hatten, und keinesfalls die ärmsten und unfähigsten Personen zum Lehrer ernannt wurden. Insgesamt sind praktisch keine Beweise vorhanden, dass sich die Gemeinden bewusst die günstigsten Kandidaten mit den geringsten Lohnansprüchen ausgesucht hätten. Überliefert ist denn auch bloss ein einziges konkretes Beispiel in der Stapfer-Enquête, dass in der Gemeinde Sembrancher VS „Celui qui l'a fait à plus bas prix. ${ }^{\text {“833 }}$ zum Lehrer gewählt worden sei - dessen Einkommen mit 70 Franken pro Jahr keineswegs ärmlich war. Der „billigste Kandidat“, wie ihn Holger Böning beschrieben hat, erscheint eher als ein Mythos, entstanden aus einem Erklärungsnotstand für das Paradox, dass trotz der vielfach geringen Einkommen dennoch zahlreiche Menschen Schullehrer werden wollten. ${ }^{864}$

Es kann somit für die meisten Fälle, wo keine stillschweigende innerfamiliär-dynastische Übergabe des Lehramts an ein Familienmitglied erfolgte oder das Lehramt gewohnheitsrechtlich an bestimmte Familien gebunden war, angenommen werden, dass bereits im Ancien Régime ein gewisser leistungsorientierter Wettbewerb nach meritokratischen Prinzipien zwischen mehreren Kandidaten um die vakanten Stellen stattgefunden hat. ${ }^{865}$ Die Bestellung eines Lehrers ohne Prüfung geschah in den meisten Fällen nur noch in Notsituationen. Viele Bewerber bedeuteten aber zugleich, dass das Lehramt zumindest für einzelne Gesellschaftsgruppen ein nicht zu unterschätzendes Mass an ökonomischer Attraktivität und sozialem Renommee ausstrahlte und dass das Lehramt grundsätzlich keine unattraktive Prekariatstätigkeit war, für die sich nur schwerlich geeignete Kandidaten finden liessen. Damit widerlegt sich das eingangs apostrophierte Vorurteil.

Doch wer bemühte sich neben Lehrersöhnen überhaupt um ein vakantes Lehramt? Über diese Kandidaten, insbesondere jene, welche die Stelle nicht erhielten, weiss man bislang jedoch noch sehr wenig. Sie sind aber von Interesse, wenn man zum einen verstehen will, wie die Selektionsprozesse funktionierten und zum anderen, aus welchen gesellschaftlichen Schichten sich die Lehrer rekrutierten. Aufgrund der immensen lokalen Heterogenität des Schulwesens kann das Kandidatenfeld jedoch bloss einzelfallspezifisch untersucht werden. Überlieferte Examensprüfungen aus diversen Archiven zu einzelnen freien Schulstellen erlauben es in einer mikrohistorischen Vorgehensweise, nicht bloss die Wahl des erfolgreichen Lehrers nachzuvollziehen, sondern ebenso das Feld an potenziellen Kandidaten zu beleuchten, woraus sich eine Reihe von neuen Fragen ergeben.

861 Schmidt u.a. (Hgg.), Stapfer-Enquête, Nr. 995: Hallau. 1 Spanische Dublone entsprach rund 135 Bz. Vgl. Brühwiler, Finanzierung: 345.

862 Schmidt u.a. (Hgg.), Stapfer-Enquête, Nr. 2048: Baar.

863 Der Lehrer verdiente 70 Franken pro Jahr plus Holzzugaben im Winter von den Schulkindern. Schmidt u.a. (Hgg.), Stapfer-Enquête, Nr. 2235: Sembrancher.

864 Böning, Traum: 224. Siehe das Zitat im Kap. 1.3.3. Zum Topos des günstigsten Kandidaten vgl. ferner: Walz, Eselsarbeit: 40; Landolt, Linth: 155.

865 Zum Begriff des meritokratischen Prinzips vgl. Meusburger, Bildungsgeographie: 11-15. 
Erstens erlaubt die Frage nach der quantitativen Anzahl an potenziellen Kandidaten direkte Rückschlüsse auf den „Attraktivitätsgrad“ des frei gewordenen Lehramtes, wobei die konkrete Schulsituation, der Schultypus und besonders die Einkommensfrage zentrale Determinanten waren. Zweitens ermöglicht die Analyse des Kandidatenfelds, insbesondere der letztlich erfolglosen Kandidaten, die Beantwortung der Frage, wer sich überhaupt für das Lehramt interessierte respektive für welche Berufs- und Altersgruppen das Lehramt eine mögliche Alternative darstellte.

In der bisherigen deutschsprachigen Schulgeschichtsforschung sind die Bewerbungsverfahren auf Elementarschulstellen und weitere Quellen zu Kandidatenexamen bislang kaum ausgewertet und meist nur holzschnittartig wiedergegeben worden, obwohl adäquates Quellenmaterial durchaus fragmentarisch vorhanden wäre. Ein einziges Beispiel eines Bewerberexamens aus Pommern von 1729 findet sich in beinahe allen sozialgeschichtlichen Forschungsergebnissen zum frühneuzeitlichen Elementarschullehrer wiedergegeben, in dem ein Schuster, ein Weber, ein Schneider, ein Kesselflicker und ein Unteroffizier für eine Schulstelle geprüft wurden. ${ }^{866}$ Mit einer inhaltlichen Analyse von Bewerbungsverfahren auf Schulmeisterstellen, den sogenannten „Verbal Prozessen“, auf der Basis der Fragestellung nach den Kulturtechnikfähigkeiten der Kandidaten hat Peter Büttner jedoch unlängst auf das Potenzial dieser noch wenig beachteten Quellen hingewiesen. ${ }^{867}$

Exemplarisch werden im Folgenden einzelne Verbalprozesse aus je einer katholischen Region Fribourg - und einer reformierten Landschaft - Basel - untersucht. Im Staatsarchiv des Kantons Basel-Landschaft sind eine Reihe von schriftlichen Berichten über Schulamtsexamen des Basler Erziehungsrats in besonders hoher Stückzahl und zeitlicher Dichte überliefert, welche in der Folge für eine exemplarische mikrohistorische Untersuchung zum Personenkreis der teilnehmenden Kandidaten analysiert werden sollen. Die hohe Dichte an Examensberichten ist der speziellen Schulstruktur der alten Basler Landschaft geschuldet, wo neben gewöhnlichen Elementarschulen in einzelnen Gemeinden sogenannte Deputatenschulen bestanden, vorwiegend in den Orten mit Zentrums- oder Verkehrsfunktion. Diese Deputatenschulen wurden durch einen städtischen Spezialfond, den Deputatenfond, finanziert und waren für lange Zeit ausschliesslich Stadtbürgern vorbehalten. Diese Stadtbürger wurden per Los erwählt und mussten sich keiner vorangehenden Prüfung stellen. ${ }^{868}$

Anhand der Deputatenschule im Marktort Sissach BL lässt sich mittels mehrerer nacheinander erfolgten Kandidatenprüfungen zwischen den Jahren 1800 und 1803 im Detail mikrohistorisch nachzeichnen, wer sich - zum Teil mehrmals - mit welchem Erfolg um die wiederholt vakant gewordene Lehrerstelle beworben hatte. Die Lehrerwahlprozedur nach der Revolution und der Etablierung des Erziehungsrats im Kanton Basel sah vor, dass die Schulinspektoren eine frei werdende Schulstelle im Kantonsblatt öffentlich publizieren und anschliessend die sich darauf gemeldeten Kandidaten in einer Prüfung im Beisein der Gemeindevorstehenden auf ihre Fähigkeiten testen mussten. Die besten drei Kandidaten sollten anschliessend dem Erziehungsrat gemeldet werden, der per Abstimmung eine Wahl traf. Der Erziehungsrat beanspruchte damit neu eine Entscheidungskompetenz für sich, die im Ancien Régime je nach Schule zwischen den Deputaten, dem Kleinen Rat von Basel und den Gemeindevorständen verteilt war. ${ }^{869}$ Damit folgte

866 Sauer, Volksschullehrerbildung: 12f. Zitiert unter anderem in: Enzelberger, Sozialgeschichte des Lehrerberufs: 39; Bölling, Sozialgeschichte: 53f.; Walz, Eselsarbeit: 66; Stefanidou-Kappmann, Geschichte des Volkschullehrers: 132.

867 Vgl. Büttner, Schreiben: 96-108.

868 Zingg, Basel: $32 \mathrm{f}$.

869 Im Ancien Régime schlugen die Deputaten zur Neubesetzung einer Deputatenschulstelle dem Kleinen Rat von Basel jeweils drei Bewerber vor, unter denen das Los entschied. Eine vorgängige Prüfung ihrer Fähigkeiten fand nicht statt. Zingg, Basel: 33. In vielen Fällen übernahm jedoch der Pfarrer durch seine vorselektionierende Prüfung die Entscheidungsgewalt. Vgl. Rothen, Lesen: $51 \mathrm{f}$. 
der Basler Erziehungsrat wie die meisten helvetischen Erziehungsräte in seiner Vorgehensweise den Ideen Stapfers, wie er sie in seinem Gesetzesentwurf zum Schulwesen gefordert hatte. ${ }^{870}$ Konflikte um die Entscheidungshoheit waren damit allerdings vorprogrammiert, insbesondere wenn sich die Gemeinden in ihrer Autonomie eingeschränkt sahen oder wider den Anweisungen des Erziehungsrats handelten. Solche Konflikte in Form von Klagen und Streitigkeiten um Lehrerwahlen und -abwahlen sind in praktisch allen Kantonen der Schweiz dokumentiert. ${ }^{871}$ Der ursprüngliche Lehrer in Sissach BL, der 65-jährige Pfarrkandidat Johan Jakob Silbernagel, dessen mangelnde Tüchtigkeit und fehlende Fähigkeiten wiederholt Anlass zu Klagen gegeben hatten, ${ }^{872}$ wurde im Winter 1799 gegen seinen Willen in Pension geschickt, wodurch die Stelle frei wurde. ${ }^{873}$ Insgesamt zehn Kandidaten bewarben sich in der Folge für die Schulstelle, darunter zwei ehemalige Soldaten, zwei Ausserkantonale, zwei Magister, ein Pfarramtskandidat und der bisherige Hilfslehrer von Riehen, Johannes Meyer, dessen Lebenswandel allerdings bei seinem vorgesetzten Pfarrer in Riehen für Unmut gesorgt hatte. So habe er „durch Schuldenmachen, manchmal durch Trinken und durch lärmenden Hausstreit mit seiner äusserst schlechten Frau, welche wohl viel Schuld an seiner eigenen Unordnung ist [...] jegliche Hoffnung auf Besserung fast gänzlich [verloren]. ${ }^{\text {874 }}$

Die Deputatenschulen waren zwar seit 1790 kein ausschliessliches Privileg für gebildete Stadtbürger mehr und standen somit auch Landbürgern und Auswärtigen zur Besetzung offen, doch zeigen die nachfolgenden Bewerberlisten eindeutig, dass sich nach wie vor vorwiegend höher gebildete Stadtbürger mit Universitätsabschluss oder Pfarramtskandidaten für Deputatenschulen bewarben, wenngleich die städtische Nachfrage nach Schulstellen auf dem Land abgenommen hatte und die Deputaten zunehmend Mühe bekundeten, geeignete Stadtbürger für die Landschulen zu gewinnen. ${ }^{875}$

Tab. 9: Kandidaten für die Schule Sissach im Januar $1800^{876}$

\begin{tabular}{lll}
\hline Name: & Herkunft: & Prüfung: \\
\hline Mathias Fankhauser von Trub im Kanton Bern. & Kt. Bern & \\
Jakob Keller, von Martelen aus dem Kanton Zürich, Feldweibel. & Kt. Zürich & Abwesend \\
M[agister]. Strübin & {$[$ Basel] } & Abwesend \\
M[agister]. [Johannes] Ernst & {$[$ Basel] } & \\
Cand[idat]. Gysendörfer & {$[$ Basel] } & \\
Johannes Meyer, Provisor in Riehen & Riehen & \\
Hans Jakob Schaub von Buus & Buus & \\
Joh. Heinrich Müller & {$[$ Basel] } & Abwesend \\
Johannes Otterey, Corporal Furrier & Unbekannt & \\
Joh. Caspar Georg & Unbekannt & \\
\hline
\end{tabular}

870 Bütikofer, Projekt: 38.

871 Vgl. beispielhaft die Konflikte im Aargau: Landolt, Executoren: 20. Zu Konflikten in Fribourg: Dévaud, École primaire: 87.

872 Zingg, Basel: $38 f$.

873 Silbernagel wehrte sich in einem Schreiben gegen den Pensionsvorschlag des Basler Erziehungsrats: StABL AA 1012, Lade 200, 07.04.01, fol. 12ff.: 02.11.1799 - [Silbernagel]; StABL AA 1012, Lade 200, 07.04.01, fol. 14f.: 18.12.1799 - Vorschlag.

874 Zingg, Basel: 43.

875 Hess, Landschaft Basel: 236ff.

876 StABL AA 1012, Lade 200, 07.04.01, fol. 15f.: 12.01.1800 - [Examen Sissach]. 
Zum Examen erschienen nur sieben der zehn Kandidaten, die drei übrigen blieben dem Examen ohne den Vermerk von Gründen fern. Den Vorschlag zur Wahl erhielt der Pfarrkandidat Gysendörfer, der schon 17 Jahre in der Gemeinde Sissach BL verbracht und sich in dieser Zeit als Erwachsenen- und „particular-Lehrer bey der minderjährigen Jugend“ das Vertrauen der Gemeinde erarbeitet und auch in der Prüfung am besten abgeschnitten hatte. ${ }^{877}$ Als studierter Theologe verfügte er zweifellos über den höchsten Bildungsgrad aller Kandidaten. Doch mit dem bisherigen Lehrer Johannes Meyer als Zweitplatzierter und dem Unteroffizier Johannes Ottery als Drittplatzierter kamen, wenn auch deutlich abgeschlagen, zwei Personen mit ausgewiesenen Kulturtechnikkompetenzen in die weiteren Vorschlagsränge. ${ }^{878}$ Gysendörfer nahm die Wahl zwar an, verliess die Schule allerdings bereits im Juli 1800 wieder, da er inzwischen eine Pfarrstelle in Tenniken BL antreten konnte. ${ }^{879}$ Die im Kapitel 2.2.10 angesprochene Moratoriumsfunktion der Schulstelle für Pfarrkandidaten wird in diesem Beispiel deutlich sichtbar.

Im August 1800 lief deshalb ein Nachfolge-Examen an. Hierbei bewarben sich zwölf Kandidaten, darunter drei bereits angestellte Landschullehrer: der Magister Heinrich Grieder, bisheriger Lehrer der Deputatenschule Bubendorf BL, Friedrich Mundwiler, Lehrer in Diegten BL und Heinrich Meyer, bisheriger Lehrer in Eptingen BL. Die ausschlaggebende Motivation für die Bewerbung der beiden letztgenannten bisherigen Landschullehrer dürfte die weitaus bessere Besoldung an der aus dem Deputatenfond finanzierten Schule gewesen sein, während die Besoldung von Bubendorf kaum von derjenigen von Sissach abfiel. Daneben fanden sich des Weiteren zwei Pfarramtskandidaten, ein Buchdrucker, drei Magister der Universität, darunter wiederum Johannes Ernst ${ }^{880}$ und Joseph Strübin, sowie zwei Hauslehrer aus der Stadt und einen Hausvater ohne Berufsangabe, vermutlich aus Sissach. Das Feld der Kandidaten war somit wiederum hauptsächlich geprägt durch Personen mit Erfahrung im Bildungswesen und einer hohen, teilweise universitären Individualausbildung. Einzig der Buchdrucker Georg Buser, der Hausvater Jakob Uster sowie der Amtsweibel Johann Jakob Freüler hatten einen unbekannten Bildungsgrad.

Tab. 10: Kandidaten in Sissach im August $1800^{881}$

\begin{tabular}{lll}
\hline Name: & Herkunft: & Prüfung: \\
\hline Cand[idat]. Eckenstein Pfarr Vicarius in Bennwil & Basel & \\
M[agister]. Heinrich Grieder, Schulmeister in Bubendorf & Basel & \\
Georg Buser, Buchdrucker in der Deckerischen Druckerei & {$[$ Basel $]$} & Abwesend \\
{$[$ Magister] Samuel Riedtmann } & {$[$ Basel $]$} & \\
Emanuel Schlichter, Informator & {$[$ Basel $]$} & Abwesend
\end{tabular}

877 StABL AA 1012, Lade 200, 07.04.01, fol. 9: 22.01 .1800 - [Examensbericht Sissach]; StABL AA 1012, Lade 200, 07.04.01, fol. 17f.: 23.01.1800 - Gemeinde Sissach.

878 StABL AA 1012, Lade 200, 07.04.01, fol. 18f.: 25.01.1800 - [Proces Verbal Sissach].

879 StABL AA 1012, Lade 200, 07.02.01, o. Pag.: 18.07.1800 - Holzach.

880 Johannes Ernst bewarb sich zudem ein Jahr später, im April 1801 um die Schulstelle in Langenbruck BL, zog sich aber ,auf den erhaltenen Bericht über das unbeträchtliche Einkommen dieses Schuldienstes“ "wieder zurück. StABL AA 1012, Lade 200, 07.01.01, o. Pag.: 19.04.1801 - [Prüfungsbericht Langenbruck]. Auch in weiteren Fällen - z.B. im Dezember 1802 in Hölstein - wurde vermerkt, dass sich Kandidaten aus der Stadt Basel aus ökonomischen Gründen wieder zurückgezogen hatten. So verzichteten etwa die beiden auch in der

Tab. 11 genannten Stadtbürger Joh. Caspar Walther und Joh. Heinrich Müller auf das anstehende Examen. StABL AA 1012, Lade 200, 07.01.01, o. Pag.: 07.12.1802 - [Prüfungsbericht Hölstein].

881 StABL AA 1012, Lade 200, 07.04.01, fol. 20f.: 06.08 .1800 - [Schulstelle Sissach]. 


\begin{tabular}{lll}
\hline Name: & Herkunft: & Prüfung: \\
\hline M[agister]. Joseph Strübin & {$[$ Basel] } & \\
Candidat Gachnang & {$[$ Basel $]$} & \\
[Magister] Johannes Ernst. Informator & {$[$ Basel $]$} & \\
Jakob Uster, Vater & unbekannt & Abwesend \\
Friedrich Mundwiler, Schulmeister in Diegten & Diegten & \\
J. Jakob Freüler, Huissier du Pouvoir Executiv & {$[$ Basel $]$} & Abwesend \\
Heinrich Meyer, Schulmeister in Eptingen & Eptingen & \\
\hline
\end{tabular}

Wie schon beim ersten Examen im Januar erschienen auch dieses Mal nicht alle gemeldeten Kandidaten zum Examen. Vier der zwölf Kandidaten blieben der Prüfung fern, darunter drei der sieben Kandidaten aus der Stadt Basel. Die Kenntnisse als auch die Fähigkeiten der acht geprüften Kandidaten unterschieden sich trotz des allgemein hohen Bildungsstands aller Kandidaten stark. Zur Wahl vorgeschlagen wurden nach absolvierter Prüfung die beiden Pfarrkandidaten Eckenstein und Gachnang sowie die beiden Magister Samuel Riedtmann und Heinrich Grieder. Berücksichtigt wurden somit vier Kandidaten mit einem überdurchschnittlich hohen Bildungsgrad, zudem waren alle Bürger der Stadt Basel. Die beiden teilnehmenden Landschulmeister schafften es dagegen trotz ihrer Berufserfahrung nicht in die engere Auswahl. Der Kandidat Ganchnang zog seine Bewerbung jedoch zurück, so dass dem Erziehungsrat die drei Kandidaten Eckenstein, Riedtmann und Grieder zur Auswahl standen. In der geheimen Abstimmung im Erziehungsrat gewann Riedtmann nach einem ersten Patt im anschliessenden zweiten Wahlgang knapp mit vier zu drei Stimmen gegen Eckenstein. ${ }^{82}$

Einzelbiografisch interessant ist die Personalie des oben aufgelisteten Johann Jakob Freüler, Weibel beim helvetischen Direktorium, der im August 1800 auf der Bewerberliste für die Schule in Sissach BL auftauchte (

Tab. 11). Ebendieser Johann Jakob Freüler hatte sich bereits im Jahr 1798 in einem Brief direkt beim Minister Philipp Albert Stapfer um eine Schulmeisterstelle beworben, worin er als seine Fähigkeiten im „Lesen und schreiben, die anfangs gründe zum Rechnen, so wie die französische Sprache. Nebst Welt Historien, Schweizergeschicht und Moral sind diejenigen Wissenschaften, worin ich anfängern Unterricht geben könnte ${ }^{\text {“883 }}$ anpries. Daraufhin richtete sich Stapfer persönlich in zwei Empfehlungsschreiben an den Erziehungsrat des Kantons Basel, man möge Freüler bei einer freien Schulstelle „,besonders in der Gegend von Waldenburg“ ${ }^{\text {“84 }}$ berücksichtigen. Dieses persönliche Vorgehen Stapfers ist insofern irritierend, als es im Widerspruch zu seinem projektierten Schulgesetz stand, in dem die Schulmeisterwahl eindeutig Sache des Erziehungsrats sein sollte und das Vorschlagsrecht den Distriktinspektoren vorbehalten sein sollte. ${ }^{885}$ Sowohl beim Examen der Schule Bubendorf BL ${ }^{886}$ als auch beim Examen in Bottmingen BL im Oktober 1800 liess sich Freüler in die Kandidatenliste eintragen, freilich ohne beidmalig am Examen zu erscheinen. ${ }^{887}$

882 StABL AA 1012, Lade 200, 07.02.01, o. Pag.: 22.08.1800 - [Ergebnis Lehrerwahl Sissach].

883 StABL AA 1012, Lade 200, 07.01.01, o.Pag.: [1798] - [Johann Jakob Freuler].

884 StABL AA 1012, Lade 200, 07.01.01, o.Pag.: 21.12.1798 - [Brief Stapfer I]; StABL AA 1012, Lade 200, 07.01.01, o.Pag.: 10.01.1799 - [Brief Stapfer II].

885 Bütikofer, Projekt: 38 .

886 StABL AA 1013, Lade 201, Mappe E, o. Pag: 08.10.1800 - [Verbal Prozess Bubendorf].

887 StABL AA 1013, Lade 201, Mappe C, o. Pag: 18.10.1800 - [Examensbericht Bottmingen]. 
Dass Freüler letztendlich keine Schulstelle fand, lag wohl mitunter an einem kritischen Schreiben des Erziehungsrats, in dem „Br. Freyler vielleicht zu allem eher den als zum Erzieher taugt“ taxiert wurde, da er „seine eignen Kinder nicht gehörig erzieht“" ${ }^{888}$. Während Direktbewerbungen beim obersten Zuständigen des Erziehungswesens, dem Minister der Künste und Wissenschaften, gewagte Einzelfälle waren, liess sich bei den neu geschaffenen kantonalen Erziehungsbehörden eine neue Praxis von Direkt- oder Blindbewerbungen nachvollziehen. Willige Lehramtsaspiranten wandten sich mitunter direkt an die Erziehungsräte, um für eine freie Schulstelle vorgeschlagen zu werden. Aus der Korrespondenz des Erziehungsrats des Kantons Säntis ist beispielsweise das Bewerbungsschreiben eines gewissen Joseph Wüest überliefert: „Vollziehungs Rath. Joseph Wüest von Montlingen möchte gern Schullmeister werden, in der Roth Montlingen. Meine Fehler die ich noch nicht kann will ich noch schönn ver bessern. Jch will anhalten so höchst das ich kann. Joseph Wüest von Montlingen an den E.R. den 5 9br. 1801““889

Diese Direktbewerbungen waren zum einen ein Ausdruck der veränderten, noch unsicheren Zuständigkeiten im Erziehungswesen. Die neuen verwaltungstechnischen Dienstwege zwischen lokaler und kantonaler Ebene erschienen vielen Zeitgenossen schwierig zu durchschauen. Andererseits stehen die Bewerbungen dem heutigen Betrachter als Zeitzeugen für ein vorhandenes Interesse an der Lehrertätigkeit im Raum, die der postulierten allgemeinen Interesselosigkeit an der Lehrertätigkeit vehement widersprechen. Vielmehr zeugen sie von einem aktiven Bemühen einzelner Personen um Schulstellen, sei es als Nachfolger eines älteren Lehrers, als Quereinsteiger oder als bisheriger Schulmeister einer anderen Schule.

Der im Jahr 1800 neugewählte Lehrer Samuel Riedtmann verliess die Schule Sissach BL allerdings bereits 1802 aus Frustration wegen fehlendem Rückhalt durch den Erziehungsrat wieder ${ }^{890} \mathrm{Im}$ September des Jahres 1802 meldeten sich somit wiederum acht Kandidaten zu einem erneuten Examen, worunter sich drei bereits angestellte Lehrkräfte, zwei Hauslehrer und ein Pfarrkandidat befanden. Zudem versuchte der ehemalige Schulmeister von Bubendorf, Johann Heinrich Scherb, wiederum an eine Deputatenschulstelle zu gelangen, nachdem dieser im Frühjahr 1799 aus unbekannten Gründen die dortige Schule verlassen hatte. ${ }^{891}$

Tab. 11: Lehramtskandidaten in Sissach im Herbst $1802^{892}$

\begin{tabular}{lll}
\hline Name: & Herkunft: & Prüfung: \\
\hline M[agister]. Heinrich Grieder, Oberlehrer in Bubendorf & Basel & \\
Joh. Caspar Walther & {$[$ Basel $]$} & Abwesend \\
Johanes Uster, Informator & {$[$ Basel $]$} & Abwesend \\
Erhard Schneider, Schulmeister in Zunzgen & {$[$ Thürnen $]$} & \\
Heinrich Meyer, Schulmeister in Eptingen & Eptingen & \\
Joh. Heinrich Müller, Instructeur des Enfants. & {$[$ Basel $]$} & Abwesend \\
[Johann] Heinrich Scherb, alt Schulmeister in Bubendorf & {$[$ Basel $]$} & Abwesend \\
Candidat Gengenbach, Pfarrvikar zu Bennwil & {$[$ Basel $]$} & Abwesend \\
\hline
\end{tabular}

888 StABL AA 1012, Lade 200, 07.01.01, o. Pag.: 20.01.1799 - [Freuler].

889 StASG HA R 133, Fasz. 1, o. Pag.: 05.11.1801 - [Josef Würst].

890 StABL AA 1012, Lade 200, 07.02.01, o. Pag.: 18.06.1801 - [Schullehrer der Gemeinde Sissach].

891 Schmidt u.a. (Hgg.), Stapfer-Enquête, Nr. 2408: Bubendorf.

892 StABL AA 1012, Lade 200, 07.04.01, fol. 48f.: 21.09.1802 - [Gemeldete Kandidaten Sissach]. 
Auffällig war bei dieser Kandidatenschau, dass sich - abgesehen von einer Ausnahme - nun nur noch Personen aus dem Bildungswesen oder mit höherer Bildung für die Stelle gemeldet hatten. Quereinsteiger aus anderen Berufsgattungen waren dagegen nicht mehr aufgeführt. Nur drei der acht gemeldeten Kandidaten hatten allerdings das angesetzte Examen absolviert, die übrigen Kandidaten waren der Prüfung ferngeblieben. Dabei wurde der Deputatenschullehrer Heinrich Grieder vor den beiden Landschulmeistern Erhard Schneider und Heinrich Meyer als bester Kandidat vorgeschlagen. Der studierte Theologe Grieder bewies die besten Kulturtechnikkompetenzen, denn er „übertrifft alle seine Collegen im Liestaler Distrikt“ in seinen Fähigkeiten als Lehrer. ${ }^{893}$ In der Examensbeurteilung hielt der zuständige Schulinspektor fest: „Br. M. Grieder zeygte sich als einen erfahrenen Landschulmann, durch seine Deutlichkeit und Faßlichkeit womit Er die Kinder unterrichtete und ihnen die vorgelegten Fragen erklärte. So daß Er den gänzlichen Beyfall des Br. Pfr. Spörlins u. der Municipal-Beamteten erhielt - Aber auch Br. Erhard Schneider hielt sich sehr gut und hat seit der Zeit da ich Jhn als Landschulmeister kenne, recht viele Fortschritte im Socratisieren, Schreiben und Rechnen gemacht, und man siehet, daß Er seine Zeit in dem Pestalozzischen Institut sehr wohl angewandt, so daß Er, wenn Er so fortfahret, bald die meisten Landschulmeister hinter sich zurück lassen wird. Auch mit seiner Probe war man wohl zufrieden.“ ${ }^{\text {(894 }}$

Trotz der hervorragenden Beurteilung wurde am Ende überraschenderweise nicht Grieder als der erstvorgeschlagene Kandidat vom Basler Erziehungsrat erwählt, sondern Erhard Schneider, den man in der Schulumfrage des Deputatenamtes von 1803 als Schullehrer von Sissach wiederfindet. ${ }^{895}$ Die beiden übrigen wechselwilligen Lehrer von Bubendorf BL und Eptingen BL verblieben stattdessen an ihren angestammten Schulorten. Den Zuschlag für Erhard Schneider gegenüber dem Theologen Heinrich Grieder war vermutlich auf dessen pädagogische Weiterbildung bei Johann Heinrich Pestalozzi in Burgdorf zurückzuführen, die er als einer von zwei Basler Zöglingen „mit guten Zeugnissen versehen“ absolviert hatte und damit die neue Lehrmethode Pestalozzis in die Basler Landschaft brachte. ${ }^{896}$ Der Erziehungsrat selbst empfahl den Pestalozzi-Absolventen in einem Schreiben vom 29. Dezember 1801 dem Pfarrer und Schulinspektor Holzach von Gelterkinden BL zur Anstellung in Läufelfingen BL oder Zunzgen BL ${ }^{897}$ und befahl schliesslich dessen Anstellung in Sissach im November 1802. ${ }^{898}$ Schneider blieb in der Folge bis 1814 in Sissach, wo unter seiner Leitung im Jahr 1808 die erste kurzzeitige Basler Lehrerbildungsanstalt ins Leben gerufen wurde. ${ }^{899}$

Dieser Exkurs in die Verwaltungsakten des Basler Erziehungsrats mit seinen umfangreichen Kandidatentabellen und peniblen Examensberichten zeigt in exemplarischer Weise - wenn auch unter den besonderen lokalen Vorbedingungen der Deputatenschulen - nicht nur das allgemeine hohe Interesse an vakanten Schulstellen durch Kandidatenlisten von bis zu über

893 StABL AA 1013, Lade 201, Mappe E, o. Pag.: 12.11.1799 - Tabelle über das Personale; zit. in: Büttner, Schreiben: 102. 894 StABL AA 1012, Lade 200, 07.04.01, fol. 50f.: 01.10.1802 - [Proces Verbal Sissach].

895 StABL AA 1012, Lade 200, 07.01.01, o. Pag.: 30.10.1803 - [Bericht Sissach].

896 Die kostspielige Ausbildung Schneiders bei Pestalozzi wurde nicht vom Erziehungsrat, sondern privat von der Basler Gesellschaft für das Gute und Gemeinnützige finanziert. StABL AA 1012, Lade 200, 07.02.01, o. Pag.: 29.12.1801 - [Erhard Schneider]. Schneiders späterer Schüler Matthias Buser äusserte an der neuen Lehrart Schneiders jedoch reichlich Kritik, dass sie „mechanisch“ gewesen sei und neben Lesen, Schreiben und Rechnen andere elementare Unterrichtsgegenstände wie Sprachlehre, Geografie oder Geschichte gefehlt hätten. Kradolfer, Lehrerleben: 25.

897 StABL AA 1012, Lade 200, 07.02.01, o. Pag.: 29.12.1801 - [Erhard Schneider].

898 StABL AA 1012, Lade 200, 07.02.01, o. Pag.: 04.11.1802 - [Miville an Pfr. Holzach].

899 Kradolfer, Lehrerleben: 56. 
einem Dutzend Interessenten, sondern auch den generell hohen Bildungsgrad der sich bewerbenden Kandidaten. Das bedeutet zum einen, dass die Bemühungen der Erziehungsräte um eine leistungs- und qualifikationsorientierte Rekrutierung allmählich Früchte trugen und zum anderen chancenlose Quereinsteiger zunehmend von sich aus den Examen fernblieben. Denn es nahmen, von wenigen Ausnahmen abgesehen, insgesamt kaum Angehörige von UnterschichtsHerkunft an den Examen teil. Kandidaten mit einem geringeren Bildungshintergrund unterlagen in den Examen den bessergebildeten Kandidaten oder erfahrenen Schulmeistern in der Regel deutlich. Die zunehmende Partizipation von Landschulmeistern und die gleichzeitig verstärkte Abwesenheit von Bürgern städtischer Herkunft ist ferner dahingehend zu erklären, dass das ungleich höhere Gehalt der Deputatenschulen besonders auf die Landschullehrer anziehend wirkte, im Vergleich zu den städtischen Schulen jedoch bescheiden blieb. Ferner zeigen die Examensberichte, dass die neuen kantonalen Erziehungsräte konsequent und leistungsorientiert nach den bestgebildetsten Kandidaten suchten, selbst wenn sie am Ende nicht immer für die Stelle gewonnen werden konnten. Peter Büttner resümiert über die Schulmeisterwahlen in der Basler Landschaft: „Hier wurden also keine tumben Schweinehirten examiniert, sondern patente Leute, die man aus einer Gruppe von Bewerbern gezielt aussuchte. ${ }^{\text {“900 }}$

Dass meritokratische Prinzipien und leistungsorientierte Examen nicht nur in der reformierten Basler Landschaft mit ihrer speziellen Schulstruktur, sondern auch zunehmend in der übrigen Helvetischen Republik zum Usus wurden, zeigen ferner zwei Lehrerprüfungslisten ohne ersichtliche Rangfolge der Kandidaten aus der katholischen Fribourger Landschaft, wo im Herbst 1800 zeitgleich zwei Schulstellen neu besetzt werden mussten. Für die vakante Schulstelle in Ecuvillens FR meldeten sich im Oktober 1800 vier Kandidaten, wovon drei aus dem Dorf selbst stammten und ein Auswärtiger aus dem Nachbardistrikt dazu kam. Letzterer war jedoch der einzige Kandidat mit Unterrichtserfahrung, daneben bewarben sich der Gemeindeschreiber des Ortes, ein Bauer und Mesmer sowie dessen jüngerer Bruder.

Tab. 12: Kandidatenliste der Lehrerwahl von Ecuvillens $1800^{901}$

\begin{tabular}{lll}
\hline Name, Alter, Zivilstand: & Herkunft: & Ersttätigkeit: \\
\hline $\begin{array}{l}\text { François Carrel de Mésiere. voyez les notes dans celle de } \\
\text { Belfaux }\end{array}$ & Mézières & Lehrer \\
\hline $\begin{array}{l}\text { François Chenaux D’Ecuvillens, le jeune agé de 26 ans } \\
\text { marié ayant un enfant Marron. }\end{array}$ & Ecuvillens & Unbekannt \\
\hline $\begin{array}{l}\text { François Gumy D’Ecuvillens agé de 35 ans marié ayant } \\
\text { un enfant - Secretaire de la municipalité }\end{array}$ & Ecuvillens & Gemeindeschreiber \\
\hline $\begin{array}{l}\text { François Chenaux L'ainé D’Ecuvillens agé de 36 ans } \\
\text { marié ayant 4 enfants Laboureur. }\end{array}$ & Ecuvillens & $\begin{array}{l}\text { Bauer/Tauner, } \\
\text { Mesmer }\end{array}$ \\
\hline
\end{tabular}

Alle Kandidaten waren zum Zeitpunkt der Bewerbung verheiratet und hatten kinderreiche Familien gegründet. Nur einer der vier Kandidaten war noch unter 30 Jahre alt, die übrigen zwischen 35 und 46 Jahre alt und damit erheblich älter. Zumindest bei drei der vier Kandidaten konnte aufgrund ihrer Ersttätigkeiten von vorhandenen Grundkenntnissen in den elementa-

900 Büttner, Schreiben: 100.

901 AEF H 437.2, o. Pag.: 12.10.1800 - Ecuvillens. 
ren Kulturtechniken ausgegangen werden. Die Gemeinde bevorzugte nach dem Examen aber nicht etwa einen einheimischen Kandidaten, sondern den auswärtigen François Carrel, der sich jedoch im Anschluss für die Schule Belfaux FR entschied, wo er sich ebenfalls beworben hatte. Entsprechend übernahm in der Folge der zweitplatzierte Sigrist François Chenaux (der Ältere) auf Wusch der Gemeinde das Amt.

Gänzlich anders sah die Kandidatenliste der Lehrerprüfung im nur wenige Kilometer entfernten Belfaux FR hinsichtlich der Herkunft und der Ersttätigkeiten aus. Hier bewarben sich ausschliesslich bereits praktizierende Lehrer mit mehrjähriger Unterrichtserfahrung um die vakante Stelle, was auf einen ausgeglichenen Wettbewerb unter den Kandidaten schliessen lässt. Freilich schien es um die Anstellungsbedingungen im Kanton Fribourg im Allgemeinen nicht zum Besten gestanden zu haben, wenn sich mühelos fünf Lehrkräfte für eine vakante andere Schulstelle finden liessen, denn die Examinationsliste liest sich durchaus auch als ein Kritiksignal der daran teilnehmenden Lehrkräfte an den übrigen Schulorten. Drei der fünf Kandidaten entstammten nicht aus der Kirchgemeinde, davon kamen zwei gar aus anderen Distrikten des Kantons nach Belfaux und nur die beiden letztgenannten Kandidaten waren Ortsansässige. ${ }^{902}$ Im Examen wurden die Kandidaten auf die Kriterien „Caractère et conduite, Cathechisme, Lecture, Ecriture, Orthographie et Grammaire, Arithmetique, Plaint chant“ und die „Methode d'enseigner" geprüft. ${ }^{903}$

Tab. 13: Kandidatenliste der Lehrerwahl von Belfaux 1800

\begin{tabular}{lll}
\hline Name, Alter, Zivilstand: & Herkunft: & Ersttätigkeit: \\
\hline $\begin{array}{l}\text { Julien Favre fils de Christophe Favre originaire de Moudon regent a } \\
\text { Riat depuis } 3 \text { ans. Marié ayant 2 enfans - agé de 37 ans. }\end{array}$ & Moudon & Lehrer \\
$\begin{array}{l}\text { Jean Schobaz de Marly District de Fribourg agé de 47 ans marié ayant 4 } \\
\text { garcons regent à Murist la moliere depuis deux ans il a eté 4 ans à l'Ecolle }\end{array}$ & Marly & Lehrer \\
$\begin{array}{l}\text { François Carel de Mésiere District de Romond agé de 46 ans Marié } \\
\text { ayant un enfant. Regent à Mesière depuis 8 ans. }\end{array}$ & Mézières & Lehrer \\
$\begin{array}{l}\text { Martin Vielle de la Corbaz paroisse de Belfaux agé de 27 ans marié } \\
\text { ayant un enfant. Il a fait l'Ecole au dit lieu avec son père ancien régent. }\end{array}$ & La Corbaz & Lehrer \\
$\begin{array}{l}\text { Etienne Larnaz de Belfaux agé de 39 ans marié ayant 4 enfans. Il a eté } \\
\text { regent en plusieurs endroits pendant 11 ans. }\end{array}$ & Belfaux & Lehrer \\
\hline
\end{tabular}

Wiederum waren alle Kandidaten verheiratet und hatten eigene Familien mit Kindern. Ebenso war bloss einer der fünf Kandidaten jünger als 30 Jahre. Gewählt wurde, wie schon erwähnt, François Carrel aus Mézières, der „a obtenu 50. voix sur 76 votants. Sa Belle voix, ses certificats de conduite, son caractère doux et aimable et surtout sa priorité sur les autres dans l'examen ont dicté le choix de la paroisse. ${ }^{\text {“94 }}$ Die Wahl fiel somit wiederum auf einen auswärtigen Kandidaten, der im Leistungstest in allen geprüften Disziplinen als bester Kandidat abgeschnitten hatte. Der Miteinbezug von schriftlichen Zeugnissen über das Verhalten in die Gesamtbewertung, die sogenannten „Certificats de conduite“, sind ferner ein wichtiger Hinweis auf die zunehmende 
Professionalisierung der Lehrerexamen an der Basis und wurden zunehmend unabdingbar für ortsfremde Kandidaten, deren Lebenswandel der Dorfbevölkerung unbekannt war. Positive Referenzen zum Charakter wurden denn auch in die Entscheidungsfindung miteinbezogen, wie Bemerkungen in gleicher Bewerberliste offenbart: Zum unterlegenen einheimischen Martin Vielle war beispielsweise notiert: „Les municipaux présent a l'examen ont approuvé sa conduite, exceptes qu'il est un peu fréquement au Cabaret. ${ }^{\text {“905 }} \mathrm{Zu}$ viele Wirtshausbesuche waren dem geforderten einwandfreien Vorbildcharakter eines Kinderlehrers in der öffentlichen Meinung abträglich, wie das Zitat zeigt.

Die beiden Examensberichte aus Fribourg bestätigen in der Gesamtschau mit den baselländischen Examensberichten die Tendenz zu einer zunehmenden leistungsorientierten Ausrichtung der Examen durch die kantonalen Erziehungsräte, aber auch durch die prüfenden Pfarrer vor Ort. Nicht der billigste, sondern der fachlich beste Kandidat wurde bewusst nach objektiven Kriterien gewählt, zumal selbst Lehrersöhne und bereits etablierte Schulmeister sich nicht mehr ausschliesslich auf ihren Vorteil berufen konnten, sondern ebenfalls vor Ort auf ihre Fähigkeiten geprüft wurden. ${ }^{906}$ Damit einher ging zum einen die Aufweichung des Primats der Lokalrekrutierung zugunsten auswärtiger Kandidaten. Die Herkunft der Kandidaten verlor an Einflusskraft. Zum anderen folgte eine schrittweise Verdrängung von Quereinsteigern ohne direkten Bezug zur Schule oder zu den Kulturtechniken durch die Präferenz von Personen mit höherer Bildung oder mit schulischer Erfahrung.

An den untersuchten Examen nahmen ferner - soweit es die Berufsbezeichnungen der Kandidaten zu rekonstruieren erlauben - kaum Angehörige der untersten Schichten teil. Weder Knechte, Mägde, Taglöhner noch sonstige Angehörige der landlosen Unterschichten hatten sich um die freien Schulstellen beworben und waren demnach nicht auf den Bewerbungslisten aufgetaucht, sondern primär Personen mit ausgewiesenen Kulturtechnikkompetenzen, insbesondere bereits praktizierende Lehrer, Hauslehrer, Dorfbeamte oder studierte Pfarramtskandidaten. An valablen Kandidaten mangelte es jedenfalls an den meisten Orten kaum.

Freilich setzte sich mit der zunehmenden Leistungsorientierung in der Helvetischen Republik unter den Prämissen des neuen Staatswesens ein Prozess der Professionalisierung in der Lehrerrekrutierung fort, der schon im Ancien Régime begonnen hatte. Gerade in jenen Regionen der Alten Eidgenossenschaft, wo die landesherrschaftliche Durchdringung bis auf die lokale Ebene funktionierte, klare normative Vorgaben in Form von verbindlichen Schulordnungen bestanden, die ökonomische Ausgestaltung des lokalen Schulwesens eine gewisse Attraktivität versprach, und wo die kantonalen Erziehungsbehörden die Wahl- und Bestätigungsautorität erfolgreich für sich beanspruchen und durchsetzen konnten, hatte sich schon vor 1798 eine funktionierende meritokratisch-leistungsorientierte Selektion etablieren können. ${ }^{907}$ Hierauf konnten die neuen helvetischen Erziehungsbehörden erfolgreich aufbauen. Wo die Wahlrechte allerdings exklusiv und direktdemokratisch bei der örtlichen Gemeinde lagen, ohne dass vorgesetzte Autoritäten eine Mitsprache bei der Kandidatenwahl hatten, wirkten nicht-meritokratische Argumente - Geburtsrecht, soziale Netzwerke oder persönliche Sympathien - oftmals noch wirkungsmächtiger als das reine Leistungsprinzip. Ein hoher Grad an Lokalautonomie im Schulwesen ist daher aus der Perspektive eines durch Leistung erzielten Fortschritts als ambivalent zu beurteilen. Zwar zeigt sich im Ringen um die Bestimmungshoheit im Schulwesen eine

905 AEF H 437.2, o. Pag.: 20.10.1800 - Belfaux.

906 Brühwiler, Finanzierung: 187.

907 Brühwiler, Finanzierung: 187. Dazu zählt auch die Lehrerbrevetierung mit schriftlichen Zertifikaten im Kanton Solothurn bereits ab 1784 nach dem Besuch der Normalschulkurse. Mösch, Solothurnische Volksschule: 90-93. 
"grosse Verankerung der jeweiligen lokalen Schule in der Bevölkerung "9908, andererseits wirkte sich ein hoher Grad an lokaler Autonomie eher hemmend auf Fortschritte im Leistungs- und Qualitätsbewusstsein in Bezug auf die Wahl der Lehrkräfte aus.

Die zunehmende Leistungsorientierung dürfte ferner auch auf das Selbstverständnis und die Identifikation der geprüften Lehrkräfte gewirkt haben. So schuf ein bestandenes Examen nicht bloss Legitimation durch den fachlichen Nachweis der Befähigung, sondern stimulierte auch das Selbstverständnis und Selbstbewusstsein der erfolgreichen Kandidaten. Die bestandene Prüfung war der Beweis ihrer Zugehörigkeit zum Kreis der „Experten“ in Sachen Kulturtechniken. Zudem schuf das - wenn auch noch unsystematische - Examinieren vermutlich eine gemeinsame Erfahrungsbasis als identitätsstiftendes Merkmal zwischen den Lehrpersonen. Inwieweit diese Vermutung aber tatsächlich in den Identitäten der Lehrer am Ende des 18. Jahrhunderts erkennbar ist, müssten nachfolgende Forschungen zeigen. 


\section{Lehrer sein - Entwicklungen von Lehrer-Biografien}

In ihrer Regionalstudie zur Zürcher Lehrerschaft um 1770 resümiert Alexandra Bloch Pfister exemplarisch zu den wichtigsten Merkmalen des beruflichen Alltages von Schulmeistern: „Das Amt des Schulmeisters war ein Neben- oder Teilerwerb, der zusätzlich zu anderen agrarischen sowie nicht-agrarischen Tätigkeiten oder Teilerwerben zumeist im Winter, teil- und zeitweise auch von mehr als einer Person betrieben wurde. ${ }^{\text {“909 }}$

Unter der paradigmatischen Annahme, dass das Lehramt als Teil der „Ökonomie des Notbehelfs“ - vergleichbar mit einem Landhandwerk - eine spezialisierte ökonomische Nische für landarme oder landlose Unterschichten darstellte, dessen Charakter auf die saisonale Teilerwerbsfunktion beschränkt blieb, muss der Frage nach den „typischen“ Formen der Ausgestaltung der Berufsbiografien von Lehrkräften nachgegangen werden. Die bisherige Forschung zum frühneuzeitlichen Schulwesen hat sich aufgrund der zumeist statischen Quellenlage und der nur spärlich vorhandenen Einzelbiografien bislang erst wenig mit der Frage der Ausgestaltung von Berufsbiografien von Elementarschullehrern auseinandergesetzt. Das Augenmerk lag vielmehr auf der Klassierung der Lehrerschaft innerhalb des sozialen Hierarchiefelds der ländlichen Gesellschaft aufgrund einzelner sozialstatusrelevanter Indizien, wobei primär die Nebenbeschäftigungen und das Einkommen untersucht wurden. Das Resultat war eine Einstufung der Lehrkräfte als mehrheitlich prekär verdienende Angehörige der sozialen Unterschichten mit einem notgedrungenen Hang zur Polyprofessionalität. ${ }^{910}$

Die Zusammenhänge zwischen den disparaten Einkommen aus der Schularbeit, den zahlreichen unterschiedlichen ausgeübten Nebentätigkeiten und der Ausgestaltung der Lebensverläufe sind freilich komplex und multikausal, wie ein Blick in die empirisch erhobenen Lebensverläufe der Lehrkräfte offenbart. Zum einen bestimmte die Höhe des jährlichen Einkommens - dessen Zusammensetzung von einer Reihe von lokalen Faktoren wie Schulgeldern, obrigkeitlichen Fonds, zusammengelegten Geldern der Hausväter beeinflusst war - die Notwendigkeit zum Ausüben von Nebentätigkeiten. ${ }^{911}$ Unklar bleibt, ob und inwiefern das Schuleinkommen auch von individuellen Faktoren wie der Diensttreue der Lehrkräfte und dem Grad der Zufriedenheit der Gemeinde mit der Lehrkraft beeinflusst wurde.

Zum anderen steuerte aber auch die jährliche Schuldauer sowohl die Höhe des jährlichen Einkommens der Lehrkräfte als auch die Restmenge an verfügbarer Zeit, um überhaupt einer Nebentätigkeit nachgehen zu können. Denn je länger eine Lehrkraft im Jahresgang als Schulmeister arbeiten musste, desto weniger Zeit blieb für Nebenbeschäftigungen und desto höher musste folglich die finanzielle Entschädigung dafür ausfallen.

Die jährliche Schuldauer und das Einkommen aus der Schultätigkeit stellen somit die beiden Schlüsselfaktoren für die gesamtberufliche Ausgestaltung dar. Da sowohl die Schuldauer pro Tag und im Jahresgang als auch die Einkommenshöhe in der Regel von den Schulgemeinden respektive den Hausvätern autonom festgelegt wurden, variierten diese jedoch in sehr heterogener Weise von Ort zu Ort, zumal die obrigkeitlichen Schulordnungen bloss die minimale

909 Bloch Pfister, Priester: 84.

910 Vgl. das Kap. 1.3.3 sowie die folgenden Kap. 3.1 und 4.1.

911 Zur Zusammensetzung von Lehrerlöhnen vgl. Brühwiler, Finanzierung: 125-172. 
Schuldauer im Winter vorschrieben, die konkrete Ausgestaltung von Sommerschulunterricht jedoch an die Gemeinden oder an die Lehrerschaft delegierten. ${ }^{912}$

Ferner bestand aus der Subordination des elementaren Schulwesens unter die Obhut der Kirche vielerorts eine direkte monetäre Verknüpfung des Lehramts mit kirchlich-liturgischen Hilfstätigkeiten aus einkommensrationalen Gründen. ${ }^{913}$ Diese gleichzeitige Kombination von Lehramt und kirchlichen Hilfsdiensten lässt die Frage aufkommen, inwiefern sich der individuelle Handlungsspielraum zur Ausübung von eigenständigen Nebentätigkeiten dadurch einschränkte beziehungsweise überhaupt gegeben war. Ebenso unklar ist, ob und unter welchen Bedingungen das Lehramt in der Lebenswelt der Lehrkräfte als Teilerwerb oder als Haupterwerb wahrgenommen wurde und wie sich die berufliche Grundkonstellation an Erwerbstätigkeiten mit der Lehramtsübernahme veränderte.

Des Weiteren ist in einer ökonomisch fokussierten Perspektive eine direkte Kausalität zwischen der Verweildauer im Lehramt und dem Schuleinkommen anzunehmen. Nur wenn sich das Ausüben des Lehramts für die Protagonisten als lohnenswert erwies, blieben die Lehrkräfte ihrem Amt längerfristig treu, so das daraus abgeleitete Postulat. Die Ausgestaltung und Dynamik der Lebensverläufe hinsichtlich der beruflichen Kontinuität, der Anzahl und der Veränderungen an Erwerbsbereichen sowie der beruflichen Mobilität tragen demnach wesentlich zum Verständnis des berufsbiografischen Verhaltens der Lehrerschaft als Handlungsakteure bei. In einem speziellen Fokus steht dabei die Generation der über 50-jährigen Lehrkräfte, von denen die umfangreichsten und damit aussagekräftigsten Berufsbiografien erwartet werden können.

Bevor auf die zu untersuchenden Kausalitäten und Interdependenzen zwischen ökonomischen Bedingungen und der Ausgestaltung der Berufsbiografien durch Nebentätigkeiten eingegangen werden kann, ist präliminär die Einkommenssituation der helvetischen Elementarschullehrer um 1800 in einer regional differenzierten Übersicht zu betrachten. Denn erst einmal muss Klarheit bestehen, wie die Besoldungslage für die helvetische Lehrerschaft überhaupt ausgestaltet war.

\subsection{Das Einkommen aus der Schultätigkeit}

„Der Lehrer sei arm, aber brav“914 - wie der Titel einer regionalen Forschungsarbeit zur aargauischen Lehrerschaft eingängig zeigt und wie bereits in der Einleitung dieser Arbeit erläutert wurde, hat sich das Element der Armut und damit verbunden die Tatsache der oftmals prekären Besoldung der Lehrer für ihre Schularbeit zu einem der zentralen Paradigmen bei der Erforschung des Elementarschulwesens etabliert. Bereits zeitgenössische Abhandlungen über das Schulwesen betonten - notabene meist in volksaufklärerischer Perspektive und mit grundsätzlich guten Absichten für die Lehrer verbunden - die mangelhafte Besoldung der Lehrerschaft. So hielt etwa der Pfarrhelfer Gottlieb Sigmund Gruner im Jahr 1790 zu den Einkommensverhältnissen der bernischen Schullehrerschaft fest: „Ihre Besoldung beläuft sich jährlich vielleicht bey den meisten auf 12, 18, hie und da auf 30-40 Cronen [...] selten höher; sehr wenige haben über dieß hinaus noch freye Wohnung und Holz, oder gar einen Gemüs- und Obstgarten, und auf das Allerhöchste Futter für eine Kuh oder Ziege. Ich zweifle sehr, ob im ganzen Lande auf Dörfern zehen Schulstellen zu finden seyen, die, alles genau berechnet, 70 Cronen einbringen. ${ }^{\text {"915 }}$

912 Vgl. zur jährlichen Schuldauer das Kap. 1.6.2.

913 Vgl. zur vertieften Betrachtung das folgende Kap. 3.3.2.

914 Brian/Stegmeier, Lehrerschaft.

915 Gruner, Bemerkungen: 107. Wie repräsentativ Gruners Beobachtungen allerdings wirklich waren, ist umstritten, zumal er seine Perspektive auf das Schulwesen ausschliesslich mit seinen persönlichen Erfahrungen und mit Berichten von „Freunden“ begründete. Vgl. die Kritik bei: Helfenberger, Aspekte: $30 f$. 
Gruners Zweifel sollten sich in einer empirischen Überprüfung zwar als falsch herausstellen, wenngleich die Grundintention seiner Aussage nicht unberechtigt war. ${ }^{916}$ Die Lehrerschaft bestätigte in den frei anzufügenden Anmerkungen am Ende des Fragebogens zur Stapfer-Enquête in zahlreichen Äusserungen ihre Unzufriedenheit mit der Gehaltshöhe. Beispielhaft wird der Unmut in der Zusatzbemerkung des Lehrers Ludwig Kurtz von Walkringen BE sichtbar: „Meine Anmerkung ist schon Längsten geweßen es seye ein allzu Sehr geringe besoldung, für eine Solche Schul, ein Schlechter Taglöhner, kan von Martini. bis auf den 25ten. Mertz, da die Schul auf hört, Ein Mehres Einko\{men\} machen als Jch [...] wan Jch nicht noch Etwan guthhertzige hausvätter in Meinem bezirck häte, dia an meine Schlechte besoldung denckte, und mir durch ihre Kinder den Winter hindurch Etwas zum Present und Trinkgelt Schicken Thäten, So Hätte Jch die Schul Längstens quittiert und aufgegeben." ${ }^{\text {"17 }}$

Unzählige weitere archivierte Berichte und Rapporte aus der Hand von Volksaufklärern, Pfarrern und Schulinspektoren bestätigen fast unisono den beschriebenen desolaten Besoldungszustand in allen Regionen der Helvetischen Republik. Von „bitterster Armuth“ und „schwärzestem Hunger“ war ebenso die Rede wie von Einkommensverhältnissen, „die bisher schlechter als der geringste Taglöhner, als der elendeste und niedrigste Copiste eines Bureau“918 ausfielen. Kombiniert ergaben jene Berichte aus der Hand der Schulvorgesetzten und die Antworten der Stapfer-Enquête in ihrer übereinstimmenden Vielzahl eine wirkungsmächtige Kulisse, die keinen Zweifel übrig liess, dass die Mehrheit der Elementarschullehrerschaft durch ihre „elende Besoldung " ${ }^{\text {"919 }}$ in prekären ökonomischen Zuständen lebte. Selbst die kommunalen Agenten als neue Mittler zwischen der helvetischen Regierung und den Gemeinden bestätigten breitflächig die desolate finanzielle Entlohnung der Elementarschullehrer, wie etwa in den zahlreichen Vorschlägen zur Verbesserung des Schulwesens im Kanton Linth exemplarisch sichtbar wird. ${ }^{920}$ Die prekäre Lohnsituation der Lehrerschaft war damit nicht nur eine Frage der Selbstperspektive, sondern vielmehr in einer breiten zeitgenössischen Wahrnehmung verankert. ${ }^{921}$

Kaum anders fiel die Bewertung der Lehrereinkommen in der später folgenden liberalen Geschichtsschreibung im 19. Jahrhundert aus. Otto Hunziker resümierte 1881 in seiner Darstellung zum Schulwesen: „Die Lehrergehalte waren je nach den Verhältnissen der Gemeinden höher oder geringer, aber durchweg ungenügend“" ${ }^{22}$ Was freilich ausblieb, war eine kritische Auseinandersetzung mit den Quellen selbst, ohne den Grundsatz ihrer Botschaft in Frage stellen zu wollen. Denn nicht selten standen handfeste Reformabsichten hinter den dramatischen Beschreibungen von Agenten, Pfarrern oder Schulinspektoren. Gerade den Schulinspektoren, deren Berichte oftmals als Grundlage späterer Forschungen zitiert wurden, lag oftmals viel daran, die Zustände in ihrem Distrikt weitaus dramatischer darzustellen als es die Schulwirklichkeit tatsächlich war, um Aufmerksamkeit und zusätzliche Mittel für ihre Schulen gewinnen zu können. So stösst man in nicht wenigen dieser summarischen Berichte über das lokale Schulwesen

916 Vgl. zur Einkommensverteilung des Kantons Bern das übernächste Kap. 3.1.2.

917 Schmidt u.a. (Hgg.), Stapfer-Enquête, Nr. 944: Walkringen.

918 LaGL HA, Kiste 27, Mappe D, o. Pag.: 27.04.1801 - Schulrapport; zit. u.a. bei Landolt, Linth: 154.

919 Die Wortwahl des Pfarrers Sutermeister zu den Einkommensverhältnissen seiner Lehrer in der Kirchgemeinde Beatenberg. StABE Helv OL 151, o. Pag.: 02.08.1798 - Beatenberg.

920 Gefragt nach Vorschlägen zur Verbesserung der Schule, wurde die Anhebung der Lehrersaläre als meistgenannter Vorschlag angebracht. „Da die Besoldung der Schullehrer in dieser Gemeinde geringe, so wäre Erhöchung deßelben zu wünschen, damit mann bey erhöchtem Solde mehr von ihnen forderen könnte." LaGL HA Protokollband 83, fol. 15: [1798] - Schulumfrage. Vgl. Rothen/Ruloff, Schulumfragen: 47.

921 Bütikofer, Staat: 208ff.

922 Hunziker, Volksschule: 21. 
auf eklatante Widersprüche, wenn etwa das Schulwesen im Gesamten als rückständig kritisiert, die einzelnen Schulen und ihre Schulmeister jedoch im gleichen Atemzug fast durchwegs als tauglich, leistungsstark und sozial angesehen eingeschätzt wurden. Ein augenfälliges Beispiel dazu liefert der Bericht des Schulinspektors Leonhard Tschudi über den Schuldistrikt Schwanden im Kanton Glarus vom Frühjahr 1801. Wurde einleitend auf den schlechten Zustand des Schulwesens insgesamt hingewiesen - „Allein schon das wass jedem auch nicht genauem Beobachter, nur zu sehr auffalt, wird auch jeden genugsam, von dem tristen und traurigen Verfalle dieser Anstalten überzeügen“ - wurde im folgenden Detailbericht dennoch bloss eine von insgesamt acht weltlichen Lehrkräften des Distrikts als unbrauchbar beschrieben, die übrigen hingegen als „tüchtig“, „tätig“, „brauchbar“, „mit gutem Zeugnis versehen“ oder „mit ordentlichen Kenntnissen ausgestattet“ prädiziert. Die Begründung für den Widerspruch lieferte Tschudi gleich mit: „Wenn ich Sie [die einzelnen Schulen und ihre Schulmeister] durchgehens noch so gelinde beurtheilte, so muss ich Jhnen sagen: dass ich den gegenwärtigen Schulzustand nach dem Maassstab des Alten gemessen, und nicht nach dem, was eine Schul Anstalt wirklich seyn sollte. Nach diesem berechnet ist doch das Schulwesen im Ganzen im traurigsten Verfall.“923

Ein grosser Teil der zeitgenössischen Defizit-Beschreibungen über das Elementarschulwesen ist folglich in der spezifischen reformorientierten Soll-Perspektive der quellenverfassenden Betrachter zu verorten und zu verstehen, und entsprach nicht zwingend der tatsächlichen lebensweltlichen und schulischen Realität vor Ort. Aus diesem Grund ist auch das Paradigma des armen, unterbezahlten und folglich sozial geächteten Schullehrers kritisch zu hinterfragen und zu präzisieren, wenngleich die Tatsache der vielfach niedrigen Besoldungslage nicht a priori in Frage gestellt wird. Insbesondere ist die Gleichung zu beleuchten, dass eine niedrige Besoldung für die Lehrertätigkeit automatisch auf Armut verwies und dies wiederum automatisch mit einem tiefen sozialen Status einherging.

Kritische Zwischenrufe zur Gefahr einer unbedachten Verallgemeinerung des Armutsparadigmas der Landschullehrer sind allerdings bereits in der älteren Forschungsliteratur zu finden. Johann Mösch hat in seiner Längsschnittstudie über das Solothurner Schulwesen beispielsweise in Abweichung zu den Forschungen von Klinke, Schneider und Zingg festgehalten: „Unsere Lehrer gehörten übrigens durchaus nicht zu den ärmsten Schichten der Bevölkerung, die meisten besassen ein eigenes Haus. Bisher ist mir denn auch kein Beispiel von Bettelfängerei, worüber anderwärts viel geklagt wurde, bekannt geworden. ${ }^{\text {992 }}$ Die Solothurner Elementarschullehrerschaft unterschied sich in schulorganisatorischer Hinsicht jedoch nicht in markanter Weise von ihren Berufskollegen aus den umliegenden Kantonen. Einzig ihre systematisierte Fortbildung zu Normalschullehrern markierte eine schulinhaltliche Differenz, diese brachte aber weder unmittelbare soziale noch ökonomische Vorteile mit sich.

Dass die Einkommensverhältnisse und der Sozialstatus der Elementarschullehrerschaft höchst komplex und vielgestaltig waren, haben die jüngeren Forschungsergebnisse von Esther Berner und Alexandra Bloch Pfister zur Zürcher Lehrerschaft noch einmal eindrücklich hervorgehoben. Esther Berner hält fest, dass das Schulmeistereinkommen der Zürcher Lehrer um 1770 im Berufsgruppenvergleich „unter demjenigen eines Handwerkers anzusetzen ist, jedoch deutlich über demjenigen eines Knechtes und auch über demjenigen in der Heimindustrie“. Ferner weist sie auf das historiografische Problem des defizitären Status des Schulmeisters aus der alleinigen Ableitung von seinem Einkommen hin. ${ }^{925}$ Demgegenüber verweist Alexandra Bloch Pfister

923 LaGL HA Kiste 27, Mappe D, o. Pag.: 27.04.1801 - Schulrapport.

924 Mösch, Solothurnische Volksschule: 105.

925 Berner, Zeichen: 93. 
auf die kleinräumigen regionalen Unterschiede hinsichtlich des Einkommens, des Vermögens und des Sozialstatus der Lehrkräfte hin: „Im Zürcher Unterland verfügten die Schulmeister im 18. Jahrhundert über einen so hohen durchschnittlichen Landbesitz, dass die mit den Müllern und Wirten zu den reichsten Professionisten gezählt werden können. Dies widerspricht dem

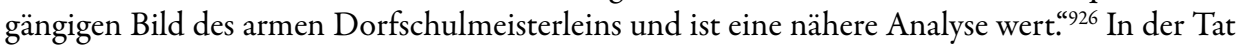
überlieferte gerade die Umfrage von 1771/72 mitunter eine Reihe von Berichten über wohlhabende Lehrkräfte im Zürcher Unterland und entlang des Zürichsees. Zum Lehrer in Thalwil ZH stand etwa geschrieben: „Dess Schulmeisters aüsserl. umstände sind also beschaffen, dass er sich auch ohne besoldung durchbringen könte. um so viel mehr, wenn die besoldung darzu kommt, u. folglich kan er sich der Schule gänzlich widmen." ${ }^{\text {"927 }}$

Die enormen regionalen Disparitäten, insbesondere die grossen Stadt-Land-Unterschiede sowie die Abhängigkeit des Einkommens vom Schultyp bei der Besoldung der Lehrerschaft hat Ingrid Brühwiler in ihrer umfangreichen Studie zur Finanzierung des Schulwesens um 1800 dargestellt. Lehrkräfte an städtischen Schulen, insbesondere Geistliche, verdienten in allen Gegenden der Helvetischen Republik deutlich mehr als Landschullehrer. Doch auch innerhalb der Städte und selbst innerhalb einzelner vermengter Schulinstitutionen existierten grosse Lohnunterschiede in vertikaler Hinsicht. Höhere Latein- und Gymnasiallehrer verdienten insgesamt besser als ihre Kollegen an Elementarschulen. Brühwiler hat ferner aufgezeigt, dass klagende Äusserungen vonseiten der Lehrerschaft über die geringe Lehrerbesoldung paradoxerweise vor allem von mittel- bis gut verdienenden Lehrkräften stammten und Lehrkräfte im Vergleich mit handwerklichen Berufen oder sogar Armengenössigen oft viel besser bezahlt waren, namentlich im Direktvergleich der Tageslöhne. ${ }^{928}$

Dazu kommt, dass bei der Betrachtung der Schulmeisterlöhne in vielen älteren Darstellungen oftmals der Umstand vergessen gegangen ist, dass die Entschädigung der Lehrer im 18. Jahrhundert unmittelbar an die zu leistende jährliche Schuldauer geknüpft war und das in den Quellen festgehaltene Jahreseinkommen nicht einer ganzjährig ausgeübten, existenztragenden Tätigkeit entsprach, wie es unserem modernen Verständnis von Berufstätigkeit und existenzsichernder Entlohnung entspricht. Die Besoldung einer Lehrkraft, welche ausschliesslich einige Wochen im Winter unterrichtete, musste gar nicht existenztagend für das gesamte Jahr sein, da in der restlichen Zeit des Jahres aus Nebenverdiensten zusätzliche Mittel dazu flossen. ${ }^{929}$

Die meisten Lehrer lebten - wie bereits dargestellt wurde - keineswegs ausschliesslich von dem Schuleinkommen beziehungsweise das Schuleinkommen entschädigte die Lehrkraft ausschliesslich für die tatsächlich aufgewendete Zeit und für ihren theoretischen Erwerbsausfall in ihrer sonstigen Tätigkeit. Klagten die Lehrer über ihren Lohn, orientierten sie sich in der Regel an einem hypothetischen Ganzjahreseinkommen als Zielgrösse, während für die Gemeinden bei der Festlegung der Besoldungshöhe nicht nur der kommunale Finanzierungsspielraum Grenzen setzte, sondern auch die ökonomische Gesamtsituation der Lehrpersonen mit deren möglichen Zusatzeinkünften aus weiteren Teilerwerbstätigkeiten wahrscheinlich sehr genau mitkalkuliert wurde. Ob den Lehrern angesichts der auf die tatsächliche Schuldauer beschränkten Besoldung wirklich keine andere Wahl blieb, „als ein äusserst karges Leben zu führen oder eine andere Einnahmequelle

926 Bloch Pfister, Priester: $98 \mathrm{f}$.

927 StAZH E I, 21.8 - Thalwil.

928 Brühwiler, Finanzierung: 280f.; $315 \mathrm{ff}$.

929 Vgl. Schmidt, Kapitel Bern: 155. Auf die Problematik der im modernen Verständnis verzerrten Projektion der absoluten Lohnhöhe als ganzjähriger Lebensunterhalt hat 1905 bereits Ernst Schneider hingewiesen: Schneider, bernische Landschule: $70 f$. 
zu suchen, [...] wobei fraglich ist, ob ihnen das Amt des Schulmeisters oder der Nebenverdienst wichtiger war ${ }^{\text {“930 }}$, und „zusätzliche Erwerbsquellen [...] deshalb absolut notwendig “931 waren, sofern es sich nicht um eine ganzjährig dauernde Schule handelte, ist eine offene Frage.

Im Gegensatz zu Ingrid Brühwilers Referenzstudie zu den Einkommens- und Finanzierungsverhältnissen mit ihren umfangreichen Stichprobenuntersuchungen richtet sich der Fokus im Folgenden auf qualitative Wertungen des Einkommensdiskurses und auf einzelne lokale Betrachtungen von Einkommensverhältnissen. Für einen breitflächigen quantitativen Vergleich fehlen zum einen für zahlreiche Naturalien konkrete Preiswerte, zum anderen sind viele Angaben schlicht zu ungenau formuliert, als dass sie einen Vergleich oder eine Hochrechnung zulassen würden. Zum anderen fehlen aus zahlreichen Regionen der Helvetischen Republik zuverlässige Überlieferungen der damaligen Marktpreise. Zwar wurden während der Helvetik sogenannte „Mittelpreistabellen“ erstellt, auf denen die aktuellen Getreide- und Weinpreise festgehalten wurden, doch bleibt unklar, wieweit sich diese Marktpreise für die Landschaft überregional interpolieren lassen.

Welche neuen Erkenntnisse hinsichtlich der Einkommen der Lehrkräfte sind nun noch zu gewinnen? Den meisten bisherigen einschlägigen Forschungsergebnissen zu Einkommensentwicklungen fehlt der Einbezug der Person des Lehrers abseits der stets untersuchten lokalstrukturellen Gunst- oder Ungunst-Faktoren. ${ }^{932}$ Es sind zum einen offene Fragen, inwieweit eine direkte oder mindestens indirekte kausale Korrelation der Einkommenshöhe mit den ausgeübten Nebentätigkeiten und mit der wirklichen Leistung beziehungsweise der Leistungsbereitschaft der Schulmeister bestanden hatten, die verschiedentlich in der Literatur betont worden sind. ${ }^{933}$ Das gleiche gilt zum anderen angesichts der festgestellten grossen Einkommensdisparitäten für die fragwürdige Postulierung der angeblich geringen sozialen Stellung der Lehrer im Dorf. ${ }^{934}$ Des Weiteren ist unklar, welchen Einfluss individuelle biografische Entwicklungen auf die Besoldung hatten. Wurde Berufstreue monetär belohnt? Stieg das Einkommen bei Stellenwechseln? Verdienten ältere Lehrkräfte mehr als jüngere Lehrer? Spielte der erstberufliche oder Ausbildungs-Hintergrund bei der Lohnfestlegung eine Rolle? Diesen Fragen wird zum einen im folgenden Kapitel, teilweise aber auch integral an anderer Stelle nachgegangen.

Bevor einzelne Einkommensverhältnisse genauer unter die Lupe genommen werden können, muss ein Referenzrahmen definiert werden, ab welcher Einkommenshöhe beziehungsweise Geldsumme eine Lehrkraft „ausreichend“ oder „gut“ verdient hatte. Hierzu wird als Differenzierungsgrenze zwischen ungenügenden und genügenden Einkommen der inoffizielle jährliche „Mindestlohn“ von 1.000 Batzen oder 100 Franken für eine ganzjährige Schultätigkeit verwendet. Der politische Diskurs um diesen inoffiziellen Mindestlohn für Lehrkräfte in der Helvetik wird im folgenden Abriss kurz erläutert.

\subsubsection{Die Frage des Mindestlohns im helvetischen Diskurs}

Die angeblich prekäre Besoldungslage vieler Schulmeister im Elementarschulwesen beschäftigte sowohl Philipp Albert Stapfer als auch sein volksbildungsaffines Umfeld seit seinem Amtsantritt als Minister des Bildungswesens. In Stapfers Umfeld wurde in Bezug auf die Lehrerschaft neben einer einheitlichen Grundbildung insbesondere die Notwendigkeit eines staatlich gesicherten

930 Landolt, Linth: 155.

931 Bloch Pfister, Priester: 109.

932 Montandon, Determinanten: 241-281; Rothen, Erkenntnisgewinn: 37ff.; Ruloff, Konkurrenz: 56f.; Schmidt, Kapitel Bern: $155 f$.

933 Vgl. das Kap. 4.1.

934 Vgl. das Kap. 4.1.2. 
besseren Einkommens intensiv diskutiert. Die Idee eines einheitlichen, staatlich garantierten fixen Lohns für Lehrer sollte nicht zuletzt mithelfen, die alten sozialen Rangunterschiede zu beseitigen und die Lehrerschaft durch eine erhöhte Wertschätzung sozial aufzuwerten, ja sogar zu Staatsbeamten werden zu lassen. ${ }^{935}$ Im Rahmen seines projektierten nationalen Schulgesetzes beabsichtigte Stapfer, einen nationalen Mindestlohn für Elementarschullehrer einführen, dessen Evolution im Rahmen der Gesetzesdiskussionen im helvetischen Parlament einen symptomatischen Einblick in die Ambivalenz von subjektiven Wünschen und Visionen der helvetischen Reformer gegenüber der ökonomischen Realität liefert.

Der von Stapfer vorgeschlagene jährliche Mindestlohn für ganzjährig unterrichtende Elementarschullehrer belief sich in seinem ersten Gesetzesentwurf vom 24. Juli 1798 unter Einschluss einer freien Wohnung mit Garten auf exorbitante 800-1.000 Franken, wobei Gemeinden mit über 8‘000 Einwohnern den Mindestlohn gar auf 1.200 Franken erhöhen sollten. ${ }^{936}$ Dieser unrealistisch hohe Geldwert orientierte sich augenscheinlich an den Salären von von höheren Stadtschullehrern und Hochschulgelehrten. Selbst hatte Stapfer an der Akademie von Bern als Dozent für Theologie gelehrt und kannte so die Besoldung für Hochschullehrer. ${ }^{937}$ In einem zweiten undatierten Entwurf des gleichen Schulgesetzes, vermutlich aber ebenfalls noch aus dem Jahr 1798, senkte Stapfer den projektierten Mindestlohn bereits kommentarlos um die Hälfte auf 400-600 Franken. ${ }^{938}$ Darin kann ein erstes Zugeständnis an die schwierige finanzielle Lage der helvetischen Zentralbehörden gelesen werden, die auch Stapfer als Minister der Künste und Wissenschaften bestens bekannt gewesen sein dürfte.

In den politischen Beratungen der helvetischen Räte war jedoch auch die reduzierte Summe chancenlos. In der Botschaft des Grossen Rates der Helvetischen Republik an den Kleinen Rat (Senat) vom 20. März 1799 war der Mindestlohn für Lehrkräfte zwar noch vorhanden, wurde aber mittlerweile massiv auf noch 150 Franken pro Jahr reduziert. ${ }^{939}$ Zeitgenössische Forderungen gingen teilweise noch weiter als Stapfer. So forderte etwa der Seeländer Distriktsinspektor Ith gleichentags in seinen Bemerkungen zu den Antworten auf die Stapfer-Enquête gar eine Anhebung der Lehrereinkommen auf durchschnittlich 100 Kronen oder 250 Franken, gleichwohl die Lehrerlöhne in seinem Distrikt im Allgemeinen bereits höher waren als anderswo. ${ }^{940}$ Der Entscheid zur Abschaffung der Feudallasten und die damit ausgebrochene Geldnot in den Kommunen sowie die mittlerweile geplünderten Staatsschätze der Kantone liessen die Besoldungsvorstellungen Stapfers in der politischen Realität zur Makulatur werden. Auch die uneinigen Räte gaben ihren Teil dazu bei. Im abschliessenden Entwurf des Schulgesetzes des Grossen Rates vom 20. November 1799 wurde der Betrag des Mindestlohnes ein weiteres Mal auf nunmehr 100 Franken reduziert. ${ }^{941}$ Obwohl letztlich nur rund ein Zehntel der ursprünglich gefor-

935 Bütikofer, Staat: 208ff; Vgl. auch den Diskurs in den diversen Korrespondenzen zahlreicher helvetischer Persönlichkeiten an Stapfer: Tosato-Rigo, Bild: 62-66.

936 BAR B0 1000/1483, Nr. 1422, fol. 241: [1798] - Projet. Vgl. das Transkript bei Luginbühl, Stapfer: 528. Zur Schulgesetzgebung während der Helvetik vgl.: Bütikofer, Projekt: 33-55.

937 Zur Biografie von Philipp Albert Stapfer vgl. die Zeittafel bei Rohr: Stapfer: 417. Die gewählte Lohnhöhe könnte massgeblich von der Zuschrift des Solothurner Priesters und Lehrers Urs Jakob Tschan beeinflusst worden sein, der für Elementarschullehrer dieselbe Besoldung forderte wie für Lehrer höherer Schulen, selbst wenn er keinen genauen Geldwert nannte. BAR B0 1000/1483, Nr. 1422, fol. 124-124v [1798] - Schulen; Tosato-Rigo, Bild: 63. Der Basler Johann Friedrich Miville veranschlagte dagegen einen monatlichen Mindestlohn von 540 Basler Batzen pro 60 Schüler, was einem Jahresgehalt von rund 650 Franken entsprach. Bütikofer, Staat: 210.

938 BAR B0 1000/1483, Nr. 1422, fol. 295: [1798] - Loi.

939 BAR B0 1000/1483, Nr. 1422, fol. 235: 20.03.1799 - Senat.

940 StABE B III 903, o. Pag.: 20.03.1799 - Bürger Präsident.

941 Luginbühl, Stapfer: 546. 
derten Lohnsumme im später gescheiterten Gesetz Eingang fand, ergab sich mit den 100 Franken pro Jahr für eine Ganzjahresschule ein konkreter Vergleichswert, der nun zumindest mit der zeitgenössischen Schulrealität in einer realistischen Relation stand. So taxierte eine Vorgabe des Schulrates von Bern im Jahr 1804 die Lohnsumme von 1.000 Berner Batzen oder 100 Franken als einen „ausreichenden Lohn“ für eine Ganzjahresschule und zum Erhalt einer vierköpfigen Familie. ${ }^{942}$ Umgerechnet auf eine zu leistende Arbeitswoche bei einer mittleren ganzjährigen Schuldauer von rund 40 Wochen ergibt diese Summe einen Mindestlohn von ungefähr 25 Batzen, 2 Franken und 3 Sols oder 1 Gulden und 30 Kreuzer pro geleistete Schulwoche. ${ }^{943}$ Diese Summe entsprach einem üblichen Arbeitslohn. ${ }^{944}$ War die Lehrkraft noch ledig oder musste zumindest noch keine Kinder versorgen, reichte eine jährliche Summe von 75 Franken oder 750 Batzen als Existenzminimum durchaus noch aus. ${ }^{945}$

Der helvetische Vollziehungsrat dekretierte ungeachtet der ungeklärten Finanzierungsfrage nach der Abschaffung der Feudallasten am 4. Dezember 1800 ein Mindestgehalt von 80 Franken mit freier Wohnung für das Halten der Winterschule. ${ }^{946}$ Damit wurde der Mindestlohn noch einmal nach unten gesenkt und der finanziellen Realität der Gemeinden angepasst, wenngleich auch diese Forderungen - besonders die freie Schulwohnung - von vielen Zeitgenossen als nicht umsetzbar angesehen wurde. Die Durchsetzung des Dekrets wurde den Kantonen beziehungsweise den kantonalen Erziehungsräten überlassen, die den Beschluss nur zögerlich oder - wie beispielsweise in Zürich - erst einmal gar nicht umsetzten. ${ }^{947} \mathrm{Zu}$ gross war die Angst vor einer Lawine aus finanziellen Forderungen, denen die kantonalen Behörden aus Mangel an Einkünften nicht Folge leisten könnten. Dennoch stellte das Dekret zumindest einen symbolischen Akt zur Verbesserung der ökonomischen Situation der Elementarschullehrer dar, an dem sich die späteren Debatten auf kantonaler Ebene in der Mediation und Restauration orientierten.

Die Mindestlohndebatte für Lehrkräfte erhielt auf der nationalen Ebene erst nach der Wiedereinführung der Zehnten und Grundzinse im Juni 1801 einen neuen Anschub und am 28. August 1801 hob der Vollziehungsrat den dekretierten jährlichen Mindestlohn auf den Wunsch mehrerer kantonaler Erziehungsräte wieder auf 100 Franken an. ${ }^{948}$ Doch auch dieses Dekret blieb angesichts der festgefahrenen politischen Lage, der parteipolitischen Streitereien und dem faktischen Fehlen einer legislativen Staatsgewalt weitgehend Makulatur, zumal viele Kantone erst noch mit der Berechnung und Nachzahlung von Einkommensausfällen durch die Abschaffung der Feudallasten beschäftigt waren. Zudem waren vielerorts die wiedererhobenen Zehnten nicht im gewünschten Umfang bezahlt worden, da es den Behörden an Autorität zur Durchsetzung mangelte. ${ }^{949}$

Der Zusammenbruch der Helvetischen Republik im Jahr 1803 und die Verlagerung der Macht auf die Kantone bedeuteten zwar das Ende des zentralstaatlichen Experiments und der Hoffnungen auf eine gesamtstaatliche Besserstellung der Lehrkräfte, war indes nicht das Ende der

942 Meyer, Langenthal: 45; Schmidt, Kapitel Bern: 154.

943 Der Berechnung liegt eine mittlere jährliche Schuldauer von 40 Wochen zugrunde, da die meisten Ganzjahresschulen - auch in Städten - den Unterricht während der Heu-, Getreide und Weinernte für mehrere Wochen aussetzten. Die Umrechnung basiert auf Berner Bz. ohne Berücksichtigung von regionalen Währungsdifferenzen: 1 Krone $=25$ Bz.; 1 Gulden = 15 Bz.; 1 Franken = 10 Bz.

944 Mösch, Ausbau: 59.

945 Schmidt, Kapitel Bern: 155.

946 Pfenniger, Luzerner Volksschule: 39; Strickler/Rufer, ASHR VI: 443.

947 Klinke, Zürich: 105.

948 Klinke, Zürich: 105; Strickler/Rufer, ASHR VII: 18, 402.

949 Vgl. die Etats an Besoldungsrückständen im Kanton Zürich, zusammengefasst in: Klinke, Zürich: 102-108. 
Reformbemühungen im Bildungswesen. Die in der Helvetischen Republik geschaffenen Erziehungsräte überdauerten den Zusammenbruch der Republik fast überall und führten ihre Arbeit nach dem Erlass der Mediationsakte weiter. In der Mediation wurde auf kantonaler Ebene denn auch möglich, was vorher auf nationaler Ebene gescheitert war: die Einführung von neuen Schulgesetzen. Darin hielten einzelne Kantone unter anderem explizite Mindestlöhne für die Lehrkräfte fest. So erhielten im Kanton Solothurn die Lehrer bereits im Jahr 1803 ein fixes Gehalt von 100 Franken pro Jahr für das Halten der Winterschule und Repetitionsunterricht im Sommer zugesichert. ${ }^{950}$ Im Kanton Waadt folgte im Jahr 1806 ein gesetzlicher Mindestlohn von 120 Franken pro Jahr. ${ }^{951}$ Im Kanton Basel belief sich das in der erneuerten Schulordnung von 1808 festgehaltene Mindestgehalt für Winter- und Sommerschulunterricht auf jährlich 60-100 Franken, abgestuft nach drei Kategorien von Schuleinrichtungen. ${ }^{952}$ Im Kanton Appenzell-Innerrhoden dauerte es bis ins Jahr 1811, bis den Lehrkräften ein fixes Gehalt von 50-150 Gulden pro Jahr zugesichert werden konnte. ${ }^{953}$ Andere Kantone, beispielsweise Zürich und Schaffhausen, verzichteten dagegen auch in den darauffolgenden Jahren auf die explizite Festschreibung einer konkreten minimalen Lohnsumme in ihren neuen Schulgesetzen. ${ }^{954}$

Der während der Helvetischen Republik diskutierte Mindestlohn für Elementarschullehrer setzte sich also in den Jahren nach dem Zusammenbruch des Zentralstaats ab 1803 teilweise auf kantonaler Ebene durch, wobei sich die festgeschriebenen Geldsummen der kantonalen Schulgesetze zwar deutlich an den nationalen Vorschlägen aus der Helvetik orientierten, jedoch im Direktvergleich stark variierten. Die kantonalen Schulgesetzgebungsprozesse ab der Mediationszeit ermöglichten somit in ambivalenter Weise zum einen die erfolgreiche Festlegung von reformorientierten neuen Ansätzen, die im zentralistischen Staatsprojekt noch gescheitert waren, legten aber zum anderen gleichzeitig den Grundstein für die grundsätzliche föderale Struktur im schweizerischen Schulwesen mit all ihren kantonalen Differenzen, die teilweise bis heute anhalten und beispielsweise im modernen Diskurs um die nationale Harmonisierung von Lehrplänen im Zuge der Lehrplanreform „Lehrplan21“ erneut zutage treten. ${ }^{955}$

\subsubsection{Regionale Einkommensverhältnisse}

Die bisherigen Forschungserkenntnisse weisen darauf hin, dass die soziale Stellung und die ökonomische Lebenssituation der Elementarschullehrer im ausgehenden 18. Jahrhundert von einer starken Heterogenität geprägt waren. Arme Schulmeister lebten mitunter in unmittelbarer Nachbarschaft zu sehr vermögenden Lehrern. Das jährliche Einkommen bildet dabei einen aus der Stapfer-Enquête zur Verfügung stehenden Indikator zur sozialen Verortung, wenngleich das Ökonomische nur einen Teilkomplex zur Ergründung des sozialen Status darstellt, und weitere wichtige Indikatoren wie Landbesitz und Vermögen als Datengrundlage fehlen. ${ }^{956}$ Diverse Forschungsarbeiten haben in der Vergangenheit die Einkommen der Elementarschullehrer für einzelne Regionen der Schweiz mit grosser Detailtreue und Akribie erhoben, soweit es die disparaten, oft lückenhaften Angaben und die Vielfalt der Naturalabgaben überhaupt zugelassen haben.

950 Mösch, Solothurnische Volksschule: 66.

951 Gindroz, Instruction publique: 18.

952 Hess, Basel: 274.

953 Grosser, Appenzell Innerrhoden: $24 \mathrm{f}$.

954 Vgl. die neue Zürcher Landschulordnung vom 20. Dezember 1803: StAZH OS AF 1, 394-408: 21.12.1803 - Gesetz, enthaltend eine Schulordnung für die Landschaft des Kantons Zürich; bzw. die Schulordnung von Schaffhausen: StASH Schule 1/554: 09.05.1804 - Landschul-Ordnung.

955 Vgl. die Argumentation der D-EDK: http://www.lehrplan.ch/kritikpunkte [27.07.2017].

956 Vgl. Bloch Pfister, Priester: 98f. 
Zahlreiche Naturalien lassen sich aber letztendlich nicht mehr in Geldwerten bestimmen und viele Angaben sind unvollständig rekonstruierbar, beispielsweise das genaue Schulgeld, wenn die Kinderzahlen oder die Schuldauer ungenau angegeben wurden. Allen Lohnerhebungen ist daher gemein, dass sie bloss Mindestwerte darstellen können und auch als solche zu verstehen sind. Doch wie sahen diese Einkommensverhältnisse nun im Spiegel des projektierten, inoffiziellen Mindestlohns von 100 Franken, 1.000 Batzen oder 67 Gulden pro Jahr konkret aus? Ein flächendeckender Vergleich aller Lehrerlöhne ist methodisch unmöglich zu bewältigen, wohl aber sind punktuelle Vergleiche in Form von exemplarischen Fallstudien möglich. In der Folge werden - abhängig von der Quellenlage - die Lehrerlöhne und ihre zeitlichen Veränderungen für einige Regionen der Helvetischen Republik genauer untersucht.

Für den heutigen Kanton Bern - territorial die helvetischen Kantone Bern und Oberland umfassend - hat Ernst Schneider eine Zusammenstellung der Lehrerlöhne unter Miteinbezug der diversen Getreide-Naturalien erstellt, ohne jedoch die erhobenen Daten räumlich differenziert zu diskutieren. ${ }^{957}$ Präzisiert man die Lohnberechnungen Schneiders für den helvetischen Kanton Bern mit den vom ihm vernachlässigten Einkommensbestandteilen in Naturalwerten, namentlich dem Holz für die Heizung der Schulstube, ${ }^{958}$ Landnutzungsrechten und dem Wert für den Bezug einer freien Schulwohnung, ${ }^{959}$ erhält man ein Bild, das nur schlecht zum Narrativ des armen Landschulmeisters passt. Bereits rund 36\% aller Berner Lehrkräfte erreichten im Jahr 1799 den Mindestlohn von 1.000 Berner Batzen oder 100 Franken pro Jahr. Weitere 24\% der Einkommen lagen in der Einkommensspanne zwischen 750 und 1.000 Berner Batzen, wovon etliche noch von weiteren nicht kalkulierbaren Naturalwerten profitierten, etwa der Benutzung von Gärten von unbekannter Grösse zum Anbau von Gemüse für den Eigenbedarf. ${ }^{960}$

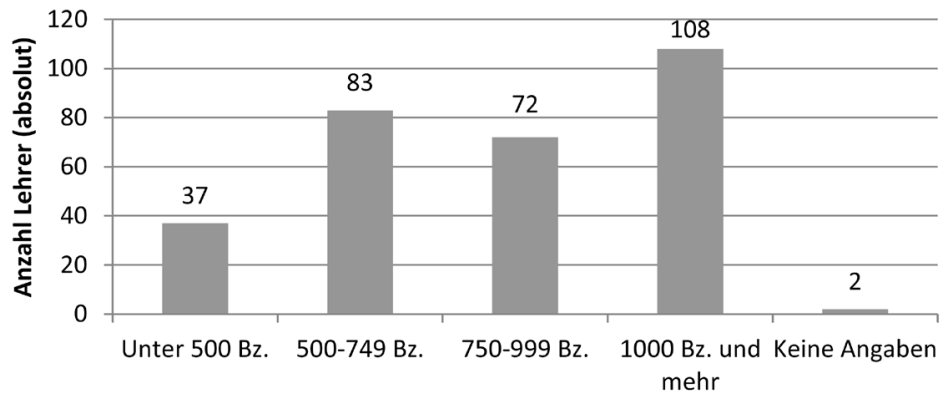

Abb. 8: Einkommensverteilung der Berner Schullehrer in Batzen 1799

957 Schneider, bernische Landschule: 205-240. Nicht berücksichtigt wurden bei Schneider hingegen der fiktive Gewinn durch eine freie Wohnstube für den Schulmeister sowie die Werte von Landbesitz und des Feuerholzes.

958 Das Klafter Holz wurde (unabhängig von der Holzsorte und ihrem Brennwert) mit 60 Bz. gerechnet. Vgl. Schmidt, Kapitel Bern: 154.

959 Für die Benutzung einer Juchart Land wurden 250 Bz. gerechnet; für eine freie Schulwohnung wurden zusätzlich 200 Bz. gerechnet. Dieser Wert berücksichtigt die teilweise schlechte Bausubstanz einzelner Schulhäuser gegenüber dem rechnerischen Wert von 250 Bz., wie ihn Heinrich Richard Schmidt und Ingrid Brühwiler verwendet haben. Vgl. Brühwiler, Finanzierung: 346; Schmidt, Kapitel Bern: 154.

960 Insgesamt mindestens 108 der 301 Lehrer des helvetischen Kantons Bern verdienten über 100 Franken. Dabei gehörte eine nicht geringe Anzahl von 46 Lehrern zu den Hintersassen ihrer Schulgemeinden (vgl. das Kap. 2.3). 
Die Verteilung der Lehrersaläre nach Einkommenshöhe zeigt, dass ganz tiefe Lehrerlöhne von jährlich unter 500 Berner Batzen (50 Franken) zwar noch existent, aber kaum mehr verbreitet waren. Demgegenüber erzielten knapp 60\% aller Berner Lehrer allein mit der Schularbeit ein potenziell existenzsicherndes Einkommen für eine vierköpfige Familie für das gesamte Jahr, unabhängig von der real unterrichteten jährlichen Schuldauer und eventuellen weiteren Nebeneinkünften. Untersucht nach der jährlichen Schuldauer wird die Kausalität von jährlicher Schuldauer und der Besoldungshöhe exemplarisch deutlich sichtbar, denn 19 der 37 Lehrkräfte mit einem Einkommen von weniger als 500 Berner Batzen arbeiteten ausschliesslich während des Winters als Lehrkraft, während nur vier davon eine ganzjährig dauernde Schule unterhielten. Demgegenüber erhielten bloss 13 der 108 Lehrkräfte mit guter Besoldung ihren Lohn für eine Winterschule, während 58 Lehrer dieser Lohngruppe das ganze Jahr über Schule hielt.

Die Gegenüberstellung der Einkommensverteilung pro Distrikt verdeutlicht ferner, dass die Tendenz zu hohen Einkommen nicht lokal auf die Stadt Bern oder einzelne Orte beschränkt blieb, sondern im helvetischen Kanton Bern bereits flächendeckende Ausmasse angenommen hatte.

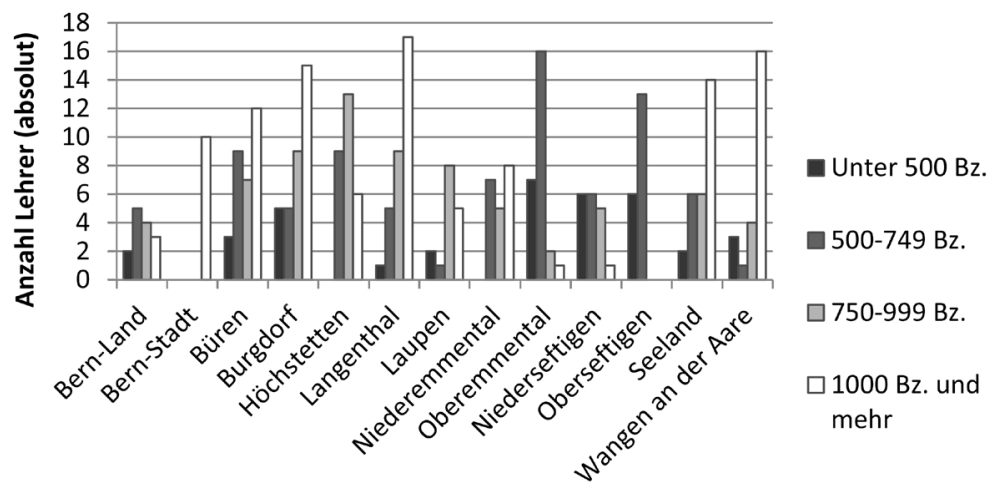

Abb. 9: Verteilung der Lehrerlöhne im Kanton Bern 1799

In der Stadt Bern wurden im Jahr 1799 gar keine Einkommen unter dem jährlichen Mindestlohn von 1.000 Batzen registriert, sämtliche Lehrkräfte beider Geschlechter - auch die erwähnten Helfer und Helferinnen - verdienten deutlich mehr als der Mindestlohn vorgab. ${ }^{961}$ Doch nicht nur in der Stadt Bern, sondern auch in den mittelländischen Distrikten Büren, Burgdorf, Langenthal, Seeland und Wangen an der Aare verdiente im Jahr 1799 die relative Mehrheit der Lehrkräfte mindestens 1.000 Berner Batzen. Allerdings sind deutliche räumliche Disparitäten zwischen den eher verkehrsgünstig gelegenen Räumen des Seelands, des Aaretals, der zentrumsnahen Orte und des stark textilgewerblich-protoindustrialisierten bernischen Oberaargaus, und den peripheren Räumen des Emmentals und des Gürbetals festzuhalten. ${ }^{962}$

961 Die mittleren Löhne in den Städten lagen deutlich höher als mit dem Maximalwert des Mindestlohns dargestellt. In der Stadt Bern belief sich der tatsächliche mittlere Lohn auf rund 5‘000 Berner Bz. pro Jahr (500 Franken). Aufgrund der stark verzerrenden Wirkung von Extremwerten bei Durchschnittsberechnungen ist auf eine Darstellung von Lohnmittelwerten bewusst verzichtet worden.

962 Vgl. die Einzelstudien zu den Lohnentwicklungen um 1800 im Kanton Bern: Schmidt, Kapitel Bern: 154ff; Rothen, Erkenntnisgewinn: 37ff. 
Makroökonomische Strukturfaktoren, insbesondere die grosse Anzahl an landwirtschaftlichen Kleinbetrieben und die starke Verbreitung von protoindustrieller Heimindustrie als Einkommensergänzung, dürften neben der guten verkehrstechnischen Erschliessung und der relativen Nähe zu lokalen Absatzmärkten in den Landstädtchen und Marktflecken als Erfolgsfaktoren für den relativen Wohlstand jener genannten Regionen herhalten, was sich wiederum in einer erhöhten Bereitschaft für Investitionen ins lokale Schulwesen manifestierte. ${ }^{963}$ Das hohe Lohnniveau für Lehrkräfte in den protoindustriell-textilgewerblich orientierten Distrikten des Berner Oberaargaus steht jedoch überraschend im Widerspruch zu bisherigen Forschungserkenntnissen, die der Protoindustrie als Strukturfaktor stets negative Auswirkungen auf das elementare Schulwesen apostrophiert haben. ${ }^{964}$ Die Protoindustrie pauschal als Ungunstfaktor auf das Elementarschulwesen abzuwerten, scheint daher als nicht angepasst - zumindest nicht für Orte, wo sich Ganzjahresschulen oder mindestens sporadisch dauernder Sommerschulunterricht etablieren konnten und die dennoch in der Nähe zu Märkten oder Verkehrswegen lagen. ${ }^{965}$

Dagegen waren die Schulen im Emmental und im Gürbetal mit den Distrikten Nieder- und Oberseftigen noch stark durch deutlich tiefere Löhne geprägt. Beide Regionen waren - um es in den Worten der modernen Volkswirtschaftslehre auszudrücken - ökonomisch „strukturschwach" und peripher gelegen. Insbesondere das Emmental war durch das Anerbenrecht und der zunehmenden Konzentration von Produktivitätsgewinnen aus der Agrarmodernisierung in den Händen der bäuerlichen Oberschichten von verstärkter sozialer Ungleichheit betroffen, woraus ungleich höhere Armenlasten für die Gemeinden resultierten und letztendlich weniger Geld für die lokale Schule bereitstand. ${ }^{966}$ Dass die beiden genannten Regionen durch schwach besoldete und weniger leistungsfähige Schulen auffielen und auch in den darauffolgenden Jahren nur wenig ins lokale Schulwesen zu investieren vermochten, war somit weniger eine Frage des Nicht-Wollens von Verbesserungen durch die verantwortlichen Pfarrer und Schulmeister, als vielmehr ein Ausdruck des strukturell bedingten Nicht-Könnens aufgrund mangelnder Ressourcen, so lange die Finanzierung des Elementarschulwesens hauptsächlich auf den Schultern der Gemeinden getragen werden musste. ${ }^{967}$

Die Person des Lehrers hatte auf diese Strukturfaktoren kaum eine Möglichkeit zur Einflussnahme, zumal offenbar eine gewisse Geringschätzung von Elementarbildung in der Bevölkerung nach wie vor vorhanden war, wie der Bericht des Oberamtmanns von 1806 aus dem Amt Seftigen zeigt: „Der Bauer soll Bauer bleiben, und dazu braucht er keine wissenschaftlichen Kenntnisse. Desto mehr bemühe man sich um die Ausbildung seines moralischen Gefühls, um seine Sittlichkeit." 968

Insgesamt deutlich bescheidener als im helvetischen Kanton Bern sah die Einkommenssituation hingegen im peripheren Berner Oberland aus, wo die Löhne im Allgemeinen markant hinter denjenigen des Berner Mittellandes zurückgeblieben waren. Bloss fünf der insgesamt 138 in der Stapfer-Enquête verzeichneten Lehrkräfte hatten ein jährliches Einkommen über dem Mindest-

963 Zur ökonomischen Bewertung der einzelnen Regionen des Kantons Bern vgl. Pfister, Strom: 309f. Zur Situation der Berner Schulen im Überblick: Schmidt, Niedere Schulen: 272.

964 Vgl. zur Bewertung der Protoindustrie als Ungunstfaktor für das Schulwesen in Bezug auf den Schulbesuch und Absenzen: Schmidt, Elementarschulen: $34 \mathrm{ff}$.

965 Schmidt, Elementarschulen: 43; Schmidt, Niedere Schulen: 272.

966 Pfister, Strom: 302-310.

967 Zur zeitlichen Entwicklung der mittleren Lehrerlöhne vgl. die grafische Darstellung der Ämter Seftigen und Signau, deren Lohnwerte bis 1806 deutlich hinterherhinkten. Auch in Sachen „Learning Outcomes“, die Fähigkeiten der Schulkinder, lagen die beiden Ämter gegenüber den stadtnahen Ämtern deutlich zurück. Schmidt, Kapitel Bern: 154, 160.

968 StABE B III 1027, fol. 2v: 20.06.1806 - Oberamtmann. 
lohn erzielt, und nur weitere 12 Lehrer kamen auf ein Salär von mindestens 750 Berner Batzen oder 75 Franken pro Jahr. ${ }^{969}$

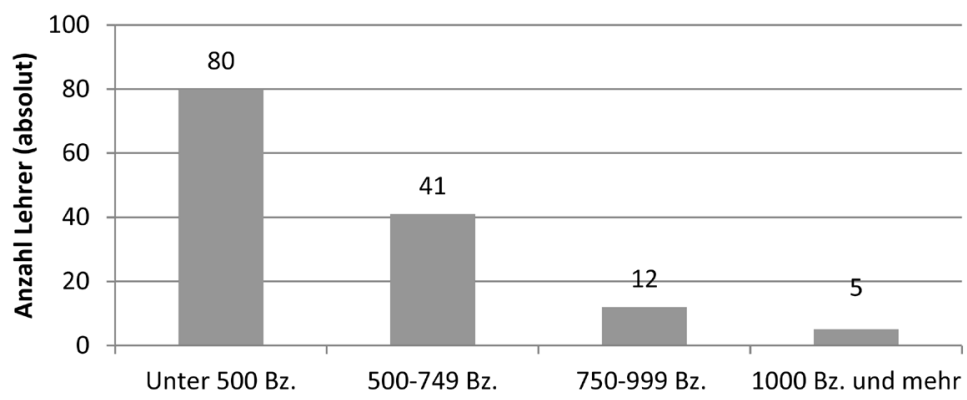

Abb. 10: Einkommensverteilung der Oberländer Lehrer in Batzen 1799

Ein erster Erklärungsansatz für die generell tieferen Jahreslöhne im Berner Oberland lag in der jährlichen Schuldauer, die insgesamt kürzer als im Berner Mittelland ausfiel. Die ganzjährig fortdauernde Schule war mit gesamthaft $12 \%$ noch wenig verbreitet und obwohl Sommerschulunterricht bereits in rund 54\% der Oberländer Schulen mindestens an einem Tag pro Woche stattfand, hielten noch rund ein Drittel aller Schulmeister, insgesamt 46 Lehrer, den Schulunterricht ausschliesslich im Winter. ${ }^{970}$ Davon entfielen 22 auf die tiefsten Einkommen unter 500 Berner Batzen, weitere 15 auf die Einkommensspanne von 500-749 Berner Batzen und 9 auf den Einkommensbereich von 750 bis 1.000 Berner Batzen pro Jahr. Von den fünf ausreichend besoldeten Lehrkräften hatten jedoch nur die beiden Stadtschullehrkräfte von Thun ganzjährig unterrichtet, die übrigen drei begnügten sich mit sporadischem Sommerschulunterricht. Demgegenüber war der ganzjährige Unterricht im helvetischen Kanton Bern bereits in rund 29\% der Schulen und tagesweiser Sommerschulunterricht in weiteren 53\% der Schulen etabliert. Folglich mussten die Lohnentschädigungen an die Oberländer Lehrkräfte nicht so hoch wie im Kanton Bern ausfallen, wenn nur im Winter und mancherorts zusätzlich ein paar Tage im Sommer der Unterricht stattfand.

Des Weiteren wies die geografische Verteilung der höchsten Löhne im Berner Oberland deutlich auf die Verkehrslage und auf zentralörtliche Funktionen als eindeutig einkommensstimulierende Faktoren hin. Ausschliesslich in den beiden Landstädten des Kantons Oberland, in Thun und Unterseen, sowie im ehemaligen Landvogteisitz Frutigen und im Hauptort des Distrikts Niedersimmental, in Erlenbach im Simmental, erreichten die Lehrereinkommen den Mindestlohn von mindestens 1.000 Berner Batzen pro Jahr.

969 Der mittlere Lohn eines Oberländer Schulmeisters belief sich auf bloss knapp 500 Berner Bz. (50 Franken), gegenüber dem mittleren Lohn von rund 770 Bz. eines Berner Lehrers (77 Franken). Die deutliche Diskrepanz zum restlichen Kanton Bern ist bereits in den mittleren Löhnen nach Distrikt gut sichtbar, wie sie Ernst Schneider berechnet hat. Vgl. Schneider, bernische Landschule: 72 (anhängende Tabelle).

970 Von den 138 vermerkten Lehrkräften des Kantons Oberland unterrichteten 17 ganzjährig, 75 im Winter mit einzelnen Sommerschultagen und 46 nur im Winter. 


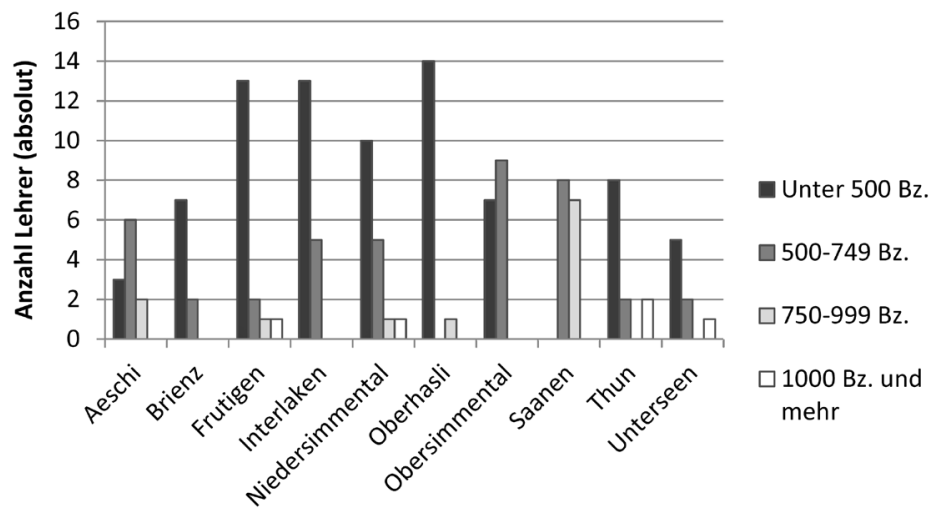

Abb. 11: Verteilung der Lehrerlöhne im Kanton Oberland 1799

Ebenso konzentrierten sich die übrigen Lehrkräfte mit Einkommen von mehr als 750 Berner Batzen pro Jahr fast ausschliesslich auf Orte mit Zentrums- und Verkehrsfunktionen: Meiringen, Reichenbach im Kandertal, Einigen, und auf die westlichen Distrikte des Kantons entlang einer Trennlinie entlang des linken Thunerseeufers bis zum Niesen. Besonders gehäuft traten sie im agrarökonomisch wohlhabenden Distrikt Saanen auf. Nur in diesem kleinen Distrikt erreichten die mittleren Jahreslöhne der Lehrer annähernd ähnliche Werte wie im mittelländischen Kornland. Die östlichen Distrikte des Berner Oberlands inklusive dem rechten Thunerseeufer wiesen dagegen alle sehr tiefe mittlere minimale Jahreslöhne auf.

Hinter den ausgeprägten räumlichen Unterschieden zwischen dem westlichen und dem östlichen Berner Oberland stehen jedoch ähnliche soziostrukturelle Kontraste wie im Berner Mittelland, die letztendlich auch auf die Ausprägung des Schulwesens abgefärbt hatten: im östlichen Berner Oberland dominierte eine eher egalitäre Verteilung von Landbesitz, Viehbesitz und Ressourcen mit der Konsequenz einer ökonomischen Stagnation, während im westlichen Teil durch die agrarökonomische Spezialisierung auf die exportorientierte Käseproduktion und die Grossherdenhaltung im Hirtenbetrieb eine zunehmende soziale Ungleichheit resultierte, aber gleichzeitig ungleich mehr Wohlstand generiert wurde. ${ }^{971}$

Dass das Berner Oberland mit Ausnahme der genannten prosperierenden Einzelorte gesamthaft eher arm blieb und sich auf finanzieller Ebene im Elementarschulwesen trotz der Impulse der Helvetischen Republik nur wenig zugunsten der Landschulmeister veränderte, zeigt sich im Lohnvergleich der Schulmeisterlöhne in der Schulumfrage von 1806. Nunmehr 16 Lehrkräfte lagen im potenziellen Einkommensbereich von mindestens 750 Berner Batzen pro Jahr, während neben den fünf bereits genannten Lehrern von 1799 keine einzige weitere Lehrkraft die Schallmauer des Mindestlohns von 1.000 Berner Batzen zu durchbrechen vermochte. ${ }^{972}$ Die Schlussfolgerung aus dem Berner Oberland, dass die Lehrer in den Berggebieten beziehungsweise in der Agrarzone der alpinen Mischwirtschaft und des Hirtenlandes insgesamt schlechter besoldet wurden als die Lehrkräfte im Mittelland, ist jedoch nicht zulässig, zieht man die mo-

971 Hauser, Wirtschafts- und Sozialgeschichte: 142f.; Pfister, Strom: 297-301, 309.

972 StABE B III 1032: [1806] - Schultabellen. Die Einkommenszusammenstellungen beinhalteten einzig die fixe Besoldung in Geld ohne Naturalabgaben, Schulgelder oder die Möglichkeit der freien Wohnung in der Schule, so dass die darin abgebildeten Einkommenswerte generell als zu niedrig einzuschätzen sind. 
netären Entwicklungen aus anderen alpinen Regionen der Helvetischen Republik mit in die Untersuchung ein.

Als ein weiteres Fallbeispiel dazu bietet sich der gemischtkonfessionelle helvetische Kanton Linth an. In einer von Hermann Landolt erstellten Zusammenstellung der Geldlöhne von 1798 für die ehemalige Landschaft Glarus erreichten neun von 25 Schulen den Mindestlohn von 67 Gulden beziehungsweise 1.000 Franken und neun weitere Schulen lagen zumindest in potenzieller Reichweite mit einem Lohn von mindestens 50 Gulden oder 75 Franken. ${ }^{973} \mathrm{Zu}$ den Ärmsten ihrer Gemeinde gehörten sieben von zehn Glarner Lehrer somit schon vor der Helvetischen Revolution nicht mehr. Interessant ist jedoch - wo es die Quellensituation erlaubt vor allem die Dynamik von Lohnentwicklungen nachzuvollziehen, wie es Heinrich Richard Schmidt exemplarisch für das Berner Kapitel aufzeigt. ${ }^{974}$

Bereits auf das Jahr 1799 konnten bei insgesamt neun Schulen der Glarner Landschaft Gehaltserhöhungen festgestellt werden, wodurch drei weitere Schulmeister die Einkommenshöhe des angedachten helvetischen Mindestlohns erreichten und insgesamt 20 der 25 Schulen eine Entschädigung von mindestens 50 Gulden auswiesen. ${ }^{975}$

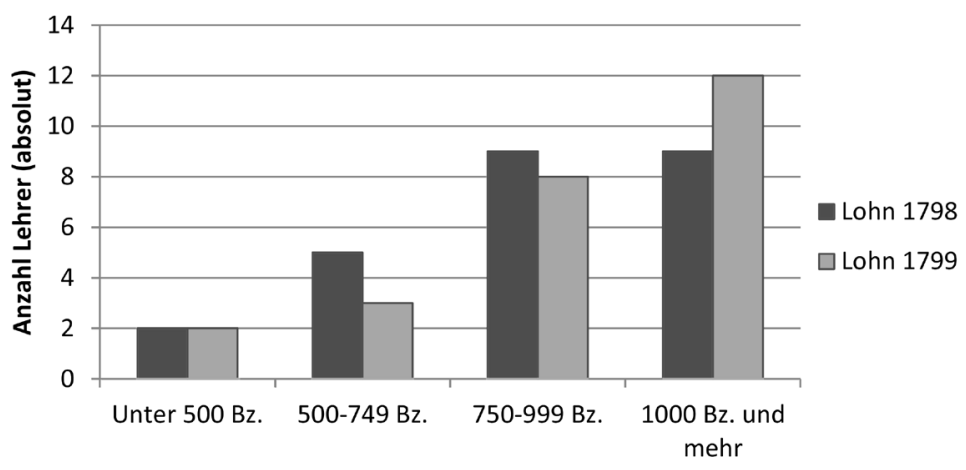

Abb. 12: Lohnentwicklung der Glarner Lehrer 1798-1799

Interessanterweise stiegen jedoch nicht primär die tiefsten Saläre überproportional an, sondern eher diejenigen des mittleren Lohnspektrums zwischen 35 und 60 Gulden pro Jahr. Das von Hermann Landolt gezeichnete Bild des armutsgeplagten Glarner Elementarschullehrers ist damit zumindest für das Glarner Haupttal zu revidieren, zumal ferner mehrere Geistliche beider Konfessionen in ihren Gemeinden die Schule hielten und für ihre geistlich-seelsorgerischen Tätigkeiten zusätzlich entschädigt wurden. Tatsächlich als grundsätzlich einkommensschwach konnten nunmehr bloss drei der 25 Schulen - jene von Oberurnen GL, Schwändi GL und Engi GL - bezeichnet werden, deren Wochenlöhne für die Schulmeister sich nicht über eineinhalb

973 Die Zusammenstellung umfasst die beiden helvetischen Distrikte Glarus und Schwanden. LaGL HA, Protokollbände 83-85: [1798] - Schulumfrage; abgedruckt in: Landolt, Linth: $154 f$.

974 Schmidt, Kapitel Bern: 154-162.

975 Im Unterschied zu den von Landolt extrahierten Geld-Angaben der Schulumfrage von 1798 erhielten gemäss der Stapfer-Enquête von 1799 die Lehrer der Schulen Linthal, Luchsingen, Nidfurn, Haslen, Elm, Glarus katholisch, Bilten und Obstalden ein Jahr später mehr Lohn. Zudem konnte beim Lehrer von Näfels die mit 80 fl. besoldete Vorsängertätigkeit addiert werden. 
Gulden beliefen. ${ }^{976}$ Anzumerken ist jedoch, dass die Schulmeisterlöhne in den ehemaligen Gemeinen Herrschaften innerhalb des neuerschaffenen Kantons Linth - Mels, Neu St. Johann, Schänis, Rapperswil und Werdenberg - im Mittel deutlich tiefer lagen als im Glarner Haupttal. ${ }^{977}$ Die ehemalige Herrschaftsform während des Ancien Régimes hatte somit aufgrund der nur schwachen obrigkeitlichen Durchdringung zu tiefen durchschnittlichen Löhnen geführt, da die Finanzierung alleinig auf Gemeindegeldern oder einzelnen Fonds beruhte.

Eine ähnliche Beobachtung konnte für den Kanton Baden, bestehend aus den ehemaligen Gemeinen Herrschaften Baden und Freie Ämter, gemacht werden. Zwar verdiente bereits rund jede zehnte Lehrkraft des Kantons im Jahr 1802 mindestens 100 Franken, doch konzentrierten sich die hohen Löhne durchwegs auf die Munizipalstädte und Marktorte. ${ }^{978}$ Konfessionelle Prägungen der Einkommensausgestaltung konnten jedoch im Direktvergleich der Lohnspannen zwischen den einzelnen Distrikten nicht festgestellt werden.

Für den Kanton Zürich führte Alexandra Bloch Pfister eine flächendeckend vergleichende Einkommenserhebung der Lehrereinkommen der Jahre 1771 und 1799 auf der Basis der Einkommenstabellen von Wilibald Klinke, unter zusätzlicher Mitberücksichtigung der Getreidepreise durch. Sie hat dabei zum einen markante Einkommensunterschiede beim Kriterium des Schultypus zwischen Hauptschullehrern und Filialschullehrern festgestellt, wobei Erstere fast doppelt so viel verdienten wie Letztere, es freilich zu einer überdurchschnittlichen Anhebung der tiefsten Einkommensklassen im untersuchten Zeitabschnitt kam. Zum anderen zeigt die Studie, dass 1799 nur noch rund 35.8\% der Zürcher Lehrerschaft weniger als 100 Pfund oder rund 75 Franken verdiente und ein weiteres Drittel der Zürcher Lehrkräfte bereits ein Einkommen von deutlich über 150 Pfund oder 100 Franken pro Jahr erzielte. ${ }^{979}$ Die höchsten Löhne konzentrierten sich auch in der Zürcher Landschaft vorwiegend in Stadt- und Seenähe, wo höhere Kinderzahlen und damit ein höheres Schulgeld auf eine tiefere Anzahl an Schuleinrichtungen trafen. ${ }^{980}$ Zudem bewirkte die Verpflichtung zu Repetier- und Sommerschulunterricht durch die Landschulordnung von 1778 eine generelle Steigerung der Lohnverhältnisse. ${ }^{981}$

Sowohl die Einkommensstratifikation nach der Lohnhöhe als auch die räumliche Verteilung der Löhne im Kanton Zürich ähneln damit in starker Weise jenen weiter oben skizzierten Verhältnissen im Kanton Bern. Ferner hat Bloch Pfister auf die enge Korrelation von Vor- und Ne-

976 Die Ganzjahresschule von Schwändi GL wurde mit bloss 45 fl. (67.5 Franken) besoldet (ergibt einen Wochenlohn von rund 1 f.), die Winterschulen von Oberurnen GL für rund 20 Wochen mit 15 fl. und von Engi GL für 18 Wochen mit 21.5 fl. (ergibt einen Wochenlohn von ca. 1 fl. 11 xr.). Keiner der drei Lehrkräfte erhielt eine freie Schulwohnung, der Lehrer von Oberurnen war jedoch gleichzeitig Kaplan und erhielt hierfür weitere 74 fl. BAR B0 1000/1483, Nr. 1374, fol. 116 [1799] - Pfarrenquête Linth; Schmidt u.a. (Hgg.), Stapfer-Enquête, Nr. 414: Schwändi; Nr. 419: Engi; Nr. 568: Oberurnen. Die Generaltabelle des Kantons Linth von 1801 bestätigt einerseits die Schulen Engi mit 18 fl. und Oberurnen mit 15 fl. Gehalt als weiterhin am schlechtesten besoldete Schulen, andererseits den Distrikt Glarus als den Raum mit den höchsten Löhnen, wobei der geringste Jahreslohn 60 fl. (90 Franken), der höchste Lohn über 400 fl. (600 Franken) betragen hat. StASG HA 132, Fasz. 1, o. Pag: [1801] - Kanton Linth.

977 Die in der Generaltabelle von 1801 vermerkten Minimal- und Maximallöhne schwankten in den ehemaligen Gemeinen Herrschaften auf ungleich tieferem Niveau: Distrikt Werdenberg: $10-68$ f.; Distrikt Schänis: 28-200 fl.; Mels: 6-222 fl.; Rapperswil: 18-196 fl.; Neu St. Johann: 9-20 fl. StASG HA 132, Fasz. 1, o. Pag: [1801] - Kanton Linth.

978 Mindestens 13 von 108 Lehrkräften verdienten im Jahr 1802 mindestens 100 Franken. Die Lohnspanne reichte in allen Distrikten des Kantons von 32 Franken bis zu 480 Franken für Stadtschullehrer. StASG HA 132, Fasz. 1, o. Pag: [1802] - Kanton Baden.

979 Die Lohnangaben sind in der Studie in Pfund angegeben. Der Umrechnungsfaktor beträgt 1 Gulden $=2$ Pfund $=15$ Bz. Nicht berücksichtigt hat Bloch Pfister in ihren Berechnungen den Wert von freiem Wohnraum und von Landbesitz. Bloch Pfister, Priester: 163ff.

980 Bloch Pfister, Priester: 100.

981 Bloch Pfister, Priester: 176. 
bentätigkeiten mit der Einkommenshöhe hingewiesen. Überdurchschnittliche Löhne erzielten nach Bloch Pfister vor allem Schulmeister, deren Vor- oder Nebenbeschäftigungen in den Tätigkeitsfeldern der Fabrikarbeit, Handel und Verwaltung, Privatunterricht, Handwerkstätigkeiten, Kirchenämter lagen oder die keine Vor- oder Nebentätigkeit ausübten. ${ }^{982}$

Für die Lehrerschaft in der ehemals bernischen Waadt berechnete Georges Panchaud die Einkommensverhältnisse aus der Stapfer-Enquête. Seinen Berechnungen zufolge verdienten 124 von insgesamt 452 Lehrkräften weniger als 100 Franken jährlich, 328 jedoch mindestens 100 Franken oder mehr pro Jahr. ${ }^{983}$ Mindestens $73 \%$ der Lehrkräfte lagen somit bereits über dem nationalen Mindestlohn. Auch der Durchschnittslohn der Waadtländer Lehrkräfte, berechnet aus dem Total an finanziellen Aufwendungen aus dem Jahr 1801, lag mit rund 140 Franken jährlich deutlich über der 100-Franken-Grenze. ${ }^{984}$ Die deutliche Mehrzahl der Waadtländer Elementarschullehrer waren somit keine „pauvres maîtres d'école“985 mehr. Vielmehr stellten sie im innerhelvetischen Vergleich bezüglich der Einkommensverhältnisse sowohl in absoluter Anzahl als auch bezüglich des mittleren Jahreslohns mit Abstand die am üppigsten verdienenden Lehrkräfte dar.

Der Hauptgrund für die hohe Einkommen in der Waadt lag in der fast flächendeckenden Verbreitung von Ganzjahresschulen, denn an rund 85\% aller Waadtländer Schulen dauerte die Schulzeit das ganze Jahr über, unterbrochen bloss von einigen Wochen Ferien während den Erntezeiten. ${ }^{966}$ Entsprechend mussten die Lehrkräfte für die gesamte Schuldauer besoldet werden und verdienten im Direktvergleich so viel wie ein Handwerker, eine Wäscherin oder ein Kleinbauer. ${ }^{987}$ Räumliche Disparitäten mit deutlich niedrigeren Jahreslöhnen traten vorwiegend in den beiden voralpinen Distrikten des Pays d'Enhaut und Aigle auf. Ferner mussten vor allem Zweitlehrkräfte, die zur Entlastung des Hauptlehrers angestellt worden waren, in der Regel mit einem tieferen Lohn auskommen. ${ }^{988}$ Auffällig ist jedoch, dass gerade im krisengeschüttelten und eher peripheren Uhrmachertal, im Vallée de Joux, trotz zeitgenössisch schwacher Konjunkturlage durchwegs sehr hohe Lehrerlöhne ausbezahlt wurden. Nicht nur der bereits erwirtschaftete Wohlstand durch die Uhrenindustrie, sondern auch ein intensives Bedürfnis nach Grundbildung für die Ausbildung der notwenigen technischen Fertigkeiten im Uhrmacherhandwerk aus der Bevölkerung und die hohe Kompatibilität von Unterricht und Heimarbeit hatten sich hier wohl zu einer besonders fruchtbaren Symbiose vereint.

Die Einkommenstopografie in der Helvetischen Republik zeichnete sich insgesamt betrachtet nicht bloss durch grosse Stadt-Land- und Schultypus-Unterschiede zwischen Hauptschulen und Filialschulen aus, sondern zudem durch massive regionale und lokale Disparitäten entlang von obrigkeitlichen Herrschaftsstrukturen, agrarökonomischen Entwicklungen, verkehrs- und zentralörtlichen Lagekriterien, sowie überlokalen Finanzierungsstrukturen. Ferner kann ein gegenseitiger Beeinflussungseffekt beobachtet werden, nämlich dass sich die Löhne einer Gegend

982 Bloch Pfister, Priester: 165-169.

983 Panchaud, écoles vaudoises: 340-351, insbes. die Übersichtstabelle auf S. 342.

984 „La Somme totale des pensions d'Instituteurs d'Écoles primaires est d'environ 67.480 francs, en évaluant à un prix moyen." Rapport du Conseil d'éducation: 7f. Bei 480 Lehrkräften ergibt dies eine mittlere Summe von rund 140150 Franken. Abzüglich der Lateinschullehrer und der Lehrer an höheren Schulen hat Panchaud einen mittleren Lohn von rund 141 Franken berechnet. Vgl. Panchaud, écoles vaudoises: 341; 344.

985 Gindroz, Instruction publique: 18.

986 Rapport du Conseil d'éducation: 7.

987 Panchaud, écoles vaudoises: $346 f$.

988 Panchaud, écoles vaudoises: 343. Zudem verweist Panchaud auf eine Reihe von Gemeinden, deren Schulmeister wie überall in der Helvetischen Republik „sans raison appartenante“ schlechter besoldet wurden als in den umliegenden Ortschaften. 
gegenseitig anglichen und sich sozusagen ähnliche Einkommens-Cluster bildeten. Solche Cluster sind beispielsweise in den Berner Oberländer Distrikten Saanen und Obersimmental, aber auch im oberen Toggenburg feststellbar, wo weitläufige Gemeinden mit zahlreichen Weilern und Nebenschulen dominierten. ${ }^{989}$ Die Cluster entstanden durch den Verzicht auf elterliche Schulgelder und die Konzentration auf kommunale Kapitalanlagen, wobei die Kapitalerträge einheitlich unter den Nebenschulen aufgeteilt wurden. Auf solche Ausgestaltungen hatten die Lehrer selbst kaum einen individuellen Einfluss. Ihre Löhne blieben ungeachtet ihrer Bildung, ihres Engagements, ihrer Diensttreue oder ihrer jährlichen Schuldauer in einem festen Rahmen bestehen.

Daneben blieb aber der Faktor der lokalen Willkür in der Festsetzung der Besoldung gleichsam von entscheidender Wirkungsmächtigkeit. Manche Lohnunterschiede lassen sich - gerade auf der lokalen Ebene zwischen einzelnen benachbarten Gemeinden mit ähnlichen strukturellen Voraussetzungen - schlicht nicht erklären.

Dass die Schulmeisterlöhne während des 18. Jahrhunderts keineswegs stagniert hatten, sondern während des gesamten Zeitraums markant angestiegen waren, zeigt ferner eine Auswertung der Gemeindeseckelmeisterrechnungen von Bettlach SO durch André Schluchter: Der Lohn des Schulmeisters für 20 bis 25 Wochen Unterricht verdoppelte sich im Zeitraum zwischen 1728/29 und 1782/83 von 20 Solothurner Kronen auf 40 Kronen und stieg im Jahr 1790/91 nochmals auf 54.38 Kronen. Daneben war der Schulmeisterlohn unter allen Lohnausgaben der Gemeinde mit Abstand der höchste Ausgabeposten der Gemeinde, während beispielsweise die Entlohnungen des Sigrists, des Harschiers, des Weidehirten, des Dorfseckelmeisters und des Wachtmeisters zumindest in der zweiten Hälfte des 18. Jahrhunderts stagnierten. ${ }^{990}$

Abseits von regionalen Entwicklungen liess sich die Einkommensausgestaltung nur in seltenen Fällen durch individuelle Merkmale und Handlungen prägen. Direkte Verhandlungen der Lehrpersonen mit den Vorgesetzten der Schulgemeinden, wie es Jakob Eggen gemäss seiner Biografie erfolgreich getan hatte und eine Verdoppelung seines Salärs erreichte, waren kollektiv eher als Ausnahmefälle zu taxieren. ${ }^{991}$ Zumindest berichten die Antworten der Stapfer-Enquête nur von wenigen expliziten Fällen von erfolgreichen Lohnverhandlungen der Schulmeister mit ihren Gemeinden. Der Lehrer Michel Leemann aus Langnau BE hatte zu seinen Einkommensverhältnissen berichtet: „ich Hab zwar im anfang meinner Schul-Jahren, etwelche Jahr nur Fünfzehen Cronen, da Hab ich die Vorgesezten um die billigkeit zubetrachten ersucht, auf dis Hin Hab ich Achtzehen Cronen erhalten, endlich beklagte ich mich noch mehr so erhielte ich jezt Zwanzig Cronen dis war mein einkommen" "992. Leemann begann seine Lehrertätigkeit im Jahr 1770, er erreichte somit in 29 Jahren einen Lohnzuwachs von einem Drittel des Ausgangslohns. Sein Einkommen von 20 Kronen oder 50 Franken war zwar relativ gering, doch verfügte Leemann zusätzlich über ein eigenes Heimwesen zur Sicherung der Subsistenz.

Dass die Lehrkräfte bei Lohnverhandlungen mit der Gemeinde bisweilen einen sehr langen Atem brauchten und der Ausgang solcher Verhandlungen höchst ungewiss blieb, illustriert nicht nur obiges Beispiel aus Langnau, sondern auch eine ausführlich beschriebene Anmerkung

989 Vgl. zum Obersimmental und Saanen die vorangegangene Abb. 11. Im Distrikt Saanen sorgten lokale Stiftungen und Vergabungen für eine fast egalitäre fixe Entschädigung aller Lehrer. Im Obersimmental waren dagegen Kapitalzinse und das Kirchengut für die Besoldung verantwortlich. In beiden Distrikten wurde jedoch mit Ausnahme von Holzgaben auf das Eintreiben von Schulgeldern verzichtet. Im oberen Toggenburg waren lokale Schulgüter für die Finanzierung verantwortlich, ebenfalls wurden keine Schulgelder erhoben.

990 Schluchter, Armut: 182.

$991 \mathrm{Zu}$ den Lohnverhandlungen von Jakob Eggen vgl. Meyer, Langenthal: 38.

992 Schmidt u.a. (Hgg.), Stapfer-Enquête, Nr. 668: Langnau im Emmental. 
des Schulmeisters Samuel Tanner von Muri bei Bern: „Bis in das Jahr 1794. ware das Einkommen der beyden Schulmeistern zu Muri und Gümligen sehr gering, es bestunde Erstlich in einer geringen Behausung im Schulhaus, sonst einem kleinen Gärtlein das sehr wenig abträgt. Zweitens in Geld 14 kr. 10. bz. [36 Franken] wovon für die Winterschule 12. kr. für die Sommerschule $2 \mathrm{kr}$. 10. bz. gerechnet waren. Dieser Lohn beträgte allso insgesamt 360. bz. folglich nicht einmahl ein Bazen auf jeden Tag im Jahr. Von dem Schuldienst war das vorsingen in der Kirche eine besondere unterschiedene Arbeit, für welche einem jeden jährlich ausgerichtet wurden an Korn neün Mäs. Den 19.ten Weinmonat 1794. erschiennen die beyden Schulmeister dieser Gemeind Bendicht Bigler zu Muri, und Rudolf Matter zu Gümligen vor der am erstern Orte gehaltenen Monatgemeind und hielten um vermehrung ihrer Besoldung an, Jhr Begehren ward gegründet und billig erfunden. [...] Auf solche Weise sollte nun nach dem Willen und Endzwek der Stiffter den bey den Schulmeistern an Zinsen zu verbeßerung ihres Lohns alljährlich ausgerichtet werden 28. kr. 8. bz. Bis in das Jahr 1797. wurde jedem von diesen Zinsen 8. kr. mitthin (anstatt 28. kr. 8. bz.) 16. kr. bezahlt. Den 5.ten Wintermonat 1797. als beyde Schulmeister, Samuel Tanner zu Muri und Rudolf Matter zu Gümligen vor der versammelten Gemeind auf die völlige Entrichtung der Zinsen von diesem Capital drangen, erhielten sie endlich mit vieler Mühe noch ein jeder 4. kr. die übrigen noch restierenden 4. kr. 8. bz. die ihnen doch mit allem Recht gehörten werden zurük behalten, und zweifelsohn nie bezahlt werden, wenn nicht höhern Orts deshalb Befehle ertheilt werden." ${ }^{\text {"993 }}$

Zwar hatte sich der jährliche Schullohn des Lehrers von Muri dank der Intervention des Vorgängers bei der Gemeinde und der daraufhin erfolgten Schaffung eines zinstragenden Fonds auf 760 Berner Batzen oder 76 Franken mehr als verdoppelt, ${ }^{994}$ dennoch blieb aufgrund des zurück gehaltenen Zinsertrags eine gewisse Frustration zurück. Da sowohl der Lehrer von Muri als auch derjenige von Gümligen keine ortsansässigen, sondern zugezogene Hintersassen waren, konnten sie ihre Anliegen in der Gemeindeversammlung nur „mit vieler Mühe“ durchsetzen. Die betroffene Gemeinde löste ihr Zinsversprechen in den darauffolgenden Jahren zugunsten ihres Lehrers doch noch ein, so dass im Jahr 1806 der Schullohn für die Schule Muri auf 32 Kronen und 14 Batzen zugenommen hatte. ${ }^{995}$ Damit erreichte der Lehrer ein Jahreseinkommen von knapp 100 Franken, was ihn in die Kategorie der ausreichend salarierten Lehrkräfte hob.

Markante Lohndifferenzen bestanden insbesondere zwischen den Geschlechtern. Die Saläre der Lehrerinnen fielen an allen munizipal- und hauptstädtischen Schulen im Vergleich zu ihren männlichen Kollegen am gleichen Ort oder sogar in den gleichen Schulinstitutionen stets tiefer aus. ${ }^{996}$ Einige Direktvergleiche aus verschiedenen Regionen der Helvetischen Republik verdeutlichen exemplarisch, wenn auch ohne Anspruch auf Vollsätndigkeit, die Lohndifferenzen zwischen Lehrerinnen und Lehrern an den gleichen Schulinstituten. ${ }^{997}$

993 Schmidt u.a. (Hgg.), Stapfer-Enquête, Nr. 1089: Muri bei Bern.

994 Der Schullohn betrug im Jahr 1799 total 24 Kronen Winterschullohn, 2 Kronen, 10 Bz. Sommerschullohn und 4 Kronen Holzgeld = 760 Berner Bz. Dazu stand dem Lehrer ein „Ein wenig Garten von schlechtem Ertrag, Etwas weniges Land zum Anpflanzen welches aber nicht als ein bleibendes Einkommen kan angesehen werden“ zum Eigenbedarf zur Verfügung. Schmidt u.a. (Hgg.), Stapfer-Enquête, Nr. 1089: Muri bei Bern.

995 Der Winterschullohn betrug 1806 neu 26 Kronen und 4 Bz. Damit verdiente der Schulmeister von Muri mit der Vorsänger-Zulage von 9 Ms. Dinkel (à 103 Bz. per Mütt) insgesamt rund 911 Berner Bz., und hatte freie Wohnung und ein kleines Gärtchen zur Verfügung. StABE B III 1028, 27.05.1806 - Muri.

996 Brühwiler, Finanzierung: $122 \mathrm{f}$.

997 Verglichen wurden Lehrkräfte mit möglichst ähnlichem Anforderungsprofil. 
Tab. 14: Einkommensvergleiche zwischen Lehrerinnen und Lehrern

\begin{tabular}{|c|c|c|c|}
\hline Schule: & Lehrer: & Lehrerin: & Differenz: \\
\hline Büren a. Aare 998 & $\begin{array}{l}100 \text { Taler } \\
\text { (300 Fr.) }\end{array}$ & $\begin{array}{l}75 \mathrm{Kr} . \\
\text { (187.5 Fr.) }\end{array}$ & $-37 \%$ \\
\hline St. Gallen 999 & $\begin{array}{l}291 \mathrm{fl} . \\
\text { (218.3 Fr.) }\end{array}$ & $\begin{array}{l}125 \mathrm{fl} . \\
\text { (93.8 Fr.) }\end{array}$ & $-57 \%$ \\
\hline Stein a. Rhein ${ }^{1000}$ & $\begin{array}{l}204 \mathrm{fl} . \\
\text { (153 Fr.) }\end{array}$ & $\begin{array}{l}97 \mathrm{fl} . \\
\text { (72.8 Fr.) }\end{array}$ & $-52 \%$ \\
\hline Begnins ${ }^{1001}$ & $\begin{array}{l}21.5 \mathrm{Ldr} . \\
\text { (344 Fr.) }\end{array}$ & $96 \mathrm{Fr}$. & $-72 \%$ \\
\hline Winterthur, Schreiblehrer ${ }^{1002}$ & $\begin{array}{l}200 \mathrm{fl} . \\
\text { (150 Fr.) }\end{array}$ & $\begin{array}{l}50 \mathrm{fl} . \\
\text { ( } 37.5 \mathrm{Fr} .)\end{array}$ & $-75 \%$ \\
\hline Zofingen $^{1003}$ & $\begin{array}{l}\text { 156.5 fl. } \\
\text { (117.4 Fr.) }\end{array}$ & $\begin{array}{l}50 \mathrm{fl} . \\
\text { (37.5 Fr.) }\end{array}$ & $-68 \%$ \\
\hline
\end{tabular}

Gleichwohl lagen zumindest die Löhne der städtischen Lehrerinnen auf einem relativ hohen Durchschnittsniveau, selbst wenn sie allesamt geringer ausfielen als die Saläre ihrer männlichen Kollegen in demselben Schultyp. Der geringere Lohn der Lehrerinnen war allerdings weder abhängig von der Schülerzahl noch von der jährlichen Schuldauer, darin ähnelten sich die verglichenen Werte allesamt zu sehr. Vielmehr war vermutlich entweder Willkür oder - wie in Begnins - die nachträglichen Errichtung der Schulanstalten entscheidend.

Systematische Lohnunterschiede zwischen jungen und älteren Lehrkräften konnten nicht gefunden werden. Das Alter der Lehrer konnte zwar in Einzelfällen - wie bereits am Beispiel des jungen Lehrers von Happerswil TG gezeigt worden ist - eine Rolle spielen, doch war die Ausgestaltung der jährlichen Schuldauer entscheidender für die Lohndifferenzen als das Alter.

Die verbreitete Naturalentschädigung mit Grundbesitz spricht für die weitgehende Zugehörigkeit der Lehrkräfte zum Stand der Kleinbauern. Viele Lehrkräfte in allen Regionen der Alten Eidgenossenschaft erhielten - auch ohne agrarischen Tätigkeitshintergrund - als Bestandteil des Einkommens Anteile an Acker-, Weide- oder Allmendland zur Nutzung. Die Parzellengrösse dieser zur Nutzung abgegebenen Flächen schwankte zwischen kleinen, flächenmässig unbestimmten Gärtchen und wenigen Juchart Land, freilich von unterschiedlicher Bodenqualität und nicht einschätzbarem monetären Wert. Da aber in der Regel kaum mehr als drei Juchart Land als Naturalbesoldung abgegeben wurde, was gemäss übereinstimmenden Angaben der Lehrer gerade für den Erhalt einer Kuh ausreichte, wird deutlich, dass den Lehrkräften nur so viel Grundbesitz zugesprochen wurde, wie für eine kleinbäuerliche Subsistenz notwendig war. ${ }^{1004}$

998 Schmidt u.a. (Hgg.), Stapfer-Enquête, Nr. 758; Nr. 759: Büren an der Aare.

999 Schmidt u.a. (Hgg.), Stapfer-Enquête, Nr. 452: St. Gallen.

1000 Schmidt u.a. (Hgg.), Stapfer-Enquête, Nr. 1018; Nr. 1019: Stein am Rhein.

1001 Schmidt u.a. (Hgg.), Stapfer-Enquête, Nr. 1792: Begnins.

1002 Schmidt u.a. (Hgg.), Stapfer-Enquête, Nr. 1137: Winterthur.

1003 Schmidt u.a. (Hgg.), Stapfer-Enquête, Nr. 2080; Nr. 2082: Zofingen.

1004 Selten wurde mehr als vier Juchart Land als Lohnbestandteil verteilt. Eine Ausnahme stellt hierbei die Schule Bätterkinden dar, wo „Der Schullehrer hat namlich, ohngefehr 4 1/2 Jucharten Matt- und Akerland, wo er sich die nöthigen Früchte, und Lebens Mittel pflanzen, und eine S. V. Kuh halten kan.“ Schmidt u.a. (Hgg.), Stapfer-Enquête, Nr. 1395: Bätterkinden. „ohn gefehr 3 Juharten Acker sehr Bös land vnd 2 stückli Matten vnd Ein stückli Weid, das er Ein S v. kühli dar Bey Er Nähren kann ohn gefehr." Schmidt u.a. (Hgg.), Stapfer-Enquête, Nr. 2225: Oberdorf. 
Die helvetische Lehrerschaft wurde gesamthaft betrachtet um 1800 allein für die Schultätigkeit mehrheitlich noch gering besoldet. Real oder zumindest potenziell sahen sich nach wie vor zahlreiche Lehrkräfte von Armut bedroht und die unsichere politische Situation hielt die ökonomische Lage der Lehrer weiterhin fragil. Gleichzeitig zeigen die verschiedenen räumlichen Beispiele jedoch einhellig, dass - mit regionalen Unterschieden - bereits eine grosse Minderheit an Lehrkräften eine Besoldung bezog, die ausreichend für den Erhalt einer mehrköpfigen Familie war oder zumindest durch den Zuzug von polyprofessionellen Teilerwerbstätigkeiten leicht zu einer ausreichenden Einkommensbasis ergänzt werden konnte. Konservativ geschätzt dürfte bereits rund ein Viertel aller helvetischen Elementarschullehrer allein durch den Ertrag des Schulamts und weiteren damit verbundenen Naturalleistungen über ein ausreichendes Jahreseinkommen verfügt haben, um jenseits von existenzieller Armut zu leben und um eine eigene Familie erhalten zu können. Vielen weiteren Lehrkräften diente das durch die Schultätigkeit erzielte Einkommen fein Kombination mit Nebentätigkeiten rner als solide Basis zur langfristigen Existenzsicherung.

Unklar bleibt bis hierhin allerdings, welchen Einfluss die drei zentralen Faktoren des Einkommens, der jährlichen Schuldauer sowie der Ausgestaltung der Nebentätigkeiten auf die persönliche Biografie der Lehrpersonen hatte und wie im reziproken Verhältnis biografisches Verhalten die Ausgestaltung der drei Faktoren mitgestaltet hat. Diese Frage steht in den folgenden Teilkapiteln im Mittelpunkt der Untersuchung. Individualbiografische Auswirkungen auf die Einkommenshöhe werden in den folgenden Kapiteln mituntersucht.

\subsection{Die Nebentätigkeiten im kollektiven Überblick}

Die polyfunktionale Ausübung von einkommensrelevanten Zweit- und Dritttätigkeiten parallel neben dem Lehramt gehörte - folgt man der bisherigen Forschungslage - zum Normalfall einer Lehrerbiografie, zumal ja bereits vier von fünf Lehrkräften eine erstberufliche Tätigkeit vor dem Lehramt ausgeübt hatten. ${ }^{1005}$ So hält Wilibald Klinke für die Zürcher Lehrerschaft um 1800 die Kausalität von Nebentätigkeiten und dem ungenügenden Einkommen aus der Schularbeit fest: „Unsere Darlegungen [...] haben gezeigt, dass die Mehrzahl der Lehrer auf Nebenverdienst angewiesen war; diese boten ihnen einerseits die Ausübung ihres früheren Berufs und andererseits Stellungen im Dienst der Kirche, die [...] in der Schule nur eine Tochteranstalt, im ,Schulmeister' ihren ,Knecht und Diener" sah." ${ }^{1006}$

Frappant ähnlich fällt auch das Fazit von Ernst Schneider über die ausgeübten Nebentätigkeiten der Berner Lehrerschaft um 1799 aus: „Dass die Schulmeister ihrem alten Berufe nicht entsagen konnten, erklärt uns die Grösse der Besoldung, die nur für die Schulzeit bestimmt war [...]; wir können ihn auch nicht als Nebenbeschäftigung bezeichnen, denn der Lehrberuf vermochte niemanden zu ernähren. Wir müssen hier einen Doppelberuf konstatieren, den die Macht der Verhältnisse erzeugt hatte. Schule und Handwerk ergänzten sich im Broterwerb; sonst aber lag natürlicherweise in dem Doppelberuf eine grosse Benachteiligung der Schule. [...] Als Nebenbeschäftigung kommen etwa kirchliche Dienste in Betracht. [...] Leichenpredigten wurden hie und da durch die Schulmeister gehalten. " 1007

1005 Vgl. das Kap. 2.2.

1006 Vgl. Klinke, Zürich: 117ff.

1007 Schneider, bernische Landschule: 87f. Zu ähnlichen Schlüssen bezüglich der Nebentätigkeiten gelangten Eduard Zingg für die Basler Lehrer und Georges Panchaud für die Waadtländer Lehrer. Zingg, Basel: 50; Panchaud, écoles vaudoises: $288 \mathrm{f}$. 
Die konstatierte Doppel- oder Polyprofessionalität war jedoch kein spezifisches Merkmal der Lehrkräfte, sondern entsprach weitgehend dem allgemeinen Charakter der noch schwach ausdifferenzierten frühneuzeitlichen Berufsausübung der Landhandwerke, besonders auf dem Land, wo noch kaum selbständige Spezialisten existierten. ${ }^{1008}$ Insofern agierten polyprofessionell tätige Lehrkräfte tatsächlich ähnlich den landarmen oder landlosen Handwerkern und übrigen Professionisten.

Gleichwohl sind direkte lineare Kausalitäten, wie sie Klinke und Schneider zwischen der jährlichen Schuldauer, den Nebentätigkeiten und der Einkommenshöhe gezogen haben, in der kollektivbiografischen Betrachtung in Frage zu stellen. Zwar bestanden - wie das vorangegangene Kapitel gezeigt hat - direkte kollektive Kausalitäten zwischen der jährlichen Schuldauer und der Einkommenshöhe. Doch zum einen wurden Nebentätigkeiten in der Praxis auch von gut verdienenden und ganzjährig unterrichtenden Lehrkräften ausgeübt, die einen Zusatzverdienst eigentlich gar nicht mehr unbedingt nötig hatten. Der Stadtberner Lehrer Niclaus Kummer, ein ehemaliger Schneider aus der Landschaft, trieb beispielsweise trotz einer ganzjährig dauernden Schule und einem hohen Einkommen von 150 Kronen oder 375 Franken während Nebenstunden als ökonomische Zusatzbeschäftigung „ein kleiner Duch handel.“1009 Gleichzeitig hatten zum anderen schlechter verdienende Lehrkräfte wie der Lehrer Johannes Wissmüller von Lütschental BE auf die Ausübung von Nebentätigkeiten verzichtet, dessen jährliches Einkommen in bloss 12 Kronen oder 30 Franken und einer freien Schulwohnung bestand, ungeachtet einer mutmasslich ganzjährig dauernden Unterrichtspflicht. ${ }^{1010}$ Auch der junge, erst 25-jährige Lehrer Jean François Paquier von Romanel-sur-Morges VD verdiente beispielsweise für das ganzjährige Halten der Schule nur „en tout 36 L. 10 S. par ans“ inklusive einer Wohngelegenheit. ${ }^{1011}$ Allerdings dauerte in dortiger Schule die tägliche Unterrichtszeit bloss drei Stunden, Pasquier selbst stammte aus einem Dorf in der erweiterten Nachbarschaft der Schule und konnte wohl noch im elterlichen Hauswesen mitarbeiten. Ferner dürften sein junges Alter und sein Zivilstand als Lediger ebenfalls wesentlichen Einfluss auf die Einkommenshöhe gehabt haben. In Anbetracht dieser persönlich-individuellen Umstände erscheint das Einkommen zwar als gering, aber nicht als Almosen.

Die grundsätzliche enorme Quantität und Vielfalt an ausgeübten Nebenbeschäftigungen durch die helvetischen Lehrkräfte haben neueste Studien zum vormodernen Schulwesen wiederholt bestätigt. ${ }^{1012}$ So vielgestaltig die Ersttätigkeiten der Lehrkräfte waren, so heterogen präsentiert sich auch die Bandbreite an ausgeübten Nebentätigkeiten mit mehr als hundert Einzeltätigkeiten, die in der Stapfer-Enquête insgesamt angeführt wurden. Ferner wurden aber neben ausserschulischen Erwerbstätigkeiten auch unbezahlte ehrenamtliche Tätigkeiten oder reine Freizeitbeschäftigungen in der gleichen Fragerubrik von den Lehrkräften mitbeantwortet.

Eine Übersicht über die kollektive Nebenbeschäftigungssituation differenziert sowohl die Art als auch die Häufigkeit von Nebenbeschäftigungen. Gruppiert sind die Nebenbeschäftigungen nach den gleichen Merkmalsklassen wie die Ersttätigkeiten. Ergänzt werden die beiden unbezahlten Merkmalsklassen „Freizeittätigkeiten“ und „Geistliche Verrichtungen“, während die Merkmalsklasse „Militärische Tätigkeiten“ als ausschliessliche Ersttätigkeit wegfällt.

1008 Meier, Handwerk: 182ff.

1009 Schmidt u.a. (Hgg.), Stapfer-Enquête, Nr. 1081: Bern.

1010 Schmidt u.a. (Hgg.), Stapfer-Enquête, Nr. 1498: Lütschental.

1011 Schmidt u.a. (Hgg.), Stapfer-Enquête, Nr. 1780: Romanel-sur-Morges.

1012 Berner, Zeichen: 97ff.; Brühwiler, Finanzierung: 222f., 228ff.; Ruloff, Schulbesuch: 101. 


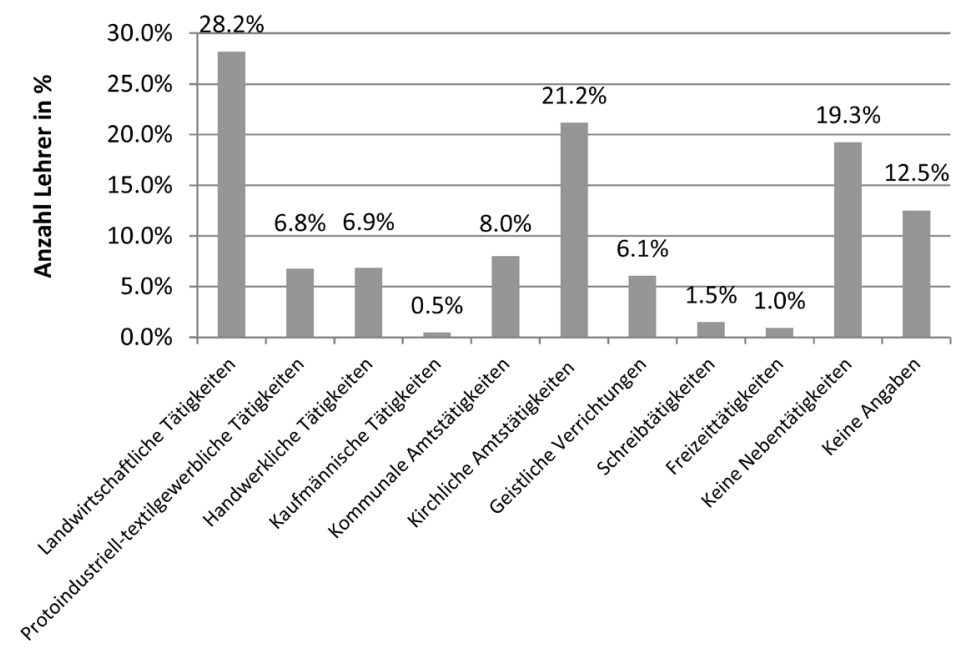

Abb. 13: Nebentätigkeiten der Lehrkräfte ${ }^{1013}$

Insgesamt mindestens 68.2\% aller Elementarschullehrkräfte der Helvetischen Republik übten gemäss ihren eigenen Vermerken in der Stapfer-Enquête neben dem Lehramt episodisch oder regelmässig eine oder mehrere ausserschulische Nebentätigkeiten zum Lehramt aus. ${ }^{1014} \mathrm{Die}$ Erwerbsbiografien von etwas mehr als zwei Dritteln aller Elementarschullehrer waren somit von anhaltender polyfunktionaler Teilerwerbsarbeit oder zumindest von Polyaktivität geprägt.

Landwirtschaftliche Nebentätigkeiten aller Art dominierten landesweit mit etwas mehr als einem Viertel Gesamtanteil nicht bloss als wichtigste Ersttätigkeiten, sondern auch mit 28.2\% als Nebenbeschäftigungen. Der Befund unterstreicht die Wichtigkeit von agrarischen Zusatzeinkommen zur unmittelbaren Subsistenzsicherung und stützt die These der weitgehenden Zugehörigkeit des Lehramts zum Milieu der kleinbäuerlichen Landwirtschaft. Zudem waren viele der späteren Lehrkräfte mit agrarischen Nebentätigkeiten bereits vor der Lehramtsübernahme in der Landwirtschaft tätig. Das Lehramt stellte somit die eigentliche „Nebentätigkeit" zur Haupttätigkeit der Kleinlandwirtschaft dar. ${ }^{1015}$ Zahlreiche Aussagen in der Stapfer-Enquête betonten dabei insbesondere die Ergänzungsfunktion der landwirtschaftlichen Tätigkeiten zum Lehramt im saisonalen Jahresgang. Der Lehrer von Flurlingen ZH notierte exemplarisch: „Jetzt hab ich nebst dem lehramt sommers zeit in den Reben zuschaffen Dan aus dem einkommen deß Schulamts kan ich mich nicht erhalten. "1016 Daneben treten in der Gesamtschau kirchliche Hilfstätigkeiten als zweithäufigste empirisch erhobene Nebentätigkeitskategorie mit über 20\% Gesamtanteil auf. Als Ersttätigkeiten spielten diese freilich noch kaum eine Rolle. ${ }^{1017}$ Sie nahmen aber als berufliche Ergänzung oder gar als

1013 Aufgrund von Mehrfachnennungen beziehungsweise mehreren Nebentätigkeiten liegt das relative Maximum an Angaben über 100\%. 233 Lehrpersonen (10\%) hatten mindestens zwei Nebentätigkeiten aufgeführt. Der Erhebung wird die Annahme vorangestellt, dass die Lehrkräfte sämtliche für sie relevanten Nebentätigkeiten aufgeführt haben beziehungsweise eine Nichtnennung von Nebentätigkeiten aus bewussten Gründen geschah.

1014 Mindestens 1.573 Lehrkräfte mit einer oder mehreren konkreten Nebentätigkeiten sind in der Stapfer-Enquête verzeichnet. Dazu kommen 288 Lehrkräfte ohne konkrete Nebentätigkeitsangaben (insgesamt 12.5\%).

1015 Vgl. ausführlicher dazu das folgende Kap. 3.2.2.

1016 Schmidt u.a. (Hgg.), Stapfer-Enquête, Nr. 465: Flurlingen.

1017 Vgl. das Kap. 2.2.10. Vgl. zur Zunahme von kirchlichen Nebentätigkeiten gegenüber den Ersttätigkeiten: Brühwiler, Finanzierung: 229f. 
Substitution von Ersttätigkeiten in der Ausgestaltung der Erwerbsbiografien eine gänzlich andere Funktion ein. Ebenso stachen kommunale Amtsfunktionen mit rund 8\% Anteil aus den übrigen Tätigkeitsfeldern in deutlich gehäufter Form heraus, zumal auch lokale Ehren- und funktionale Kommunalämter als Ersttätigkeiten noch kaum aufgezählt wurden. Übrige handwerkliche, protoindustriell-textilgewerbliche oder kaufmännische Tätigkeiten wurden dagegen von den Lehrkräften nur noch marginal als Nebenbeschäftigungen erwähnt, obwohl sie als Ersttätigkeiten noch eine starke kollektivbiografische Bedeutung hatten. Daraus wird erkennbar, dass mit der Lehramtsübernahme in den meisten Fällen - mit Ausnahme der zuvor landwirtschaftlich Tätigen - eine grundsätzliche Veränderung des biografischen Settings einherging.

Eine markante Minderheit von mindestens 19.3\% aller helvetischen Elementarschullehrkräfte gab allerdings in ihren Antworten auf die Frage III.11.h der Stapfer-Enquête zu Protokoll, explizit keine weiteren ausserschulischen Nebentätigkeiten neben dem Lehramt auszuüben. ${ }^{1018}$ Das Lehramt konnte folglich entweder als vollwertige Erwerbstätigkeit zur finanziellen Absicherung ausreichen oder nicht wenige Lehrkräfte hatten im Umkehrschluss freiwillig auf die weitere Ausübung ihrer Ersttätigkeiten verzichtet und ihre Erwerbsbiografie somit entscheidend verändert.

Die Fragestellung III.11.h schuf allerdings sowohl inhaltliche als auch temporale Mehrdeutigkeiten auf interpretativer Basis, da zum Ersten der Wahrheitsgehalt der gemachten Aussagen quellenkritisch zu hinterfragen ist. So hat Georges Panchaud durch den Zuzug weiterer Dokumente an einem Einzelbeispiel bewiesen, dass es die Lehrkräfte mit der Beantwortung der Nebentätigkeiten - anders als beim Einkommen - mit der Wahrheit nicht immer so genau nahmen. ${ }^{1019}$ Zum Zweiten war der Terminus der Nebentätigkeiten an sich nicht eindeutig definiert. Inhaltlich bestand so eine Unsicherheit für die beantwortenden Lehrkräfte, ob sich die Frage einzig auf öffentliche Tätigkeiten bezog, oder auch auf berufliche oder gar private Aktivitäten. ${ }^{1020}$ Zum Dritten schuf die Frage eine doppelte temporale Mehrdeutigkeit, denn einerseits konnte eine verneinende Antwort einzig den Sachverhalt einer gleichzeitig oder unmittelbar nach den Schulstunden ausgeübten Tätigkeit verneinen, wie es der Lehrer von Hattenhausen TG beschrieben hatte: „Jm Winter lege ich manchmahl noch zu meinem eigenen Nachtheil, alle andern Verrichtung bey seit, u warte meinem Schuhl Beruf Treü u fleißig ab. ${ }^{1021}$ Andererseits konnte sich eine Antwort auf die Ausübung von Nebentätigkeiten aber auf das ganze Jahr beziehen und grundsätzlich die Ausübung anderer Nebentätigkeiten im Jahresverlauf bestätigen oder negieren. Die Problematik akzentuiert sich beispielsweise in der Antwort des Lehrers von Aussersihl ZH, der zu seinen Nebentätigkeiten notiert hatte: „Nein ein Treuer lehrer hat keine Zeit darzu. ${ }^{\text {“1022 }}$ Die Aussage bezog sich in jenem Fall auf das gesamte Jahr, da der zitierte Schulmeister das ganze Jahr über seine Schule hielt, doch wird dies erst unter dem Einbezug der jährlichen Schuldauer klar ersichtlich. Entsprechend bieten die Beantwortungen, insbesondere die verneinenden Antworten, ein Sammelsurium an Interpretationsmöglichkeiten an. Zumindest für das Problem des temporalen Bezugs des Nichtausübens von Tätigkeiten kann in Ansätzen die jährliche Schuldauer als Indikator für die im Jahresgang aufgewendete Zeit für den Schulunterricht Antworten geben.

1018 Bei insgesamt mindestens 384 Lehrkräften sind keine Nebentätigkeiten genannt. 54 weitere Lehrkräfte widmeten sich einzig dem Privat- bzw. Zusatzunterricht in Nebenstunden und 6 Lehrkräfte hatten einzig Freizeitbeschäftigungen als Nebentätigkeiten notiert. Total: 444 Lehrkräfte.

1019 Siehe das Beispiel des Lehrers von Oron-la-Ville VD, dessen Aussagen nach keinen weiteren Nebenbeschäftigungen durch spätere Klagen beim Erziehungsrat widerlegt werden konnten: Panchaud, écoles vaudoises: 290.

1020 Vgl. die Kritik an der Fragestellung bei: Panchaud, écoles vaudoises: 289.

1021 Schmidt u.a. (Hgg.), Stapfer-Enquête, Nr. 813: Hattenhausen.

1022 Schmidt u.a. (Hgg.), Stapfer-Enquête, Nr. 251: Aussersihl. 
Da die Schule pro Tag an den meisten Orten kaum länger als sechs Stunden dauerte, bedeutete das Ausüben von Nebentätigkeiten an sich nicht zwingend eine Einschränkung der schulischen Tätigkeiten im Sinne von negativen Auswirkungen auf das Schulhalten oder auf die Qualität des Unterrichts. ${ }^{1023}$ Berichte und Klagen über Schulmeister, die simultan während der Schulstunden ihr Handwerk oder protoindustriell-textilgewerbliche Tätigkeiten fortgeführt hätten, sind hinlänglich bekannt. ${ }^{1024}$ Ein Blick in die Zürcher Schulumfrage von 1771/72 widerlegt jedoch einen breitflächigen Absentismus der Lehrkräfte während der Unterrichtszeiten, bestätigt einen fast durchwegs hohen Ausübungsfleiss und entpuppt den Absentismusvorwurf als Rhetorik von professionalisierungsorientierten Kreisen. ${ }^{1025}$

Kurzfristige Absenzen des Lehrers wurden in der Regel mit Stellvertretungslösungen durch Familienmitglieder pragmatisch gelöst. Doch wo ein geeigneter Schulraum fehlte und die Schule in der Wohnstube des Schulmeisters abgehalten werden musste, konnten durchaus unterrichtsstörende Interferenzen zutage treten, wenn Familienmitglieder den gleichen Raum als simultane Produktionsstätte für Heimarbeit oder für handwerkliche Tätigkeiten gebrauchten und die Unterrichtstätigkeit durch Lärm oder beengte Platzverhältnisse beeinträchtigt wurden. Allerdings war die Verantwortlichkeit für solche schulqualitätshemmenden Umstände eher den Gemeinden anzulasten als den Lehrpersonen. Das generelle Postulat, dass Nebentätigkeiten in grundsätzlich schädlicher Konkurrenz zur Schule gestanden hätten, ist daher nicht per se statthaft.

Dass die Ausübung von Nebentätigkeiten hingegen in einer engen kausalen Wechselwirkung zur jährlichen Schuldauer stand, erscheint angesichts der grösstenteils schuldauerbezogenen Besoldung der Lehrkräfte als evident. Die empirische Überprüfung zeigt denn auch, dass das grundsätzliche Ausüben von Nebentätigkeiten eng mit der jährlich zu leistenden Schuldauer korrelierte.

Tab. 15: Schuldauer pro Jahr und Nebentätigkeiten

\begin{tabular}{lcc}
\hline Jährliche Schuldauer: & $\begin{array}{c}\text { Anzahl Lehrer ohne } \\
\text { Nebentätigkeiten: }\end{array}$ & $\begin{array}{c}\text { Anzahl Lehrer mit } \\
\text { Nebentätigkeiten: }\end{array}$ \\
\hline Ganzjährige Schule $^{1026}$ & $277(62.3 \%)$ & $781(42.0 \%)$ \\
Winter- und Sommerschule $^{1027}$ & $96(21.7 \%)$ & $503(27.0 \%)$ \\
Nur Winterschule & $71(16.0 \%)$ & $555(29.8 \%)$ \\
Keine Angabe & 0 & $22(1.2 \%)$ \\
\hline Total & $444(100 \%)$ & $1.861(100 \%)$ \\
\hline
\end{tabular}

1023 De Vincenti-Schwab, Landschulen: 21.

1024 Ein Beispiel einer Klage: „In kleineren Schulen. hab ich Sie etwann auch schon bey den Spinn- und spul-Räderen zu angetroffen, aber mein wohl-gefahlen nicht darüber bezeüget." StAZH E I, 21.8 - Uster.

1025 Vgl. das Kap. 4.1.2.

1026 Als ganzjährige Schule wurden sowohl entsprechende Quellenaussagen als auch eine Schuldauer von mindestens 40 Wochen pro Jahr gezählt.

1027 Die Zählung beinhaltet sämtliche Formen von Schulunterricht nach der traditionellen Schulzeit von einem oder mehreren Tagen im Sommer, der aber nicht durchgehend stattgefunden hat. Eine feinere Ausdifferenzierung der Schulperioden erscheint angesichts der Vielfalt an zeitlichen Modellen von Sommerschulen als methodisch wenig sinnvoll.

1028 Inklusive der wenigen ausschliesslichen Sommerschulen im Appenzell, im Toggenburg und in Teilen der Zürcher Oberlandes. Als reine Winterschulen wurden Schulen mit einer jährlichen Schuldauer von weniger als 20 Wochen pro Jahr und keinerlei Hinweisen auf Sommerschulunterricht gezählt. Als Referenzdatum für das Schulende wurde nicht der Ostertermin vom 24. März 1799, sondern der mittlere Ostertermin vom 8. April gewählt. Daraus ergibt sich eine Schuldauer von rund 21 Wochen, von der jedoch die schulfreien Weihnachtstage abgezählt werden müssen. Vgl. zur Berechnung der Schuldauer die Referenz bei: Brühwiler, Finanzierung: 200. 
In der Tat waren es überwiegend jene Schulmeister, deren Schulen entweder das ganze Jahr über dauerten oder die zumindest während der Sommermonate für einige Tage ebenfalls Unterricht halten mussten, welche gleichzeitig keine Nebentätigkeiten notierten. Fast zwei Drittel der Lehrer ohne Nebentätigkeiten hielten ihre Schulen als durchgängige Ganzjahresschule, unterbrochen nur durch wenige Wochen Ferien während den agrarischen Erntezeiten im Hochsommer und im Frühherbst. Dagegen standen nur etwas über zwei Fünftel der Lehrkräfte mit Nebenbeschäftigungen ebenfalls einer ganzjährig dauernden Schule vor.

Ganzjährig dauernde Schulen waren zudem, wie die Auswertung zeigt, in der schulischen Realität um 1800 längst keine „Rarität“ mehr, wie es Holger Böning postuliert hat, sondern ein bereits weit verbreitetes Phänomen. ${ }^{1029}$ Bereits mindestens $45.9 \%$ der Lehrkräfte standen einer ganzjährig dauernden Schule vor. Die relative Mehrheit der Lehrer mit Nebentätigkeiten unterrichtete zwar noch nicht ganzjährig und verfügte damit grundsätzlich über freie zeitliche Ressourcen im Jahresgang, um anderen einkommensrelevanten Tätigkeiten nachgehen zu können oder zu müssen. Nebentätigkeiten wurden vor allem dann ausgeübt, wenn die Schuldauer nicht ganzjährig war und damit die jährliche Besoldung allein mutmasslich nicht ausreichte.

Allerdings verhinderte auch die allmähliche Ausweitung der jährlichen Schuldauer durch zumindest einzeltägigen Sommerschulunterricht nicht per se, dass die Lehrer keinen durchgehenden Dritttätigkeiten mehr nachgehen konnten. Zwar konnten die Lehrkräfte in den weitgehend schulfreien Wochen der Sommermonate, wenn die Kinder der Landbevölkerung im agrarischen Produktionszyklus als notwendige Arbeitskräfte für die arbeitsintensive Heu-, Getreide- oder Traubenernte gebraucht wurden, ebenfalls einer anderen Einkommenstätigkeit nachgehen, die nicht verzeichnet worden ist. Dennoch band die lokale Schule durch die Etablierung von Sommerunterrichtsangeboten die Lehrer in zeitlicher Hinsicht auch in den Frühlings-, Sommerund Herbstmonaten verstärkt an sich, selbst wenn die Sommerschule zeitlich bloss auf einen oder wenige Tage pro Woche beschränkt blieb.

Kausalitäten zwischen der jährlichen Schuldauer und dem Ausüben von Nebentätigkeiten sind ferner empirisch besonders stark bei zentralörtlichen Schulen feststellbar. Mindestens 23.5\% der Lehrkräfte ohne Nebentätigkeiten arbeiteten bei der Umfrageerhebung an einer Stadtschule oder in einem bedeutenden Marktflecken, doch davon standen seinerseits $96 \%$ gleichzeitig ganzjährig ihrer Schule vor. ${ }^{1030}$ Der Vollzeitlehrer ohne Nebentätigkeiten war damit zumindest an zentralörtlichen Elementarschulen schon zum bedeutenden kollektiven Phänomen geworden. Zwar bedeutete eine Anstellung an einer zentralörtlichen Elementarschule mit einem ganzjährigen Arbeitspensum somit nicht automatisch, dass keine Nebenbeschäftigungen mehr ausgeübt wurden, doch zentralörtliche Elementarschullehrer konnten sich den Verzicht auf Nebentätigkeiten oder die Ausübung von unbezahlten Freizeitaktivitäten aufgrund ihres meist höheren Einkommens tendenziell eher leisten als ihre Berufskollegen auf dem Land. Nebentätigkeiten wurden somit grundsätzlich einkommensunabhängig ausgeübt, denn selbst gut verdienende Lehrkräfte hatten Nebenbeschäftigungen aufgeführt. Allerdings sind die monetär höheren Einkommen der zentralörtlichen Lehrer angesichts des deutlich teureren Lebensumfelds der Städte zu relativieren und dürfen nicht direkt mit Landschullehrerlöhnen verglichen werden. Der kollektiv häufige Verzicht ist ferner als ein deutliches Indiz für eine bewusste Spezialisierung auf das Lehramt zu deuten.

1029 Vgl. Böning, Traum: 224.

1030 Insgesamt 104 Lehrkräfte aus zentralörtlichen Schulen waren in den 444 Lehrern ohne Nebentätigkeiten inkludiert (23.5\%). Davon lehrten 100 Lehrkräfte ganzjährig an ihren Schulen, was rund einem Drittel aller zentralörtlichen Schulen entsprach. 
Der enge Zusammenhang von zentralörtlicher Lage, einer ganzjährigen Schuldauer und dem Verzicht auf Nebentätigkeiten ist auch bei den wenigen verzeichneten Lehrerinnen in der Stapfer-Enquête sichtbar. Knapp die Hälfte aller Lehrerinnen notierte keine expliziten Nebenbeschäftigungen und ihre jährliche Schuldauer belief sich fast allesamt - mit Ausnahme der Landschullehrerin von Ciernes Picat VD - auf das ganze Jahr. ${ }^{1031}$ Weshalb indes fast die Hälfte der Lehrerinnen auf die Ausübung von Nebentätigkeiten verzichtete, ist den Quellen nicht zu entnehmen. Die Berner Lehrerin Maria Sprüngli antwortete auf die entsprechende Frage lapidar: „Die pflichtmäßige Besorgung der Schule laßen ihr keine Zeit zu andern Beschäfftigungen übrig. "1032

Neben der mangelnden Zeit für weitere Nebentätigkeiten aufgrund der ganzjährigen Unterrichtsdauer dürften jedoch fehlende Ersttätigkeitskenntnisse abseits der Schule eine weitere Erklärung darstellen, denn nur ein halbes Dutzend aller Lehrerinnen ohne Nebentätigkeiten listeten in der Umfrage eine konkrete Ersttätigkeit ausserhalb der Schule auf. Alle übrigen Lehrerinnen waren entweder aus Lehrerfamilien stammend, vom Jugendalter an zur Lehrerin erzogen worden oder hatten keine konkrete Erstberufsangabe hinterlassen. Zu den fehlenden spezifischen Erstberufskenntnissen kam der Umstand, dass Frauen gewohnheitsrechtlich prinzipiell der Zugang sowohl zu kirchlichen Hilfsdiensten als auch zu kommunalen Hilfsämtern verwehrt blieb. Die Konfession als struktureller Faktor blieb dagegen in der Frage nach der Ausübung von Nebentätigkeiten ohne Wirkung. ${ }^{1033}$

Die quantitative Asynchronität von ausgeübten Erst- und Nebentätigkeiten - wäre das Lehramt im Sinne eines Notbehelfs einzig eine zusätzliche Nebentätigkeit zu den bisherigen Ersttätigkeiten geblieben, müssten Ersttätigkeiten und Nebentätigkeiten quantitativ in etwa gleich oft genannt worden sein - verweist auf eine tiefergreifende Veränderung der Erwerbsbiografien der betroffenen Individuen durch die Lehramtsübernahme. Diese biografischen Veränderungen innerhalb der Lebensphase als Lehrer werden im Folgenden untersucht.

\subsection{Die Ausgestaltung der Berufsbiografien}

Die Konsequenzen der Übernahme der Lehramtstätigkeit und die damit verbundenen biografischen Dynamiken sind - abgesehen von einzelnen Bestandsaufnahmen von Nebentätigkeiten auf kantonaler Ebene - noch kaum untersucht worden, zumal die postulierte Linearität der erstberuflichen Tätigkeitsausübung und die Rolle des Lehramtes als reiner Ergänzungserwerb angesichts der bereits festgestellten hohen Zahl an Lehrkräften ohne explizite Nebentätigkeiten kollektivbiografisch insgesamt in Frage zu stellen sind. Ebenso widersprechen die zuvor dargestellten passablen Einkommensverhältnisse für eine bedeutende Minderheit der Lehrkräfte der kausalen Annahme, dass die Lehrkräfte ausschliesslich aus ökonomischen Gründen zur Ausübung von Nebentätigkeiten gezwungen waren.

Wenn ferner in der bisherigen Forschung die Frage nach der sozialen Verortung der Lehrkräfte aufgeworfen wurde, sind zumeist die Erst- und Nebentätigkeiten zusammengefasst untersucht worden, ohne die dazwischen liegenden Veränderungen mit einzubeziehen. Ausnahmen bilden einzig die Studien von Bloch Pfister zur Zürcher Lehrerschaft und von Georges Panchaud

1031 Mindestens 32 Lehrerinnen hatten 1799 keine Nebentätigkeit vermerkt. Hiervon arbeiteten 28 in einer städtischen Schuleinrichtung und vier weitere an Landschulen, alle mit einer ganzjährigen Unterrichtsdauer. Einzig die Lehrerin Susanne Saugy von Ciernes Picat VD unterrichtete bloss während vier Monaten im Winter. Schmidt u.a. (Hgg.), Stapfer-Enquête, Nr. 1996: Ciernes Picat.

1032 Schmidt u.a. (Hgg.), Stapfer-Enquête, Nr. 1078: Bern.

103360 der 444 Lehrpersonen ohne Nebentätigkeiten (13\%) waren der katholischen Konfession zuzuordnen. 
zur Waadtländer Lehrerschaft, wo Erst- und Nebentätigkeiten gesondert betrachtet wurden. ${ }^{1034}$ Dabei steht besonders die Frage Im Zentrum, ob die Übernahme des Lehramtes die bisherige Grundkonstellation der Lebensverläufe veränderte oder nicht. Es ist zudem denkbar, dass das Lehramt von bestimmten Professionsgruppen in lebenszyklischer Weise nur zeitweilig ausgeübt wurde, etwa von Bauernsöhnen, die auf die Übernahme des elterlichen Hofes warteten. ${ }^{1035}$ Es stellt sich somit die Frage, welche biografischen Konsequenzen die Übernahme des Lehramts mit sich brachte: Verlagerten die Lehrkräfte ihre einkommensrelevanten Erwerbstätigkeiten exklusiv auf das Lehramt und verzichteten auf ihre Ersttätigkeiten oder übernahmen sie das Lehramt in der Funktion einer Ergänzungstätigkeit neben den bisherigen Tätigkeiten? Konnten sich nur wohlhabende Lehrkräfte einen Verzicht von Nebentätigkeiten leisten? Wurde das Lehramt nur während einer gewissen Lebensphase ausgeübt?

Ein direkter Vergleich der in der Stapfer-Enquête festgehaltenen Tätigkeitsangaben aus der berufsbiografischen Erstphase bei der Frage III.11.g mit der später ausgeübten Berufsphase als Lehrkraft bei der Frage III.11.h ermöglicht Aufschlüsse über die grundsätzliche Entwicklung der Tätigkeitsprofile der Elementarschullehrerschaft. ${ }^{1036}$ Der Vergleich der beiden statischen Angaben von Erst- und Haupttätigkeit(en) erlaubt so einen Blick auf die Dynamik der zwischen beiden biografischen Phasen liegenden Veränderungen in den jeweiligen Erwerbsbiografien.

Obwohl die 2.305 vorliegenden Teilbiografien der helvetischen Elementarschullehrerschaft allesamt durch individuelle Einflüsse und Entscheidungen geprägt waren, sind in der chronologischen Abfolge ihrer Lebensverläufe dennoch kollektiv ähnliche Verhaltens- und Ausgestaltungsweisen feststellbar, die sich typologisieren lassen. Ausgehend von den beiden im zweiten Hauptkapitel skizzierten unterschiedlichen Pfaden des Diensteinstiegs ins Lehramt - dem Einstieg ohne Ausübung einer Ersttätigkeit und dem Einstieg nach dem Ausüben von einer oder mehrerer Ersttätigkeiten - ergaben sich unter dem Einbezug der Lehrtätigkeit und der aufgelisteten Nebenbeschäftigungen bis zum Zeitpunkt der Umfrageerhebung in der empirischen Realität drei grundsätzliche typische Entwicklungsprofile von Lebensverläufen: erstens lineare Lebensverläufe ohne ausserschulische Erst- und Nebentätigkeiten, zweitens durch das Lehramt und wahlweise weiteren Tätigkeiten erweiterte Lebensverläufe und drittens diskontinuierliche Lebensverläufe mit fundamentalen Wechseln der Tätigkeiten vor- und nach der Lehramtsübernahme. In der Folge werden diese drei hauptsächlichen Lebensverlaufstypen charakterisiert und auf ihre prägenden Faktoren untersucht.

\subsubsection{Lineare Lebensverläufe}

Der reformierte, zum Zeitpunkt der Umfrage 32-jährige Lehrer Jacob Geiger vom Marktflecken Ermatingen TG schrieb in seiner Beantwortung der Stapfer-Enquête, er sei „vorher nirgendswo gewesen, hat auch keinen Beruf getrieben, und hat neben dem Lehramte gar keine andere Verrichtungen." ${ }^{1037}$

1034 Bloch Pfister, Priester: 160-172; Panchaud, écoles vaudoises: 253-289.

1035 Zum Gedanken der lebenszyklisch bedingten Tätigkeitsausübung vgl. Meier, Handwerk: 183.

1036 Dem Vergleich liegt die Annahme zugrunde, dass die Nebentätigkeiten wahrheitsgemäss benannt wurden. Die Problematik der unvollständigen Auflistung von Nebentätigkeiten lässt sich methodisch nicht umgehen, weshalb die vorliegenden Lebensverlaufsprofile zwangsläufig unvollständig und die errechneten quantitativen Verhältnisse stets bloss Minimalcharakter haben. Von mindestens 458 Lehrkräften (19.8\% aller Lehrer) konnte aufgrund fehlender oder ungenauer Angaben kein Lebensverlaufsprofil erstellt werden.

1037 Schmidt u.a. (Hgg.), Stapfer-Enquête, Nr. 793: Ermatingen. 
Geiger verschrieb sich in seiner bisherigen 14-jährigen Erwerbsbiografie ausschliesslich der Lehrertätigkeit. Als Waisenkind und guter Schüler wurde er schon als Jugendlicher vom ehemaligen Ortslehrer als Gehilfe angestellt, um der wachsenden Kinderzahl des Orts zu begegnen, bevor er später zum Hauptschulmeister ernannt wurde. ${ }^{1038}$ Eine ganzjährig dauernde Schule, ein sehr gut dotiertes Einkommen von insgesamt 239 fl. und 44 xr. (359 Franken) sowie eine freie Schulwohnung ermöglichte es ihm, auf jegliche weitere berufliche Tätigkeiten zu verzichten, obwohl er seine Besoldung als nicht angemessen empfand. ${ }^{1039}$

Zahlreiche weitere Berufsbiografien im Kollektiv der Elementarschullehrer bestanden wie das gerade präsentierte Beispiel ausschliesslich aus dem Lehramt als einzige exklusiv ausgeübte Tätigkeit. Diese Lebensverläufe ohne berufsbiografische Veränderungen werden in der Folge als „linear" beschrieben, da ihnen ein fundamentaler ausserschulischer Erwerbstätigkeitswechsel fehlt. In Bezug auf das untersuchte Kollektiv an Elementarschullehrern bedeutet eine lineare Berufsbiografie folglich nichts anderes, als dass die untersuchten Personen vom Jugendalter an bis zum Zeitpunkt der Umfrageerhebung immer nur Schullehrer waren und keine weiteren ausserschulischen Erst- und Nebentätigkeiten ausgeübt hatten. Mindestens $6.4 \%$ des gesamten Lehrerkollektivs wiesen eine ebensolche ausschliessliche Lehrtätigkeit als exklusive Berufstätigkeit seit dem Jugendalter auf, ohne jemals eine andere nennenswerte Tätigkeit als diejenige des Schulmeisters vermerkt zu haben. ${ }^{1040}$

Dass es sich hierbei um eine eigenständige biografische Ausprägung und nicht bloss um noch nicht abgeschlossene Berufsbiografien von Junglehrern handelte, bestätigt der Generationenvergleich, denn rund ein Drittel aller Lehrer ohne Erst- und Nebentätigkeiten war zum Zeitpunkt der Umfrage bereits über fünfzig Jahre alt und somit bereits in der Lebensphase der endgültigen Ausdifferenzierung der Erwerbsbiografie. ${ }^{1041}$ Darunter befanden sich auch Lehrkräfte im weit fortgeschrittenen Alter. Der 77-jährige Lehrer Salomon Wildermuth aus Grüningen ZH schrieb, er: „Habe niemahl Keinen anderen beruf gehabt, als daß ich schon in der frühen jugend mich zum Lehren gebrauchen laßen, und schon im 17tn jahrs meines alters diser dienst mir anvertraut worden ist. Habe auch Heüt zu tag keine andere geschäfte als was den Schulberuf angehet, und warte selbiger noch alle tag $a b$, indeme (dem Höchsten seye dank) noch gut gesicht, Gehör, und Gedächtnuß Habe. “1042

Lehrkräfte ohne Erst- und Nebentätigkeiten entsprechen am stärksten dem Typus eines bewusst gewählten beruflichen Spezialisten oder Professionisten im Sinne der „pédagogues de profession“. In erster Linie gehörten Lehrersöhne zu den Lehrkräften mit einem rein linearen Lebensverlauf. Mindestens bei 22 der 147 Lehrkräfte mit einer ausschliesslich schulischen Beschäftigung ist eine familiär-dynastische Berufsweitergabe in der Stapfer-Enquête bezeugt, die Dunkelziffer dürfte jedoch noch um einiges höher gelegen haben. Lehrersöhne hatten mit dem frühen Einstieg ins Lehramt beim Vater oder bei anderen Familienmitgliedern die besten Voraussetzungen, um sich das spezifische Wissen des Unterrichtens anzueignen und um später exklusiv davon leben zu können. Allerdings kann das Phänomen von linearen Lehrerbiografien nicht ausschliesslich auf den Vorteil der innerfamiliären Wissensweitergabe beziehungsweise

1038 Mayer, Ermatingen: 5-71.

1039 „Aus dieser Beant\{wort\}ung der vorgelegten Fragen ist leicht zu sehen, daß die Belohnungen den Geschäften des Schullehrers nicht so sehr angemeßen.“ Schmidt u.a. (Hgg.), Stapfer-Enquête, Nr. 793: Ermatingen.

1040 Insgesamt 147 Lehrkräfte sind dem Typus der linearen Berufsbiografie zuzuordnen.

1041 Von den 147 Lehrpersonen waren 36 Personen unter 30 Jahre alt (25\%), 61 Personen zwischen 30-49 Jahre (41\%) und 49 Personen über 50 Jahre alt (33\%). Eine Person blieb ohne bestimmbares Alter (1\%).

1042 Schmidt u.a. (Hgg.), Stapfer-Enquête, Nr. 472: Grüningen. 
auf Lehrersöhne allein zurückgeführt werden, zumal zahlreiche Lehrersöhne auch anderen Erwerbstätigkeiten nachgingen. Auch gute Schüler oder Waisen wie der obgenannte Lehrer Geiger waren prädestiniert, sich exklusiv dem Lehramt zu verschreiben. Das mittlere Amtsübernahmealter belief sich auf 24.4 Jahre, der Median lag etwas tiefer bei 22 Jahren.

Das einleitende Beispiel des Ermatinger Lehrers Geiger zeigt ferner, dass eine exklusive berufliche Spezialisierung auf das Lehramt grossmehrheitlich unter der Prämisse des Vorhandenseins zweier lokalstruktureller Bedingungen möglich war - entweder einer ganzjährig dauernden Schule oder zumindest einer Besoldungshöhe, die einen Verzicht auf andere Erwerbstätigkeiten ermöglichte. Ganzjährig dauernde Schulen machten denn auch die grösste Gemeinsamkeit der Lehrkräfte ohne weitere ausserschulische Erst- und Nebentätigkeiten aus.

Tab. 16: Schuldauer der Lehrer mit linearem Lebensverlauf

\begin{tabular}{lccc}
\hline Jährliche Schuldauer: & Anzahl Lehrer: & $\begin{array}{c}\text { Davon an zentral- } \\
\text { örtlichen Schulen: }\end{array}$ & $\begin{array}{c}\text { Einkommen über } \\
\mathbf{1 . 0 0 0} \text { Batzen: }^{1043}\end{array}$ \\
\hline Ganzjähriger Unterricht & $107(73 \%)$ & 39 & $67(63 \%)(5)$ \\
Winter- und Sommerschule & $19(13 \%)$ & 0 & $6(31.6 \%)(2)$ \\
Nur Winterschule & $21(14 \%)$ & 0 & $0(8)$ \\
\hline Total & $147(100 \%)$ & 39 & 73 \\
\hline
\end{tabular}

Mindestens rund drei Viertel aller Lehrkräfte mit linearem Biografieverlauf standen ganzjährig ihrer Schule vor. ${ }^{1044}$ Davon waren wie der als Beispiel angeführte Lehrer Geiger überdurchschnittlich viele, rund 27\%, in zentralörtlichen Schulen angestellt, von denen alle zudem einer ganzjährig dauernden Schule vorstanden. ${ }^{1045}$ Nur an ländlichen Schulen tauchten in geringem Umfang Lehrkräfte mit linearen Biografien bei einer beschränkten jährlichen Schuldauer auf, nur sehr Wenige unterrichteten jedoch überhaupt einzig in den Wintermonaten. Was diese Lehrkräfte in den unterrichtsfreien Zeiträumen während der übrigen Monate denn wirklich taten, entzieht sich aufgrund der Quellenlage weitgehend unserer Kenntnis.

Lehrkräfte mit linearen Erwerbsverläufen neigten trotz ihrer ausschliesslichen Spezialisierung auf das Lehramt wenig zur Intensivierung ihrer Unterrichtstätigkeiten mittels zusätzlichen kostenpflichtigen Privatstunden. Eine der wenigen Ausnahmen war der 52-jährige Lehrer der Schule von Steinshof ZH im Zürcher Oberland: „Nun aber ehe dem vom 14. Jahr meines Alters, wie dato noch nebend obiger Schul-Zeit mit nebend Schulen und Haus-Lehren beschäftiget. ${ }^{1046}$ Schulische Nebentätigkeiten als Ergänzung zum regulären Unterricht, etwa das Angebot von kostenpflichtigen Privatstunden zu Randzeiten, blieben insgesamt sowohl in kollektiver Optik

1043 In die Berechnungen einbezogen wurden einzig die ausgewiesenen Geld- und Holzwerte. Das Klafter Holz ist nach Brühwiler mit 6 Franken bzw. 60 Bz. gerechnet worden (Brühwiler, Finanzierung: 346). Auf die Mitberechnung von weiteren Getreide- und Naturalwerten ist aufgrund der grossen regionalen Preisdifferenzen sowie der zahlreichen ungenauen Angaben durch die Lehrkräfte verzichtet worden. Daher sind die Berechnungen als Mindestwerte zu verstehen. Die Zahl in Klammern entspricht der Anzahl Lehrkräfte mit einem Wochenlohn von mehr als 25 Batzen/2 Franken, aber unklarem Gesamttotal der Einkünfte.

1044 Vgl. zur jährlichen Schuldauer von Lehrkräften ohne Ersttätigkeiten das Kap. 2.2.1.

1045 Insgesamt 39 der 147 Lehrpersonen mit linearem Lebensverlauf arbeiteten zum Zeitpunkt der UmFrage in einer zentralörtlichen Schule.

1046 Schmidt u.a. (Hgg.), Stapfer-Enquête, Nr. 541: Steinshof. 
als auch bezogen auf die Lehrkräfte mit linearem Lebensverlauf ein wenig beobachtetes Phänomen. Bloss insgesamt 82 Lehrkräfte oder rund 3.6\% aller helvetischen Lehrer vermerkten in der Umfrage ein solches Zusatzangebot. Davon lebte die Hälfte dieser Lehrkräfte, 42 Personen, an einem zentralörtlichen Standort in einer Stadt oder in einem Marktflecken. Selbst unter den 147 Lehrern mit exklusiver Spezialisierung auf den Unterricht erwähnten nicht mehr als 23 Lehrkräfte zusätzlichen Privatunterricht explizit. Nur gerade sieben der 40 Lehrkräfte mit linearer Biografie und ohne ganzjährige Schularbeitszeit widmeten sich Nebenschuldiensten oder betätigten sich als Privatlehrer in vermögenden Einzelhaushalten. Selbst bei ganzjährig unterrichtenden Lehrkräften blieben im Tagesgang zwar stets noch Nebenstunden als ökonomisch nutzbare Zeit übrig, die allerdings ebenfalls nur von einer kleinen Minderheit der Lehrer für kostenpflichtigen Privatunterricht genutzt wurde. Zudem konzentrierten sich Privatschulangebote insgesamt ebenfalls sehr stark auf zentralörtliche Schulen. ${ }^{1047}$

In Bezug auf die Kausalität von Lagebedingungen und Privatschulangeboten sind somit drei Schlussfolgerungen zu ziehen: Erstens bestand offensichtlich fast ausschliesslich nur in zentralörtlichen Gemeinden eine genügend starke Nachfrage nach zusätzlichem kostenpflichtigen Schulunterricht vonseiten zahlungskräftiger und zahlungswilliger Eltern, damit es sich für die öffentlichen Elementarschullehrer überhaupt lohnte, ein entsprechendes Bildungsangebot zu etablieren. Das bedeutet nicht, dass in ländlichen Gemeinden die Nachfrage nach Elementarbildung per se geringer war, wie oftmals postuliert worden ist. Hält man das vielfach postulierte Desinteresse der Landbevölkerung an Elementarbildung für einen weitgehenden Mythos der Zeitgenossen - dazu geben die vereinzelt am Rande erwähnten Privatschullehrer in ländlichen Gemeinden Anlass ${ }^{1048}$ - scheint zweitens in ländlichen Gemeinden weniger die Nachfrage nach Zusatzbildung geringer gewesen zu sein, sondern vielmehr die Konkurrenz durch private Bildungsanbieter ungleich grösser, so dass es für die Lehrpersonen schlicht zu wenig ökonomischen Sinn machte, Privatschulunterricht anzubieten. Ein Teil des notwendigen Wissenskanons war noch stark ins Private ausgelagert und unterstand schlicht noch nicht der Kompetenz der Schulmeister. So sind etwa die elementaren Kalkulationskenntnisse, das sogenannte „Bauernrechnen“, in der Regel noch ausserhalb der Institution Schule durch kundige Bauern oder Hausväter vermittelt worden. Drittens verhinderte wohl die verbreitete Armut der Landbevölkerung vielerorts eine Expansion von bezahlpflichtigen Unterrichtstätigkeiten der öffentlichen Schullehrer. Die Dorfschullehrer konnten zwar mit zusätzlichen Bildungsangeboten als lokale Konkurrenten auf diesem informellen privaten Bildungsmarkt in Erscheinung treten, hatten im Gesamtkollektiv bis zur Jahrhundertwende um 1800 aber noch weitgehend auf diese naheliegende Einkommensmöglichkeit verzichtet.

Das jährliche Einkommen beeinflusste die Möglichkeit der exklusiven Spezialisierung auf das Lehramt im Zusammenspiel mit der jährlichen Schuldauer. Mindestens 67 der 107 Lehrkräfte mit ganzjährigem Unterricht und linearem Lebensverlauf verdienten um 1799 mutmasslich den Mindestlohn von 1.000 Batzen oder 100 Franken, während von den übrigen 40 Lehrpersonen bloss mindestens sechs weitere den Mindestlohnwert erreichten. Von den Lehrkräften mit linearem Lebensverlauf, deren Schuldauer auf den Winter beschränkt war, erzielte zwar keine ein absolutes Jahreseinkommen in der Höhe des Mindestlohns, mindestens acht Lehrer erhielten aber zumindest Wochenlöhne in der Höhe von mindestens 25 Batzen/2 Franken, was hochge-

1047 Bloss 19 der 107 ganzjährig unterrichtenden Lehrer mit linearer Biografie übten schulische Nebentätigkeiten als Haus- und Privatunterricht aus (17\%). Davon arbeiteten aber 12 an einer zentralörtlichen Schule.

1048 Beispielhaft sei auf die Privatschule des Lehrers Johannes Ender in Marbach SG verwiesen. Schmidt u.a. (Hgg.), Stapfer-Enquête, Nr. 1223: Marbach. 
rechnet auf das gesamte Jahr ebenfalls für den hypothetischen Mindestlohn reichte. Da in der frankophonen Waadt die jährliche Schuldauer verbreitet ganzjährig dauerte und entsprechend die Löhne dort insgesamt am üppigsten ausgestattet waren, traten Lehrer mit linearem Berufsverlauf hier besonders häufig auf. ${ }^{1049}$ Für die Lehrkräfte mit linearem Lebensverlauf ist die kausale Verbindung von jährlicher Schuldauer, dem Jahreseinkommen und dem Verzicht auf weitere Erwerbstätigkeiten zu bestätigen.

Hinsichtlich der Geschlechterverhältnisse ist in der empirischen Erhebung eine schwache Präferenz der Lehrerinnen zu linearen Lebensverläufen festzustellen. Insgesamt befanden sich mindestens 13 Lehrerinnen unter den 147 Lehrpersonen mit einem linearen Lebensverlauf.

Einige grundsätzliche Probleme bleiben jedoch aufgrund der Quellenlage bestehen. Weitgehend unfassbar ist, ob die Lehrkräfte mit linearem Lebensverlauf tatsächlich keine weiteren ökonomischen Tätigkeiten vor- oder neben dem Lehramt ausübten, insbesondere jene Lehrkräfte mit keiner ganzjährigen Schuldauer und die wenigen Lehrerinnen. Dass jedoch bloss lebenszyklisch bedingt auf die Ausübung von weiteren Tätigkeiten verzichtet worden wäre, kann angesichts der zahlreichen älteren Lehrkräfte ausgeschlossen werden.

\subsubsection{Kontinuierlich-erweiterte Lebensverläufe}

Nur ein kleiner Teil der Lehrkräfte ohne Ersttätigkeitsausübung wies nach den Erkenntnissen des vorangegangenen Kapitels einen linearen Lebensverlauf auf. Die meisten - mindestens 58\% aller Lehrkräfte ohne aufgeführte Ersttätigkeiten - übten zwar nach ihren eigenen Angaben keine Ersttätigkeiten aus, erwähnten aber nach der Lehramtsübernahme zusätzlich zu ihrem Lehramt mindestens eine weitere Nebentätigkeit zu ihrem Berufsprofil. Exemplarisch verweist die Antwort des Lehrers Jean Christophe Paquier aus La Chiésaz VD darauf: „[Frage III.11.g:] $\mathrm{Jl}$ a été à Dizy instituteur, la seule vocation à laquelle il se soit voué. [Frage III.11.h:] Jl y réunit les fonctions de l'Eglise, alternativement avec les autres instituteurs de la Paroisse. ${ }^{\text {1050 }}$ Das Lehramt stellte somit die biografische Konstante, eine neue Nebentätigkeit die Erweiterung dar.

Ebenso stellt sich die erwerbsbiografische Situation bei der Mehrzahl an Lehrkräften, für die das Lehramt nicht die erste ausgeübte Tätigkeit darstellte, sondern erst in einer zweiten biografischen Phase als neue ergänzende Tätigkeit hinzutrat, bedeutend komplexer dar. Das Lehramt trat entweder als neue polyprofessionelle Erweiterung zum bisherigen Tätigkeitsprofil auf, wobei die Lehrkräfte ihre ursprünglichen Ersttätigkeiten weiterhin ausübten, oder es gesellten sich noch weitere mit dem Lehramt verbundene Tätigkeiten hinzu. Das Lehramt stellte somit selbst die biografisch erweiternde Tätigkeit als polyprofessioneller Teilerwerb dar, während das ursprüngliche Erwerbssetting vor der Lehramtsübernahme grundsätzlich unverändert blieb und kontinuierlich weiter ausgeübt wurde.

Mindestens $42.7 \%$ aller helvetischen Lehrkräfte wiesen zum Zeitpunkt der Umfrageerhebung einen Lebensverlauf auf, der durch eine Erweiterung ihres Tätigkeitsprofils gekennzeichnet war. ${ }^{1051}$ Polyprofessionalität stellte damit in Übereinstimmung mit den bisherigen Forschungsresultaten die relativ häufigste Form an Berufsprofilen dar, betraf allerdings insgesamt weniger als jede zweite helvetische Lehrkraft. Von einer Dominanz der Polyprofessionalität in Bezug

104948 der 147 Lehrer mit linearem Lebensverlauf stammten aus der Waadt.

1050 Schmidt u.a. (Hgg.), Stapfer-Enquête, Nr. 1773: La Chiésaz.

1051 Mindestens 709 Lehrkräfte übten neben dem Lehramt ihre Ersttätigkeiten weiter aus und weitere 276 Lehrpersonen führten zwar nur das Lehramt als Ersttätigkeit, aber gleichzeitig weitere Nebentätigkeiten auf. Die Summe von 985 Lehrern entspricht $42.7 \%$ aller helvetischen Lehrkräfte. 
auf die Lebensverläufe von Elementarschullehrern zu sprechen, wäre daher falsch. Bedeutende konfessionelle und generationelle Differenzen konnten ebenso nicht festgemacht werden. Wer behielt seine Ersttätigkeiten auch nach der Lehramtsübernahme bei? Ein Vergleich zeigt deutliche Präferenzen einzelner Tätigkeitsgruppen zum Erhalt der Ersttätigkeiten neben dem Lehramt.

Tab. 17: Tätigkeitsgruppen mit Ausübungskontinuität

\begin{tabular}{lccc}
\hline Tätigkeit: & Ersttätigkeit: & $\begin{array}{c}\text { Davon als Nebentätig- } \\
\text { keit weiter ausgeübt: }\end{array}$ & In Prozent: \\
\hline Landwirtschaftliche & 756 & 378 & $50.0 \%$ \\
Protoindustriell-textilgewerbliche & 255 & 101 & $39.6 \%$ \\
Handwerkliche & 370 & 128 & $34.6 \%$ \\
Kaufmännische & 28 & 1 & $3.6 \%$ \\
Kommunale & 30 & 12 & $40 \%$ \\
Kirchliche & 22 & 8 & $36.4 \%$ \\
Schreiber & 22 & 6 & $27.3 \%$ \\
Studium & 140 & 97 & $69.3 \%$ \\
\hline
\end{tabular}

Neben Geistlichen, die ihre religiösen Verrichtungen auch neben der Schule grösstenteils weiterführten, war die Ausprägung der berufsbiografischen Erweiterung durch das Lehramt besonders bei Personen mit landwirtschaftlichem Tätigkeitshintergrund oft zu beobachten. Beispielhaft überlieferte der Lehrer Johannes Schmid von Rothenhausen TG: „[III.11.g:] Jch war vorher alle Zeit daheim gewesen, Und meinen Beruf war auf den Gütteren zu Arbeiten [III.11.h:] Nebst dem Lehramte, hab ich Verrichtungen auf den Gütteren."1052

Mindestens 50\% der agrarisch ersttätigen Lehrkräfte blieb - wie der obgenannte Lehrer Johannes Schmid - der Landwirtschaft auch nach der Lehramtsübernahme treu ${ }^{1053}$ Damit manifestiert sich zum einen die ungeheure Wichtigkeit der agrarischen Subsistenz als die bedeutsamste Ergänzungsfunktion und als Stützpfeiler für das ökonomische Bestehen vieler Lehrerhaushalte. Die hohe zeitliche Kompatibilität des Schulhaltens mit agrarischen Tätigkeiten im saisonalen Jahresgang wurde in zahlreichen Lehrerantworten hervorgehoben, ebenso wie die Möglichkeit der Arbeitsteilung im Familienverbund. ${ }^{1054}$ Letzteres bestätigt die Antwort des Lehrers Peter Möry von Epsach BE: „Jch war zu Epsach und hatte Landes Arbeit [...] Jm Sommer Landes Arbeit, im Winter Überlaße ich dieselbe meiner Familje. ${ }^{\text {"1055 }}$

Zum anderen weist die hohe Konstanz von landwirtschaftlichen Tätigkeiten als Nebentätigkeiten zum Lehramt auf das bereits bei der Betrachtung der Ersttätigkeiten festgestellte Indiz hin, dass das Lehramt gerade für kleinbäuerliche Schichten als saisonale Ergänzungstätigkeit besonders begehrt war, wenn die jährliche Schuldauer noch begrenzt war. Denn gerade überall dort, wo die jährliche Schuldauer noch einzig auf den Winter oder bloss auf eine kurze Sommer-

1052 Schmidt u.a. (Hgg.), Stapfer-Enquête, Nr. 371: Rothenhausen.

1053 Mindestens 378 der 756 Lehrer mit agrarischem Hintergrund hatte neben dem Lehramt weiterhin landwirtschaftliche Tätigkeiten ausgeführt.

1054 Vgl. zur umstrittenen Frage einer von Mattmüller postulierten grundsätzlichen Kompatibilität von agrarischer Subsistenzsicherung und handwerklich bzw. protoindustriellen Tätigkeiten: Zimmermann, Dorf und Land: 101.

1055 Schmidt u.a. (Hgg.), Stapfer-Enquête, Nr. 838: Epsach. 
schule - wie im obgenannten Fall von Epsach BE ein Tag pro Woche - beschränkt blieb, brachte das Lehramt für agrarisch Tätige den grössten Mehrwert als zusätzlichen Teilerwerb. Es unterrichtete denn auch die deutliche Mehrheit der kontinuierlich agrarisch tätigen Lehrkräfte an einer Schule mit begrenzter jährlicher Schuldauer. 35\% dieser agrarisch tätigen Lehrkräfte waren ausschliesslich als Winterschullehrer angestellt, weitere $40 \%$ mussten bloss an einzelnen Tagen im Sommer zusätzlich unterrichten, während bloss 25\% einer ganzjährig dauernden Schule vorstanden. ${ }^{1056}$ Entsprechend befanden sich zum einen zahlreiche Nebenschulen, zum anderen praktisch ausschliesslich Landschulen, kaum aber zentralörtliche Schulen unter den Arbeitsstätten für kontinuierlich agrarisch tätige Lehrer. ${ }^{1057}$ Dass bei der Festlegung der Entlöhnung ferner die agrarischen Subsistenzmöglichkeiten bei ebensolchen Lehrkräften stillschweigend mit einberechnet wurde, kann angenommen werden, was teilweise die niedrigen Lehrerlöhne auf dem Land zu erklären vermag.

Kaum zu einer kontinuierlichen Weiterausübung des erlernten Metiers neben dem Lehramt neigten dagegen paradoxerweise ehemalige Handwerker. Bloss jeder dritte Handwerker blieb seiner Tätigkeit auch nach der Lehramtsübernahme als zusätzliche Einkommensquelle treu. Dadurch entkräftet sich der pauschale Vorwurf der „Schädlichkeit“ von Handwerkern als Elementarschullehrkräfte, wie er etwa in Zürich formuliert wurde ${ }^{1058}$, von selbst, indem ein Grossteil der Handwerker von sich aus auf eine Weiterausübung während- oder nach der Schulzeit nach eigenen Angaben verzichtete. Dieser Befund bedeutet, dass die Lehramtstätigkeit für die Mehrheit der ehemaligen Handwerker offensichtlich lohnenswerter oder zumindest gleichwertig wie ihr Ersthandwerk erschien.

Betrachtet man die fünf häufigsten Handwerke unter den handwerklichen Ersttätigkeiten im Hinblick auf eine kontinuierliche Ausübung neben dem Lehramt, werden jedoch deutliche Unterschiede zwischen den einzelnen Berufsgruppen sichtbar:

Tab. 18: Ausübungskontinuität der häufigsten Handwerke

\begin{tabular}{lcc}
\hline Tätigkeit: & Als Ersttätigkeit genannt: & $\begin{array}{c}\text { Davon als Nebentätigkeit } \\
\text { weiter ausgeübt: }\end{array}$ \\
\hline Schuster & 75 & $24(32 \%)$ \\
Schneider & 58 & $25(43 \%)$ \\
Küfer & 22 & $11(50 \%)$ \\
Zimmermann & 33 & $7(21 \%)$ \\
Schreiner & 25 & $15(60 \%)$ \\
\hline
\end{tabular}

Holzverarbeitende Handwerke des landwirtschaftlichen Bedarfsgewerbes - Schreiner und Küfer - hielten ihrem erlernten Handwerk neben dem Lehramt am stärksten die Treue. Mehr als die Hälfte der ehemaligen Schreiner und Küfer übte neben dem Lehramt weiterhin ihr Handwerk aus. Demgegenüber zeigten Angehörige der textilen Massenhandwerke wie Schuster und

1056 Von den 378 Lehrkräften mit kontinuierlichen agrarischen Tätigkeiten standen 135 einer reinen Winterschule vor, 147 unterrichteten im Winter und an einzelnen Sommertagen, 96 betrieben eine Ganzjahresschule.

1057 Bloss 5 der 378 Lehrkräfte mit kontinuierlichen agrarischen Tätigkeiten arbeiteten an einer zentralörtlichen Schule, wovon alle kleine Landstädtchen waren (Altstätten, zwei in Andelfingen, Bülach, Neunkirch).

1058 Vgl. zum Vorwurf gegen Handwerker im Lehramt das Kap. 2.2.3. 
Schneider eine geringere Neigung zum Beibehalten ihrer Tätigkeiten. Der Lehrer von Sigriswil BE ersetzte etwa mit dem Lehramt und dem Kommunalamt des Distriktrichters sein Schneiderhandwerk, blieb aber gleichwohl nebenbei in der Landwirtschaft tätig. ${ }^{1059}$

Ähnliches kann für die ehemals protoindustriell-textilgewerblich tätigen Lehrkräften postuliert werden. Bloss zwei von fünf ehemals protoindustriell-textilgewerblich tätigen Lehrkräften führten ihre ursprüngliche Erwerbsarbeit neben oder nach dem Lehramt weiter. Das Beibehalten der Ersttätigkeiten begründeten die Lehrkräfte - wenn überhaupt - als ökonomische Notwendigkeit. Der Lauwiler Lehrer Johannes Rudy, ein ehemaliger Posamenter, hielt beispielhaft fest: „Er treibt neben dem Lehramte seinen Beruf, weil er sonst verhungern müßte. "1060 Das kollektive Verhalten des mehrheitlichen Abwendens von der Ersttätigkeit durch die ehemaligen Schuster, Schneider und Weber zeigt ferner, dass insbesondere jene Branchen der ländlichen Produktion mit der grössten lokalen Konkurrenz - Bekleidungshandwerke und die Textilproduktion - in besonderem Masse bereit waren, ihre Ersttätigkeit gegen das Lehramt einzutauschen und damit einen radikalen Bruch der erwerbsbiografischen Entwicklung einzugehen. Ebenso bevorzugten die meisten ehemaligen Angehörigen der übrigen Nischengewerbe von Handel, Verwaltungsund Kirchentätigkeiten die Aufgabe der Ersttätigkeit zugunsten des Lehramts und weiterer neuer Teilerwerbe. ${ }^{1061}$

Am weitaus häufigsten trat in der relativen Betrachtung das Lehramt bei Geistlichen als reine Ergänzungstätigkeit im Lebensverlauf auf. Das bietet Anlass für eine vertiefte Betrachtung.

\section{Die geistlichen Lehrer}

Bei den meisten Lebensverläufen der im Elementarschulwesen involvierten Geistlichen beider Konfessionen nahm das Lehramt eine Erweiterungsfunktion ein, da sie das Lehramt in der Regel als Nebentätigkeit zu den eigentlichen geistlichen Verrichtungen ausübten. Mindestens 69\% der geistlichen Lehrkräfte sind denn auch dazu zu zählen, selbst wenn die einzelnen Momente der biografischen Sequenzen zu zeitlich unterschiedlichen Lebenszeitpunkten stattfanden. ${ }^{1062}$ Angesichts der zuvor festgestellten Häufigkeit von Privat- und Hauslehrerbetätigungen während der Studienzeit ergibt sich ein typisierbarer Lebensverlauf für Geistliche beider Konfessionen mit minimalen konfessionstypischen Unterschieden zwischen katholischen und reformierten Geistlichen. ${ }^{1063}$

Der typische Lebensverlauf eines Geistlichen mit Berührungspunkten zum Elementarschulwesen präsentiert sich - nimmt man die Biografiefragmente der Geistlichen aus der Stapfer-Enquête als Vorlage - in folgenden Sequenzen: Auf den Besuch der Elementarschule und der höheren Lateinschule oder nach entsprechendem Privatunterricht als Jugendlicher folgte eine post-adoleszente, zeitlich begrenzte Lebensphase durch das Studium an einer Hochschule, oftmals im Ausland. Dabei wurden als biografische Episode während der Studienzeit erste Erfahrungen als Privat- und Hauslehrer in wohlhabenden Bürgerhaushalten gesammelt, meist um die Kosten für die Lebensführung und für das Studium zu stemmen. Nach dem Abschluss der Studien folgte in der Regel

1059 „Jst vorher bey Seinen vatter Gewesen, und hat das Schnider handwerck, nebst feldarbeit verrichtet. Jst neben dem Lehramt districkts Richter, muß auch andere Haus und Feldarbeit verichten, wil die belohnung im Lehramt vil zu klein, nur dem abzuwarten." Schmidt u.a. (Hgg.), Stapfer-Enquête, Nr. 1440: Sigriswil.

1060 Mit 14 Neutalern oder rund 60 Franken war das Einkommen des Lauwiler Lehrers tatsächlich eher tief, allerdings besass er ein eigenes Haus und hatte das Lehramt bereits seit 38 Jahren ausgeübt. Schmidt u.a. (Hgg.), StapferEnquête, Nr. 2224: Lauwil.

1061 Vgl. das folgende Kap. 3.3.3.

1062 Mindestens 97 der 140 Geistlichen wiesen eine insgesamt ähnliche kontinuierliche Biografie auf.

1063 Vgl. zur Privat- und Hauslehrertätigkeit von Studenten das Kap. 2.2.10. 
eine zeitlich unbegrenzte, in Einzelfällen mitunter lebenslang andauernde Lebensphase des Wartens auf eine freie Pfrund. Überbrückt wurde dieses Moratorium mit kirchlichen Hilfstätigkeiten als katholischer Kaplan oder als reformierter Pfarrhelfer. Häufige Stellenwechsel waren dabei keine Seltenheit. Hierbei mussten in konfessioneller Differenzierung katholische Ordens- und Weltgeistliche - je nach lokaler Organisation - auch den Elementarschuldienst bedienen, während reformierten Geistlichen das Ausüben des lokalen Schuldienstes freiwillig überlassen war. Einzig in der Basler Landschaft bestanden einzelne Schuleinrichtungen, die bis kurz vor der Helvetischen Revolution exklusiv städtischen reformierten Geistliche als Alternative zu Pfarrhelferstellen vorbehalten waren. Erst relativ spät rückte als Höhepunkt der Berufskarriere eine Priester- oder Pfarrerpfründe in Reichweite. Nach der Berufung auf eine Pfarr- oder Priesterpfrund im mittleren bis späten Erwachsenenalter arbeiteten Geistliche beiderlei Konfession jedoch nur noch ausnahmsweise in Notsituationen oder auf freiwilliger Basis aktiv im Elementarschulwesen. Beschäftigungen im Elementarschulwesen hatten somit grundsätzlich den Charakter einer primär episodischen oder aber freiwillig ausgeübten Tätigkeit für jüngere Geistliche.

Stellvertretend für diesen geschilderten Lebensverlaufstypus ist die Antwort des damals 33-jährigen Lehrers und Priesters Franz Joseph Durrer aus Kerns OW auf die Stapfer-Enquête zu betrachten: „Der erste Beruf den ich hatte, war der Priesterstand. Da habe ich zu erst zwey Jahre in Lucern, ein Jahr zu Freyburg im Uechtland, und die übrigen Jahre zu München in Bayern studiert. Jn München war ich 8 Jahre, wo ich neben meinem Studieren mit Unterrichtung der Kinder mich beschäftigte. Jch blieb dort noch 2 Jahre, da ich schon Priester war, bis ich endlich zur Schulpfrundt nach Hause berufen wurde. Hier ist auch mit der Schulpfrundt die Organistenpfrundt verbunden, und so andere Verrichtungen im Gottesdienst, die insgemein mit der Organistenpfrundt verknüpfet sind. ${ }^{\text {"1064 }}$

Im eindrücklichen Lebensverlauf des reformierten siebzigjährigen Stadtbasler Mädchenschullehrers Samuel Wettstein wird ferner die typische, bisweilen langjährige Moratoriumssituation von Geistlichen exemplarisch sichtbar: „Und zwanzig Jahre ist es, daß ich Praeceptor der Mägdlein Schul im mindern Basel bin. Die Frage betreffend: Wo ich vorher gewesen? was ich vorher für einen Beruf gehabt? So habe ich in ehrerbietigster Antwort zu melden, daß ich Anno 1760. zu einem Pfarrer nach Neüreüth, welches eine Reformierte Gemeinde, und eine Stunde weit von Carlsruhe ist, berufen worden. Diese Berufung ist hernach von dem Herrn Marck Graf von Baden Durlach bestätiget, und solche Bestätigung mir schriftlich zugestellt worden. Nachdem ich nun solchem Pfarrdienste Vier Jahre vorgestanden, hat sich mein Herz gar hefftig wiederum nach dem Vatterland gesehnet: Daher ich abgebätten und bey dem Herrn Markgraf um die Entlassung von meinem Pfarrdienste angehalten, und diselbe nach meinem Verlangen erhalten habe. [...] Nicht lange hernach bin ich nach Muttenz zu dem seligen Pfarrer Annoni, als Vicarius gekommen, und habe Sechs Jahre lang den ganzen Pfarrdienst für Jhn versehen, und bin bey Jhm geblieben biß an sein seliges End. - Nachgehends bin ich zu dem Pfarrer Burghart selig, auf Gelterkinden, als Vicarius gekommen, und habe auch Sechs Jahr lang daselbst vicarirt, und die Pfarrgeschäfte versehen. Hernach habe ich in Rigoldswyl anderthalb Jahr lang vicarirt; ein halbes Jahr bey deß Pfarrer Rothen selig Lebzeiten; und ein Jahr lang nach seinem Tode, da ich bey der Wittfrauen als PfarrVicarius das Gnaden Jahr, wie man es damahls genennet hat, versehen." ${ }^{065}$

Wie viele Geistliche auf dem Weg zur Pfarrer- beziehungsweise Priesterpfrund stecken blieben und niemals das eigentliche Berufsziel erreichten, muss indes auf der Basis der untersuchten Quellen offen bleiben. Doch nicht nur Heimweh wie im obenstehenden Fall bewog einzelne

1064 Schmidt u.a. (Hgg.), Stapfer-Enquête, Nr. 2150: Kerns.

1065 Schmidt u.a. (Hgg.), Stapfer-Enquête, Nr. 2457: Basel. 
Geistliche, auf eine exklusive Karriere als Geistlicher zu verzichten und sich mit dem sozial niedrigeren Schulamt abzugeben. In der selbstironischen Antwort des katholischen Frühpredigers und Schullehrers Joseph Wenk von Schmerikon SG findet man einen atypischen, dem Muster eines hierarchisch aufsteigenden Karriereverlaufs mit dem Ziel einer Priesterpfrund entgegenlaufenden Lebensverlauf: „84 gemeinds Genossen, wie auch ungefehr 27 Beysäss bestelen den Lehrer, und Fruh Messer auf ein jahr, er heist Joseph Wenk gebürtig von da, schmerken 54 Jahr, und 3 monath alt weltgeistlicher künftig Mayen Tag ist es das 3te Jahr, das er schul Lehrer ist, er ist vor einigen Jahren im Linthäl Cantons Glarus 5 et 1/2 Jahr Pfarrer gewessen, weil er aber in einem so rohen winterloch in Siberien sich nicht lebendig wolte begraben lassen, hat er bej lieben Pfarrfindern höflich Urlaub gegeben und aber Füchsen, und häsen gutte Nacht gesagt. ${ }^{1066}$ Weitere Nebentätigkeiten zusätzlich zum Lehramt - mit Ausnahme von unbezahlten Freizeitaktivitäten - nahmen Geistliche gemäss den Angaben aus der Stapfer-Enquête kaum an.

Ganz anders gestalteten weltliche Lehrkräfte ihre Berufsprofile. Nicht nur das Lehramt an sich, sondern auch weitere Tätigkeiten traten als zusätzliche Ergänzung zu den veränderten Biografieprofilen hinzu. In der kollektiven Betrachtung fielen besonders zwei besoldete Zusatztätigkeiten auf, die mit dem Lehramt zusammen für eine fundamentale Veränderung der Erwerbssituation sorgten: kirchliche Mesmer- und besoldete Kommunalhilfsdienste. Da diesen Tätigkeiten aufgrund der limitierten zeitlichen Aufwände im Jahresgang grundsätzlich eine Nebentätigkeitsfunktion attestiert werden kann, werden sie als erwerbsbiografische Ergänzung angeschaut, wenngleich sie auch substituierend wirken konnten oder in Form von diskontinuierlichen Erwerbsausgestaltungen auftraten.

\section{Die „Mesmer-Lehrer“}

Die quantitativ häufigste Erweiterungs- und Ersatztätigkeit zum Lehramt stellten neben landwirtschaftlichen Tätigkeiten die kirchlichen Hilfsdienste dar. ${ }^{1067}$ Neben den Schulmeistern waren die weltlichen Kirchendiener als Zuständige für die kirchlichen Belange von zentraler personeller Bedeutung für die Dorfpfarrer, die beiden Ämtern gleichermassen als Vorgesetzte vorstanden. ${ }^{1068}$ Wie vom Schulmeister wurden auch vom Mesmer eine angemessene Bildung in den elementaren Kulturtechniken und ein vorbildhafter, tugendsamer Lebenswandel erwartet. Entsprechend lag es aus praktischen Gründen nahe, beide Ämter in Personalunion zu vereinen. Dabei wurden die Schulmeister zur Übernahme von Aufgaben des niederen oder des höheren Küsterdienstes verpflichtet, oder - was in der Alten Eidgenossenschaft seltener geschah - dem bereits angestellten Küster wurde das Schulamt als Zusatzaufgabe übertragen. ${ }^{1069}$ Die Verbindung von Schul- und Kirchenhilfsdiensten war in der Alten Eidgenossenschaft bei beiden Konfessionsgruppen seit langem weit verbreitet. So berichtete der Lehrer Hans Heinrich Bräm aus Dällikon ZH: „Seit undenklichen zeiten, ware der Schuldienst, und der Sigersten oder Meßmer dienst, mit einanderen vereinigt, und Beyde dienst wurden von einer Persohn versehen, das Einkommen von Beyden diensten ist so durch einander gekommen, daß niemand mehr weißt was davon $\mathrm{Zu}$ dem eint oder anderen dienst gehört. ${ }^{\text {"1070 }}$

1066 Schmidt u.a. (Hgg.), Stapfer-Enquête, Nr. 446: Schmerikon.

1067 Zur Rolle der kirchlichen Hilfsdienste als Ersatztätigkeit vgl. das nächste Kap. 3.3.2.

1068 Die Subordination der Schulmeister unter die Pfarrer war keine eindeutige Angelegenheit. In der Zürcher „Anleitung für die Landschulmeister"von 1771, welche 1775 neu aufgelegt und 1779 in Basel rezipiert wurde, wurde beispielsweise moniert, dass viele Schulmeister ihre Pflichten gegenüber den Pfarrern nicht kannten. Berner, Zeichen: 246.

1069 Walz, Eselsarbeit: 57f.; Geissler, Schulgeschichte: 48. Vgl. das Kap. 2.2.7.

1070 Schmidt u.a. (Hgg.), Stapfer-Enquête, Nr. 1104: Dällikon. Die langandauernde Verbindung der beiden Ämter wurde auch andernorts betont, etwa in Hinwil ZH: „Nebet denen Schul geschäften. versehe noch der Sigristdienst. Der Schon bis auf 100 Jahre, mit dem Schuldienst verbunden war." Schmidt u.a. (Hgg.), Stapfer-Enquête, Nr. 29: Hinwil. 
Kein Zusatzamt war folglich gesamtschweizerisch unter Lehrkräften stärker verbreitet als der krichliche Hilfsdienst. Mindestens 21.6\% aller nicht-geistlichen helvetischen Elementarschullehrer übten neben dem Schulamt gleichzeitig ein oder mehrere kirchliche Nebenämter aus. ${ }^{1071}$ Die kirchlichen Hilfsdienste nahmen somit beim helvetischen Lehrerkorps nach den landwirtschaftlichen Tätigkeiten die quantitativ bedeutsamste kollektivbiografische Stellung als lebensverlaufserweiternde oder -verändernde Nebentätigkeit ein. ${ }^{1072}$ In der Lebensverlaufsperspektive ersetzten das Lehramt und Kirchenhilfsdienste zusammen im empirischen Vergleich zumeist Ersttätigkeiten im Sinne eines diskontinuierlichen Lebensverlaufs. ${ }^{1073}$ In mindestens 53\% aller Berufsbiografien mit kirchlichen Hilfstätigkeiten verdrängten diese die zuvor ausgeübten Ersttätigkeiten gemeinsam mit dem Lehramt. Daneben traten kirchliche Hilfsämter mit rund 39\% vorwiegend in erwerbsbiografisch erweiternder Funktion auf, dies grossmehrheitlich bei Lehrkräften ohne Ersttätigkeiten. ${ }^{1074}$ Die Übernahme des Lehramts wurde damit in der Regel gleich zu einem Doppelamt, da kirchliche Hilfsdienste kaum als Ersttätigkeiten ausgeübt wurden und folglich mit oder nach der Lehramtsübernahme zur Erwerbsbiografie dazukamen. ${ }^{1075}$

Doch nicht nur in der Alten Eidgenossenschaft, sondern auch in den Dorfgemeinden der deutschen Territorien waren sogenannte „Küster-Lehrer“ ein weit verbreitetes Phänomen. ${ }^{1076}$ Küster-Lehrer genossen kraft ihres kirchlichen Zusatzamtes ein gewisses gesteigertes soziales Prestige, wie ein Forschungsbericht zum Kirchspiel Oldenburg resümiert: „Der ,Schulmeister ist ein Mann mit gewissen geistigen Fähigkeiten, der neben seinen kirchlichen Diensten als Küster und Organist die Kinder lesen und schreiben, manchmal auch etwas mehr lehrt. [...] Als Hauptlehrer [...] gilt er durchaus als respektabler Mann, die Verbindung von kirchlichem Dienst und Schulhalten mindert zumindest im 18. Jahrhundert sein soziales Ansehen nicht - im Gegenteil, auf das Schulamt fällt durch die kirchlichen Ämter ein gewisser Glanz. Umgekehrt setzte die Anstellung als Küster Lesen, Schreiben und Bibelkenntnisse voraus. “1077 Die Nähe zur Kirche hielt auch den Schulmeistern in der Alten Eidgenossenschaft aufgrund der noch geringen Ausdifferenzierung der Schule von der Kirche ein gewisses soziales Prestige bereit, das in der Personalunion mit dem Mesmeramt oder anderen kirchlichen Hilfstätigkeiten natürlicherweise noch multipliziert werden konnte. ${ }^{1078}$

In der räumlichen Verbreitung von Lehrern mit Kirchenhilfsdiensten existierten beträchtliche regionale und konfessionelle Unterschiede. Über die Nebenbeschäftigungen der Lehrer der Zürcher Landschaft urteilt Wilibald Klinke: „Gewöhnlich war der Schulmeister zugleich Si-

1071 Mindestens 488 von 2.216 weltlichen Lehrern wiesen in ihren Antworten eine explizite kirchliche Zusatzbeschäftigung aus.

1072 Ingrid Brühwiler errechnete in ihrer rund 200 Lehrpersonen umfassenden Stichprobe einen Anteil an kirchlichen Nebenbeschäftigungen von insgesamt 44\%. Darin sind jedoch kirchliche Hilfsdienste und geistliche Verrichtungen der Seelsorge gleichsam zusammengezählt, was die Differenz zu den hier präsentierten Zahlen erklärt, zumal in der Stichprobe bewusst katholische Distrikte der Zentralschweiz mit einer hohen Anzahl an KaplanLehrern berücksichtigt wurden. Vgl. Brühwiler, Finanzierung: $222 \mathrm{f}$.

1073 Vgl. zu den diskontinuierlichen Lebensverläufen das folgende Kap. 3.3.3.

1074 Mindestens 257 der 488 Lehrer mit kirchlichen Hilfsdiensten wiesen einen diskontinuierlichen beruflichen Lebensverlauf auf, bei 190 Lehrern als Ergänzung. Hierbei sind alleine mindestens 143 Erwähnungen auf Lehrkräfte ohne Ersttätigkeiten zurück zu führen. Die übrigen Nennungen entfielen auf nicht rekonstruierbare Lebensverläufe.

1075 Vgl. zu den kirchlichen Ersttätigkeiten das Kap. 2.2.7.

1076 Neugebauer, Niedere Schulen: 229f.; Prass, Agrargeschichte: 63.

1077 Günther-Arndt, Oldenburg: 10. Zur Rolle der Küster-Lehrer wird auf die umfangreiche Arbeit von Sabine Eibl zu Küstern im Fürstbistum Münster verwiesen: Eibl, Küster.

1078 Bloch Pfister, Priester: 110. 
grist und Vorsinger. ${ }^{\text {“1079 }}$ Alexandra Bloch Pfister berechnet in ihrer Studie etwas exakter, dass 21.8\% aller Zürcher Lehrer 1799 ein Kirchenamt als Sigrist oder Vorsänger innehatten, gegenüber 19.6\% im Jahr 1770. ${ }^{1080}$ Der Grund für die Zunahme lag in der erneuerten Zürcher Schulordnung von 1778, die proaktiv zur Verbindung von Schul- und Mesmerdienst zur Stärkung des Lehrereinkommens aufforderte: „Auch soll bey erledigten Schuldiensten genau darüber gehalten werden, dass an denjenigen Orten, wo der Schul- Vorsinger- und Sigrist-Dienst abgesondert ist, weil an den meisten Orten keiner allein genugsame Besoldung hat für sich selbst zu bestehen, die Sigrist- und Vorsinger-Dienste, wo es möglich und nöthig befunden wird, mit dem Schuldienst vereinigt und verbunden werden. " 1081

In der ebenso mehrheitlich reformierten Waadt übten dagegen „quelque deux cents régents, plus de la moité du corps enseignant “1082 einen Kirchenhilfsdienst aus. Einen ähnlich hohen Anteil an Lehrern mit kirchlichen Nebentätigkeiten verzeichneten mit 39\% der reformierte Kanton Basel und mit 38\% der mehrheitlich katholische Kanton Fribourg. ${ }^{1083}$ In den übrigen Kantonen oszillieren die Werte allerdings auf deutlich tieferem Niveau. Weniger als jeder fünfte Lehrer hatte in den helvetischen Kantonen Schaffhausen, Bern, Thurgau, Zürich, Linth, Oberland und Wallis ein kirchliches Hilfsdienstamt inne. Im helvetischen Kanton Oberland waren gar nur 5\% der Lehrer zusätzlich Mesmer oder hatten eine andere auxiliare Gottesdienstfunktion inne. Unterschiede in der Übernahme von kirchlichen Hilfsdiensten konnten ferner entlang der konfessionellen Trennlinie festgestellt werden. Drei von vier Lehrern mit kirchlichen Nebentätigkeiten liessen sich zur reformierten Konfession zuteilen, was aber den konfessionellen Grundverteilungsverhältnissen im Sample der helvetischen Lehrerschaft entspricht. ${ }^{1084}$ Allerdings zeigten in den gemischtkonfessionellen Kantonen Baden, Linth, Säntis und Solothurn fast ausschliesslich die katholischen Lehrer eine ausgeprägte Präferenz für kirchliche Zusatzämter, während die reformierten Landschullehrer dieser Kantone kaum in Kirchenhilfsdiensten arbeiteten. ${ }^{1085}$ Einzig im mehrheitlich reformierten, gemischtkonfessionellen Kanton Thurgau neigten reformierte Schulmeister des Öfteren zur Ausübung von Kirchenämtern als ihre katholischen Kollegen, was am starken Einfluss der Zürcher Landeskirche und der Zürcher Obrigkeit gelegen haben mag.

Doch auch innerhalb der Kantone zeigten sich mitunter markante regionale Unterschiede. Im helvetischen Kanton Bern traten Lehrer mit kirchlichen Nebenbeschäftigungen vorwiegend im Mittelland in den Distrikten Burgdorf, Langenthal, Niederemmental, Wangen und BernLand auf, kaum aber in den westlichen Distrikten. Im Kanton Aargau konzentrierten sie sich überwiegend in den beiden Distrikten Brugg und Zofingen.

Die zunehmende obligatorische Verbindung von Schul- und Kirchenämtern schloss eine freie Entscheidung der Lehramtsanwärter zu Ausübung der Kirchendienste aus. Entsprechend bestanden keine Präferenzen einzelner Berufsgruppen zur Ausübung von Kirchendiensten.

1079 Klinke, Zürich: $117 f$.

1080 Bloch Pfister, Priester: 87; 167.

1081 Erneuerte Schul- und Lehr-Ordnung für die Schulen der Landschaft Zürich 1778: 7.

1082 Panchaud, écoles vaudoises: 288; 297.

1083 Die Werte zum Kanton Fribourg haben aufgrund der zahlreichen fehlenden Antworten auf die Stapfer-Enquête keinen abschliessenden Charakter.

1084 Insgesamt 358 der 488 Lehrer mit kirchlichen Nebentätigkeiten waren reformiert, 130 katholischer Konfession. Vgl. zur konfessinellen Gesamtverteilung der Lehrerschaft das Kap. 1.6.2.

1085 Die absolute Anzahl katholischer Lehrer spricht hierbei für sich: Baden: 11 von 13 (total); Linth: 15 von 15; Säntis: 32 von 36; Solothurn: 18 von 18; Thurgau: 8 von 24. 
Differenziert nach der Art des ausgeführten Kirchendienstes, war mindestens ein Drittel aller mit zusätzlichen Kirchendiensten ausgestatteten Lehrer als „niedere Mesmer“ tätig gewesen, rund zwei Drittel übernahmen „höhere“ Mesmerdienste. ${ }^{1086}$

Tab. 19: Häufigkeit der kirchlichen Nebenämter

\begin{tabular}{lcc}
\hline Kirchenamt: & Anzahl Nennungen: & In Prozent: \\
\hline Vorsänger & 230 & $47.3 \%$ \\
Mesmer/Sigrist & 153 & $31.5 \%$ \\
Vorbeter & 133 & $27.4 \%$ \\
Vorleser & 117 & $24.1 \%$ \\
Organist & 56 & $11.3 \%$ \\
Kinderlehre & 33 & $6.8 \%$ \\
Leichengebete & 19 & $3.9 \%$ \\
\hline
\end{tabular}

Das Amt des Vorsängers oder „Kantors“ des Kirchenchors war dabei mit einem Anteil von 47\% das am häufigsten von Schulmeistern ausgeführte kirchliche Nebenamt. Da die Gesangsfähigkeiten ein integraler Bestandteil der Lehrerkandidatenprüfung war, lag der Schluss nahe, gesangstechnisch begabte Lehrer auch als Vorsänger einzustellen. Während des Gottesdienstes übernahmen viele Lehrer zudem durch ihre Lesekenntnisse das Vorlesen oder Vorbeten von Bibelstellen. Mehr als jeder fünfte Schulmeister mit kirchlichen Nebenämtern betätigte sich als Vorbeter oder Vorleser. Andere brachten ihre musischen Fähigkeiten als Organist oder als Kirchenmusikant ein. ${ }^{1087}$ Die genannten Einzelfunktionen des höheren Mesmer-Dienstes wurden in der Regel jedoch nicht einzeln, sondern beliebig kombiniert ausgeführt, wobei die Vorleser-, Vorbeter- und Vorsänger-Tätigkeit meistens miteinander verbunden waren.

In nicht wenigen Fällen übergaben die Pfarrer zudem die christliche Kinderlehre vor dem sonntäglichen Gottesdienst an die Schullehrer, obwohl die christliche Unterweisung eigentlich in den Aufgabenbereich der Pfarrer gehörte und im Gegensatz zu den Küster-Lehrern der deutschen Territorien streng genommen nicht mehr Teil der Elementarschulaufgaben war. ${ }^{1088}$

Seltener und als regionale Besonderheit fast ausschliesslich auf die mittelländischen Distrikte des Kantons Bern beschränkt war das Vortragen von Leichengebeten und Leichenreden bei Beerdigungen, zumeist in der Kombination mit der sonntäglichen Kinderlehre. ${ }^{1089}$ Das Halten von Leichenpredigten war den bernischen Schulmeistern zwar schon im Jahr 1703 durch eine Ratsverordnung offiziell verboten worden, dennoch zeigt die Praxis vor Ort aus der Stapfer-Enquête, dass dieser regionale Brauch trotz obrigkeitlichen Verboten bis zum Ende des 18. Jahrhunderts

1086 Vgl. zur Differenzierung der Kirchenhilfsdienste die Ausführungen im Kap. 2.2.7.

1087 Neben dem Bedienen der Kirchenorgel betätigten sich einzelne Lehrer ferner mit ihren Blasinstrumenten am Gottesdienst, so etwa in Kölliken AG: „Boßart blaset die Posaune. Matter den zincken, beym gesang in der Kirche." Schmidt u.a. (Hgg.), Stapfer-Enquête, Nr. 2102: Kölliken.

1088 Nach der Einschätzung von Ursula Walz gehört die Christenlehre vielerorts in den Aufgabenbereich des Küsterlehrers. Walz, Eselsarbeit: 59.

1089 Bis auf zwei Ausnahmen in den Gemeinden Burg FR und Ramsen SH war die Abdankungsreden- und Leichengebetstätigkeit ausschliesslich in Gemeinden des Kantons Bern mit dem Lehramt verbunden. 16 jener 19 in der Stapfer-Enquête überlieferten Lehrer übten daneben die Kinderlehre an Stelle des Pfarrers aus. 
im Oberaargau und unteren Emmental überdauerte. ${ }^{1090}$ Eine knappe Handvoll Fälle dokumentieren zudem die Nebentätigkeit als Totengräber, einem in der Frühen Neuzeit als „unehrlichen Beruf “ sozial geächteten Amt. ${ }^{1091} \mathrm{Ob}$ diese Totengräber-Schulmeister allerdings wirklich unter einem niedrigerem sozialen Status litten, muss in Frage gestellt werden, da sie allesamt gleichzeitig das Mesmeramt ausführten, das wiederum soziales Ansehen versprach. Zuletzt wurden den Schulmeistern in einigen lokalen Fällen das Aussprechen von Hochzeitssegen, das öffentliche Verkünden des Neujahrs oder „Abdankungen bey Feürsbrunsten und bey Aufrichtung Neüwer Hüser “ ${ }^{\text {1092 }}$ als pseudoreligiös-rituelle Zusatzaufgaben übertragen. ${ }^{1093}$

Das Altersspektrum der Mesmer-Lehrer reichte in den Extrema vom erst 17-jährigen Lehrer in Rutschwil ZH bis zum 79-jährigen Greis in Affoltern ZH. ${ }^{1094}$ Unterteilt in 10-Jahres-Kohorten, zeigt sich eine relativ ausgeglichene Altersverteilung zwischen den drei Generationen.

Tab. 20: Verteilung der Lehrer mit kirchlichen Nebentätigkeiten nach Alterskohorten

\begin{tabular}{lccc}
\hline Alterskohorte: & Anzahl Lehrer: & In Prozent: & Anteil an Kohorte: \\
\hline unter 20 Jahre & 12 & $2.5 \%$ & $29.3 \%$ \\
20-29 Jahre & 75 & $15.4 \%$ & $20.7 \%$ \\
30-39 Jahre & 129 & $26.5 \%$ & $24.3 \%$ \\
40-49 Jahre & 113 & $23.2 \%$ & $21.9 \%$ \\
50-59 Jahre & 98 & $20.2 \%$ & $23.0 \%$ \\
60-69 Jahre & 46 & $9.5 \%$ & $18.6 \%$ \\
über 70 Jahre & 11 & $2.3 \%$ & $17.5 \%$ \\
keine Altersangabe & 4 & $0.8 \%$ & $14.3 \%$ \\
\hline Total & 488 & $100 \%$ & $22.0 \%$ \\
\hline
\end{tabular}

Der Anteil an kirchlichen Nebenbeschäftigungen oszilliert relativ konstant und altersunabhängig um 20\%. Erst bei den älteren Lehrern über 60 Altersjahren nahm der relative Anteil an Mesmerdiensten innerhalb ihrer Altersgruppe ab, was zwei Erklärungsansätze offenbart. Die ältesten Lehrer verzichteten entweder zunehmend auf die Ausübung von Kirchendiensten durch freiwillige Rücktritte und der frühzeitigen Weitergabe an jüngere Nachfolger, oder aber sie hatten dieselben Funktionen gar noch nicht im ähnlichen Umfang übernommen wie ihre jüngeren Berufskollegen. Letztere These stützt sich auf die oben erwähnten obrigkeit-

1090 Schneider, bernische Landschule: 88. Der Lehrer von Bätterkinden BE beschrieb den gewohnheitsrechtlichen Brauch mit folgenden Worten: „da es die Gewohnheit in diesen Gegenden ist, daß man bey den Begräbnißen der Verstorbenen so genante Leichreden pflegt zu halten, so muß der Schullehrer selbige verrichten." Schmidt u.a. (Hgg.), Stapfer-Enquête, Nr. 1395: Bätterkinden. Vgl. ferner die Biografie des Lehrers Johann Samuel Boschung in: Helfenberger, (Normal-)Lehrer: 141.

1091 Beispielhaft der Lehrer von Grub SG: „Jetzt hat er noch nebend seinem Lehramt den Mesmer und Todten Gräber dienst und das weben." Schmidt u.a. (Hgg.), Stapfer-Enquête, Nr. 1247: Grub. Zu den „unehrlichen Berufen“ vgl. Dubler, unehrliche Berufe.

1092 Schmidt u.a. (Hgg.), Stapfer-Enquête, Nr. 1450: Wynigen.

1093 Beispielhaft: „Erstlichen ist einem schulmeister vergünstiget gewesen, um seinen dienst zu erbesseren, zur wienacht zeit denen Kilchsgenossnen daß neüe jahr an zu wünschen, so jezt aber nit mehr ist." Schmidt u.a. (Hgg.), Stapfer-Enquête, Nr. 2509: Hochdorf.

1094 Schmidt u.a. (Hgg.), Stapfer-Enquête, Nr. 339: Rutschwil; Nr. 1100: Affoltern. 
lich forcierten Zunahmen an Mesmer-Lehrern in der Zürcher Landschaft seit 1770. Denn bei der Altersgruppe der unter 20-Jährigen gab überraschenderweise fast jeder dritte Junglehrer bereits eine kirchliche Hilfstätigkeit als Nebenbeschäftigung an. Damit zeigt sich, dass kirchliche Hilfsaufgaben nicht als meritokratische Ehrenämter erst zu einem späteren Zeitpunkt an lebenserfahrene Männer oder nach einer ökonomischen Notlage zur Verbesserung des Einkommens, sondern in den allermeisten Fällen gleich von Beginn weg an die Lehramtseinsteiger vergeben wurden.

Die Verbindung von Schul- und Mesmerdiensten ist demnach als relativ statisch zu bezeichnen, die, einmal an die Schulmeister übertragen, nur in seltenen Fällen von den Schulmeistern oder den Gemeinden einseitig aufgelöst wurde. So lange die personelle Kontinuität gewahrt blieb, bestand auch die Aufgabenverbindung. Der Einfluss der Gemeinden auf die Neuvergabe oder eine Ablösung der Kirchenhilfsdienste kann demnach als sehr gering eingeschätzt werden. Einzig an jenen Orten, wo das Lehramt und die Kirchenhilfsdienste noch nicht zusammengelegt und vereint waren, konnte ein sozialer Druck vonseiten der Pfarrer oder der Gemeinden auf ältere Lehrkräfte ausgeübt werden, bei Zeichen von Altersmüdigkeit die kirchlichen Hilfsfunktionen abzugeben.

Die Zusammenführung von Schul- und Kirchenhilfsdiensten lag jedoch nach wie vor in der freien Entscheidungskompetenz der einzelnen Gemeinden, wodurch eine lokal völlig differente Praxis entstand, selbst dort, wo landesherrliche Ordnungen für die gesamte Landschaft bestanden. Das Zusammenführen des Schuldienstes und des Mesmerdienstes in Personalunion bot sich in der Realität des Alltagslebens sowohl aus der Sicht der Pfarrer als auch aus der Sicht der Lehrer und Mesmer als pragmatische Lösung an, zumal die Besoldung der einzelnen Tätigkeiten alleine nicht zum Überleben ausreichte, zusammengezählt jedoch ein durchaus vernünftiges Einkommen ergeben konnte. ${ }^{1095}$ Gerade weil Kirchenhilfsdienste im Gegensatz zum Schuldienst als ganzjährige Funktion ausgeübt wurden, lag die Höhe der Besoldung nicht selten über der Entlohnung für den bloss saisonal während der Wintermonate ausgeübten Schuldienst.

Ob der Lohn für das kirchliche Hilfsamt oder der Schullohn reichhaltiger ausgestattet war, hing nicht nur von der jährlichen Schuldauer ab, sondern war von der kommunalen Vermögenslage abhängig und folglich von Ort zu Ort ebenfalls komplett unterschiedlich. Verlässliche Angaben zum Verhältnis der beiden Einkommensgrössen auf einer breiten Quellenbasis sind aus der Stapfer-Enquête nicht zu extrahieren, weil die Lehrer entweder die kirchlichen Zusatzeinkommen nicht deklariert hatten, diese nicht vom Schuleinkommen zu trennen waren oder gar nicht erst speziell dafür besoldet wurden. Es kann daher nur auf Einzelquellen mit beschränkter Aussagekraft zurückgegriffen werden, um die Einkommensverhältnisse holzschnittartig zu illustrieren. Zudem muss der unterschiedliche Zeitaufwand zur Ausübung der einzelnen Tätigkeiten berücksichtigt werden, der wiederum besoldungsrelevant sein konnte.

Der Lehrer von Sattel SZ erhielt zum Beispiel für das Halten einer reinen Winterschule von Martini bis Ostern im Vergleich zum ganzjährig ausgeübten Mesmeramt folgende Entschädigung: „die Ehmalige obrigkeit zahlte Jährlich wägen der Schul, und Für die Mandat zu verkünden: das Jahr hindurch $12 \mathrm{gl}$ : Es ist aber zu wüssen das Ein Schullehrer auch zugleich Sigerist in der pfarrey ist, für welchen dienst Er Jährlich in dem gantzen hat $80 \mathrm{gl}$. ${ }^{1096}$ Das jährliche Einkommen aus dem Mesmeramt belief sich somit auf das Sechsfache des Schuldiensteinkommens.

1095 Die Kombination von kirchlichen Ämtern mit dem Schuldienst wurde den Gemeinden des Kantons Zürich erst mit der Schulordnung von 1803 normativ nahegelegt. Vgl. Bloch Pfister, Priester: 87.

1096 Schmidt u.a. (Hgg.), Stapfer-Enquête, Nr. 2022: Sattel. 
Andernorts waren Kirchendienste jedoch gänzlich ohne zusätzliche Besoldung an die Schulmeister übertragen, wie der Lehrer von Lonay VD festhielt: „conduit le Chant des Psaumes a l'Eglise et fait les prières le Dimanche, ne recevant pour cela aucun salaire. “1097

Ein eindeutiges Muster in der Besoldungshöhe für Kirchenhilfsdienste gegenüber den Lehrergehältern konnte nicht festgestellt werden. Einzig ein Stadt-Land-Graben war bei den Besoldungsverhältnissen der Nebenämter bemerkbar. In städtischen Schulen mit einer generell weitaus höheren durchschnittlichen Schulbesoldung nahmen die Zusatzentschädigungen für Kirchendienste in den meisten Fällen nur noch eine stark untergeordnete finanzielle Bedeutung ein. Beispielsweise belief sich die Entschädigung für ein ganzjähriges Vorbeten und das Halten der sonntäglichen Kinderlehre beim katholischen Stadtschullehrer von Arbon TG bloss auf die unwesentliche Summe von 17 Gulden bei einem Gesamteinkommen von total 229 Gulden und 44 Kreuzern, was den Lehrer aber dennoch nicht vom Verfassen einer diesbezüglichen Lohnklage abhielt. ${ }^{1098}$ Ebenso erhielt der Stadtschullehrer von Altstätten SG als jährlichen Vorsängerlohn bloss 5 Gulden gegenüber 300 Gulden Schuleinkommen, einer freien Wohnung und einem Stück Land zur Gewinnung von Torf zum Heizen der Stube im Winter. ${ }^{1099}$ In Moudon VD betrug die Entschädigung für den Katechismusunterricht 20 Franken gegenüber dem Schuleinkommen von 400 Franken. ${ }^{1100}$ Diese wenigen Beispiele verdeutlichen den bloss symbolhaften Charakter der Entschädigungen für Kirchenhilfsdienste bei den grundsätzlich besser besoldeten Stadtschullehrern.

Trotz der oftmals wichtigen finanziellen Entschädigung stiess die Verpflichtung zur Ausübung von Kirchenhilfsdiensten bei einigen Schulmeistern auf Kritik, wobei besonders der Zeitverlust zu Lasten der Schule oder gesundheitliche Gründe hervorgehoben wurden: „Neben dem Lehramte liegt mir noch besonders ob, das Kantorat, welches mich verpflichtet, des Sommers wochentlich in sechs, des Winters aber in sieben gottesdienstlichen Stunden vorzusingen. Schon lange, und dato besonders, nähre den Wunsch bei mir, daß dieser sehr beschwerliche Posten von dem Schulamte getrennt, und einem andern Bürger besonders aufgetragen werden mögte; weil dardurch meine Gesundheit untergraben und zerrüttet, und für die ohnehin häufigen Schulgeschäfte wochentlich einige Stunden verlohren wird." ${ }^{1101}$

Mitunter wurde der Mesmerdienst auch bewusst aufgegeben, um mehr Zeit für das Lehramt zu gewinnen, wie der Lehrer von Signau BE beschrieb: „Wahre eniche Jahre Siegerist; und Gemeinds-Schreiber; hat aber diese 2. Posten Aufgegeben: um sich der Anwachßenden SchulArbeit beßer zu wiedmen "1102 Ähnlich kritisch sahen aber teilweise auch andere Lehrkräfte abseits von kirchlichen Zusatzämtern das grundsätzliche Ausführen von Nebentätigkeiten. So beschrieb der Lehrer Johann Heinrich Vogt aus Arbon TG seinen zeitlichen Interessenskonflikt folgendermassen: „Vorher hatte mich 6 Jahre in Zürich aufgehalten und auf meiner erlernten Knopfmacher Profeßion gearbeitet. Bey meiner Zurückkunft, hatte mir eine große Kundschaft erworben, weil ich aber bald für den Provisor, bald für den Schulmeister, die Schule halten, auch privat Unterricht geben mußte, so wurde in meinen Profeßions-Geschäften merklich gehindert,

1097 Schmidt u.a. (Hgg.), Stapfer-Enquête, Nr. 1918: Lonay.

1098 „Die Schulbedienung welche mit so vielen Nebenverrichtungen begleitet ist, hat mich da, und dort wegen der so geringen Besoldung (besonders in dieser klemmen Zeit) zum grossen Schaden gebracht. Bitte flehendlichst mir diesen Schaden auf einige Art wieder zu verringern; - doppelte Anstrengung in meinem Lehramt solle der Dank der mir erweisenden Wohlthaten beweisen. Schmidt u.a. (Hgg.), Stapfer-Enquête, Nr. 815: Arbon.

1099 Schmidt u.a. (Hgg.), Stapfer-Enquête, Nr. 1204: Altstätten.

1100 Schmidt u.a. (Hgg.), Stapfer-Enquête, Nr. 1758: Moudon.

1101 Schmidt u.a. (Hgg.), Stapfer-Enquête, Nr. 679: Frauenfeld.

1102 Schmidt u.a. (Hgg.), Stapfer-Enquête, Nr. 723: Signau. 
so daß mir nur noch eine kleine Kundsamme bey behalten konnte, welche noch gegenwärtig mit Knopfmacher Arbeit versehe. Anmerkung: Obgleich das Zutraun der Aeltern, der Fleiß der Kinder und der Segen der Himmels, meine kleine Besoldung um viel vergrößerten, so ware die Treibung meiner Profeßion, besonders bei diesen schon lang klemmen Zeiten, sehr nothwendig, welches mir aber oft den Schlaf raubt." ${ }^{1103}$

Dass einzelne Lehrer ihre Kirchenhilfsdienste wie der Lehrer von Signau BE trotz des zu vermutenden höheren sozialen Kapitals wieder abgaben, stellt die Frage nach der sozialen Identität. Ob sich diese Lehrer in ihrer beruflichen Identität eher als Kirchendiener oder als Schulmeister verstanden, ist nicht rekonstruierbar, zumal die schulischen Quellengrundlagen natürlich die schulische Identität als Lehrer in den Vordergrund treten liessen. Allerdings gibt es textanalytische Indizien, dass zuweilen bei einzelnen Individuen die kirchendienstliche Identität überwog - sei es aus Besoldungs- oder aus Prestigegründen. Beispielhaft unterschrieb der Schulmeister der unteren Schule von Sarnen OW mit: „Organist und Schullehrer“, zumal das schulische Einkommen mit 36 Gulden gegenüber dem Organisten-Lohn von 97 Gulden pro Jahr deutlich geringer ausfiel, obwohl beide Geschäfte ganzjährig ausgeübt werden mussten. ${ }^{1104}$ Der finanzielle Aspekt schien somit die stärkere Identifikation zu erwirken. Auch der Klingnauer Lehrer unterzeichnete seine Antwortschrift mit: „Kirchen-Diener und Schul-Lehrer in Klingnau. “1105 Eine kollektive Einschätzung der Identitätsstiftung ist jedoch nicht möglich und wäre ein eigenes Forschungsanliegen.

\section{Die Lehrer mit kommunalen Amtsfunktionen}

Eine bislang von der Forschung noch wenig beachtete, aber in kollektivbiografischer Betrachtung überdurchschnittlich häufig ausgeübte Erweiterungs- und Ersatztätigkeit zum Lehramt stellten kommunale und kantonale Amtsfunktionen dar. ${ }^{1106}$ Insgesamt rund 8\% aller helvetischen Lehrer übten im Frühjahr 1799 eine ebensolche Amtsfunktion als Nebentätigkeit aus. ${ }^{1107}$ $\mathrm{Zu}$ unterscheiden sind hierbei die unbezahlten Ehrenämter, die oft schon im Ancien Régime existierten, von den neu geschaffenen, in der Regel bezahlten Amtsaufgaben der helvetischen Kommunalverwaltung.

Die Besetzung von Gemeindeämtern durch Landschullehrer war zwar schon im Ancien Régime vorgekommen. Wie die Zürcher Schulumfrage von 1771/72 im zeitlichen Vergleich zeigt, übten um 1770 rund 7\% der Zürcher Lehrkräfte ein traditionelles Kommunalamt aus, beispielsweise als Amtsrichter, Gerichtsvogt, Geschworener oder Gemeindeschreiber. ${ }^{1108}$

Der überwiegende Teil der zum Zeitpunkt der UmFrage Im Frühjahr 1799 mit kommunalen Amtstätigkeiten ausgestatteten Lehrer, rund 85\%, hatte ihr Amt aber mutmasslich erst nach der Revolution angetreten, da kaum Kommunalämter in kontinuierlicher Manier weitergeführt wurden. ${ }^{1109}$ Elementarschullehrer zeigten damit eine ausgesprochen starke Affinität für die neue helvetische Verwaltungsorganisation, was sich auch in der Verteilung der Amtsaufgaben widerspiegelt.

1103 Schmidt u.a. (Hgg.), Stapfer-Enquête, Nr. 47: Arbon.

1104 Schmidt u.a. (Hgg.), Stapfer-Enquête, Nr. 2157: Sarnen.

1105 Schmidt u.a. (Hgg.), Stapfer-Enquête, Nr. 2284: Klingnau.

1106 Zur Funktion der kommunalen Ämter als berufsbiografischer Ersatz vgl. das folgende Kap. 3.3.3.

1107 Insgesamt sind 185 Lehrkräfte mit Kommunalämtern als Nebenbeschäftigungen gezählt worden. Davon zählten 42 zur katholischen Konfession (23\%).

1108 Bloch Pfister, Priester: 87.

1109 Vgl. die Ausführungen zur Ämterausübung vor der Revolution im Kap. 2.2.6. 
Tab. 21: Ausgeübte Kommunalämter der Lehrkräfte 1799

\begin{tabular}{lcc}
\hline Bezahlte Ämter: & Anzahl Lehrer: & In Prozent: \\
\hline Gemeindeschreiber & 50 & $27 \%$ \\
Agent & 39 & $21 \%$ \\
Unteragent & 28 & $15 \%$ \\
Inspektor & 4 & $2 \%$ \\
Anderes Amt & 12 & $6 \%$ \\
\hline Ehrenämter: & & \\
\hline Munizipalitätsmitglied & 20 & $11 \%$ \\
Richter & 12 & $6 \%$ \\
Verwalter/Säckelmeister & 9 & $5 \%$ \\
Weibel & 8 & $5 \%$ \\
Anderes Amt & 3 & $2 \%$ \\
\hline Total Nennungen & $185^{1110}$ & $100 \%$ \\
\hline
\end{tabular}

$\mathrm{Zu}$ den häufigsten von Schulmeistern ausgeführten Kommunalaufgaben gehörte mit knapp 27\% der Nennungen die Tätigkeit des Gemeindeschreibers für die neu gewählten Gemeindebehörden. Als funktionale Hilfstätigkeit hatte diese Aufgabe indes nicht unbedingt den Charakter eines politischen Amtes und die Übernahme durch die Schulmeister war insofern naheliegend, als dass deren Ausführung primär vertiefte Lese- und Schreibkompetenzen verlangte, wozu folglich nur geübte Leser und Schreiber in Betracht gezogen werden konnten, was wiederum ganz in der funktionalen Logik der neuen Republik lag. Unter den neuen politischen Amtsfunktionen der Helvetischen Republik dominierte die Funktion des Agenten mit $21 \%$ aller Nennungen deutlich, gefolgt vom Amt des Unteragenten mit 15\%. Weitere kommunale Hilfsämter ohne grosses Sozialprestige, etwa das Amt des Viehinspektors, des Ungeltners oder des Steuereintreibers, versahen $8 \%$.

Die Berufung von Lehrern in Ämter mit einem hohen Kulturtechnikkompetenzbedarf kann somit als positiven Leistungsausweis für die Kulturtechnikkompetenzen der Lehrer verstanden werden. Der Pfarrer von Seengen AG notierte etwa zum jungen Schulmeister von Tennwil AG: „der Schulmeister ist Jacob Fischer, von dennweil, 23. Jahre alt, noch ledig: [...] und da er ein wahrer Schönschreiber ist, so beschäfftiget er sich neben der Schule, und den Sommer hindurch meistens mit copiren, womit er genug zuthun hat. daneben ist er dermal agent." ${ }^{\text {"1111 }}$

Neben den zweifellos vorhanden gewesenen notwendigen Kulturtechnikkompetenzen der Lehrer dürften zwei weitere Gründe dazu beigetragen haben, dass nicht wenige Lehrer sich als Gemeindeschreiber, Agenten oder Unteragenten aktiv in die Verwaltungsstruktur der Republik einbinden liessen. Erstens erhofften sich viele Lehrer durch die Partizipation in den Verwaltungsstrukturen der neuen Regierung eine Verbesserung ihrer ökonomischen und sozialen Position und nahmen die neu zu besetzenden Repräsentationsämter an, sei es um eines zusätzlichen Einkommens willen oder aus „egoistischer Berechnung“ zur Anbiederung an die neue

111014 Personen übten mindestens zwei Amtsfunktionen aus, eine Person, der Lehrer von Signy-Avenex VD, hatte als „Sous-Agent, Jnspecteur du Bétail, Secretaire de Commune; et Percepteur“" sogar vier Kommunalämter gleichzeitig. Schmidt u.a. (Hgg.), Stapfer-Enquête, Nr. 1679: Signy-Avenex.

1111 Schmidt u.a. (Hgg.), Stapfer-Enquête, Nr. 2101: Tennwil. 
Ordnung gewesen. ${ }^{1112}$ In den Anmerkungen des Lehrers und Agenten des Dorfes Libingen SG kann zumindest der Wunsch nach einer Einkommensverbesserung bei „öffentlichen Beamten“ als Leitmotiv nachvollzogen werden, obwohl jener Lehrer bereits vor der Helvetischen Revolution als Gemeindevorgesetzter zur funktionalen Elite des Dorfes gehörte: „Jch wünsche und ver Hoffe besonders, daß die Würdige Bürger, denen es zu kommt, oder ob liegt, in dieser Sache zu Disponieren, nach dem Sie dieses, in Erwegung gezogen, und meine geringe besoldung gegen die Arbeit ein gesehen haben werden, mir solchen um ein merkliches zu vermehren trachten werden. Jch schmeichle mir um desto mehr solches zu er halten, weil ich einer seiths aus dennen Gesetzen gesehen, das die ofentliche Beamttete eine zimliche angenehme besoldung haben. Und anderseiths das Sie nicht nur bereithwilige, sondern auch auf geklärte Bürger wünschen. Und aus diesem wurd nicht nur folgen daß ich mein große Familien beßer durch bringen, sondern auch daß ich dem Unterricht der Jugend besser obligen, und in Voll kommern Stand setzen könnte."1113

Ökonomische Motive allein hatten aber kaum dazu beigetragen, eines der neuen politischen oder funktionalen Ämter der helvetischen Verwaltung anzunehmen, zumal die Besoldung der Agenten für lange Zeit unklar blieb und erst am 5. Februar 1799 auf die Einkommensspanne zwischen 50 und 240 Franken respektive 500 bis 2.400 Batzen definiert wurde. ${ }^{1114}$ Über die tatsächlich ausbezahlten Beträge für kommunale Amtstätigkeiten fanden sich in der StapferEnquête freilich nur sehr spärliche Hinweise, wobei eine immense Spannbreite der Beträge zu beobachten war. Der Lehrer von Stettlen BE erhielt beispielsweise für das Gemeindeschreiberamt ein relativ hohes Gehalt von jährlich 4 Kronen oder 100 Batzen zugesprochen, während sich zum Vergleich sein jährliches Schulgehalt auf 30 Kronen oder 750 Batzen belief. ${ }^{115}$ Als Fleischinspektor verdiente der Lehrer von Kleinhüningen BS dagegen jährlich 5 Pfund oder 60 Batzen. ${ }^{116}$

Vielerorts blieben die Bezahlungen allerdings aufgrund der verschlechterten finanziellen Lage der Helvetischen Republik aus, zumal die Gemeinden zumeist wenig Lust verspürten, für die Besoldung der helvetischen Ämter in die Bresche zu springen. Bereits Ende das Jahres 1799 häuften sich die Demissionsgesuche helvetischer Beamter markant und rissen trotz des Amtszwangs bis zum Ende der Helvetischen Republik nicht mehr ab. ${ }^{117}$ Demgegenüber waren einzelne niedere Amtsfunktionen des Ancien Régimes bisweilen von finanzieller Attraktivität gewesen, wie der Klage des Lehrers von Hochdorf LU über den Abgang des ehemaligen Landgerichtschreiberamts zu entnehmen war, das einen finanziellen Verlust von 80 Gulden bedeutete. ${ }^{118}$ Andernorts, in Bürglen OW, war das Verlesen von obrigkeitlichen Mandaten mit bloss einem Gulden oder 15 Batzen jährlich salariert worden. ${ }^{1119}$

In den Augen der neuen Eliten scheinen die Lehrer in ihrer prekären Zwitterstellung zwischen den Dorfgenossen und der Kirche geradezu das ideale Scharnier zur Einflussnahme durch die neuen Obrigkeiten der Republik gewesen zu sein, denn als Dorfgenossen waren sie einerseits

1112 Klinke, Zürich: 118.

1113 Schmidt u.a. (Hgg.), Stapfer-Enquête, Nr. 1201: Libingen.

1114 Strickler/Rufer, ASHR Bd. III, Nr. 287: 1029.

1115 Schmidt u.a. (Hgg.), Stapfer-Enquête, Nr. 1302: Stettlen.

1116 Schmidt u.a. (Hgg.), Stapfer-Enquête, Nr. 2329: Kleinhüningen.

1117 Weber, Landgemeinden: 82-88.

1118 Schmidt u.a. (Hgg.), Stapfer-Enquête, Nr. 2509: Hochdorf. Bei einem Schul- und Mesmereinkommen von 132 Gulden entspricht der entgangene Betrag einer Höhe von $60 \%$ des Schuleinkommens.

1119 „Jtem daß Grichtschreiber amt, so jahr für jahr ertragen 80 gl“" Schmidt u.a. (Hgg.), Stapfer-Enquête, Nr. 1939: Bürglen. 
gesellschaftlich legitimiert, um Order der Regierung im zentralistischen Verständnis von oben nach unten weiter zu reichen, andererseits waren die Lehrer im Gegensatz zu den Pfarrern und alten Notabeln vom Misstrauen der konterrevolutionären Reaktion gegenüber dem neuen Staat befreit. Die Lehrerschaft war somit aus der Sicht der helvetischen Patrioten geradezu ideal, um auf der lokalen Ebene zum staatstragenden Exekutivorgan zu werden. Die neuen Regierungsstatthalter wurden denn auch vom Vollziehungsdirektorium in der Instruktion vom 10. Mai 1798 explizit angewiesen, bei der Wahl ihrer kommunalen Beamten auf deren Patriotismus und ausdrückliche Sympathie zur neuen Ordnung zu achten. ${ }^{1120}$

Daneben darf der Aspekt des sozialen Kapitals zur Steigerung des sozialen Ansehens innerhalb der Dorfgemeinde nicht vernachlässigt werden, das die Ausübung eines kommunalen Ehrenamtes potenziell bot. Dieses Kapital musste nicht in einem direkt proportionalen Verhältnis zum ökonomischen Kapital der Person stehen. ${ }^{1121}$ Besonders die Ausübung der traditionellen unbezahlten „Ehrenämtern“ - Richter, Geschworener, Verwalter von Gütern und Kassen, Weibel - waren mit einem hohen symbolischen Wert verbunden, aus dem sich soziales Prestige für den Amtsträger ableiten liess. Nur wer zum Kreis der dörflichen Honoratioren zählte und über eine gewisse Autorität und Akzeptanz innerhalb seiner Lokalgesellschaft verfügte, wurde für diese Ämter vorgeschlagen. Traditionell bekleideten solche Ämter die Angehörigen der dörflichen „Oberschicht“, die „Dorfaristokratie“, sowie eher überdurchschnittlich gebildete Personen. ${ }^{1122}$ Regionalstudien zur Ämterbesetzung aus Deutschland weisen allerdings auf regional unterschiedliche Besetzungsmuster hin, wobei die dörflichen Spitzenämter keineswegs exklusiv den dörflichen Oberschichten vorbehalten, sondern mitunter breiteren Schichten zugänglich waren. ${ }^{1123}$

Der Zugang zu kommunalen Ehrenämtern konnte ferner auch aufgrund von informellen Klientelbeziehungen zur Ausübung von sozialer Macht durch die Vermittlung von Abhängigen geschehen. Christian Simon warnt davor, diese in den Quellen meist nicht leicht ersichtlichen Beziehungen zwischen der bäuerlichen Dorfaristokratie und ihrer abhängigen Klientel zu übersehen: „Nicht der grösste Bauer musste im Gemeinderat sitzen, es konnten von ihm abhängige Halbbauern oder gar Tauner und bessere Handwerker solche Stellen besetzen, wenn sie nur seine Interessen respektierten und in Entscheidungssituationen wahrnahmen. ${ }^{1124}$ Trotz der Vorbehalte von Christian Simon kann das Ausüben ebensolcher Ehrenämter als ein partieller Indikator für eine gesicherte Stellung innerhalb der Dorfgemeinschaft und für ein gesteigertes soziales Prestige im Sinne eines Aufstiegs in die Funktionselite des Dorfes dienen. Aus der Zürcher Schulumfrage von 1771/72 sind beispielhaft Indizien für einen gewissen höheren sozialen Status bei Lehrern mit einem kommunalen Ehrenamt überliefert, wobei der resultierende höhere Status nach Bloch Pfister „unabhängig vom Schulmeisteramt war “1125 und ausschliesslich aus dem Nebenamt resultierte.

Führungsfunktionen und die obersten Ehrenämter erreichten Lehrer im Ancien Régime und zu Beginn der Helvetischen Republik jedoch nur selten. Beispielhaft übte der mit 50 Kronen oder 1.250 Berner Batzen überdurchschnittlich gut besoldete Lehrer von Bleienbach BE als absolute Ausnahmeerscheinung das Präsidium seiner Gemeinde aus, nachdem er vorher bereits

1120 Manz, Landschaft: 150; Strickler, ASHR Bd. I, Nr. 117: 1060-1069.

1121 Vgl. Berner, Zeichen: 104-112; Schnyder, Unterschiede: 160.

1122 Berner, Zeichen: 104.

1123 Vgl. Trossbach/Zimmermann, Dorfes: 92ff.; Trossbach, Bauern: 28.

1124 Simon, bäuerliche Revolution: 171f.

1125 Bloch Pfister, Priester: 111. 
als Gemeindeweibel tätig gewesen war: „Ja! er \{ist $\}$ auch Weibel, und Munizipalpresident. [...] das Einkommen \{ist\} bestehet im durchschnit in kr. 50. Jährlich, bestehet in einer Wohnung, Ligende Gütter und etwas Geld. ${ }^{1126}$ Insgesamt war mit 29\% bloss weniger als jedes dritte Kommunalamt, das 1799 von Lehrkräften ausgeübt wurde, ein solches „Ehrenamt“ mit potenziell hohem Sozialprestige.

Für die Übernahme der neuen politischen Ämter der Helvetischen Republik gilt der Rückschluss auf ein zusätzliches soziales Kapital hingegen nur bedingt. Aufgrund des Umstands, dass die Inhaber der neuen politischen Ämter nicht durch die Dorfgemeinschaften gewählt werden konnten, sondern von den Distriktstatthaltern eigenmächtig bestimmt wurden, hatten die kommunalen Amtsträger der Helvetik von Beginn weg ein demokratisches Legitimationsproblem, obwohl sich die Mehrzahl der Amtsträger aus der ortsansässigen Bevölkerung rekrutierte. ${ }^{1127}$ Dieses undemokratische Vorgehen beraubte die Gemeinden ihres traditionellen Vorschlagsrechts, was angesichts der Parolen von Freiheit und Gleichheit ein Rückschritt hinter die verbürgten Rechte des Ancien Régimes bedeutete und das Vertrauen in die neue Verfassung untergrub. ${ }^{128}$

Vielerorts stiessen diese neuen Ämter und ihre Amtsträger daher auf die Missgunst der Bevölkerung, insbesondere in jenen Regionen des Landes, wo die neue Staatsordnung selbst von Beginn weg auf hartnäckigen Widerstand stiess oder wo im Zuge des Zweiten Koalitionskrieges die französischen Truppen verjagt worden waren. Dort begegnete man den Repräsentanten der neuen Ordnung mit Argwohn und die Amtsausübung konnte rasch zu gravierenden sozialen Konflikten innerhalb der Dorfgemeinschaft führen, wie das Beispiel des Schulmeisters Mathias Mooss aus Unterillnau ZH lebhaft illustriert: „Als Johannes Brunnschweiler von Ober-Jllnau Agent worden, ist er wie viele Agenten im schreiben und geschriebnes lesen nicht woll geübt gewesen, wie es dieser Beruf erfordert, da Hat er mir die Unteragenten Stelle angetragen: zu erst hab ich mich geweigert, aus liebe zu meinem Vaterland, demselben zu dienen, wie, und womit ich könne, hab ich die Stelle angenommen. Durch Annehmung dieser Stelle gieng es mir wie manchem. Die aritstokratisch denkenden Bürger in der Gemeind und auf den Höfen wurden mir feindlich: die Feindseligkeit steig so hoch, daß sie mich wollten um den Schuldienst bringen. Jemehr ich ihnen diente mit vorlesen und erklären der Geseze und Volksblätter je feindlicher sie mir worden sind Jch ward genöthigt mich an den Regierungs- und Unterstatthalter zu wenden der mir ein Schreiben mitgetheilt der Gemeind vorzulesen, oder vorlesen zu lasen daß sie bey oberkeitlicher Strafe mich ungkänkt lassen sollen. Weil sie sahen, daß sie mir nichts anheben konten, sonnen sie, mich auf andere Art zu beschädigen. [...] Unsere Gemeind gab mir Jährlich ein Fuder Holz zur Schulstube. Sie fiengen an die Höfe, wo in unsere Schule gehören müssen jährlich auch ein Fuder Holz geben oder wir sie lassen sie nicht mehr in unsre Schule ein: die besser Denkenden haben gemeint, daß diesen Leuten Ernst sey: sie sorgten für den Schulmeister, daß er ein Fuder Holz mehr bekomme, ich aber habe ihren List bald gemerkt. Die Hofleute haben sich nicht zu einem Fuder Holz verstehen wollen, haben mit Agasul, das zur Schul Ottiken gehörte, diesen Winter eine eigene Schule gehabt, die aber vom Erziehungsrath noch nicht bestähtigt ist, Auf diese Art haben sie mich um diesen Schullohn können bringen. "1129 Der hervorgerufene Widerstand gegen die Repräsentanten der neuen Ordnung konnte sich, wie im obigen Beispiel dargestellt, mitunter empfindliche ökonomische Auswirkungen in Form

1126 Schmidt u.a. (Hgg.), Stapfer-Enquête, Nr. 663: Bleienbach.

1127 Nur 13\% aller Lehrer mit Kommunalämtern entstammten nicht aus dem Schulort.

1128 Manz, Landschaft: 48f.

1129 Schmidt u.a. (Hgg.), Stapfer-Enquête, Nr. 118: Unterillnau. Vgl. auch Bloch Pfister, Priester: 168. 
von Einkommenseinbussen und weiteren sozialen Konsequenzen nach sich ziehen. Manz und Weber skizzieren in ihren regional fokussierten Arbeiten zu Basel und Zürich eine Fülle von Konflikten zwischen den neuen Agenten und den Munizipalitäten, die sich teilweise in den Lehrerantworten auf die Stapfer-Enquête wiederfinden. Konfliktträchtig war nicht nur die Ablösung der alten Dorfvorsteher durch revolutionstreue Kräfte, sondern ebenso die vielfältigen zu übernehmenden Aufgaben und die daraus resultierende Machtfülle der Agenten, die häufige Anmassung von Kompetenzen, ein bisweilen überhebliches Auftreten der neuen Repräsentanten, die fehlende demokratische Partizipation der Dorfbürger, willkürliche Handlungen der Agenten sowie die ausbleibende Besoldung der Dorfbeamten. ${ }^{1130}$ An anderen Orten führte die Unbeliebtheit der neuen politischen Ämter, passiver Widerstand der Dorfbevölkerung oder der soziale Druck zum Wunsch, sie wieder abgeben zu können, wie es der Lehrer von Grafstal ZH erbat: „auch dermahlen Ober Agent posten Welches ich sehr Wünschte demselben entlasen zu werden". 1131

Die Motivation zur Ausübung von politischen Ämtern nahm insbesondere ab, wenn die Lehrer aufgrund des seit Juli 1799 möglichen Amtszwangs unfreiwillig in das Amt gedrängt oder daran gehindert wurden, das Amt wieder abgeben zu können. Mindestens ein Fall einer erzwungenen Amtsübernahme ist denn auch in der Stapfer-Enquête vermerkt, wobei der betroffene Lehrer allerdings bereits im Ancien Régime ein kommunales Ehrenamt ausgeübt hatte und somit über ein entsprechendes soziales Ansehen verfügt haben musste: „Demnach haben die Gemeindsgenoßen, wieder meinen Willen mich zu einem Municipal-Beamteten erwählt. Vorher war ich Geschworner." ${ }^{1132}$

Die Wirkung der neuen politischen Ämter auf den sozialen Status der Lehrkräfte bleibt daher von ambivalenter Bedeutung. Einerseits konnte sich das soziale Ansehen durch die gesteigerte Wichtigkeit der Bildung in Form der erforderlichen Kulturtechnikkompetenzen steigern. Ihre Kenntnisse machten die Schulmeister zu wichtigen Trägern der neuen Ordnung. Sicherlich setzten sich viele Lehrer zudem in ihren Amtsfunktionen uneigennützig für das allgemeine Wohl ihrer Dorfgenossen ein und erlangten dadurch verstärkte soziale Achtung in ihrer Dorfgemeinschaft. Auf der anderen Seite schuf die Nähe und Abhängigkeit zur neuen Ordnung eine offene Angriffsfläche für Konflikte, insbesondere mit den alten Eliten der Lokalgemeinschaft. ${ }^{1133}$ Die Übernahme eines neuen politischen Amtes stellte somit ein bedeutendes Reputationsrisiko dar, sofern die Lokalgemeinschaft der neuen Ordnung mehrheitlich kritisch gegenüberstand oder das Verhalten des Lehrers in seiner Nebenamtsfunktion als deviant betrachtete. Entsprechend konnte sich eine schlechte Reputation des Lehrers aufgrund seines Kommunalamtes in negativer Weise auf den Schulbesuch und damit auf das Einkommen des Lehrers auswirken.

Im Folgenden wird die soziale Zusammenstellung der Lehrer mit Amtsfunktionen genauer beleuchtet. Unter der Prämisse einer auf Erfahrung und Ansehen basierenden Vergabe der Kommunalämter interessiert die generelle Altersverteilung auf die Generationskohorten, wobei das Axiom einer Bevorzugung älterer Lehrkräfte als „erfahrene“ und sozial gesicherte Persönlichkeiten vor jungen, noch ohne über ein soziales Kapital verfügende Lehrer zu klären ist.

1130 Manz, Landschaft: 164ff.; Weber, Landgemeinden: 72-81.

1131 Schmidt u.a. (Hgg.), Stapfer-Enquête, Nr. 42: Grafstal.

1132 Schmidt u.a. (Hgg.), Stapfer-Enquête, Nr. 290: Herrliberg. Zum Amtszwang in der Helvetischen Republik vgl. Manz, Landschaft: 166; Stricker, ASHR Bd. IV: 927ff.

1133 Bloch Pfister, Priester: 168f. 
Tab. 22: Ausübung der Kommunalämter nach Alterskohorten

\begin{tabular}{lcccc}
\hline Alterskohorte: & Bezahltes Amt: & In Prozent: & Ehrenamt: & In Prozent: \\
\hline unter 20 Jahre & 0 & $0.0 \%$ & 0 & $0 \%$ \\
20-29 Jahre & 24 & $18.0 \%$ & 6 & $11.5 \%$ \\
30-39 Jahre & 35 & $26.3 \%$ & 15 & $28.8 \%$ \\
40-49 Jahre & 36 & $27.1 \%$ & 16 & $30.8 \%$ \\
50-59 Jahre & 24 & $18.0 \%$ & 6 & $11.5 \%$ \\
60-69 Jahre & 10 & $7.5 \%$ & 6 & $11.5 \%$ \\
70 Jahre und älter & 3 & $2.3 \%$ & 3 & $5.8 \%$ \\
Keine Angabe & 1 & $0.8 \%$ & 0 & $0 \%$ \\
\hline Total & 133 & $100.0 \%$ & 52 & $100 \%$ \\
Durchschnittsalter & 42.3 Jahre & & 44.2 Jahre & \\
\hline
\end{tabular}

Weder wenig erfahrene, junge Lehrer, noch ältere Männer jenseits des 50. Altersjahres waren für die bezahlten Kommunalämter der helvetischen Verfassung besonders stark zu gewinnen, sondern vornehmlich Lehrer zwischen dem 30. und 49. Lebensjahr. Diese Daten korrespondieren exakt mit den Durchschnittswerten zum Alter der Agenten aus den Arbeiten von Matthias Manz zur Basler Landschaft und von Hans Weber zu Zürich: Die Mehrzahl der Agenten in beiden Untersuchungsregionen war zwischen 30 und 49 Jahre alt, der Altersdurchschnitt lag zwischen 40.5 und 43.5 Jahren. ${ }^{1134}$

Doch nicht nur bei der Besetzung der Agenten- respektive der Unteragentenstellen drängten sich Lehrer des mittleren Erwachsenenalters auf, sondern auch in den Ehrenämtern. Gerade die Verwalterdienste von kommunalem Vermögen, Kirchmeier- und Säckelmeisterdienste, wurden mehrheitlich an ältere, gestandene Männer vergeben. Der Grund lag einerseits im benötigten Erfahrungsschatz zur Ausübung dieser Aufgaben, andererseits im sozialen Kapital verankert, das sich diese Männer durch jahrelange Loyalität in ihrer Lokalgemeinschaft erarbeitet hatten. Für die Erklärung der Altersstratifikation zwischen den neuen politischen Ämtern und den traditionellen Kommunalämtern kann das Fazit von Manz für die Agenten der Basler Landschaft hinzugezogen werden: „Die Instabilität der Revolution und die Ungewissheit des fremdartigen helvetischen Experiments vermochte jüngere Männer eher anzusprechen als ältere, die sich an die vielleicht nicht zufriedenstellenden, aber geordneten Verhältnisse gewöhnt haben dürften." ${ }^{1135}$

Die sozio-ökonomische Herkunft der Lehrer mit Amtsfunktionen deutet eine weitere Besonderheit in der Besetzung der kommunalen Ämter an. Die Zusammenstellung der Ersttätigkeiten der Lehrer mit kommunalen Amtsfunktionen ergab eine deutliche Präferenz von Bauern respektive Taunern, denn mindestens zwei Fünftel der Lehrer mit Dorfämtern hatte vor der Übernahme des Lehramts in der Landwirtschaft gearbeitet. ${ }^{1136}$ Wenngleich der Güter- beziehungsweise der Grundbesitz als zuverlässige Grösse zur Einschätzung der sozialen Stellung

1134 Manz, Landschaft: 152; Weber, Landgemeinden: 173.

1135 Manz, Landschaft: 152.

1136 Mindestens 79 der 185 Lehrer mit Kommunalämtern als Nebentätigkeit waren zuvor landwirtschaftlich tätig. 
fehlt, weist dieser Umstand auf einen kontinuierlichen sozio-ökonomischen und räumlichen Zusammenhang zwischen der Kombination von Schuldienst und der Übernahme von Dorfämtern im Ancien Régime hin, den Esther Berner in ihrer Züricher Studie beschreibt. Demnach traten 1771 die meisten Fälle von Lehrern mit einem Dorfamt in den ackerbaulich geprägten Regionen des Kantons auf, hingegen kaum im stärker industrialisierten Oberland und ebenfalls kaum in den wohlhabenden Gemeinden entlang des Zürichsees. „Dies legt die Vermutung nahe, dass sich in ackerbäuerlichen und sozial wahrscheinlich traditioneller strukturierten Regionen Schulmeister tatsächlich häufiger aus der oberen dörflichen Mittelschicht rekrutierten. "1137

Es ist anzunehmen, dass viele Schulmeister als Angehörige der dörflichen Funktionselite die neuen bezahlten Ämter nach der Revolution bewusst besetzten. Zudem waren typische Berufe der grundbesitzlosen dörflichen Unterschicht - Taglöhner, protoindustrielle Weber, Handwerker der Textilbranche - kaum unter den Ersttätigkeiten der Lehrer mit Amtsfunktionen vertreten, was ein weiteres starkes Indiz für die Übernahme der neuen Ämter durch Angehörige der Funktionselite ist. Für eine bewusste Übernahme von Amtsfunktionen spricht zudem die Tatsache, dass ein weiteres Fünftel jener Lehrer explizit keine weiteren Ersttätigkeitsangaben machte, also mutmasslich einzig als Schulmeister arbeitete. Der Grund hierzu dürfte vorwiegend in den genannten Kulturtechnikkompetenzen gelegen haben.

Die Überprüfung des räumlichen Zusammenhangs zwischen Ersttätigkeiten und der Übernahme von Kommunalämtern im gesamtschweizerischen Kontext ergibt freilich ein ambivalentes Bild: Kommunale Ämter als Zusatzbeschäftigungen traten in den Kantonen des zentralen schweizerischen Mittellands in der Tat überdurchschnittlich oft auf. Im neu geschaffenen Kanton Aargau übten gleich 18\% der Lehrer des Kantons eine kommunale Zusatzbeschäftigung aus, was mehr als dem Doppelten des gesamthelvetischen Mittels entspricht. Doch auch in den Kantonen Bern (13\%), Schaffhausen (12\%), Solothurn und Baden (je 11\%) hatte mehr als jeder zehnte Lehrer ein Kommunalamt als Zusatzbeschäftigung. Alle diese Räume waren zwar geprägt durch traditionellen Ackerbau, wiesen aber auch einzelne protoindustrialisierte Regionen aus, in denen durchaus etliche Lehrer mit Dorfämtern auftraten, beispielsweise im Berner Oberaargau zwischen Langenthal und Zofingen und im Aargau zwischen dem Hallwilersee und dem Bözberg. Deutlich unterdurchschnittlich traten Kommunalämter als Nebentätigkeiten dagegen in den Kantonen Zürich (4\%), Thurgau (4\%) und Fribourg (5\%) auf. Kommunalämter waren sowohl bei städtischen Lehrern als auch bei Landschulmeistern gleichermassen vorkommend. Im konfessionellen Vergleich sind nur geringe Differenzen erkennbar, es entfielen 22.7\% der Lehrer mit Kommunalämtern auf den katholischen Glauben, 77.3\% auf das reformierte Glaubensbekenntnis.

Im Vergleich zu anderen Berufsgruppen wurden Schulmeister jedoch trotzdem nur zurückhaltend als Agenten bestimmt. Sowohl Manz als auch Weber zählten in ihren auf die Agenten fokussierten Untersuchungen bloss eine knappe Handvoll Schullehrer als Agenten in ihren Kantonen. ${ }^{1138}$

Im Gegensatz zu landwirtschaftlichen, protoindustriellen oder textilgewerblichen Tätigkeiten, welche „en passant“ vor- und nach der Schulzeit als Nebentätigkeiten ausgeführt werden konnten, nahmen einige der kommunalen Amtsfunktionen ungleich mehr Zeit in Anspruch und waren für die Schulmeister folglich weniger flexibel zu handhaben. Besonders das Distriktrichteramt nahm mit wöchentlich fixen Verhandlungstagen relativ viel Zeit in Anspruch, was die betroffenen Schullehrer zwang, entweder ihren Unterricht ausfallen zu lassen oder einen

1137 Berner, Zeichen: 103. Dass es sich ausschliesslich um Hauptschullehrer gehandelt habe, wie Berner postuliert, kann jedoch in der gesamthelvetischen Perspektive nicht bestätigt werden.

1138 Manz, Landschaft: 152; Weber, Landgemeinden: 176. 
Stellvertreter an ihrer Stelle unterrichten zu lassen. So berichtete der Lehrer von Reichenburg SZ: „Und weil Niemand anwesend ware, der sich für den vacanten schuldienst freüen wollte wurde ich, obwohlen dazumahlen ich schon von dem Wahl Korps alß Bezirk Richter erwöhlt ware, genöthiget selben wieder anzunehmen. Jch besuche alle Montag das Gericht, an welchem Tage dann die schule, so wie nach altem Gebrauch jeder schullehrer in der Woche die Vollmacht ein Recreations-Tag zu geben hatte, ebenfalls unterbleibt. Bin ich mehrere Tage abwesend, so übernimmbt Bürger Bruder Pfarrer Anton Wilhelm meine Burde." ${ }^{\text {"139 }}$

In Sennhof $\mathrm{ZH}$ setzte der abwesende Lehrer dagegen lieber seinen Sohn als Vertretung ein, wenn er seine Aufgaben als Distriktrichter bewältigen musste: „Neben dem Lehramt ist \{er\} noch Distriktsrichter, Da aber seine Geschäfte ihn Oftmals von der Schule weg beruffen, so ist ihm sein Sohn, von 19. Jahrn alt zu gegeben, welcher schon vor 2 Jahren, von den. Examinatoren, Examiniert worden ist, ihm die Schule zu übergeben." ${ }^{1140}$ Dass ein Schulmeister gleichzeitig noch ein oder mehrere Dorfämter versah und sich vertreten lassen musste, wurde mitunter von den Vorgesetzten kritisch beurteilt. Beispielhaft sei der Andelfinger Pfarrer Oechslin aus der Zürcher Enquête von 1771 zitiert: „Allerdings leydet das Schul Wesen darunter. Der einte von meinen schulmeistern ist noch Zehenden-Mann im Schloss. Um desswillen im Sommer entweder ein anderer die schul zu weilen hält oder allzu früh wieder geendigt wird. [...] Es giebt, doch nicht so offt, Intervalla zu Neben Geschäften besonders des Zehenden Mannes er sucht aber die Schul entweder durch seinen Sohn oder den andern Schulmeister versehen zu lassen. " ${ }^{1141}$

Da die jährliche Schuldauer von fast der Hälfte der Lehrkräfte mit einem Kommunalamt bereits ganzjährig dauerte, sind die zeitlichen Konflikte nicht von der Hand zu weisen. ${ }^{1142}$ Das Einspringen von weiteren Personen wurde jedoch von den Pfarrern vielfach als unumgängliche Tatsache geduldet und dem Ausüben von Dorfämtern wurde angesichts der vielerorts knappen Besoldungssituation ein gewisses Verständnis entgegen gebracht. ${ }^{1143}$ Die unbefriedigende Situation der durch die Nebenämter verursachten häufigen Absenzen sorgte dennoch für vielfache Klagen und beschäftigte die kantonalen Erziehungsräte dahingehend, dass die betroffenen Schulmeister aufgefordert wurden, vom Schuldienst oder von der Nebentätigkeit zurückzutreten: „weil es den Ordnungen und Pflichten eines Schulmeisters zuwider sei, ein Amt zu bekleiden, dem er ohne Verabsäumung des erstern Genüge leisten könne, und man keine Titulaturschulmeister haben wolle, die zwar das Einkommen bezögen, aber ihrem Berufe nicht persönlich und ununterbrochen oblägen. "1144 Die betroffenen Lehrpersonen sahen die Ausübung von Kommunalämtern selbst mitunter ebenfalls kritisch, wie der Lehrer von Aarburg AG festhielt: „Er ist Organist, auch Municipalität-Schreiber letzterer Posten ist für die Schule nachtheilig "1145

\subsubsection{Diskontinuierliche Lebensverläufe}

Bisweilen standen die ausgeübten Erst- und späteren Nebentätigkeiten in keinem direkten Zusammenhang, wie das Beispiel des Lehrers Jean Pierre Rubattel aus Valeyres-sous-Rances VD zeigt, der notiert hatte: „[III.11.g:] Ma Vocation à été Graveur en Bois pour les Toiles peintes

1139 Schmidt u.a. (Hgg.), Stapfer-Enquête, Nr. 855: Reichenburg.

1140 Schmidt u.a. (Hgg.), Stapfer-Enquête, Nr. 565: Sennhof.

1141 Zit. aus: Berner, Zeichen: 105.

1142 Mindestens 77 der 185 Lehrer mit Kommunalämtern als Nebentätigkeiten unterrichteten ganzjährig an ihrer Schule (42\%).

1143 Berner, Zeichen: $105 f$.

1144 Zit. nach: Klinke, Zürich: 119.

1145 Schmidt u.a. (Hgg.), Stapfer-Enquête, Nr. 2096: Aarburg. 
[III.11.h:] Je suis Tisseran Je travaille à tems perdu." 1146 Solche Lebensverläufe sind unter dem Miteinbezug des Lehramtes als eine eigene erwerbsbiografische Veränderung als „diskontinuierlich“ im Sinne einer kompletten Veränderung des Erwerbsprofils zu bezeichnen. Mindestens $31 \%$ aller helvetischen Elementarschullehrkräfte wiesen ebensolche bruchhaften Lebensverläufe mit einer kompletten Umdisposition der Erwerbstätigkeiten aus. ${ }^{1147}$ Rund jede dritte helvetische Lehrkraft verzichtete folglich entweder auf die angestammte Ersttätigkeit für die exklusive Ausübung des Lehramts oder ersetzte die Ersttätigkeiten wie im oberen Beispiel gleich durch neue Zusatztätigkeiten neben dem Lehramt.

Aus der Diskontinuität zwischen Erst- und Nebentätigkeiten eröffnen sich folglich zwei Fragefelder. Erstens: Welche Ersttätigkeiten wurden im helvetischen Lehrerkollektiv im Vergleich zugunsten des Lehramtes besonders oft aufgegeben oder zumindest nicht mehr erwähnt? Zweitens: Durch welche Tätigkeiten wurden die aufgegebenen Ersttätigkeiten - wenn überhaupt - ersetzt? Eine Aufschlüsselung nach den Ersttätigkeiten verschafft einen Überblick zu ersten Frage:

Tab. 23: Aufgegebene Ersttätigkeiten der Lehrer

\begin{tabular}{lccc}
\hline Ersttätigkeit: & $\begin{array}{c}\text { Nennungen als } \\
\text { Ersttätigkeit: }\end{array}$ & $\begin{array}{c}\text { Anzahl der substitu- } \\
\text { ierten Tätigkeiten: }\end{array}$ & In Prozent: \\
\hline Landwirtschaftliche & 756 & 301 & $39.8 \%$ \\
Protoindustriell-textilgewerbliche & 255 & 120 & $47.1 \%$ \\
Handwerkliche & 370 & 205 & $55.4 \%$ \\
Kaufmännische & 28 & 22 & $78.5 \%$ \\
Kommunale & 30 & 16 & $53.3 \%$ \\
Soldaten & 67 & 50 & $74.6 \%$ \\
Kirchliche & 22 & 5 & $22.7 \%$ \\
Schreiber & 22 & 13 & $59.1 \%$ \\
Studium & 140 & 38 & $27.1 \%$ \\
\hline Total & \multicolumn{4}{|}{} \\
\hline
\end{tabular}

Wie im vorangegangenen Kapitel zur Ausübungskontinuität bereits festgestellt wurde, neigten unter den drei quantitativ grössten Tätigkeitsgruppen die ehemaligen Handwerker mit $55 \%$ am stärksten dazu, ihre bisherigen Tätigkeiten für das Schullehramt aufzugeben. Darunter befanden sich vorwiegend Schuster und Schneider, deren ökonomische Konkurrenzsituation wohl ausschlaggebend für den berufsbiografischen Wechsel gewesen war. Ferner gehörten ehemalige Soldaten, Kaufmannsbeschäftigte und Schreibtätige zu den Berufsgruppen mit geringer Kontinuität beziehungsweise einer hohen Neigung zum biografischen Wechsel ins Lehramt.

Deutlich geringer fiel die Ablösung landwirtschaftlicher Tätigkeiten zugunsten des Lehramtes aus. Bloss etwa zwei von fünf ehemaligen Bauern oder Taunern, rund $40 \%$, gaben ihre agrarischen Beschäftigungen zeitweilig oder ganz auf. Darin widerspiegelt sich einmal mehr die enorme Bedeutung von landwirtschaftlichen Tätigkeiten zur Subsistenzsicherung. Zudem muss bei jenen 40\% an Lehrkräften mit substituierten landwirtschaftlichen Tätigkeiten der Vorbehalt angebracht wer-

1146 Schmidt u.a. (Hgg.), Stapfer-Enquête, Nr. 1692: Valeyres-sous-Rances.

1147 Es sind mindestens 715 Lebensverläufe ohne Kontinuitäten zwischen Erst- und Nebentätigkeiten empirisch festgestellt worden. Darunter befanden sich 13 Lehrerinnen, von denen bis auf zwei Ausnahmen alle auf weitere Nebentätigkeiten verzichteten. Dazu kommen 55 Lehrkräfte mit mehr als einer neuen Nebentätigkeit. 
den, dass ebendiese Tätigkeiten stillschweigend entweder im Familienverbund durch die Ehefrau oder die Kinder weitergeführt werden konnten oder von den Lehrkräften als Alltagshandlungen zur Sicherung der Subsistenz nicht mehr als erwähnenswert taxiert wurden. Ebenso zeigten protoindustriell-textilgewerblich Tätige mit bloss $47 \%$ eine kollektiv geringere Neigung zur Aufgabe ihrer Ersttätigkeiten zugunsten des Lehramts. Das Verhalten überrascht angesichts der postulierten Kompatibilität protoindustrieller Tätigkeiten mit weiteren Tätigkeiten wenig. ${ }^{1148}$

Die Ergebnisse stimmen grundsätzlich mit bisherigen Forschungserkenntnissen überein. Zur Frage der bewussten Aufgabe von zusätzlichen Tätigkeiten durch die Übernahme des Schuldienstes hat Alexandra Bloch Pfister in ihrer Studie zur Zürcher Lehrerschaft eine grundsätzliche Abnahme von Nebenbeschäftigungen zwischen 1770 und 1799 registriert: „Bloss knapp ein Drittel der Professionisten-Schulmeister und die Hälfte der in der Protoindustrie tätigen Schulmeister behielten diese Tätigkeiten nach der Übernahme einer Schulstelle bei. Es scheint gegen das Ende des Jahrhunderts seltener und vermutlich schwieriger geworden zu sein, die Schularbeit neben und zusätzlich zur Landwirtschaft mit einer Berufstätigkeit zu verbinden. "1149 Eine ähnliche Tendenz hat auch Wolfgang Neugebauer für Preussen-Brandenburg festgehalten, wo im gleichen Zeitraum der Anteil an Lehrkräften ohne Nebentätigkeiten stark zunahm. ${ }^{1150}$ Die aus der Stapfer-Enquête gewonnenen Daten unterstützen diese Erkenntnisse im Grundsatz, wenngleich ein zeitlicher Referenzvergleich fehlt, um Bloch Pfisters These einer systematischen Destratifikation der Polyprofessionalität durch die Lehramtsübernahme zu verifizieren.

Zur Klärung der zweiten Frage nach dem Ersatz der aufgegebenen Ersttätigkeiten zeigt die Häufigkeitsverteilung in den Biografieprofilen eindeutige Tendenzen.

Tab. 24: Neu ausgeübte Ersatztätigkeiten zum Lehramt

\begin{tabular}{lcc}
\hline Tätigkeit: & Als Ersatztätigkeit: & In Prozent: \\
\hline Landwirtschaftliche & 104 & $13.5 \%$ \\
Protoindustrielle & 17 & $2.2 \%$ \\
Handwerkliche & 15 & $1.9 \%$ \\
Kaufmännische & 8 & $1.0 \%$ \\
Kommunale & 91 & $11.8 \%$ \\
Kirchliche & 257 & $33.3 \%$ \\
Verwaltung & 5 & $0.6 \%$ \\
Keine Nebentätigkeiten & 225 & $29.2 \%$ \\
Privatunterricht & 39 & $5.0 \%$ \\
Freizeit & 9 & $1.1 \%$ \\
\hline Total & 770 & $100 \%$ \\
\hline
\end{tabular}

Fast jede dritte Lehrkraft, die auf eine weitere Ausübung ihrer Ersttätigkeiten verzichtete, nahm neben dem Lehramt gar keine Nebentätigkeiten mehr an. ${ }^{1151}$ Einen ebensolchen Lebensverlauf hatte beispielhaft der Lehrer Hans Ulrich Weiler von Rickenbach ZH notiert: „[III.11.f/g:]

1148 Vgl. Zimmermann, Dorf und Land: 101.

1149 Bloch Pfister, Priester: 170f.

1150 Neugebauer, Schulwirklichkeit: 324.

1151 Mindestens 225 der 715 Lehrkräfte mit diskontinuierlichem Lebensverlauf erwähnten neben dem Schuldienst keine weiteren ausserschulischen Tätigkeiten mehr. 
Mein Beruff habe ich angetretten, mit Martini Anno 82. Vorher habe ich das Weber-Handwerk getrieben [III.11.h:] Jezt habe ich keine andere Verrichtungen als nur meinem Schul Amt abzuwarten." 1152

Insbesondere jüngere Lehrkräfte neigten zur Tendenz, landwirtschaftliche Tätigkeiten zugunsten des Lehramts oder anderer Ausübungen abzutauschen. So traten 56\% der unter 30-jährigen Lehrkräfte ihre agrarischen Ersttätigkeiten gegen das Lehramt oder andere Tätigkeiten ab, während nur 33\% der Verzichtsangaben auf Erwachsene des mittleren Alters und 36\% auf ältere Erwachsene von über 50 Jahren entfielen. ${ }^{153}$ Geistliche und ehemalige Kirchenhilfsdiener gaben ihre Ersttätigkeiten in der Regel mit der Lehramtsübernahme nicht auf, sondern nutzten - wie im vorangegangenen Kapitel bereits skizziert - das Lehramt primär als Ergänzungstätigkeit.

Unter der Prämisse, dass der Verzicht exklusiv zugunsten des Lehramtes als bewusste Entscheidung erfolgte, strebte eine kollektiv markante Anzahl von Lehrkräften eine bewusste berufliche Spezialisierung an, was das Lehramt als eigenständige Tätigkeit implizit aufwertet. Auf die Fortführung ihrer Ersttätigkeiten zugunsten des Lehramts verzichteten interessanterweise Angehörige aus sämtlichen Berufsgruppen gleichermassen. Sowohl ehemals landwirtschaftlich Tätige als auch ehemalige Handwerker und protoindustrielle Heimarbeiter sahen in bedeutendem Masse auf ihre Ersttätigkeiten zugunsten einer exklusiven Lehramtsausübung ab. ${ }^{1154}$ Ermöglicht wurde dieser Verzicht in erster Linie durch eine ausgedehnte jährliche Schuldauer, denn fast zwei Drittel dieser Lehrkräfte arbeitete an einer ganzjährig dauernden Schule und bloss noch $7 \%$ jener Lehrkräfte waren einzig im Winter unterrichtspflichtig. ${ }^{155} \mathrm{~W}$ ie schon für die linearen Lebensverläufe festgehalten wurde, galt auch für zahlreiche weitere Erwerbsbiografien: Je länger die Schule im Jahresgang dauerte, desto stärker konzentrierten sich die Lehrkräfte auf das Lehramt als exklusive Tätigkeit. Dass zudem bereits fast jede zehnte Lehrkraft überhaupt keine Nebentätigkeiten mehr erwähnte, unterstützt trotz der verhältnismässig hohen Unsicherheit bezüglich des Wahrheitsgehalts der Aussagen den Eindruck, dass das Schulhalten zur Sicherung des Lebensunterhalts zunehmend ausgereichte und durch die Intensivierung der jährlichen Beschulungsdauer, der gesteigerten Bildungsnachfrage von unten und eventuell auch durch Lohnmassnahmen vonseiten der Gemeinden tatsächlich ein allmählicher Destratifizierungsprozess ablief. ${ }^{1156}$ Zudem dürfte mit der fortdauernden Ausübung des Lehramts zusätzlich ein verstärkendes Moment der beruflichen Pfadabhängigkeit eingesetzt haben. ${ }^{1157}$

Wenn einzelne Tätigkeiten neben dem Lehramt durch andere ersetzt und ausgetauscht wurden, fiel das Ergebnis meist kollektiv ähnlich aus. Mit Abstand die häufigste Ersatztätigkeit neben dem Lehramt waren ebenfalls bei allen Berufsgruppen gleichermassen kirchliche Hilfsdienste, deren lokalstrukturelle Verbindung mit dem Lehramt die Lehrkräfte oftmals einer individuellen Wahlmöglichkeit beraubte. Während die kirchlichen Hilfsdienste vielerorts verpflichtend an das Lehramt gekoppelt waren, geschah die Übernahme von kommunalen Funktionen dagegen

1152 Schmidt u.a. (Hgg.), Stapfer-Enquête, Nr. 207: Rickenbach.

1153 Von den 125 Lehrkräften von unter 30 Jahren mit diskontinuierlichem Lebensverlauf gaben 65 ihre agrarischen Tätigkeiten auf (56\%). Dagegen taten bloss 113 von 344 Lehrern zwischen 30-49 Jahren (33\%) und weitere 88 von 244 Lehrern über 50 Jahren (36\%) das gleiche. 2 Lehrkräfte waren ohne Altersangabe.

1154 Unter den 225 Lehrkräften ohne Nebentätigkeiten befanden sich mindestens 89 ehemals agrarisch Tätige, 38 protoindustriell-textilgewerblich Tätige, 54 handwerklich Tätige, 7 kaufmännisch Tätige, 8 ehemalige Soldaten und mindestens 23 polyprofessionell Tätige.

1155 Von den 225 Lehrkräften unterrichteten 142 (63\%) ganzjährig, 68 mit Sommerschulen (30\%) und 15 nur im Winter (7\%).

1156 Vgl. Bloch Pfister, Priester: 172-183.

1157 Zur Dienstdauer der Lehrkräfte vgl. das folgende Kap. 3.4. 
in der Regel freiwillig. Kommunale Hilfsdienstämter traten als viertwichtigste Ersatztätigkeit auf. Hierbei neigten vor allem ehemals landwirtschaftlich Tätige zum Ersatz mittels kommunaler Aufgaben. ${ }^{1158}$

Landwirtschaftliche Tätigkeiten dienten ihrerseits zwar ebenfalls als Ersatztätigkeiten, allerdings quantitativ seltener und vorwiegend für ehemals handwerklich tätige Lehrer. ${ }^{1159}$ Hier kann angenommen werden, dass es sich vornehmlich um kombinierte kleinbäuerliche Landhandwerker handelte, wie eine Bemerkung des Lehrers Jakob Kohli aus Oberhünigen BE bescheint: „schuster gesel. Er hat ein Abscheiniges Mageres Heimathli, Darauf er Viel Schuldig ist, muss also für die Zinsen und abgaben sorgen." ${ }^{160}$

Weitere handwerkliche, protoindustriell-textilgewerbliche, kaufmännische oder VerwaltungsTätigkeiten wurden dagegen neben der Lehramtsübernahme kaum zusätzlich neu ausgeführt. Eine der wenigen Ausnahmen war die Lehrerin Louise Canet aus Nyon VD, die aufgrund der Invalidität ihres Mannes einem Nebenerwerb als „Marchande détailliste en très petit“ nachging. ${ }^{1161}$ Noch seltener war die Reduktion von einzelnen Tätigkeitsbereichen in polyprofessionellen Erwerbsbiografien mit mehreren Ersttätigkeiten zugunsten des Schulamtes. Bloss etwa in drei Dutzend Fällen konnte ein Verzicht auf Teilerwerbsfelder zugunsten der Schultätigkeit festgehalten werden. ${ }^{1162}$ Wenn allerdings polyprofessionelle Teiltätigkeiten aufgegeben wurden, betraf dies in der Regel eine nichtagrarische Tätigkeit, etwa die Ausübung eines Handwerks oder protoindustriell-textilgewerbliche Tätigkeiten, währenddessen die agrarischen Tätigkeiten in der Mehrheit fortgeführt wurden. ${ }^{1163}$

Mindestens ein Drittel aller helvetischen Lehrkräfte hatte somit ihre Berufsbiografie mit der Lehramtsübernahme grundlegend verändert, wovon wiederum ein beachtlicher Teil im Sinne einer Destratifizierung zugunsten des Lehramts auf weitere Erwerbstätigkeiten verzichtete. Der Schlüsselfaktor für diesen Prozess stellte die Ausgestaltung der jährlichen Schuldauer dar.

\subsection{Die Dienstdauer}

Wenn das Lehramt eine prekäre „Not- und Hilfstätigkeit“ war, in die man sich nur aus ökonomischer Notwendigkeit oder aus lebenszyklisch bedingten Motiven flüchtete, dürfte sich dies folglich in der Dauer der Dienstausübung als kollektiv eher kurzzeitig ausgeführte Tätigkeit niedergeschlagen haben. Zudem dürfte unter dieser Annahme die Volatilität des Arbeitsfeldes der Elementarschule beziehungsweise die Wechselhäufigkeit der Lehrkräfte relativ hoch gewesen sein. Bislang ist aber wenig darüber bekannt, wie das elementare Schulwesen mit den sich wandelnden Anforderungsprozessen der frühneuzeitlichen Arbeitsmärkte interagiert hat. ${ }^{1164}$ Ebenso unerforscht ist die Rolle des frühneuzeitlichen elementaren Schulwesens als eigener spe-

1158 Allein mindestens 42 der 91 Kommunalämter wurden von Lehrern mit nicht mehr erwähntem agrarischem Hintergrund angegeben. So schrieb der Lehrer Hans Buess von Zeglingen BL: „war ehr dessen ein Thauner. Jst neben dem Lehramt noch Agent." Schmidt u.a. (Hgg.), Stapfer-Enquête, Nr. 1475: Zeglingen. Es gilt jedoch der Vorbehalt, dass die erstlich genannten agrarischen Tätigkeiten unausgesprochen gleichwohl im Familienverbund weitergeführt wurden.

1159 Mindestens 38 der 104 Nennungen von agrarischen Nebentätigkeiten gehen auf ehemalige Handwerker zurück.

1160 Schmidt u.a. (Hgg.), Stapfer-Enquête, Nr. 870: Oberhünigen.

1161 Schmidt u.a. (Hgg.), Stapfer-Enquête, Nr. 1684: Nyon.

1162 Mindestens 37 Lehrkräfte wiesen eine Reduktion ihrer Ersttätigkeiten im Vergleich mit den Nebentätigkeiten zum Schulamt auf.

1163 Von den 37 Fällen mit einer Reduktion der Ersttätigkeiten blieb in 22 Fällen die landwirtschaftliche Tätigkeit beibehalten und demgegenüber nur in 8 Fällen darauf verzichtet.

1164 Vgl. Ehrenpreis, Perspektive: 94. 
zifischer Arbeitsmarkt und das Verhalten der zentralen Arbeitsmarktakteure, der Lehrerschaft, innerhalb dieses Marktes. Hierbei eröffnen sich erstens Fragen zur grundsätzlichen Verweildauer der Lehrkräfte im Beruf, zweitens zum sozialen Mobilitätsverhalten innerhalb des Arbeitsmarktes Schule und drittens zum generellen Fluktuationsverhalten der Lehrkräfte.

Die Diensttreue der Elementarschullehrerschaft musste für den helvetischen Bildungsminister Philipp Albert Stapfer von eminentem Interesse gewesen zu sein, denn seine Enquête erhob durch die Frage III.11.f „Wie lang ist er Schullehrer?" gezielt die Ausübungsdauer der helvetischen Lehrer. Mit dem Erheben der Dienstdauer der Lehrkräfte brachte Stapfer einen gänzlich neuen protostatistischen Wert in das Fragenset zum Elementarschulwesen ein, denn im Vergleich mit den anderen vorangegangenen zeitgenössischen Schulumfragen aus dem Ancien Régime und aus den ersten Monaten der Helvetischen Republik, die vor der Stapfer-Enquête in einzelnen Kantonen durchgeführt worden waren, war die Dienstdauer der Schulmeister bislang noch nie explizit erhoben worden. ${ }^{165}$ Die Frage zielte vermutlich auf die statistische Bestätigung der von Stapfer vermuteten „Schulerbärmlichkeit“ des Elementarschulwesens ab, wenngleich die Motive für die Initialisierung der Frage nach der Dienstdauer letztendlich unklar bleiben. ${ }^{1166}$ Quellenkritisch weist die Beantwortung durch die Lehrkräfte eine doppelte inhaltliche Unschärfe bezüglich der Gesamtdauer des Lehrer-Seins auf. Vielerorts, besonders aber in den französischsprachigen Landesteilen der Waadt, des Wallis und des Kantons Fribourg, beantworteten die Lehrkräfte in dieser Rubrik einzig die Verweildauer an der aktuellen Schulstelle im Jahr 1799 und nicht ihre gesamte Dienstdauer seit ihrer Erwählung als Lehrer. Zahlreiche andere Lehrer antworteten des Weiteren mit ungenauen Angaben auf den Zeitpunkt des Berufsbeginns, wie ,von Jugend auf “ oder „seit etlichen Jahren“, was den erhobenen Daten eine methodisch zu berücksichtigende Unschärfe verleiht. ${ }^{1167}$ Es ist folglich davon auszugehen, dass zahlreiche Lehrer zum Zeitpunkt der Umfrage bereits deutlich länger im Amt standen, als sie dies in der Stapfer-Enquête vermerkten. Dennoch erlauben die vorhandenen Daten zur Dienstdauer eine flächendeckende Erhebung der minimalen Diensttreue der Elementarschullehrer. Damit lässt sich die These prüfen, ob das Lehramt kollektivbiografisch als eher kurzfristig gedachte ökonomische Not- und Ausweichtätigkeit im Sinne der „Pédagogues d'occasion“ oder aber als langfristig orientierte, bewusste Spezialisierung als „Pédagogues de profession“ nach Georges Panchaud ausgeübt wurde.

Die bisherigen quantitativ orientierten Forschungsergebnisse zur Dienstdauer der helvetischen Lehrkräfte auf der Basis der Stapfer-Enquête weisen allesamt auf eine grundsätzlich lang andauernde Dienstausübung hin. Während die älteren kantonalen Schulgeschichtsforschungen der Frage nach der Dienstdauer der Lehrer erstaunlicherweise weitgehend ausgewichen sind - nur Georges Panchaud hat eine detaillierte Liste der „Années de service des régents en fonction en 1799“ für die Waadtländer Lehrerschaft erstellt und festgestellt, dass die Lehrer mehrheitlich „attachés à leur mé-

1165 Eine Ausnahme stellte die fast zeitgleich mit der Stapfer-Enquête initiierte Aargauer Schulumfrage vom 9. Januar 1799 dar, die in der Frage III.3 ebenfalls nach der „Dienstzeit“ der Lehrer fragte. Vgl. den gedruckten Fragebogen: LaGL HA Kiste 27, Mappe C, o. Pag.: 09.01.1799 - Aargau.

1166 Vgl. Rohr, Stapfer: 76f.

1167 Zur Methodik der Datenerhebung: Die Dienstdauer wurde in Halbjahresschritten aufgenommen. Alle im Jahr 1798 neu in das Lehramt eingestiegenen Lehrkräfte wurden mit 0.5 Dienstjahren gezählt. Bei Monatsangaben wurde jeweils auf das letzte Halbjahr abgerundet. Z.B. „1 Jahr 8 Monate“ = 1.5 Jahre. Eine leichte Verzerrung durch nicht berücksichtigte weitere Dienstdauerangaben in anderen Bereichen der Beantwortung kann für Einzelfälle nicht ausgeschlossen werden. Ebenso führen fehlende oder ungenaue Dienstdauerangaben zum Umstand, dass die erhobenen Daten bloss den Charakter eines Mindestwerts haben. Für fehlende oder ungenaue Dienstdauerangaben wurde der Mindestwert von 0.5 Jahren eingesetzt. Die Fehlerquote für fehlende Dienstdauerangaben beträgt insgesamt 53 Fälle oder $2.3 \%$. 
tier " blieben $^{1168}$ - zeigen neuere Forschungsergebnisse ein relativ einheitliches Bild. Aus der interregionalen Stichprobe von Ingrid Brühwiler sowie aus der Regionalstudie von Pius Landolt zu den Aargauer Lehrern kristallisieren sich bei einem ähnlichen Umfang von je rund 200 untersuchten Lehrpersonen einmütig das Mittel von rund 13 Dienstjahren heraus. ${ }^{1169}$ Dieser Durchschnittswert korrespondiert im überregionalen Vergleich gut mit der mittleren Dienstdauer von rund zwölf Jahren im deutschen Niederstift Münster, errechnet aus einer ähnlich grossen Fallgruppe von 188 Lehrpersonen unterschiedlichen Alters. ${ }^{1170}$ Michael Ruloff hat seinerseits aus einer Stichprobe von 99 Lehrkräften eine mittlere Diensttreue von über 14 Jahren berechnet. ${ }^{1171}$ Gar noch höhere regionale Werte von 18 bis 20 Jahren hat Peter Büttner in seiner lokalen Studie erhalten, allerdings auf der Basis einer deutlich kleineren Stichprobe von bloss rund drei Dutzend Lehrkräften. ${ }^{1172} \mathrm{Da}$ die Grösse des Stichprobenumfangs einen offensichtlichen Einfluss auf die Dienstdauerwerte hat, werden im Folgenden sämtliche zur Verfügung stehenden Daten analysiert.

Die minimale mittlere Dienstdauer aller 2.305 untersuchten helvetischen Elementarschullehrer aus der Stapfer-Enquête belief sich zum Zeitpunkt der Umfrage und unabhängig vom wirklichen Alter der Lehrkräfte auf 14.0 Jahre. Unter dem Ausschluss der 2.3\% an Lehrpersonen mit fehlenden oder unpräzisen Dienstdauerangaben, für die der rechnerische Minimalwert von 0.5 Jahren für die Schulperiode zwischen dem Martinstag 1798 und dem Erhebungszeitpunkt im Februar 1799 eingesetzt wurde, steigt die minimale Dienstdauer auf durchschnittlich rund 14.3 Jahre an. Damit bestätigen und präzisieren sich weitgehend die bereits erwähnten Mittelwerte aus den umfangreichen Stichproben von Ingrid Brühwiler, Pius Landolt und Michael Ruloff. Der Medianwert aller Dienstdauerangaben lag leicht tiefer bei rund 11 Jahren, was allerdings primär dem relativ hohen Anteil von rund $8.5 \%$ an Neueinsteigern mit weniger als einem Jahr an Diensterfahrung geschuldet ist. ${ }^{1173}$ Die Verteilung der Dienstdauerangaben nach zunehmender Dauer in Jahren, zusammengefasst in 5-Jahres-Blöcke, fällt mit sinkender Tendenz pro fortschreitende Dienstdauer höchst ungleichmässig aus.

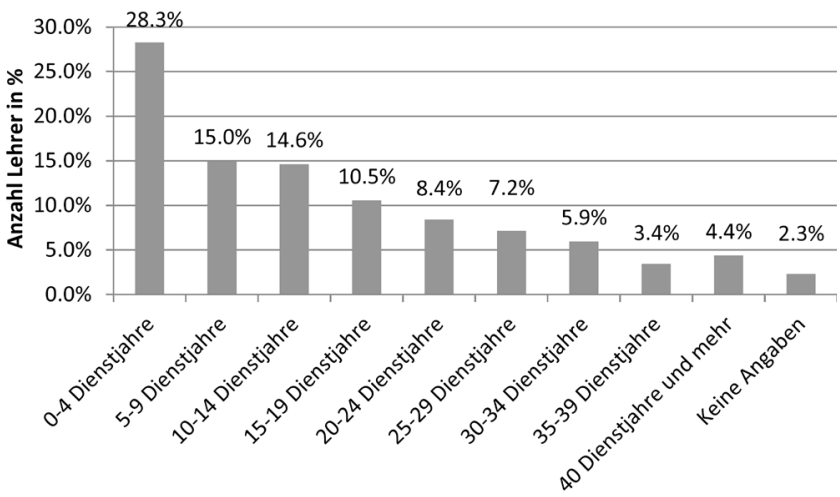

Abb. 14: Verteilung der Lehrer nach Anzahl Dienstjahren

1168 Panchaud, écoles vaudoises: 266.

1169 Brühwiler, Finanzierung: 230; Landolt, Executoren: $19 f$.

1170 Bölsker-Schlicht, Münster: 200ff.

1171 Ruloff, Schulbesuch: 118.

1172 Büttner, Schreiben: 89.

1173 Insgesamt 197 Lehrer wiesen eine Dienstdauer von weniger als einem Jahr aus, wobei die erwähnten $2.3 \%$ an Lehrkräften ohne genaue Dienstangaben nicht inkludiert sind. 
Insgesamt 28.3\% aller Lehrkräfte waren als relativ grösste Gruppe bis zum Frühjahr 1799 - unabhängig von ihrem Alter - erst seit weniger als fünf Jahren als Lehrer tätig und standen somit mutmasslich noch nicht lange in ihrem Amt. Auf den ersten Blick hatte somit ein markanter Anteil an Lehrern noch keine langjährige Unterrichtserfahrung. Doch ist die kausale Schlussfolgerung, dass die relative Mehrheit der Lehrkräfte erst kurzzeitig im Amt stand, aus mehreren Gründen unvollständig. Die relative Häufung von Dienstdauerangaben unter fünf Jahren ist einerseits nicht monokausal auf die zuvor angesprochenen Berufsanfänger mit weniger als einem Jahr an Diensterfahrung zurückzuführen, denn neben den bereits erwähnten $8.5 \%$ an Neueinsteigern dominierten innerhalb der ersten Dienstjahreskohorte vorwiegend Lehrkräfte mit mindestens zwei bis vier Jahren Diensterfahrung. ${ }^{174}$ Dahinter konnte einerseits eine gesteigerte Fluktuationshäufigkeit in den Jahren unmittelbar vor oder nach der Helvetischen Revolution stehen, die es im Anschluss noch zu prüfen gilt. Andererseits konnte eine verstärkte Neueinstellung von zusätzlichen Neben- oder Unterschullehrern in bestehenden Schuleinrichtungen in den Jahren unmittelbar vor der Revolution auf einen bereits laufenden Prozess des Ausbaus von Schulangeboten durch eine gesteigerte Nachfrage nach Elementarbildung vonseiten der Bevölkerung hindeuten.

Zudem war der hohe Anteil an Lehrkräften mit erst wenigen Dienstjahren nicht automatisch gleichzusetzen mit der Anzahl an jungen Lehrkräften von unter 30 Altersjahren. Denn die Lehrkräfte mit weniger als fünf Jahren Diensterfahrung waren zwar im Durchschnitt erst 32.7 Jahre alt und damit wesentlich jünger als der Gesamtdurchschnitt, ${ }^{1175}$ doch waren bloss rund ein Viertel jener Lehrpersonen mit weniger als fünf Jahren Diensterfahrung noch unter 30 Jahre alt und somit noch ,jung“. Ältere Lehrkräfte mit einer kurzen, in zahlreichen Fällen wohl unvollständig angegebenen minimalen Dienstdauer verzerren somit die Darstellung.

Jenem knappen Drittel an Lehrkräften mit verhältnismässig wenigen Dienstjahren standen aber im Umkehrschluss die mehr als zwei Drittel Elementarschullehrkräfte mit einer deutlich längeren Berufserfahrung gegenüber. Mit 29.3\% hatte eine fast genauso grosse Anzahl an Lehrern eine Berufserfahrung von mindestens zwanzig Jahren in ihrer Biografie aufzuweisen, während sich ein weiteres knappes Drittel relativ gleichförmig zwischen fünf und zwanzig Dienstjahren verteilte. In der Helvetischen Republik arbeiteten somit überwiegend Lehrkräfte mit mindestens mehrjähriger bis hin zu langjähriger Berufserfahrung, unabhängig von ihrem Alter zum Zeitpunkt der Erhebung.

Im regionalen Vergleich der einzelnen Kantone waren diesbezüglich nur geringe Unterschiede feststellbar. Zwischen den Mittelwerten der Dienstdauer aus den einzelnen Kantonen bestanden zwar leichte - teilweise überlieferungsbedingte - Differenzen, doch zeichnete sich überall ein simultanes Bild von einer grundsätzlich langjährig ausgeübten Dienstdauer von mindestens zehn Jahren und mehr ab. ${ }^{1176}$ Die Werte der mittleren minimalen Dienstdauer schwankten pro Kanton zwischen 10.6 und 15.8 Jahren. Die katholischen Lehrkräfte wiesen dabei mit 10.8 Jahren eine leicht tiefere mittlere minimale Dienstverweildauer auf als die reformierten Lehrkräf-

1174 Die Dienstdauerangaben von 0-4 Jahren (abzüglich der Lehrkräfte ohne klare Angaben) verteilten sich wie folgt: 0-1 Jahr: 197 Lehrkräfte (30\%); 1-2 Jahre: 93 Lehrkräfte (14\%); 2-3 Jahre: 131 Lehrkräfte (20\%); 3-4 Jahre: 120 Lehrkräfte (18\%); 4-5 Jahre: 111 Lehrkräfte (17\%).

1175 Vgl. die Altersstruktur im Anhang II.

1176 Aargau: 13.5 Jahre; Baden: 13.7 Jahre; Basel: 15.2 Jahre; Bern: 14.1 Jahre; Fribourg: 15.8 Jahre; Léman: 15.4 Jahre; Linth: 10.6 Jahre; Oberland: 12.4 Jahre; Säntis: 12.8 Jahre; Schaffhausen: 15.4 Jahre; Solothurn: 13.5 Jahre; Thurgau: 13.9 Jahre; Waldstätten: 10.7 Jahre; Zürich: 15.8 Jahre; insgesamt: 14.0 Jahre. Der fehlende Mittelwert im Kanton Wallis resultiert aus der unvollständigen oder fehlenden Beantwortung der Frage III.11.f in zahlreichen Fragebogen sowie in der insgesamt geringen Anzahl an überlieferten Antwortschriften. 
te mit durchschnittlich 14.8 Jahren. Diese Disprepanz ist vor allem auf die ungleich kürzere Dienstdauer der katholischen Geistlichen zurück zu führen, da viele Kapläne langfristig eine besser bezahlte und komfortablere Priesterpfründe anstrebten und das Kaplaneiamt bloss als vorübergehendes Moratorium betrachteten. ${ }^{1177}$

Allerdings verlief eine zweite Bruchlinie konfessionsübergreifend zwischen den Agrarzonen des Landes, denn zu den Regionen mit der verhältnismässig niedrigsten mittleren Diensttreue der Lehrerschaft zählten die vor- und inneralpinen Kantone Linth, Oberland, Säntis, Wallis und Waldstätten. Ungeachtet der unterschiedlichen Konfessionszugehörigkeit wiesen die Lehrkräfte des vor- und inneralpinen Hirtenlandes die gesamthaft geringste Neigung zu einem langjährigen Verbleib im Schulamt auf, wenngleich die mittleren minimalen Ausübungsdauerwerte von zehn bis knapp 13 Jahren nur leicht unter dem Gesamtmittel zu liegen kamen und die Differenz in ihrer Bedeutung relativiert werden muss.

Gründe für die leicht schwächer ausgeprägte Berufstreue der vor- und inneralpinen Lehrkräfte gegenüber ihren mittelländischen Berufskollegen sind sowohl in sozioökonomischen als auch in schulorganisatorischen Bereichen zu suchen. Die finanzielle Attraktivität des Lehramtes litt durch den höheren Grad an Armut unter der Bevölkerung des vor- und inneralpinen Raumes und den daraus resultierenden geringeren kommunalen Besoldungsmöglichkeiten für die Schulmeister. Die Gemeinden hatten mit einer grösseren Anzahl an versorgungsbedürftigen Armen zu kämpfen, was die finanziellen Ressourcen für das Elementarschulwesen schmälerte. Zudem konnten die stark schwankenden täglichen Schülerzahlen aufgrund der rauen Witterung und der schwierigen Schulwegverhältnisse in den Berggebieten einen markanten Einfluss auf den Schullohn haben, sofern die Kinder ein Tagschulgeld bezahlen mussten und dieses den Hauptbestandteil des Lehrereinkommens ausmachte. ${ }^{1178}$ Michael Ruloff hat in seiner Studie an zahlreichen lokalen Fallbeispielen nachgewiesen, dass die Länge des Schulweges signifikant negativ mit dem Schulbesuch korreliert hat. Je entfernter die Kinder vom Ort der Schule lebten und je länger ihr Schulweg war, desto schwächer wurde die Schule besucht, was insbesondere in den weit verstreuten Bergsiedlungen der Fall war. ${ }^{1179}$ Das wirkte sich nicht nur auf die Qualität des Unterrichtsbesuchs und auf den Erfolg der Beschulung aus, sondern eben auch auf die Einkommensverhältnisse der Lehrer. Zahlreiche Aussagen in der Stapfer-Enquête untermauern denn auch qualitativ diese Korrelation. Der reformierte Pfarrer Caspar Bernet von Mühlehorn GL berichtete über den Schulbesuch in seiner Gemeinde: „Jtzt in der Winterschule besuchen die Schule aufs meiste 26. Kinder. [...] Es könnten und sollten aber in die 60ig Kinder zur Schule kommen. Allein die wichtigsten Hindernisse sind:

1. Vie: Elltern brauchen ihre Kinder zu andern Geschäften bey Hause.

2. Das entfernte Wohnen vieler Kinder von der Schule.

3. Schlechtes Anhalten mancher Elltern, ihre Kinder zuschicken.

4. Armuth der Elltern!!! [sic.]“1180

Ähnlich argumentierte der katholische Lehrer Christophorus Götti im nur wenige Kilometer entfernten toggenburgischen Wildhaus SG über den stark schwankenden saisonalen Schulbesuch: "Jn dem Sommer wird in der Schul gehalten, auser an Sonn, und Feyrtagen. An welchen

1177 Vgl. das Kap. 2.2.10.

1178 Vgl. zur Bedeutung des Schulwegs in Bergregionen: Ruloff, Schulbesuch: 102f; ferner auch: Landolt, Linth: 124f.; Luginbühl, Stapfer: 68f.

1179 Ruloff, Schulbesuch: 223.

1180 Schmidt u.a. (Hgg.), Stapfer-Enquête, Nr. 587: Mühlehorn. 
tägen mehrere Kinder in die Schul kommen. nemlich von 6 bis 16 und 17 Jährige; und ware bis anhero eine Anzahle von 30 bis auf 40 Kinder (mehr und weniger.) An den Werchtägen wurde dieselbige weniger besucht, und zwar aus folgenden Ursachen. 1.stens. Wegen der allzu großen Armuth, besonders zu Winterszeit. 2. die schlechte Kleydung. 3. die Weitschichtige Entfernung von dem Schulhause. wurde also zu Winters zeit Besucht. a. von Knaben an der Anzahl. 8. b. von Madchen. 13. ${ }^{“ 1181}$ Neben der verbreiteten Armut der Bevölkerung in den Berggebieten und dem Unwillen der Eltern, die Kinder regelmässig in die Schule zu schicken, waren zusätzlich schulorganisatorische Gründe von verstärkend fluktuationsfördernder beziehungsweise Dienstdauer-hemmender Wirkung auf die Lehrerschaft im vor- und inneralpinen Raum. Die allgemeine Armut und ein gewisses Desinteresse der Bevölkerung an der Elementarbildung ihrer Kinder blieben jedoch keineswegs auf den alpinen Wirtschaftsraum beschränkt, sondern wurden auch in den übrigen Regionen der Helvetischen Republik fast unisono als Hemmnisse der Schulentwicklung beklagt.

Eine signifikante Rolle spielte aber im inner- und voralpinen Raum die Ausgestaltung des Lehrerwahlrechts, das wiederum von der ehemaligen Herrschaftsform abhängig war. Entscheidend war, wer die Hoheit über das Wahlrecht des Lehrers innehatte, wie es ausgeübt wurde und wie lange die Anstellung des Lehrers ihre Gültigkeit besass. So mussten sich beispielsweise im Kanton Appenzell Innerrhoden die gewählten Lehrer periodisch einer Prüfung durch den grossen zweifachen Landrat unterziehen und konnten jederzeit abgesetzt werden. ${ }^{1182}$ Noch prekärer stand es um die personelle Kontinuität in jenen Schulorten, wo ausschliesslich die Gemeinden das Wahl- oder Bestätigungsrecht innehatten beziehungsweise ebendieses Wahlrecht von der Kirche und der Obrigkeit in langjährigen Aushandlungskämpfen in den Bereich der Lokalautonomie der Kommunen überführen konnten. Mit Ausnahme des ehemaligen Untertanengebiets des Berner Oberlands, wo fast überall die lokalen Pfarrer in Zusammenarbeit mit den Dorfvorgesetzten oder der lokalen Obrigkeit die Lehrer bestätigt hatten, dominierte die direkte Wahl des Schulmeisters durch die Gemeindemitglieder in offener oder geheimer Mehrheitswahl im gesamten übrigen vor- und inneralpinen Raum der Kantone Wallis, Waldstätten, Linth und Säntis. ${ }^{1183}$ Gemeinsam ist den drei letztgenannten neuen Kantonen zudem, dass sie - im Gegensatz zum ehemaligen Untertanengebiet des Berner Oberlands - entweder aus ehemaligen Landorten oder ehemaligen Gemeinen Herrschaften beziehungsweise zugewandten Orten bestanden.

Allerdings bewirkte die alleinige Wahlhoheit der Gemeinde alleine noch keine generell verkürzte Dienstdauer, wohl aber in Kombination mit einer beschränkten Geltungsdauer der Amtsbestätigung gegenüber dem Schulmeister. Wo die Wahl des Lehrers nach dem bestandenen Examen nicht dauerhaft oder bis auf Widerruf geschah, sondern der Lehrer jährlich oder zumindest in regelmässigen Abständen neu um sein Amt anhalten musste, wuchs die Wahrscheinlichkeit auf eine willkürliche Abwahl markant, was sich wiederum verkürzend auf die Dienstdauer der Lehrerschaft auswirkte. So wurden etliche Schulmeister des Glarnerlandes, in einzelnen Gemeinden der ehemaligen Fürstabtei St. Gallen sowie in vereinzelten Orten der Zentralschweiz

1181 Schmidt u.a. (Hgg.), Stapfer-Enquête, Nr. 521: Wildhaus.

1182 Grosser, Appenzell Innerrhoden: 12f.

1183 Das ausschliesslich den Gemeindegenossen zugestandene Lehrerwahlrecht bestand zwar bereits als altes Kommunalprivileg im Ancien Régime, in einigen Gemeinden wurde die öffentliche Wahl des Schulmeisters durch die Gemeinde allerdings erst mit der Helvetischen Revolution als Neuerung eingeführt. Der Lehrer von St. Josefen SG beschrieb seine Wahl: „Den Schullehrer hat bestelt: Officialis von St. Gallen. bis anno 1797. Von da haben mich die Gemeinds-Hausväter an der jährlichen Gemeinds Versamlung, und seithero bestättet." Schmidt u.a. (Hgg.), Stapfer-Enquête, Nr. 1166: St. Josefen. 
nicht nur ausschliesslich durch die Gemeinde gewählt, sondern unterstanden zudem dem jährlichen Urteil der Dorfgenossen, dem sie sich teilweise jedes Jahr von neuem aussetzen mussten. ${ }^{1184}$ Besonders ausgeprägt trat die Kombination von ausschliesslich kommunaler Wahlhoheit mit annueller Bestätigungspraxis in den ehemals Gemeinen Herrschaften und Untertanenlanden der Ostschweiz auf, insbesondere in den neuen helvetischen Distrikten Ober- und Unterrheintal, Werdenberg, Wald, Flawil und Schänis in den neuerschaffenen Kantonen Linth und Säntis. Die Praxis der jährlichen Wiederbestätigung beziehungsweise die Neuwahl des Schulmeisters fand dabei bei beiden Konfessionsgruppen gleichermassen statt und war daher kein konfessionelles, sondern ein regionales Phänomen einer schwachen obrigkeitlichen Herrschaftsdurchdringung auf die kommunale Ebene. In jenen Gemeinden mussten die Lehrer jedes Jahr von neuem mit einer „schmeichlerischen Ansprache“ vor der Dorfversammlung um das Lehramt anhalten, was die personelle Kontinuität und damit die Verweildauer der Lehrer im Amt gegenüber Regionen mit fixen Wahlmodellen teilweise reduzierte. ${ }^{1185}$

Eine exemplarische quantitativ-empirische Auswertung der Generaltabellen der Distrikte Unter- und Oberrheintal im Kanton Säntis bestätige denn auch eine leicht verminderte mittlere minimale Dienstdauer gegenüber dem Mittelwert des gesamten Kantons für beide Konfessionsgruppen. ${ }^{1186}$ Auch im Obwaldner Distrikt Sarnen und im französischsprachigen Teil des Wallis war die temporäre oder jährliche Neu- beziehungsweise Wiederwahl des Lehrers eine verbreitete Praxis. In der katholischen Zentralschweiz und im Wallis bewirkte jedoch die verbreitete Übertragung des Lehramtes an die geistlichen Kapläne einen zusätzlich höheren Fluktuationsgrad und eine eher kürzere Dienstdauer. Auch hier wurden die Kapläne in der Regel von den Gemeinden erwählt.

In den übrigen ehemals Gemeinen Herrschaften, aber auch in den städtischen Untertanengebieten des Mittellandes, trat die Form der kommunalen annuellen Lehrerwahl hingegen nur vereinzelt und ohne spezifische geografische Häufung in Erscheinung. Einzig in den ostschweizerischen Kantonen Schaffhausen und Thurgau wies je rund ein Dutzend Schulorte ebenfalls eine annuelle Bestätigungspraxis des Lehrers auf, ohne dass freilich ein räumliches Muster erkennbar gewesen wäre. Zwar existierten überall in der Helvetischen Republik vereinzelt befristete Anstellungen der Lehrkräfte auf der Basis von ein- oder mehrjährigen Kontrakten, die Kombination von kommunaler Wahlhoheit und annueller Wiederwahlpraxis beschränkte sich räumlich jedoch deutlich auf den inneralpinen Raum sowie auf die Ostschweiz und war damit weitgehend deckungsgleich mit den relativ tiefen Dienstdauermittelwerten jener Kantone.

Die möglichen negativen Folgen dieser jährlichen Bestätigungspraxis durch die Gemeinden, insbesondere die fehlende personelle Kontinuität und die damit einhergehende fehlende individuelle Schulentwicklung aus der persönlichen Beziehung zwischen Pfarrer und Lehrer blieben nicht unbeachtet. Den kritischen Anmerkungen des katholischen Pfarrers Anton Specker von St. Margrethen SG kann exemplarisch entnommen werden: „Jch glaube nicht, daß ein Ort zu finden, wo die Schule schlimmer bestellet ist als hier. denn es ereignet sich, daß Jedes Jahr ein anderer Lehrer von der Gemeinde durch das Mehr gewählet wird, der etwas schreiben und lesen

1184 In wenigen Fällen wurde das Bestätigungsintervall auf zwei bis drei Jahre ausgedehnt. Vgl. beispielhaft: Schmidt u.a. (Hgg.), Stapfer-Enquête, Nr. 537: Berschis; Nr. 1198: Kirchberg.

1185 Vgl. Baumann, Alltag: 70; Landolt, Linth: 153.

1186 Im Distrikt Oberrheintal betrug die mittlere Dienstdauer im Jahr 1800 beispielsweise nur 10.8 Jahre und im Distrikt Unterrheintal 9.0 Jahre, im gesamten Kanton Säntis jedoch 12.8 Jahre. StASG HA R 132, Fasz. 1, o. Pag.: [1800] - District Unter Rheintal; StASG HA R 132, Fasz. 1, o. Pag.: [1800] - District Unter Rheintal catholischer Religion; StASG HA R 132, Fasz. 1, o. Pag.: [1800] - District Ober Rheintal; StASG HA R 132, Fasz. 1, o. Pag. [1800] - evangelischen Schulen in dem District Oberrheintal. 
Kann. Jch bin nunn im 3ten Jahre hier, und hab schon 2 unterschiedene Lehrer erlebt. Jch drang gleich beym Antritt dieser Pfarre darauf, man möchte doch einen Jungen wizigen Menschen, der fähig ist, anderwerts unterrichten Lassen erstl. im Lesen, dann schreiben, und auch rechnen. Aber alles war umsonst. Nunn bin ich genöthiget zu bitten mich hiereinfals zu unterstüzen. Freylich ist der fond nicht hinlänglich für einen Tüchtigen Mann. Allein man Könnte ihm etwa eine Anweisung auf gut, oder feld machen."1187

Neben der fehlenden personellen Kontinuität liess das annuelle Wahlrecht der Gemeinden die Schulmeister bisweilen zu einem Spielball in kommunalen Machtkonflikten werden. So zeigt die summarische Antwort des katholischen Pfarrers von Altstätten SG auf die Stapfer-Enquête zur katholischen Schule in Vorder Chornberg SG im Rheintal: „Der Schullehrer a. wurde bisher von den Rhodgenoßen, b. so ganz willkürlich bestellt, daß beynahe c. alle Jahre ein andrer auftritt; je d. nachdem die einte, oder anderte Fakzion [sic] gesiegt. Man übergeht daher zuversichtlich die unbedeütende Schilderung des wirklichen Schullehrers, der erst diesen Winter durch zu unterrichten angefangen. ${ }^{1188}$ Mitentscheidend für die jährliche (Wieder-)Wahl des Lehrers waren daher nicht nur seine Fähigkeiten, sondern oft auch die willkürliche, zufällige Laune der Dorfversammlung und sachfremde Gründe wie das Bürgerrecht, ob die bewerbenden Personen armengenössig waren oder die persönlichen Beziehungen zu den Dorfmagnaten, was besonders auswärtige Kandidaten abschreckte. ${ }^{189}$

Allerdings waren in der empirischen Bestandesaufnahme auch in Gemeinden mit jährlicher Wiederwahlpflicht mitunter Lehrkräfte zu finden, die trotz der annuellen Wiederbestätigungspflicht bis zu über dreissig Jahre lang Schule gehalten hatten, was die zuvor geäusserte Kritik der Pfarrer empirisch stark relativiert. ${ }^{1190}$ Es war also durchaus möglich, selbst unter diesen als willkürlich beschriebenen Umständen das Lehramt in einer langfristigen Perspektive auszuüben. Das bedeutet zum einen, dass sich einzelne Schulmeister durchaus mit den gegebenen Umständen erfolgreich arrangieren konnten, ohne dass sich diese nachteilig auf ihre Berufsausübung ausgewirkt hätten. Ebenso bedeutet der Befund von zahlreichen langjährigen Wiederanstellungen zum anderen, dass längst nicht alle Gemeinden willkürlich handelten, sondern sich in der Regel von einer kollektiven Rationalität leiten liessen und offensichtlich in vielen Fällen mit der Leistung ihrer Schulmeister grundsätzlich zufrieden gewesen waren.

Die überlieferte Kritik vonseiten der Pfarrer an der jährlichen Wiederwahlpraxis ist demnach zum anderen im Kontext der Machtkämpfe um die Bestimmungshoheit im Elementarschulwesen zu deuten. Sie ist denn auch vor allem als ein Ausdruck des Einflussverlusts vonseiten der kirchlich-obrigkeitlichen „Verlierer“ gegenüber den Kommunen zu lesen und die Kritik an der jährlichen kommunalen Wahlpraxis zielte wohl vor allem darauf, im neuen zentralistisch organisierten Staatswesen die an die Gemeinden verlorenen Kompetenzen der Bestimmungshoheit im elementaren Schulwesen wiederzuerlangen. Die Praxis des annuellen direktdemokratischen Wahlrechts der Gemeinden unter gänzlichem Ausschluss der Pfarrer ist in ihrer Wirkung auf die Dienstdauer und die personelle Kontinuität der Lehrkräfte zwar insgesamt als ambivalent zu beurteilen, da sie Missbrauch und Willkür vonseiten der Gemeinden zwar tendenziell eher er-

1187 Schmidt u.a. (Hgg.), Stapfer-Enquête, Nr. 1267: St. Margrethen.

1188 Schmidt u.a. (Hgg.), Stapfer-Enquête, Nr. 1321: Vorder Chornberg.

1189 Baumann, Alltag: 70.

1190 Beispielsweise sei auf die reformierten Lehrer der Kirchgemeinde Thal SG verwiesen, die - mit einer Ausnahme trotz der jährlichen Antragspflicht zwischen 26 und 31 Dienstjahre aufgewiesen haben. Schmidt u.a. (Hgg.), Stapfer-Enquête, Nr. 1269: Thal, Buechberg, Buriet, Buechen. 
möglichte als unter der Mitsprache der Pfarrer, in der Realität vor Ort funktionierte das Modell jedoch weitgehend und verhinderte langjährige Lehrerkarrieren keineswegs.

Neben der ambivalent wirkenden und beurteilten Wahlpraxis war ferner das Moment der Schulgründung für die mittlere Dienstdauer der Lehrkräfte von bedeutender limitierender Relevanz. Etliche der Schulen, insbesondere die zahlreichen Nebenschulen in den weitläufigen Kirchspielen der voralpinen Gegenden, entstanden erst im letzten Drittel des 18. Jahrhunderts, manche Schulen sogar erst in den Jahren unmittelbar vor der Helvetischen Revolution. ${ }^{1191}$ Folglich ist die Dienstdauer der dort unterrichtenden Lehrkräfte - sofern sie nicht schon zuvor an einem anderen Ort unterrichtet hatten - unter anderem vom Gründungsmoment der Schule bestimmt worden und konnte in manchen Fällen noch gar nicht langjährig sein.

Sämtliche Forschungen, die sich bislang mit der Dienstdauer der helvetischen Lehrer beschäftigt haben, betonen gleichermassen die Gleichzeitigkeit zwischen eben erst ins Amt gekommenen Lehrern und bis zu über sechzig Jahre lang tätig gewesenen Schulmeistern, was jedoch dem fotografischen Charakter der Quelle als Momentaufnahme geschuldet ist. Der zum Zeitpunkt der Umfrage am längsten im Amt stehende Lehrer der Helvetischen Republik war der 77-jährige Salomon Wildermuth, Lehrer im Landstädtchen Grüningen ZH, mit einer Dienstdauer von insgesamt „60. jahr, und etlich Monnat. ${ }^{\text {“192 }}$ Neben der enormen Bandbreite der Dienstdauer vom eben erst zum Lehrer ernannten Einsteiger bis zum Lehrer mit über sechzig Jahren Berufserfahrung sorgt der Miteinbezug der vielen jungen Lehrkräfte in eine momentbezogene Durchschnittsberechnung für eine gewisse Verzerrung des mittleren Dienstalters nach unten, zumal jüngere Lehrer naturgemäss eine weniger lange Dienstdauer aufweisen konnten als alte Lehrer. Ein höherer Anteil an jungen Lehrkräften im Lehrerkorps bedeutete jedoch nicht automatisch eine niedrigere mittlere Berufserfahrung, wenn gleichzeitig auch das Amtsübernahmealter tief war. So wiesen beispielsweise die Lehrkräfte des Kantons Léman trotz eines überdurchschnittlich hohen Anteils an unter 30-jährigen Lehrkräften von 28\% eine ebenso hohe mittlere Berufserfahrung aus wie die Lehrkräfte der Kantone Basel und Schaffhausen, deren Amtseinstieg im Durchschnitt deutlich später erfolgt war. ${ }^{193}$

Die Altersstruktur der kantonalen Lehrerkorps war somit nur zweitrangig, denn ein erst dreissigjähriger Lehrer konnte bereits seit mehr als zehn Jahren in seinem Beruf tätig sein, sofern er bereits seit seiner Jugend als Lehrergehilfe gearbeitet hatte. Jedoch konnten ältere Quereinsteiger mit einer geringen Diensttreue die Werte in die andere Richtung verzerren. Eine Untersuchung der mittleren Dienstdauer ohne eine altersdifferenzierte Berücksichtigung der unterschiedlichen Altersgenerationen ist demnach nur von beschränktem Aussagegehalt. ${ }^{1194}$ Vielmehr muss die minimale mittlere Dienstdauer generationenspezifisch und unter Ausschluss der jüngsten Lehrkräfte untersucht werden, um die wirkliche Diensttreue der älteren Lehrkräfte abschätzen zu können. Stratifiziert nach Zehn-Jahres-Alterskohorten zum Zeitpunkt der Umfrage offenbart sich eine kontinuierliche, fast linear zunehmende mittlere Diensttreue von fünf bis acht Dienstjahren pro fortschreitendes Altersdezennium der Lehrkräfte.

1191 Bloch Pfister, Priester: 172. Als Beispiel für eine Schulgründung einer Nebenschule unmittelbar vor 1798 sei auf die Schule von Tann ZH verwiesen: Schmidt u.a. (Hgg.), Stapfer-Enquête, Nr. 474: Tann.

1192 Schmidt u.a. (Hgg.), Stapfer-Enquête, Nr. 472: Grüningen.

1193 Vgl. zum Amtsübernahmealter das Kap. 2.2.

1194 Das gilt besonders für die zuvor angesprochene Darstellung der „Années de service des régents en fonctions en 1799“ bei Georges Panchaud, wo ebendiese Altersdifferenzierung fehlt. Vgl. Panchaud, écoles vaudoises: 266. 
Tab. 25: Mittlere Dienstdauer der Lehrer nach Altersgruppen

\begin{tabular}{lrcc}
\hline Altersgruppe: & Anzahl Lehrer: & Anteil in Prozent: & Anzahl Dienstjahre: \\
\hline Unter 30-Jährige & 422 & $18.3 \%$ & 3.2 \\
30-39-Jährige & 563 & $24.4 \%$ & 8.2 \\
40-49-Jährige & 532 & $23.1 \%$ & 13.7 \\
50-59-Jährige & 441 & $19.1 \%$ & 20.9 \\
60-69-Jährige & 252 & $10.9 \%$ & 28.5 \\
Über 70-Jährige & 65 & $2.8 \%$ & 35.6 \\
Keine Altersangabe & 30 & $1.4 \%$ & 6.3 \\
\hline Total Lehrkräfte & 2.305 & $100 \%$ & 14.0 \\
\hline
\end{tabular}

Die mittlere minimale Anzahl an Dienstjahren aller über dreissigjährigen Lehrkräften, die insgesamt $80.4 \%$ des gesamten helvetischen Lehrerkorps ausmachten, lag bereits bei 16.5 Jahren und somit rund zweieinhalb Jahre über dem Gesamtmittel aller Lehrkräfte. Die über Fünfzigährigen wiesen dagegen eine mittlere minimale Diensttreue von 24.7 Jahren auf, der Medianwert lag noch höher bei rund 26 Dienstjahren. Bei den ältesten, über siebzigjährigen Lehrern konnte gar eine mittlere minimale Dienstzeit von 35.6 Jahren und einen Medianwert von rund 40 Dienstjahren eruiert werden. Die simple Schlussfolgerung aus den Werten ist, dass, je älter eine Lehrperson zum Zeitpunkt der Umfrage war, desto länger hatte sie bereits im Schuldienst gestanden.

Die markante Differenz zwischen dem arithmetischen Mittel und dem ungleich höheren Medianwert ist bei den über Fünfzigjährigen auf minimierende Verzerrungen der Mittelwerte durch ältere Quereinsteigende in das Lehramt zurückzuführen. Der vermutlich älteste Quereinsteiger war zum Zeitpunkt der Umfrage mit 64 Altersjahren der Lehrer Etienne François Contard von Sembrancher VS, der erst seit November 1798 als Lehrer in seiner Gemeinde diente. ${ }^{1195}$ Ein Blick auf die älteste Alterskohorte der über 50-jährigen Lehrkräfte verdeutlicht, dass die älteren Lehrer tatsächlich in kollektivbiografischer Einmütigkeit grösstenteils - in den Worten von Georges Panchaud - „attachés à leur métier“ geblieben und eine grundsätzlich langandauernde, hohe Berufstreue auswiesen.

Tab. 26: Verteilung der Dienstjahre der Lehrer über 50 Jahre

\begin{tabular}{|c|c|c|c|c|c|c|c|c|}
\hline & \multicolumn{8}{|c|}{ Anzahl Dienstjahre: } \\
\hline & $0-4$ & $5-9$ & $10-14$ & $15-19$ & $20-24$ & $25-29$ & $30-34$ & $35+$ \\
\hline $\begin{array}{l}\text { 50-jährige und ältere } \\
\text { Lehrer }(N=758) \text { : }\end{array}$ & $70^{1196}$ & 57 & 64 & 63 & 91 & 113 & 124 & 176 \\
\hline $\begin{array}{l}\text { Anteil an Kohorte } \\
\text { in \%: }\end{array}$ & $9 \%$ & $7 \%$ & $8 \%$ & $8 \%$ & $12 \%$ & $15 \%$ & $16 \%$ & $23 \%$ \\
\hline
\end{tabular}

1195 Schmidt u.a. (Hgg.), Stapfer-Enquête, Nr. 2235: Sembrancher.

1196 Es sind zwanzig Lehrkräfte mit unklaren oder fehlenden Dienstdauerangaben mitberücksichtigt, deren Wert in der Berechnungsmethodik auf 0.5 Dienstjahre gesetzt wurde. Der reale Anteil an über fünfzigjährigen Lehrkräften mit weniger als fünf Dienstjahren liegt bei 6.6\% (total 50 Lehrer), wobei der grösste Anteil mit 34 Fällen (68\%) auf die Alterskohorte der 50- bis 59-jährigen Lehrer entfiel. 
Sehr kurzfristige Anstellungen von weniger als fünf Jahren Dauer, die entweder aus unvollständigen Dienstdauerangaben resultierten oder aber im weiteren Sinn als Notoption für den Lehrer oder als Nothandlung der Schulgemeinde bei mangelnden Kandidaten deutbar sind, konnten unter den über fünfzigjährigen Lehrkräften zwar festgestellt werden, allerdings nur in einem bescheidenen Umfang von insgesamt weniger als 10\%. Bloss 16\% aller älteren Lehrkräfte jenseits des fünfzigsten Altersjahrs waren mutmasslich seit weniger als zehn Jahren im Schuldienst tätig gewesen, die deutliche Mehrheit der älteren Lehrkräfte hatte hingegen bereits wesentlich länger im Lehramt gearbeitet. Auf der anderen Seite offenbart sich in der Verteilung der Dienstjahre bei über fünfzigjährigen Lehrkräften eine deutliche Tendenz zu einer sehr langen Dienstausübung. Fast ein Viertel aller Lehrkräfte von über fünfzig Altersjahren stand bereits seit mindestens 35 Jahren im Schuldienst. Des Weiteren arbeitete mehr als die Hälfte der über fünfzigjährigen Lehrer schon seit mindestens 25 Jahren im Lehramt, zwei Drittel immerhin seit mindestens 20 Jahren. Dadurch bestätigt sich, dass der Rückgriff auf alte Menschen aus Not oder aus Mangel eines anderen Kandidaten nur noch in Ausnahmefällen geschah und ältere Quereinsteiger kollektivbiografisch eine klare Ausnahme bildeten, selbst wenn sie eine beliebte Anekdote in älteren Schulgeschichtsbeschreibungen darstellten, um die angebliche Unzulänglichkeit des elementaren Schulwesens zu illustrieren. Für die zum Zeitpunkt der Erhebung „älteren“ Lehrkräfte ab dem fünfzigsten Lebensjahr, deren Dienstbeginn in das letzte Viertel des 18. Jahrhundert fiel, kann somit eine ausgeprägt hohe Berufstreue konstatiert werden. Diese war fast gänzlich unabhängig von schulorganisatorischen oder ökonomischen Determinanten. Zumindest für die vor 1760 geborenen Lehrkräfte war das Lehramt grossmehrheitlich keine berufsbiografische Notoption, in die man sich bei Bedarf flüchtete und in ökonomisch guten Zeiten wieder verliess, sondern die Übernahme des Lehramts bedeutete vielmehr eine prägende biografische Entscheidung von bedeutender Kontinuität bis hin zum Erbprivileg für die Nachkommenschaft, das die Lehrer mithin bis ins hohe Alter behalten werden wollten.

Natürlich weiss man aus diesem statischen Befund nicht, ob nach 1799 in Bezug auf die Dienstausübung ein gegenläufiger Trend einsetzte oder nicht. Ebenso bleibt offen, ob die zum Zeitpunkt der Umfrage noch jungen Lehrkräfte in ihrem biografischen Werdegang am Ende ihrer Berufskarriere ebenfalls eine ähnlich langandauernde Berufstreue aufgewiesen haben wie ihre damals älteren Kollegen, die den Jungen zumindest als potenzielle Vorbilder gegolten haben dürften. Es ist jedoch anzunehmen, dass sich um 1800 auch junge Lehrkräfte angesichts der hohen Berufstreue ihrer älteren Kollegen durchaus in einer langfristig orientierten Perspektive für ihre Tätigkeit interessiert haben dürften, wenngleich man das empirische Ergebnis der älteren Generationen nicht automatisch als direkte Entwicklungsvorlage für die jüngeren Lehrer deuten darf.

In Bezug auf die drei Lebensverlaufstypen sind denn auch klare Unterschiede in der Verweildauer im Lehramt auszumachen. Wenig erstaunlich wiesen die Lehrkräfte mit linearem oder mit linearergänztem Lebensverlauf ohne Ersttätigkeiten die durchschnittlich längste Dienstdauer von rund 17.9 Jahren auf. Die lange Ausübungsdauer ist zum einen auf den bestehenden familiär-dynastischen Charakter des Lehramts in vielen Gemeinden zurückzuführen, indem der Vater dieses so lange wie möglich ausübte, um gleichzeitig seinen Sohn als sicheren Nachfolger aufzubauen. Einzelne zusätzlich angefügte Aussagen von Lehrersöhnen über die Dienstdauer ihrer Väter untermauern die grundsätzlich hohe Diensttreue der Elementarschullehrer in der dynastischen Berufsweitergabe im späten Ancien Régime. So berichtete der Lehrer François David Murisier von Cully VD stellvertretend für zahlreiche Lehrkräfte von der Dienstdauer seines Vaters: „Jl a toujours été voué à la vocation qu'il exerce, son père ayant exercé la même vocation 58 années."1197 
In der Stapfer-Enquête finden sich mühelos mindestens ein Dutzend weitere freiwillig platzierte Angaben über die Dienstdauer von Lehrer-Vätern. Diese beliefen sich etwa in Aesch ZH auf 54 Jahre, in Klingnau AG auf 52 Jahre, in Steineloh TG auf 47 Jahre, in Teufen AR auf 33 Jahre, in Goldbach BE auf 30 Jahre oder in Vinelz BE auf 19 Jahre. ${ }^{1198}$ Nicht nur die zum Zeitpunkt der Umfrage älteren Lehrer von über fünfzig Jahren, sondern bereits ihre Vorgänger hatten das Lehramt grundsätzlich langjährig ausgeübt, bevor sie es an ihre Söhne weitervererbt hatten. Wer das Lehramt einmal als ökonomische Ressource besass, war somit schon im späten Ancien Régime bestrebt, es durch eine langjährige Ausübung zu sichern und seinen Spezialisierungsvorteil wenn möglich in eine familiär-dynastische Tradition zu überführen, wie es auch in anderen Handwerksberufen der Fall war. Damit wurde dem Lehramt als immaterielle Ressource einen nicht unwesentlichen sozialen „Wert“ zugesprochen. Zum anderen ermöglichte der festgestellte, teilweise sehr frühe Diensteinstieg von guten Schülern und direkt ins Lehramt eingestiegenen Personen eine langjährige Ausübung.

Deutlich geringere, wenn auch immer noch langjährige Dienstdauerangaben sind bei kontinuierlich-erweiterten und diskontinuierlichen Lebensverläufen feststellbar. Lehrkräfte, die das Lehramt als biografische Erweiterung ausübten, standen ihrer Schule im Mittel seit rund 12.6 Jahren vor. Lehrkräfte, die sich zur Substitution ihrer Ersttätigkeiten entschieden, standen im Durchschnitt seit 13.8 Jahren im Schuldienst. Selbst die geistlichen Lehrkräfte, die das Lehramt oft bloss aus Pflichtgründen ausführten und - wie die reformierten Geistlichen in der Basler Landschaft - das Lehramt als lebenszyklisch bedingtes Moratorium betrachteten, wiesen eine grundsätzlich langjährige Dienstausübung auf. Reformierte Geistliche waren im Mittel seit 14.6 Jahren im Lehramt tätig. Und auch die katholischen Geistlichen hatten mit durchschnittlich 9.5 Jahren zwar eine geringere Dienstdauer, dennoch lag auch bei ihnen der Trend bei einer eher langfristigen Ausübung. ${ }^{1199}$

Die Langjährigkeit der Dienstausübung lässt sich zumindest nicht kollektiv mit dem Mangel an geeigneten oder willigen Kandidaten erklären, zumal auch Lehrersöhne sich immer öfter in einem Examen beweisen mussten, durch bessere Konkurrenten je nach Wahlpraxis jederzeit um ihr Amt gebracht werden konnten und auch Lehrer ohne familiär-dynastischen Bezug zum Lehramt eine lange Diensttreue aufwiesen. Dabei steckt vor allem in der Besoldungsfrage ein eklatanter Widerspruch, denn die empirisch festgestellte, kollektiv lange Berufsausübung der älteren Lehrergenerationen steht in deutlichem Gegensatz zur vielfach bestätigten prekären Besoldung und den zahlreichen Klagen aus der Hand der Lehrer über ihre angeblichen oder tatsächlich mangelhaften Einkommensverhältnisse.

Mehrere qualitative Beispiele verdeutlichen, dass sich keine direkte Kausalität zwischen dem Einkommen und der Diensttreue ziehen lässt beziehungsweise nicht nur gut besoldete Schulmeister durch eine hohe Berufstreue auffielen. So erhielt der siebzigjährige Lehrer Melchior Kautz von Pfyn TG, der mit 52 Jahren einer der am längsten im Amt stehenden Lehrkräfte der gesamten Helvetischen Republik war, für rund 22-23 Wochen Winterschule nur „dreysig guldin Sat solang die schul dauren thut" ${ }^{1200}$ was nur knapp dem wöchentlichen Mindestlohn von 1.5 Gulden entsprach. Noch weniger verdiente der 73-jährige Lehrer Christen Huser von Wattenwil BE. Trotz 51 Dienstjahren erhielt er für rund zwanzig Wochen Unterricht im Winter und einer Sommerschule von einem Tag pro Woche nur rund 375 Berner Batzen. ${ }^{1201}$ Ebenso wurde der Lehrer Johannis

1198 Schmidt u.a. (Hgg.), Stapfer-Enquête, Nr. 1313: Aesch; Nr. 2284: Klingnau; Nr. 66: Steineloh; Nr. 506: Teufen; Nr. 1356: Goldbach; Nr. 851: Vinelz.

1199 Zur Moratoriumsfunktion vgl. das Kap. 2.2.10.

1200 Schmidt u.a. (Hgg.), Stapfer-Enquête, Nr. 240: Pfyn.

1201 „Das ganze Einkommen belauft sich Jahr für Jahr auf 15. kr." Für die Schulwohnung musste der Lehrer sogar noch 8 kr. Hauszins bezahlen. Schmidt u.a. (Hgg.), Stapfer-Enquête, Nr. 963: Wattenwil. 
Weyer von Unterhittnau ZH trotz 55 Jahren Schuldiensterfahrung bloss mit 3 Pfund und zweieinhalb Mütt Getreide besoldet. ${ }^{1202}$ Entscheidender als die Diensttreue war die jährliche Schuldauer für die Einkommenshöhe. So hielten sämtliche Lehrkräfte mit mehr als 50 Dienstjahren und einem Einkommen von mindestens 100 Franken ihre Schule ganzjährig.

Der marginale Einfluss der realen Einkommenshöhe auf die Dienstdauer spiegelt sich ferner in der Diensttreue der weitaus besser verdienenden zentralörtlichen Lehrkräfte wieder. Im gesamtschweizerischen Durchschnitt standen die zentralörtlichen Schulmeister mit mindestens 15.7 Dienstjahren trotz ihrer bedeutend höheren Löhne nur wenig länger im Dienst als ihre Kollegen auf dem Land.

Tab. 27: Mittlere Dienstdauer der zentralörtlichen Lehrer

\begin{tabular}{lccc}
\hline Altersgruppe: & Anzahl Lehrer: & In Prozent: & Dienstdauer: \\
\hline Unter 30-Jährige & 50 & $15.9 \%$ & 3.1 \\
30-39-Jährige & 67 & $21.3 \%$ & 8.9 \\
40-49-Jährige & 72 & $22.9 \%$ & 14.3 \\
50-59-Jährige & 62 & $19.7 \%$ & 22.3 \\
60-69-Jährige & 40 & $12.7 \%$ & 27.7 \\
Über 70-Jährige & 15 & $4.8 \%$ & 35.7 \\
Keine Angabe & 8 & $2.5 \%$ & 8.7 \\
\hline Total Lehrkräfte & 315 & $100 \%$ & 15.7 \\
\hline
\end{tabular}

Hinsichtlich der mittleren minimalen Dienstdauer der einzelnen Alterskohorten unterscheiden sich die zentralörtlichen Lehrkräfte kaum vom Gesamtkollektiv. Das Sample an zentralörtlichen Elementarschullehrern weist zwar im Gegensatz zu den Landschulmeistern ein leicht höheres Durchschnittsalter von 44.5 Jahren gegenüber 42.9 Jahren für Landschulmeister auf, was sich insbesondere auf den relativen Überhang an über sechzigjährigen Lehrern im zentralörtlichen Umfeld rückführen lässt. In der Diensttreue unterscheiden sich zentralörtliche Elementarschullehrer aber kaum von ihren ländlichen Kollegen und insbesondere die älteren zentralörtlichen Elementarschullehrer neigten ebenso wie ihre Berufskollegen auf dem Land zu einer ausgesprochen langen Berufsausübung, ungeachtet der Frage nach einem allfälligen Fluktuationsverhalten.

Aus der gleichförmigen Diensttreue der zentralörtlichen Lehrer kann ferner geschlossen werden, dass sich - trotz der ungleich grösseren Anzahl an gebildeten Personen - die einmal gewählten Lehrkräfte erfolgreich in ihrer Tätigkeit festsetzen konnten. Sie litten nicht unter einem erhöhten Konkurrenzdruck, obwohl zentralörtliche Schulmeister besser besoldet waren als Landschulmeister und damit für ein konkurrierendes Verhalten der Schulmeister stärker prädestiniert gewesen wären.

Das bei vielen Landschullehrern noch geringe Einkommen aus dem Schuldienst stand aber offensichtlich nicht im Widerspruch zu einer kollektiv langfristigen Ausübung. Gerade die Beobachtung, dass Lehrkräfte mit sehr geringen Löhnen kollektiv eine ebenso lange Dienstausübung aufwiesen wie gut verdienende Lehrer, zeigt die Grenzen von ausschliesslich ökonomisch fokussierten Erklärungsversuchen für das kollektive Berufsverhalten. Folglich müssen nicht-mo- 
netären Anreizen als Erklärungsindizien für die lange Verweildauer von gering verdienenden Lehrkräften im Lehramt eine starke Wirkung zugesprochen werden.

Trotz der vielfach zweifellos ungenügenden monetären Entschädigung spricht die lange Dienstausübung paradoxerweise für einen hohen Grad an Zufriedenheit mit dem Amt, eine hohe intrinsische Motivation für dessen Ausübung beziehungsweise für nicht-monetäre Werte wie soziales Kapital, was das Lehramt langfristig lohnenswert machte. ${ }^{1203}$ Zudem weist die lange Ausübungsdauer auf eine soziale Position innerhalb der Lokalgesellschaft hin, die sich zumindest langfristig nicht nachteilig für die Amtsinhaber ausgewirkt haben dürfte. Denn wäre das soziale Ansehen der Lehrkräfte wirklich derart schlecht gewesen, wie es die zahlreichen älteren Darstellungen beschrieben haben und wäre die reale Einkommenshöhe von entscheidender Wichtigkeit für die Amtsausübung gewesen, wären die Lehrer als rational handelnde Akteure kaum so lange in ihrem Amt gestanden. Vielmehr hätten sie sich ökonomisch und sozial lohnenswerteren Tätigkeiten zur Verbesserung ihrer sozioökonomischen Lage zugewandt.

Die Einstufung des Elementarschullehramtes als temporäres oder bloss lebenszyklisch ausgeübtes Not- und Ausweichgeschäft muss durch das Indiz der ausserordentlich hohen Diensttreue der älteren helvetischen Lehrkräfte als Klischee paraphrasiert werden. Damit sollen einzelne anderslautende Aussagen in der Stapfer-Enquête, die den provisorischen Charakter ihrer Amtsausübung hervorhoben, zwar keinesfalls negiert werden, doch gehören sie angesichts der langen mittleren Dienstausübungsdauer des Kollektivs zum Diskurs einer Minorität. Wichtiger als die reale absolute Höhe des Einkommens aus der Schultätigkeit scheint für die Lehrerschaft die Planbarkeit und Sicherheit des Schuleinkommens gewesen zu sein. Eines der wesentlichen Merkmale einer frühneuzeitlichen Unterschichtenexistenz - die Unmöglichkeit zur langfristigen Lebensplanung - traf somit für die Elementarschullehrerschaft trotz der vielerorts prekären Besoldungslage nicht mehr zu. ${ }^{1204}$

Mit der Annahme des Lehramtes hatte sich die Mehrheit der Lehrkräfte zudem offensichtlich für eine berufliche Spezialisierung entschieden, aus deren Pfadabhängigkeit sie nicht mehr zurücktraten und die von einer Mehrheit in langfristiger Absicht weiterverfolgt wurde, weil sie als einkommenssichere Ergänzungstätigkeit einen positiven Effekt auf die ökonomische Situation der Hauswirtschaft und auf das soziale Ansehen erwirkte.

Zwischen den Geschlechtern zeigten sich bezüglich der mittleren Dienstdauer nur schwache Gegensätze. Die wenigen in der Stapfer-Enquête vermerkten Lehrerinnen stachen im Gegensatz zu ihren männlichen Berufskollegen mit einer leicht geringeren minimalen Dienstdauer von durchschnittlich 9.8 Jahren hervor. Wie bei den Männern variierte auch bei den Lehrerinnen die Anzahl an absolvierten Dienstjahren stark zwischen eben erst im Herbst 1798 eingesetzten Lehrerinnen und Frauen mit mehreren Jahrzehnten an Diensterfahrung. Am längsten im Lehramt stand zum Zeitpunkt der Umfrage die Landschullehrerin Elisabetha Hess-Schlaginhaufen, Witwe des Johannes Hess von Hefenhofen TG, mit rund 36 Jahren Unterrichtsdienst. ${ }^{1205}$ Der Umstand der kleinen Fallzahlen und die teilweise fehlenden Angaben zur genauen Dienstdauer wirken sich in ungleich schwerwiegenderer Weise auf die Aussagekraft der Mittelwerte aus, da rund 10\% aller Lehrerinnen

1203 Vgl. Büttner, Schreiben: 89.

1204 Vgl. Hippel, Unterschichten: 15.

1205 Schmidt u.a. (Hgg.), Stapfer-Enquête, Nr. 75: Hefenhofen. Elisabetha Hess starb allerdings bereits im Jahr darauf, worauf ihr Neffe im Dezember $1800 \mathrm{ihr}$ Schulamt übernahm. Vgl. Widmer, Das thurgauische Volksschulwesen: 116. Zur 50-jährigen Nonne Françoise Giroult von der Ursulinen-Mädchenschule in Estavayer-le-Lac FR wurde zwar eine noch längere Dienstdauer von insgesamt 40 Jahren eruiert, doch scheint sich diese Angabe auf den Eintritt in den Orden zu beziehen und nicht auf die Unterrichtstätigkeit als Lehrerin in der Mädchenschule. 
keine genauen Dienstdauerangaben machten. Die über dreissigjährigen Lehrerinnen standen im Durchschnitt seit mindestens 11.3 Jahren im Dienst, also rund fünf Jahre weniger lang als ihre männlichen Kollegen. Trotzdem kann auch für die wenigen Lehrerinnen aller Alterskohorten analog zu ihren männlichen Kollegen eine grundsätzlich langfristig orientierte Amtsausübung festgehalten werden. Ein möglicher Grund für die leicht tiefere mittlere minimale Dienstdauer der weiblichen Lehrpersonen ist dem Effekt der retardierten Schulgründungen von Mädchenschulen geschuldet, da Mädchenschulen mit Frauen als Unterrichtende in der Regel erst aus der Ausdifferenzierung einer bestehenden gemischtgeschlechtlichen Schuleinrichtung entstanden.

Die festgehaltene relativ lange Diensttreue der älteren Lehrergenerationen in Stadt und Land, bei beiden Konfessionen und beiden Geschlechtern wirft eine Reihe von weiteren Fragen auf. Die Dienstdauer alleine sagt denn noch wenig über den tatsächlichen Verlauf von „typischen“ Lebensverläufen aus, zumal der reine Zahlenwert mögliche berufsbiografische Brüche ebenso kaschiert wie die Frage nach Stellenwechseln während der Lehramtsausübung. Die reale Dynamik hinter der Amtssausübung erschliesst sich erst in einer differenzierten Betrachtung des lehramtlichen Mobilitätsverhaltens. Zuverlässige Indikatoren für die Rekonstruktion der Lebensverläufe als Lehrperson liegen zum Ersten in der geografischen Herkunft als Abgleich für eine lehramtliche Mobilität, zum Zweiten in der Anzahl an Stellenwechseln und zum Dritten in der Häufigkeit von Unterbrüchen während der Dienstzeit. Freiwillige oder erzwungene Stellenwechsel liessen einerseits eine berufliche Mobilität während der Dienstzeit entstehen, andererseits provozierten mannigfache individuell-private oder äussere Faktoren zeitweilige Unterbrüche in der Ausübung der Lehrtätigkeit. Damit verbunden ist zum einen die Anschlussfrage nach der Fluktuationshäufigkeit im helvetischen Lehrerkorps und nach den biografischen Gründen für einen Stellenwechsel oder einen zeitweiligen Unterbruch. Zum anderen muss der als idealtypisch angenommene kontinuierliche Karriereverlauf als Lehrkraft kritisch in Frage gestellt werden, der in etlichen Fällen nicht linear, sondern mitunter diskontinuierlich verlief.

\subsection{Das Mobilitätsverhalten}

Die Vorstellung, dass die ärmeren Menschen in der Frühen Neuzeit im schroffen Gegensatz zur heute noch kaum zu räumlicher Mobilität geneigt, ihr gesamtes Leben stationär „auf dem Dorf“ oder ,in der Stadt“ verbracht und nur Angehörige der Oberschichten überhaupt ein mobiles Verhalten an den Tag gelegt hätten, sind nach wie vor von starker Persistenz im populären, modernisierungstheoretisch geprägten Denken über den gesellschaftlichen Charakter des Ancien Régimes. ${ }^{1206}$ Die jüngere Gesellschaftsgeschichte hat jedoch mit der fortschreitenden Untersuchung der sozialen Unterschichten deutlich herausgearbeitet, dass längst nicht nur Söldner und die ärmsten und teilweise kriminalisierten Angehörigen der sozial Deklassierten wie Bettler, Vagabunden, Prostituierte und Fahrende, sondern auch vermögendere Bevölkerungsschichten stark an räumlichen Wanderungsbewegungen partizipiert hatten. Eine generell erhöhte (Binnen-)Mobilität von eigentumsschwachen und wenig bodengebundenen Bevölkerungsschichten an wirtschaftliche prosperierende Orte sind denn auch in Lokalstudien für diverse Räume der Schweiz nachgewiesen worden, wenngleich die Bewegungsfreiheit der Unterschichten im Ancien Régime vielerorts durch obrigkeitliche oder kommunale Auflagen, wie Hintersassengelder, Einzugsgelder oder einen erschwerten Liegenschaftserwerb, eingeschränkt war und erst die 
Helvetische Republik die gesetzlichen Grundlagen für eine ungehinderte Niederlassung ihrer Bürger schuf. ${ }^{1207}$

Dennoch hatten sich bereits im Ancien Régime vielfältige regionale Mobilitätsmuster herausgebildet. Das räumliche Spektrum der Mobilität reichte von innerdörflich-mikroskaliger Mobilität, Land-Stadt-Wanderungen, interregionaler Migration von Ost nach West bis hin zu temporärer Auswanderung ins Ausland im Rahmen von Solddiensten oder anderen beruflichen Tätigkeiten, dauerhafter Auswanderung in durch Epidemien oder Kriege entvölkerte Gebiete in Europa oder - wenn auch im 18. Jahrhundert erst zögerlich - nach Übersee. Der zunehmende Bevölkerungsdruck, Benachteiligungen durch das Erbrecht oder gar die aktive Abschiebepraxis von Armen durch die Obrigkeit stellten weitere Stimuli für ein mobiles Verhalten dar. ${ }^{1208}$ Räumliche Wanderungen waren somit für viele Menschen des ausgehenden 18. Jahrhunderts eine Sache des Alltäglichen. ${ }^{1209}$ Das gilt auch für die helvetischen Lehrkräfte im Elementarschulwesen, obschon wir zuvor eine grundsätzlich ausgeprägte Lokalrekrutierung, eine starke Diensttreue und die Tendenz zu einer langandauernden Amtsausübung als eher mobilitätshemmende Faktoren konstatiert haben.

Mit dem quantitativen räumlichen und sozialen Mobilitätsverhalten der Elementarschullehrerschaft hat sich die schweizerische Schulgeschichtsforschung insgesamt bislang noch wenig auseinander gesetzt, obwohl die Stapfer-Enquête eine überaus gute Grundlage zur Erforschung des Fluktuations- und Mobilitätsverhaltens bietet. Denn Stapfers Umfrage hielt nicht bloss den geografischen Herkunftsort der Lehrkräfte fest, der mit dem Schulort zum Zeitpunkt der Umfrage verglichen werden kann, sondern - kombiniert mit den Fragen III.11.f und III.11.g zur Dienstdauer und zu den vorherigen Berufstätigkeiten - lassen sich aus den drei Fragestellungen des Fragebogens umfassende individuelle Mobilitätsprofile für jede Lehrkraft rekonstruieren. Eine Rekonstruktion des gesamten biografischen Bewegungsverhaltens der Lehrkräfte bis zum Zeitpunkt der Umfrage schafft gegenüber dem herkömmlich praktizierten Vergleich von geografischer Herkunft und Schulort einen bedeutenden Erkenntnismehrwert. Zum einen lässt sich die Frage der Mobilität nach den biografischen Lebensphasen differenzieren, zum anderen können versteckte Bewegungen innerhalb einer Lebensphase - etwa die Rückkehr an einen Ort oder Unterbrüche - greifbar gemacht werden. Ferner können damit auch die Motive für räumliche Bewegungen sowie deren räumliche Distanz festgehalten werden.

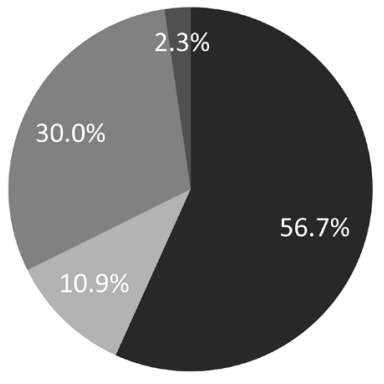

Keine Mobilität

Ersttätigkeitliche Mobilität

- Lehramtliche Mobilität

Mobilität nur zu

Ausbildungszwecken

Abb. 15: Mobilitätsverhalten der Lehrer 1799

1207 Pfister, Strom: 126f.; Schmidt, Handlungsstrategien: 245f.

1208 Pfister, Strom: 129f.; Pfister, Bevölkerungsgeschichte: 44-58; 104-116.

1209 Steve Hochstadt beziffert ländliche Bevölkerungsbewegungen auf 20\% bis 35\% der erwachsenen Personen auf Basis verschiedener Lokalstudien zu Deutschland: Hochstadt, Migration: 209. 
Von den 2.305 erfassten Elementarschullehrern der Stapfer-Enquête machten insgesamt 1.308 Lehrkräfte oder maximal 56.7\% keinerlei Angaben zu einem biografischen Mobilitätsverhalten in irgendeiner Form während ihres bisherigen Lebensverlaufs. Nur wenig mehr als die Hälfte aller Lehrer hatte somit mutmasslich bis zum Zeitpunkt der Umfrageerhebung noch nie für eine längere Zeit ihren Heimatort verlassen und unterrichtete zum Zeitpunkt der Umfrageerhebung immer noch an ihrem Geburtsort. Eine markante Minderheit von mindestens $43.2 \%$ aller Lehrer wies dagegen Formen von zeitweiligem oder dauerhaft mobilem Verhalten in ihrer Biografie auf. ${ }^{1210}$ Davon entfielen allerdings rund ein Viertel der Wanderungsbewegungen ausschliesslich auf die vorschulische Lebensphase vor der Übernahme des Lehramtes. Solddienste im Ausland zählten ebenso dazu wie handwerkliche Ausbildungserwerbe an Orten ausserhalb der Herkunftsgemeinde, ${ }^{1211}$ Gesellenjahre, ${ }^{1212}$ Studienaufenthalte von Geistlichen an Universitäten, Handelsreisen in entfernte Städte, ${ }^{1213}$ der Spracherwerb oder Aufenthalte in fremdsprachigen Landesteilen. ${ }^{1214}$ In den Biografien der Lehrer widerspiegelt sich somit auf den ersten Blick wenig mehr als das Abbild der unterschiedlichen Verhaltensweisen von einzelnen Tätigkeitsgruppen in der heterogenen frühneuzeitlichen Gesellschaft, die durchaus von einem gewissen Mass an räumlicher und zeitlicher Mobilität geprägt war.

So vielfältig die Rekrutierungsbasis der Lehrerschaft war, so vielgestaltig zeigten sich auch deren Biografien hinsichtlich des Mobilitätsverhaltens. Auffällig war unter den erstberuflich mobilen Personen eine stark ausgeprägte Rückkehrmobilität in die Herkunftsgemeinde. Mindestens 59\% aller erstberuflich mobilen Lehrkräfte kehrten nach einer gewissen Zeit in der Fremde vermutlich ganz bewusst - wieder in ihre Herkunftsgemeinde zurück und übernahmen dort im Anschluss das Lehramt. ${ }^{1215}$ In einigen Fällen ist denn auch ein direkter Zusammenhang des Rückkehrzeitpunkts aus der Fremde mit der Vakanz der heimischen Schulstelle bestätigt worden. Der Lehrer von Flawil SG notierte beispielhaft: „in meiner frühen Jugend kamme in die Frömbde, um die Handlung, u Französische Sprach in etwas zuerlernen, bey meiner Heimkunft auf mein Vatter Sälig, auch Schull Lehrer geworden."1216

1210 Bei insgesamt mindestens 997 Lehrkräften konnte anhand der Angaben aus der Stapfer-Enquête eine Lebensphase ausserhalb des genannten Geburtsortes rekonstruiert werden, wovon 252 Bewegungen von ausschliesslich erstberuflicher Natur waren, 53 reine Wanderungen zu Ausbildungszwecken und die übrigen 692 registrierten Bewegungen im Zusammenhang mit der Elementarschule entstanden. Miteinbezogen in die Berechnung des Mobilitätsverhaltens als Lehrkraft sind neben Schulstellenwechseln in andere Schulgemeinden sowohl Schulstellenwechsel innerhalb der gleichen Schulgemeinde, beispielsweise von einer Neben- zu einer Hauptschule oder von einer Hauslehrerstelle an eine öffentliche Schule, als auch ein tägliches Mobilitätsverhalten als „Wanderlehrer" durch das Pendeln zwischen verschiedenen Schulinstitutionen, selbst wenn die Lehrkraft ihren Wohnort als Lebensmittelpunkt räumlich nicht verändert hatte.

1211 „Zwey Jahre in Stein am Rhein, in der Lehrzeit zu einem Beck; 3 Jahre in Winterthur in Condition u. 1 1/2 Jahr in St: Gallen." Schmidt u.a. (Hgg.), Stapfer-Enquête, Nr. 247: Steckborn.

1212 ,vorher war ich außer lands 10. Jahr. Auff Meiner profesion nemlich ein Maurer und Steinhauer bin ich. und hab gearbeitet im Elsas Teütschland Bayern u. so v: "Schmidt u.a. (Hgg.), Stapfer-Enquête, Nr. 2295: Nussbaumen.

1213 "Jch Lernte in Augspurg die Kaufmanschaft vermögers halben aber konte ich sie nicht vortsezen“. Schmidt u.a. (Hgg.), Stapfer-Enquête, Nr. 416: Mitlödi.

1214 "Jst vorher schon im 14ten Jahr seines Alters in Loblicher Stadt Genf gewesen, um die Französische Sprache zu lernen weilen er als Kaufmanns-Bedienter eintretten sollte: und war in dieser Stadt bey einem bekannten Schuhster am Tisch; um zugleich dieses Handwerk zu lernen. Da die Handelschaft sank, und keine neüen Kaufmannsbedienten, begehrt wurden, arbeitete er einige Zeit auf dem Handwerk, auch selbst bey Hause. Bald hernach war er als Schullehrer beruffen." Schmidt u.a. (Hgg.), Stapfer-Enquête, Nr. 320: Kyburg.

1215 Von den 252 hauptsächlich erstberuflich mobilen Lehrkräften kehrten nur 104 oder $41 \%$ bis zum Erhebungszeitpunkt der Umfrage nicht in ihre Herkunftsgemeinde zurück.

1216 Schmidt u.a. (Hgg.), Stapfer-Enquête, Nr. 1144: Flawil. 
Die Rückkehrmobilität traf vorwiegend auf Lehrersöhne zu, aber auch auf die wenigen ehemaligen Söldner, die - sofern sie den Kriegsdienst überlebt hatten - wiederum zuerst in ihrer Heimatgemeinde Fuss zu fassen versuchten. Die von der älteren Forschung eingangs konstatierte hohe Zahl an Ortsansässigen ist an sich zwar nicht falsch, bedeutete aber keineswegs, dass sich die Leute nicht aus ihren Heimatorten fortbewegt hätten. Die rein geografisch orientierten Vergleiche von Herkunftsort und Schulort verdeckten so beispielsweise die markanten Rückkehrbewegungen während der erstberuflichen Tätigkeitsphase.

Drei Viertel aller biografischen Mobilitätsbewegungen entstanden jedoch im hauptsächlichen Zusammenhang mit dem elementaren Schulwesen selbst - entweder zu Ausbildungszwecken zum Lehrer oder zur Ausübung eines vakanten Lehramtes ausserhalb der Herkunftsgemeinde. Mindestens rund ein Drittel aller helvetischen Lehrkräfte hatte sich somit dauerhaft oder zumindest zeitweilig aus hauptsächlich lehramtlichen Gründen an einen anderen Ort aufgehalten. Noch wenig bekannt sind aber die gewählten Pfade von schulberuflicher Mobilität sowie die konkreten Ursachen und Motive für eine zeitweilige oder dauerhafte Veränderung des Wohnund Lebensortes im Zusammenhang mit einer Schulstellenwahl.

In der Terminologie der modernen Migrationsforschung wird oft von vertreibenden „Push“- und anziehenden „Pull-Faktoren“ gesprochen, welche die Entscheidungen des migrierenden Individuums beeinflussen. Frei gewordene oder neu geschaffene Schulstellen mussten etwa neu besetzt werden, wozu geeignete Kandidaten gesucht wurden, die nicht immer aus der unmittelbaren Lokalgesellschaft rekrutiert werden konnten. Wie im Kap. 2.4 bereits dargestellt wurde, mangelte es in den meisten Regionen der Helvetischen Republik zwar selten an lokal verfügbaren willigen Lehramtskandidaten, doch bot eine freie Schulstelle auch etablierten Lehrern von ausserhalb der betroffenen Schulgemeinde mitunter eine Chance auf eine bessere Besoldung oder auf ein neues soziales Lebensumfeld. Freie Lehrerstellen oder Schulneugründungen bedeuteten somit immer auch die Möglichkeit eines Stellenwechsels und bildeten eine Grundlage für eine gewisse berufiche Mobilität in doppelter, horizontal-geografischer als auch vertikal-sozialer Hinsicht.

Daneben existierten Formen von temporärer Mobilität oder von Mobilität ohne Veränderung des Lebensmittelpunktes in den Reihen der Lehrerschaft. So ist etwa die bereits erwähnte lokale Wanderarbeit als „Wanderlehrer“ durch das reihum gehende Umherpendeln zwischen mehreren Dorfgemeinden oder die saisonale grenzüberschreitende Wanderung in eine andere Region, wie beispielsweise die „Hollandgängerei“ im Nordwesten Deutschlands dokumentiert. ${ }^{1217}$ Temporäre oder dauerhafte Mobilität konnte somit eine aktive und innovative Strategie zur Verbesserung der wirtschaftlichen Gesamtsituation sein, sofern es die Umstände notwendig machten. ${ }^{1218}$ Hierzu muss nun untersucht werden, ob und in welchem Umfang ein berufsbiografisch mobiles Verhalten der Lehrkräfte als eine kollektive Aktivstrategie innerhalb der Elementarschullehrerschaft angewandt wurde. Ebenso konnten familiäre oder freundschaftliche Bande zu einer anderen Schulgemeinde oder zum lokalen Pfarrer, eine freie Schulwohnung oder bessere Schuleinrichtungen als anziehende „Pull-Faktoren“ wirken, die es zu untersuchen gilt.

Demgegenüber trieb die Not der Zeitumstände andere Lehrkräfte in die Ferne, was insbesondere für die Revolutions- und Kriegsjahre 1798 und 1799 nicht zu vernachlässigen ist. In den willkürlich-anarchischen Zuständen des Machtvakuums unmittelbar nach der Revolution hatten etliche Lehrkräfte ihre Stelle bei Konflikten mit der Gemeinde verloren. Unzählige Berichte zu Konflikten um die Abwahl oder die Absetzung von Schulmeistern sind denn

1217 Trossbach, Agrargesellschaft: 117ff. Vgl. zum Anteil an „Hollandgängern“ im Lehramt im Niederstift Münster: Bölsker-Schlicht, Münster: 197-201.

1218 Trossbach, Agrargesellschaft: 118. 
auch in den kantonalen Archiven dokumentiert. ${ }^{1219}$ Daneben waren wirtschaftliche Armut, eskalierte soziale oder politische Konflikte am bisherigen Wohnort und die Hoffnung auf bessere Lebensumstände und mehr Lebensqualität die zentralen Faktoren, die vielerorts in Europa die Menschen in „pushende“, räumliche Bewegung versetzten. Ferner konnten auch viele Lehrersöhne nicht einfach als Hilfsschulmeister des Vaters auf dessen Ableben warten, wenn sie zeitgleich einen eigenen Hausstand gründen wollten, die Schulpfrund aber bloss für den Erhalt einer Haushaltung ausreichte. Entsprechend zog es gerade viele Lehrersöhne an ortsfremde Schulen, wo sie in der Folge auf eine mögliche Rückkehr an den Herkunftsort warteten und in der Fremde arbeiteten, bis zu Hause die Arbeitsstelle oder zumindest das elterliche Heimwesen frei wurde.

In einem ersten Schritt muss die Frage geklärt werden, wie viele freie Schulstellen überhaupt als initiierender „Pull-Faktor“ für eine Wanderungsbewegung bestanden. Erst von dieser Ausgangslage kann anschliessend untersucht werden, wie oft und mit welchen Motiven Lehrkräfte an eine andere Schulstelle gewechselt haben.

\subsubsection{Die Fluktuationsquote}

Trotz der limitierten Informationsdistribution und der zuvor festgestellten grundsätzlich langen Verweildauer der Lehrkräfte im Lehramt stellte das Elementarschulwesen einen Arbeitsmarkt dar, der durchaus von personellen Veränderungen geprägt war. Diese Dynamiken sollen in der Folge untersucht werden, denn sie werfen eine Reihe von neuen Fragen auf: Wie viele Lehrer mussten überhaupt pro Jahr neu berufen werden? Entwickelten die politischen Umwälzungen der Helvetischen Republik eine erhöhte Dynamik innerhalb des Lehrerkorps, entstanden gar zeitlich-räumliche Konjunkturen des Schulstellenwechsels? Wurden jüngere oder besser gebildete Lehrkräfte bei Neubesetzungen bevorzugt? Gab es lokale oder regionale Treibkräfte oder gar fluktuationsfördernde Strukturen im Elementarschulwesen? Verliessen einzelne Professionsgruppen das Lehramt in kollektiver Weise wieder?

Die Forschungslage präsentiert sich hierzu noch als sehr disparat. Im Kanton Waadt mit seiner ausgesprochen mobilen Lehrerschaft lag die Fluktuationsrate im kantonalen Lehrerkorps während der vier ersten revolutionären Jahre bei rund $17 \% .{ }^{1220}$ Andere ältere Schulgeschichten betonen jedoch einen markanten Anstieg an willkürlich abgesetzten Schulmeistern im ersten Revolutionsjahr 1798 durch das entstandene politische Vakuum und die mangelnde Autorität der neuen Behörden gegenüber den Gemeinden. Zudem hätten in den Folgejahren viele Lehrkräfte den Schuldienst aus Unzufriedenheit mit der helvetischen Regierung, aus Konsternation angesichts der teilweise verschlechterten finanziellen Verhältnisse oder aus persönlicher Resignation angesichts der unsicheren Zeiten quittiert. ${ }^{1221}$ Entsprechend scheinen die Jahre der Helvetischen Republik generell von einer erhöhten Fluktuationskonjunktur geprägt gewesen zu sein und stellen einen denkbar problematischen Betrachtungszeitpunkt dar.

Da die Stapfer-Enquête als zeitliche Momentaufnahme keine direkte Einschätzung der realen Fluktuation im Elementarschulwesen erlaubt, muss wiederum auf zeitnahe Quellen aus Regio-

1219 Einige Streitfälle zogen sich bisweilen über Jahre hinweg. Beispielhaft sei der Fall des ehemaligen Lehrers Salomon Wyss von Biglen BE genannt, der im Jahr 1798 abgesetzt wurde, aber hartnäckig bis mindestens ins Jahr 1801 durch zahlreiche schriftliche Eingaben beim Berner Erziehungsrat eine finanzielle Wiedergutmachung und eine neue Schulstelle zu erstreiten versuchte. Vgl. StABE B III 906, o. Pag.: 13.06.1801 - Wyss.

1220 „En quatre ans, plus de septante de tous les âges [von 417 Lehrern].“ Panchaud, écoles vaudoises: 265.

1221 Klinke, Zürich: $32 \mathrm{f}$. 
nalarchiven zur Klärung der Frage nach dem regionalen Bedarf an Schulmeistern als Ergänzung zurückgegriffen werden, die Veränderungen des Lehrerkorps über einen längeren Zeitraum abzubilden vermögen. Anhand von zwei Fallbeispielen aus den beiden regionalen Schulumfragen von Basel und St. Gallen werden im Vergleich der Personalangaben mit der Stapfer-Enquête denn auch Einblicke in die Häufigkeit von Neubesetzungen von Schulstellen möglich. Eine flächendeckende Beantwortung der Frage Ist jedoch nicht möglich, da in zahlreichen summarischen Quellen zum Schulwesen oftmals die Namen der Lehrkräfte nicht mitnotiert wurden, was einen personellen Vergleich verunmöglicht.

Ein personeller Abgleich der in der reformierten Basler Landschaft tätigen Landschulmeister vom Frühjahr 1798 mit dem Lehrkorps im Frühjahr 1799 ergibt einen Personalwechsel bei fünf von insgesamt 53 Schulen innerhalb des ersten Revolutionsjahres oder eine Fluktuationsquote von knapp 10\%. ${ }^{1222}$ Ausgerechnet einer der angeblich fachlich besten Lehrer der Basler Landschaft, Martin Schneider von Langenbruck BL, hatte dabei seinen Dienst zugunsten einer Distriktgerichtsschreiber-Stelle quittiert. Der Langenbrucker Pfarrer urteilte 1798 über ihn: „Seine Tüchtigkeit ist so bekannt, daß nicht nötig viel davon zu sagen; diß einzige ist genug; wenn alle Schulmeister solche Geschicklichkeit für den Unterricht im Lesen, Schreiben, Rechnen und Sin-

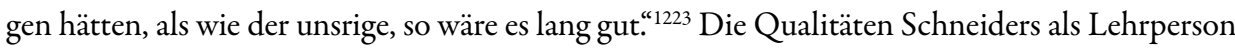
stachen ferner bei den Ergebnissen der Schülerexamen deutlich heraus, wo seine Schulkinder hervorragende Lese- und Schreibkenntnisse aufwiesen. ${ }^{1224}$ Im neuen Verwaltungsapparat eröffneten sich allerdings durchaus attraktive berufliche Alternativen für einzelne begabte Lehrkräfte. Sein Nachfolger wurde nach einem kurzen Intermezzo der 25-jährige Martin Jenny, ein begabter ehemaliger Schüler Schneiders. ${ }^{1225}$ Eine weitere Schulstelle wurde durch den Tod des Vorgängers ledig, drei weitere Stellen durch ungeklärte Abgänge, obwohl zwei der drei Abgehenden noch im Jahr 1798 das Vertrauen der Gemeinde genossen und die Schule also wohl freiwillig verlassen hatten. ${ }^{1226}$ Eine Schule, die Kinderschule von Tecknau BL, geleitet durch die Lehrerin Anna Schäublin, wurde dagegen 1799 nicht mehr gehalten. ${ }^{1227}$ Drei der fünf neuen Lehrer waren zwar jünger als ihre Vorgänger, doch nur der erwähnte Martin Jenny war noch unter 30 Jahre alt. Knapp 10\% der baselländischen Lehrerschaft erneuerte sich somit binnen des ersten Revolutionsjahres, wobei die neu zu besetzenden Stellen vorwiegend mit lebenserfahrenen Männern von über 30 Altersjahren und nicht mit jungen Kandidaten besetzt wurden.

In einem etwas längeren Zeitabschnitt zwischen den Jahren 1799 und 1803, vergleichbar mit Georges Panchauds zuvor zitierten Zeitraum, erfolgten bei 12 von insgesamt 47 Schulen ein Wechsel des Lehrers - also bei 25\% der Schulen. Dabei waren bloss vier der zwölf neuen Lehrer unter 30 Jahre alt gewesen, ansonsten erhielten wiederum ältere, erfahrene Männer der mittleren Alterskohorte in der Basler Landschaft den Vorzug. Fast alle dieser neuen Lehrer wurden jedoch in ihren Fertigkeiten als gut bis sehr gut beschrieben, erfüllten somit die in sie gesteckten

1222 StABL AA 1012, Lade 200, 07.01.01, fol. 1-314: [1798] - Bericht. Fluktuationen fanden bei den fünf Schulen Langenbruck BL, Münchenstein BL, Oberdorf BL, Rickenbach BL und Rünenberg BL statt.

1223 StABL AA 1012, Lade 200, 07.01.01, fol. 132: 27.03.1798 - Bericht.

1224 Vgl. Rothen, Lesen.

1225 Schmidt u.a. (Hgg.), Stapfer-Enquête, Nr. 2228: Langenbruck. Eine Probeschrift Martin Jennys, die seine Qualitäten im Schönschreiben dokumentiert, liegt im Staatsarchiv Baselland in den Examensakten zur definitiven Bestätigung Jennys im Frühjahr 1801: StABL AA 1012, Lade 200, 07.01.01, o. Pag.: 17.04.1801 - Probeschrift.

1226 Einzig der abgegangene Lehrer von Rünenberg hatte das Vertrauen der Gemeinde nicht besessen. StABL AA 1012, Lade 200, 07.01.01, fol. 247: 16.03.1798 - Bericht.

1227 StABL AA 1012, Lade 200, 07.01.01, fol. 217: [1798] - Bericht. 
Erwartungen. ${ }^{1228}$ Hinsichtlich der Ersttätigkeiten der abgetretenen und neuen Lehrkräfte ist jedoch keine spezifische Ablösungsbewegung einer bestimmten Professionsgruppe erkennbar, was zum einen gegen eine lebenszyklisch bedingt ausgeführte Berufstätigkeit spricht, zum anderen keine regionale Verdrängung von bestimmten Professionsgruppen bestätigt. ${ }^{1229}$ Damit verfestigt sich die Feststellung aus dem Kap. 2.4, dass die Basler Erziehungsräte sehr viel Wert auf die Qualität und die fachlichen Qualifikationen der anzustellenden Kandidaten gelegt und bewusst erfahrene, wenngleich ältere Personen auswählten.

Eine in weiten Teilen ähnliche Entwicklung wie in der Basler Landschaft kann im gemischtkonfessionellen Ostschweizer Kanton Säntis beobachtet werden. Hierzu wurden zwei zeitnahe Zeitpunkte aus Drittquellen - 1797 und 1800 - mit der Stapfer-Enquête verglichen. Beim Vergleich von 86 registrierten katholischen Schulen aus dem Territorium der St. Galler Fürstabtei von 1797 mit der Stapfer-Enquête von 1799 hatten insgesamt 14 von 74 Lehrkräften ihre Stelle verlassen, wovon einer gestorben war und zwei weitere Lehrer ihr Lehramt an ihre Söhne weiter gegeben hatten. Das bedeutete eine Fluktuationsquote von 19\% innerhalb von 24 Monaten während des ersten Revolutionsjahres. ${ }^{1230}$ Elf der 14 neuen Lehrkräfte waren jünger als ihre Vorgänger, acht davon noch unter 30 Jahre alt. Aufgrund von fehlenden Ersttätigkeitsangaben in der St. Galler Umfrage können jedoch keine professionsbedingten Ablösebewegungen untersucht werden.

Aus den im Herbst 1800 zuhanden des Erziehungsrats verfassten Generaltabellen über das Schulwesen des Kantons Säntis, die zehn der insgesamt 13 Distrikte des Kantons Säntis umfassten, kann anhand eines Abgleichs mit den entsprechenden Stapfer-Antworten von 1799 eine Fluktuationsquote von rund $11 \%$ des Personals innerhalb von 18 Monaten berechnet werden. ${ }^{1231}$ Mindestens 19 der 165 in den Generaltabellen verzeichneten Lehrpersonen waren demnach in der Stapfer-Enquête anderthalb Jahre zuvor noch nicht verzeichnet. Von diesen 19 neuen Lehrern waren mindestens zwölf jünger als ihre Vorgänger, womit die meisten freigewordenen Stellen mit jüngeren Lehrern besetzt wurden. Mindestens acht dieser 19 neuen Lehrer waren noch unter 30 Jahre alt gewesen. Im Gegensatz zu Basel setzten die Autoritäten im Schulwesen des Kantons Säntis somit - bewusst oder unbewusst - stärker auf eine Verjüngung ihres Lehrerkorps. Der Vergleich der Ersttätigkeiten der abgetretenen und neuen Lehrer wies dagegen wie beim Basler Fallbeispiel keine systematischen Ablösungsprozesse einzelner Professionsgruppen auf.

Interpoliert man die beiden regionalen Fluktuationswerte von Basel und St. Gallen in zurückhaltender Weise auf die gesamte Helvetische Republik, musste im Durchschnitt pro Jahr rund

1228 Ein Personalwechsel zwischen 1799 und 1803 erfolgte in den Schulen Bottmingen, Bretzwil, Bubendorf, Diegten, Gelterkinden, Höstein, Oberdorf, Oltingen, Ramlinsburg, Rickenbach, Sissach und Waldenburg.

1229 Auf 3 ehemalige Handwerker, 3 Posamenter, 2 Theologen, 2 agrarisch Tätige und 1 Lehrer von Jugend her bzw. 1 Person ohne konkrete Angabe folgten 3 Posamenter, 3 agrarisch Tätige, 2 Handwerker sowie 1 Theologe, 1 Taglöhner, 1 Lehrer vom Jugendalter an und 1 Person ohne konkrete Angabe.

123015 Schulen aus der Fürstabtei St. Gallen antworteten nicht auf die Stapfer-Enquête oder ihre Antworten sind nicht überliefert. So bleiben 71 namentlich bekannte Lehrkräfte zum Direktvergleich. BiASG III D 94, fol. 1-344: [1797] - Bericht.

1231 StASG HA 132, Fasz. 1, o. Pag. : [1800] - General-Tabelle. Die Generaltabellen müssen im Spätsommer/Herbst 1800 als Zusammenfassung entstanden sein, als der Erziehungsrat des Kantons Säntis nochmals die Fragebögen der Stapfer-Enquête an seine Lehrer versandte. Es fehlen die Generaltabellen der reformierten Distrikte Herisau, Teufen und Wald (heutiger Kanton Appenzell Ausserrhoden) sowie die Stadtschulen der reformierten Stadt St. Gallen. Vgl. Rothen/Ruloff, Schulumfragen: 51. 
ein Zehntel aller Schulstellen laufend neu besetzt werden. ${ }^{1232}$ Eine erhöhte Fluktuationskonjunktur kann für die Jahre 1798 bis 1800 tatsächlich vermutet werden, denn beide exemplarisch betrachteten Untersuchungsräume zeigen im genannten Zeitraum verstärkte personelle Wechsel. Allerdings ist der Untersuchungszeitraum während der Revolution an sich problematisch, da nicht nur politische und gesellschaftliche Auseinandersetzungen zu mehr Konflikten führten, sondern die explodierende Verwaltungstätigkeit der helvetischen Behörden gleichzeitig ungleich mehr Konflikte festhielt und überlieferte, die im Ancien Régime oft keinen Eingang in die Schriftlichkeit gefunden hätten.

Im Folgenden wird die lehramtliche Mobilität der helvetischen Lehrkräfte ab dem Zeitpunkt der Lehramtsübernahme in Bezug auf die Quantität von Stellenwechseln, den Bewegungsradien der Lehrkräfte und in Bezug auf soziale Aufstiegs- oder Abstiegsbewegungen genauer untersucht.

\subsubsection{Lehramtliche Mobilität}

Dass nicht jede Lehrkraft trotz der festgestellten starken lokalen Bindung lebenslang an der gleichen Schulstelle blieb, hat die im vorangegangenen Abschnitt diskutierte Fluktuationshäufigkeit gezeigt. Rekrutierte sich die Lehrerschaft mehrheitlich lokal, konnte folglich nur ein geringer Teil der Lehrer eine berufliche Mobilität als Lehrkraft aufweisen. Peter Büttner attestiert der helvetischen Lehrerschaft in seiner Studie denn auch eine insgesamt geringe Fremdrekrutierung und damit eine geringe lehramtliche Mobilität, allerdings auf der Basis einer quantitativ schmalen Stichprobe. ${ }^{1233}$

Die Häufigkeit von spezifisch lehramtlicher Mobilität ist für die Vormoderne jedoch noch weitgehend unerforscht. Zunächst soll eine Lehrer-Autobiografie zur Frage der schulischen Mobilität in qualitativer Betrachtung konsultiert werden. Der Autobiografie des bereits erwähnten Schulmeisters Jakob Eggen kann exemplarisch entnommen werden, dass der genannte Lehrer während seines Lebens an insgesamt vier Schulen in einem relativ weitläufigen Radius von knapp 100 Kilometern und in zwei verschiedenen Sprachregionen tätig war. Seine Schullehrerkarriere startete Eggen in seinem Heimatweiler Schwarzenmatt bei Boltigen BE im Berner Oberland, nachdem er zuvor einen erstberuflichen Aufenthalt als Schuhmacherlehrling in der Waadt absolviert hatte. Nach drei Jahren Tätigkeit als Lehrer im Oberland konnte er dank seinen Französischkenntnissen an die deutsche Schule im waadtländischen Aigle VD wechseln. Heimweh und Langeweile liessen ihn jedoch schon nach einem Jahr zurück in den deutschsprachigen Teil des Berner Untertanenlandes, nach Langenthal BE, ziehen, bevor er nach etlichen Jahren des Wirkens im Städtchen Aarberg BE seine letzte Schulstelle für weitere 24 Jahre annahm, wo er letztendlich verstarb. Während seines Wirkens in Langenthal bewarb sich Eggen zudem um die Stadtschulstelle im weit entfernten Altstätten SG. ${ }^{1234}$ Die Biografie Eggens weist damit nicht nur einen mehrfachen Stellenwechsel mit einer markanten mehrfachen interregionalen Mobilität innerhalb des Berner Untertanenlandes auf, sondern auch eine alternierende Wanderungsbewegung über die Sprachgrenzen vom deutschsprachigen Oberland in die französischsprachige Waadt und - zumindest probeweise - eine überregionale Mobilität in ein weit entferntes eidgenössisches Territorium, freilich stets innerhalb der konfessionellen Grenzen bleibend. Zudem wies Eggens Biografie eine vertikale Land-Stadt-Mo-

1232 Die mittleren Dienstdauerangaben der Lehrkräfte unterstreichen diese Einschätzung: Mindestens 244 Lehrkräfte oder $10.5 \%$ aller helvetischen Elementarschullehrer wiesen eine minimale Dienstdauer von weniger als einem Jahr auf. Vgl. das Kap. 3.4.

1233 Vgl. Büttner, Schreiben: 89.

1234 StABE DQ 177.19, S. 1-75: 23.06.1839 - Kurze Lebensbeschreibung; Meyer, Langenthal: 24-44. 
bilität im Sinne eines sozialen „Aufstiegs“ auf, da er vom einfachen, armen Landschulmeister zu einem passabel verdienenden landstädtischen Schullehrer aufgestiegen war. Es stellt sich somit die Frage, ob eine gewisse schulische Mobilität zur Normbiografie von Lehrern vor 1800 gehörte, oder ob Jakob Eggens mehrfache Berufsmobilität als Lehrkraft eher ein atypisch singuläres Verhalten gewesen war.

Einer empirischen Kontrolle unterworfen, stellt sich die Feststellung einer generellen Lokalrekrutierung und damit einer insgesamt geringen schulischen Mobilität der Lehrkräfte nur als bedingt zutreffend heraus. Insgesamt wiesen 745 Lehrkräfte oder mindestens 32\% aller Lehrpersonen ein schulbedingtes Bewegungsverhalten in ihrer Biografie als Lehrkraft auf. ${ }^{1235}$ Eine Schulstelle war somit für rund jede dritte Lehrkraft ein Grund, ihren Herkunftsort zeitweilig oder dauerhaft zu verlassen.

Die Bewegungspfade von lehramtlich mobilen Lehrkräften gestalteten sich allerdings vielgestaltig. Auffällig war der Umstand, dass zahlreiche Lehrpersonen, die ihr Auskommen in Schulorten ausserhalb der Herkunftsgemeinde gefunden hatten, analog der erstberuflich mobilen Lehrkräfte bei sich bietender Gelegenheit einer Vakanz wieder in ihre Herkunftsgemeinden zurückmigrierten und damit zum Zeitpunkt der Umfrageerhebung wieder als Ortsansässige zählten.

Mindestens 23\% aller 745 lehramtlich mobilen Lehrkräfte waren im Verlauf ihrer Berufskarriere als Lehrkraft wieder an ihren Herkunftsort zurückgekehrt und übten das Lehramt zum Zeitpunkt der Umfrageerhebung wieder in ihrer Herkunftsgemeinde aus. ${ }^{1236}$ Als anziehende Kräfte für eine Rückkehr wirkte zum einen das volle Burgerrecht gegenüber dem Hintersassen-Status an anderen Orten. Wenn auswärts lebende Burger in wirtschaftliche Not gerieten, mussten sie in ihre Heimatgemeinde zurückkehren, selbst wenn sie diese erst kurz zuvor verlassen hatten. ${ }^{1237}$ Zum anderen dürften persönliche Beziehungen, familiäre Netzwerke oder die Übernahme von elterlichen Erbschaftsteilen eine wesentliche Rolle gespielt haben. Der hohe Anteil an ortsansässigen Lehrkräften war somit nicht nur das Produkt einer bevorzugten Lokalrekrutierung der Gemeinden, sondern auch eines gleichzeitigen bewussten Rückkehr-Verhaltens vonseiten der Lehrkräfte.

Die Häufigkeit der gewählten Bewegungsradien der lehramtlich mobilen Lehrkräfte zum Zweck der Besetzung einer ortsfremden Schulstelle sortierte sich erstaunlicherweise nicht in gleichförmig abnehmendem Masse mit zunehmender Distanz zum Herkunftsort. Die lehramtlichen Wanderungen erfolgten in einer dualen Gleichzeitigkeit entweder als Nahwanderung im Rayon der umliegenden Nachbargemeinden des Herkunftsortes innerhalb eines beschränkten Radius von weniger als fünf Kilometern oder dann gleich in deutlich grösserer Distanz von mehr als zehn Kilometern zum Herkunftsort. Dabei blieben die Lehrkräfte aber in den allermeisten Fällen im eigenen Kanton und innerhalb der konfessionellen Grenzen, wie die folgende Analyse der Bewegungsdistanzen sämtlicher Lehrkräfte mit lehramtlicher Mobilität aufzeigt. ${ }^{1238}$

1235 Vgl. die Abb. 15 im Kap. 3.5.

1236 Mindestens 171 Lehrkräfte, die ihren Herkunftsort aus schulischen Gründen verlassen hatten, kehrten später im Verlauf ihrer Berufsbiografie wieder zurück. Offen bleibt, ob es sich hierbei um Ortsbürger oder um Hintersassen handelte.

1237 Schmidt, Handlungsstrategien: 246.

1238 Gemessen wurde jeweils die maximale Bewegungsdistanz als Luftlinie vom Herkunftsort (Ortsmitte) bis zum jeweils entferntesten Punkt in der Biografie als Lehrkraft (Ortsmitte) mithilfe der lizenzfrei zugänglichen DufourKarte der Schweiz sowie mit dem online abrufbaren Distanzmessungs-Tool auf www.map.geo.admin.ch. In natura konnten die zurückgelegten Wege aufgrund der nicht mitberücksichtigten Topografie deutlich länger oder kürzer gewesen sein, da weder der genaue Wohnort der Lehrpersonen, noch der genaue zeitgenössische Standort der Schulen bekannt ist. 
Tab. 28: Bewegungsradius der lehramtlich mobilen Lehrer

\begin{tabular}{lccc}
\hline Zurückgelegte Distanz: & $\begin{array}{c}\text { Lehrer mit schulischer } \\
\text { Mobilität: }\end{array}$ & In Prozent: & $\begin{array}{c}\text { Davon Lehrer mit } \\
\text { freier Wohnung: }\end{array}$ \\
\hline Unter 5 Kilometer & 267 & $35.8 \%$ & $89(33 \%)$ \\
5 bis 10 Kilometer & 91 & $12.2 \%$ & $46(50 \%)$ \\
Über 10 Kilometer & 258 & $34.6 \%$ & $192(74 \%)$ \\
Interkantonal & 80 & $10.6 \%$ & $57(71 \%)$ \\
International & 36 & $4.8 \%$ & $21(58 \%)$ \\
Keine Angaben & 13 & $1.9 \%$ & - \\
\hline Total & 745 & $100 \%$ & $405(54 \%)$ \\
\hline
\end{tabular}

Die relative Mehrheit von rund 36\% aller lehramtlich mobilen Lehrkräfte bewegte sich innerhalb des gleichen Kantons im überschaubaren Nahbereich von unter fünf Kilometern Distanz zum Herkunftsort, um eine Schulstelle zu besetzen. Durch die geografische Nähe zum Geburtsort war in der Regel keine Verlagerung des Wohnorts an den Schulort notwendig. Das Lebenszentrum konnte so bestehen bleiben und Nebentätigkeiten aller Art, insbesondere aber agrarische Tätigkeiten, konnten am Herkunftsort problemlos weitergeführt werden, da ein täglicher Fussmarsch in genannter Distanz vom Wohn- zum Schulort im Bereich des Möglichen lag. ${ }^{1239}$ Eine freie Schulwohnung war folglich nicht zwingend notwendig, um die Schulstelle annehmen zu können. Zudem konnten ebensolche lokalmigrierende Lehrkräfte ihr soziales Netzwerk an persönlichen Beziehungen am Herkunftstort aufrechterhalten und wahrscheinlich verdankten nicht wenige Lehrer ihre Stelle im Nachbarort genau einem solchen individuellen Netzwerk von persönlichen Beziehungen oder klientelistischen Abhängigkeiten, die in der klein fragmentierten Lebenswelt der Landbevölkerung dennoch über die engen kommunalen Grenzen hinausragten. Insofern agierten diese sich kleinräumig bewegenden Lehrkräfte nicht anders als ihr bäuerlich geprägtes Umfeld, das durchaus mit seiner erweiterten Nachbarschaft in austauschendem Kontakt stand.

War im nahen Umfeld jedoch keine Schulstelle frei, entschieden sich fast ebenso viele der lehramtsmobilen Lehrkräfte, rund 34\%, zur erweiterten Binnenmigration innerhalb ihres Herkunftskantons mit einer Distanz von mehr als zehn Kilometern Distanz zum Herkunftskort, also oft auch ausserhalb des Herkunftsdistrikts. Obwohl mit der Abwanderung in eine andere Gemeinde oft der Verlust der Bürgerrechte und der sozial niedrigere Status als Hintersasse einhergingen, verblieben die Mehrheit der Lehrer trotz der allmählichen Auflösung der Abzugsbeschränkungen zwischen den eidgenössischen Orten primär unter der ständischen Rechtsprechung innerhalb des Herkunftsterritoriums. Zudem scheint der Gedanke vorgeherrscht zu haben, dass - wenn ein räumlicher Umzug unumgänglich war - man das Glück eher in der grösseren Ferne suchen sollte.

Interkantonale Wanderungsbewegungen zu schulischen Absichten waren dagegen im Kollektiv der helvetischen Lehrerschaft eine Marginalerscheinung, selbst in der Nähe von Kantonsgrenzen lebende Lehrkräfte überquerten ebensolche aus Gründen der Stellensuche trotz der Kleinräumigkeit der eidgenössischen Territorien nur sehr selten. Bloss rund jede zehnte lehramtlich mobile Lehrperson hatte sich für eine Schulstelle ausserhalb des eigenen Kantons entschieden. Noch stär-

1239 Längere tägliche Fussmärsche sind mitunter als notwendig akzeptiert worden. So lief beispielsweise der Lehrer J. Georg Bühlmann täglich rund 2.5 Kilometer von Holzmannshaus TG nach Sirnach, wofür er jeweils rund eine Dreiviertelstunde benötigte. Neben der Schulzeit bewirtschaftete er weiterhin seine landwirtschaftlichen Güter und trieb das Weberhandwerk. Schmidt u.a. (Hgg.), Stapfer-Enquête, Nr. 914: Sirnach. 
ker wirkten freilich die konfessionellen Grenzen, die praktisch nie überschritten wurden, sowie die Aussengrenzen der Alten Eidgenossenschaft als Grenzen der lehramtlichen Mobilität.

Ein grundsätzlich mobilitätsfördernder Faktor für eine erweiterte Wanderung ausserhalb des Nachbarschaftsrayons stellte das Vorhandensein einer freien Wohnung im Schulhaus, das Bezahlen eines Zinsbeitrags für die Miete einer Wohnung als Teil der Besoldung oder zumindest, dass der Lehrer bei den Hausvätern des Dorfes gratis „in Kost“ gehen durfte, dar. ${ }^{1240}$ Insbesondere der zuvor beschriebene hohe Grad an Mobilität in der Waadt lässt sich stark auf das schon dichte Vorhandensein von Schulhäusern mit integrierten Schulwohnungen in den Waadtländer Gemeinden zurückführen. Doch auch insgesamt ist der Zusammenhang zwischen dem Radius von lehramtlicher Mobilität und dem Vorhandensein von Schulwohnungen für die Lehrerschaft hoch evident. Je weiter entfernt die Schulstelle vom Herkunftsort der Lehrer lag, desto höher war der Anteil an Lehrkräften mit einer freien Schulwohnung. Weiter entfernte Schulstellen von mehr als fünf Kilometern Distanz zum Heimatort wurden somit von einer Mehrheit der Lehrkräfte nur angenommen, wenn eine Schulwohnung oder zumindest eine finanzielle Beteiligung an den Wohnkosten gesichert war. Der Mehrheit der lehramtlich mobilen Lehrkräfte kann somit eine ganz bewusste Rationalität bei der Wahl ihrer Schulorte attestiert werden. Nur wenige Lehrer gingen das Risiko ein, in eine weit entfernte Gemeinde zu ziehen, ohne einen Anspruch auf eine gesicherte Wohnsituation zu haben.

Ebenso selten wie die Landesgrenzen wurden die Grenzen der Sprachräume innerhalb der Helvetischen Republik auf der Suche nach einer freien Lehrerstelle passiert. Sind räumliche Bewegungen über die Sprachgrenze in den Berufsbiografien zu finden, dienten sie vorwiegend der sprachlichen Ausbildung zum Erlernen der jeweils anderen Sprache. Hierbei wurde die Sprachgrenze in beiden Richtungen überschritten. Vereinzelte deutschsprachige Lehrer berichteten ebenso von Aufenthalten in der Waadt zum Erlernen der französischen Sprache wie französischsprachige Lehrkräfte Aufenthalte in der Deutschschweiz festhielten. ${ }^{1241}$ Insgesamt war der Austausch über die Sprachgrenzen hinweg jedoch sehr gering, obwohl Fremdsprachenkenntnisse zumindest in Einzelfällen durchaus ein Bildungsvorteil und damit ein wichtiger Referenzpunkt für die Lehrperson bei Stellenwechseln sein konnten. ${ }^{1242}$ Solche Vorteile blieben allerdings lokal beschränkt auf städtische Schuleinrichtungen oder auf Orte, wo aus der Bevölkerung heraus ein Interesse an der Vermittlung einer Fremdsprache an die Kinder bestand. ${ }^{1243}$ Eine grundsätzliche

1240 Als lehramtlich mobile Lehrkräfte mit freier Schulwohnung wurde nur gezählt, wer in der Stapfer-Enquête am Schulort entweder explizit ein freies Wohnrecht im Schulhaus oder einen Hauszins für die eigenen Mietkosten festgehalten hat. Ferner sind fremdverköstigte Lehrkräfte mitgezählt worden, auch wenn deren genauer Ort der Beherbergung meist unklar blieb, da damit ein wesentlicher Teil der Lebenskosten während der Schulzeit übernommen wurde. Der Lehrer von Bibern SO, Niklaus Segeser aus Bannwil BE, hielt etwa zu seinem Einkommen fest, dass er „Nebst meiner kost in der kerre bej den Hauß vätteren deiser gemeine“ zirkulierte, also während der Schulzeit als Kostgänger reihum bei jeweils anderen Familien lebte und dort wohl auch wohnte. Schmidt u.a. (Hgg.), Stapfer-Enquête, Nr. 2398: Bibern. Blieb unklar, ob die ortsfremde Lehrperson im Schulhaus oder auf Gemeindekosten wohnte, wurde kein Wert erhoben.

1241 „Jst vorher schon im 14ten Jahr seines Alters in Loblicher Stadt Genf gewesen, um die Französische Sprache zu lernen.“ Schmidt u.a. (Hgg.), Stapfer-Enquête, Nr. 320: Kyburg; „Quand j’ais communié, mon pére me plaça chez le Citoyen Joneli, à présent Préfect National du Canton de l'Oberland pour apprendre la Langue Allemande." Schmidt u.a. (Hgg.), Stapfer-Enquête, Nr. 1973: Villeneuve.

1242 Vgl. die Anekdote Eggens, wie seine Französischkenntnisse die prüfenden Pfarrer während des Lehrerexamens zur lateinischen Konversation zwang. Meyer, Langenthal: 32.

1243 Beispielhaft sei auf die Schule des wohlhabenden Weindorfes Ligerz BE verwiesen, dessen Lehrer die Schulkinder in Französisch unterrichtete, wohl aufgrund der Nähe des Ortes zur Sprachgrenze sowie des hohen französischsprachigen Bevölkerungsanteils im Dorf. Schmidt u.a. (Hgg.), Stapfer-Enquête, Nr. 780: Ligerz; Dubler, Ligerz. Der Lehrer von Ligerz BE galt zumindest in den Augen des Distriktinspektors Pfarrer Ith wegen seiner 
Tendenz zu einer breiteren Ost-West-Wanderung im 18. Jahrhundert, wie sie Christian Pfister für die Berner Bevölkerung formuliert hat, konnte anhand des Mobilitätsverhaltens der helvetischen Lehrerschaft nicht nachgewiesen werden. ${ }^{1244}$

Das bewusste Sammeln von schulischer Praxiserfahrung an anderen Schulstellen spielte in den zeitgenössischen Überlegungen zur Qualität von Lehrpersonen noch eine untergeordnete Rolle, da vorherige berufliche Praxiserfahrung noch kein - zumindest offizielles - Kriterium bei der Schulmeisterwahl war. Erst mit der Revolution und den organisatorischen Professionalisierungsbemühungen seitens der kantonalen Erziehungsräte wurde die lehramtliche Erfahrung in der Lehrerrekrutierung verstärkt zu einem unterschwelligen Selektionskriterium, wie die Zunahme von bereits etablierten Schulmeistern in den Berichten über Lehrerprüfungen dokumentierten. ${ }^{1245}$ Als Indikator für die Dynamik der berufsbiografischen Entwicklung der Lehrkräfte ist die Schulpraxiserfahrung jedoch von hoher Relevanz. Wiederum ist die Studie von Georges Panchaud die einzige verlässliche quantitative Referenz aus der bisherigen Schulgeschichtsforschung, der über die rund 400 Waadtländer Lehrer in summarischer Weise festgehalten hat, dass der Grossteil der Lehrer ihren Stellen zwar treu blieb, andererseits aber gleichwohl rund 40\% der Waadtländer Lehrerschaft bereits mindestens einmal zuvor die Schulstelle gewechselt hatte. „Nous avons ainsi une catégorie des maîtres dont l'activité n'est nullement limitée géographiquement et que l'on voit enseigner en divers endroits du pays." ${ }^{1246}$ Insgesamt wiesen mindestens $19.5 \%$ aller Lehrkräfte des helvetischen Elementarschulwesens eine gesicherte Schulpraxiserfahrung mit mindestens einer vorangegangenen Stelle an einem weiteren Schulort vor dem in der Umfrage erfassten Unterrichtsort aus. Knapp jede fünfte Lehrkraft hatte somit zum Zeitpunkt der Umfrage bereits vorgängig an einem anderen Ort beziehungsweise in einer anderen Schule als Lehrperson gearbeitet. ${ }^{1247}$ Die helvetische Lehrerschaft war in ihrer Gesamtheit zwar tatsächlich noch mehrheitlich standorttreu, dennoch wies bereits eine beachtliche Minorität der Elementarschullehrerschaft nicht nur eine lehramtliche Mobilität zum Zweck der Gewinnung einer Schulstelle auf, sondern hatte ferner durch aktive Stellenwechsel an Schulpraxiserfahrung an Drittorten gewonnen.

Tab. 29: Anzahl Lehrer mit Schulpraxiserfahrung

\begin{tabular}{lcc}
\hline Anzahl vorherige Schulstellen: & Anzahl Lehrer: & In Prozent: \\
\hline Keine & 1.855 & $80.5 \%$ \\
1 & 309 & $13.4 \%$ \\
2 & 92 & $4.0 \%$ \\
3 & 30 & $1.2 \%$ \\
4 und mehr Stellen & 19 & $0.8 \%$ \\
\hline Total & 450 & $100 \%$ \\
\hline
\end{tabular}

Sprachkenntnisse als der „vorzüglichste [Lehrer] von allen“, wie er im Begleitschreiben zu den Antworten auf die Stapfer-Enquête festhielt. StABE B III 903, o. Pag.: 20.03.1799 - Bürger Präsident.

1244 Pfister, Strom: $129 \mathrm{f}$.

1245 Vgl. das Kap. 2.4.

1246 Panchaud, écoles vaudoises: 262-266.

1247 Mindestens 450 Lehrer hatten vor 1799 an einer weiteren Schuleinrichtung gearbeitet. Bei einer unklaren Anzahl an lehramtlichen Stationen als Lehrer wurden in der Datenerhebungsmethode - sofern in der Mehrzahl genannt - die Angabe als 2 Berufsstationen gezählt. Hauslehrerdienste, Privatunterricht sowie die explizite Erwähnung von Hilfsdiensten in der innerfamiliären Berufsweitergabe wurden ebenfalls als einfache Unterrichtserfahrung mitgezählt. Die Mitarbeit bei einem anderen Lehrer zu reinen Ausbildungszwecken wurde dagegen nicht berücksichtigt, ebenso wenig wie eine Unterbrechung der Unterrichtstätigkeit am gleichen Ort. 
Rund zwei Drittel aller Lehrkräfte mit vorangegangener Unterrichtspraxis wiesen einzig eine vorgängige Stelle als Lehrperson aus. Nur ein weiteres Fünftel hielt mindestens zwei weitere vorgängige Schulstellen in der Umfrage fest. Eine Praxiserfahrung an mehr als zwei vorangegangenen Schulstellen stellte dagegen die deutliche Ausnahme dar, denn insgesamt nur 49 Lehrkräfte oder 2\% aller Lehrer notierten zum Zeitpunkt der Umfrage mindestens drei oder mehr vorangehende Schulstellen in ihrer Beantwortung. Alleiniger Spitzenreiter in Sachen lehramtlicher Praxiserfahrung war mit insgesamt sechs vorgängigen Schulstellen der damals 59-jährige Lehrer Jean David Wagnière aus Lussy-Sur-Morges VD gewesen, der bereits „A Onnens 2 ans. à Demoret 5 ans a St. Sulpice 2 ans. à Eclepens 6. a St. Saphorin sous Chêbres 12. a Mont le Grand 13. en tout 40 ans ${ }^{\text {"1248 }}$ gearbeitet hatte.

Im interkantonalen Vergleich der Anzahl an Stellenwechseln der lehramtlich mobilen Lehrkräfte bestätigte sich einerseits die von Georges Panchaud beobachtete aussergewöhnlich hohe Mobilität und damit eine verstärkte Fluktuation der Lehrkräfte in der Waadt. Andererseits war diese verstärkte Mobilität kein ausschliesslich regionales Phänomen der französischsprachigen Waadt, denn auch die helvetischen Kantone Bern und Fribourg verzeichneten in ihren kantonalen Lehrerkorps einen überdurchschnittlich hohen Anteil an Lehrkräften mit Schulpraxiserfahrung an mehreren Orten. Mit 29\% Gesamtanteil hatte rund jeder vierte bernische Lehrer zum Zeitpunkt der Umfrage bereits an mehr als einer Schule unterrichtet. Gleiches galt - unter dem Vorbehalt der unvollständigen Datenlage - für die Fribourger Lehrerschaft, wo sich der Anteil an lehramtlich mobilen Lehrern ebenfalls mindestens 29\% belief. Im westlichen Mittelland war das periodische Wechseln der Schulstelle somit keine Seltenheit mehr und rund jede dritte Schule zwischen dem Genfersee und dem Aargau wurde durch eine Lehrkraft geführt, die bereits zuvor an anderen Schulen unterrichtet hatte.

Im Kanton Basel hatten mit knapp 23\% immerhin mehr als ein Fünftel aller Lehrer an anderen Orten Schulpraxiserfahrung gesammelt, wobei jedoch die Meisten zuvor als Privatschullehrer oder Hauslehrer in der Stadt Basel tätig gewesen waren. In den übrigen, östlich des helvetischen Kantons Bern gelegenen Kantonen, schwankten die relativen Anteile an Lehrern mit mehreren vorangegangenen Schulstellen in ihrer Berufskarriere auf tieferem Niveau zwischen sechs und achtzehn Prozentpunkten, freilich ohne dass ein deutliches konfessionelles oder wirtschaftsräumliches Muster erkennbar wäre.

Tab. 30: Lehrer mit Schulpraxiserfahrung nach Alterskohorten

\begin{tabular}{lcc}
\hline Alterskohorten: & Anzahl Lehrer: & In Prozent: \\
\hline Unter 20 Jahre & 5 & $12.2 \%$ \\
20-29 Jahre & 70 & $18.4 \%$ \\
30-39 Jahre & 103 & $18.3 \%$ \\
40-49 Jahre & 112 & $21.0 \%$ \\
50-59 Jahre & 95 & $21.8 \%$ \\
60-69 Jahre & 53 & $20.9 \%$ \\
70 Jahre und älter & 7 & $10.8 \%$ \\
Keine Angabe & 5 & $16.1 \%$ \\
\hline Total: & 450 & $19.6 \%$ \\
\hline
\end{tabular}

1248 Schmidt u.a. (Hgg.), Stapfer-Enquête, Nr. 1746: Lussy-sur-Morges. 
Zwischen der Praxiserfahrung an anderen Orten und dem Alter der Lehrkräfte zum Zeitpunkt der Erhebung besteht allerdings kein direkt korrelierender Zusammenhang. Obwohl hätte vermutet werden können, dass ältere Lehrer aufgrund ihrer länger andauernden Dienstzeit eher mehr Schulstationen in ihrer Biografie aufwiesen als jüngere Lehrer, waren ältere Lehrkräfte unter den Lehrern mit vorheriger Schulpraxiserfahrung keineswegs überrepräsentiert.

Von den total 450 Lehrkräften mit vorgängiger Schulpraxiserfahrung waren 155 Lehrer oder $34.4 \%$ bereits mindestens 50 Jahre alt, was einem Anteil von $20.5 \%$ an der gesamten Alterskohorte aller über 50-jährigen Lehrkräfte entspricht. Doch auch die mittlere Altersgeneration zwischen 30 und 50 Altersjahren wies rund 20\% an Lehrkräften mit Schulpraxiserfahrung auf. Auf der anderen Seite hielten ebenso bereits eine Handvoll Jünglinge von unter 20 Altersjahren während ihrer kurzen Berufsphase als Lehrkraft schon mehr als eine Schulstelle inne, wie das Beispiel des erst 18-jährigen Lehrers aus Ülikon ZH illustriert, der im Frühjahr 1799 berichtete: „Alt, 18 Jahr. [...] Schullehrer, hier 2 Jahr. Vorher 1 1/2 Jahr Schullehrer zu Üriken. “1249

Auch bei den unter 30-jährigen Lehrkräften hatte im Durchschnitt jede fünfte Lehrperson schon mindestens einmal zuvor die Schulstelle gewechselt. Eine eindeutige Evidenz von zunehmendem Alter und zunehmenden Stellenwechseln kann daher nicht erkannt werden. Damit zeigt sich, dass der Anteil an stellenwechselnden Lehrkräften über alle Alterskohorten verteilt ungefähr stabil war und somit nur ein bestimmter Prozentsatz jeder Alterskohorte bewusst auf lehramtliche Mobilität als Aktivstrategie setzte.

Demgegenüber waren zentralörtliche Schullehrer unter den Lehrkräften mit vorgängiger Berufspraxis leicht überproportional vertreten, denn rund 25\% der Lehrkräfte mit mindestens einer vorhergehenden Schulstelle arbeiteten zum Zeitpunkt der Erhebung in einer zentralörtlich gelegenen Schule. Dies entspricht einem relativen Anteil von insgesamt 35\% aller zentralörtlichen Elementarschullehrer. ${ }^{1250}$ Zentralörtliche Lehrkräfte wiesen damit rund anderthalb mal so häufig einen schulischen Stellenwechsel in ihrer Biografie als Lehrer auf, verglichen mit dem Gesamtmittel aller Lehrer. Dieser - wenn auch bloss indizienhafte - Befund spricht für eine sich im Wandel begriffene Praxis der Lehrerrekrutierung im zentralörtlichen Schulwesen. Hier wirkten offenbar bereits vor 1800 eine generell höhere Leistungsorientierung und eine gleichzeitig stärker abgeschwächte Kultur der Lokalrekrutierung. Konkrete Unterrichtserfahrungen als Schullehrer traten hier neben dem Beherrschen der Kulturtechniken zunehmend als ein bedeutendes Erfolgskriterium bei Lehrerprüfungen im städtischen Umfeld auf.

Eine weitaus eindeutigere Evidenz bestand hingegen beim Vergleich der häufigsten Ersttätigkeiten der Lehrkräfte mit Schulpraxiserfahrung und dem Radius ihrer lehramtlichen Mobilität. Insgesamt rund 54\% der lehramtlich mobilen Lehrkräfte mit vorgängiger Unterrichtserfahrung an Drittorten arbeiteten ausschliesslich im Schulwesen und notierten entweder nur schulische Tätigkeiten, Hauslehrerdienste oder gar keine Ersttätigkeiten in der Stapfer-Enquête. ${ }^{1251}$ Sie agierten bei der Wahl ihrer Schulstellen räumlich am stärksten ungebunden, wie die nachfolgende Grafik anhand der vier wichtigsten Ersttätigkeiten von Lehrkräften mit vorgängiger Schulpraxiserfahrung zeigt.

1249 Schmidt u.a. (Hgg.), Stapfer-Enquête, Nr. 302: Ülikon.

1250 Mindestens 111 der 315 zentralörtlichen Elementarschullehrer hatten mindestens einmal ihre Schulstelle gewechselt.

1251 Mindestens 240 der 450 Lehrer mit Praxiserfahrung hatten keine Ersttätigkeit ausgeübt. 


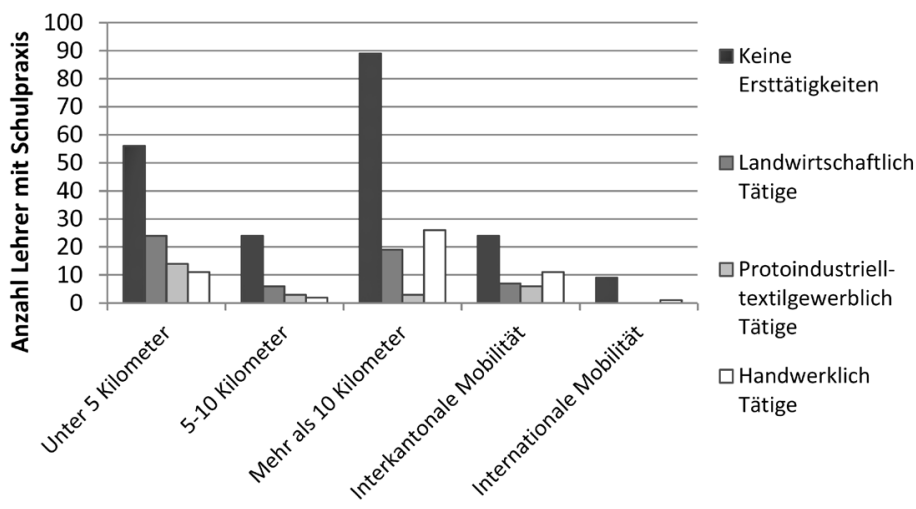

Abb. 16: Ersttätigkeiten und Distanz von vorgängigen Schulstellen

Demgegenüber entstammten bloss 60 Lehrkräfte oder 15\% der lehramtlich mobilen Lehrkräfte aus einem agrarischen Tätigkeitsfeld. Davon verblieben die Meisten jedoch räumlich im Nachbarschaftsrayon von weniger als fünf Kilometern tätig. Weitere 47 Lehrer oder 10\% hatten einen handwerklichen Professionshintergrund. Ihr Mobilitätsverhalten war - wie das der ausschliesslich als Lehrkräfte tätigen Lehrer - deutlich weitreichender und überlokal fokussiert. Vertreter anderer Ersttätigkeiten - insbesondere protoindustriell-textilgewerbliche und handelsgewerbliche Tätigkeiten - blieben dagegen marginal und ebenfalls vorwiegend lokal orientiert. ${ }^{1252}$ Lehramtliche Praxiserfahrung an überlokal entfernten Orten wiesen damit neben den hochmobilen Geistlichen hauptsächlich allein auf die Lehrertätigkeit spezialisierte Personen oder Personen mit einem handwerklichen Tätigkeitshintergrund auf, die sich weitgehend von der agrarischen Subsistenz oder von protoindustriellen Tätigkeiten gelöst hatten und entsprechend nicht mehr der Orts- und Bodengebundenheit eines eigenen Heimwesens oder eines Webstuhls unterlagen. Hierin wird am ehesten jene Gruppe sich bewusst spezialisierender und „professionalisierender" Lehrkräfte manifest, die - nach den Worten Panchauds - räumlich ungebunden keine geografischen Limiten mehr kannte und für die das Lehramt nicht mehr bloss eine Ergänzungstätigkeit oder ein „Notbehelf“ war, sondern eine erstrebenswerte Haupteinkommenstätigkeit, der sie ganz bewusst folgten.

Sowohl das Führen eines landwirtschaftlichen Heimwesens als auch die hausgebundene Heimtextilproduktion bedeuteten dagegen eine zwangsläufige Ortsgebundenheit, die eine Übernahme eines weiter entfernten Schulamtes von mehr als fünf Kilometern Distanz hemmte, was die überaus tiefen Anteile an vormals agrarisch oder heimindustriell tätigen Lehrkräften unter den Lehrern mit mehrfacher Stellenbesetzung erklärt.

Neben dem Radius der Wanderungsbewegungen und der Häufigkeit von Stellenwechseln sind ferner der Ausgangs- und Zielort der Wanderungen von hoher berufsbiografischer Relevanz. Die Frage, ob durch einen Stellenwechsel bewusst ein sozialer Aufstieg angestrebt wurde, wurde in der bisherigen Forschungsliteratur jedoch noch kaum angegangen.

\subsubsection{Soziale Mobilität}

Trotz des zuvor konstatierten relativ bescheidenen Fluktuationsgrades innerhalb des Arbeitsumfeldes der Elementarschule, konnten Stellenwechsel auch bewusst dazu verwendet werden, 
um an eine besser bezahlte oder prestigeträchtigere Schulstelle zu gelangen. Solche Schulen waren am ehesten in Städten oder an Marktorten gelegen. Analysiert man die Herkunft und die Mobilitätsabfolge der Schulstationen aller 450 schulisch mobilen Lehrer mit mindestens einem vorangegangenen Stellenwechsel unter dem Blickpunkt der beiden ständisch differenten Raumkategorien „Land“ und „Zentraler Ort“, ergeben sich sechs grundsätzliche Möglichkeiten von Wanderungsbewegungen innerhalb des Arbeitsmarktes der Elementarschule. Erstens Wanderungen von Landschullehrkräften in einen Zentralort, zweitens Wanderungen von zentralörtlichen Lehrkräften aufs Land, drittens rein ländliche beziehungsweise rein zentralörtliche Wanderungsbewegungen sowie fünftens Rückkehrbewegungen ländlicher Lehrer von zentralörtlichen Schulen zurück an eine Landschule und sechstens in umgekehrter Richtung von zentralörtlichen Schulen zu Landschulen und wieder zurück in den Zentralort.

Tab. 31: Wanderungsbewegungen der lehramtlich mobilen Lehrer

\begin{tabular}{lcc}
\hline Wanderungsbewegung: & Anzahl Lehrer: & In Prozent: \\
\hline Land-Land & 293 & $65.1 \%$ \\
Land-Zentralort & 36 & $7.9 \%$ \\
Zentralort-Land & 29 & $6.4 \%$ \\
Zentralort-Zentralort & 29 & $6.4 \%$ \\
Land-Zentralort-Land & 17 & $3.8 \%$ \\
Zentralort-Land-Zentralort & 14 & $3.1 \%$ \\
Ohne räumliche Mobilität & 32 & $7.1 \%$ \\
\hline Total Lehrkräfte & 450 & $100 \%$ \\
\hline
\end{tabular}

Die rekonstruierten Bewegungsprofile der Lehrkräfte mit Stellenwechseln sprechen bezüglich der favorisierten Zielorte eine eindeutige Sprache: Lehrpersonen von ländlicher Herkunft blieben grundsätzlich auf dem Land tätig und wechselten bei Stellenwechseln primär an eine andere Landschule. Ebenso verblieben Schulmeister von zentralörtlichen Schulen bei einem Stellenwechsel mehrheitlich im gleichen Umfeld, wenn möglich sogar am gleichen Ort. ${ }^{1253}$ Die ständisch-rechtlichen Grenzen zwischen Land und Stadt bewiesen damit trotz ihrer allmählichen Auflockerung seit der Mitte des 18. Jahrhunderts ihre nach wie vor bedeutsame Wirkungsmacht und wurden in kollektiver Einmütigkeit von den Lehrkräften beiderlei Herkunft strikt respektiert.

Eine gewisse Zentralort-Land-Bewegung der unteren und mittleren städtischen Bevölkerungsschichten - sowohl als saisonale als auch als permanente Rückwanderung aufs Land - haben allerdings bisherige Studien für Deutschland belegt, deren Verallgemeinerbarkeit hinsichtlich ihrer Quantität ist jedoch offen. ${ }^{1254}$ Von zentralörtlicher Herkunft zu sein bedeutete zudem nicht, automatisch über einen höheren sozialen Status als die Landbewohner zu verfügen oder gar ein voll-

1253 Darunter sind die mindestens 32 Lehrkräfte ohne effektive räumliche Mobilität zu zählen, die innerhalb des gleichen Ortes - in der Regel an einem Zentralort - zuvor entweder Privatunterricht gegeben oder in einer anderen Schuleinrichtung tätig waren.

1254 Pfister, Bevölkerungsgeschichte: 106; Hochstadt, Migration: 202-206; Zu den Stadt-Land-Rückwanderungen, deren Ausmass zumindest im 19. Jahrhundert „erheblich“ gewesen sein mussten: Langewiesche, Wanderungsbewegungen: 18ff. 
berechtigter Bürger zu sein. In der breiten sozialen Heterogenität der Städte und Marktflecken, die Hintersassen ebenso einschloss wie Taglöhner, Dienstknechte, Handwerker und Bauern von unterschiedlichstem sozialem Rang, verliefen die sozialen Bruchlinien in genauso komplexer Art und Weise wie in den Landdörfern. Die Schlussfolgerung, dass ein Wechsel vom städtischen Milieu aufs Land gleichzusetzen mit einem sozialen Abstieg war, ist daher nicht a priori statthaft.

Die ständischen Grenzen übergreifende Bewegungen von Landschullehrern in die Städte blieben im kollektivbiografischen Wanderungsverhalten aber ebenso die Ausnahme, wie Wanderungen von zentralörtlichen Lehrern an Landschulen. Insgesamt bloss 53 Lehrer von nachweislich ländlicher Herkunft hatten in ihrem lehramtlichen Curriculum vitae einen zeitweiligen oder dauerhaften Wechsel an eine zentralörtliche Schule verzeichnet, waren somit im Laufe ihrer Berufskarriere als Lehrkraft in einen Zentralort gezogen. Den umgekehrten Weg vom Zentralort aufs Land gingen noch weniger Lehrkräfte. Gänzlich in den Bereich der unkonventionellen Ausprägungen gehörte dagegen ein zeitweiliges Pendeln über die ständischen Grenzen. Nur wenig mehr als jeweils eine Handvoll Schulmeister versuchten zuerst an einer Landschule beziehungsweise an einer zentralörtlichen Schule ihr Glück, bevor sie im Anschluss wieder zurück an eine zentralörtliche oder ländliche Schule wechselten.

Daraus ergeben sich zwei Schlussfolgerungen: Die soziale Permeabilität zwischen der Landschaft und den Zentralorten blieb zum Ersten in Bezug auf den die Lehrertätigkeit noch ebenso eingeschränkt wie für andere Berufsbereiche, beispielsweise für Landhandwerke. Trotz der mannigfachen gesellschaftlichen und wirtschaftlichen Veränderungsprozessen, die in der zweiten Hälfte des 18. Jahrhunderts immer stärker zu gesellschaftlichen Verwerfungen und neuen Bruchlinien führten, wirkten sich die Standesschranken auch am Ende des 18. Jahrhunderts de facto immer noch äusserst prägend auf die Lebenserfahrungen der einfachen Bevölkerung aus. Landschullehrer drangen zumindest unmittelbar vor und nach der Helvetischen Revolution noch wenig in den städtischen Raum ein, wodurch sich zum Zweiten die Konkurrenzsituation der Lehrer in den Städten noch nicht wesentlich verändert hatte. Zentralörtliche Schulen waren trotz ihrer ungleich höheren Besoldung einerseits noch keine „Magnete“, die talentierte Landschulmeister en masse zur Verbesserung ihrer Lebenssituation anzogen. Andererseits wurden aber auch noch kaum talentierte Lehrkräfte bewusst und aktiv von anderen Orten abgeworben. Zu dominant wirkte das Lokalrekrutierungsprinzip auch in den leistungsorientierteren Zentralorten.

Ein wesentlicher Faktor für die noch bescheidene Dynamik zwischen Stadt und Land dürften die noch schwach ausgebauten Kommunikationskanäle gewesen sein, denn vakante Schulstellen wurden noch primär über die - in ihrer Reichweite limitierten und je nach Persönlichkeit des Pfarrers völlig unterschiedlich ausgeprägten - persönlichen Netzwerke der betroffenen Lokalgeistlichen bekannt gegeben. Symptomatisch zeigt sich diese Informationsdistribution über pfärrerliche Netzwerke exemplarisch am beruflichen Werdegang Eggens, dessen Schulstellenwechsel von Aigle VD nach Langenthal BE massgeblich durch private pfärrerliche Korrespondenzen überhaupt erst angeregt und ermöglicht wurden. ${ }^{1255}$ Ebenso dürften die reformierten Lehrkräfte von bernischer Herkunft aus dem unter bernischem Kirchenrecht stehenden Solothurner Distrikt Bucheggberg den Kommunikationskanälen der Berner Pfarrer vor Ort gefolgt sein. Entsprechend hatte der beschränkte Distributionsradius von Informationen die lehramtliche Mobilität und damit die Möglichkeit zum aktiven Stellenwechsel limitiert. So erweist sich denn auch die hohe Quote an lokaler Rekrutierung nicht bloss als eine Umsetzung von obrigkeitlichen Normen und dem Wunsch der Dorfgenossen, sondern gleichsam als ein Resultat von noch eingeschränkten Kommunikationsflüssen. Das Rekrutierungsfeld beziehungsweise der Kandidatenkreis für jede vakante Schulstelle 
war denn auch nur so gross, wie die Informationen über die pfärrerlichen Korrespondenznetzwerke und durch orale Verbreitung räumlich diffundiert werden konnte.

Überlokale Ausschreibungen von vakanten Schulstellen existierten vor der Helvetischen Revolution noch kaum, sondern kamen erst mit dem postrevolutionären Zuwachs an Drucksachen und Publikationsmedien auf. Interregionale Tages- und Wochenzeitungen druckten nach 1800 etwa zunehmend freie Schulstellen in ihren Inseratespalten, wodurch sich der potenzielle Adressatenkreis deutlich vergrösserte, selbst wenn die regelmässige Zeitungslektüre noch ein Luxus der wohlhabenderen Gesellschaftsschichten war. ${ }^{1256}$ Zudem begannen einzelne kantonale Erziehungsräte, vakante Stellenmeldungen zentral und systematisch zu sammeln. Die Berner Landpfarrer wurden demnach vom bernischen Erziehungsrat angehalten, freie Schulstellen inklusive der zu erwartenden Besoldung an den kantonalen Erziehungsrat zu übermitteln. ${ }^{1257}$ Damit sollte zum einen zweifellos eine raschere Wiederbestellung von vakanten Schulstellen ermöglicht werden, zum anderen dachten die Erziehungsräte wohl aber auch an eine bewusste Steuerung des Lehrpersonals, wer wohin geschickt werden könnte.

Eng mit der Frage nach der Bewegungsrichtung bei Stellenwechseln verbunden ist denn auch die Anschlussfrage nach einer vertikalen sozio-ökonomischen Mobilität. Führte der Wechsel einer Schulstelle im Allgemeinen - im Besonderen aber an eine zentralörtliche Schule - zu einer ökonomischen und sozialen Besserstellung? Wiederum aus der Autobiografie von Jakob Eggen wissen wir beispielsweise, dass sich bereits ein erfolgreiches Bewerben um eine besser besoldete Schulstelle dahingehend finanziell gelohnt hatte, dass ihm im Anschluss der Lohn an seiner bisherigen Wirkungsstätte in Langenthal BE markant erhöht worden war. ${ }^{1258}$ Manchmal reichte somit bloss die Drohung, die Schulstelle zu wechseln, um eine Lohnerhöhung zu erhalten. Wenn Lehrer ihre Stellen wechselten - war das Einkommen also ein leitendes Motiv?

Ob ein Orts- beziehungsweise ein Schulstellenwechsel - in die Stadt oder zwischen zwei Landschulen - auch wirklich zu einer ökonomischen Besserstellung führte, kann in Ansätzen durch Einkommensvergleiche bei Lehrkräften mit mindestens einer vorhergegangenen Schulstelle geklärt werden. Der Vergleich ist aufgrund der Zeitgleichheit der Betrachtung methodisch zwar nur von hypothetischer Natur, da uns aus der Stapfer-Enquête einzig die Lohnwerte vom Erhebungszeitpunkt im Frühjahr 1799 zum Vergleich bereit stehen und Besoldungsveränderungen im Laufe der Zeit zwischen den Stellenwechseln nicht rekonstruiert werden können. Dennoch ermöglichen die vorliegenden Daten zu den Einkommensverhältnissen anhand einer genaueren Betrachtung von Einzelbeispielen eine punktuelle Einschätzung, ob sich ein Stellenwechsel für die Lehrerschaft finanziell auszahlte oder nicht. In der Folge soll auf eine Reihe von exemplarischen Einkommensbetrachtungen durch Stellenwechsel näher eingegangen werden.

Von besonderem Interesse für die Frage nach einer sozialen Mobilität durch ein verbessertes Einkommen sind zum ersten jene Lehrkräfte, die von einer Landschule an eine zentralörtliche Schule gewechselt hatten. In einer Stichprobe von zehn untersuchten Lehrkräften konnten alle ihr Einkommen durch den Stellenwechsel teilweise massiv steigern, wie die nachfolgende Tabelle illustriert. ${ }^{1259}$

1256 Vgl. hierzu die Studie von Michael Ruloff: Ruloff, Presse.

1257 Zahlreiche Meldungen von Lokalpfarrern über vakante Stellen im Kanton Bern sind für die gesamte Zeit der Helvetischen Republik im Staatsarchiv Bern aufbewahrt. Exemplarisch sei auf die Meldung des Pfarrers Ith zur freien Schule von Lüscherz BE verwiesen: StABE B III 903, o. Pag.: 07.01.1799 - Siselen.

1258 Meyer, Langenthal: 38; vgl. die Ausführungen im Kap. 3.1.2.

1259 Zur Untersuchung herbeigezogen wurden einzig Lehrkräfte, deren Einkommen komplett aus Geldzahlungen bestand, um Verzerrungen durch allfällige nicht berechenbare Naturalwerte möglichst zu vermeiden. Auf eine Berücksichtigung der regionalen Währungsschwankungen bei der Umrechnung der Geldwerte in Franken wurde der Einfachheit halber verzichtet. Da etliche der Lehrkräfte zudem eine freie Wohnung oder weitere Naturalleistungen beanspruchen konnten, die nicht mit eingerechnet sind, sind die vorliegenden Geldwerte als Minima zu betrachten. 
Tab. 32: Einkommensveränderungen von Land-Stadt-Wanderungen

\begin{tabular}{|c|c|c|c|c|}
\hline Name, Schulort 1799: & $\begin{array}{l}\text { Schulischer } \\
\text { Karriereverlauf: }\end{array}$ & $\begin{array}{l}\text { Einkommen erste } \\
\text { Schulstelle: }\end{array}$ & $\begin{array}{l}\text { Einkommen letzte } \\
\text { Schulstelle: }\end{array}$ & Differenz: \\
\hline $\begin{array}{l}\text { Abram Jsaac Guignard, } \\
\text { Montricher }\end{array}$ & Les Bioux-Montricher & $104 \mathrm{Fr}$. & $\begin{array}{l}167 \text { Fr. } \\
+ \text { Wohnung }\end{array}$ & $+44 \%$ \\
\hline $\begin{array}{l}\text { Samuel Jacob Massard, } \\
\text { Bern }\end{array}$ & Blonay-Bern & $240 \mathrm{Fr}$. & $\begin{array}{l}715 \mathrm{Fr} . \\
+ \text { Wohnung }\end{array}$ & $+298 \%$ \\
\hline $\begin{array}{l}\text { Jean Daniel Dêtraz, } \\
\text { Staint-Saphorin }\end{array}$ & $\begin{array}{l}\text { Essertes-Molondens- } \\
\text { Echandens-St. Saphorin }\end{array}$ & $80 \mathrm{Fr}$. & $\begin{array}{l}137 \text { Fr. } \\
+ \text { Wohnung }\end{array}$ & $+71 \%$ \\
\hline $\begin{array}{l}\text { Jean David Chollet, } \\
\text { Lausanne }\end{array}$ & Morrens-Lausanne & $50 \mathrm{Fr}$. & $\begin{array}{l}228 \text { Fr. } \\
+ \text { Wohnung }\end{array}$ & $+456 \%$ \\
\hline $\begin{array}{l}\text { David Samuel Goy, } \\
\text { Lausanne }\end{array}$ & Prilly-Lausanne & $160 \mathrm{Fr}$. & $\begin{array}{l}224 \text { Fr. } \\
\text { Keine Wohnung }\end{array}$ & $+140 \%$ \\
\hline $\begin{array}{l}\text { Peter Ammann, } \\
\text { Langenthal BE }\end{array}$ & Roggwil-Langenthal & $75 \mathrm{Fr}$. & $\begin{array}{l}\text { 190.4 Fr. } \\
+ \text { Wohnung }\end{array}$ & $+254 \%$ \\
\hline $\begin{array}{l}\text { Henri Rudolph, } \\
\text { Payerne }\end{array}$ & Stettlen-Payerne & 75 Fr. & $\begin{array}{l}154 \text { Fr. } \\
\text { Keine Wohnung }\end{array}$ & $+205 \%$ \\
\hline $\begin{array}{l}\text { Jean Louis Pache, Lau- } \\
\text { sanne }\end{array}$ & Sullens-Lausanne & $96 \mathrm{Fr}$. & $\begin{array}{l}300 \mathrm{Fr} . \\
\text { Keine Wohnung }\end{array}$ & $+313 \%$ \\
\hline $\begin{array}{l}\text { Pierre François Reymondin, } \\
\text { Lausanne }\end{array}$ & Pully-Lausanne & $178 \mathrm{Fr}$. & $\begin{array}{l}186 \text { Fr. } \\
\text { Keine Wohnung }\end{array}$ & $+4 \%$ \\
\hline $\begin{array}{l}\text { Johannes Walser, } \\
\text { Altstätten }\end{array}$ & Hinterforst-Altstätten & $66 \mathrm{Fr}$. & $\begin{array}{l}\text { 126.5 Fr. } \\
+ \text { Wohnung }\end{array}$ & $+191 \%$ \\
\hline
\end{tabular}

Als Landschullehrer an eine zentralörtliche Schule zu ziehen, erwies sich in allen untersuchten Fällen als zwar ökonomisch lukrativ, war aber selten der Fall. Bis zu einer Vervierfachung des Einkommens war demnach möglich, zudem lagen die zentralörtlichen Löhne durchwegs über dem anvisierten jährlichen Mindestlohn für Elementarschullehrer. Kein einziger der Lehrer erwähnte jedoch das Einkommen als leitendes Motiv für seinen Stellenwechsel. Obwohl die Frage nicht explizit gestellt war, fanden sich selbst in den Anmerkungen der Lehrkräfte am Ende des Fragebogens keinerlei freiwillig platzierte Hinweise auf eine Einkommenssteigerung als zentrales Motiv zum Wechsel an eine zentralörtliche Schule. Gleichwohl können wir anhand der Autobiografie von Jakob Eggen als Vertreter dieses Mobilitätstypus annehmen, dass sich die wechselwilligen Lehrkräfte durchaus vom angebotenen Lehrerlohn bei der Entscheidung zum Stellenwechsel leiten liessen. Hinsichtlich der Einkommensentwicklung sind ferner jene wenigen Spezialfälle, bei denen ländliche Lehrkräfte erst in einer zentralörtlichen Schule, dann wieder auf dem Land gearbeitet hatten, von grossem Interesse. Die meisten dieser ländlichen Lehrkräfte, die eine zentralörtliche Schule wieder zugunsten einer Landschule verlassen hatten, konnten ihr einmal erworbenes Einkommen behalten oder gar noch ausbauen. Der Lehrer Johannes Thommet von Müntschemier BE, der bei Mühleberg BE ein eigenes Heimwesen besass, hatte beispielsweise sowohl an verschiedenen Landschulen, als auch an einer Stadtschule gearbeitet: „Zu erst zu Jeüss, K. Murten zu Laupen, in der Stadt, zu Galmiz, K. Murten, auf der Ledi; K. Mühliberg, und seit 5. Jahren zu Müntschemier. ${ }^{\text {"1260 }}$ Hinsichtlich seines Einkommens gelang es dem genannten Leh- 
rer trotz des Wegzugs von der Stadtschule Laupen zumindest seinen Besitzstand zu wahren, denn er verdiente in der Seeländer Landgemeinde exakt genauso viel wie mutmasslich zuvor in der Stadtschule Laupen, nämlich rund 45 Kronen oder 112.5 Franken. ${ }^{1261}$

In ökonomischer Hinsicht noch erfolgreicher verlief die Berufskarriere des Lehrers von Koppigen BE, Jakob Kräuchi, dessen Einkommen sich auf seinen vier Berufsstationen gar noch vermehrt hatte. Aus dem nahegelegenen Bäriswil BE stammend, arbeitete Kräuchi: „Zu Bäriswyll Jahr 4, - zu Laupen Jahr 6 - zu Lyßach bey Burgdorf Jahr 4 - zu Roggwyll Jahr 3 - und Hier das 1te Jahr. "1262 Dabei verdiente er in Bäriswil BE 22 Kronen zuzüglich sechs Klafter Holz und einer Jucharte Land, in Laupen BE 45 Kronen, in Lyssach BE 36 Kronen und 20 Batzen plus eine freie Schulwohnung mit Garten, in Roggwil BE mindestens 30 Kronen plus eine freie Schulwohnung und das Nutzungsrecht an einer Jucharte Allmendland, und endlich in Koppigen BE „Francen 127. bz. 4. xr. 1“ zuzüglich einer freien Schulwohnung und eines Gärtchens. ${ }^{1263}$ Allerdings gelang es nicht jedem Lehrer, der eine städtische Schule verliess oder verlassen musste, seinen Besitzstand zu bewahren. Ein sehr anschauliches Beispiel dafür lieferte der Lehrer David Andrist von Erlenbach im Simmental BE. Selbst aus dem benachbarten Därstetten BE stammend, hatte der genannte Lehrer - in ähnlicher Weise wie der eingangs beschriebene Jakob Eggen - zunächst eine steil aufsteigende Schulmeisterkarriere als Landschulmeister an drei Schulen im Oberaargau durchlaufen. Vom Seeländer Städtchen Nidau BE, wo er „mit Lektionengeben im Schreiben, Rechnen Clavier spielen, bis zur Revolution, genugsam beschäftigt meine Nebenstunden zu nüzen [war]; durch dieselbe aber ist mir mein nöthiger Nebenverdienst entrißen, ich bin von den Franken bis aufs lezte Hemd geplündert, von den Anhängern an die alte Staatsverfaßung, wegen meiner Anhänglichkeit an die neüe, bitter gehaßet worden; darum wählte ich mir um die Hälfte der Besoldung Erlenbach, wo ich jzt meine StrümpfweberProffess. daneben treiben muß. ${ }^{\text {“1264 }}$

Tatsächlich belief sich die jährliche Besoldung Andrists mit 60 Kronen nur noch auf knapp die Hälfte des vorherigen Einkommens als Stadtschullehrer in Nidau. ${ }^{1265}$ Dennoch verdiente Andrist am Marktort Erlenbach BE mit rund 150 Franken pro Jahr immer noch das Drei- bis Fünffache seiner Lehrerkollegen in den unmittelbaren Nachbarschulen derselben Kirchgemeinde, obwohl er nur wenig mehr Zeit für den Unterricht aufwenden musste. ${ }^{126}$ In dieser ausdrücklichen Form des erzwungenen Ortswechsels und des damit verbundenen ökonomischen Verzichts war der genannte Lehrer zwar ein extremer Einzelfall, als sozialen Abstieg kann der Lebensverlauf des genannten Lehrers angesichts des immer noch sehr hohen Einkommens im Gegensatz zu

1261 Auch in Müntschemier verdiente der Lehrer insgesamt 44-45 Kronen. Der Schullohn der Stadtschule Laupen betrug im Jahr 1799 total 45 Kronen. Von den anderen Schulen fehlen die Daten, da keine Antworten auf die Stapfer-Enquête vorliegen. Dem Einkommensvergleich liegt die hypothetische Annahme zugrunde, dass die Lehrkräfte am vorherigen Ort dasselbe Einkommen erzielt hätten wie es die Stapfer-Enquête für das Jahr 1799 auswies, ohne Einbezug von allfälligen Lohnveränderungen. Schmidt u.a. (Hgg.), Stapfer-Enquête, Nr. 1068: Laupen.

1262 Schmidt u.a. (Hgg.), Stapfer-Enquête, Nr. 862: Koppigen.

1263 Schmidt u.a. (Hgg.), Stapfer-Enquête, Nr. 648: Roggwil; Nr. 862: Koppigen; Nr. 1068: Laupen; Nr. 1348: Bäriswil; Nr. 1438: Lyssach.

1264 Schmidt u.a. (Hgg.), Stapfer-Enquête, Nr. 1389: Erlenbach im Simmental.

1265 Der obere Stadtschullehrer von Nidau verdiente 134 Kronen zuzüglich mehrerer Naturalabgaben.

1266 Die reine Geldbesoldung der drei umliegenden Schulen in der Kirchgemeinde Erlenbach im Simmental belief sich auf 27.5 Franken in Latterbach BE (11 Kronen), 42.5 Fr. in Ringoldingen BE (17 Kronen) und 50 Fr. in Oey BE (20 Kronen). In allen drei Schulen wurde im Sommer nur eine eintägige Sommerschule pro Woche gehalten, während die Sommerschule in Erlenbach zwei Tage pro Woche dauerte. Schmidt u.a. (Hgg.), Stapfer-Enquête, Nr. 1390: Latterbach; Nr. 1391: Ringoldingen; Nr. 1415: Oey. 
seinen Berufskollegen jedoch nur in Anführungszeichen bezeichnet werden. Vielmehr zeigt der vorliegende Fall, dass persönliche Netzwerke oder familiäre Bindungen, die hinter der Entscheidung Andrists für die Schule Erlenbach vermutet werden können, in Krisenzeiten einen starken Einfluss auf das Mobilitätsverhalten hatten.

Insgesamt verliessen zentralörtliche Lehrkräfte ihre gut bezahlten Schulstellen mehrheitlich erst, wenn zumindest die vorherige Einkommenshöhe gewahrt werden konnte. Daraus lässt sich ein zumindest indirektes ökonomisches Leitmotiv stark vermuten. Gleichwohl blieb der Kreis an Personen mit reellen beruflichen und sozialen Aufstiegschancen im ausgehenden 18. Jahrhundert noch sehr eingeschränkt, sofern man städtischen und zentralörtlichen Räumen diese Funktionalität zuschreibt. Regelrechte soziale „Aufstiegs-Biografien“ durch das Lehramt, wie jene des späteren Seminardirektors Hermann Krüsi in Gais AR oder des Armenschullehrers Matthias Buser in Basel, wurden erst nach der Jahrhundertwende zu einem breiteren Phänomen. Vor 1800 waren solche biografischen Erfolgsgeschichten in der Lehrertätigkeit freilich noch seltene Einzelfälle.

Bei Schulstellenwechseln auf dem Land zwischen zwei Landschulen ist ein differenzierteres und zugleich disparateres Bild festzuhalten. Manchen Lehrkräften gelang es, durch einen Schulstellenwechsel zu einem gleichen Schultyp ihre Einkommenslage massiv zu verbessern. Der Lehrer Friedrich Schärer von Untersteckholz BE hielt beispielhaft fest: „13. Jahre ward er Schulmeister für ober- und unter-Stekholz; nach dem diese Schulen getrennet worden, so ist er ein Jahr der Schule Unterstekholz vorgestanden; darnach versahe er 7. Jahre lang der Schuldienst zu zu Wangen, im Kanton Bern. Auf eine gemachte Gradification hin, ist er wiederum bald 1 1/2 Jahr bey seiner ehemaligen Schule Unterstekholz. [...] Das Einkommen, welches die Gemeinde zwar nur für den gegenwärtigen Schulmeister bestimmt hat, betragt an Geld Kronen 32. Denn ist 2. Juharten frisch zur Schule gewittmet Allmend-Land, da aber solches sehr naß und ungebauen, so kann dem jährlichen Altrag, aufs Höchste gerechnet werde. kr: 8. Summa kr. 40“ ${ }^{1267}$

Mit der Gratifikation verbesserte Schärer seinen Gesamtlohn um einen Viertel auf 1.00 Franken für bloss 6 Monate Schuldienst. Obwohl die alte Stelle zu Wangen an der Aare ebenfalls relativ gut bezahlt war, ${ }^{1268}$ schien er die Stelle in seiner Heimatgemeinde bevorzugt zu haben, zumal die Schuldauer kürzer und die Stelle näher an seinem Wohnort lag.

Indes, bei Schulstellenwechseln aus Rückkehrmotiven resultierte nicht immer eine ökonomische Verbesserung für die Lehrkraft. Der Lehrer von Toffen BE verzichtete etwa durch seinen Wechsel an die Heimatschule auf mehr als die Hälfte seines vorherigen Gehalts als Lehrer in Belp BE. ${ }^{1269}$ Auch bei anderen rückkehrenden Lehrkräften konnte ein bisweilen markanter Einkommensverlust durch die Rückkehr festgestellt werden. ${ }^{1270}$ Hierbei scheinen ungenannte, nicht-monetäre Motive wie das volle Burgerrecht, ein höheres soziales Ansehen oder familiärklientelistische Netzwerke wirkungsmächtiger gewesen zu sein als die reine Einkommenshöhe.

1267 Schmidt u.a. (Hgg.), Stapfer-Enquête, Nr. 649: Untersteckholz.

1268 Der Schullohn zu Wangen a.A. betrug für die Ganzjahresschule 22 Kronen, 10 1⁄2 Mütt Dinkel, 12 Klafter Holz, eine Wohnung und einen Garten, was eine Entschädigung von über 160 Franken ergab. Es ist aber unklar, ob die Schulstelle in Wangen ebenfalls einen Lohnzuwachs erfuhr. Schmidt u.a. (Hgg.), Stapfer-Enquête, Nr. 957: Wangen an der Aare.

1269 In Belp BE verdiente der Lehrer wohl rund 125 Franken, während er in Toffen BE nur noch 50 Fr. einnahm. Beide Schulorte boten ihren Lehrern eine freie Wohnung bzw. eine Hauszinszahlung an. Schmidt u.a. (Hgg.), Stapfer-Enquête, Nr. 1514: Belp; Nr. 1515: Toffen.

1270 Der Lehrer von Vich VD verdiente 1799 mit 122 Franken nur noch einen Drittel des Gehalts, das er an seiner vorherigen Schule in Begnins VD mit 21.5 Louis d'or (344 Franken) erzielt hätte. Schmidt u.a. (Hgg.), StapferEnquête, Nr. 1792: Begnins; Nr. 1805: Vich. 
Diese Motive erscheinen aber im Angesicht der zuvor festgehaltenen häufigen Rückkehrbewegungen von Lehrkräften an ihre Herkunftsschule von kollektiver Bedeutung. Offensichtlich überwogen die rechtlichen und sozialen Vorteile des Unterrichtens in der Heimatgemeinde die monetären Anreize. Nicht nur die normativen Vorgaben, sondern auch regionale Eigenheiten der Schulorganisation und individuelle Entscheidungen bewirkten somit - wie Rebekka Horlacher aus ihren Erkenntnissen zu einer Zufallsstichprobe an Lehrkräften über das Mobilitätsverhalten festgehalten hat - dass „eine gewisse räumliche Mobilität auch für den Lehrer des Ancien Régimes kein Fremdwort gewesen ist." ${ }^{1271}$

\subsubsection{Unterbrüche}

Trotz der im vorangehenden Kapitel konstatierten langen durchschnittlichen Ausübungsdauer war das Lehramt in einigen Fällen keine kontinuierlich ausgeübte Tätigkeit. Zwar hielten die meisten Lehrer ihrem Amt durchwegs die Treue, doch finden sich auch Beispiele von Lebensverläufen mit kurzen oder teilweise längeren Unterbrüchen bei der Ausübung der Unterrichtstätigkeit. So berichtete der Lehrer von Täuffelen BE exemplarisch: „hat auf das Anhalten der Vorgesezten und der Gemeinde die Schule diesen Winter angenohmen. Vorher hat er die gleiche Schule 25. Jahr Versehen als: von 1759. bis 1784. sein Beruff ware ein Leinweber und Landarbeit." 1272

Konkrete Gründe für einen Unterbruch der Lehrertätigkeit wurden in der Stapfer-Enquête jedoch selten explizit erwähnt und sind dementsprechend nicht als repräsentativ anzusehen. Ein sicherlich bedeutsamer Grund für einen zeitweiligen Berufsunterbruch dürfte das mangelhafte Einkommen aus dem Schuldienst gewesen sein, wie uns die ausführliche Antwort des Lehrers von Montet FR zeigt: „il n'a jamais quitté Son lieu de naissance \& la profession étoit de cultiver Un petit dommaine, il y a Six ans qu'il a d'éja été Régent l'espace d'un an, vu le modique Salaire, aux prieres même de la dite Commune refusa de continuer, après quelques temps elle lui proposa de la refaire, et l'accepta encore pour un an, et demanda de nouveau Sa démission et cela raison la charté des vivres, et comme les denrées ètant venues a fort bas prix il reprit la dite école aux Suffrages de la Commune." ${ }^{1273}$

Wenn die Ersttätigkeit lukrativer wurde als das Ausüben des Lehramts konnten durchaus eine Abkehr vom Lehramt und eine Rückkehr zur Ersttätigkeit stattfinden. Den Lehrkräften mit Ausübungsunterbrüchen eine rein ökonomisch bestimmte Handlungsweise vorzuhalten, unterschlägt jedoch ihren individuellen Handlungsspielraum und man wird ihnen als selbstgestaltenden sozialen Akteuren nicht gerecht, zumal auch eine Vielzahl individueller, persönlicher Gründe einen unterbrochenen Tätigkeitsverlauf produzieren konnten.

Konflikte mit den Eltern, dem vorgesetzten Pfarrer oder der Schulgemeinde, persönliche Interessensverschiebungen, Veränderungen im persönlichen sozialen Netzwerk in der Gemeinde oder veränderte schulische Rahmenbedingungen konnten sich genauso als Treibkräfte für einen Karriereunterbruch auswirken. Andernorts hatten familiäre Verpflichtungen die zeitweilige Aufgabe des Lehramts bewirkt, wie das Beispiel des Lehrers Franz Albert Wilhelm von Reichenburg SZ verdeutlicht: „Weil ich da viele müssige Stunden hatte, besuchte ich offt die schule, und leistete dem dazumahligen schullehrer, der zur selbigen Zeit zugleich unser Pfarrer ware, einige Hilfe. Dieser, weil die schule ihme nebend seinen pfärrlichen Verrichtungen zu Beschwerth. vorkamme, überredte mich auf künftigen Martini 1784 die schule anzunehmen. Endlichen ge-

1271 Horlacher, Leutnant: 25.

1272 Schmidt u.a. (Hgg.), Stapfer-Enquête, Nr. 879: Täuffelen.

1273 Schmidt u.a. (Hgg.), Stapfer-Enquête, Nr. 198: Montet (Glâne). 
horchte ich seinem Willen, und zeigte bey der Martinus Gemeinde anno 84zig dem Volke mein verlangen. Richtig wurde ich an der Stelle alß schullehrer angenohmen. Sieben volle Jahre behielte ich meinen Dienst, alß ich wegen häüsslichen Angelegenheiten diesen von Hand geben musste anno 1791, so übernahm selben mein Br[uder]. District schreiber Aloyß Wilhelm. Er behielte ebenfalß denselben bis Martini - 98. Nun aber ware er genöthiget, wegen Annahme seines schreiber Amtes, der schule aufzukünden: Und weil Niemand anwesend ware, der sich für den vacanten schuldienst freüen wollte wurde ich, obwohlen dazumahlen ich schon von dem Wahl Korps alß Bezirk Richter erwöhlt ware, genöthiget selben wieder anzunehmen."1274 Eine quantitativ gesicherte Einschätzung der Häufigkeit von unterbrochenen Lehrerkarrieren ist aufgrund der Lückenhaftigkeit der Quellen und der Freiwilligkeit der Angabe nicht möglich. Insgesamt wiesen aber mit rund zwei Dutzend gesichert überlieferten Fällen nur sehr wenige Biografien einen diskontinuierlichen Verlauf mit einem zeitweiligen Ausstieg aus der Lehrertätigkeit und einer späterer Rückkehr darauf, wenngleich eine mindestens ebenso hohe zusätzliche Dunkelziffer vermutet werden muss. In der Regel waren die helvetischen Lehrer jedoch ihrem übernommenen Amt lückenlos treu geblieben, wenn auch nicht zwingend für die gesamte Dienstdauer am gleichen Schulort. Das lässt den indirekten Folgeschluss zu, dass eine bloss temporäre lebenszyklische Ausübung des Lehramts durch bestimmte Professionsgruppen nicht existierte.

\subsection{Freizeit und Mitgliedschaft in Sozietäten}

Für die ausserschulischen Aktivitäten der Lehrerschaft interessierte sich Philipp Albert Stapfer in seiner Schulumfrage ganz im Gegensatz zum zeitgleich versendeten Fragebogen an die Geistlichkeit nicht. Während die Geistlichkeit in der Pfarrer-Enquête von 1799 „in einer überraschenden Vielseitigkeit “1275 zu ihren Studien, ihren wissenschaftlichen Lieblingsbeschäftigungen, der Mitgliedschaft in gelehrten Gesellschaften und zu besonderen Verdiensten befragt wurden, fehlten in der zeitlich parallelen Schulumfrage entsprechende Fragen an die Lehrerschaft. ${ }^{1276}$ Leonhard Haas hat zu den Motiven Stapfers zur ungleich genaueren Befragung der Geistlichen resümiert: „Aus all dem geht hervor, dass Stapfer sich der Bedeutung und Funktion der Geistlichkeit in seiner Zeit in unserem Land ganz bewusst war, da er mit Absicht Bildungsgrad und Staatsbewusstsein in unserem Volke heben wollte."1277

Bei der Elementarschullehrerschaft ging Stapfer dagegen in vorurteilsbehafteter Denkweise von einem weitgehend mangelhaften Zustand bezüglich des individuellen Bildungsgrades und des persönlichen Werdegangs aus, was letztendlich eine explizite Erhebung für ihn obsolet werden liess, obwohl Stapfer durch persönliche Korrespondenzen von Landschullehrkräften eigentlich durchaus Kenntnis von individuellen Fortbildungsbemühungen und der Teilnahme an Veranstaltungen von bildungsaffinen Vereinigungen hatte. Da aber konkrete Fragen im Fragebogen an die Lehrer fehlen, sind Erkenntnisse über die arbeitsfreie Zeit der Lehrerschaft nur anhand von spärlich vorhandenen freiwilligen Zusatzbemerkungen überhaupt greifbar.

Reine arbeitsfreie Zeit zur Erholung oder zur Pflege persönlicher Interessen im modernen Verständnis von „Freizeit“"vermerkten Landschullehrkräfte in Ermangelung einer konkreten Frage-

1274 Schmidt u.a. (Hgg.), Stapfer-Enquête, Nr. 855: Reichenburg.

1275 Haas, Innerschweiz: 510.

1276 Vgl. den Fragebogen zu den Personalverhältnissen in der Pfarr-Enquête von 1799. Die Personalverhältnisse der katholischen Geistlichkeit werden im Rahmen eines laufenden Dissertationsprojekts durch Mauro Di Cioccio an der Universität Bern erforscht.

1277 Haas, Innerschweiz: 510f. 
stellung in der Regel in ihren Antwortschriften kaum. Die freien Stunden neben dem Lehramt während der aktiven Schulunterrichtsperiode wurden entweder von weiteren ökonomischen Tätigkeiten zur Sicherung der Subsistenz ausgefüllt oder für nicht näher definierte „Hausgeschäfte" verwendet, wobei auch dort eine ökonomische Komponente vermutet werden muss. Der zeitliche Raum für eine individuelle Fortbildung durch private Lektüre oder Schreibtätigkeiten blieb meistens auf kleine Zeitfenster in Abendstunden beschränkt, doch bleiben diese konkreten alltagsgeschichtlichen Handlungen aufgrund mangelnder Angaben für allgemeine Rückschlüsse weitgehend verborgen. Die Nichterwähnung bedeutet freilich nicht, dass sich Lehrkräfte nicht Beschäftigungen der persönlich-individuellen Musse abseits von ökonomischen Zwängen der Erwerbsarbeit widmen konnten. Explizite Freizeitaktivitäten ohne ökonomische Wertschöpfung für die Lehrkraft tauchten in der Stapfer-Enquête zwar bloss fragmentarisch in Erscheinung, erlauben aber dennoch einen beschränkten Einblick in das Leben der Lehrkräfte.

Hinter der Erwähnung von nicht ökonomisch motivierten Freizeitaktivitäten steckte eine scharfe sozialräumliche Distinktion, denn solcherlei freiwillige Zusatzangaben fanden sich praktisch ausschliesslich in Antworten von zentralörtlichen, privaten und geistlichen Lehrkräften notiert, deren ungleich bessere ökonomische Situation überhaupt erst ein gewisses Mass an freier Zeit für Musse erlaubte. Landschullehrkräfte von weltlicher Herkunft berichteten dagegen so gut wie nie von unbezahlten Freizeitaktivitäten oder Beschäftigungen zur reinen Musse. Insgesamt fanden sich bloss 16 explizite Erwähnungen von Freizeitaktivitäten in der Umfrage, wovon elf auf zentralörtliche und bloss fünf auf ländliche Lehrkräfte entfielen. Acht jener Lehrkräfte gehörten zudem dem geistlichen Stand an. Die Schlussfolgerung, dass die kollektive Nichterwähnung von Freizeitaktivitäten in der Stapfer-Enquête bei Landschulmeistern direkt ein reales Vorhandensein von solchen Aktivitäten im zeitgenössischen Alltag negiert, ist zwar diskursanalytisch nicht zulässig, da ja eine entsprechende Fragestellung im Fragebogen Stapfers fehlte und eine Nichterwähnung nicht automatisch gleichzusetzen ist mit einem historischen Nicht-Vorhandensein. Dennoch kann aufgrund des sozial deutlich eingeschränkten Personenkollektivs mit Freizeitbeschäftigungen davon ausgegangen werden, dass nicht-besoldete Freizeitaktivitäten erst durch eine hohe Grundbesoldung überhaupt erst möglich wurden und somit ein fast ausschliessliches Privileg von zentralörtlich-wohlhabenden oder geistlichen Lehrkräften waren.

Die Bandbreite der vermerkten Freizeitaktivitäten reichte indes von häuslichen, schriftstellerischen bis hin zu vielfältigen (natur-)wissenschaftlichen Betätigungen. Der Herisauer Privatschullehrer und Theologe Johann Graf konnte sich gemäss seiner eigenen Angaben neben seinen Schulstunden sowohl der privaten Lektüre, als auch ausgedehnten Wanderungen widmen: „Neben meiner Schule sind Lectur, Alpenreislein auf unser Säntisergebirg, Naturaliensammeln und der Anbau eines Kraut, und Blumengärtchens meine Verrichtungen oder Erholungen." ${ }^{1278}$ Hinter der Aufzählung an Freizeitbeschäftigungen steckte in diskursanalytischer Betrachtung nicht nur das historisch Gewesene, sondern oftmals auch der berechnende Versuch einer bewussten Selbstakzentuierung gegenüber den Empfängern der Umfrage, dem Minister der Künste und Wissenschaften und den kantonalen Erziehungsräten. So sollte etwa die Erwähnung von naturkundlichen oder literarischen Beschäftigungen ein wissenschaftliches Grundinteresse als Kernbotschaft mittransportieren, um eine gewissenhafte und aktive Gelehrsamkeit im Sinne der Aufklärung zu demonstrieren. In diesem Kontext ist auch die eher kurios anmutende Aufzählung an Freizeitbeschäftigungen des Basler Gymnasiallehrers und Theologen Johannes Frey 
zu verorten: „Neben dem Schulamte wende ich meine Zeit an philosophische Untersuchungen, oder zur Erholung an meine Lieblingsbeschäftigung in electrischen Versuchen, wie auch zum Besuch der öffentlichen Lesegesellschaft, bey welchen ich seit ihrem Ursprung zum Bibliothekar angenommen worden. Ueberdies habe ich viele verschiedene Abhandlungen über allerhand Gegenstände, worunter etliche gekrönte Preisschriften waren, verfertiget, und einige in Druck herausgegeben; unter welchen ein Werkchen: ,Auswahl der Lehren und Thaten Jesu' mir einen grossen und langwierigen Religionsstreit zugezogen hatte. "1279 Wenngleich unklar bleibt, welchen wissenschaftlichen Zweck die erwähnten „elektrischen Versuche“ hatten, so diente ihre Erwähnung wohl ebenso wie die genannten Preisschriften und das umstrittene Büchlein primär der Selbstpositionierung des Lehrers als aktiver wissenschaftlicher Gelehrter. Ferner ist die explizite Betonung des Konflikts mit den alten Obrigkeiten als eine Loyalitätsbekundung für die neue revolutionäre Regierung zu deuten.

Eine ähnliche Funktion der bewussten Imagepflege kann ferner hinter der Schilderung des städtischen Lehrers Johannes Werenfels aus Kleinbasel vermutet werden: „Die übrige Zeit bringt er als Volontaire auf dem Bureau des Unterstatthalters zu. “1280 Die Erwähnung von ehrenamtlichen Tätigkeiten im Dienste der neu geschaffenen Verwaltung diente wohl auch hier bewusst dazu, sich gegenüber der neuen Regierung günstig zu positionieren.

Dass Lehrer hingegen als Schreib- und teilweise auch als Rechenkundige gerne für Schreibtätigkeiten aller Art in der Verwaltung oder in schreiblastigen Gewerben eingesetzt wurden, ist naheliegend. Der reformierte Stadtschullehrer von Glarus, Jakob Steinmüller, führte aufgrund seiner elaborierten Kulturtechnikkompetenzen in seiner Freizeit die Buchhaltung der Apotheke: „nach meiner geendeten Schul Arbeit aber finde ich mein vergnügen in Führung einer Buchhaltung, und Correspondenz, bey einer Apotheck, die mit einem Associé gemein habe." ${ }^{1281}$ Schriftstellerische Betätigungen sowie die aktive Teilnahme an einer Lesegesellschaft waren auffallende Merkmale, die sich in etlichen anderen Biografien städtischer Lehrkräfte wiederfanden. So betätigte sich ferner der Zürcher Stadtschullehrer Johann Jakob Hirschgartner ebenfalls als Schriftsteller: „Neben dem Lehramte schrieb er die Stemmatologiam Thuricensems X. Tom. Die geschriebne Zeitung, von 1759. bis izt 1799. 14. Tom. Meditirt und schreibt für die liebe Schuljugend eint- und andere Pièces, auch kleine Poësien." ${ }^{1282}$

Schriftstellerische Aktivitäten fanden sich jedoch auch bei einzelnen wenigen Landschullehrern vermerkt. Eine bemerkenswerte Ausnahme eines schriftstellerisch tätigen Landschullehrers von ländlich-handwerklicher Herkunft war Sebastien Reymond, reformierter Lehrer im Städtchen Echallens VD, der neben seiner Zusatzarbeit als Schreiner und Drechsler noch Zeit für das Verfassen einer politischen Schrift fand: „En Eté il travaille du menuisier \& tourneur, aime beaucoup la lecture; L'Eté dernier il a composé deux brochures en dialogues, l'une sur les droits féodaux \& l'autre Sur les bourgeoisies; ils ont été imprimés; Jl a composé un essai Sur les moyens de perfectionner l'éducation nationale, qu'il a envoyé à la chambre Administrative du Léman, et quelques autres petits manuscrits. "1283

Aufgewachsen als Bauernkind im abgelegenen Vallée de Joux im Waadtländer Jura illustriert der obgenannte Lehrer idealtypisch, dass mitunter auch Landleute nicht bloss als passive Konsumenten der zunehmenden Literalität, sondern verstärkt auch als aktive Produzenten von öffent-

1279 Schmidt u.a. (Hgg.), Stapfer-Enquête, Nr. 1470: Basel.

1280 Schmidt u.a. (Hgg.), Stapfer-Enquête, Nr. 2456: Basel.

1281 Schmidt u.a. (Hgg.), Stapfer-Enquête, Nr. 559: Glarus.

1282 Schmidt u.a. (Hgg.), Stapfer-Enquête, Nr. 257: Zürich.

1283 Schmidt u.a. (Hgg.), Stapfer-Enquête, Nr. 1704: Echallens. 
licher Schriftlichkeit verstanden werden müssen, selbst wenn es sich hier nur um einen freiwillig überlieferten Einzelfall handelte.

Die am häufigsten vermerkte Beschäftigung zur reinen Musse blieb jedoch das Lesen diverser Lektüren zur individuellen Fortbildung. So hielt es der Lehrer Johann Jakob Roth aus der Deputatenschule von Buckten BL fest: „Bey noch übrigen Musse Stunden gerne etwas nützliches in deutsch und Lateinischen Schriftstellern, und Zeitschriften, zur Aufklärung, list; und im Früh Jahr und Sommer sich mit Besorgung seines Küchen Gartens, und Genuß. Pflanzen gerne beschäftiget" 1284

Dass insbesondere die geistlichen Lehrkräfte eine Auseinandersetzung mit verschiedener Lektüre in der Umfrage mehrfach betonten, scheint ferner angesichts der von Stapfer erwarteten Führungsrolle der Geistlichen im Bildungswesen kein Zufall zu sein, sondern liest sich vielmehr ebenfalls als ein Versuch einer positiven Selbstpositionierung, wie obiges Zitat mit dem Verweis auf die Aufklärung exemplarisch verdeutlicht. Es ist denn auch anzunehmen, dass zumindest einige der geistlichen Lehrkräfte von den Fragen in der zeitgleich versandten Pfarrerumfrage gewusst und ihre Beantwortung in der Schul-Enquête entsprechend angepasst hatten.

Ein weiteres Themenfeld, das im Zusammenhang mit Freizeitaktivitäten angeschnitten wurde, war die Mitgliedschaft von Lehrkräften in Sozietäten. ${ }^{1285}$ Stapfer befürwortete persönlich die Mitgliedschaft von Elementarschullehrern in regionalen Lesegesellschaften oder in gelehrten Sozietäten als ein geeignetes Mittel zur Verbesserung des professionellen Bewusstseins der Lehrer, zu ihrer individuellen Fortbildung und nicht zuletzt zum Informationsaustausch zwischen den helvetischen Behörden und der Lehrerschaft. ${ }^{1286}$ So waren vereinzelte Lehrkräfte in Lesegesellschaften oder reformorientierten Sozietäten aktiv, wenngleich diese Zirkel und Vereine in der Regel den lokalen und regionalen Eliten in den Städten vorbehalten blieben und Landbürger bloss gelegentlich Aufnahme fanden. ${ }^{1287}$ Es würde den Rahmen der vorliegenden Arbeit sprengen, sämtliche in Sozietäten tätige Lehrer zu identifizieren, weshalb einzig das Quellenkorpus der Stapfer-Enquête auf Beteiligungen in Sozietäten geprüft wurde. Dabei konnte - wie die vorherigen Zitate zeigen - mindestens eine Hand voll Lehrkräfte identifiziert werden, die ihre Mitgliedschaft in einer Sozietät bekannten. Hierbei erfreuten sich naturgemäss Bildungsgesellschaften, insbesondere Lesegesellschaften, des grössten Zuspruchs, was durch den Zweck der gemeinsamen Beschaffung und des Austauschs von Büchern als einleuchtend erscheint. ${ }^{1288}$ Der geistliche Unterschullehrer von Schwyz SZ, Joseph Dominik Abegg, notierte beispielsweise: „ich [...] rechne es mir zu sondren Ehre ein Mitglied der Litterar-Oeconomischen Gesellschafft zu seyn, die in hier vor weniger Zeit errichtet worden."1289

Die genannte kleine Gesellschaft, zu der unter anderem der bekannte Kommandant und Politiker Alois Reding ${ }^{1290}$ und der Kaplan-Lehrer Josef Augustin Schibig ${ }^{1291}$ angehörten, war eine

1284 Schmidt u.a. (Hgg.), Stapfer-Enquête, Nr. 2226: Buckten.

1285 Unter einer Sozietät wird ein freiwilliger „Zusammenschluss von Individuen verstanden, dem eine feste Vereinbarung zugrunde liegt, ein ,Gesellschaftsvertrag “" Darin ist mindestens der spezifische Zweck geregelt, welcher in der Regel „,eine Absicht zur Reform“ im politischen, sozialen, ökonomischen, wissenschaftlichen oder künstlerischen Bereich im Rahmen der Aufklärung beinhaltet. Erne, Sozietäten: $17 \mathrm{f}$.

1286 Tosato-Rigo, Bild: 60f.

1287 Im Hof, Geleitwort: 13.

1288 Im Hof, Geleitwort: 12.

1289 Schmidt u.a. (Hgg.), Stapfer-Enquête, Nr. 2054: Schwyz.

1290 Alois Reding war Kommandant der Schwyzer Truppen beim Franzoseneinfall im Frühjahr 1798, später Erster Landammann der Helvetischen Republik. Vgl. Wiget, Reding.

1291 Schibig war selbst Lehrer in Iberg SZ. Nr. 2025: Oberiberg; Kälin, Aufklärung: 180. 
Zweiggesellschaft der „Literarischen Sozietät“ von Johann Heinrich Zschokke und beschäftigte sich intensiv mit dem Schulwesen und der Armenpflege im Kanton Schwyz. ${ }^{1292}$ Auch der reformierte Geistliche und Lehrer im toggenburgischen Oberhelfenschwil SG, Johann Heinrich Schweizer, war in einer lokalen Lesegesellschaft aktiv: „daneben ist er auch ein Mitglied der Lese Gesellschaft in Wattweil. ${ }^{\text {“293 }}$ Der geistliche St. Galler Stadtschullehrer Jacob Zollikofer seinerseits war Mitglied der Literarischen Gesellschaft St. Gallen, in der Vertreter aus Handel und Gewerbe Zeitungen, Zeitschriften und „die mannigfaltigen Neuerscheinungen in der Literatur" studierten. ${ }^{1294}$ Von einigen weiteren Lehrkräften kann eine Mitgliedschaft oder zumindest eine gewisse Nähe zu Sozietäten vermutet werden, von anderen weiss man es aus Sekundärquellen. Im Sozietäten-Lexikon von Emil Erne sind beispielsweise die „Lesegesellschaft Stein am Rhein “1295 vermerkt, gegründet durch den Schaffhauser Theologen und Lehrer in Hemishofen SH, Johannes Büel, oder die „Rheintalische Lesegesellschaft“ in Altstätten, gegründet durch einen reformierten Stadtschullehrer, vermutlich handelte es sich dabei um Jacob Schläpfer. ${ }^{1296}$ Ein indirekter Bezug zwischen den vielfältig tätigen Sozietäten und der Elementarschullehrerschaft bestand ferner in diversen initiierten Preisausschreiben zur Verbesserung des Schulwesens, an denen manchmal auch Lehrer teilnahmen. Als ein Beispiel kann die 1778 in St. Gallen gegründete „Gesellschaft der Freunde des Guten“ angeführt werden, welche mehrere Preisaufgaben zur Reform der öffentlichen Schulen stellte und auch einen Lehr-Kalender eines Lehrers abdruckte. ${ }^{1297}$ Auch Wilibald Klinke berichtete von Teilnahmen von Lehrern an Preisausschreibungen, etwa des Lehrers von Oberembrach ZH bei der „Naturforschenden Gesellschaft“ in Zürich. ${ }^{1298}$ Andere Lehrkräfte wandten sich mitunter mit ihren eigenen Reformvorstellungen für das Volksschulwesen in schriftlichen Entwürfen direkt an Stapfer, so etwa Joseph Anton Huber aus Ermatingen TG oder Paulus Dünner aus Weinfelden TG. ${ }^{1299}$

Insgesamt entfielen Mitgliedschaften von Lehrkräften in reformaufklärerischen Sozietäten fast ausschliesslich auf studierte geistliche Lehrkräfte. Da die meisten Sozietäten nur in den grösseren Städten angesiedelt waren und die Mitgliedschaft auf persönlichen Netzwerken beruhte, welche oft in höheren Bildungseinrichtungen wie Universitäten geknüpft wurden, waren auch die Berührungspunkte mit der Elementarschullehrerschaft entsprechend limitiert. Diese Einschätzung erhebt jedoch keinen Anspruch auf Vollständigkeit, denn dazu müssten Mitgliederlisten von Sozietäten breitflächig und systematisch untersucht werden.

1292 Kälin, Aufklärung: 64f.

1293 Schmidt u.a. (Hgg.), Stapfer-Enquête, Nr. 1189: Oberhelfenschwil, Wasserfluh.

1294 Erne, Sozietäten: 297. Schmidt u.a. (Hgg.), Stapfer-Enquête, Nr. 399: St. Gallen.

1295 Erne, Sozietäten: 159f.; auch bei Noll, Hofrat: $51 \mathrm{f}$.

1296 Erne, Sozietäten: 347.

1297 Erne, Sozietäten: 292ff.

1298 Klinke, Zürich: 116; Schmidt u.a. (Hgg.), Stapfer-Enquête, Nr. 122: Embrach.

1299 Tosato-Rigo, Bild: 62; BAR B0 1000/1483, Nr. 1422, fol. 40-43v: [1799] - Huber; BAR B0 1000/1483, Nr. 1422, fol. 44-51: [1799] - Dünner. 


\section{Der soziale Status}

„Meist führte der niedere Lehrer, von jedermann verachtet, gedemütigt und verspottet, ein entsagungsvolles und von Hunger geprägtes Leben. "1300 Zahlreiche Forschungsergebnisse haben den sozialen Status der Elementarschullehrer auf der Grundlage der disparaten Einkommensverhältnisse als grundsätzlich tief eingestuft. ${ }^{1301}$ Wer bloss ein solcherart geringes Einkommen bezog, musste von geringem sozialem Rang sein, so die pauschale, erst jüngst in Kritik geratene Schlussfolgerung. ${ }^{1302}$

Dass freilich eine rein ökonomisch fokussierte Perspektive auf die Lehrerschaft zu kurz greift, haben zahlreiche Indizien der bisherigen Untersuchung bereits angedeutet. Am deutlichsten haben die langen Dienstausübungswerte trotz geringen absoluten Einkommen und die zahlreichen diskontinuierlich-ersetzenden Lebensverläufe die Grenzen einer wirtschaftlichen Argumentationsweise aufgezeigt und auf immaterielle Werte verwiesen. So gilt es dieses bereits mehrfach angesprochene soziale oder „symbolische“ Kapital der Lehrerschaft zu ergründen, das in der zeitgenössischen Wahrnehmung ökonomische Defizite mitunter auszugleichen vermochte und das in keiner direkten Kausalität mit dem Wohlstand einer Person stehen musste.

Da den Lehrerantworten hierzu keine verlässlichen Informationen entnommen werden können, bedingt es den Einbezug einer Aussenperspektive auf die Lehrerschaft. Als Indikatoren für diese nur schwer rekonstruierbaren immateriellen Wertzuschreibungen dienen zum einen Einschätzungen zu den konkreten Fähigkeiten der Lehrer und zur grundsätzlichen Zufriedenheit der Gemeinden mit der Arbeit der Lehrer. Zum anderen erlauben die Zivilstand- und Familienverhältnisse aufgrund der ständisch-sozialen Restriktionen in Bezug auf das Heiraten einen Rückschluss auf die gesellschaftliche Position der Lehrer.

\subsection{Die Fähigkeiten und das Ansehen}

„Die knappen Finanzen und die schlechte soziale Stellung der Schulmeister bildeten die Grundübel der alten Schule. Diese Tatsache widerspiegelte sich in der niedrigen Besoldung. Wo der Lehrer weniger verdiente als ein Taglöhner, bewarb sich keine begabte Persönlichkeit um einen solchen Posten."1303

Aufgrund der noch fehlenden einheitlichen und systematischen Lehrerausbildung und der vielfach niedrigen monetären Besoldung begleitete die vormodernen Lehrkräfte des 18. Jahrhunderts stets das pauschale Attest einer damit einhergehenden mangelhaften fachlichen und pädagogischen Kompetenz beziehungsweise eines niedrigen Bildungsgrades. Entsprechend müsse kausal auch ihre Amtsausübung mangelhaft gewesen sein, was sich wiederum in einer generell geringen sozialen Achtung in der Dorfgesellschaft manifestiert habe, so der geläufige Tenor in der älteren Forschungslandschaft. ${ }^{1304}$

Zeitgenössische Berichte und Klagen aus der Feder von vorgesetzten Pfarrern und Schulinspektoren über die geringe Tauglichkeit der Schulmeister sind denn auch zur Genüge in den Archi-

1300 Enzelberger, Sozialgeschichte des Lehrerberufs: $25 \mathrm{ff}$.

1301 Tuggener, Lehrer: 53-56; Walz, Eselsarbeit: 60.

1302 „Besonders krass verdeutlicht die kärgliche Besoldung sein geringes Ansehen“. Landolt, Linth: 154; Vgl. zur Kritik an der Kausalität: Brühwiler, Finanzierung: 316.

1303 Baumann, Alltag: 70.

1304 Tuggener, Lehrer: 54ff; Klinke, Zürich: 90f., 113-116. 
ven vorzufinden. In einem Brief des Pfarrers Gottlieb Samuel Lauterburg an den helvetischen Bildungsminister Stapfer mit Verbesserungsvorschlägen für das Elementarschulwesen ist exemplarisch eine Reihe von Klagen zum Bildungsgrad der Elementarschullehrer zu lesen: „Wir haben auf dem Lande noch wenig taügliche Schullehrer. An diesem Mangel ist hauptsächlich die so sehr geringe Besoldung Schuld, um welche sie an den meisten Orten Schule halten müssen. [...] Entweder ist der Schullehrer ein etwas bemitelter Mann, und dann nimmt er die Schule an zur Erwerbung eines Nebenverdienstes, neben derselben hat er dann seine häuslichen Geschäfte, welche ihm keine Zeit lassen, welche er zum Lesen und Studieren über die zwekmässigere Führung seines Amtes anweden könnte [...] oder es ist ein Armer der einen Schuldienst nimmt, und der würde verhungeren müssen, wenn er nicht neben der Schule einen Gewerb triebe, wordurch er verdienen könnte, dass er mehr seinen Leib nähren und kleiden als seinen Geist zu nüzlicher Besorgung seines Schuldienstes aufklären mögte. [...] Wenn also die Schullehrerbesoldungen so karg bleiben, wie sie an den meisten Orten auf dem Lande sind, so werden wir uns noch lange vergeblich nach fähigeren Lehrern sehnen, als wir bisher beynahe durchgehend haben. [...] Noch ist sehr wenigen beyzubringen, dass ein tüchtiger Schullehrer etwas mehr verstehen müsse, als ordentlich lesen, und das Erlernte recitieren zu lassen. Unter meinen 5. Schullehreren ist nur Einer der eine ordentliche Handschrift führt. Die Rechtschreibung versteht Keiner; Rechnen können sie zur Nothdurft alle, aber nur Einer ist im Stand, darzu durch Prinzipien anzuführen. Von der Kunst die Geistesfähigkeiten der Lehrlinge auszuforschen, und zu entwikeln, wissen sie sich keinen Begrif zu machen."1305

Konkret wurde den Lehrkräften in mannigfacher Weise vorgeworfen, sie seien in Bezug auf die Vermittlung der elementaren Kulturtechniken fachlich meist unfähig gewesen, hätten ebensolche Kulturtechniken selbst nur mangelhaft beherrscht und über mangelnde intellektuelle Verständnisfähigkeiten verfügt. ${ }^{1306}$ Gemessen am eigenen, von höheren städtischen oder geistlichen Schulen und den Universitäten geprägten Bildungsgang, empfanden die meisten schulreformerisch aktiven Geistlichen den Bildungsgrad ihrer untergebenen Landschulmeister ebenso automatisch als „zu niedrig“wie deren Gehalt im Vergleich mit einem Pfarrersgehalt als prekär erschien. Ihr „Realbild“ von der Schulwirklichkeit musste zwangsläufig negativ konnotiert sein, wenn das „Idealbild“ einer aufgeklärten Schule mit besser gebildeten und besoldeten Lehrern angestrebt werden sollte. Ferner bestand für die meisten Schulreformer eine direkte Kausalität zwischen den Fähigkeiten eines Schulmeisters und dessen Besoldung, wonach sich in der Konsequenz durch das geringe Einkommen meist nur intellektuell mangelhafte Personen für das Lehramt finden liessen. ${ }^{1307}$ Die Idee einer grundsätzlich leistungsabhängigen Besoldung an der Stelle der Zeitbesoldung wuchs bereits um 1800, setzte sich aber erst in der ersten Hälfte des 19. Jahrhunderts durch, beispielsweise im Kanton Bern, wo 1835-36 ein allgemeines Lehrerexamen in Bern für Primarlehrer eingeführt wurde, dessen Ausgang für die Schulmeister lohnrelevant war. ${ }^{1308}$

1305 BAR B0 1000/1483, Nr. 1422, fol. 62: 03.04.1799 - Lauterburg; Vgl. auch: Tosato-Rigo, Bild: 63.

1306 Vgl. Montandon, Determinanten: $57 \mathrm{ff}$. Zu den minimalen elementaren Kulturtechniken um 1800 gehören die Fähigkeiten des Lesens von Gedrucktem und Handgeschriebenem, des handschriftlichen Schreibens in der Muttersprache sowie des Beherrschens der einfachen Ziffern.

1307 Tuggener, Lehrer: 59. Die Kausalität zwischen Einkommen und der Leistung wird u.a. auch bei Landolt betont: „Die Besoldung übte einen wesentlichen Einfluss auf die Tätigkeit der Schulmeister aus. Überall dort wo gute Löhne bezahlt wurden, waren auch die Leistungen der Lehrer entsprechend besser." Landolt, Linth: 155. Vgl. auch Schneider, bernische Landschule: 101.

1308 Dieses Leistungsexamen diente Jeremias Gotthelf als historischen Rahmen für seinen Schulmeisterroman, insbesondere die Reaktion und der Widerstand der als , ungenügend“ qualifizierten älteren Lehrer widerspiegelt sich darin. Hofer, Lehrertaxation: 182f. 
Doch was Schulreformer und Volksaufklärer als zeitgenössischen Missstand in oft bewusst übertriebenem Masse artikulierten, um die Einrichtung von zentralisierten Lehrerbildungsstätten, eine höhere Lehrerbesoldung oder die Umsetzung anderer Massnahmen zur Verbesserung der Lage der Schulmeister zu erwirken, entwickelte sich im Laufe der älteren Forschungstradition unter der liberalen Perspektive des späteren 19. Jahrhunderts diskursiv verselbständigt und sich zu einem breit tradierten Stereotyp. Freilich war dieses Vorurteil der mangelhaften Tauglichkeit der Elementarschullehrer nie einer empirischen Überprüfung unterzogen worden. Die fehlende systematische Lehrerbildung war Beweis genug. Die Fülle an negativen Berichten entwickelte sich zudem selbst zu einer empirischen Basis, deren Narrativ kein Widerspruch mehr duldete.

Um die fachlichen Unzulänglichkeiten der Lehrer zusätzlich pejorativ zu demonstrieren, verwiesen sowohl die zeitgenössischen Volksaufklärer wie der zuvor zitierte Pfarrer Lauterburg als auch später zahlreiche ältere Forschungsarbeiten gerne auf die sichtbar mangelhafte Grammatik und fehlerhafte Orthografie in den Antworten der Lehrer auf die Stapfer-Enquête. ${ }^{1309}$ Das hatte zur Folge, dass die unbedarfte Orthografie der Lehrkräfte zu einem historiografischen Problem stilisiert wurde: „Betrachtet man die von den Schulmeistern ausgefüllten stapferschen Fragebogen, so lässt sich der durchschnittliche Bildungsgrad der Lehrer leicht feststellen. Die Schrift, vielmehr aber die Rechtschreibung und der Satzbau lassen auf geringe Schulbildung schliessen." 1310

In der Tat hatten viele Lehrer Mühe, sich grammatikalisch und orthografisch einheitlich auszudrücken. Einzelne Wörter - etwa phonetisch schwierige oder umgangssprachlich ungewohnte Fremdwörter - wurden bisweilen in Dutzenden von unterschiedlichen Varianten geschrieben. ${ }^{1311}$ Die Gründe dieser orthografischen Schwächen lagen aber nach Alfred Messerli nur zum einen im mangelhaften Unterricht des Lehrers, zum anderen fehlten adäquate Hilfsmittel, etwa Grammatikanleitungen, und die meisten Schreibenden - notabene bis in die Eliten hatten Schwierigkeiten mit der deutschen Hochsprache, die sich markant vom Dialekt unterscheidet. ${ }^{1312}$ Der ex-post formulierte Vorwurf der mangelhaften Grammatikkenntnisse an die Lehrerschaft ist insofern problematisch, als bis zum Ende des 18. Jahrhunderts noch gar keine standardisierte Rechtschreibung existierte und in den zur Verfügung stehenden und verwendeten Schulbüchern die grammatikalischen Standards alles andere als einheitlich waren. ${ }^{1313}$ So wähnten sich Lehrer bisweilen im Recht, wenn sie die Schreibweise aus einer alten Bibel als allgemeingültig übernahmen. ${ }^{1314}$ Auch hinsichtlich der Sauberkeit des Schriftbildes wurden die Lehrer teilweise harsch kritisiert, doch ist es rein spekulativ zu behaupten, hinter einer zittrig wirkenden Handschrift hätte pauschal ein ungeübter Schreiber mit mangelhaftem Intellekt gestanden. ${ }^{1315}$ Altersbedingte Einflüsse konnten ebenso gut für eine unregelmässige Handschrift sorgen, wie Ablenkung während des Schreibprozesses oder schlechtes Schreibmaterial. Peter Büttner hat denn auch die Notwendigkeit einer Differenzierung hinsichtlich der Schreibfertigkeiten der Lehrer betont und mit einer Serie von Quellenausschnitten aus der Stapfer-Enquête

1309 Büttner, Schreiben: 77ff; Brühwiler, Finanzierung: 316.

1310 Landolt, Linth: 153.

1311 Exemplarisch sichtbar wird die Problematik am Begriff „Examinatorenkonvent“, der von den Zürcher Elementarschullehrkräften in der Stapfer-Enquête in vielen unterschiedlichen Schreibweisen wiedergegeben wurde, etwa als ,ägsamen nathoren“ oder „Exsaminathoren“. Bloch, Schreiben: 263.

1312 Messerli, Lesen: 562.

1313 Klinke, Zürich: 153. Die erste Auflage des Dudens als Grundlage der deutschen Einheitsorthografie erscheint erst 1880 beim Verlag Bibilographisches Institut in Leipzig.

1314 Messerli, Lesen: 563.

1315 Luginbühl, Stapfer: 111. 
belegt, dass ein Grossteil der Lehrer die stapferschen Fragen sehr wohl in flüssiger Korrespondenz- und Schönschrift beantwortet hatte, wodurch sie ihre Schreibkünste hinlänglich demonstrierten. ${ }^{1316}$

Es stellt sich angesichts der weiter oben dargestellten disparaten Einkommensverhältnissen die fundamentale Frage, wie „gut“ die helvetischen Lehrkräfte die Vermittlung der elementaren Kulturtechniken tatsächlich beherrschten, wie es um ihr Ansehen in der Lokalbevölkerung stand und ob direkte ökonomische Kausalitäten zwischen den Fähigkeiten und dem Einkommen bestanden. Dass jedoch längst nicht jeder Lehrer fachlich ungenügend und sozial ausgegrenzt war, zeigten bereits die leistungsorientierten Lehrerexamina. Zudem belegen Lobesworte an die Adresse der Lehrer, wie beispielsweise in der Zürcher Schulumfrage von 1771/72 zum Schulmeister von Hottingen $\mathrm{ZH}$ vermerkt worden ist, einen hohen Bildungsgrad und ein soziales Ansehen: „Geschworner Leonhard Tuggener, æt. 45, ein frommer, verständiger und erfahrner mann, der neben dem, was jeder schulmstr. kann, auch die music, schreib- und rechenkunst, die anfänge der lateinischen und französischen sprache versteht, grundlich und gar practisch mit den kindern catechisirt, der wenn es nöthig wäre, einen pfarr-dienst mit nutzen versehen könnte, vielleicht der beste schulmstr. im ganzen land“. ${ }^{1317}$ Doch war jener obgenannte Lehrer bloss ein Einzelfall, eine löbliche Ausnahme, oder vielmehr die Regel?

Es stellt sich folglich die Frage, inwieweit serielle Quellenbestände von niedriger Provenienz neben qualitativen Einzelquellen neue Erkenntnisse zu den fachlichen Fähigkeiten und zum sozialen Ansehen der Lehrkräfte zu liefern vermögen. Da die Stapfer-Enquête als direkt an die Lehrerschaft adressierte Umfrage eine Aussensicht nur in wenigen Einzelfällen zu geben vermag, muss hierfür auf andere Quellenbestände zurückgegriffen werden. Nur selten fügten die Pfarrer oder kommunalen Vorgesetzten eine Schlussbemerkung an oder füllten den Fragebogen gleich selbst aus. Wenn doch, wurden aber neben kritischen Voten durchaus nicht selten einzelne Lehrkräfte für ihr Engagement oder für ihre Fähigkeiten im Schulwesen gelobt. Beispielhaft berichtete der Pfarrer Gottlieb Lauterburg von Kallnach BE über seinen Dorfschullehrer: „Es sey mir erlaubt, obiger, von dem Schullehrer selbst verfertigten, Beantwortung noch folgendes als Beylage beyzufügen. Erstlich verdient der gegenwärtige Schullehrer, deßen Treüe, Fleiß, Fähigkeiten und außerordentliche Mühewalt im Unterricht der ohne anvertrauten sehr zahlreichen Menge von Kindern sich gewiß auszeichnen, alles Lob, um so mehr, da nicht sowohl der mit seiner vielfaltigen Mühe in keiner Propertion stehende kleine Schullohn, als vielmehr die Liebe zu seiner Gemeind und der Mangel an einem andern tüchtigen Subject ihn bis hieher bewogen haben diese Schullehrer-Stelle ferner beyzubehalten. "1318

Lob für die Fertigkeiten einzelner Lehrkräfte findet man auch in summarischen Berichten aus pfärrerlicher Hand, beispielsweise im Schulbericht zur reformierten Gemeinde Wattwil SG, geschrieben vom reformierten Pfarrer von Wattwil, J. Belandt: „Der Schullehrer auf dem Schmidberg ist B. Stephan Cappler [...]. Nota: Billig muß ich diesem Mann, der nach der bisherigen dürftigen und mangelhaften Lehr Methode allen übrigen Schullehrern als ein Muster der Nachahmung vorgestelt zu werden verdiente, der von Natur viele pädagogischen Talente besizt, und in der treüsten Anwendung derselben vor der Zeit grau geworden - alles Lob ertheilen. Die Reinheit seines moralischen Carakters - Die Güte seines Herzens sein ausdaurender Eifer im

1316 Büttner, Schreiben: 78.; 82ff. Kalligrafisch äusserst raffiniert geschmückte Antwortbögen zeugen von der hohen Schreibkunst einzelner Lehrkräfte, beispielsweise der Antwortbogen aus Rebstein SG: Schmidt u.a. (Hgg.), Stapfer-Enquête, Nr. 1225: Rebstein.

1317 StAZH E I 21.5.39 - Riesbach; auch zit. in: Bloch Pfister, Priester: 111.

1318 Schmidt u.a. (Hgg.), Stapfer-Enquête, Nr. 860: Kallnach. 
Erziehungsgeschäft, dem er sich ausschließlich widmet, und mit der möglichsten Wärme der Seele ergeben ist, machen ihn der Achtung jedes Rechtschaffenen würdig." ${ }^{319}$

Aus quellenkritischer Perspektive erstaunen die pfärrerlichen Lobesworte in der Stapfer-Enquête im Gegensatz zur mannigfaltig geäusserten Kritik in direkten Schreiben an den Bildungsminister freilich wenig. So hatten die Pfarrer als Vorgesetzte der Lehrer gleichwohl ein starkes Eigeninteresse an positiven Darstellungen ihres Schulwesens, trugen sie doch über ihr Mitspracherecht bei der Lehrerbestellung und in der Aufgabe zur konstanten individuellen Weiterbildung ihrer Lehrkräfte selbst eine starke Mitverantwortung für den Zustand des elementaren Schulwesens. Kritik am Zustand des Schulwesens vonseiten der Pfarrer schloss also gleichzeitig Lob oder zumindest ein neutrales Verhältnis zu den ihnen untergebenen Schulmeistern nicht aus. ${ }^{1320}$

Zahlreiche fragmentarische Einzeldokumente, vor allem aber einzelne regionale Schulumfragen aus dem Ancien Régime und aus der Frühphase der Helvetischen Republik, deren Adressaten die vorgesetzten Pfarrer waren, können die Fragen nach den Fähigkeiten und dem geschätzten Ansehen der Lehrkräfte als neue Erkenntnisgewinne nicht nur punktuell, sondern auch in quantitativer Betrachtungsweise beantworten. Insbesondere die bereits gut erforschte Zürcher Umfrage von 1771/72, aber auch die noch weitgehend unbekannte UmFrage in der St. Galler Fürstabtei von 1796, die UmFrage Im Kapitel Bern von 1780, die Basler Umfragen von 1798 und 1803 sowie die Aargauer Umfrage von 1799 stellen allesamt Grundlagen für serielle Untersuchungen der Fragestellungen nach den Fähigkeiten und dem Sozialstatus der Schullehrer dar. ${ }^{1321}$ Denn anders als der als voreingenommen zu taxierende helvetische Bildungsminister Stapfer interessierten sich die volksbildungsaffinen Initiatoren all jener regionalen Umfragen wenn auch aus völlig unterschiedlichen Motiven - durchaus ergebnisoffen für die realen Kenntnisse der Lehrkräfte oder für die Stellung der Lehrkräfte in ihren Dörfern.

\subsubsection{Das Beherrschen der Kulturtechniken und der Amtsfleiss}

Ein charakterlich-moralisch einwandfreier Lebenswandel, Fleiss und Sittlichkeit galten als unabdingbare Tugenden für einen Schulmeister, wichtiger noch als das eigentliche Beherrschen der elementaren Kulturtechniken. Denn der persönliche Eifer und der mustergültige Charakter galten als Grundlage für die Bildung der Kinder zu guten und sittlichen Christenmenschen, während die elementaren Kulturtechniken bloss als Mittel zum Zweck dazu dienten. „Die Schule hatte somit eine doppelte Funktion zu erfüllen. Einerseits war sie Garantin eines funktionierenden gesellschaftlichen Zusammenlebens, andererseits half sie, auf individueller Ebene das Seelenheil zu sichern. Der Schlüssel-Begriff war in beiden Fällen die Sittenerziehung. Durch sie sollten sowohl der Wohlstand des Volkes als auch die Ehre Gottes befördert werden. Religiös fundierte Werte und das Ziel einer reibungslos funktionierenden Gemeinschaft waren aufeinander bezogen. Warum dem so war, wird bei einem Blick auf den Wertekanon, der in der Schule vermittelt werden sollte, klar: Zu vermeiden seien Müssiggang und Bequemlichkeit, angestrebt hingegen Arbeitsamkeit, die aber nicht in erster Linie im Hinblick auf ökonomische Wertschöpfung verstanden wurde, sondern als sittliche Beschäftigung, als gewünschte Alternative zu Bettel und Müssiggang. Mässigkeit sollte als anvisierte Tugend positiv der zu vermeidenden

1319 Schmidt u.a. (Hgg.), Stapfer-Enquête, Nr. 1194: Wattwil, Steintal, Schmidberg, Schönenberg, Scheftenau, Hummelwald, Wattwilerberg.

1320 Berner, Zeichen: 106; Ruloff, Schulbesuch: 70.

1321 Die folgenden quantitativen Auswertungen wurden als Zwischenergebnisse bereits publiziert: Rothen, Erkenntnisgewinn: 40ff. Die genannten Umfragen sind im Kap. 1.5.3 vorgestellt worden. 
Üppigkeit, Gefrässigkeit, Wollust, Ungezämtheit, Unbändigkeit und der Verschwendung gegenüberstehen. Weiter sollte durch die Schule ein allgemein gottgefälliges Leben gefördert werden, um Mutwillen, Liederlichkeit und Unehrlichkeit auszurotten. Das eingeforderte sittliche oder gottgefällige Leben war also nicht nur auf die Beziehung des Individuums zu Gott, sondern durchaus auch auf das individuelle Handeln in der Gemeinde bezogen. Aus diesem Grund war religiöse Erziehung auch für das reibungslose Funktionieren der Gemeinde zentral." ${ }^{1322}$

Entsprechend überwogen die religiösen Inhalte im Unterricht die reinen Kulturtechniken und der Lehrer glich in seiner Funktion eher einem weltlichen Kirchendiener als einem säkularen Wissensvermittler. Der fachliche Kanon im Elementarschulwesen selbst war bis zum Ende des 18. Jahrhunderts aus moderner Optik betrachtet noch sehr bescheiden, wenn auch lokal von sehr heterogener Gestalt. Grundsätzlich wurde unterrichtet, was an Bildung lokal nachgefragt wurde beziehungsweise „was ein Jeder Haus-Vater Beliebet.“ ${ }^{1323}$ Als zentrale Kulturtechnik zum Verständnis der Bibel stand neben dem Memorieren, dem Auswendiglernen von katechetischen Fragen und Psalmen, das Erlernen des Lesens im Zentrum der schulischen Bildungsvermittlung. Gute Fähigkeiten im sauberen Buchstabieren und flüssigen Lesen von gedruckter Schrift waren denn auch die fachlichen Minimalanforderungen für den Erhalt einer Schulmeisterstelle. ${ }^{1324}$ Das Lesen von Handschriften stellte bereits eine fortführende Stufe des Leseunterrichts dar. Erst nach dem Erlernen der Buchstaben und des Lesens erfolgte in der Regel das Schreiben für die älteren Schulkinder. Entsprechend nahm diese Kulturtechnikkompetenz nur eine untergeordnete Stellung im Lerncurriculum der Elementarschulen ein. Das Schreiben wurde aber in allen Schulen der Helvetischen Republik unterrichtet und Schreibkenntnisse zählten zu den minimalen fachlichen Grundanforderungen an jeden Schulmeister. Allerdings bedeutete die Vermittlung von Schreibfähigkeiten in der schulischen Realität an den meisten Orten bloss das simple Nachmalen von Buchstaben nach vorgefertigten Schreibvorschriften. Nach Peter Büttner bedeutete das Abschreiben zwar die zentrale Unterrichtsmethode im elementaren Schreibunterricht und war sowohl bei der Lehrerschaft als auch bei den Schülern bis zum Ende des 18. Jahrhunderts weitgehend unbestritten. ${ }^{1325}$ Dennoch geht aus der Stapfer-Enquête hervor, dass eigenständiges, auswendiges Schreiben - „so daß die Kinder im Stand sind Jhre Gedancken, zu Papier zu bringen "1326 - auch in zahlreichen Elementarschulen praktiziert wurde und einzelne Lehrpersonen sehr wohl einen anspruchsvollen Schreibunterricht anboten. ${ }^{1327}$

Mathematikunterricht war im Gegensatz zu den Kulturtechniken Lesen und Schreiben, die zur unmittelbaren Vermittlung der religiösen Kenntnisse und für verwaltungstechnische Tätigkeiten benötigt wurden, keine Kernkompetenz der vormodernen Schule im engeren Sinn. Deshalb tauchte der Rechenunterricht weder in Schulordnungen verbindlich auf, noch wurde das Rechnen flächendeckend und intensiv unterrichtet. Zudem bestand ein bisweilen mächtiger Privat-

1322 De Vincenti-Schwab, Landschulen: 17.

1323 Schmidt u.a. (Hgg.), Stapfer-Enquête, Nr. 2322: Härkingen.

1324 Vgl. das Kap. 2.4.

1325 Büttner, Schreiben: 178ff.

1326 Schmidt u.a. (Hgg.), Stapfer-Enquête, Nr. 2122: Bottenwil.

1327 Vgl. die Antwort des Lehrers Michael Knuti aus Richebach im Niedersimmental: „Die Buchstäb werden nach dem Alphabet vorgeschrieben, und dem Anfänger gezeigt, wie die Feder ergriffen, und jeder Buchstab gezogen werden müße, hernach werden einzelne, ganze Wörter und Zeilen vorgeschrieben, Endlich dicktiert, die Fehler bezeichnet und vom Kind nochmal abgeschrieben, auch wird zulezt dem Kind ein Gegenstand vorgestelt und es muß seine eigne Gedanken darüber aufsezen, auch diese Aufsäze werden Corigiert, und nach Gutfinden des Lehrers abgeändert und ausgebeßert, hernach von den Lehrnnenden nochmal abgeschrieben." Schmidt u.a. (Hgg.), Stapfer-Enquête, Nr. 1410: Richebach. 
markt, der mathematische Kenntnisse ausserschulisch vermittelte. Weitere Fachkompetenzen wurden nicht gefordert und nur sehr wenige Elementarschulen boten ein darüber hinausgehendes Fächerangebot an Realien oder Fremdsprachen an.

Wenn man von der Grundannahme ausgeht, dass das eigene Beherrschen der elementaren Kulturtechniken die Voraussetzung für die daraus resultierende Qualität des Unterrichts darstellte, stellt sich die Frage, als wie gut die Fähigkeiten der Lehrer in den einzelnen fundamentalen Kulturtechniken Lesen, Schreiben und Rechnen in einer quantitativen Perspektive von Zeitgenossen eingeschätzt wurden. Fünf räumlich und konfessionell unterschiedliche Fallbeispiele von seriell auswertbaren Quellenbeständen aus der Zeit unmittelbar vor- oder während der Helvetischen Republik vermitteln einen quantitativen, gleichwohl mikrohistorischen Einblick über die effektiven Fähigkeiten der Lehrkräfte.

\section{Das Fallbeispiel Distrikt Kulm}

In einem summarischen Antwortbericht des reformierten Pfarrers Daniel Rytz aus dem aargauischen Distrikt Kulm auf die Aargauer Schulumfrage vom Frühjahr 1799, deren Distribution sich zeitlich mit der Stapfer-Enquête überschnitt, findet sich ein tabellarisches Verzeichnis der Fähigkeiten von insgesamt 31 Lehrern im Lesen, Schreiben, Singen und Rechnen. Die Beantwortung stammt von einem einzigen Pfarrer, woraus eine sehr hohe standardisierte Vergleichbarkeit der Bewertungen resultiert. ${ }^{1328}$

Tab. 33: Lehrer-Fähigkeiten im Distrikt Kulm 1799

\begin{tabular}{lccc}
\hline Bewertung: & Lesen: & Schreiben: & Rechnen: \\
\hline Sehr gut & 15 & 2 & 0 \\
Gut & 9 & 16 & 15 \\
Mittelmässig & 6 & 5 & 2 \\
Schlecht & 0 & 3 & 4 \\
Keine Angabe & 1 & 5 & 10 \\
\hline
\end{tabular}

„Gut und richtig“ las fast die Hälfte der insgesamt 31 Lehrkräfte, ebenso viele lasen zumindest „gut“ oder „ordentlich“. Kein Lehrer schnitt dagegen mit dem Prädikat „schlecht“ beim Lesen ab, was hingegen bei den Schreib- und Rechenkenntnissen auf mindestens 10\% zutraf. Dennoch verstand es die deutliche Mehrheit der Lehrer dieses Distrikts, zumindest „mittelmässig“ bis „schön“ zu schreiben, „ordentlich 3 stimmig“ bis „gut 4 stimmig“ zu singen und mit den „4 Species“ die Grundoperationen der elementaren Mathematik zu beherrschen. Insgesamt vier Lehrkräfte des Distrikts „sind in Ansehen der Fähigkeiten allen anderen weit überlegen“, so das generelle Fazit des Schulinspektors: „doch schreiben noch die mehreren eine saubere Handschrift und die letzten eine leserliche. Mit der Rechenkunst geben sich nur wenige ab, aus Mangel der Zeit, und aus Mangel der Schüler die das rechnen zu lernen begehren. Doch sind die mehreren im Stand die 4 Species zu Rechnen. [...] die mehrsten Schullehrer lesen richtig mit Verstand und Kenntniss der Sachen. Doch fehlt Jhnen die Übung den Jnhalt des gelesenen mit eigen Worten andern zu erzählen, oder andern über das gelesene zu fragen. "1329 
Aus der tabellarischen Übersicht wird deutlich, dass sämtliche Lehrkräfte dieses reformierten Distrikts über genügend bis sehr gute Lese- und weitgehend über genügend bis gute Singkenntnisse verfügten. Um das Sinnverständnis von Gelesenem und um die Schreibkenntnisse stand es offenbar schon etwas kritischer, dennoch verfügten die meisten Lehrkräfte immer noch über zumindest genügende Kenntnisse. Erstaunlicherweise beherrschten die meisten Lehrer zudem die mathematischen Grundoperationen, unabhängig vom existierenden Angebot in ihrer Schule, das weitaus magerer ausfiel. Dass in den Schulstuben des Kulmer Distrikts im Jahr 1799 kaum gerechnet wurde, war also primär der geringen lokalen Nachfrage nach schulischer Vermittlung geschuldet und nicht ein Ausdruck mangelnder Kenntnisse der Lehrerschaft. Aus dem schulischen Angebot, wie es Stapfer in seiner Enquête erfragt hatte, lässt sich somit nicht kausal auf die fachlichen Fähigkeiten der Lehrkräfte schliessen beziehungsweise die Lehrkräfte konnten in der Regel weitaus mehr, als sie in der nachfrageorientierten Schulwirklichkeit anboten.

Hinsichtlich der generationenspezifischen Unterschiede zeigte sich, dass die Fertigkeiten von erfahrenen, älteren Lehrkräften tendenziell besser eingestuft wurden als von jungen Lehrern mit eher wenig Berufserfahrung.

Tab. 34: Lehrer-Fähigkeiten im Distrikt Kulm nach Alter 1799

\begin{tabular}{lccccccccc}
\hline & \multicolumn{3}{c}{ Unter 30-Jährige: } & \multicolumn{3}{c}{ 30-49-Jährige: } & \multicolumn{3}{c}{ Über 50-Jährige: } \\
\hline Bewertung: & Lesen & $\begin{array}{c}\text { Schrei- } \\
\text { ben }\end{array}$ & $\begin{array}{c}\text { Rech- } \\
\text { nen }\end{array}$ & $\begin{array}{c}\text { Lesen } \\
\text { Sehr gut }\end{array}$ & $\begin{array}{c}\text { Schrei- } \\
\text { ben }\end{array}$ & $\begin{array}{c}\text { Rech- } \\
\text { nen }\end{array}$ & $\begin{array}{c}\text { Lesen } \\
\text { Schrei- } \\
\text { ben }\end{array}$ & $\begin{array}{c}\text { Rech- } \\
\text { nen }\end{array}$ \\
Gut & 1 & 0 & 0 & 7 & 1 & 0 & 5 & 1 & 0 \\
Mittelmässig & 2 & 1 & 0 & 3 & 4 & 1 & 1 & 0 & 1 \\
Schlecht & 0 & 2 & 1 & 0 & 0 & 2 & 0 & 1 & 1 \\
Keine Angabe & 0 & 1 & 3 & 0 & 3 & 5 & 1 & 1 & 2 \\
\hline Total & & 6 & & & 14 & & & 11 & \\
\hline
\end{tabular}

In der Beurteilung des Schreibens und Rechnens erhielten ältere Lehrkräfte kaum mehr die Prädikate „schlecht“ oder „mittelmässig“, sondern mehrheitlich eine gute bis sehr gute Bewertung für ihre Kenntnisse, während sich bei den unter Dreissigjährigen gute und eher bescheidene Bewertungen die Waage hielten.

Des Weiteren sind die vier bestgenannten Schulmeister des Kulmer Distrikts hinsichtlich ihres Einkommens interessant, denn nach der oben postulierten negativen Kausalität von Einkommen und Fähigkeiten hätten sie als Beste gleichzeitig über die höchsten Lehrerlöhne verfügen müssen. Allerdings lagen bloss drei der vier besten Lehrkräfte im obersten Viertel der Einkommen und nicht als Bestverdienende, während als Antithese etliche andere als "gut" taxierte Lehrer deutlich weniger als den Durchschnittslohn des Distrikts verdienten und gleichzeitig mindestens zwei als bloss mässige Schreiber taxierte Lehrer mit ihrem Lohn über dem Durchschnitt lagen. ${ }^{1330}$ Der Lohn und die Fähigkeiten der Lehrer standen in diesem Fallbeispiel somit nur in einer beschränkten Korrelation.

1330 Der mittlere Lohn im Distrikt Kulm lag bei rund 32 fl., der tiefste Lohn bei 9.5 fl., der höchste Lohn bei 60 fl. Als fachlich beste Lehrkräfte wurden im Bericht die Lehrer Samuel Müller der Ältere aus Unterkulm (20 fl. + 5 Mütt Getreide), Johann Stadler aus Birrwil (40 fl.), Heinrich Erismann aus Gontenschwil (50 fl.) und Hans Rudolf 
Gute fachliche Leistungen erfreuten ferner nicht nur die vorgesetzten Pfarrer, sondern konnten sich im verstärkt leistungsorientiert denkenden neuen Staatswesen der Helvetischen Republik durchaus auch pekuniär bezahlt machen. Im Distrikt Brugg wurden etwa im Jahr 1802 an die „vorzüglichsten Schullehrer“ Belohnungsprämien ausbezahlt. In einem Verzeichnis waren gleich zwölf der insgesamt 33 genannten Lehrer als „vorzüglich“ aufgelistet, wobei angemerkt wurde, dass drei der Schulmeister bereits im Vorjahr belohnt worden waren und „dass für dieses Jahr andere belohnt werden [sollen], die ungefähr gleiche Verdienste mit jenen haben." ${ }^{1331}$ Im Kanton Linth wurden im Sommer 1801 insgesamt 528 Franken an die Schulinspektoren der Distrikte übergeben: „dass solche als eine Gratification bestimmt seyen, die Lehrer zum Eifer und Fleiss aufzumunteren, und zwar sollen sie davon 2/3, an die dürftigst besoldeten Schulmeistern, 1/3 aber auch an Verdienstvolle, mit einem Aufmunterungs-Schrieben begleitet, Versenden und Verwenden."

Die Gelder wurden anschliessend in die Distrikte weitergegeben und dort relativ gleichmässig unter den Lehrern verteilt, wie zwei Bestätigungsschreiben aus den Distrikten Glarus und Schwanden belegen. Tatsächlich erhielten zwar fast alle Schulmeister einen Teil der Summe zugesprochen, die angewiesene überproportionale Verteilung zugunsten der tiefsten Einkommen zum Ausgleich der Lohndisparitäten geschah allerdings nicht. Die höchsten Gratifikationen erhielten nämlich zum einen der katholische Lehrer von Glarus mit dem zuvor dritthöchsten Lehrerlohn seines Distrikts und zum anderen der Lehrer von Schwanden mit dem höchsten Lohn seines Distrikts. ${ }^{1333}$ Die Belohnung von bereits zuvor „verdienstvollen“ Schulmeistern war den Distriktinspektoren offensichtlich wichtiger gewesen als den Ausgleich von Lohnungleichheiten, selbst wenn die Distriktinspektoren keine Rechenschaft über die Gründe ihrer Verteilung abgeben mussten. $\mathrm{Ob}$ die beiden belohnten, bereits gut verdienenden Lehrkräfte auch gleichzeitig die fachlich besten Lehrer ihres Distrikts waren, muss dagegen offen bleiben.

\section{Das Fallbeispiel Basel}

Dass die oben beschriebene Lehrerschaft des Distrikts Kulm in ihren fachlichen Fertigkeiten keine Ausnahme, sondern eher die Regel darstellte, lässt sich anhand der beiden Basler Schulumfragen von 1798 und 1803 nachzeichnen, worin ebenfalls die Fähigkeiten der Lehrer der reformierten Basler Landschulen in den elementaren Kulturtechniken erhoben wurden. In seiner ersten Umfrage vom Frühjahr 1798 wollte das neu konstituierte Erziehungskomitee wissen, „Ob er [der Lehrer] zu seinem Amte tüchtig sey, besonders für den Unterricht im Lesen, Schreiben Rechnen und Singen?" 1334 Insgesamt 53 Lehrkräfte, darunter eine Lehrerin, wurden in der Folge von den Pfarrern aus der Landschaft detailliert bewertet. Die Umfrage des Basler Deputatenamts von 1803 befragte wiederum die weitgehend personell gleich gebliebenen Lokalpfarrer der Landschaft zum Zustand ihrer Schulen mit der Frage: „Wie seine [des Lehrers] Fähigkeiten

Hauri aus Hirschtal (32 fl.) explizit hervorgehoben. Die Oberlehrer von Dürrenäsch und Beinwil verdienten jedoch trotz „schlechter“ bzw. „mittelmässiger“ Schreibkenntnisse 45 fl. bzw. 46 fl. Der höchste Lohn von 60 fl. ging an den mit „guten“ Kenntnissen bewerteten Lehrer Hans Jacob Merz von Menziken.

1331 StAAG HA 9131, o. Pag.: [1802] - Brugg.

1332 LaGL HA Protokollband 86, fol. 44: 10.08.1801 - Protokoll des Erziehungsrates.

1333 Der katholische Schulmeister von Glarus und der Lehrer von Schwanden erhielten je 12 Franken, die übrigen Schulmeister der Distrikte Glarus und Schwanden dagegen nur zwischen 4 und 8 Franken. LaGL HA Kiste 27, Mappe C, o. Pag.: 22.09.1801 - Schulinspektor des Distrikts Glarus; LaGL HA Kiste 27, Mappe D, o. Pag.: 16.06.1802 - Schulinspektor des Distrikts Schwanden. Vgl. zu den Löhnen von 1798: Landolt, Linth: 154 und die Abb. 12 im Kap. 3.1.2.

1334 StABL AA 1012, Lade 200, 07.01.01, fol. 2: [1798] - Bericht. 
beschaffen seyen?“ Insgesamt beinhaltet diese Umfrage Einschätzungen zu 47 Lehrkräften des baselländischen Elementarschulwesens. ${ }^{1335}$

Tab. 35: Lehrer-Fähigkeiten im Kanton Basel 1798 und 1803

\begin{tabular}{lrrrrrr}
\hline & \multicolumn{2}{c}{ Lesen: } & \multicolumn{2}{c}{ Schreiben: } & \multicolumn{2}{c}{ Rechnen: } \\
\hline Bewertung: & 1.798 & 1.803 & 1.798 & 1.803 & 1798 & 1803 \\
Sehr gut & 9 & 7 & 7 & 6 & 5 & 4 \\
Gut & 38 & 26 & 35 & 19 & 13 & 7 \\
Mittelmässig & 3 & 9 & 5 & 9 & 7 & 4 \\
Schlecht & 3 & 5 & 3 & 10 & 13 & 2 \\
Keine Angabe & 0 & 0 & 3 & 3 & 15 & 30 \\
\hline Total & 53 & 47 & 53 & 47 & 53 & 47 \\
\hline
\end{tabular}

Die weitgehende personelle Kontinuität der bewertenden Pfarrer und der Schulmeister garantiert eine direkte Vergleichbarkeit der beiden Bewertungen von 1798 und 1803. Wiewohl die Basler Landpfarrer in der Summe kritischer mit ihren untergebenen Lehrern umgingen, ähneln die Ergebnisse der gesamten Basler Landschaft in ihren groben Zügen stark dem Bericht aus dem zuvor beschriebenen Aargauer Distrikt Kulm. Die zentralen Kulturtechnikkompetenzen des Lesens und Schreibens wurden von einer grossen Mehrheit der Lehrkräfte in den Augen der Pfarrer „gut“ bis „sehr gut“ beherrscht. Dies schlug sich insbesondere im realen Schulerfolg der baselländischen Schulkinder nieder, denn zeitgleich mit der Umfrage erstellte Examenstabellen von Schülerprüfungen belegen, dass die schulabgehenden Kinder der Basler Landschaft zu fast $100 \%$ lesen und grossmehrheitlich schreiben konnten, wenn sie mit 12 bis 15 Jahren die Schule verliessen. ${ }^{1336}$ Obwohl man die höchst subjektiven Bewertungsmassstäbe der einzelnen Pfarrer in beiden Fällen - den Beurteilungen der Lehrer als auch der Schülerexamen - nicht kennt, bedeutet die offenkundige Kausalität von guten Kulturtechnikkompetenzen mit dem hohen Schulerfolg in der Konsequenz nichts Geringeres, als dass die Pfarrer wahrheitsgemäss von einem Schulwesen berichteten, das innerhalb seiner Anspruchsgrenzen weitgehend reibungslos funktionierte. Zudem lässt sich dadurch die tragende Rolle der Elementarschullehrerschaft bei der erfolgreichen flächendeckenden Verbreitung der Alphabetisierung kausal belegen.

Etwa ein halbes Dutzend Lehrkräfte stach im Jahr 1803 mit besonderen positiven Kenntnissen hervor, so der bereits erwähnte Lehrer Emanuel Heinzgen von Muttenz BL, dessen Kenntnisse „für einen Dorfschulmeister vortrefflich “1337 gewesen seien, oder der Lehrer und Gemeindepräsident Johannes Gysin von Hölstein BL, zu dem notiert war: „wenige seinesgleichen (so gut!); mit Neigung zu mathematischen Kenntnissen, besonders Arithmetik und Geometrie, auch Fortschritte in Algebra; unterrichte einige Kinder in der Regul de tri-quinta; keine schlechte Handschrift." ${ }^{1338}$

Die deutliche Mehrheit der Lehrkräfte wurde im Lesen zu beiden Zeitpunkten als mindestens „hinlänglich“ bis „sehr gut“ taxiert, ebenso wie eine Mehrheit im Schreiben eine gute Bewertung

1335 StABL AA 1012, Lade 200, 07.03.01, o. Pag.: [1803] - Berichte.

1336 Vgl. die Studie zum Schulerfolg der basellandschaftlichen Kinder: Rothen, Lesen.

1337 StABL AA 1012, Lade 200, 07.03.01, o. Pag.: [1803] - Muttenz.

1338 StABL AA 1012, Lade 200, 07.03.01, o. Pag.: 28.09.1803 - Bennwil. 
erhielt. Augenfällig ist allerdings, dass die Lehrerschaft fünf Jahre später in sämtlichen Kulturtechnikkenntnissen deutlich kritischer beurteilt wurde. Hinter der Zunahme an mittelmässigen und mangelhaften Bewertungen stand aber nicht etwa eine plötzliche Verschlechterung der Kompetenzen der Lehrkräfte, zumal sich nur ein Fünftel des Lehrerkorps personell verändert hatte, sondern sie ist als ein Zeichen einer veränderten Erwartungshaltung an die Schule zu deuten. Die Lehrer wurden also nicht etwa fachlich schlechter, sondern die schon vor der Helvetischen Revolution eingesetzten Professionalisierungsbemühungen der Basler Obrigkeit im Bereich der Elementarschule schlugen sich nun in einer gesteigerten Anspruchshaltung gegenüber der Lehrerschaft nieder. Der Quellenvergleich von 1798 und 1803 belegt somit empirisch die zugenommene Kritik am Elementarschullehrer und seinen Fertigkeiten als ein Ausdruck eines Wandels der Anforderungserwartungen an die elementare Lehrerschaft.

Im Gegensatz zum Distrikt Kulm wurden die älteren Basler Lehrkräfte jedoch insgesamt deutlich kritischer beurteilt und erhielten deutlich schlechtere Bewertungen als ihre jüngeren Amtskollegen.

Tab. 36: Fähigkeiten der Lehrer im Kanton Basel 1803 nach Alter

\begin{tabular}{lccccccccc}
\hline & \multicolumn{3}{c}{ Unter 30-Jährige: } & \multicolumn{3}{c}{ 30-49-Jährige: } & \multicolumn{2}{c}{ Über 50-Jährige: } \\
\hline Bewertung: & Lesen & $\begin{array}{c}\text { Schrei- } \\
\text { ben }\end{array}$ & $\begin{array}{c}\text { Rech- } \\
\text { nen }\end{array}$ & $\begin{array}{c}\text { Lesen } \\
\text { Sehrei- } \\
\text { ben }\end{array}$ & $\begin{array}{c}\text { Rech- } \\
\text { nen }\end{array}$ & $\begin{array}{c}\text { Lesen } \\
\text { Schrei- } \\
\text { ben }\end{array}$ & $\begin{array}{c}\text { Rech- } \\
\text { nen }\end{array}$ \\
\hline Gut & 2 & 1 & 0 & 2 & 1 & 1 & 3 & 4 & 3 \\
Mittelmässig & 1 & 2 & 2 & 8 & 8 & 2 & 17 & 9 & 3 \\
Schlecht & 2 & 2 & 0 & 3 & 1 & 1 & 4 & 6 & 3 \\
Keine Angabe & 0 & 0 & 0 & 0 & 3 & 1 & 5 & 7 & 1 \\
\hline Total & 0 & 0 & 3 & 0 & 0 & 8 & 0 & 3 & 19 \\
\hline
\end{tabular}

Explizit „schlechte“ Bewertungen entfielen ausschliesslich auf Lehrkräfte jenseits des dreissigsten Lebensjahrs. Bezüglich des Schreibens und Rechnens standen ferner insbesondere die erfahrenen, über fünfzigjährigen Lehrer paradoxerweise am stärksten in der Kritik. Die Resultate verweisen auf eine veränderte Wahrnehmung der Generationen durch die beurteilenden Pfarrer, wie es auch in einzelnen Studien aus deutschen Territorien festgestellt worden ist. ${ }^{1339}$ Ein höheres Alter wurde in den reformorientierten Kreisen offenbar zunehmend gleichgesetzt mit geistigem Stillstand, einem grundsätzlichen Unwillen für Reformen und mit vermuteter Opposition gegen jegliche Neuerungen. Jungen Menschen wurde dagegen eine stärkere „Formbarkeit" durch Reformen und eine erhöhte Bereitschaft zur Umsetzung von neuen Ideen zugesprochen, weshalb sie in einem eventuell günstigeren Licht beurteilt wurden.

Da nur wenige Lehrer überhaupt einen rudimentären Mathematikunterricht in ihrem Schulunterricht anboten, wurde die relative Mehrheit der Basler Lehrer in dieser Fähigkeit nicht bewertet. Wie schon für den Distrikt Kulm vorangehend festgehalten, bedeutete das Fehlen von Rechnen als angebotenes Unterrichtsfach aber keineswegs, dass die Lehrkräfte selbst nicht rechnen konnten und dass die Schulkinder vor Ort nicht rechnen lernten. Vielmehr manifestieren sich drei strukturelle Probleme hinter dem Absentismus von Mathematikunterricht im Elemen-

1339 In den Visitationsberichten des Landkapitels Karlstatt von 1791/92 im Hochstift Würzburg konnte ein ähnliches Generationengefälle festgestellt werden, denn es wurden häufig junge Lehrer mit Lob bedacht. Schraut, Mädchenbildung: 43f. 
tarschulwesen vor 1800: zum Ersten wurden zahlreiche Schulkinder bereits vor dem Erlernen des Rechnens von ihren Eltern aus dem öffentlichen Unterricht genommen, da Rechnen als letztfolgende Kulturtechnik nicht für die Admission zum Abendmahl verlangt wurde und die Kinder als Arbeitskräfte in der elterlichen Hausökonomie gebraucht wurden. Zum Zweiten existierte oft nur eine geringe Nachfrage vonseiten der Eltern, da gerade das Rechnen ausserhalb der Schule in ausserschulischen Lernorten vermittelt wurde. Insbesondere das sogenannte „Bauernrechnen“ wurde oftmals privat gelehrt, entweder durch einen lokalen Bauern oder durch einen speziell dafür angestellten Privatlehrer, wie ein Eintrag in den Luzerner Schultabellen von 1798 bei der Gemeinde Sempach LU festhielt: „hie und da hätt ein Bauer einen Rechenmeister." ${ }^{\text {"340 }}$ Es brauchte somit die Lehrer und die öffentliche Schule gar nicht zwingend, um den Kindern das Rechnen zu lehren. Vielmehr stand der Lehrer, sofern er Rechnen integrativ im Unterricht oder als fakultativer kostenpflichtiger Zusatzunterricht anbot, in direkter freier Konkurrenz mit anderen begabten Dorfbürgern, woraus zum einen handfeste soziale Konflikte resultieren konnten, zum anderen den Lehrkräften ein zeitlich-finanzielles Risiko entstand, wenn die Nachfrage nach dem Zusatzdienst gering blieb. Dieser Umstand der weitgehend privaten Substitution des Mathematikunterrichts hatte zum Dritten die Zirkelfolge, dass viele Schulmeister aufgrund mangelnder Anwendung ihre eigenen Mathematikkenntnisse mit der Zeit wieder verlernten und nach einer gewissen Zeit von sich aus nicht mehr als Unterrichtsfach anboten.

Die Ergebnisse aus dem Distrikt Kulm und aus der Basler Landschaft mit ihrem gleichlautenden Ergebnis einer weitgehend kompetenten Lehrerschaft korrespondieren im internationalen Vergleich stark mit den Ergebnissen einer summarischen Fähigkeiten-Analyse der Lehrer aus dem norddeutschen Niederstift Münster. Hierbei wurden die Lehrkräfte ohne Altersstratifizierung in den Unterrichtsfächern Lesen, Schreiben und Religion geprüft und benotet, wobei die Mehrheit der Hauptschullehrer und zumindest rund ein Drittel der Nebenschullehrer eine „mehr als mittelmässige " Bewertung erreichten. ${ }^{1341}$ Zudem negieren die vorgestellten quantitativen Resultate das Vorurteil, dass breitflächig grundsätzlich unqualifizierte Personen im Lehramt gestanden hätten. Freilich, gute fachliche Fähigkeiten im Umgang mit den Kulturtechniken machten aber noch nicht automatisch einen guten Lehrer aus und vice versa bedeutete mangelhafte Kenntnisse zu haben nicht zwingend, ein schlechter Lehrer zu sein. Die angewendete Lehrart, als auch passende charakterliche Eigenschaften und Sozialkompetenzen, wie Geduld, einen guten Umgang mit den Kindern und Verständnis zur Wissensvermittlung, gehörten damals wie heute ebenso zum Pflichtenheft eines guten Lehrers und wurden als Kriterien auch von den Pfarrern in den jeweiligen Beurteilungen mitberücksichtigt. Ein Beispiel aus Riehen BS und Bettingen BL von 1798 zeigt auf, dass gute Kulturtechnikkenntnisse zwar das Fundament eines guten Lehrers bildeten, nicht aber vor kritischen Einschätzungen bewahrte: „B. Bassler hat zwar eine saubere Handschrift, ist auch der Orthographie und des Rechnens wohl erfahren, allein zum Jugendlehrer scheint er nicht gebohren zu seyn; er ist zu langsam, zu schläferig, und weiss sich den Kindern weder fasslich noch weis zu machen; auch ist er nicht im Stande, eine beträchtliche Anzahl Kinder in der Ordnung zu erhalten. B. Meyer kann zwar sauber schreiben und gut lesen, ist besonders stark im Singen und spielt die Orgel in unsrer Kirche gut, wäre auch lebhaft genug, allein zum Schullehrer dünkt er uns ebenfalls untüchtig zu seyn; Er bleibt sich selbst nicht gleich; einmal allzustrenge, das ander mal allzu nachsichtig; ist rauh gegen die Kinder, oft sogar grob und mit Schimpfwörtern um sich werfend, hat weder Ordnung, noch Methode. Beyde Schulmeister sind von den Kindern nicht respektiert. ${ }^{1342}$ Beide kritisierten Lehrer

1340 BAR B0 1000/1483, Nr. 1454, fol. 7-8, 23: [1799] - Schultabellen Luzern.

1341 Bölsker-Schlicht, Münster: 206ff.

1342 StABL AA 1012, Lade 200, 07.01.01, fol. 221: 13.03.1798 - Bericht. 
gehörten mit weit über 200 Franken Einkommen pro Jahr zu den bestverdienenden Lehrern der Basler Landschaft. Der erstgenannte Lehrer Johann Jakob Bassler brachte als studierter Theologe zwar eine hohe Vorbildung mit, dennoch lief seine Schule schlecht, wie er in seiner Antwort auf die Stapfer-Enquête zugeben musste: „Seit einiger Zeit wird die hiesige Schule schlecht besucht, sehr viele Eltern schicken ihre Knaben auf Lörach in die lateinische Schule; viele behalten ihre Kinder ganz daheim. "1343

Eine hohe Besoldung des Lehrers und eine universitäre Vorbildung garantierten somit allein noch keinen besseren Schulerfolg, wenn die charakterlichen Eigenschaften des Lehrers nicht passend waren. Demgegenüber fiel das Urteil gegen den bereits 73-jährigen Lehrer von Lauwil BL trotz seiner fachlichen Schwächen sehr milde aus: „derjenige zu Lauwil ist ein schwacher, abgelebter Greis, der wie alle alte Leute bey seiner wolhergebrachten Mode bleibt, und allen Neuerungen grau ist. Doch nimmt er, wenigstens so lange ich in der Schule gegenwärtig bin, gerne Belehrung an. Er hat die Gabe in Zeit von einem Vierteljahre auch die ungeschiktesten Kinder ohne Anstoss lesen zu lehren; so viel vermag Gedult und angestrengte Aufmerksamkeit! Und wirklich lesen, im Ganzen genommen die Kinder von Lauwil sehr gut. Jn der Religion kann er keinen Unterricht erteilen, weil er selbst nicht mehr geben kann, als er empfangen hat. [...] Sein Sohn, der eine saubere Handschrift hat, gibt Unterricht im Schreiben, und ich muss es ihm nachrühmen, dass die meisten Kinder bey ihm gut profitiren. "1344

Die hohen Sozialkompetenzen des Lehrers überwogen in diesem Beispiel die kritisierten Mängel an Reformbereitschaft, dennoch funktionierte der schulische Grundauftrag offensichtlich weiterhin zur Zufriedenheit von Pfarrer und Gemeindevorgesetzten, zumal der Sohn des Lehrers zu dessen Unterstützung den Schreibunterricht übernommen hatte. Auch bei anderen Lehrkräften der Basler Landschaft wurden bisweilen mangelhafte Kenntnisse der Kulturtechniken festgehalten, dennoch standen diese Lehrer in punkto Charakter und Fleiss bisweilen in einem sehr guten Licht. Gesamtheitliche Betrachtungen von Kulturtechnikkenntnissen und Sozialkompetenzen wurden unter dem Stichwort der „Amtsausführung“ in diversen regionalen Schulumfragen erhoben. Sie dienen als Grobeinschätzungsrahmen für die Qualität des Elementarschulwesens. Die Frage nach der Amtsführung wurde denn auch 1803 an die baselländischen Pfarrer gestellt: „Ob er [der Lehrer] sich seine Amtsverrichtungen fleissig angelegen seyn lasse?"1345

Tab. 37: Der Amtsfleiss der Basler Lehrer 1803

\begin{tabular}{lcccc}
\hline Bewertung: & Anzahl Lehrer: & Unter 30-Jährige: & 30-49-Jährige: & Über 50-Jährige: \\
\hline Tüchtig & 43 & 5 & 13 & 25 \\
Untüchtig & 4 & 0 & 0 & 4 \\
\hline Total & 47 & 5 & 13 & 29 \\
\hline
\end{tabular}

Die überwiegende Mehrheit der baselländischen Lehrkräfte wurde von ihren vorgesetzten Pfarrern nicht nur als mehrheitlich fachlich kompetent, sondern zugleich als tüchtige Schulmeister angesehen, die ihre Amtsverrichtungen mit genügend Fleiss und Hingabe erfüllten, unabhängig vom Schultyp, der Vorbildung, der Fähigkeiten oder des Einkommens. Der attestierte durchwegs hohe Grad an Fleiss spricht denn auch für eine grundsätzlich hohe intrinsische Motivation

1343 Schmidt u.a. (Hgg.), Stapfer-Enquête, Nr. 2065: Riehen.

1344 StABL AA 1012, Lade 200, fol. 49: [1798] - Bericht.

1345 StABL AA 1012, Lade 200, 07.03.01 - Berichte. 
der Lehrkräfte zur Ausübung ihres Amtes, ungeachtet der realen Besoldungsverhältnisse. Dieser Befund ist insofern von besonderer Bedeutung, da er der weiter oben skizzierten Darstellung widerspricht, die Lehrkräfte hätten ihre Lehrtätigkeit nur mit schwachem Interesse und - als Nebenerwerb von subsidiärer Bedeutung - vernachlässigend ausgeübt. Selbst wenn die Fähigkeiten der einzelnen Lehrkräfte stark unterschiedlich ausgeprägt sein mochten, ihre Amtstätigkeit übten fast alle Lehrkräfte mit grossem Fleiss und Eifer aus. Zwar bestand bei drei der vier bezüglich ihres Fleisses bemängelten Lehrer eine direkte Kausalität zwischen mangelndem Fleiss und eher mässigen Fähigkeiten, nicht aber in umgekehrter Abfolge. Auffällig ist einzig, dass sämtliche im Jahr 1803 als untüchtig bezeichnete Lehrkräfte bereits über 50 Jahre alt waren und nicht einer Deputatenschule vorstanden.

Dennoch hatten von den Pfarrern kritisierte fachliche Kompetenzen oder Amtsverrichtungen keine unmittelbaren personellen Konsequenzen für die Lehrerschaft. Etliche im Frühjahr 1798 aufgrund ihrer Fähigkeiten, ihrer Amtsausführung oder ihres Lebenswandels kritisierte Lehrer der Basler Landschaft standen fünf Jahre später immer noch im Dienst, teilweise mit denselben wiederholten Vorwürfen. Beispielsweise stand der Lehrer von Augst BL, Johannes Liechtlin, dessen Fähigkeiten und Lebenswandel bereits 1798 stark kritisiert worden waren, im Jahr 1803 immer noch seiner Schule vor. ${ }^{1346}$

Den möglichen Einwand, dass es sich bei der reformierten Basler Landschaft um einen einzigartig progressiven Bildungsraum innerhalb der konfessionell zersplitterten Alten Eidgenossenschaft handelte, dessen Landschulen sich durch die obrigkeitliche Sonderfinanzierung des städtischen Deputatenfonds finanziell und durch den hohen Anteil an studierten Theologen personell stark von den übrigen Regionen abgehoben hatten, kann durch Ergebnisse aus weiteren regionalen Umfragen entkräftet werden.

\section{Das Fallbeispiel Fürstabtei St. Gallen}

Eine Schulumfrage zum Zustand der katholischen Landschulen in der gemischtkonfessionellen Ostschweizer Fürstabtei St. Gallen von 1796/97 ermöglicht eine quantitative Einschätzung der allgemeinen Unterrichtsfähigkeiten von insgesamt 86 katholischen Lehrern. Dazu zählten integral neben dem fachlichen Beherrschen der Kulturtechniken auch die angewendete Unterrichtsmethodik und das persönliche Engagement der Lehrer. Die durch die Pfarrer zu beantwortende Frage der Umfrage lautete: „Unterrichtet er gut und fleissig?“. Die Beantwortung erfolgte zwar ohne systematisierte Terminologie, dennoch liess sich aus den Aussagen der Grad der Zufriedenheit relativ deutlich abschätzen und in die bisher verwendete Kategorisierung einteilen. ${ }^{1347}$

Tab. 38: Fähigkeiten der Lehrer in der Fürstabtei St. Gallen 1796

\begin{tabular}{lccccc}
\hline Bewertung: & Anzahl Lehrer: & Unter 30-Jährige: & 30-49-Jährige: & Über 50-Jährige: & Keine Angabe: \\
\hline Sehr gut & 9 & 2 & 2 & 5 & 0 \\
Gut & 35 & 5 & 18 & 10 & 2 \\
Mittelmässig & 30 & 4 & 16 & 7 & 3 \\
Mangelhaft & 4 & 0 & 3 & 1 & 0 \\
Keine Angabe & 8 & 2 & 3 & 1 & 2 \\
\hline Total & 86 & 13 & 42 & 24 & 7 \\
\hline
\end{tabular}

1346 StABL AA 1012, Lade 200, 07.03.01, o. Pag.: 25.09.1803 - Augst.

1347 BiASG III D 94, fol. 1-344: [1797] - Bericht. 
Bei rund der Hälfte aller katholischen Lehrer der Fürstabtei, insgesamt 44 Lehrkräften, gab der Unterricht beziehungsweise die Amtsführung der Lehrkräfte zu keinerlei Beanstandungen Anlass und wurde von den Pfarrern mit "gut“ bis „sehr gut“ eingestuft. Die Unterrichtsqualität eines weiteren Drittels aller Lehrer wurde als „mittelmässig“ beurteilt, so etwa der 39-jährige Lehrer von Neu St. Johann SG: „was anfangende Kinder betrift so hat er in diesem Fache grosses Lob, allein für Kinder die schon weiter fortschritte gemacht haben, ist er nicht gewachsen. Doch man muss mit ihm Vorlieb nehmen, weil man keinen Tauglichern haben kann. "1348 Bloss rund 5\% der Lehrer wurden hingegen bezüglich ihres Unterrichts als mangelhaft eingestuft, so etwa der 46-jährige Lehrer von Ganterschwil SG, dessen Unterricht: „so arm selig als sich es ein bilden lass “1349 gewesen sei. Altersdifferenziert entsteht ein leicht disparates Bild, sowohl bei der Betrachtung der Anzahl gut bis sehr gut bewerteten Lehrkräften als auch bei den mangelhaft bis mittelmässig eingestuften Lehrern. So wurden in den beiden Alterskohorten der unter Dreissigjährigen genauso wie bei den über Fünfzigjährigen deutlich mehr Lehrkräfte als gut bis sehr gut eingestuft, während bei den 30-49-jährigen Lehrern sich die eher besser Bewerteten mit den eher schlechter Bewerteten die Waage halten. Insgesamt widerspiegelt sich aber auch in der Fürstabtei St. Gallen eine grossmehrheitliche Satisfaktion der lokalen Vorgesetzten mit der unmittelbaren Amtsausübung der Lehrkräfte.

\section{Das Fallbeispiel Luzern}

In der Frühphase der Helvetischen Republik lancierte der Luzerner Erziehungsrat im November 1798 eine Enquête von zwölf Fragen zum elementaren Schulwesen, adressiert an die Unterstatthalter der Luzerner Distrikte, wobei die fünfte Frage „Wie steht der Lehrer seinem Amte vor ?" lautete. ${ }^{1350}$ In der Auswertung der tabellarisch festgehaltenen Ergebnisse, als dessen Urheber Franz Regis Krauer gilt, ${ }^{1351}$ offenbarte sich ebenfalls eine mehrheitlich positive Einschätzung des Amtsfleisses der 78 erfassten katholischen Luzerner Lehrer.

Tab. 39: Die Amtsausführung der Luzerner Lehrer 1798-991352

\begin{tabular}{|c|c|c|c|c|c|}
\hline Bewertung: & Anzahl Lehrer: & Unter 30-Jährige: & 30-49-Jährige: & Über 50-Jährige: & Keine Angabe: \\
\hline Sehr gut & 5 & 0 & 4 & 0 & 1 \\
\hline Gut & 43 & 9 & 21 & 7 & 6 \\
\hline Mittelmässig & 13 & 3 & 4 & 4 & 2 \\
\hline Schlecht & 4 & 1 & 0 & 2 & 1 \\
\hline Keine Angabe & 13 & 0 & 0 & 2 & 11 \\
\hline Total & 78 & 13 & 29 & 15 & 21 \\
\hline
\end{tabular}

Deutlich mehr als die Hälfte der Luzerner Lehrkräfte hatten ihre Amtsausübung in den Augen der Unterstatthalter „gut“, einige sogar „sehr gut“ erfüllt. Darunter fielen insbesondere jene rund zwei Dutzend Lehrkräfte, die seit der Errichtung der Lehrerfortbildungsanstalt in St. Ur-

1348 BiASG III D 94, fol. 151-154: [1797] - Bericht.

1349 BiASG III D 94, fol. 95-98: 14.02.1797 - Bericht.

1350 Pfenniger, Luzerner Volksschule: 41.

1351 Fuchs, Grenzen: 122-128.

1352 BAR B0 1000/1483, Nr. 1454, fol. 1-23v: [1799] - Schultabellen Luzern. Die Tabellen wurden am 10. Januar 1799 zusammen mit Vorschlägen zur Verbesserung des Schulwesens an Stapfer geschickt und sind deshalb im Bundesarchiv aufbewahrt. BAR B0 1000/1483, Nr. 1451, fol. 62-63: 10.01.1799 - Erziehungsrat des Kantons Luzern. 
ban die Normalschulmethode erlernt und bei sich eingeführt hatten. Neben weltlichen Lehrern standen im Kanton Luzern auch zahlreiche gebildete Geistliche als Lehrer im Dienst, von denen einige freiwillig oder aus Mangel eines Lehrers eine Schule führten. ${ }^{1353}$ Sie waren denn auch die Schlüsselpersönlichkeiten in der Verbreitung der Normalmethode auf der Landschaft und verfügten selbst über gute Kenntnisse der Kulturtechniken. Allerdings erfüllten auch zahlreiche weltliche Lehrkräfte ohne seminaristische Fortbildung in St. Urban die Anforderungen in guter Weise. Bloss 5\% der Lehrer wurden dagegen ausdrücklich als ungenügend bezeichnet, etwa ein knappes weiteres Fünftel wurde als „mittelmässig“ eingeschätzt. Kritisiert wurden dabei vor allem die alte Lehrart und mangelnde Kulturtechnikkompetenzen. Der Luzerner Erziehungsrat erkannte denn auch weniger im Fleiss der Lehrkräfte ein Verbesserungspotenzial, sondern sah in der „Unlust der Lehrer“ aufgrund des bescheidenen Lohns und wegen des fehlenden „Willens der Eltern, die mit sehr wenigem zufrieden sind“ die grösseren Übel. ${ }^{1354}$

In alterstratifizierter Betrachtung schnitten einzig die ältesten Lehrkräfte ab 50 Altersjahren in der Tendenz etwas schlechter $\mathrm{ab}$ als ihre jüngeren Amtskollegen, was wohl ebenfalls auf die in ihrer Alterskohorte gänzlich fehlende Ausbildung in St. Urban zurückzuführen ist. Die Berichte des Luzerner Erziehungsrats aus den Folgejahren 1801 und 1803 bestätigten indes die Feststellung, dass die Fähigkeiten der Lehrkräfte auch in der Folge mehrheitlich als genügend bis gut bezeichnet wurden, sich Fortschritte aufgrund von Initiativen einzelner lokaler Pfarrer festhalten liessen und 1803 nur noch wenige Lehrer unter dem Grad der Mittelmässigkeit standen. ${ }^{1355}$

\section{Das Fallbeispiel Berner Oberland}

Bereits im Jahr 1780 wurde die Lehrerschaft im bernischen Kapitel Bern, einem Verwaltungsbezirk rund um die Stadt Bern, hinsichtlich ihrer Fähigkeiten beurteilt. Der überwiegende Teil der Lehrerschaft, rund 87\%, war dabei als tüchtig und fleissig eingestuft worden. ${ }^{1356}$ Die Frage nach der Amtsführung der Lehrer beschäftigte um die Weihnachtszeit des Jahres 1800 auch die Verwaltungskammer des neu geschaffenen reformierten Kantons Oberland, ehemals Teil des Berner Untertanengebiets. Die bis ins Frühjahr 1801 verfassten Antwortschreiben der lokalen Pfarrer zeichneten freilich ein disparates Bild von der Amtsführung ihrer Lehrkräfte. Aufgrund der fehlenden Nennung der Namens- und Altersangaben der Lehrer kann aus dieser Umfrage keine altersstratifizierte Differenzierung vorgenommen werden.

Tab. 40: Die Amtsführung der Oberländer Lehrer $1800^{1357}$

\begin{tabular}{lcc}
\hline Bewertung: & Anzahl Lehrer: & In Prozent: \\
\hline Sehr gut & 6 & $4 \%$ \\
Gut & 29 & $19 \%$ \\
Ausreichend & 67 & $44 \%$ \\
Mangelhaft & 49 & $33 \%$ \\
\hline Total & 151 & $100 \%$ \\
\hline
\end{tabular}

1353 BAR B0 1000/1483, Nr. 1454, fol. 3-4, 23: [1799] - Schultabellen Luzern.

1354 BAR B0 1000/1483, Nr. 1451, fol. 56-58: 10.01.1799 - Allgemeine Übersicht; Pfenniger, Luzerner Volksschule: 41.

1355 Vgl. Egli, Schulreform in der Praxis: 52-55.

1356 Schmidt, Kapitel Bern: 157.

1357 StABE Helv OL 41, o. Pag.: [1800-1801] - Berichte über die Schulen. 
Die Mehrheit der Lehrkräfte arbeitete zwar auch im Berner Oberland - gemessen an den Anfordernissen der Lokalbevölkerung - zumindest „ausreichend“ bis „gut“, allerdings wurde gleichzeitig ein ungleich grösserer Teil der Lehrer von der vorgesetzten Geistlichkeit als eher „mangelhaft“ in ihrer Amtsführung gesehen als in den übrigen untersuchten Regionen. Besonders die Schulmeister des östlichen Berner Oberlands, der ökonomisch ärmeren Zone der alpinen Mischwirtschaft, wurden markant stärker kritisiert als ihre Berufskollegen in den westlichen Talschaften. Für den mangelhaften Zustand lokalisierten die Pfarrer drei hauptsächliche Ursachen: eine mangelhafte Besoldung, eine schlechte Grundbildung der Schulmeister sowie ein mangelndes Bildungsverständnis in der Bevölkerung. Der Pfarrer von Gsteigwiler bei Interlaken BE resümierte denn auch in resignierendem Tonfall: „Wollte Gott! ich könnte diese Frage mit einem freudigen Ja! beantworten, aber da liegt eben eine der würksamsten Ursachen de jammervollen Zustands unsrer Schulen. Meine Schulmeister haben alle mehr oder weniger, guten Willen, aber was that man je, um sie aufzumuntern, oder ihnen Mittel an die Hand zu geben, sich selbst zu unterrichten? Was that man je für unsre Landschulen? Zeigte man nicht immer, man sehe es lieber, sie seyen zu schlecht, als zu gut? [...] Zum Religionsunterricht sind diese Männer auf keine Weise zu gebrauchen und wenn Sie es auch wären, so haben sie keine Zeit dazu, da sie nach vollendetem mühsamen Frondienste, die einen sogleich zur Nadel, die andern zur Holzaxt, etc. zurückkehren müssen, um sich und die ihrigen ein kümmerliches Unterkommen zu verschaffen. Von einer vernünftligen bürgerlichen Moral ist gar nicht die Rede; die meisten üben sie praktisch in Einfalt und Redlichkeit, soweit als ihre Begriffe gehen und sie allenfalls unmittelbar hingelenkt werden; aber kein deutlicher, bestimmter Begrif, den sie systematisch andern beybringen könnten, liegt davon in ihrem Verstande und selbst, wenn der Pfarrer auf der Kanzel und nebenher dieses thut, so heist es bey unserm Volke, das bey dem einreisenden neuen Heidentum je länger je mystischer, aber deswegen eben nicht besser wird, er predige wie ein Heide. Das Schreiben derjeinigen, die nach Landesart noch für Meister der Kunst gehalten werden, ist ein schrekliches Gekritzel und an Orthographie ist dabei nicht zu gedenken. Als ich hieher kam, war die edle Schreibkunst fast gänzlich verlohren; in keiner Schule schrieb man, ich arbeitete, was ich konnte, um diesen so unaussprechlich nöthigen Theil des Lehrers wieder aufzubringen. Neu schreibt man in den meisten Schulen, aber wie? [...] Die Gleichgültigkeit der Eltern hiebey ist ganz unglaublich. Vom Rechnen ist nur keine Rede. das ist eine Wissenschafft, selbst für die Schulmeister die alles übersteigt, was sie sich denken können, obschon sie ganz simple Rechnungen nach ihrer eignen Art nach zu machen verstehen, aber mit Ziffern zu rechnen, wie die Herrenleuthe, behaupten selbst die weisesten Vorsteher unser Gemeine, sey für Baurenkinder eine ganz unmögliche Sache." 1358

Erklärungsansätze, warum die Schulmeister über unterschiedliche fachliche Fähigkeiten in den elementaren Kulturtechniken verfügten, sind somit nicht nur im individuellen Intellekt, den fehlenden normativen Vorgaben und der unsystematischen Vorbildung der Individuen zu suchen, sondern mitunter auch stark in den Erwartungshaltungen der Lokalbevölkerung an die Schulmeister. So berichtet der Pfarrer von Hilterfingen BE in derselben Oberländer Schulumfrage von 1800 praktisch analog zum Gsteigwiler Pfarrer betreffend des Themas Schreiben: „Was das Schreiben anbetrifft, so sind darunter einiche, die schön schreiben, die andern aber weniger schön; aber gleichwol ist unter allen keiner, der recht (das heisst orthographisch) schreiben kann. Allein sie selbst die Schulmeister, und auch der weit grössere Theil unserer Gemeinds Angehörigen stehen in der festen Beglaubigung, dass diese Kunst für sie, und ihre Kinder eben nicht nöthig seye. ${ }^{\text {1359 }}$

1358 StABE Helv OL 41, Nr. 749: 01.03.1801 - Berichte über die Schulen.

1359 StABE Helv OL 41, Nr. 458v: 25.12.1800 - Berichte über die Schulen. 
Schön- und Rechtschreiben wurde offenbar von einem Grossteil der Lokalbevölkerung schlicht nicht als notwendig erachtet und als Bildungsziel verlangt, ergo mussten die Lehrer der genannten Gemeinden diese Fähigkeit nicht unter Beweis stellen, um ihre Tätigkeit zur Zufriedenheit der Gemeinde ausführen zu können. Die lokale Erwartungshaltung an den Lehrer ist somit einerseits nicht nur eine Schlüsselgrösse zum Verständnis des schulischen Angebots, sondern die Fertigkeiten der Schulmeister bildeten andererseits gleichzeitig ein Spiegelbild der gesellschaftlichen Vorstellungen ab, was die Schule leisten musste. Im schwierigen Diskurs um die Einführung neuer Methoden - etwa der Normalmethode - wird die fragile Position des Lehrers gegenüber der Lokalbevölkerung und ihrem Bildungsbedürfnis deutlich, das oft nicht deckungsgleich mit der Erwartungshaltung der Pfarrer war.

Kaum ein anderes Bild vom hohen Fleiss und der guten Amtsausführung der Lehrkräfte liefert ein Blick über die Grenze nach Norddeutschland. Auch im Niederstift Münster gaben in den Visitationsprotokollen von 1783/84 bloss etwa 10\% der insgesamt 164 Lehrer Anlass zu Tadel, rund 90\% der Lehrer erfüllten ihre Aufgaben dagegen „gut“ oder zumindest „ohne Klage“. Wenn es zu Klagen kam, wurde am häufigsten mangelnder Fleiss oder Trunksucht bemängelt. ${ }^{1360}$ Über Lehrerinnen sind insgesamt aus den konsultierten Quellensammlungen nur wenige spärliche Berichte zu ihrem Unterrichtserfolg und ihren Amtsfleiss auffindbar. Die Arbeit der Hilfslehrerinnen der beiden Mädchenschulen der Stadt St. Gallen wurden beispielsweise am Rande einer Schülerinnenprüfung aus dem Jahr 1801 summarisch beurteilt. Hierbei erhielt die Ehefrau des Lehrers Johann Jakob Stähelin, Maria Elisabeth Stähelin, Lobesworte, wohingegen sich die beiden Helferinnen der zweiten Mädchenschule nicht auszuzeichnen vermochten. ${ }^{1361}$

Angesichts der Resultate aus den quantitativ untersuchten Quellen zu den einzelnen Kulturtechnikkompetenzen, dem Amtsfleiss und der Amtsführung kann dem Resümee von Fritz Osterwalder eine gesamthelvetische Gültigkeit zugesprochen werden, dass der allgemeine Zustand des Lehrpersonals um 1800 „nicht allzu schlecht“ gewesen sein dürfte. Die Mehrheit der Lehrer hatte sich in der Stapfer-Enquête als Tatbeweis schriftlich in einer Art und Weise geäussert, dass kaum angenommen werden kann, sie gehörten zu den ungebildetsten Schichten der Gesellschaft. ${ }^{1362}$

Die offensichtliche Diskrepanz zwischen der Vielzahl an Klagen über die angebliche Untauglichkeit der Lehrer um 1800 und den oben präsentierten seriellen Resultaten einer grundsätzlich positiven Würdigung der Fähigkeiten der Lehrer ist daher wohl das Produkt einer doppelten Perspektivität auf das vormoderne Schulwesen. Gemessen an den Massstäben der „alten Schule“ und an den Forderungen der Lokalbevölkerung bestand ein gut funktionierendes, erfolgreiches Schulwesen mit einem flächendeckend äusserst hohen Durchdringungsgrad und grösstenteils zumindest ,genügend“ gebildeten Lehrkräften. Als ,ungenügend“ und „untauglich“ erschienen das Schulwesen und mit ihm die Schulmeister erst durch die Brille der volksaufklärerischen Reformer mit ihren Visionen einer „besseren“ Volksschule. Die Pfarrer nahmen als Vorgesetzte und Bewertende dabei selbst eine ambivalente Rolle ein, indem negative Schwarzmalerei zwar mehr Aufmerksamkeit generierte, zu negative Berichte jedoch einer übertriebenen Selbstkritik gleichkamen.

\subsubsection{Das Ansehen in den Gemeinden}

Angesichts der oben attestierten grundsätzlichen Zufriedenheit der vorgesetzten Pfarrer mit den Fähigkeiten und der Amtsführung ihrer Lehrkräfte stellt sich die Anschlussfrage, wie es um

1360 Bölsker-Schlicht, Münster: 209f.

1361 „B. Stähelin [...] An seiner Frau hat er eine sehr gute, an seiner Mutter eine schwache Hülfe. [...] B. Erpf [...] Seine Gehülfinnen zeichnen sich nicht aus." StASG HA R 132, Fasz. 2, o. Pag.: 06.05.1801 - Mädchen Examen.

1362 Osterwalder, Vorgeschichte: 81; Ruloff, Schulbesuch: 70. 
das soziale Ansehen der Lehrer in den Gemeinden stand. Die Wahrnehmung der Gemeindebürger musste nicht mit der Optik der Pfarrer - als sozialständisch „Fremde“ oft selbst in Konflikten mit den Gemeinden stehend - übereinstimmen. Entsprach die apostrophierte minderwertige, erbarmungswürdige Position des „armen Dorfschulmeisterleins“ im lokalen Sozialgeflecht einer kollektiven historischen Realität oder ist es vielmehr ebenfalls ein verselbständigtes Klischee der Historiografie?

Der Blick auf einzelne Quellenfragmente der Stapfer-Enquête, etwa die Antwort des Lehrers von Utzensdorf BE, bestätigt die Einschätzung eines prekären Sozialstatus grundsätzlich: „aber wie ist ein Lehrer bey uns in den augen vieler Elteren und kinder bey denselben angesehen, gewiß nicht viel mehr als ein Hirth der Schweinen [...] und dieß ist fast überall, daß ein Armer Mann er mag so Ehrlich und so Rechtdenkend seyn als er wil, dennoch in den augen vieler Menschen nur Verspottet und Verachtet und seine Treüe mit undank belohnet wird."1363

Andere zeitgenössische Quellen sahen die Beziehung zwischen dem Lehrer und der Dorfbevölkerung freilich weitaus differenzierter. Als Indikator für das soziale Ansehen dient das Vertrauen der Gemeinde gegenüber dem Lehrer. In der grossen Zürcher Schulumfrage von 1771/72 wurde das Vertrauen der Lehrer mittels der Frage B.a.5. „Achtung in der Gemeinde und bei den Kindern?" systematisch erhoben. Darin berichteten einige Pfarrer von einem hohen Ansehen ihrer Lehrer. Der Pfarrer von Fehraltorf ZH hielt beispielsweise über seinen Schulmeister fest: „In ansehung seiner Schularbeit stehet der SchulMstr bey der Gemeind in grosser Achtung, er wird von jedr mann desswegen, erhebt, gelobt u. gerühmt; Auch bey den kinderen insgemein hat er forcht u. liebe; hat freylich aber nöthig dass er von s. Pfahrer unterstüzt werde, welches auch aufrichtig und in aller treüe geschieht. O Wann die Glider von einem ehrs. Stillstand von solcher art u. beschaffenheit wärind wie der SchulMstr ach mit was freüdigkeit u. mit was für einem erwünschten nuzen könte doch nit ein lehrer in diesem Weingarten des herrn arbeiten."1364 Zum Lehrer in Andelfingen ZH stand dagegen, er sei „des Trunks halber renomiert, doch weißt er gebrendts und ungebrendts sowohl zu vertragen, daß ihme niemand einen taumlenden rausch vorwerfen kann" und daher von der Gemeinde und den Kindern „gar verachtet“. ${ }^{1365}$

Unbestritten ist, dass es sowohl Lehrkräfte mit einem sehr hohen sozialen Status als auch nur gering geachtete Lehrer gab. Insbesondere der zuvor diskutierte, empirisch belegte berufsbiografische Befund einer Dominanz von kirchlichen Nebenämtern musste zahlreichen Lehrkräften ein zusätzliches soziales Kapital verschafft haben, so dass deren soziale Stellung insgesamt nicht allzu prekär gewesen sein konnte. Es stellt sich jedoch die Frage, wie die verschiedenen Meinungen zum Vertrauen der Gemeinden in ihre Lehrer quantitativ verteilt waren. Die Forschungsresultate der gut untersuchten Enquête von 1771/72 sprechen hierbei für sich. Andrea de Vincenti-Schwab hält nach einer summarischen Sichtung der Umfrage fest, dass sich „die positiven und negativen Beispiele [...] ungefähr die Waage halten "1366. Dagegen resümiert Alexandra Bloch Pfister, dass von der Gemeinde schlechter geachtete Schulmeister seltener erwähnt wurden und die deutliche Mehrheit der Lehrer mehrheitlich geachtet war. ${ }^{1367}$ Esther Berner präzisiert die Beobachtungen in ihrer etwas später folgenden Untersuchung quantitativ und

1363 Schmidt u.a. (Hgg.), Stapfer-Enquête, Nr. 1406: Utzenstorf.

1364 StAZH E I 21.3 - Responsion.

1365 StAZH E I, 21.2 - Andelfingen. Bloch Pfister hat das Zitat wohl durch einen Transkriptionsfehler fälschlicherweise als Belobigung aufgefasst. Vgl. Bloch Pfister, Priester: 110. Zit. auch in: Schwab, Schulmeister: 38.

1366 De Vincenti-Schwab, Landschulen: 22.

1367 Bloch Pfister, Priester: 113. 
hält rund 60\% der Zürcher Lehrer um 1771 für mindestens „geachtet“. ${ }^{1368}$ Eine Auswertung der Enquête auf die Frage nach der Achtung der Lehrer in der Gemeinde und von Seiten der Kinder hat die bisherigen Forschungsresultate bestätigt.

Tab. 41: Das Ansehen der Zürcher Lehrer 1771/721369

\begin{tabular}{lcc}
\hline Bewertung: & Anzahl Lehrer: & In Prozent: \\
\hline Hat das vollumfängliche oder mehrheitliche Vertrauen: & 244 & $68 \%$ \\
Unterschiedliches Vertrauen & 58 & $16 \%$ \\
Gemeinde hat kein Vertrauen & 25 & $7 \%$ \\
Keine Angabe & 27 & $8 \%$ \\
Unklare Beantwortung & 4 & $1 \%$ \\
\hline Total: & 358 & $100 \%$ \\
\hline
\end{tabular}

Mehr als zwei Drittel aller Zürcher Lehrer besassen das vollumfängliche oder zumindest mehrheitliche Vertrauen ihrer Gemeinde und hatten damit eine mutmasslich gefestigte soziale Position im Dorf inne. Nur ganz wenige Lehrkräfte genossen gar kein Vertrauen in ihren Gemeinden und sind damit als potenzielle gesellschaftliche Aussenseiter identifizierbar. Die Gründe für einen fehlenden Rückhalt in der Bevölkerung waren zwar vielgestaltig, aber allesamt sehr stark mit persönlichen charakterlich-moralischen Eigenschaften verknüpft, wobei jedoch unklar bleibt, ob in den Antworten vorwiegend die Ansichten der Pfarrer oder tatsächlich jene der Gemeinden abgebildet wurden. Genannt wurde in der Umfrage bei fehlendem Vertrauen unter anderem ein unangebrachter Umgang mit den Schulkindern, ${ }^{1370}$ das schlechte Verhalten von Familienangehörigen ${ }^{1371}$ oder explizit der Ehefrau, ${ }^{1372}$ Trunksucht ${ }^{1373}$ oder der bereits diskutierte Schulmeisterstolz: „nur der Schulmster zu oberuster hat das unglück das seine Gemeind Ihm das herz nie recht hat, und ist doch gwüss ein Ehrlicher mann. bloss Er ist Arm, ein wenig einfaltig und bildet sich doch von sich selbst vill ein." ${ }^{374}$

Auffällig ist jedoch, dass eine schwächere Kausalität zwischen den fachlichen Fähigkeiten der Lehrkräfte und ihrem Ansehen in der Gemeinde bestand als zwischen den charakterlich-moralischen Eigenschaften und dem Ansehen. Fachlich schlechte Lehrpersonen konnten durchaus das Vertrauen der Bevölkerung geniessen, während gleichzeitig fachlich gute Lehrer einen Vertrauensmangel beklagen mussten. ${ }^{1375}$ Bloch Pfister hat über die Ursachen der sozialen Achtung der Schullehrer festgehalten: „Achtung wurde dem Schulmeister [...] aufgrund seines sozialen Status, den der Schulmeister vor der Amtsübernahme eingenommen hatte, sowie aufgrund sei-

1368 Berner, Zeichen: 107.

1369 StAZH E I + E II, A 313 - Zürcher Schulumfrage 1771/72.

1370 „Aber was die Kinder anbetrifft, dass auch dise weder liebe noch forcht haben, das das ist seine schuld; Dann er hat keine rechte art, mit den Schülern zu handlen." StAZH E I, 21.3 - Greifensee.

1371 „Sein liederlicher Sohn hat ihn in schlechten Credit bey der gemeind gebracht." StAZH E II, 164 - Elsau.

1372 „hätte noch mehr Achtung bey der Gemeind u: kindern, wenn er ein besser weib hätte. Iz ist er von derselben frey, davon man alles gute erwartet." StAZH E I, 21.6 - Oberrieden.

1373 „nur wünschte, dass Heinrich Winkler, Schul-Meister zu Theilingen, besser thäte hausen, und weniger trinken, so stuhnde er, bey der gemeinde und den Kinderen, in besserer achtung." StAZH E I, 21.9 - Theilingen.

1374 StAZH E I, 21.8 - Oberuster.

1375 „Die Fähigkeiten des Schulmeisters sind sufficient gnug seinem beruff abzuwarten. [...] Bey der gemeind hat er einen aber nicht so gar grossen credit." StAZH E II, 164 (191-206) - Elsau. 
nes Charakters und Verhaltens entgegengebracht; die Art der Berufsausübung war dabei nur von untergeordneter Bedeutung. "1376 Das soziale Ansehen erwuchs also aus dem Amt selbst, nicht aus der Amtsausübung.

Ein Blick in die Basler Landschaft weist darauf hin, dass die Zürcher Lehrerschaft um 1771 hinsichtlich ihres Ansehens in der Gemeinde keine regionale Ausnahme darstellte. Eine quantitativ noch deutlichere Sprache spricht die Basler Umfrage von 1798. Auch hier wurden die Pfarrer gefragt, „Ob er [der Lehrer] das Zutrauen der Gemeine besitze? “1377

Tab. 42: Das Vertrauen gegenüber den Basler Lehrern 1798

\begin{tabular}{lcc}
\hline Bewertung: & Anzahl Lehrer: & In Prozent: \\
\hline Vollumfängliches oder mehrheitliches Vertrauen & 43 & $80 \%$ \\
Kein Vertrauen & 7 & $13 \%$ \\
Keine Angabe & 4 & $7 \%$ \\
\hline Total: & 54 & $100 \%$ \\
\hline
\end{tabular}

Vier von fünf Landschullehrern der Basler Landschaft genossen im Jahr 1798 das Vertrauen ihrer Schulgemeinde in vollem oder mehrheitlichem Umfang. Lediglich eine sehr geringe Anzahl von Lehrern stand in ihrer Gemeinde ohne Vertrauen da. Als Gründe für fehlendes Vertrauen in die Lehrerschaft wurden in der Basler Landschaft - ebenso wie knapp dreissig Jahre zuvor in Zürich - entweder das fortgeschrittene Alter des Lehrers oder mangelndes Erziehungstalent, moralisch-charakterliche Defizite, Gewalttätigkeit gegenüber den Schulkindern, Alkoholismus oder häusliche Missstände als Argumente angeführt. Tatsächlich waren fünf der sieben Lehrkräfte ohne Vertrauen bereits über 50 Jahre alt. Das individuelle Verhalten und der Charakter der Lehrperson standen im Zentrum der Argumentation um die Frage des Vertrauens vonseiten des Dorfes. Im Umkehrschluss mussten charakterliche Kritikpunkte jedoch keineswegs bedeuten, dass sie automatisch den Verlust des kommunalen Vertrauens bewirkten. In derselben Basler Umfrage zeigten beispielsweise die Gemeindebürger von Gelterkinden BL gegenüber ihrem noch jungen, erst 24-jährigen Lehrer Adam Wirz in Bezug auf dessen Alkoholismus Nachsicht und sprachen ihm öffentlich in der Kirche das Vertrauen aus, zumal er Besserung gelobte. ${ }^{1378}$ Der Wahlmodus zur Lehrerbestellung hatte keinen Einfluss auf die Zufriedenheit der Gemeinden mit ihren Lehrern, was unter der Prämisse der starken Einflussnahme des städtischen Deputatenamts erstaunt. Unter den sieben Lehrern ohne Vertrauen standen sowohl Lehrkräfte, die von den Pfarrern und vom Deputatenamt ohne kommunale Mitsprache eingesetzt worden waren, als auch Lehrer, bei deren Einsetzung die Gemeinde ein Mitspracherecht innehatte. Dass mangelnde Mitsprache automatisch zu einer kritischeren Haltung gegenüber den Lehrern geführt haben könnte, bestätigte sich nicht. Ebenso wenig war von der vermeintlichen Opposition der Landbewohner gegen Stadtbürger in den Deputatenschulen zu spüren. ${ }^{1379}$

1376 Bloch Pfister, Priester: 114.

1377 StABL AA 1012, Lade 200, fol. 1-314: [1798] - Bericht. Kein Vertrauen bessassen die Lehrer der Schulen Augst (42 Jahre alt), Bettingen (38 Jahre alt), Frenkendorf (70 Jahre alt), Oltingen (62 Jahre alt), Riehen ( 53 Jahre alt), Rünenberg (56 Jahre alt) und Sissach (64 Jahre alt).

1378 StABL AA 1012, Lade 200, 07.01.01, fol. 112: 17.03.1798 - Bericht.

1379 Vgl. zum Vorwurf, dass Stadtschullehrer mit sozialen Vorurteilen auf der Landschaft zu kämpfen hatten: Zingg, Basel: 42 . 
Noch deutlicher fiel die Vertrauensfrage im kleinen Aargauer Distrikt Kulm aus. Auf die Frage IX.4: „Ist die Gemeinde mit dem Lehrer und seinen Verrichtungen zufrieden?" vermerkte der beantwortende Pfarrer summarisch, dass sämtliche der 31 aufgeführten Lehrer das vollumfängliche Vertrauen ihrer Gemeinde besassen, unabhängig vom sozialen Status, dem Schultyp oder ihren zuvor attestierten individuellen Fähigkeiten: „Durchgehends werden die Lehrer von den Kindern geliebt, und besizen die Zufriedenheit und das Zutrauen ihrer Gemeinden welches sie wegen Jhrem Eyfer und Fleiss in Jhrem Beruf und treüen Erfüllung ihrer Pflichten billig verdienen. Ein Zeügniss das auch ich Jhnen mit Freüden hier ertheile."1380

Da sämtliche ausgewerteten Quellenbestände aus verschiedenen Regionen ein ähnliches Bild zeichnen, kann postuliert werden, dass die Schulmeister in der gesamten Helvetischen Republik zumindest in der Einschätzung der Pfarrer und trotz deren grossen subjektiven Betrachtungsunterschiede in der Regel das Vertrauen ihrer Mitbürger genossen. Die Lehrkräfte erfüllten offensichtlich und grossmehrheitlich die Anforderungen, die in nicht überlieferten, heterogenen und vielschichtigen Aushandlungsprozessen mit der Lokalgesellschaft und den vorgesetzten Pfarrern für eine funktionierende Schule definiert wurden. Der hohe Grad an Vertrauen der Gemeinden zu ihren Schulmeistern lässt des Weiteren den Schluss zu, dass die meisten Lehrer über eine gesicherte soziale Position in ihrem dörflichen Umfeld verfügten, unabhängig von ihrer sozialen oder geografischen Herkunft.

Das festgehaltene Vertrauen stellte die unabdingbare Basis für eine erfolgreiche langfristige Berufsausübung dar und war für die Lehrerschaft mindestens ebenso wichtig wie das Vertrauen des direkt vorgesetzten Pfarrers. Gerade die hohe Autonomie der Lokalgesellschaften hinsichtlich der (Ab-)Wahlmöglichkeiten und die grundsätzlich freie Schulwahl der Eltern für ihre Kinder brachten die Lehrer in eine vulnerable Abhängigkeitssituation gegenüber der Lokalbevölkerung. Die Lehrer waren an den meisten Orten auf einen regelmässigen und hohen Schulbesuch aus finanziellen Gründen angewiesen, denn das Schulgeld stellte zumindest für eher tief besoldete Lehrer von Nebenschulen eine wesentliche Einkommensquelle dar. ${ }^{1381}$ Entstand eine Konfliktsituation mit Teilen der Gemeinde, hatten die Lehrkräfte in der Regel die schwächere Position inne. Selbst das Vertrauen und die Unterstützung des lokalen Pfarrers halfen dann meist nicht mehr viel, wie ein Exkurs zu einem überlieferten Konflikt um die Lehrerstelle in der Gemeinde Zweisimmen BE zeigt.

Im Winter 1798 war ein Machtkampf zwischen Teilen der Gemeinde, dem Pfarrer und den neuen Autoritäten der helvetischen Zentralregierung zulasten des Dorflehrers Jakob Ültschi eskaliert. Im Protokoll des Oberländer Erziehungsrats vom 3. Dezember 1798 wurde in der Causa festgehalten: „Mehrere Bürger des Orts hatten vor dem Pfarrer die Entlassung des bisherigen Schullehrers verlangt, indem sie zugleich ein neues Subjekt mitbrachten, welches die Stelle des abgehenden ersezen sollte. [...] Der Pfarrer selbst bezeugt in seinem Schreiben seine Zufriedenheit mit dem Dienst Eifer des angeklagten. Der Erziehungsrat erkennt: Die Forderung und das Verfahren der Ankläger seye rechtswidrig. Der angeklagte Br. Jakob Ültschi seye in seiner Stelle als Schullehrer wieder eingesezt."

Die vorgebrachten Vorwürfe für den Absetzungsversuch waren gemäss der Verteidigungsschrift des angeklagten Lehrers unter anderem mangelnde Singkenntnisse, mangelnde Empathie mit den Schulkindern und eine zu harte körperliche Züchtigung mit der Gefahr des Erblindens

1380 BAR B0 1000/1483, Nr. 1423, fol. 220-226: 30.03.1799 - Kulm.

1381 Brühwiler, Finanzierung: 130-139.

1382 StABE Helv OL 42, fol. 2 f. - Manual. 
eines Kindes, was der Lehrer jedoch vehement bestritt. ${ }^{1383}$ Weil sich die Lage aber trotz des Entscheids des Erziehungsrats und der Rückendeckung durch den Pfarrer und anderer Honoratioren nicht besserte, ein Grossteil der Gemeinde die Absetzung des Lehrers forderte und diesem den Zutritt zum Schulhaus verwehrte, verfügte der Erziehungsrat am 31. Dezember 1798 zähneknirschend und doppeldeutig: „Der Erziehungs Rath äussert seinen Unwillen gegen das gesezwidrige Verfahren der Bürger zu Zweisimmen und erkennt: 1. Da keine bestimmte Anzeige [...] gegen den Bürger Ültschi geschehen seye, so könne der Erziehungs Rath keineswegs seine Entlassung bewilligen [...]. 2. Zur Verhütung eines fernern Handels um einer Schädlichen Vernachlässigung des Schulbesuchs solle der Br. Ültschi einstweilen und bis zur endlichen Entscheidung von seiner Stelle suspendirt seyn. "1384

Der besagte umstrittene Lehrer Ültschi legte in der Folge am 19. Januar 1799 freiwillig sein Schulamt nieder, seine Forderung nach einer finanziellen Entschädigung wurde vonseiten des Erziehungsrats zwar anerkannt, aber wahrscheinlich aus finanziellen Gründen von der Verwaltungskammer an die Gemeinde weiterdelegiert. ${ }^{1385}$ Der Fall verdeutlicht exemplarisch nicht nur die augenfällig schwache Position der neuen helvetischen Behörden mit ihren Autoritätsproblemen und die tatsächliche Verteilung der Machtverhältnisse zwischen Pfarrer, Lehrer und Dorfbevölkerung, sondern beweist ferner die immanente Abhängigkeit der Schulmeister von einem intakten Vertrauensverhältnis zur Lokalgemeinschaft, das für die Lehrkräfte wichtiger war als die Beziehung zum vorgesetzten Pfarrer. Auch in den übrigen Landesteilen fanden ähnliche Konflikte mit durchaus gleichem Ausgang statt. ${ }^{1386}$ Ferner konnte fachliche Schwächen als Kritik gegen unerwünschte Lehrer angeführt werden. Fachliche Kritik reichte jedoch - das zeigt das Beispiel auf - in der Regel nicht aus, um einen Lehrer abzusetzen.

Um das Vertrauen der Bevölkerung zu gewinnen und langfristig halten zu können, war daher vonseiten der Lehrkräfte nicht nur eine aktive Anpassung an die lokalen Wünsche und Bildungsbedürfnisse im Sinne der erwähnten Aushandlungsprozesse um das Curriculum und die Bildungsinhalte vonnöten, sondern auch die Erfüllung des sich verändernden ideellen Berufsbildes in den Augen der Lokalgesellschaft. Die Lehrkräfte übernahmen mit der Amtsübernahme einen tätigkeitsspezifischen Habitus, dessen Ausdruck die gesellschaftlich projizierte moralisch-charakterliche Vorbildfunktion des Lehrers als sittlich-moralischer Erzieher der Jugend zum Christentum war. Sie disziplinierten sich in der Folge selbst soweit, dass sie in der Mehrheit dieses gesellschaftliche Erwartungsbild erfüllten, quasi als eine Art selbsterfüllende Prophezeiung. Der vielfach attestierte moralisch-charakterlich einwandfreie Lebenswandel der Lehrkräfte ist denn auch eher als ein Produkt der dichotomen Abhängigkeit von der Lokalgesellschaft und von der Geistlichkeit zu verstehen, denn als Voraussetzung. Entsprechend zielte die geäusserte Kritik an den Schulmeistern in der Regel stärker auf ihren Charakter und den Lebenswandel als auf ihre Berufsausübung.

Ferner stand auch das allmähliche Verschwinden von Körperstrafen aus dem Unterricht in Verbindung mit den veränderten gesellschaftlichen Vorstellungen, an die sich die Lehrerschaft anpassen musste. Entgegen der landläufigen Vorstellung, dass der Prügelstock und physische Gewalt an den Schulkindern in der Schule des Ancien Régimes eine Alltäglichkeit gewesen sei, verschwanden körperliche Züchtigungen bereits um 1800 weitgehend aus den Schulräu-

1383 StABE Helv OL 43, fol. 23-30 - Beilagen.

1384 StABE Helv OL 42, fol. 4f. - Manual.

1385 StABE Helv OL 42, fol. 6f. - Manual.

1386 Vgl. die Konflikte um die Lehrerbestellung in Knonau ZH und Mettmenstetten ZH: Lengwiler/Rothenbühler/ Ivedi, Schule macht Geschichte: 24ff. 
men. ${ }^{1387}$ Die zunehmende Anwendung von pädagogischen Strafen bei deviantem Verhalten der Schulkinder an der Stelle von physischer oder psychischer Gewalt geschah zum einen im Kontext des schon länger andauernden philanthropischen Diskurses um den „richtigen“ Umgang mit der Jugend, zum anderen als ein Prozess einer veränderten Wahrnehmung der elterlichen Erziehung. Hierbei verschob sich die „Züchtigungshoheit“ über die Kinder im ausgehenden 18. Jahrhundert verstärkt exklusiv zu den Eltern als Träger der Erziehungsverantwortung. Das bedeutete in der Praxis, dass die Eltern zunehmend nicht mehr bereit waren, körperliche Strafen an ihren Kindern durch die Schulmeister zu akzeptieren. ${ }^{1388}$

$\mathrm{Zu}$ roh und gewalttätig agierende Schulmeister verloren durch die freie Schulwahl der Eltern nicht nur Schulkinder als wichtige Einkommensbestandteile, sondern dazu auch zunehmend die Achtung und das Ansehen in ihrer Gemeinde. Der Lehrer Ludwig Kurtz aus Walkringen BE hielt das von ihm empfundene Dilemma aus seiner Sicht folgendermassen fest: „Ein Schul Lehrer mus allerhand Widerwertigkeiten und verdrüße von Elteren und Kinderen den Winter durch haben; den es gibt Elteren die ihre Kinder verzärtlen, und wan ein Schullehrer Nur ein wenig die Zucht Ruthen braucht, So ist es bey Elteren und Kinderen gefählt, dennoch wolten sie geschickte Kinder haben, und der Schullehrer solte ihnen alle bosheiten und Unarten Laßen Nachfolgen, und Wan der Schullehrer die Zucht Ruthen über seinen Willen offtmahls brauchen mus, So gehen die kinder nach haus und geben ihren Elteren allerhand Unwarheiten vor. So das ein Schullehrer bald nicht weis wie er sich verhalten solle das einem jeden Recht seye." 1389

Was von den Lehrern als Sittenzerfall und Disziplinlosigkeit gewertet wurde, war freilich ein Ausdruck der allmählichen Veränderung des Idealbildes des Lehrers. Erwartet wurden aus elterlicher Sicht von einem Schulmeister zunehmend ein fürsorglich-ruhiges Gemüt und die Anwendung von pädagogischen Strafen. Man kannte verschiedene Mittel, um gewaltlos deviantem Verhalten der Kinder zu begegnen, etwa Strafaufgaben, Nachsitzen oder beschämende Massnahmen, wobei die Kinder zuhinterst auf einer „Schandbank“ Platz nehmen oder Täfelchen mit aufgemalten Schweinen oder Eseln umhängen mussten. ${ }^{1390}$ Der abnehmende Einsatz von körperlichen Züchtigungen um 1800 war somit stark einem veränderten Anspruchsverhalten der Elternschaft geschuldet, an das sich die Schullehrer reaktiv anpassen mussten, wollten sie einer leeren Schulstube, Konflikten mit den Eltern und dem Verlust des Ansehens in der Gemeinde vorbeugen. Das individuelle soziale Ansehen hing damit nicht zuletzt von der Adaptationsfähigkeit der Schulmeister an die sich wandelnden gesellschaftlichen Vorstellungen ab.

Wenn das Ansehen der Lehrkräfte als geringer als dasjenige eines Taglöhners oder Schweinehirten taxiert worden ist, so musste sich dies nach der plausiblen Erkenntnis von Andrea Schwab nicht unbedingt auf die Berufsausübung an sich oder auf die finanzielle Lage der Schullehrer bezogen haben, sondern vielmehr auf das Abhängigkeitsverhältnis zur Gemeinde: „Wie der Tagelöhner auf immer wieder neue Anstellungen durch seinen Meister angewiesen ist, auch willkürlich fortgejagt werden kann, so muss sich auch der Schulmeister Neuwahlen stellen und kann von seiner Gemeinde jederzeit abgesetzt werden. "1391

Die Vergleiche mit angeblich sozial tiefer gestellten Berufsgruppen hatten für die Zeitgenossen ferner die rhetorische Funktion, auf die vulnerable Situation der Lehrkräfte gegenüber den

1387 Siehe dazu die Fragmentstudie auf der Basis von Quellen aus dem Kanton Linth von 1798: Rothen/Ruloff, Schulumfragen: 44ff.

1388 Rothen/Ruloff, Schulumfragen: 45.

1389 Schmidt u.a. (Hgg.), Stapfer-Enquête, Nr. 944: Walkringen. Vgl. Fuchs, Lehrerperspektiven: $165 f$.

1390 De Vincenti-Schwab, Landschulen: 24.

1391 Schwab, Schulmeister: 41. 
Gemeinden aufmerksam zu machen. Allerdings, so hat Schwab zu Recht angefügt, hatten die Abhängigkeitsverhältnisse durchaus eine reziproke Komponente. Die vielfach von den Schulmeistern ausgesprochenen Drohungen, das Lehramt bei mangelnden Verbesserungen aufzugeben, hatten an manchen Orten sicherlich ihre Wirkung gegenüber der Lokalgemeinden nicht verfehlt und wiesen die Schullehrer einerseits als Träger von Spezialwissen aus, die doch nicht so leicht ersetzbar waren. ${ }^{1392}$ Andererseits ist in den Verzichtsdrohungen wiederum das Indiz eines neu gewachsenen Selbstbewusstseins der Lehrkräfte erkennbar, das sich nahtlos in den bereits weiter oben angesprochenen Prozess einer allmählichen Emanzipation des Lehrerstandes von den Gemeinden und den Pfarrern einreiht. ${ }^{1393}$

Gerade im vielkritisierten sogenannten „Schulmeisterstolz“ einzelner Lehrer wird dieses wachsende Selbstbewusstsein und eine zunehmende Selbstidentifikation durch den spezifischen qualifikatorischen Wissensvorsprung in den elementaren Kulturtechniken gegenüber der erst langsam alphabetisierten Gesellschaft indizienhaft sichtbar. So vermerkte der Pfarrer zum Lehrer von Dättlikon ZH im Jahr 1771: „Er hat eine zimmlich gaab von Schulmstr-stolz, dahero Er auch in eint $u$ : anderen sachen oft lieber nach s. eignen Gutdunken verfahren will, u: mann also darüber immer müh hat jhne zurecht zuweissen etc." ${ }^{1394}$

Widerspruch gegen die Ratschläge der Pfarrer konnte aus traditionellen Auffassungen von Kulturtechnikpraktiken und der Ablehnung von Neuerungen resultieren, wie Alfred Messerli an Beispielen zur Schreibpraxis aufgezeigt hat. ${ }^{1395}$ Der zunehmende Widerspruch in Form des ausgedrückten Berufsstolzes ist aber - wie für die deutschen Lehrer von Margret Rosenbaum festgehalten - auch in der Schweiz als Zeichen einer zunehmenden Emanzipation der Schullehrer von den Pfarrern zu verstehen. ${ }^{1396}$ Des Weiteren ist der Vorwurf eines zu ausgeprägten Stolzes der Schulmeister vonseiten der Gemeinden mitunter auch als ein Ausdruck von Neid auf den Wissensvorsprung der Lehrer zu interpretieren. Ob die Helvetische Republik mit dem Verbeamtungsdiskurs im provisorischen Schulgesetz und mit der Stapfer-Enquête als direkt an die Lehrer gewandtes Medium die Emanzpation der Lehrkräfte zusätzlich befeuert hat, bleibt hingegen eine offene Frage und böte Anlass zu weiteren Untersuchungen.

\subsection{Die Familienverhältnisse}

$\mathrm{Zu}$ den zentralen nichtberuflichen Aspekten eines jeden Lebensverlaufs zählt neben den Freizeitbeschäftigungen die Frage nach den Familienverhältnissen. Heiraten, das Gründen einer eigenen Familie und das Aufziehen von Kindern liefern wertvolle Hinweise auf die Lebensumstände der frühneuzeitlichen Lehrpersonen, zumal familiäre Entwicklungen immer im Zusammenhang mit zahlreichen beruflichen, ökonomischen und sozial-rechtlichen Determinanten standen. Das Eingehen einer Ehe, der Eheschliessungszeitpunkt und die daraus resultierenden Familienstrukturen sind demnach auch als ein Ausdruck von sozialen und ökonomischen Positionen zu deuten, die zum einen aus der zuvor bestandenen Berufsbiografie resultierten und zum anderen Rückschlüsse auf das Sozialprestige der untersuchten Personen zulassen.

Die Rekonstruktion des Heiratsverhaltens der Elementarschullehrkräfte liefert daher wichtige Indizien zu ihrer sozialen Positionierung im lokalen Hierarchiegefüge und die Familiengrösse

1392 Schwab, Schulmeister: 41.

1393 Vgl. das Zitat der Rücktrittsdrohung des Lehrers Philipp Jakob Wolf im folgenden Kapitel 4.3.

1394 StAZH E I, 21.2 - Dättlikon.

1395 Vgl. zum Schulmeisterstolz: Messerli, Lesen: 563.

1396 Vgl. Rosenbaum, Untersuchungen: 222. 
gibt Auskunft über die wirtschaftliche Tragfähigkeit des Lehrerseins im Kontext der individuellen Berufsausgestaltungen. Beides lässt sich aus der Stapfer-Enquête mit den Antworten auf die Frage III.11.e: „Hat er Familie? Wie viele Kinder?“ für das gesamte Kollektiv der Elementarschullehrkräfte als Teil der Lebensphase als aktive Lehrkraft erheben und systematisch auswerten.

\subsubsection{Das Heiratsverhalten}

\section{Voraussetzungen zur Ehe}

Die Ehe bot als religiös-juristische Institution den einzig legitimen normativen Rahmen für die Geschlechtergemeinschaft von Mann und Frau im 18. Jahrhundert. Neben der monopolisierten „einzig akzeptierten Form, sexuelle Beziehungen auszuleben “1397, war die Ehe aber auch die Voraussetzung zur sozio-ökonomischen Emanzipation vom Elternhaus durch die Bildung einer Wirtschaftsgemeinschaft und die Gründung eines eigenen Haushalts. Das Gründen eines eigenen Hausstands durch Heirat war nach dem Prinzip der Hausherrschaft ein zentrales soziales Ziel, um als Hausvater unter die gleichberechtigten Genossen der Dorfgemeinschaft integriert zu werden. ${ }^{1398}$ Das Moment der Heirat markiert somit einen bedeutenden Übergang im individuellen Lebensverlauf, wenngleich sich dessen subjektive Bedeutung für den Einzelnen aus den untersuchten Quellenbeständen freilich nicht mehr erschliessen lässt.

Das Eingehen einer Ehepartnerschaft unterlag in der Frühen Neuzeit nicht ausschliesslich der freien Willensentscheidung der betroffenen Ehepartner, sondern war durch eine Reihe von äusseren ökonomischen, institutionellen und sozialen Faktoren entscheidend mitbestimmt. Zum Ersten schränkte sich der Heiratsmarkt des 18. Jahrhunderts durch die lokaldemografischen Voraussetzungen - das Verhältnis von heiratsfähigen Frauen und Männern zueinander - ein. Nicht überall gab es genügend ehefähige Frauen, damit jeder Mann eine Ehe eingehen konnte. Zum Zweiten bewirkten obrigkeitlich-institutionelle und kommunale Ehebeschränkungen, etwa das Eheverbot für Arme, der Verlust des Bürgerrechts oder hohe Einkaufskosten bei der Heirat einer ortsfremden Person oder bei einer konfessionellen Mischehe, eine starke Beschränkung der Möglichkeit der freien Eheschliessung. ${ }^{1399}$ Ferner konnte das vorherrschende Erbrecht, zum Beispiel das Anerbenrecht, den Kreis der heiratsfähigen Personen stark reduzieren, wenn nur der jüngste oder der älteste Sohn vollumfänglich erbberechtigt war. ${ }^{1400}$ Zudem konnte die Eheschliessung von gewissen individuellen ökonomischen Bedingungen abhängen, insbesondere ob das heiratswillige Paar genügend Einkommen für den Unterhalt eines eigenen Haushalts und für die Versorgung der mitunter erweiterten Familie - Eltern, Geschwister und weitere Hausangehörige - aufbringen konnte. ${ }^{1401}$

1397 Westphal, Einleitende Überlegungen: 17; Pfister, Bevölkerungsgeschichte: 29.

1398 Schmidt, Dorf und Religion: 241 .

1399 Höpflinger, Bevölkerungswandel: 20f. Armen-Ehen wurden beispielsweise durch die Pflicht des Bräutigams, Bewaffnung und Uniformierung für die Miliz zu stellen, verhindert. Der Verlust des kommunalen Bürgerrechts hingegen hatte mitunter einen Ausschluss vom Allmend-Zugang zur Folge, was insbesondere Hintersassen und Tauner mit nicht subsistenzfähigen Haushalten empfindlich betraf. Vgl. Head-König, Les politiques étatiques: 201, 207. Die Schule konnte mitunter Nutzniesserin von Ehehindernissen sein, etwa wenn Gelder aus nicht erwünschten Heiraten für die Schule bestimmt wurden. Ein solcher lokaler Schulfond fand sich beispielsweise in der Stadt Bülach ZH: „Da bey uns sind Anno 1781. eine Freyschul so muß ein jedwede Frömde Weibs Persohn, die sich an einen unsern Bürgern Verheürathet, 10. lb. Geld an dieselbige geben." Schmidt u.a. (Hgg.), StapferEnquête, Nr. 1323: Bülach.

1400 Baumann, Eheanbahnung: 44.

1401 Hareven, Familiengeschichte: 52. 
Neuere sozialgeschichtliche Forschungen unterstreichen allerdings die Problematik der Konstruktion von monokausalen Zusammenhängen zwischen Eheschliessungen und der ökonomischen Unabhängigkeit der Individuen, da die Vorstellung vom ökonomisch unabhängigen Einzel-Haushalt aufgrund der Vielfalt an zeitgleich nebeneinander existierenden Familienstruktur- und Familienwirtschaftsformen oft nicht der frühneuzeitlichen Realität entsprach, sondern vielmehr ein Produkt der modernen Optik ist. ${ }^{1402}$ Des Weiteren muss berücksichtigt werden, dass die Ehe im 18. Jahrhundert als soziale Zielvorgabe eine zunehmend geringere Rolle zu spielen begann. Die sogenannte „sexuelle Revolution“ bewirkte als Teil gesellschaftlicher Transformationsprozesse des 18. Jahrhunderts durch die allmähliche Erosion des traditionellen Sexual-Kodex und durch einen „Autoritätsverlust der Eltern“ ${ }^{1403}$ eine geringere Rücksichtnahme auf den traditionellen Normenhorizont. ${ }^{1404}$ Konkret bedeutete dies eine Abschwächung der normativen Ehebeschränkungen in der gesellschaftlichen Praxis und eine Vervielfältigung von gemeinschaftlichen Lebensformen im zeitgleichen Nebeneinander.

Diese geringere Rücksichtnahme auf normative Grenzen im gesellschaftlichen Zusammenleben wirkte sich auch auf die Frage aus, wer sich mit wem verheiraten konnte. Zwar wurde trotz der zunehmenden Veränderung der sozialen Schichtung in der ländlich-dörflichen Gesellschaft durch das Anwachsen von nichtagrarisch tätigen Gruppen „nach wie vor vorzugsweise innerhalb des eigenen sozio-professionellen Umfelds und innerhalb des persönlichen Beziehungskreises geheiratet " ${ }^{\text {"1405 }}$ und bei der Wahl des Ehepartners spielten praktische Überlegungen zum Erhalt des Familienvermögens oder von ökonomischen Vorteilen immer noch eine wichtige Rolle. ${ }^{1406}$ Der individuelle Faktor der Liebe trat aber verstärkt neben ökonomische und äussere Zwänge. Daraus resultierten vermehrt schichtübergreifende, standesuntypische Ehen, nonkonforme Prekariatsbeziehungen innerhalb der landlosen Schichten und illegitime Konkubinatsverhältnisse, welche ausserhalb der kommunalen Kontrolle und Logik eines „social checks“ im Rahmen von bäuerlich-traditionalen Normen standen. ${ }^{1407}$ Die Zunahme von sogenannten „Bettelhochzeiten“ besitzloser Menschen sowie das verbreitetere und frühere Heiraten unter den kleinbäuerlichen Taunern waren Ausdrücke dieser neuen sozialen Entwicklungen. ${ }^{1408}$ Kontroverse Forschungsergebnisse aus der neueren Familiengeschichte betonen zudem die individuellen „impliziten Wahlentscheidungen“ der Akteure hinsichtlich des Heiratszeitpunkts und der Familienplanung im Sinne einer bewussten oder unbewussten Rationalität: Eine späte Heirat konnte beispielsweise als bewusster Akt dazu dienen, die Familiengrösse zu begrenzen,

1402 Duhamelle/Schluhmbohm, Strategien der Eheschliessung: 14f. Methodisch ist eine Typenbildung, die unter „Familie“ oder „Haushalt“ bloss die zusammenlebenden Blutsverwandten versteht, zu kurz greifend, ebenso wie das „Ganze Haus“ nach Otto Brunner, das zum Beispiel interfamiliäre Bindungen übersieht. Neuere Forschungen betonen das Nebeneinander von Mehr- und Ein-Generationenfamilien, flexiblen Haushalten mit temporärem Dienstgesinde und wechselnden Beziehungen zwischen Haushalten im 18. Jahrhundert. Vgl. Mitterauer, Familie als historische Sozialform: 37-45; Hareven, Familiengeschichte: 50-58; Herrmann, Familie, Kindheit, Jugend: $70-75$.

1403 Huggel, Einschlagsbewegung: 507.

1404 Die markante Zunahme von sittengerichtlicher Delinquenz im 18. Jahrhundert (u.a. Brautschwangerschaften, uneheliche und ungewollte Kinder) dokumentieren den sozialen Wandel des Verfalls traditioneller, kommunaler Normen zugunsten von Individualismus und Marktorientierung. Vgl. die Lokalstudie von Heinrich Richard Schmidt zu Worb. Schmidt, Dorf und Religion: 236-240.

1405 Schmidt, Dorf und Religion: 238; Trossbach, Bauern: 40. Head-König, Ehe.

1406 Prass, Agrargeschichte: 108; Trossbach/Zimmermann, Dorfes: 137-140; Zschunke, Oppenheim: 175.

1407 Schmidt, Dorf und Religion: 238f. Trossbach, Bauern: 41.

1408 Trossbach, Agrargesellschaft: 117; Hippel, Unterschichten: 27. 
um diese der vorhandenen ökonomischen Ressourcenlage anzupassen. ${ }^{1409}$ Ein hinaufgesetztes Heiratsalter konnte konkret nicht nur zur biologischen Verringerung der Kinderzahl der Ehepartner dienen, sondern zudem ein Nebeneinander von Angehörigen dreier Generationen vermeiden oder zumindest zeitlich enger begrenzen, was insbesondere für die krisenanfällige kleinbäuerliche Subsistenzwirtschaft als ökonomisch durchaus sinnvoll erschien. ${ }^{1410}$ Fundamentale Kritik an Kausalbeziehungen zwischen Heiratsverhalten, Bevölkerungswachstum und vorhandenen materiellen Ressourcen im Zusammenhang mit dem „european marriage pattern“ hat ferner Josef Ehmer anhand verschiedener empirischer Studien zur demografischen Entwicklung geäussert, zumal gerade in Gegenden mit gesteigerten landwirtschaftlichen Erträgen paradoxerweise parallel dazu das Heiratsalter und die Ledigenquoten anstiegen. ${ }^{1411}$ Die Familie war somit als ursprünglichste Form von sozialer Zusammengehörigkeit nie bloss ein passives Produkt struktureller Umstände und normativer Vorgaben, sondern im umgekehrten Sinne auch ein gestaltender Akteur von sozialem Wandel und ein Produkt von aktiven Wahlentscheidungen. ${ }^{1412}$ $\mathrm{Zu}$ den wichtigsten demografischen Parametern zählt das Alter der Ehepartner bei der Erstehe, welches im Raum der heutigen Schweiz am Ende des 18. Jahrhunderts stark variierte. Im 17. Jahrhundert lag das Erstheiratsalter in den traditionell bäuerlichen Regionen für Frauen bei durchschnittlich 28 Jahren, für Männer bei 31 Jahren, während in den bereits protoindustrialisierten Gegenden die Frauen mit 25-26 Jahren, Männer mit 27-28 Jahren etwas früher heirateten. ${ }^{1413}$ Der Zeitpunkt der Erstheirat erfolgte somit im Verhältnis zur durchschnittlichen Lebensdauer bei beiden Geschlechtern erst relativ spät. Für das 18. Jahrhundert hat der Soziologe und Demograf François Höpflinger eine zweifache Entwicklung des Heiratsverhaltens festgehalten: „Zum Ersten blieb eine erhebliche Zahl von Frauen und Männer zwangsläufig unverheiratet. Der Anteil an Ledigen nahm im späten 18. und frühen 19. Jahrhundert in verschiedenen Regionen deutlich zu, zum Teil auf mehr als 20\%. [...] Zum Zweiten wurde recht spät geheiratet. Im 18. und 19. Jahrhundert lag das mittlere Erstheiratsalter der Männer im Allgemeinen zwischen 27 und 29 Jahren, wenn nicht sogar höher. [...] Das mittlere Erstheiratsalter der Frauen lag zwischen 25 und 26 Jahren, wobei in einigen Regionen auch höhere Werte beobachtet wurden." ${ }^{1414}$

Das mittlere Heiratsalter sank demnach im Verlauf des 18. Jahrhunderts leicht, wobei in protoindustrialisierten Gegenden eine Tendenz zu früheren Erstheiraten vorlag. Den Hauptgrund für das hohe mittlere Erstheiratsalter ist indes im stark angestiegenen Mündigkeitsalter zur Heirat auf 24 bis 25 Jahre zu suchen, mit dem besonders in reformierten Gegenden gegen Armenehen und gegen das Strapazieren der ökonomischen Tragfähigkeit anzukämpfen versucht wurde. ${ }^{1415}$ Das eher späte Erstheiratsalter von unteren Gesellschaftsschichten korrespondiert jedoch auffallend eng mit demografischen Erkenntnissen aus Nord- und Westeuropa, wo Mehrgenerationenhaushalte eher seltener auftraten und Zweigenerationenhaushalte als sogenanntes „european marriage pattern“ dominierten. Für ländliche Gemeinden in Nordfrankreich ergaben Analysen Erstheirats-Durchschnittswerte von rund 25 bis 27 Jahren für Frauen und etwas darüber liegend für Männer; in England waren 46\% der 25-29-jährigen Frauen und 50\% der gleichaltrigen

1409 Hareven, Familiengeschichte: 52.

1410 Mitterauer, Mythos: 62f.

1411 Ehmer, Heiratsverhalten: 66; Pfister, Bevölkerungsgeschichte: 81f.

1412 Hareven, Familiengeschichte: 65f.; Mitterauer, Familie als historische Sozialform: 22.

1413 Holenstein, Beschleunigung: 314.

1414 Höpflinger, Bevölkerungswandel: 21. Ähnliche Werte präsentiert Richard van Dülmen für verschiedene, meist deutsche Städte und Orte: Van Dülmen: Kultur und Alltag: 134f.

1415 Schmidt, Dorf und Religion: 195f.; Head-König, Ehe. 
Männer verheiratet. ${ }^{1416}$ In der deutschen Stadt Oppenheim lag das durchschnittliche männliche Erstheiratsalter zwischen 1776 und 1794 bei 28.8 Jahren, für Frauen bei 25.1 Jahren. ${ }^{1417}$ Das Heiratsverhalten unterlag jedoch markanten sozialen Unterschieden. Angehörige der dörflichen und städtischen Oberschichten - Beamte, Bäcker, Metzger, Krämer - heirateten in der Tendenz deutlich früher als Bauern, Handwerker und Taglöhner. Warteten Bauern besonders in Gebieten mit geschlossener Vererbung oftmals mit einer Heirat zu, um ihren Besitzstand zu wahren und gegebenenfalls eine ebenfalls vermögende Frau zu heiraten, mussten Letztere erst genügend Vermögen für eine Heirat erarbeiten und konnten aufgrund ihrer geringeren sozialen Stellung überdies nur noch relativ „ältere“ Frauen heiraten, was wiederum die Familiengrösse eher tief hielt. ${ }^{1418}$

Entgegen dem Eindruck der Ehe als ausschliessliche Existenzberechtigung von Paarbeziehungen, waren ferner auch Formen des informellen Zusammenlebens ohne Eheschliessung nicht ungewöhnlich, denn angesichts der zuvor beschriebenen hohen normativen Hürden lag eine Eheschliessung für eine nicht unbeachtliche Anzahl von Menschen ausserhalb ihrer Reichweite. ${ }^{1419}$ Diese Formen der Paarbeziehungen sind noch nicht umfassend erforscht worden, scheinen aber trotz der rigiden normativen Determinanten von den Obrigkeiten zumindest geduldet worden zu sein. Ihre formaljuristische Illegalität konnte jedoch den Ruf, die Ehre beziehungsweise das soziale Kapital einer Person abträglich sein.

\section{Das Heiratsverhalten in kollektiver Übersicht}

Für die kollektivbiografische Untersuchung der helvetischen Elementarschullehrerschaft markiert die Heirat ein deutlich greifbares Moment in den individuellen Lebensverläufen, wenngleich aufgrund der wachsenden Pluralität individueller Handlungsmöglichkeiten nicht von einer starren kausalen Abfolge zwischen Stellenantritt, Heirat und Reproduktion ausgegangen werden darf. Neuere Forschungen tendieren dazu, die verschiedenen Etappen des Lebens als fortschreitenden Prozess aufzufassen und die Eheschliessung ebenso wie die Übernahme einer Stelle als allmählichen Übergang wahrzunehmen, in dem der konkrete Akt der Heirat beziehungsweise des Stellenantritts bloss das biografisch erfassbare Moment darstellt. ${ }^{1420}$ Eine Heirat bedeutete denn meist auch bloss die offizielle Legitimierung einer bereits schon zuvor geknüpften und vielfach gepflegten Paarbeziehung, welche sich nach der Heirat weiterzog. Zu klären bleibt jedoch die Frage nach einer biografischen Kausalität zwischen der Heirat und der Ausübung des Lehramtes als ökonomische Sicherungstätigkeit.

Die Quellen der Stapfer-Enquête erlauben es zwar bloss in sehr wenigen Fällen, den Eheschliessungszeitpunkt genau zu eruieren und eignen sich daher nicht zur Erhebung von mittleren Erstheiratsalter-Daten, ebenso wenig wie sich der genaue Zeitpunkt der Übernahme des Lehramts in allen Fällen zweifelsfrei festlegen lässt. Sie lassen aber eine Reihe von indirekten Fragen

1416 Der Begriff des „european marriage pattern“ geht auf John Hajal zurück und umschreibt ein spezifisches Heiratsmuster von späten Heiraten und dem Gründen von eigenen Haushalten. Vgl. Hajnal, marriage: 101-145. Das Konzept wird ausführlich und kritisch diskutiert bei: Ehmer, Heiratsverhalten: 15-33; Mitterauer, Mythos: 61f.; Pfister, Bevölkerungsgeschichte: 24-29.

1417 Zschunke, Oppenheim: 173f.

1418 Ehmer, Heiratsverhalten: 67-69; Pfister, Bevölkerungsgeschichte: 84; Trossbach/Zimmermann, Dorfes: 137f; Zschunke, Oppenheim: 173. Die Vorstellung, dass das Heiratsverhalten der Unterschichten durch erst zu erwerbenden Vermögensbesitz determiniert war, ist stark durch die Bevölkerungstheorie von Thomas Robert Malthus geprägt, weshalb diese Argumentationslinie generell kritisch paraphrasiert werden muss.

1419 Schmidt-Voges, Ehe-Stand: 129.

1420 Duhamelle/Schlumbohm, Strategien der Eheschliessung: 22ff. 
zum Zivilstand der Lehrkräfte im Jahr 1799 zu. Mittels der doppelten Frage III.11.e: „Hat er Familie? Wie viele Kinder?“ ist zum einen die flächendeckende Erhebung des Zivilstands der Lehrkräfte zum Zeitpunkt der Umfrage als statische Bestandsaufnahme möglich. Die Antworten wurden in fünf Kategorien eingeteilt: „verheiratet“, „,verwitwet“, „ledig“, „Zölibat“1421 und „Keine Angabe“. ${ }^{1422}$ Damit können einerseits quantitativ, alters- und geografisch-konfessionell differenzierte Zivilstandwerte zum interregionalen Vergleich bereitgestellt werden, andererseits lässt sich prüfen, ob sich die Lehrerschaft in ihrem Heiratsverhalten analog zu den bisherigen Forschungsergebnissen zu sozialen Unterschichten verhielt oder ob ein grundsätzlich anderes, abweichendes Heiratsverhalten feststellbar ist. Zudem lassen sich die einzelnen Generationen gezielt nach ihrem Zivilstand und nach versteckten Dynamiken zwischen den Generationen untersuchen. Weiter dienen Erkenntnisse zum Zivilstand der Lehrkräfte wie oben angedeutet als Indikator für ihren sozialen Status, zumal aus obgenannten Gründen besonders die gesellschaftlichen Unterschichten unter Heiratsrestriktionen litten, während eine Heirat und das Gründen eines eigenen Hausstandes zu einem gewissen sozialen Ansehen innerhalb der Lokalgemeinschaft verhalf. Über die soziale Herkunft der geehelichten Ehepartner schweigt sich die Enquête leider aus, was die Rekonstruktion von sozialhierarchischen Veränderungen durch statushöhere oder -tiefere Ehepartner verunmöglicht.

Eine quantitative Untersuchung der Familienverhältnisse der helvetischen Lehrerschaft ist ferner von einem doppeltem Erkenntnisinteresse geleitet, da man zum Ersten bei einer qualitativen Sichtung des Quellenmaterials auf grosse inhaltliche Widersprüchlichkeiten zur Frage einer Kausalität von Lehramtsausübung und Heirat stösst. Aus der Antwort des damals 27-jährigen, sich im „idealen“ Heiratsalter befundenen Lehrers Niklaus Joss von Oberthal BE kann beispielsweise entnommen werden, dass sein Schuleinkommen eine Heirat bislang verhindert habe: „Niklaus Joß, von Worb, im Merzmonat 1772. Gebohren, ist Unverheyratet (und wird so lang das Einkomen das gleiche bleibt, es nie Nötig finden, sich zu verhäüraten, und den noch eine Frau zu erhalten) hat seit Sechs Jahren diese Schule [... Summe des Einkommens L. 100“" ${ }^{1423}$

Die Klammerbemerkung des späteren Politikers im bernischen Grossen Rat und Amerikaauswanderers verschleiert allerdings, dass sein Schuleinkommen von umgerechnet rund 1.000 Berner Batzen im Vergleich zu anderen Lehrkräften nicht etwa gering, sondern gar überdurchschnittlich hoch gewesen war, dem von Stapfer geforderten Mindestlohn für Lehrkräfte entsprach und von Zeitgenossen als eine genügende Besoldung für eine Ganzjahresschule angesehen wurde, um eine Familie zu ernähren. ${ }^{1424}$ Diese inhaltliche Diskrepanz zwischen den festgehaltenen subjektiven Aussagen zum Zusammenspiel von Heirat und Einkommen der Lehrkräfte bietet daher Anlass für eine eingehendere Untersuchung.

1421 Zum Zölibat wurden sämtliche unterrichtenden katholischen Mönche, Priester, Priesterkandidaten und Kapläne gezählt. Nicht berücksichtigt wurde hingegen die oftmals freiwillige Ehelosigkeit von reformierten Pfarrern oder Pfarrkandidaten.

1422 Die Doppelfrage zu den Familienverhältnissen hat den nachteiligen Effekt, dass bei der Datenerhebung relativ viele Antworten als ,unklar" kategorisiert werden mussten, wenn unklar blieb, welchen Frageteil die gemachte Aussage betraf. Zur Methodik der Zivilstanderhebung: Erwähnten die Lehrpersonen eigene Kinder, wurden sie als „verheiratet“ gezählt, auch wenn die Ehefrau nicht explizit erwähnt wurde. Als „ledig“ wurde dagegen nur gezählt, wer ausdrücklich „ledig“", ,unverheiratet“ oder „garçon/célibataire“ vermerkt hatte. Ebenso wurden nur ausdrückliche Erwähnungen von Verwitwung gezählt. Katholische Welt- und Ordensgeistliche wurden als zölibatäre Zwangsledige separat aufgeführt, um die allgemeine Ledigenquote nicht zu verfälschen.

1423 Schmidt u.a. (Hgg.), Stapfer-Enquête, Nr. 968: Oberthal. 100 Livres suisses entsprachen genau 1.000 Berner Bz. Vgl. Kap. 3.1.2.

1424 Niklaus Joss wanderte 1831 nach New Philadelphia in Ohio in die Vereinigten Staaten von Amerika aus. Vgl. Pfister, Strom: 132. 
Zum Zweiten stecken in den bisherigen regionalen Forschungsergebnissen zum Zivilstand der helvetischen Lehrkräfte markante Deutungswidersprüche, obwohl das rekonstruierte Bild fast überall identisch war. In verschiedenen quantitativen Auswertungen der Stapfer-Enquête im Zuge der diversen kantonalen Schulgeschichten sind fast ausnahmslos hohe Heiratsquoten bei den Elementarschullehrkräften konstatiert worden. Für die helvetischen Kantone Aargau und Baden erhob Pius Landolt eine hohe Heiratsquote von $75 \%$ der Lehrkräfte, ohne allerdings auf die Altersstratifikation einzugehen. ${ }^{1425}$ Eine hohe Anzahl an verheirateten Lehrern wurde ferner für die Kantone Zürich und Bern konstatiert. Zur Begründung hat Wilibald Klinke für die Zürcher Lehrerschaft resümiert: „Vorwiegend waren es Ältere und Verheiratete, die sich für Schulstellen meldeten. Das geringe Ansehen und die unzulängliche Besoldung der Lehrer waren nicht dazu angetan, junge Leute zu ermutigen, sich dem mühevollen Schulamte zu widmen. "1426 Eine ähnliche Begründung führte auch Ernst Schneider für den Kanton Bern ins Feld, der ebenfalls überwiegend ältere und verheiratete Lehrer registriert hat: „Vor die Tatsache, dass wir relativ wenige junge Ledige treffen, setzen wir ein Warum, zumal Besoldung und Lehrerwohnung meistens besser zu solchen, als zu Familienvätern passten. Wir vermuten eher eine Antwort zu finden in der Interesselosigkeit der jungen Leute für die Schule, als in der Bevorzugung des bewährten Alters. Bedenken wir die Geringschätzung des Lehrers und der Schule und die landläufige Meinung, dass diese ein Faulbett für träge Leute sei, so können wir begreifen, dass dem junge Blut, das einmal lieber die Freiheit geniessen will und dann zu was Besserem sich geboren fühlt, sich nicht angezogen fühlte. ${ }^{\text {"1427 }}$

Die Interpretationen Schneiders und Klinkes müssen jedoch angesichts des mittleren Amtsübernahmealters der Lehrkräfte von unter 30 Jahren im gesamtschweizerischen Vergleich einer kritischen Revision unterworfen werden. ${ }^{1428}$ Georges Panchaud hat demgegenüber den Anteil von rund einem Viertel Ledigen in der Waadt gerade mit dem tiefen Durchschnittsalter der Waadtländer Lehrer erklärt: „Qu’un quart des régents ne soit pas marié, le jeune âge de beaucoup d'entre eux l'explique. Si la loi autorisait les mariages des garçons dès l'âge de seize ans accomplis et des filles dès quatorze ans, les traitements sont si bas que les jeunes gens hésitent à se marier, craignant de ne pouvoir subvenir aux besoins d'une famille. “1429

Allerdings war einerseits rund ein Drittel jener von Panchaud vermerkten ledigen Lehrer der Waadt bereits über dreissig Jahre alt gewesen und somit nicht mehr als ,jung“ im zeitgenössischen Verständnis aufzufassen, andererseits war bereits fast jeder dritte unterdreissigjährige Lehrer der Waadt schon verheiratet gewesen, was seiner These widerspricht. ${ }^{1430}$ Das ökonomische Argument der ungenügenden Besoldung zum Erhalt einer Familie fand dagegen bei Panchaud ebenso wie schon zuvor bei Klinke und Schneider wiederkehrenden Eingang in die Erklärung, obgleich die Waadt die mit Abstand höchsten Lehrerlöhne aufwies und die Mehrheit der Lehrkräfte mindestens den politisch angestrebten Mindestlohn verdient hatten. ${ }^{1431}$

Die einzige Region mit einem vergleichsweise besonders tiefen Wert an verheirateten Lehrern stellte die katholische Zentralschweiz dar. Der Grund hierfür lag aber weniger in einem regional veränderten Heiratsverhalten der Lehrer, sondern war primär der Tatsache geschuldet, dass

1425 Landolt, Executoren: 20.

1426 Klinke, Zürich: $116 f$.

1427 Schneider, bernische Landschule: 89.

1428 Vgl. Zum Amtsübernahmealter das Kap. 2.2.

1429 Panchaud, écoles vaudoises: $285 \mathrm{f}$.

143030 der total 97 ledigen Lehrkräfte der Waadt waren zum Zeitpunkt der Umfrage bereits über 30 Jahre alt, während 36 der 116 unter 30 -jährigen Lehrer verheiratet waren.

1431 Vgl. zu den Waadtländer Einkommensverhältnisssen das Kap. 3.1.2. 
dort besonders viele an den Zölibat gebundene Welt- und Ordensgeistliche im Schuldienst tätig waren. Nach der Zählung von Joseph Durrer standen den insgesamt 46 Geistlichen und zehn Ledigen bloss 21 verheiratete weltliche Lehrer gegenüber. ${ }^{1432}$ In anderen katholischen Kantonen, etwa dem Kanton Solothurn, unterschieden sich die Anteile an verheirateten Lehrern im kantonalen Lehrerkorps jedoch kaum von den oben skizzierten Erkenntnissen aus den grossen reformierten Kantonen. Für den hohen Anteil an verheirateten Lehrern im mehrheitlich katholischen Kanton Solothurn hat Johann Mösch dagegen eine grundsätzliche Präferenz der Solothurner Obrigkeit für verheiratete Kandidaten verantwortlich gemacht - ein Argument, das freilich in den anderen älteren Darstellungen zum Schulwesen nie aufgeführt wurde. ${ }^{1433}$

Welche neuen Erkenntnisse vermag die gesamthafte Betrachtung der Zivilstandverhältnisse aus den Antworten der Stapfer-Enquête zu liefern? Die deutliche Mehrheit aller weltlichen Lehrpersonen in der Helvetischen Republik war ungeachtet ihres Alters, ihrer Konfession und ihrer Herkunftsregion zum Zeitpunkt der Umfrage verheiratet. Unter dem Ausschluss der dem Zölibat unterworfenen, zwangsweise ledig lebenden katholischen Geistlichen waren mindestens 75.8\% aller Lehrkräfte im Frühjahr 1799 zumindest einmalig verheiratet oder verwitwet, während die Anzahl der explizit als „ledig“ vermerkten Lehrkräften bloss maximal 17\% betrug. ${ }^{1434}$ Insofern bestätigt die Gesamtschau die bisherigen kantonalen Resultate in globo.

Zwischen den einzelnen helvetischen Kantonen variierten die Mindestwerte der verheirateten Lehrer, wie von der bisherigen Forschung festgehalten, entlang der konfessionellen Grenzen in schwach signifikantem Masse. In den ausschliesslich reformierten Kantonen Aargau, Basel, Bern, Oberland, Schaffhausen ${ }^{1435}$ und Zürich waren altersunabhängig zwischen $77 \%$ (im Kanton Aargau) und 85\% (im Kanton Zürich) der Lehrkräfte mindestens einmalig verheiratet oder verwitwet und lediglich $8 \%$ bis $14 \%$ der Lehrer hatten demgegenüber explizit den Zivilstand „ledig“ ungeachtet ihres Alters vermerkt. In den gemischtkonfessionellen Kantonen oszillierte die Mindestquote an verheirateten oder verwitweten reformierten Lehrkräften bereits etwas stärker, zwischen rund 70\% im mehrheitlich reformierten Kanton Waadt und 93\% im reformierten Distrikt Bucheggberg des Kantons Solothurn. Die Mindestheiratsquote für alle reformierten Lehrkräfte, sowohl aus den rein reformierten Kantonen als auch aus den gemischtkonfessionellen Gebieten, lag bei insgesamt 78.7\%, als ledig wurden dagegen mindestens 15.3\% aller reformierten Lehrkräfte verzeichnet. ${ }^{1436}$ Die Mindestanzahl an verheirateten oder verwitweten katholischen Lehrkräften lag im konfessionellen Direktvergleich dagegen deutlich unter den Werten der reformierten Lehrkräfte. Bloss $61.4 \%$ aller weltlichen katholischen Lehrpersonen waren selbst nach dem Ausschluss der zölibatären Geistlichen zum Zeitpunkt der Erhe-

1432 Durrer, Urkantonen: 24. Insgesamt 3.8\% aller in der Stapfer-Enquête vermerkten helvetischen Elementarschullehrkräften (88 Personen) unterstanden als katholische Welt- oder Ordensgeistliche dem Zölibat und blieben daher zwangsweise ledig.

1433 Mösch, Solothurnische Volksschule: 93.

1434 Total Verheiratete oder Verwitwete: 1680 (75.8\%); Ledige: 377 (17.0\%); Keine oder unklare Angabe: 160 (7.2\%); total: 2217. Selbst einige der an den Zölibat gebundenen katholischen Geistlichen hätten wohl gerne eine eigene Familie gegründet. Zumindest in der Antwort des Kaplans Fridolin Schwyter von Galgenen SZ ist auf die Frage III.11.e nach der Anzahl Kinder eine gewisse Frustration anzumerken, antwortete er wortwörtlich: „Darf keine machen!!“ Schmidt u.a. (Hgg.), Stapfer-Enquête, Nr. 449: Galgenen.

1435 Unter Auslassung des einzigen katholischen Lehrers des Landstädtchens Diessenhofen kann die Lehrerschaft des Kantons Schaffhausen als komplett reformiert betrachtet werden.

14361450 Lehrkräfte reformierter Konfession waren verheiratet oder verwitwet (78.7\%), 282 als ledig vermerkt (15.3\%), 110 Lehrpersonen (5.9\%) waren ohne eindeutigen Zivilstand: total 1842 reformierte Lehrkräfte. 
bung den Bund der Ehe eingegangen, mindestens 25.2\% waren hingegen noch ledigen Standes gewesen. ${ }^{1437}$

Die unterschiedliche Altersstruktur der jeweiligen kantonalen Lehrerkorps, insbesondere des Kantons Waldstätten mit einer hohen Anzahl an jungen Lehrern unter dreissig Jahren, wirkte sich teilweise verzerrend auf die Zivilstandsangaben aus. Eine altersstratifizierte Betrachtung des Zivilstandes ermöglicht daher einen differenzierteren Einblick in das Heiratsverhalten der Lehrkräfte. Besonders die älteren Altersgruppen ab dem dreissigsten Lebensjahr sind hierbei von Interesse, da sie über dem mittleren Amtsübernahmealter der Lehrertätigkeit lagen, und für die unter dreissigjährigen Lehrer von einer naturgemäss hohen Ledigenquote ausgegangen werden kann, da ja auch das mittlere Erstheiratsalter für Männer bei knapp dreissig Jahren lag. In einem ersten Schritt sind die Zivilstandsangaben der Lehrkräfte gemäss ihres Alters im Jahr 1799 in 10-Jahres-Kohorten eingeteilt worden, um einen intergenerationellen Überblick zu ermöglichen.

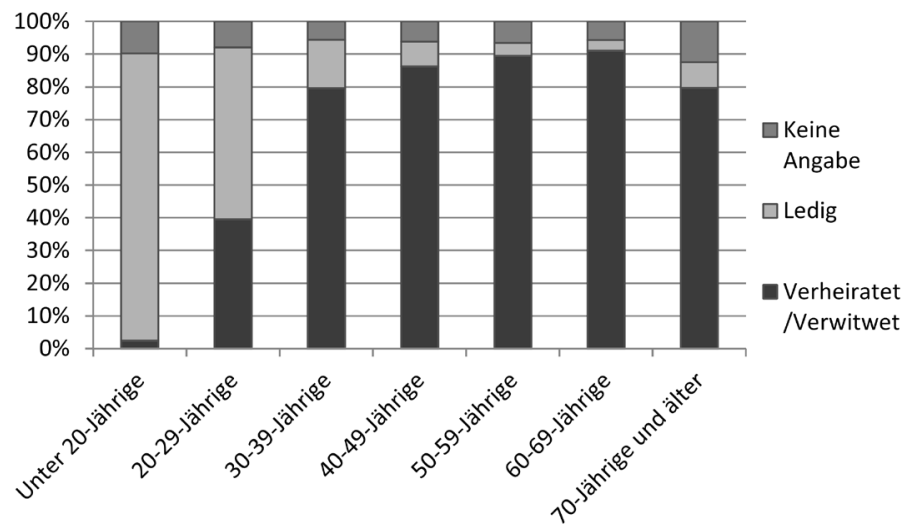

Abb. 17: Zivilstand der Lehrer in Alterskohorten ${ }^{1438}$

Eine Heirat im jugendlichen Alter vor dem zwanzigsten Régime theoretisch zwar möglich, kam jedoch in der empirisch ermittelten Realität in den Reihen der Lehrerschaft fast gar nicht vor. Die einzige Ausnahme eines verheirateten Lehrers von unter zwanzig Jahren und damit der jüngste verheiratete Lehrer der gesamten Stapfer-Enquête überhaupt war der damals erst 19.5-jährige gebürtige Franzose François Louïs Bonnelance in Jouxtens-Mézery VD gewesen. ${ }^{1439}$ Ehen vor dem 25. Lebensjahr waren aber aufgrund des angestiegenen Mündigkeitsalters generell eher als Ausnahme zu taxieren. Während in der Altersgruppe aller unter dreissigjährigen Lehrkräfte mit mindestens 35.8\% etwas mehr als jede dritte Lehrkraft bereits verheiratet

1437231 Lehrkräfte katholischer Konfession waren verheiratet oder verwitwet (61.4\%), 95 als ledig vermerkt (25.2\%), 50 Lehrpersonen (13.3\%) waren ohne eindeutigen Zivilstand: total 376 katholische Lehrkräfte (ohne die 88 zölibatären Geistlichen).

1438 In der Berechnung wurden die aufgrund des Zölibats gezwungenermassen ledig lebenden katholischen Geistlichen ausgenommen, um einer Verzerrung der Datensätze vorzubeugen. Die abgebildeten Zivilstsandangaben sind aufgrund des Anteils an fehlenden Angaben (Kategorie „Keine Angabe“) als Mindestwerte zu verstehen.

1439 Seine Ausbildung erhielt er in der École de Charité in Lausanne, bereits ab seinem 17. Lebensjahr arbeitete er als Lehrer in Chavannes-près-Renens VD. Schmidt u.a. (Hgg.), Stapfer-Enquête, Nr. 1852: Jouxtens-Mézery. 
gewesen war, stieg die Anzahl an verheirateten Lehrkräften in der nachfolgenden Alterskohorte der 30-39-Jährigen auf bereits knapp vier Fünftel oder mindestens $79.8 \%$ an. In allen nachfolgenden Alterskohorten ab dem vierzigsten Lebensjahr belief sich die Quote von mindestens einmal verheirateten Lehrkräften auf über $80 \%$ und kulminierte bei einem maximalen Anteil von über $90 \%$ bei den 60-69-jährigen Lehrern. Einzig bei den ältesten, über siebzigjährigen Lehrern sank die Anzahl an Verheirateten oder Verwitweten wieder leicht auf rund 81\%, allerdings verschleiern hier zahlreiche unklare Antworten die tatsächlichen Verhältnisse.

Im umgekehrten Verhältnis sank die gesicherte Ledigen-Quote bei allen über dreissigjährigen Lehrern bei jeder Alterskohorte konstant bis zum Minimalwert von 3.2\% bei den 60-69-Jährigen. Selbst bei einer theoretischen Summierung aller Lehrkräfte ohne eindeutige Zivilstandsangabe als „potenzielle Ledige“ zu den eindeutig als ledig ausgewiesenen Lehrkräften schrumpfte die Quote von maximal möglichen ledigen Lehrern ab dem vierzigsten Lebensjahr auf konstant unter 15\%. In kollektivbiografischer Betrachtung waren somit altersunabhängig rund vier von fünf weltlichen Lehrkräften zum Betrachtungszeitpunkt mindestens einmalig verheiratet gewesen. Im Folgenden sollen nun die Zivilstände der beiden Generationen der „älteren“ Lehrkräfte von über fünfzig Altersjahren und der ,jungen“ Lehrkräfte von unter dreissig Jahren gesondert betrachtet werden.

\section{Das Heiratsverhalten der älteren Lehrer}

Die Heirats- beziehungsweise Ledigenquote der über fünfzigjährigen Lehrkräfte ist von besonderem kollektivbiografischen Aussagewert, da in der Regel nach dem fünfzigsten Altersjahr eine Erst-Ehe nur noch in Ausnahmefällen eingegangen wurde. ${ }^{1440}$ Somit entspricht dieser Wert weitgehend der endgültigen Heirats- beziehungsweise Ledigenquote und ist der demografisch aussagekräftigste Indikator für Vergleiche mit den bisherigen Forschungsresultaten der historischen Demographie. ${ }^{1441}$ Diese Heiratsquote von mindestens einmalig verheirateten Lehrern von über fünfzig Altersjahren lag wie in der Abbildung 17 oben dargestellt mit leichten regionalen Differenzen - die katholische Zentralschweiz und das ebenfalls katholische Wallis ausgenommen - in den meisten Regionen markant bei über $80 \%$, im gesamthelvetischen Durchschnitt gar bei mindestens $89.3 \% .{ }^{1442}$

Die definitive Ledigenquote - unter Ausklammerung der zölibatär lebenden katholischen Geistlichen - belief sich dagegen auf bloss 3.8\%. Weitere rund 6.9\% der über fünfzigjährigen Lehrer hatten die Frage nach dem Zivilstand nicht eindeutig beantwortet. In kollektiver Einmütigkeit standen somit mindestens acht von zehn Lehrkräften jenseits des fünfzigsten Lebensjahres in praktisch allen Landesteilen der Helvetischen Republik im Bund der Ehe und hatten eigene Familien gegründet.

Diese hohe Gesamtzahl an mindestens einmalig verheirateten Lehrkräften respektive die sehr geringe Anzahl an definitiv ledig gebliebenen Lehrkräften von maximal 11\% bei den über Fünfzigjährigen in der gesamten Helvetischen Republik ergeben unter dem Axiom der Zugehörigkeit der Lehrer zu den sozialen Unterschichten ein atypisch hohes Heiratsverhalten der Lehrkräfte. Insbesondere die im Umkehrschluss erhaltene endgültige Ledigenquote lag damit

1440 Eine solche Ausnahme ist in der Antwort zur Stadt Vevey VD zu finden, bei der zum 52-jährigen Lehrer Jean Emanuel Mottier die Bemerkung: „Jl est marié depuis peu“ notiert war. Schmidt u.a. (Hgg.), Stapfer-Enquête, Nr. 1784: Vevey.

1441 Höpflinger, Bevölkerungswandel: 23.

1442 Die Heiratsquote der über fünfzigjährigen Lehrer nach Kantonen: Aargau: 83.3\%; Baden: 87.5\%; Basel: 87.5\%; Bern: 89.7\%; Fribourg: 84.2\%; Léman: 90.8\%; Linth: 94.1\%; Oberland: 93.5\%; Säntis: 83.3\%; Schaffhausen: 88.9\%; Solothurn: 85.7\%; Thurgau: 93.0\%; Waldstätten: 69.2\%; Wallis: 50.0\%; Zürich: 92.0\%. 
deutlich unter den von der bisherigen demografischen Forschung postulierten Werten von 20\% bis 30\% an zwangsweise ledig gebliebenen Personen der sozialen Unterschichten aus Gründen der Armut oder aufgrund von Ehehindernissen. ${ }^{1443}$ Diese überaus hohe Mindestverheiratungsquote der Lehrkräfte lässt zum einen den Schluss zu, dass keiner der oben beschriebenen wirtschaftlichen oder sozialen Ehebeschränkungsfaktoren einen signifikanten Einfluss auf die älteren Lehrkräfte gehabt hatte. Zum anderen gilt es die Konfession als Wirkungsfaktor zu relativieren, da einzig die katholischen Lehrkräfte des Kantons Waldstätten eine signifikant tiefere Verheiratungsquote aufwiesen, demgegenüber aber die katholischen Lehrer Solothurns, Fribourgs und der gemischtkonfessionellen Kantone in ihrem Heiratsverhalten nur gering vom Gesamtmittel abwichen. Ebenso spielten angesichts des kollektiv gleichförmigen Resultats weder die Ersttätigkeit noch die vorherrschende regionale Wirtschaftsform oder der Schultypus eine entscheidende Rolle, ob sich eine Lehrkraft im Laufe ihres Lebensverlaufs verheiraten konnte oder nicht. Insbesondere Letzteres weist auf eine insgesamt geringe Bedeutung der realen Höhe des Schuleinkommens für das Heiratsverhalten hin, zumal Lehrer an Nebenschulen in der Regel schwächer besoldet wurden als an Hauptschulen, sich aber dennoch genauso eifrig verheirateten. ${ }^{1444}$ Das reale kollektive Heiratsverhalten der älteren Lehrkräfte widerspricht damit der eingangs zitierten subjektiven Wahrnehmung des durchaus wohlhabenden Lehrers aus Oberthal BE und entlarvt dessen Behauptung als zeitgenössisch-typisches Klagemuster der einkommensstärkeren Lehrer. ${ }^{1445}$

Vielmehr müssen nicht-ökonomische Kausalitäten und gesellschaftlich-soziale Mechanismen zur Erklärung der festgestellten überaus hohen Verheiratungsrate der Lehrkräfte untersucht werden. Das vielerorts tatsächlich prekäre Schuleinkommen verhinderte jedenfalls das Eingehen einer Ehe und die Gründung einer eigenen Familie ebenso wenig wie der stets vermutete „schlechte Ruf “ der Lehrer in der Lokalgesellschaft ein Hinderungsgrund gewesen wäre. Das Heiratsverhalten kann seinerseits als ein positiv stimulierender Indikator eines geglückten Aufstiegs aus der potenziellen Armengenössigkeit gelten, da das Argument des armutsbedingten Zwangsledig-Bleibens für Lehrkräfte empirisch offensichtlich nicht zutraf. Die hohe Zahl an endgültig verheirateten Lehrern lässt gar die gegenteilige Schlussfolgerung zu, dass Lehrkräfte erst durch das Lehramt und das damit verbundene Zusatzeinkommen eine sozio-ökonomische Festigung erfuhren, wodurch sämtliche obrigkeitlichen und lokalen sozio-ökonomischen Heiratsbarrieren gegen Bettelhochzeiten wegfielen. Diese Erkenntnis schliesst freilich Beobachtungen aus der bisherigen Forschung nicht aus, wonach gezielt bereits verheiratete Personen aus Gründen ihrer persönlichen charakterlichen Integrität, ihrer gefestigten Stellung in der Lokalgesellschaft als Hausvater oder aber aus karitativen Versorgungsgründen von der Lokalbevölkerung oder der Obrigkeit für das Lehramt ausgewählt wurden, zumal nicht offenkundig ist, ob die Eheschliessungen öfter vor oder nach der Lehramtsübernahme stattgefunden hatten.

Wer hingegen als Lehrkraft bis ins hohe Alter endgültig ledig geblieben war, hatte diesen $\mathrm{Zu}$ stand entweder freiwillig als bewusste persönliche Entscheidung des eigenen Lebensentwurfs oder aus anderen individuellen Gründen, beispielsweise aufgrund von körperlichen oder gesundheitlichen Beeinträchtigungen, gewählt. Der Lehrer Louis Samuel Ducros aus Yverdon-lesBains VD berichtete etwa: „il n'est pas marié par raison de santé délicate. “1446 Krankheiten oder körperliche Gebrechen konnten das Eingehen eines Ehebündnisses erschweren, da aufgrund der

1443 Höpflinger, Bevölkerungswandel: 23-32; Pfister, Bevölkerungsgeschichte: 26, 84.

1444 Vgl. Zur niedrigeren Besoldung von Nebenschullehrern das Kapitel 3.1.2.

1445 Vgl. Schmidt u.a. (Hgg.), Stapfer-Enquête, Nr. 968: Oberthal.

1446 Schmidt u.a. (Hgg.), Stapfer-Enquête, Nr. 1420: Yverdon-les-Bains. 
Notwendigkeit einer gesunden Arbeitskraft aus gesellschaftlicher Sicht grosser Wert auf die körperliche Unversehrtheit der Ehepartner gelegt wurde. ${ }^{1447}$ Die obige Beantwortung wirkt freilich wie eine Rechtfertigung und könnte demnach ein Indiz sein, dass auch gegenüber den Lehrkräften, von denen ja nicht die Ausübung von physisch anstrengenden Arbeiten erwartet wurde, die soziale Erwartungshaltung eines gesunden Körpers im gesellschaftlichen Normenbild bestand. Allerdings bedeutete eine Erkrankung, schwere Invalidität oder eine sonstige körperliche Behinderung in der Realität keinesfalls a priori einen Zwang zum Ledig-Bleiben. So hatte der zuvor im Kapitel 2.2.1 erwähnte körperlich behinderte Lehrer von Itingen BL dennoch eine Familie mit Kindern gründen können, ebenso wie sein invalider Arbeitskollege in Pohlern BE sich trotz einer schweren Beinverletzung aus seiner Jugendzeit gleichwohl verheiraten konnte. ${ }^{1448}$ Gerade in diesen geschilderten Einzelbeispielen dürfte das Lehramt mit seiner gesicherten Einkommensgarantie und eventuell das soziale Ansehen aus der Lehrertätigkeit neben den zwischenmenschlichen Ursachen ein wichtiger Treiber für die erfolgreichen Eheschliessungen gewesen sein.

Daneben konnten unfreiwillige äussere Einflüsse, wie nicht ermöglichte oder tolerierte Liebesoder Sexualbeziehungen, aber auch Versorgungspflichten für nahe familiäre Angehörige als weitere Determinanten für eine nicht ermöglichte Heirat gewirkt haben. ${ }^{1449}$

Signifikante Einschränkungen aufgrund der vormals ausgeübten Ersttätigkeit oder aufgrund von Nebentätigkeiten konnten dagegen nicht festgestellt werden. Einzig unter der sehr kleinen Teilgruppe der reformierten Geistlichen im städtischen Schulwesen liess sich eine schwach signifikante Tendenz zu einem „freiwilligen Zölibat“ feststellen, was aber aufgrund der durchwegs höheren Besoldung der städtischen Schulmeister ebenfalls nicht ökonomisch begründet werden kann, sondern vielmehr als Ausdruck des Selbstverständnisses als Geistlicher oder in einer verstärkten freiwilligen Hinwendung zu einer sexuellen Askese gedeutet werden muss. Dennoch waren unter Ausschluss der zölibatären katholischen Geistlichen auch im städtischzentralörtlichen Umfeld der Helvetischen Republik mindestens rund 77.9\% der Lehrer über fünfzig Jahren mindestens einmalig verheiratet oder verwitwet. ${ }^{1450}$

Die insgesamt festgehaltene Konstanz der hohen Heiratsquote bei den älteren Alterskohorten ab dem fünfzigsten Altersjahr weist ferner auf einen möglichen hohen Grad an Wiederverheiratungen hin. Die hohe Müttersterblichkeit bei der Geburt sowie die generelle Gefahr von Krankheiten und Mangelernährung aus Armut hielten das Sterberisiko der Frauen im 18. Jahrhundert ungeachtet ihres Alters hoch. Der frühe Tod des Ehepartners und damit das Risiko der Verwitwung gehörte zur bitteren Realität frühneuzeitlicher Lebensverläufe, wie ihn beispielsweise der erst 45-jährige Lehrer aus Frittenbach BE in dramatischen Worten beschrieb: „Jch habe kein

1447 Vgl. Baumann, Eheanbahnung: 44.

1448 Schmidt u.a. (Hgg.), Stapfer-Enquête, Nr. 715: Pohlern.

1449 Die Annahme von nicht ermöglichten oder nicht tolerierten Liebesbeziehungen als Begründung für den Zivilstand ist in der Stapfer-Enquête nicht explizit festgehalten worden und ist folglich rein hypothetischer Natur. Das Argument von familiären Versorgungspflichten als mögliche Erklärungen für ein individuelles Ledig-Bleiben wurde dagegen in der Stapfer-Enquête etliche Male implizit erwähnt. Zwei Beispiele dienen zur Verdeutlichung: „der Beck ist Ledigen Stands unterhalt aber durch beyhilf dieses Dienstes zwey Arme dürftige Wäisen Kinder, von seinem Bruder der vor 8 Jahren durch ein Unglükts Fall das Leben verlohren." Schmidt u.a. (Hgg.), Stapfer-Enquête, Nr. 1478: Berneck: „mein Name heist Karl Franz Russi, [...] War unverheirathet, jedoch ernähren sich 2. alte geschwisterte bey mir." Schmidt u.a. (Hgg.), Stapfer-Enquête, Nr. 1934: Andermatt.

1450 Mindestens sechs der 19 geistlichen Basler Stadtschullehrer (32\%) und drei von 17 St. Galler Stadtschullehrer (17\%) waren bis ins höhere Alter ledig geblieben. Insgesamt waren 13 der 118 weltlichen zentralörtlichen Lehrer von über 50 Jahren ledigen Standes gegenüber mindestens 92 verheirateten oder verwitweten Lehrern. 13 weitere Lehrkräfte waren ohne genaue Zivilstandsangabe geblieben. 
Familie, ich bin zwar verheiratet gewesen, aber der Herr hat sie von diesem Jamerthal weggenomen, und Sither bin ich un verheiratet geblieben." ${ }^{1451}$

Ein früher Tod des Ehepartners konnte die zurückgebliebene Familie durch das Wegfallen der Arbeitskraft in eine wirtschaftlich kritische Situation, einen „Rollenergänzungszwang “, bringen, der eine rasche Wiederverheiratung des überlebenden Ehepartners bedingte. ${ }^{1452}$ Insbesondere Witwer mit unmündigen Kindern hatten nach Christian Pfister erheblich bessere Aussichten auf eine Zweit-Ehe als Witwen, wenngleich die Chance auf eine Wiederverheiratung allerdings gegen Ende des 18. Jahrhunderts für beide Geschlechter insgesamt zurückgegangen sei. ${ }^{1453} \mathrm{Da}$ mit lässt sich erklären, weshalb in der Stapfer-Enquête empirisch kaum Witwer und Witwen vorzufinden waren. Bloss 1.4\% aller helvetischen Lehrkräfte hatten ihren Zivilstand zum Zeitpunkt der Umfrage explizit als verwitwet bezeichnet. ${ }^{1454}$ Selbst bei den ältesten Lehrern über dem sechzigsten Lebensjahr war weniger als jeder Zehnte zum Zeitpunkt der Umfrage als verwitwet überliefert. ${ }^{1455}$ Der Grund für die fortdauernd hohe Verheiratungsquote bei den älteren Generationen könnte folglich unter anderem in einer häufiger praktizierten Wiederverheiratung bei Verwitwung gelegen haben. Der 65-jährige Lehrer von Kappelen BE, Benedikt Arn, berichtete über seine Familienverhältnisse beispielsweise: „Drey erwachsne Kinder in der Ehe, das zweyte Weib mit vier erwachsnen Stiefkindern." ${ }^{1456}$

Aus der gesamten Stapfer-Enquête konnte quantitativ mindestens ein weiteres Dutzend an Lehrkräften festgestellt werden, die bereits in der zweiten Ehe lebten. Die Dunkelziffer dürfte jedoch bedeutend höher gelegen haben, da es sich um eine freiwillig hinzugefügte Information handelte, die nicht spezifisch durch den Fragebogen erhoben worden war. Eine abschliessende Beurteilung des Einflusses von Mehrfachheiraten ist durch das vorhandene Quellenmaterial somit nicht möglich.

Die ökonomische Situation der Lehrkräfte dürfte bei Wiederverheiratungen freilich eine ambivalente Rolle gespielt haben. Einerseits konnte sich das gesicherte, idealerweise genügend hohe Schuleinkommen für frisch verwitwete Lehrer positiv auf ihre Attraktivität auf dem lokalen Heiratsmarkt ausgewirkt und Wiederverheiratungen beschleunigt haben. Andererseits bot eine Wiederverheiratung nur dann die Chance auf eine ökonomische Besserstellung, wenn die neue Gattin über eine entsprechend lukrative Mitgift verfügte. ${ }^{1457}$ In der Tat profitierten zumindest in Einzelfällen Lehrkräfte von ökonomisch attraktiven Zweit-Ehepartnerinnen, wie eine Reihe von expliziten Bemerkungen zum 46-jährigen Lehrer Rudolf Messer in Messen SO aus einem Visitationsprotokoll zum Solothurner Distrikt Bucheggberg erahnen lassen: „jetz ein begüterter Landbauer. [...] frisch verheyr: hat aus erster Ehe 4 Söhne v. 12 - $14-20$ - 25 Jahren - 2 Töchter von 22 u. 7. J. [...] eine 2te reiche Heyrath macht Jhn dieser Arbeit [als Lehrer] ein wenig abgeneigter, aber darum nicht träge. ${ }^{1458}$ Selbst mit 36 Kronen oder 90 Franken Jahreseinkommen zwar bei weitem kein Geringverdiener, dürfte dem genannten Schulmeister und

1451 Schmidt u.a. (Hgg.), Stapfer-Enquête, Nr. 667: Frittenbach.

1452 Vgl. Zschunke, Oppenheim: 190; Mitterauer, Familienzyklus: 79-88.

1453 Pfister, Bevölkerungsgeschichte: 29.

1454 Insgesamt nur 33 der total 2.305 Lehrkräfte hatten im Frühjahr 1799 in der Stapfer-Enquête ihren Zivilstand explizit als verwitwet vermerkt.

1455 Mit Ausnahme der Alterskohorte der über Sechzigjährigen waren stets weniger als 2\% der Lehrkräfte pro Alterskohorte verwitwet. Erst ab dem 60. Altersjahr stieg der Anteil an Verwitweten auf 3.6\% respektive 6.3\% ab dem 70. Altersjahr.

1456 Schmidt u.a. (Hgg.), Stapfer-Enquête, Nr. 829: Kappelen.

1457 Vgl. Menolfi, Tod: 113.

1458 BAR B0 1000/1483, Nr. 1460, o. Pag.: [20.02.1799] - Bucheggberg. 
ehemaligen Schreiner mit der Heirat einer wohlhabenden Bäuerin trotz - oder gerade wegen noch minderjähriger Kinder aus erster Ehe die Sicherung seiner sozio-ökonomischen Position erfolgreich gelungen sein. ${ }^{1459}$ Wenn auch nur als Einzelfall überliefert, zeigt das gerade erwähnte Beispiel dennoch, dass Elementarschullehrer mitunter intakte Chancen auf die Vermählung mit vermögenden Ehepartnerinnen hatten. ${ }^{1460}$

In einem umgekehrten Sinn dürfte hingegen aber auch ein tiefes Schuleinkommen einen markanten Druck auf frisch verwitwete Lehrkräfte ausgeübt haben, sich rasch wieder zu vermählen, um durch die zusätzliche Arbeitskraft oder durch das Vermögen der Ehefrau eine stabile und gesicherte Familienwirtschaft zu erreichen - gerade wenn noch unmündige Kinder zu ernähren waren. Das Schuleinkommen könnte daher eine doppelte Katalysator-Funktion in Bezug auf den Erhalt des Ehestands gehabt haben. Somit könnte der empirisch festgestellte kollektiv tiefe Wert an verwitweten Lehrkräften nicht bloss das Resultat einer unsicheren Quellenüberlieferung sein, sondern ebenso der Evidenz ökonomischer Überlegungen beziehungsweise des Zwangs zur Sicherung der Familienwirtschaft der betroffenen Personen entsprungen sein.

Zusammenfassend kann festgehalten werden, dass mit Ausnahme der zölibatär lebenden katholischen Geistlichen das Eingehen einer Ehegemeinschaft und das Gründen eines eigenen Familienstandes zur „typischen“ Biografie fast eines jeden weltlichen Schulmeisters um 1800 gehörte. Die aussergewöhnlich konstante und hohe minimale Heiratsquote von über $80 \%$ respektive die tiefe Quote an lebenslang ledig gebliebenen Schulmeistern bei den älteren Lehrergenerationen von über fünfzig Altersjahren stehen für eine bemerkenswert atypische Entwicklung einer zu den Unterschichten hinzugezählten Personengruppe des ausgehenden 18. Jahrhunderts. Weder institutionelle, rechtliche noch wirtschaftliche Ehehindernisse wirkten sich in der realen Lebenswelt in irgendeiner Form beschränkend auf die Lehrkräfte aus.

Daraus ergeben sich drei Erklärungshypothesen: Zum Ersten, dass es gerade das Lehramt mit seinem stabilen, abschätzbaren Zusatzeinkommen und dem damit verbundenen hohen sozialen Prestige war, das eine stark katalysierende soziale Wirkung auf die Lehrkräfte ausübte. Die Schulmeistertätigkeit mit ihrer Einkommensergänzung funktionierte somit einerseits als ökonomischer Türöffner und Garant zur Gründung des eigenen Familienstandes und steigerte durch das soziale Prestige aus der Amtstätigkeit die Attraktivität von ledigen und verwitweten Schulmeistern auf dem lokalen Heiratsmarkt. Andererseits dürfte sich das vielerorts prekär bemessene Schulmeistersalär paradoxerweise fördernd auf das Gründen eines eigenen Ehestands ausgewirkt haben, da dieses Zusatzeinkommen nur im Rahmen einer erweiterten Hauswirtschaft und unter Mitwirkung beider Ehepartner einen tatsächlich lohnenden Einkommenssprung nach vorne ermöglicht hat. Unwahrscheinlich scheint hingegen, dass das kollektive Heiratsverhalten der Lehrer einzig dem oben angesprochenen gesamtgesellschaftlichen Prozess einer Abschwächung der Ehehindernisse geschuldet gewesen war, denn dazu sind die Resultate ungeachtet der sozialen und geografischen Herkunft der Lehrkräfte zu gleichförmig.

Diese Erkenntnisse stützen zum Zweiten insgesamt den Erklärungsansatz von Ehmer, dass sich das Heiratsverhalten der Elementarschullehrer vordergründig „um das Behaupten oder Erlangen bestimmter - knapper und meist an ein Erbe gebundener - sozialer Positionen und nicht um materielle Ressourcen schlechthin" drehte. ${ }^{1461}$ Wird das Lehramt als eine ebensolche knappe soziale Position betrachtet, deren ökonomische Grundlage in der Regel die familienwirtschaft-

1459 Schmidt u.a. (Hgg.), Stapfer-Enquête, Nr. 2365: Messen.

1460 Der reformierte Pfarrer Christoph Ferdinand Moser empfahl in einem Taschenbuch für Lehrer etwa, dass Lehrer eine Gattin suchen sollten, die „nicht ganz ohne Mittel ist und in gutem Rufe stehet“. Tröhler, Schulkritik: 107.

1461 Ehmer, Heiratsverhalten: 69; Pfister: Bevölkerungsgeschichte: 81f. 
liche kleine Bauernwirtschaft oder der unabhängige Handwerksbetrieb darstellte, wird auch das Heiratsverhalten der Lehrer schlüssig erklärbar, zumal eine Heirat und das Gründen eines eigenen Familienstandes gleichzeitig die Position des Lehrers als Teil der dörflichen Funktionselite gegenüber den übrigen Hausvätern abzusichern half. Selbst wenn wir den sozialen Status der Ehepartner nicht kennen, wurde die Heirat zum notwendigen Akt der sozialen Sicherung, was ohne ein gewisses Mass an verbundenem Sozialprestige unmöglich gewesen wäre.

Die hohe Zahl an verheirateten Lehrkräften ist aber zum Dritten gleichzeitig auch als eine nicht freiwillige Entwicklung und als ein Abbild gesellschaftlicher Vorstellungen und Zwänge zu deuten, wie das Rangeln nach sozialen Positionen schon angedeutet hat. Die idealisierten religiösen Moral- und Charaktervorstellungen von Sittsamkeit und Rechtschaffenheit verlangten implizit nach einem mündigen Hausvater als Vorbild für die Jugend. Daraus lässt sich der reziproke Druck auf die Lehrkräfte ableiten, heiraten zu müssen, um ihr soziales Ansehen, ihr Sozialkapital vollständig zu erlangen beziehungsweise aufrecht zu erhalten.

Das Eingehen einer Ehe war für die Schulmeister quasi ein gesellschaftlicher Zwang, um in den Stand der Hausväter aufgenommen zu werden und um überhaupt erst vom Sozialkapital des Lehramts zu profitieren. In diesem Kontext sind denn auch mitunter skurrile überlieferte Rechtshändel zu verstehen, wie der gescheiterte Versuch eines verzweifelten Lehrers, mittels eines gewaltsam verabreichten Geldpfands an eine ledige Frau ein Eheversprechen einzufordern. ${ }^{1462}$ Auch die literarische Anekdote der gescheiterten Kiltgang-Bemühungen des fiktiven Protagonisten Peter Käser in Gotthelfs Schulmeisterroman „Leiden und Freuden eines Schulmeisters" sind in diesem Kontext als mehr als nur das literarisch ausgeschmückte jugendliche Buhlen um das andere Geschlecht zu deuten, sondern als Notwendigkeit, um soziales und wirtschaftliches Kapital zu erlangen. ${ }^{1463}$ Entsprechend sahen sich die Lehrkräfte - vielleicht noch stärker als andere Professionisten - mit der Herausforderung bei der Brautschau konfrontiert, eine Ehefrau mit ebenso einwandfreiem Leumund und einem mitunter höheren sozialen Ansehen zu gewinnen. So sind denn auch Versuche von Lehrkräften, sich in einen höheren Stand der Dorfelite einzuheiraten - namentlich mit Töchtern von Vollbauern, wie Gotthelfs fiktiver Schulmeister es versucht hat oder beim zuvor genannten Beispiel des Lehrers Messer erfolgreich gelungen war - nicht nur unter der ökonomischen Perspektive des wirtschaftlichen Zugewinns, sondern auch unter dem Blickwinkel der Sicherung und Vermehrung des eigenen Sozialkapitals zu betrachten.

Ebenso versteht sich der bereits weiter oben angesprochenen ökonomische „Rollenergänzungszwang“. Erst die Ehefrau vervollständigte die familiäre Hauswirtschaft und ermöglichte mit ihrer Arbeitskraft das ökonomische Überleben des zuvor ledigen oder verwitweten Lehrers. Der Zwang auf die Lehrkräfte zu heiraten manifestiert sich somit in einer ökonomischen und in einer gesellschaftlichen Dimension gleichermassen.

An dieser Stelle ist über die Rolle der Frauen als Ehefrauen der Schulmeister zu reflektieren, nahmen sie doch eine offensichtliche Schlüsselfunktion im Diskurs um das Heiratsverhalten der Lehrkräfte ein. Die weibliche Arbeitskraft trug denn gleich in mehrfacher Weise zum familiären Haushaltseinkommen bei: zum einen übernahmen die Lehrer-Ehefrauen während der schulischen Abwesenheiten des Lehrers die alltäglichen subsistenzwirtschaftlichen Tätigkeiten im Hauswesen oder - wo vorhanden - auf dem landwirtschaftlichen Hofgut. Zum anderen

1462 Vgl. Van Dülmen, Kultur und Alltag: 142.

1463 Auf Käsers vergebliche und nicht standesgemässe Bemühungen um die Bauerntochter Stüdin erfolgt wohl nicht zufälligerweise die Erwähnung von Schulden, der ungenügenden wirtschaftlichen Haushaltungsweise des Protagonisten sowie dessen Probleme um Anerkennung in der Dorfgemeinschaft. Gotthelf, Leiden. 
arbeiteten nicht wenige Lehrer-Ehefrauen aktiv als Hilfslehrerinnen zur Unterstützung in den Schulstuben mit, um bei grossen Kinderzahlen den Schulmeister zu entlasten oder um die Anstellung eines kostenpflichtigen Adjunkten als Hilfslehrer - und damit Geldabflüsse aus dem Haushaltseinkommen - zu vermeiden. Die grundsätzliche Wahrnehmung, dass Frauen „nur sehr selten professionell tätig waren“, ist angesichts der aktiven Rolle vieler Schulmeister-Ehefrauen kritisch zu paraphrasieren. ${ }^{1464}$ Betrachtet man die Haushalte der Schullehrer abseits ihres Amtes als gewöhnliche „Polyprofessionisten“, so dürfte diese Erkenntnis für die meisten Ehefrauen beziehungsweise Haushalte im Lokalgefüge gegolten haben.

Neben der ökonomischen Rolle fiel den Ehefrauen von Schulmeistern aber auch eine wichtige soziale Funktion zu, die sie von anderen Ehefrauen des dörflichen Gesellschaftsgeflechts unterschied: diejenige der Bewahrerin des schulmeisterlichen Ansehens. Das soziale Kapital des Schulmeisters hing - wie bei den Betrachtungen zum Ansehen der Lehrkräfte im Kap. 4.1.2 bereits festgehalten - nicht nur von seinem eigenen individuellen Betragen beziehungsweise seiner Wahrnehmung durch die Lokalgemeinschaft $a b$, sondern war zu guten Teilen auch durch das soziale Ansehen der Ehefrau mitbeeinflusst. Zwei Negativbeispiele dienen der Verdeutlichung: In der Zürcher Schulumfrage von 1771/72 wurde zum Ansehen des Lehrers in Oberrieden $\mathrm{ZH}$ notiert: „hätte noch mehr Achtung bey der Gemeind u: kindern, wenn er ein besser weib hätte. Iz ist er von derselben frey, davon man alles gute er-wartet." ${ }^{\text {1465 }}$

In ähnlich negativer Weise wurde der mangelnde Schulerfolg des Lehrers Johannes Meyer in Bettingen BL begründet: „Meyers Wandel ist anstössig durch Schuldenmachen, manchmal durch Trinken, und durch lärmenden Hausstreit mit seiner äusserst schlechten Frau, welche wohl viel Schuld an seiner eignen Unordnung ist." ${ }^{1466}$

Nicht zwingend der gesellschaftliche Stand, sondern vielmehr der Charakter der Ehefrau verstärkte oder hemmte das soziale Kapital des Schulmeisters in mitunter eklatanter Weise. Wiederum antizipiert die literarische Idealisierung von Käsers Ehefrau in Gotthelfs Schulmeisterroman als „treue, fromme Frau [...], die zu ihm hält, sparsam wirtschaftet und ihm an Taktgefühl und natürlicher Frömmigkeit überlegen ist ${ }^{\text {“1467 }}$ die wichtige Rolle der Ehefrau als „Bewahrerin“ des fragilen sozialen Kapitals.

\section{Das Heiratsverhalten der jüngeren Lehrer}

Nicht nur die älteren Lehrkräfte sind bezüglich ihrer Zivilstandverhältnisse von Interesse, auch bei den jüngeren Lehrkräften lohnt sich ein genauer Blick. Hinsichtlich der Generationengruppe der jüngeren, unter Dreissigjährigen stellt sich die Frage, ob trotz der Statik der Momentaufnahme der Umfrage dennoch Aussagen zur Dynamik des Verheiratungsprozesses gemacht werden können. Zur besseren Übersicht sind daher auch die Zivilstandsangaben der Lehrkräfte zwischen dem 30. und 39. Lebensjahr mit aufgeführt. So zeigen die Zivilstandsangaben der jüngeren Lehrkräfte bei genauerem Hinsehen - in Altersgruppen von jeweils zwei Altersjahren zusammengefasst - eine fast lineare Entwicklung des Heiratsverhaltens, selbst wenn der genaue Zeitpunkt der Verheiratung offen bleibt. 


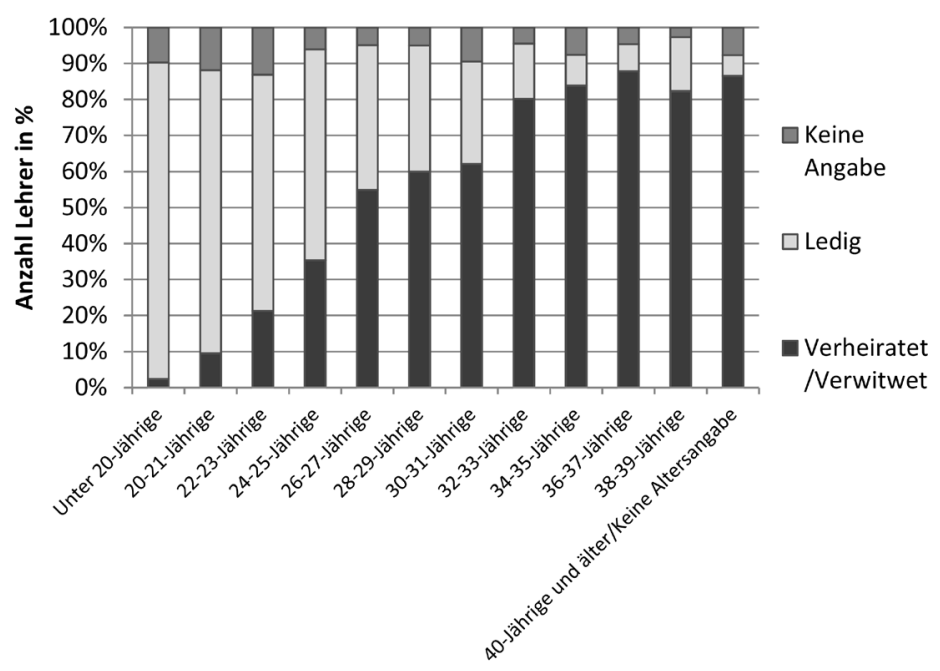

Abb. 18: Zivilstand aller Lehrer bis 40 Jahre in Alterskohorten ${ }^{1468}$

Im Vergleich der Zivilstandsangaben zwischen den einzelnen Zweijahres-Alterskohorten stiegen die relativen Anteile an verheirateten Lehrkräften beinahe linear um über 10\% pro Zweijahresalterskohorte an. War erst knapp jede zehnte Lehrkraft der Kohorte der 20- bis 21-Jährigen verheiratet, galt dies ab dem 26. Lebensjahr bereits für mindestens jede zweite Lehrperson. Damit wiesen die jungen helvetischen Lehrkräfte um 1800 im Vergleich mit dem zuvor diskutierten mittleren Erstheiratsalter von rund 27 bis 29 Jahren gemäss der Studie von François Höpflinger ein kollektiv leicht früheres Erstheiratsalter auf, sofern man die 50\%-Schwelle an Verheirateten als Referenz nimmt. Ein frühes Heiraten vor dem 24. Altersjahr stellte sich dagegen bei der jüngeren Lehrerschaft um 1800 in kollektiver Weise als noch deutlich untypisch heraus, was sich durch die in der Regel zu diesem Alterszeitpunkt noch ungefestigte ökonomische Stellung, die noch anhaltende Ausbildungs- oder Gesindedienstsituation und damit mit dem Nichterreichen der Mündigkeit erklären lässt. ${ }^{1469}$ Gleiches galt etwa für junge Handwerkergesellen, die nach ihrer Lehrzeit erst ihre mitunter mehrjährige Wanderzeit und die Meisterprüfung ablegen mussten, bevor sie heiraten durften. ${ }^{1470}$ Bloss eineinhalb Dutzend Lehrer unter 24 Altersjahren waren zum Zeitpunkt der Umfrage bereits verheiratet. Gerade jene Fälle zeigen aber exemplarisch auf, dass die Grenze der Mündigkeit von rund 25 Altersjahren prinzipiell variabel war und durchaus jüngeren Personen das Eingehen einer Ehe gestattet wurde, zumal diese Personen offenbar die ökonomische Tragfähigkeit für das Eingehen einer Ehe nicht strapazierten. Es ist angesichts des im Kapitel 2.2 festgestellten mittleren Amtsübernahmealter von rund 29 Jahren anzunehmen, dass auch die Lehrkräfte der älteren Generationen nicht verbreitet vor dem 25. Lebensjahr hei-

1468 Vgl. den Abdruck in: Rothen, Erkenntnisgewinn: 43. In der Berechnung wurden wiederum die zwangsweise ledig lebenden katholischen Geistlichen ausgenommen, um einer Verzerrung der Datensätze vorzubeugen. Die Zivilstände der Lehrkräfte ohne Altersangabe sind in der Spalte „40-Jährige und älter“ inkludiert.

1469 Zur Bedeutung des Gesindedienstes als Spezifikum der europäischen Gesellschaftsentwicklung und des Zusammenhangs mit dem Heiratsalter: vgl. Mitterauer, Sozialgeschichte der Familie: 73-83.

1470 Menolfi, Tod: 111. Die Dauer des Wanderzwangs - wenn er auch offenbar aus finanziellen Gründen von vielen Gesellen nicht eingehalten wurde - hat Thomas Meier in seiner Studie zum Landhandwerk im Zürcher Unterland mit durchschnittlich zwei bis drei Jahren angegeben. Meier, Handwerk: 212f. 
rateten, wenngleich sich diese Annahme mit den vorliegenden Quellen nicht verifizieren lässt. Die steigenden Werte an verheirateten Lehrkräften ab dem 26. Altersjahr korrespondieren zudem nicht nur mit dem Mündigkeitsalter, sondern ebenfalls gut mit den Beobachtungen aus Forschungen zu heimkehrenden Söldnern, die ein ähnliches kollektives Verhalten zeigten und sich meist erst nach dem Ablauf des Soldvertrages und ihrer Rückkehr ungefähr ab dem 28. Lebensjahr in der Heimat vermählten. ${ }^{1471}$ Bei den 32-33-Jährigen stieg der Anteil an Verheirateten bereits auf mindestens über $80 \%$ an. Der kulminierende Wert an verheirateten Lehrkräften von mindestens vier Fünfteln trat somit spätestens ab dem 33. Altersjahr auf und blieb anschliessend über alle nachfolgenden Alterskohorten konstant hoch. Ein kollektiver Trend zu eher späten Heiraten zur Verminderung der Fertilität kann dadurch ausgeschlossen werden.

Gab es einzelne Berufsgruppen, die durch die Lehramtsübernahme oder aufgrund ihrer erstberuflichen Voraussetzungen rascher heiraten konnten und einen höheren Anteil unter den jüngeren Lehrkräften stellten als andere? In der Ersttätigkeitsstruktur der jung verheirateten Lehrkräfte unter dreissig Altersjahren sind deutliche Präferenzen sichtbar, welche Berufsgruppen eher die Möglichkeit hatten, jung zu heiraten.

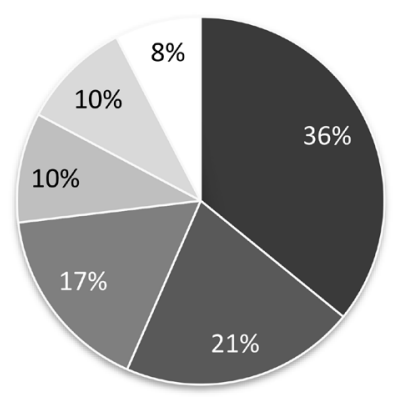

\author{
- Landwirtschaftliche \\ Tätigkeit \\ - Keine Ersttätigkeit \\ - Handwerkliche Tätigkeit \\ Protoindustriell- \\ textilgewerbliche Tätigkeit \\ Andere Ersttätigkeit \\ Keine Angaben
}

Abb. 19: Ersttätigkeiten der verheirateten Lehrkräfte unter 30 Jahren

Rund jede fünfte jung verheiratete Lehrkraft unter dreissig Jahren hatte keinen Erstberuf ausgeübt gehabt, was dem proportionalen Anteil an Lehrkräften ohne Erstberuf insgesamt entsprach. Gleichwohl stellten die Lehrersöhne oder direkt zum Lehrer ausgebildeten Schulmeister die zweitgrösste relative Sozialgruppe unter den jung verheirateten Lehrkräften. Unter den bereits verheirateten Lehrkräften unter dreissig Altersjahren befanden sich ferner nur sehr wenige protoindustriell-textilgewerbliche Heimarbeitende, obwohl diese Professionsgruppe gemäss bisherigen Forschungsresultaten durch das Zusatzeinkommen der Heimarbeit am stärksten zu einem früheren Erstheiratsalter und einem lockeren Sexualverhalten geneigt hatte. ${ }^{1472}$ Bloss jeder zehnte verheiratete Lehrer unter dreissig Jahren hatte vor dem Lehramt als Weber gearbeitet. Ebenso niedrig war mit rund $17 \%$ der Anteil an ehemaligen Handwerkern unter den jungen verheirateten Lehrern. Die relative Mehrheit von rund 36\% an jungen verheirateten Lehrkräften entstammte dagegen dem kleinbäuerlich-landwirtschaftlichen Umfeld und war vor- oder neben dem Lehramt mit agrarischen Tätigkeiten oder mit der Taglöhnerei beschäftigt gewesen.

1471 Pfister, Strom: 129.

1472 Vgl. zum früheren Heiratsverhalten in protoindustrialisierten Gebieten: Head-König, Ehe; Huggel, Einschlagsbewegung: $490 \mathrm{f}, 495 \mathrm{ff}$. 
Kleinbäuerlicher Besitz oder mindestens kleinbäuerlicher Gesindedienst zur Sicherung des familieneigenen Ernährungsbedarfs in der polyprofessionellen Kombination mit dem zumeist monetär besoldeten Lehramt offenbarte sich damit als häufigste ökonomische Grundlage für eine frühzeitige Heirat. Der Umstand, ob der agrarische Besitz bereits auf die Lehrkraft übertragen worden war oder ob der Lehrer noch im elterlichen Familienverbund mitwirkte - was zumindest bei einigen Lehrkräften zwischen den Zeilen vermutet werden konnte - scheint dabei zweitrangig gewesen zu sein. Die Wichtigkeit von landwirtschaftlichen Einkommensmöglichkeiten ist jedenfalls gerade bei den Junglehrkräften offensichtlich, was wiederum mit der bereits mehrfach diskutierten These einer zunehmenden Konzentration auf agrarische Tätigkeiten einhergeht, wie es Bloch Pfister postuliert hat. ${ }^{1473}$ Die protoindustrielle Weberei in Heimarbeit hatte dagegen keinen signifikanten Einfluss auf ein verbreitet früheres Heiratsverhalten von erstberuflich protoindustriell tätigen Lehrkräften und wirkte sich somit nicht als zusätzlichen Katalysator für besonders frühe Hochzeiten aus, wodurch insbesondere „Bettelhochzeiten“ bei den Lehrkräften auf der unsicheren ökonomischen Basis der Heimarbeit weitgehend ausgeschlossen werden können.

Eine nicht unerhebliche Rolle zur Familiengründung spielte ferner die Verfügbarkeit von freiem Wohnraum. Der Bezug einer freien Wohnung im Schulhaus als Naturalbestandteil oder als Hauszins als Teil der Besoldung konnte die Basis für eine rasche Familiengründung für Berufsanfänger bilden. ${ }^{1474}$ Unter den bereits verheirateten unter dreissigjährigen Lehrkräften profitierte denn auch eine bedeutende Minderheit von rund 36\% gesichert von einer freien Wohnmöglichkeit, während bloss 23\% der ledigen Altersgenossen ebenfalls eine freie Wohnung nutzen konnten. Weitere $10 \%$ der jung verheirateten Lehrer erhielten zumindest eine finanzielle Entschädigung in Form eines Hauszinses, wenn kein Schulhaus verfügbar war. Mehr als jede zweite junge Lehrkraft von unter dreissig Altersjahren mit freier Wohnung als Einkommensbestandteil, rund 59\%, stammte zudem von ausserhalb der Schulgemeinde. Eine freie Schulwohnung war somit gerade bei den jungen Lehrern nicht nur ein wichtiger Einflussfaktor auf das Mobilitäts-, sondern auch auf das Heiratsverhalten. ${ }^{1475}$

Eine schwache Signifikanz konnte ferner bei der mittleren minimalen Dienstdauer zwischen verheirateten und ledigen Lehrkräften von unter dreissig Altersjahren festgestellt werden.

Tab. 43: Mittlere minimale Dienstdauer der Lehrer unter 30 Jahren

\begin{tabular}{|c|c|c|c|c|c|c|c|}
\hline Alter & Unter 20 & $20-21$ & $22-23$ & $24-25$ & $26-27$ & $28-29$ & Total: \\
\hline Zivilstand & Jahre: & Jahre: & Jahre: & Jahre: & Jahre: & Jahre: & \\
\hline Verheiratet & 2.0 & 2.3 & 2.3 & 3.2 & 4.3 & 5.6 & 4.2 \\
\hline Ledig & 1.1 & 2.1 & 2.5 & 2.9 & 3.9 & 5.7 & 2.9 \\
\hline
\end{tabular}

Die verheirateten Lehrkräfte unter dreissig Altersjahren standen 1799 mit 4.2 Jahren im Durchschnitt bereits mehr als ein Jahr länger im Amt als ihre noch ledigen Berufskollegen mit 2.9

1473 Vgl. Bloch Pfister, Priester: 172.

1474 Schmidt, Kapitel Bern: 155.

1475 Von den 145 verheirateten Junglehrkräften unter dreissig Altersjahren profitierten mindestens 52 von einer freien Wohnung, 67 hatten keine freie Schulwohnung und 26 Antworten blieben unklar. Demgegenüber hatten bloss 52 der 228 ledigen Junglehrkräfte unter 30 Altersjahren eine freie Wohnung, 176 wohnten anderweitig oder in unklaren Verhältnissen. Mindestens 61 der insgesamt 102 Junglehrkräfte mit eigener freier Schulwohnung stammten ferner nicht aus dem Schulort. 
Jahren. Zwar ist der Befund nicht für alle Altersgruppen zwischen dem zwanzigsten und dem dreissigsten Altersjahr gleichermassen zutreffend, die Tendenz ist jedoch über das gesamte Generationenspektrum der jungen Lehrkräfte eindeutig. Je früher eine Lehrkraft ihr Amt übernehmen und sich damit eine gesicherte ökonomische Basis schaffen konnte, desto früher konnte sie sich danach in der biografischen Lebensphase als Lehrkraft verheiraten. Damit wird eine mögliche direkte temporale Kausalität zwischen der Lehramtsübernahme und dem Eingehen in den Ehestand evident. Der Befund einer fast linearen Zunahme an verheirateten jungen Lehrkräften mit zunehmendem Alter beweist ferner, dass zumindest viele der jungen Lehrkräfte nicht bereits als verheiratete Personen das Lehramt übernahmen, wie es Klinke und Schneider in ihren zuvor zitierten Studien vermutet haben, sondern dass die Heirat vielmehr in kausaler zeitlicher Abfolge erst nach der Lehramtsübernahme erfolgte. Das Zusatzeinkommen des Lehramts konnte in zweierlei Hinsicht die Aussichten auf eine frühere Heirat und Familiengründung verbessern, indem es gewichtigen Ehehindernissen entgegenwirkte.

Erstens vermochte der Zusatzverdienst die zeitliche Verzögerung der Eheschliessung durch das ansonsten notwendige Warten auf das väterliche Erbe zu verringern oder - wo das Anerbenrecht galt - nicht erbberechtigte Kinder in einen heiratsberechtigten Status versetzt haben. Zahlreiche Antworten von Lehrern aus der Stapfer-Enquête lassen denn auch wenig Zweifel offen, dass die Übernahme des Lehramts die Legalisierung der wohl meistens vorher schon bestandenen Beziehung beschleunigte. Das zeitnahe Folgen der Heirat auf die Amtsübernahme verdeutlicht dies, wie uns zwei nachfolgende Beispiele aus der Stapfer-Enquête exemplarisch zeigen: „Jch heiße Konrad Riby, bin hießiger Gemeinds-Bürger 26. Jahre alt 4 Jahr verheyrathet, habe keine Kinder, bin 5 Jahr Schulmeister. ${ }^{\text {(1476 }}$ Ebensolches berichtete der Lehrer aus Wangen an der Aare BE. Auch bei ihm lag die Heirat in zeitlich nahem Abstand zur Übernahme des Lehramts: „Der Schullehrer [...] von hier gebürtig, 27. Jahr alt, und frisch verheirathet ist, der circa 1. 1/2 Jahr diesem Beruf vorgestanden." ${ }^{4477}$

Über ein Dutzend weitere Beispiele von ähnlichen Aussagen untermauern empirisch den evidenten temporalen Zusammenhang von Lehramtsübernahme und Heirat in einer zeitnahen Abfolge, insbesondere bei den jung verheirateten Lehrkräften von unter dreissig Jahren. ${ }^{1478}$ Dem steht bloss ein einziges gefundenes Beispiel einer Verheiratung vor der Lehramtsübernahme gegenüber. ${ }^{1479}$ Wenngleich dieser kleine Quantifizierungsvergleich aufgrund seiner quelleninhärenten Unvollständigkeit und der quantitativ schmalen Basis nicht als repräsentativ für das gesamte Lehrerkollektiv an unter dreissigjährigen Lehrern angesehen werden darf, sprechen die Indizien eine klare Sprache. Die Übernahme des Lehramts mit dem gesicherten finanziellen Zusatzeinkommen wirkte sich somit in positiv-stimulierender Weise auf die Möglichkeit einer Heirat innerhalb der persönlichen Biografie der Lehrkräfte aus, was wiederum als Indiz für einen durch das Lehramt gesicherten sozialen Status hinweist.

1476 Schmidt u.a. (Hgg.), Stapfer-Enquête, Nr. 1054: Gottlieben.

1477 Schmidt u.a. (Hgg.), Stapfer-Enquête, Nr. 957: Wangen an der Aare.

1478 Bei mindestens 15 der insgesamt 145 verheirateten Lehrkräfte von weniger als 30 Altersjahren konnten eindeutige Hinweise auf einen Heiratszeitpunkt nach der Lehramtsübernahme festgestellt werden (Cergnat VD, Gottlieben TG, Grosshöchstetten BE, Herblingen SH, Hosenruck TG, Lignerolle VD, Niederweningen ZH, Prilly VD, Schlattingen SH, Seon AG, Sullens VD, Staufen AG, Trogen AR, Uerzlikon ZH, Wangen a.A. BE). Auch bei älteren Lehrern fanden sich vereinzelte Hinweise auf eine der Amtsübernahme nachfolgende Heirat etwa beim Lehrer von Amriswil TG: „ich verheürathete mich im 22 Jahr meines Alters, erzeügte sinther 13 Kinder, von welchen noch 7 am Leben \{sich\} befinden, [...] Jch wurde 1788. von E: E: Kirchen-Ausschuß einhellig zum Vorsinger in die Kirche zu Someri und Amrischweil erwählt - Also war mein Schul Dienst 19 Jahr und mein Alter ist 38 Jahr." Schmidt u.a. (Hgg.), Stapfer-Enquête, Nr. 85: Amriswil.

1479 Schmidt u.a. (Hgg.), Stapfer-Enquête, Nr. 521: Wildhaus. 
Zweitens garantierte der gesicherte Schulverdienst ein Mindesteinkommen, das im Gegensatz zu anderen besitzschwachen Dorfbürgern das Risiko einer frühzeitigen Armengenössigkeit verringerte und das heiratswillige Paar vom Makel der „sozialen Eheuntauglichkeit“ aufgrund von drohender Armut befreite. ${ }^{1480}$ Obwohl viele Lehrkräfte explizit betont hatten, das Schuleinkommen allein reiche nicht aus, um eine Familie zu ernähren, gründeten sie paradoxerweise dennoch fast ausnahmslos eigene Familien durch eine Heirat unmittelbar nach der Amtsübernahme, wodurch sich die prekäre wirtschaftliche Situation als mögliches Ehehindernis in der Realität deutlich negiert. Denn im Zusammenspiel mit agrarischer Subsistenzwirtschaft oder anderen Einkommenstätigkeiten reichte der Zusatzverdienst des Schulhaltens aus, um nicht als „Armenehen“ zu gelten. Wirksame ökonomische Ehehindernisse sind daher für die Lehrkräfte des Elementarschulwesens um 1800 weitestgehend auszuschliessen und positionieren die Lehrkräfte wiederum in den sozio-ökonomischen Mittelschichten. Das Lehramt mit seinem klar abschätzbaren Zusatzeinkommen erscheint im Gegenzug als ein Katalysator für eine raschere Eheschliessung gewirkt zu haben, zumal sich nicht nur jüngere, sondern auch viele ältere, verwitwete Lehrkräfte wieder verheirateten.

Daneben mussten positiv konnotierte, immaterielle Einflussfaktoren entscheidend mitgewirkt haben, um den Schulmeistern die festgestellte aussergewöhnlich hohe Heiratsattraktivität zu bescheren. Wie Josef Ehmer in seiner vergleichenden Studie zum mitteleuropäischen und englischen Heiratsverhalten dargestellt hat, kann das Heiratsverhalten frühneuzeitlicher Personen nicht alleinig auf der Basis von ökonomischen Ressourcen erklärt werden, da auch Inhaber „generativ nicht vollwertiger Stellen" heirateten und insbesondere die ländlichen Unterschichten in vielen Regionen Mitteleuropas im 18. Jahrhundert stark anwuchsen. Vielmehr betont Ehmer die Heirat als Akt der bewussten sozialen Platzierung innerhalb einer Sozialstruktur. ${ }^{1481}$ Für die Elementarschullehrerschaft liegt die Vermutung nahe, dass mit dem Lehramt ein gesteigertes soziales Prestige und damit ein möglicher Aufstieg in die dörfliche Funktionselite verbunden war, was ledige Schulmeister einerseits zu attraktiven Partien für eine Heirat machte, selbst wenn sie als Hintersassen in fremden Gemeinden arbeiteten oder zuvor eine prekär besoldete Berufstätigkeit ausgeübt hatten. Nicht zuletzt dürften die von Seiten der Kirchenzucht geforderten einwandfreien moralischen und charakterlichen Eigenschaften sowie der untadelige Lebenswandel als Grundvoraussetzungen für Lehramtskandidaten die persönliche Attraktivität der Schulmeister auf dem lokalen Heiratsmarkt gefördert haben. Andererseits dürfte zumindest in jenen Kantonen, wo die Obrigkeit ein traditionelles Mitspracherecht bei der Lehrerbestellung gehabt hatte, die artikulierte Präferenz für verheiratete Männer im Lehramt für einen gewissen reziproken sozialen Druck auf die noch ledigen Lehrer zur Heirat gesorgt haben. Erst die Heirat sicherte dem Elementarschullehrer seinen vollwertigen Platz als Hausvater innerhalb der lokalen Funktionselite endgültig zu.

Inwieweit äussere Heiratszwänge, beispielsweise illegitime Schwangerschaften als Förderfaktor mitgewirkt haben könnten, darüber kann nur spekuliert werden, denn in vielen Gegenden waren intime Beziehungen zwischen Verlobten trotz der strengen Kirchenzucht eine geduldete Tatsache. ${ }^{1482} \mathrm{Da}$ jedoch ein einwandfreier Leumund und ein tadelloses sittlich-moralisches Betragen als Grundbedingungen für die Anstellung zum Schulmeister galten, dürften erzwungene Heiraten aufgrund drohender Illegitimität unehelicher Kinder gleichwohl nur selten vorgekommen sein. Der grosse soziale Makel einer unehelichen Schwangerschaft konnte aber

1480 Vgl. Höpflinger, Bevölkerungswandel: 20f; Head-König, Ehehindernisse.

1481 Ehmer, Heiratsverhalten: 67ff.

1482 Menolfi, Tod: $111 \mathrm{f}$. 
durchaus als perfides Druckinstrument gegen unliebsame Personen verwendet werden, wie der Lehrer aus Unterillnau ZH festhielt, der mit einigen Bauern seines Dorfes in Fehde lag: „Jch hab oben eine kleine Anmerkung gemacht wegen Verfolgungen, der Aristokraten gegen mir, aber es ist nur ein Ueberblik gegen dem Ganzen. Wenn ich ein ganzen Abriß machen sollte von den Verfolgungen die ich dieß Jahr hab erdulden müssen so gäbe es ein weitläufiges Schreiben, aber ich weil nur ein Beyspiel anführen, woraus Sie Vieles schliessen können: Das älteste unter meinen 4 Kinderen ist ein Mädchen von 24 Jahren und war schon 3 Jahre mit einem Gesellen vom gleichen Alter versprochen gewesen, und verwiechnen May auch von ihm schwanger geworden: es kam so weit, daß sie beyde an einem Freytagnachts abgeredt kommenden Sonntag die Hochzeit verkünden zulassen, und den Montag darauf, auf Zürich kupulieren zulassen. Am Samstag wurde dieß Geschäfft ruchtbar, und alle Arestokraten lauften zu, und brachten ihn so weit, daß er sich weg machte, und mir meine Tochter ließ in solchem Stande sizen. Aber er ist der aller schlimste Aristokrat gewesen, sonst hätten sie nicht so viel gegen ihn vermögen. Einer dieser Aristokraten, der ein Vogtkind hatt, daß 1800 fl. baar Geld hatte, gieng und versprach ihm, wenn er das thun, so müsse er dies Mensch haben wenn er wieder nach Hause komme. Dieser hat ihm Wort gehalten: denn so bald wir vor dem Distrikt unseren Prozeß, gegen diesen schlechten Menschen haben lassen ausmachen, kommt er wieder heim, und macht Heurat mit dem gedachten Vogtkind: Jez ligt mein Tochter schon 6 Wochen krank an einer unglüklichen Gebuhrt, die mich bis auf 50 fl. kostet." ${ }^{1483}$

Hinweise auf illegitime Kinder durch die Lehrkräfte liessen sich in der gesamten Stapfer-Enquête nirgends finden, obwohl durchaus von einer gewissen Dunkelziffer an illegitimen Zeugungen ausgegangen werden muss, da zwischen $2 \%$ bis $5 \%$ aller Geburten illegitimen Ursprungs waren. ${ }^{1484}$ Dass auch Lehrer sich bisweilen der Schwängerung oder der Brautschwangerschaft schuldig gemacht hatten, zeigen einzelne Fälle aus lokalen Kirchengerichtsverhandlungen. ${ }^{1485}$ Die stigmatisierende Tragweite von (ungerechtfertigten) Vorwürfen der illegitimen Schwängerung gegenüber Lehrpersonen finden wir unter anderem wiederum in einer Episode von Gotthelfs Schulmeisterroman „Leiden und Freuden eines Schulmeisters“ im fiktiven Lebensschicksal des Lehrers Peter Käser anschaulich geschildert. ${ }^{1486}$ Zumindest was die möglichen Konsequenzen solcher Anschuldigungen anging - öffentliche Massregelung, den Verlust der Autorität im Dorf und letztlich den Verlust der Stelle - scheint das fiktionale Bild keineswegs überzeichnet und nahe an der Realität gehalten.

Das Nichtauftauchen von Illegitimitätsfällen in der Stapfer-Enquête erstaunt aus quellenkritischer Sicht jedoch keineswegs, hätten sich die Lehrkräfte durch solche allzu offenherzigen "Selbstanzeigen“ gegenüber ihren vorgesetzten Instanzen selbst diskreditiert und gegen ihr wichtigstes Anstellungskriterium, den moralisch einwandfreien Lebenswandel und vorbildlichen Charakter, verstossen. Doch auch in den zeitnahen regionalen Schulumfragen, die durch die vorgesetzten Pfarrer und nicht durch die Lehrer selbst ausgefüllt wurden, waren illegitime Kinder unter den charakterlich-moralischen Schwächen der Lehrkräfte im Gegensatz zu Trunkenheit, Faulheit oder übermässiger Rohheit gegenüber den Kindern nie ein Thema. Eine systematische Auswertung von kirchlichen Ehegerichtsprotokollen nach dem Vorkommen von Lehrpersonen könnte diese hier offen bleibende Frage klären.

1483 Schmidt u.a. (Hgg.), Stapfer-Enquête, Nr. 118: Unterillnau.

1484 Vgl. Schmidt, Dorf und Religion: 231-237. Zschunke errechnete für die Stadt Oppenheim einen Anteil an ausserhalb der Ehe geborener Kinder von $5 \%$ für die Jahrhundertwende zum 19. Jahrhundert. Zschunke, Oppenheim: 149.

1485 Schmidt, Dorf und Religion: 212.

1486 Vgl. die Kapitel 22-27 in: Gotthelf, Leiden. Mahlmann-Bauer, Spiegel: 70. 


\section{Das Heiratsverhalten der Lehrerinnen}

Eine geschlechtergetrennte Betrachtung der Zivilstandverhältnisse bringt aufgrund der geringen Anzahl an namentlich überlieferten Lehrerinnen in der Stapfer-Enquête zwar nur einen bescheidenen Erkenntnisgewinn, doch weisen die Ergebnisse der Zivilstandsangaben auf einen schwachen geschlechtsspezifischen Unterschied beim Heiratsverhalten hin. Mindestens 29 der total 66 namentlich bekannten Lehrerinnen waren zum Zeitpunkt der Umfrage verheiratet oder verwitwet, was bloss einen Anteil von 44\% ergibt. Unter dem Ausschluss der sechs zölibatär lebenden Ordensschwestern wiesen sich immerhin 26 Lehrerinnen oder 39\% ungeachtet ihres Alters als ledig aus.

Tab. 44: Zivilstand der Lehrerinnen 1799

\begin{tabular}{lcccc}
\hline Zivilstand: & Unter 30-Jährige: & 30-49-Jährige: & Über 50-Jährige: & Keine Angabe: \\
\hline Ledig & 10 & 9 & 6 & 1 \\
Verheiratet & 1 & 9 & 12 & 0 \\
Verwitwet & 0 & 2 & 4 & 1 \\
Zölibat & 2 & 3 & 1 & 0 \\
Keine Angabe & 2 & 2 & 1 & 0 \\
\hline Total & 15 & 25 & 24 & 2 \\
\hline
\end{tabular}

Zehn dieser 26 ledigen Lehrerinnen waren zwar zum Zeitpunkt der Erhebung noch unter dreissig, fünfzehn weitere jedoch bereits über dreissig Jahre alt. Die jüngste in der Stapfer-Enquête vermerkte verheiratete Lehrerin, Jeanne Baud aus Nyon VD, war mit 27 Jahren zudem wesentlich älter als der jüngste verheiratete männliche Berufskollege. ${ }^{1487}$ Rund 10\% der Lehrerinnen waren zum Zeitpunkt der Umfrage überdies bereits verwitwet, wobei der verstorbene Ehemann aber nicht zwingend selbst Lehrer sein musste, sondern durchaus andere Berufstätigkeiten ausüben konnte. ${ }^{1488}$ In der Altersgruppe der über 50-jährigen Lehrerinnen war zum Zeitpunkt der Erhebung immer noch mindestens ein Viertel der Lehrerinnen, 6 von 24, unverheiratet.

Im Gegensatz zu den Männern setzte sich der Ledigenstatus bei den Lehrerinnen somit auch im fortgeschrittenen Alter in deutlicherem Masse fort. Insgesamt haben Forschungen zur historischen Demografie einen ähnlich hohen Anteil an definitiv ledigen Frauen von bis zu einem Drittel einer Frauengeneration für das späte 18. Jahrhundert in der Schweiz festgehalten. ${ }^{1489} \mathrm{Die}$ ungleich höhere Ledigenquote der Lehrerinnen kann im Vergleich zu den männlichen Kollegen einerseits als Indiz für eine bewusst gewählte Entscheidung gegen eine Heirat und gegen die Gründung einer Familie angesehen werden. Als Grundlage für eine Präferenz des Ledigbleibens kann andererseits das selbst erwirtschaftete Einkommen angeführt werden, das - wenn auch in der Regel unter den äquivalenten Salären der männlichen Kollegen am jeweiligen Ort liegend dennoch in der Regel gut zum Unterhalt eines Einzelhaushalts ausreichte. ${ }^{1490}$ Die ökonomische Notwendigkeit einer Heirat zum Zweck der hauswirtschaftlichen Arbeitsteilung entfiel so, was

1487 Schmidt u.a. (Hgg.), Stapfer-Enquête, Nr. 1683: Nyon.

1488 In wenigen Fällen standen die Tätigkeiten der Ehemänner miterwähnt, so etwa bei der Lehrerin Françoise Schwartzfeger von Nyon VD, die sich "feme du Tonnelier Henry Schwartzfëger" genannt hatte. Sie entstammte damit nachweislich nicht aus einem Lehrerhaushalt. Schmidt u.a. (Hgg.), Stapfer-Enquête, Nr. 1681: Nyon.

1489 Perrenoud, Ehelosigkeit.

1490 Vgl. das Kap. 3.1.2. 
die Rolle des Mannes als „Ernährer“ überflüssig machte. Zudem könnte eine durch das Einkommen bewirkte soziale Emanzipation der Lehrerinnen im Zusammenspiel mit den traditionellen gesellschaftlichen Vorstellungen von nicht in öffentlichen Funktionen arbeitenden Ehefrauen dazu geführt haben, dass sich etliche der Lehrerinnen bewusst für ein freiwilliges Ledigbleiben entschieden, um ohne soziale Stigmatisierung ihrem Beruf nachgehen zu können. ${ }^{1491}$

Des Weiteren hatten natürlich die zuvor genannten individuellen Gründe für ein lebenslängliches Ledigbleiben der Männer auch geschlechterübergreifend für die Lehrerinnen ihre Gültigkeit, etwa nicht erfüllte Liebesbeziehungen oder innerfamiliäre Versorgungspflichten. Aufgrund der kaum vorhandenen Ausführungen in der Stapfer-Enquête kann über die tatsächlichen Ursachen für das Ledigbleiben der meisten Lehrerinnen jedoch nur spekuliert werden beziehungsweise muss auf einzelbiografische Erkenntnisse beschränkt bleiben.

Dass Lehrerinnen dagegen zwangsweise ledig bleiben und den Schuldienst bei einer Heirat quittieren mussten, kann zumindest für das ausgehende 18. Jahrhundert noch entschieden verneint werden. Im Gegenteil, es fanden bei manchen Schulreformern im nahen Ausland - etwa im katholischen Bayern - sogar Bestrebungen statt, gezielt verheiratete Frauen für den Lehrerinnenberuf zu gewinnen. So forderte Herzog Maximilian IV. im Jahr 1799, dass „vorzüglich wohlgesittete, besonders verheiratete Frauen, die mit den nötigen Kenntnissen versehen sind, ermuntert werden, öffentliche Unterrichts- und Erziehungsanstalten, nach einem dem gesellschaftlichen Zwecke entsprechenden Plane zu errichten " ${ }^{1492}$. Die politischen Diskussionen um eine Zölibatspflicht für Lehrerinnen entstanden denn auch erst deutlich später in der zweiten Hälfte des 19. und in der ersten Hälfte des 20. Jahrhunderts. Die aufkommende Forderung nach einem Tätigkeitsverbot für verheiratete Lehrerinnen stand zum einen im Zusammenhang mit der jeweiligen aktuellen konjunkturell bedingten Stellenmarktsituation. Besonders in der Zwischenkriegszeit herrschte ein gesamtschweizerischer Überfluss an Lehrpersonal aufgrund von rückgängigen Schülerzahlen und von Sparbemühungen von Bund und Kantonen. ${ }^{1493}$ Zum anderen drehte sich der Diskurs um die Frage nach der angeblichen „Doppelbelastung“ von verheirateten Frauen. Im bürgerlich-patriarchalen Familienbild konnte eine Frau nicht "gehörig“ einer Schule vorstehen, wenn Sie gleichzeitig noch ihre familiären Pflichten zu erfüllen hatte. Des Weiteren wurde ins Feld geführt, dass verheiratete Lehrerinnen, deren Ehemänner wirtschaftlich gut genug zum Erhalt einer Familie situiert waren, in Zeiten von hoher Arbeitslosigkeit zu Gunsten von stellenlosen ledigen Frauen oder jungen Männern zurücktreten sollten. ${ }^{1494}$ In einzelnen katholischen Gegenden wurde zudem das Argument vorgeführt, dass schwangere Lehrerinnen eine „unschickliche“ Wirkung auf ihre jugendlichen weiblichen Zöglinge haben könnten. ${ }^{1495}$ Gesetzliche Grundlagen für ein Zwangszölibat für Elementarschullehrerinnen wurden im Deutschen Reich und in Teilen Österreichs freilich erst im späten 19. Jahrhundert geschaffen. ${ }^{1496}$

Noch später und bloss fragmentarisch hielt der Versuch einer gesetzlichen Diskriminierung von Frauen im Lehramt in der Schweiz Einzug. Einzig im Kanton Zürich hatten die männlichen Stimmberechtigten im Jahr 1912 über ein Gesetz zu bestimmen, welches ein Zwangszölibat für

1491 Crotti, Lehrerinnen: 87-94. Die Antworten auf die Stapfer-Enquête liefern jedoch keine stichhaltigen Hinweise zur Bestätigung dieser These.

1492 Zit. aus: Nachbaur, Lehrerinnenzölibat: 20.

1493 Lengwiler/Rothenbühler/Ivedi, Schule macht Geschichte: 189f.

1494 Hodel, Massnahmen: 729ff.

1495 Nachbaur, Lehrerinnenzölibat: 26.

1496 Zum Zwangszölibat in Deutschland siehe: Bölling, Sozialgeschichte: 96-102; Badische Gesetz- und Verordnungsblätter: 441; zu Vorarlberg: Nachbaur, Lehrerinnenzölibat: 36. 
Lehrerinnen etablieren wollte. ${ }^{1497}$ Paradoxerweise arbeiteten bis zu diesem Zeitpunkt im Vergleich mit anderen Kantonen aber erst sehr wenige weibliche Lehrkräfte im Kanton Zürich, darunter kaum verheiratete Lehrerinnen. Der Versuch eines gesetzlichen Ausschlusses von verheirateten Frauen aus dem Lehrerberuf und die Zölibatsfrage scheiterten in der Folge nicht nur 1912 an der Urne, sondern auch in weiteren Anläufen in den Jahren 1921 und 1943. ${ }^{1498}$ In allen übrigen Landesteilen der Schweiz entstanden dagegen trotz teilweise ähnlicher politischer Vorstösse auf legislativer Ebene keine Gesetzeserlasse zum Aufbau von ähnlichen zivilstandrechtlichen Schranken für verheiratete Lehrerinnen. Gleichwohl wirkten unterschwellig zeitweise spürbare Vorbehalte gegenüber verheirateten Lehrerinnen fort und verheiratete Lehrerinnen wurden bisweilen bis zur nächsten konjunkturellen Phase des Lehrermangels nach dem Zweiten Weltkrieg aktiv bei der Stellenvergabe diskriminiert oder waren - wie im Kanton Bern - im Bereich der Sozialabgaben von finanziellen Kürzungen betroffen. ${ }^{1499}$

Im direkten Vergleich der Geschlechter eröffnet sich somit ein gesellschaftliches Paradox: Von Männern wurde erwartet, dass sie sich als Lehrer verheirateten, um als gesellschaftliches Vorbild zu dienen. Frauen sollten dagegen als Lehrerinnen ledig bleiben, wenn sie sich in jungen Jahren für das Lehramt entschieden.

\subsubsection{Die Familiengrösse}

Der im vorangegangenen Kapitel festgestellte Befund einer insgesamt hohen Verheiratungsrate bei allen helvetischen Lehrkräften lässt die Frage folgen, wie gross ein durchschnittlicher Schulmeisterhaushalt war und ob sich die Lehramtstätigkeit als stabiler Einkommensfaktor auf die Familiengrösse auswirkte. Bisherige regionale Forschungen zur durchschnittlichen Kinderzahl respektive zu Geburtenzahlen bei den sozialen Unterschichten um 1800 haben die irrige moderne Vorstellung einer Kausalität von Armut und hohen Geburtenraten in Form von weit verbreiteten Grossfamilien mit zehn oder mehr Kindern dekonstruiert. Sie betonen stattdessen eine Dominanz der „mittelgrossen Familien“ von vier bis sieben Kindern, zu differenzieren nach dem sozialen Stand der untersuchten Gruppen, wobei einerseits eine hohe Geburtenzahl aufgrund der hohen Säuglings- und Kindersterblichkeit noch keine grosse Nachkommenschaft automatisch garantierte, andererseits die hohe Sterblichkeit der Ehefrauen sowie das generell hohe Heiratsalter im „european marriage pattern" die potenzielle Kinderzahl eingeschränkt haben. ${ }^{1500}$

Weiter muss den Ehepartnern eine individuell kontrollierte, bewusste innereheliche Geburtenplanung zugestanden werden, beispielsweise in Form einer gewollten Kinderlosigkeit, durch bewusste Enthaltsamkeit, durch gezielte Empfängnisverhütung oder durch eine asketische Lebensweise aufgrund von Glaubensüberzeugungen. ${ }^{1501}$ Es wird folglich davon ausgegangen, dass

1497 Das zürcherische Gesetz von 1912 forderte: „Primar- und Sekundarlehrerinnen, die sich verheiraten, haben vor dem Abschluss der Ehe von ihrem Amte zurückzutreten." Vgl. Hohl, Wählbarkeit: 97.

1498 Bloch Pfister, Priester: 523; Lengwiler/Rothenbühler/Ivedi, Schule macht Geschichte: 189-194.

1499 Beispielsweise warben Stelleninserate für offene Lehrerstellen explizit um „männliche Bewerber“. Lengwiler/Rothenbühler/Ivedi, Schule macht Geschichte: 193f. Im Kanton Bern wurden im Jahr 1936 als Massnahme gegen das „Doppelverdienertum“ verheirateten Lehrerinnen 60\% der Alterszulagen gestrichen. Scandola, Lehrerschaft: 303-309.

1500 Höpflinger, Bevölkerungswandel: 57f., 70. Die Annahme eines generellen Kinderreichtums vorindustrieller Familien ist eine irrige Fehleinschätzung und beruht auf nicht repräsentativen Bildern kinderreicher Oberschichtsfamilien. Durch das verbreitete Fremdstillen bei Ammen und einem niedrigeren Heiratsalter folgte eine raschere Geburtenfolge bei Oberschichtsfamilien als bei der breiten Masse der Bevölkerung. Mitterauer, Mythos: 68.

1501 Vgl. Hareven, Familiengeschichte: 51ff; Höpflinger, Bevölkerungswandel: 58; Mitterauer, ledige Mütter: 33ff.; Mitterauer, Mythos: 68; Mitterauer, Sozialgeschichte der Familie: 42. 
die Lehrkräfte als handelnde Akteure ihre Familienplanung mit dem Blick auf die ihnen zur Verfügung stehenden ökonomischen Ressourcen nach rationalen Gesichtspunkten gestaltet hatten, denn - so kann postuliert werden - es hatte niemand ein Interesse daran, Kinder zu zeugen, die nicht ernährt oder gar zum Armutsrisiko für die eigene Haushaltung werden konnten. Die kindliche Arbeitskraft wurde zwar in der Wirtschaft des ganzen Hauses ebenso benötigt wie diejenige der Ehefrau, dennoch ist die Vorstellung von Kinderreichtum als Strategie zur Armutsverhinderung und zur Altersvorsorge als eine moderne Betrachtungsweise zu apostrophieren.

Es stellt sich somit die Frage, ob die Lehrkräfte in einem kollektiven Verhalten eine bewusste oder unbewusste Familienplanung im Angesicht ihrer verfügbaren ökonomischen Ressourcen betrieben haben. ${ }^{1502}$ Aus Untersuchungen zur reformierten Stadt Genf haben wir von der Tatsache Kenntnis, dass ärmere Handwerkerhaushalte im 18. Jahrhundert eher zu kleineren Familiengrössen tendierten als wohlhabendere Kaufmannsfamilien. ${ }^{1503}$ Ebenso konstatiert Peter Zschunke in seiner Fallstudie zur gemischtkonfessionellen Stadt Oppenheim die Tendenz, dass insbesondere die mittleren Vermögensklassen im Durchschnitt mehr Kinder hatten als die übrigen Familien der Stadt. ${ }^{1504}$ Ähnliche sozialständisch-stratifizierte Ergebnisse hat Thomas Meier beim Vergleich von Haushaltsgrössen unterschiedlicher Handwerksgruppen präsentiert, wobei die Branchen der nahrungsmittelverarbeitenden Handwerke und des Gastgewerbes die höchsten, Bau- und textilgewerbliche Handwerke die niedrigsten Haushaltsgrössen aufwiesen. ${ }^{1505}$

Die durchschnittliche Kinderzahl pro Lehrerhaushalt ist demnach - wenn auch unter der Prämisse eines zunehmenden Autoritätsverlusts der lokalen sozialen Normen - in einem doppelten Erkenntnisinteresse zu deuten: erstens als ein Resultat ökonomischer und struktureller Determinanten und zweitens als ein Ausdruck von individuellem Handeln im Sinne einer bewussten Familienplanung unter sich wandelnden sozialen und ökonomischen Bedingungen. ${ }^{1506}$ Die sich aus der Anzahl vermerkter Kinder ergebende mittlere Haushaltsgrösse unter dem Axiom einer Kernfamilie, bestehend aus Mutter, Vater und Kindern, ist demnach ein Indikator zur Abschätzung der ökonomischen Tragfähigkeit der Lehrerhaushalte, selbst wenn eine absolute Datengenauigkeit durch die im vorangegangenen Kapitel angesprochene Pluralität der Haushaltsformen abseits der Kernfamilie und der in den Haushalten möglicherweise darin inkludierten erweiterten Verwandtschafts- und Gesindebeziehungen nicht erreichbar ist. Gerade bei vielfach vermerkten erwachsenen Kindern, Eltern und Geschwistern ist nicht mehr rekonstruierbar, ob und inwieweit diese noch zum Kernfamilienhaushalt der Lehrkräfte zählten oder nicht. Das zeigt die Aussage des katholischen Lehrers Bernhard Muntwiler von Spreitenbach AG exemplarisch: „hat zwey Kinder einen Sohn und ein Mädchen, da sie aber erwachsen Seind so haben sie keine verbindung mehr mit der Schuhle noch seynd Sie eine hindernus derselbigen. "1507 Zudem kennt man aus den Angaben der Stapfer-Enquête das Alter der Ehepartner nicht, was eine Einschätzung der Fertilität der einzelnen Haushalte verunmöglicht.

Im empirischen kollektiven Vergleich hatten insgesamt 91.1\% aller verheirateten Lehrkräfte in der Helvetischen Republik zum Zeitpunkt der UmFrage Im Frühjahr 1799 mindestens ein eigenes Kind gezeugt, unabhängig vom tatsächlichen Alter der Lehrkräfte. Nur 8.9\% der Lehrer-

1502 Vgl. Höpflinger, Bevölkerungswandel: 59.

1503 Die mittlere Kinderzahl lag in Genf um 1798 bei 2.23 Kindern, wobei 2-Kinder-Haushalte am häufigsten ermittelt wurden. Perrenoud, population: 114-117.

1504 Zschunke, Oppenheim: 195ff.

1505 Meier, Handwerk: $124 \mathrm{f}$.

1506 Vgl. Hareven, Familiengeschichte: 52.

1507 Schmidt u.a. (Hgg.), Stapfer-Enquête, Nr. 2300: Spreitenbach. 
Ehepaare waren dagegen zum Zeitpunkt der Umfrage ohne eigene Kinder geblieben oder deren Kinder waren allesamt der Kindersterblichkeit zum Opfer gefallen. ${ }^{1508}$ Von jenen wenigen kinderlosen Ehepaaren entfielen altersstratifiziert ein knappes Drittel der Angaben auf Lehrkräfte unter dreissig Altersjahren (27.5\%), fast die Hälfte auf die Altersgruppe der 30-49-Jährigen (48.3\%) während bloss jede vierte kinderlos verheiratete Lehrkraft bereits das fünfzigste Altersjahr überschritten hatte (24.2\%). Die deutliche Mehrzahl der kinderlos gebliebenen oder durch die Kindersterblichkeit kinderlos gewordenen Ehen beschränkte sich somit naturgemäss auf jüngere und erst seit kurzem verheiratete Lehrkräfte. Gemessen am Anteil aller verheirateten Lehrkräfte über fünfzig Jahren betrug der Anteil an kinderlos gebliebenen Lehrpersonen nur noch bescheidene 6.3\%. ${ }^{1509}$ Daraus lässt sich zum einen ableiten, dass - ungeachtet der Konfession, der ökonomischen Situation der Haushalte, des schulischen Einkommens, des Schultyps und des Alters der Ehefrau(en) - beinahe allen längerdauernden Ehen von Schullehrern auch Kinder entsprossen. Eigene Kinder zu haben, bedeutete zum einen die generative Absicherung des eigenen Besitzes und die Möglichkeit zur quasi-dynastischen Weitergabe des Lehramts in der Familie.

Zum anderen blieb Kinderlosigkeit im fortgeschrittenen Alter, wie sie stellvertretend der 65-jährige Lehrer Johann Jakob Silbernagel aus Sissach BL äusserte, kollektivbiografisch eine absolute Seltenheit: „Bin zwar seit Anno 1770. verehelichet, aber familien oder Kinder haben wir niemahls keine gehabt “1510. Erklärungsansätze für eine Kinderlosigkeit bis ins hohe Alter neben einer bewussten freiwilligen Entscheidung gegen Kinder liefern die Quellen selbst nur zurückhaltend und in kaum generalisierbarer Menge. Eine atypisch späte Heirat konnte ebenso ein Grund sein, ${ }^{1511}$ wie die anhaltend hohe Kindersterblichkeit, ${ }^{1512}$ ein bereits fortgeschrittenes Alter der Ehefrau oder die mutmassliche Unfruchtbarkeit eines Ehepartners. ${ }^{1513}$ Anhaltende Kinderlosigkeit in der Ehe bedeutete jedoch mitunter auch einen bedeutsamen sozialen Makel für die betroffenen Ehepaare, eine Nichterfüllung der Eheschliessung, ja gar eine Strafe Gottes für etwaige frühere Sünden. Kinder zu zeugen, war demnach nicht nur eine Frage des individuellen Wollens der Ehepaare, sondern auch das Ergebnis eines gesellschaftlichen Drucks, um das volle Ansehen in der Lokalgemeinschaft zu geniessen. ${ }^{1514}$

Für die Lehrkräfte, deren fragile soziale Position stark vom sozialen Kapital abhing, das mutmasslich bedeutend aus ihrem Amt erwuchs, bedeutete dieser Umstand, dass das Zeugen von Kindern genauso wie das Eingehen der Ehe ein impliziter gesellschaftlicher Zwang war, um ihr soziales Kapital in der Lokalgesellschaft aufbauen und erhalten zu können. Durch Kinderlosigkeit drohte somit nicht nur der Verlust der privilegierten innerfamiliären Weitergabe von Spezialisten-Wissen, sondern auch eine eventuelle Stigmatisierung durch den Spott der Mitbürger. Der Nachhall des gesellschaftlichen Drucks zum Erzeugen von Kindern ist ferner in einzelnen Aussagen von Lehrkräften mit Kindern deutlich spürbar, wie die Antwort des erst 29.5-jährigen

1508149 verheiratete oder verwitwete Lehrkräfte ohne Kinder-Angabe von insgesamt 1.680 verheirateten/verwitweten Lehrkräften.

150936 Lehrkräfte ohne Kinder-Angabe von 657 verheirateten oder verwitweten Lehrkräften über 50 Jahren. Vgl. nachfolgende Abbildung 20.

1510 Schmidt u.a. (Hgg.), Stapfer-Enquête, Nr. 1602: Sissach.

1511 „Jean Emanuel Mottier [...] âgé de 52 ans; Jl est marié depuis peu» Schmidt u.a. (Hgg.), Stapfer-Enquête, Nr. 1.784: Vevey.

1512 „hat keine Kinder mehr, sonder nur ein Frau.“ Schmidt u.a. (Hgg.), Stapfer-Enquête, Nr. 340: Seuzach.

1513 „Jch Bin zwar vereyrathet aber unsere Ehe ist nicht mit Kindern gesegnet“. Schmidt u.a. (Hgg.), Stapfer-Enquête, Nr. 1009: Opfertshofen.

1514 Van Dülmen, Kultur und Alltag: 80f. 
Lehrers Christopherus Götti von Wildhaus SG zeigt, die fast wie eine Rechtfertigung klingt: „Er hat Zwey Kinder bis anhero, weil er erst in dem 4ten Jahr verhäurathet ist." ${ }^{1515}$

Doch wie gross waren Lehrerfamilien und wirkten sich konfessionelle, regionale oder schulorganisatorische Determinanten auf die Familiengrösse von Lehrerfamilien aus? Ingrid Brühwiler hat aus ihrer Stichprobe von 229 Lehrern eine durchschnittliche Haushaltsgrösse von 3 bis 4 Personen errechnet, mit signifikanten Unterschieden zwischen katholischen und reformierten Lehrkräften. ${ }^{1516}$ Die grösste überlebende Kernfamilie ohne Mitberücksichtigung von allfälligem Dienstgesinde besass vermutlich der Lehrer Salomon Steffen in Neftenbach ZH, der „ein Frau und 15. lebendige Kinder ${ }^{1517}$ zu seiner Familie zählen konnte. Grossfamilien wie die beiden oben beschriebenen mit sieben oder mehr Kindern waren jedoch in der Gesamtbilanz aller Lehrer-Familien eher eine Ausnahmeerscheinung und machten bloss rund $8.7 \%$ aller Lehrer-Familien aus, veritable Grossfamilien mit zehn und mehr Geburten wiesen nur $0.7 \%$ aller Lehrerfamilien aus. ${ }^{1518}$

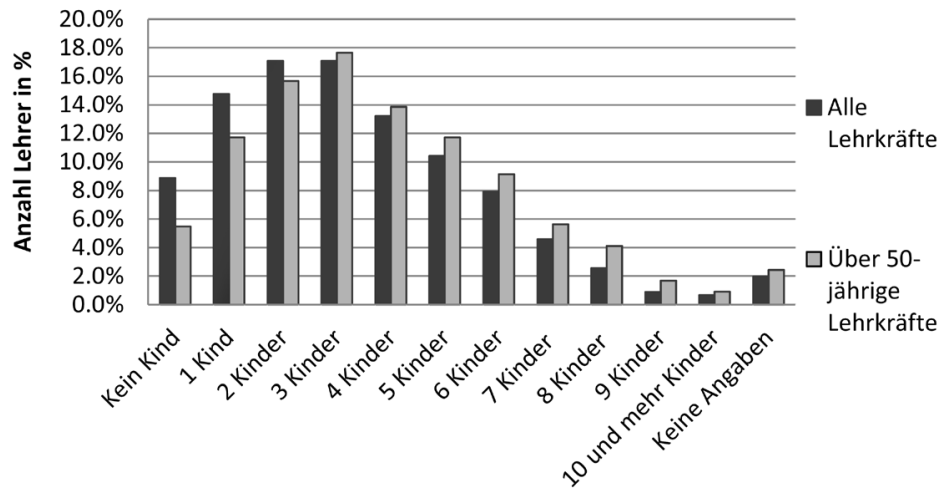

Abb. 20: Anzahl Kinder pro Lehrerhaushalt aller Lehrer

Altersunabhängig dominierten Zwei- und Dreikinderhaushalte im Kollektiv der verheirateten Lehrkräfte. Die durchschnittliche Kinderzahl aller verheirateten Lehrkräfte lag denn auch bei insgesamt 3.6 Kindern pro Familie, ohne dass signifikante konfessionelle Differenzen festgestellt werden konnten. ${ }^{1519}$ Ebenso unbedeutend war die Differenz zwischen Lehrerfamilien an zentralörtlichen und ländlichen Schulen. ${ }^{1520}$ Für den Kinderreichtum einer Lehrerfamilie

1515 Schmidt u.a. (Hgg.), Stapfer-Enquête, Nr. 521: Wildhaus.

1516 Der konfessionelle Unterschied begründet sich in der Mitberücksichtigung von zölibatär lebenden Geistlichen in der Stichprobe. Brühwiler, Finanzierung: 230-233.

1517 Schmidt u.a. (Hgg.), Stapfer-Enquête, Nr. 179: Neftenbach.

1518 Zur Methodik der Berechnung der Kinderzahlen: Sämtliche in der Umfrage vermerkten, gezeugten und zum Zeitpunkt der Umfrage noch lebenden Kinder (ohne Gestorbene, Ungeborene oder Grosskinder, sofern angegeben) sowie Stiefkinder eines Haushalts wurden zur Bestimmung der Grösse der Kernfamilie gezählt. Eine leichte Verzerrung des Datensamples durch bereits erwachsene, ausserhalb der Kernfamilie lebende Kinder oder im Haushalt mitlebenden Eltern und weiteren Verwandten ist mit zu berücksichtigen, dürfte sich aber durch die Nichtzählung ungenauer Angaben (z.B. „hat Kinder“) weitgehend ausgeglichen haben.

1519 Insgesamt 1.524 Lehrkräfte mit Kindern. Der Median lag bei 3.0 Kindern. Katholische Lehrerfamilien wiesen im Mittel 3.50 Kinder aus, reformierte Lehrerfamilien 3.60 Kinder.

1520 Zentralörtliche Lehrerfamilien umfassten mit durchschnittlich 3.46 Kindern nur kaum merklich kleinere Familieneinheiten als ländliche Lehrerfamilien mit 3.61 Kindern. 
war neben dem Alter des Ehepartners beziehungsweise deren Fertilität auch die Dauer der Ehe entscheidend, denn wer erst spät heiratete, zeugte in der Regel auch weniger Kinder als früh verheiratete Paare, deren Ehe entsprechend länger dauerte. Obwohl wir den Erstheiratszeitpunkt der Lehrkräfte zumeist nicht kennen und daher die Ehedauer nicht zu rekonstruieren vermögen, erscheint der Zusammenhang von Kinderzahl und Ehedauer evident, so dass auch die mittleren Kinderzahlen altersstratifiziert betrachtet werden müssen, unter der Annahme, dass ältere Lehrkräfte in der Regel länger verheiratet waren als jüngere. Entsprechend konnten jüngere verheiratete Lehrkräfte nach dem Erhebungszeitpunkt noch auf weiteren Nachwuchs zählen, während dies bei älteren Lehrkräften jenseits des fünfzigsten Lebensjahrs nur noch eher selten der Fall war, sofern die Heirat nicht sehr spät oder mit einer deutlich jüngeren Partnerin stattgefunden hatte.

Die durchschnittliche Kinderzahl der älteren, über fünfzigjährigen Lehrkräften kann daher analog zur endgültigen Ledigenquote als definitive Familiengrösse angeschaut werden. Vergleicht man die mittleren Kinderzahlen pro Altersdezennium, bestätigt sich die Entwicklung einer zunehmenden mittleren Kinderzahl mit steigendem Alter: Hatten die unter 30-jährigen Lehrkräfte im Durchschnitt erst 1.8 Kinder gezeugt, stieg der Wert bei den 30-39-jährigen Lehrkräften auf 2.9 Kinder und kulminierte bei den 40-49-jährigen Lehrern bei durchschnittlich 4.1 Kinder pro Lehrerfamilie. Erst ab dem sechzigsten Lebensjahr sank die mittlere Kinderzahl aufgrund von vermehrt vermerkten Todesfällen wieder auf 3.7 Kinder, wobei zudem die meisten der genannten Kinder zu diesem Zeitpunkt bereits erwachsen waren und ökonomisch wahrscheinlich mehrheitlich autonom beziehungsweise ausserhalb des Elternhauses lebten. Aufgrund der im vorherigen Kapitel dokumentierten Heiratsentwicklung mit dem mittleren Erstheiratsalter von 26 bis 32 Jahren ist die Altersgruppe der über fünfzigjährigen Lehrkräfte, wo Erstheiraten nur noch ausnahmsweise vorkamen und die meisten bestehenden Ehen schätzungsweise bereits rund zwei Jahrzehnte oder länger angedauert hatten, von besonderem Interesse. Anhand dieser älteren Lehrkräfte kann ferner zuverlässig abgeschätzt werden, welches Potenzial eine frischverheiratete, junge Lehrperson zum gleichen Zeitpunkt bezüglich ihrer zukünftigen Familienplanung hatte. Im Folgenden konzentriert sich die Untersuchung daher auf die mindestens einmalig verheirateten oder bereits verwitweten über fünfzigjährigen Lehrkräfte mit vermerkten Kindern.

Knapp 12\% der über Fünfzigjährigen hatten zum Zeitpunkt der Umfrage erst oder nur ein Kind gezeugt. Kleinfamilien waren damit eher eine Randerscheinung. Wie in der Gesamtschau hatten aber auch die älteren Lehrkräfte in relativer Mehrheit vorzugsweise entweder zwei oder drei Kinder gezeugt. Mindestens fünf oder mehr gezeugte Kinder kamen allerdings mit rund einem Drittel Anteil bei den über fünfzigjährigen Lehrkräften etwas öfter vor als noch in der Gesamtschau, worin sich die nun in den meisten Fällen abgeschlossene Familienplanung ohne den nach unten verzerrenden Effekt der jüngeren Lehrer mit unvollständiger Familienplanung widerspiegelt.

Die favorisierte Kinderzahl einer „typischen“ Lehrerfamilie am Ende ihrer Familienplanungsphase nach dem fünfzigsten Altersjahr lag demnach in einer relativ breiten Bandbreite zwischen zwei und vier Kindern. Nur selten wuchs die Kinderzahl jedoch auf mehr als sieben Kinder an. Die durchschnittliche Familiengrösse eines Haushalts eines mindestens 50-jährigen Lehrers belief sich daher unter der stillschweigenden Zuzählung der Ehefrau auf mindestens vier bis sechs Personen. Diese mittlere Familiengrösse von vier bis sechs Personen korrespondiert einerseits mit den Ergebnissen historisch-statistischer Analysen aus West- und Mitteleuropa, deren Mittelwerte zwischen 4 und 5.5 Personen pro Haushalt lagen, ${ }^{1521}$ andererseits mit lokalen 
Studien aus der Schweiz zur Grösse von Landhandwerksfamilien, deren mittlere Personenzahl ebenfalls zwischen vier und sechs Personen lag. ${ }^{1522}$ Signifikante konfessionelle Unterschiede bei der mittleren Kinderzahl konnten im Gegensatz zu Brühwilers zuvor zitierten Untersuchung durch den Ausschluss der zölibatär lebenden Geistlichen auch bei der älteren Lehrerschaft von über 50 Altersjahren nicht mehr festgestellt werden, bei beiden Konfessionsgruppen oszillierte die mittlere Kinderzahl bei rund 4 Kindern. ${ }^{1523}$

Dienstgesinde als mögliche Erweiterung der Lehrerhaushalte war nach den Angaben in der Stapfer-Enquête im Allgemeinen nur sehr selten anzutreffen. Bloss in insgesamt einem Dutzend der 2.305 Lehrerhaushalte war explizit eine zusätzliche Dienstkraft als Magd oder in einem Fall als Dienstknabe aufgeführt worden, worunter sechs der zwölf Lehrkräfte mit Dienstgesinde Geistliche waren. ${ }^{1524}$ In mindestens zwei Fällen waren die aufgeführten Mägde aber als Schwestern gleichzeitig Familienangehörige, was eine systematische methodische Trennung von Familienmitgliedern und Dienstgesinde erschwert. Insgesamt zeigt der Befund aber, dass - abgesehen von Geistlichen mit ihrem deutlich höheren Einkommen - selbst die vermögendsten Lehrkräfte nicht zu einer Erweiterung ihrer Haushalte durch Dienstgesinde tendierten. Das zeigt ferner, dass der ökonomische Spielraum der Lehrkräfte nach oben hin doch deutlich begrenzt war und nicht beliebig zur Entlastung der eigenen Arbeitskraft ausgenutzt werden konnte. Ferner verdeutlicht der Befund, dass - im Gegensatz zu den wohlhabenden „ehaften“ Professionistengruppen mit gewerblichem Monopolanspruch, etwa Müller, Schmiede oder Wirte - in den Reihen der Lehrerschaft keine dauerhafte Substitution von eigenen Kindern durch Dienstgesinde erfolgte. ${ }^{1525}$ Für die Weitergabe des Professionswissens reichte zum einen ein aus der Familie stammender männlicher Nachfolger in der Regel aus, zum anderen scheint die Volatilität des Lehramtes durch die kommunale Vergabepraxis ein erheblich grösseres Risiko dargestellt zu haben, als dass es der erbliche Besitz von professionsspezifischem Eigentum wie eine Mühle, eine Schenke oder eine Schmiede gewesen war. Zudem sorgte die weit verbreitete Integration des eigenen männlichen Nachwuchses, der Ehefrau des Lehrers oder guten Schülern als Adjunkten für den Umstand, dass keine weiteren externen Arbeitskräfte im Anstellungsverhältnis in der Familienwirtschaft benötigt wurden.

Regional variierte die mittlere Kinderzahl der über fünfzigjährigen Lehrer zwar zwischen minimal 2.7 Kindern im Kanton Fribourg und maximal 5.2 Kindern im Kanton Linth, allerdings ohne dass ein klar erkennbares regionales Muster entlang der Wirtschafts- oder Agrarzonen auszumachen gewesen wäre. Doch dass gerade im Kanton Linth, deren Lehrerschaft in der bisherigen regionalen Forschung als besonders ärmlich beschrieben wurde, die höchsten Kinderzahlen

1522 Für die Zürcher Unterländer Handwerker errechnete Meier einen Durchschnitt von 5.1 Personen pro Handwerkerhaushalt. Meier, Handwerk: $124 \mathrm{f}$.

1523 Total 657 Lehrkräfte, davon 579 reformierte (durchschnittliche Kinderzahl: 4.01 Kinder), 78 katholischer Religion (durchschnittlich 4.06 Kinder).

1524 Eine gewisse kleine Dunkelziffer an weiteren Lehrkräften mit angestelltem Dienstgesinde in ihren Haushalten kann vermutet werden, insbesondere in den Haushalten von Geistlichen. Unter den weltlichen Elementarschullehrern hatte der Lehrer von Mönchaltorf ZH einen Knaben als Dienstboten, die Lehrer von Autigny FR, Bürglen UR, Flums SG, Lungern OW und Oberegg SG je eine Magd notiert. Zudem wiesen zwei reformierte Geistliche in Nidau BE und St. Gallen SG sowie die vier katholischen Kapläne in Isenthal UR, Mannens FR, Niederwil ZG und Steinebrunn TG jeweils Mägde als Teil ihres Haushaltes aus.

1525 Vgl. Meier, Handwerk: 129f. Als „Ehaften“ wurden für das Gemeinwesen unentbehrliche, konzessionspflichtige Gewerbebetriebe samt Gebäuden bezeichnet, die von obrigkeitlichen Sonderrechten und Monopolschutz profitierten. Dazu gehörten Mühlen, Tavernen, Schmieden, Backhäuser, Bäder, Metzgereien, Gerbereien und Färbereien. Vgl. Dubler, Ehaften. 
pro Lehrkraft festgestellt werden konnte, lässt aufhorchen. ${ }^{1526}$ Offenbar galt das Regulativ einer freiwilligen restriktiven Familienplanung bei beschränkten ökonomischen Ressourcen nur bedingt, denn die Linther Lehrerschaft stand ökonomisch weitaus besser da als bislang von der Forschung beschrieben. ${ }^{1527}$ Ein regionaler Vergleich mit der mittleren Kinderzahl der ökonomisch deutlich besser situierten reformierten Pfarrer aus dem genannten Kanton ist durch die Pfarrer-Enquête von 1799 möglich: Die zwölf über fünfzigjährigen reformierten Pfarrer des Kantons Linth wiesen beispielhaft im Frühjahr 1799 eine mittlere Kinderzahl von 4.7 Kindern auf. ${ }^{1528}$ Die Bandbreite der Kinderzahl reichte dabei von einem bis zu zwölf Kindern. Der nur leicht tiefere Wert an Kindern pro Pfarrerhaushalt kann zwar einerseits der tieferen Mortalität der Kinder aufgrund besserer medizinischer und hygienischer Versorgung geschuldet sein. Andererseits ähnelten sich die Resultate trotz des markanten Einkommensunterschieds, so dass auch der Linther Lehrerschaft eine relativ grosse ökonomische Tragfähigkeit ähnlich den Pfarrern zugesprochen werden kann.

Den Stadt-Land-Unterschied bezüglich Kinderzahl und Familiengrösse hat die jüngere historische Demografieforschung als evident beschrieben, wobei die Städte gegenüber dem Land mit ungleich tieferen Haushaltsgrössen zwischen drei und vier Personen hervortraten. ${ }^{1529}$ Bei den Kinderzahlen der zentralörtlichen über fünfzigjährigen Lehrkräften konnte jedoch nur ein sehr schwacher Trend festgestellt werden. Ihre mittlere Kinderzahl lag mit 3.7 Kindern nur leicht unter dem Gesamtmittel von 4.0 Kindern. ${ }^{1530}$ Zwei Ursachen konnten für diese Entwicklung eruiert werden: Zum einen blieb knapp jede zehnte zentralörtliche Lehrkraft von mehr als fünfzig Altersjahren trotz dem Eingehen einer Ehe komplett kinderlos. Zum anderen traten ZweiKinder-Haushalte in leicht deutlicherem Masse zutage. Trotz des ungleich höheren jährlichen Schuleinkommens und der damit verbundenen ökonomischen Privilegierung präferierten zentralörtliche Lehrerhaushalte damit eine leicht kleinere Familiengrösse von mehrheitlich zwei bis drei Kindern, wobei der absolute Schwerpunkt bei Zwei-Kinder-Haushalten lag. Grossfamilien von mehr als sechs Kindern waren im städtischen Milieu der Lehrkräfte bisweilen eine grosse Ausnahme und sogar noch seltener als bei Landschullehrern.

Die überwiegend im zentralörtlichen Milieu agierenden Lehrerinnen bestätigten diesen Sachverhalt, denn die mittlere Anzahl an Kindern aller Lehrerinnen belief sich auf bloss 2.3 Kinder, diejenige der über fünfzigjährigen verheirateten Lehrerinnen nur unwesentlich höher auf bloss durchschnittlich 2.4 Kinder. Die maximale in der Umfrage festgehaltene Kinderzahl einer Lehrerin lag mit sechs Kindern denn auch markant unter den Kinderzahlen der männlichen Berufskollegen. ${ }^{1531}$ Neben der bereits konstatierten schwachen Tendenz zum Ledigbleiben neigten die Lehrerinnen, wenn sie den Bund der Ehe eingingen, des Weiteren nicht zur Gründung von grösseren Familieneinheiten, sondern bevorzugten eher die kleinere, aus heutiger Optik moderne bürgerliche Kleinfamilie mit maximal vier Personen pro Haushalt als Ideal.

Elementarschulmeister tendierten somit insgesamt weder zur Gründung von Grossfamilien mit dem Risiko von familiärer Armengenössigkeit noch zu gänzlich kinderlosen Ehen und eher sel-

1526 Vgl. Landolt, Linth: $154 \mathrm{f}$.

1527 Siehe die Erkenntnisse im Kap. 3.1.2.

1528 BAR B0 1000/1483, Nr. 1374, fol. 1-188: [1799] - Pfarrenquete Linth. Vgl. Rothen, Erkenntnisgewinn: 44.

1529 Vgl. Mitterauer, Mythos: 51, 64f.; Perrenoud, population: 103-106, 140.

1530 Total 91 Lehrkräfte. Ohne Kinder: 9 (10\%); ein Kind: 8 (9\%); zwei Kinder: 20 (22\%); drei Kinder: 15 (16\%); vier Kinder: 13 (14\%); fünf Kinder: 10 (11\%); sechs Kinder: 7 (8\%); sieben und mehr Kinder: $6(7 \%)$; Keine Angabe: $3(3 \%)$.

1531 Total 17 Lehrerinnen. Einzig die Witwe Colladon aus Rolle VD hatte sechs Kinder geboren. Schmidt u.a. (Hgg.), Stapfer-Enquête, Nr. 1951: Rolle. 
ten zu Kleinfamilien mit bloss einem Nachkommen. Letzteres war aufgrund der nach wie vor hohen Kindersterblichkeit ein zu grosses Risiko, am Ende ohne Nachfolger dazustehen. Vielmehr bevorzugten sie bewusst oder unbewusst oft Familienstrategien, die den Erbfortgang und den Eigenbedarf an familiären Arbeitskräften sicherten, aber gleichzeitig die ökonomischen Grenzen ihrer Familienwirtschaft weitgehend respektierten. Die durchschnittliche Kinderzahl von rund vier Kindern bei den über 50-jährigen Lehrkräften spricht jedoch für eine Familienplanung, die im Vergleich zu sozialen Unterschichten von einem überdurchschnittlichen ökonomischen und sozialen Wohlstand zeugt. Zumindest ist keine generell tiefe Kinderzahl feststellbar, was auf eine ökonomisch prekäre Situation hingewiesen hätte. Einen eindeutig korrelierenden Einfluss der Einkommenshöhe auf die Familiengrösse konnte aufgrund der Heterogenität der Einkommensverhältnisse nicht festgehalten werden. Lehrkräfte mit tiefem Einkommen neigten ebenso wenig zu einer geringeren Kinderzahl wie Lehrer mit dem Mindestlohn von 1.000 Batzen nicht zu grösseren Familien tendierten. Eine Kernfamilie von fünf bis sechs Personen inklusive der Ehefrau entsprach somit der ökonomischen Tragfähigkeit eines durchschnittlichen helvetischen Landschullehrerhaushalts, wobei jedoch Zusatzerträge aus Nebenbeschäftigungen ebenso einflossen wie die Arbeitskraft der Ehefrau und der Kinder im Zuge der Familienwirtschaft.

Im städtischen Umfeld blieb die mittlere Kernfamiliengrösse der Elementarschullehrer trotz des deutlich höheren Besoldungsertrags paradoxerweise leicht geringer, was den Einfluss von sozialen Parametern, etwa die geringere Kindersterblichkeit oder die bessere hygienisch-medizinische Situation, hervorhebt. Ferner dürften neue gesellschaftliche Ideal-Normen - die bürgerliche Kleinfamilie - vermehrt als Orientierungsrahmen für die Familienplanung von städtischen Lehrkräften gedient haben.

In beiden Fällen, sowohl bei den Landschullehrern als auch bei den städtischen Schulmeistern, war Kinderreichtum aus Armut jedoch kein Thema. Kinder zu zeugen war zum einen ein Akt der gesellschaftlichen Pflichterfüllung, um das soziale Kapital aufrecht zu erhalten und um nicht sozial stigmatisiert zu werden. Zum anderen stellt die überdurchschnittlich hohe Kinderzahl aber ein weiteres Indiz für eine gesicherte ökonomische Basis dar, die den Elementarschullehrer von den ökonomischen Unterschichten abhebt und ihn in die Mittelschicht einordnen lässt.

\subsection{Rücktritt und Pension}

Angesichts der im Kap. 3.4 festgehaltenen langen durchschnittlichen Ausübungsdauer des Lehramts stellt sich die Frage nach dem Zeitpunkt der Beendigung der berufsbiografischen Phase als Lehrkraft beziehungsweise nach dem Zeitpunkt des Ausscheidens aus der Lehramtsausübung. Die historische Demografie verneint jedoch die Existenz einer Lebensphase ohne Berufsausübung im Alter für die Menschen der Frühen Neuzeit. Höpflinger hält diesbezüglich fest: „Die wirtschaftliche Lage älterer Menschen wurde bis ins 20. Jahrhundert primär durch ihre Arbeitskraft und ihre Besitzverhältnisse bestimmt. Bis ins 20. Jahrhundert hinein war Arbeit ,bis ins Grab für die grosse Mehrheit der Bevölkerung ein unabdingbares Muss."1532 Ausschlaggebend für das Weiterverfolgen der Erwerbstätigkeit bis zum Tod waren primär die individuellen Einkommensverhältnisse, denn ohne das regelmässige Einkommen aus einer Erwerbsarbeit drohte unweigerlich der Fall in die Armut und Hunger, da noch keine gesellschaftlichen Mechanismen zur Versorgung von älteren, nicht mehr erwerbsfähigen Menschen existierten. Zudem vermochten die wenigsten Menschen während ihrer Erwerbszeit bedeuten- 
de Ersparnisse zu akkumulieren, um sich einen vorzeitigen Ruhestand durch angespartes Vermögen leisten zu können. Bis zum Ende des 18. Jahrhunderts oblag die Versorgung von alten Menschen daher vorrangig ihren Nachkommen und Verwandten, Pensionen als finanzielle Absicherung gab es noch kaum. ${ }^{1533}$

Nach den Erkenntnissen der bisherigen Forschungen verblieben die meisten helvetischen Lehrkräfte tatsächlich bis zu ihrem Tod oder „bis [ihre] körperlichen und geistigen Kräfte versagten " 1534 in ihrem Schulamt aktiv tätig. Die Stapfer-Enquête dokumentiert denn auch eine Reihe von Fällen, in denen der amtierende Schulmeister zum Zeitpunkt der Umfrage frisch verstorben war und entweder noch kein neuer oder bloss ein provisorischer Nachfolger die Umfrage ausgefüllt hatte. ${ }^{1535}$ Auch in anderen regionalen Umfragen wurden immer wieder einzelne „ledige“ Schulstellen wegen des unerwarteten Ablebens des bisherigen Stelleninhabers angezeigt, sofern kein Lehrersohn oder anderweitiger Nachfolger kurzfristig als Ersatz bereit stand. ${ }^{1536}$ Klinke hielt daraus die Erkenntnis fest: „Meist behielten die Schulmeister ihre Stelle bis zum Ableben bei; Rücktritte des Alters wegen kamen nur ausnahmsweise vor. ${ }^{\text {“1537 }}$

Ganz so abrupt und ohne biografische Veränderungen sah die Realität freilich nicht aus. Alterte ein Schulmeister zusehends und war er nicht mehr in der Lage, seine Amtsgeschäfte vollends auszuführen, übernahm ein oder mehrere Gehilfen eine allmählich substituierende Funktion, wie exemplarisch zuvor beim Lehrer von Lauwil BL dargestellt worden ist. ${ }^{1538}$ Das System der Schulgehilfen - unabhängig ob innerfamiliär oder von ausserhalb rekrutiert - ermöglichte vielen älteren Lehrkräften nicht nur eine Erleichterung im Schulalltag, sondern auch einen schrittweisen Rückzug aus ihren Schulgeschäften. In wenigen Ausnahmefällen und Notsituationen wurden sogar bereits abgetretene, aber noch lebende Lehrer wieder reaktiviert. Da der eigentliche Lehrer von Hinterwil AG wegen des Verdachts auf Münzfälschung von der Berner Obrigkeit inhaftiert wurde, musste sein bereits in den Ruhestand gesetzter Vater die Schule „biß aus gangs dießes Handels “1539 weiterführen.

Angesichts der steigenden allgemeinen Lebenserwartung und der zunehmenden Reformbemühungen im elementaren Schulwesen erhielt auch der Diskurs um den Umgang mit alten Lehrern verstärkte Aufmerksamkeit. Zum einen versprachen sich Schulreformer von einem Generationenwechsel und einer Verjüngung des Lehrerkorps eine raschere Durchsetzung ihrer neuen Ausbildungsmodelle und Methoden, da sie jüngere Lehrkräfte als reformoffener einschätzten als ihre älteren Kollegen. Insbesondere Letzteres fand unter reformerisch gesinnten Zeitgenossen verbreitet Zuspruch, denn ältere und alte Lehrer jenseits des sechzigsten Lebensjahres hatten nicht nur mit zunehmenden körperlichen Gebrechen und Alterskrankheiten zu kämpfen, sondern man vermutete bei ihnen zugleich die stärkste Opposition gegen schulische Reformen und einen verbreiteten Unwillen, ihre Lehrmethoden und Unterrichtsgegenstände zu modernisieren. Beispielhaft beschrieb der Pfarrer der Gemeinde Steig SH seinen Schulmeister: „Der

1533 Van Dülmen, Kultur und Alltag: 206f.

1534 Walz, Eselsarbeit: 76.

1535 Als Beispiel dient der Antwortbogen der Schule von Ellighausen TG, wo als Randbemerkung hinzugefügt wurde, „Der Schulmeister ist diese Woche gestorben, u. kein neüer erwählt worden.“ Schmidt u.a. (Hgg.), StapferEnquête, Nr. 790: Ellighausen. Die Stapfer-Enquête ist als Quellensammlung, die sich an die aktiven Lehrkräfte wandte, insgesamt nur beschränkt geeignet, um Informationen über die Pensionsfrage zu erhalten.

1536 Beispielhaft sei der Tod des Johann Jacob Schaffner in Anwil BL, vermerkt in der Basler Landschulumfrage von 1803 genannt: StABL AA 1012, Lade 200, 07.03.01, o. Pag.: 22.09.1803 - Oltingen.

1537 Klinke, Zürich: 117.

1538 Vgl. Kap. 4.1.1.

1539 Schmidt u.a. (Hgg.), Stapfer-Enquête, Nr. 2100: Hinterwil. 
jzige Schulmeister heißt: Rudolf Rauschenbach, vormals ein Gerber; ein guter, fleißiger Mann, aus dem man in jüngern Jahren einen sehr brauchbaren Kinderlehrer hätte bilden können, der aber nunmehr, weil er $70 \mathrm{Jahr}$ alt ist, weder Kraft noch Lust hat, eine neue bessere Schulmethode auszuführen. [...] Ein tüchtiger Mann, ein besseres Schulhauß und die bestimmte Verordnung daß die Gemeindsgenossen ihre Kinder in diese und in keine andere Schule dürften gehen lassen, würden die Ordnung wieder herstellen, und dieser Schule ihren vorigen Fler geben. "1540

Zum anderen zielten die wesentlichen Bemühungen zur sukzessiven Hebung der allgemeinen Volksbildung auf die Ausbildungsqualität des Lehrpersonals und somit prioritär auf junge Lehrkräfte oder Lehramtsaspiranten. Doch damit sich die Reformen rasch in der Gesellschaft niederschlagen und der angestrebte Wandel auch Früchte tragen konnte, brauchten die neu ausgebildeten Junglehrkräfte im Anschluss freie Schulstellen, um ihre neu erlernten Methoden und Lehrinhalte überhaupt unterrichten zu können. Entweder die Entlassung „schlechter“ Lehrer oder eine vorzeitige Ruhestellung von alten Schullehrern durch das Auszahlen eines Ruhegehalts, einer Pension, waren die sich anbietenden Alternativen, um einen Generationenwechsel zu forcieren. Der Kardinalpunkt für eine erfolgreiche Generationenverjüngung stellte dabei die Frage nach der Finanzierung von Pensionen dar. Denn ohne eine finanzielle Entschädigung in Form einer regelmässigen Pension oder zumindest einer einmaligen Abfindungszahlung war kaum ein Schulmeister bereit, vorzeitig von seinem Amt zurückzutreten.

Wie der angedachte Mindestlohn für Lehrkräfte entwickelte sich auch die Frage nach einer Pension für altgediente Elementarschullehrer zu einer kontroversen Diskussion, die zeitgleich von unten in der Lehrerschaft und von oben bei den politischen Entscheidungsträgern der neuen Republik geführt wurde. Im Zusammenhang mit der geplanten Aufwertung der gesamten Lehrerschaft zu staatlichen Beamten gedachte Philipp Albert Stapfer einen Pensionsanspruch für alte Lehrkräfte in seinen Schulgesetzesentwürfen durch den politischen Gesetzgebungsprozess auf landesweiter Ebene einzuführen. Im siebten Artikel des zweiten Kapitels des ersten Schulgesetzesentwurfs vom 24. Juli 1798 schrieb Stapfer: „Denjenigen, welche das Alter von 65 Jahren werden erreicht und ihre Pflichten als Lehrer getreu erfüllt haben, soll eine Pension ertheilt werden, welche ihr Alter vor Mangel sichern wird. Sie kann nicht den bisherigen Gehalt ihrer Lehrerbesoldung übersteigen, aber sie darf nicht weniger als die Hälfte desselben betragen. Das Vollziehungs-Directorium wird sie auf den Vortrag der Verwaltungskammer hin bestimmen. "1541 Mit dem bewussten Offenlassen einer konkreten Anspruchshöhe zugunsten der flexiblen Formulierung eines Minimaleinkommens versuchte Stapfer, der Heterogenität der Schulmeisterlöhne auf einer pragmatischen Ebene zu begegnen. Allerdings liess der Gesetzesvorschlag offen, wer die Pensionen bezahlen sollte. Im späteren Entwurf des Schulgesetzes, das der Grosse Rat der Helvetischen Republik am 20. März 1799 zuhanden des Senats verabschiedet hatte, und im Entwurf aus dem helvetischen Senat vom 20. November 1799, waren die Passagen zur Pension der Lehrer aber wieder gestrichen worden. ${ }^{1542}$

Die Pensionsfrage ereilte damit ein ähnliches Schicksal wie die Mindestlohndebatte. ${ }^{1543}$ Denn obwohl die kantonalen Erziehungsräte gerne alte Schulmeister in die Pension schicken wollten, fehlte dazu meist schlicht das Geld in den Staats- beziehungsweise Kantonskassen. In die

1540 Schmidt u.a. (Hgg.), Stapfer-Enquête, Nr. 1041: Steig.

1541 Übersetzt bei Luginbühl, Stapfer: 528, 539. BAR B0 1000/1483, Nr. 1422, fol. 240: 24.07.1798 - Projet; Das Original ist auf Französisch geschrieben und liegt in zwei fast identischen Fassungen archiviert vor. Vgl. Bütikofer, Projekt: 39.

1542 BAR B0 1000/1483, Nr. 1422, fol. 235: 20.03.1799 - Senat; Luginbühl, Stapfer: 546.

1543 Vgl. zur Mindestlohndebatte das Kap. 3.1.1. 
Bresche springen sollten wiederum die Gemeinden, deren finanzielle Situation aber nach der Abschaffung der Feudallasten in der Regel nicht besser war. Nur einzelne wohlhabende Gemeinden und Städte konnten es sich leisten, ihre älteren Lehrkräfte durch eine Pension vorzeitig abtreten zu lassen. Das Städtchen Vevey VD ermöglichte beispielsweise den Lehrern seiner höheren Schule eine Pension, die fast die Höhe der Besoldung der aktiven Lehrkräfte erreichte: „Lorsque les Jnstituteurs du Collège de Vevey n'ont pu remplir leurs fonctions, soit à cause de leur âge avancé, soit à cause de maladies; le Conseil Municipal leur a toujours accordé, soit un Suffragant Successif, avec lequel ils partageoient leur pension, soit une pension de retraite: Jl en est actuellement un, qui étant émérité à cause de son grand âge, reçoit deux cents francs par Année "1544 Die Gemeindefinanzen entschieden somit letztendlich, ob sich ein altgedienter Lehrer zur Ruhe setzen konnte oder nicht und wie hoch die reale Rente ausfiel. Eugène Dévaud hat die gegenseitig paralysierende Situation zwischen den kantonalen Erziehungsräten und den Gemeinden mit den Worten formuliert: „Le Conseil [d'Éducation] aurait souhaité pouvoir accorder des pensions de retraite aux instituteurs trop âgés pour pouvoir enseigner avec fruit. La fâcheuse situation financière de la République helvétique ne lui permit pas de réaliser ce désir." ${ }^{1545}$

Die Gemeinden anerkannten zwar teilweise die vom Erziehungsrat angeordneten Begehren um Pensionszahlungen, etwa in der Fribourger Gemeinde Praz FR, wo ein siebzigjähriger Lehrer für eine Pension von 64 Franken zurücktreten konnte. Andernorts wurden ähnliche Begehren von den Gemeinden jedoch abgelehnt. ${ }^{1546}$ Fehlte den Gemeinden das Geld oder der politische Wille für Pensionszahlungen, wurde in manchen Fällen dem Nachfolger einen Teil seines Gehalts abgezogen, um den alten Schulmeister dennoch abtreten zu lassen. „Tel est létat du bénéfice de l'Jnstitutr. Reformé de Bottens. Jl est à observer que le Regt. Menétrey agé de 67 Ans, ayant 50 Ans de Service de Régence et affligé de quelques infirmitez avoit obtenu du Cidevant Gouvernement de Berne la permission de se Choisir un Sufragant il se Seroit arrangé avec Jean Jaques Tzaud Régt. à Peney pr. fonctioner à Sa place en lui donnant une partie de son bénéfice. "1547 Das Modell der Finanzierung von Lehrerrenten über das Gehalt des Nachfolgers wurde ab 1794 in Preussen institutionalisiert, wobei der pensionierte Lehrer einen Drittel seines vorherigen Gehalts zugesprochen erhielt. ${ }^{1548}$ Unschwer wird verständlich, dass solche Lösungen von Pensionsansprüchen zulasten der neuen Lehrkräfte bisweilen auf erbitterten Widerstand der betroffenen aktiven Lehrer stiess, wie die Äusserung des Zürcher Stadtschullehrers Philipp Jakob Wolf exemplarisch zeigt: „Fünf u: zwanzig Mütt Kernen Fünfzehn Eimer Wein. Neünzig u: fünf Gulden Geld aus dem Obmann Amt u: Stifftsverwalterey. Sechs Klaffter Buchenholz aus dem Sihlamt: welches aber diesmal die Municipalitaet nicht will abfolgen laßen, weil selbiges einen Theil des Stadtguts ausmacht. - und 4. Klaffter Tannenholz aus dem Frau Münster Amt. Dieses ganze fixe Einkommen ist dem, wegen ansteigendem Alter u: abnehmenden Kräfften vor zwey Jahren entlaßenen Lehrer: Hs. Rudolf Hagenbuch von Zürich; der 63. Jahre alt ist; zwey Töchter hat u. 30. Jahre lang in den Schulen fleißig gearbeitet hat, nebst freyer Wohnung auf der Schule Lebenslänglich geordnet worden. [...] Da hiemit dem jezigen Schullehrer, vom Fixen Einkommen Nichts zukömmt, sondern die sehr zufälligen, dermalen sich immer verminder-

1544 Die Lehrer des Collèges von Vevey VD verdienten 1799 zwischen 220 und rund 320 Franken pro Jahr, zuzüglich einer Vielzahl von Naturalien und freiem Wohnrecht. Schmidt u.a. (Hgg.), Stapfer-Enquête, Nr. 1784: Vevey.

1545 Dévaud, École primaire: 99.

1546 Merz, Landschulen: 74; Dévaud, École primaire: 100.

1547 Schmidt u.a. (Hgg.), Stapfer-Enquête, Nr. 1724: Bottens.

1548 Grunder, Hungerleider: 163. 
den Accidenzien, als Namenstag u. Gutjahr \&c. deren Betrag auf ca. 25. Louisdor steigen mag, sein ganzes Einehmen ausmachen; u: von der Vertröstung, Einst das Fixe zubekommen Nichts zuleben hat - so wird er - obschon der Unterricht der Knaben sein angenehmstes u. liebtes Geschäfft: er auch der Achtung sr: Vorsteher, der Liebe sr: Schüler u. des Zutrauens des Publikums versichert ist - wenn keine Unterstützung von Seite der hohen Regierung, oder sonst woher, ihm aufhilft, doch aus Noth gezwungen werden, seine Stelle zuquittiren." 1549

Dass sich - wie im obigen Beispiel mit 25 Louis d'Or oder 400 Franken - gerade gut bis sehr gut verdienende Lehrkräfte über entgangene Einkommen zugunsten von pensionierten Vorgängern enervierten, fügt sich in die Beobachtung Brühwilers ein, dass sich vordergründig vermögendere Lehrkräfte über ihre Einkommensverhältnisse beschwerten. ${ }^{1550}$ Doch auch geringer verdienende Lehrkräfte mussten bisweilen einen Teil ihres Einkommens abtreten, wie das Beispiel von Knonau ZH zeigt, wo der Schulmeister auf $60 \mathrm{fl}$. eigenes Einkommen weitere rund $20 \mathrm{fl}$. an Pensionsgeldern für den noch lebenden vorherigen Schullehrer für sich beanspruchte. ${ }^{1551}$

Der Versuch, die Pensionskosten für abtretende Lehrer auf das Gehalt der Nachfolger zu überwälzen, war aber insofern ein Risiko für die Gemeinden, als dass die Gemeinden unter Umständen keinen geeigneten Nachfolger fanden, der bereit war, diese schlechteren finanziellen Konditionen zu akzeptieren. In Lugnorre FR scheiterte deswegen die Amtsübergabe, denn „personne ne se présenta à l'examen " und der alte Lehrer musste in der Folge die Schule weiterführen. ${ }^{1552}$ Die politischen Diskussionen auf der helvetischen Ebene um eine gesamtstaatliche Lösung der Pensionsfrage und der Aufwertung der Elementarschullehrer zu Staatsbeamten schufen unter den Lehrkräften eine juristisch ungeklärte Situation, da der Entwurf des Schulgesetzes vielerorts als provisorisches Reglement in Kraft gesetzt wurde. ${ }^{1553}$ Doch daraus wurden neue konfliktträchtige Ansprüche gegenüber den kantonalen Behörden abgeleitet, die letztendlich Eingang in den Verwaltungsakten und damit in die Überlieferungssituation fanden.

Der Diskurs um Pensionen lässt sich aber auch unten an der Basis bei den Lehrkräften rückverfolgen, wo sich die Lehrer zur Frage des Amtsaustritts in vielfacher Weise äusserten. Nicht wenige alte Lehrer wünschten sich eine vorzeitige Beendigung ihrer Lehrtätigkeit und merkten dies als freiwillige Anmerkungen in der Stapfer-Enquête an. Allein das wiederholte Auftreten von Äusserungen zur Rücktrittsthematik zeigt, dass die Frage des altersbedingten Rücktritts zumindest unter den älteren Lehrkräften von Bedeutung war. So lautete die Antwort des 76-jährigen Lehrers von Unterberikon AG auf die gesamte Stapfer-Enquête kurz - und mit einer Prise bewusstem Sarkasmus angereichert: „Jhr Thuont gantz Recht an mich begähren Daß ich mich vor Eüch Soll erklären Ob ich der schuoll dienst noch wölle Treiben Oder der selbige wölle laßen bleiben weill ich sechs und sibenzig Jahr im Alter schon zweü und fünffzig Jahr schuoll gehalten So Möcht ich Jetzt ein Rüöhigs Läben vnd Thuon die schuoll mit Danckh auff gäben."1554 Neben der geschilderten Amtsmüdigkeit waren körperliche Altersgebrechen ein ebenso häufig genannter Grund für einen freiwilligen Rücktritt. Am Willen manch älterer Lehrer zur Übergabe des Amtes an einen jüngeren Kandidaten mangelte es jedenfalls nicht, wie die Schlussbemerkung zum Schulmeister von Bruggen SG verdeutlicht: „Beklagt sich wegen schlechter Besoldung sollte neüe Einrichtungen gemachet werden die er wegen seinen Alter aus Zuführen

1549 Schmidt u.a. (Hgg.), Stapfer-Enquête, Nr. 253: Zürich.

1550 Vgl. Brühwiler, Finanzierung: 317.

1551 Schmidt u.a. (Hgg.), Stapfer-Enquête, Nr. 1318: Knonau.

1552 Dévaud, École primaire: 100.

1553 Tosato-Rigo, Bild: 58; Luginbühl, Stapfer: 111.

1554 Schmidt u.a. (Hgg.), Stapfer-Enquête, Nr. 2269: Unter Berikon. 
nicht mehr tauglich wäre bittet er seiner $\mathrm{Zu}$ gedencken ihm den Meßmer Dienst in etwas $\mathrm{Zu}$ verbeßern damit er durch diesen sich ernehren können, er wolle seine Stellen alsdan gerne einem jüngeren und tauglichen Subjt. Überlaßen."1555

Allerdings wurde der Anspruch auf eine Pension - wenn an die neuen helvetischen Behörden appelliert wurde - zunehmend in meritokratischer Denkweise nicht zuletzt vom Engagement, den Fähigkeiten und der Diensttreue des Lehrers abhängig gemacht, wie Protokolle des Aargauer Erziehungsrats exemplarisch überliefert haben. Nicht jede Lehrperson sollte einen automatischen Anspruch auf eine Pension haben, sondern nur langjährigen, verdienstvollen Lehrkräften sollte eine Rente gewährt werden, während fachlich kritisierte oder bloss kurzfristig angestellte Lehrer ohne Entschädigung ausgehen sollten. ${ }^{1556}$ Meritokratische Argumente und die Diensttreue wurden aber auch vonseiten der Lehrerschaft vorgebracht, um den Anspruch auf eine Pension zu untermauern: „Sollte nicht ein Schullehrer, der bald 40. Jahre einer Landschule vorgestanden, und über 60. Jahre alt ist, welchem das Loos bis dahin bessere Plätze und Stellen versagt, nicht ein Lebenslängliches Gnadengehalt verdient haben, oder noch zu einem bessern und ruhigern Posten können gebraucht werden, der seiner sonstigen Dienste zum besten des Vaterlandes nach all seinem Vermögen und Talenten willig anbietet?"1557

Sich vor dem eigenen Tod von der Berufstätigkeit zurückziehen zu können, blieb für die meisten älteren Lehrkräfte um 1800 noch ein ferner Wunschtraum, erst an wenigen Orten war die Utopie bereits zur Realität geworden. Eine flächendeckende und zufriedenstellende Lösung der Rentenfrage für ausgediente Schulmeister scheiterte während der Helvetik zum einen an den ungeklärten Kompetenzzuteilungen zwischen den Gemeinden und den kantonalen Behörden, zum anderen am anhaltenden Geldmangel und Handlungswillen auf sämtlichen Ebenen des helvetischen Zentralstaats. Dennoch zeigt die Tiefe der Diskussionen um 1800 über alle Handlungsebenen hinweg eine ungeahnte Fortschrittlichkeit, insbesondere im Spiegel der noch folgenden rund 150 Jahre bis zur Etablierung eines gesamtstaatlichen Rentensystems in der Schweiz nach dem Zweiten Weltkrieg. Der argumentativ vielfältige Diskurs in der Lehrerschaft zur Frage von Pensionen beweist ferner, dass sich die Arbeits- und Lebenswelt der Menschen um 1800 durch die zunehmende Lebenserwartung und die gleichzeitig gestiegenen gesellschaftlichen Anforderungen an die Berufstätigkeiten grundlegend zu wandeln begannen und neue Lösungen notwendiger denn je wurden.

1555 Schmidt u.a. (Hgg.), Stapfer-Enquête, Nr. 736: Bruggen.

1556 Landolt, Executoren: 22.

1557 Schmidt u.a. (Hgg.), Stapfer-Enquête, Nr. 2226: Buckten. 



\section{Schlussfolgerungen}

Genauso wenig, wie es im ausgehenden 18. Jahrhundert „die eine“ Elementarschule gab, existierte „der“ Elementarschullehrer. Vielfalt und die „Gleichzeitigkeit des Ungleichzeitigen“ 1558 prägten das schweizerische Elementarschulwesen ebenso wie seine Lehrerschaft. Personen beiderlei Geschlechts, aus den unterschiedlichsten Tätigkeitsfeldern, aus allen Altersstufen, mit den verschiedensten Lebensverläufen und mit unterschiedlichem sozialem und wirtschaftlichem Status arbeiteten um 1800 als Elementarschullehrer. ${ }^{1559}$ Hinter jeder einzelnen Lehrperson stand ein individueller Lebensweg, der von einer Vielzahl von subjektiven „inneren“ Erfahrungen, Handlungen und Entscheidungen geprägt war, gleichwohl aber auch „von aussen“ wirkenden Einflüssen von lokalen, regionalen und konfessionell bedingten sozio-ökonomischen Strukturen unterlag und diese wiederum mit ihren Reaktionen reproduzierte. Dennoch vermag die kollektivbiografische Betrachtung der Lebensverläufe anhand der Angaben aus der Stapfer-Enquête von 1799 kollektive Gemeinsamkeiten dieses auf den ersten Blick völlig heterogen wirkenden historischen Personenkollektivs zu identifizieren.

Das Bild von der Schweizer Elementarschullehrerschaft am Ende des 18. Jahrhunderts ist durch zahlreiche negativ konnotierte Pauschalisierungen geprägt, die bis in die heutige Forschungslandschaft der Geschichts- und Erziehungswissenschaften fortwirken. Selbst in modernen Handbüchern der Erziehungswissenschaften wird der vormoderne Lehrer bisweilen immer noch als armer „Hungerleider“ dargestellt, „von jedermann verachtet, gedemütigt und verspottet“. 1560 Dieses historiografisch gewachsene Zerrbild des armen, charakterlich und fachlich defizitären Elementarschullehrers des ausgehenden 18. Jahrhunderts ${ }^{1561}$, das den Ausgangspunkt der vorliegenden kollektivbiografischen Untersuchung auf der Basis der Lehrerantworten aus der Stapfer-Enquête bildete, ist hinsichtlich des Kollektivs der Schweizer Elementarschullehrer von 1799 in verschiedenster Hinsicht grundlegend zu revidieren, besonders aber mit Blick auf die untersuchten Fragestellungen der sozialen Herkunft, der Lebensverläufe und des sozialen Status der helvetischen Lehrkräfte.

\subsection{Die soziale Herkunft}

Leitende Stereotype zur sozio-ökonomischen Herkunft der vormodernen Lehrerschaft besagen, dass sich aufgrund der kargen Besoldungsverhältnisse bloss die ärmsten Angehörigen der sozialen Unterschichten für das Lehramt interessiert und kaum valable Kandidaten zur Verfügung gestanden hätten. Einzelne Quellenaussagen in der Stapfer-Enquête bestätigen mitunter dieses Armuts- und Unterschichtenparadigma. ${ }^{1562}$

1558 Neugebauer, Niedere Schulen: 247.

1559 Vgl. Berner, Zeichen: 103.

1560 Enzelberger, Sozialgeschichte des Lehrerberufs: 25; Terhart, Lehrer: 286.

1561 Vgl. zum historiografischen Bild der vormodernen Lehrerschaft die Ausführungen im Kap. 1.3.3.

1562 „aber wie ist ein Lehrer bey uns in den augen vieler Elteren und kinder bey denselben angesehen, gewiß nicht viel mehr als ein Hirth der Schweinen, aber wie kommt es die Lehrer auf dem Land sind Meistens arme Leüthe, denn ein Bemidtleter und angesehener gehet nicht in die Schul, denn die meisten Einkünffte sind sehr gering, das ein Lehrer nicht Einmahl genugsamen unterhalt für seyn Weib und kinder hat. [...] Ganz eine andere bewandtniß hat es also mit den Pfareren auf dem Land, dieselben haben denn hingegen meistens sehr große Einkünffte, und diese können ihre Tage Fröhlich zubringen." Schmidt u.a. (Hgg.), Stapfer-Enquête, Nr. 1406: Utzenstorf. 
In der empirischen Überprüfung erweisen sich diese Einschätzungen des Lehramts als unbeliebte Tätigkeit für sozial Schwache aber als bewusste rhetorische Übertreibungen. Die Schweizer Elementarschullehrer rekrutierten sich zwar auf den ersten Blick aus einer Vielzahl von Einzeltätigkeiten, davon wiesen in der kollektiven Betrachtung aber wenige Gruppen eine verstärkte Präferenz zur Lehramtsübernahme auf. Diese Tätigkeitsgruppen unterscheiden sich teilweise stark von den Forschungserkenntnissen aus den deutschen Territorien. Während Invalide, ehemalige Soldaten und gescheiterte Theologen entgegen dem hartnäckigen Klischee der deutschen Bildungsforschung kaum im Schweizer Elementarschullehramt auftauchten, wurden überwiegend Menschen aus kleinbäuerlichen Verhältnissen und Angehörige des Bekleidungshandwerks zum Lehrer ernannt. Kleinbauern, Schuster, Schneider und Weber dominierten - mit wenigen regionalen Ausnahmen überall in der gesamten Helvetischen Republik - unter den Berufsgruppen, die das Lehramt ohne vorangehenden familiären Bezug übernommen hatten. ${ }^{1563}$

Obwohl die Mehrheit der zuvor in der Landwirtschaft tätigen Personen keiner eindeutigen soziohierarchischen Schichtung zugeordnet werden können, weisen eine Reihe von Indizien darauf hin, dass es sich hierbei - zusammen mit den erwähnten Handwerkern - grösstenteils um Angehörige der lokalen Mittelschichten handelte, die ganz bewusst das Lehramt als Ressource besetzten oder aber bewusst von den dörflichen Eliten implementiert wurden. ${ }^{1564}$ Zum einen wurde kaum ein Angehöriger der untersten sozialen Schichten der landlosen agrarischen Hilfsdienste zum Lehrer gewählt. Hirten, Sennen, Fischer, Holzfäller, Dienstboten und Dienstknechte sind nur in wenigen Handvoll Fällen verbrieft. Ebenso wenig traten landlose Taglöhner oder Fabrikarbeiter in besonderer Häufigkeit in Erscheinung. Eine Vergabe des Lehramts aus karitativen Zwecken der Armenversorgung durch die Gemeinden lässt sich damit ausschliessen. Die Besitzgrössen der landwirtschaftlich tätigen Personen waren zwar in der Eigenbeschreibung fast durchwegs als klein taxiert worden, umfassten aber in der Regel eine subsistenzsichernde landwirtschaftliche Betriebsgrösse von bis zu drei Jucharten Land. Andere Lehrkräfte erhielten zusätzlich zum monetären Schuleinkommen Gärten, Schulwohnungen oder Landnutzungsrechte als Naturallohnbestandteile, was ihnen eine erweiterte Subsistenz erlaubte. Nicht wenige der Textilhandwerker und Weber besassen überdies eigene Landgüter im Eigenbesitz oder zur Pacht, wie ein lokales Beispiel aus Diegten BL zeigt. ${ }^{1565}$ Auch im Zürcher Unterland rekrutierten sich die Lehrkräfte stark aus der lokalen Mittelschicht, wie regionale Forschungsarbeiten aufzeigen. ${ }^{1566}$

Nicht nur die Vertreter der gesellschaftlichen Unterschichten fehlten jedoch weitgehend im helvetischen Lehrerkollektiv, sondern auch gegenüber den klassischen dörflichen Oberschichten zeichnete sich eine Distinktion ab. Müller, Wirte, Bäcker, Metzger, Schmiede oder Öler übernahmen kaum je die Lehramtstätigkeit an einer Landschule. Genauso waren Angehörige des städtischen Bürgertums einzig als Geistliche im elementaren Schulwesen tätig, nicht aber exklusiv als Elementarschullehrer. ${ }^{1567}$

Des Weiteren ist die postulierte Einkommensarmut der Elementarschullehrer stark zu relativieren. Zwar variierten um 1800 die Einkommen aufgrund von strukturellen und lokalen Faktoren von Schule zu Schule und von Lehrkraft zu Lehrkraft sehr stark. Doch trotz der grossen Disparitäten und einer nicht zu negierenden Willkür waren längst nicht mehr alle Elementar-

1563 Vgl. das Kap. 2.2.

1564 Auch Bölling nimmt eine Einstufung der Lehrer in die Mittelschichten vor: Bölling, Sozialgeschichte: 77.

1565 Stöcklin, Diegten: 33.

1566 Bloch Pfister, Priester: 109f.; Meier, Handwerk: 238.

1567 Vgl. das Kap. 2.2. 
schullehrer arme Schlucker. In allen Regionen der Helvetischen Republik, speziell aber in der frankophonen Waadt und in den Zentralorten, verdienten zahlreiche Lehrkräfte genug, um sich und eine kleine Familie mit dem Schulverdienst zu versorgen. Die jährliche Schuldauer erweist sich in Bezug auf die Einkommen als wichtigster Strukturfaktor. Zumindest dort, wo die Schule durchgehend das ganze Jahr über oder zumindest mit Sommerschulunterricht erweitert gehalten wurde, erreichten die Saläre in der Regel den inoffiziellen Mindestlohn von rund 100 Franken pro Jahr, womit eine Familie versorgt werden konnte. Geschätzt rund jede vierte helvetische Lehrkraft erreichte diesen Lebensstandard um 1800 alleinig aus der Schultätigkeit. Ein weiteres Drittel der helvetischen Lehrerschaft verdiente ferner zwar allein aus der Schultätigkeit noch zu wenig, in Kombination mit anderen Tätigkeiten im Jahresgang - Kirchenhilfsdienste oder landwirtschaftliche Ergänzungstätigkeiten - aber genug, um sich die Existenz langfristig zu sichern. Damit scheiden sie aus der klassischen Unterschichtszuschreibung, die auf der nicht gegebenen Möglichkeit zur langfristigen Existenzsicherung basiert, aus. Zudem stiegen trotz der politischen Krisenjahre paradoxerweise nicht die tiefsten, sondern die Löhne der oberen Einkommensgruppen unter der Lehrerschaft stetig an, wie einzelne regionale Untersuchungen zeigen. Es wäre wünschenswert, wenn diesem Umstand in zukünftigen Forschungen noch weitere Beachtung geschenkt würde, ob sich die Tendenz im 19. Jahrhundert fortsetzte oder bloss ein Ausdruck der noch fehlenden institutionalisierten Entscheidungen auf der Ebene der kantonalen Erziehungsverantwortlichen war.

Gerade die vermögenderen Lehrkräfte zeichneten sich ferner als lauteste Klagende in Sachen Einkommensungerechtigkeit aus, wobei sie sich in der Regel an den deutlich höheren Löhnen der ständisch differenten Pfarrer orientierten. Dieser unerfüllte Blick an die Spitze der kommunalen Verdiensthierarchie war es, der die Lehrerschaft in ihrer zeitgenössischen Selbstperspektive wie auch aus der Sicht der vorgesetzten Pfarrer arm erscheinen liess. Hierin liegt denn auch der markante Unterschied in der Betrachtung der Einkommensverhältnisse aus der heutigen Forschungssicht, bei der die Einkommen primär untereinander und mit ähnlichen beruflichen Herkunftsgruppen verglichen worden sind.

Die Besoldungssituation vor Ort blieb aber mehrheitlich durch die lokale Zusammensetzung der Finanzquellen und durch die jährlich erwünschte Schuldauer von den Hausvätern bestimmt. Individuelle Initiativen vonseiten der Lehrkräfte zur Steigerung ihrer Einkommensverhältnisse blieben vom guten Willen und den finanziellen Möglichkeiten der Gemeinden abhängig. Individuelle Merkmale wie die geografische Herkunft, die Leistung oder die Berufstreue hatten dagegen noch kaum Einfluss auf die Einkommensausgestaltung. Höchstens das Alter der Lehrkräfte konnte in Einzelfällen einkommensrelevant sein, denn jüngere Lehrer verdienten teilweise weniger als Ältere. Die lokalen Verhältnisse determinierten jedoch insgesamt den Finanzierungsspielraum im Schweizer Elementarschulwesen bis weit ins 19. Jahrhundert hinein weiter. Ferner lässt sich die These der älteren Forschungstradition nicht erhärten, dass Armut oder konjunkturelle Krisen zu bedeutenden Motiven für die Lehramtsübernahme wurden. Es ist trotz der umfassenden Quellenbestände schwierig, entsprechende eindeutige Aussagen aus der Hand von Lehrkräften zu finden. Zudem erscheint in der Perspektive der Lehrer deutlich häufiger das widersprüchliche Klagemuster, dass sich die Lehrer aufgrund des gering besoldeten Lehramts als arm bezeichneten und nicht, dass das Lehramt als ein Armutsverhinderungsfaktor funktioniert hätte oder dass sie schon vor der Lehramtsübernahme bereits arm gewesen seien.

Makroskalige ökonomische Schwankungen und Strukturwandlungsprozesse mit ihren daraus resultierenden Veränderungen in den einzelnen Biografien sind zeitlich retardierte, meist versteckte Prozesse, die den Betroffenen selbst oftmals verborgen bleiben und erst in breiteren 
quantitativen Vergleichen zum Vorschein treten. Zudem sind wirtschaftliche Strukturwandlungsprozesse oft regional unterschiedlich ausgeprägt, indem verschiedene Professionsgruppen in zeitlich-räumlicher Gleichzeitigkeit sehr ungleich betroffen sind. Ebenso schwierig bis unmöglich ist es, kurzfristige Effekte von Armut und Arbeitslosigkeit aufgrund der politischen Krisenjahre um 1800 von langfristigen konjunkturellen Schwankungen zu unterscheiden, deren Wurzeln zeitlich weiter zurück im Ancien Régime lagen und sich erst zum Zeitpunkt der Umfrage akzentuierten. Wohl kann hinter einzelnen Berufsbiografien - etwa bei den ehemaligen „Lapidaires“ der Waadt oder bei den Webern und Bekleidungshandwerkern des Mittellandes, wo grosse kleinräumige Konkurrenz herrschte - ein strukturelles Movens angenommen werden, von einer kollektivbiografischen Relevanz zu sprechen wäre aber verfehlt.

Im Weiteren ist das zuvor erwähnte Bild des Lehrers als „Hungerleider“ im direkten Wortsinn zu verneinen, denn die Lehrerschaft litt gerade aufgrund ihrer starken Verwurzelung in der Landwirtschaft - wie die Analysen von Erst- und Nebentätigkeiten belegen - und durch die zahlreichen Naturaleinkommensbestandteile wohl seltener Hunger als die übrigen frühneuzeitlichen Personenkollektive. Sprachen Lehrer in ihren Antworten - wie im einleitenden Zitat - direkt von Hunger und Armut, waren die Äusserungen primär im übertragenen Sinn gemeint. Ungeachtet des Wahrheitsgehalts der Informationen dürfen die Quellen aus der Hand der Lehrkräfte nicht wortwörtlich gelesen, sondern müssen als subjektive, interessegeleitete Äusserungen kritisch paraphrasiert werden, zumal den Lehrerantworten zwar eine gewissen Naivität anhaftet, gleichwohl aber den Lehrkräften der Adressat bekannt war und daher eindeutige sozio-ökonomische und politische Absichten hinter der Art der Beantwortungen steckten.

Jürgen Diderich hat passend zur Verortung der Lehrerschaft im Sozialgefüge anhand der Einkommen für die vormoderne deutsche Lehrerschaft gefolgert, dass das „arme Dorfschulmeisterlein“ zwar ärmer als selbständige Bauern, aber nicht ärmer als deren Taglöhner war und Handwerker genauso abhängig von der Konjunktur der Landwirtschaft waren wie Lehrer. Die vielfach als kränkend empfundene Naturalentlöhnung oder das Reihum-Verpflegen an den Tischen der wohlhabenden Bauern verlieh den Lehrern zudem in Krisenzeiten eine erhöhte Sicherheit. ${ }^{1568}$ Direkte Taglohnvergleiche bezeugen denn auch, dass die Schuleinkommen zwar oft unter dem Verdienst von Handwerksprofessionisten lagen, aber deutlich über den Einkünften von Heimindustriellen oder Taglöhnern anzusiedeln sind. ${ }^{1569}$

Die hohe Zahl an Direkteinsteigern ins Lehramt und das relativ niedrige Amtsübernahmealter weisen zudem eindeutig auf eine bewusste Laufbahnwahl der meisten Kandidaten hin. Exklusiv auf das Lehramt als einzige spezialisierte Erwerbstätigkeit setzte altersunabhängig bereits rund jede fünfte Lehrkraft des späten Ancien Régime. Darunter befanden sich zum einen Lehrersöhne und -töchter, die das Schulamt in der unsystematischen Anlehrepraxis als familiäres Erbe übernahmen. Die innerfamiliäre Berufsweitergabe reichte jedoch durch den stetigen Ausbau des elementaren Schulwesens am Ende des 18. Jahrhundert nicht mehr aus, um sämtlichen freien Schulstellen zu besetzen. So fanden zum anderen zunehmend gute Schüler, aber - entgegen der Klischees der älteren historischen Bildungsforschung - nur selten Waisen oder körperlich Beeinträchtigte auf direktem biografischem Weg ins Lehramt. Die familiär-dynastische Sicherung des Lehramts innerhalb der Lehrerfamilien über Generationen hinweg war zwar ein verbreitetes Phänomen, keineswegs aber ein dominierendes. ${ }^{1570}$ Denn nicht zu vernachlässigen ist die vielfach geäusserte intrinsische ,innere Disposition“, die als Motiv für die Lehramtsübernah-

1568 Diderich, Lehrer: 239.

1569 Vgl. Berner, Zeichen: 93; Brühwiler, Finanzierung: $315 f$.

1570 Vgl. das Kap. 2.2.1. 
me von Exponenten aus allen möglichen Tätigkeitsfeldern geäussert wurde. Zahlreiche Personen wollten bewusst Lehrer werden, selbst wenn die Eltern andere Tätigkeiten ausgeübt hatten. Die Möglichkeit dazu bot sich im Besonderen an Schulen mit ganzjähriger Unterrichtsdauer, woraus ein entsprechend hohes Einkommen resultierte.

An geeigneten Kandidaten für die Elementarschule mangelte es in der Regel nirgends. Wie verschiedene regionale Untersuchungen anhand von seriellen Quellen ergeben haben, standen in den meisten Orten genügend Kandidaten zur Besetzung einer freigewordenen Schulstelle bereit, was den Topos des angeblich gering geschätzten Lehramts demontiert. Vielmehr macht das breite Vorhandensein von Kandidaten aus dem Lehramt eine mitunter bewusst angestrebte Berufsoption und umkämpfte, attraktive ökonomische Ressource fernab eines „Notbehelfs“. Nur noch selten wurde eine Lehrkraft in stiller Wahl oder aus Mangel an einer Alternativperson „gezwungenermassen“ gewählt. Leistungsexamen etablierten sich um 1800 zunehmend breitflächig und auch ausserhalb von Regionen, wo obrigkeitliche Schulordnungen eine Leistungsprüfung normativ institutionalisiert hatten. Zum Lehrer gewählt wurde in der Regel um 1800 nicht mehr der „billigste“ oder einzig verfügbare, sondern ungeachtet der finanziellen Entschädigungshöhe überall der fachlich „beste“ Kandidat, wie Examensberichte belegen. Doch selbst die unterlegenen Kandidaten entstammten nicht aus den sozialen Unterschichten, zumal zumindest an einzelnen Orten erfolgreiche Lehramtskandidaten sogar für die Amtseinsetzung bezahlen mussten. ${ }^{1571}$

An den meisten Orten wurden zwar bei der Lehrerwahl nach wie vor lokale Kandidaten gegenüber auswärtigen Personen bevorzugt. Rund 73\% aller Lehrer waren zum Zeitpunkt der Umfrage Ortsansässige - Bürger oder Hintersassen, was aber angesichts der wachsenden Leistungskultur zum einen ein Ausdruck von einschränkenden normativen Grundsätzen - etwa im Zürcher Untertanengebiet - war, zum anderen den noch fehlenden Kommunikationsmedien und -netzwerken für die Distribution von freien Stellen geschuldet war. Ferner versteckte sich hinter der Herkunft oftmals eine Rückkehrmobilität, die Lehrer waren also bewusst an die heimische Schulstelle zurückgekehrt. Zudem hielt ein rein kommunales Wahlrecht - vorwiegend in den ehemaligen Gemeinen Herrschaften und Landorten vorkommend - auswärtige Personen ab, die Schule zu übernehmen, sofern keine persönlich-klientelistischen Beziehungen bestanden. Wo dagegen die normativen Regeln - wie in der Berner Landschaft und in der Waadt lockerer und leistungsorientierter waren, traten Ortsfremde deutlich häufiger als Lehrer auf, vor allem wenn keine finanziellen Benachteiligungen drohten. ${ }^{1572}$

Studierte Theologen waren als aktive Lehrkräfte im Schweizer Elementarschulwesen des ausgehenden 18. Jahrhunderts nur noch in katholischen Gebieten weit verbreitet. In den reformierten Landesteilen - mit Ausnahme der Basler Deputatenschulen - wurden sie bereits zur gänzlichen Ausnahmeerscheinung. Zwar standen die Geistlichen beider Konfessionen noch in einer engen biografischen Verbindung mit dem Bildungswesen, allerdings beschränkten sich ihre Aktivitäten in der Regel auf episodische Phasen des Privat- und Hausunterrichts in städtischen Bürgerhäusern, vornehmlich während der Studienjahre.

Katholische Weltgeistliche mussten auf ihrem Karrierepfad zur Priesterpfründe - vor allem in der Zentralschweiz - oft mit den Kaplaneipflichten auch das lokale Elementarschulwesen übernehmen, das die Gemeinden aus Kostengründen zusammengelegt hatten. Für katholische Geistliche im Rang eines Kaplans nahm das Elementarschulamt die oftmals unfreiwillige Funktion eines zeitlich unlimitierten Moratoriums auf dem Weg zu einer Priesterstelle ein. Reformierte Exspektanten verzichteten dagegen auf einen Wechsel in die Elementarschule und 
übernahmen Lehraufträge ausschliesslich an städtischen vermengten und höheren Schulen. ${ }^{1573}$ Die Betätigung der gut ausgebildeten gebildeten katholischen Kapläne und Priester sowie die insulare Verbreitung der Normalschulmethode sorgten zumindest in einzelnen Regionen der katholischen Schweiz bis zum Ende des 18. Jahrhunderts für einen „katholischen Bildungsvorsprung " in Bezug auf eine Erweiterung der Unterrichtsfächer und der Anwendung moderner Unterrichtsmethoden, wie es Heinrich Richard Schmidt jüngst bezeichnet hat. ${ }^{1574}$

Hierin, in der Präsenz der katholischen Kapläne und in der veränderten Ausbildungssituation, liegen denn auch die markantesten konfessionell bedingten Einflüsse in Bezug auf die Lebensverhältnisse der Elementarschullehrer. Die neue Lehrmethode sorgte nicht nur für einen Konkurrenzeffekt unter den katholischen Lehrkräften und zwischen weltlichen und geistlichen Lehrern, sondern wirkte sich auch stimulierend auf die reformierten Schulen der umliegenden Kantone aus, denen allmählich ihr „Rückstand“ bewusst wurde. Es erstaunt kaum, dass gerade die Zeit der Helvetischen Republik zu einem Versuchslabor für Lehrerbildungsinstitutionen wurde. Das flächendeckende, engmaschige Elementarschulwesen der Alten Eidgenossenschaft gilt daher trotz seiner lokalen Heterogenität als eine der zentralen konfessionsübergreifenden gesellschaftlichen Errungenschaften des Ancien Régimes.

\subsection{Die Lebensverläufe}

In Bezug auf die vormoderne Lehrerschaft ist verschiedentlich postuliert worden, dass das Lehramt eine klassische „Not- und Hilfstätigkeit“ im Kontext der „Ökonomie des Notbehelfs“ gewesen sei. ${ }^{1575}$ Folgt man dieser Argumentation in der Lebensverlaufsperspektive, hätte das Lehramt nicht nur vorwiegend von armutsbedrohten Personen ausgeübt werden müssen, sondern auch hinsichtlich der berufsbiografischen Ausgestaltung bloss eine temporäre, mitunter lebenszyklisch begrenzte Nebenrolle bei Polyprofessionisten eingenommen. Diese Folgerungen erweisen sich jedoch in der kollektivbiografischen Betrachtung der Lebensverläufe als falsch, denn das Lehramt erwies sich als ein höchst attraktives Tätigkeitsfeld, wie zahlreiche Indizien aus der Untersuchung der Lebensverläufe belegen.

Bereits das kollektiv frühe Amtsübernahmealter in der Lebensphase der erweiterten Adoleszenz widerspricht dem Postulat einer Not- und Hilfstätigkeit. Die relative Mehrzahl aller helvetischen Lehrkräfte stieg vor dem 30. Lebensjahr in das Lehramt ein, wie anhand des errechneten Amtsübernahmealters von durchschnittlich 29 Jahren dargestellt wurde. Nicht etwa „Ältere und Verheiratete"1576 übernahmen in allen Regionen mehrheitlich das Lehramt, sondern Jüngere und Ledige; ältere Quereinsteiger bildeten die deutliche Ausnahme. Selbst unter den zum Zeitpunkt der Umfrage älteren Lehrkräften von über 50 Altersjahren war die Mehrzahl schon als junge Erwachsene in die Lehrtätigkeit eingestiegen. Fast alle Tätigkeitsgruppen waren dieser Tendenz des frühen Einstiegs in der Lebensphase des jungen Erwachsenenalters gefolgt. Das spricht, wie die zuvor erwähnte innere Disposition, für eine bewusste berufsbiografische Entscheidung im Sinne einer Spezialisierung, hinter der die Lehrkräfte offensichtlich eine längerfristige Option sahen und dem Amt einen hohen Grad an Attraktivität zusprachen.

Ebenso widerlegt die hohe mittlere Dienstdauer aller Lehrkräfte von rund 14 Jahren das Motiv einer kurzfristigen, aus wirtschaftlich-opportunistischen Gründen gewählten Tätigkeitssaus-

1573 Vgl. das Kap. 2.2.10.

1574 Schmidt, Bildungsvorsprung: 91-105; Schmidt, Elementarschulen: 44ff.

1575 Vgl. das Zitat von Trinks im Kap. 2.2.8.

1576 Vgl. das Zitat von Klinke im Kap. 2.2. 
übung. Eine bloss lebenszyklisch beschränkte Ausübung des Lehramts als ökonomische Moratoriumstätigkeit kann zudem durch die lange Dienstausübungsdauer der über 50-jährigen Lehrkräfte von durchschnittlich 25 Jahren für die überwiegende Mehrzahl der weltlichen Lehrkräfte entschieden verneint werden. Wer einmal Lehrer wurde, gab diese Spezialisierung in der Regel nicht mehr preis und blieb sein Leben lang Lehrer. Daraufhin verweist die stetig zunehmende Diensttreue der älteren Lehrkräfte im Kollektiv.

Eine grundsätzlich lebenszyklisch beschränkte Tätigkeit blieb das Lehramt einzig für katholische Kapläne und für die regionale Ausnahme der geistlichen Deputatenlehrer in der reformierten Basler Landschaft, wenngleich auch bei diesen beiden Gruppen eine grundsätzlich langjährige Berufstreue empirisch feststellbar ist. ${ }^{1577}$ Es bleibt angesichts der Quellenlage jedoch eine offene Frage, ob gewisse andere Professionsgruppen unter den sich verändernden strukturellen Bedingungen das Lehramt nach 1800 wieder verliessen.

Des Weiteren entsprach das Postulat des Schuldienstes als untergeordnete Nebentätigkeit in einer polyprofessionell orientierten Berufsbiografie nur einer Minderheit der untersuchten Lebensverläufe. Das kontinuierliche Nebeneinander von Ersttätigkeiten und dem Lehramt als Erweiterungstätigkeit traf lediglich auf rund zwei von fünf Lehrkräften zu. Einzig für Geistliche und für viele landwirtschaftlich Tätige nahm das Lehramt, sofern die jährliche Schuldauer auf die Winterschule oder wenige Tage Sommerunterricht beschränkt blieb, eine kollektive polyprofessionelle Ergänzungsfunktion in den Berufsprofilen ein. Das grundsätzliche Ausüben von Nebentätigkeiten korrelierte denn auch eng mit der jährlich zu leistenden Schuldauer.

Das Lehramt war um 1800 denn auch bereits für eine bedeutende Minderheit der Lehrkräfte ein Vollzeitjob, was sich in der Ausgestaltung der Lebensveräufe stark niederschlug. Zwar wies erst ein kleiner Teil des Lehrerkollektivs einen völlig linearen Berufsverlauf mit einer exklusiven berufsbiografischen Spezialisierung auf das Lehramt seit dem Jugendalter und ohne Nebentätigkeiten auf, doch mindestens ein Drittel aller Lehrkräfte hatte mit der Lehramtsübernahme ihre Berufsbiografie grundlegend in einem diskontinuierlichen Verlauf verändert und Erwerbstätigkeiten zugunsten des Lehramts aufgegeben oder zumindest stark reduziert. Vor allem Handwerker des Bekleidungsgewerbes und protoindustrielle Weber verzichteten weitgehend auf ihre Ersttätigkeiten, was die Anzahl an exklusiv auf das Lehramt spezialisierten Lehrern zusätzlich erhöhte und auf einen voranschreitenden Prozess der allmählichen Destratifizierung und Spezialisierung hinweist. ${ }^{1578}$ Hauptsächlicher Treiber dieses Prozesses der zunehmenden Konzentration auf das Lehramt war wiederum die Ausdehnung der jährlichen Schulzeit, die zunehmend eine zeitliche Konkurrenz für das Ausüben von Nebentätigkeiten schuf. Gleichzeitig zeigt die Verdrängung der ehemaligen Tätigkeiten, dass sich das Ausüben der Lehrertätigkeit offensichtlich ökonomisch oder sozial besser lohnte.

Im Sinne dieser festgestellten Destratifizierung und Spezialisierung während des Lebensverlaufs wird für eine Ausweitung der Definition der „pédagogues de profession“ von Georges Panchaud ${ }^{1579}$ plädiert: nicht bloss die wenigen Lehrkräfte mit einer formalisierten Ausbildung sollten darunter verstanden werden, sondern auch jene zahlreichen Lehrkräfte, deren Lebensverlauf sich massgeblich dem Unterrichten unterordnete. Dazu zählen einerseits die Lehrkräfte mit einem linearen Lebensverlauf und der exklusiven Spezialisierung auf das Lehramt, andererseits jene Lehrkräfte, die in diskontinuierlicher Weise bewusst auf weitere Nebentätigkeiten verzichteten und ebenso diejenigen mit einer langjährigen kontinuierlichen Ausübung des Lehramts

1577 Vgl. das Kap. 3.3.

1578 Zur These der Destratifizierung vgl. Bloch Pfister: 109.

1579 Panchaud, écoles vaudoises: 254; vgl. das Zitat im Kap. 2.2. 
von mehr als 15 Jahren. Entsprechend dieser erweiterten Definition, die langjährige Berufstreue und eine berufsbiografische Fokussierung auf das Lehramt an Stelle der noch kaum existierenden formalisierten Ausbildung miteinbezieht, ist die Mehrheit der helvetischen Lehrkräfte am Ende des 18. Jahrhunderts als „Bildungsexperten“ und nicht mehr als zufällig im Amt gelandete Amateure einzuordnen. ${ }^{1580}$

Nach der Lehramtsübernahme wies die Mehrzahl der Berufsbiografien keine wesentlichen Veränderungen der lehramtlichen Grundkonstellation mehr auf. Schulberufliche Mobilität und aktive Stellenwechsel waren kollektiv unter der Lehrerschaft ncoh schwach ausgeprägt, wenngleich im Durchschnitt pro Jahr etwa jede zehnte helvetische Schulstelle frei wurde. ${ }^{1581}$ Erst rund ein Drittel aller Lehrkräfte verliess zur Besetzung einer Schulstelle oder aus Gründen der Lehrerausbildung ihre geografische Herkunftsgemeinde. Nur in wenigen Regionen der damaligen Schweiz existierte überhaupt eine gewisse Mobilitätskultur unter der Lehrerschaft, etwa im Berner Mittelland, in der Waadt und unter den katholischen Kaplan-Lehrern der Zentralschweiz. Hemmend auf die Mobilität der Lehrer wirkten sich zum einen restriktive Schulordnungen aus, die - wie in Zürich - eine Bevorzugung lokaler Kandidaten verlangte. Ebenso hemmend war hingegen das in den ehemaligen Gemeinen Herrschaften verbreitete exklusive Gemeindewahlrecht mit jährlicher Bestätigungspraxis. Diese strukturellen Umstände förderten Willkür und Parteilichkeit, was auf ortsfremde Personen abschreckend wirkte. Ferner limitierten die erst schwach ausgeprägten überlokalen Kommunikationsmöglichkeiten und -medien die Distribution von freien Schulstellen über grössere Distanzen, weshalb bis zur Revolution noch kein „Stellenmarkt“ im eigentlichen Sinne existierte und wechselwilligen Lehrkräften oft schlicht das Wissen um freie Stellen fehlte. Des Weiteren hemmte die agrarische Subsistenznotwendigkeit das Ausweichen in die Fremde. Die Verfügbarkeit einer freien Schulwohnung wurde dabei zu einem zentralen Kriterium, denn je weiter entfernt vom Herkunftsort eine Schulstelle lag, desto höher stieg der Anteil an Lehrkräften mit Wohngelegenheiten im Schulhaus. Die räumlich grössten Distanzen nahmen überdies Lehrkräfte in Kauf, die sich vom Jugendalter her exklusiv auf das Lehramt vorbereitet hatten. ${ }^{1582}$

Die Grenzen der ehemaligen Herrschaftsgebiete wurden jedoch noch kaum überschritten, ebenso wie die Landes-, Sprach- und Konfessionsgrenzen der beruflichen Mobilität enge Grenzen setzten. Trotz einer allmählichen Erosion der obrigkeitlichen Bewegungsbeschränkungen war der räumliche Lebensalltag der untersuchten Personen am Ende des 18. Jahrhunderts noch stark von den ständisch-lokalen Grenzen determiniert. Entsprechend gering war denn auch der Anteil an Lehrkräften mit schulischer Praxiserfahrung an Drittorten. Erst knapp jede fünfte Lehrkraft konnte bis zum Zeitpunkt der Umfrageerhebung Praxiserfahrung an mindestens einer vorgängigen Schule aufweisen. Da Praxiserfahrung noch kein entscheidendes Kriterium bei der Wahl von neuen Schulmeistern war, brachte ein Schulstellenwechsel noch keinen systematischen Vorteil für die Lehrpersonen bei Lehrerexamen. Wenn Lehrkräfte aber eine Schulstelle wechselten, blieben sie zudem in fast kollektiver Einmütigkeit dem gleichen räumlich-ständischen Schultyp treu. Wechsel von Landschulen an zentralörtliche Schulen und umgekehrt waren Ausnahmefälle. Entsprechend selten waren Lebensverläufe mit einem deutlichen sozialen Auf- oder Abstieg durch einen bewussten Schulstellenwechsel festzustellen. Gerade die ständische Stadt-Land-Grenze zeichnete sich um 1800 noch als persistenter Strukturfaktor aus.

1580 Unter die genannten Kriterien fielen insgesamt mindestens 1.300 Lehrer oder 56\% des Kollektivs.

1581 Vgl. das Kap. 3.5.1.

1582 Vgl. das Kap. 3.5.2. 
Lehrer zu sein war im Gegensatz zu vielen Tätigkeiten der Frühen Neuzeit längst kein unsicherer Lebensentwurf mehr, wie die Lebensverläufe der untersuchten Lehrkräfte belegen. ${ }^{1583}$ Das stabile und abschätzbare Einkommen aus der Schularbeit sorgte für die notwendige finanzielle Sicherheit und machte das Leben als Lehrer langfristig planbar. Die allmähliche Ausdehnung der jährlichen Schuldauer sorgte zudem für einen Einkommenszuwachs, der andere Erwerbstätigkeiten zunehmend obsolet machte. Die festgestellte langjährige Diensttreue, die nur wenigen unterbrochenen Lehrerkarrieren und die noch schwache Volatilität auf dem „Arbeitsmarkt Schule“ zeugen des Weiteren von einer hohen kollektiven Konstanz der Berufsausübung. Am bedeutsamsten für die Ausgestaltung und Entwicklung der Berufsbiografien zeichneten sich von den untersuchten Strukturfaktoren letztlich die lokalen Organisationsstrukturen verantwortlich, wie es auch Wolfgang Neugebauer für das deutsche Elementarschulwesen festgehalten hat. ${ }^{1584}$ So stand das schulische Einkommen in einem direkten kausalen Zusammenhang mit der jährlichen Schuldauer. Diese bestimmten in der Regel die Gemeindebürger in Eigenregie, ebenso wie die dafür zu bezahlende Entschädigung zu einem grossen Teil aus kommunalen Quellen floss. Je länger die Schule dauerte, desto höher fiel die Entschädigung für die Schulmeister aus. Ebenso bestanden kausale Zusammenhänge zwischen der jährlichen Schuldauer und der Ausübung beziehungsweise dem Nichtausüben von Nebentätigkeiten. Je länger die Schule dauerte, desto eher konnten die Lehrer auf Zusatztätigkeiten verzichten. Im Umkehrschluss sind die Kausalitäten jedoch nicht zulässig. So verzichteten auch tief besoldete Lehrer mitunter auf Nebentätigkeiten, während andere Lehrer für eine bloss eingeschränkte jährliche Schuldauer dennoch ein höheres Einkommen bezogen als Kollegen mit ganzjähriger Unterrichtspflicht.

Grosse Differenzen in den Lebensverläufen zeigten sich aufgrund der Lokalstrukturen besonders zwischen zentralörtlichen Lehrkräften und Landschullehrern. Die stark verbreitete ganzjährige Schuldauer an zentralörtlichen Schulen sorgte für ein entsprechend hohes Einkommen, das keine Nebentätigkeitenausübung mehr zwingend bedingte. Zentralörtliche Lehrkräfte neigten daher am stärksten zu linearen Lebensveräufen.

Individuelle Initiativen zur Einkommenssteigerung durch eine Verlängerung der angebotenen Schulzeit vonseiten der Lehrer oder durch Privatunterricht in Nebenstunden waren insgesamt selten angewandte Handlungsstrategien. Angesichts der Konkurrenz von privaten Bildungsvermittlern und noch ungeklärten inhaltlichen Kompetenzzuteilungen des öffentlichen Schulwesens - besonders im Bereich der elementaren Mathematik, die oft als „Bauernrechnen“ von einzelnen Dorfbürgern vermittelt wurde - war solchen Versuchen freilich noch wenig Erfolg bescheiden.

Da ferner das Lehramt bei beiden Konfessionen an vielen Orten von den Gemeinden mit kirchlichen Hilfsdiensten - vorwiegend dem Mesmeramt - verbunden wurde, ergab sich eine zwangsläufig polyprofessionelle Tätigkeitssituation für die betroffenen (männlichen) Lehrkräfte. Mindestens jeder fünfte helvetische Lehrer hatte denn eine kirchliche Hilfstätigkeit als Zusatzamt zum Schuldienst auszuüben, was neben agrarischen Tätigkeiten zur Subsistenzsicherung die kollektivbiografisch zweithäufigste Nebentätigkeit darstellte. Diese kirchlichen Hilfstätigkeiten boten den männlichen Lehrkräften in der Regel eine zusätzliche Besoldung, weshalb etwa die

1583 Zum Postulat der grundsätzlichen Unsicherheit von frühneuzeitlichen Lebensverläufen vgl. Mayer, Lebensverlauf: 449.

1584 „Ebenso blieben im 17. und 18. Jahrhundert lokale Kräfte von in der Regel ausschlaggebender Bedeutung für Prägung und Leistung der niederen Schulen in Land und Stadt, wichtiger als landesherrliche Ordern und Ordnungen, als obrigkeitliche Patente und Reglemente unter den Bedingungen vormoderner bzw. frühmodern-staatlicher ,Verwaltung'- Realität." Neugebauer, Niedere Schulen: 225. 
Zürcher Obrigkeit ihre Gemeinden aktiv dazu drängte, die prekären Lehrerlöhne mit den Entschädigungen für kirchliche Hilfsdienste aufzustocken. Zudem versprachen gewisse kirchliche Dienste ein zusätzliches soziales Kapital, weshalb diese Dienste unter der Lehrerschaft trotz der vielfach fehlenden Entscheidungsfreiheit grundsätzlich beliebt waren.

Freier Handlungsspielraum für individuelle berufsbiografische Entscheide spielte dennoch eine Rolle bei der Wahl von Nebenbeschäftigungen. So liess sich fast jeder zehnte Lehrer nach der Revolution für das Ausüben eines kommunalen Amtes einbinden, vor allem für die besoldeten neuen Ämter der helvetischen Verwaltungsstrukturen. Im Gegensatz zu den kirchlichen Hilfsdiensten erfolgte deren Ausübung in der Regel auf freiwilliger Basis und als individueller Entscheid. Darin manifestiert sich einerseits der Versuch der neuen Regierung, über die Lehrkräfte in ihrer Zwitterstellung zwischen den Dorfbürgern und den Geistlichen verbindliche Partner für ihre Reformprojekte auf der lokalen Ebene gewinnen zu können. Die Elementarschullehrer schienen hierzu als politisch neutrale „Bildungsexperten“ im Gegensatz zu den Pfarrern als Ausführungswerkzeuge der politischen Dekrete geeigneter, da die Lehrer von den Säkularisierungsmassnahmen unberührt blieben. Die kollektiv hohe und freiwillige Mobilisierung der zahlreichen Lehrkräfte für die neue helvetische Verwaltung bedeutete andererseits, dass die Ideen der neuen Regierung unter den Lehrkräften besonders Zuspruch fanden. Diese anfängliche Begeisterung wich jedoch schon bald der Ernüchterung ob der ausbleibenden Besoldung und der wachsenden Opposition von Teilen der Bevölkerung gegen die neue Regierung. So verlangten bereits im Frühjahr 1799 die ersten Lehrkräfte wieder von ihren Ämtern entbunden zu werden. Zudem ist der kollektiv markante Einstieg der mittleren Erwachsenenjahrgänge in die neuen Kommunalämter als ein Versuch zu werten, sich in der dörflichen Funktionselite auch unter den revolutionären Veränderungen zu etablieren. Denn die traditionellen Kommunalämter des Ancien Régimes, deren Ausübung den lokalen Eliten vorbehalten waren und ein hohes soziales Ansehen voraussetzten, wurden vor und nach der Revolution nur in geringem Masse durch vorwiegend ältere - Lehrkräfte ausgeübt. Hierin manifestiert sich denn auch die einzige wirkliche Generationendifferenz zwischen jüngeren und älteren Lehrkräften.

Ferner lag in der nicht tolerierten Ausübung von Kommunal- und Kirchenhilfsämtern der markanteste Geschlechterunterschied in Bezug auf die Lebensverläufe. Ehefrauen von Lehrern arbeiteten zwar zumeist als informelle Helferinnen in den Schulstuben ihrer Männer mit, eigene Schulen erhielten sie aber in der Regel nur in wohlhabenden Zentralorten als Mädchen- oder Kleinkinderlehrerinnen. Auf dem Land waren Lehrerinnen dagegen eine Ausnahme. Allerdings umfasst das untersuchte Kollektiv schlicht zu wenige Frauen, um aussagekräftige Differenzen in der berufsbiografischen Perspektive herauszuarbeiten.

\subsection{Der soziale Status}

Der soziale Status der Elementarschullehrer ist zwar als grundsätzlich heterogen, insgesamt aber als hoch einzuschätzen und als weitgehend losgelöst von den realen Einkommensverhältnissen zu verstehen. ${ }^{1585}$ Die in verschiedenen regionalen Quellenbeständen attestierte grundsätzliche Zufriedenheit der vorgesetzten Pfarrer mit den fachlichen Fähigkeiten und dem Amtsfleiss der Lehrer, aber auch das breite Vertrauen der Lokalbevölkerung in ihre Schulmeister, stehen im schroffen Gegensatz zu den zahlreichen kritischen Einzelberichten zum angeblich prekären sozialen Status der Lehrer. ${ }^{1586}$ Der hohe Grad an Zufriedenheit und das kommunale Vertrauen

1585 Zur Heterogenität des sozialen Status vgl. Bloch Pfister, Priester: 109; Berner, Zeichen: 103.

1586 Vgl. das Kap. 4.1. 
sind jedoch markante Indizien, dass sich die meisten Lehrkräfte trotz ihrer ambivalenten Situation zwischen den Pfarrern und den Hausvätern vor Ort in einer grundsätzlich stabilen und sozial geachteten Position befanden und das Schulwesen - gemessen an den Anforderungen des Ancien Régimes - gut funktionierte. Erkenntnisse aus der jüngeren Alphabetisierungsforschung stützen diesen Befund, denn ohne gute Lehrer wäre auch das hohe Alphabetisierungsniveau vieler eidgenössischer Regionen nicht erreichbar gewesen. ${ }^{1587}$

Die bereits mehrheitlich vor der Revolution zum Standard gewordene Leistungsorientierung bei der Kandidatenselektion festigte die fragile Position der Lehrer zwischen ihren vorgesetzten Pfarrern und der Lokalgemeinden zusätzlich. Gerade in den ehemaligen städtischen Untertanengebieten, wo Wahl- und Bestätigungskompetenzen durch die Schulordnungen von den Obrigkeiten für sich reklamiert wurden, bestand ein Rechtfertigungsdruck vonseiten der Obrigkeiten, dass die von ihnen bestätigten Lehrpersonen ihrer Aufgabe würdig waren. Das verlieh den Lehrkräften Legitimation, schuf Selbstbewusstsein - den „Schulmeisterstolz“ - und wirkte wohl auch identitätsstiftend, wobei Letzteres als noch offene Forschungsfrage einer genaueren Prüfung bedürfte. Generell liegt in Fragen zur Identitätsentwicklung der Schulmeister noch viel Potenzial für weitere Forschungen, ebenso wie sich in den zahlreich archivierten Examensberichten zu Lehrerwahlen noch viel über die Selektionsprozesse und zur Dynamik in einzelnen Schulen in Erfahrung bringen liesse.

Sowohl die Selbstzuschreibungen eines tiefen sozialen Ansehens durch die Lehrkräfte in der Stapfer-Enquête als auch in den zeitgenössischen und späteren Fremdzuschreibungen dürften vom Motiv eines bewussten Schlechtredens zur Generierung von Aufmerksamkeit dominiert worden sein. Malte man den Lehrerstand in den schwärzesten Farben als wirkungsmächtige Negativfolie, garantierte dies mehr Aufmerksamkeit und Zustimmung für angestrebte Reformvorschläge. Ebenso wie Lohnvergleiche nach oben zu den Pfarrern, nahm die Lehrerschaft auch mit der Einordnung ihrer sozialen Position nach unten in die sozialen Unterschichten die Rolle des „Opfers“ ein. Daraus entwickelte sich jedoch eine wirkungsmächtige Meistererzählung in der historischen Pädagogik, die fortan das historische Bild der Lehrerschaft prägen sollte und unhinterfragt rezipiert wurde.

Zwischen der ökonomischen Situation und dem sozialen Ansehen musste keine direkte Kausalität bestehen. Die simple Gleichung, dass aus den vielfach tiefen Lehrerlöhnen automatisch Armut und damit ein tiefer sozialer Status einherging, ist nach den gewonnenen Erkenntnissen zur Schweizer Elementarschullehrerschaft um 1800 zu verwerfen. Soziales Ansehen generierte sich auch ungeachtet der Einkommensverhältnisse und übertrug sich primär vom Amt auf die Person, denn das Schulmeisteramt hielt für die Inhaber mitunter selbst ein immaterielles soziales Kapital bereit. ${ }^{1588}$ Dieses soziale Kapital vermochte sogar wesentliche ökonomische und rechtliche Defizite zu kompensieren.

Nirgendwo zeigt sich die Diskrepanz von Wahrnehmung, Anspruch und Realität so eindrücklich wie im Heiratsverhalten der helvetischen Elementarschullehrer. So erscheint die überdurchschnittlich hohe kollektive Heiratshäufigkeit von rund 80\% aller Lehrkräfte als ein Ausdruck von hohem sozialem Kapital, das den Lehrkräften das Eingehen einer Ehe und das Gründen einer Familie ermöglichte. ${ }^{1589}$ Die sozialen Heiratsbeschränkungen galten für die Lehrkräfte des ausgehenden 18. Jahrhunderts offensichtlich kaum mehr. Daraus kann geschlossen werden, dass aus dem Amt als gemeinsamer Nenner selbst eine immaterielle Wertzuordnung erwuchs, die es Personen

1587 Vgl. zur Alphabetisierungsfrage: Schmidt, Alphabetisierungsforschung: 149-172.

1588 Böning, Revolution: 149; Bloch Pfister, Priester: 109f.; Gruner, Bemerkungen: 115.

1589 Vgl. das Kap. 4.3. 
aus allen Professionsgruppen, Hintersassen und Einheimischen gleichermassen erlaubte, eine Ehe schliessen zu können. Selbst im Kontext der sich allmählich aufweichenden gesellschaftlichen Normen im Zuge der „sexuellen Revolution “ ${ }^{1590}$ genossen die frühneuzeitlichen Tätigkeitsgruppen der Unterschichten kein vergleichbares Privileg, was dessen Aussergewöhnlichkeit hervorhebt. Das gesicherte Zusatzeinkommen und das soziale Ansehen des Lehramts wirkten zusammen als sozialer Katalysator und ermöglichten es den Trägern, vorzeitig und unabhängig von der tatsächlichen Einkommenssumme aus dem Lehramt eine Familie gründen zu können.

Gleichzeitig war das Eingehen einer Ehe für die Schulmeister aber auch eine unausgesprochene soziale und ökonomische Pflicht, aus der sich überhaupt erst das vollumfängliche soziale Kapital erschloss, da sowohl die individuelle Mündigkeit von der Heirat abhing als auch vom Schulmeister eine Vorbildfunktion gegenüber den Mitbürgern erwartet wurde. Erst die Heirat machte den Schulmeister zum angesehenen und gleichberechtigten Mitbürger, sofern die Ehefrau auch den charakterlich-moralischen Vorbildvorstellungen entsprach. ${ }^{1591}$ Die Kausalität von Lehramtsübernahme und Eheschliessung ist ferner in der zeitlichen Dimension greifbar, denn zahlreiche Heiraten erfolgten zeitnah nach der Lehramtsübernahme, kaum aber zuvor. Dabei galt, dass je früher die Amtsübernahme erfolgte, desto früher konnte auch geheiratet werden. In der ökonomischen Betrachtung wirkte ferner das knappe, je nach jährlicher Schuldauer bloss als Zusatzverdienst bemessene Einkommen einen indirekten Heiratszwang auf die Lehrer aus, indem erst die zusätzliche Arbeitskraft einer Ehefrau als Rollenergänzung innerhalb der Familienwirtschaft den Einkommenssprung des Lehramts in Wert setzte.

Das Eingehen einer Ehe gehörte kollektiv zum Lebensverlauf von fast jedem helvetischen Lehrer um 1800 und stellt die deutlichste Gemeinsamkeit aller weltlichen Lehrpersonen im untersuchten Kollektiv dar. Diesen Ehen entsprangen in der Regel auch Kinder, ungeachtet der tatsächlichen Einkommen, denn mehr als 90\% der verheirateten Lehrkräfte von über 50 Jahren hatten Kinder gezeugt. Eine typische Lehrerfamilie umfasste in der Regel meist zwei bis drei Nachkommen, also vier bis fünf Personen. Damit waren Lehrerhaushalte im Durchschnitt deutlich grösser als die Haushalte typischer Unterschichtsangehöriger und die Lehrkräfte verhielten sich ähnlich wie andere erforschte Berufsgruppen der sozialen Mittelschichten, etwa die Handwerker des Zürcher Unterlands. ${ }^{1592}$ Dahinter steht wohl weniger eine Orientierung am erst entstehenden Bild der bürgerlichen Familie, als vielmehr der Wunsch, seine Besitzgüter und gegebenenfalls auch das Lehramt an einen überlebenden Nachkommen weitergeben zu können, gleichwohl aber die zur Verfügung stehenden ökonomischen Ressourcen auszuschöpfen. Die überdurchschnittliche Familiengrösse - besonders der älteren Altersgruppen im Kollektiv - ist damit ein deutliches Indiz für eine stabile, gesicherte Mittelschichtsexistenz, getragen von einem stabilen Einkommen, wichtigen Einkommenszusätzen wie eine freie Schulwohnung, einer langfristigen Ausübungsperspektive und einem hohen immateriellen Kapital für den Amtsinhaber.

Es war gesamthaft betrachtet die lokale Lebenswelt, die lokalen Struktur- und Organisationsfaktoren, die das Leben und die Lebensverläufe der Lehrerinnen und Lehrer am Ende des 18. Jahrunderts

1590 Vgl. dazu die Ausführungen im Kap.4.2.1; Schmidt, Dorf und Religion: 236-240.

1591 Die soziale Herkunft der Lehrer-Ehefrauen spielte an sich nur eine untergeordnete Rolle für den Ruf des Ehemanns, während - wie Beispiele im Kap. 4.1.2 gezeigt haben - charakterliche Schwächen der Ehefrau mitunter negativ auf das Ansehen des Lehrers zurückfallen konnten. Von der Schulmeister-Ehefrau wurde in der Regel wie vom Lehrer ein tugendsamer Charakter und einwandfreier Lebenswandel vorausgesetzt. Natürlich konnte die Heirat einer Ehepartnerin aus höherem Stand das lokale Ansehen des Lehrers mutmasslich ebenfalls positiv beeinflussen, doch fehlen hierzu empirische Forschungen, aus welchen sozialen Schichten die Ehefrauen von Lehrern stammten.

1592 Vgl. beispielhaft zur durchschnittlichen Haushaltsgrösse von Handwerkern im Zürcher Unterland: Meier, Handwerk: $124 f$. 
massgeblich prägten. Gleichwohl sind in den Lebensverläufen der Lehrpersonen Momente der indivduellen Entscheidung und aktiv angewandte Handlungsstrategien zu erkennen, die zeigen, dass die ,einfache Bevölkerung“ an der Schwelle zur Moderne über beachtliche Handlungsspielräume verfügte und nicht einfach bloss auf Strukturen reagierte. Gerade die zahlreichen Paradoxa in Bezug auf das Einkommen, die berufliche Ausübung der Lehramts- und Nebentätigkeiten sowie des Ansehens belegen, dass man die Menschen der Frühen Neuzeit nicht mit den Massstäben der Moderne - mit ökonomisch rationalem Denken, mit Karriereplanung und bruchlosen Lebensverläufen - messen darf. Der doppelt getrübte Blick - durch die Historiografie und durch die zeitgenössischen Motive - muss erst überwunden werden, um zu erkennen, dass die Lehrerschaft in einer sozialen Schlüsselposition stand: sei es als „Bildungsexperten“ und Motoren der Alphabetisierung, als Angehörige der lokalen „Funktionselite“ oder einfach als vielleicht profitierende Klientel der wohlhabenden Lokaleliten, die ihre Patronage durch die Vergabe des Lehramts als attraktive Nische im dörflichen Erwerbsgefüge ausübte. So präsentiert sich die Elementarschullehrerschaft am Ende des 18. Jahrhunderts als ein Kollektiv avant la lettre, zwar noch ohne kollektives Bewusstsein oder Organisation, aber geprägt von zahlreichen berufsbiografischen Gemeinsamkeiten.

In vielerlei Hinsicht offenbart die Betrachtung des historischen Lehrerkollektivs von 1799 zudem Parallelen zur Gegenwart, was den Rekurs auf die Geschichte so lohnenswert macht. Bezugspunkte zur Gegenwart finden sich etwa in den Lohndiskussionen. Die zahlreichen Lohnklagen der Lehrkräfte am Ende des 18. Jahrhunderts erweisen sich als eine grosse kontinuierliche Diskurslinie bis in die heutige Zeit. Wie eine Studie von Charles Landert zur Berufszufriedenheit der Deutschschweizer Lehrkräfte jüngst ergab, stellt die Lohnentwicklung neben den schulischen Reformen den grössten Unzufriedenheitsfaktor der Lehrkräfte dar. ${ }^{1593}$ Verändert hatten sich indes die Parameter der Wahrnehmung. Während sich um 1800 vor allem besser verdienende Lehrer beklagten, ärmere Lehrkräfte sogar um ihre Existenz kämpfen mussten, entstehen die heutigen Klagen aus Vergleichen mit anderen Berufsfeldern mit ähnlichen Qualifikationsprofilen.

Untrennbar mit der monetären Entschädigung verbunden bleibt bis in die Moderne die Frage des gesellschaftlichen Ansehens der Lehrkräfte. So wird die Lohnhöhe der Lehrpersonen vielfach als ein Ausdruck der gesellschaftlich zugeschriebenen Wertschätzung für den Lehrerberuf und die Bildung angesehen. Gerade die grossen kantonalen Unterschiede hinsichtlich der Lohnsituation für Lehrpersonen in der Schweiz lassen Diskussionen um die grundsätzliche gesellschaftliche Investitionsbereitschaft in das Bildungswesen periodisch wieder aufkommen. Ebenso stellt sich immer wieder die politische Frage, mit welchen Berufsgruppen die Lehrerschaft in Lohnfragen adäquat verglichen werden darf. Daneben sind das von der Gesellschaft zugeschriebene und das von den Lehrkräften selbst wahrgenommene immaterielle soziale Ansehen Dauerbrenner in den Diskussionen um die Attraktivität von Bildungsarbeit. Bis heute schreiben sich Lehrkräfte angesichts der gesellschaftlich auf die Schule transformierten Aufgaben oft ein eher defizitäres gesellschaftliches Ansehen zu. Derweil attestieren auch in der Moderne bisweilen Spötter den Lehrpersonen Arroganz, Jammerei und übermässige Privilegien. Auch hier zeigt ein Blick in die Geschichte der Lehrerschaft, dass hinter dem jeweiligen zeitgenössischen Selbstbild und der Fremdwahrnehmung oft grosse Lücken klaffen, deren Ursachen die diskursiv unterschiedlichen Erwartungshaltungen sind, was ein Lehrer tun und was er sein soll.

Ebenso bleibt die individuelle Persönlichkeit der Lehrperson bis in die Moderne ein zentraler Angelpunkt bei Diskursen nach der Qualität von Schule und Unterricht. Der vormodernen 
Forderung nach einem einwandfreien tugendsam-sittlichen Verhalten entsprechen die heutigen Diskussionen um die Vorbildfunktion von Lehrkräften in beinahe identischer Weise. Doch auch berufsbiografische Voraussetzungen und Entwicklungen sind immer wieder Gegenstand von Debatten. Moderne Forderungen nach mehr beruflichen Quereinsteigern zur Deckung von freien Schulstellen und Diskussionen um eine bessere Einbindung von Berufsanfängern zur Senkung der Austrittsquoten aus dem Lehrerberuf verdeutlichen in fast anachronistischer Weise, dass die Berufsbiografien von Lehrpersonen trotz der Professionalisierung der Ausbildung nach wie vor von starken Diskontinuitäten geprägt sind.

Geblieben sind auch die starke kommunale Verankerung der Volksschule und die kantonale Entscheidungshoheit im elementaren Bildungswesen. Lehrer und Lehrerinnen werden auch heute noch von den kommunalen Schulpflegen angestellt, entlassen und beaufsichtigt, auch wenn sie nicht mehr jederzeit entlassen werden können. ${ }^{1594}$ Die Kantone bestimmen bis anhin föderalistisch und mehrheitlich autonom über ihre Bildungsangelegenheiten, erst in den letzten Jahren sind interkantonale Harmonisierungsbemühungen zumindest für die einzelnen Sprachregionen - man denke an das Projekt HarmoS und den Lehrplan21 als dessen Umsetzung - auf der politischen Agenda von ersten Erfolgen gekrönt gewesen. 


\section{Tabellen- und Abbildungsverzeichnis}

\subsection{Tabellenverzeichnis}

Tab. 1: Indikatoren der Kollektivuntersuchung ................................ 57

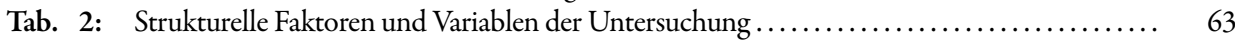

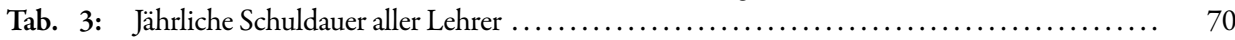

Tab. 4: Lehrkräfte ohne Ersttätigkeiten nach Alterskohorten ......................... 109

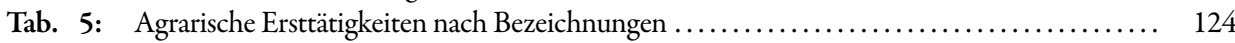

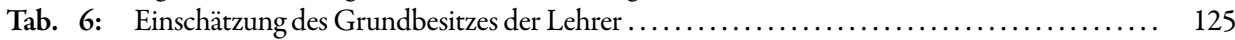

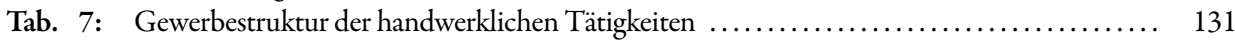

Tab. 8: Amtsübernahmealter der ehemaligen Handwerker ........................... 134

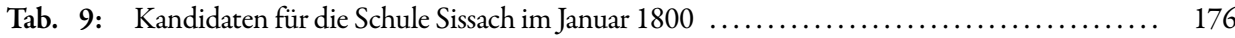

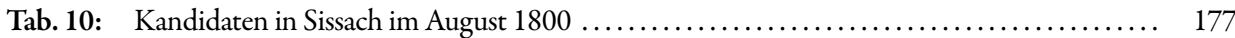

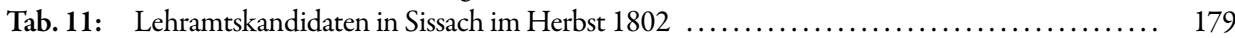

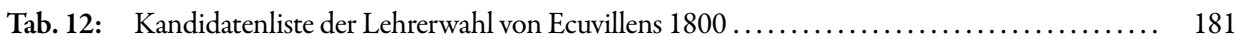

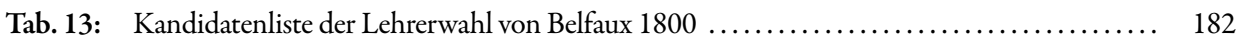

Tab. 14: Einkommensvergleiche zwischen Lehrerinnen und Lehrern ..................... 204

Tab. 15: Schuldauer pro Jahr und Nebentätigkeiten ................................. 209

Tab. 16: Schuldauer der Lehrer mit linearem Lebensverlauf . . . . . . . . . . . . . . . . . . . . . . . 214

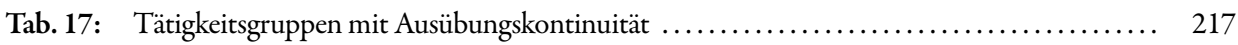

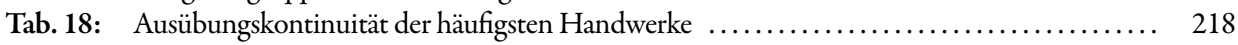

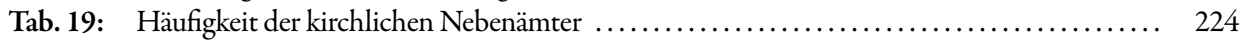

Tab. 20: Verteilung der Lehrer mit kirchlichen Nebentätigkeiten nach Alterskohorten ........... 225

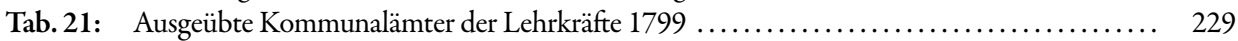

Tab. 22: Ausübung der Kommunalämter nach Alterskohorten ......................... 234

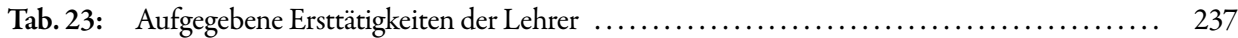

Tab. 24: Neu ausgeübte Ersatztätigkeiten zum Lehramt .............................. 238

Tab. 25: Mittlere Dienstdauer der Lehrer nach Altersgruppen ........................... 249

Tab. 26: Verteilung der Dienstjahre der Lehrer über 50 Jahre ........................... 249

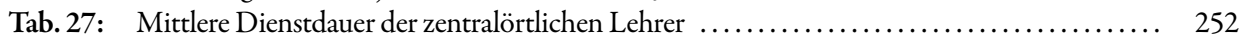

Tab. 28: Bewegungsradius der lehramtlich mobilen Lehrer ............................ 263

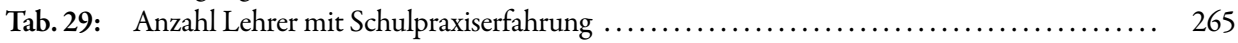

Tab. 30: Lehrer mit Schulpraxiserfahrung nach Alterskohorten ......................... 266

Tab. 31: Wanderungsbewegungen der lehramtlich mobilen Lehrer ...................... 269

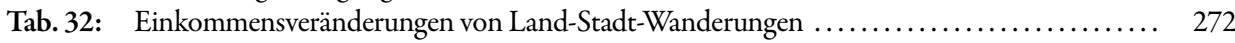

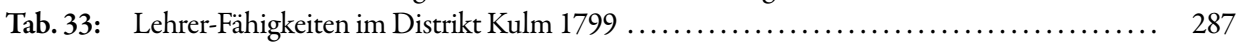

Tab. 34: Lehrer-Fähigkeiten im Distrikt Kulm nach Alter 1799 .......................... 288

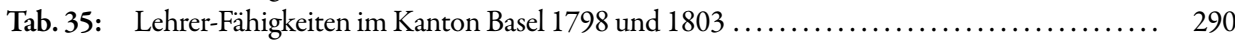

Tab. 36: Fähigkeiten der Lehrer im Kanton Basel 1803 nach Alter .......................... 291

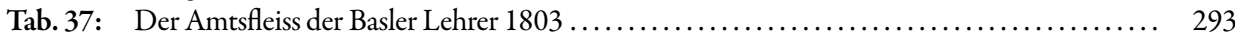

Tab. 38: Fähigkeiten der Lehrer in der Fürstabtei St. Gallen $1796 \ldots \ldots \ldots \ldots \ldots \ldots \ldots \ldots \ldots \ldots \ldots \ldots \ldots$

Tab. 39: Die Amtsausführung der Luzerner Lehrer 1798-99 ............................. 295

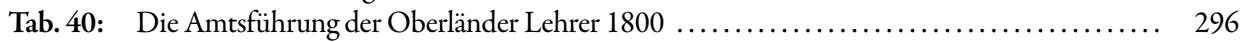

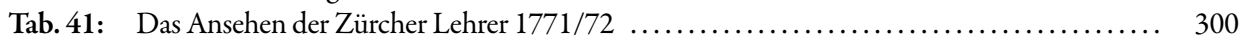

Tab. 42: Das Vertrauen gegenüber den Basler Lehrern 1798 ........................... 301

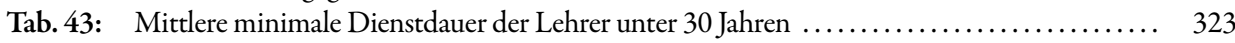

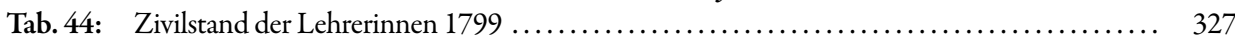

Tab. 45: Altersstruktur der Elementarschullehrkräfte um 1799 ...................... 432 


\subsection{Abbildungsverzeichnis}

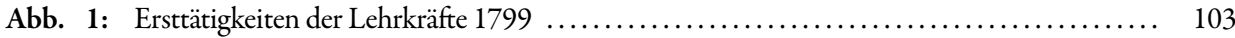

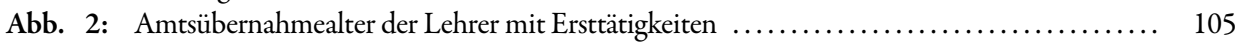

Abb. 3: Amtsübernahmealter der Lehrerinnen ................................ 107

Abb. 4: Amtsübernahmealter der Lehrer ohne Ersttätigkeiten $\ldots \ldots \ldots \ldots \ldots \ldots \ldots \ldots \ldots \ldots \ldots, 110$

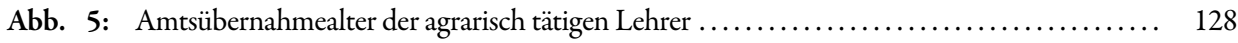

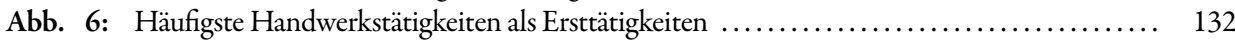

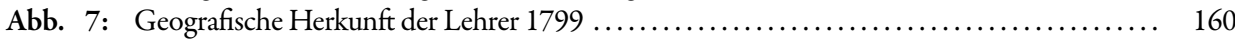

Abb. 8: Einkommensverteilung der Berner Schullehrer in Batzen 1799 .................... 194

Abb. 9: Verteilung der Lehrerlöhne im Kanton Bern 1799 ............................ 195

Abb. 10: Einkommensverteilung der Oberländer Lehrer in Batzen 1799 ................... 197

Abb. 11: Verteilung der Lehrerlöhne im Kanton Oberland 1799 ......................... 198

Abb. 12: Lohnentwicklung der Glarner Lehrer 1798-1799 ........................... 199

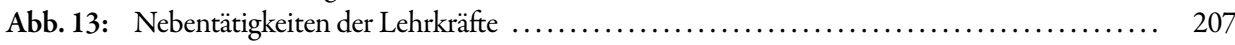

Abb. 14: Verteilung der Lehrer nach Anzahl Dienstjahren ........................... 242

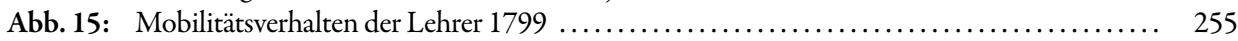

Abb. 16: Ersttätigkeiten und Distanz von vorgängigen Schulstellen ....................... 268

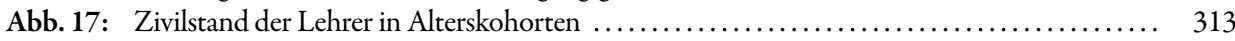

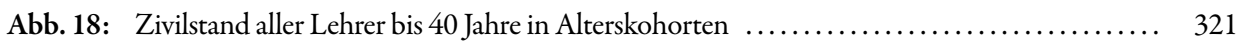

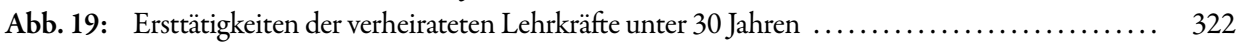

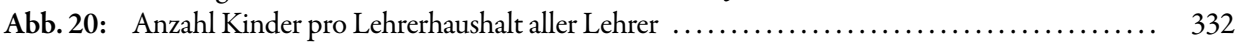




\section{Bibliografie}

\subsection{Abkürzungen}

\section{Allgemeine Abkürzungen:}

Bd. Band

f. folgende Seite

ff. fortfolgende (übernächste) Seite

fol. Folio

Hrsg. Herausgeber

Hgg. Herausgebende

Kap. Kapitel

o.N. ohne Nummerierung/Paginierung

o. Pag. ohne Paginierung

s.n. sine nomine (ohne Autor)

u.a. und andere (Mit-Autoren)

v. verso (Rückseite)

Vgl. Vergleiche

zit. in: zitiert in:

\section{Abkürzungen für Währungen:}

$\begin{array}{ll}\text { Bz. } & \text { Batzen } \\ \text { fl. } & \text { Gulden } \\ \text { Fr. } & \text { Franken } \\ \text { kr. } & \text { Kronen } \\ \text { Ldr. } & \text { Louis d'or } \\ \text { lb. } & \text { Pfund } \\ \text { s. } & \text { Schilling } \\ \text { xr. } & \text { Kreuzer }\end{array}$


Abkürzungen für Zeitschriften:

AJ: Appenzellische Jahrbücher

APuZ: Aus Politik und Zeitgeschichte

AV: $\quad$ Annales Valaisannes

BIOS: Zeitschrift für Biographieforschung, Oral History und Lebensverlaufsanalysen

BzL: Beiträge zur Lehrerbildung

BZ: Berner Zeitung

$\mathrm{CEH}$ : Central European History

$\mathrm{CH}$ : Cartographica Helvetica

ETHE: Encounters in Theory and History of Education

HLS: Historisches Lexikon der Schweiz

IASL: Internationales Archiv für Sozialgeschichte der deutschen Literatur

IhG: Innerrhoder Geschichtsfreund

MhVS: Mitteilungen des historischen Vereins des Kantons Schwyz

NZZ: Neue Zürcher Zeitung

SAV: Schweizerisches Archiv für Volkskunde

SGWS: Schweizerische Gesellschaft für Wirtschafts- und Sozialgeschichte

SZB: Schweizerische Zeitschrift für Bildungswissenschaften ${ }^{1595}$

SZG: Schweizerische Zeitschrift für Geschichte

TBG: Thurgauische Beiträge zur vaterländischen Geschichte

VSWG: Vierteljahrschrift für Sozial- und Wirtschaftsgeschichte

ZfP: $\quad$ Zeitschrift für Pädagogik

ZhG: Zeitschrift des Vereins für hessische Geschichte

$\mathrm{ZpH}: \quad$ Zeitschrift für pädagogische Historiographie

1595 Die Schweizerische Zeitschrift für Bildungswissenschaften änderte ihren Namen mehrmals von „Bildungsforschung und Bildungspraxis/Education et recherche“ $\mathrm{zu}$ „Schweizerische Zeitschrift für Erziehungswissenschaft“. 


\subsection{Ungedruckte Quellen}

\section{Archives de l'État du Canton Valais (AEVS):}

H 4.65, o. Pag.: 09.03.1799 - Sous-préfet [du district] de Sembrancher [Joris]. Questions aux instituteurs. Etat des écoles, 9 mars 1799.

\section{Archives de l'État de Fribourg (AEF) :}

H 437.2, o. Pag.: 12.10.1800 - Notes sur les Régents qui se sont présentés pour l'école d'Ecuvillens District Fribourg le 128 bre 1800 .

H 437.2, o. Pag.: 20.10.1800 - Notes sur la Capacité des Regents qui se sont presentés à l'éxamen pour la régence de Belfaux district de Fribourg Le 20. 8bre 1800.

\section{Bischöfliches Archiv St. Gallen (BiASG):}

III D 94, fol. 1-344: [1797] - Bericht über den moralischen Zustand aller Pfarreyen in Teritorio St. Galli de Anno 1797.

\section{Bundesarchiv (BAR):}

B0 1000/1483, Nr. 1422, fol. 40-43v: [1799] - Huber kathol. Schulmstr. in Ermatingen C. Thurgau.

B0 1000/1483, Nr. 1422, fol. 44-51: [1799] - Gedanken über Schulwesen von P. Dünner, Schulmstr. in Weinfelden. Meynungen und Wünsche eines thurgäüischen Landschullehrers über das Schulwesen.

B0 1000/1483, Nr. 1422, fol. 62: 03.04.1799 - Über Volks-Schulen, ihre Mängel und Verbesserung Zweytes Heft. Von Gottlieb Samuel Lauterburg Pfarrer in der Lenk.

B0 1000/1483, Nr. 1422, fol. 90-125: [1798] - Uiber Die öffentlichen Schulen von B. Tschann öffentlichem Lehrer der schönen Wissenschaften in Solothurn 1798.

B0 1000/1483, Nr. 1422, fol. 233-238: 20.03.1799 - Der grosse Rath an den Senat.

B0 1000/1483, Nr. 1422, fol. 239-248v: [24.07.1798] - Projet de Loi sur les écoles élémentaires.

B0 1000/1483, Nr. 1422, fol. 292-298: [1798] - Projet de Loi sur les écoles élémentaires.

B0 1000/1483, Nr. 1423, fol. 220-226: 30.03.1799 - Beantwortung der Fragen über den Zustand der Schulen im Distrikt Kulm Canton Aargäü.

B0 1000/1483, Nr.1451, fol. 56-58: 10.01.1799 - Allgemeine Übersicht des Schulwesens im Kanton Luzern, [10. Januar 1799]. B0 1000/1483, Nr. 1451, fol. 62-63: 10.01.1799 - Der Erziehungsrat des Kantons Luzern dem Bürger Minister der Künste und Wissenschaften, 10. Jenner 1799.

B0 1000/1483, Nr. 1454, fol. 1-23v.: [1799] - Schultabellen Luzern.

B0 1000/1483, Nr. 1460, o. Pag.: [20.02.1799] - Übersicht aller, der Aufsicht des Erziehungs-Comissars über den Bucheggberg Distrikts Biberist Cantons Solothurn anvertrauten Schulen auf den, für die Personal und Lokal-Kenntniss im Eingang des Jahres 1799 angestellten Besuch hin.

B0 1000/1483, Nr. 1374, fol. 1-188: [1799] - Pfarrenquête Linth.

\section{Kantonsbibliothek St. Gallen (KaBSG):}

VMs 935, fol. 1-393: [1739-1745] - Schul-Tagebuch Johann Jakob Ambühl.

\section{Landesarchiv Glarus (LaGL):}

HA Protokollband 83, fol. 1-80: [1798] - Schulumfrage.

HA Protokollband 84, fol. 1-265: [1798] - Schulumfrage.

HA Protokollband 85, fol. 1-275: [1798] - Schulumfrage.

HA Protokollband 86, fol. 1-100: [1800-1802] - Protokoll des Erziehungsrates.

HA Kiste 27, Mappe C, o. Pag.: 22.09.1801 - Der Schulinspektor des Distrikts Glarus an den Erziehungsrat des Cantons Linth. HA, Kiste 27, Mappe D, o. Pag.: 27.04.1801 - Schulrapport.

HA Kiste 27, Mappe D, o. Pag.: 16.06.1802 - Der Schulinspektor des Distrikts Schwanden an den Erziehungsrat des Cantons Linth.

\section{Staatsarchiv Aargau (StAAG):}

HA 9131, o. Pag.: [1802] - Auszug aus den Schulrapporten des Bezirks Brugg.

HA 9131, o. Pag.: [1802] - Rapport über die Schule Fahrwangen Kirchspiel Seengen Bezirk Lenzburg.

HA 9131, o. Pag.: [1802] - Etat der ersten und zweiten Töchterschule Aarau.

HA 9405, o. Pag.: 14.08.1801 - Akten das Schulwesen betreffend - Namen und Geschlechts Register aller in dem Kanton Baden angestellten Schullehrer, 14. August 1801. 


\section{Staatsarchiv Basel-Landschaft (StABL):}

AA 1012, Lade 200, 07.01.01, o.Pag.: [1798] - [Johann Jakob Freuler].

AA 1012, Lade 200, 07.01.01, o.Pag.: 21.12.1798 - [Brief Stapfer I].

AA 1012, Lade 200, 07.01.01, o.Pag.: 10.01.1799 - [Brief Stapfer II].

AA 1012, Lade 200, 07.01.01, o. Pag.: 20.01.1799 - [Brief des Erziehungsrats an Stapfer wegen Br. Freuler].

AA 1012, Lade 200, 07.01.01, fol. 1-314: [1798] - Bericht über den Zustand der Landschulen.

AA 1012, Lade 200, 07.01.01, o. Pag.: 17.04.1801 - Probeschrift Martin Jenny.

AA 1012, Lade 200, 07.01.01, o. Pag.: 19.04.1801 - [Prüfungsbericht Langenbruck].

AA 1012, Lade 200, 07.01.01, o. Pag.: 07.12.1802 - [Prüfungsbericht Hölstein].

AA 1012, Lade 200, 07.01.01, o. Pag.: 30.10.1803 - [Bericht Sissach].

AA 1012, Lade 200, 07.02.01, o. Pag.: 18.07.1800 - Der Erziehungsrat des Kantons Basel an Bürger Holzach.

AA 1012, Lade 200, 07.02.01, o. Pag.: 22.08.1800 - [Ergebnis Lehrerwabl Sissach].

AA 1012, Lade 200, 07.02.01, o. Pag.: 18.06.1801 - [Schullehrer der Gemeinde Sissach].

AA 1012, Lade 200, 07.02.01, o. Pag.: 29.12.1801 - [Brief an Pfr. Holzach betreffend Erhard Schneider].

AA 1012, Lade 200, 07.02.01, o. Pag.: 04.11.1802 - [Brief von Miville an Pfr. Holzach].

AA 1012, Lade 200, 07.03.01, o. Pag.: [1803] - Berichte über den Zustand und die Besoldungsverhältnisse der Landschulen im Jahre 1803.

AA 1012, Lade 200, 07.03.01, o. Pag.: 25.09.1803 - Augst.

AA 1012, Lade 200, 07.03.01, o. Pag.: 28.09.1803 - Bennwil.

AA 1012, Lade 200, 07.03.01, o. Pag.: [1803] - Muttenz.

AA 1012, Lade 200, 07.03.01, o. Pag.: 22.09.1803 - Oltingen.

AA 1012, Lade 200, 07.04.01, fol. 12ff.: 02.11.1799 - [M.J. Jakob Silbernagel].

AA 1012, Lade 200, 07.04.01, fol. 14f.: 18.12.1799 - Vorschlag über die Besoldungen der Schullehrer in Sissach.

AA 1012, Lade 200, 07.04.01, fol. 15f.: 12.01.1800 - [Examen Sissach].

AA 1012, Lade 200, 07.04.01, fol. 9: 22.01.1800 - [Examensbericht Sissach].

AA 1012, Lade 200, 07.04.01, fol. 17f.: 23.01.1800 - Die Municipalitet der Gemeinde Sissach an den B. Pfahrherr und

Inspector der Schulen in den District Gelterkinden.

AA 1012, Lade 200, 07.04.01, fol. 16a-16b: [17.08.1800] - [Probeschriften Ernst/Grieder].

AA 1012, Lade 200, 07.04.01, fol. 18f.: 25.01.1800 - [Proces Verbal Sissach].

AA 1012, Lade 200, 07.04.01, fol. 20f.: 06.08.1800 - [Schulstelle Sissach].

AA 1012, Lade 200, 07.04.01, fol. 48f.: 21.09.1802 - [Gemeldete Kandidaten Sissach].

AA 1012, Lade 200, 07.04.01, fol. 50f.: 01.10.1802 - [Proces Verbal Sissach].

AA 1013, Lade 201, Bd. 24 (B I), fol. 1-241: [1798] - Tabellen über die Land Schulen des Kantons Basel 1798.

AA 1013, Lade 201, Mappe C, o. Pag.: 18.10.1800 - [Examensbericht Bottmingen].

AA 1013, Lade 201, Mappe E, o. Pag.: 12.11.1799 - Tabelle über das Personale der Schul Lehrer des Distrikts Liestall.

AA 1013, Lade 201, Mappe E, o. Pag: 08.10.1800 - [Verbal Prozess Bubendorf].

\section{Staatsarchiv Bern (StABE):}

B III 204-208, o. Pag.: [1764] - Pfarrberichte mit Bevölkerungstabellen.

B III 209, o. Pag.: [1780] - Pfarrberichte aus dem Kapitel Bern von 1780.

B III 903, o. Pag.: 02.01.1799 - Der Erziehungs-Rath des Cantons Bern, an die sämtlichen Schullehrer des Cantons.

B III 903, o. Pag.: 07.01.1799 - Bürger Präsident und Beysitzer des Erziehungsrathes, Siselen den 7. Jänner 1799.

B III 903, o. Pag.: 20.03.1799 - Bürger Präsident und Beysitzer des Erziehungsrathes in Bern, Siselen den 20ten Merz 1799.

B III 906, o. Pag.: 13.06.1801 - Der Br. Salomon Wyss in Herzogenbuchsee Vice-Schulmeister zu Thörigen.

B III 1027, fol. 2v: 20.06.1806 - Oberamtmann von Oberseftigen.

B III 1032: [1806] - Schultabellen der Amtsbezirke Ober- und Niedersimmental, Saanen, Frutigen, Interlaken und Oberhasle.

B VI 213, o. Pag.: [1783-1823] - Berechnung der Durchschnitte der Getreidpreise auf dem Markt von Bern. Seit Anno 1783 bis 1823 .

DQ 177.19, S. 1-75: 23.06.1839 - [Eggen Jakob]: Kurze Lebensbeschreibung.

Helv OL 41, o. Pag.: [1800-1801] - Berichte über die Schulen 1800. Antworten der Pfarrherren auf die Aufforderung der Verwaltungskammer vom 9. Dezember 1800 über den Zustand der Schulen zu berichten.

Helv OL 42, fol. 1-250: [1798-1803] - Manual des Erziehungsrates.

Helv OL 43, fol. 1-250: [1798-1802] - Beilagen zu den Verhandlungen des Erziehungsrates.

Helv OL 151, o. Pag.: 02.08.1798 - Bericht über die, in der Gemeinde auf St. Beattenberg, Canton Oberland, District Unterseen, bestehende Schulen. 


\section{Staatsarchiv Schaffhausen: (StASH):}

Schule 1/1-17, Schulherrenprotokolle, Bde. 9-16.

\section{Staatsarchiv St. Gallen: (StASG):}

HA R 130, Fasz. 3, o. Pag.: 11.11.1800 - Daniel Rimmensperger.

HA R 132, Fasz. 1-8, o. Pag.: [1800] - Antwortbögen auf die Stapfer-Enquête.

HA R 132, Fasz. 1, o. Pag.: [1800] - General Tabelle der evangelischen Schulen in dem District Unter Rheintal, Anno 1800.

HA R 132, Fasz. 1, o. Pag.: [1800] - General Tabelle der Schulen im District Unter Rheintal catholischer Religion, Anno 1800.

HA R 132, Fasz. 1, o. Pag.: [1800] - General Tabelle der catholischen Schulen im District Ober Rheintal, Anno 1800.

HA R 132, Fasz. 1, o. Pag.: [1800] - General Tabelle der evangelischen Schulen in dem District Oberrheintal, Anno 1800.

HA R 132, Fasz. 2, o. Pag.: 12.11.1800 - Reglement nach welchen die Schulmeister Examina im Kanton Säntis vorgenommen werden sollen, 12. Wintermonat 1800 .

HA R 132, Fasz. 2, o. Pag.: 06.05.1801 - Übersicht dessen was in den Mädchen Examen am 6. Maj 1801 vorgekommen ist.

HA R 132, Fasz. 7, o. Pag.: [1800] - Bemerkungen Über die eingegangenen Schriften der katholischen Schulen des Distrikts Liechtensteig.

HA R 132, Fasz. 8, o. Pag.: [1800] - Antworten über die Fragen, von dem Zustand der Schullen, der Katholischen Gemeinde Leütenspurg [Lütisburg].

HA R 133, Fasz. 1, o. Pag.: 05.11.1801 - [Josef Würst].

HA R 133, Fasz. 1, o. Pag.: 12.12.1800 - Prüffung der Kompetenten für die Schuel-Lehrer-Stelle zu Andwil.

\section{Staatsarchiv Zug (StAZG):}

F I., o. Pag.: 07.05.1802 - Verwaltungskammer des Kantons Zürich, 07. May 1802.

\section{Staatsarchiv Zürich (StAZH):}

StAZH E I 21.1-21.9, E II 163, E II 164, A 313 - Schulumfrage 1771/1772.

\section{Zentral- und Hochschulbibliothek Luzern (ZHB):}

BB Ms 513.4, Bd. 1-7 - Zwanzigtausend Tage aus dem Leben des Xaver Unternährer, Lehrer (1884-1906).

\subsection{Gedruckte Quellen}

Erneuerte Schul-Ordnung für der Stadt Bern deutsche Landschaft. Gedruckt in Hoch-Obrigkeitlicher Druckerey 1720 und frisch aufgelegt 1759, Bern 1759.

Erneuerte Schul- und Lehr-Ordnung für die Schulen der Landschaft Zürich. Aus Hoch-Obrigkeitlichem Befehl zum Druck befördert, [o.O.] 1778.

Fragen über den Zustand der Schulen im Canton Aargau, 9. Januar 1799, LaGL HA Kiste 27, Mappe C, o. Pag: 09.01.1799.

General-Tabelle über den Zustand der Schulen im Kanton Säntis, im Jahr 1800, StASG HA R 132, Fasz. 1, o. Pag.: [1800]. General-Tabelle über den Zustand der Schulen im Kanton Linth Anno 1801, StASG HA R 132, Fasz. 1, o. Pag.: [1801]. General-Tabelle über den Zustand der Schulen im Kanton Baden im Jahr 1802, StASG HA R 132, Fasz. 1, o. Pag.: [1802]. Gesetz, enthaltend eine Schulordnung für die Landschaft des Kantons Zürich, StAZH OS AF 1, 394-408: 21.12.1803.

Gruner, Gottlieb Sigmund, Bemerkungen über den Zustand der Schulen des ehmaligen deutschen Bernergebiets, mit Ausnahme der Städten. Niedergeschrieben Anno 1790, in: Steinmüller, Johann Rudolf, Helvetische SchulmeisterBibliothek, allen Schullehrern und Freunden des Schulwesens gewidmet, Bd. 1, St. Gallen 1801: 87-160.

Landschul-Ordnung, StASH Schule 1/554: 09.05.1804.

Ordnung, welche auf der Landschafft des löbl. Stands Basel, So wohl Den Verrichtung des Gottesdienstes, Anstellung der Kirchenzucht, Heiligung des Sabbaths und Unterrichtung der Jugend, Als auch Anderen, die Gottesforcht und Ehrbarkeit betreffenden Geschäften und Handlungen in Obacht zu nehmen, Aus denen alten vormahls vorgeschriebenen Ordnungen zusammen gezogen, und nun frischer Dingen zu halten befohlen Anno MDCCLIX, Basel 1759, StABS Bf 1, Mandate 1756-1765: 22-30: 05.03.1759.

Rapport du Conseil d'éducation du canton du Léman, sur l'état des Ecoles dans ce Canton, Sur ses travaux, et sur les vues qui l'ont dirigé. 1801: 1-38.

Schmidt, Heinrich Richard/Messerli, Alfred/Osterwalder, Fritz/Tröhler, Daniel (Hgg.), Die Stapfer-Enquête. Edition der helvetischen Schulumfrage von 1799, Bern 2015.

Strickler, Johannes/Rufer, Alfred (Hgg.), Aktensammlung aus der Zeit der Helvetischen Republik ASHR (1798-1803), 11 Bde. Bern 1886-1911. 


\subsection{Literatur}

Abegg, Gottfried, Beiträge zur Geschichte des urnerischen Schulwesens, in: Pädagogischer Blätter 2 (1895): 40-691.

Albrecht, Peter/Hinrichs, Ernst (Hgg.), Das niedere Schulwesen im Übergang vom 18. zum 19. Jahrhundert, Tübingen 1995.

Alheit, Peter, Biographie-/Lebenslaufforschung, in: Krüger/Grunert, Wörterbuch: 89-93.

Apel, Hans Jürgen/Horn, Klaus-Peter/Lundgreen, Peter/Sandfuchs, Uwe (Hgg.), Professionalisierung pädagogischer Berufe im historischen Prozess, Bad Heilbrunn 1999.

Ariès, Philippe, Geschichte der Kindheit, 16. Aufl., München 2007.

Aubry, Carla/Westberg, Johannes (Hgg.), History of Schooling. Politics and Local Practice, Frankfurt am Main 2012.

Badertscher, Hans/Grunder, Hans-Ulrich (Hgg.), Geschichte der Erziehung und Schule in der Schweiz im 19. und 20. Jahrhundert, Bern 1997.

Baumann, Anette, Eheanbahnung und Partnerwahl, in: Westphal/Schmidt-Voges/Baumann, Vulcanus: 25-49.

Baumann, Max, Alltag und Kultur, in: Bucher, Sankt-Galler Geschichte: 44-94.

Beier, Inna, Carl August Zeller (1774-1846). Die Theorie der Elementarschule und ihre Transformation in eine pädagogische Praxis, Münster 2015.

Berner, Esther, Im Zeichen von Vernunft und Christentum. Die Zürcher Landschulreform im ausgehenden 18. Jahrhundert, Köln 2010.

Berner, Hans, Basel (Kanton). 3.5 - Religiöses und kulturelles Leben, in: Historisches Lexikon der Schweiz (HLS): URL: http://www.hls-dhs-dss.ch/textes/d/D7387.php [10.05.2018].

Birrer, Raphaela, Lehrermangel wird sich zuspitzen, in: Tagesanzeiger, 15.08.2017: 4.

Bloch, Alexandra, „Schreiben thut bleiben“. Die Schulreform auf der Zürcher Landschaft in den 1770er-Jahren, in: Holzhey/Zurbuchen, Löcher: 249-266.

Bloch Pfister, Alexandra, Priester der Volksbildung. Der Professionalisierungsprozess der Zürcher Volksschullehrkräfte zwischen 1770 und 1914, Zürich 2007.

Bödeker, Hans Erich/Hinrichs, Ernst (Hgg.), Alphabetisierung und Literalisierung in Deutschland in der Frühen Neuzeit, Tübingen 1999.

Bölling, Rainer, Sozialgeschichte der deutschen Lehrer. Ein Überblick von 1800 bis zur Gegenwart, Göttingen 1983.

Bölsker-Schlicht, Franz, Die Visitationsprotokolle Bernard Overbergs von 1783/84 als Grundlage für eine Quantifizierung des Landschulwesens im Niederstift Münster, in: Hanschmidt, Schulvisitationsprotokolle: 186-212.

Bondeli, Martin, Kantianismus und Fichteanismus in Bern. Zur philosophischen Geistesgeschichte der Helvetik sowie zur Entstehung des nachkantischen Idealismus, Basel 2001.

Böning, Holger, Revolution in der Schweiz. Das Ende der Alten Eidgenossenschaft. Die Helvetische Republik (17981803), Frankfurt am Main, 1985.

Böning, Holger, Der Traum von Freiheit und Gleichheit. Helvetische Revolution und Republik (1798-1803) - Die Schweiz auf dem Weg zur bürgerlichen Demokratie, Zürich 1998.

Bosche, Anne, Form und Reform der Schule im freien Markt. Schulentwicklung im Ancien Régime, in: SZB 2/30 (2008): 259-274.

Bossard, Carl, Bildungs- und Schulgeschichte von Stadt und Land Zug. Eine kulturgeschichtliche Darstellung der zugerischen Schulverhältnisse im Übergang vom Ancien Régime zur Moderne, Zug 1984.

Boucard, Louis, L'école primaire valaisanne à la fin du XVIII. siècle et son histoire de 1798 à 1830, St. Maurice 1938.

Bourdieu, Pierre, „Die biographische Illusion“, in: BIOS 3/1 (1990): 75-81.

Boyer, Ludwig, Johann Ignaz Felbigers Fibeln und ihr Beitrag zur Alphabetisierung in Österreich, in: Internationale Schulbuchforschung 19/1 (1997): 221-238.

Brakensieck, Stefan, Welche Erfahrungen begründen eine Generation? Prosopographische Befunde aus der Übergangszeit vom Ancien Régime zum 19. Jahrhundert, in: Schulz/Grebner, Generationswechsel: 43-55.

Brändli, Sebastian/Landolt, Pius/Wertli, Peter, Die Bildung des wahren republikanischen Bürgers. Der aargauische Erziehungsrat 1798-1998, Aarau 1998.

Brändli, Sebastian, Skylla und Charybdis in der Bildungsgeschichte. Methodische und perspektivische Bemerkungen zur disziplinären Entwicklung in der Schweiz, in: SZG 3/61 (2011): 290-314.

Braun, Rudolf, Industrialisierung und Volksleben. Die Veränderungen der Lebensformen in einem ländlichen Industriegebiet vor 1800 (Zürcher Oberland), Zürich 1960.

Braun, Rudolf, Das ausgehende Ancien Régime in der Schweiz. Aufriss einer Sozial- und Wirtschaftsgeschichte des 18. Jahrhunderts, Göttingen 1984.

Braun-Bucher, Barbara, Die Lateinischen und Hohen Schulen, in: Holenstein, Berns goldene Zeit: 272-276.

Brian, Sarah/Stegmeier, Andreas, Der Lehrer sei arm, aber brav. Eine kleine Geschichte der aargauischen Lehrerschaft am Beispiel ihrer Kantonalkonferenz, Baden 2000. 
Brückner, Erika, Die retrospektive Erhebung von Lebensverläufen, in: Mayer, Lebensverläufe: 374-403.

Brühwiler, Ingrid, Schwache Schulen und arme Lehrer? Sozioökonomische Aspekte des Bildungswesens um 1800, in: Tröhler, Volksschule: 119-134.

Brühwiler, Ingrid, Teachers' salaries in the Helvetic republic, c. 1800, in: Aubry/Westberg, History of Schooling: 68-89.

Brühwiler, Ingrid, Finanzierung des Bildungswesens in der Helvetischen Republik. Vielfalt - Entwicklungen - Herausforderungen, Bad Heilbrunn 2014.

Bruning, Jens, Elementarschule, in: Enzyklopädie der Neuzeit Online, Ed. Friedrich Jaeger, <http://dx.doi. org/10.1163/2352-0248_edn_a0889000> [22.11.2017].

Brunner, Otto/Conze, Werner/Koselleck, Reinhard (Hgg.), Geschichtliche Grundbegriffe. Historisches Lexikon zur politisch-sozialen Sprache in Deutschland, Bd. 1, Stuttgart 1972.

Bucher, Silvio (Hrsg.), Sankt-Galler Geschichte. Frühe Neuzeit: Bevölkerung, Kultur, Bd. 4, St. Gallen 2003.

Bütikofer, Anna, Staat und Wissen. Ursprünge des modernen schweizerischen Bildungssystems im Diskurs der Helvetischen Republik, Bern 2006.

Bütikofer, Anna, Das Projekt einer nationalen Schulgesetzgebung in der Helvetischen Republik (1798-1803), in: Criblez, Bildungsraum: 33-56.

Büttner, Peter, Schreiben lehren um 1800, Hannover 2015.

Casagrande, Giampietro (Hrsg.), Ticino 1798-1998: Dai baliaggi italiani alla Repubblica cantonale. Percorsi - Documenti - allestimento architettonico - oggetti storici e d'arte, Bd. 2, Lugano 1999.

Caspard, Pierre, Lehrer. 1 - Mittelalter und Ancien Régime, in: Historisches Lexikon der Schweiz (HLS), URL: http:// www.hls-dhs-dss.ch/textes/d/D10428.php [17.11.2017].

Conze, Werner, Beruf, in: Brunner/Conze/Koselleck, Geschichtliche Grundbegriffe: 490-507.

Crespo, Maria, Verwalten und Erziehen. Die Entwicklung des Zürcher Waisenhauses 1637-1837, Zürich 2001.

Criblez, Lucien/Jenzer, Carlo, Zur Situation und Entwicklung der Schulgeschichte in der Schweiz, in: SZB 2/17 (1995): 210-239.

Criblez, Lucien (Hrsg.), Bildungsraum Schweiz. Historische Entwicklung und aktuelle Herausforderungen, Bern 2008.

Crotti, Claudia/Oelkers, Jürgen (Hgg.), Ein langer Weg. Die Ausbildung der bernischen Lehrkräfte von 1798 bis 2002, Bern 2002.

Crotti, Claudia, Lehrerinnen - frühe Professionalisierung. Professionsgeschichte der Volksschullehrerinnen in der Schweiz im 19. Jahrhundert, Bern 2005.

Crotti, Claudia/Gonon, Philipp/Herzog, Walter (Hgg.), Pädagogik und Politik. Historische und aktuelle Perspektiven. Festschrift für Fritz Osterwalder, Bern 2007.

Dachverband Lehrerinnen und Lehrer Schweiz (LCH), Medienmitteilung. Löhne der Lehrpersonen sind nicht konkurrenzfähig, Zürich 26. Juni 2014, https://www.lch.ch/fileadmin/files/documents/Medienmitteilungen/140626_ Medienmitteilung_LCH_Loehne_Lehrpersonen.pdf [16.10.2017].

Dantl, Georg, Vom Schullehrling zum Schulmeister. Geschichte der Lehrerbildung im 19. Jahrhundert, Weiden 1989.

Daum, Matthias, Der Herr Lehrer ist ein Exot. Sie wollen unterrichten, nicht erziehen und verwalten - was Männer an der Primarschule reizt, in: NZZ, 23.03.2010: 40.

Depkat, Volker, Zum Stand und zu den Perspektiven der Autobiographieforschung in der Geschichtswissenschaft, in: BIOS 2/23 (2010): 170-187.

Derron, Marianne/Zimmermann, Christian von (Hgg.), Jeremias Gotthelf. Neue Studien, Hildesheim 2014.

Dévaud, Eugène, L'École primaire Fribourgeoise sous la République helvétique 1798-1803, Fribourg 1905.

De Vincenti-Schwab, Andrea, Schule vor Ort. Die Zürcher Landschulen am Ende des 18. Jahrhunderts, in: Tröhler/ Hardegger, Zukunft: 14-25.

De Vincenti, Andrea, Schule der Gesellschaft. Wissensordnungen von Zürcher Unterrichtspraktiken zwischen 1771 und 1834, Zürich 2015.

Dickson, Patricia, Eine Berufung im Bann der Viruskrise, in: Bildung Schweiz 5 (2020), S. 12-14.

Di Cioccio, Mauro, Zwischen Barockfrömmigkeit und Vernunft, Ancien Régime und Helvetik. Der Luzerner Welt- und Ordensklerus im ausgehenden 18. Jahrhundert, unveröffentlichte Masterarbeit, Universität Bern 2013.

Di Cioccio, Mauro, Der katholische Schweizer Klerus am Ende des 18. Jahrhunderts, in: Schweizerische Gesellschaft zur Erforschung des achzehnten Jahrhunderts: Tagungsband zur Tagung „Politische Schweiz, gelehrte Schweiz, imaginierte Schweiz. Kohäsion und Disparität im Corpus helveticum des 18. Jahrhunderts“ vom 23.-25. November 2017 (unveröffentlichter Tagungsbeitrag).

Diderich, Jürgen, Der Lehrer, in: Lenzen, Erziehungswissenschaft: 228-252.

Dolton, Peter/Marcenaro-Gutierrez, Oscar, 2013 Global Teacher Status Index,https://www.varkeyfoundation.org/ sites/default/files/documents/2013GlobalTeacherStatusIndex.pdf [13.12.2017].

Dubler, Anne-Marie, Der „Hintersässe“ - ein armer Fremder, ein Gemeindemitglied ohne politische Rechte? Zur gesellschaftlichen Stellung der Nichtburger im Emmental des 17. und 18. Jahrhunderts, in: SAV 2/89 (1993): 143-164. 
Dubler, Anne-Marie, Beruf. Vom Mittelalter bis 1800, in: Historisches Lexikon der Schweiz (HLS), URL: http://www. hls-dhs-dss.ch/textes/d/D13737.php [23.11.2017].

Dubler, Anne-Marie, Ehaften, in: Historisches Lexikon der Schweiz (HLS), URL: http://www.hls-dhs-dss.ch/ textes/d/D13731.php [23.11.2017].

Dubler, Anne-Marie, Handwerk, in: Historisches Lexikon der Schweiz (HLS), URL: http://www.hls-dhs-dss.ch/ textes/d/D13954.php [23.04.2018].

Dubler, Anne-Marie, Ligerz, in: Historisches Lexikon der Schweiz (HLS), URL: http://www.hls-dhs-dss.ch/textes/d/ D443.php [23.11.2017].

Dubler, Anne-Marie, Mündigkeit, in: Historisches Lexikon der Schweiz (HLS), URL: http://www.hls-dhs-dss.ch/ textes/d/D10367.php [23.11.2017].

Dubler, Anne-Marie, Patrizische Orte, in: Historisches Lexikon der Schweiz (HLS), URL: http://www.hls-dhs-dss.ch/ textes/d/D26422.php [23.11.2017].

Dubler, Anne-Marie, Unehrliche Berufe, in: Historisches Lexikon der Schweiz (HLS), URL: http://www.hls-dhs-dss. $\mathrm{ch} /$ textes/d/D25613.php [12.05.2018].

Dubler, Anne-Marie, Ungeld, in: Historisches Lexikon der Schweiz (HLS), URL: http://www.hls-dhs-dss.ch/textes/d/ D26199.php [25.04.2018].

Duhamelle, Christophe/Schluhmbohm, Jürgen (Hgg.), Eheschliessungen im Europa des 18. und 19. Jahrhunderts, Göttingen 2003.

Duhamelle, Christophe/Schluhmbohm, Jürgen, Einleitung: Vom „europäischen Heiratsmuster“ zu Strategien der Eheschliessung? in: Duhamelle/Schluhmbohm, Eheschliessungen: 11-34.

Duisen, Bettina, „Biographieforschung“ - Reflexionen zum Anspruch und Wirkung eines sozialwissenschaftlichen Paradigmas, in: BIOS 26/2 (2013): 163-176.

Durrer, Josef, Die Schulen in den Urkantonen im Jahre 1799. Nach den Materialien der helvetischen Schulstatistik, Bern 1879 .

Eberhard, Fabian/Pastega, Nadja, Wenn es Lehrern an Wissen mangelt, in: Sonntagszeitung, 12.06.2016: 6.

Ebert, Berthold, Vom Schul-„,Meister“"zum Schullehrer - der Volksschullehrer im 19. Jahrhundert, in: Wenzel, Lehrerbild: $37-44$.

Ebert, Jochen/Trossbach, Werner (Hgg.), Dörfliche Erwerbs- und Nutzungsorientierungen (Mitte 17. bis Anfang 19. Jahrhundert). Bausteine zu einem überregionalen Vergleich, Kassel 2016.

Egli, Roger, Schulreform in der Praxis. Luzerner Landschullehrer und die St. Urbaner Normalmethode, unveröffentlichte Lizentiatsarbeit, Universität Bern 2009.

Ehmer, Josef, Heiratsverhalten, Sozialstruktur, ökonomischer Wandel. England und Mitteleuropa in der Formationsperiode des Kapitalismus, Göttingen 1991.

Ehrenpreis, Stefan/Lotz-Heumann, Ute, Reformation und konfessionelles Zeitalter, Darmstadt 2002.

Ehrenpreis, Stefan, Erziehungs- und Schulwesen zwischen Konfessionalisierung und Säkularisierung. Forschungsprobleme und methodische Innovationen, in: Schilling/Ehrenpreis, Konfessionalisierung: 19-34.

Ehrenpreis, Stefan, Eine integrierte Erziehungs- und Schulgeschichte als neue Perspektive der europäischen Frühneuzeitforschung, in: $\mathrm{ZpH}$ 2/2010: 91-95.

Eibl, Sabine, Küster im Fürstbistum Münster. Stabsdisziplinierung, Gemeindeansprüche und Eigeninteressen im konfessionellen Zeitalter, Münster 2016.

Eigenmann, Ines, Brachland für Bildung? Das Schulwesen in den Distrikten Frauenfeld und Tobel zur Zeit der Helvetik, in: Gnädinger, Abbruch: 113-128.

Enzelberger, Sabina, Sozialgeschichte des Lehrerberufs. Gesellschaftliche Stellung und Professionalisierung von Lehrerinnen und Lehrern von den Anfängen bis zur Gegenwart, Weinheim 2001.

Erne, Emil, Die schweizerischen Sozietäten. Lexikalische Darstellung der Reformgesellschaften des 18. Jahrhunderts in der Schweiz, Zürich 1988.

Fallet, Estelle/Veyrassat, Béatrice, Uhrenindustrie, in: Historisches Lexikon der Schweiz (HLS), URL: http://www. hls-dhs-dss.ch/textes/d/D13976.php [23.11.2017].

Fankhauser, Andreas, Die „Staats=Machine“der Helvetischen Republik. Institutionelle und personelle Kontinuität innerhalb eines revolutionären Verwaltungsapparats, in: Schläppi, Umbruch: 65-82.

Fankhauser, Andreas, Helvetische Republik, in: Historisches Lexikon der Schweiz (HLS), URL: http://www.hls-dhsdss.ch/textes/d/D9797.php [23.11.2017].

Fankhauser, Andreas, Helvetische Revolution, in: Historisches Lexikon der Schweiz (HLS), URL: http://www.hls-dhsdss.ch/textes/d/D17217.php [23.11.2017].

Fend, Helmut, Geschichte des Bildungswesens. Der Sonderweg im europäischen Kulturraum, Wiesbaden 2006.

Fetscherin, Rudolf, Geschichte des bernischen Schulwesens. Zweite Periode. Von der Reform bis zur Landschulordnung 1765, in: Pionier 16 (1895): 10-182. 
Flückiger, Ernst, Die Stadtschulen von Murten. Zur Hundertjahrfeier der Sekundarschule Murten 1950, Laupen 1950. Flückiger Strebel, Erika, Zwischen Wohlfahrt und Staatsökonomie. Armenfürsorge auf der bernischen Landschaft im 18. Jahrhundert, Zürich 2002.

Flueler, Elisabeth, Die Geschichte der Mädchenbildung in der Stadt Basel, Basel 1984.

Fuchs, Markus, Die gesetzlichen Grundlagen des niederen Schulwesens in der Helvetischen Republik im Vorfeld der Schul-Enquête, in: Tröhler, Volksschule: 75-88.

Fuchs, Markus, Der rationale Staat und seine bürokratischen Grenzen. Philipp Albert Stapfer auf der Suche nach den Antworten der Luzerner Schul-Enquête, in: ZpH 2 (2010): 122-128.

Fuchs, Markus, Lehrerinnen- und Lehrerperspektiven in der Helvetischen Republik, Bad Heilbrunn 2015.

Gallus, Alexander, Biographik und Zeitgeschichte, in: APuZ 12/(2005): 40-46.

Geissler, Gert, Schulgeschichte in Deutschland von den Anfängen bis zur Gegenwart, Frankfurt 2011.

Gindroz, André, Histoire de l'Instruction publique dans le Pays de Vaud, Lausanne 1853.

Glass, David Victor/Eversley, David Edward (Hgg.), Population in history. Essays in historical demography, Chicago 1965.

Glaus, Beat, Der Kanton Linth der Helvetik, Schwyz 2005.

Gnädinger, Beat (Hrsg.), Abbruch - Umbruch - Aufbruch. Zur Helvetik im Thurgau, Frauenfeld 1999.

Godenzi, Luca, Die Anfänge der staatlich organisierten Lehrerbildung im Kanton Zürich. Die Weiterbildungskurse für Landschullehrer auf dem Riedtli (1806-1808), in: phAkzente 2 (2007): 32-35.

Gotthelf, Jeremias, Leiden und Freuden eines Schulmeisters, Bd. 1, Bern 1838.

Greyerz, Kaspar von/Bischof, Franz Xaver, Konfessionalismus, in: Historisches Lexikon der Schweiz (HLS), URL: http://www.hls-dhs-dss.ch/textes/d/D43511.php [17.11.2017].

Grosser, Hermann, Der Zustand der Schulen und deren Verbesserungen in Appenzell I.-Rh. zu Zeit der Helvetik (17981803), Separatdruck aus dem „Appenzeller Volksfreund“, Appenzell 1944.

Grosser, Hermann, Das Schulwesen von Appenzell Innerrhoden, in: Archiv für das Schweizerische Unterrichtswesen 48 (1962): 7-65.

Grosser, Hermann, Die Appenzell-innerrhodischen Antworten über das Schul- und Kirchenwesen auf die Rundfragen von 1799, in: IhG 18 (1973): 48-85.

Grube, Norbert, Schulwirklichkeit? Wissensproduktion über Volksschulen in Holstein und in der Helvetischen Republik um 1800, in: Tröhler, Bildungspolitik: 181-198.

Grunder, Hans Ulrich, P.A. Stapfer Enquête von 1799 und die Folgen - oder: „...die gänzliche Zerstörung des Föderalismus“. Ein Beispiel aus der Schweiz, in: Liedtke, Hausaufgabe: 100-119.

Grunder, Hans Ulrich (Hrsg.), „Der Kerl ist verrückt!“ Das Bild des Lehrers und der Lehrerin in der Literatur und in der Pädagogik, Zürich 1999.

Grunder, Hans Ulrich, Lehrkräfte in der Literatur und in der Pädagogik, in: Grunder, Bild des Lehrers: 7-14.

Grunder, Hans Ulrich, Das Lehrerbild in der Karikatur, in: Grunder, Bild des Lehrers: 155-159.

Grunder, Hans Ulrich, Der Lehrer als Hungerleider und andere Lehrerbilder, in: Grunder, Bild des Lehrers: 160-167.

Grunder, Hans Ulrich (Hrsg.), Aus der Geschichte lernen? Die historische Perspektive in der Ausbildung von Lehrerinnen und Lehrern, Baltmannsweiler 2011.

Gruntz-Stoll, Johannes, Appenzeller Schüler und Gehilfen Pestalozzis. Hermann Krüsi, Johannes Niederer, Johann Georg Tobler, Herisau 1985.

Gruntz-Stoll, Johannes/Steiner, Edmund, Tafeln klappern, Griffel kreischen. Lötschentaler Schulgeschichte(n), Bern 2008.

Gschwind, Franz, Bevölkerungsentwicklung und Wirtschaftsstruktur der Landschaft Basel im 18. Jahrhundert: Ein historisch-demographischer Beitrag zur Sozial- und Wirtschaftsgeschichte mit besonderer Berücksichtigung der langfristigen Bevölkerungsentwicklung von Stadt (seit 1100) und Landschaft (seit 1500), Basel 1977.

Guggenheim, Willy (Hrsg.), Juden in der Schweiz. Glaube - Geschichte - Gegenwart, Küsnacht 1983.

Günther-Arndt, Hilke/Klattenhoff, Klaus/Wissmann, Friedrich, Vom Seminar zur Universität 1793-1993. 200 Jahre Lehrerbildung in Oldenburg, Oldenburg 1993.

Günther-Arndt, Hilke, „...nicht bloß ein verständiger und zu seinem Geschäfte geschickter sondern auch ein guter Mensch..... Zur Geschichte der Lehrerbildung in Oldenburg 1793-1993, in: Günther-Arndt/Klattenhoff/Wissmann, Universität: 9-40.

Haas, Leonhard, Die Innerschweiz in den Enquêten der Helvetik, in: Der Geschichtsfreund, Bd. 124 (1971): 508-530. Haener, Ruth, Schweizer Rohstoff Bildung, in: NZZ, 19.12.2016: 16.

Hajnal, John, European marriage patterns in perspective, in: Glass/Eversley, Population: 101-145.

Hammerstein, Notker/Herrmann, Ulrich (Hgg.), Handbuch der deutschen Bildungsgeschichte, Bd. 2, München 2005.

Hanschmidt, Alwin (Hrsg.), Elementarschulverhältnisse im Niederstift Münster im 18. Jahrhundert. Die Schulvisitationsprotokolle Bernard Overbergs für die Ämter Meppen, Cloppenburg und Vechta 1783/84, Münster 2000. 
Harders, Levke/Lipphardt, Veronika, Kollektivbiografie in der Wissenschaftsgeschichte als qualitative und problemorientierte Methode, in: Traverse 2/13 (2006): 81-91.

Hareven, Tamara K., Familiengeschichte, Lebenslauf und sozialer Wandel, Frankfurt a.M. 1999.

Hattie, John/Zierer, Klaus, Visible Learning: Auf den Punkt gebracht, 2. Aufl., Baltmannsweiler 2018.

Hauer, Wolfram, Lokale Schulentwicklung und städtische Lebenswelt. Das Schulwesen in Tübingen von seinen Anfängen im Spätmittelalter bis 1806, Stuttgart 2003.

Hauser, Albert, Schweizerische Wirtschafts- und Sozialgeschichte, Erlenbach 1961.

Häusler, Beat, Flecken, in: Historisches Lexikon der Schweiz (HLS), URL: http://www.hls-dhs-dss.ch/textes/d/ D7870.php [23.11.2017].

Head-König, Anne-Lise, Les politiques étatiques coercitives et leur influence sur la formation du mariage en suisse au XVIIIe siècle, in: Duhamelle/Schlumblohm, Eheschliessungen: 189-214.

Head-König, Anne-Lise/Schnegg, Brigitte (Hg.), Armut in der Schweiz (17.-20. Jh.). SGWS Heft 7, Zürich 1989.

Head-König, Anne-Lise, Auswanderung - 1 Formen der Auswanderung, in: Historisches Lexikon der Schweiz (HLS), URL: http://www.hls-dhs-dss.ch/textes/d/D7988.php [23.04.2018].

Head-König, Anne-Lise, Ehe, in: Historisches Lexikon der Schweiz (HLS), URL: http://www.hls-dhs-dss.ch/textes/d/ D7975.php [23.11.2017].

Head-König, Anne-Lise, Ehehindernisse, in: Historisches Lexikon der Schweiz (HLS), URL: http://www.hls-dhs-dss. ch/textes/d/D16109.php [23.11.2017].

Heer, Oswald/Blumer-Heer, J.J., Historisch-geographisch-statistisches Gemälde der Schweiz. Der Kanton Glarus, Bd. VII, St. Gallen 1846.

Heinemann, Manfred (Hrsg.), Der Lehrer und seine Organisation, Stuttgart 1977.

Helfenberger, Marianne, Aspekte der Vorgeschichte der institutionalisierten Lehrerbildung im Kanton Bern 1798-1830, in: Crotti/Oelkers, Ein langer Weg: 27-74.

Helfenberger, Marianne, Die Berner (Normal-)Lehrer zwischen 1807 und 1830, in: Tröhler, Bildungspolitik: 127-145.

Henry, Philippe, Fremde Dienste, in: Historisches Lexikon der Schweiz (HLS), URL: http://www.hls-dhs-dss.ch/ textes/d/D8608.php [02.05.2018].

Herrmann, Ulrich (Hrsg.), „Das pädagogische Jahrhundert“. Volksaufklärung und Erziehung zur Armut im 18. Jahrhundert in Deutschland, Weinheim 1981.

Herrmann, Ulrich, Lehrer - professional, Experte, Autodidakt, in: Apel/Horn/Lundgreen/Sandfuchs (Hgg.), Professionalisierung pädagogischer Berufe: 408-428.

Herrmann, Ulrich, Familie, Kindheit, Jugend, in: Hammerstein/Herrmann, Handbuch: 69-96.

Hess, Johann W., Geschichte des Schulwesens der Landschaft Basel bis 1830, Basel 1896.

Hinrichs, Ernst, „Ja das Schreiben und das Lesen.... Zur Geschichte der Alphabetisierung in Norddeutschland von der Reformation bis zum 19. Jahrhundert, in: Albrecht/Hinrichs, Übergang: 371-391.

Hippel, Wolfgang von, Armut, Unterschichten, Randgruppen in der Frühen Neuzeit, München 1995.

Hochstadt, Steve, Migration in Preindustrial Germany, in: CEH 3/16 (1983): 195-224.

Hodel, Gottfried, „Kinder, immer nur Kinder, aber Lehrer bringt keiner!“ Bildungspolitische Massnahmen zur Steuerung des Bedarfes an Primarlehrkräften in den Kantonen Bern und Solothurn zwischen 1848 und 1998, Bern 2005.

Hofer, Markus, Leiden und Freuden eines Schulmeisters: historische Hintergründe der Lehrertaxation, in: Derron/ Zimmermann, Gotthelf: 181-201.

Hofstetter, Rita, Les lumières de la démocratie. Histoire de l'école primaire publique à Genève au XIXe siècle, Bern 1998.

Hofstetter, Rita u.a. (Hgg.), Une école pour la Démocratie. Naissance et développement de l'école primaire publique en Suisse au 19e siècle, Bern 1999.

Höhener, Hans-Peter, Zentralistische oder föderalistische Schweiz? Die Gebietseinteilung in der Helvetik 1798 bis 1803 und ihre Darstellung in Karten, in: CH 17-18 (1998): 21-31.

Hohl, Agnes, Wählbarkeit der Frauen in Behörden. Mitarbeit im Rahmen der „natürlichen Grenzen“, in: Staatsarchiv Zürich: Verfassungsgeschichte: 96-98.

Holenstein, André, „Gute Policey“ und lokale Gesellschaft im Staat des Ancien Régime. Das Fallbeispiel der Marktgrafschaft Baden (-Durlach), Epfendorf 2003.

Holenstein, André, Reform und Rationalität. Die Enquêten in der Wissens- und Verwaltungsgeschichte der Helvetischen Republik, in: Tröhler, Volksschule: 13-32.

Holenstein, André (Hrsg.), Berns goldene Zeit. Das 18. Jahrhundert neu entdeckt, Bern 2008.

Holenstein, André, Die Helvetik als reformabsolutistische Republik, in: Schläppi, Umbruch: 83-104.

Holenstein, André/Kapossy, Béla/Tosato-Rigo, Danièle (Hgg.), Reichtum und Armut in den schweizerischen Republiken des 18. Jahrhunderts. Akten des Kolloquiums vom 23.-25. November 2006 in Lausanne, Genf 2010.

Holenstein, André, Beschleunigung und Stillstand. Spätes Ancien Régime und Helvetik (1712-1802/03), in: Kreis, Geschichte der Schweiz: 311-361. 
Holenstein, André, Mitten in Europa. Verflechtung und Abgrenzung in der Schweizer Geschichte, Baden 2014.

Holenstein, André, Bauern - Frühe Neuzeit, in: Historisches Lexikon der Schweiz (HLS), URL: http://www.hls-dhsdss.ch/textes/d/D16370.php [23.11.2017].

Holenstein, André, Gemeine Herrschaften, in: Historisches Lexikon der Schweiz (HLS), URL: http://www.hls-dhs-dss. ch/textes/d/D9817.php [23.11.2017].

Holzhey, Helmut/Zurbuchen, Simone (Hgg.), Alte Löcher - neue Blicke. Zürich im 18. Jahrhundert: Aussen- und Innenperspektiven, Zürich 1997.

Höpflinger, François, Bevölkerungswandel in der Schweiz. Zur Entwicklung von Heiraten, Geburten, Wanderungen und Sterblichkeit, Grüsch 1986.

Höpflinger, François, Alter, in: Historisches Lexikon der Schweiz (HLS), URL: http://www.hls-dhs-dss.ch/textes/d/ D2826.php [23.11.2017].

Horlacher, Rebekka, Der helvetische Lehrer als ausgemusterter Leutnant? Historiographische Mythen und empirische Daten über den Lehrer der Helvetik, in: Tröhler, Bildungspolitik: 15-28.

Hörsch Waltraud/Bannwart Josef, Luzerner Pfarr- und Weltklerus 1700-1800. Ein biographisches Lexikon, Luzern 1998.

Huber, Peter, Fluchtpunkt Fremdenlegion. Schweizer im Indochina- und Algerienkrieg 1945-1962, Zürich 2017.

Hug, Anna, Die St. Urbaner Schulreform an der Wende des 18. Jahrhunderts, Zürich 1920.

Huggel, Samuel, Die Einschlagsbewegung in der Basler Landschaft: Gründe und Folgen der wichtigsten agrarischen Neuerung im Ancien Régime, 2 Bde., Liestal 1979.

Hunziker, Otto (Hrsg.), Geschichte der Schweizerischen Volksschule in gedrängter Darstellung mit Lebensabrissen der bedeutenderen Schulmänner und um das schweizerische Schulwesen besonders verdienter Personen bis zur Gegenwart, 3 Bde., Zürich 1881-1882.

Hunziker, Otto, Vorarbeiten zu einer schweizerischen Schulgeschichte des 19. Jahrhunderts, Separatdruck aus der „Schweiz. Lehrerzeitung“, Nr. 8-11, 1903.

Illi, Martin/Zangger, Alfred, Stadt-Land-Beziehungen, in: Historisches Lexikon der Schweiz (HLS), URL: http:// www.hls-dhs-dss.ch/textes/d/D7881.php [23.11.2017].

Im Hof, Ulrich/Staehelin, Andreas (Hgg.), Handbuch der Schweizer Geschichte, Bd. 2, Zürich 1977.

Im Hof, Ulrich, Ancien Régime, in: Im Hof/Staehelin, Andreas, Handbuch: 673-784.

Im Hof, Ulrich, Geleitwort. Zur Rolle der Sozietäten im 18. Jahrhundert zwischen Utopie, Aufklärung und Reform, in: Erne, Sozietäten: 11-14.

Jacobi, Juliane, Mädchen- und Frauenbildung in Europa. Von 1500 bis zur Gegenwart, Frankfurt 2013.

Jeismann, Karl-Ernst, Ludwig Natorps Beitrag zur Bildungsreform 1804-1840, in: Schmitt/Tosch, Erziehungsreform: 11-39. Jenzer, Carlo/Jenzer, Susi, Lehrer werden - einst und jetzt. 200 Jahre solothurnische Lehrerbildung, 150 Jahre Lehrerseminar, Grenchen 1984.

Jenzer, Carlo, Die Schulklasse. Eine historisch-systematische Untersuchung, Bern 1991.

Jörin, Ernst, Der Aargau 1798-1803. Vom bernischen Untertanenland zum souveränen Grosskanton, Aarau 1929.

Kälin, Paul, Die Aufklärung in Uri, Schwyz und Unterwalden im 18. Jahrhundert. Separatdruck der MhVS, Bd. 45, Schwyz 1946.

Keiner, Edwin/Tenorth, Heinz-Elmar, Schulmänner, Volkslehrer, Unterrichtsbeamte. Ergebnisse und Probleme neuerer Studien zur Sozialgeschichte des Lehrers in Deutschland, in: IASL 6 (1981): 198-222.

Kellerhals-Maeder, Andreas, Weisst du, wieviel Sternlein stehen? Die protostatistischen Erhebungen im Kanton Bern zwischen 1528 und 1831, Lizentiatsarbeit, Bern 1985.

Kesper-Biermann, Sylvia, Staat und Schule in Kurhessen 1813-1866, Göttingen 2001.

Kleinau, Elke/Opitz, Claudia (Hgg.), Geschichte der Mädchen- und Frauenbildung. Vom Mittelalter bis zur Aufklärung, Bd. 1, Frankfurt 1996.

Klinke, Wilibald, Das Volksschulwesen des Kantons Zürich zur Zeit der Helvetik (1798-1803), Zürich 1907.

Kocka, Jürgen, Sozialgeschichte zwischen Strukturgeschichte und Erfahrungsgeschichte, in: Schieder/Sellin, Sozialgeschichte in Deutschland: 67-88.

Konrad, Franz-Michael, Geschichte der Schule. Von der Antike zur Gegenwart, München 2007.

Körner, Martin, Stadt. 3 - Frühe Neuzeit, in: Historisches Lexikon der Schweiz (HLS), URL: http://www.hls-dhs-dss. ch/textes/d/D7875.php [23.11.2017].

Koselleck, Reinhard, Einleitung, in: Brunner/Conze/Koselleck, Geschichtliche Grundbegriffe: XIII-1.

Kradolfer, Wilhelm (Hrsg.), Ein Lehrerleben vor hundert Jahren. Aufzeichnungen des Basler Armenschullehrers Matthias Buser (1788-1848), Basel 1930.

Kreis, Johann Georg, „Predigen - oh Lust und Freude“. Erinnerungen eines Thurgauer Landpfarrers 1820-1906, Zürich 1998. 
Kreis, Georg (Hrsg.), Die Geschichte der Schweiz, Basel 2014.

Kriemler, Daniel, Basler Lesegesellschaft 1825-1915. Eine Kollektivbiographie im sozialen und politischen Kontext der Basler Geschichte des 19. Jahrhunderts, Basel 2017.

Krüger, Heinz-Hermann/Grunert, Cathleen (Hgg.), Wörterbuch Erziehungswissenschaft, 2. Aufl. Opladen 2006.

Krüsi, Hermann, Erinnerungen aus meinem pädagogischen Leben und Wirken vor meiner Vereinigung mit Pestalozzi, während derselben und seither, Stuttgart 1840.

Krüsi, Hermann, Meine Bestrebungen und Erfahrungen im Gebiete der Volkserziehung: dargestellt in Briefen an Freunde, Gais 1842.

Kuhlemann, Frank-Michael, Modernisierung und Disziplinierung. Sozialgeschichte des preussischen Volksschulwesens 1794-1872, Göttingen 1992.

Kupfer, Claude/Weingarten, Ralph, Zwischen Ausgrenzung und Integration. Geschichte und Gegenwart der Jüdinnen und Juden in der Schweiz, Zürich 1999.

Landert, Charles, Die Berufszufriedenheit der Deutschschweizer Lehrerinnen und Lehrer (2014). Bericht zur vierten Studie des Dachverbandes Lehrerinnen und Lehrer Schweiz (LCH), Zürich 2014.

Landolt, Hermann, Die Schule der Helvetik im Kanton Linth 1798-1803 und ihre Grundlagen im 18. Jahrhundert, Zürich 1973.

Landolt, Niklaus, Tauner - Politische Stellung, in: Historisches Lexikon der Schweiz (HLS), URL: http://www.hlsdhs-dss.ch/textes/d/D16378.php [18.04.2018].

Landolt, Pius, „Sichere und unermüdete Executoren: Erziehungsräte in der Helvetik (1798-1803), in: Brändli/Landolt/ Wertli, republikanischen Bürgers: 8-33.

Lang, Robert, Schulgeschichte des Kantons Schaffhausen, Separatabdruck aus der Festschrift des Kantons Schaffhausen zur Bundesfeier 10. August 1901, Schaffhausen 1901.

Langewiesche, Dieter, Wanderungsbewegungen in der Hochindustrialisierungsperiode. Regionale, interstädtische und innerstädtische Mobilität in Deutschland 1880-1914, in: VSWG 1/64 (1977): 1-40.

Lehmann, Kai, Projekt 1719. Lebenserwartung im 17. und 18. Jahrhundert in der Herrschaft Schmalkalden, in: ZhG 116 (2011): 137-162.

Lengwiler, Martin/Rothenbühler, Verena/Ivedi, Cemile, Schule macht Geschichte. 175 Jahre Volksschule im Kanton Zürich 1832-2007, Zürich 2007.

Lenzen, Dieter (Hrsg.), Erziehungswissenschaft. Ein Grundkurs, 6. Aufl., Hamburg 2004.

Liedtke, Max (Hrsg.), Hausaufgabe Europa. Schule zwischen Regionalismus und Internationalismus, Bad Heilbrunn 1993.

Luginbühl, Rudolf, Philipp Albert Stapfer, helvetischer Minister der Künste und Wissenschaften (1766-1840), Basel 1902.

Lundgreen, Peter, Sozialgeschichte der deutschen Schule im Überblick. Teil I: 1770-1918, Göttingen 1980.

Lundgreen, Peter, Die Feminisierung des Lehrerberufs: Segregierung der Geschlechter oder weibliche Präferenz? Kritische Auseinandersetzung mit einer These von Dagmar Hänsel, in: ZfP 45/1 (1999): 121-136.

Mahlmann-Bauer, Barbara (Hrsg.), Jeremias Gotthelf und die Schule. Katalog zur Ausstellung in der Gotthelf-Stube in Lützelflüh, Bern 2009.

Mahlmann-Bauer, Barbara, Leiden und Freuden eines Schulmeisters, ein Spiegel für Schulmeister und ihre Vorgesetzten, in: Mahlmann-Bauer, Gotthelf: 68-79.

Maissen, Thomas, Geschichte der Schweiz, Baden 2010.

Manz, Matthias, Die Basler Landschaft in der Helvetik 1798-1803. Über die materiellen Ursachen von Revolution und Konterrevolution, Liestal 1991.

Marion, Gilbert, Pfarrer (reformiert) - soziale Herkunft und Stellung, in: Historisches Lexikon der Schweiz (HLS), URL: http://www.hls-dhs-dss.ch/textes/d/D11522.php [23.11.2017].

Marti, Hanspeter, Klosterkultur und Aufklärung in der Fürstabtei St. Gallen, St. Gallen 2003.

Martin, Ernst, Johann Heinrich Pestalozzi und die alte Landschaft Basel. Die Wirkungsgeschichte der pestalozzischen Pädagogik, Liestal 1986.

Mattmüller, Markus/Schluchter, André, Vorwort, in: Schluchter, Agrarzonen der Alten Schweiz: 5-7.

Mattmüller, Markus, Die Umfragen der Helvetik, in: Simon, Dossier Helvetik: 243-245.

Mattmüller, Markus, Bauern und Tauner im schweizerischen Kornland um 1700, in: SZG 53 (2003): 379-395.

Mattmüller, Markus, Agrarverfassung. 3 - 18.-20. Jahrhundert, in: Historisches Lexikon der Schweiz (HLS), URL: http://www.hls-dhs-dss.ch/textes/d/D13699.php [23.11.2017].

Mayer, August, Geschichte von Ermatingen, 3. Teil: 1600-1800, in: TBG 38 (1898): 5-71.

Mayer, Karl Ulrich (Hrsg.), Lebensverläufe und sozialer Wandel, Kölner Zeitschrift für Soziologie und Sozialpsychologie, Sonderheft 31, Opladen 1990.

Mayer, Karl Ulrich, Lebensverlauf, in: Schäfers/Zapf, Handwörterbuch: 446-460. 
Mayer, Christine, Die Anfänge einer institutionalisierten Mädchenerziehung an der Wende vom 18. zum 19. Jahrhundert, in: Kleinau/Opitz, Frauenbildung: 372-392.

Mayer, Christine, Erziehung und Schulbildung für Mädchen, in: Hammerstein/Herrmann, Handbuch: 188-212.

Mayer, Marcel, Leinwand, in: Historisches Lexikon der Schweiz (HLS), URL: http://www.hls-dhs-dss.ch/textes/d/ D13958.php [23.11.2017].

Meier, Bruno/Sauerländer, Dominik/Stauffacher, Rudolf (Hgg.), Revolution im Aargau. Umsturz - Aufbruch - Widerstand 1798-1803, Aarau 1997.

Meier, Fritz, Sturmläuten für die Aargauer Schule. Weiss-Blätter mit Variationen zur Entstehung des aargauischen Schulgesetzes von 1835, Aarau 1986.

Meier, Thomas, Handwerk, Hauswerk, Heimarbeit. Nicht-agrarische Tätigkeiten und Erwerbsformen in einem traditionellen Ackerbaugebiet des 18. Jahrhunderts (Zürcher Unterland), Zürich 1986.

Menolfi, Ernest, Ehe, Geburt und Tod: Zur Bevölkerungsentwicklung bis 1800, in: Bucher, Sankt-Galler Geschichte: 107-130.

Merki, Christoph Maria, Sozialgeschichte, in: Historisches Lexikon der Schweiz (HLS), URL: http://www.hls-dhs-dss. ch/textes/d/D8431.php [23.11.2017].

Merz, Richard, Die Landschulen des alten Murtenbiets. Auszug aus Freiburger Geschichtsblätter XXIX. Band, Freiburg 1928.

Messerli, Alfred, Literale Normen und Alphabetisierung im 18. und 19. Jahrhundert in der Schweiz, in: Bödeker/Hinrichs, Literalisierung: 309-326.

Messerli, Alfred/Chartier, Roger (Hgg.), Lesen und Schreiben in Europa 1500-1900. Vergleichende Perspektiven, Basel 2000.

Messerli, Alfred, Das Lesen von Gedrucktem und das Lesen von Handschriften - zwei verschiedene Kulturtechniken? in: Messerli/Chartier, Europa: 235-246.

Messerli, Alfred, Lesen und Schreiben 1700 bis 1900. Untersuchungen zur Durchsetzung der Literalität in der Schweiz, Tübingen 2002.

Meusburger, Peter, Bildungsgeographie. Wissen und Ausbildung in der räumlichen Dimension, Heidelberg 1998.

Meyer, Reinhard, Hundert Jahre Sekundarschule Langenthal. Dargestellt im Anschluss an die frühern Schulverhältnisse, Langenthal 1933.

Mitterauer, Michael, ledige Mütter. Zur Geschichte illegitimer Geburten in Europa, München 1983.

Mitterauer, Michael, Sozialgeschichte der Jugend. Frankfurt am Main 1986.

Mitterauer, Michael/Sieder, Reinhard, Vom Patriarchat zur Partnerschaft. Zum Strukturwandel der Familie, 4. Aufl., München 1991.

Mitterauer, Michael, Die Familie als historische Sozialform, in: Mitterauer/Sieder, Patriarchat: 21-45.

Mitterauer, Michael, Der Mythos von der vorindustriellen Grossfamilie, in: Mitterauer/Sieder, Patriarchat: 46-71.

Mitterauer, Michael, Die Entwicklung zum modernen Familienzyklus, in: Mitterauer/Sieder, Patriarchat: 72-99.

Mitterauer, Michael, Sozialgeschichte der Familie. Kulturvergleich und Entwicklungsperspektiven. Basistexte Wirtschafts- und Sozialgeschichte Bd. 1, Wien 2009.

Modoux, Valérie, Les Ecoles de Charité de Lausanne, in: Holenstein, Berns goldene Zeit: 269.

Montandon, Jens, Die Organisation von Schule aus konfessioneller Perspektive, in: Tröhler, Volksschule: 89-102.

Montandon, Jens, Utzenstorfer Anfänge, in: Mahlmann-Bauer, Gotthelf: 16-22.

Montandon, Jens, Gemeinde und Schule. Determinanten lokaler Schulwirklichkeit zu Beginn des 19. Jahrhunderts anhand der bernischen Schulumfrage von 1806, Nordhausen 2011.

Mösch, Johann, Die Solothurnische Volksschule vor 1830. Der Einzug der Normalmethode in die solothurnische Volksschule 1782-1798, Bd. 4, Solothurn 1918.

Mösch, Johann, Die solothurnische Schule in ihrem Auf- und Ausbau, Olten 1930.

Müller, Felix, Die Schule - eine Bestandesaufnahme, in: Meier/Sauerländer/Stauffacher, Aufbruch: 246-248.

Nachbaur, Ulrich, Lehrerinnenzölibat. Zur Geschichte der Pflichtschullehrerinnen in Vorarlberg im Vergleich mit anderen Ländern, Regensburg 2011.

Neugebauer, Wolfgang, Absolutistischer Staat und Schulwirklichkeit in Brandenburg-Preussen, Berlin 1985.

Neugebauer, Wolfgang, Niedere Schulen und Realschulen, in: Hammerstein/Herrmann, Handbuch: 213-261.

Noll, Hans, Hofrat Johannes Büel von Stein am Rhein 1761-1830. Ein Freund grosser Zeitgenossen, Frauenfeld 1930.

Notz, Emil, Die säkulare Entwicklung der Kaufkraft des Geldes für Basel in den Perioden 1800-1833 und 1892-1923 nebst internationalen Vergleichen, Jena 1925.

Noverraz, Daniel, La formation des maîtres dans le canton de Vaud. Du XVIe siècle au XXIe siècle, Yens-sur-Morges 2008.

Ochsner, Martin, Die schwyzerischen Schulberichte an Minister Stapfer, in: MhVS 20 (1909): 205-310.

Oelkers, Jürgen/Osterwalder, Fritz (Hgg.), Pestalozzi - Umfeld und Rezeption. Studien zur Historisierung einer Legende, Basel 1995.

Osterwalder, Fritz, Zur Vorgeschichte der pädagogischen Konzepte Pestalozzis, in: Oelkers/Osterwalder, Pestalozzi: 52-91. 
Panchaud, Georges, Les écoles vaudoises à la fin du régime bernois, Lausanne 1952.

Pape, Elise, Der biographische Ansatz in Frankreich. Entstehung und aktuelle Entwicklungen, in: BIOS 2/22 (2009): 283-292.

Perrenoud, Alfred, La population de Genève du seizième au début du dix-neuvième siècle. Étude démographique. Structures et mouvements, Bd. 1, Genève 1979.

Perrenoud, Alfred, Ehelosigkeit, in: Historisches Lexikon der Schweiz (HLS), URL: http://www.hls-dhs-dss.ch/ textes/d/D16110.php [23.11.2017].

Perrenoud, Alfred, Lebenszyklus, in: Historisches Lexikon der Schweiz (HLS), URL: http://www.hls-dhs-dss.ch/ textes/d/D15991.php [23.11.2017].

Peyer, Hans Conrad, Verfassungsgeschichte der alten Schweiz, Zürich 1978.

Pfammatter, David, Schule als Teil der Lebenswelt. Einflussfaktoren und Entwicklung von Fricktaler und Unteraargauer Schulen des ausgehenden 18. Jahrhunderts im Vergleich, Nordhausen 2014.

Pfenniger, Paul, Zweihundert Jahre Luzerner Volksschule 1798-1998, Luzern 1998.

Pfister, Christian, Bevölkerungsgeschichte und historische Demographie 1500-1800. Enzyklopädie deutsche Geschichte, Bd. 82, München 1994.

Pfister, Christian, Geschichte des Kantons Bern seit 1798. Im Strom der Modernisierung. Bevölkerung, Wirtschaft und Umwelt 1700-1914, Bd. 4, Bern 1995.

Pfister, Ulrich, Politischer Klientelismus in den Landgebieten der frühneuzeitlichen Schweiz, in: Schluchter, Agrarzonen der Alten Schweiz: 143-158.

Pietzko, Nadine, Lehrmittellandschaften um 1800, in: Tröhler, Bildungspolitik: 83-102.

Prass, Reiner, Grundzüge der Agrargeschichte. Vom dreissigjährigen Krieg bis zum Beginn der Moderne (1650-1880), Bd. 2, Köln 2016.

Radeff, Anne, Kleinhandel, in: Historisches Lexikon der Schweiz (HLS), URL: http://www.hls-dhs-dss.ch/textes/d/ D26300.php [25.04.2018].

Reimann, Martha, Die Geschichte der Arauer Stadtschulen von ihren Anfängen bis zum Ende der bernischen Herrschaft (1270-1798), Aarau 1914.

Reinhardt, Sybille: Erwachsenenalter, in: Krüger/Grunert, Wörterbuch: 116-204.

Reininghaus, Wilfried, Migrationen von Handwerkern. Anmerkungen zur Notwendigkeit von Theorien, Konzepten und Modellen, in: Schulz, Handwerk in Europa: 195-212.

Reiser, Rudolf, Lehrergeschichte(n). Ein historischer Streifzug von der Germanenzeit bis zur Gegenwart, München 1984.

Ries, Markus, Klerus - Neuzeit, in: Historisches Lexikon der Schweiz (HLS), URL: http://www.hls-dhs-dss.ch/ textes/d/D26998.php [04.04.2018].

Roca, René (Hg.), Katholizismus und moderne Schweiz. Basel 2016.

Rohr, Adolf, Philipp Albert Stapfer. Minister der Helvetischen Republik und Gesandte der Schweiz in Paris 1798-1803, Baden 2005.

Rosenbaum, Margret, Untersuchungen zur Veränderung des Selbstverständnisses des Lehrers während der Aufklärung in Deutschland. Ein Beitrag zur Geschichte des Volksschullehrerberufes, Köln 1970.

Rosenmund, Moritz, Volksbildung als Verzichtsleistung: Annäherung an die politische Ökonomie des Zürcher Landschulwesens im 18. Jahrhundert, in: Tröhler/Schwab, Volksschule im 18. Jahrbundert: 51-64.

Rothen, Marcel, Lesen - Schreiben - Rechnen. Aspekte von Schulwirklichkeit und der schulische Alphabetisierungserfolg in der Basler Landschaft am Ende des Ancien Régime, unveröffentlichte Masterarbeit, Universität Bern 2012.

Rothen, Marcel, Die Lehrer an niederen Schulen in der Helvetischen Republik. Erkenntnisgewinn einer kollektivbiographischen Untersuchung der Stapfer-Enquête von 1799, in: Tröhler, Bildungspolitik: 29-48.

Rothen, Marcel/Ruloff, Michael, Die vergessenen Schulumfragen der Helvetischen Republik, in: Tröhler, Volksschule: 33-54.

Ruch, Rahel, Die Examinierung der Schaffhauser Lehrerinnen und Lehrer im 18. Jahrhundert, unveröffentlichte Seminararbeit, Universität Bern 2014.

Ruloff, Michael, Lehrerinnen und Lehrer in der Schweizer Presse (1800-1830), Bern 2014.

Ruloff, Michael, Konkurrenz, Eifersucht und Schulbesuch um 1800, in: Tröhler, Bildungspolitik: 49-60.

Ruloff, Michael, Schule und Gesellschaft um 1800. Der Schulbesuch in der Helvetischen Republik, Bad Heilbrunn 2017.

Rutschi, Sandra, Artikel: Primarlehrer bleiben rar, in: BZ, 21.01.2015.

Rutz, Andreas, Lehrer/in, in: Enzyklopädie der Neuzeit Online, Ed. Friedrich Jaeger. <http://dx.doi.org/10.1163/23520248_edn_a2461000> [22.11.2017].

Salamin, Michel, Dans les écoles valaisannes 1798-1815, in: AV 2/65 (1990): 45-80.

Sauer, Michael, Volkschullehrerbildung in Preussen. Die Seminare und Präparandenanstalten vom 18. Jahrhundert bis zur Weimarer Republik, Köln 1987. 
Scandola, Pietro, Von der Standesschule zur Staatsschule. Die Entwicklung des Schulwesens in der Schweizerischen Eidgenossenschaft 1750-1830 am Beispiel der Kantone Bern und Zürich, in: Schmale/Dodde, Revolution: 582-625.

Scandola, Pietro/Rogger, Franziska/Gerber, Jürg (Hgg.), Lehrerinnen und Lehrer zwischen Schule, Stand und Staat. Geschichte des Bernischen Lehrervereins. Jubiläumsband 100 Jahre BLV, Münsingen 1992.

Scandola, Pietro, Lehrerschaft und Lehrerverein bis zum Zweiten Weltkrieg, in: Scandola/Rogger/Gerber, Staat: 1-62.

Schäfers, Berhard/Zapf, Wolfgang (Hgg.), Handwörterbuch zur Gesellschaft Deutschlands, 2. erw. Aufl., Opladen 2001.

Scheipl, Josef/Seel, Helmut, Die Entwicklung des österreichischen Schulwesens von 1750-1938, Graz 1985.

Schenda, Rudolf, Volk ohne Buch. Studien zur Sozialgeschichte der populären Lesestoffe 1770-1910, Frankfurt a.M. 1970.

Scherwey, Johann, Die Schule im alten deutschen Bezirk des Kantons Freiburg. Von den Anfängen bis zum Jahr 1848, Freiburg 1943.

Scheurer, Janine, „Pastoris virtus maxima nosse suos“. Alphabetisierung und Schulwesen in der ländlichen Gemeinde Gachnang (TG) im 17. und 18. Jahrhundert, unveröffentlichte Masterarbeit, Universität Bern 2016.

Schibler, Peter, Schulalltag im alten Bern, Betadruck aus dem Berner Jahrbuch 1982, Bern 1981.

Schieder, Wolfgang/Sellin, Volker (Hgg.), Sozialgeschichte in Deutschland. Entwicklungen und Perspektiven im internationalen Zusammenhang, 3 Bde. Göttingen 1986.

Schiess, Emil, Hermann Krüsi. Pestalozzis ältester Gehilfe und Mitarbeiter, Separatdruck aus AJ 54/55, Trogen 1928.

Schiffler, Horst/Winkeler, Rolf, Tausend Jahre Schule. Eine Kulturgeschichte des Lernens in Bildern, Stuttgart 1985.

Schilling, Heinz/Ehrenpreis, Stefan (Hgg.), Konfessionalisierung und Säkularisierung. Forschungsperspektiven, europäische Fallbeispiele und Hilfsmittel, Münster 2003.

Schläppi, Daniel (Hrsg.), Umbruch und Beständigkeit. Kontinuitäten in der Helvetischen Revolution von 1798, Basel 2009.

Schläppi, Daniel, Die Helvetik (1798-1803) - Neue Ansätze zum Verhältnis von Wandel und Kontinuität anhand von Sondierbohrungen an einer paradigmatischen Epochenschwelle, in: Schläppi, Umbruch: 9-24.

Schlegel, Johann Jakob, Drei Schulmänner in der Schweiz. Lebensbild von Johann Rudolf Steinmüller, Antistes und biographische Skizzen über H. Krüsi und J.J. Wehrli, Seminardirektoren, Zürich 1879.

Schleifer-Stöckli, Karin, Nidwalden. 4.1.1 - Von der Helvetik zum Bundesstaat (1798-1848), in: Historisches Lexikon der Schweiz (HLS), URL: http://www.hls-dhs-dss.ch/textes/d/D7411.php [23.11.2017].

Schluchter, André (Hrsg), Die Agrarzonen der Alten Schweiz, ITINERA 10, Basel 1989.

Schluchter, André, Zur Armut auf der solothurnischen Landschaft des ausgehenden Ancien Régime, in: Head-König/ Schnegg, Armut: 159-184.

Schluchter, André, Agrarzonen, in: Historisches Lexikon der Schweiz (HLS), URL: http://www.hls-dhs-dss.ch/ textes/d/D13930.php [23.11.2017].

Schmale, Wolfgang/Dodde, Nan L. (Hgg.), Revolution des Wissens? Europa und seine Schulen im Zeitalter der Aufklärung (1750-1825). Ein Handbuch zur europäischen Schulgeschichte, Bochum 1991.

Schmidt, Heinrich Richard, Dorf und Religion. Reformierte Sittenzucht in Berner Landgemeinden der Frühen Neuzeit, Stuttgart 1995.

Schmidt, Heinrich Richard, Neue Ergebnisse der Alphabetisierungsforschung für die Schweiz und Südwestdeutschland um 1800, in: Tröhler, Volksschule: 149-172.

Schmidt, Heinrich Richard, Schweizer Elementarschulen im 18. und 19. Jahrhundert zwischen Konfession und Lebenswelt, in: Crotti/Gonon/Herzog, Pädagogik und Politik: 31-52.

Schmidt, Heinrich Richard, Niedere Schulen, in: Holenstein, Berns goldene Zeit: 266-272.

Schmidt, Heinrich Richard, Die Stapfer-Enquête als Momentaufnahme der Schweizer Niederen Schulen vor 1800, in: $\mathrm{ZpH}$ 15/2 (2009): 98-112.

Schmidt, Heinrich Richard, Handlungsstrategien und Problembereiche der Armenfürsorge im Alten Bern, in: Holenstein/Kapossy/Tosato-Rigo, Reichtum: 239-252.

Schmidt, Heinrich Richard, Volksbildung in Mitteleuropa im Spiegel der Stapferschen Enquête von 1799, in: Schmitt/ Böning/Greiling/Siegert, Entdeckung: 19-42.

Schmidt, Heinrich Richard, Bildungsvorsprung des Schweizer Katholizismus um 1800?, in: Roca, Katholizismus: 91105.

Schmidt, Heinrich Richard, Die Schulen im Kapitel Bern während des langen 18. Jahrhunderts, in: Tröhler, Bildungspolitik: 147-164.

Schmidt, Heinrich Richard/Egger, Michael, Alphabetisierung, Schulbesuch und Lektüre im Kontext dörflicher ökonomischer Strukturen des Kantons Zürich, in: Ebert/Trossbach, Nutzungsorientierungen: 99-127.

Schmidt-Voges, Inken, „Weil der Ehe-Stand ein ungestümmes Meer ist...“ - Bestands- und Krisenphasen in ehelichen Beziehungen in der Frühen Neuzeit, in: Westphal/Schmidt-Voges/Baumann, Vulcanus: 89-162.

Schmitt, Hanno/Tosch, Frank (Hgg.), Erziehungsreform und Gesellschaftsinitiative in Preussen 1798-1840, Berlin 1999. 
Schmitt, Hanno/Böning, Holger/Greiling, Werner/Siegert, Reinhard (Hgg.), Die Entdeckung von Volk, Erziehung und Ökonomie im europäischen Netzwerk der Aufklärung, Bremen 2011.

Schneider, Ernst, Die bernische Landschule am Ende des XVIII. Jahrhunderts, Bern 1905.

Schnyder, Albert, „Feine Unterschiede“ auf dem Dorf. Zur Analyse der Sozialstruktur der ländlichen Gesellschaft im schweizerischen Kornland des ancien régime, in: Tanner/Head-König, Bauern: 159-168.

Schnyder, Albert, Landwirtschaft. 3 - Frühe Neuzeit, in: Historisches Lexikon der Schweiz (HLS), URL: http://www. hls-dhs-dss.ch/textes/d/D13933.php [23.11.2017].

Schraut, Sylvia/Pieri, Gabrielle, Katholische Schulbildung in der Frühen Neuzeit. Vom „guten Christenmenschen“ zu „tüchtigen Jungen“ und „braven Mädchen“. Darstellung und Quellen, Paderborn 2004.

Schraut, Sylvia, Einführung. Mädchenbildung im katholischen Raum, in: Dies./Pieri, Gabrielle, Katholische Schulbildung: 13-70.

Schröder, Wilhelm Heinz (Hrsg.), Lebenslauf und Gesellschaft. Zum Einsatz von kollektiven Biographien in der historischen Sozialforschung, Stuttgart 1985.

Schröder, Wilhelm Heinz, Kollektive Biographien in der historischen Sozialforschung: Eine Einführung, in: Schröder, Lebenslauf: 7-17.

Schröder, Wilhelm Heinz, Kollektivbiographie als interdisziplinäre Methode in der Historischen Sozialforschung: Eine persönliche Retrospektive, Köln 2011.

Schulz, Andreas/Grebner, Gundula (Hgg.), Generationswechsel und historischer Wandel. Sonderdruck Historische Zeitschrift Beiheft 36, München 2003.

Schulz, Knut (Hrsg.), Handwerk in Europa. Vom Spätmittelalter bis zur frühen Neuzeit, München 1999.

Schwab, Andrea, Wissen um zu handeln - Handeln um zu wissen. Die Zürcher Schulumfrage 1771/1772 in ihren Kontexten, in: Tröhler/Schwab, Volksschule im 18. Jahrhundert: 31-50.

Schwab, Andrea, Der Schulmeister in der vormodernen Volksschule. Vom Wahrheitsgehalt einer Karikatur, in: phAkzente 1 (2007): 38-42.

Schweizerisches Idiotikon. Wörterbuch der schweizerdeutschen Sprache, Bd. 2, Frauenfeld 1885.

Seel, Helmut, Einführung in die Schulgeschichte Österreichs, Innsbruck 2010.

Seemann, Hans Richard, Die Schulpraxis in der Lehrerbildung. Eine historisch-systematische Untersuchung, Weinheim 1964.

Sialm, Placidus, Das Unterrichts- und Erziehungswesen in den schwyzerischen Teilen der Kantone Waldstätten und Linth zur Zeit der Helvetik (1798-1803). Separatdruck der MhVS, Bd. 48, Einsiedeln 1949.

Simon, Christian, Die Helvetik: eine bäuerliche Revolution? Bäuerliche Interessen als Determinanten revolutionärer Politik in der Helvetik, in: Tanner/Head-König, Bauern: 169-186.

Simon, Christian (Hrsg.), Dossier Helvetik. Sozioökonomische Strukturen - Frauengeschichte/Geschlechtergeschichte, Bd. 2, Basel 1997.

Simon-Muscheid, Katharina, Gesellen, in: Historisches Lexikon der Schweiz (HLS), URL: http://www.hls-dhs-dss.ch/ textes/d/D16371.php [17.11.2017].

Staatsarchiv Zürich (Hrsg.), Kleine Zürcher Verfassungsgeschichte 1280-2000. Zürich 2000.

Stadler, Hans, Schulwesen. 1 - Mittelalter und Frühe Neuzeit, in: Historisches Lexikon der Schweiz (HLS), URL: http://www.hls-dhs-dss.ch/textes/d/D10396.php [17.11.2017].

Stefanidou-Kappmann, Olga, Zur Geschichte des Volksschullehrers, in: Grunder, Bild des Lehrers: 131-141.

Stöcklin, Peter, Zur sozialen Schichtung in der Baselbieter Gemeinde Diegten um 1800, in: Simon, Dossier Helvetik: 21-40.

Stone, Lawrence, Prosopography, in: Daedalus, 100 (1971): 46-79.

Stratmann, Hildegard, Lehrer werden. Berufliche Sozialisation in der Volksschullehrer-Ausbildung in Westfalen (18701914), Münster 2006.

Strehler, Hedwig, Beiträge zur Kulturgeschichte der Zürcher Landschaft. Kirche und Schule im 17. und 18. Jahrhundert, Lachen 1934.

Suter, Meinrad, Zürich (Kanton). 2 - Herrschaft, Politik und Verfassung vom Hochmittelalter bis zum Ende des 18. Jahrhunderts, in: Historisches Lexikon der Schweiz (HLS), URL: http://www.hls-dhs-dss.ch/textes/d/D7381. php [23.11.2017].

S. n., Pfarrer Leonhard Hohl von Wolfhalden. Ein Nekrolog, in: AJ 1 (1854): 39-48.

S. n., Ein Beitrag zur Geschichte der Lehrerbildung im Kanton Appenzell A. Rh., in: AJ 3/6 (1862): $79-87$.

Tanner, Albert/Head-König, Anne-Lise (Hgg.), Die Bauern in der Geschichte der Schweiz, SGWS, Heft 10, Zürich 1992.

Tanner, Albert, Alltagsgeschichte, in: Historisches Lexikon der Schweiz (HLS), URL: http://www.hls-dhs-dss.ch/ textes/d/D8093.php [23.11.2017].

Tanner, Albert, Baumwolle, in: Historisches Lexikon der Schweiz (HLS), URL: http://www.hls-dhs-dss.ch/textes/d/ D13961.php [23.11.2017]. 
Tenorth, Heinz-Elmar, Professionen und Professionalisierung. Ein Bezugsrahmen zur historischen Analyse des „Lehrers und seiner Organisation“, in: Heinemann, Organisation: 457-476.

Tenorth, Heinz-Elmar, Geschichte der Erziehung. Einführung in die Grundzüge ihrer neuzeitlichen Entwicklung, Weinheim 2010.

Terhart, Ewald, Lehrer, in: Krüger/Grunert, Wörterbuch: 285-291.

Theilkäs, Lorenz, Die Idee der „respublica ethica“ als Grundlage für Stapfers helvetische Bildungspolitik, in: Tröhler, Bildungspolitik: 231-248.

Tobler, Hans Jakob, Die Gestalt des Lehrers bei Pestalozzi, Zürich 1969.

Töpfer, Thomas, Die „Freyheit“ der Kinder. Territoriale Politik, Schule und Bildungsvermittlung in der vormodernen Stadtgesellschaft. Das Kurfürstentum und Königreich Sachsen 1600-1815, Tübingen 2012.

Tosato-Rigo, Danièle, Das Bild des Lehrers in der Helvetik, in: Tröhler, Volksschule: 55-73.

Tosato-Rigo, Danièle, Paroles de témoins: Vers une pluralisation du récit historique, in: ETHE 15 (2014): 137-159.

Tosato-Rigo, Danièle/Savoy, Damien, Schulumfrageneifer in den Kantonen Freiburg und Léman, in: Tröhler, Bildungspolitik: 103-126.

Tosato-Rigo, Danièle, Waadt. 2.2.3 - Proteste, Rebellionen und Reformbestreben, in: Historisches Lexikon der Schweiz (HLS), URL: http://www.hls-dhs-dss.ch/textes/d/D7395.php [23.11.2017].

Tosato-Rigo, Danièle, Waadt. 3.2 - Gesellschaft und Wirtschaft vom Mittelalter bis 1798, in: Historisches Lexikon der Schweiz (HLS), URL: http://www.hls-dhs-dss.ch/textes/d/D7395.php [23.11.2017].

Tosch, Frank, Lassen sich Lehrkräfte gut ausbilden? Zur Professionalisierung von Lehrerinnen und Lehrern, in: Grunder, Geschichte: 243-270.

Trinks, Karl, Die Sozialgestalt des Volksschullehrers. Stuttgart 1980.

Tröhler, Daniel, Erziehung oder Unterricht? Lehrerbildung in der Helvetik und die Rolle Pestalozzis, in: BzL 15/3 (1997): 293-303.

Tröhler, Daniel/Schwab, Andrea (Hgg.), Volksschule im 18. Jahrhundert. Die Schulumfrage auf der Zürcher Landschaft in den Jahren 1771/1772, Bad Heilbrunn 2006.

Tröhler, Daniel, Schulgeschichte und historische Bildungsforschung. Methodologische Überlegungen zu einem vernachlässigten Genre pädagogischer Historiographie, in: Tröhler/Schwab, Volksschule im 18. Jahrhundert: 65-93.

Tröhler, Daniel/Hardegger, Urs (Hgg.), Zukunft bilden. Die Geschichte der modernen Zürcher Volksschule, Zürich 2008.

Tröhler, Daniel (Hrsg.), Volksschule um 1800. Studien im Umfeld der Stapfer-Enquête 1799, Bad Heilbrunn 2014.

Tröhler, Daniel, Die Stapfer-Enquête 1799 als historischer Meilenstein und historiographische Chance, in: Tröhler, Volksschule: 7-12.

Tröhler, Daniel, Die helvetischen Schulmeister und die Schulkritik um 1800, in: Tröhler, Volksschule: 103-118.

Tröhler, Daniel (Hrsg.), Schule, Lehrerschaft und Bildungspolitik um 1800. Neue Studien im Umfeld der Stapfer-Enquête von 1799, Bad Heilbrunn 2016.

Tröhler, Daniel, Die bildungsgeschichtliche Relevanz der Stapfer-Enquête, in: Tröhler, Bildungspolitik: 7-14.

Trossbach, Werner, Bauern 1648-1806, München 1993.

Trossbach, Werner/Zimmermann, Clemens (Hgg.), Agrargeschichte. Positionen und Perspektiven, Stuttgart 1998.

Trossbach, Werner, Beharrung und Wandel „als Argument“. Bauern in der Agrargesellschaft des 18. Jahrhunderts, in: Trossbach/Zimmermann, Agrargeschichte: 107-136.

Trossbach, Werner/Zimmermann, Clemens, Die Geschichte des Dorfes. Von den Anfängen im Frankenreich bis zur bundesdeutschen Gegenwart, Stuttgart 2006.

Tuggener, Heinrich, Der Lehrer. Studien über Stand, Beruf und Bildung des Volksschullehrers, Zürich 1962.

Van Dülmen, Richard, Kultur und Alltag in der Frühen Neuzeit. Das Haus und seine Menschen: 16.-18. Jahrhundert, 4. Auf., München 2005.

Vischer, Eduard, Die Wandlungen des Verhältnisses der Schule zu Kirche und Staat in Basel von der Mitte des 18. bis gegen Ende des 19. Jahrhunderts, Zürich 1931.

Walz, Ursula, Eselsarbeit für Zeisigfutter. Die Geschichte des Lehrers, Frankfurt a.M. 1988.

Wartburg-Adler von, Marianne, Die Lehrerinnen. Ein Beitrag zu ihrer Sozialgeschichte von 1862-1918. Im Spiegel der Schweizerischen Lehrerinnenzeitung und der Schweizerischen Lehrerzeitung, Diss. Univ. Zürich 1988.

Wartburg-Adler von, Marianne, Der steinige Weg zur Professionalisierung: Die Lehrerin in der Schweiz, in: Badertscher/Grunder, Geschichte der Erziehung: 441-467.

Wartburg-Ambühl von, Marie- Louise, Alphabetisierung und Lektüre. Untersuchung am Beispiel einer ländlichen Region im 17. und 18. Jahrhundert, Bern 1981.

Weber, Hans, Die Zürcherischen Landgemeinden in der Helvetik 1798-1803, Diss. phil. Universität Zürich, Zürich 1971. 
Weber, Max, Wirtschaft und Gesellschaft. Grundriss der Sozialökonomik, Bd. 1, Tübingen 1922.

Wehler, Hans-Ulrich, Deutsche Gesellschaftsgeschichte. Vom Feudalismus des Alten Reiches bis zur defensiven Modernisierung der Reformära 1700-1815, Bd. 1, München 1987.

Wenzel, Hartmut (Hrsg.), Lehrer, Lehrerbild und Lehrerbildung. Bilder zur Geschichte des Lehrerberufs in Mitteldeutschland. Katalog zur Ausstellung der Franckeschen Stiftungen vom 28. Januar bis 25. März 2007, 2. Aufl., Halle 2008.

Westphal, Siegrid/Schmidt-Voges, Inken/Baumann, Anett, Venus und Vulcanus. Ehen und ihre Konflikte in der Frühen Neuzeit, München 2011.

Westphal, Siegrid, Venus und Vulcanus. Einleitende Überlegungen, in: Westphal/Schmidt-Voges/Baumann, Vulcanus: 9-24.

Wicki, Dieter, Der aargauische Grosse Rat 1803-2003. Wandel eines Kantonsparlaments - eine Kollektivbiografie, Baden 2006.

Widmer, Johann Jakob, Das thurgauische Volksschulwesen unter der Helvetik, in: TBG 30 (1890): 57-125.

Wiget, Josef, Alois Reding, in: Historisches Lexikon der Schweiz (HLS), URL: http://www.hls-dhs-dss.ch/textes/d/ D7276.php [23.11.2017].

Wolter, Stefan C./Denzler, Stefan, Ökonomische Erklärungen zur Feminisierung des Lehrberufes. Folgen von anhaltender Diskriminierung von Frauen in der Privatwirtschaft, in: phAkzente 4 (2003): 23-25.

Wulf, Christoph/Zirfas, Jörg, Generation/Generationsverhältnisse, in: Krüger/Grunert, Wörterbuch: 215-221.

Würgler, Andreas, Eidgenossenschaft, in: Historisches Lexikon der Schweiz (HLS), URL: http://www.hls-dhs-dss.ch/ textes/d/D26413.php [17.11.2017].

Würgler, Andreas, Schirmherrschaften [Schirmorte], in: Historisches Lexikon der Schweiz (HLS), URL: http://www. hls-dhs-dss.ch/textes/d/D9830.php [09.03.2018].

Zingg, Eduard, Das Schulwesen auf der Landschaft Basel nach den amtlichen Berichten an das Erziehungs-Comité vom März 1798, Liestal 1898.

Zimmerli, Walther Ch./Malaguerra, Carlo/Künzli, Rudolf/Fischer, Markus, Zukunft Bildung Schweiz. Anforderungen an das schweizerische Bildungssystem 2030, Akademien der Wissenschaften Schweiz, Bern 2009.

Zimmermann, Clemens, Dorf und Land in der Sozialgeschichte, in: Schieder/Sellin, Sozialgeschichte in Deutschland: 90-112.

Zschunke, Peter, Konfession und Alltag in Oppenheim. Beiträge zur Geschichte von Bevölkerung und Gesellschaft einer gemischtkonfessionellen Kleinstadt in der Frühen Neuzeit, Wiesbaden 1984.

Zymek, Bernd, Konjunkturen einer illegitimen Disziplin. Entwicklung und Perspektiven der schulhistorischen Forschung in der Bundesrepublik Deutschland, in: Albrecht/Hinrichs, Übergang: 1-14. 


\section{Anhang}

\subsection{Anhang I: Stapfer-Enquête Fragebogen}

I. Lokal-Verhältnisse.

I.1 Name des Ortes, wo die Schule ist.

I.1.a Ist es ein Stadt, Flecken, Dorf, Weiler, Hof?

I.1.b Ist es eine eigene Gemeinde? Oder zu welcher Gemeinde gehört er?

I.1.c $\mathrm{Zu}$ welcher Kirchgemeinde (Agentschaft)?

I.1.d In welchem Distrikt?

I.1.e In welchen Kanton gehörig?

I.2 Entfernung der zum Schulbezirk gehörigen Häuser. In Viertelstunden.

I.3 Namen der zum Schulbezirk gehörigen Dörfer, Weiler, Höfe.

I.3.a Zu jedem wird die Entfernung vom Schulorte, und

I.3.b die Zahl der Schulkinder, die daher kommen, gesetzt.

I.4 Entfernung der benachbarten Schulen auf eine Stunde im Umkreise.

I.4.a Ihre Namen.

I.4.b Die Entfernung eines jeden.

II. Unterricht.

II.5 Was wird in der Schule gelehrt?

II.6 Werden die Schulen nur im Winter gehalten? Wie lange?

II.7 Schulbücher, welche sind eingeführt?

II.8 Vorschriften, wie wird es mit diesen gehalten?

II.9 Wie lange dauert täglich die Schule?

II.10 Sind die Kinder in Klassen geteilt?

III. Personal-Verhältnisse.

III.11 Schullehrer.

III.11.a Wer hat bisher den Schulmeister bestellt? Auf welche Weise?

III.11.b Wie heißt er?

III.11.c Wo ist er her?

III.11.d Wie alt?

III.11.e Hat er Familie? Wie viele Kinder?

III.11.f Wie lang ist er Schullehrer?

III.11.g Wo ist er vorher gewesen? Was hatte er vorher für einen Beruf?

III.11.h Hat er jetzt noch neben dem Lehramte andere Verrichtungen? Welche?

III.12 Schulkinder. Wie viele Kinder besuchen überhaupt die Schule?

III.12.a Im Winter. (Knaben/Mädchen)

III.12.b Im Sommer. (Knaben/Mädchen)

IV. Ökonomische Verhältnisse.

IV.13 Schulfonds (Schulstiftung)

IV.13.a Ist dergleichen vorhanden?

IV.13.b Wie stark ist er?

IV.13.c Woher fließen seine Einkünfte?

IV.13.d Ist er etwa mit dem Kirchen- oder Armengut vereinigt?

IV.14 Schulgeld. Ist eines eingeführt? Welches?

IV.15 Schulhaus.

IV.15.a Dessen Zustand, neu oder baufällig?

IV.15.b Oder ist nur eine Schulstube da? In welchem Gebäude?

IV.15.c Oder erhält der Lehrer, in Ermangelung einer Schulstube Hauszins? Wie viel?

IV.15.d Wer muß für die Schulwohnung sorgen, und selbige im baulichen Stande erhalten?

IV.16 Einkommen des Schullehrers.

IV.16.A An Geld, Getreide, Wein, Holz etc.

IV.16.B Aus welchen Quellen? aus 
IV.16.B.a abgeschaffenen Lehngefällen (Zehnten, Grundzinsen etc.)?

IV.16.B.b Schulgeldern?

IV.16.B.c Stiftungen?

IV.16.B.d Gemeindekassen?

IV.16.B.e Kirchengütern?

IV.16.B.f Zusammengelegten Geldern der Hausväter?

IV.16.B.g Liegenden Gründen?

IV.16.B.h Fonds? Welchen? (Kapitalien)

I. Anmerkung. Den Beantwortungen dieser Fragen können nach Belieben noch allerley Anmerkungen und Nachrichten beygefügt werden.

II. Anmerkung. Jeder Schullehrer soll die Beantwortung dieser Fragen doppelt schreiben; die erste Abschrift hat er sogleich seinem Agenten zu übergeben. Der Agent wird sie durch den Unterstatthalter und Regierungsstatthalter an den Minister der Künste und Wissenschaften gelangen lassen. Die zweyte Abschrift hat der Schullehrer dem Distriktsinspektor einzuhändigen.

III. Anmerkung. Jedermann ist gebeten, die Beantwortung und die Einsendung soviel möglich zu beschleunigen.

\subsection{Anhang II: Altersstruktur der Elementarschullehrer}

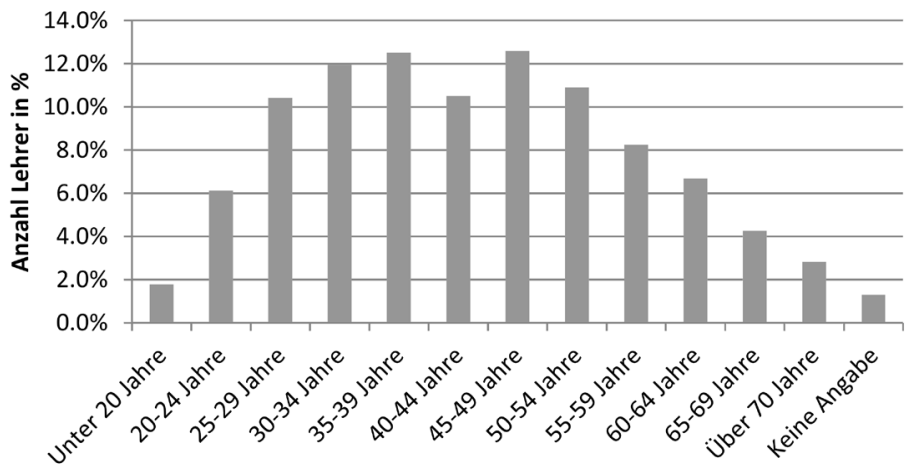

Tab. 45: Altersstruktur der Elementarschullehrkräfte um 1799 


\section{Dank}

Die vorliegende Arbeit wäre ohne die Mitwirkung einer Vielzahl von Personen niemals entstanden. Allen gilt mein herzlicher Dank!

Mein grösster Dank gilt meinem Doktorvater Prof. Dr. Heinrich Richard Schmidt, dem ich den Zugang zum frühneuzeitlichen Schulwesen und zur Stapfer-Enquête überhaupt erst verdanke. Seine Leidenschaft und Engagement für die Erforschung des Schulwesens motivierten mich, dieses Dissertationsprojekt anzunehmen. Für das in mich gesetzte Vertrauen, die zahlreichen konstruktiven Gespräche und wertvollen Ratschläge, die geduldige Begleitung sowie den allzeit herzlichen Umgang bedanke ich mich von ganzem Herzen.

Ebenso sehr bedanke ich mich herzlich bei Prof. Dr. Danièle Tosato-Rigo für ihre wertvolle kritische Begleitung des Entstehungsprozesses der Arbeit, aber auch für die wohlwollenden und aufmunternden Worte in Krisenzeiten.

Weiter gilt mein Dank dem Projektteam des Stapfer-Editionsprojekts von 2009-2015, Prof. Dr. Alfred Messerli, Prof. Dr. em. Fritz Osterwalder und Prof. Dr. Daniel Tröhler, für den intellektuellen Austausch während der Projektphase. Darin eingeschlossen sei das erweiterte wissenschaftliche Begleitumfeld des Stapfer-Projekts, speziell Dr. Rebekka Horlacher, Dr. Andrea De Vincenti, Dr. Daniel Töpfer, Dr. Ingrid Brühwiler, Dr. Norbert Furrer, alle ReferentInnen und Gäste unserer Tagungsveranstaltungen sowie alle ehemaligen Projektmitarbeitenden.

Zu grossem Dank verpflichtet bin ich im Weiteren Prof. Dr. André Holenstein und allen Teilnehmenden der Doktorierendenkolloquien Holenstein/Schmidt der Jahre 2012-2017 für ihre kritischen, stets Verbesserungs- und lösungsorientierten Rückmeldungen auf die vorgelegten Diskussionsthemen in konstruktiver Gesprächsatmosphäre.

Dank gebührt auch Michael Egger für die Weitergabe der St. Galler Schulumfrage von 1797 und den engagierten Mitarbeitern der Staatsarchive Aargau, Basel-Landschaft, Bern, Glarus, Schaffhausen, St. Gallen und Fribourg für den Zugang zu den diversen Quellenbeständen.

Ein herzliches Dankeschön geht ferner an Silvia Frei, Michael Suter, Simone Gerber, Salome Marschall, Dr. Noëmi Rui, Janine Scheurer, Dr. Melanie Salvisberg, Lorenz Theilkäs und Mauro Di Cioccio für das Gegenlesen des Prüfungsmanuskripts.

Zuletzt danke ich meiner Familie und speziell meiner geliebten Frau Chantal für die moralische Unterstützung, das Daumendrücken und all die vielen kleinen guten Dinge, die einem an das Leben ausserhalb der Dissertation erinnert haben.

Bern, im Jahr 2020 
Elementarschullehrer - und wenige Lehrerinnen - sind in der

Schweiz um 1800 meist sozial hoch geachtete, fachkompetente Spezialisten mit lebenslanger Amtsausübung.

Entgegen landläufiger Klischees weist die Schweizer Elementarschullehrerschaft am Ende der Frühen Neuzeit trotz ihrer sozio-ökonomischen und konfessionellen Heterogenität eine Vielzahl von biografischen Gemeinsamkeiten auf und ist weder von kollektiver Armut noch von sozialer Verachtung geprägt.

Mittels einer kollektivbiografischen Analyse werden in der Studie die Lebensverläufe von über 2.300 Lehrkräften altersstratifiziert verglichen, ihre Rekrutierung und soziale Herkunft untersucht sowie Auswirkungen finanzieller, organisationsstruktureller und lokaler Faktoren auf die Ausgestaltung der Berufsbiografien aufgezeigt. Familienverhältnisse, Mobilitätsverhalten, Nebentätigkeiten und Fähigkeitsbewertungen erlauben Rückschlüsse auf den sozialen Status im Gesellschaftsgefüge und identifizieren die Lehrerschaft als Angehörige der sozio-ökonomischen Mittelschicht mit hohem immateriellem Sozialkapital.

\section{Studien zur Stapfer-Schulenquête von 1799}

herausgegeben von Daniel Tröhler, Alfred Messerli, Fritz Osterwalder und Heinrich Richard Schmidt

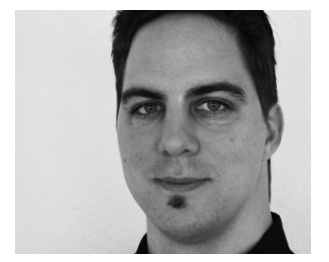

\section{Der Autor}

Marcel Rothen, geboren 1986, Studium der Geschichte und Geografie an der Universität Bern 2006-2012. Studium des Höheren Lehramts an der Pädagogischen Hochschule Bern 2010-2013. Von 2009-2012 wissenschaftlicher Mitarbeiter und von 2012-2018 Doktorand bei Prof. Dr. Heinrich Richard Schmidt (Universität Bern) und Prof. Dr. Danièle Tosato-Rigo (Université de Lausanne) im Rahmen des interdisziplinären Nationalfondsprojekts „Das niedere Schulwesen in der Schweiz am Ende der Frühen Neuzeit. Edition und Auswertung der Stapfer-Enquête von 1798/99“ (www.stapferenquete.ch). Promotion im Jahr 2018. Seit 2014 Gymnasiallehrer am Gymnasium/FMS Lerbermatt in Köniz sowie 2019 Lehrbeauftragter für Schriftkunde am Historischen Institut der Universität Bern. 